NUREG/CR-6084

PNL-8750

$\mathrm{AC}, \mathrm{AI}, \mathrm{A} 5, \mathrm{RG}$,

9C, 9D, 9E, 9H

\title{
Value Impact Analysis of \\ Generic Issue 143, "Availability \\ of Heating, Ventilation, Air \\ Conditioning (HVAC) and \\ Chilled Water Systems"
}

Manuscript Completed: September 1993

Date Published: November 1993

Prepared by

P. M. Daling, J. E. Marler, T. V. Vo, H. Phan, J. R. Friley

Pacific Northwest Laboratory

Richland, WA 99352

Prepared for

Division of Safety Issue Resolution

Office of Nuclear Regulatory Research

U.S. Nuclear Regulatory Conimission

Washington, DC 20555-0001

NRC FIN L1915 


\section{AVAILABILITY NOTICE}

Availability of Reterence Materials Cited in NAC Publications

Most documents clted in NRC publications will be avallable from one of the following sources:

1. The NRC PubHc Document Room, 2120 L Street, NW, Lower Level, Washington, DC 20555-0001

2. The Superintendent of Documents, U.S. Government Printing Offlce. Mall Stop SSOP. Washington, DC $20402-9328$

3. The National Technical information Service, Springfield, VA 22161

Although the listing that follows represents the majority of documents cited in NAC publications, it is not intended to be exhaustlve.

Referenced documents avallable for inspection and copying for a fee from the NRC Public Document Poom include NAC correspondence and internal NR nemoranda; NRC Offlce of Inspection and Enforcement bulletins, clrculars, Information notices, inspe in and investigation notices: Licensee Event Reports; vendor reports and correspondence; Commission papers; and applicant and IIcensee documents and correspondence.

The following documents in the NUREG serles are avallable for purchase from the GPO Sales Program: formal NRC staft and contractor reports. NRC-sponsored conterence proceedings, and NRC bosklets and brochures. Also avallable are Regulatory Guides. NRC regulations in the Code of Federal Regulations, and Nuclear Regulatory Commission Issuances.

Documents avallable from the National Technical Information Service Include NUREG series reports and technical reports prepared by other federal agencies and reports prepared by the Atomic Energy Commission, forerunner agency to ine Nuclear Regulatory Commission.

Documents avallable from public and speclai technical libraries include all open literature items, such as books, Journal and perlodical articles, and transactions. Federal Register notices, federal and state legislation, and congressional reports can usually be obtained from these librarles.

Documents such as theses, dissertations, foreign reports and translations, and non-NRC conference proceedlings are avallable for purchase from the organization sponsoring the publication clted.

Single coples of NRC draft reports are avallable free, to the extent of supply, upon written request to the Office of Information Resources Management. Distribution Section, U.S. Nuclear Regulatory Commission. Washington. OC 20555-0001.

Coples of Industry codes and standards used in a substantive manner in the NRC regulatory process are maintained at the NRC Library, 7920 Norfolk Avenue. Bethesda, Maryland, and are avallable there for reference use by the public. Codes and standards are usually copyrighted and may be purchased from the originating organization or. If they are American Natlonal Standards, trom the American National Standards Institute, 1430 Broadway. New York, NY 10018

\section{DISCLAIMER NOTICE}

This report was prepared as an account of work sponsored by an agency of the United States Government. Neither the United States Government nor any agency thereot, or any of their employees, makes any warranty, expresed or implied, or assumes any legal ilability of responsibility for any third party's use, or the results of such use of any intormation, apparatus, product or process disclosed in this report, or represents that its use by such third perty would not infringe privately owned rights. 


\section{ABSTRACT}

This study evaluates the values (benefits) and impacts (costs) associated with potential resolutions to Generic Issue 143, "Availability of HVAC and Chilled Water Systems." The study identifies vulnerabilities related to failures of HVAC, chilled water, and room cooling systems; develops estimates of room heatup rates and safety-related equipment vulnerabilities following losses of HVAC/room cooler systems; develops estimates of the core damage frequencies and public risks associated with failures of these systems; develops three proposed resolution strategies to tliis generic issue; and performs a value/impact analysis of the proposed resolutions. Existing probabilistic risk assessments for four representative plants, including one plant from each vendor, form the basis for the core damage frequency and public risk calculations. Both internal and external events were considered. It was conciuded that all three proposed resolution strategies exceed the $\$ 1,000 /$ person-rem cost-effectiveness ratio. Additional evaluations were performed to develop "generic" insights on potential design-related and configuration-related vulnerabilities and potential high-frequency ( $1 \mathrm{E}-04 / \mathrm{RY}$ ) accident sequences that involve failures of HVAC/room cooling functions. It was concluded that, although high-frequency accident sequences may exist at some plants, these high-frequency sequences are plant-specific in nature or have been resolved through hardware and/or operational changes. The plant-specific Individual Plant Examinations are an effective vehicle for identification and resolution of these plant-specific anomalies and hardware configurations. 


\section{CONTENTS}

ABSTRACT ................................

EXECUTIVE SUMMARY .................... Xxi

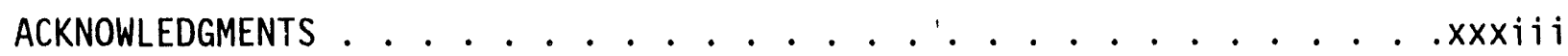

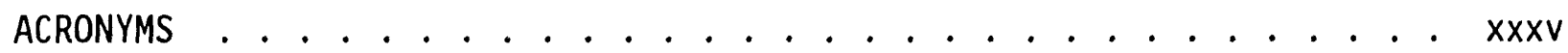

1.0 INTRODUCTION AND BACKGROUND $\ldots \ldots \ldots \ldots$

1.1 FAILURE OF ROOM COOLING . . . . . . . . . . 1.2

1.1.1 Electrical Switchgear Room Cooling Failures . . . . 1.2

1.1.2 Loss of Control Room Cooling . . . . . . . . 1.4

1.1.3 Loss of Emergency Core Cooling System (ECCS)
Room Cooling. . . . . . . . . . . . 1.7

1.1.4 Diesel Generator Enclosure Ventilation Systems . . . 1.8

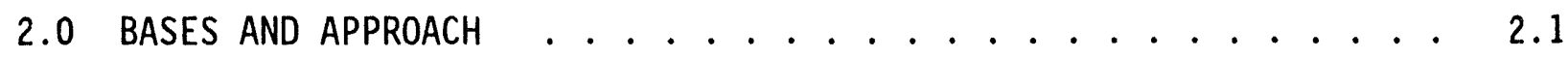

2.1 ESTABLISH LIST OF REPRESENTATIVE PLANTS . . . . . . . . 2.1

2.2 IDENTIFY ESF DEPENDENCIES ON ROOM COOLERS . . . . . . . 2.9

2.3 IDENTIFY BASIC EVENTS INVOLVING R.OOM COOLER FAILURES $\ldots \ldots$

2.4 DEVELOP LIST OF CUT SETS INVOLVING ROOM COOLER FAILURES . . . 2.11

2.5 IDENTIFY AFFECTED ACCIDENT SEQUENCES . . . . . . . . 2.12

2.5.1 Electrical Switchgear Room Cooling Failure . . . . 2.12

2.5.2 Loss of Control Room Cooling . . . . . . . . 2.13

2.6 QUANTIFY AFFECTED CORE DAMAGE FREQUENCY AND PUBLIC RISKS . . 2.13

2.7 EXTERNAL EVENTS ANALYSIS . . . . . . . . . . . 2.15

3.0 IDENTIFICATION OF AfFECTED PARAMETERS . . . . . . . . . 3.1

3.1 WESTINGHOUSE PRESSURIZED WATER REACTOR . . . . . . 3.1

3.1.1 Plant Description .................. 3.1

3.1.2 Safety System Description and Systems Analysis .... 3.1 
3.1.3 Event Tree Analysis ............. . . 3.13

3.2 GENERAL ELECTRIC CO. BOILING WATER REACTOR . . . . . . 3.39

3.2.1 Plant Description . . . . . . . . . 3.39

3.2.2 Plant Systems ..................... 3.41

3.2.3 Event Tree Analysis ............ . . 3.49

3.3 COMBUSTION ENGINEERING PRESSURIZED WATER REACTOR . . . . 3.76

3.3.1 Plant Description ............. . . 3.76

3.3.2 Safety System Description and Systems Analysis . . . 3.77

3.3.3 Event Tree Analysis ............ 3.91

3.4 BABCOCK AND WILCOX PRESSURIZED WATER REACTOR (PWR) . . . 3.112

3.4.1 Plant and Site Description . . . . . . . . 3.112

3.4.2 Safety System Description and Systems Analysis . . . 3.113

3.4.3 Event Tree Analysis . . . . . . . . . 3.130

4.0 QUANTIFICATION OF AFFECTED CORE DAMAGE FREQUENCY AND PUBLIC

RISKS FROM INTERNAL EVENTS ................ . . 4.1

4.1 ANALYSIS UF THE AFFECTED CDF AND PUBLIC RISKS AT THE

REPRESENTATIVE WESTINGHOUSE PWR ............ 4.1

4.1 .1 Loss of Roon Cooling As An Initiator........ 4.1

4.1.2 Room Cooler Failure Contributions to Other
Accident Sequences at the Representative W PWR . . . 4.20

4.1.3 Total Affected CDF and Public Risks for the

Repre ntative W PWR ........... . 4.29

4.2 ANALYSIS OF AFFECTED CDF AND PUBLIC RISKS FOR THE

REPRESENTATIVE BWR .............. . . 4.31

4.2.1 Loss of Room Cooling As An Initiator....... . 4.31

4.2.2 Room Cooler Failure Contribution to Accident

Sequences at the Representative BWR ....... 4.41

4.2.3 Total Affected Core Damage Frequency and Public

Risks ................ . . 4.54 
4.3 ANALYSIS OF AFFECTED CDF AND PUBLIC RISKS FOR THE REPRESENTATIVE COMBUSTION ENGINEERING PWR . . . . . . 4.56

4.3.1 Core Damage Frequency Calculations ....... 4.56

4.3.2 Public Risk Calculations ............ . 4.65

4.4 ANALYSIS OF AFFECTED CDF AND PUBLIC RISKS FOR THE REPRESENTATIVE BABCOCK AND WILCOX PWR . . . . . . . . 4.67

4.4.1 Loss of Room Cooling as an Initiator....... 4.74

4.4.2 Room Cooling Failure as a Contributing Event to Other Accident Sequences at the Representative B\&W PWR .............. 4.93

4.4.3 Total Affected Core Damage Frequency and Public Risks for the Representative B\&W PWR ...... . 4.97

5.0 EXTERNAL EVENTS . . . . . . . . . . . . . . 5.1

5.1 ASSESSMENT OF AFFECTED CDF DUE TO SEISMIC EVENTS . . . . . 5.1

5.1.1 Approach to Calculation of Seismic-Induced HVAC and Room Cooler Failures......... 5.2

5.1.2 Affected Seismic CDF Calculations for a Representative W PWR .......... . 5.8

5.1.3 Affected Seismic CDF Calculations for a GE BWR . . . 5.13

5.2 ASSESSMENT OF AFFECTED CDF DUE TO INTERNAL FIRES . . . . . 5.17

5.2.1 Fire Causes Loss of Emergency Switchgear Room Cooling ............. 5.19

5.2.2 Fire Causes Loss of DC Equipment Room Cooling . . . 5.22

5.2.3 Fire Causes Loss of Control Room Cooling . . . . . . . 5.24

5.3 ASSESSMENT OF AFFECTED CDF DUE TO FLOODS . . . . . . . 5.26

5.3.1 Analysis of Floods for $W$ and CE PWRs and BWRs . . . 5.26

5.3.2 Analysis of Floods for a B\&W PWR . . . . . . . 5.39

5.4 ASSESSMENT OF AFFECTED CDF DUE TO TORNADOES . . . . . . . 5.45

5.5 TOTAL CORE DAMAGE FREQUENCY AND PUBLIC RISKS DUE TO EXTERNAL EVENTS . . . . . . . . . . . . . . . . . 5.52 
6.0 GENERIC INSIGHTS ............................ 6.1

6.1 DESIGN DIFFERENCES AND SIMILARITIES . . . . . . . . 6.3

6.1 .1 ESF Pump Rooms . . . . . . . . . . . . 6.3

6.1 .2 Control Room HVAC Systems . . . . . . . 6.5

6.1.3 Diesel Generator Room Cooling . . . . . . . 6.6

6.1.4 ESF Switchgear and DC Equipment Room Cooling . . . 6.7

6.1.5 Shared Capabilities Between Two Units at the Same Site 6.8

6.2 EVALUATION OF PLANT-SPECIFIC ACCIDENT SEQUENCES . . . . . . 6.9

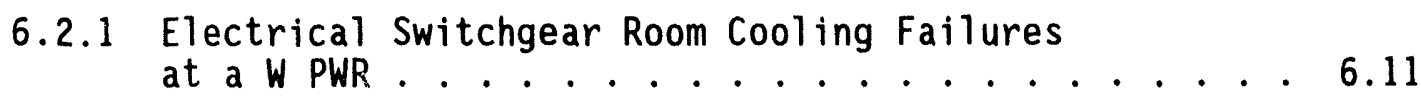

6.2 .2 Electrical Switchgear Room Cooling Failures
at a BWR. . . . . . 6. . . . . . . . . .

6.2.3 Electrical Switchgear Room Cooling Failures at a W PWR .............. 6.12

6.2.4 DC Equipment Room Cooling Failures at a CE PWR . . . 6.13

6.2.5 Loss of RHR Pump Room Cooling at a W PWR . . . . . 6.14

6.2.6 Common-Cause Failure of Control Room and Relay
Room HVAC . . . . 6. 6. . . . . . . . .

6.2.7 Various HVAC Deficiencies at a BWR . . . . . 6 6.16

6.2.8 Ventilation and Fire Damper Errors at Four
Plants . . . . 6 6.17 6.17

6.2.9 Loss of Control Room Cooling at a W PWR . . . . . 6.18

6.2.10 ESFAS Cabinet Failure at a CE PWR . . . . . . . 6.19

6.2 .11 Loss of Switchgear Room Cooling at a W PWR . . . . . 6.20

6.2.12 Loss of Control Room Cooling at a CE PWR . . . . . 6.21

6.3 COMPARISONS OF REPRESENTATIVE PLANT-AFFECTED CDFS TO
OTHER PLANTS $\ldots .6 .21$

6.3.1 Affected CDF for Plant CE-2 ......... 6.22

6.3.2 Affected CDF for Plant BW-2 . . . . . . . 6.27 
6.3.3 Affected CDF for Plant W-2 . . . . . . . . . 6.30

6.3.4 Affected CDF for Plant BWR.2.......... 6.33

6.3.5 Affected CDF For Plant BWR-3 . . . . . . . . 6.38

6.3.6 Comparisons Between Affected CDF for Representative Plants and Other Plants Analyzed . . 6.39

6.4 EXTERNAL EVENTS . . . . . . . . . . . . . . . 6.39

7.0 DESCRIPTION OF ALTERNATIVE RESOLUTIONS . . . . . . . . . . 7.1

7.1 DESCRIPTION OF RESOLUTION ELEMENTS . . . . . . . . 7.1

7.1.1 Perform Room Heatup Calculations and Thermal

"Fragility" Analyses ............ . 7.1

7.1.2 HVAC/Room Cooler System Design Review . . . . . 7.3

7.1.3 Enhanced Preventive Maintenance and Testing

Program ............. . . 7.3

7.1 .4 Improve Emergency Procedures . . . . . . . . 7.4

7.1.5 Install Remote Room Temperature Monitors/Alarms . . 7.4

7.1.6 Increase Environmental Qualification

7.1.7 Install Portable Air Cooling Equipment . . . . . 7.6

7.1.8 Install Permanent Backup Room Cooling Systems . . . 7.6

7.1.9 Install Thermal Barriers Between Heat-Producing
Components and Thermally Sensitive Components . . 7.6

7.1.10 Electrical Cabinet Tests . . . . . . . . . 7.7

7.1.11 Airflow Test Program . . . . . . . . . . . 7.7

7.2 DESCRIPTION OF ALTERNATIVES TO RESOLUTION OF GIN-143 $\ldots 7.8$

7.2.1 Improve Detection and Recovery Capabilities . . . 7.8

7.2.2 Hardware Changes . . . . . . . . . . . . . 7.9

7.2.3 Additional Testing and Hardware Changes . . . . . 7.10

8.0 VALUE-IMPACT ASSESSMENT . . . . . . . . . . . . . . . 8.1 
8.1 CALCULATION OF BeNEFITS ...................... 8.1

8.1.1 Risk Reduction Resulting From Alternative 1 . . . 8.4

8.1.2 Risk Reduction Resulting from Alternative $2 \ldots . .8$

8.1.3 Risk Reduction Resulting from Alternative $3 \ldots . .8 .5$

8.2 CALCULATION OF COSTS . . . . . . . . . . . 8.5

8.2.1 Onsite Consequences . . . . . . . . . 8.6

8.2 .2 Cost Calculations ............ 8. . 8.10

8.3 VALUE-IMPACT ASSESSMENT . . . . . . . . . . . . 8.19

9.0 REFERENCES . . . . . . . . . . . . . . . . . . 9.1

$\begin{aligned} \text { APPENDIX A - REVIEW OF LICENSEE EVENT REPORT DATA INVOLVING } & \ldots \\ \text { HVAC AND ROOM COOLER FAILURES - } 1980 \text { TO } 1991 \ldots . . . & \text { A.1 }\end{aligned}$

APPENDIX B - SYSTEMS ANALYSIS AND MINIMAL CUT SETS FOR THE REPRESENTATIVE WESTINGHOUSE PRESSURIZED WATER

REACTOR . . . . . . . . . . . . . . B.1

APPENDIX C - SYSTEMS ANALYSIS AND MINIMAL CUT SETS FOR THE REPRESENTATIVE BOILING WATER REACTOR ......... C.1

APPENDIX D - SYSTEMS ANALYSIS AND MINIMAL CUT SETS FOR THE REPRESENTATIVE COMBUSTION ENGINEERING PRESSURIZED

WATER REACTOR ..................... D.

APPENDIX E - SYSTEMS ANALYSIS AND DOMINANT MINIMAL CUT SETS

FOR THE REPRESENTATIVE BABCOCK AND WILCOX PRESSURIZED

WATER REACTOR ...................... E.

APPENDIX $F$ - THERMAL ANALYSIS AND TEMPERATURE SENSITIVITIES IN ROOMS REQUIRING HVAC AND ROOM COOLERS ......... F.1 


\section{FIGURES}

ES-1 Illustration of Total Value: Impact Ratios for the Three

Proposed Alternative Resolutions............. xxxii

2.1-1 Illustration of Approach Used in This Study . . . . . . . 2.2

3.1-1 Event Tree for $T_{1}$ - Loss of Offsite Power . . . . . . . . 3.17

3.1-2 Event Tree for $T_{1}$ - Station Blackout . . . . . . . . . . . 3.18

3.1-3 Event Tree for $\mathrm{T}_{2}$ - Loss of Main Feedwater . . . . . . . . 3.20

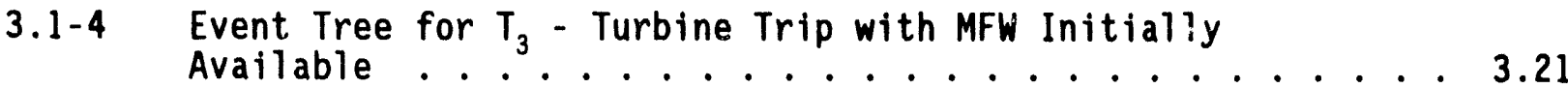

3.1-5 Event Tree for $T_{D C X}$ - Loss of DC Bus . . . . . . . . . . . 3.23

3.1-6 Event Tree for $\mathrm{T}_{S G}$ - Steam Generator Tube Rupture . . . . . . 3.24

3.1-7 Event Tree for A - Large LOCA . . . . . . . . . . . . . . 3.25

3.1-8 Event Tree For $S_{1}$ - Medium LOCA . . . . . . . . . . . . . . 3.26

3.1-9 Event Tree for $S_{2}$ - Small LOCA . . . . . . . . . . . . 3.28

3.1-10 Event Tree for $S_{3}$ - Very Small LOCA . . . . . . . . . . . . 3.29

3.1-11 Event Tree for TK - Anticipated Transient Without SCRAM . . . 3.31

3.1-12 Event Tree for $\mathrm{T}_{S W}$ - Loss of Electrical Switchgear Room

Cooling ...................... 3.33

3.1-13 Event Tree for $T_{c R}-$ Loss of Control Room Air
Conditioning System . . . . . . . . . . . . . . 3.36

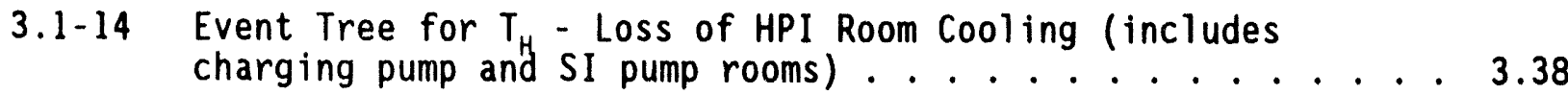

3.1-15 Event Tree for $\mathrm{T}_{\text {LP }}$ - Loss of Low-Pressure Injection
Pump Room Cooling . . . . . . . . . . . . . . . 3.40

3.2-1 Event Tree for Large LOCA . . . . . . . . . . . . . 3.51

3.2-2 Event Tree for Intermediate LOCA . . . . . . . . . . . 3.53

3.2-3 Event Tree for Small LOCA . . . . . . . . . . . . . . 3.54

3.2-4 Event Tree for Smal1-Small LOCA . . . . . . . . . . . 3.57 
3.2-5 Event Tree for Loss of Offsite Power (LOOP) . . . . . . . 3.58

3.2-6 Event Tree for Station Blackout . . . . . . . . . 3.64

3.2-7 Event Tree for Loss of Power Conversion System . . . . . . . 3.67

3.2-8 Event Tree for Transient with Power Conversion System

Initially Available . . . . . . . . . . . . . 3.70

3.2-9 Event Tree for Loss of Feedwater . . . . . . . . . . . 3.72

3.2-10 Event Tree for Inadvertent Open Relief Valve . . . . . 3.73

3.2-11 Event Tree for Two Stuck-Open Safety Relief Valves . . . . . 3.74

3.2-12 Event Tree for Anticipated Transients Without SCRAM . . . . 3.75

3.3-1 Small LOCA Event Tree . . . . . . . . . . . . 3.94

3.3-2 Medium LOCA Event Tree . . . . . . . . . . . . . 3.96

3.3-3 Large LOCA Event Tree . . . . . . . . . . . . . . 3.97

3.3-4 Steam Generator Tube Rupture Event Tree . . . . . . . . . . 3.98

3.3-5 Secondary Line Break Event Tree . . . . . . . . . . 3.100

3.3-6 Feedwater Line Break Event Tree . . . . . . . . . . 3.102

3.3-7 Grouped Transients Event Tree . . . . . . . . . . 3.103

3.3-8 Loss of Main Feedwater/Condensate Pumps Event Tree . . . . . 3.104

3.3-9 Station Blackout Event Tree . . . . . . . . . . . 3.107

3.3-10 ATWS Event Tree . . . . . . . . . . . 3.109

3.4-1 Transient Event Tree . . . . . . . . . . . . 3.133

3.4-2 Small LOCA Event Tree . . . . . . . . . . . 3.136

3.4-3 Medium LOCA Event Tree . . . . . . . . . . . . . 3.137

3.4-4 Large LOCA Event Tree . . . . . . . . . . . . . . 3.137

3.4-5 Steam Generator Tube Rupture Event Tree . . . . . . . . 3.139

3.4-6 Anticipated Transient Without SCRAM Event Tree . . . . . . . 3.140

3.4-7 Loss of Electrical Equipment Room Cooling Event Tree . . . . 3.142 
3.4-8 Loss of Control Room Cooling Event Tree . . . . . . . . . 3.143

4.1-1 HRA Event Tree for Recovery from Room Cooler Initiators . . 4.5

4.1-2 Total Room Cooler Initiator Core Damage Frequency

Distribution ............... . . 4.13

4.1-3 Pie Chart Illustrating Contributions of Each Initiator to the CDF from Room Cooler Initiating Events ....... 4.14

4.1-4 Total Room Cooler Initiator Public Risk Distribution . . . . 4.21

4.1-5 Total Room Cooler Contributing Event Core Damage Frequency Distribution . . . . . . . . . . . . 4.25

4.1-6 Pie Chart Illustrating Contributions of Each Initiator to the CDF from Room Cooler Contributing Events . . . . . 4.26

4.1-7 Total Room Cooler Contributing Event Public Risk Distribution . . . . . . . . . . . . . 4.30

4.2-1 Total Room Cooler Initiator Core Damage Frequency Distribution . . . . . . . . . . . . . . . .

4.2-2 Pie Chart I1lustrating Contributions of Each Initiator to the CDF from Room Cooler Initiating Events ...... 4.38

4.2-3 Total Room Cooler Initiacor Public Risk Distribution for the Representative BWR ........... 4.43

4.2-4 Sequence Contributions to Total Affected CDF for the Representative BWR - Internal Contributors . . . . . . 4.50

4.2-5 Cumulative Affected CDF Distribution for Internal Contributors at the Representative BWR ......... 4.51

4.2-6 Affected Public Risk Distribution for Internal Contributors - Representative BWR

4.3-1 Affected CDF Distribution for the Representative CE PWR . . 4.63

4.3-2 Pie Chart Illustrating Contributions of Affected Accident Sequences to Total CDF for the Representative CE PWR . . . . 4.64

4.3-3 Affected Public Risk Distribution for the Representative CE PWR .................. 4. 4.68

4.3-4 Pie Chart Illustrating Relative Contributions of Accident Sequences to Affected Public Risk for the Representative CE PWR . 
4.4-1 Pie Chart Illustrating Relative Contributions of Affected Accident Sequences to Affected CDF . . . . . . 4.95

4.4-2 Pie Chart Illustrating Relative Contributions of Affected Accident Sequences to Affected Public Risk . . . . 4.100

5.1-1 Affected Seismic CDF by Initiator for a W PWR . . . . . 5.9

5.1-2 Affected Seismic CDF by Initiator for a GE BWR . . . . . . 5.15

5.3-1 Event Tree for Flood-Induced Failure of Emergency

Switchgear Room HVAC . . . . . . . . . . . 5.28

5.3-2 Event Tree for Flood-Induced Loss of DC Equipment Room HVAC . . . . . . . . . . . . . . 5.35

5.3-3 Event Tree for Equipment Room Flooding . . . . . . . . 5.41

5.3-4 Event Tree for HPI Pump Room Flooding . . . . . . . . 5.41

5.3-5 Event Tree for Turbine Building Flood . . . . . . . . 5.42

5.4-1 Tornado Intensity Regions . . . . . . . . . 5.46

6.1-1 Comparison of Affected Core Damage Frequency for

Eight LWRs . . . . . . . . . . . . . . 6.41

8.1-1 Illustration of Value:Impact Ratios Relative to $\$ 1000 /$ Person-Rem Cost-Effectiveness Measure . . . . . . 8.22 


\section{TABLES}

ES-1 Summary of Affected CDF and Public Risk Results for the Representative Plants in this Study...........xxiii

ES-2 Matrix of Vulnerabilities Versus Resolution Elements . . . .xxviii

ES-3 Summary of Alternative Resolutions to GI-143 . . . . . . . xxix

ES-4 Summary of Benefits of Alternative Resolutions to GI-143 . . . xxx

ES-5 Summary of Per-Plant and Total Costs for Each Resolution

Alternative .................. xxxi

ES-6 Best Estimate Value:Impact Ratios (\$/person-rem) . . . . xxxii

2.1-1 Plant Designs Reviewed in This Study . . . . . . . . . . 2.4

2.1-2 HVAC/Room Cooler LER Frequencies for Each Nuclear Power

Plant (1980 to 1992) .................. 2.6

3.1-1 Events Involving Room Cooler Failures Identified in Fault

Trees ................... 3.3

3.1-1 Event Tree Identifiers . . . . . . . . . . 3.15

3.2-1 Estimated Time to Failure for Room Cooling Sensitive

3.2-2 Event Tree Nomenclature . . . . . . . . . . . 3.50

3.3-1 Safety System Dependencies on Room Cooling . . . . . . . . 3.93

3.4-1 Final List of Internal Initiating Events . . . . . . . 3.132

4.1-1 Nuclear Power Plant Operational Data for 1985 to 1991 . . . . 4.2

4.1-2 P.oom Cooler Initiating Event Frequencies . . . . . . . 4.3

4.1-3 Success Criteria for Loss of Room Cooling Function

Initiators ................. 4.6

4.1-4 Affected Parameters and Values for Basic Events in Room
Cooler Initiator Event Trees . . . . . . . . 4.10

4.1-5 Assessed Mean Frequencies of Room Cooler Initiator Sequences . 4.14

4.1-6 Summary of Minimal Cut Sets with Frequencies Greater

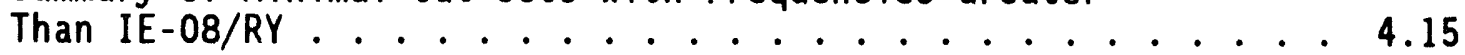


4.1-7 Conditional Probabilities of APBs Resulting from

Transient Initiators ............ . 4.17

4.1-8 Partitioning of APBs into Source Term Groups ........ . 4.19

4.1.9 Affected Accident Sequences and Base-Case Frequencies . . . . 4.26

4.1-10 Minimal Cut Sets with Frequencies Greater Than 1E-8/RY . . . . 4.27

4.1-11 Conditional Probabilities of APBs Resulting from LOCA

and LOOP Plant Damage State Groupings......... 4.29

4.2-1 Success Criteria for Loss of Room Cooling Function

Initiators .................... 4.32

4.2-2 Affected Parameters and Values for Basic Events in

Room Cooler Initiator Event Trees . . . . . . . . 4.35

4.2-3 Calculated Frequencies of Room Cooler Initiator

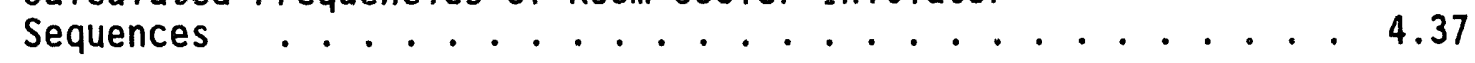

4.2-4 Summary of Minimal Cut Sets with Frequencies Greater

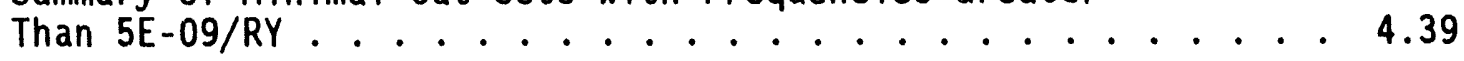

4.2-5 Conditional Probabilities of APBs Resulting from HVAC/

Room Cooler Initiators ............ 4.41

4.2-6 Partitioning of APBs into Source Term Groups . . . . . . 4.42

4.2-7 Initiating Events and Frequencies .......... 4.44

4.2-8 Basic Events Potentially Affected by GI 143 at the
Representative BWR . . . . . 4. 4. 4. . . . . .

4.2-9 Basic Event Cumulative Cut Set Frequency . . . . . . . 4.45

4.2-10 Affected Sequences and Plant Damage States ....... 4.46

4.2-11 Affected Cut Set Allocation Summary . . . . . . . . . 4.47

4.2-12 Affected Accident Sequences and Frequencies for Room
Cooler Contributing Events at the Representative BWR . . . . 4.49

4.2-13 PDS-1 Risk Calculation .............. . . 4.53

4.2-14 PDS-8 Risk Calculation . . . . . . . . . . . 4.53

4.2-15 PDS-10 Risk Calculation . . . . . . . . . . . 4.56

4.3-1 List of Affected CUt Set Elements and Values for the
Representative CE PWR ......................... 
4.3-2 Affected Accident Sequences and Calculated Frequencies for the Representative CE PWR . . . . . . . . . . . . . . 4.64

4.3-3 Cut Sets with Frequencies Greater Than 5E-08/RY . . . . . . 4.65

4.3-4 Affected Public Risk Calculations for the Representative CE PWR ....................... 4.69

4.3-5 Affected Accident Sequences and Calculated Public Risk for the Representative CE PWR ......... . . . . . 4.73

4.4-1 SSF HVAC System Reliability Data . . . . . . . . . . . . . 4.77

4.4-2 Affected Parameters and Values for Room Cooler Initiator Minimal Cut Sets .................. . 4.82

4.4-3 Loss of Electrical Equipment Room Cooling Cut Sets . . . . . 4.83

4.4-4 Loss of Control Rooin Cooling Cut Sets (without auxiliary shutdown panel).................. 4,85

4.4-5 Loss of Control Room Cooling Cut Sets (with auxiliary shutdown pane1).................... 4.88

4.4-6 Core Damage Frequency and Percentage Contribution . . . . . . 4.91

4.4-7 Public Risk Calculations for Room Cooler Initiator Sequences . 4.92

4.4-8 Summary of Affected CDF for HVAC/Room Cooler Contributor Accident Sequences .................. 4.94

4.4-9 Affected Public Risk Calculations for the Representative B\&W PWR . . . . . . . . . . . . . . . . . 4.98

5.1-1 Median Fragility and Response Values Used in Analysis...................... . 5.5

5.1-2 Summary of Affected Seismic CDF for a Representative PWR . . . 5.9

5.1-3 Affected Seismic CDF for a GE BWR . . . . . . . . . . . . . 5.14

5.2-1 Affected CDF from Internal Fires . . . . . . . . . . . . 5.19

5.2-2 Parameter Values for Calculating $Q_{E S W}$ and $Q_{E D G-H V A C}$. . . . . . 5.21

5.2-3 Parameter Values for Calculating $Q_{A}$, . . . . . . . . . . 5.23

5.3-1 Summary of Flood-Induced Affected CDF Results for W
and CE PWRs and GE BWRs......... . . . . . . . . . . 27 
5.3-2. Parameter Values Used to Evaluate HPI/R and LPI/LPR . . . . . 5.38

5.3-3 Summary of the Affected Flond-Induced CDF for a B\&W PWR . . . . 5.43

5.4-1 Design Basis Tornado Characteristics . . . . . . . . . . . 5.46

5.4-2 Tornado Strike Probabilities . . . . . . . . . . . . . 5.48

5.5-1 Summary of Affected Core Damage Frequency Due to $\ldots . . . . .5 .52$

5.5-2 External Event Public Risk Calculations for the

Representative $W$ and CE PWRs ............. . 5.55

5.5-3 External Event Public Risk Calculations for the Representative BWR ................. . 5.55

5.5-4 Flood Risk Calculations for the Representative B\&W PWR . . . 5.58

5.5-5 Summary of Affected Public Risk Values from External

Events . . . . . . . . . . . . . . . 5.59

6.1-1 Results of Sensitivity Study . . . . . . . . . . . . . 6.9

6.3-1 Affected Core Damage Frequency for Plant CE-2 . . . . . . . . 6.23

6.3-2 Affected Core Damage Frequency for Plant BW-2 . . . . . . . . 6.27

6.3-3 Assessment of Affected Core Damage Frequency for

Plant W-2.................... 6.32

6.3-4 Affected CDF for Plant BWR-2 . . . . . . . . . . . . . 6.34

6.3-5 Affected CDF for Plant BWR-3 . . . . . . . . . . . . 6.40

6.3-6 Comparison of Affected CDFs for Nine LWRs . . . . . . . . . . 6.40

7.1-1 Matrix of Vulnerabilities versus Resolution Elements . . . . 7.2

7.2-1 Summary of Alternative Resolutions to GIN-143 . . . . . . . 7.9

8.1-1 Summary of Affected Core Damage Frequency and Public

8.1-2 Detailed Core Damage Frequency Results for This
Value-Impact Assessment . . . . . . . . . . . . . . 8.3

8.2-1 Estimated Occupational Exposures for Implementation,
Operation, and Maintenance of Resolution Alternatives . . . . 8.6

8.2-2 Summary of Averted Onsite Property Damage Costs . . . . . . . 8.9 
8.2-2 Summary of Averted Onsite Property Damage Costs . . . . . . 8.9

8.2-3 Summary of Averted Offsite Property Damage Costs . . . . . . . 8.11

8.2-4 Summary of Cost Estimates for Each Resolution Element . . . . 8.11

8.3-1 Summary of Benefits of Alternative Resolutions to GI 143 ................... . . . . . . . . . . .

8.3-2 Summary of Per-Plant and Total Costs for Each Resolution Alternative .............. . 8.20

8.3-3 Best Estimate Value: Inpact Ratios (\$/person-rem) . . . . . 8.21 


\section{EXECUTIVE SUMMARY}

This project evaluates the present designs and reliability of heating, ventilation, and air conditioning (HVAC) and room cooler systems in nuclear power plants in support of Generic Issue (GI) 143. The core damage frequencies (CDFs) and public risks associated with these systems were estimated for four representative nuclear power plants, including one from each nuclear steam supply system (NSSS) vendor. The specific objectives include the following:

1. Identify areas that are particularly vulnerable to loss of HVAC or ruom cooling.

2. Based on existing data, evaluate the HVAC and chilled water systems' failure frequencies leading to a loss of heat removal capability from the areas containing safety-related equipment.

3. Determine the vulnerabilities of safety-related systems and components to failure of HVAC and chilled water systems that are reflected in actual operating experience.

4. Estimate the CDF and public risks that are associated with failure of HVAC and chilled water systems.

5. Develop alternative resolutions to this issue and perform value/impact analyses of each alternative.

This report presents transient thermal calculations that were per.formed to develop time-temperature profiles in various safety-related equipment rooms, including engineered safety feature (ESF) pump rooms, $A C$ and $D C$ equipment rooms, and the control room. Limiting failure temperatures for mechanical and electrical equipment in these rooms were determined based on information obtained from utilities and vendors. The key conclusions from these evaluations are that:

- The control room is the location of many temperature-sensitive components.1 Heatup of the control room leads to heatup of electrical components inside cabinets and panelboards, which could lead to spurious signals, readings, alarms, and equipment actuations.

- $\quad D C$ equipment rooms contain numerous temperature-sensitive components, including battery chargers and inverters. Loss of this equipment due to room cooling failure could lead to a plant trip and simultaneous failure of $D C$ control power to safety-related components needed to respond to the plant trip.

- Diesel generator ventilation systems are important to the operability of diesel generator control cabinets. Failure of the diesel generator room ventilation system could result in diesel generator control 
system failure in as little as 15 to 20 minutes. Recovery is thought to be not possible under this time constraint.

- Heatup of ESF pump rooms following loss of room cooling could lead to pump motor failure. However, heatup rates are such that a substantial amount of time is available to restore room cooling or take other corrective action to cool ESF pump rooms.

Existing probabilistic risk assessments (PRAs) were used as the basis for quantifying the effects of HVAC and room cooler systems on CDF and public risks. Both internally and externally initiated events were considered in the PRA calculations. Modifications to the PRAs were made, where necessary, to incorporate room cooler failures as a potential contributor to loss of a safety system function. Loss of room cooling was also evaluated as a potential accident sequence initiating event.

The key results from the PRA evaluation are shown in Table ES-1. This table presents the results of the CDF and public risk calculations performed to quantify the contributions of HVAC/room cooler failures to internally and externally initiated accident sequences. The values listed in the columns labeled "Internal" are the sum of the affected CDFs from accident sequences initiated by transients caused by loss of HVAC/room cooling systems and the affected CDF from other plant transients to which HVAC/room cooler failures contribute.

The total affected CDFs were calculated to be approximately 1E-05/ reactor year (RY) for all four representative plants. The CDF resulting from external events (earthquakes, fires, and floods) contributes about 63 to $97 \%$ of this value, depending upon the plant. The affected public risk values for all four plants were calculated to range from about two to four person-rem/RY. As with the affected CDF values, the public risk values were dominated by external events.

The results presented in the table are applicable to the specific plants evaluated. Due to major differences in HVAC and room cooling system configurations among plants, other plants may have significantly higher or lower affected CDFs and public risk values. These plants represent a wide range of site environmental conditions, including hot, dry desert and hot, humid climates.

An assessment was performed to develop insights on the applicability of these plants' designs and HVAC system configurations to the rest of the plants. Generic insights were also developed on the applicability of potential high CDF accident sequences found in the literature to the population of nuclear power plants. The identified vulnerabilities ranged from design inadequacies to deficient operating, maintenance, and test procedures, and included the following:

- Installation errors during plant construction or modification could disable water systems that remove heat from ESF pump rooms and essential chillers. 
TABLE ES-1. Summary of Affected CDF and Public Risk Results for the Representative Plants in This Study(a)

\begin{tabular}{|c|c|c|c|c|}
\hline & \multicolumn{4}{|c|}{ Plant Type } \\
\hline & W PWR & $B W R^{(c)}$ & CE PWR (d) & $B \& W P^{(e)}$ \\
\hline \multicolumn{5}{|l|}{ Affected CDF/YR } \\
\hline - Internal Events & $4.1 E-06$ & $5.4 E-07$ & $1.3 \mathrm{E}-06$ & $1.2 E-06$ \\
\hline - External Events & $8.2 E-06$ & 8.1E-06 & $8.2 E-06$ & $9.6 \mathrm{E}-06$ \\
\hline TOTAL & $1.2 \mathrm{E}-05$ & $8.6 \mathrm{E}-06$ & $9.5 E-06$ & $1.1 \mathrm{E}-05$ \\
\hline \multicolumn{5}{|l|}{$\begin{array}{l}\text { Affected Public Risks } \\
\text { person-rem/RY }\end{array}$} \\
\hline - Internal Events & 1. $7 \mathrm{E}+00$ & $9.9 E-02$ & $7.2 E-01$ & $1.7 \mathrm{E}-01$ \\
\hline - External Events & $1.6 E+00$ & $3.9 E+00$ & $1.6 E+00$ & $2.9 E+00$ \\
\hline TOTAL & 3.3 & 4.0 & 2.3 & 3.1 \\
\hline \multicolumn{5}{|c|}{$\begin{array}{l}\text { (a) } \\
\text { (b) Westinghouse pressurized water reactor. } \\
\text { (c) Boiling water reactor. } \\
\text { (d) Combustion Engineering pressurized water reactor. } \\
\text { (e) Babcock and Wilcox pressurized water reactor. }\end{array}$} \\
\hline
\end{tabular}

- Test and maintenance errors, particularly failure to return safetyrelated HVAC components to service properly, could disable one or more trains of HVAC.

- Inadequate test procedures could also result in failure to return HVAC components to service properly.

- Failed or malfunctioning ventilation and fire dampers can result in a total loss of room cooling to safety-related equipment rooms.

- Inadequate attention to testing, inspection, and preventive maintenance of HVAC and room cooling system components significantly degrades their reliability.

- Design errors have resulted in inadequate ventilation airflow to certain rooms and to certain areas within rooms. One design error was identified involving location of one train of vital DC equipment in a switchgear room for the other train.

- Examples were found of situations in which temperatures inside electrical cabinets exceeded design basis temperatures, although room ambient temperatures were below their maximum values. Design basis assumptions that internal cabinet temperatures are $20^{\circ} \mathrm{F}$ higher than 
the room temperature for cabinets cooled by natural convection may not be valid under all conditions. The causes of higher-than-expected temperatures appear to be inadequate airflow balance in the room (i.e., dead spots) and blockage of airflow through the cabinets by the equipment and equipment racks inside the cabinets. For cabinets cooled by forced-air ventilation (i.e., cabinets provided with fans), fan maintenance and operability has been identified as a cause of high internal cabinet temperatures. Therefore, failures of cabinet components due to high temperatures may occur even though room ambient temperatures are below design maximum values.

- Low priority appears to be placed on maintaining cabinet fans in proper working condition. Cabinet fan failures have caused internal components to overheat, leading to spurious actuations and malfunctions of safety-related equipment.

- Actual temperatures in safety-related equipment rooms are typically not monitored in control rooms. Other indications are used to detect failures of HVAC/room cooling in safety-related equipment rooms (e.g., fan start/run, chiller start/run, damper positions). The fact that there are few or no direct room temperature indications may result in operators being unable to detect room cooling failures, which could lead to failure of a safety-related component.

- Based on discussions with personnel responsible for operation of chillers, it appears that oversizing chillers may degrade their performance and reliability. For example, operating a chiller at $20 \%$ capacity is more harmful than operating at or near $100 \%$ capacity. Additionally, intermittent operation of a chiller is less desirable than continuous operation. The design and operational characteristics of chillers can therefore affect their reliability.

- Fire protection system designs and reviews have resulted in identification of inadequate separation between electrical cables feeding redundant trains of HVAC systems.

- Loading too heavily individual divisions of vital DC control power whose components are sensitive to elevated room temperatures may result in failure of significant portions of safety-related systems if the HVAC systems fail.

- Rapid failure of emergency onsite $A C$ power systems will result from failure of emergency diesel generator (EDG) room ventilation systems. No recovery from failure of the EDG room ventilation systems is thought possible, because the time available is less than 30 minutes and in some cases less than 15 minutes.

- Numerous instances were found in which plants had emergency procedures available to respond to losses of HVAC/room cooling functions. In 
other instances, relevant emergency procedures did not exist. Portable fans used for loss of HVAC events were observed to be missing in some plants.

- A tradeoff was identified between isolating ESF pumps in small cuivicles to protect them from fires and floods and placing them in large rooms. Small rooms heat up much more rapidly than large rooms, and the failure probabilities, given loss of cooling, are higher for small rooms than for large rooms. However, this effect competes with the increased vulnerability to external events and common-cause failures that result from placement of ESF pumps in large, open rooms.

In most cases, these were concluded to be plant-specific concerns. However, potential generic vulnerabilities were identified, including the effects of ventilation and fire dampers on HVAC unavailability, potential underestimating of temperatures inside electrical cabinets, and possibly a lack of adequate test/inspection/maintenance procedures and training relative to HVAC and room cooling systems. Relative to the latter vulnerability, this was not the situation observed at the light water reactors (LWRs) visited in this study. However, due to many examples of such events described in various documents and LERs, this was judged to be a potential generic vulnerability.

To add some perspective to the affected CDFs calculated for the representative plants, a review and limited-scope quantitative evaluation of five additional PRAs was performed. The quantification of these additional plants' CDFs was much less rigorous than that performed for the representative plants. However, the affected CDFs for the additional plants are believed to be acceptable for comparison purposes.

The affected CDFs from internal events that were calculated for the nine plants (four representative plants and five additional plants) ranged from about 1E-07/RY to 1E-05/KY. The arithmetic mean across all nine plants is about 3.9E-06/RY. Thus, the mean is within about a factor 6 higher and a factor of 18 lower relative to maximum and minimum affected CDFs, respectively. (The lowest affected CDF was removed from this calculation because it was not possible to make all modifications to the plant's existing PRA necessary for a valid comparison.) This was not considered to be a large variation, given the difference in the level of detail between the assessments of the representative plants and the five additional plants. It was concluded that the four representative plants used in this study adequately represent the population of nuclear power plants in terms of the CDFs and public risks attributable to HVAC and room cooler failures.

Some relatively high CDFs related to failures of HVAC and room cooling systems were observed for some plants. Although it appears that the average affected CDF for the entire population of plants is in the $1 E-05$ to $1 E-06 / R Y$ range, there appear to be some plant-specific accident sequences at other plants that may be as high as $1 \mathrm{E}-04 / \mathrm{RY}$. In most cases, the high-frequency, plant-specific accident sequences were shown to be highly conservative estimates or to have been significantly reduced through hardware and/or operational changes. The PRAs performed in support of the individual plant 
examinations (IPEs) have identified plant-specific anomalies and hardware configurations that have been or will be resolved. The IPEs appear to be ideal vehicles for identifying and resolving plant-specific HVAC- and room coolerrelated issues.

The external events analyses yielded affected CDF estimates in the ange 8E-06/RY to about 1E-05/RY and affected public risk estimates of between about 2 and 4 person-rem/RY. These values are significantly largei than the affected CDF and public risks associated with internal events. Key conclusions derived from the external events analysis included these:

- Fires were found to dominate the affected external event CDF. Floods were also found to be significant contributors the external event CDF and public risk estimates.

- Room coolers and HVAC equipment are less susceptible to seismicinduced failures than other plant components such as pumps, switchgear, and water storage tanks, leading to the conclusion that HVAC equipment is more vulnerable to fires than to other external events. The resistance to damage in seismic events also provides substantial protection against tornado-generated missiles and high winds. This tends to minimize the contributions of seismic events and tornadoes to the affected CDF.

- It was observed that the affected fire-induced CDF is a much larger fraction of the total fire-induced CDF than the corresponding fraction of the seismic-induced CDF. The main reason for this is that the HVAC and room cooling equipment is much less vulnerable to seismic-induced failures than other safety system components such as pumps. However, room coolers and HVAC equipment are as vulnerable to fire-induced failures, including fires affecting control and power cables, as other safety-related components.

- For both PWRs and BWRs, the affected seismic CDF is dominated by a few accident sequences. The dominant accident sequences primarily involve station blackout situations, although the exact causes of station blackout differ somewhat among plant types. Seismic-induced failures of suction sources (tanks) and emergency switchgear were the dominant contributors. Failures of HVAC systems were not among the dominant contributors.

- Tornadoes were demonstrated to contribute insignificantly to the affected external event CDF because plant structures and buildings provide protection from tornado-induced high winds and missiles. Tornadoes have effects on HVAC components similar to seismic events; i.e., it is unlikely that a tornado will fail HVAC equipment and not the safety-related equipment supported by the HVAC system (the effects of a tornado 
are not likely to be localized in the HVAC equipment room). Therefore, failures of components other than HVAC equipment will dominate the tornado-induced CDF.

- Flood-induced accident sequences were observed to contribute approximately $10 \%$ of the affected CDF due to external events. Similar to tires, flood effects are likely to be concentrated in a certaili area of the plant. Therefore, it is possible that a flood could cause failure of HVAC equipment and not directly affect the operability of the equipment supported by the HVAC function.

These conclusions are believed to be generically applicable to all U.S. nuclear power plants. The external events analyses noted no significant plant-specific anomalies that would lead one to believe that the HVAC/room cooler systems at the plants examined in this study are any more or less vulnerable than other plants to external events that may fail HVAC and room cooling equipment. Failure probabilities for HVAC/room coolers subjected to the various external events were shown to be lower than for other safetysystem components.

Three alternative resolution strategies for GI-143 were developed in this study. As mentioned previously, the alternative resolutions are composed of several elements, each designed to prevent or mitigate one or more of the vulnerabilities discussed above. Table ES-2 summarizes the resolution elements and indicates the vulnerabilities addressed by each. The resolution elements were combined into three comprehensive resolution strategies, or alternatives, that were developed to bound the range of possible costs and benefits resulting from resolution of GI-143. The first alternative is the minimum improvement alternative and combines plant evaluation elements and procedural/maintenance improvements to prevent or mitigate potential losses of room cooling. The second alternative combines the elements of Alternative 1 with relatively minor hardware changes designed to improve detection and recovery capabilities. The third alternative results in maximum improvement to HVAC/room cooler reliability and combines the elements of Alternative 2 with additional testing programs and hardware changes. Each alternative addresses, to some extent, all of the vulnerabilities identified in Section 2. The three alternatives are summarized in Table ES-3.

A value-impact assessment was performed to determine the costeffectiveness of each of these three alternatives. Standard methods and data were used to the extent possible to perform these calculations. The public risk benefits of the potential alternative resolutions to this issue were calculated in terms of reductions in CDF and public risks. The approach to this analysis was to modify the risk calculation models used in the PRA calculations performed in this study. Modifications were made to the models at the cut set level. The modifications represent the potential improvements in HVAC/room cooler system reliability and the abilities of operators to recover from a loss of one of these functions that is anticipated to result from implementation of the resolution alternatives. These modifications and the resulting changes in CDF and public risks are described in the following text. 


\section{TABLE ES-2. Matrix of Vulnerabilities Versus Resolution Elements ${ }^{(a)}$}

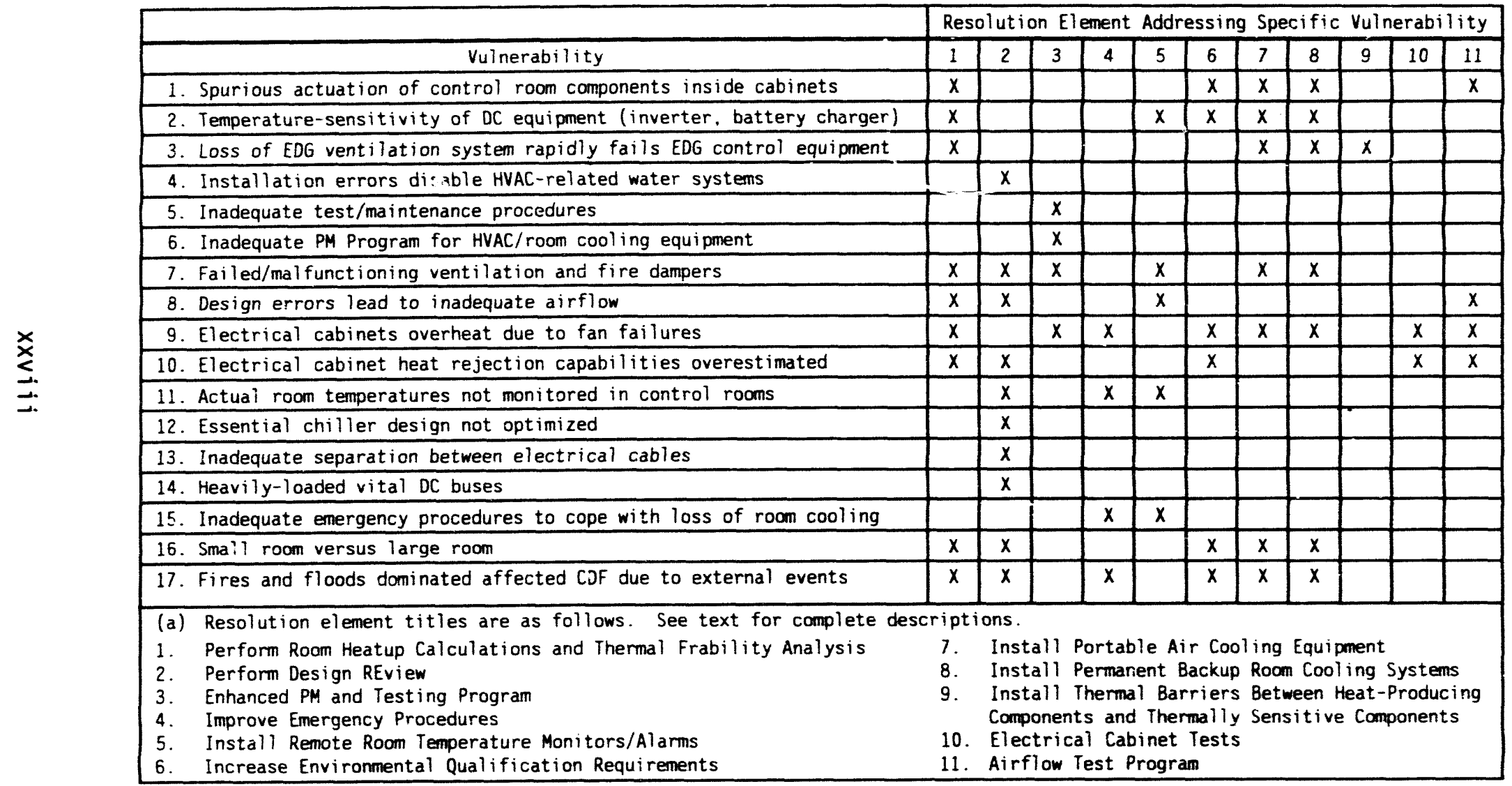




\section{TABLE ES-3. Summary of Alternative Resolutions to GI-143}

\begin{tabular}{|c|l|}
\hline Alternative & \multicolumn{1}{|c|}{ Resolution Elements } \\
\hline 1 & 1. Perform Room Heatup Calculations and Thermal Fragility Analyses \\
& 2. Perform Design Review \\
& 3. Enhanced PM and Testing Program \\
& 4. Improve Emergency Procedures \\
\hline 2 & 1. Perform Room Heatup Calculations and Thermal Fragility Analyses \\
& 2. Perform Design Review \\
& 3. Enhanced PM and Testing Program \\
& 4. Improve Emergency Procedures \\
& 5. Install Remote Temperature Monitors/Alarms \\
& 6. Install Portable Room Cooling Equipment \\
\hline 3 & 1. Perform Room Heatup Calculations and Thermal Fragility Analyses \\
& 2. Perform Design Review \\
& 3. Enhanced PM and Testing Program \\
& 4. Improve Emergency Procedures \\
& 5. Install Remote Room Temperature Monitors/Alarms \\
& 7. Increase Environmental Qualification Requirements \\
& 8. Install Permanent Backup Room Cooling Systems \\
& 9. Install Thermal Barriers Between Heat-Producing Components and \\
& 10. Electrical Cabinet Tests \\
& 11. Airflow Test Program \\
\hline
\end{tabular}

Estimates of the onsite consequences of the three resolution alternatives were developed, including increased occupational exposures due to implementation, operation, and maintenance activities associated with each alternative. The averted occupational doses and economic consequences associated with reduced accidents were also calculated. These latter costs are treated as cost offsets and are deducted from the total NRC and industry implementation, operation, and maintenance costs.

The preliminary value-impact assessment combines the results of the cost and risk calculations. These results of the public risk reduction calculations, or the benefits of the alternative resolutions to GI-143, are summarized in Table ES-4. The table shows the per-plant reductions in CDF and public risks associated with implementation of each of the alternatives and the total life-cycle public risk reduction. The total public risk reduction is defined as the per-plant risk integrated over all current plants and the average remaining lifetimes of these plants.

The costs of each alternative resolution are presented in Table ES-5. This table shows the implementation, operation/maintenance, NRC, onsite consequences, onsite property damage, and offsite property damage costs for each 
TABLE ES-4. Summary of Benefits of Alternative Resolutions to GI-143

\begin{tabular}{|l|c|c|c|}
\hline & \multicolumn{3}{|c|}{ GI -143 Resolution } \\
\hline \multicolumn{1}{|c|}{ Parameter } & 1 & 2 & 3 \\
\hline Per-plant reduction in CDF/RY & $2.4 \mathrm{E}-06$ & $4.5 \mathrm{E}-06$ & $6.7 \mathrm{E}-06$ \\
\hline $\begin{array}{l}\text { Per-plant reduction in public risks (person- } \\
\text { rem/RY) }\end{array}$ & $8.4 \mathrm{E}-01$ & $1.3 \mathrm{E}+00$ & $2.0 \mathrm{E}+00$ \\
\hline Total integrated risk reduction (person-rem) & $2.2 \mathrm{E}+03$ & $3.6 \mathrm{E}+03$ & $5.2 \mathrm{E}+03$ \\
\hline
\end{tabular}

alternative resolution. The top half of the table presents the per-plant costs, and the bottom half presents the total integrated costs. All costs are discounted to 1993 dollars.

Table ES- 6 shows the value-impact ratios for each alternative. The ratios were calculated by dividing the total discounted costs by the total public risk reduction. The table shows the net value:impact ratio, calculated without the cost offsets for onsite and public property damage, as well as the net value: impact ratio (includes cost offsets). These value: impact ratios are illustrated in Figure ES-1 relative to the value of $\$ 1000$ /person-rem used to determine cost-effectiveness. As shown, all of the resolution alternatives exceed the $\$ 1000 /$ person-rem cost-effectiveness ratio, both in terms of the net and total value:impact ratios. 
TABLE ES-5. Summary of Per-PIant and Total Costs for Each Resolution Alternative

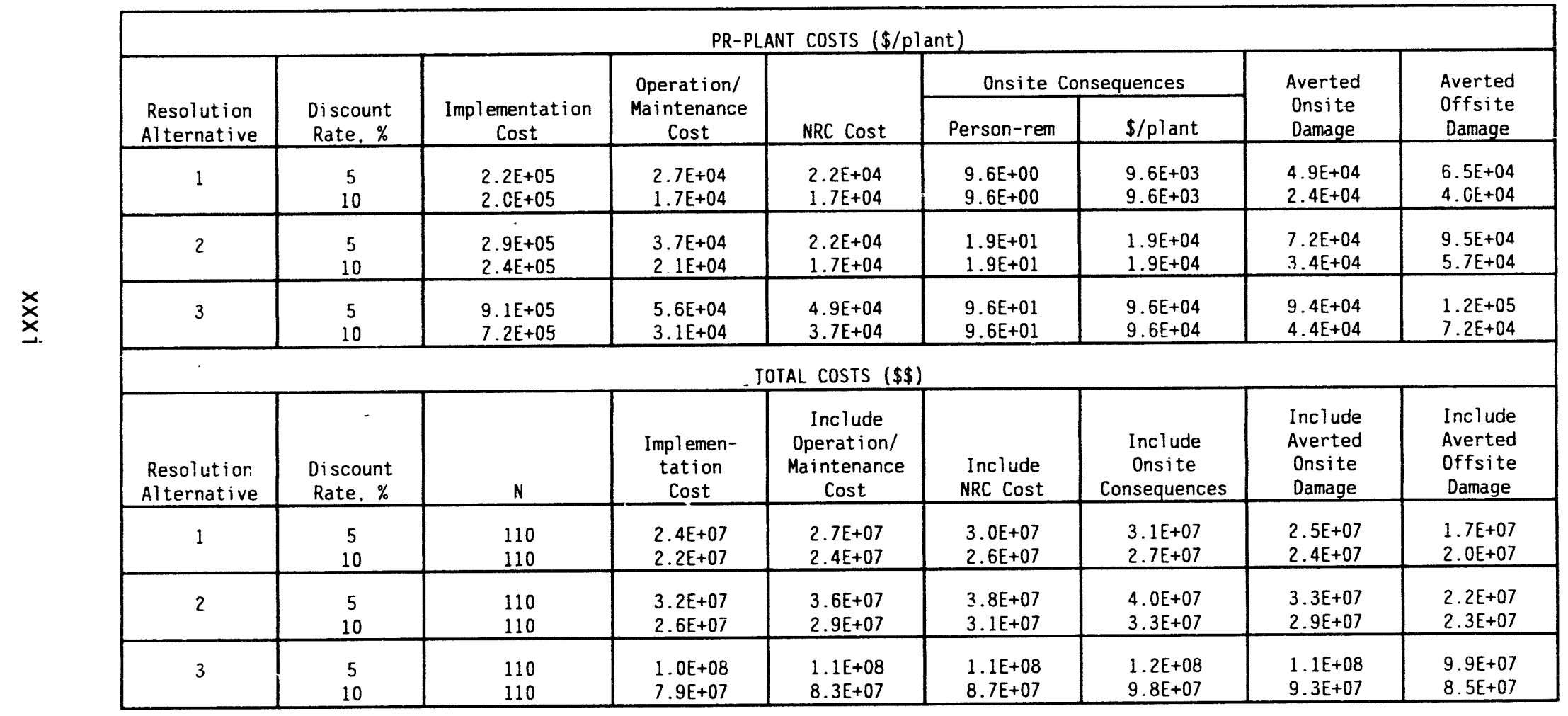


IABLE ES-6. Best Estimate Value:Impact Ratios (\$/person-rem)

\begin{tabular}{|c|c|c|c|}
\hline $\begin{array}{c}\text { Resolution } \\
\text { Alternative }\end{array}$ & $\begin{array}{c}\text { Discount } \\
\text { Rate, } \%\end{array}$ & $\begin{array}{c}\text { Net } \\
\text { Cost:Benefit }\end{array}$ & $\begin{array}{c}\text { Total } \\
\text { Cost:Benefit }\end{array}$ \\
\hline 1 & 5 & $8.2 E+03$ & $1.4 \mathrm{E}+04$ \\
& 10 & $8.8 \mathrm{E}+03$ & $1.2 \mathrm{E}+04$ \\
\hline 2 & 5 & $6.2 \mathrm{E}+03$ & $1.1 \mathrm{E}+04$ \\
& 10 & $6.4 \mathrm{E}+03$ & $9.2 \mathrm{E}+03$ \\
\hline 3 & 5 & $1.9 \mathrm{E}+04$ & $2.3 \mathrm{E}+04$ \\
& 10 & $1.6 \mathrm{E}+04$ & $1.9 \mathrm{E}+04$ \\
\hline
\end{tabular}

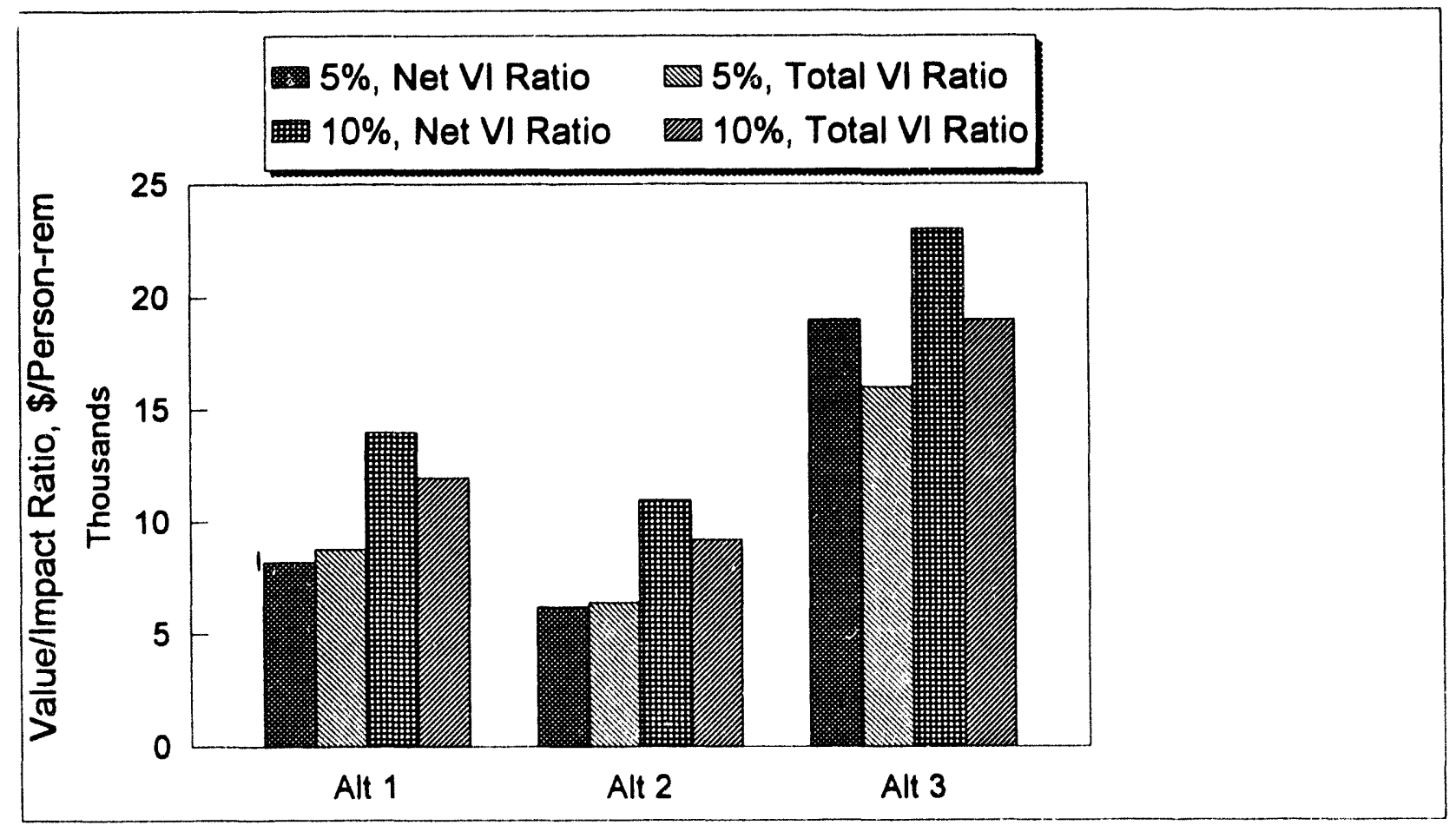

FIGURE ES-1. Illustration of Total Value:Impact Ratios for the Three Proposed Alternative Resolutions 


\section{ACKNOWLEDGMENT}

The authors would like to express their appreciation to the following individuals for their guidance and assistance during the preparation of this document; Mr. Vincent Leung of the U.S. Nuclear Regulatory Commission for his guidance and encouragement; Mr. P.J. Pelto and Mr. R.H.V. Gallucci, PNL, for technical reviews of the information in the document; Ms. Sheila Bennett, PNL, for her patience and skill in editing the document; and to the many NRC and Utility staffmembers who assisted in arranging and conducting plant visits and providing technical information in support of this project. 


\section{ACRONYMS}

\begin{tabular}{|c|c|}
\hline $\begin{array}{l}\text { ADS } \\
\text { AFW } \\
\text { AHU } \\
\text { AOV } \\
\text { APB } \\
\text { ASP } \\
\text { ATWS } \\
\text { B\&W } \\
\text { BWR } \\
\text { BWST } \\
\text { CCW } \\
\text { CDF } \\
\text { CE } \\
\text { CRD } \\
\text { CS } \\
\text { CST } \\
\text { DHR } \\
\text { ECCS } \\
\text { EDG } \\
\text { EFW } \\
\text { ESF } \\
\text { ESW } \\
\text { FSAR } \\
\text { CE } \\
\text { HEPA } \\
\text { HPC I } \\
\text { HPCS } \\
\text { HPI } \\
\text { HPR } \\
\text { HVAC } \\
\text { IPE } \\
\text { LOCA } \\
\text { LOOP } \\
\text { LOSP } \\
\text { LPCI } \\
\text { LPCS } \\
\text { LPI } \\
\text { LPR } \\
\text { LPSW } \\
\text { LWR } \\
\text { MCC } \\
\text { MDP } \\
\text { MFW } \\
\text { MOV } \\
\text { MSIV } \\
\text { NRC } \\
\text { NSS } \\
\text { PCS }\end{array}$ & $\begin{array}{l}\text { Automatic Depressurization System } \\
\text { Auxiliary Feedwater } \\
\text { Air Handling Unit } \\
\text { Air-operated Valve } \\
\text { Accident Progression Bin } \\
\text { Auxiliary Shutdown Panel } \\
\text { Anticipated Transient Without SCRAM } \\
\text { Babcock and Wilcox } \\
\text { Boiling Water Reactor } \\
\text { Borated Water Storage Tank } \\
\text { Component Cooling Water } \\
\text { Core Damage Frequency } \\
\text { Combustion Engineering } \\
\text { Control Rod Drive } \\
\text { Containment Spray } \\
\text { Condensate Storage Tank } \\
\text { Decay Heat Removal } \\
\text { Emergency Core Cooling System } \\
\text { Emergency Diesel Generator } \\
\text { Emergency Feedwater } \\
\text { Engineered Safety Feature } \\
\text { Essential Service Water } \\
\text { Final Safety Analysis Report } \\
\text { General Electric } \\
\text { High-Efficiancy Particulate Air } \\
\text { High Pressure Coolant Injection } \\
\text { High Pressure Core Spray } \\
\text { High Pressure Injection } \\
\text { High Pressure Recirculation } \\
\text { Heating, Ventilation, and Air Conditioning } \\
\text { Individual Plant Examination } \\
\text { Loss of Coolant Accident } \\
\text { Loss of Offsite Power } \\
\text { Loss of Station Power } \\
\text { Low Pressure Coolant Injection } \\
\text { Low Pressure Core Spray } \\
\text { Low Pressure Injection } \\
\text { Low Pressure Recirculation } \\
\text { Low Pressure Service Water } \\
\text { Light Water Reactor } \\
\text { Motor Control Center } \\
\text { Motor-driven Pump } \\
\text { Main Feedwater } \\
\text { Motor-operated Valve } \\
\text { Main Stream Isolation Valve } \\
\text { Nuclear Regulatory Commission } \\
\text { Nuclear Steam Supply System } \\
\text { Power Conversion System }\end{array}$ \\
\hline
\end{tabular}




$\begin{array}{ll}\text { PDS } & \text { Plant Damage State } \\ \text { PNL } & \text { Pacific Northwest Laboratory } \\ \text { PORV } & \text { Power-operated Relief Valve } \\ \text { PRA } & \text { Probabilistic Risk Assessment } \\ \text { PWR } & \text { Pressurized Water Reactor } \\ \text { RCIC } & \text { Reactor Core Isolation Cooling } \\ \text { RCP } & \text { Reactor Coolant Pump } \\ \text { RCS } & \text { Reactor Coolant System } \\ \text { RHR } & \text { Residual Heat Removal } \\ \text { RPS } & \text { Reactor Protection System } \\ \text { RWCU } & \text { Reactor Water Cieanup } \\ \text { RWST } & \text { Refueling Water storage tank } \\ \text { RY } & \text { Reactor-year } \\ \text { SBO } & \text { Station Blackout } \\ \text { SDC } & \text { Shutdown Cooling } \\ \text { SG } & \text { Steam Generator } \\ \text { JGTR } & \text { Steam Generator Tube Rupture } \\ \text { SOV } & \text { Solenoid-operated Valve } \\ \text { SRV } & \text { Safety Relief Valve } \\ \text { SSF } & \text { Standby Shutdown Facility } \\ \text { TDP } & \text { Turbire-Driven Pump } \\ \text { W } & \text { Westinghouse }\end{array}$




\subsection{INTRODUCTION AND BACKGROUND}

Generic Safety Issue (GSI) 143, "Availability of Chilled Water Systems and Room Cooling," is concerned with the avallability of cooling services provided by chilled water and heating, ventilation, and air conditioning (HVAC) systems and related auxiliaries to provide temperature control in rooms outside containment with safety-related equipment. The basic objective of this project is to evaluate the present designs and reliability of HVAC and chilled water systems in nuclear power plants and the consequences of potential system failures. Specific objectives include

- Identifying areas that are particularly vulnerable to loss of HVAC or room cooling

- Based on existing data, evaluating the HVAC and chilled water systems' failure frequencies leading to a loss of heat removal capability from the areas containing safety-related equipment

- Determining the vulnerabilities of safety-related systems and components to failure of HVAC and chilled water systems that are reflected in actual operating experience

- Estimating the core damage frequency (CDF) and public risks that are associated with failure of HVAC and chilled water systems

- Developing alternative resolutions to this issue and performing value/impact analyses of each alternative.

The scope of this issue includes the operability of equipment and systems in rooms cooled by HVAC and chilled water systems. Failures other than those that may be induced by environmental conditions that are controlled by HVAC and chilled water systems are not included e.g., maintenance errors, wear-out failures not caused by high temperature conditions, and control circuitry failures, such as short-to-ground faults, that are not caused by high temperatures). Failure to provide cooling water to remove heat from plant equipment [e.g., residual heat removal (RHR) and component cooling water (CCW) heat exchangers] are not included. Failure to provide cooling water to the se heat exchangers is addressed in other GSIs (e.g., GSI 51, "Improving the Reliability of Open-Cycle Service Water Systems," and GI-153, "Loss of Essential Service Water in (WRs"). The scope does include failure to provide c001ing to rooms occupied by these components. The scope does not include the effects of high temperatures on personnel in control rooms and other areas of the plants; the effects of high temperatures on components in the control room are included. In addition, the srope is limited to the cooling functions provided by HVAC and chilled water systems and does not include air cleaning and heating functions that may be provided by these systems. 
This report contains the results of the second task of this project. The objectives of this task are to

- collect summary-level information on the design and operation of engineered safety features (ESFS) at a representative cross-section of nuclear power plants currentiy in operation

- identify and describe accident sequences that could potentially involve failures of room cooling and HVAC functions as contributing events

- identify and catalogue basic events and reliability data that explicitly or implicitly address fallures of room cooling or HVAC functions

- develop and quantify additional event trees for potential initiating events involving losses of room cooling functions, where needed

- quantify the affected CDF and public risks associated with accident sequences involving loss of room cooling.

The information in this report provides quantitative information on the values of affected parameters and affected CDFs associated with losses of room cooling functions at commercial nuclear power plants. Value-impact calculations were performed by modifying the affected parameters in this report to account for resolution of this issue either through hardware changes or changes to operating and maintenance practices at nuclear power piants. The effects of these changes were quantified in terms of the reduction in CDF and public risks that result from the proposed resolution as well as the costs to develop, implement, operate, and maintain the proposed fixes.

\subsection{FAILURE OF ROOM COOLING}

As mentioned previously, the scope of this study includes HVAC and room cooler systems that function to remove heat from rooms containing safetyrelated components. Key safety-related systems requiring room cooling include electrical switchgear rooms, the control room, diesel generator enclosures, and various emergency core cooling system (ECCS) pump rooms. Operating experience indicates that failures of these room cooling systems could have significant effects on plant safety. Several room cooler failure events and information on potential accident sequences involving room cooler failures are described below.

\subsubsection{Electrical Switchgear Room Cooling Failures}

Electrical switchgear rooms house equipment that is necessary to provide control power, to safety-related equipment and motive power to $A C$-powered safety-related pumps and valves. Failure of switchgear room cooling could cause electrical components to malfunction, resulting in failure or spurious actuation of ESFs. Some relevant examples of such events are described below. 
- Lois (1992) presented information on a potential accident sequence involving loss of electrical switchgear room cooling at a Westinghouse (W) pressurized water reactor (PWR). This accident sequence was identified from the plant's Individual Plant Examination (IPE). The event described by Lois involves a loss of switchgear room cooling during a loss of offsite power (LOOP) with one diesel generator operable. Such a sequence would lead to core damage. Although Lois was most interested in an accident sequence consisting of loss of switchgear room during a LOOP event, it pointed out the importance of this failure. Relatively high CDFs were calculated by Lois (1992), which further justifies an explicit analysis of this failure as an initiating event.

- An event at a BWR occurred (Licensee Event Report [LER] 86-016) in which it was found that both trains of the electrical switchgear room cooling system were inoperable. The event occurred during a performance verification test when an operator error caused a water regulating valve to fail to open, resulting in failure of emergency service water (ESW) flow into the switchgear room cooler's condenser. An operator repositioned the valve from $100 \%$ to $0 \%$ and the valve opened. Similar results occurred when the other train of switchgear room cooling was tested. Such failures could render one or both of the switchgear room cooling systems inoperable. If a loss of coolant accident (LOCA) had occurred simultaneously, the plant's low-pressure emergency core cooling system (ECCS) could fail.

The LER noted that the circulating air in the switchgear rooms are cooled during normal operations by the Reactor Building chilled water (RBCW) system. During a LOCA, the RBCW system is isolated and the switchgear room cooling units are automatically started. The waterregulating valve automatically opens to all essential service water (ESW) flow into the room cooler. Without ESW flow, the room cooler units would trip, causing a loss of cooling to the emergency switchgear and emergency load center rooms. Although the fans would also trip, it is possible to restart the fans from the control room, which would circulate air and partially remove the heat generated by the electrical components in the rooms. The maximum temperature the components are qualified to operate in is $104^{\circ} \mathrm{F}$. Should the temperature rise above this value, it is uncertain what the effects on the electrical components would be. If the electrical components had failed, AC power to the low-pressure coolant injection (LPCI) and core spray (CS) systems would have failed.

- At a W PWR, it was determined that a loss of cooling in a Train B emergency switchgear room will result in loss of cooling to Train $A$ inverters and battery chargers. This could result in a common mode failure that could affect both trains of vital control power. During a root cause analysis, it was observed that cooling to two battery board rooms was reversed. Consequently, failure of Train B switchgear room 
cooling could result in inoperability of Train A equipment. At the time, the Train B chiller for the switchgear rooms was inoperable, but both air handling units (AHUS) were operable. The Train A chiller and AHUs were operable.

The licensee responded to these observations by performing thermal analysis calculations to determine the temperature rise within the switchgear rooms following loss of room cooling. It was determined that the ambient temperature within the room would reach the $104 \circ \mathrm{F}$ maximum design temperature in 27 to 44 hours. At this point, the equipment in the room would technically be inoperable, and the plant would enter a technical specification requirement to bring the plant to hot shutdown in one hour. The calculations also showed that, at an initial temperature of $100^{\circ} \mathrm{F}$, it will take about 10 hours to reach the $104^{\circ} \mathrm{F}$ maximum temperature. As a result, the 1 icensee implemented requirements to monitor room temperatures every two hours following loss of the room chillers and would be required to shut down if the temperature in either room exceeded $100^{\circ} \mathrm{F}$. The 1 icensee al so implemented a requirement that, following loss of Train B cooling, the door between the Train A and Train $B$ switchgear rooms will be opened to circulate cooled air from the Train A room to the Train B room. The licensee also installed portable ventilation ducts and fans to circulate the cooled air.

- A potential accident sequence was discovered at a Combustion Engineering (CE) PWR that could be initiated by loss of cooling to the DC equipment room. The potential accident was initiated by loss of one essential chiller, causing the ambient temperature in the $D C$ equipment room to rise. Electrothermal links are provided to allow fire dampers to close in the ventilation ductwork for this room, effectively halting all ventilation airflow. After the room temperature had risen to equipment qualification temperatures, a vital $A C$ inverter was postulated to fail. The inverter failure would actuate ESFs; close main steam isolation valves (MSIVs), effectively failing main'feedwater; and cause a turbine trip and reactor SCRAM. At the same time, one train of nonsafety auxiliary feedwater AFW and alternate feedwater from condensate pumps would fail due to loss of control solenoids for feedwater downcomer isolation valves. The safety-related steam-driven AFW pump would al so fail following battery depletion, because the control power for the pump comes from this bus. A motor-driven AFW pump powered from a second bus would be available. Therefore, this transient effectively fails four of five potential AFW sources. In addition, because one diesel generator control and field flashing system is powered from this bus, failure of this equipment also results in blackout of one diesel generator.

\section{1 .2 Loss of Control Room Cooling}

A search for room-cooling-related LERs (see Appendix A) and other events pointed out the relatively high frequencies of fallures of one or more trains of control room air conditioning (CRAC) systems. Reviews of documentation $n$ these events pointed out the importance of cooling to instrumentation and control system cabinets in the control room and adjacent rooms that are cooled 
by the CRAC system. Overheating of electrical components has been observed to cause spurious actuations of safety systems and spurious readings and alarms in the control room. Some relevant examples of such everts are described below.

- During a fire protection review at a boiling water reactor (BWR), it was discovered that an electric power feeder cable for a $600-V$ AC motor control center (MCC) was routed through a fire zone for which equipment from the same $A C$ power division was required for safe shutdown. The two MCCs provide $A C$ power to the main control room and relay room HVAC equipment. It was possible that a fire could cause a loss of power to the HVAC and emergency ventilation fans for these rooms. Engineering evaluations indicated that the temperature in the control/relay room could $r$ ise to $130^{\circ} \mathrm{F}$ without HVAC, far in excess of the $104^{\circ} \mathrm{F}$ maximum temperature for the components in the room. Should this equipment fail, the equipment for controlling and monitoring the safe shutdown process would be rendered inoperable.

- An event involving failure of CRAC systems at a W PWR (Chiramal) pointed out the potential for spurious actuations of equipment and spurious readings and alarms on control panels. The event involved failure of all control room ventilation resulting in an increase in control room ambient temperature. The control room ventilation system is a two-train system. Train A had been removed from service for maintenance; the Train B chiller tripped due to low oll level. Efforts to restart the Train B chiller failed, initiating the loss-of-control-room-cooling event.

A short time (45 minutes) arter the initial Train B chiller trip, the control room received numerous al arms, including high average tempera. ture in a reactor coolant loop and pressurizer level. Approximately two hours into the event, the control room operators started to reduce power as required by plant technical specifications. Operators also opened instrument cabinet doors, which allowed cool air to circulate from the air conditioned computer room. Portable fans and ducts were installed to move cool air from the computer room door to the cabinets. Approximately three hours into the event, the control room ventilation system was returned to service and declared operable. Because of previous experience with overheating of instrumentation and control (I\&C) systems, plant operators anticipated the problem alarms and responded correctly to the spurious alarms.

During the event, operators recalled the maximum ambient temperature near the cabinets as being about $90^{\circ} \mathrm{F}$, well below the technical specification limit of $120^{\circ} \mathrm{F}$. Design bases for the I\&C cabinet indicated a temperature rise of $20^{\circ} \mathrm{F}$ above room ambient temperature, so the maximum expected temperature in the cabinet should have been approximately $110^{\circ} \mathrm{F}$. However, following the event, temperature measurements indicated that internal cabinet air temperatures ranged from $73^{\circ} \mathrm{F}$ near the bottom to a maximum of $109 \circ \mathrm{F}$ near the top under ambient temperature conditions of $72^{\circ} \mathrm{F}$, resulting in a maximum temperature rise of about $37 \circ \mathrm{F}$. Thermo- 
couples placed directly on the instrument racks measured $115^{\circ} \mathrm{F}$ at the middle and $125^{\circ} \mathrm{F}$ at the top rack. Based on these measurements, the temperature at the top rack during the event may have been as high as $143^{\circ} \mathrm{F}$, which exceeded the card performance test of $140^{\circ} \mathrm{F}$ (12-hour cycle). Based on this observation, it is concluded that electronic components inside cabinets can be exposed to potentially damaging temperatures at ambient temperatures significantly below control room technical specification limits.

- An electronic failure in an ESF actuation system (ESFAS) cabinet resulted'in spurious actuation of several ESF signals at a CE PWR. A spurious automatic start of an emergency diesel generator (EDG), operation of the ESF load sequencer, and a load-shed signal in one safetyrelated bus were experienced. The cause of the event was traced to an overheated ESF load sequencer cabinet (a fan had failed), which allowed the ESF load sequencer module to overheat and malfunction. The malfunction resulted in the load sequencer sending a continuous load-shed signal to an emergency bus, preventing automatic and manual loading of electrical loads onto the safety-related bus and EDG.

To clear the load-shed signal, the ESFAS cabinet was deenergized, the normal supply breaker of bus was closed, undervoltage relays were jumpered, and the leads of the load-shed relays were lifted. Control fuses for one train of high-pressure safety injection (HPSI), lowpressure safety injection (LPSI), and containment spray pumps were removed prior to deenergizing the cabinet to prevent automatic startup of the pumps. During the initial phase of the event, the Train B essential chiller had tripped (low refrigerant level), rendering all Train B equipment inoperable. Because both trains of HPSI, LPSI, and containment spray were inoperable, the plant entered into a technical specification condition which required it to be brought to hot shutdown within one hour.

- At a CE PWR, during full power operations, both trains of emergency control room cooling became inoperable. One train of control room cooling was secured for maintenance when the second train tripped on overcurrent.

- An operator error at a W PWR during full-power operation was discovered that resulted in both trains of control room emergency cooling to be inoperable. One train had been secured for maintenance; later, it was discovered that the tagout was placed on the other train.

- Both trains of control room emergency cooling were inoperable at a W PWR during full-power operation. Both essential chillers had failed. One chiller tripped due to a failed temperature switch, and the other chiller failed to start due to a malfunction in the actuation system. At the same PWR, a second event occurred, which resulted in failure of both 
trains of control room cooling. One train was secured for maintenance on the service water system, and the other train was discovered to have a falled inlet damper. Similar events were reported to have occurred at the second unit at the site, also a W PWR.

- At a W PWR during full-power operation, both trains of control room ventilation were determined to be inoperable. One train was secured for maintenance on the service water system, and personnel mistakenly secured the second train of service water to the control room chillers.

- At a BWR operating at full power, both control room ventilation chillers tripped, rendering both trains of control room emergency ventilation inoperable. The chiller trips were caused by low refrigerant (freon) levels and level switch setpoint drift.

- At a W PWR, both trains of control room emergency ventilation were inoperable at $100 \%$ power. One control room air AHU was secured for maintenance, and the other AHU failed when its motor shaft sheared.

\subsubsection{Loss of Emergency Core Cooling System (ECCS) Room Cooling}

Room coolers are provided in ECCS pump rooms to maintain ambient temperatures below maximum design temperatures for the pumps and valves. Room coolers are referred to as "attendant equipment" and are tested in accordance with the technical specifications for the ECCS equipment. Fallure of the room cooler is considered equivalent to failure of the applicable ECCS pump and may result in the pump being declared inoperable until the room cooler can be returned to service. Some relevant examples of such events are described below.

- At a CE PWR during full power operation, both emergency feedwater pumps were declared inoperable. One pump was secured for maintenance, and the secord was declared inoperable when a stuck-open valve in the essential service water system rendered the pump room cooler inoperable.

- At a W PWR, a failed damper was discovered during power operations that resulted in insufficient ventilation flow to a high-pressure ECCS pump room. It is possible that the pump motor would have overheated if a demand for the pump had been signaled. It was also determined that a design requirement that had existed since initial operation to urovide temporary ventilation to these pumps rooms during an accident was never implemented in the emergency operating procedures. Thus, operators would have had no procedural guidance to implement the temporary cooling requirements, and the pumps may have overheated and failed during an accident.

- The high-pressure coolant injection (HPCI) system at a BWR was declared inoperable when it was discovered that seismically qualified fire protection switches could trip both HPCI room coolers during a seismic event. The vulnerability had existed since initial operation of the plant. At the same plant, the HPCI system was declared inoperable when 
the HPCI room coolers were inoperable during power operation (96\%). One cooler had been isolated to correct flow problems in the essential service water system, and the other cooler would not operate when a thermal breaker opened during testing.

- At a BWR, when attempting to place residual heat removal (RHR) pump room coolers into service, neither cooler would start, rendering both RHR trains inoperable. One room cooler would not start because of a failed fan start switch and the other due to a failed airflow dampers (mechanical binding).

- At a W PWR, both trains of a high-pressure injection system were inoperable at full power. The drive belts to one room cooler were found to be broken, and the other room cooler was out of service for maintenance.

\subsubsection{Diesel Generator Enclosure Ventilation Systems}

Emergency diesel generator (ECG) enclosures are typically cooled by air circulated through the enclosure by large exhaust fans. No chilled water systems are provided to cool the circulating air. This is a relatively simple system, although the following examples indicate that failures have occurred in the past.

- At a BWR operating at full power, it was discovered that five recirculation damper actuators in the EDG ventilation system were inoperable due to seal failures. Failure of these dampers would result in a loss of airflow in the EDG enclosure and cause the temperature to rise. EDG control equipment in the enclosure could overheat and fail, resulting in failure of one division of emergency $A C$ power.

- A design error in the supply dampers of the EDG ventilation system caused the system to be inoperable. It was discovered that the dampers would fail closed, preventing outside air from circulating through the room. A similar occurrence was identified at a W PWR, in which it was determined that supply dampers would fail closed on a loss of instrument air.

- A potential common mode failure of the EDG ventilation system supply fans was identified at a BWR. It was determined that the fans were susceptible to cracking due to frequent stops and starts (the fans autostart on a EDG start signal).

- During a routine review of the EDG loading sequence at a W PWR, it was observed that manual actions were necessary to start the EDG ventilation system. The ventilation system was designed to automatically start when the diesels start.

The events and accident sequences described on the previous pages are included in the evaluation of the affected CDF and public risks presented in this document. The discussion was intended to provide perspective on the 
types of room cooling systems and the safety systems affected by room cooling as well as to illustrate the effects of room cooler failures on plant safety. A more exhaustive search for relevant operating history is discussed in Appendix A of this document. 


\subsection{BASES AND APPROACH}

This chapter describes the approach used in this project to quantify the affected core damage frequency (CDF) and public risks associated with failure of the room cooling function at commercial nuclear power plants. This approach, which is illustrated in Figure 2.1-1, consists of five main technical steps:

- Establish list of representative plants

- Identify engineered safety feature (ESF) dependencies on HVAC/room coolers

- Develop list of cut sets involving room cooler failures

- Identify affected accident sequences

- Quantify affected CDF and public risk.

Each of the main steps depicted in Figure 2.1-1 is described in this chapter.

\subsection{ESTABLISH LIST OF REPRESENTATIVE PLANTS}

The first step in this analysis is to identify a set of representative plants to be used as the basis for the affected CDF and public risk calculations. As shown in Figure 2.1-1, two main inputs were used to select the plants: 1) a review of HVAC/room cooler designs, and 2) a review of LER data on HVAC system and room cooler failures.

The first criterion for selecting the representative plants was the degree of "typicality" exhibited by the various room cooler system designs at various nuclear power plants. This was evaluated in terms of the following parameters:

- plant age

- design philosophy (e.g., large, centralized HVAC/room cooling systems versus a large number of smaller systems)

- large versus small pump rooms or cubicles

- extent to which cross-connecting capability may be used between units at multi-unit sites

- differences that might arise due to differences in plant types [i.e., pressurized water reactor (PWR) versus boiling water reactor (BWR)] or 


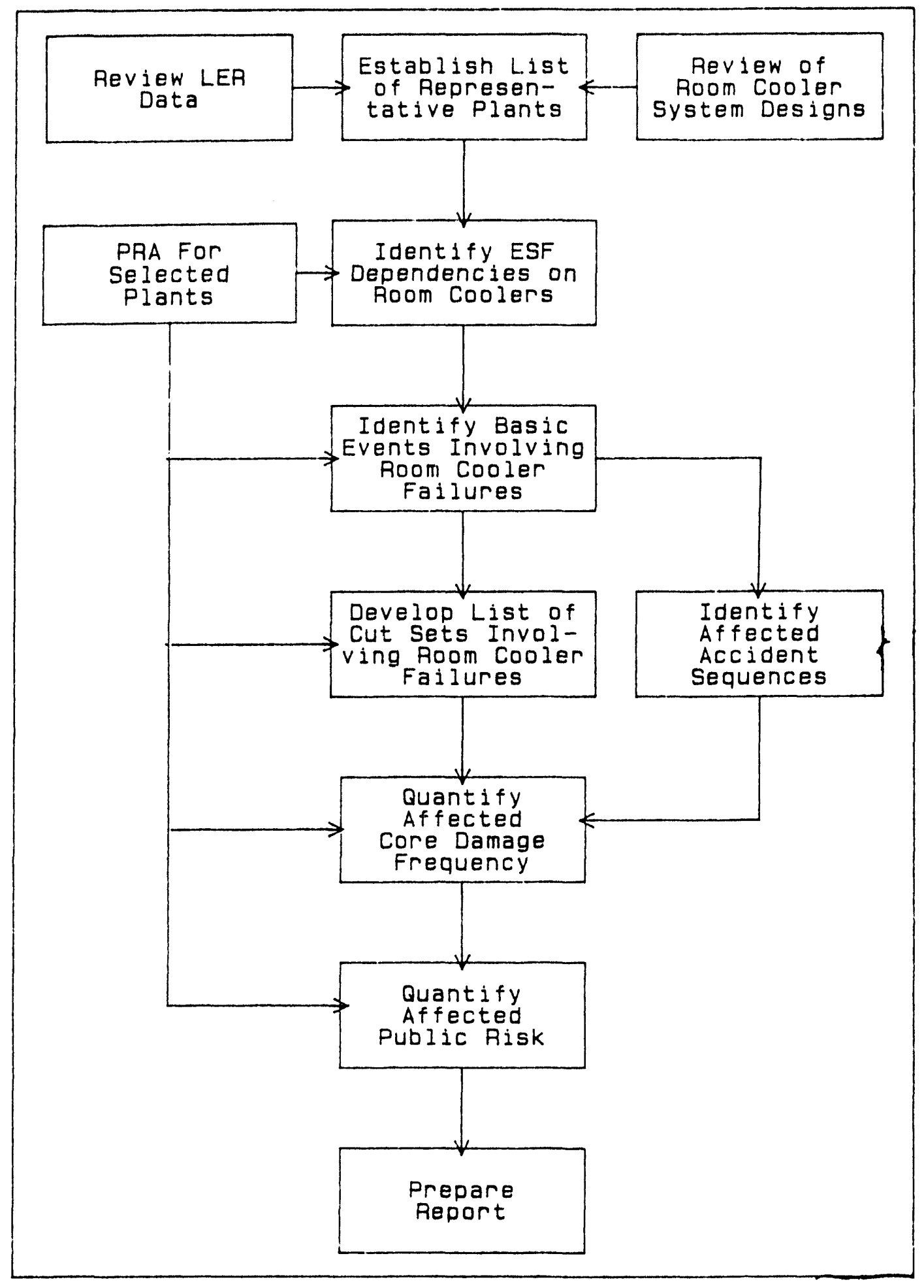

FIGURE 2.1-1. Illustration of Approach Used in This Study 
due to differences in reactor vendors [i.e., Westinghouse (W) PWRs versus Combustion Engineering (CE) PWRs versus Babcock and Wilcox (B\&W) PWRs versus General Electric (GE) BWRs]

- differences in room cooler designs that are attributable to the source of cooling water (i.e., plants using fresh water versus marine or estuarine service water sources)

Previous experience with service water systems indicated that, in general, plants located in marine or estuarine environments used large, centralized heat exchangers and intermediate cooling loops to remove heat from components requiring cooling, whereas fresh water plants were more likely to use a large number of relatively small heat exchangers that were cooled by raw cooling water pumped directly from the source to the components. This possibility was examined here.

Final safety analysis reports (FSARs) and design information from a number of nuclear power plants were reviewed to develop insights on the bulleted items listed above. The plant designs reviewed and the major characteristics of each plant are shown in Table 2.1-1.

No significant commonalities or groupings among old plant designs versus new plants were detected in the review. 01d plants did not exhibit HVAC/room cooler design features or design philosophies that were substantially different from new plants. There were, of course, significant differences in HVAC/room cooler designs among the plants reviewed, but the age of the plant. did not appear to make a difference.

Based on the plant design reviews, it was determined that there is no "generic" room cooler and HVAC system design that could represent the entire population of plants. Each plant had unique design features which, in some cases, were relatively subtle. For example, one plant located component cooling water (CCW) pumps in a large, open area along with other safety-related pumps. Room cooling in this area was provided by a single, large air handling unit (AHU). Chilled water was not required to maintain room temperatures below pump design bases. A second plant located CCW pumps in small cubicles that required chilled water room coolers to maintain temperatures below the CCW pump design basis.

There were no significant commonalities or groupings among plant types or vendors detected in the review. Each veno'or appeared to provide plantspecific room cooling system designs. The different vendors did not appear to use predominantly large centralized heat exchangers in lieu of small local heat exchangers, nor did they appear to provide predominantly large versus small rooms or cubicles for safety-related equipment. One commonality among all the plant designs reviewed was that the control room HVAC system was separate and isolated from all other room cooling functions. The control room HVAC systems were predominantly separated from other room coolers in all 
IABLE 2.1-1. Plant Designs Reviewed in This Study

\begin{tabular}{|l|c|c|c|}
\hline \multicolumn{1}{|c|}{ Plant Name } & Plant Type & Vendor & Wa:er Source Type \\
\hline Sequoyah 1 & PWR & W & Fresh \\
Perry 1 & BWR & GE (a) & Fresh \\
Grand Gulf 1 & BWR & GE & Fresh \\
Calvert Cliffs 1 & PWR & CE & Marine \\
Palo Verde & PWR & CE & Fresh \\
Surry 1 & PWR & W & Fresh \\
Fermi 2 & BWR & GE & Fresh \\
Oconee 1 & PWR & B\&W & Fresh \\
Brunswick 1 & BWR & GE & Estuarine \\
South Texas 1 & PWR & W & Fresh \\
Pilgrim & BWR & GE & Marine \\
\hline (a) General Flectric Corporation. \\
\hline
\end{tabular}

areas, including refrigeration (chillers), duct work, fans, power supply, and dampers. Consequently, a representative plant would exhibit this characteristic.

No significant commonalities among room cooler designs were found based on the water source type. Room coolers using chilled water were typically cooled by an intermediate cooling loop and did not receive cooling water directly from the plant water source. Thus, no general statements are made about differences in HVAC/room cooler designs that are attributable to the plant water source.

Based on these design reviews, it appears that there are no "generic" HVAC/room cooler designs among the population of U.S. nuclear reactors. Each plant appears to have "tailor-made" room cooling system designs to fit the characteristics of each plant, probably on the basis of space limitations and particular plant configurations. As a result, a plant from each vendor was selected for the detailed CDF and public risk calculations. This was done to ensure the results are applicable to a large fraction of plants and to determine if there are significant differences in HVAC/room cooling-related CDF or public risk among vendors or plant types even though the HVAC/room cooler designs appear not to be vendor-or plant-type-specific.

The second criterion for selection of plants for the detailed calculations was apparent vulnerability to HVAC/room cooler failures. The goal was to select plants that appear to be more vulnerable than others, based on the frequencies at which room cooler failures occur, yet are not outliers in terms of being uniquely vulnerable to HVAC/room cooler failures. Plants that are not vulnerable based on historical data could potentially skew the results of 
the CDF and public risk calculations in a nonconservative fashion, resulting in misleading conclusions if the calculations indicate this issue is not important. On the other hand, if a uniquely vulnerable plant were to be selected based on a very higlı HVAC/room cooler failure rate, the results could be excessively high and misleading as to its application to other plants.

A preliminary assessment of $\mathrm{HVAC} /$ room cooler failure data was performed to select the plants for the detalled CDF and public risk calculations. plant-specific room cooler vulnerability was assumed to be proportional to the frequencies of Licensee Event Reports (LERs) involving room coolers, as reported in the Task 1 database report for this generic issue. Table 2.1-2, which is based on data reported in Appendix $A$, shows the annual frequencies of HVAC/room cooler failures at each nuclear power plant. The plants are separated by vendor.

Table 2.1-2 illustrates a couple of interesting points. It appears that BWRs have about twice the room cooler LER frequency, averaging about $0.25 / R Y$ for all BWRs, as $W$ and CE PWRs (averaging about $0.1 / R Y$ ). B\&W plants appear to experience the fewest room cooler failures.

The second item relates to the plant selection for the value-impact analysis. The plants with the highest LER frequencies (defined as plants having LER frequencies greater than 0.5/RY) are highlighted on Table 2.2. As shown, of the W PWRs, Sequoyah-1 is on the high-failure list, but Surry is not. In fact, Surry reported no LERs involving room cooler failures over the 1980 to 1992 period. The other plants on the high-failure-frequency list include Catawba ( 7 years of commercial operation), Callaway ( 8 years), South Texas 1 and 2 ( 4 and 3 years, respectively), and Wolf Creek ( 7 years). These are relatively new plants, and the high LER frequency may be a result of shakedown or learning curve effects on the room coolers.

None of the CE or B\&W plants were placed on the high LER frequency list, although Palisades and Palo Verde-1 (both CE) were near the arbitrarily assigned cutoff of $0.5 / R Y$.

of the BWRs, Grand Gulf 1, Clinton 1, Fermi 2, and Perry 1 are on the high-frequency list. Again, note that all these plants are relatively new, with Grand Gulf having the largest number of operating years, seven. The older plants appear to experience fewer room-cooler-related LERs than newer plants.

Based on these data, plants were selected in terms of vulnerability to room cooler failures. These plants appear to not be outliers in terms of being excessively vulnerable, yet have experienced HVAC/room cooler failures at high frequencies relative to the other plants. Detailed probabilistic risk assessments (PRAs) exist for these plants. 
IABLE 2.1-2, HVAC/Room Cooler LER Frequencies for Fach Nuclear Power Plant (1980 to 1992)

\begin{tabular}{|c|c|c|c|c|}
\hline & $\begin{array}{c}\text { Year } \\
\text { Entered } \\
\text { Commercial } \\
\text { Operation }\end{array}$ & $\begin{array}{c}\text { Years of } \\
\text { Comm. } \\
\text { Operation } \\
\text { Since } 1980\end{array}$ & $\begin{array}{c}\text { Number of } \\
\text { LERs Since } \\
1980\end{array}$ & $\begin{array}{c}\text { Annual } \\
\text { Frequency }\end{array}$ \\
\hline \multicolumn{5}{|l|}{ Westinghouse PWRs } \\
\hline Beaver Valley 1 & 76 & 12 & 0 & 0.000 \\
\hline Beaver Valley 2 & 87 & 5 & 0 & 0.000 \\
\hline Ginna & 70 & 12 & 0 & 0.000 \\
\hline Haddam Neck & 67 & 12 & 0 & 0.000 \\
\hline Indian Pt. 2 & 74 & 12 & 1 & 0.083 \\
\hline Indian Pt. 3 & 76 & 12 & 0 & 0.000 \\
\hline Salem 1 & 77 & 12 & 1 & 0.083 \\
\hline Salem 2 & 81 & 11 & 2 & 0.182 \\
\hline Seabrook & & & & \\
\hline Yankee Rowe & 60 & 12 & 0 & 0.000 \\
\hline Millstone 3 & 86 & 6 & 0 & 0.000 \\
\hline North Anna 1 & 78 & 12 & 0 & 0.000 \\
\hline North Anna 2 & 80 & 12 & 0 & 0.000 \\
\hline Catawba 1 & 85 & 7 & 4 & 0.571 \\
\hline Catawba 2 & 85 & 7 & 0 & 0.000 \\
\hline Farley 1 & 77 & 12 & 2 & 0.167 \\
\hline Farley 2 & 81 & 11 & 1 & 0.091 \\
\hline \multicolumn{5}{|l|}{ Harris 1} \\
\hline McGuire 1 & 81 & 11 & 3 & 0.273 \\
\hline McGuire 2 & 84 & 8 & 0 & 0.000 \\
\hline Robinson 2 & 71 & 12 & 2 & 0.167 \\
\hline Sequoyah 1 & 81 & 11 & 9 & 0.818 \\
\hline Sequoyah 2 & 82 & 10 & 0 & 0.000 \\
\hline Summer & 84 & 8 & 2 & 0.250 \\
\hline Surry 1 & 72 & 12 & 0 & 0.000 \\
\hline Surry 2 & 73 & 12 & 0 & 0.000 \\
\hline Turkey Pt. 3 & 72 & 12 & 1 & 0.083 \\
\hline Turkey Pt. 4 & 73 & 12 & 0 & 0.000 \\
\hline \multicolumn{5}{|l|}{ Watts Bar 1} \\
\hline Watts Bar 2 & & & & \\
\hline Vogtle 1 & 87 & 5 & 2 & 0.400 \\
\hline Vogtle 2 & 89 & 3 & 1 & 0.333 \\
\hline Byron 1 & 85 & 7 & 1 & 0.143 \\
\hline Byron 2 & 87 & 5 & 0 & 0.000 \\
\hline Cook 1 & 75 & 12 & 0 & 0.000 \\
\hline Cook 2 & 78 & 12 & 1 & 0.083 \\
\hline Call away & 84 & 8 & 5 & 0.625 \\
\hline Kewaunee & 74 & 12 & 0 & 0.000 \\
\hline
\end{tabular}


IABLE 2.1-2. (contd)

\begin{tabular}{|c|c|c|c|c|}
\hline & $\begin{array}{c}\text { Year } \\
\text { Entered } \\
\text { Commercial } \\
\text { Operation }\end{array}$ & $\begin{array}{l}\text { Years of } \\
\text { Comm. } \\
\text { Operation } \\
\text { Since } 1980\end{array}$ & $\begin{array}{c}\text { Number of } \\
\text { LERs Since } \\
1980\end{array}$ & $\begin{array}{c}\text { Annual } \\
\text { Frequency }\end{array}$ \\
\hline $\begin{array}{l}\text { Point Beach } 1 \\
\text { Point Beach } 2\end{array}$ & $\begin{array}{l}70 \\
72\end{array}$ & $\begin{array}{l}12 \\
12\end{array}$ & $\begin{array}{l}0 \\
0\end{array}$ & $\begin{array}{l}0.000 \\
0.000\end{array}$ \\
\hline Prairie Island I & 73 & 12 & 0 & 0.000 \\
\hline Prairie Island 2 & 74 & 12 & 0 & 0.000 \\
\hline Zion 1 & 73 & 12 & 1 & 0.083 \\
\hline Zion 2 & 74 & 12 & 0 & 0.000 \\
\hline Braidwood 1 & 88 & 4 & 1 & 0.250 \\
\hline Braidwood 2 & 88 & 4 & 1 & 0.250 \\
\hline $\begin{array}{l}\text { Comanche Peak } 1 \\
\text { Comanche Peak } 2\end{array}$ & 90 & 2 & 0 & 0.000 \\
\hline South Texas 1 & 88 & 4 & 4 & 1.000 \\
\hline South Texas 2 & 89 & 3 & 2 & 0.667 \\
\hline Wolf Creek & 85 & 7 & 6 & 0.857 \\
\hline Diablo Canyon 1 & 85 & 7 & 0 & 0.000 \\
\hline Diablo Canyon 2 & 86 & 6 & 0 & 0.000 \\
\hline San Onofre 1 & 68 & 12 & 0 & 0.000 \\
\hline Trojan & 76 & 12 & 3 & 0.250 \\
\hline All Westinghouse Plants & & 472 & 56 & 0.119 \\
\hline \multicolumn{5}{|l|}{ Babcock and Wilcox PWRs } \\
\hline TMI 1 & 73 & 12 & 1 & 0.083 \\
\hline TMI 2 & & & & \\
\hline Crystal River 3 & 77 & 12 & 0 & 0.000 \\
\hline Oconee 1 & 73 & 12 & 2 & 0.167 \\
\hline Oconee 2 & 74 & 12 & 0 & 0.000 \\
\hline Oconee 3 & 74 & 12 & 0 & 0.000 \\
\hline $\begin{array}{l}\text { Bellefonte } 1 \\
\text { Bellefonte } 2\end{array}$ & & & & \\
\hline Davis Besse & 78 & 12 & 0 & 0.000 \\
\hline ANO-1 & 74 & 12 & 0 & 0.000 \\
\hline Rancho Seco & 75 & 12 & 2 & 0.167 \\
\hline All B\&W Plants & & 96 & 5 & 0.052 \\
\hline \multicolumn{5}{|c|}{ Combustion Engineering PWRs } \\
\hline Calvert Cliffs 1 & 75 & 12 & 1 & 0.083 \\
\hline Calvert Cliffs 2 & 77 & 12 & 2 & 0.167 \\
\hline Maine Yankee & 72 & 12 & 0 & 0.000 \\
\hline Millstone 2 & 75 & 12 & 0 & 0.000 \\
\hline St. Lucie 1 & 76 & 12 & 0 & 0.000 \\
\hline St. Lucie 2 & 83 & 9 & 0 & 0.000 \\
\hline
\end{tabular}


IABLE 2.1-2. (contd)

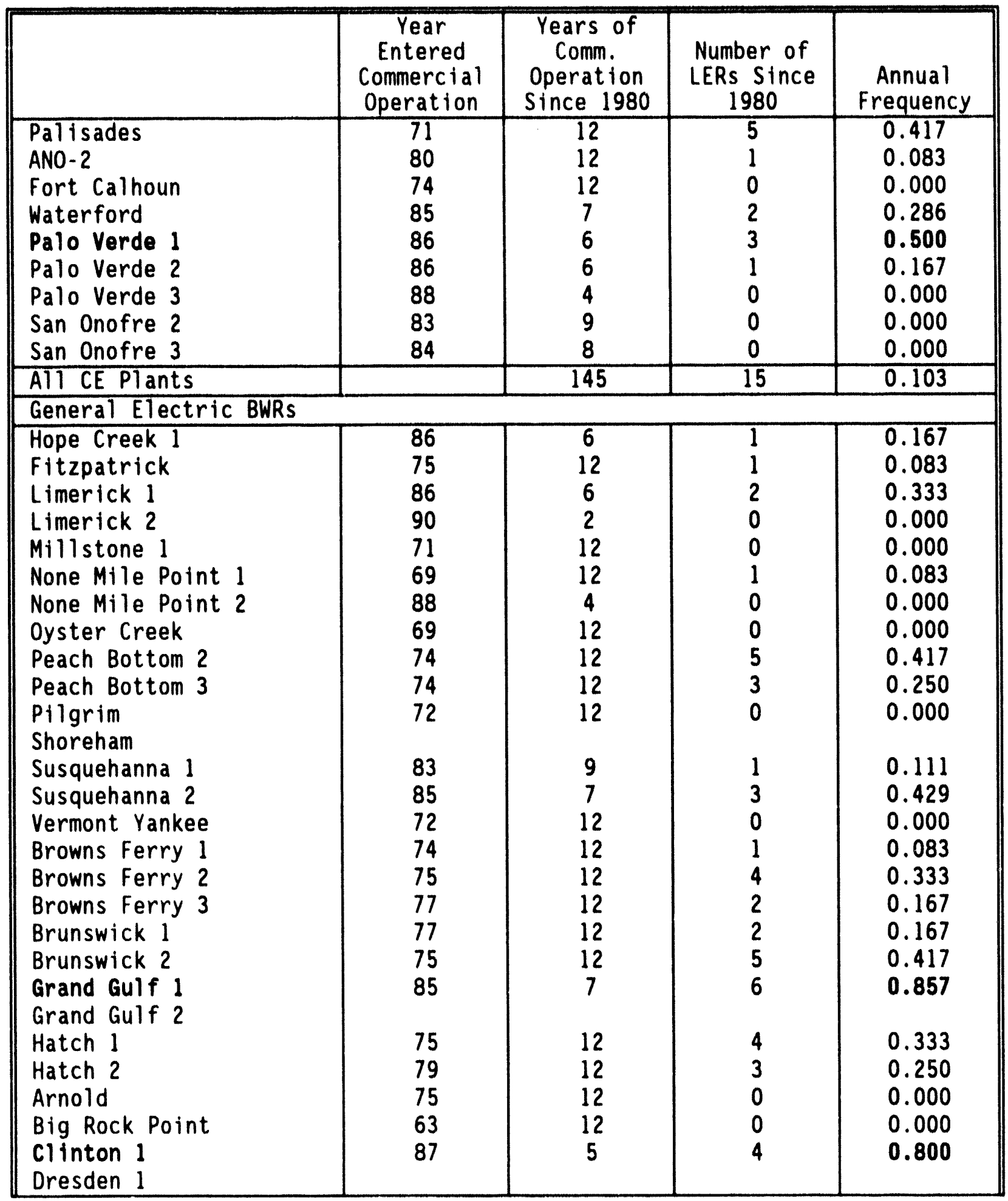


IABLE 2.1-2. (contd)

\begin{tabular}{|c|c|c|c|c|}
\hline & $\begin{array}{c}\text { Year } \\
\text { Entered } \\
\text { Commercial } \\
\text { Operation }\end{array}$ & $\begin{array}{l}\text { Years of } \\
\text { Comm. } \\
\text { Operation } \\
\text { Since } 1980\end{array}$ & $\begin{array}{c}\text { Number of } \\
\text { LERs Since } \\
1980\end{array}$ & $\begin{array}{c}\text { Annual } \\
\text { Frequency }\end{array}$ \\
\hline $\begin{array}{l}\text { Dresden 2 } \\
\text { Dresden } 3 \\
\text { Fermi 2 } \\
\text { Lacross }\end{array}$ & $\begin{array}{l}70 \\
71 \\
88\end{array}$ & $\begin{array}{c}12 \\
12 \\
4\end{array}$ & $\begin{array}{l}2 \\
5 \\
5\end{array}$ & $\begin{array}{l}0.167 \\
0.417 \\
1.250\end{array}$ \\
\hline $\begin{array}{l}\text { Lasalle } 1 \\
\text { Lasalle } 2 \\
\text { Monticello } \\
\text { Quad Cities } 1 \\
\text { Quad Cities } 2 \\
\text { Perry } 1\end{array}$ & $\begin{array}{l}84 \\
84 \\
71 \\
73 \\
73 \\
87\end{array}$ & $\begin{array}{l}8 \\
8 \\
12 \\
12 \\
12 \\
5\end{array}$ & $\begin{array}{l}4 \\
0 \\
0 \\
5 \\
6 \\
6\end{array}$ & $\begin{array}{l}0.500 \\
0.000 \\
0.000 \\
0.417 \\
0.500 \\
1.200\end{array}$ \\
\hline $\begin{array}{l}\text { Perry 2 } \\
\text { Cooper } \\
\text { River Bend } \\
\text { WNP-2 }\end{array}$ & $\begin{array}{l}74 \\
86 \\
84\end{array}$ & $\begin{array}{c}12 \\
6 \\
8\end{array}$ & $\begin{array}{l}3 \\
2 \\
3\end{array}$ & $\begin{array}{l}0.250 \\
0.333 \\
0.375\end{array}$ \\
\hline All GE Plants & & 361 & 89 & 0.247 \\
\hline
\end{tabular}

\subsection{IDENTIFY ESF DEPENDENCIES ON ROOM COOLERS}

The next step in this analysis is to identify the engineered safety features (ESFs) at the selected nuclear plants that exhibit some dependency on the room cooling function. This is accomplished through reviews of design data and PRA documentation and is supplemented by information obtained during visits to the representative plants. Lists of system and functional dependencies were developed for each ESF at the representative plants.

As discussed above, visits were made to the representative plants to collect site-specific information relevant to this analysis, specifically, to 1) collect information needed to determine the temperature rises following loss of room cooling in rooms containing safety-related equipment and sensitivity of components to failures at high temperatures; 2 ) discuss with plant personnel the design and operation of HVAC/room cooler systems; and 3) identify and discuss potential accident sequences, recovery actions, and test/ maintenance requirements. General information that was requested from the plants includes

- thermal loads in rooms containing safety-related equipment from operation of the equipment and, in some rooms, from piping systems containing heated water 
- capabilities of the safety-related equipment to withstand relatively high temperatures

- possible actions that could be taken to respond to losses of room cooling, including actions to restore or supplement cooling in these rooms.

- Room Cooler system Design and Operation - general flow diagram for room cooler system(s), including cooling water source (e.g., cooled directly by service water or plant includes intermediate chilled water cooling loop between service water system and room coolers), list of safetyrelated rooms requiring room cooling, and overall system flow rates and heat removal capacity(ies); operating procedures to cope with loss of room cooling.

- Auxiliary Buflding Layout Information - description and dimensions of ECCS pump rooms, control room, electrical switchgear rooms, battery rooms, and diesel generator rooms; capacities of room coolers provided in these rooms; assessments of heat generation rates from equipment and piping systems contained in these rooms.

- Vital Equipment Information - location and equipment qualification information (Appendix $R$ and environmental qualification) on all ECCS equipment in rooms requiring room cooling, including pumps, valves, electrical power supplies, control circuits, electrical cabinets, etc.

- External events (fire, seismic, flood) - drawings of fire zones, seismic analyses of HVAC/room cooler systems.

Checklists were developed to guide the discussions with plant personnel and record information obtained during the discussions and during walkthroughs of the plants.

\subsection{IDENTIFY BASIC EVENTS INVOLVING ROOM COOLER FAILURES}

This step uses the lists of system and functional dependencies developed in the previous step and the detailed systems analyses and fault trees presented in the PRA documentation to identify and catalogue the basic events in the fault trees that involve HVAC/room cooler failures. In general, fault trees were developed for each ESF and, in some cases, for different operational modes of a particular ESF. For example, two fault trees may be developed for the high-pressure emergency core cooling system (ECCS) function; one for the injection phase following an accident and one for the recirculation phase. Different fault trees are typically developed for these phases because of major differences in operational parameters, such as pump suction source, length of time, valve states, etc. The lists of dependencies helped to identify the applicable fault trees containing HVAC/room cooler fallures and helped to isolate the portions of the fault trees that may contain HVAC/room cooler failures as basic events. Modifications were made to the fault trees, 
where needed, to incorporate HVAC/room cooler fallures that were dismissed or otherwise not addressed in the existing PRAs. The output of this step was a list of basic events that result in fallure of the room cooling functions at the representative plants.

\subsection{DEYELOP LIST OF CUT SETS INYOLYING ROOM COOLER FAILURES}

The purpose of this step in the analysis is to collect the cut sets that include contributions from HVAC/room cooler fatlures. This is the actual first step in quantifying the affected CDF and public risk associated with this issue. All cut sets in the representative plant's PRA were reviewed to identify those containing the basic events identified in the previous step.

As discussed above, some fault trees require modification to incorporate HVAC/room cooler fallures. These modifications consisted of adding a series of events or additional branches to the fault trees to represent HVAC/room cooler fallures. In general, these events are equivalent to fallure of the equipment in the room (e.g., loss of low pressure injection (LPI) pump room cooling is equivalent to loss of the pump due to mechanical or testing/ maintenance failures). As a result, three new cut sets were developed for systems that did not include HVAC/room cooler fallures in the fault trees; one cut set involving fallure of the fan to start, one involving failure of the fan to run for the required time, and one involving fallure of the fan due to testing/maintenance. For example, a new cut set was developed by substituting an ECCS pump room cooler failure for the pump mechanical fallure. This example is illustrated below.

Initial cut sets for LPI failure

Failure of LPI = [Fallure of LPI room cooler fan 1A (Train A) to run for six hours AND failure of LPI valve (Train B) to open].

Modified'cut sets

Failure of LPI = [Failure of LPI room cooler fan $1 A$ (Train A) to start AND failure of LPI valve (Train B) to open]

$\underline{\mathrm{OR}}$

[Failure of LPI room cooler fan IA to run for six hours AND failure of LPI Jalve (Train B) to open]

QR

[Failure of LPI room cooler fan IA due to test/ maintenance AND failure of LPI valve (Train B) to open]. 
This is only an example and is not representative of any particular plant or LPI system.

\subsection{IDENTIEY AFFECTED ACCIDENT SEOUENCES}

In this step, the accident sequences involving ESF fallures that include contributions from failures of HVAC/room cooling are identified. This information is needed to quantify the affected CDF and public risks. This step was accomplished by reviewing the event trees included in the PRAs to identify the applicable ESF fallures. This activity derives accident sequences that were explicitly evaluated in the representative plants' PRAs.

In general, room cooler failures are not modeled as initiating events in PRAs. Rather, they are modeled as contributors to ESF system failures; e.g., room cooler failures may contribute to the unavailability of the LPI function. A second activity was performed at this step to derive additional accident sequences that were not explicitly modeled in the PRAs. Bertucio and Brown (1990) addressed room cooler failures as initiating events but, because of very long room heatup times and because portable fans are available to mitigate room cooler failures, this event was not considered as a separate initiator. However, such modeling will be performed in this study for completeness.

In this step, room cooler failures were modeled as initiating events that, assuming additional safety functions fail, could potentially lead to core damage. Additional event trees were developed, and new accident sequences were derived using the approach in the NUREG-1150 PRAs. Systemic event trees similar to those in the NUREG-1150 PRAs were constructed for the following initiating events:

- Loss of electrical switchgear room cooling

- Loss of ECCS pump room cooling

- Loss of control building/control room cooling.

This list of potential initiating events was developed based on information in past PRAs and reviews of historical data. These events were considered in the NUREG-1150 PRAs but were dismissed for various reasons; however, operating experience indicates that they should not be eliminated offhand. Brief descriptions of the relevant operating events used to select these initiating events are provided below.

\subsubsection{Electrical Switchgear Room Cooling Failure}

Lois (1992) presented information on a potential event involving loss of electrical switchgear room cooling at a W PWR. Although Lois was most interested in an accident sequence consisting of loss of switchgear room during a LOOP event, it pointed out the importance of this failure. Lois calculated 
relatively high CDFs, which further justify an explicit analys is of this failure as an initiating event. Furthermore, an event at a BWR occurred (LER 86-016) in which it was found that both trains of the electrical switchgear room cooling system were inoperable, and which would have resulted in failure of the plant's low-pressure ECCS systems.

\subsubsection{Loss of Control Room Cooling}

A search for room-cooling-related LERs (see Appendix A) performed for this study pointed out the relatively high frequencies of failures of one or more trains of the control room air conditioning (CRAC) system. Furthermore, an event involving failure of CRAC systems at McGuire (Chiramal 1986) pointed out the potential for spurious actuations of equipment and spurious readings and alarms on control panels. At McGuire, technical specifications require the following;

- If one train of the CRAC system is declared inoperable, the inoperable system must be restored within seven days or the plant must be in at least hot shutdown within six hours and in cold shutdown within the next 30 hours.

- If both trains of CRAC are inoperable, action must be initiated within one hour to place the unit in hot shutdown within the next six hours.

Therefore, loss of CRAC is not likely to lead to an automatic reactor trip but could ultimately require a manual trip. This event was retained as an initiating event and modeled in this study.

The remaining events in the list were taken from the NUREG-1150 PRAs and the Individual Plant Examination (IPE) PRAs submitted to the NRC. Operating experience summarized in Appendix $A$ indicates there is a reasonable justification for further evaluation of these events as initiators.

The event trees for these initiating events were constructed from information collected from site visits, PRAs, and other plant-specific analyses. The accident sequences obtained from the event trees were then quantified using the quantitative results from the fault trees developed in the PRA systems analyses. All sequences were retained in the quantification process and were analyzed further for potential operator recovery actions. The sequences were then requantified to include the effects of operator recovery actions.

\subsection{QUANTIFY AFFECTED CORE DAMAGE FREQUENCY AND PUBLIC RISKS}

Two methods were used in this study to calculate the affected CDF and public risks associated with HVAC and room cooler failures. The first method was applied to develop estimates of the affected CDF and public risks for the representative plants in which the available PRA information was insufficient to directly quantify the HVAC and room cooler system contributions. For these 
plants, new minimal cut sets were developed to incorporate HVAC/room cooler failures into the calculations. The new cut sets were developed based on the ESF system requirements subsequent to various initiating events, including general plant transients, LOOP transients, loss of coolant accidents (LOCAs), and losses of specific HVAC systems. The new cut sets were then programmed into a spreadsheet to facilitate the CDF and risk calculations and to perform the uncertainty analyses. An add-in computer software package was implemented in the spreadsheet to perform Lat in Hypercube sampling to quantify the mean and median CDF and risk values and to calculate the 5\%/95\% confidence bounds.

The second method used in this study was applied to plants with sufficient PRA information to calculate the affected CDF and risk values directly. The Systems Analysis and Risk Assessment (SARA) and Integrated Reliability and Risk Analysis Software (IRRAS) (Russel and Sattison 1990) computer codes were used to quantify the contribution of room cooler failures to accident sequences that were quantified in the PRAs (e.g., accident sequences initiated by LOCAs and transients). SARA and IRRAS provide the capability to examine the risk impact of nuclear power plant generic issues on plant CDF and risk.

The SARA and IRRAS computer codes and associated data provided the cut set information necessary to calculate each plant's CDF and to identify cut sets containing HVAC and room cooler failures. The cut sets that included room cooler failures were separated from the others, quantified, and then summed to calculate the affected CDF. The other cut sets, i.e., those not including room cooler failure events, are unaffected by this issue and were not considered further. The NUREG-1150 PRAs were then used to assign the cut sets to the appropriate accident progression bins (APBs), determine the plant damage states (PDSs), bin the accidents into appropriate source terms groups, use the source terms to determine the consequences of accidents, and then calculate public risks. The progression from accident sequences through consequences were taken from the NUREG-1150 PRAs. Public risks were calculated by multiplying the affected accident frequencies and consequences.

For the accidents initiated by loss of room cooling, each individual event in the event trees, with the exception of the initiating events, was quantified in the plants' PRAs. Cut sets were then taken from the NUREG-1150 PRAs, via the SARA computer code, to model the progression of each accident from room cooler failure through safety system failures to core damage. The unavailabilities of safety system components were then modified, where appropriate, to account for the prior failures of room coolers that could affect safety system operability. For example, if one train of electrical switchgear room cooling failed, and all recovery actions failed, it is assumed that all safety system components served by the switchgear in that train were unavailable. The equipment served by the other train is not affected but may fail due to other causes. The net effect was to increase the unavailability of safety systems served by the electrical switchgear room coolers. If the second train of electrical switchgear room cooling should fail and not be recovered, the unavailability of all safety systems served by that switchgear 
was set to 1.0. For example, failure of both trains of switchgear room cooling may result in failure of all LPI and high-pressure injection (HPI) systems at a particular plant.

Uncertainty calculations were performed after the affected cut sets were identified and quantified, and the evaluation of public risks was completed. The uncertainty calculations were based on the failure distributions given in the NUREG-1150 PRAs for each individual cut-set element. The outputs of these calculations included the $95 \%$ confidence intervals (i.e., the upper limit at which there is a 95\% probability that the actual CDF is lower than this value and the lower limit at which there is a $95 \%$ probability that the actual CDF is higher than this value), the mean, and median values. The uncertainty analysis provides an indication of the level of confidence in the results.

\subsection{EXTERNAL EVENTS ANALYSIS}

The effects of HVAC and room cooling failures on the CDF resulting from earthquakes, fires, and floods, referred to as "external events," were also developed in this report. The quantitative bases for the external events analysis performed in this study were taken from other studies. The principal sources of information for this analysis were the detailed external events analyses in NUREG/CR-4550, Volumes 3 and 4' (Bohn et a. 1. 1990; Lambright et al. 1990). These documents provided detailed assessments of plant CDFs arising from external events. Additional key information sources included the 0conee IPE (Duke Power Co. 1990) and the Surry IPE (VEPCO 1990). This chapter identifies and quantifies the external event accident sequences involving failures of HVAC and room cooling systems.

The approach used by Bohn et al. and Lambright et al. consisted of three major activities. The first was a comprehensive external event screening process in which negligible contributors to external event CDF were eliminated from further analysis. The screening analyses performed by Bohn and Lambright eliminated all external events except seismic events and fires. Thus, the affected CDFs from seismic events and fires are examined in detail in this chapter. For completeness, analyses of the affected CDF due to floods and tornadoes were also performed in this study. Additional descriptions of the approaches taken to quantify the HVAC/room cooler contributions to external event CDF are presented in Section 5. 


\subsection{IDENTIFICATION OF AFFECTED PARAMETERS}

This section describes detailed reviews of the probabilistic risk assessments (PRAs) for the representative plants selected in Section 2. The main objectives of this review were to

- collect summary-level information on the design and operation of engineered safety features (ESFs)

- identify and describe accident sequences that could potentially involve failures of room cooling and HVAC functions

- identify and catalogue basic events and reliability data that explicitly or implicitly address failures of room cooling or HVAC functions.

This represents the activities necessary to identify the affected parameters in the PRAs that involve room cooler failures. These activities are also necessary to identify potential modifications to the PRAs to incorporate HVAC/room cooler failures in cases where these events were not included in the core damage frequency (COF) and public risk models.

As discussed in Section 2, four plants, one from each vendor, were selected to represent a cross-section of U.S. nuclear power plants. Separate subsections are provided that contain a brief description of each plant and descriptions of the ESFs, including design characteristics, functions, and dependencies; descriptions of the fault trees, event trees, and accident sequences that potentially include contributing failures of HVAC and room cooling functions; and reliability data for basic events.

\subsection{WESTINGHOUSE PRESSURIZED WATER REACTOR}

\subsubsection{Plant Description}

This pressurized water reactor (PWR) contains two nuclear power plant units. Each unit is a four-loop Westinghouse (W) PWR capable of producing $1128 \mathrm{MW}$ of electrical power (MWe) per unit. Unit 1 entered commercial operation in July 1981, and Unit 2 in June 1982.

\subsubsection{Safety System Description and Systems Analysis}

This section contains summary-level descriptions and simplified schematic diagrams of the principal safety systems and presents the fault tree analyses performed by Bertucio and Brown (1990) on these systems. This information was necessary to identify the elements of the minimal cut sets in the existing plant PRA that involve failure to provide room cooling functions to safety systems. A secondary, but no less important, objective was to develop modifications to the systems analyses to model room cooler failures in important systems that were dismissed by Bertucio and Brown as insignificarit contributors. The most relevant example is one involving room cooler failures in the diesel generator and electrical switchgear rooms. Bertucio and Brown

\section{1}


stated that these failures were not modeled because it was decided that, "... the combinations of fan failures and service water system (SWS) failures were of low enough probability to be of minimal contribution to loss of power to components." Nonetheless, such failures were modeled here to develop comprehensive models of the dependencies of safety system operability on room coolers.

The following safety-related systems were identified in this section as having a dependency on room cooling functions:

- Safety injection system (SI pump room cooler)

- Charging system (CS pump room cooler)

- Low-pressure injection/recirculation system (LPI/R pump room cooling)

- Auxiliary feedwater system (AFW pump room coolers)

- Containment spray system (CSS pump room coolers)

- Component cooling water system (CCW; not dependent upon HVAC but has physical interface with HVAC system)

- Emergency service water system (ESW; not dependent upon HVAC but has physical interface with HVAC system)

- Electric power system (emergency diesel generator enclosure ventilation system, ESF switchgear room HVAC, DC equipment room HVAC).

As shown, room coolers are provided for the SI pump, CS pump, LPI/R pump, turbine-driven AFW pump, and CSS pump rooms. Centralized HVAC systems are provided for cooling the general area in which motor-driven AFW pumps and CCW pumps are located. A dedicated ventilation system is provided for each diesel generator enclosure. In addition, a safety-related control room emergency HVAC system is provided for the main control room.

The safety systems listed above that exhibit some dependency on HVAC or room cooling functions are briefly described below. The information in the following subsections also includes an assessment of the effects of HVAC/room cooler failures on the safety systems. Detailed descriptions of the safety systems, including system schematics, are presented in Appendix B, which also contains the fault trees for each safety system dependent upon HVAC or room cooling systems. Table 3.1-1 presents a list of the basic events or cut set elements identified in the fault tree analysis. This table summarizes all of the HVAC/room cooler failure events identified from the safety system fault trees and systems analyses developed by Bertucio and Brown. 
TABLE 3.1-1. Events Involving Room Cooler Failures Identified in Fault Trees

\begin{tabular}{|c|c|c|}
\hline Event Designator & $\begin{array}{r}\text { Event Description } \\
\end{array}$ & $\begin{array}{c}\text { Unavaila- } \\
\text { bility }\end{array}$ \\
\hline \multicolumn{3}{|c|}{ Auxiliary Feedwater System (AFW) $\quad$ Fault Tree AFW-2 } \\
\hline AFW-XDM-OC-1124 & AFW manual damper 1124 fails closed & $1.0 \mathrm{E}-3$ \\
\hline AFW-XDM-OC-1682 & AFW manual damper 1682 fails closed & $1.0 \mathrm{E}-3$ \\
\hline AFW-FAN-FS-TDPA & AFW AC emergency fan fails to start & $3.0 \mathrm{E}-3$ \\
\hline AFW-FAN-FR-TDPA5 & AFW AC emergency fan fails to run for $5 \mathrm{hr}$ & $1.5 \mathrm{E}-4$ \\
\hline$A F W-X D M-O C-1124$ & AFW manual damper 1124 fails closed & $1.0 \mathrm{E}-3$ \\
\hline AFW-XDM-OC- 1682 & AFW manual damper 1682 fails closed & $1.0 E-3$ \\
\hline AFW-FAN-FS-TDPD & AFW DC emergency fan fails to start & $3.0 \mathrm{E}-3$ \\
\hline AFW-FAN-FR-TDPD5 & AFW DC emergency fan fails to run for $5 \mathrm{hr}$ & $1.5 \mathrm{E}-4$ \\
\hline \multicolumn{3}{|c|}{ Charging System - Recirculation $\quad$ Fault Tree CHR } \\
\hline CHP-FAN-FS-1BB & Charging fan 1B-B fails to start & $3.0 \mathrm{E}-3$ \\
\hline CHP-FAN-FS-1BB & Charging fan $1 B-B$ fails to start ${ }^{(a)}$ & $3.0 \mathrm{E}-3$ \\
\hline CHP-FAN-FR-1BB24 & Charging fan $1 \mathrm{~B}-\mathrm{B}$ fails to run for $24 \mathrm{hr}$ & $7.2 E-4$ \\
\hline CHP-FAN-FR-1AA24 & Charging fan $1 \mathrm{~A}-\mathrm{A}$ fails to run for $24 \mathrm{hr}$ & $7.2 E-4$ \\
\hline \multicolumn{3}{|c|}{$\begin{array}{lll}\text { Containment Spray System (CSS) } & \text { Fault Tree CSSCHR } \\
\text { Containment Spray System - Recirculation Mode } & \text { Fault Tree CSR } \\
\end{array}$} \\
\hline CSS-FAN-FS-MDPIA & Containment spray MDP1A fails to start & $3.0 \mathrm{E}-3$ \\
\hline CSS-FAN-FR-P1A24 & Containment spray MDP1A fails to run $24 \mathrm{hr}$ & $7.2 E-4$ \\
\hline CSS-FAN-TM-MDPIA & CS MDP $1 A-A$ unavailable due to $T / M$ & $2.0 \mathrm{E}-3$ \\
\hline CSS-FAN-FS-MDP1B & Containment spray MDP1B fails to start & $3.0 E-3$ \\
\hline CSS-FAN-FR-P1B24 & Containment spray MDP1B fails to run $24 \mathrm{hr}$ & $7.2 \mathrm{E}-4$ \\
\hline CSS-FAN-TM-MDP1B & CS MDP $1 B-B$ unavailable due to $T / M$ & $2.0 \mathrm{E}-3$ \\
\hline \multicolumn{3}{|c|}{ Low Pressure System - Cold Leg Recirculation $\quad$ Fault Tree LPCHR } \\
\hline LPR-FAN-FS-1AA & LPR Fan 1A-A fails to start & $3.0 \mathrm{E}-3$ \\
\hline LPR-FAN-FR-1AA24 & LPR Fan 1A-A fails to run for $24 \mathrm{hr}$ & $7.2 E-4$ \\
\hline LPR-FAN-TM-IAA & LPR Fan IA-A unavailable due to $T / M$ & $2.0 \mathrm{E}-3$ \\
\hline LPR-FAN-FS - 1BB & LPR Fan 1B-B fails to start & $3.0 \mathrm{E}-3$ \\
\hline LPR-FAN-FR-1BB24 & LPR Fan 1B-B fails to run for $24 \mathrm{hr}$ & $7.2 E-4$ \\
\hline LPR-FAN-TM-1BB & LPR Fan 1B-B unavailable due to $T / M$ & $2.0 \mathrm{E}-3$ \\
\hline \multicolumn{3}{|c|}{ Safety Injection (SI) System - Recirculation $\quad$ Fault Tree SIREC } \\
\hline PHI-FAN-FS-1BB & PHI Fan 1B fails to start & $3.0 \mathrm{E}-3$ \\
\hline PHI - FAN-FR-1BB24 & PHI Fan $1 \mathrm{~B}$ fails to run for $24 \mathrm{hr}$ & $7.2 E-4$ \\
\hline PHI - FAN-FS - IAA & PHI Fan 1A fails to start & $3.0 \mathrm{E}-3$ \\
\hline PHI-FAN-FR-1AA24 & PHI Fan 1A fails to run for $24 \mathrm{hr}$ & $7.2 E-4$ \\
\hline
\end{tabular}


IABLE 3.1-1. (contd)

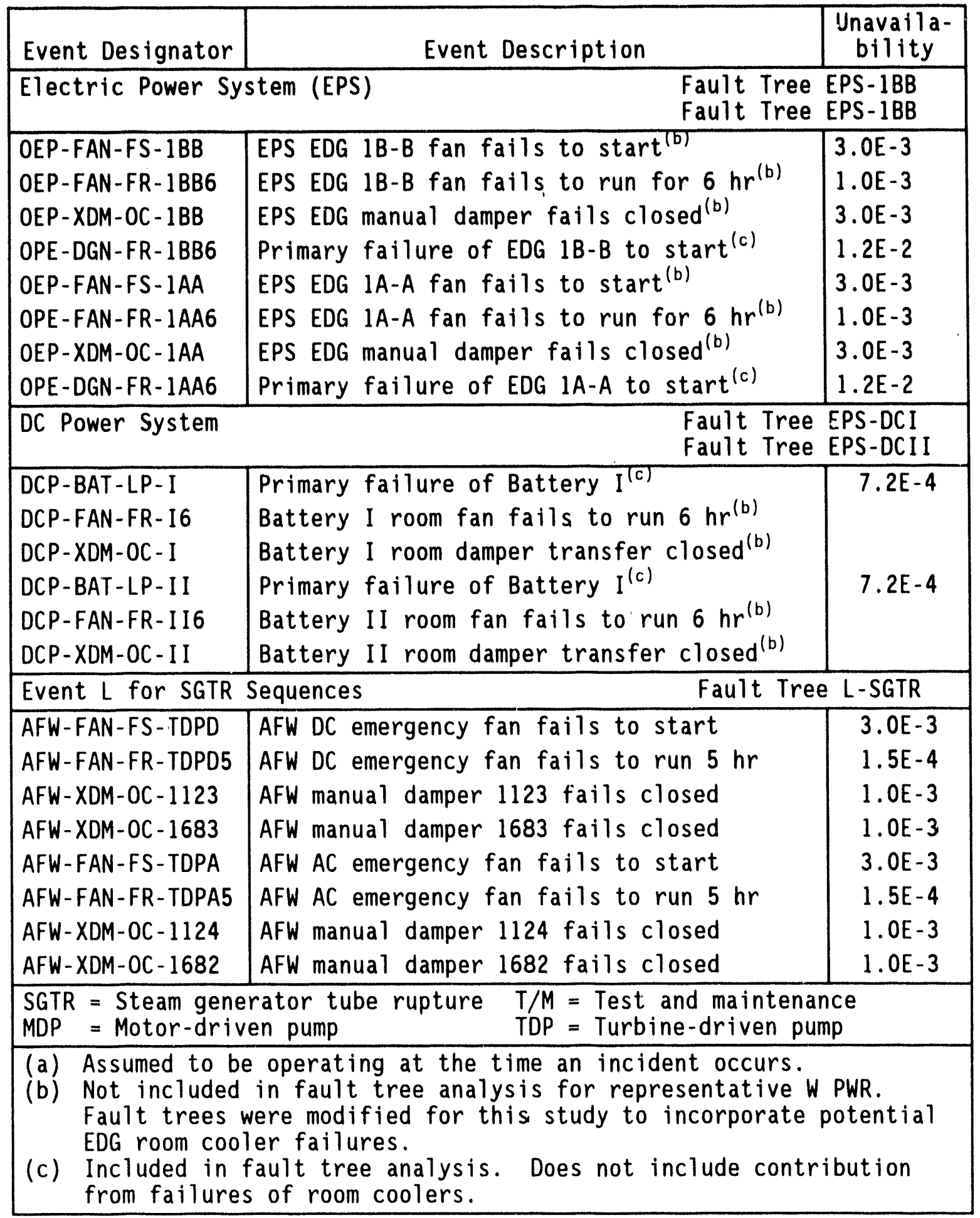




\subsubsection{Safety Injection System}

The safety injection (SI) system, together with the charging system (see subsection 3.1.2.2) perform the high-pressure coolant injection (HPI) and recirculation (HPR) functions. The SI system is initiated upon loss of reactor coolant system (RCS) coolant or steam line break conditions. The SI system is automatically actuated by the ESF actuation system (ESFAS), but it can also be actuated manually if the ESFAS fails.

The SI system includes two redundant $100 \%$ capacity trains. Upon receipt of an ESF signal, the two SI pumps start automatically, drawing suction from the refueling water storage tank (RWST). Room coolers in the SI pump room are interlocked to start automatically when the pumps start. Suction is taken from the RWST from a single line containing a normally open motor-operated valve (MOV) and check valve in series. The two pumps discharge to a common line that delivers flow to all four RCS cold legs. This configuration constitutes the injection mode of the SI system.

Changeover from injection to recirculation mode of the SI system requires operator intervention. In this mode, the SI pumps take suction from the discharge of the low pressure recirculation (LPR) pumps, which have taken suction from the containment pump. Operator action is required to open the MOVs, which permit SI suction to be taken from the discharge of the LPR pumps.

SI system dependencies are 1isted in Appendix B. Of interest to this study are the dependencies on the SI pump room coolers. It was indicated by Bertucio and Brown (1990) that room cooling is not necessary during the injection phase, because the pumps can operate without room cooling for the short time required to complete injection. Room cooling is required, however, for the much longer time frames associated with recirculation. As a result, only the fault tree for failure of SI during recirculation was examined further in this analysis.

A simplified fault tree for the SI system in the recirculation mode is shown in Appendix B. As shown in the fault tree, failure of HPI fan 1B-B contributes to failure to provide sufficient flow through pipe segment 22 (PS 22), representing failure of HPI Train B. Not shown in the fault tree is failure of HPI fan $1 A-A$, which contributes to failure to provide sufficient flow through PS 24 (Train A). The branch of the fault tree involving PS 24 is identical to the branch involving PS 22 except for specific pipe segment and valve numbers (Train A versus Train B) and is not shown. Because the HPI fan failures are connected to the intermediate event, "Insufficient Flow Through PS 22 (recirculation)," through logical "OR" gates, these fan failures are functionally equivalent to all the other basic events shown on the figure, including HPI pump failures, plugged/mispositioned valves, and the HPI actuation signal failures. Although not shown in the fault tree, it was observed that HPI fans $1 A-A$ and $1 B-B$ are completely separate; i.e., they are actuated by separate actuation logic channels, powered from separate $A C$ buses, and are controlled through separate $125-V$ vital buses. Motor control centers for Trains $A$ and $B$ are also located in separate ESF switchgear rooms. 


\subsubsection{Charging System}

The charging pumps, together with the SI pumps, perform the HPI and HPR functions at the representative W PWR. The charging system consists of two centrifugal charging pumps (CCP) and one positive displacement charging pump (PDP). Neglecting the PDP because of leakage and reliability problems, the charging system consists of two $100 \%$ redundant pump trains that share a common RWST suction line and common injection line into the RCS cold legs.

Under normal operations, one CCP is operating to provide reactor coolant makeup. In this mode, the CCP takes suction from the volume control tank (VCT) and delivers makeup flow through two normally open MOVs in series. The charging pumps also provide seal injection flow to the reactor coolant pump (RCP) seals.

Under accident conditions, the ESFAS automatically initiates charging system operation in the injection mode. The second CCP is started, the RWST isolation valves are opened, and the MOVs on either side of the boron injection tank are opened, allowing flow to be delivered to the RCS cold legs. Should automatic actuation fail to occur, or if feed-and-bleed cooling were required, the system can be operated manually. Room coolers are interlocked to start automatically when the pumps start.

In the recirculation mode, the charging pumps take suction from the LPR pump discharge. It is necessary to manually accomplish this switchover by opening MOVs that permit charging system and SI system suction to be taken from the LPR pump discharges.

Charging system dependencies on room cooling are similar to the SI system. Charging pump room cooling is required only during the recirculation phase because of the short duration of the injection phase. A complete list of charging system dependencies is presented in Appendix B.

Two fault trees were developed by Bertucio and Brown (1990) for the charging system, one for the injection mode and one for the recirculation mode. Only the recirculation mode fault tree, designated CSR, contained basic events involving room cooler failures. A simplified CSR fault tree illustrating the dependencies of the charging system on room cooling is shown in Appendix B.

The charging system fault tree demonstrates that failure of charging fans $1 A-A$ and $1 B-B$ are functionally equivalent to fallure of charging pumps $1 A-A$ and $1 B-B$, respectively. Also, it was assumed by Bertucio and Brown that charging pump $1 A-A$ and fan $1 A-A$ are normally running, so a basic event for failure of this equipment to START is not included in the fault tree. Failure to RUN for 24 hours is included. Finally, it was shown that the room coolers for the Train A and B charging pumps are completely separate from each other; i.e., they receive separate actuation signals and are powered from different 6.9-kV shutdown boards. Basic event data for the charging fans were presented in Table 3.1-1. 


\subsubsection{Low-Pressure Injection/Recirculation System}

The residual heat removal (RHR) system provides emergency coolant injection and recirculation following loss-of-coolant accidents (LOCAs) in which the primary system has been depressurized. Under these conditions, the RHR system is referred to as the low pressure injection (LPI) or low-pressure recirculation (LPR) systems. The RHR system also provides the shutdown cool. ing function. In addition, LPI/LPR provides primary containment overpressure protection by delivering low-pressure sprays to the containment atmosphere.

The LPI/LPR system is composed of two $100 \%$-capacity, redundant pump trains (see Appendix B). During the injection mode, LPI pumps take suction from the RWST and discharge through a check valve, two locked-open manual valves, the RHR heat exchanger, an air-operated valve (AOV), and an MOV, all arranged in series, into the RCS cold legs. Each of the lines to the RCS cold legs contains two check valves to isolate the LPI system from the highpressure RCS. LPI/LPR room coolers start automatically when the pumps start.

In recirculation mode, the LPR pump trains take suction from the containment sump. Discharge into the RCS cold legs follows the same path as the injection mode. Opening of the sump suction valves occurs automatically upon reaching low (29\%) RWST level.

LPI/LPR system dependencies include pump room cooling, although it is required only during recirculation mode because of the short duration of the injection mode. A complete list of dependencies is presented in Appendix B.

The LPI LPR system fault trees given by Bertucio and Brown (1990) were reviewed to identify basic events involving room cooler failures. Only the cold leg recirculation mode fault tree, designated LPCHR, contained basic events involving room cooler failures. A simplified LPCHR fault tree illustrating the dependencies of the LPI/LPR system on room cooling is shown in Appendix $B$. Basic event data for the LPI/LPR room coolers were presented in Table 3.1-1.

As demonstrated by the LPCHR fault tree, failures of the LPR fans are functionally equivalent to failure of the LPI/LPR pumps. Neither LPR pumps $1 A-A$ or $1 B-B$ nor their attendant room coolers are normally operating components, so the fault tree includes separate events for failure of the pumps (and fans) to start as well as failure to run for 24 hours. Unavailability of the fans due to testing and maintenance is also included. Note that failure of LPR requires failures of Trains $A$ and $B$. Therefore, a single room cooler failure will not disable the entire LPI/LPR system.

\subsubsection{Auxiliary Feedwater System}

The function of the auxiliary feedwater (AFW) system is to provide feedwater to the steam generators (SGS) to allow continued heat removal from the primary system when main feedwater (MFW) is not available. The AFW system consists of three trains (see Appendix B); two are provided with motor-driven pumps (MDPs), and the third is provided with a turbine-driven pump (TDP). Each MDP discharges to two of the four SGs. The TDP, which is twice the 
capacity of each MDP, is capable of discharging to all four SGs. Each pump takes suction through a common header from the condensate storage tank (CST) or from one of two SWS headers.

The two MDPs automatically start, and the TDP throttle/trip valve opens automatically to start the TDP upon receipt of an AFW actuation signal. The signal also causes the normally closed AOVs in the AFW supply lines to the SGs to open automatically. TDP room coolers are interlocked and start automatically when the pump starts. Automatic switchover to the SWS supply headers is accomplished upon recelpt of a low AFW pump suction pressure, which indicates that the CST water supply is becoming depleted. This is done by automatically opening the SWS header isolation valves.

Room cooling is required for the TDP but is not required for MDPs, which are located in open rooms and are environmentally qualified for high-energy line break ganditions-postulated to be more severe than loss of room cooling conditions.

The AFW fault trees developed by Bertucio and Brown (1990) were reviewed to identify HVAC/room cooling related basic events. Only fault trees AFW2 and L-SGTR fault trees contained room cooler failures; simplified versions of these two fault trees are presented in Appendix B. Basic event data for TDP room cooler fallures that were identified in these fault trees were shown in Table 3.1-1.

TDP room cooling may be provided by either an $A C$ - or a $D C$-powered fan. Failure of both fans is required to result in fallure of TDP room cooling. These fans are simply exhaust fans and are not provided with chilled water to cool the room. Heat is exhausted to the large open general area outside the TDP room at the plant. Again, as with previous safety systems, fallure of the TDP room coolers is functionally equivalent to failure of the pump. Failure of the MDP room coolers was not included in the fault trees, because the MDPs are expected to function adequately under loss of room cooling conditions.

\subsubsection{Containment Spray System}

The containment spray system (CSS) provides part of the capability for containment pressure suppression during the injection phase of a LOCA and containment heat removal capabilities during the recirculation phase following a LOCA. Pressure suppression is accomplished by spraying cool water from the RWST to condense steam in the containment; this is referred to as the containment spray injection (CSI) mode. When the RWST is depleted, the CSS is switched to containment spray recirculation (CSR) mode, in which containment heat removal is accomplished by drawing water from the containment sump and

(a) Room heatup calculations for the AFW MDP room were performed by the utility in support of a 10 CFR 50 Appendix $R$ (fire protection) submittal to the NRC. The results of these calculations confirmed that a highenergy line break in this room produces more severe ambient temperatu:e conditions than a loss of room cooling. 
circulating through heat exchangers before discharging it to the containment. The switchover from CSI to CSR modes is made through a combination of automatic and operator actions.

The CSS, shown in Appendix B, contains two 100\%-capacity pump trains, each with a centrifugal pump, heat exchanger, and associated piping and valves. Both CSS pumps are normally in a standby condition and start automatically when signalled to do so by the ESFAS. Upon receipt of a highdifferential-pressure signal between the lower containment compartment and the annulus between the ice condenser and the outer containment wall, the pumps start and the normally open CSS MOVs in the CSS pump suction lines and the normally closed MOVs in the CSS pump discharge lines automatically open.

CSS dependencies include, among other things, CSS pump room cooling. Room coolers in the CSS pump rooms must operate successfully to prevent overheating and fallure of the CSS pumps.

Two fault trees were developed by Bertucio and Brown for the containment spray system: one for the injection mode and one for the recirculation mode. Only the recirculation mode fault tree, designated CHR, contained basic events involving room cooler failures. A simplified CHR fault tree fllustrating the dependencies of the containment spray system on room cooling is shown in AppendiX $B$. Basic event data were presented in Table 3.1-1.

As shown in the CHR fault tree in Appendix B, failure of CSS room coolers is functionally equivalent to fallure of the CSS pumps. This system is not normally operating, so the fault trees include basic events for failure of the room coolers to START, fallure to RUN, and failure due to TEST/MAINTENANCE. The CSS room coolers start automatically when the CSS pumps start.

\subsubsection{Component Cooling Water System}

The CCW system provides cooling water to various ESF components, including RHR, SI, and CSS. The CCW system also provides cooling water to the reactor coolant pump (RCP) thermal barriers.

The CCW system at the representative $W$ PWR is a closed cooling system (as shown in Appendix B) that is shared by both reactor units at the site. The CCW system includes five centrifugal pumps and three heat exchangers (HXs). Normal alignment of the CCW system is as follows:

$\begin{array}{lll}\text { Unit 1 } & \begin{array}{l}\text { Train 1A ESF equipment } \\ \text { RCP thermal barrier } \\ \text { Train 1B ESF equipment }\end{array} & \text { CCW Pump 1A-A, CCW HX A } \\ \text { Unit 2 } & \begin{array}{l}\text { Train 2A ESF equipment } \\ \text { RCP thermal barrier } \\ \text { Train 2B ESF equipment }\end{array} & \text { CCW Pump C-S, CCW HX C } \\ & \text { CCW Pump 2A-A, CCW HX B }\end{array}$


The remaining pumps (i.e., CCW pumps $1 B-B$ and $2 B-B$ ) are normally standby and serve as backups to the normally running pumps during normal operation. The backup pumps start automatically upon receipt of a low pressure signal in the discharge header. In addition, each pump receives an automatic start signal from the corresponding train of ESFAS.

The CCW pumps take suction from the CCW return lines from the ESF equipment they serve. They discharge through the $C C W$ heat exchangers to the $C C W$ supply lines to the ESF equipment they serve. A fraction of the flow from CCW pumps $1 A-A$ or $1 B-B$ is routed through the RCP thermal barrier booster pumps to the Unit 1 RCP thermal barriers and is returned to the suction header for the CCW pumps.

CCW/AFW pump space is common to both systems. This space is relatively large compared to the SI and LPI pump room and is cooled by space coolers which are cooled by the SWS. The pump motors are environmentally qualified to meet high-energy line break criteria, which are more severe than conditions produced in the event of a loss of room cooling. This assumption was confirmed through a review of room heatup calculations performed in support of a 10 CFR 50 Appendix $R$ submittal to the NRC. Therefore, because of the environmental qualification and the open nature of the CCW/AFW room, it was assumed by Bertucio and Brown (p. 4.6-51) that the $C C W$ pumps do not require room c001ing for continued operation.

The CCW system can function without room cooling in the CCW pump space. Since there are no dependencies on room cooling, the CCW system is not modeled explicitly in this study, although some $\mathrm{CCW}$ dependencies are considered further in this analysis (e.g., RCP seal cooling).

\subsubsection{Essential Service Water System}

The ESW system (referred to as the essential raw cooling water system at the representative W PWR) provides cooling water to various front-line, safety-related components, including HPI, LPI, and CSS. The ESW system also provides cooling water to the CCW and electric power system (EPS) and serves as an alternate water supply source for the AFW system. This system, in general, provides cooling water to the various chillers that are used to remove heat from rooins containing safety-related equipment.

The ESW system is an open-cycle system that serves both units at the site. The ESW system draws water from a river and contains eight pumps; four are normally in operation (two per unit), and the remaining four are started automatically by the ESFAS. Separate supply headers are provided for each ESF train (i.e., Trains $1 A$ and $1 B$ at Unit 1 and $2 A$ and $2 B$ at Unit 2) for a total of four supply headers. Water flows from the supply headers into branch lines serving the various components listed as follows:

- SI and charging pump oil coolers and room coolers

- RHR pump room coolers

- CSS heat exchangers 
- Emergency diesel generator (EDG) unit coolers

- Turbine-driven AFW pump

- CSS heat exchangers

- Emergency switchgear room (also known as shutdown board room) air conditioner water chillers

- CCW heat exchangers

- Other nonessential loads.

ESW dependencies include AC power for motive power for the pump motors and for motive and control power to valve motors; $D C$ power for control power for the MDPs, TOPs, and AOVs; and ESFAS for automatic actuation. Interfaces include the components listed above. In addition, the AFW system may be aligned to draw water from the ESW system. No dependencies on ESW pump room cooling were identified.

The ESW system can function without room cooling in the ESW pump space. The pumps are self-cooled and require no room cooling for continued operation. Since the ESW system is not dependent on room cooling, the ESW system is not modeled explicitly in this study. However, safety-related HVAC/room cooling system dependencies on the ESW system are considered further in this analysis (e.g., LPI/R pump room cooling is dependent upon the ESW system to remove heat from the pump roon coolers).

\subsubsection{Electric Power System}

The function of the electric power system (EPS) is to provide $A C$ and $D C$ power to safety-related components. The EPS, illustrated in Appendix B, includes separate $A C$ and $D C$ subsystems. Each subsystem is divided into four trains serving the two reactor units.

$A C$ Trains $1 A$ and $B B$ serve unit 1 and Trains $2 A$ and $2 B$ serve unit 2. Each $A C$ train includes one 6.9-kV AC shutdown board and two 480-V AC shutdown boards. Eachl of the 6.9-kV shutdown boards is normally supplied by the offsite power grid or by the plant's main generator. Each board also has an EDG unit that automatically starts upon loss of the normal power supply.

DC Trains I and I! generally serve Unit $I$ and Trains III and IV generally serve Unit 2. Some DC loads, such as the turbine-driven AFW pump, are crossconnected between units. Each 125-V DC battery board supplies two 120-V AC vital instrument power boards through 120-V AC vital inverters. The 120-V AC vital instrument power boards can alternatively be supplied from the $480-V$ AC shutdown boards through 50-kVA instrument power transformers.

During normal operation, the EPS is dependent upon offsite power. In general, however, operation of the EPS is not dependent on other plant systems. A notable dependency that was not modeled by Bertucio and Brown was the ESW system, which is used to remove heat from EDGs and for cooling of the 
shutdown board rooms (also referred to as emergency switchgear rooms). It was stated that the probability of failure of the doubly redundant ESW system to provide EDG cooling was far less than the probability of EDG failure and did not merit further attention. In the case of the switchgear room, the combinations of fan failures and ESW failures were of low enough probability that their contribution to EPS failure was insignificant. However, because of potential vulnerabilities of multiple ESF components to failure of switchgear room cooling, an analysis of switchgear room cooler failures as potential initiating events was performed in this study (See Section 4).

Failure of the fans to $\mathrm{COO}^{\mathrm{i}}$ the EDG rooms is functionally equivalent to failure of an EDG to start or run. The EDG enclosures are cooled by large exhaust fans that remove heated air from the enclosure and exhaust to the atmosphere. No cooling water is provided to cool the air. Room heatup calculations shown in Appendix $F$ indicate that room temperatures will exceed the failure temperatures for electrical equipment (EDG controls) and switchgear located in the EDG enclosure in less than 30 minutes, if the ventilation system malfunctions. This allows insufficient time to repair the ventilation system in time to prevent failure of backup AC power. Possible causes of failure of the ventilation system include failure of an exhaust fan and failure of an air damper to open in each EDG enclosure.

Dependencies on room cooling to battery rooms were examined in this study. Discussions with plant personnel indicated that overheating is not a concern in regard to battery operability. Low ambient temperatures may affect battery operability, but heating systems are not in the scope of this study. High temperatures can affect the operability of $A C$ inverters and battery chargers, and room cooling to these areas is addressed in this study. The EPS fault trees, simplified as with previous fault trees, are shoun in Appendix $B$. Basic event data identified on these fault trees were presented in Table 3.1-1.

\subsubsection{Engineered Safety Features Actuation System}

The engineered safety features actuation system (ESFAS) is designed to sense plant parameters, determine whether or not predetermined safety limits are being exceeded, and, if they are, to determine which ESF components are required to respond to the condition that exists. The ESFAS then sends actuation signals to the required ESF components.

The ESFAS consists of both analog and digital circuitry. The analog portion of the ESFAS provides redundant channels that monitor various plant parameters. The digital circuitry portion provides two redundant logic trains that receive inputs from the analog channels and provide the necessary logic to actuate required ESF components.

The ESFAS is dependent on the AC power subsystem to provide 125-V AC for instrumentation and the $D C$ power subsystem to provide power for instrumentation and logic circuits. Interfaces with the specific functions that rely on the ESFAS for actuation include 
- Reactor trip, if not provided by the reactor protection system

- Proper sequencing of ESF power loads, including cold leg injection isolation valves, charging pumps, SI pumps, LPI pumps and associated valving, and motor-driven AFW pumps.

- Phase A containment isolation

- Steam line isolation

- Main feedwater isolation

- Starting EDGs to ensure backup power supply

- Containment spray actuation

- Phase B containment isolation

- ESW and CCW pump start

- Automatic switchover of the RHR (LPR) pumps from the injection mode to the recirculation mode.

No additional dependencies were modeled by Bertucio and Brown; however, the present study examined the dependency of the ESFAS on control room cooling.

\subsubsection{Heating, Ventilation, and Air Conditioning System}

The plant heating, ventilation, and air conditioning (HVAC) system was not modeled as a distinct system by Bertucio and Brown. It was addressed, however, in the fault tree models in which room cooling functions were required. For example, room cooling is required for operation of LPI/LPR pumps during the recirculation mode. Therefore, the LPR fault trees contained the various segments of the HVAC system that serve the LPI/LPR pump rooms. The HVAC functions were included through the ESF system interfaces with the ESW system, which is the heat sink for the ESF pump areas, and through room cooling fans which are required for room cooling. Specific events involving failures of room cooling functions are addressed in Section 3.1.3.

\subsubsection{Event Tree Analysis}

This section provides an overview of the event tree analysis in the existing PRA and highlights the accident sequences delineated in the event trees that contain room cooler failure elements. Each event tree defines accident sequences, including an initiating event, failure/success of safety systems, and operator actions necessary to respond to the initiating events. The accident sequences may result in core damage or in successful mitigation of the event, depending upon the particular system(s) and operator actions that fail or are successful. The events shown on the event trees roughly correspond to the top events on the fault trees described previously. 
Bertucio and Brown developed eleven event trees, which are listed below:

- Loss of offsite power (LOOP) (2 event trees; one for sequences in which at least one EDG is available $\left[T_{1}-L O O P\right]$ and one for station blackout $\left.\left[\mathrm{T}_{1}-\mathrm{SBO}\right]\right)$

- Transients with power conversion system (PCS) unavailable $\left(T_{2}\right)$

- Transients with PCS initially available $\left(T_{3}\right)$

- Loss of one $D C$ bus $\left(T_{D C X}\right)$

- Steam genlerator tube rupture $\left(T_{S G}\right)$

- Large LOCA (A)

- Medium LOCA $\left(S_{1}\right)$

- Smali lOCA $\left(S_{2}\right)$

- Very small LOCA $\left(S_{3}\right)$

- Anticipated transient without SCRAM (ATWS).

These event trees are presented in separate subsections. In addition, each subsection briefly describes the accident sequences that may involve room cooler failures, as identified from the fault tree analyses presented previously. Quantification of the accident sequence frequencies involving room cooler failures is presented in Section 4. Much of this discussion is taken from Bertucio and Brown. Abbreviations used in the event trees are presented in Table 3.1-2.

\subsubsection{Loss of Offsite Power Event Trees}

The primary safety functions required to respond to LOOPs include reactor subcriticality, core heat removal, RCS integrity (including RCP seal cooling since the RCP seals are treated as part of the RCS pressure boundary), and containment. Failure to provide reactor SCRAM results in failure to achieve subcriticality and transfers to the ATWS event tree discussed later. Failure to provide SG cooling leads to a demand for "feed and bleed" cooling, which requires successful HPI and opening of power-operated relief valves (PORVs). Failure to provide these functions results in core damage. Successful feed and bleed cooling leads to demand for coolant recirculation and containment systems during the recirculation phase. Failure of relief valves to close results in a LOCA and requires transfer to the $S_{2}$ event tree. Failure of RCP seal cooling (i.e., loss of both thermal barrier cooling and seal injection) leads to a condition in which the RCP seals are vulnerable to failure. 


\section{TABLE 3.1-2. Event Tree Identifiers}

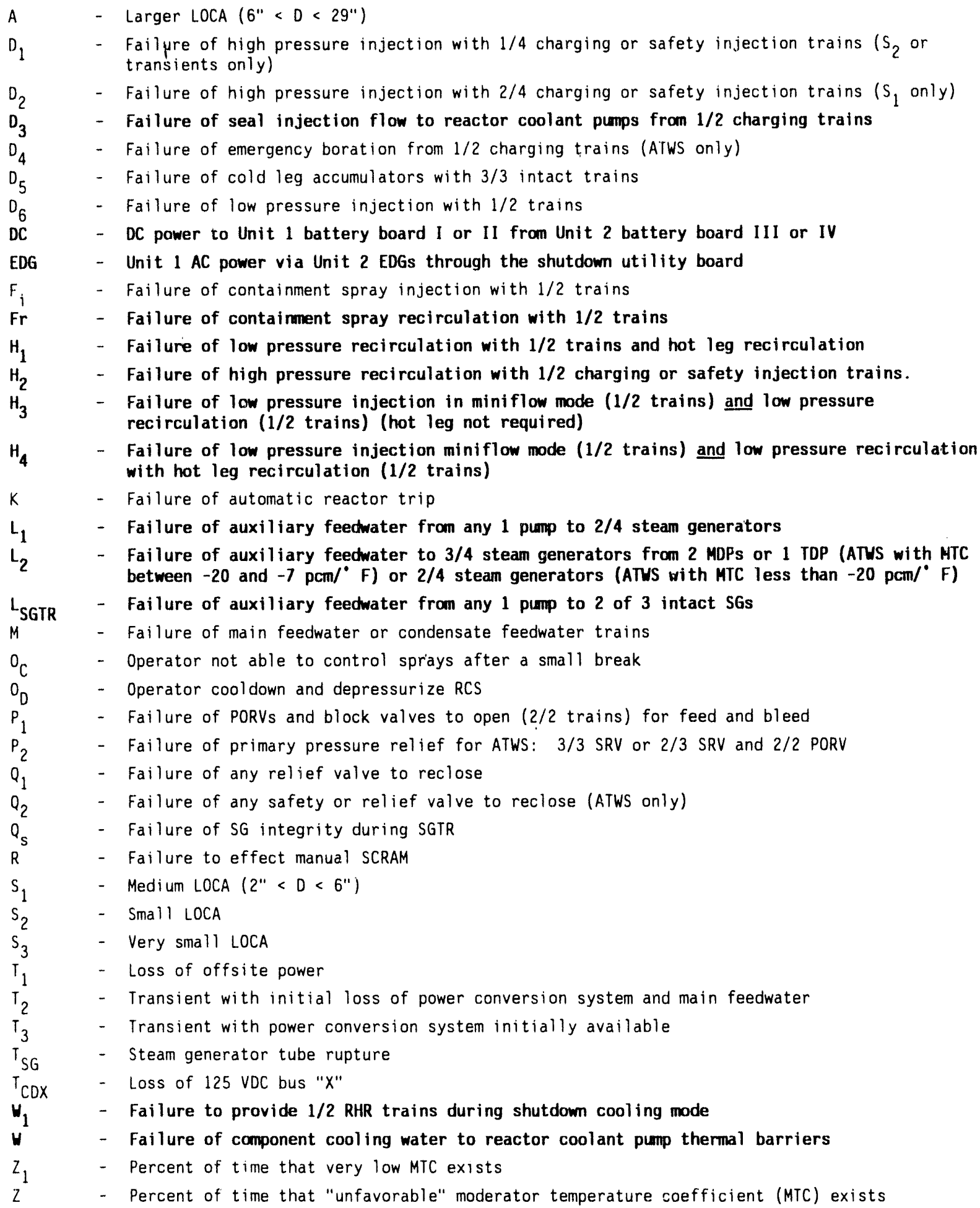

Events that include room cooling dependencies are in bold type. 
As stated above, two event trees were developed by Bertucio and Brown to evaluate LOOPs. Figure 3.1-1 presents the $T_{1}-$ LOOP event tree, in which at least one EDG is available. Figure 3.1-2 presents the $T_{1}$-SBO tree (station blackout). Accident sequences that include contributions from HVAC or room cooler failures are shown in bold type. The affected sequences, i.e., sequences that include HVAC or room cooling contributions, are those involving events L1 (AFW failure), H3 (LPI/R failure), and H2 (HPR failure). Brief descriptions of the affected accident sequences are presented below.

Sequence 4 (TIL1) in Figure 3.1-1 represents failure of SG heat removal but successful feed-and-bleed cooling (successful operation of one charging pump or one SI pump and opening of both PORVS). Long-term cooling would be provided by essential core cooling system (ECCS) recirculation from the containment sump and successful operation of the RHR heat exchangers. Sequences 5 and 6 (TILIH2 and TILIH3) lead to core damage due to failure to provide long-term cooling (i.e., unsuccessful feed-and-bleed cooling in the recirculation mode). Feed-and-bleed cooling is dependent upon successful operation of the HPI pumps, which are, in turn, dependent upon HPI pump room coolers. Sequence 5 involves failure of the HPR system, and Sequence 6 involves failure of the LPR system. Both HPR and LPR are dependent upon the respective system's pump room coolers.

Sequence 7 (TILIPI) involves failure to provide core heat removal through the SGs and failure to open both PORVS, which leads to failure to establish feed-and-bleed cooling. Sequence 8 (T1L1D1) is similar to Sequence 7 except that feed-and-bleed cooling fails due to failure to establish safety injection flow with the charging or SI system.

The affected accident sequences on the $S B O$ event tree, Figure 3.1-2, are those involving events $L$ ( $A F W$ - TDP), EDG ( $A C$ power from Unit 2 EDG), and $D C$ (DC power from Unit 2). Each of these events represents a system that requires successful operation of an HVAC or room cooling function. These sequences are described below.

Sequence 3 (T1-1H-EDG) represents $S B O$, nonrecovery of $A C$ power for one hour, and failure to provide $A C$ power from an EDG at Unit 2. However, DC power is successfully cross-connected from Unit 2, and RCP seal integrity is maintained. Thus all essential safety functions are being provided, and the sequence represents a long-term stable SBO. Sequence 4 (T1-1H-EDG-SL) represents a seal LOCA, but $A C$ power and HPI flow are restored prior to core uncovery. Sequence 5 (TI-IH-EDG-SLNSL) leads to core damage due to a seal LOCA and failure to restore $A C$ power before core uncovery occurs. RCP seal cooling is dependent upon successful operation of the HVAC system serving the CCW pump area. Successful operation of the EDGs is dependent on the EDGs enclosure ventilation system.

In Sequence $6(T 1-1 H-E D G-D C)$ the DC power cross-connect from Unit 2 fails, but $A C$ power is restored within seven hours and no core damage occurs. Sequence 8 (T1-1H-EDG-DC-7H) represents failure to recover $A C$ power within seven hours and leads to core damage. Sequences 8 and 9 are similar to Sequences 4 and 5 except the DC power cross-connect from Unit 2 rails and the Unit 1 batteries fail (depletion) at four hours. 


\begin{tabular}{|c|c|c|c|c|c|c|c|c|c|c|c|c|}
\hline LOOP & RPS & $\begin{array}{c}\text { RVs } \\
\text { Close }\end{array}$ & $\begin{array}{l}\text { AFW } \\
2 / 4 \\
\text { SGs }\end{array}$ & $\begin{array}{l}\text { Seal } \\
\text { Injct } \\
\text { Flow }\end{array}$ & $\begin{array}{l}\text { CCW } \\
\text { Thrm1 } \\
\text { Barr }\end{array}$ & HPI & $\left|\begin{array}{l}\text { PORVs } \\
\text { Open }\end{array}\right|$ & LPI/R & HPR & & & \\
\hline $\mathrm{Tl}$ & $\mathrm{K}$ & Q1 & $\mathrm{L} 1$ & D3 & w & D1 & Pl & H3 & H2 & Sequence & Core & Comments \\
\hline
\end{tabular}

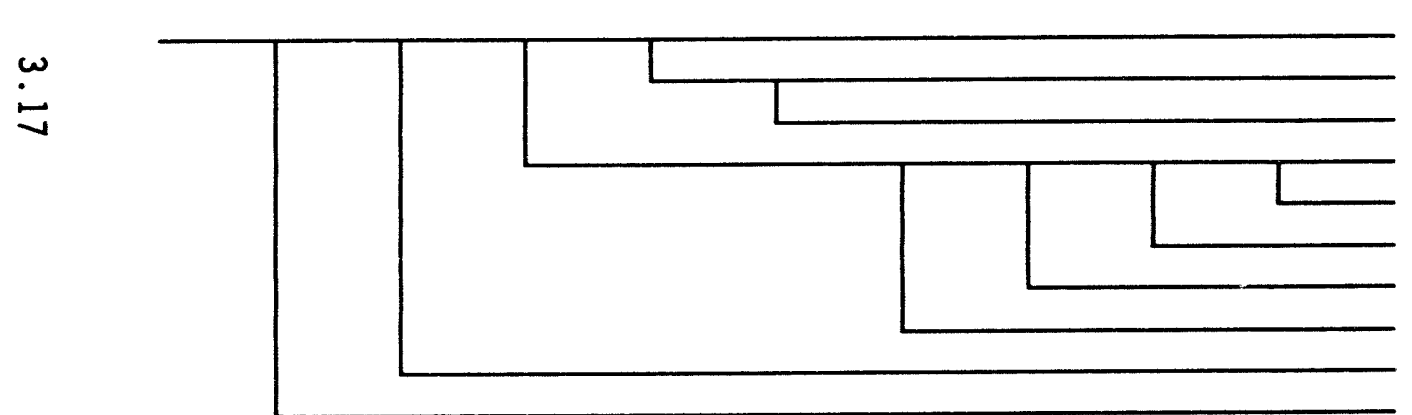

1. $T 1$

2. T1D3

3. TID3W

4. TILI

5. T1L1H2

6. TILIH3

7. TILIPI

8. TILIDI

9. T1Q1

10. TIK

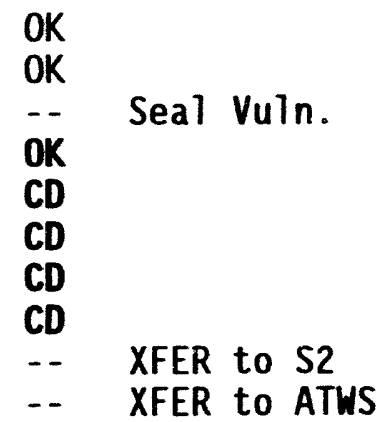

FIGURE 3.1-1. Event Tree for $T_{1}$-Loss of Offsite Power 


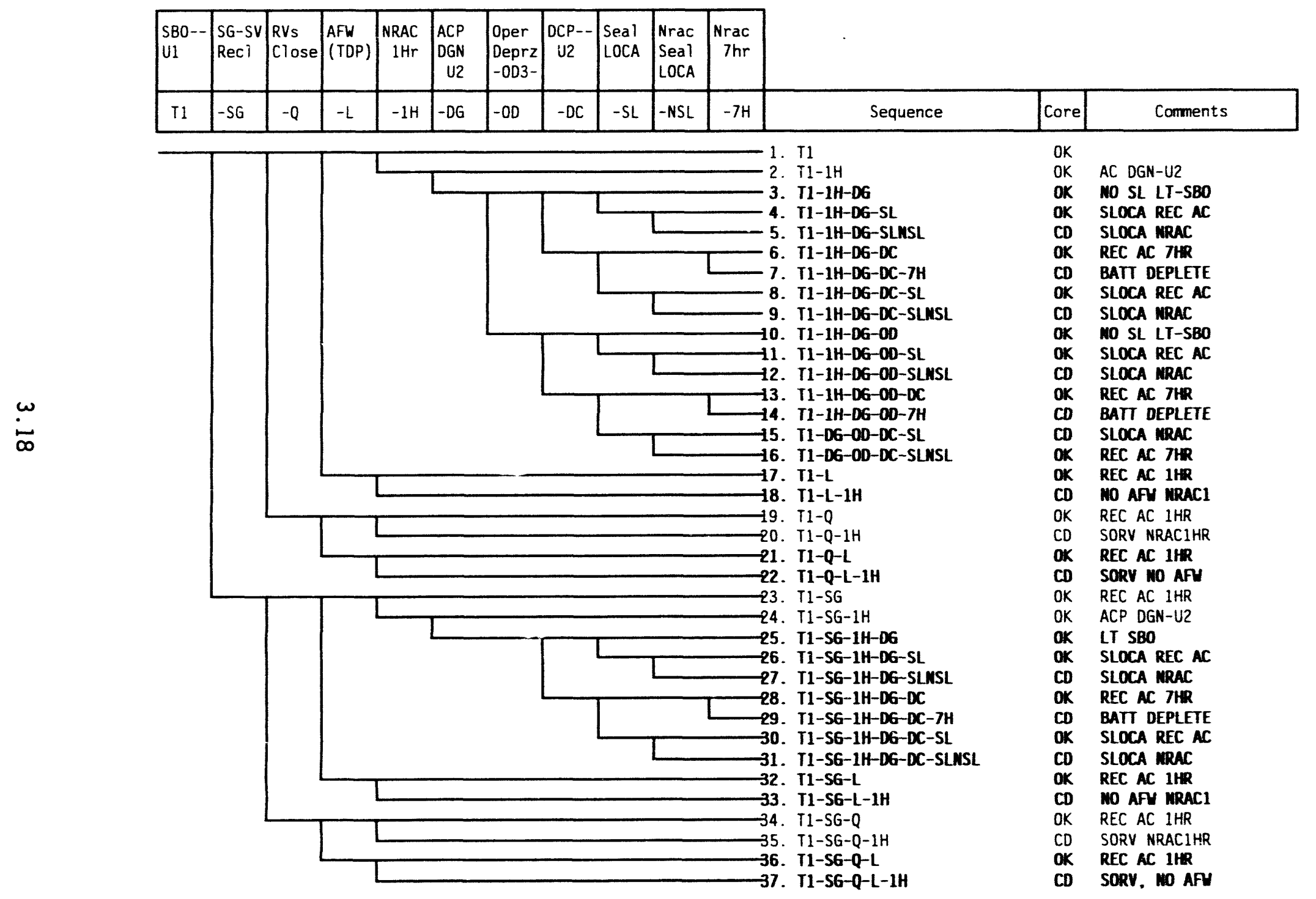

FIGURE 3.1-2. Event Tree for $T_{1}$ - Station Blackout 
Sequences 10 to 16 are similar to Sequences 3 through 9 except that the operator does not depressurize the RCS, so the former sequences remain at high pressure. This results in more rapid core uncovery times for seal LOCA sequences because of higher flow rates from the RCP seal break.

Sequence 17 represents failures of the AFW system but recovery of AC power within one hour, allowing restoration of HPI flow and AFW. Sequence 18 leads to core damage because of the inability to restore HPI and AFW flow due to fallure to recover $A C$ power. AFW and HPI pumps are dependent upon successful operation of room coolers in the respective pump rooms.

Sequences 21 and 22 represent possible transient-induced LOCAs due to failure of a PORV to reclose. When the PORVs fail to close, the sequence is similar to a small LOCA. Block valves are also disabled due to the loss of power. Sequences 21 and 22 include the additional random failures of AFW.

Sequences 25 through 31 are similar to Sequences 5 through 16 except that operator depressurization of the primary system is not necessary. These sequences also involve a faulted $S G$, which will provide cooldown of the primary system. Sequences 32, 33, 36, and 37 are similar to Sequences 17, 18, 21 , and 22, except that the former sequences also include a faulted SG in addition to the other failures.

\subsubsection{Transient With PCS Initially Unavailable Event Tree}

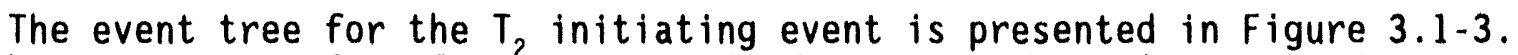
The three primary safety functions required to respond to these transients include subcriticality, SG makeup for core heat removal, and RCS integrity. RCS integrity implies the need for RCP seal integrity, which requires seal injection flow or CCW flow to the RCP thermal barriers. Failure of AFW leads to failure of core heat removal through the SGs, leading to a demand for feedand-bleed cooling. ECCS recirculation is required if feed-and-bleed is successful.

This event tree is similar to the $T_{1}$-LOOP event tree (Figure 3.1-1) except the initiating event for this tree involves a loss of MFW rather than loss of station power. As a result, the discussion of the affected accident sequences is similar to that presented in subsection 3.1.3.1 and will not be repeated here. Systems requiring HVAC/room cooling for successful operation include AFW (event Ll on Figure 3.1-3), LPR (event H3) and HPR (event H2). Room cooling of the respective pump rooms is needed for long-term pump operation.

\subsubsection{Transient With PCS Initially Available Event Tree}

The event tree for a transient with PCS initially available $\left(T_{3}\right)$ is shown in Figure 3.1-4. This event tree is similar to event trees for $T_{1}-$ LOOP (Figure 3.1-1) and $T_{2}$ (Figure 3.1-3) except for additional sequences that include failure of MFW. The success criteria for this event tree are also the same as those for $T_{1}-$ LOOP and $T_{2}$ event trees; $i . e$. , subcriticality, SG makeup for core 


\begin{tabular}{|c|c|c|c|c|c|c|c|c|c|c|c|c|}
\hline $\begin{array}{l}\text { Loss } \\
\text { of } \\
\text { MFW }\end{array}$ & RPS & $\begin{array}{l}\text { RVs } \\
\text { Close }\end{array}$ & $\begin{array}{l}\text { AFW } \\
2 / 4 \\
\text { SGS }\end{array}$ & $\begin{array}{l}\text { Seal } \\
\text { Injct } \\
\text { Flow }\end{array}$ & $\begin{array}{l}\text { CCW } \\
\text { Thrml } \\
\text { Barr }\end{array}$ & HPI & $\begin{array}{l}\text { PORVs } \\
\text { Open }\end{array}$ & $L P I / R$ & HPR & & & \\
\hline $\mathrm{T} 2$ & K & Q1 & Ll & D3 & $W$ & D1 & PI & H3 & $\mathrm{H} 2$ & Sequence & Core & Comments \\
\hline
\end{tabular}

$\stackrel{\omega}{\tilde{\sigma}}$

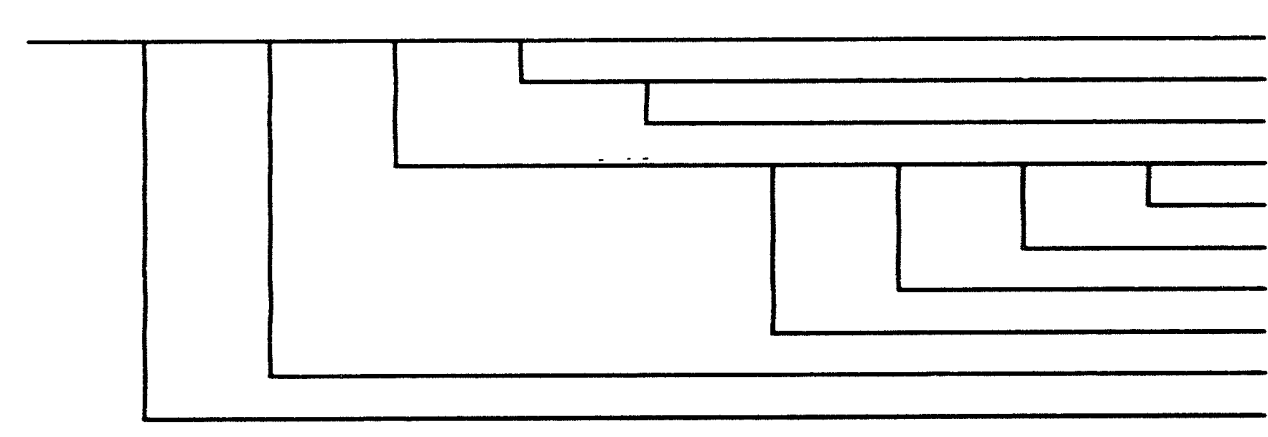

\section{1. $\mathrm{T} 2$}

2. $\mathrm{T} 2 \mathrm{D} 3$

3. $\mathrm{T} 2 \mathrm{D3W}$

4. T2L1

5. T2LIH2

6. T2LIH3

7. T2LIPI

8. T2LID1

9. $\mathrm{T} 2 \mathrm{Q} 1$

10. T2K

\begin{tabular}{ll} 
OK & \\
OK & \\
\hline OK & Seal Vuln. \\
CD & \\
CD & \\
CD & \\
CD & \\
-- & XFER to S2 \\
-- & XFER to ATWS
\end{tabular}

FIGURE 3.1-3. Event Tree for $T_{2}$ - Loss of Main Feedwater 


\begin{tabular}{|c|c|c|c|c|c|c|c|c|c|c|c|c|c|}
\hline $\begin{array}{l}X \text { Xient } \\
\text { W/MFW } \\
\& \text { PCS }\end{array}$ & RPS & $\begin{array}{l}\text { RVs } \\
\text { Close }\end{array}$ & $\begin{array}{l}\text { AFW } \\
2 / 4 \\
\text { SGS }\end{array}$ & MFW & $\begin{array}{l}\text { Seal } \\
\text { Injet } \\
\text { Flow }\end{array}$ & $\begin{array}{l}\text { CCW } \\
\text { Thrm1 } \\
\text { Barr }\end{array}$ & HPI & $\begin{array}{l}\text { PORVs } \\
\text { Open }\end{array}$ & LPI/R & HPR & & & \\
\hline $\mathrm{T} 2$ & K & Q1 & $\mathrm{Ll}$ & $M$ & D3 & $W$ & D1 & P1 & H3 & $\mathrm{H} 2$ & Sequence & Core & Comments \\
\hline
\end{tabular}

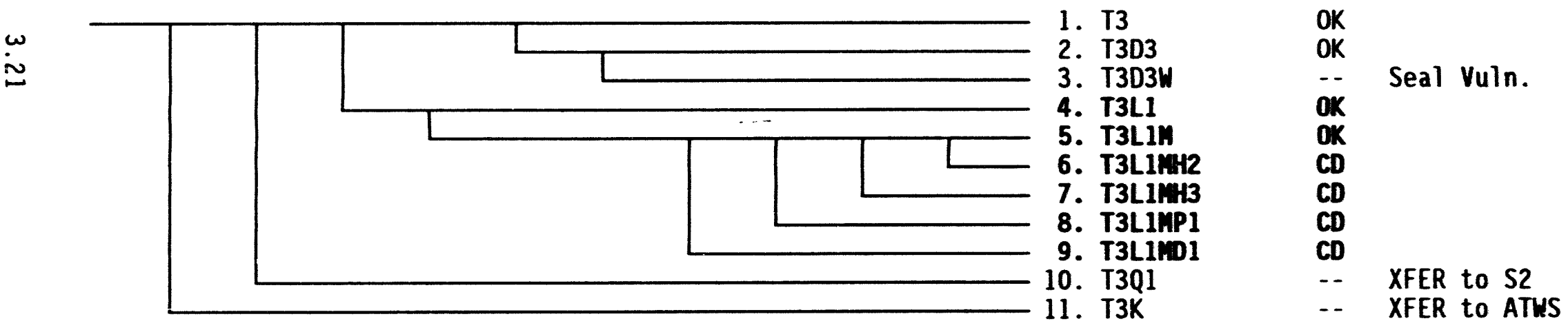

FIGURE 3.1-4. Event Tree for $\mathrm{T}_{3}$ - Turbine Trip with MFW Initially Available 
heat removal, and RCS integrity. However, feed-and-bleed cooling is needed only if both AFW and MFW fail. Also, the need for RCP seal cooling is implied by the requirement for RCS integrity, and ECCS recirculation is required for successful feed-and-bleed cooling. The discussion of affected accident sequences is also similar to that presented in subsection 3.1.3.1, except for the additional failure of MFW that is required to result in fallure to remove core heat through the SGs.

\subsubsection{Loss of One DC Bus Event Tree}

The event tree for loss of one $D C$ bus $\left(T_{D C X}\right)$ is shown in Figure 3.1-5. This event tree is similar to event trees for $T_{1}$-LOOP (Figure 3.1-1) and $T_{2}$ (Figure 3.1-3) except that the initiating events are different. The success criteria for this event tree are also the same as those for $T_{1}-L .00 P$ and $T_{2}$ event trees; i.e., subcriticality, SG makeup for core heat removal, and RCS integrity. Feed-and-bleed cooling is needed if AFW fails. Also, the need for RCP seal cooling is implied by the requirement for RCS integrity, and ECCS recirculation is required for successful feed-and-bleed cooling. The discussion of affected accident sequences is also similar to that presented in subsection 3.1.3.1 except for the initiating event.

Loss of room cooling is a mechanism that could potentially lead to failure of a DC bus. Loss of room cooling could also cause battery chargers and inverters to fail, which would lead to loss of the associated DC bus. Loss of room cooling to $D C$ equipment is addressed as an initiating event, and the CDF is quantified in Section 4.

\subsubsection{5, Steam Generator Tube Rupture Event Tree}

The event tree for steam generator tube rupture (SGTR) ( $T_{S G}$ ) is shown in Figure 3.1-6. The initiating event begins with a double-ended break of a single SG tube, causing a breach of the primary pressure boundary into the secondary side pressure boundary (i.e., primary coolant leaks into the secondary coolant system). The three primary safety functions required to respond to this event include reactor SCRAM, core heat removal, and operator control of RCS pressure. Operator pressure control requires RCS cooldown using nonfailed SGs and depressurization of the primary system through the use of pressurizer sprays or PORV opening.

Following the SGTR event, SI will actuate on low pressurizer pressure. Turbine trip, MFW isolation, and AFW start will occur on the SI signal. Procedures then instruct the operator to identify and isolate the ruptured SG, which is accomplished by closure of the main steam isolation valve (MSIV), AFW inlet valve, SG blowdown line, and TDP steam admission valve. The operator is then instructed to cool Jown the RCS as rapidly as possible using the good SGs, and to then depres irize the RCS (pressurizer sprays or PORVs) to below the pressure in the rupcured $S G$, thus terminating flow through the break and stabilizing the reactor. 


\begin{tabular}{|c|c|c|c|c|c|c|c|c|c|c|c|c|}
\hline $\begin{array}{l}\text { Loss } \\
\text { of DC } \\
\text { Bus }\end{array}$ & RPS & $\begin{array}{l}\text { RVs } \\
\text { Close }\end{array}$ & $\begin{array}{l}\text { AFH } \\
2 / 4 \\
\text { SGS }\end{array}$ & $\begin{array}{l}\text { Seal } \\
\text { Injet } \\
\text { Flow }\end{array}$ & $\begin{array}{l}\text { CCW } \\
\text { Thrm1 } \\
\text { Barr }\end{array}$ & HPI & $\begin{array}{l}\text { PORVs } \\
\text { Open }\end{array}$ & $L P I / R$ & HPR & & & \\
\hline TDC & $k$ & $\mathbf{Q} 1$ & LI & D3 & $W$ & D1 & P1 & H3 & H2 & Sequence & Core & Comments \\
\hline
\end{tabular}

$\tilde{\omega}_{\omega}^{\omega}$

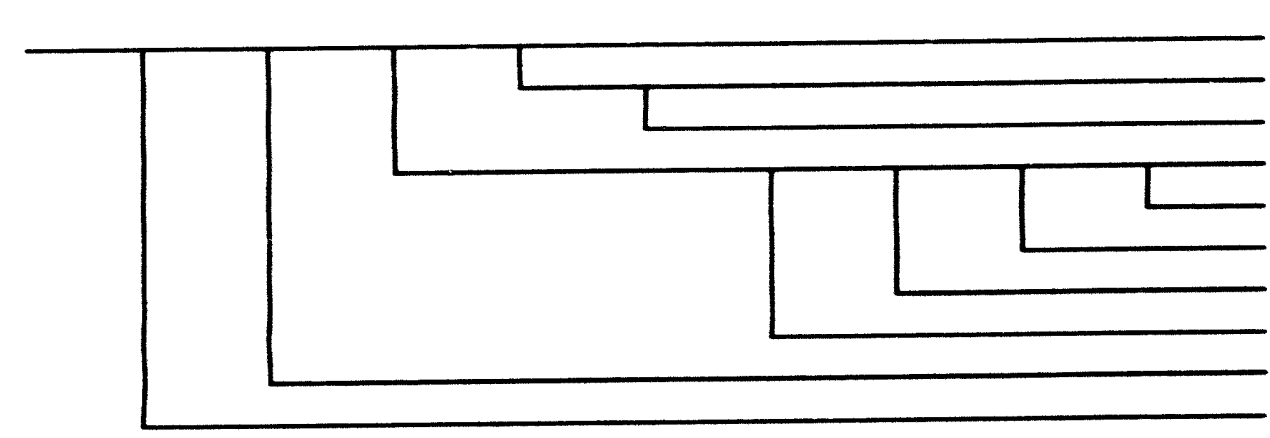

1. TDC

2. TDCD3

3. TDCD3W

4. TDCLI

5. TOCLIH?

6. TOCLIH3

7. TDCLIPI

8. TOCL1D1

9. TDCU1

10. TDCK

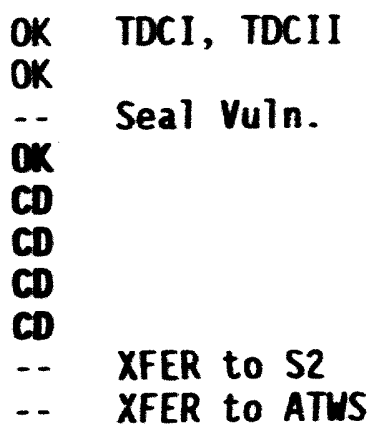

FIGURE 3.1-5. Event Tree for $T_{D C X}$ - Loss of DC Bus 


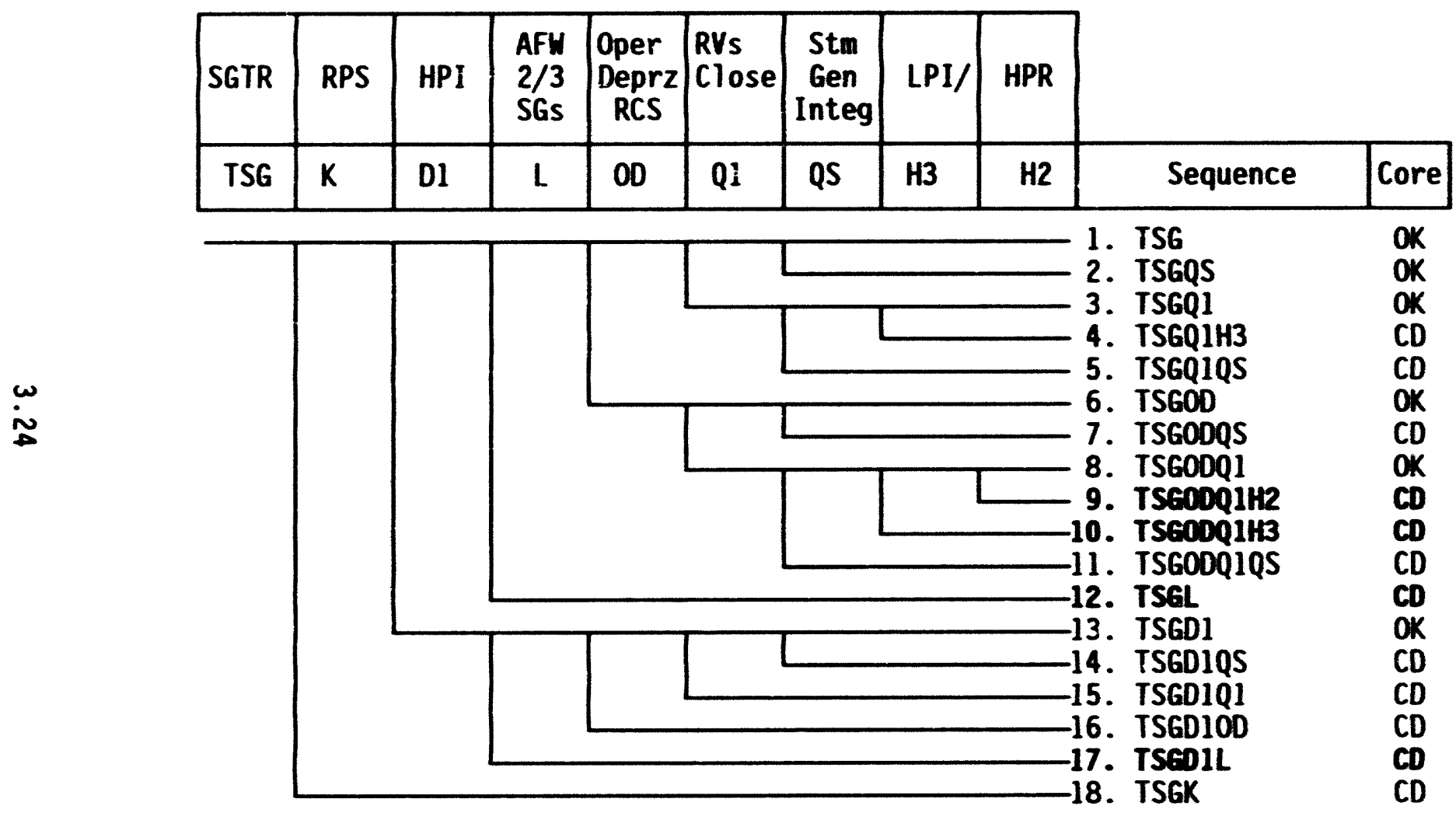

FIGURE 3.1-6. Event Tree for $\mathrm{T}_{S 6}$ - Stean Generator Tube Rupture 
HVAC and room cooler fallures appear in the analys is of events $L, H 2$, and H3. These events appear in accident sequences $9,10,12$, and 17 . Recovery from room cooler fallures was included in the analys is of these [SF failures (see Section 4).

Sequences 9 and 10 represent failure of SG integrity and occur at high pressures because of operator fallure to depressurize the RCS. Because of high break flows, the RWST inventory will be depleted through the unisolated SG. A stuck-open relief valve occurs early in the sequence and results in the requirement for recirculation from the sump. HPR is required because of the previous fallure to depressurize the reactor.

Sequence 12 represents a SGTR with loss of AFW. Loss of AFW following other transients initiates feed-and-bleed cooling. However, feed-and-bleed cooling requires sustained pressure on the primary system, which is counter to the recovery from a SGTR. Bertucio and Brown (1990) state that this sequence was considered a core damage sequence based on a limited previous evaluation.

Sequence 17 is similar to Sequence 12 except for the additional failure of HPI early in the sequence. This sequence leads to core damage through the combination of loss of SG integrity, loss of SI with the HPI system, and loss of SG cooling.

\subsubsection{Large LOCA Event Tree}

The large LOCA (A) event tree is shown in Figure 3.1-7. Bertucio and Brown (1990) assumed that RPS is not required because subcriticality will occur due to voiding of the core during a large LOCA blowdown. Successful injection of the RWST will maintain the core in a subcriticil state.

Successful heat removal in the injection phase was assumed to require flow from one of two LPI trains and three of three accumulators (ACC) to intact RCS loops. It was also stated that a success path involving flow from

\begin{tabular}{|c|c|c|c|c|c|}
\hline $\begin{array}{c}\text { Large } \\
\text { LOCA }\end{array}$ & LPI & ACC & LPR & \multicolumn{3}{|}{} \\
\hline A & D6 & D5 & H1 & Sequence & Core \\
\hline
\end{tabular}

\begin{tabular}{llllll}
\hline & $L$ & 1. & $A$ & OK \\
2. & AH1 & CD \\
3. & AD5 & CD \\
4. & AD6 & CD
\end{tabular}

EIGURE 3.1-7. Event Tree for A - Large LOCA 
two of four HPI trains would provide adequate core heat removal in place of one of two LPI trains. However, because there are very few faults that would fail LPI but not HPI or LPR, this success path was not included.

Success of the containment spray system (CSS) is not required to prevent core damage and is not included in the event tree. Successful operation of one CSS train in recirculation mode and its heat exchanger is adequate to prevent containment failure by steam overpressurization.

The only affected accident sequence involving room cooler failures is Sequence $2(A H 1)$. This sequence leads to core damage due to failure to provide low pressure recirculation cooling, which is dependent upon LPR pump room cooling. No other system can provide the volume of flow needed under large LOCA conditions.

\subsubsection{Medium LOCA Event Tree}

The medium LOCA $\left(S_{1}\right)$ event tree is shown in Figure 3.1-8. The two safety systems required in the injection phase are core heat removal and containment pressure suppression. In the recirculation phase, the required safety functions include core heat removal and containment heat removal. Success of HPI or RPS will provide reactor subcriticality. HPI is required for core heat removal, so RPS performs no unique function for medium LOCAs. Therefore, as with large LOCAs, the RPS is not required to maintain reactor subcriticality.

The medium LOCA accident sequences that involve room cooler failures include those involving failure of LPI/R (event H4) and HPR (event H2). These sequences involve failure to provide the late core heat removal function. Successful late core heat removal requires successful initiation of one of four HPR trains and one of two LPR trains. Accident Sequence 2 (S1H2) leads to core damage due to failure to provide HPR cooling. Accident Sequence 3 (S1H4) fails to provide LPR from the sump that is required to support HPR (i.e., the SI pumps take suction off the discharge of the LPR pumps).

\begin{tabular}{|c|c|c|c|c|c|}
\hline $\begin{array}{c}\text { Med } \\
\text { LOCA }\end{array}$ & HPI & LPI/R & HPR & \multicolumn{2}{|}{} \\
\hline S1 & D2 & H4 & H2 & Sequence & Core \\
\hline
\end{tabular}

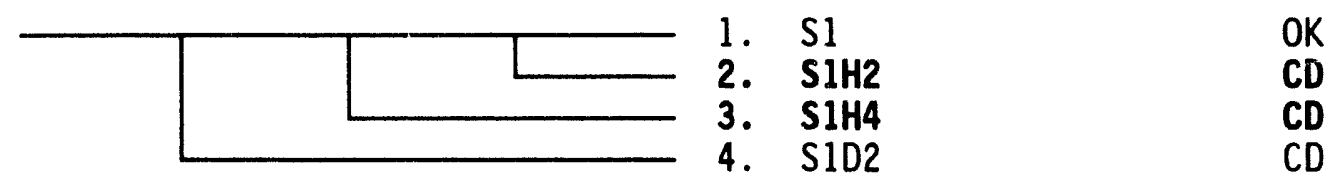

FIGURE 3.1-8. Event Tree For $S_{1}$ - Medium LOCA 


\subsubsection{Small LOCA Event Tree}

The small LOCA $\left(S_{2}\right)$ event tree is presented in Figure 3.1-9. Safety functions required in response to a small LOCA include reactor subcriticality, early core heat removal, late core heat removal, and late containment pressure suppression.

The primary method of core heat removal is through the use of HPI (one of four trains) and AFW (one of three AFW loops). Feed and bleed cooling using one of four HPI trains, may be used if AFW fails by opening an additional PORV (this requires operator action). Core heat removal in the recirculation phase can be provided by one of four HPR trains and one of two LPF. trains with its heat exchanger.

The events in the small LOCA event tree that involve loss of room cooling contributions include L1 (AFW - two of four SGs), W1 (RHR), H3 (LPI/R), and H2 (HPR). These sequences are highlighted in bold type on Figure 3.1-9.

Sequence 2 represents a small LOCA followed by failure of the HPR system which leads to core damage. Sequence 3 represents failure of LPR from the sump. Sequence 2 is recoverable by secondary blowdown, which would allow the LPR system to inject into the core. Sequence 3 is not recoverable by secondary blowdown.

Sequences 4 through 8 represent small LOCAs with failure of containment spray systems, which are not needed for containment pressure suppression or heat removal. Pressure suppression is provided by the ice condenser. Heat removal is provided by AFW and later by LPR with its heat exchanger. Failure of CSS affects the timing of the sequence by prolonging the ECCS injection phase. There is sufficient time for operators to cool down and depressurize the primary system, so HPR is not needed. Sequences 4 and 6 represent stable conditions. Sequence 5 leads to core damage due to failure of LPR after successful depressurization. Sequences 7 and 8 represent core damage due to failure of HPR and LPR, respectively.

Sequences 9 through 12 represent small LOCA sequences with simultaneous failure of AFW systems to provide SG cooling. Feed-and-bleed cooling is necessary to prevent core damage. Sequence 9 represents successful feed-andbleed cooling. Sequences 10 and 11 lead to core damage due to failure of HPR and LPI/R, respectively. Sequence 12 represents core damage due to failure of an operator to open a PORV, thus increasing break flow rates and removing additional decay heat.

\subsubsection{Very Smal1 LOCA Event Tree}

The very small LOCA $\left(S_{3}\right)$ event tree is shown in Figure 3.1-10. Success criteria for a very smal1 LOCA are similar to a small LOCA $\left(S_{2}\right)$; the main difference results from timing considerations that affect recirculation 


\begin{tabular}{|c|c|c|c|c|c|c|c|c|c|c|c|}
\hline $\begin{array}{l}\text { Smal1 } \\
\text { LOCA }\end{array}$ & RPS & HPI & $\begin{array}{l}\text { AFW } \\
2 / 4 \\
\text { SGs }\end{array}$ & $\begin{array}{l}\text { PORV } \\
\text { Open }\end{array}$ & $\begin{array}{l}\text { Cont } \\
\text { Spray } \\
\text { Injct }\end{array}$ & $\begin{array}{l}\text { Oper } \\
\text { Deprz } \\
\text { RCS }\end{array}$ & LPI/R & HPR & \multicolumn{3}{|l|}{} \\
\hline S2 & K & D1 & L1 & P1 & F1 & OD & H3 & H2 & Sequence & Core & Comments \\
\hline
\end{tabular}

$\underset{\infty}{\omega}$

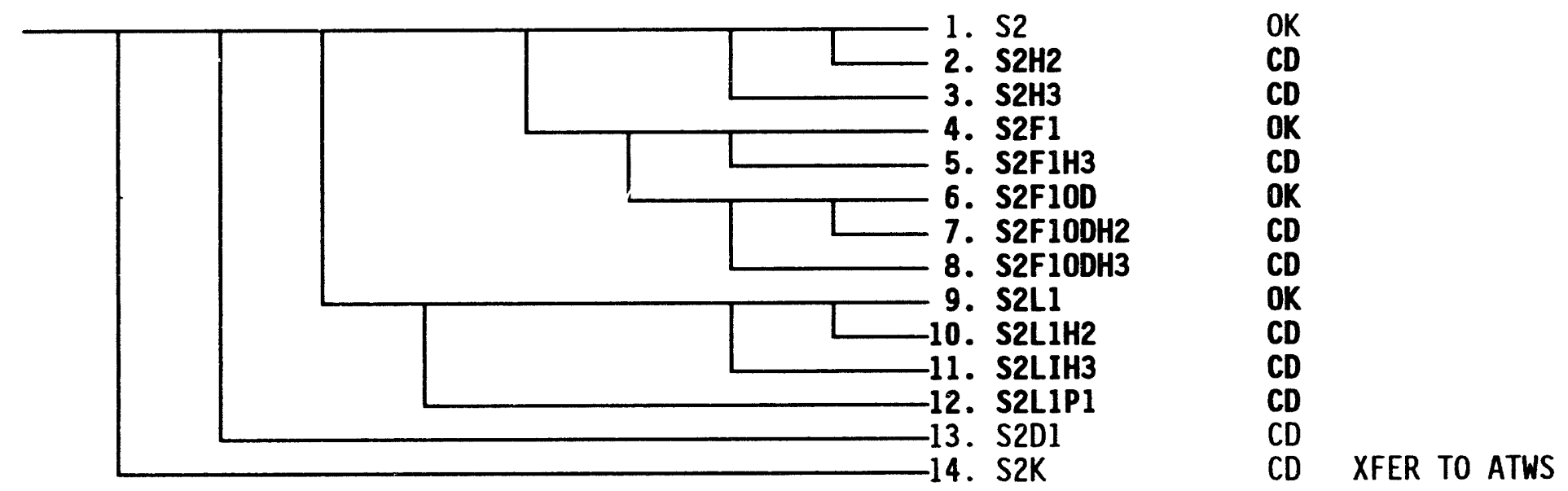

FIGURE 3.1-9. Event Tree for $S_{2}$ - Small LOCA 


\begin{tabular}{|c|c|c|c|c|c|c|c|c|c|c|c|c|c|}
\hline $\begin{array}{l}\text { Very } \\
\text { Sma11 } 1 \\
\text { LOCA }\end{array}$ & RPS & $\mathrm{HPI}$ & $\begin{array}{l}\text { AFW } \\
2 / 4 \\
\text { SGS }\end{array}$ & $\mid \begin{array}{l}\text { PORVs } \\
\text { Open }\end{array}$ & $\begin{array}{l}\text { Cont } \\
\text { Spray } \\
\text { Injct }\end{array}$ & $\begin{array}{l}\text { Oper } \\
\text { Cntrl } \\
\text { Spray }\end{array}$ & $\begin{array}{l}\text { Oper } \\
\text { Deprz } \\
\text { RCS }\end{array}$ & RHR & LPI/R & HPR & & & \\
\hline S3 & K & D1 & LI & P1 & F1 & $O C$ & OD & $W 1$ & H3 & $\mathrm{H} 2$ & Sequence & Core & Commer,ts \\
\hline
\end{tabular}
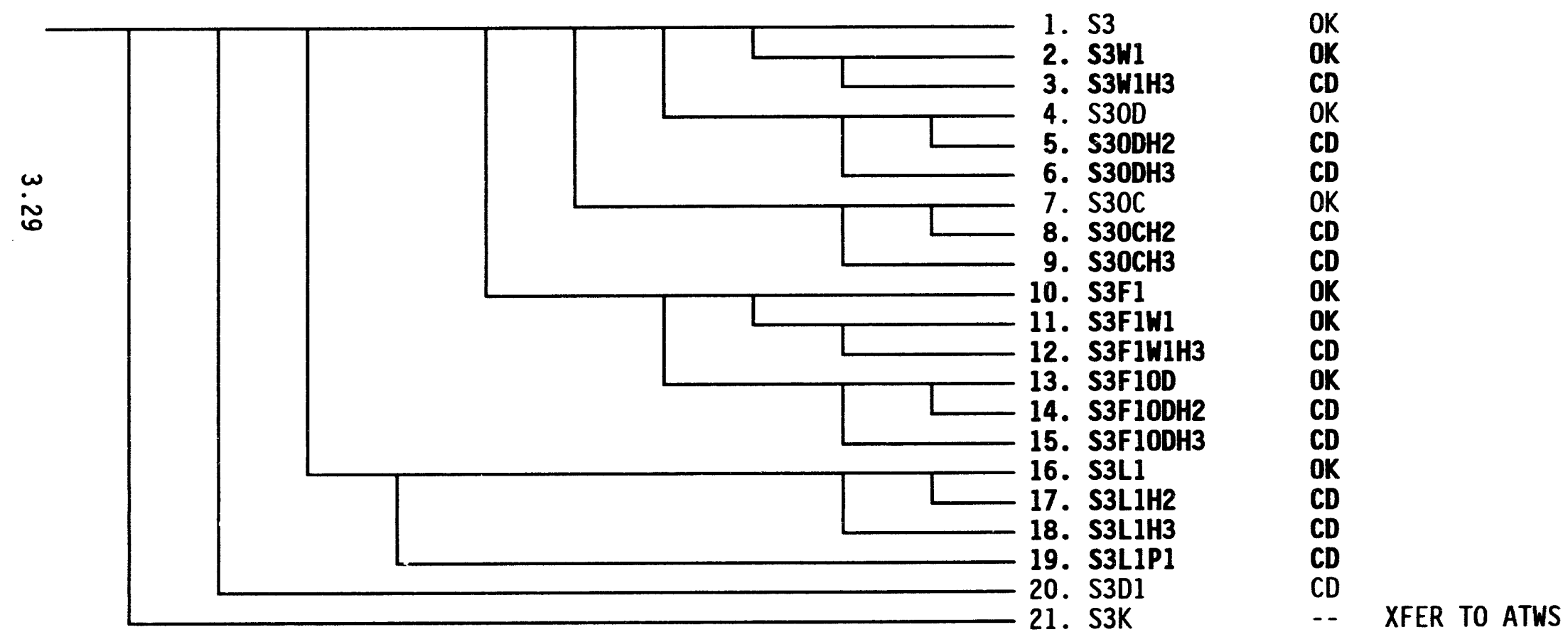

FIGURE 3.1-10. Event Tree for $S_{3}$ - Very Smal1 LOCA 
requirements. For very small breaks, containment is not likely to repressurize. Operators may be able to control the CSS and prolong the injection phase of the accident. This means that if the break is small enough, the reactor may be cooled down and depressurized prior to depletion of the RWST, and there will be no need to proceed to a recirculation phase. In addition, it may be possible for $\mathrm{S}_{3}$ LOCAs to initiate closed-cycle RHR operation. All other $\mathrm{S}_{3}$ success criteria are the same as $S_{2}$ success criteria.

Events on the very small LOCA event tree that include room cooler failure contributions are L1 (AFW - 2/4 SGs), W1 (RHR), H3 (LPI/R), and H2 (HPR). The affected sequences are in bold type on Figure 3.1-10 and are briefly described below.

Sequence 2 involves a very small LOCA followed by unavailability of the RHR system. In this case, LPR cooling is required to provide long-term core cooling. Sequence 3 leads to core damage due to failure of LPR.

Sequences 4 through 6 represent the case in which operators fail to depressurize the primary system, and blowdown continues until RWST depletion. This forces switchover to recirculation. Sequence 4 represents successful mitigation. Sequences 5 and 6 lead to core damage due to failure of HPR and LPR systems, respectively.

Sequences 7,8 , and 9 represent the situation in which the break size is large enough that operators cannot control the CSS, leading to depletion of the RWST and forcing switchover to recirculation. Sequence 7 represents successful mitigation and Sequences 8 and 9 lead to core damage due to failure of HPR and LPR systems, respectively.

Sequences 10 through 15 represent sequences in which the CSS fails, necessitating a prolonged injection phase. These sequences are analogous to Sequences 1 through 6 .

Sequences 16 through 19 represent failure of AFW systems to remove heat through the SGS, thus necessitating feed-and-bleed cooling. Both PORVs must open to allow decay heat removal through the PORVs. Sequence 16 represents successfui feed-and-bleed cooling. Sequences 17, 18, and 19 represent failure to establish feed-and-bleed cooling due to failure of HPR, LPR, and PORVs, respectively. These sequences lead to core damage.

\subsubsection{Anticipated Transient Without SCRAM (ATWS) Event Tree}

Sequences with failure to SCRAM were transferred from the previous event trees to the ATWS event tree shown in Figure 3.1-11. Success criteria for transients initiated at high power (25\% or greater) are different from transients initiated at low power. Success criteria stated by Bertucio and Brown (1990) were based on not allowing RCS pressure to exceed 3200 psi.

Peak RCS pressure is related to the value of the reactor's moderator temperature coefficient (MTC). A critical value of MTC exists above which 


\begin{tabular}{|c|c|c|c|c|c|c|c|c|c|c|c|}
\hline ATWS & MRT & $\begin{array}{l}\text { PWR } \\
\text { Leve1 }\end{array}$ & $\begin{array}{l}\text { MTC } \\
\text { Low }\end{array}$ & $\begin{array}{c}\text { MTC } \\
\text { Unf }\end{array}$ & TBT & PPR & $\begin{array}{r}\text {-AFW } \\
3 / 4 \\
\text { SGS }\end{array}$ & RVC & HPI & \multicolumn{2}{|l|}{} \\
\hline TK & R & PL & Z1 & Z & T & P2 & L2 & Q2 & D4 & Sequence & Core \\
\hline
\end{tabular}

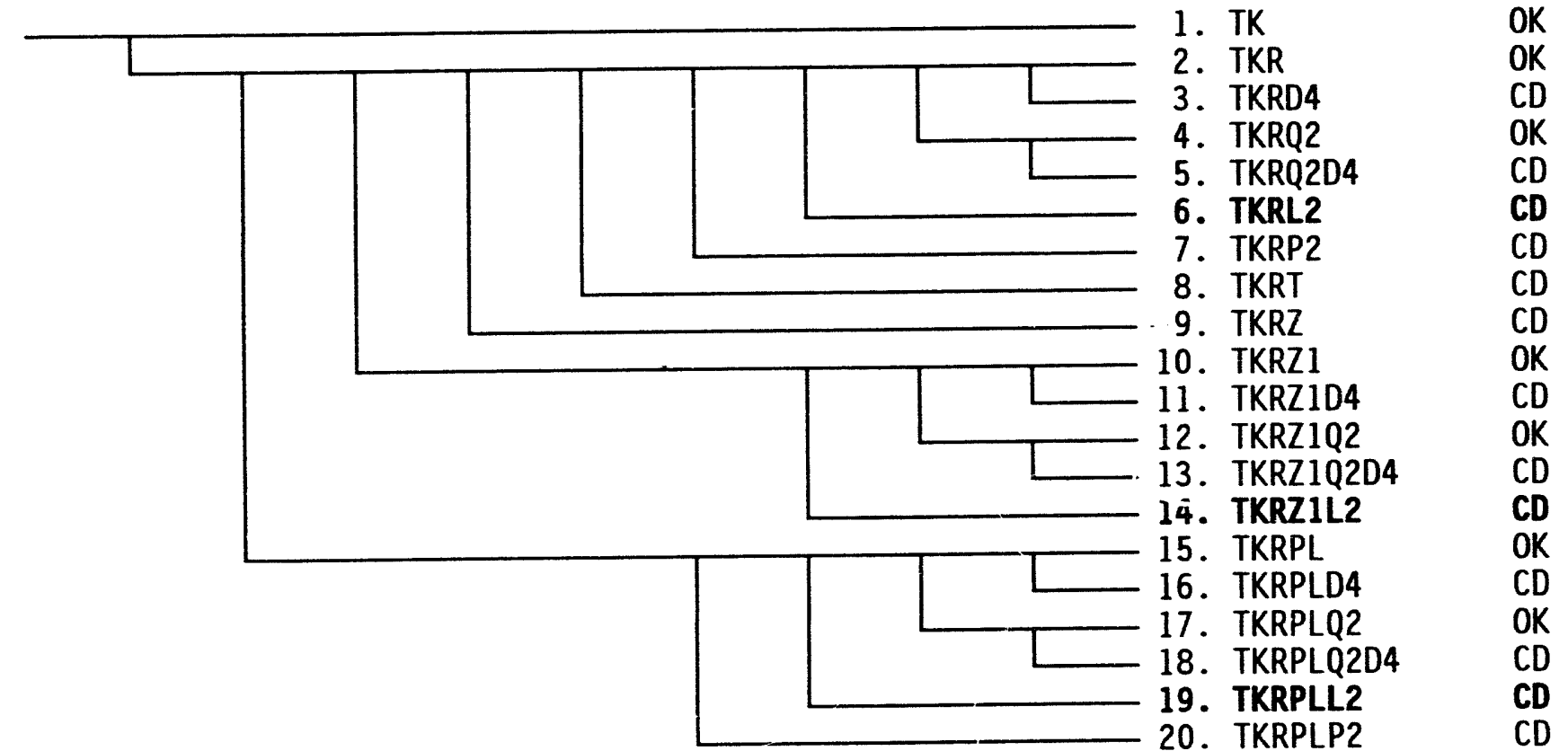

FIGURE 3.1-11. Event Tree for TK - Anticipated Transient Without SCRAM 
there is insufficient negative feedback to maintain RCS pressure below 3200 psi, regardless of relief valve operation. Transients initiated from low power have no restrictions on MTC, and the reactor can be maintained below 3200 psi if relief valves open successfully.

At high power, turbine trip is required to prevent core damage. Failure to trip the turbine may lead to overcooling of the RCS cold legs, thus adding positive reactivity to the core and leading to RCS overpressurization, regardless of relief valve operation. Turbine trips were not required to mitigate low-power transients.

Emergency boration and SG inventory makeup, either from MFW or enhanced AFW, were required for all ATWS events.

Enhanced AFW (event L2 on Figure 3.1-11) is the only event in the ATWS event tree that could potentially involve room cooler failure contributions. The AFW TDP room must be cooled to maintain pump operability, either via an $A C$ - or DC-powered exhaust fan. Three ATWS sequences $(6,14$, and 19) involve event $L 2$.

Sequence 6 represents failure of enhanced AFW, causing loss of SG heat removal and resulting in primary system pressure increase above the shutoff head of the charging pumps, thus preventing boron injection.

Sequence 14 represents the percentage of time that the MTC is low enough that turbine trip and relief valve operation are not necessary to control primary system pressure below 3200 psi. Emergency boration and AFW are required. Sequence 14 leads to core damage due to failure of AFW.

Sequence 19 represents ATWS initiated from low power. This means that there is no concern about MTC and turbine trip. As with Sequence 14, emergency boration and AFW are required. Sequence 19 leads to core damage due to failure of AFW.

\subsubsection{Loss of Electrical Switchgear Room Cooling}

The event tree for a loss of electrical switchgear room cooling $\left(T_{S W}\right)$ is shown in Figure 3.1-12. This event tree was developed for this study; $1 . e$. , was not developed by Bertucio and Brown (1990). As shown, loss of switchgear room cooling does not result in an automatic reactor trip. Rather, if loss of room cooling continues for a sufficient period of time, the temperature will rise within the switchgear room to the point at which the equipment within the rooms may fail. However, because of long heatup times, there is a significant amount of time available to recover from this initiating event. Up to 27 hours are available following loss of switchgear room cooling before the room temperature would exceed the design basis $104^{\circ} \mathrm{F}$. This allows a substantial amount of time to install temporary ductwork and fans or implement alternative room cooling capabilities. 


\begin{tabular}{|c|c|c|c|c|c|c|c|c|c|c|c|c|c|c|}
\hline $\begin{array}{l}\text { Loss } \\
\text { ESF } \\
\text { Swgr }\end{array}$ & Revry & $\begin{array}{c}\text { Man } \\
\text { SCRAM }\end{array}$ & $\begin{array}{l}\text { RVs } \\
\text { Close }\end{array}$ & $\begin{array}{l}\text { AFW } \\
2 / 4 \\
\text { SGs }\end{array}$ & MFW & $\begin{array}{l}\text { Seal } \\
\text { Injct } \\
\text { Flow }\end{array}$ & $\begin{array}{l}\text { CCW } \\
\text { Thrml } \\
\text { Barr }\end{array}$ & HPI & $\begin{array}{l}\text { PORVs } \\
\text { Open }\end{array}$ & LPI/R & HPR & & & \\
\hline TSW & RSW & $K^{\prime}$ & Q1 & LI & M & D3 & W & D1 & P1 & H3 & $\mathrm{H} 2$ & Sequence & Core & Comments \\
\hline
\end{tabular}

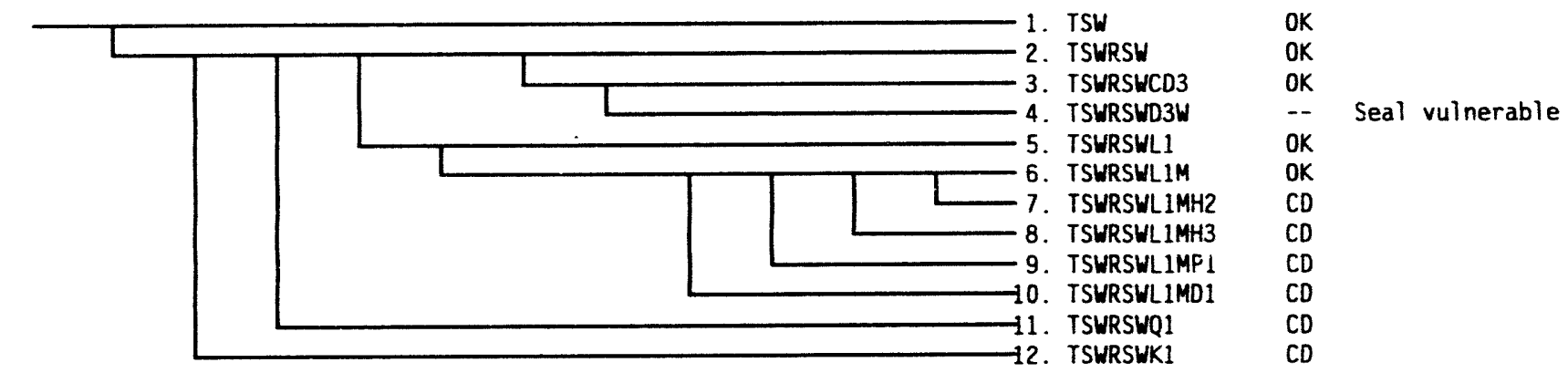

FIGURE 3.1-12. Event Tree for $\mathrm{T}_{\mathrm{SW}}$ - Loss of Electrical Switchgear Room Cooling 
If this does not occur, the plant would be required by technical specifications to begin an orderly shutdown. Failure of the electrical switchgear, which includes MCCs for ECCS pumps and MOVs, results in loss of AC power to the affected division of ECCS equipment.

Failure of electrical switchgear room cooling would be detected through normal ambient room temperature measurements taken once per shift. Local temperature monitors are provided in each room, but there are no remote temperature indications or alarms for these rooms in the control room. Fan operability is monitored remotely in the control room, so fan failures would be detected more quickly than high temperature readings in the rooms. Modeling of switchgear room cooling failure detection and repair activities is presented in Section 4.0 .

If this event should occur and recovery of room cooling fail, the plant must be manually tripped. Failing to manually trip the plant event tree is similar to that for a transient with PCS initially available. The safety system failure probabilities will be modified somewhat from those given by Bertucio and Brown (1990) to reflect the higher failure probability that results from operation of the electrical switcingear in an uncooled room. Cescriptions of the core damage sequences are provided below.

Sequences 1, 2, and 3 represent successful mitigation of this transient either through successful recovery of room cooling or successful reactor trip and all essential safety functions are being provided. Sequence 4 (TSWRSWDW) leads to core damage due to a seal LOCA and failure to restore seal injection flow and flow to the RCP thermal barrier before core uncovery occurs. The RCP seal failure model is

Prob. at $\begin{aligned} & \text { Prob. } \\ & \text { Prob. Core } \\ & \text { Damage } \\ & \text { seal LOCA }\end{aligned} * \begin{aligned} & \text { Prob. } \\ & \text { seal LOCA } \\ & \text { occurs }\end{aligned} * \begin{aligned} & \text { Prob. no } A C \\ & \text { prior to core } \\ & \text { uncovery }\end{aligned}$

The first term in this equation is the probability that $A C$ power is not restored within 90 minutes of a loss of seal cooling. The probabilities for seal LOCA, the second term, were developed during the NUREG-1150 process and include 16 seal LOCA scenarios, each with a specific uncovery time and probability. The third term is the probability of nonrecovery of $A C$ power for each specific core uncovery time. The uncovery times and probabilities for the RCP seal LOCA model used here are presented in Table D.5-3 of Bertucio and Brown.

Sequence 5 (TSWRSWL1) represents stable hot shutdown with SG inventory provided by MFW, after failure of AFW. Sequence 6 (TSWRSWLIM) represents failure of SG heat removal but successful feed-and-bleed cooling (successful operation of one charging pump or one SI pump and opening of both PORVs). Long-term cooling would be provided by ECCS recirculation from the sump and successful operation of the RHR heat exchangers.

Sequence 7 (TSWRSWL1MH2) represents core damage due to failure to provide HPR for long-term cooling. HPI pump MCCs are located in the switchgear 
room and are presumed to fail when room temperatures exceed the design room temperatures, depriving the affected HPI pump of motive power. Sequence 8 (TSWRSWLIMH3) is similar to Sequence 7 except that LPR systems are unavailable. As with the HPI pumps, failure of the switchgear room cooling function will ultimately fail the LPI/LPR pump MCCs located in the switchgear room.

Sequences 9 and 10 represent failure to initiate feed-and-bleed cooling after loss of AFW. In Sequence 9 (TSWRSWL1MP1), feed-and-bleed cooling fails due to failure of two of two PORVs to open. In Sequence 10 (TSWRSWLIMD1), feed-and-bleed cooling fails due to failure to establish safety injection flow. SI pump MCCs are located in the switchgear rooms in which room cooling has failed.

Sequence 11 represents a transient-induced LOCA (see event tree for $S_{2}$ ) and Sequence 12 represents an ATWS sequence, even though the reactor trip is a manual action in this case.

\subsubsection{Event Tree for Loss of Control Room Cooling}

The event tree for a loss of control room cooling $\left(T_{C R}\right)$ is shown in Figure 3.1-13. This event tree was developed in this study. As with loss of electrical switchgear room cooling, loss of control room cooling does not result in an automatic reactor trip. Rather, if loss of control room cooling continues for a sufficient period of time, the temperature will rise within the control room to the point at which the equipment within the room may fail. According to plant operators, the most sensitive equipment in the areas served by the control room cooling system are the ESF load sequencers. A malfunction of the ESF load sequencers could send a continuous load-shed signal to one or more trains of vital AC power buswork. This would result in loss of backup $A C$ power in the train affected by the ESF load sequencer. Failure to provide loss of cooling to the ESF load sequencer cabinets may occur either as a result of a loss of cooling to the general control room area or failure of fans located in the ESF load sequencer cabinets (fans are provided for these cabinets at some plants).

Another vulnerable control room component is the computer. Although not safety-related, the computer provides rapid access to information that would otherwise have to be collected manually. For example, loss of cooling to an ECCS pump would alarm in the control room as "AUXILIARY BUILDING VENTILATION TROUBLE" and not necessarily indicate which specific room cooler is malfunctioning. The control room operator would then go to the computer to determine which cooler is malfunctioning. If the computer is malfunctioning, an operator would need to proceed to each potential ECCS pump to determine the source of the failure.

Failure of control room cooling would most likely be detected by operators noticing an increase in temperature. During normal operations, control room cooling is provided by a nonsafety-related normal cooling system. 
$\omega$

w

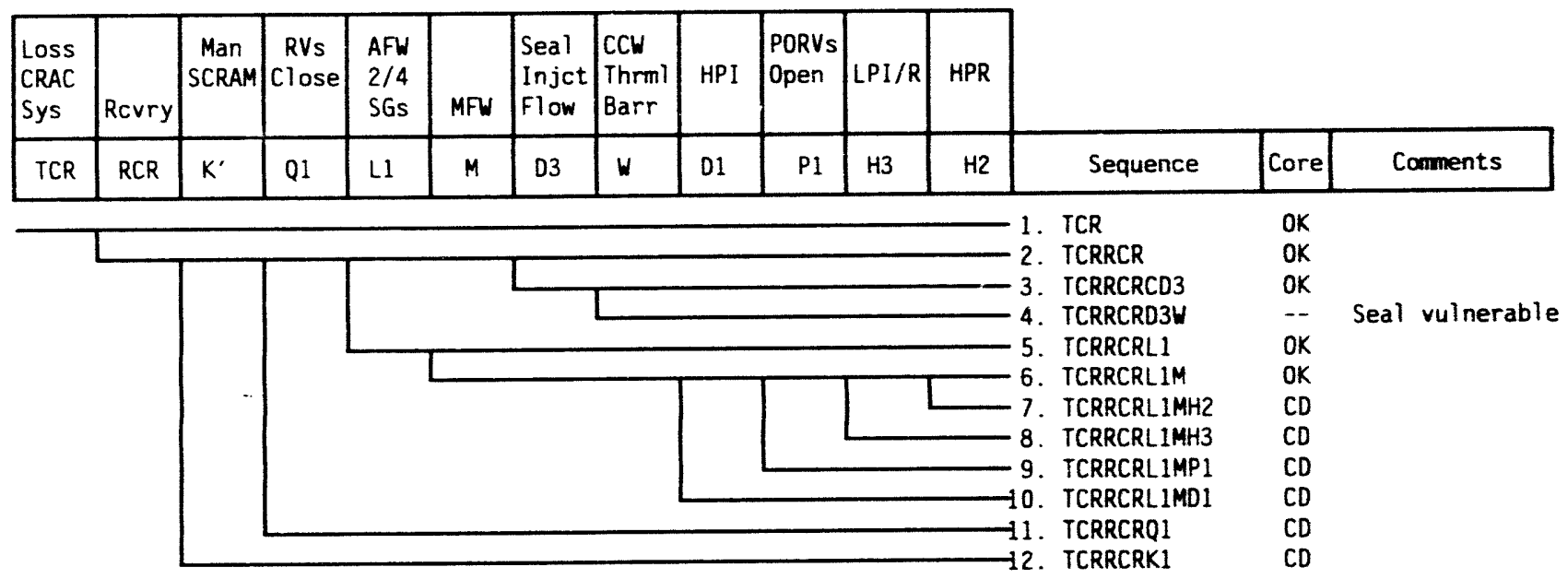

FIGURE 3.1-13. Eyent Tree for $T_{C R}$ - Loss of Control Room Air Conditioning System 
Under accident conditions, the normal control room HVAC system is isolated, and an emergency control room HVAC system is started. The emergency system provides redundant trains of control room HVAC, including separate fans, chillers, filters, ductwork, and dampers. The emergency system is relatively complex because of requirements to maintain control room habitability. For example, the system must be capable of being isolated from outside air and capable of actuation in the presence of excessive radiation levels and toxic gases in the outside atmosphere. For this reason, the LER review presented in Appendix A found many instances of spurious actuations of the emergency control room HVAC system. Control room temperature and system operability is continuousiy monitored and alarmed in the control room.

Control room cooling failures have occurred in the past, resulting in spurious readings and indications from control room panels (see Section 2). Such spurious readings could mislead operators into taking incorrect actions or could cause failures that result in inadvertent safety system operation or failure to detect actual problems in the plant. Should the control room temperature rise to a certain temperature, the plant would be required by technical specifications to begin an orderly shutdown. This temperature was established to maintain ambient temperatures below those that could cause failures or malfunctions of electronic equipment within cabinets in the control room.

As with the loss of switchgear room cooling event tree, the event tree for loss of control room cooling is similar to that for the transient with PCS initially available. The description of accident sequences following loss of control rooll cooling is similar to the description of accident sequences in subsection 3.1.3.11 and will not be repeated here. The major differences between sequences are the possible failures in the control room that could "mislead" operators or cause spurious, incorrect readings and alarms. These differences were accounted for in the quantification process (see Section 4).

\subsubsection{Event Tree for Loss of Safety Injection Pump Room Cooling}

The event tree for a loss of SI pump room cooling $\left(T_{H}\right)$ is shown in Figure 3.1-14. This event tree was developed in this study. As with loss of electrical switchgear room cooling, loss of SI pump room cooling does not result in an automatic reactor trip. Technical specifications applicable to operability of the SI pumps are also applicable to "attendant" equipment such as room coolers, which must function for the SI pump to be operable. Should an SI pump room cooler be ceslared inoperable, the SI pump served by that room cooler is also considered inoperable. Portable cooling may be installed to allow continued plant operation; however, NRC approval would be needed. For the representative W PWR, the relevant technical specification is paraphrased below:

- Should one train of safety injection be declared inoperable, the plant must proceed to hot shutdown within the following 30 hours and to cold shutdown within the following six hours. 


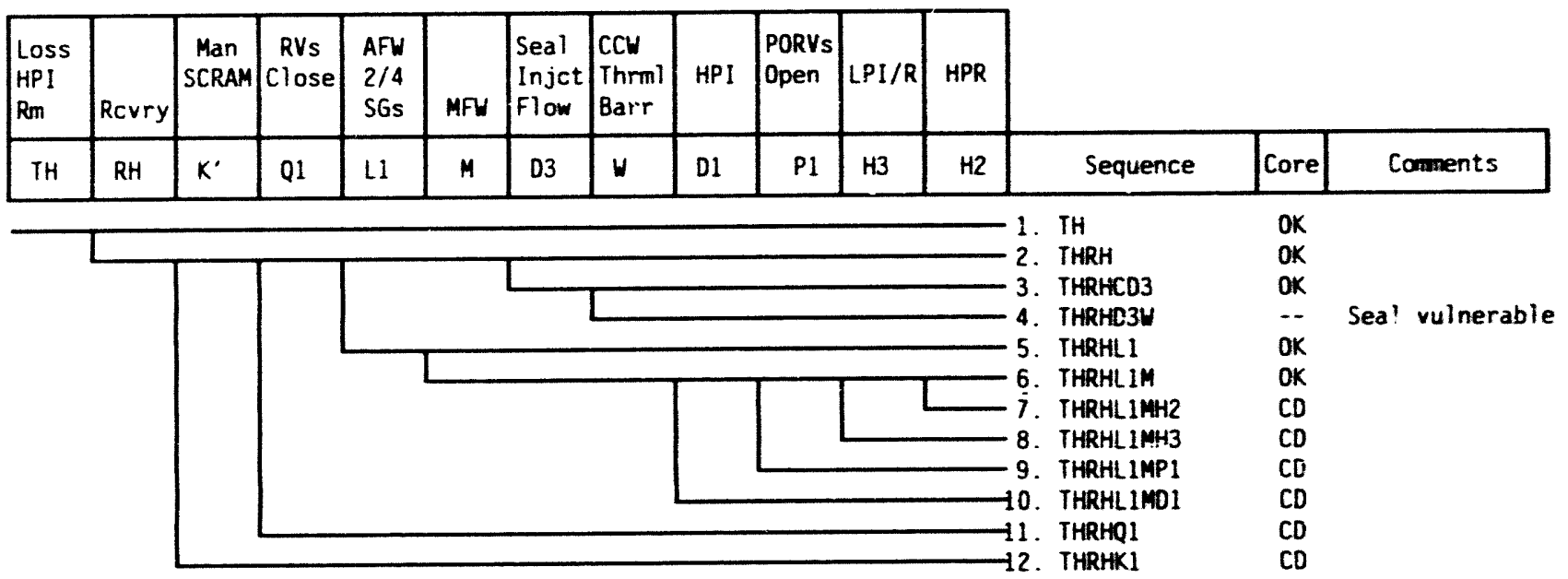

FIGURE 3.1-14. Event Tree for $T_{H}$ - Loss of HPI Rom Cooling (includes charging pump and SI pump rooms) 
- Should both trains of safety injection be declared inoperable, the plant must immediately initiate a controlled shutdown and be at hot shutdown within the following four hours.

This allows approximately 30 hours to recover SI room cooling capability if one train of room cooling falls, and four hours to recover if both trains fail.

Should this event occur and recovery of room cooling fail, the plant must be manually tripped. The event tree for falling to marually irip the plant is similar to that for a transient with PCS initially available. Des criptions of the core damage sequences are similar to the sequences described in the loss of switchgear room cooling event; however, one major difference is that the probability of SI system fallure, designated as events $D 1$ and $H 2$ in Figure 3.1-14 HPI and HPR must be reevaluated because room cooler fallures render these systems inoperable. This quantification is discussed in Section 4.0 .

\subsubsection{Event Tree for Loss of LPI/LPR Room Cooling}

The event tree for a LPI/LPR pump room (also referred to as the residual heat removal room) cooling $\left(T_{L P}\right)$ is shown in Figure 3.1-15. This event tree was developed for this study. As with loss of electrical switchgear room cooling, loss of LPI/LPR pump room cooling does not result in an automatic reactor trip. Technical specifications applicable to operability of the LPI/LPR pumps are also applicable to "attendant" equipment such as room coolers, which must function for the LPI/LPR pump to be operable. Should an LPI/LPR pump room cooler be declared inoperable, the LPI/LPR pump served by that room cooler is also considered inoperable. The relevant technical specification discussed in subsection 3.1.3.14 applies to these rooms.

If this event occurs and recovery of room cooling fails, the plant must be manually tripped. The event tree for failing to manually trip the plant is similar to that for a transient with PCS initially available. Descriptions of the core damage sequences are similar to the sequences described in the loss of switchgear room cooling event; however, one major difference is that the probability of LPI/LPR system failure, designated as event $\mathrm{H3}$ in Figure 3.1-15, must be reevaluated, because room cooler failures render these systems inoperable. This quantification is discussed in Section 4.

\subsection{GENERAL ELECTRIC CO. BOILING WATER REACTOR}

\subsubsection{Plant Description}

The representative boiling water reactor (BWR) contains a single unit with 1250-MWe capacity. The General Electric (GE) reactor is housed in a Mark III containment. The station began commercial operation in July 1985. 


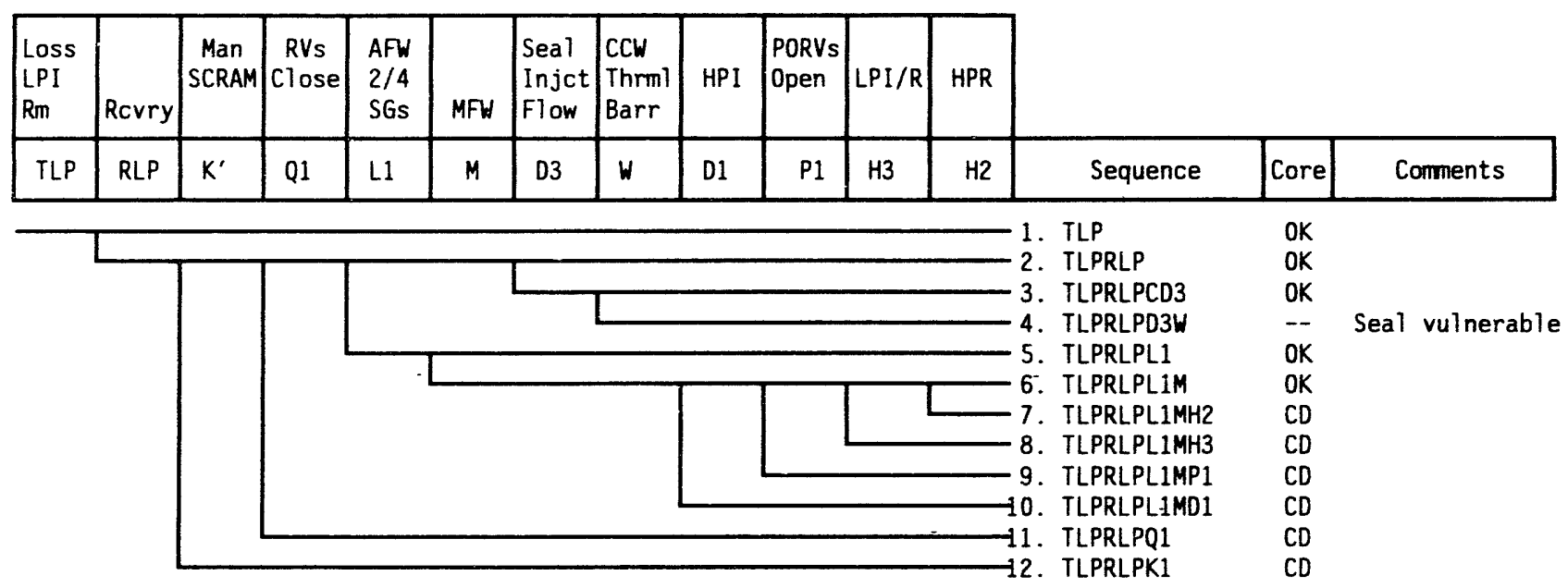

FIGURE 3.1-15. Event Tree for $T_{L P}$ - Loss of Low-Pressure Injection Pump Room Cooling 


\subsubsection{Plant Systems}

This section contains a brief description and simplified schematics of the systems important to providing safety functions (e.g., core cooling, containment cooling) in preventing core damage. The summary descriptions are taken from the NUREG-CR/4550 (Drouin et a1. 1989) and include each system design characteristics, functions, dependencies, and applicability to room cooling or HVAC failure. There are 23 systems described; however, only eight of the systems are affected by this issue.

The following safety-related systems were identified as systems having a dependency on room cooling functions:

- High-pressure core spray (HPCS) system

- Reactor core isolation cooling (RCIC) : stem

- Low-pressure core spray (LPCS) system

- Low-pressure coolant injection (LPCI) system

- Residual heat removal (RHR): suppression pool cooling (SPC) system

- Residual heat removal (RHR): shutdown cooling (SDC) system

- Residual heat removal (RHR): containment spray (CS) system

- Emergency power system (EPS)

The two primary systems that provide room cooling for the above systems are the standby service water (SSW) system and the emergency ventilation system (EVS). Table 3.2-1 estimates the time to failure for equipment susceptible to failure without room cooling, based on information in Druin et al. (1989).

This section provides an overview of the system analyses and fault tree analyses performed by Druin et al. (1989) for the representative BWR. Additional details can be found in Appendix $C$.

\subsubsection{High-Pressure Core Spray (HPCS) System}

The HPCS system provides coolant to the reactor vessel during accidents in which pressure remains high. The system consists of a single train with MOVs and a MDP. Suction is taken from either the condensate storage tank (CST) or the suppression pool. Injection to the reactor vessel is via a spray ring mounted inside the core shroud. Most of the HPCS system is located in a separate room in the Auxiliary Building with fire/flood doors. A simplified schematic of the HPCS system is provided in Appendix $C$. 
IABLE 3.2-1. Estimated Time to Failure for Room Cooling Sensitive Equipment

\begin{tabular}{|l|r|}
\hline EQUIPMENT & TIME TO FAILURE \\
\hline EDG A & 15 minutes \\
EDG B & 15 minutes \\
EDG C & 15 minutes \\
RHR A pump & 4 hours \\
RHR B pump & 4 hours \\
RHR C pump & 4 hours \\
HPCS pump & 12 hours \\
LPCS pump & 4 hours \\
RCIC pump & 12 hours \\
\hline
\end{tabular}

The HPCS system is automatically initiated and controlled or may be manually started. Operator intervention is required to throttle flow to prevent the HPCS injection valve from opening and closing in response to the reactor vessel level.

The HPCS dependencies are listed in Appendix $C$. Room cooling to the HPCS pump is provided by the EVS. The HPCS pump was assumed by Drouin et al. (1989) to fail in 12 hours without room cooling. Room heatup calculations following loss of room cooling presented in Appendix $F$ confirm that the room will heat up to the maximum operating temperature of the pump within about 12 hours. Failure rate data also presented in Appendix $F$ indicate that the pump will continue to operate at temperatures up to about $250^{\circ} \mathrm{F}$; however, the pump failure rate increases significantly at higher ambient temperatures.

A simplified fault tree diagram for the HPCS system is shown in Appen. dix C. As shown, HPCS room cooling failure is functionally equivalent to failure of the HPCS pumps, the same dependence exhibited by the W PWR ECCS systems. Failure of the HPCS pumps and failure of the HPCS room rooler roth lead to failure of the HPCS system to provide coolant to the reactor vessel. The main difference is in the timing of HPCS functional failure. Write fail. ure of the pumps results in immediate loss of HPCS, time is availab?e foilowing loss of HPCS room cooling before HPCS functional failure occur:

\subsubsection{Reactor Core Isolation Cooling (RCIC) System}

The RCIC system provides coolant to the reactor vessel durisig aicinents in which system pressure remains high. The system consists of a sisigle rain with MOVs and a TDP. Suction is taken from either the CST or tine siespression pool. The RCIC pump discharges the water to the "B" residual hes! riovil (RHR) system header, which discharges to the "B" feedwater line. fur the flow is recirculated through the turbine lube oil cooler. Most of 1.4 ?.IC system is located in a separate room in the Auxiliary Building. The FCIC system is physically located in a different quadrant of the building than the HPCS system. A simplified schematic of the RCIC system is provided in Appendix C. 
The RCIC system is automatically initiated and controlled or may be manually started. Operator intervention is required to prevent either vessel overfill or continuous system trip/restart cycles, and to set up the system for continuous operation when battery depletion is imminent.

RCIC pump room cooling is provided by the EVS. Room cooling failure was assumed by Drouin et a1. (1989) to fail the RCIC pump in 12 hours (see Appendix $F$ for transient thermal analysis results and assessment of failure rate versus ambient temperature).

Steam for the RCIC pump turbine comes from the "A" main steam line. The RCIC system is the only steam-driven system. Temperature sensors are located in the RCIC equipment room and steam-line tunnel. Sensors trip at $185^{\circ} \mathrm{F}$ in case of a pipe break. A RCIC turbine trip occurs on high turbine exhaust pressure, high reactor water level, low pump suction pressure, low steam pressure, or an auto isolation signal.

A simplified RCIC fault tree diagram is shown in Appendix C. Similar to the W PWR, failure of the RCIC room cooling system is functionally equivalent to failure of the RCIC pump; the main difference is that failure of the RCIC room cooler does not immediately result in RCIC pump failure, thus failure of the system to provide coolant to the reactor vessel. Time is available following loss of RCIC pump room cooling to repair the room cooler or provide supplemental cooling capabilities before the pump fails due to high room temperature.

\subsubsection{Control Rod Drive (CRD) System}

The CRD system is a backup source for HPI. The CRD pumps take suction from the condenser hotwell makeup/reject line provided by the CST. Excess condensate from the condenser is rejected to the CST by the condensate system. Two pumps provide pressure to two different discharge paths. The first path is through the hydraulic control units' (HCUs) cooling header. Flow is controlled by one of two air operated control valves. The second path is through the HCU charging headers. Host of the CRD system is located in the Auxiliary Building. A simplified schematic of the CRD system is provided in Appendix C.

Both CRD pumps are required at the start of an accident when the CRD system is the only makeup source. The first discharge path fails closed while the second path fails open on a loss of the instrument air system (IAS). However, the secondary path to the HCU charging headers is restricted and is insufficient to provide adequate cooling requirements by itself.

The CRD pump $A$ is powered by $A C$ Division 1, with control and actuation power supplied by DC Division 1. The CRD pump B is powered by AC Division 2 with control and actuation power supplied by DC Division 2. Instrument air is required for operating the flow control valves. Manual actuation is required for the system; however, CRD pump $A$ is normally operating. 
The CRD pumps are cooled by the component cooling water (CCW) system and CRD pump room coolers. Room cooling and pump-motor cooling failures are assumed not to fail CRD pumps during short-term operation. The demand for CRD is a short-term action and must be accomplished quickly following a transient or LOCA. Therefore, sufficient time is available following loss of CRD room cooling to complete the CRD function before room temperatures could result in CRD pump failure. Therefore, fault trees were not developed in this study for the CRD system.

\subsubsection{Low-Pressure Core Spray (LPCS) System}

The LPCS system provides coolant to the reactor vessel during accidents in which vessel pressure is low. The ADS can be used in conjunction with the LPCS to attain a low enough system pressure for injection to occur. The system is a single train system consisting of motor-operated and manual valves and a MDP. Most of the LPCS system is located in the Auxiliary Building. The LPCS pump takes water from the suppression pool through strainers. It is automatically initiated and controlled or may be started manually. A simplified schematic of the LPCS system is provided by Appendix C.

The LPCS system major dependencies include, among other things, LPCS pump room cooling. Room cooling is provided by the EVS, which is described later. Room cooling failure was assumed by Drouin et al. (1989) to fail the LPCS pump in four hours.

The fault tree diagram developed for the LPCS system by Drouin et al. was simplified in this study, and the simplified fault tree diagram is shown in Appendix C. As shown, failure of LPCS pumps and failure of LPCS pump room cooling are functionally equivalent. Failure of either the LPCS pump or the LPCS room cooler results in failure of the associated LPCS division to provide coolant to the reactor vessel.

\subsubsection{Low-Pressure Coolant Injection (LPCI) System}

The LPCI system provides coolant to the reactor vessel during accidents in which system pressure is low. The ADS can be use in conjunction with the LPCI system to attain a low enough RCS pressure for injection to occur. The LPCI system is but one mode of the residual heat removal (RHR) system and, as such, shares components with othe: modes.

The LPCI system is a three-train system consisting of MOVs and MDPs. Trains $A$ and $B$ each have two heat exchangers in series downstream of the pump; Train $C$ is dedicated to injection and has no heat exchangers. Cooling water flow to the heat exchangers is not required; for the LPCI mode. The LPCI pump suction source is the suppression pool. Most of the LPCI system is located in the Auxiliary Building. The LPCS is automatically initiated and controlled or may be started manualiy. A simplified schematic of the LPCI system is provided in Appendix $C$. 
The LPCS system is dependent upon LPCS pump room cooling. A11 LPCS pumps require pump couling and room cooling. Room cooling failure was assumed by Drouin et al. to fail the RHR pumps in four hours (see Appendix F).

The fault tree diagram developed for the LPCS system tree is shown in Appendix C. As with previous safety systems, failure of LPCI pump room cooling is functionally equivalent to failure of the LPCI pumps.

\subsubsection{Residual Heat Removal (RHR): Suppression Pool Cooling (SPC) System}

The SPC system removes decay heat from the suppression pool during accidents. The SPC system is one mode of the RHR system and, as such, shares components with other modes.

The SPC system is a two-train system consisting of MOVs and MDPs. Each train has two heat exchangers in series downstream of the pump; cooling water flow to the heat exchanger is required for the SPC mode. The SPC suction source is the suppression pool. The pumps are located in the Auxiliary Building in an enclosed room with fire/flood doors. A simplified schematic of the SPC system is shown in Appendix C.

The S.PC system is manually initiated and controlled. The operator is required to align the system and to start the pumps. Injection flow from either pump/heat exchanger train to the suppression pool is sufficient to accomplish the SPC function.

The RHR pumps require pump cooling and room cooling. Room cooling failure was assumed by Drouin et a1. to fail the RHR pumps in four hours.

The simplified SPC fault tree diagram is shown in Appendix C. Basically, failure of the RHR pump room coolers is functionally equivalent to failure of the RHR pumps; the key difference is that failure of the RHR pumps results in immediate failure of the RHR function. Failure of the RHR pump room coolers results in a gradual heatup of: the RHR room; time is available to implement repairs to the RHR pump room coolers and restore cooling to the RHR pump room before the pumps fail due to overheating.

\subsubsection{Residual Heat Removal (RHR): Shutdown Cooling (SDC) System}

The SDC system removes decay heat during accidents in which reactor vessel integrity is maintained. The SDC is one mode of the RHR system and, as such, shares components with other modes.

The SDC system is a two-train system consisting of MOVs and MDPs. Each train has two heat exchangers in series downstream of the pump; cooling water flow to the heat exchanger is required for the SDC mode. The SDC system suction source is one recirculation pump's suction line. The SDC pumps are located in the Auxiliary Building in an enclosed room with fire/flood doors. A simplified schematic of the SDC system is provided in Appendix C. 
The SDC system is manually initiated and controlled. The operator is required to align the system and to start the pumps. Since the RHR pumps are used for shutdown cooling, the SDC system dependencies on room cooling are the same as the SPM room cooling dependencies.

\subsubsection{Residual Heat Removal (RHR): Containment Spray (CS) System}

The CS system suppresses pressure in the containment during accidents. The CS system is one mode of the RHR system and, as such, shares comporients with other modes.

The CS system is a two-10op system consisting of MOVs and MDPs. There are two heat exchangers in series per loop; cooling water flow to the heat exchanger is required for CS mode. The CS suction source is the suppression pool. The pumps are located in the Auxiliary Building in an enclosed room with fire/flood doors. The CS system is automatically initiated and controlled or may be manually initiated. A simplified schematic of the CS system is provided in Appendix $C$.

The CS system is manually initiated and controlled. The operator is required to align the system and to start the pumps. Since the RHR pumps are al so used for $C S$, the CS system dependencies on room cooling are the same as the SPM room cooling dependencies.

\subsubsection{Emergency Power System (EPS)}

The EPS consists of the $A C$ and $D C$ power divisions required by the ESF to safely shut down the plant. Both $A C$ and $D C$ power are divided into three separate divisions. Divisions 1 and 2 are for the majority of the ESF, and Division 3 is dedicated to the HPCS system and its required support systems. A schematic of the EPS is shown in Appendix $C$.

The ESF AC divisions normally receive power from one of three offsite sources through ESF transformers. Each ESF bus has a standby EDG which is available to supply bus loads upon a loss of normal AC power. These EDGs may be started manually or automatically. Each ESF DC division consists of two battery chargers, which normally supply the load, and a bank of batteries that functions as a backup.

Most of the EPS is located in the Diesel Building and in compartmentalized rooms within the Auxiliary Building. Room cooling is required for the EDG rooms. Diesel generators were assumed by Drouin et al. (1989) to fail in fifteen minutes without room cooling. Appendix $F$ indicates a temperature rise of about $60^{\circ} \mathrm{F} /$ hour will result if room cooling fails and the EDGs are running. EPS failure will result from failure of control systems and switchgear located in the EDG enclosure. Depending upon the initial temperature of the EDG room, 15 minutes is a reasonable approximation for the amount of time following loss of room cooling and failure of electrical equipment in the room.

The battery and switchgear rooms were assumed by Drouin et al. to not require room cooling during accident conditions. This is similar to the 
representative W PWR, although a safety-related area cooler is provided for these rooms. As shown in Appendix $F$, the heat loads are relatively small in these large, open rooms so that the heatup rates following loss of room cooling are low; perhaps as much as 24 hours are needed to reach the room design maximum temperature. As discussed in subsection 3.1.2.8, batteries are not particularly sensitive to high ambient temperatures. The rooms are required to be ventilated to prevent hydrogen gas buildup and are also heated, but room cooling is not necessary.

The fault tree diagram developed for the EPS was broken up into three tries. Each tree corresponds to a different division (1, 2, or 3). The EPS fault trees were simplified by "pruning" the branches that did not lead to room cooling failure. The "pruned" branches were left as undeveloped events. The simplified EPS fault tree diagrams are shown in Appendix $C$. As shown, failure of the EDG ventilation system is functionally equivalent to failure of the EDGs, themselves. In contrast to failure of pump room coolers discussed in previous sections, time is not available to effect repairs to the EDG ventilation system before the EDG control systems overheat and fail.

\subsubsection{Standby Service Water (SSW) System}

The SSW system provides heat removal from plant auxiliaries that require cooling water during an emergency shutdown of the plant. The system is made up of three independent trains, each consisting of a MDP, MOVs, and heat exchangers. Train $C$ is dedicated to the HPCS system.

Each SSW pump takes water from the cooling tower basins, circulates water through the heat exchangers for each load, and returns the water to the towers through a motor-operated discharge valve. Each train has its own discharge valve. A schematic of the SSW system is shown in Appendix C.

The SSW pumps are located in pump houses near the cooling tower, away from other buildings on the site. Room cooling is provided to the SSW pumps. However, loss of room cooling was assumed by Drouin et al. not to fail the pumps. Each pump house has normally open louvers on the walls. Current from the cooling towers provides ample ventilation. Design calculations performed by the licensee confirmed that natural cooling was adequate to maintain the pump temperatures below the equipment qualification temperature for the pump, even under extreme outside temperature conditions.

The SSW system and EVS work jointly to provide room cooling for the EDGs and safety-related pump rooms. The room cooling fault trees were simplified by "pruning" the branches that did not include room cooling failures. The "pruned" branches were left as undeveloped events. The simplified room cooling failure fault trees for the RHR A, B, and C, and LPCS are shown in Appendix C. Refer to the EVS section for room cooling failure fault trees in the EDG rooms, RCIC pump room, and HPCS pump room. 


\subsubsection{Emergency Ventilating System (EVS)}

The EVS maintains suitable temperatures in safety-related equipment rooms to prevent component failures. The EVS cools the 1) standby EDG rooms, 2) pump structure service water pump rooms, and 3) pump rooms for the RHR, RCIC, HPCS, and LPCS systems. A schematic of the EVS is shown in Appendix C.

Three independent subsystems, one per EDG room and each with 100\% capacity, are provided for the EDG rooms to maintain an indoor design temperature of $120^{\circ} \mathrm{F}$. This system relies on forced ventilation and air circulation to remove heat from the EDG rooms. Heat is exhausted to the atmosphere; no air cooling is provided. Each diesel unit is provided with a fan damper system connected to the respective diesel engineered safety features bus. The fan is controlled to start on EDG startup and stop on EDG shutdown. The damper opens on the same signals.

Each safety-related pump room is provided with one full-capacity fancoil unit to prevent the room temperature from exceeding $150^{\circ} \mathrm{F}$ during pump operation. The SSW system provides cooling water for the fan-coil units, which start automatically when the associated ECCS pump starts.

The ECCS pump room coolers are all cooled by the SSW system. The motive force for the fans for the RCIC, LPCS, and RHR-A pump room is provided by AC Division 1. The fans for RHR-B and RHR-C pump rooms are powered by Division 2; the HPCS pump room fan is powered by HPCS dedicated AC Division 3.

Drouin et a1. (1989) assumed that failure of the EVS would fail operating EDGs in 15 minutes. The low-pressure ECCS pumps were assumed to fail within four hours after loss of the associated room cooling. The HPCS and RCIC pumps were assumed to fail within 12 hours after loss of room cooling. Appendix $F$ describes calculated room heatup rates following loss of room cooling and subsequent failure rates at various temperatures for these components.

The EVS and SSW system work jointly to provide room cooling for the EDGs and safety-related pumps. The simplified room cooling failure fault trees for the RHR A, B, and C, and LPCS pump rooms are developed under the SSW section. Room cooling failure fault trees in the EDG rooms, RCIC pump room, and HPCS pump room are shown in Appendix $C$.

\subsubsection{Heating, Ventilation, and Air Conditioning (HVAC) System}

The HVAC systems were not modeled as a contributor to the representative BWR core melt frequency. This was "... based on the degree of separation in the design of HVAC systems at the representative BWR, the low heat loads in critical equipment areas such as the AC bus rooms, and the generally slow effects of loss of HVAC equipment which ail low time for corrective action before a plant trip would occur (Drouin et al. 1989)." Although these observations are accurate, this study will evaluate the contributions of these systems to the overall CDF at the representative BWR, including the 
temperature rises in rooms following loss of HVAC, failure rates of components in the rooms when exposed to high temperatures, and the ability of plant operators to respond to loss of HVAC events.

\subsubsection{Event Tree Analysis}

This section provides an overview of the 12 event trees developed for the representative BWR. Each event tree defines one or more accident sequences, each accident sequence includes an initiating event, failure/ success of safety systems, and the resulting consequence to the reactor core and containment. There are 12 initiating events analyzed in the PRA (Drouin et al.

1989). Two of the initiating events, $V$ and $R$, were eliminated from the analysis due to their low probability of occurrence. The TIAS initiator was quantified under the loss of PCS event tree because of their similar plant response. Event tree abbreviations are described in Table 3.2-2.

Nine events in Table 3.2-2 contain room cooling failure cut set elements, B, B1, U1, U2, V2, V3, W1, W2, and W3. On1y the accident sequences containing one of these nine events and leading to core damage pertain to this issue. The event trees and applicable accident sequences are discussed in the following subsections.

\subsubsection{Large LOCA Event Tree}

The large LOCA (A) initiating event is a large break LOCA (steam $\geq 0.4 \mathrm{ft}^{2}$, liquid $\geq 0.04 \mathrm{ft}^{2}$ ), which disrupts the normal operation of the plant and requires mitigation. The event tree is shown in Figure 3.2-1. There are four event sequences that lead to core damage, 7, 14, 21, and 26 . of these, only Sequence 26 contains cut set elements related to room cooling failure.

SEQUENCE 26 - A large LOCA (A) occurs, which generates a reactor SCRAM condition, and the RPS successfully inserts all the rods into the core $(/ C)$. Offsite power remains available (/LOOP). Feedwater/condensate may or may not still be available. However, with only feedwater/condensate injecting, the condenser would soon be depleted and is therefore not shown on the tree. Water level drops below Level 2, and HPCS is demanded but fails to function (U1). The water level continues to decrease and, at Level 1, LPCS and LPCI are demanded but both fail to function (V2, V3). Pump room cooling failure affects the operability of these two systems. The SSW cross-tie did not function (V4). At this point, all coolant makeup is lost. The core eventually uncovers and a damage state results.

\subsubsection{Intermediate LOCA Event Tree}

The intermediate LOCA (S1) initiating event is an intermediate break LOCA (steam 0.13-0.4 $\mathrm{ft}^{2}$, liquid 0.007-0.4 $\mathrm{ft}^{2}$ ) that disrupts the normal operation of the plant and requires mitigation. The event tree is shown in 


\section{TABLE 3.2-2. Event Tree Nomenclature}

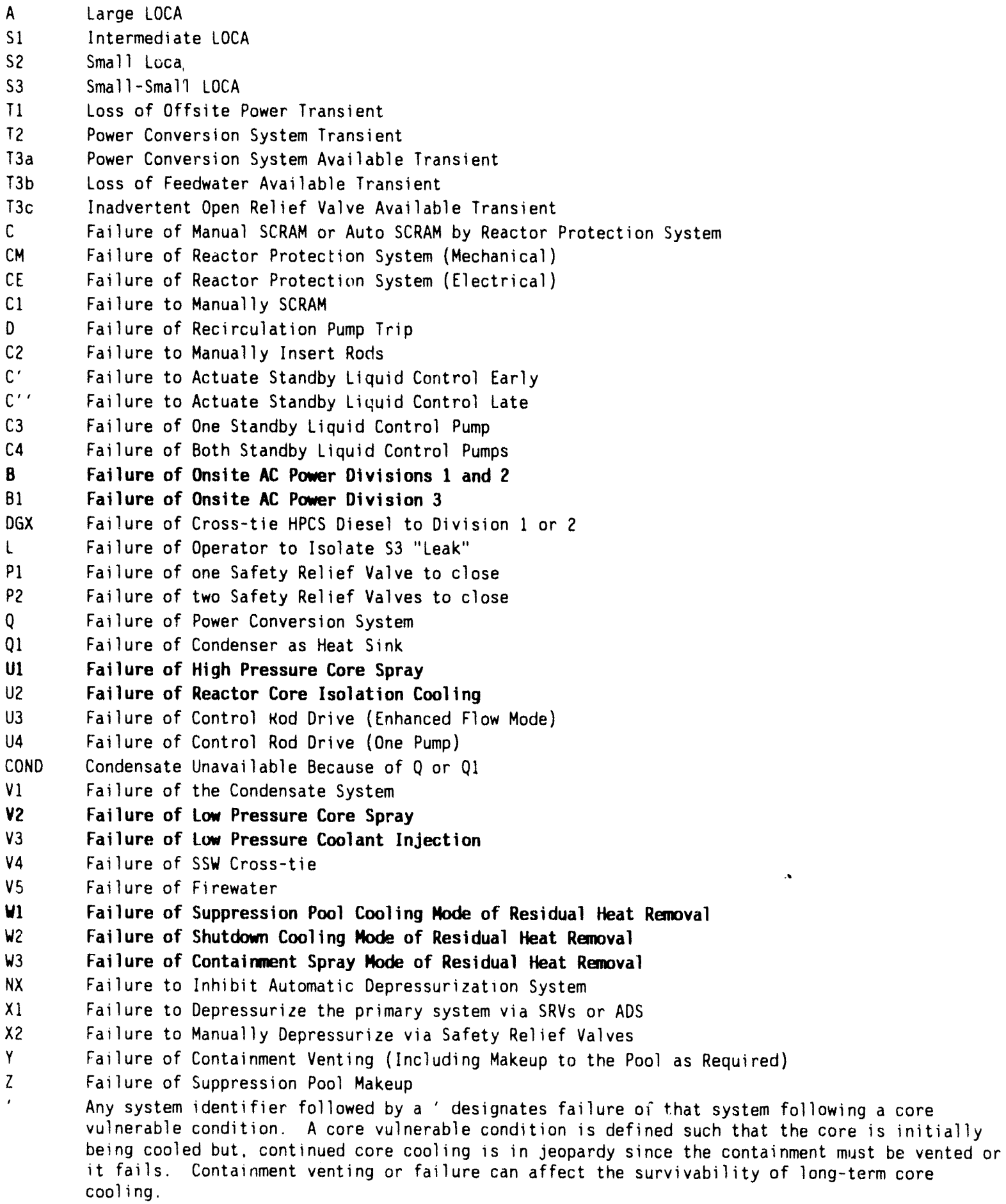

NOTE: Affected events, i.e., those that depend on successful room cooling for long-term operation, are in bold type. 


\begin{tabular}{|c|c|c|c|c|c|c|c|c|c|c|c|c|}
\hline $\begin{array}{l}\text { Large } \\
\text { LOCA }\end{array}$ & RPS & $\begin{array}{c}\text { Offsite } \\
\text { Power }\end{array}$ & HPCS & LPCS & LPCI & SPM & $\begin{array}{c}\text { SSW-B } \\
\text { Cross-tie } \\
\text { LPCI-B }\end{array}$ & $\begin{array}{l}\text { RHR- } \\
\text { SPC Mode }\end{array}$ & $\begin{array}{c}\text { RHR- } \\
\text { CS Mode }\end{array}$ & $\begin{array}{l}\text { Contain- } \\
\text { ment } \\
\text { Venting }\end{array}$ & & \\
\hline A & c & LOOP & U1 & V2 & V3 & $z$ & V4 & $w_{1}$ & W3 & Y & Sequence & Core \\
\hline
\end{tabular}

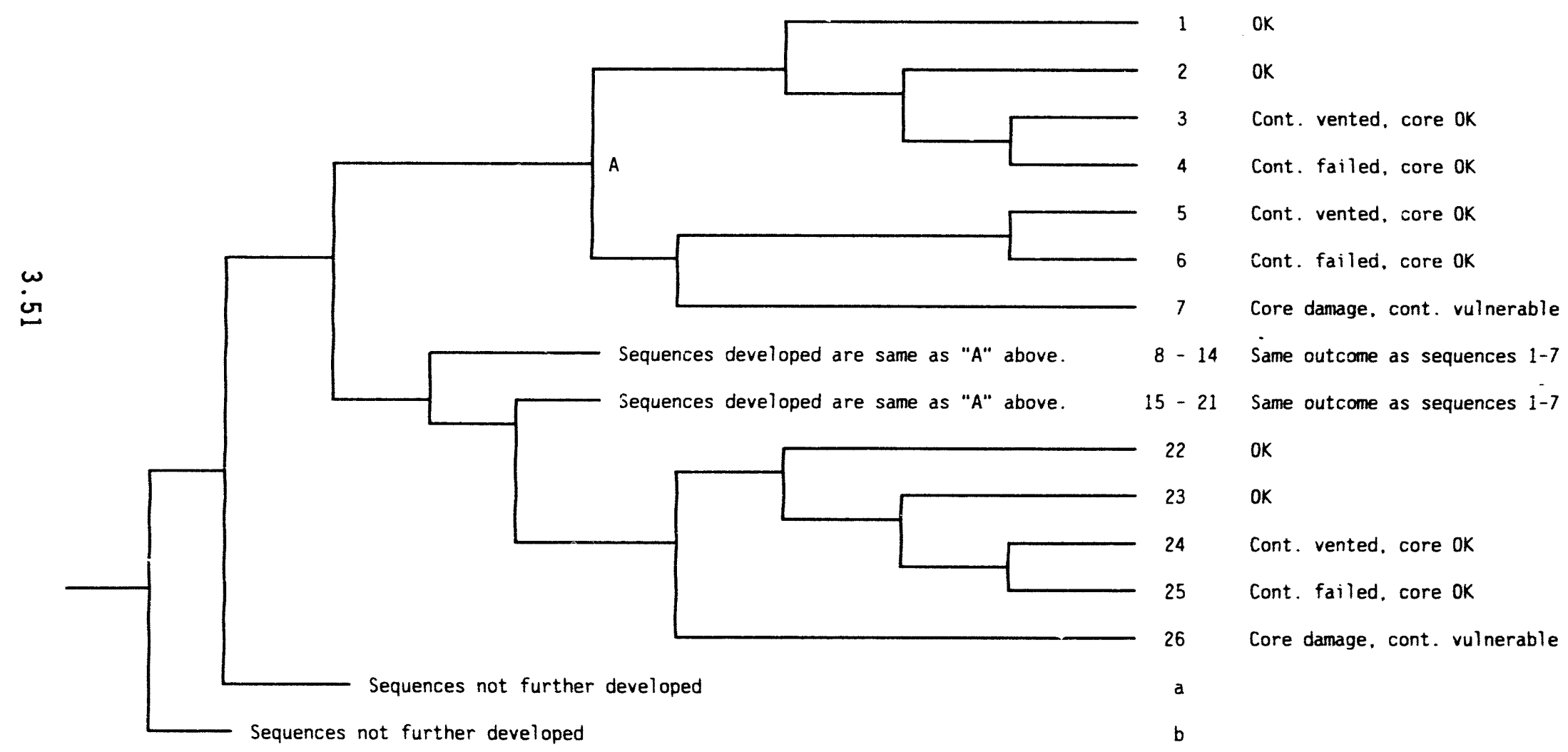

FIGURE 3.2-1. Event Tree for Large LOCA 
Figure 3.2-2. There are six event sequences of the event tree that lead to core damage; of the six, only Sequences 27 and 28 contain cut set elements related to room cooling failure.

SEQUENCE 27 - An intermediate LOCA (S1) occurs, which generates a reactor SCRAM condition, and the RPS successfully inserts all the rods into the core (/C). Offsite power remains available (/LOOP). Feedwater/condensate may or may not still be available. However, with only feedwater/condensate injecting, the condenser would soon be depleted and is therefore not shown on the tree. Water level drops below Level 2 and HPCS fails (UI). The reactor vessel was successfully depressurized except that LPCS, LPCI, and SSW cross-tie failed to function when demanded. The HPCS (U1), LPCS (V2), and LPCI (V3) systems depend on their respective pump room cooling functions. At this point, all coolant makeup is lost. The core eventually uncovers and a damage state results.

SEQUENCE 28 - This sequence is the same as Sequence 27 except that vesse depressurization never occurred, so LPCS, LPCI and SSW cross-tie cannot inject (X1). At this point, all coolant makeup is lost. The core eventually uncovers and core damage results.

\subsubsection{Small LOCA Event Tree}

The small LOCA (S2) initiating event is a small break LOCA (steam $<0.13 \mathrm{ft}^{2}$, liquid $<0.007 \mathrm{ft}^{2}$ ) that disrupts the normal operation of the plant and requires mitigation. The event tree is shown in Figure 3.2-3. There are six event sequences of the event tree that lead to core damage: $12,13,19,20,37$, and 38 ; all six contain cut set elements related to room cooling failure. The affected events in these sequences include U1 (HPCS), V2 (LPCS), V3 (LPCI), W1 (RHR - SPC mode), and W3 (RHR - CS mode), which are all dependent on their respective pump room coolers.

SEQUENCE 12 - A smal1 LOCA (S2) occurs, which generates a reactor SCRAM condition, and the RPS successfully inserts all the rods into the core $(/ C)$. Offsite power remains available (/LOOP). Water level drops below Level 2, HPCS and RCIC are demanded but HPCS fails to function. Coolant makeup is being provided by $\mathrm{RCIC}$. The residual heat from the reactor is being transferred to the suppression pool; thus pool temperature is increasing. At $95^{\circ} \mathrm{F}$, operators are instructed to initiate SPC, which subsequently fails (W1). At 7.84 psig, CS is demanded. CS also fails (W3). At this point, containment pressure increases to the isolation trip point of the RCIC turbine on high turbine exhaust pressure. The vessel is manually depressurized $\left(/ X_{2}\right)$. However, condensate, LPCS, LPCI, SSW cross-tie, and firewater fail to function. At this point, all coolant makeup is lost. The core eventually uncovers, resulting in a damage state in a vented containment.

SEQUENCE 13 - Same as Sequence 12 except that vessel depressurization never occurred, so condensate, LPCS, LPCI, SSW cross-tie, and firewater cannot inject (X2) after RCIC is lost. At this point, all coolant makeup is lost. The core eventually uncovers, resulting in a damage state in a vented containment. 


\begin{tabular}{|c|c|c|c|c|c|c|c|c|c|c|c|c|c|c|}
\hline $\begin{array}{l}\text { Inter } \\
\text { med. } \\
\text { LOCA }\end{array}$ & RPS & $\begin{array}{c}\text { Offsite } \\
\text { Power }\end{array}$ & HPCS & $\begin{array}{l}\text { Man/Auto } \\
\text { Depres- } \\
\text { suriz. }\end{array}$ & LPCS & $\angle P C I$ & SPM & $\begin{array}{l}\text { Man/4uto } \\
\text { Depres- } \\
\text { suriz. }\end{array}$ & $\begin{array}{c}\text { SSW-B } \\
\text { Cross-tie } \\
\text { LPCI-B }\end{array}$ & $\begin{array}{c}\text { RHR- } \\
\text { SPC Mode }\end{array}$ & $\begin{array}{c}\text { RHR- } \\
\text { CS Mode }\end{array}$ & $\begin{array}{l}\text { Contain- } \\
\text { ment } \\
\text { Venting }\end{array}$ & & \\
\hline \$1 & C & LOOP & U1 & $x 1$ & v2 & V3 & $z$ & $x_{1}$ & V4 & W1 & W3 & Y & Sequence & Core \\
\hline
\end{tabular}

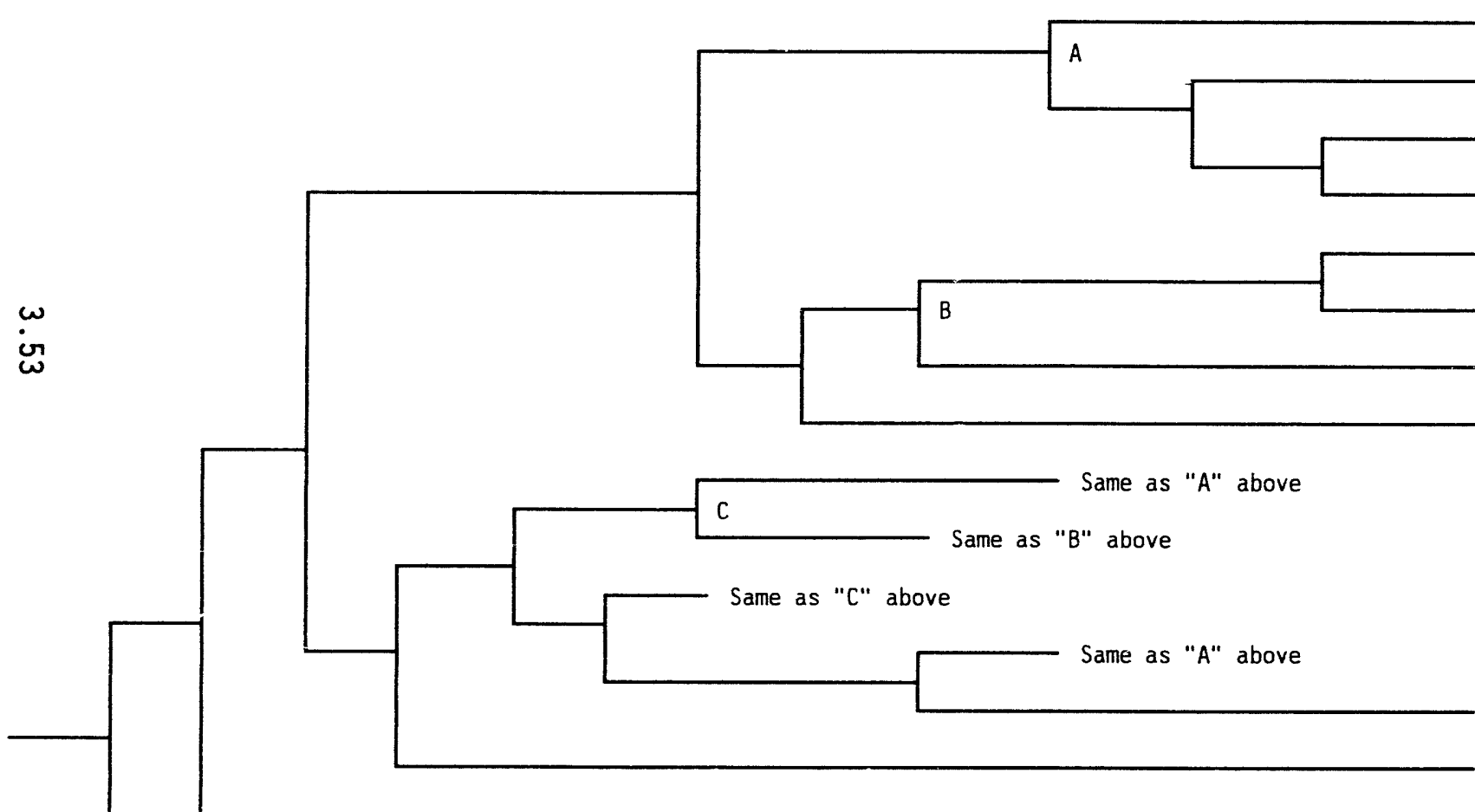

Sequences not further developed

Sequences not further developed

\section{OK}

OK

Cont. vented, core OK Cont. failed, core OK Cont. vented, core OK Cont. failed, core OK Core damage, cont. vuln. Core damage, cont. vuln. 9 - 12 Same outcome as $1-4$ 12 - 15 Same outcome as $5-7$ $14-22$ Same outcome as $9-15$ $23-26$ Same outcome as $1-4$ Core damage, cont. vuln. Core damage, cont. vuln. b

FIGURE 3.2-2. Event Tree for Intermediate LOCA 


\begin{tabular}{|c|c|c|c|c|c|c|c|c|c|c|c|c|c|c|c|}
\hline $\begin{array}{l}\text { Small } \\
\text { tOCA }\end{array}$ & RPS & $\begin{array}{c}\text { Offsite } \\
\text { Power }\end{array}$ & $\begin{array}{l}\text { Onsite } \\
\text { Power }\end{array}$ & HPCS & RCIC & $\begin{array}{l}\text { Man/Auto } \\
\text { Depres - } \\
\text { suriz. }\end{array}$ & $\begin{array}{c}\text { Conden } \\
\text { sate }\end{array}$ & LPCS & LPCS & $\begin{array}{c}\text { SSW-B } \\
\text { Cross-tie } \\
\text { LPCI-B }\end{array}$ & $\begin{array}{c}\text { RHR- } \\
\text { SPC Mode }\end{array}$ & $\begin{array}{c}\text { RHR- } \\
\text { CS Mode }\end{array}$ & $\begin{array}{l}\text { Contain- } \\
\text { ment } \\
\text { Venting }\end{array}$ & & \\
\hline s2 & C & LOOP & B & U1 & U2 & $\mathrm{x} 1$ & V1 & v2 & v3 & v4 & W1 & W3 & $Y$ & Sequence & Core \\
\hline
\end{tabular}

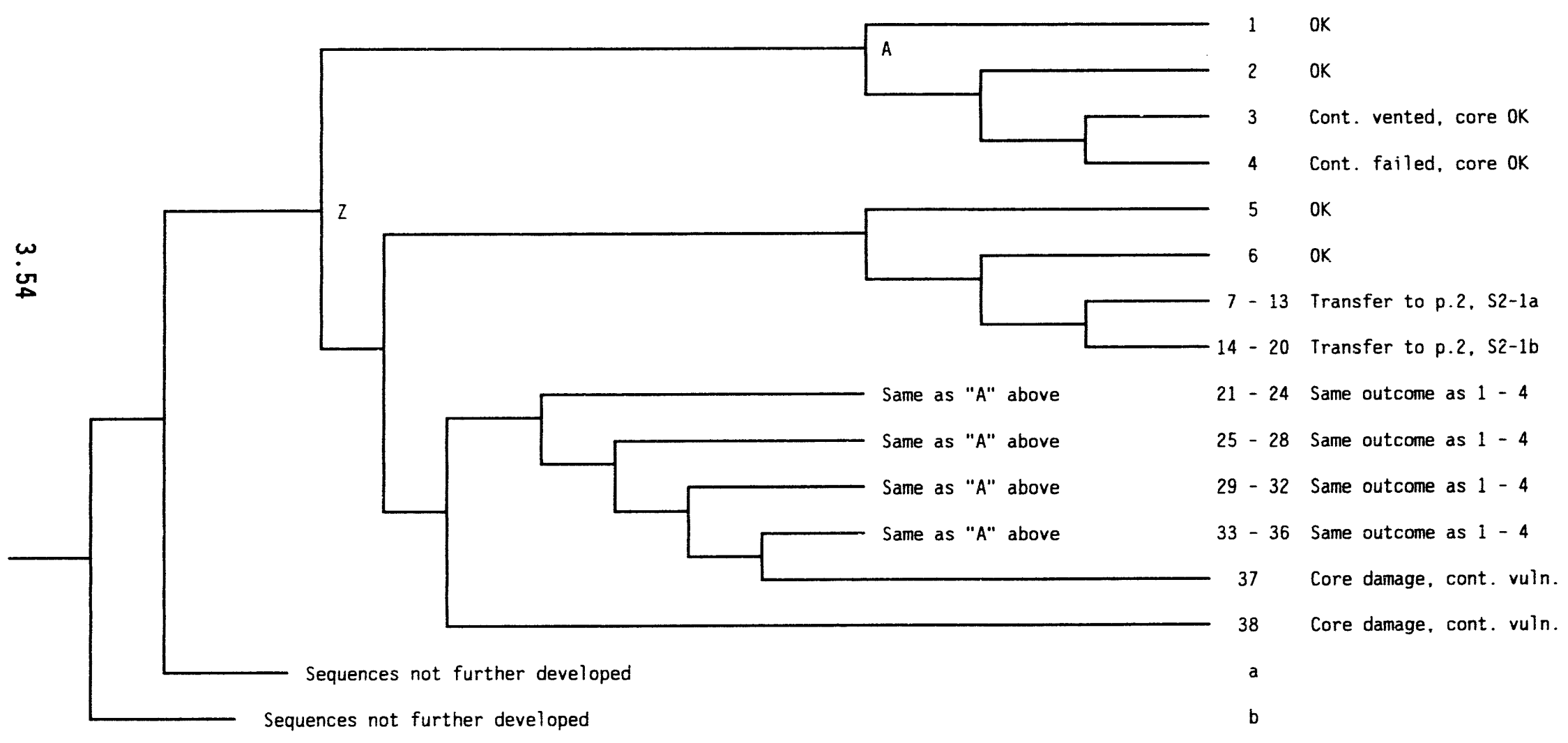

FIGURE 3.2-3. Event Tree for Small LOCA 


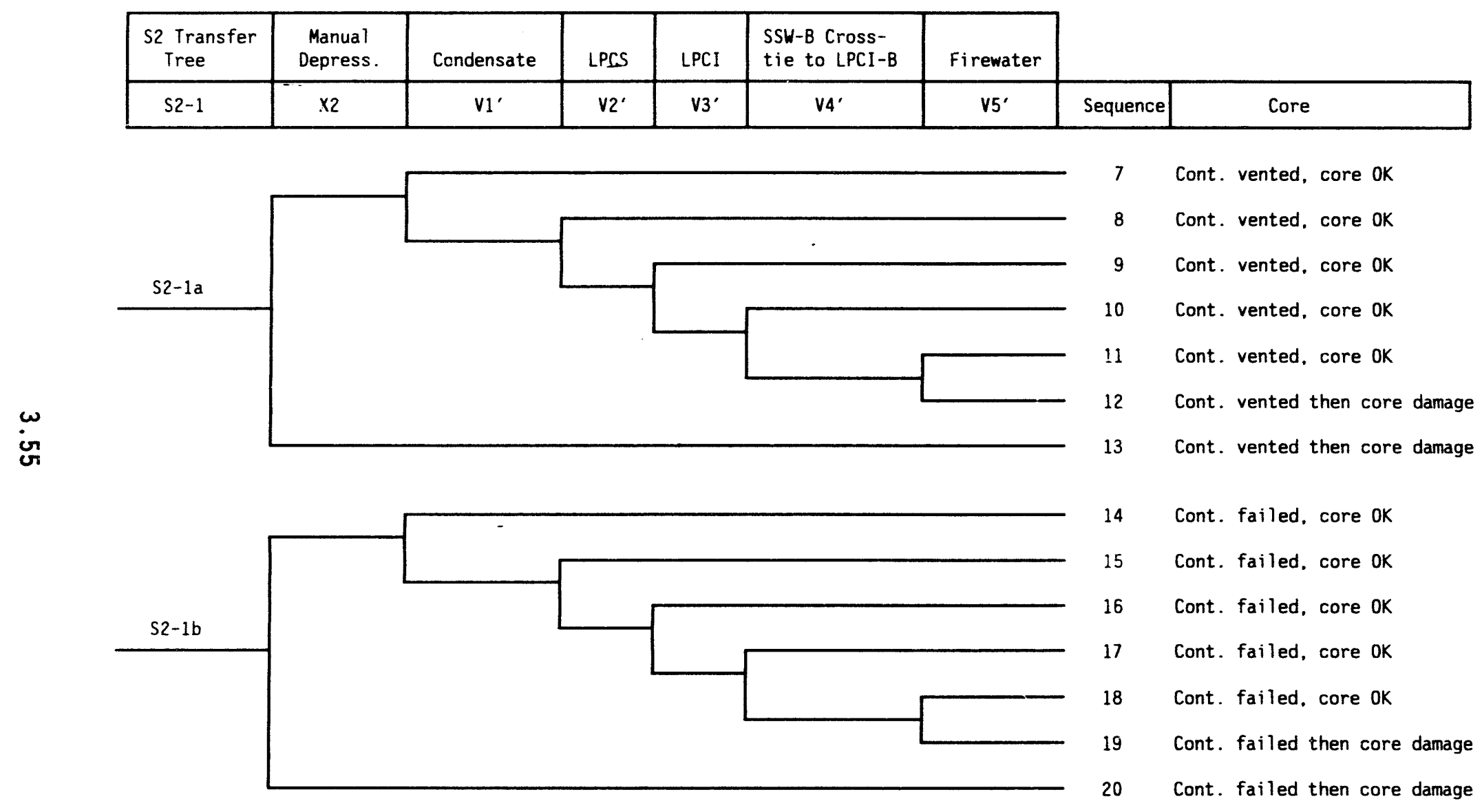

NOTE: The prime symbol, ', denotes systems actuated after reactor coolant makeup was successful for a period of time and then failed.

FIGURE 3.2-3. (contd) 
SEQUENCES 19 and 20 - Same as Sequences 12 and 13 except that containment venting never occurred $(Y)$. Core damage occurs in an intact containment, which is now vulnerable.

SEQUENCE 37 - A sma11 LOCA (S2) occurs, wich generates a reactor SCRAM condition, and the RPS successfully inserts all the rods into the core $(/ C)$. Offsite power remains available (/LOOP). Water level drops below Level 2 , HPCS and RCIC are demanded but fail to finction. Vessel depressurization occurs; however, condensate, LPCS, LPCI, and SSW cross-tie do not function. At this point, all coolant makeup is lost. The core eventually uncovers and a damage state results.

SEQUENCE 38 - Same as Sequence 37 except that vessel depressurization never occurred, so condensate, LPCS, LPCI and SE'N cross-tie cannot inject (X1). At this point, all coolant makeup is lost. The core eventually uncovers, resulting in a damage state.

\subsubsection{Small-Small LOCA Event Tree}

The small-small LOCA (S3) initiating event is a recirculation pump seal break and can be isolated. If the operator does not recognize the break and fails to isolate, it is categorized as an S2 LOCA. The event tree is shown in Figure 3.2-4. Two sequences, $a$ and $b$, lead to core damage. These sequences behave like a small LOCA (S2) and a PCS transient without SCRAM (T3a), respectively, and are transferred to these event trees.

\subsubsection{Loss of Offsite Power (LOOP) Event Tree}

The loss of offsite power (LOOP) (T1) transient evert tree is shown in Figure 3.2-5. There are 22 event sequences of the event tree that lead to core damage; of these 22, a11 but Sequences 110, 118, and 129 contain cut set elements related to room cooling failure.

SEQUENCE 17 - A LOOP transient (T1) occurs which generates a reactor SCRAM condition, the RPS successfully inserts all the rods into the core $(/ C)$, and a diesel successfully starts (/B). SRVs open and close to relieve the pressure surge callsed by the SCRAM (/P1, /P2). Water level drops below Leve1 2, HPCS and RCIC are demanded, but HPCS fails to function. Coolant makeup is being provided by RCIC. The residual heat from the reactor is being transferred to the suppression pool, thus the pool temperature is increasing. At $95^{\circ} \mathrm{F}$, the operator is instructed to initiate SPC, which subsequently fails (W1). The vessel is depressurized, but SDC fails (W2). At 7.84 psig, CS (W3) is demanded and it fails. At this point, the containment pressure increases to the isolation trip point of the RCIC turbine on high turbine exhaust pressure. CRD, LPCS, LPCI, SSW cross-tie, and firewater all fail to function. At this point, all coolant makeup is lost. The core eventually uncovers, resulting in a damage state in a vented containment.

SEQUENCE 23 - Same as Sequence 17 except that containment venting failed (Y). Although containment venting does not occur, core damage occurs before the containment is challenged on overpressurization. 


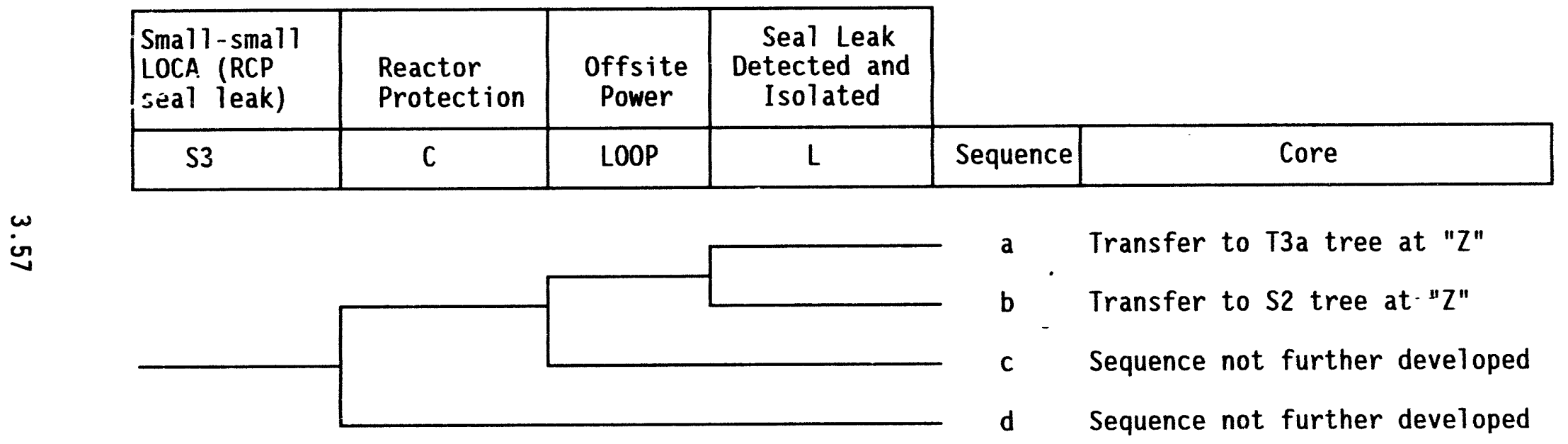

FIGURE 3.2-4. Event Tree for Smal1-Small LOCA 


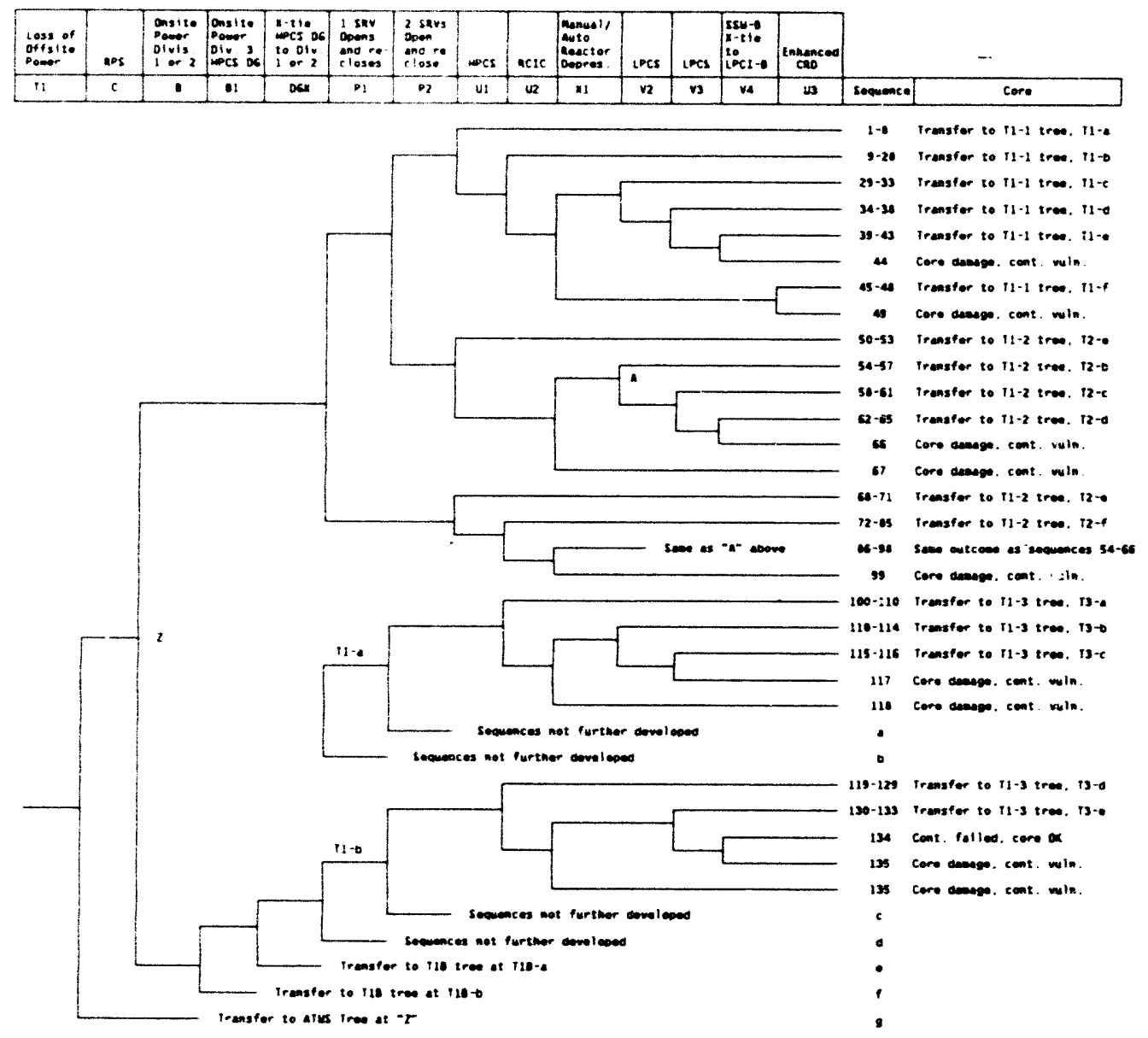

FIGURE 3.2-5. Event Tree for Loss of Offsite Power (LOOP) 


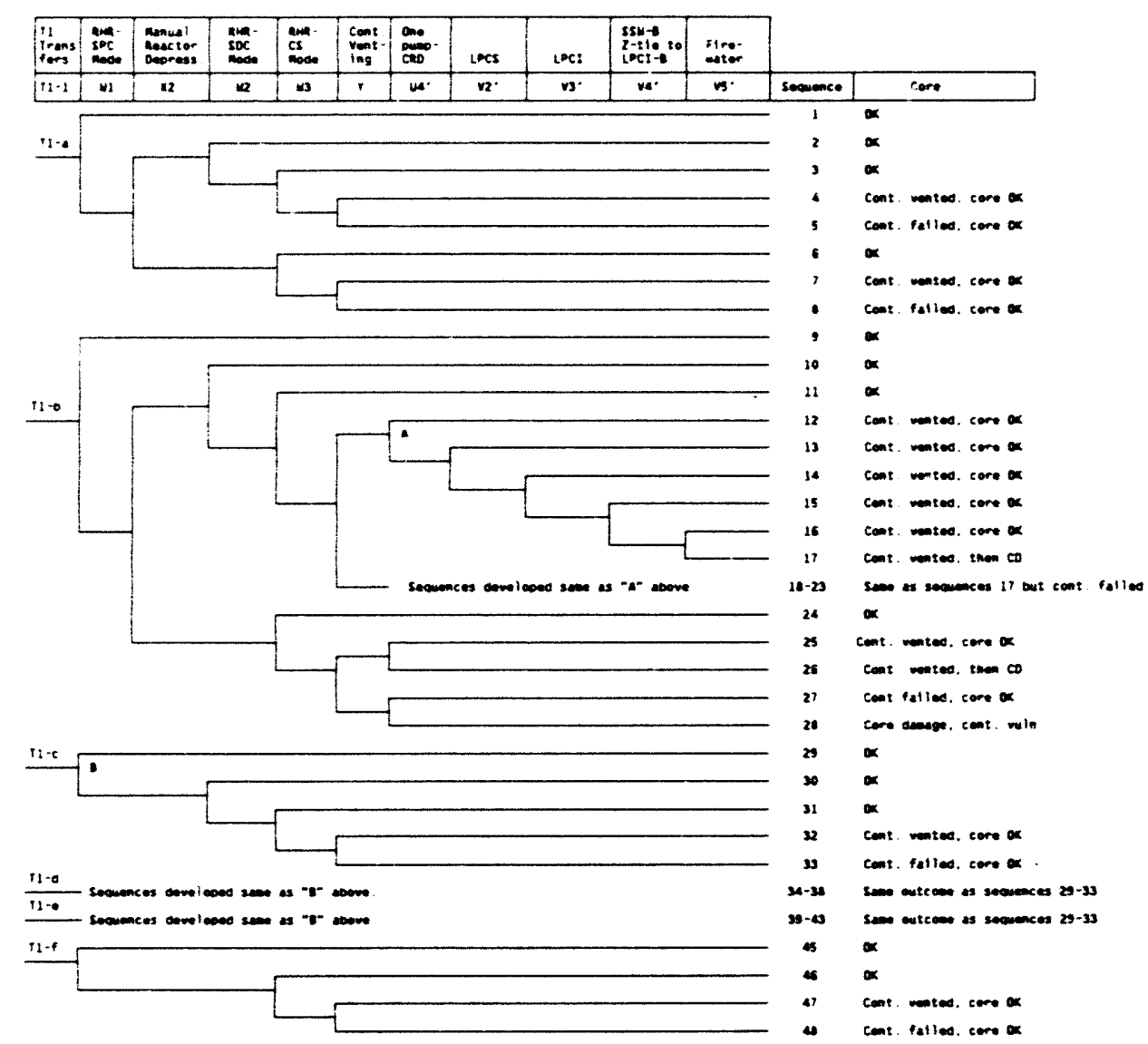

FIGURE 3.2-5. (contd) 


\begin{tabular}{|c|c|c|c|c|c|c|c|c|c|c|}
\hline $\begin{array}{l}\text { T1 } \\
\text { Trans } \\
\text { fer }\end{array}$ & $\begin{array}{l}\text { RHR- } \\
\text { SPC } \\
\text { Mode }\end{array}$ & $\begin{array}{l}\text { RHR- } \\
\text { CS } \\
\text { Mode }\end{array}$ & $\begin{array}{l}\text { Contain- } \\
\text { ment } \\
\text { Vent ing }\end{array}$ & $\begin{array}{l}\text { Manual } \\
\text { Reactor } \\
\text { Depress }\end{array}$ & LPCS & LPCI & $\begin{array}{c}\text { SSW-B } \\
\text { Cross-tie } \\
\text { LPCI-B }\end{array}$ & $\begin{array}{l}\text { Fire- } \\
\text { water }\end{array}$ & & \\
\hline$T 1-2$ & $W 1$ & W3 & $r$ & $x 2$ & V2. & v3. & $V 4^{\prime}$ & V5. & Sequence & Core \\
\hline
\end{tabular}

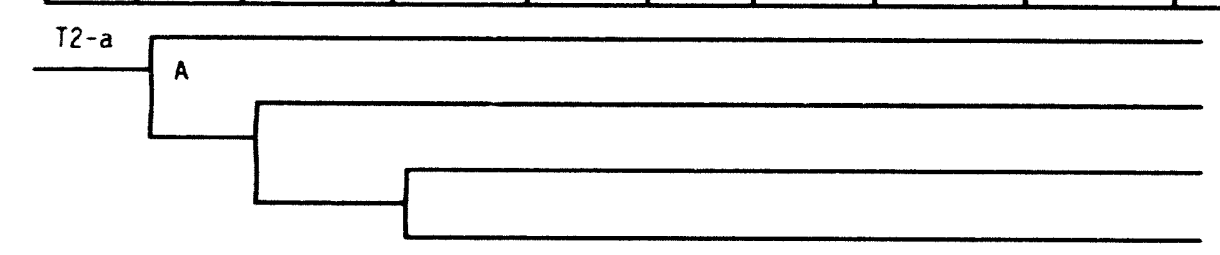

50

OK

OK

52 Cont. vented. core OK

$T 2-b$

Sequences developed same as "A" above T2-c

Cont. failed, core OK

Sequences developed same as "A" above

Outcome same as seq. $50-53$

T2-d

58-61 Outcone same as seq. $50-53$

Sequences developed same as "A" above
T2-e

8-61 Outcome same as seq. 50-53

$\omega$

g

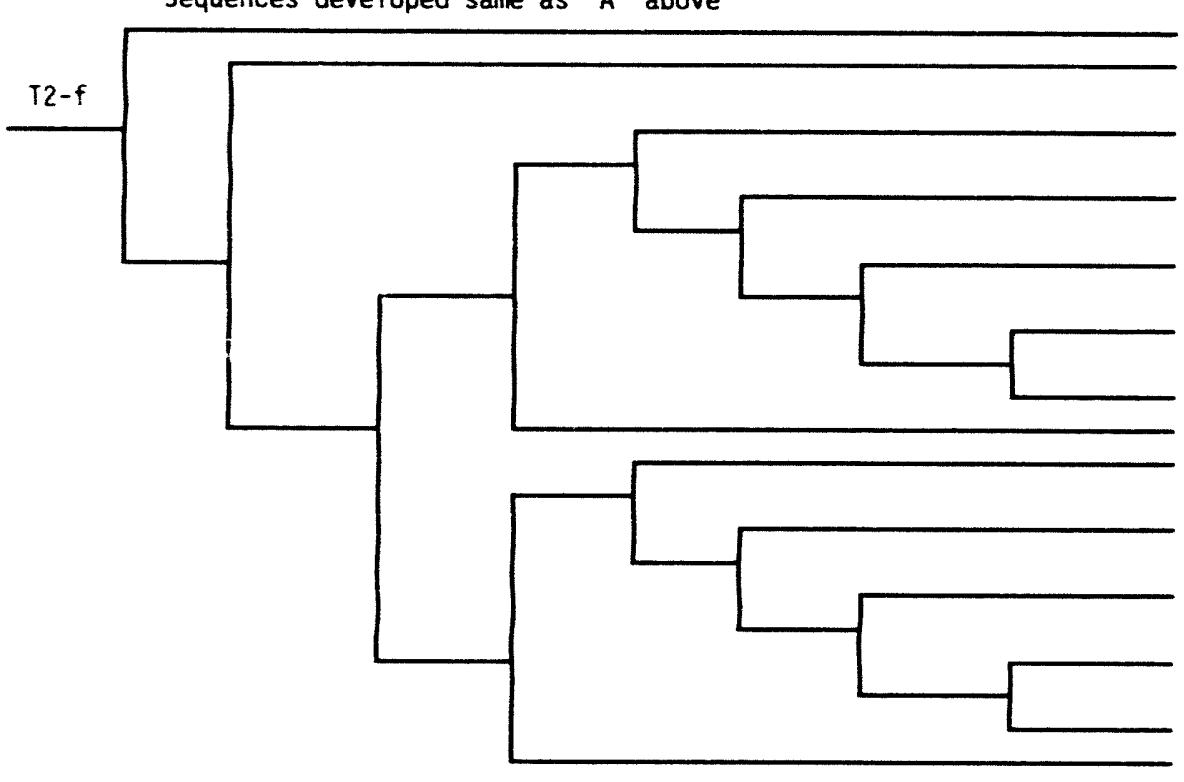

68-71 Outcome same as seq $50-53$

72 OK

$73 \quad O K$

74 Cont. vented, core OK

75 Cont. vented, core OK

76 Cont. vented, core OK

77 Cont. vented, core OK

78 Cont. vented. then $C D$

79 Cont. vented, then $C D$

80 Cont. failed, core OK

81 Cont. failed, core OK

Cont. failed, core OK

Cont. failed, core OK

Core damage, cont, vuln. Core damage, cont. vuin.

FIGURE 3.2-5. (contd) 


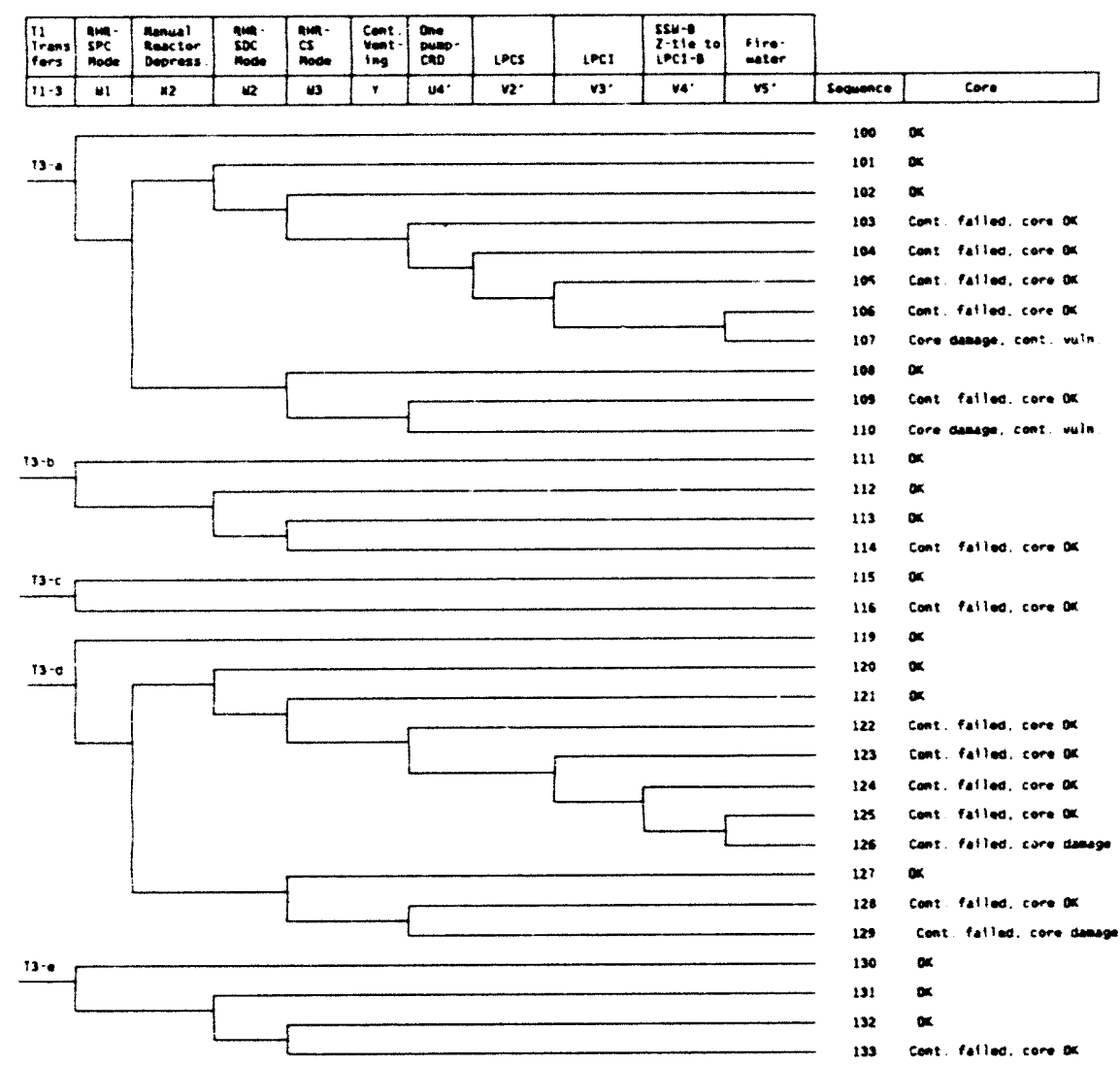

FIGURE 3.2-5. (contd) 
SEOUENCE 26 - Same as Sequence 17 except that the low-pressure systems cannot inject because reactor depressurization failed. The core eventually uncovers, resulting in a damage state in a vented containment.

SEQUENCE 28 - Same as Sequence 23 except that SDC and LPI systems cannot inject, because reactor depressurization failed. Core damage occurs in an intact containment.

SEOUENCE 44 - HPCS, RCIC, LPCS, LPCI, and SSW cross-tie all fail to function. At this point, all coolant makeup is lost. The core eventually uncovers, resulting in a damage state. The containment is in a vulnerable condition.

SEOUENCE 49 - Same as Sequence 44 except that vessel depressurization never occurred, so LPCS, LPCI, and SSW cross-tie cannot inject (XI), and CRD failed to function. At this point, all coolant makeup is lost. The core eventually uncovers and a damage state results. The containment is in a vulnerable condition.

SEQUENCE 66 - Same as Sequence 44 except that two SRVs failed to reclose (P2). The core eventually uncovers and a damage state results. The containment is in a vulnerable condition.

SEQUENCE 67 - Same as Sequence 66 except the reactor depressurization failed (X1), so no low-pressure systems can be used. The core eventually uncovers and a damage state results. The containment is in a vulnerable condition.

SEOUENCE 78 - Same as Sequence 17 except that one SRV failed to reclose (P1). The core eventually uncovers, resulting in a damage state in a vented containment.

SEQUENCE 79 - Same as Sequence 78 except reactor depressurization failed. The core eventually uncovers, resulting in a damage state in a vented containment.

SEQUENCE 84 - Same as Sequence 78 except that containment venting did not occur. Core damage occurs in an intact containment, which is now vulnerable.

SEQUENCE 85 - Same as Sequence 84 except reactor depressurization failed. Core damage occurs in an intact containment, which is now vulnerable.

SEOUENCE 98 - Same as Sequence 66 except that one SRV failed to reclose (P1) instead of two (P2).

SEQUENCE 99 - Same as Sequence 67 except that one SRV failed to reclose (P1) instead of two (P2).

SEOUENCE 107 - Same as Sequence 23 except that onsite power for Divisions 1 and 2 fails, and the HPCS EDG is cross-tied to supply power to Division 1.

SEQUENCE 117 - Same as Sequence 44 except that onsite power for Divisions 1 and 2 fails, and the HPCS diesel is cross-tied to supply power to Division 1. 
SEQUENCE 126 - Same as Sequence 107 except that onsite power for Divisions 1 and 2 falls, and the HPCS diesel is cross-tied to supply power to Division 2. The SSW cross-tie to LPCI-B was tried and failed.

SEQUENCE 135 - A LOOP of transient (T1) occurs, which generates a reactor SCRAM condition, and the RPS successfully inserts all the rods into the core $(/ C)$. Both Divisions 1 and 2 EDGs fail (B). The HPCS diesel is cross-tied to supply power to Division 2. SRVs open and close to relieve the pressure surge caused by the SCRAM $(/ P 1, / P 2)$. The water level drops below Level 2 and RCIC is demanded, but fails (U2). The reactor is tied to LPCI-B, but fails. At this point, all coolant makeup is lost. The core eventually uncovers, resulting in a damage state in an intact containment, which is now vulnerable.

SEQUENCE 136 - Same as Sequence 135 except that the reactor fails to depressurize $(X 1)$; thus, LPCI and SSW-B cross-tie to LPCI-B cannot inject.

\subsubsection{Station Blackout Event Tree}

Loss of offsite power (LOOP) and sequences involving failure of both emergency $A C$ Divisions 1 and 2 are referred to as SBO sequences and are developed in a separate event tree in this section. The event tree is shown in Figure 3.2-6. There are 18 event sequences of the event tree that lead to core damage; all 18 contain cut set elements related to room cooling failure. Affected events include B1 (HPCS EDG), U1 (HPCS), and U2 (RCIC). Event B1 is dependent on successful EDG enclosure ventilation, and $U 1$ and $U 2$ are dependent on successful operation of their respective pump room coolers.

SEQUENCE 2 - A LOOP transient (T1) occurs, which generates a reactor SCRAM condition, and the RPS successfully inserts all the rods into the core and is followed by a loss of Divisions 1 and 2 onsite power (B). The HPCS EDG is functioning and supplying power $(/ B 1)$. The operator does not cross-tie the HPCS EDG. The SRVS open and close to relieve the pressure surge caused by the SCRAM $(/ P 1, / P 2)$. The water level drops below Level 2, and HPCS and RCIC are demanded, but HPCS fails to function (U1). RCIC starts injecting water into the core (/U2). The residual heat from the reactor is being transferred to the suppression pool, and the pool temperature is increasing, thereby also increasing containment pressure. With RHR unavailable (no power), the containment pressure eventually increases to the RCIC turbine high exhaust pressure trip. The reactor is then depressurized, and firewater is successfully connected and is now providing coolant makeup. The batteries eventually deplete, resulting in closure of the SRVs. The operator fails to open the RCIC steam line after the SRVs close following battery depletion. The reactor vessel repressurizes above the shut off head of the firewater pumps. Without coolant makeup, core damage occurs.

SEQUENCE 3 - 'Same as Sequence 2 except that coolant makeup was not provided by firewater. At this point, all coolant makeup is lost. The core eventually uncovers and a damage state results. The CHR events cannot be asked ino power) and the containment is in a vulnerable condition. 


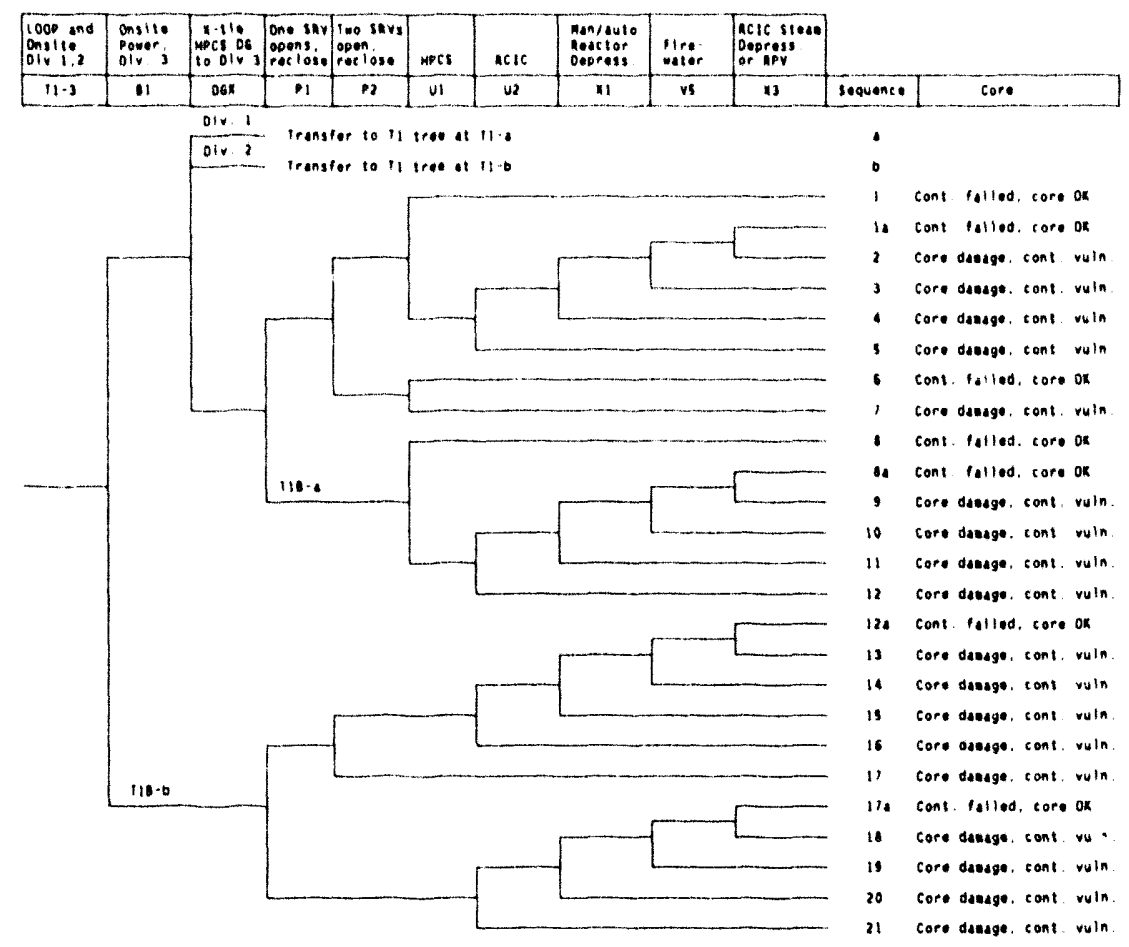

FIGURE 3.2-6. Event Tree for Station Blackout

SEQUENCE 4 - Same as Sequence 3 except that firewater could not function, because reactor depressurization failed to occur. At this point, all coolant makeup is lost. The core eventually uncovers, resulting in a damage state. The CHR system is unavailable (no power), and the containment is in a vulnerable condition.

SEQUENCE 5 - Same as Sequence 4 except that RCIC failed to function when demanded. At this point, all coolant makeup is lost. The core eventually uncovers, requlting in a damage state.

SEQUENCE 7 - Same as Sequence 2 except that the two SRVs fail to reclose. At this point, all coolant makeup is lost. The core eventually uncovers, result ing in a damage state. The CHR events cannot be asked (no power), and containment is in a vulnerable condition.

SEQUENCES 9-12 - Same as Sequences 2 through 5 except that one SRV failed to open and reclose.

SEQUENCE 13 - Same as Sequence 2 except that the HPCS EDG failed to function, thus failing H.PCS.

SEQUENCE 14 - A LOOP transient (T1) occurs, which generates a reactor SCRAM condition, and the RPS successfully inserts all the rods into the core. This 
is followed by a loss of Divisions 1 and 2 onsite power (B). The HPCS EDG fails to function, thus failing Division 3 and HPCS (B1). The SRVs open and close to relieve the pressure surge caused by the SCRAM (/P1, /P2). The water level drops below Level 2, and RCIC starts injecting water into the core (/U2). The residual heat from the reactor is being transferred to the suppression pool, and the pool temperature is increasing, thereby also increasing containment pressure. With RHR unavailable (no power), the containment pressure eventually increases to the RCIC turbine high exhaust pressure trip. The reactor is then depressurized $(/ X 1)$, but firewater fails to provide coolant makeup (V5). The core eventually uncovers, resulting in a damage state. The CHR system is unavailable (no power), and the containment is in a vulnerable condition.

SEQUENCE 15 - Save as Sequence 4 except that the HPCS diesel failed to function, thus failing HPCS.

SEQUENCE 16 - A LOOP transient (T1) occurs, which generates a reactor SCRAM condition; the RPS successfully inserts all the rods into the core, but a loss of Divisions 1 and 2 onsite power (B) follows. The HPCS EDG fails to function, thus failing Division 3 and HPCS (BI). The SRVs open and close to relieve the pressure surge caused by the SCRAM $(/ P 1, / P 2)$. The water level drops below Level 2, and RCIC is demanded but fails to function (U2). At this point, all coolant makeup is lost. The core eventually uncovers, resulting in a damage state.

SEQUENCE 17 - A LOOP transient occurs, generating a reactor SCRAM, the RPS successfully inserts all the rods into the core, followed by a loss of Divisions 1 and 2 onsite power $(B)$. The HPCS EDG fails to function, thus failing Division 3 and HPCS (B1). Two SRVs fail to reclose (P2). This is beyond the capacity of the RCIC system, so RCIC cannot be successful. The core eventually uncovers and core damage results.

SEQUENCES $18-20$ - Same as Sequences 2 through 4 except that HPCS EDG failed to function, thus failing HPCS, and one SRV fails to reclose.

SEQUENCE 21 - A LOOP transient (T1) occurs, generating a reactor SCRAM condition, and the RPS successfully inserts all the rods into the core. This is followed by a loss of Divisions 1 and 2 onsite power (B). The HPCS EDG fails to function, thus failing Division 3 and HPCS (B1). One SRV fails to reclose (P1) and RCIC fails to function (U2). At this point, all coolant makeup is lost. The core eventually uncovers and core damage results. The CHR events cannot be successful (no power), and the containment is in a vulnerable condition.

\subsubsection{Loss of Power Conversion System Event Tree}

Loss of power conversion system transient disrupts the normal operation of the plant and requires immediate reactor SCRAM and subsequent mitigating action to cool the core and containment. The event tree is shown in Figure 3.2-7. There are six event sequences of the event tree that lead to core 
damage, $18,25,28,30,51$, and 56 . All six contain cut set elements related to room cooling failure. Affected events include U1 (HPCS), U2 (RCIC), V2 (LPCS), V3 (LPCI), W1 (RHR - SPC), and W3 (RHR - CS).

SEQUENCE 18 - A loss of PCS transient (T2) occurs, which generates a reactor SCRAM condition, and the RPS successfully inserts all the rods into the core $(/ C)$. Offsite power remains available (/LOOP). SRVs open and close to relieve the pressure surge caused by the SCRAM $(/ P 1, / P 2)$. Water level drops below Level 2, HPCS and RCIC are demanded but HPCS fails to function. Coolant makeup is being provided by RCIC. The residual heat from the reactor is being transferred to the suppression pool; therefore, pool temperature is increasing. At $95^{\circ} \mathrm{F}$, operators are instructed to initiate SPC (W1), which subsequently fails. The vessel is depressurized, but SDC fails (W2). At 7.84 psig, CS is demanded and subsequently fails (W3). At this point, containment pressure increases to the isolation trip point of the RCIC turbine on high turbine exhaust pressure. Condensate, CRD, LPCS, LPCI, SSW cross-tie, and firewater fail to function. At this point, coolant makeup is lost. The core eventually uncovers, resulting in a damage state in a vented containment.

SEQUENCE 25 - Same as Sequence 18 except that containment venting never occurred. Core damage occurs in an intact containment, which is now vulnerable.

SEQUENCE 28 - Same as Sequence 18 except that the low-pressure systems cannot inject because reactor depressurization failed.

SEQUENCE 30 - Same as Sequence 28 except that containment venting never occurred. Core damage occurs in an intact containment, which is now vulnerable.

SEQUENCE 51 - A loss of PCS transient (T2) occurs, which generates a reactor SCRAM condition, and the RPS successfully inserts all the rods into the core $(/ C)$. Offsite power remains available (/LOOP). SRVs open and close to relieve the pressure surge caused by the SCRAM (/P1, /P2). Water level drops below level 2, and HPCS and RCIC fail to function. The reactor was depressurized $(/ X 1)$; however, condensate, LPCS, LPCI, and SSW cross-tie all fail to function. At this point, all coolant makeup is lost. The core eventually uncovers, resulting in a damage state.

SEQUENCE 56 - Same as Sequence 51 except that depressurization is unsuccessful $(X 1)$. Since the reactor remains at high pressure, the low-pressure coolant makeup systems cannot be used. The operator attempts to align the two control rod drive pumps for enhanced flow, but this also fails. At this point, all coolant makeup is lost. The core eventually uncovers, resulting in a damage state. 


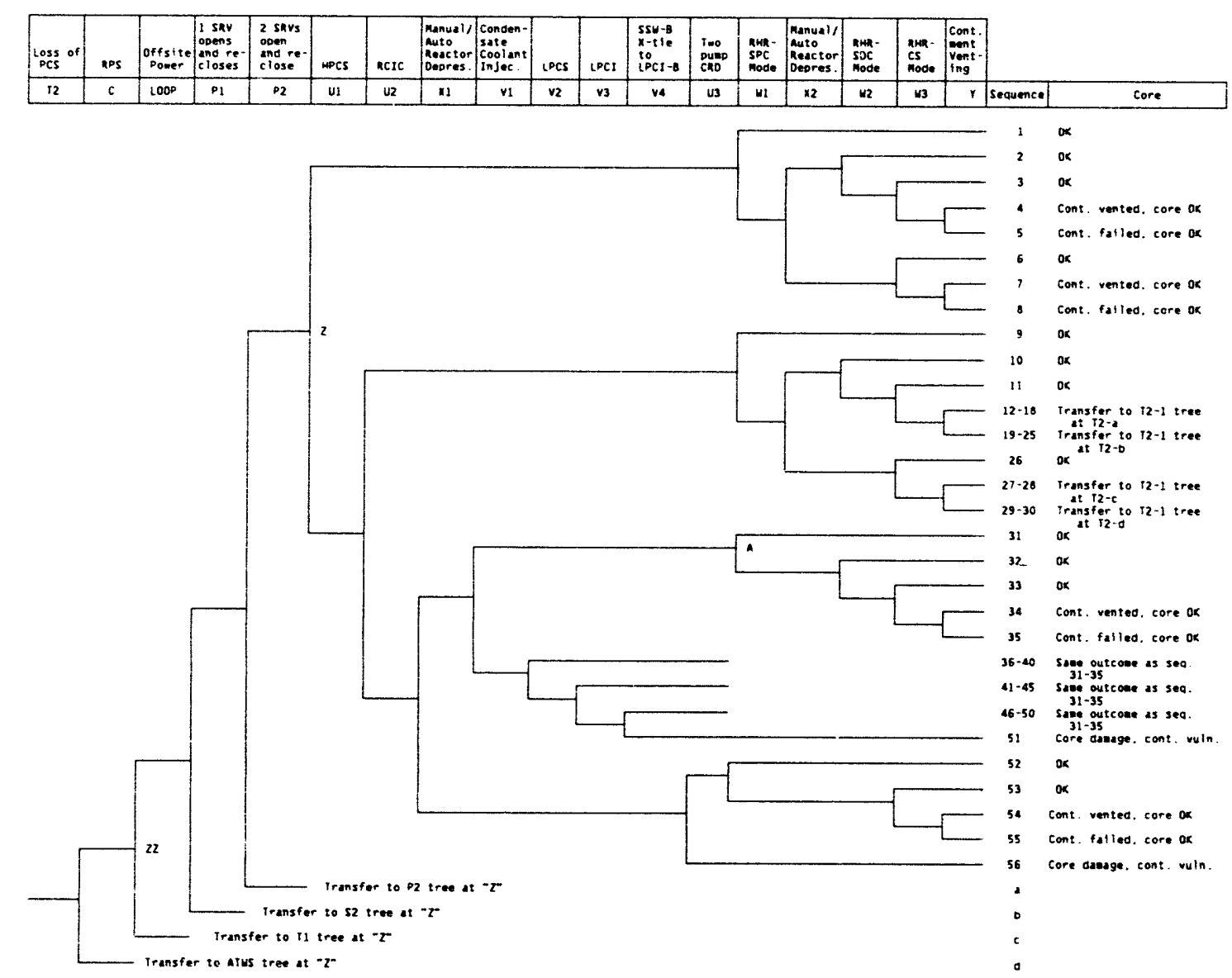

FIGURE 3.2-7. Event Tree for Loss of Power Conversion System 


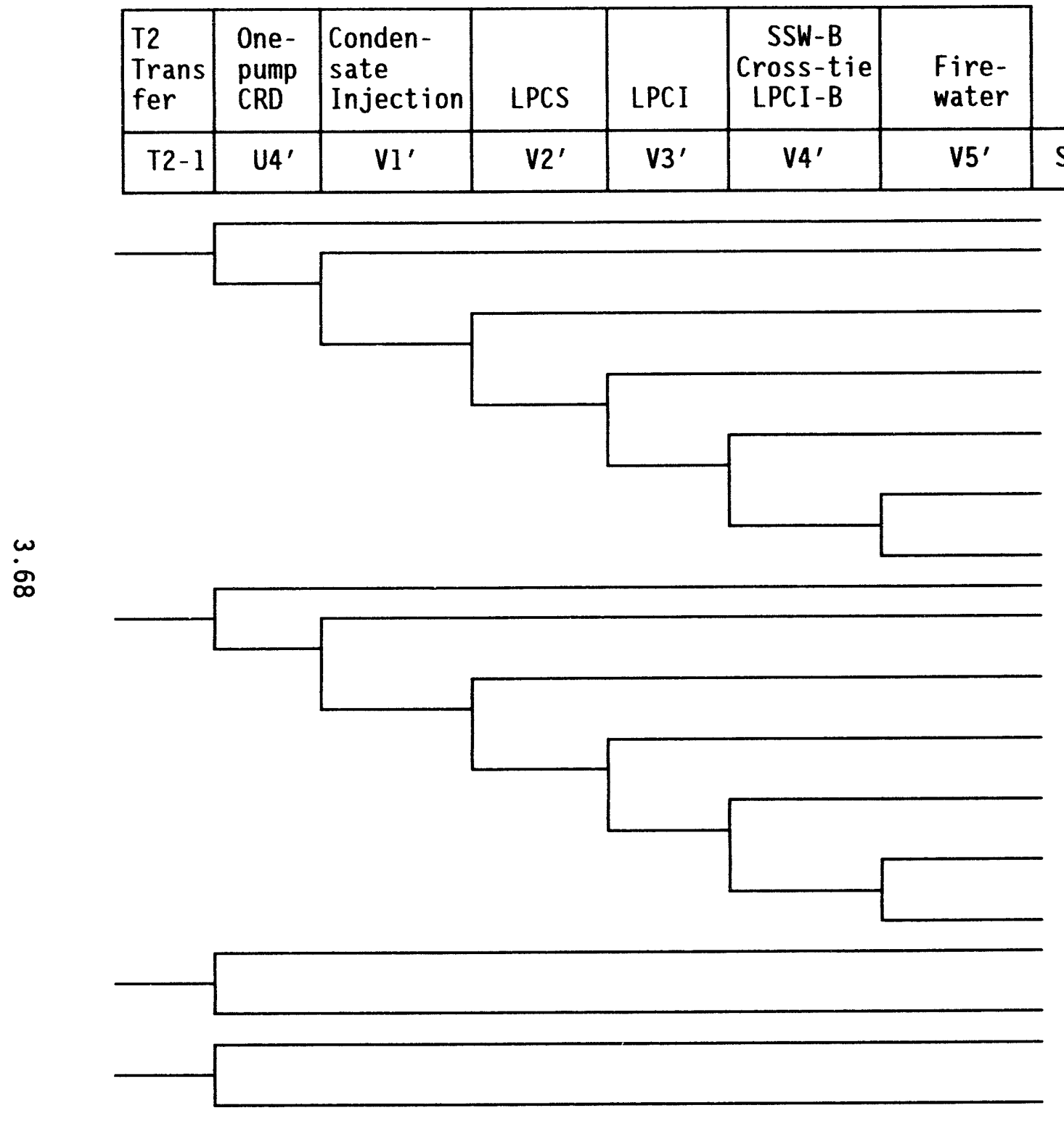

Sequence

Core

Cont. vented, core OK Cont. vented, core OK

14 Cont. vented, core OK

15 Cont. vented, core OK

16 Cont. vented, core OK

17 Cont. vented, core OK

18 Core damage, cont. vuln.

19 Cont. failed, core OK

20 Cont. failed, core OK

21 Cont. failed, core OK

22 Cont. failed, core OK

23 Cont. failed, core OK

24 Cont. failed, core OK

25 Core damage, cont. vuln.

27 Cont. vented, core OK

28 Cont. failed, then CD

29 Cont. failed, core OK

30 Core damage, cont. vuln.

FIGURE $3.2-7$. (contd) 


\subsubsection{Power Conversion System Available Event Tree}

Transients, in which PCS is initially available but is subsequently lost while the plant is being shut down, disrupt the normal operation of the plant and require immediate reactor SCRAM and subsequent mitigating action to cool the core and containment. The event tree is shown in Figure 3.2-8. There are nine event sequences of the event tree that lead to core damage. Of these nine core damage sequences, all contain cut set elements related to room cooling failure. Sequences containing events U1 (HPCS), U2 (RCIC), V2 (LPCS), V3 (LPCI), W2 (RHR - SPC), and W3 (RHR - CS) require pump room cooling for longterm operation of their respective systems.

SEQUENCE 19 - A transient (T3A) occurs, which generates a reactor SCRAM condition, and the RPS successfully inserts all the rods into the core $(/ C)$. Offsite power remains available (/LOOP). SRVs open and close to relieve the pressure surge caused by the SCRAM (/P1, /P2) and PCS fails. Water level drops below Leve1 2; HPCS and RCIC are demanded, but HPCS fails to function. Coolant makeup is being provided by RCIC. The residual heat from the reactor is being transferred to the suppression pool; therefore, pool temperature is increasing. At $95^{\circ} \mathrm{F}$, the operator is instructed to initiate SPC (W1), which subsequently fails. The vessel is depressurized, but SDC fails (W2). When containment pressure reaches $7.48 \mathrm{psig}$, CS is demanded and subsequently fails (W3). At this point, containment pressure increases to the isolation trip point of the RCIC turbine on high turbine exhaust pressure. CRD, condensate, LPCS, LPCI, SSW cross-tie, and firewater fail to function, so all coolant makeup is lost. The core eventually uncovers and the result is a damage state in a vented containment.

SEQUENCE 24 - Same as Sequence 19 except that condensate was not available as coolant makeup.

SEQUENCE 31 - Same as Sequence 19 except that containment venting never occurred.

SEQUENCE 36 - Same as Sequence 24 except that containment venting never occurred.

SEQUENCE 39 - Same as Sequence 19 except that the low-pressure systems cannot be used because reactor depressurization failed.

SEQUENCE 41 - Same as Sequence 39 except that containment venting never occurred. Core damage occurs in an intact containment, which is now vulnerable.

SEQUENCE 62 - A PCS transient (T3A) occurs, which generates a reactor SCRAM condition, and the RPS successfully inserts all the rods into the core $(/ C)$. Offsite power remains available (/LOOP). SRVs open and close to relieve the pressure surge caused by the SCRAM (/P1, /P2), and PCS fails. Water level drops below Level 2. HPCS and RCIC fail when demanded. The reactor vessel is depressurized, but condensate, LPCS, LPCI, and SSW cross-tie all fail to function. At this point, all coolant makeup is lost. 

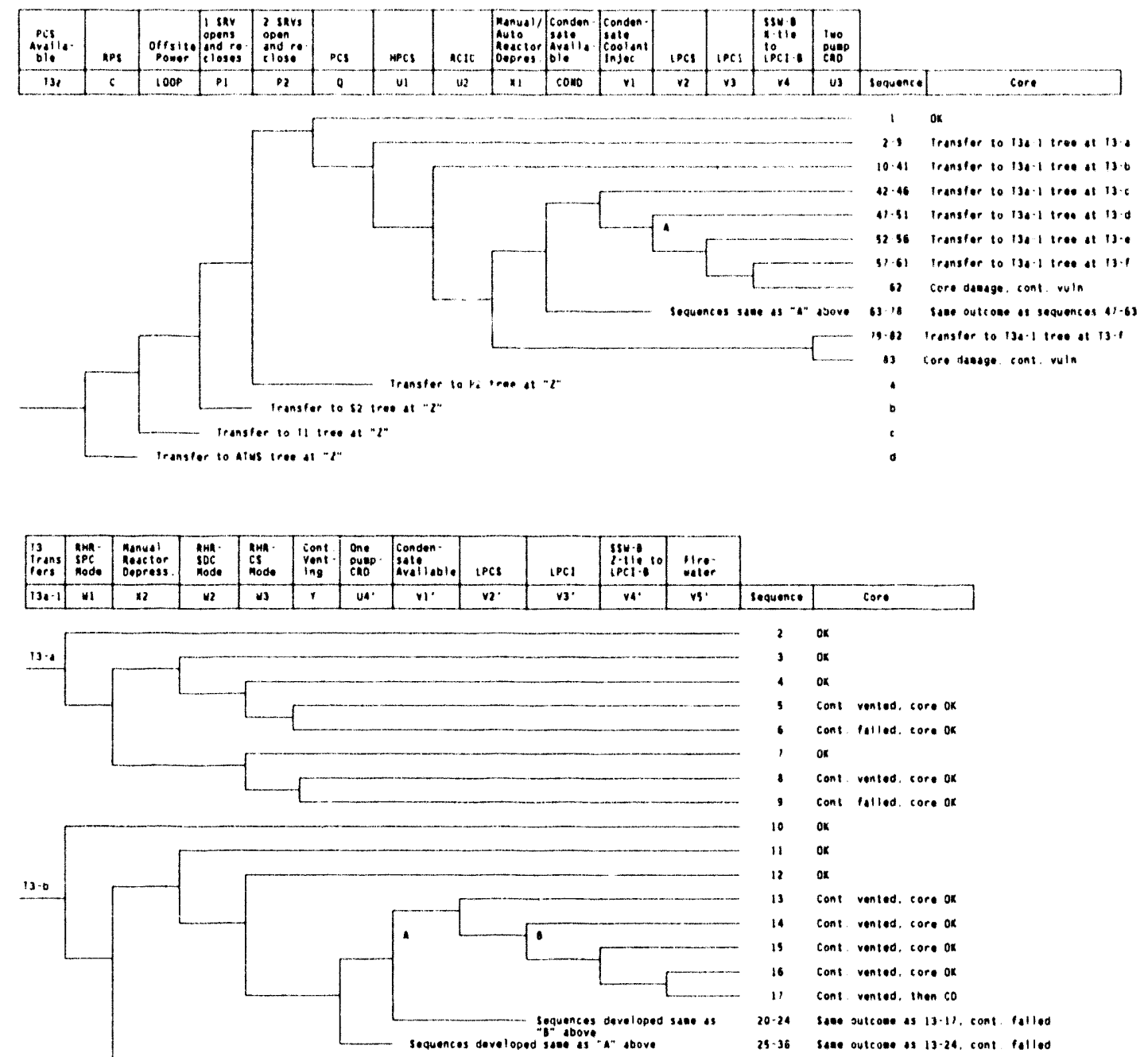

- cont called core ax

ox

ox

cont vented. core ox

cont vented, core or

cont vented, core ox

cont vented. core ox

cont. vented, then $c 0$

sace sutcone as 13-11, cont falled

25-36 sase outcone as 13-24, cont felled

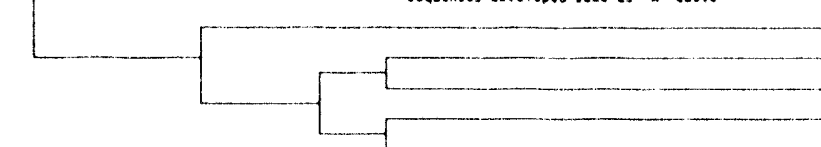

ox

36 Cont. vanted, corn or

cont vanted. then co

cont. fulled. core ok

core datenge. cont ruin

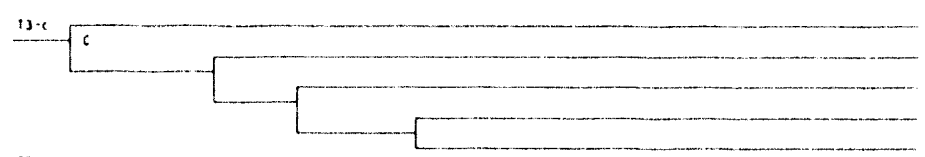

or

ok

ox

Cont. vented. tore $0 x$

46 cont vented, sore or

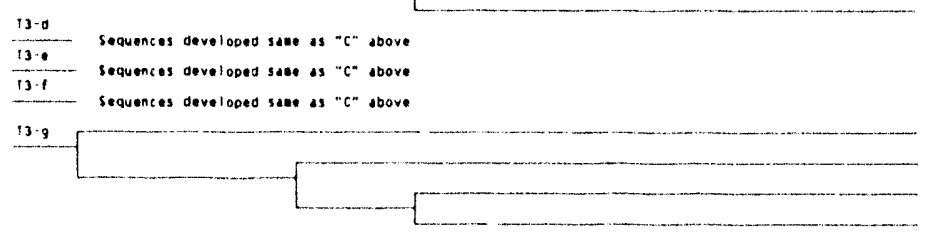

1) $\$ 1$ Sale outcone as 3.94 .42 .46

52.56 sane outcone 13 sog $42-46$

51.61 5ape outcone as seq. 42.46

is ox

so $0 x$

81 Cont vented tane ox

s2 cont fatled. core or

FIGURE 3.2-8. Event Tree for Transient With Power Conversion System Initially Available 
SEOUENCE 78 - Same as Sequence 62 except that condensate was not available when demanded.

SEQUENCE 83 - Same as Sequence 62 except that vessel depressurization never occurred, so that condensate, LPCS, LPCI, and SSW cross-tie cannot inject (XI) and CRD failed to function. At this point, all coolant makeup is lost. The core eventually uncovers, resulting in a damage state.

\subsubsection{Loss of Feedwater Event Tree}

A loss of feedwater event (T3B) is similar to a loss of PCS. The plant loses feedwater, but the steam side of the PCS may still be operable, as may the condensate system. A loss of feedwater transient disrupts the normal operation of the plant and requires mitigation. The event tree is shown in Figure 3.2-9. There are three event sequences of the event tree that lead to core damage: 23, 40, and 45. All three seque ces contain events exhibiting dependencies on pump room cooling, including $U$ (HPCS), U2 (RCIC), V2 (LPCS), V3 (LPCI), W1 (RHR - SPC), W2 (RHR SDC), and W3 (RHR - CS).

SEOUENCE 23 - A loss of feedwater transient (T3B) occurs, which generates a reactor SCRAM condition, and the RPS successfully inserts all the rods into the core $(/ C)$. Offsite power remains available (/LOOP). SRVs open and close to relieve the pressure surge caused by the SCRAM $(/ P 1, / P 2)$. Water level drops helow Leve1 2. HPCS and RCIC fail when demanded. The reactor vessel is depressurized $(/ X 1)$. Condensate, LPCS, LPCI, and SSW cross-tie all fail to function. The core eventually uncovers and results in a damage state.

SEOUENCE 40 - Same as Sequence 23 except that condensate is not available for coolant makeup.

SEQUENCE 45 - Same as Sequence 23 except that vessel depressurization never occurred so that condensate, LPCS, LPCI, and SSW cross-tie can not inject (X1) and CRD failed to function. The core eventually uncovers, and the result is a damage state.

\subsubsection{Inadvertent Open Relief Valve (IORV) Transient Event Tree}

Should a primary system SRV inadvertently open during power operation, steam will be discharged to the suppression pool through the SRV tail pipe line. If attempts to close the valve are unsuccessful, the plant is manually tripped and shutdown procedures commence. The event tree is shown in Figure 3.2-10. Two sequences, $A$ and $B$, lead to core damage; these sequences behave like a small LOCA (S2) and an anticipated transient without SCRAM (T), respectively, and are transferred to these event trees.

\subsubsection{1' Two Stuck-Open SRVs Event Tree}

Two stuck-open SRVs (P2) event tree is a transfer tree for other transient initiators and is not its own initiator. The event tree is shown in Figure 3.2-11. Two sequences, 17 and 18, lead to core damage; both contain cut set elements related to room cooling failure. Affected events include Ul 


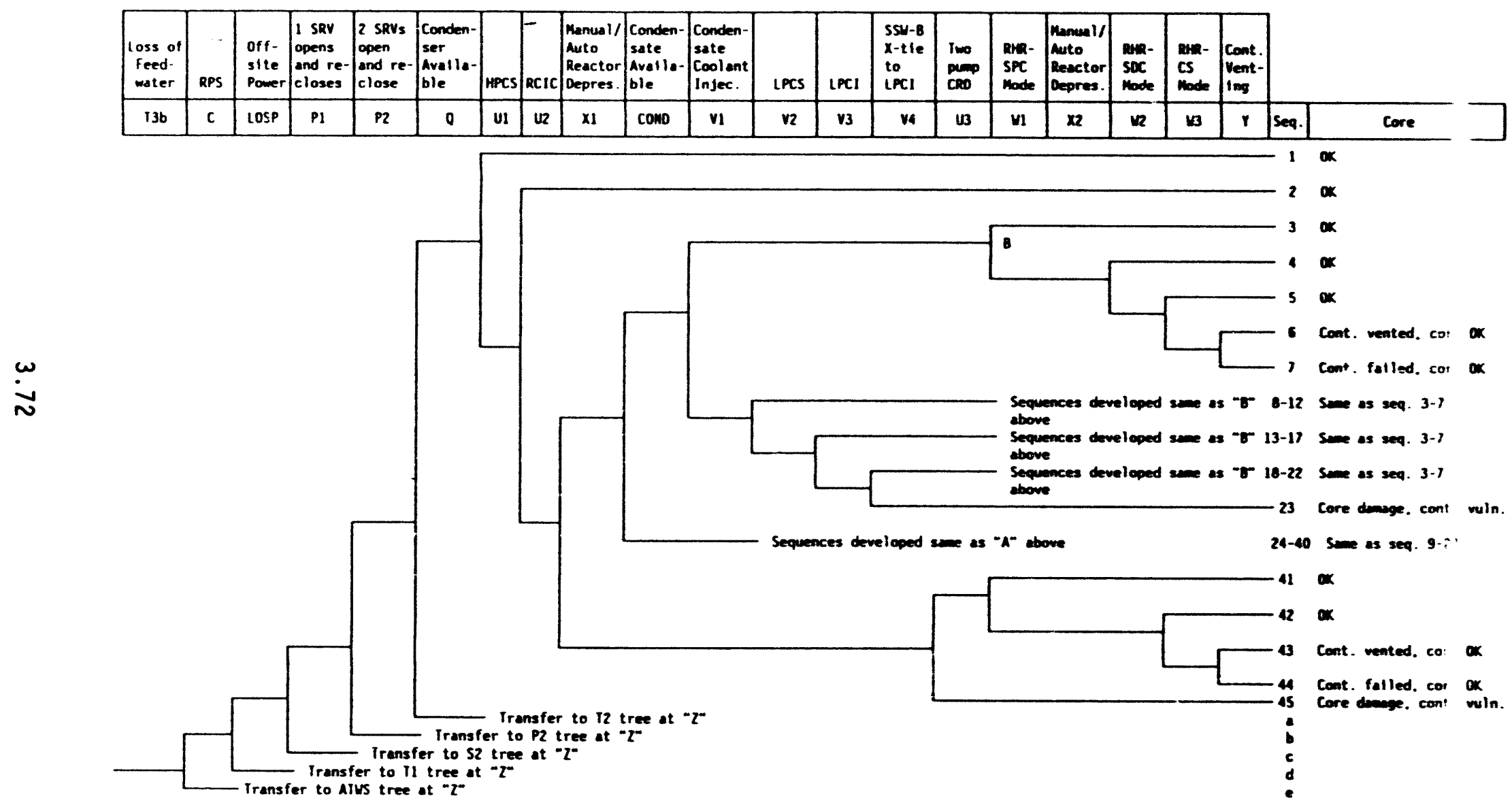

FIGURE 3.2-9. Event Tree for Loss of Feedwater 


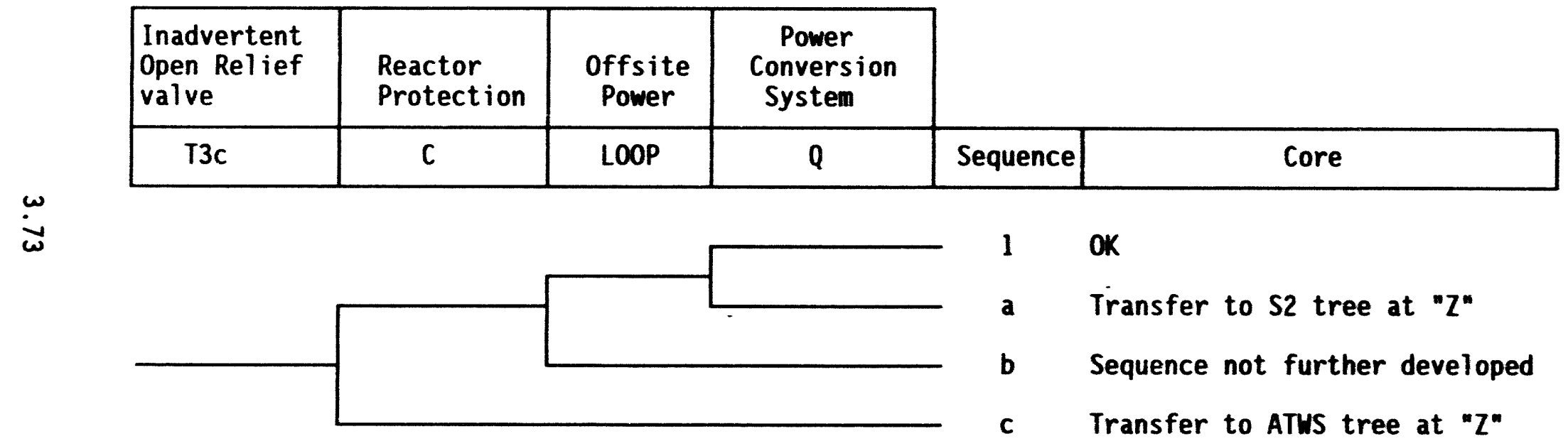

FIGURE 3.2-10. Event Tree For Inadvertent Open Relief Valve 


\begin{tabular}{|c|c|c|c|c|c|c|c|c|c|c|}
\hline $\begin{array}{l}2 \text { stuck- } \\
\text { open SRV } \\
\text { Transfer } \\
\text { Tree }\end{array}$ & HPCS & $\begin{array}{l}\text { Man/Auto } \\
\text { Reactor } \\
\text { Depres- } \\
\text { surize }\end{array}$ & LPCS & LPCI & $\mid \begin{array}{l}S S W-B \\
x-t i e \\
\text { to } \\
\text { LPCI-B }\end{array}$ & $\begin{array}{l}\text { RHR- } \\
\text { SPC } \\
\text { Mode }\end{array}$ & $\begin{array}{l}\text { RHR- } \\
\text { CS } \\
\text { Mode }\end{array}$ & $\mid \begin{array}{l}\text { Contain- } \\
\text { ment } \\
\text { Venting }\end{array}$ & & \\
\hline P2 & u1 & $x_{1}$ & $y_{2}$ & v3 & $v_{4}$ & $H 1$ & H3 & $r$ & Sequence & Core \\
\hline
\end{tabular}

$\stackrel{\omega}{\not}$

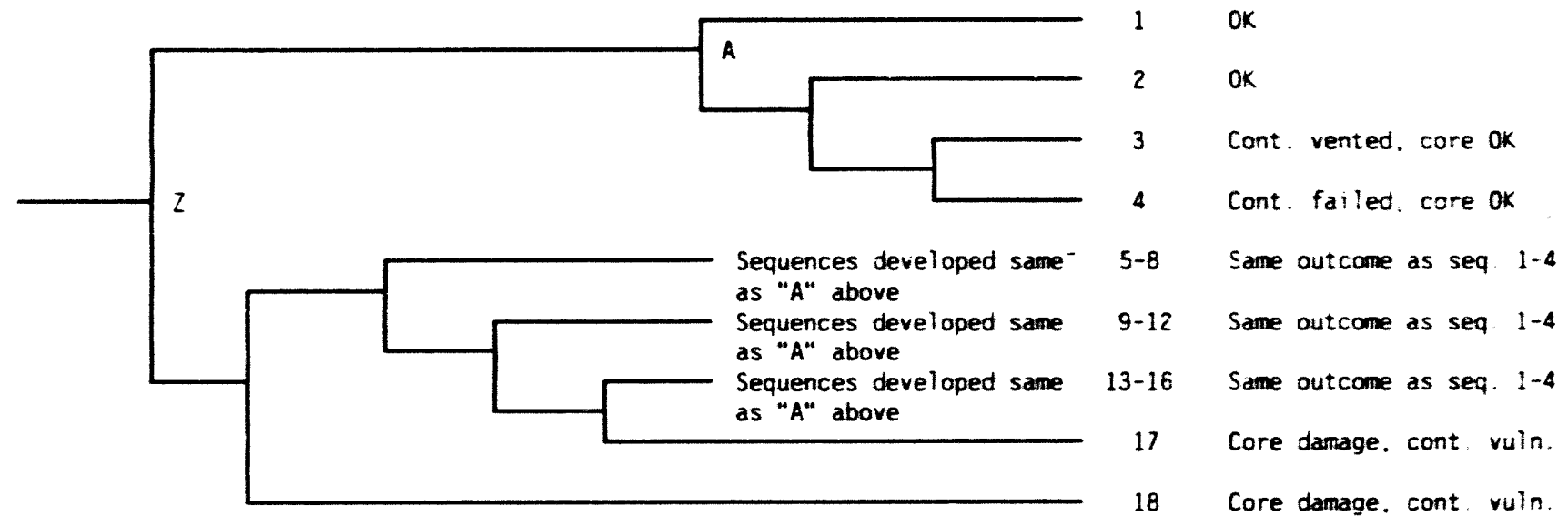

FIGURE 3.2-11. Event Tree for Two Stuck-0pen Safety Relief Valves 
(HPCS), V2 (LPCS), V3 (LPCI), W1 (RHR - SPC), and W3 (RHR - CS). These systems are dependent upon pump room cooling functions for long-term operation.

SEQUENCE 17 - A plant transient involving two stuck-open SRVs occurs. Water level drops below Level 2; HPCS fails to function (U1); the reactor vessel is depressurized $(/ X 1)$. LPCS, LPC I, and SSW cross-tie fail to function. At this point, all coolant makeup is lost. The core eventually uncovers and the result is core damage.

SEQUENCE 18 - Same as Sequence 17 except that vessel depressurization never occurs, so LPCS, LPCI, and SSW cross-tie cannot inject (X1). At this point, all coolant makeup is lost. The core eventually uncovers and a damage state results.

\subsubsection{Anticipated Transient Without SCRAM (ATWS) Event Tree}

The ATWS event tree is a transfer tree for all the LOCA and transient initiators with subsequent failure of the RPS. The event tree is shown in Figure 3.2-12. There are 21 sequences that lead to core damage; only nine

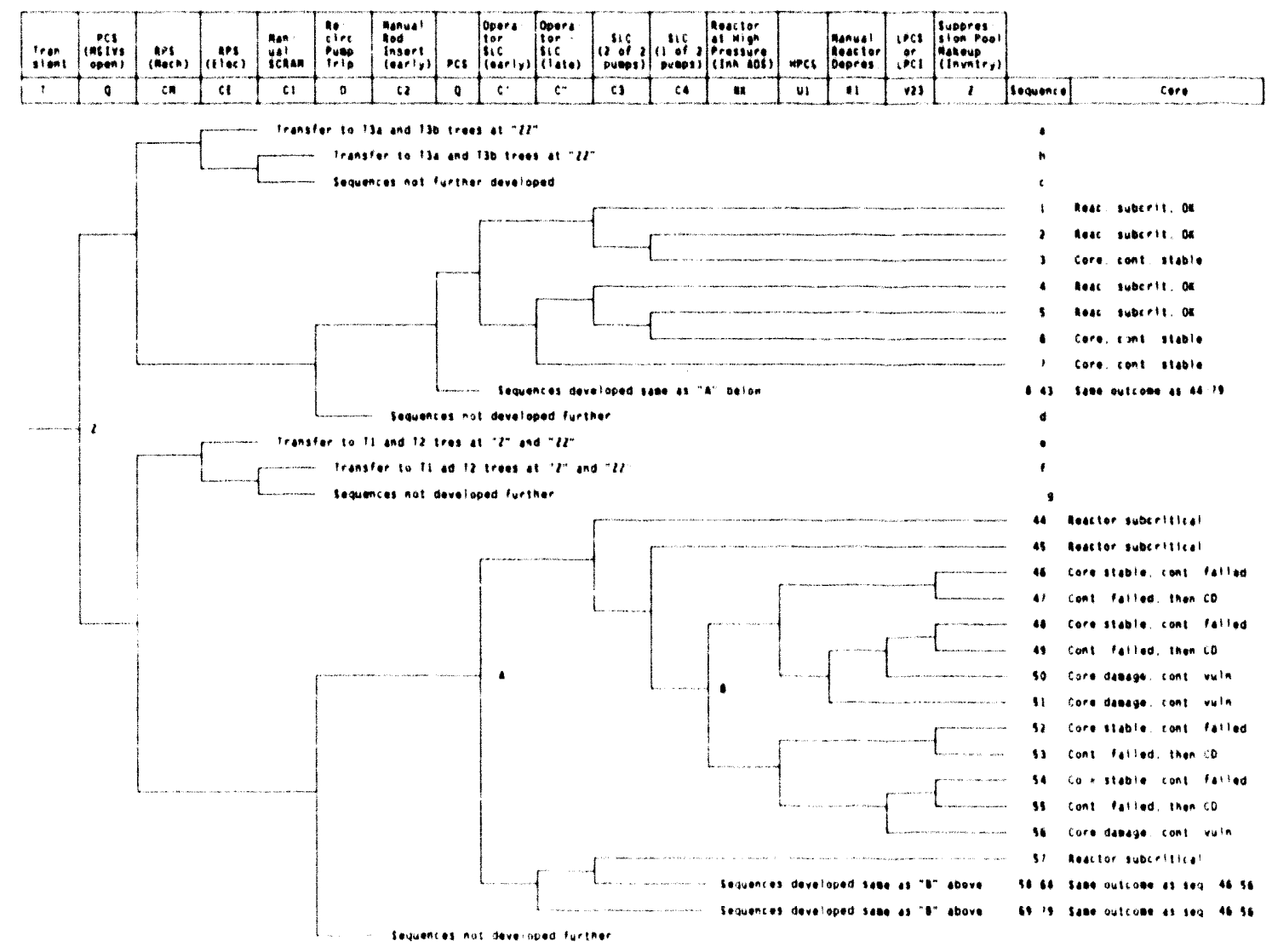

EIGURE 3.2-12. Event Tree for Anticipated Transients Without SCRAM 
contain cut set elements related to room cooling fallure, including sequences $50,51,56,62,63,68,73,74$, and 79 . The affected events include UI (HPCS) and V23 (LPCS or LPCI). These systems depend on pump room cooling for longterm operation.

SEOUENCE 50 - A transient occurs in which the PCS is not initially available. A reactor SCRAM is required but is unsuccessful because the mechanical portion of the RPS falls. An initial pressure increase occurs in the RCS, caused by a power imbalance when the turbine is tripped. This pressure increase is adequately handled by the SRVs. The recirculation pumps trip, which causes an increase in the voiding. The increased voiding causes a reduction in moderator effectiveness, and the power level equilibrates around $30 \%$. The operator actuates both of the SLC system pumps early and inhibits the ADS, which keeps the reactor at high pressure. Both SLC pumps fall to function, and the power level remains at 30\%. The reactor water level drops below Level 2, and the HPCS falls to function. The operator successfully depressurizes the reactor. LPCS and LPCI fail to function. The core eventually uncovers, resulting in core damage. The containment is vulnerable to fallure at this point.

SEOUENCE 51 - Same as Sequence 50 except that after HPCS fallure, operators fall to depressurize the reactor vessel, and LPCS and LPCI were unable to inject $\left(X_{1}\right)$.

SEQUENCE 56 - Same as Sequence 50 except that operators did not need to depressurize, since ADS was not inhibited. The core eventually uncovers, resulting in core damage. The containment is vulnerable at this point.

SEOUENCES 62, 63, AND 68 - Same as Sequences 50, 51, and 56 except operator actuates SLC 1ate.

SEOUENCES 73, 74, AND 79 - Same as Sequences 50, 51, and 56 except operator fails to actuate SLC.

\subsection{COMBUSTION ENGINEERING PRESSURIZED WATER REACTOR}

\subsubsection{Plant Descriotion}

The representative Combustion Engineering (CE) PWR contains three nuclear power plant units. The CE design consists of two independent primary coolant loops. Each unit, operating at full power, produces about $3817 \mathrm{MWt}$, for a nominal electric generating capacity of $1270 \mathrm{MWe}$. Unit 1 entered commercial operation in January 1986, Unit 2 in September 1986, and Unit 3 in January 1988. These plants are located in a hot, desert environment, and exhibit a relatively high reliance on HVAC and room cooler systems to maintain ambient temperatures that are conducive to equipment operability as well as to human occupational comfort. 


\subsubsection{Safety System Description and Systems Analysis}

This section presents summary-level descriptions and simplified schematic diagrams of the principal safety systems and presents the fault tree analyses on these systems. This information was used to identify the elements of the minimal cut sets in the existing plant PRA that involve failure to provide room cooling functions to safety systems (Arizona Public Service Co. 1992). A secondary objective was to develop modifications to the systems analyses to model room cooler fallures in important systems that were not addressed in the existing PRA.

The following subsections describe the safety systems that exhibit some dependency on HVAC or room cooler systems, discuss the fault trees for the systems that are dependent upon room cooling, and identify the cut set elements that represent fallures of one or more trains of room cooling equipment. Comprehensive descriptions of all safety systems at the $p l a n t$ and the detailed fault trees for each system are presented in Appendix D. For completeness, all of the safety systems included in the existing PRA are reviewed in Appendix $D$. However, cut set data are presented for only the systems that are dependent upon room cooling.

The safety-related systems that are dependant upon HVAC/cooling to support their operation are listed below:

- High-pressure safety injection (HPSI pump room coolers)

- Low-pressure safety injection (LPSI pump room coolers)

- Containment spray (CS pump room coolers)

- Auxiliary feedwater (AFW pump room coolers)

- Essential cooling water (EW pump room coolers)

- $D C$ equipment room (essential HVAC)

- ESF switchgear room (essential HVAC)

- Control room (CR HVAC).

Descriptions and analyses of these and other safety-related systems are provided in this section. Dependencies on HVAC/room cooler systems are identified and described for each of the safety systems.

\subsubsection{High-Pressure Safety Injection}

The HPSI system is a part of the safety injection (SI) system. HPSI functions to inject borated water into the reactor coolant system (RCS) following a small-break LOCA in which RCS pressure is expected to remain high (1255 psig) for a long period of time. HPSI is also capable of providing core heat removal for extended periods of time following a LOCA, and is used to 
inject borated water into the RCS to increase shutdown margin following a rapid cooldown of the primary system due to steam line rupture or a steam generator tube rupture (SGTR).

The HPSI system consists of two redundant, 100\%-capacity trains, each with one HPSI pump, one hot-leg injection line, and four branch headers. Each header discharges through a HPSI valve to a RCS cold leg. During the injection phase following a LOCA, the HPSI pumps take suction from the refueling water tank (RWT), which is also the initial suction source for the lowpressure safety injection (LPSI) and containment spray (CS) systems. The HPSI pumps are rated such that $75 \%$ of the flow of one of the pumps is enough to maintain adequate RCS inventory and boration for any of the three sequences 1isted above. Appendix D provides a schematic of the HPSI system.

The HPSI system also provides a long-term core cooling function referred to as high-pressure safety recirculation (HPSR). In this mode, the HPSI pumps recirculate primary coolant from the containment sump back to the RCS. This mode is automatically initiated by a recirculation actuation signal (RAS) when the RWT reaches a low-level set-point of $7.4 \%$. At that time, the ESFAS opens containment sump valves and automatically aligns the HPSI and CS pump suction to the containment sump.

During normal operation, the Auxiliary Building HVAC system provides cooling to the HPSI pump cubicles. Following a safety injection actuation system (SIAS) signal, the normal room cooling system is tripped, and dedicated emergency room coolers in each cubicle are started. Each room cooler consists of a fan and air cooling coils. The fan recirculates air inside the cubicle, passing the air over the cooling coils to transfer heat to chilled water from the essential chilled water (EC) system. The fan is powered from a Class IE 480-V AC MCC. High temperature alarms are provided, which alarm in the control room when ambient temperatures in the HPSI pump cubicles reach $105^{\circ} \mathrm{F}$.

ESF emergency load sequencers located in the control room actuate the HPSI pumps. The ESF load sequencers are located in cabinets and are cooled by cabinet fans. Cooling to the control room is provided by the control room emergency ventilation system. The load sequencers automatically load-shed the HPSI pump (and other safety-related equipment loads) from the associated emergency bus upon a loss of power (LOP) signal. After the diesel generator is up to speed and supplying power to the emergency bus, the HPSI pump is sequenced on if an SIAS or containment spray actuation signal (CSAS) is present.

Failure of the HPSI pumps due to high room temperatures was included in the existing PRA. This HPSI failure mode could result from failure of the HPSI pump room coolers. Calculations indicated that the HPSI room could reach a maximum temperature of $199^{\circ} \mathrm{F}$ within 24 hours following a loss of room cooling (see Appendix F). If the pump room door were to be opened two hours after loss of the room cooler, the maximum temperature was calculated to be $165^{\circ} \mathrm{F}$. These temperatures were determined not to immediately result in HPSI pump failure, although the reliability of the pumps is significantly degraded. 


\subsubsection{Low-Pressure Safety Injection}

The low-pressure safety injection (LPSI) system is also a part of the SI system. LPSI functions to inject borated water into the RCS following a large-break LOCA. LPSI is also used for small LOCAs and SGTR events when HPSI has failed. Control room operators must depressurize the RCS to below 140 psia to permit LPSI flow. The LPSI system also provides for .PSR in the event that both trains of HPSI are failed or if HPSI fails during the recirculation mode. The LPSI pumps are tripped upon receipt of a RAS and must be restarted by control room operators to initiate LPSR. The LPSI pumps are also used for shutdown cooling, in which RCS inventory is circulated through the shutdown cooling heat exchangers and LPSI pumps and then returned to the reactor vessel.

The LPSI system consists of two redundant, 100\%-capacity trains, each with one LPSI pump and two branch headers. Each branch header discharges through its own injection MOV into a RCS cold leg. During the injection phase following a LOCA, the LPSI pumps take suction from the RWT, which is also the initial suction source for the HPSI and CS systems. A common RWT header is provided for the LPSI, HPSI, and CS pumps. For LPSR operation, the LPSI pumps take suction from the containment sump. The containment sump header is also a common header for the LPSI, HPSI, and CS pumps. A simplified schematic of the LPSI system is provided in Appendix D.

Similar to the HPSI system, the Auxiliary Building HVAC system provides cooling to the LPSI pump cubicles during normal operation. If a SIAS signal occurs, the normal room cooling system is tripped, and dedicated emergency room coolers in each cubicle are started. Each room cooler consists of a fan and air-cooling coils. The fan recirculates air inside the cubicle, passing the air over the cooling coils to transfer heat to chilled water from the EC system. The fan is powered from a Class $1 E$ 480-V AC MCC. High temperature alarms are provided that alarm in the control room when ambient temperatures in the LPSI pump cubicles reach $105^{\circ} \mathrm{F}$.

ESF emergency load sequencers actuate the LPSI pumps. The load sequencers automatically load-shed the LPSI pump (and other safety-related equipment loads) from the associated emergency bus upon a loss of power (LOP) signal. After the EDG is up to speed and supplying power to the emergency bus, the LPSI pump is sequenced on if a SIAS or containment spray actuation signal (CSAS) signal is present.

Failure of the LPSI pumps due to high room temperatures was included in the existing PRA. This LPSI failure mode could result from failure of the LPSI pump room coolers. Calculations indicated that the LPSI room could reach a maximum temperature of $189^{\circ} \mathrm{F}$ within 24 hours following a loss of room cooling. If the pump room door were to be opened two hours after loss of the room cooler, the maximum temperature was calculated to be $168^{\circ} \mathrm{F}$. If no backup cooling to the LPSI pump cubicle is established, the LPSI pumps will fail within 24 hours. If the pump room door is opened within two hours following 
the loss of room cooling, the reliability of the pumps is significantly degraded and the pump failure probability is increased above the probability used when room cooling is available.

\subsubsection{Containment Spray System}

The primary function of the containment spray (CS) system is to provide a cool spray of water into the containment following a LOCA, steam line break, or feedwater line break. This water spray, delivered through CS header nozzles, maintains containment integrity by reducing containment pressure and temperature and limits the leakage of airborne radioactivity from the containment.

The CS system consists of two redundant and independent trains, each with its own CS pump. Each CS train is normally aligned to pass flow though a shutdown cooling heat exchanger and a CS control MOV, and to discharge borated water through a dual set of spray nozzle headers located in the upper part of the Containment Building. The CS system is automatically actuated by a CSAS, which occurs at high containment pressure. ESF emergency load sequencers actuate the CS pumps. The pumps take suction from the RWT during the injection phase and from a common suction line with the HPSI and LPSI pumps from the containment sump during the recirculation phase. Pump suction is automatically transferred to the containment sump upon receipt of a RAS signal when low RWT inventory is reached. The shutdown cooling heat exchangers provide cooling to the CS injection water during both injection and recirculation phases. The heat exchangers are cooled by the essential cooling water (EW) system. A simplified diagram of the CS system is provided in Aprendix D.

Similar to the HPSI and LPSI systems, the Auxiliary Building HVAC system provides cooling to the CS pump cubicles during normal operation. Should a SIAS signal occur, the normal room cooling system is tripped, and dedicated emergency room coolers in each cubicle are started. Each room cooler consists of a fan and air cooling coils similar in design to the LPSI/HPSI pump room coolers. The fan is powered from a Class $1 E$ 480-V AC MCC. High temperature alarms are provided, which alarm in the control room when ambient temperatures in the CS pump cubicles reach $105^{\circ} \mathrm{F}$.

Failure of the CS pumps due to high room temperatures was included in the existing ,PRA. This failure mode could result from failure of the CS pump room coolers. Calculations indicated that the CS pump room could reach a maximum temperature of $189^{\circ} \mathrm{F}$ within 24 hours following a loss of room cooling. If the pump room door were to be opened two hours following loss of the room cooler, the maximum temperature was calculated to be $168^{\circ} \mathrm{F}$. If no backup cooling to the CS pump cubicle is established, the CS pumps will fail within 24 hours. If the pump room door is opened within two hours following the loss of room cooling, the reliability of the pumps is significantly degraded and the pump failure probability is increased above the probability used when room cooling is available. 


\subsubsection{Shutdown Cooling System}

The shutdown cooling system (SDC) is used to reduce the temperature of the RCS following reactor shutdown from approximately $350^{\circ} \mathrm{F}$ to the refueling temperature of $124^{\circ} \mathrm{F}$, and maintain heat removal for an extended period of time. The SDC system can also operate following an accident to remove heat through the SDC heat exchanger. The LPSI pumps are normally used during shutdown cooling. The SDC system is also used during a SGTR event. During such an event, operators are required to reduce RCS pressure to minimize the RCS-to-secondary side leak. Operators would also cool down and depressurize the RCS to SDC entry conditions, establish SDC, and then cool the RCS to refueling temperature and pressure conditions.

The SDC system consists of two redundant, 100\% capacity trains. The LPSI or CS pumps circulate RCS water from nozzles on each RCS hot leg, through an SDC heat exchanger, and back into the RCS through the four LPSI injection lines. CS pumps are used only when RCS temperatures are $200^{\circ} \mathrm{F}$. Three MOVS are provided to isolate the SDC system from the RCS hot leg. Each SDC loop is interlocked to remain closed until RCS pressure is below 410 psia. A simplified diagram of the SDC system is provided in Appendix D.

The pumps and discharge valves used by SDC are the same as those described for LPSI (subsection 3.3.2.2) and CS (subsection 3.3.2.3) systems. The only major SDC components not covered previously are the SDC suction valves. One suction valve per train is a Class $1 E$ 125-V DC-powered MOV, and the other two per-train are Class $1 E$ 480-V AC-powered MOVs.

As discussed in subsections 3.3.2.2 and 3.3.2.3, dedicated emergency room coolers in each LPSI and CS pump room are started if a pump is in operation. Each room cooler consists of a fan and air-cooling coils; the fan is powered from a Class $1 E$ 480-V AC MCC. High temperature alarms are provided, which alarm in the control room when ambient temperatures in the LPSI and CS pump cubicles reach $105^{\circ} \mathrm{F}$.

\subsubsection{Auxiliary Feedwater System}

The auxiliary feedwater (AFW) system provides water to the steam generators (SGs) during normal, abnormal, and emergency conditions for removal of decay heat from the primary coolant system. The AFW system consists of three AFW pumps (two safety-related and one nonsafety), associated piping, valves, and instrumentation necessary to deliver water to the secondary sides of the SGs. One safety-related AFW pump is turbine-driven and the other is motordriven. The nonsafety-related AFW pump is motor-driven. A simplified drawing of the AFW system is shown in Appendix D.

The safety-related portion of the AFW system consists of two completely redundant trains. The TDP is provided with turbine steam supply lines from each SG. The MDP is a Class IE pump powered from the Division 2 ESF switchgear. Each essential AFW pump takes independent suction from the condensate 
storage tank (CST) and discharges to one or both SGs through the downcomer feedwater lines. A backup water source, requiring local-manual operation, is available from the reactor makeup water tank (RMWT). The nonessential portion of the AFW system includes a class-powered, nonseismically qualified MDP. The nonessential pump takes suction from the CST; no connection to the RMWT is provided. The nonessential pump is used during plant startup as well as during emergency conditions.

The AFW system is used for secondary-side heat removal. Under smallbreak LOCA conditions, AFW must be delivered to at least one SG from one of the three AFW pumps. For RCS depressurization (if HPSI has failed), AFW flow must be delivered to two SGs from one of three AFW pumps. Under feedwater and main steam line-break conditions, AFW flow must be delivered from at least one AFW pump to the unaffected SG. Under LOOP, loss of MFW, and most other transient conditions, AFW flow must be delivered to at least one SG from one of the three AFW pumps. Under SBO conditions, the turbine-driven AFW pump must supply AFW to one SG for at least two hours. During later stages of an SBO event, AFW must be supplied from at least one AFW pump to one SG for at least 24 hours following recovery of offsite power.

During normal power operations, the AFW system is in standby mode. Following a plant trip, an auxiliary feedwater actuation signal (AFAS) is generated in response to low level in either SG. The ESF load sequencers then automatically start both essential AFW pumps. The AFAS automatically aligns the AFW pumps to the appropriate SG and control SG level without operator intervention. However, operators are directed to override automatic control of the AFW pump discharge throttle valves to more closely control SG levels. The nonessential (Train N) AFW pump is the preferred means of feeding the SGs following a normal reactor trip, followed, in order of preference, by the Train B MDP and then the Train A TDP. Operating procedures call for remote startup of the Train $N$ pump unless a main steam isolation signal (MSIS) is present, which results in closure of the downcomer feedwater isolation valves (FWIVs), which disables the Train N pump flowpath.

Normal c:oling to the essential AFW pump rooms, located in separate compartments in the main steam support structure (MSSS), is provided by the Auxiliary Building normal AHUs. Upon receipt of a SIAS or CSAS, the normal cooling system is tripped and room cooling is provided by essential room coolers, consisting of a fan and air-cooling coils. The EC system provides chilled water to the essential AFW pump room coolers.

The Train A (turbine-driven) AFW pump room cooler is powered from Train A 480-V AC MCC. The Train B (essential motor-driven) AFW pump room cooler is powered from Train B $480-V$ AC MCC.

Division 2 ESF switchgear provides motive power to the nonessential AFW MDP. Breaker control power is provided by Channel A 125-V DC distribution panel. Failure of this panel may result from failure of the $D C$ equipment room HVAC system. 
The existing PRA includes models of the normal and emergency HVAC systems for the essential AFW pump rooms. Calculations indicated that the essential MDP will survive for at least 12 hours with no HVAC and has a $50 \%$ chance of surviving for 24 hours without room heat removal. Similar calculations indicate a high probability that the turbine-driven AFW pump will survive for 24 hours without room cooling. In addition, both essential pumps are likely to survive at least 24 hours with only normal HVAC systems unavailable. However, normal HVAC is isolated through closure of isolation dampers by a SIAS resulting from LOCA, steam or feedwater line breaks, and SGTR events, and will be unavailable under these conditions. A dominant event resulting in AFW system unavailability involves successful start of an essential AFW pump but failure to start the appropriate EC system chiller that serves the essential AFW pump room cooler. The essential AFW pump then fails due to extreme room temperature.

\subsubsection{Chemical and Volume Control System}

The chemical and volume control system (CVCS) provides the following functions :

- CVCS provides reactor coolant pump (RCP) seal injection and bleedoff control. Therefore, the CVCS is used to maintain RCS integrity by preventing RCP seal LOCAs. One charging pump is needed to maintain adequate seal cooling.

- CVCS provides borated water used to shut down the reactor following an anticipated transient without SCRAM (ATWS)

- CVCS provides water to the auxiliary pressurizer spray system (APSS) used to maintain operator control of RCS pressure when normal pressurizer sprays are unavailable.

The CVCS removes water from the RCS via the letdown line and passes the water through the regenerative heat exchanger, letdown heat exchanger, and purification ion exchanger and then discharges the cooled and purified water into the volume control tank (VCT). The VCT water is then returned to the RCS using one or more charging pumps. The water returning to the RCS passes through the regenerative heat exchanger, where it removes heat from the incoming letdown flow. Flow upstream of the heat exchanger is diverted to the RCP seal line. The seal injection water flows through a seal injection filter and heat exchanger prior to entering the RCP seals. Flow downstream of the regenerative heat exchanger supplies normal charging. A simplified drawing of the CVCS is provided in Anpendix $D$.

The CVCS includes three positive displacement charging pumps, which normally take suction from the VCT. The VCT is used to accumulate letdown water from the RCS. Normal makeup for the VCT is provided by the RMWT and the RWT. If the VCT is unavailable, the charging pumps can take suction from the RWT. 
The Auxiliary Building normal HVAC system provides cooling to the CVCS pump cubicles during normal operation. Each pump also has its own dedicated room cooler, which is in operation when the associated pump is running. Each room cooler consists of a fan and air-cooling coils similar in design to the LPSI/HPSI pump room coolers. The fan is powered from a Class $1 E$. 480-V AC MCC.

Calculations indicated that the charging pulups are capable of withstanding a total loss of room cooling without threatening pump operability over its intended mission time. These calculations were reviewed and judged to be adequate to demonstrate a lack of dependence on room cooling to charging pump survivability under loss of room cooling conditions.

\subsubsection{Essential Chilled Water System}

The essential chilled water (EC) system is a support system that provides chilled water to essential HVAC systems for the Control Building, Auxiliary Building, and MSSS. Essential HVAC and EC systems are safetyrelated systems that cool safety-related equipment rooms during emergencies.

The EC system is a normally standby system consisting of two $100 \%$ capacity, redundant, chilled water trains. Each train includes its own chiller, pump, expansion tank, chemical addition tank, control valves, piping, and instrumentation. Each train is a closed-loop system, and the trains are not cross-connected. Cooling water for the chiller condensers is provided by the EW system (see subsection 3.3.2.8). A simplified diagram of the EC system is provided in Appendix D.

The EC system provides chilled water to the following air conditioning units (ACUs) and AHUs:

- Control room AHU

- HPSI pump rooms

- LPSI pump rooms

- ESF switchgear rooms (including battery rooms)

- DC equipment rooms (includes inverters, battery chargers)

- Electrical penetration rooms

- AFW pump rooms

- CS pump rooms

- EW pump rooms 
The EC system is normally standby and is actuated when the ESFAS starts the safety-related components in the rooms identified above. The EC system may also be started manually from the control room or locally from its switchgear.

Most of the relevant safety-related equipment room cooling information was presented in previous sections (e.g., HPSI pump room cooling, LPSI pump room cooling). It is important to note that failure of the EC system could lead to failure of the safety-related components in rooms cooled by room coolers that need the EC system to reject heat. In the existing PRA, it was assumed that the EC system must operate for 24 hours following an accident. This was stated to be conservative, because even a few hours of EC operation is sufficient to prevent room temperatures from exceeding extreme environmental conditions. Calculations provided by the utility were reviewed, and this conclusion was judged to be adequately founded.

EC pump and chiller room cooling was not modeled in the existing PRA. The pumps and chillers are located in relatively large rooms compared with the much smaller HPSI, LPSI, and CS pump cubicles. Therefore, it would take much longer to heat the EC pump/chiller rooms to the point at which degradation would be expected. Based on the loss-of-HVAC analyses performed by the utility, it was concluded that the EC pump room temperature will not exceed equipment qualification temperatures within 24 hours. This conclusion is warranted based on the available information. However, if the calculations in Section 4 indicate that failure of $E C$ pumps is an important contributor to the CDF, further analyses will be performed to determine actual heatup rates in these rooms.

The existing PRA determined that EC system failures were dominated by common-cause failures of the chillers and EC pumps. Common-cause failures of the EW and SP pumps were also found to affect the availability of the EC system. In addition, it was found that scenarios in which one train of EC has already failed as a result of the initiating event or due to failures other than the EC system, the dominant failures for the other EC train included autostart failures due to load sequencer faults, maintenance unavailability, control circuit faults, and chiller run failures. The ESF load sequencers are located in an area adjacent to the control room cooled by the control room ACUs. Since the load sequencers are important to actuation of safety-related components, failure of the ESF load sequencers due to failure of control room cooling functions will be explicitly modeled in the study.

\subsubsection{Essential Cooling Water System}

The essential cooling water (EW) system removes heat from safety-related components at the plant, with the exception of the EDGs. The safety-related EW system removes heat from the essential chillers and shutdown cooling heat exchangers, and rejects heat to the essential spray pond (SP) system. The EW 
system also serves as a backup for the nuclear cooling water system, which removes heat from the fuel pool cooling heat exchangers, RCPs, control element drive mechantsms (CEDMs), and normal chillers.

The EW system consists of two redundant, closed-loop flow trains. One loop serves Train A shutdown cooling heat exchanger and Train A essential chiller, while the other EW loop serves Train B equipment. Each train includes a pump, heat exchanger, surge tank, piping, valves, controls, and instrumentation. Water is cooled by the EW heat exchanger, which rejects heat to the SP system, and is then pumped to the essential chiller and SDC heat exchanger before returning to the EW heat exchanger. Either EW loop is sufficient to allow safe plant shutdown. Appendix $D$ presents a simplified diagram of the EW system.

ESF load sequencers send autostart signal on AFAS, SIAS, LOP, control room essential filtration actuation signal (CREFAS), and control room ventilation isolation actuation signal (CRVIAS). In the presence of a LOP signal, the ESF load sequencer first load-sheds the EW pumps and then restarts them after the EDG starts and the $4.16-\mathrm{kV}$ bus is repowered.

EW pump areas are cooled by an emergency ACU (see subsection 3.3.2.7). Cooling water for these spaces is provided by the EC system, which is in turn cooled by the EW system. Therefore, failure of the EC system could result in failure of the EW pumps due to extreme temperatures. Calculations indicated that the EW pump room could reach a maximum temperature of $189 \circ \mathrm{F}$ within 24 hours following a loss of room cooling (see Appendix F). If the pump room door were to be opened at two hours following loss of the room cooler, the maximum temperature was calculated to be $168^{\circ} \mathrm{F}$. If no backup cooling to the CS pump cubicle is established, the CS pumps will fail within 24 hours. It was determined that the reliability of the pumps is significantly degraded if room cooling fails. Therefore, the pump failure probability is increased above the probability used when room cooling is available.

\subsubsection{ESF Switchgear "DC Equipment" Room HVAC}

The main function of the ESF switchgear room HVAC system is to provide room cooling to a specific elevation of the Control Building that houses the ESF switchgear, DC equipment, and battery rooms. These areas are provided with both normal and essential HVAC systems. During normal plant operations, these areas are serviced by two normally running AHUs. In the case of SIAS or LOOP signals, the switchgear areas will be isolated from the normal AHUs by closing air-operated HVAC dampers, and the switchgear areas will then be served by the essential HVAC system. Separate trains of essential HVAC are provided for each division of switchgear. Each train of essential HVAC includes two essential ACUs, which are started automatically. One ACU in each train provides intake and exhaust area for the switchgear and battery rooms and draws return air from the DC equipment room. The other ACU supplies cooled air to only the DC equipment room. A simplified diagram of the ESF switchgear room cooling system is provided in Appendix D. 
The ESF switchgear room normal AHU consists of a cooling coil and fan. Chilled water is provided by the nonsafety-related normal chilled water (WC) system. The normal HVAC system is designed to maintain room temperatures between 60 and $77^{\circ} \mathrm{F}$. The essential ACUs are similar in design but have smaller capacities than the normal AHUs. Each essential ACU is sized to remove the heat load of its associated rooms. Cooling water is provided by the EC system. The essential ACUs are designed to maintain room temperatures between 40 and $104^{\circ} \mathrm{F}$ to prevent equipment in the rooms from overheating and possibly failing.

The HVAC system is provided with fusible-link fire dampers that are dropped by either high room temperature or actuation of the fire protection system. Closure of a fire damper results in isolation of the respective room from outside air sources and all AHUs.

ESF switchgear room cooling dependencies include these:

- Normal AHUs require nonclass 480-V AC power to start and run. The essential ACUs require Class $1 E 480-V$ AC power to start and run. Class IE 125-V DC power is required for the isolation dampers.

- The normal HVAC system AHUs require chilled water from the WC system. The essential ACUs require chilled water from the EC system.

- Instrument air is required for operation of the isolation dampers and to hold open the normal AHU chilled water inlet valves. Failure of IA results in failure of the normal HVAC system but not the essential ACUs.

The existing PRA stated that the most sensitive equipment in the DC equipment rooms was qualified to operate at ambient temperatures up to $104^{\circ} \mathrm{F}$. However, further investigations were performed, and it was determined that the equipment can actually operate up to $122^{\circ} \mathrm{F}$.

Failure of equipment in rooms is dependent on the length of time that room cooling is unavailable and on the condition of the plant at the time that room cooling is lost. It was stated in the representative CE plants existing PRA that the time before equipment failure ranged from about 45 minutes following a LOCA to as much as 12 hours following a LOOP. More time is available when the plant is in a normal operating condition. Failure times are also dependent on the type of failure that occurs. For example, closure of the HVAC dampers cuts off all airflow into the room. Temperature rise under these conditions will be much more rapid than the temperature rise experienced when cooling water is lost to an ACU but the fan continues to run. Calculations relative to the $D C$ equipment room indicate that it would take up to 24 hours for temperatures to reach the $122^{\circ} \mathrm{F}$ solid-state equipment failure temperature if cooling water fails but the fans continue to run. 


\subsubsection{Control Room HYAC}

The control room HVAC system provides cooling to the control room, control instrumentation cabinets, computer room, and various office spaces in the Control Bullding. The control room HVAC system includes a normally operating system and a two-train essential system. The normal HVAC system includes a normal AHU consisting of a cooling coll and fan. The cooling coll is provided with water from the nonessential WC system to cool the passing air flow. The essential control room HVAC system is provided with two redundant AHUs that are provided with chllled water from the safety-related EC system. Upon receipt of an SIAS, CRVIAS, CREFAS, or LOOP signal, the normal HVAC system is isolated by automatic closure of air-operated dampers, and both essential AHUs are started. A simplified diagram of the control room HVAC system is shown in Appendix D.

System dependencies and interfaces include the following:

- The ESFAS signals normal HVAC isolation dampers to close and starts the essential AHUS.

- Normal AHUs require nonclass $480-V A C$ power to start and run. The essential AHUs require Class $1 E$ 480-V AC power to start and run. Class IE 125-V DC power is required to actuate the isolation damper solenoid values to open or close.

- The normal control room HVAC system AHUs require chilled water from the WC system. The essential AHUs require chilled water from the EC system.

- Instrument air is required for operation of the isolation dampers and to hold open the normal AHU chilled water inlet valves.

The ESF load sequencers were identified as the equipment, cooled by the control room HVAC system, of most concern nelative to extreme temperatures. This equipment was qualified to operate at temperatures up to $120 \circ \mathrm{F}$. The load sequencer cabinets are provided with normally running fans that pull air from the control room into the cabinet to enhance cooling and exhaust air back to the control room atmosphere. Failure of the fans could result in heatup of the electronics and fallure of the load sequencers.

Total failure of the control room HVAC system was stated in the existing PRA to result in ambient temperatures of about $120 \circ \mathrm{F}$ in 15 hours following loss of cooling. The calculations leading to this conclusion were reviewed in this study and judged to provide an adequate basis.

\subsubsection{Class IE 4.16-kV AC Power System (PB)}

The Class 1E 4.16-kV AC power system provides continuous $A C$ power to two divisions of safety-related equipment loads. Power may be received from either the preferred offsite power source or from the EDGs. The PB system 
consists of two separate, redundant, 100\%-capacity Class 1E 4.16-kV buses. These buses are powered from offsite sources through the nonclass $1 E$ power systems (13.8-kV and 4.16-kV systems) via the ESF service transformers. If offsite power is unavallable, each bus is also automatically supplied standby power from its respective EDG. A simplified schematic of the PB system is shown in Appendix D.

These Class 1E loads are supplied by the PB system:

- Motor-driven AFW pump (Train B)

- Essential spray pond pumps

- Containment spray pumps

- High-pressure safety injection pumps

- Low-pressure safety injection pumps

- Essential cooling water pumps

- Essential chiller

Each bus also provides power to three Class $1 E$ load centers per bus (six total) that step power down to $480-V$ AC for smaller loads. This system feeds 480-V AC power to the 480-V AC MCCs described below. The loads on both Class 1E 4.16-kV buses are listed in Appendix D.

The Class IE 480-V AC MCCS are a separate system that distributes $480-V$ $A C$ power from the $480-V$ switchgear system to various valve motors, small fans, battery chargers, voltage regulators, and other small $480-\mathrm{V}$ loads. The $480-V$ power MCC system consists of eight MCCs (four per load group) located in the electrical penetration rooms (6) and the Control Building ESF switchgear rooms (2). The MCCs are metal-enclosed cabinets cooled by air circulated through inlet louvers in the bottom of the cabinet and outlet louvers at or near the top. Fans are provided in some instances to enhance air circulation through the cabinets. The existing PRA stated that room cooling for these cabinets was not needed for the required 24-hour mission time. This assumption is examined further in this study.

The balance of plant (BOP) ESF actuation system (ESFAS) provides automatic sequencing of loads onto the PB buses. Upon loss or degradation of offsite power to either bus, the BOP ESFAS will trip normal and alternate offsite power supply breakers, start onsite EDGs, load-shed the buses, close EDGs output breakers, and sequence safety-related equipment loads back onto the buses.

The PB system is indirectly dependent upon control room HVAC. The BOP ESFAS cabinets are located adjacent to the control room. If control room HVAC 
is lost, the BOP ESFAS cabinets inay overheat and generate spurlous load-shed signals. Problems with the cabinet fans have been experienced in the past, resulting in elevated temperatures in the load sequencer cabinets, which resulted in a continuous load-shed signal being sent to the PB system buses. This effectively rendered one entire train of safety equipment, including HPSI, LPSI, CS, and AFW pumps, inoperable because of the inability to load the equipment onto the bus. Failure of load sequencers is explicitly modeled in the existing PRA as well as in this study.

The 4.16-kV buses were indicated, based on HVAC analyses, to not require room cooling to function properly over the 24-hour misston time required in the existing PRA.

\subsubsection{Standby Generating System}

The Class $1 \mathrm{E}$ standby generating system provides an independent source of onsite electric power for both trains of ESF equipment. This system consists of two EDGs connected to the 4.16-kV buses described in subsection 3.3.2.11. The EDGs are separate from and independent of each other and are capable of providing all needed electrical power to ESF components for at least seven hours. The EDGs are housed in separate rooms in a Seismic Category 1 structure that provides missile and fire protection between rooms to maintain physical separation. The standby generating system is shown in Appendix $D$;

Each EDG room is provided with a once-through ventilation system that is automatically started when the EDGs start. The ventilation system consists of intake and exhaust fans, ductwork, and dampers. The intake fan pulls outside air into the EDG roum through a normally closed damper that must open to permit outside air into tile room. The exhaust fans pull the air past the EDGs and exhaust to the atmosphere to remove heat. The existing PRA assumes that the EDG building HVAC system is not needed to maintain operability over the required seven-hour mission time. However, loss of EDGS HVAC will be considered as a contributor to fallure of the onsite power system in this study due to the rapid heatup rates in these rooms given a loss of cooling. Perhaps as little as 15 minutes following loss of HVAC may be needed to fail the solid state EDG control equipment housed in the room.

The following system dependencies and interfaces are included:

- Class IE 125-V DC power is needed for engine/generator control and for field flashing.

- The EDGs supply 4.16-kV AC power to the ESF PB buses.

- The EDGs are started automatically by the BOP ESFAS on loss or degraded offsite power, AFAS, SIAS, or CAS signals. The EDGs may also be started manually from the control room. 
- The essential spray pond pump is required to provide cooling water to remove heat from the intake air, fuel ofl, jacket water, and lube ofl coolers.

As mentioned above, the existing PRA did not model the EDG room ventilation system. Fallures of this system are considered in this study as potential contributors to fallure of the diesels to run for the required seven-hour period following their actuation.

\subsubsection{Class 1E 125-V DC Power System}

The Class 1E 125-V DC power system provides a source of cont inuous power for the four independent groups of Class IE DC loads and vital inverters. There are four channels of $125-V$ DC power, two associated with each load group, as shown in Appendix $D$. Each channel consists of a battery, a DC control center, and dedicated battery charger, which is located in a separate room. Each DC equipment control center, including the vital inverters and battery chargers, is located in a separate room.

The DC equipment rooms are cooled under normal plant operating conditions by the Auxiliary Bullding normal HVAC system. Under accident conditions, the normal HVAC system is isolated, and the essential HVAC system is started. The equipment most sensitive to high temperatures are the solid state components in battery chargers, vital AC inverters, and backup voltage regulators. Failure temperatures for these components were estimated to be $122^{\circ} \mathrm{F}$ ( see Appendix F).

\subsubsection{Event Tree Analys is}

This section provides an overview of the event tree analys is in the existing PRA and highlights the accident sequences delineated in the event trees that contain room cooler fallure elements. Each event tree defines accident sequences, including an initiating event and failure/success of safety systems and operator actions necessary to respond to the initiating events. The accident sequences may result in core damage or in successful mitigation of the event, depending upon the particular system(s) and operator actions that fail or are successful. The events shown on the event trees roughly correspond to the fault trees described previously.

The representative CE PRA developed a total of ten event trees. These event trees are listed below:

- Small lOCA

- Medium LOCA 
- Large LOCA

- Steam generator tube rupture (SGTR)

- Secondary line break

- Feedwater line break

- Grouped transients

- Loss of MFW/condensate pumps

- Station blackout

- Anticipated transient without SCRAM (ATWS).

These event trees are described in separate subsections. In addition, each subsection briefly describes the accident sequences that may involve room cooler failures, as identified from the fault tree analyses presented previously. Quantification of the accident sequence frequencies involving room cooler fallures is presented in Section 4.0.

In Section 3.3.2, the safety-related systems that exhibit dependencies on HVAC and room cooling functions were identified. This information was used to identify the accident sequences on the event trees that include systems dependent upon room cooling. The dominant cut sets comprising these accident sequences were then identified from the existing PRA, modified as necessary to incorporate room cooling failures, and then quantified. The quantification process is described in Section 4.3.

As discussed above, certain systems were identified in Section 3.3 .2 as exhibiting a dependency on HVAC or room cooling. These systems and the specific dependencies are presented in Table 3.3-1. This table helps to identify the specific room cooling dependencies in the event trees discussed in the following sections.

\subsubsection{Sinall LOCA Event Tree}

The small LOCA event tree shown in Figure 3.3-1 applies to all RCS ruptures inside containment with equivalent break diameters between 0.38 and 3.0 in. Pipe breaks less than 3.0 in. require secondary side cooling, because insufficient water would be passed through the ruptured pipe to remove decay heat. Small LOCA mitigation systems required to operate include reactor protection system (RPS) for reactor trip, HPSI, AFW, and secondary steam removal. HPSR is required once the RWT is depleted. HPSI failure may be compensated for by rapid RCS depressurization and actuation of LPSI. 
IABLE 3.3-1. Safety System Dependencies on Room Cooling

\begin{tabular}{|l|l|}
\hline \multicolumn{1}{|c|}{ Safety-Related System } & \multicolumn{1}{|c|}{ Room Cooling Dependency } \\
\hline High-pressure safety injection & HPSI pump room cooling(a) \\
\hline Low-pressure safety injection & LPSI pump room cooling(a) \\
\hline Containment spray system & CS pump room cooling \\
\hline Auxiliary feedwater system & AFW pump room cooling \\
\hline Standby generating system & Diesel generator room ventilation \\
\hline Essential cooling water system & EW pump room cooling (a) \\
\hline 125-V vital DC power & $\begin{array}{l}\text { ESF switchgear room cool ing, affects } \\
\text { control breaker power to safety-related } \\
\text { pumps and essential HVAC systems }\end{array}$ \\
\hline $\begin{array}{l}\text { Engineered safety features } \\
\text { actuation system (ESFAS) }\end{array}$ & $\begin{array}{l}\text { Control room essential HVAC (cools BOP } \\
\text { ESFAS cabinets) }\end{array}$ \\
\hline 480-V motor control centers & ESF switchgear room cooling \\
\hline $\begin{array}{l}\text { (a) These systems are also indirectly dependent upon control room cooling } \\
\text { that may affect safety system actuation via spurious signals from BOP } \\
\text { ESFAS cabinets and load sequencers. }\end{array}$ \\
\hline
\end{tabular}

There are five core damage sequences shown on the small LOCA event tree

(all sequences include small LOCA initiator):

- Reactor trip failure, HPSI failure (Sequence 9)

- HPSI fallure, depressurization or LPSI failure (Sequence 7)

- HPSI failure, depressurization/LPSI success, LPSR failure (Sequence 6)

- HPSI success, secondary side cooling failure (Sequence 4)

- HPSI success, secondary cooling success, HPSR failure, depressurization/ LPSR failure (Sequence 3).

The remaining sequences represent successful mitigation of a small LOCA.

The events on the Small LOCA event tree that contain HVAC or room cooling elements include HPSI (HPSI pump room cooling), secondary heat removal (room 


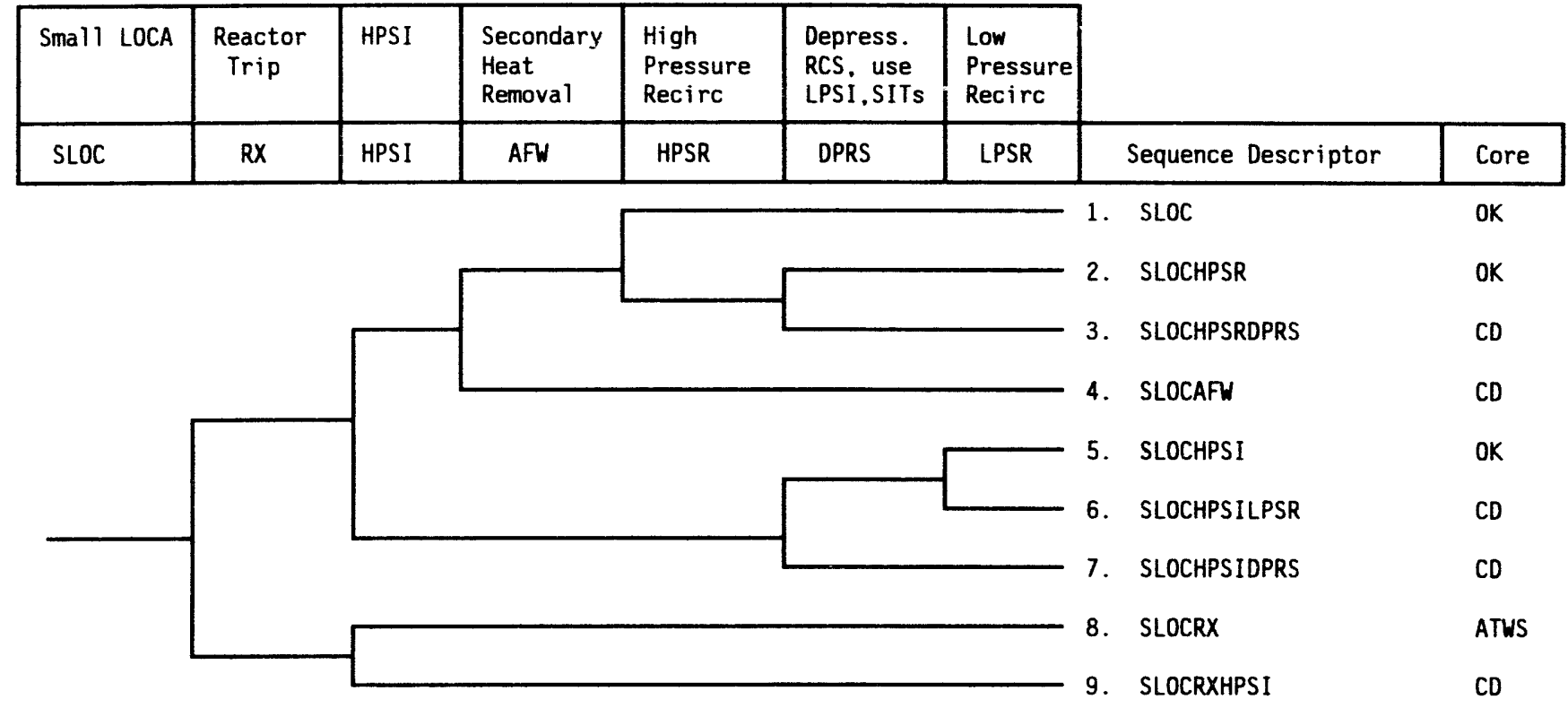

FIGURE 3.3-1. Small LOCA Event Tree 
cooling to AFW pumps), and LPSI/LPSR (LPSI pump room cooling). As a result, Sequences $3,4,6,7$, and 9 contain cut sets that include elements involving room cooler failures.

\subsubsection{Medium LOCA Event Tree}

The medium LOCA is initiated by random RCS pipe breaks with an effective equivalent diameter between 3.0 and 6.0 in. Pipe breaks of this size do not require secondary side cooling, because sufficient water would be passed through the ruptured pipe to remove decay heat. However, RCS pressure does not decrease below the shutoff head of the LPSI pumps for several hundred seconds. The medium LOCA event tree is shown in Figure 3.3-2. Medium LOCA mitigation systems required to operate include

- Reactor protection system (RPS) for reactor trip.

- Safety injection tanks (SITS) (RCS pressure would drop below the SIT setpoint, allowing the SITs to inject borated water into the core).

- HPSI.

- Core heat removal via HPSR (switchover from the RWT to the containment sump for HPSI pump suction is required for long-term core cooling) and containment heat removal via the containment sprays/shutdown coding (SDC) heat exchanger (necessary to reduce containment pressure and cool sump water injected into the RCS for long-term recirculation cooling).

- Hot-leg injection (HLI) via the HPSI pumps is also required to prevent boron precipitation in the core. Operators must open hot-leg injection valves from the control room, per procedure, for successful hot-leg injection.

The four core damage sequences shown on Figure 3.3-2 are

- SIT failure (Sequence 5)

- SIT success, HPSI failure (Sequence 4)

- SIT success, HPSI success, HPSR or CS failure (Sequence 3)

- SIT success, HPSI success, HPSI and CS success, HLI failure (Sequence 2).

Events involving loss of room cooling include HPSI/HPSR and CS failures. These systems contain pumps that are located in rooms provided with essential room coolers. Failure of the room coolers could lead to failure of the safety-related pumps. 


\begin{tabular}{|c|c|c|c|c|c|c|c|}
\hline $\begin{array}{l}\text { Medium } \\
\text { LOCA }\end{array}$ & $\begin{array}{l}\text { Reactor } \\
\text { Trip }\end{array}$ & SITS & HPS I & $\begin{array}{l}\text { Core and } \\
\text { Cont. Heat } \\
\text { Removal (HPSR, } \\
\text { CS and SDHX) }\end{array}$ & $\begin{array}{l}\text { Hot Leg } \\
\text { Injection }\end{array}$ & & \\
\hline MLOC & RX & SITS & HPS I & CLR & HLI & Sequence Descriptor & Core \\
\hline
\end{tabular}

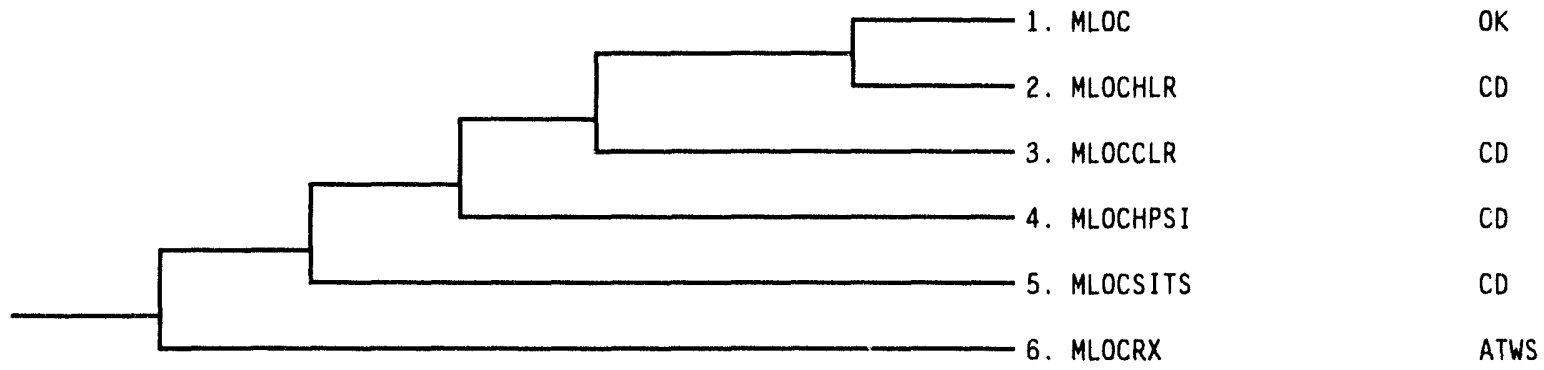

FIGURE 3.3-2. Medium LOCA Event Tree

\subsubsection{Large LOCA Event Tree}

Large LOCAs are defined as RCS ruptures with equivalent break diameters greater than six inches. Blowdown of the RCS occurs in a matter of seconds or minutes, depending on the size and location of the pipe break. The SITs are needed to rapidly refill the reactor vessel. Failure of SITs leads to early core damage. Following successful SIT injection, the LPSI pumps are required to maintain water in the reactor vesse1. The capacities of the HPSI pumps are insufficient to provide injection for large LOCAs. Boron concentrations in the water injected by the SIT and LPSI systems (from the RWT) ensure reactor subcriticality.

The injection phase lasts approximately 20 minutes and is terminated by low water level in the RWT. At this time, an RAS signal is generated that switches HPSI and CS pump suction to the containment sump and stops LPSI pumps. HPSR is required to recirculate water to the RCS while CS is required for containment heat removal (necessary to reduce containment pressure) and, in conjunction with the SDC heat exchanger, provides a sump water heat rejection path for long-term recirculation cooling. In the event that HPSI pumps fail, LPSI pumps may be restarted and aligned to accomplish the same function.

If HPSR and CS are successfuT, HLI via the HPSI pumps is also required to prevent boron precipitation in the core. Operators must open HLI valves from the control room, per procedure, for successful HLI. Failure to establish HLI results in core damage. 
The large LOCA event tree is shown in Figure 3.3-3. The five core damage sequences initiated by large LOCAs are

- SIT failure (Sequence 7)

- SIT success, LPSI failure (Sequence 6)

- SIT success, LPSI success, HPSR or CS failure, LPSR or CS failure (Sequence 5)

- SIT success, LPSI success, HPSR failure, LPSR success, HLI failure (Sequence 4)

- SIT success, LPSI success, HPSR and CS success, HLI failure (Sequence 2).

Large LOCA events that are affected by room cooler failures include HPSI/HPSR, LPSI/LPSR, and CS systems (respective pump room coolers). Failure of the room coolers, if not recovered, will lead to failure of the safetyrelated pump.

\subsubsection{Steam Generator Tube Rupture Event Tree}

The steam generator tube rupture (SGTR) event tree shown in Figure 3.3-4 is initiated by rupture of one or tubes in one SG, causing primary coolant to

\begin{tabular}{|c|c|c|c|c|c|c|c|}
\hline $\begin{array}{l}\text { Large } \\
\text { LOCA }\end{array}$ & $\begin{array}{c}\text { SIT } \\
\text { Cold Legs }\end{array}$ & LPSI & $\begin{array}{l}\text { Core and } \\
\text { Cont. Heat } \\
\text { Removal (HPSR, } \\
\text { CS and SDHX) }\end{array}$ & $\begin{array}{l}\text { Core and } \\
\text { Cont. Heat } \\
\text { Removal (LPSR, } \\
\text { CS and SDHX) }\end{array}$ & $\begin{array}{l}\text { Hot Leg } \\
\text { Injection }\end{array}$ & & \\
\hline LL & SIT & LPSI & HCLR & LCLR & HLR & Sequence Descriptor & Core \\
\hline
\end{tabular}

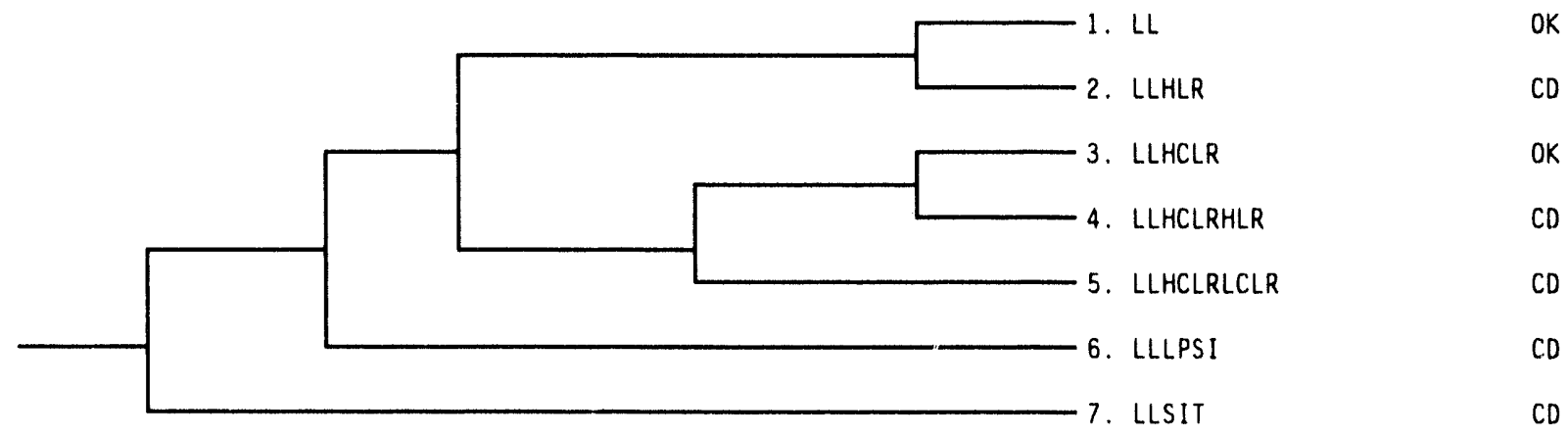

FIGURE 3.3-3. Large LOCA Event Tree 


\begin{tabular}{|c|c|c|c|c|c|c|c|c|c|c|}
\hline $\begin{array}{l}\text { Steam } \\
\text { Generator } \\
\text { Tube } \\
\text { Rupture }\end{array}$ & $\begin{array}{l}\text { Reactor } \\
\text { Trip }\end{array}$ & HPSI & $\begin{array}{l}\text { Secondary } \\
\text { Cool to } \\
\text { Intact } \\
\text { SG }\end{array}$ & $\begin{array}{l}\text { Depres RCS, } \\
\text { Infect with } \\
\text { SITS and } \\
\text { LPSI }\end{array}$ & $\begin{array}{l}\text { Isolate } \\
\text { Ruptured } \\
\text { SG }\end{array}$ & $\begin{array}{l}\text { Depres. to } \\
\text { SDCL Press. } \\
\text { (APSS, PRZ } \\
\text { vent, ADVS. } \\
\text { TBVS) }\end{array}$ & $\begin{array}{l}\text { Shutdown } \\
\text { Cool ing }\end{array}$ & $\begin{array}{c}\text { Refill } \\
\text { RWT }\end{array}$ & & \\
\hline SGTR & RX & HPSI & SG2C & DP1 & LEAK & DEPR & SDCL & RWT & Sequence Descriptor & Core \\
\hline
\end{tabular}

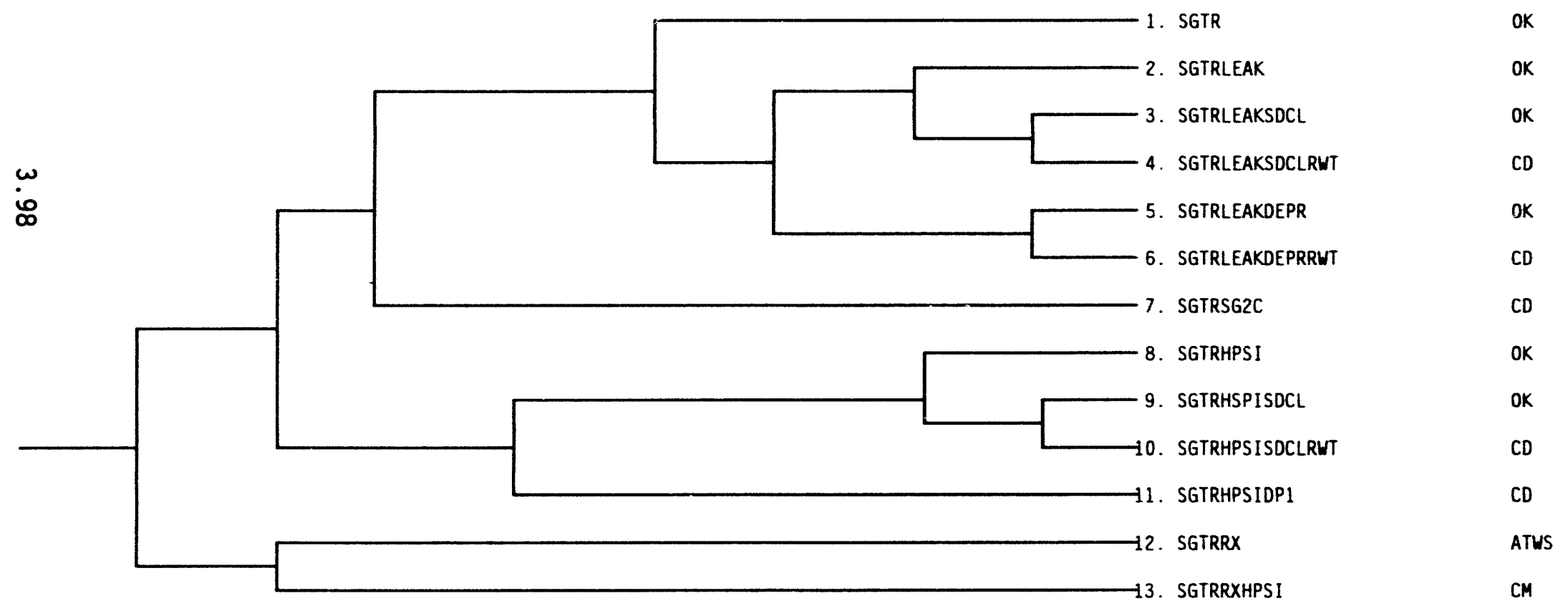

FIGURE 3.3-4. Steam Generator Tube Rupture Fvent Tree 
leak to the secondary side. Complete rupture of a single tube, resulting in a leak rate of $400 \mathrm{gpm}$ into the secondary coolant, was chosen in the existing PRA as the representative SGTR event. This leakage rate is significantly higher than the capacity of the charging system (132 gpm) so RCS inventory will continue to decrease until an automatic reactor trip occurs on low pressurizer level or loss of subcooling.

Followirg the reactor trip, steam flow to the turbine is terminated and turbine bypass valves (TBVs) open to dump steam to the condenser. If TBVs are not available, main steam safety valves (MSSVs) would lift to relieve steam pressure. Operators may also open atmospheric dump valves (ADVs) to relieve steam pressure. Feedwater flow is throttled automatically. If MFW is unavailable, the AFW system is started automatically or manually on low SG level. Alternate feedwater (AltFW) may also be used to cool the intact SG. A SIAS signal would also be generated on low pressurizer level.

Operators would next attempt to isolate the affected SG using radiation alarms on the SG blowdown and main steam line area. Operators must then isolate the affected SG by closing the appropriate ADVs, MSIVs, and MFIVs. Operators must also' c00l down and depressurize the RCS to a pressure slightly above that in the affected SG (minimize primary coolant leakage through the ruptured tube). RCS cooling is provided by the secondary coolant flow through the intact SG. When the reactor is stabilized and the ruptured SG isolated, the RCS will be cooled down to entry conditions for the SDC system for long-term cooling. Operators must monitor the RWT and CST to ensure adequate inventory for the cooldown.

These six core damage sequences were identified on the SGTR event tree (Figure 3.3-4):

- Failure of reactor trip, HPSI failure (Sequence 13)

- HPSI failure, RCS depressurization failure (Sequence 11)

- HPSI failure, success of RCS depressurization with LPSI injection, failure of SDC, failure to refill RWT (Sequence 10)

- HPSI success, failure to cool intact (Sequence 7)

- HPSI success, successful cooling of intact SG, failure to isolate ruptured SG, failure to depressurize to SDC entry conditions, failure to refill RWT (Sequence 4)

- HPSI success, successful cooling of intact SG, failure to isolate ruptured $S G$, successful depressurization to $S D C$ entry conditions, failure of SDC, failure to refill RWT (Sequence 3).

Room cooling failures are associated with events involving LPSI, HPSI, and SDC functions, as well as failure to provide secondary cooling to the intact SG. Room cooling failures are contributors to failures of HPSI, LPSI, and AFW pumps. 


\subsubsection{Secondary Line Break Event Tree}

The large steam (secondary) line break event tree is shown in Figure 3.3-5. This event involves fallure of the steam line from the SG to the turbine. Fallure of this line would result in a rapid steam flowrate out the break and would cause a rapid cooldown of the SGs and RCS, causing a rapid decrease in RCS temperature and pressure and an increase in core reactivity.

Depressurization of the SGs results in closure of the MSIVs, which isolates the SGs from each other, and closes the main feedwater isolation valves (MFIVs). Closure of the MFIVs terminates MFW flow to both SGs. Following MFIV closure, AFW will start when SG levels fall to the low level setpoint. AFW flow will be started to only the intact SG; AFW flow to the affected SG is prevented by the AFAS logic (low pressure in affected SG). Pressure continues to decrease to the SIAS setpoint, at which HPSI is initiated. Failure of HPSI in conjunction with a stuck control rod will lead to recriticality and core damage. If HPSI is successful, borated water is injected into the RCS by the HPSI pumps, ensuring a subcritical condition in the event that a control rod is stuck. Following successful HPSI and secondary cooling actuation, operators initiate plant cooldown through controlling ADVs or by opening MSIS bypass valves in the unaffected steam line.

\begin{tabular}{|c|c|c|c|c|c|c|c|}
\hline $\begin{array}{l}\text { Second- } \\
\text { ary Line } \\
\text { Break }\end{array}$ & $\begin{array}{l}\text { Reactor } \\
\text { Trip }\end{array}$ & $\begin{array}{l}\text { No Stuck } \\
\text { Rod } \\
\text { (Return } \\
\text { to Crit) }\end{array}$ & $\begin{array}{l}\text { Second- } \\
\text { ary } \\
\text { Cool ing } \\
(\text { AFW })\end{array}$ & HPSI & $\begin{array}{l}\text { Secondary } \\
\text { Cooling } \\
\text { (AYtFW) }\end{array}$ & & \\
\hline SSLB & RX & SROD & AFW & HPS I & ALFW & Sequence Descriptor & Core \\
\hline
\end{tabular}

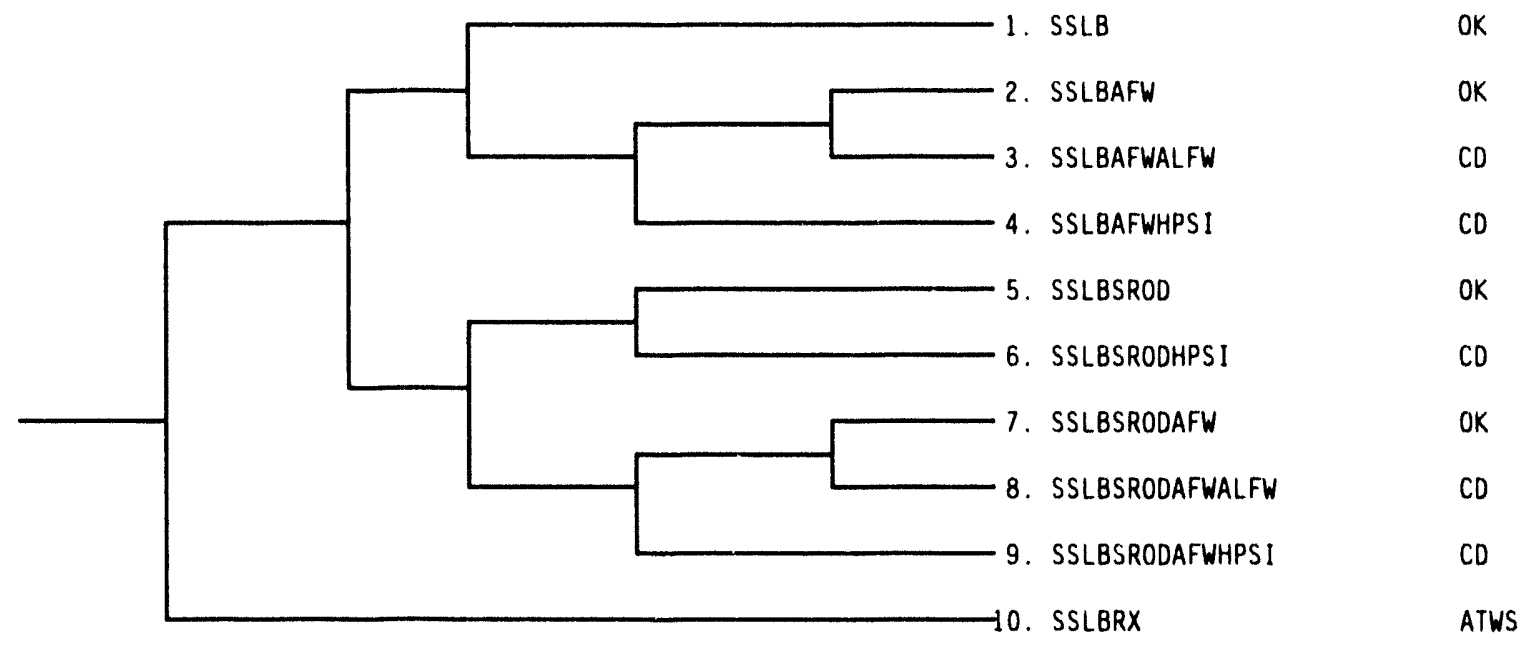

EIGURE 3.3-5. Secondary Line Break Event Tree 
These five core damage sequences are shown in Figure 3.3-5:

- Stuck rod, secondary cooling fallure, HPSI fallure (Sequence 9)

- Stuck rod, secondary cooling fallure, HPSI success, AltFW failure (Sequence 8)

- Stuck rod, secondary cooling success, HPSI failure (Sequence 6)

- No stuck rod, secondary cooling (AFW) failure, HPSI failure (Sequence 4)

- No stuck rod, secondary cooling (AFW) failure, HPSI success, AltFW failure (Sequence 3 ).

Room cooler failures are potential contributors to failure of HPSI pumps and AFW pumps.

\subsubsection{Feedwater Line Break Event Tree}

The event tree for feedwater line break (FLB) initiating events is shown in Figure 3.3-6. This event tree shows the sequence of events following rupture of an economizer line or blowdown line that cannot be isolated fron the SGs. The initiating event would result in rising RCS temperature and pressure, possibly low feedwater system pressure, and decreasing SG water levels. An automatic reactor trip would then occur (high RCS temperature, high pressurizer pressure, high containment pressure, or low SG water level). Containment isolation/safety injection signals are also generated on high containment pressure. Main steam isolation will also occur and the SGs will be isolated from each other. Main steam isolation will also initiate AFW for both SGs. However, the AFAS logic will allow AFW flow to only the intact SG (differential pressure between SGs results in isolation of the low-pressure $S G)$. Failure of secondary side cooling results in core damage.

RCS integrity must also be maintained following this event. Pressurizer safety valves (PSVS) will lift to relieve the RCS pressure transient and must reseat to prevent a Small LOCA. HPSI will be required for inventory makeup in the event that one or more PSVs do not reseat. HPSI failure is assumed to result in core damage. Long-term recirculation cooling requires switchover to HPSR when the RWT becomes empty. Failure of HPSR leads to core damage.

The three core damage sequences for feedwater line break initiating events are then

- AFW failure (Sequence 5) 


\begin{tabular}{|c|c|c|c|c|c|c|c|}
\hline $\begin{array}{l}\text { Fead- } \\
\text { water } \\
\text { Line } \\
\text { Break }\end{array}$ & $\begin{array}{l}\text { Reactor } \\
\text { Trip }\end{array}$ & $\begin{array}{l}\text { Second- } \\
\text { ary } \\
\text { Cooling } \\
\text { (AFW) }\end{array}$ & $\begin{array}{l}\text { RCS in- } \\
\text { tegrity } \\
\text { (No stuck } \\
\text { open PSV) }\end{array}$ & $\begin{array}{c}\text { HPSI } \\
\text { (1/2 pumps, } \\
3 / 4 \text { lines) }\end{array}$ & $\begin{array}{c}\text { HPSR } \\
(1 / 2 \text { pumps } \\
3 / 4 \text { lines })\end{array}$ & & \\
\hline FLB & $R X$ & SGC & RCSI & HPS I & HPSR & Sequence Descriptor & Core \\
\hline
\end{tabular}

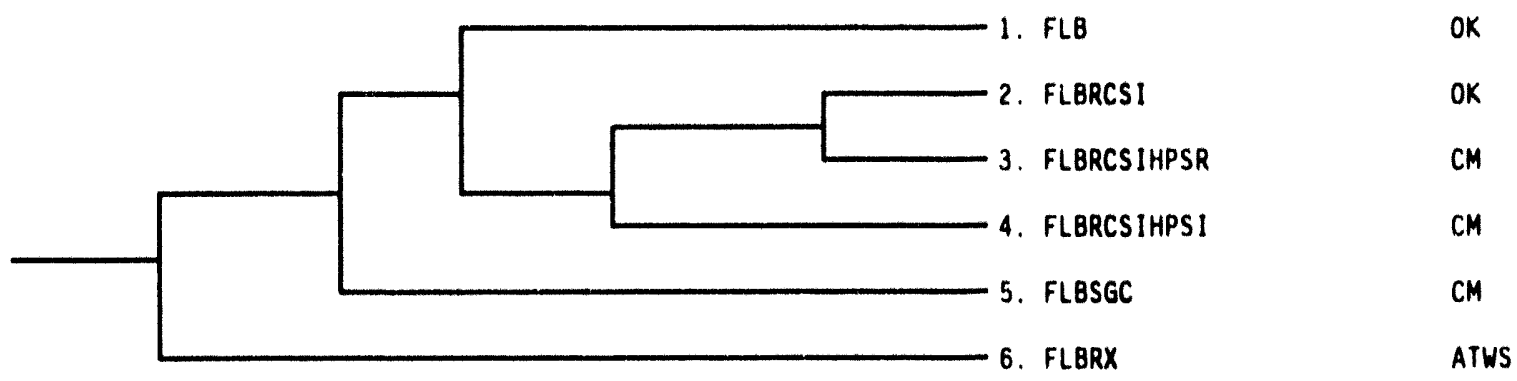

EIGURE 3,3-6. Feedwater Line Break Event Tree

- AFW success, RCS integrity fallure, HPSI failure (Sequence 4)

- AFW success, RCS integrity failure, HPSI success, HPSR failure (Sequence 3 ).

Room cooling failures appear in all three sequences as potential contributors to failure of AFW and HPSI pumps.

\subsubsection{Grouped Transients Event Tree}

Grouped transients are initiating events that result in reactor trip, demand for AFW or AltFW to remove RCS heat, and demand for ADVs, TBVs, or MSSVs to relieve steam pressure. Grouped transients include events such as turbine protective trips, generator protective trips, spurious MSIV closure, control rod drops, RCS parameter perturbations (e.g., reduced RCS flow), loss of instrument air, loss of room cooling systems, and loss of cooling water systems. Initially, these transients only require SG cooling and steam relief for mitigation. The event is terminated when long-term SG cooling and steam relief are established. However, the possibility of induced LOCAs, either through failure of a PSV to reseat or to failure of RCP seals, is also examined. For these types of events, HPSI and HPSR systems are required to prevent core damage.

Failure of RCF shaft seals could occur as a result of certain combinations of loss of seal cooling, loss of seal injection, and operator failure to secure the pumps. Transients that cause a reactor trip and result in loss of RCP seal cooling support systems are the most likely causes of RCP seal LOCAs. Examples include transients that result in loss of nuclear cooling water, loss 
of plant cooling water, LOOP, and SBO. For the three former events, operators may use the EW system as a backup source of RCP seal cooling/injection water.

Three core damage sequences are shown in the grouped transients event tree (Figure 3.3-7):

- Failure of secondary cooling (AFW and AltFW; Sequence 5)

- Successful secondary cooling, fallure of RCS integrity, HPSI failure (Sequence 4)

- Successful secondary cooling, fallure of RCS integrity, HPSI success, HPSR fallure (Sequence 3).

As with many previous event trees, failure of room cooling is a contributor to failure of AFW and HPSI pumps that would render these systems inoperable. Failure of EW pump room cooling could render the backup source of RCP seal cooling/injection water inoperable. No dependencles were identified related to room cooling systems for the nuclear and plant cooling water systems.

Loss of offsite power (LOOP) initiators use the Grouped Transients event tree. LOOP results in loss of forced RCS flow (power lost to RCPs), loss of main condenser vacuum, loss of MFW, and EDG startup. TBVs and AltFW systems are unavailable. The ioss of RCS circulation causes a reactor trip, which decreases overall average RCS temperature and pressurizer pressure. The loss of secondary cooling then causes an increase in primary and secondary system pressures until MSSVs lift to control secondary pressure. Steam generator levels will be decreasing, necessitating a demand for AFW. RCS cooling is

\begin{tabular}{|c|c|c|c|c|c|c|c|}
\hline $\begin{array}{l}\text { Miscellaneous } \\
\text { Reactor Trip } \\
\text { or } \\
\text { Transient }\end{array}$ & $\begin{array}{l}\text { Reactor } \\
\text { Trip }\end{array}$ & $\begin{array}{l}\text { Second- } \\
\text { ary Cool } \\
\text { (AFW or } \\
\text { (AItFW) }\end{array}$ & $\begin{array}{l}\text { RCS integrity } \\
\text { (No RCP Seal } \\
\text { LOCA or stuck } \\
\text { Open PSV }\end{array}$ & HPSI & HPSR & & \\
\hline$R X$ & RXTR & SGC & RCSI & HPSI & HPSR & Sequence Descriptor & Core \\
\hline
\end{tabular}

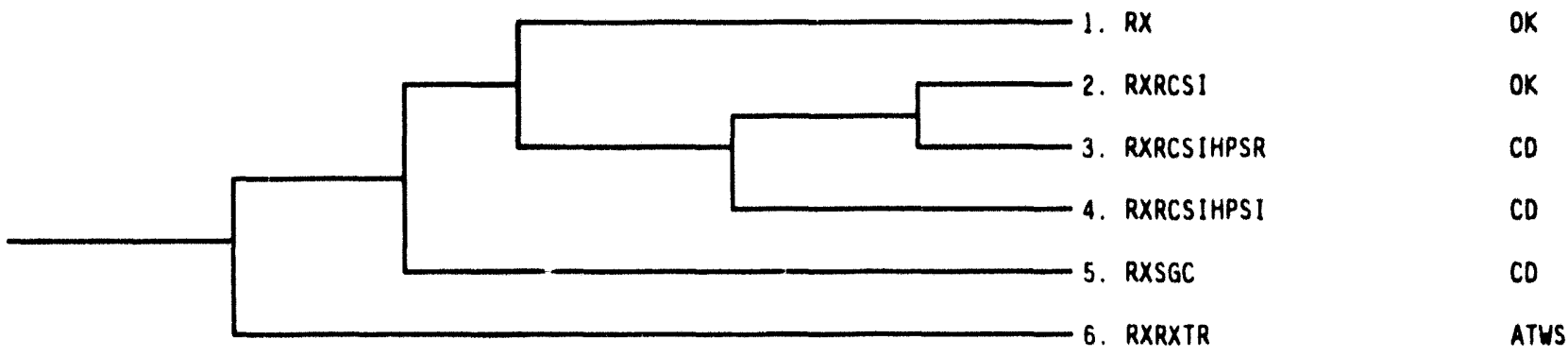

EIGURE 3,3-7. Grouped Transients Event Tree 
then provided by secondary cooling and steam relief through MSSVs. Failure of secondary cooling or fatlure of MSSVs or ADVs results in core damage.

Following successful secondary heat removal, RCS integrity must be maintained to prevent small LOCAs, as with other grouped transients. Normal RCP seal cooling and seal injection are unavallable when offsite power is lost. Operators are required to either restart a charging pump to regain seal injection or to back up nuclear cooling water with EW if RCP seal cooling is lost. HPSI and HPSR are required for inventory makeup.

Diesel generators are actuated on loss of power to the 4.16-kV AC bus. After the diesel generators are up to speed and voltage, the load sequencers will load the ESF buses, providing power to HPSI pumps, motor-driven AFW pumps, EW pumps, spray pond pumps, and MOVs assoclated with each system. The possibility of diesel generator fallure due to fallure of its room ventilation system is examined in this study.

\subsubsection{Less of Main Feedwater/Condensate Pumps Event Tree}

The loss of MFW event tree shown in Figure 3.3-8 may be initiated by any failures that result in loss of all MFW, including loss of all MFW pumps, loss of all condensate pumps, and loss of condenser vacuum. Loss of the former two components sends a trip signal to the MFW pumps. This event is somewhat different than the grouped transients. RCS response following the loss of MFW is as follows. First, SG levels decrease following the loss of MWF to the

\begin{tabular}{|c|c|c|c|c|c|c|c|c|}
\hline $\begin{array}{l}\text { Loss of Main } \\
\text { Feedwater/ } \\
\text { Condensate } \\
\text { Pumps }\end{array}$ & $\begin{array}{l}\text { Reactor } \\
\text { Trip }\end{array}$ & $\begin{array}{l}\text { Second- } \\
\text { ary } \\
\text { Cooling } \\
\text { (AFW) }\end{array}$ & $\begin{array}{l}\text { Secondary } \\
\text { Cooling } \\
\text { (AltFW) }\end{array}$ & $\begin{array}{l}\text { RCS integ- } \\
\text { rity (Pres- } \\
\text { surizer SRV } \\
\text { not Open) }\end{array}$ & HPSI & HPSR & & \\
\hline FW & RX & AFW & ALFW & RCSI & HPSI & HPSR & Sequence Descriptor & Core \\
\hline
\end{tabular}

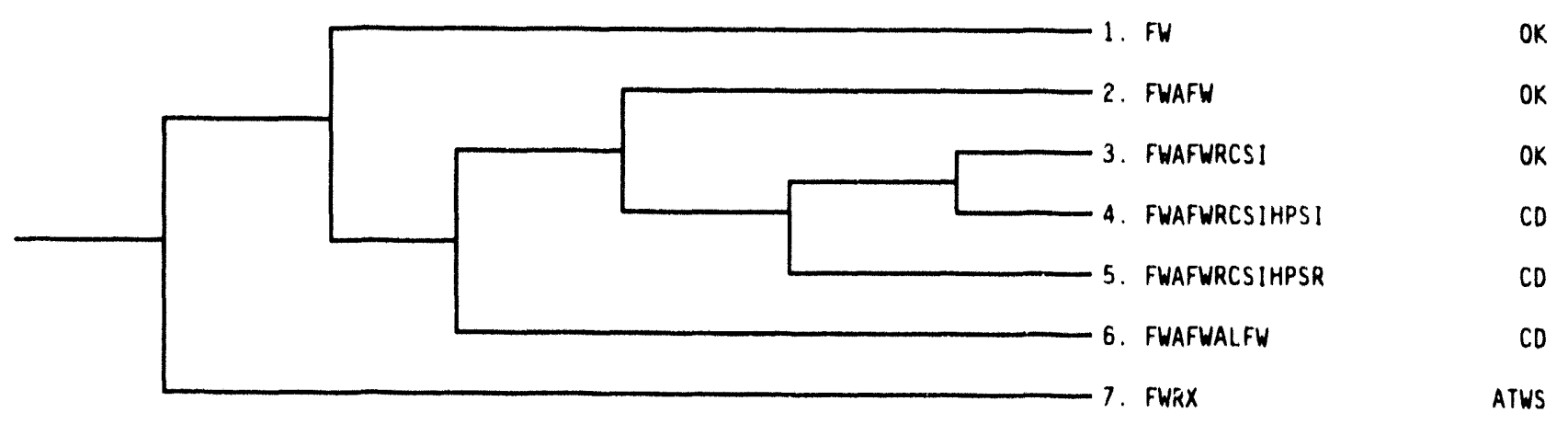

FIGURE 3.3-8. Loss of Main Feedwater/Condensate Pumps Event Tree 
low-level setpoint that trips the reactor. AFW is started to provide secondary cooling to the SGs. If AFW falls, AltFW may be used for secondary heat removal. Fallure of AFW and AltFW results in core damage. However, if AFW falls, RCS pressure will rise to the PSV setpoint before AltFW is aligned, resulting in a possible small LOCA due to stuck open PSV. This requires HPSI and HPSR for mitigation of the induced small LOCA. Failure of HPSI or HPSR following a stuck-open PSV results in core damage.

Figure 3.3-8 shows the three core damage sequences associated with this initiator:

- AFW fallure, AltFW fallure (Sequence 6)

- AFW fallure, AltFW success, RCS integrity fallure (stuck-open PSV), HPSI fallure (Sequence 4)

- AFW fallure, AltFW success, RCS integrity failure (stuck-open PSV), HPSI success, HPSR fallure (Sequence 5).

Room cooling fallures may result in fallure of AFW and HPSI pumps.

\subsubsection{Station Blackout Event Tree}

Station blackout (SBO) results from LOOP and loss of power to the 4.16-kV ESF buses. Loss of the ESF buses may result from failure of EDGs or power distribution equipment. Equipment independent of $A C$ power, including the turbine-driven AFW pumps and MSSVs/ADVs', must be used initially to mitigate this event. The motor-driven AFW pumps, HPSI, LPSI, CS, and essential HVAC systems are unavailable due to the loss of all AC power. Essential spray pond pumps are not available for RCP seal cooling and shutdown decay heat removal. MFW is also unavailable due to loss of power to MFW pumps.

Following the transient, secondary heat removal must be established using the turbine-driven AFW pump to restore RCS heat removal and ADVs for secondary steam removal. Control power to the ADVs is provided by batterypowered vital' $A C$ and $D C$ buses. The batteries can supply power for approximately two hours, so initial plant cooldown can proceed for at least this length of time. Following battery depletion, the ADVs would fail closed and the turbine-driven AFW pump would most likely trip, resulting in SGs boiling dry in about 30 minutes (secondary steam removal via the MSSVs would continue). The RCS would then heat up and the PSVs would ifft to reduce primary system pressure. Core uncovery would occur in the next 30 minutes. Restoration of offsite power within three hours would prevent this sequence from progressing to core damage.

Should the turbine-driven AFW pump fail to delivery secondary coolant to the SGs, offsite power must be restored within one hour to start a motordriven AFW pump and prevent core damage. Failure to restore offsite power within one hour following loss of the turbine-driven AFW pump would lead to core damage. In addition, if offsite power is not restored in time to prevent PSVs from lifting, a small LOCA may result if all PSVs do not reseat. RCP 
seals may also be degraded if offsite power is not restored within two hours (seal cooling and injection are unavallable due to loss of AC power). HPSI and HPSR must be established to prevent core damage, should a stuck-open PSV or RCP seal LOCA occur. Long-term secondary cooling is required even without the occurrence of an induced small LOCA. Fallure of long-term secondary cooling via the AFW system results in core damage.

The Station Blackout event tree is shown in Figure 3.3-9. Eight core damage sequences are presented in the SBO event tree:

- Early AFW fallure, failure to restore offsite power within one hour (Sequence 12)

- Early AFW fallure, successful restoration of offsite power within one hour, RCS integrity fallure, HPSI or HPSR fallure (Sequence 11)

- Early AFW fallure, successful restoration of offsite power within one hour, RCS integrity failure, HPSI and HPSR success, long-term secondary cooling fatlure (Sequence 10)

- Early AFW fallure, successful restoration of offsite power within one hour, RCS integrity maintained (no demand for HPSI or HPSR), long-term secondary cooling fallure (Sequence 8 )

- Early AFW success, fallure to restore offsite power within three hours (Sequence 6)

- Early AFW success, successful restoration of offsite power within three hours, RCS integrity failure, HPSI or HPSR failure (Sequence 5)

- Early AFW success, successful restoration of offsite power within three hours, RCS integrity fallure, HPSI and HPSR success, long-term secondary cooling fallure (Sequence 4)

- Early AFW success, successful restoration of offsite power within three hours, RCS integrity maintained (no demand for HPSI or HPSR), long-term secondary cooling fallure (Sequence 2).

Room cooling dependencies are exhibited in the probabilities of diesel generator fallures, AFW and HPSI pump fallures, and fallure of vital AC and DC buses (which will be accelerated under loss of DC equipment room cooling conditions). 


\begin{tabular}{|c|c|c|c|c|c|c|c|c|c|}
\hline $\begin{array}{l}\text { Station } \\
\text { Blackout }\end{array}$ & $\begin{array}{l}\text { Reactor } \\
\text { Trip }\end{array}$ & $\begin{array}{l}\text { Second- } \\
\text { ary } \\
\text { Cool ing } \\
\text { (AFW } \\
\text { Train A) }\end{array}$ & $\begin{array}{l}\text { Restore } \\
\text { Power } \\
\text { Within } \\
1 \mathrm{hr}\end{array}$ & $\begin{array}{l}\text { Restore } \\
\text { Power } \\
\text { Within } \\
3 \mathrm{hr}\end{array}$ & $\begin{array}{l}\text { RCS } \\
\text { Integrity } \\
\text { (No RCP } \\
\text { Seal LOCA) }\end{array}$ & HPSI/HPSR & $\begin{array}{l}\text { Secondary } \\
\text { Cool ing } \\
\text { Long term } \\
\text { (AFU) }\end{array}$ & & \\
\hline TM & K & LI & B1 & B2 & Q2 & $r$ & L2 & Sequence Descriptor & Core \\
\hline
\end{tabular}

$\stackrel{\omega}{\circ}$

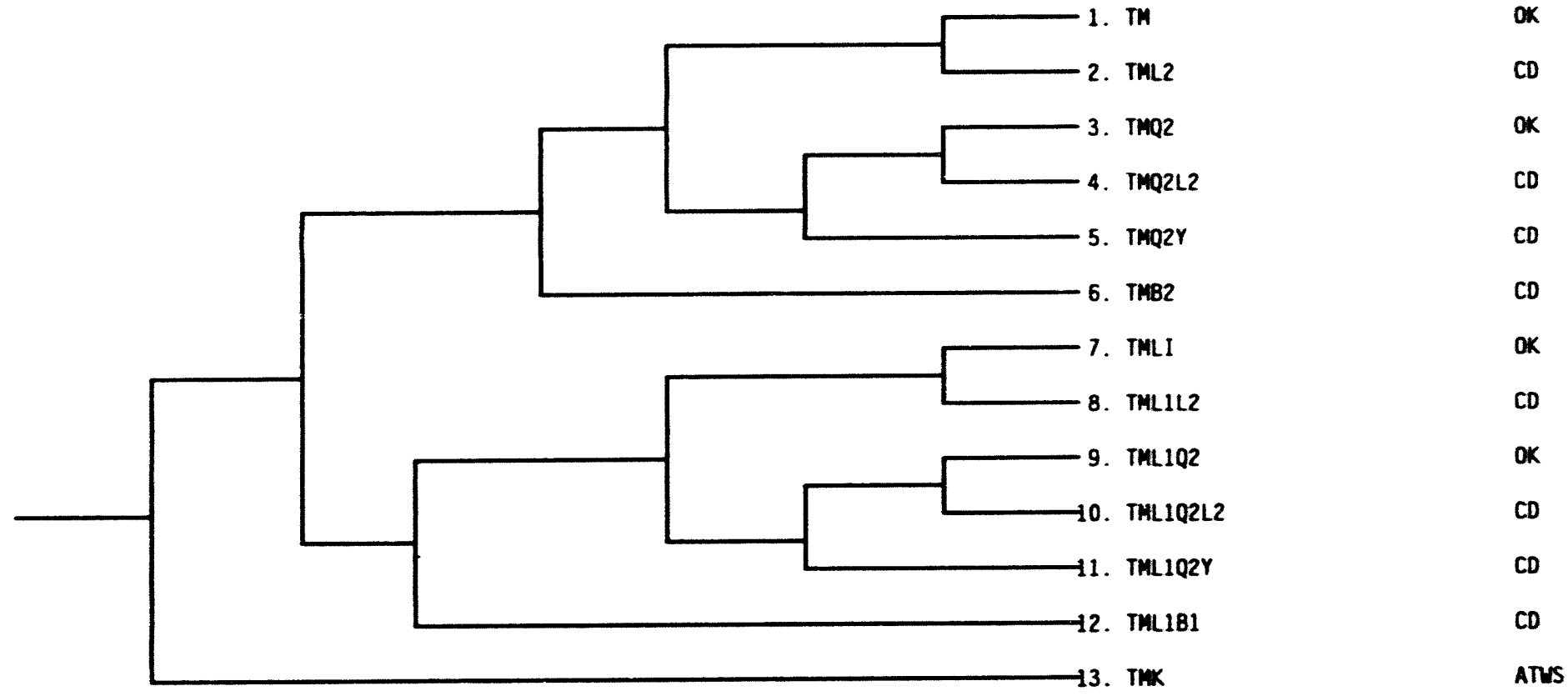

FIGURE 3.3-9. Station Blackout Event Tree 


\subsubsection{Anticipated Transient Without SCRAM Event Tree}

Anticipated transients without SCRAM (ATWS) events are defined as events that cause reactor trip parameters to be reached, followed by a failure to SCRAM the reactor. This results in increasing RCS temperatures, which tend to reduce reactivity, as well as pressure increases that may result in stresses exceeding RCS pressure boundary limits. Boron injection using the charging pumps is required to shut down the reactor and reduce average RCS temperature and pressure

The pressure rise following an ATWS is affected by the following:

- Feedwater must be supplied to SGs to remove decay heat.

- PSVs must open to relieve primary system pressure.

- Under some conditions, the turbine must be tripped to prevent an overcooling transient.

- Moderator temperature coefficient must be negative enough to bring the reactor to a subcritical condition before stress limits are reached.

The ATWS event tree, which contains transfers from the previous event trees in which a transient is followed by failure to SCRAM, is shown in Figure 3.3-10. This event tree contains failure of three reactor trip subsystems, including failure of signals to the reactor trip breakers (may be caused by failure of sensors, signal processors, and RPS output signals), failure of reactor trip breakers (which can be mitigated by manually deenergizing the control element drive mechanism motor-generator set control cabinets), and mechanical failures of the control rods. Deenergizing the control element drive mechanism (CEDM) motor-generator (MG) sets can be done manually from the control room or by deenergizing the appropriate $480-V$ AC buses.

Failure of HVAC and room cooling systems may have positive and negative effects on mitigation of ATWS events. On the positive side, failure of room cooling to the 480-V AC buses may result in a trip of the CEDM MG sets, which will deenergize the control rods. This will effectively trip the reactor unless the control rods are mechanically stuck in the withdrawn position. On the negative side, failure of room cooling to the AFW pump room may cause failure of the pumps and loss of secondary cooling. Failure of HPSI pump room cooling may result in HPSI pump failure and loss of this source of borated water to shut down the reactor.

\subsubsection{Loss of DC Equipment Room HVAC Initiating Event}

Loss of DC equipment room HVAC, including both normal and essential HVAC systems, will result in heatup of the room. The equipment in these rooms includes inverters, battery chargers, and voltage regulators for the Class $1 E$ 125-V DC system and Class IE 120-V AC instrument control system. Eventually, 


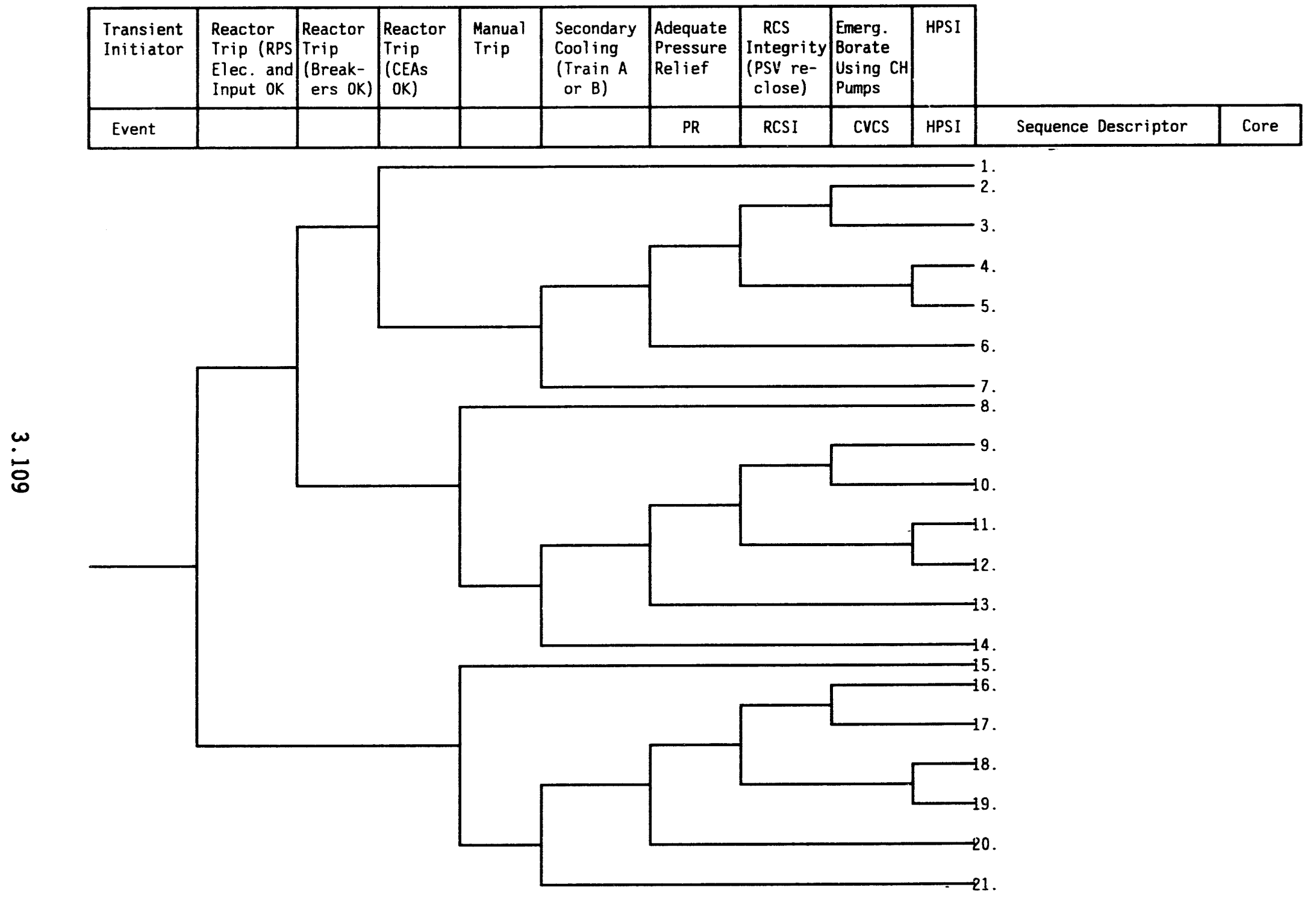

FIGURE 3.3-10. ATWS Event Tree 
room temperatures will exceed the design room temperature of $104^{\circ} \mathrm{F}$, and solid state equipment within the room will begin to fail at approximately $122^{\circ} \mathrm{F}$ (see Appendix F).

This initiating event is complex. The systems that support the $D C$ equipment room HVAC are also the systems that are supported by the equipment in the rooms. In addition, these support systems also support the front-line systems, including ECCS systems, standby AC power, and secondary cooling systems. As a result, failure of DC equipment room HVAC may result in plant conditions requiring reactor trip and may simultaneously fail one or more divisions of ESF components required to mitigate the reactor trip transient. The grouped transients event tree is used to model this initiating event.

An important aspect of this initiator is the time available to provide cooling to the equipment room before failure of the equipment occurs. Room heatup modeling shown in Appendix $F$ indicates the following:

- Assuming all airflow is lost to the DC equipment room, approximately 12 hours are available to restore room cooling. This could happen as a result of spurious actuation of the fire protection system, accidental dropping of HVAC dampers in the supply ducts to the DC equipment room, or loss of the AHU fans. Operators would be made aware of this type of failure via high room temperature or fire protection actuation alarms in the control room. Cooled air may be supplied by opening doors and placing portable fans or blowers in appropriate locations.

- Up to 24 hours may be available to restore room cooling in the event that chilled water is lost to the cooling coils in the essential AHUs. Thus air circulation would be available to remove a portion of the heat generated by the equipment in the room.

Modeling this initiating event closely follows the grouped transients event tree. However, at each node in the event tree, the question must be asked whether the loss of DC equipment room HVAC and failure to restore room cooling has resulted in failure of support systems for ESF components needed to mitigate this transient.

Initial modeling in the existing PRA determined that this event could lead to a significant CDF on the order of 1E-3 per year. The specific sequence of events is as follows:

- Loss of Channel A or B DC equipment room HVAC and failure to restore room cooling fail solid state equipment in the room. This results in a plant trip causing the MSIVs and FWIVs to close, isolating MFW.

- Loss of one channel of DC equipment fails one train of safety-related AFW, one of two trains of ECCS and the EW system. Loss of Channel $A$ fails the turbine-driven AFW pump (Train A). Loss of Channel B DC power fails the Train B motor-driven AFW pump. 
- Loss of Channel A DC equipment fails auxiliary relays that provide control power to solenoids for the downcomer FWIV, which causes the valves to fail closed, effectively isolating the nonclass IE AFW train and AltFW via the condensate pumps.

- Also failed are the diesel generator controls for field flashing, which are needed to start the associated diesel generator.

The outcome of failure of Channel A equipment is that four out of five potential sources of secondary cooling are lost, leaving only the motor-driven AFW pump to provide secondary cooling. Failure of the MDP to provide flow to the SG would result in core damage. Channel B DC power failure is less severe than failure of Channel $A$, because only two of the five potential sources of feedwater are failed. The main difference between the two channels is that the downcomer FWIVs are not powered from Channel $B$ and would remain open following loss of Channel B. This leaves AltFW and the nonclass AFW system available to provide secondary cooling.

The utility has since implemented plant modifications to reduce the CDF associated with loss of DC equipment. These are the following:

- It was observed that the Channel A equipment was loaded more heavily than the other channels. Changes to DC power supplies were implemented for several loads, which increased the reliability of the AFW system. Fewer AFW-related loads are now powered directly from the Channel A DC equipment.

- Train A downcomer isolation valve logic was modified to fail open (rather than fail closed) on loss of Channel A DC power.

- The nonessential AFW pump will be modified to provide DC control power directly from the Channel A battery charger in the event the DC bus fails. A transfer switch located outside the control room will provide this capability.

- All four Class $1 E$ equipment rooms will be provided with high temperature alarms in the control room to alert operators of HVAC failures before room temperatures can degrade equipment.

The existing PRA indicated that these modifications resulted in a decrease in CDF from about $1 E-3$ to the present $9 E-5$ per reactor-year.

\subsubsection{Control Room HVAC Initiating Event}

The control room contains numerous temperature-sensitive components that may result in failure of ESF equipment necessary to mitigate the transient. The control room is cooled by a normally operating HVAC system and is provided with a safety-related essential HVAC system. Failure of both the normal and essential systems, in combination with failure of operators to restore room cooling, could lead to failure of the temperature-sensitive equipment. 
Failure of two cabinets in particular could seriously degrade the plants' ability to mitigate a transient: the two ESF load sequencer cabinets located in a room adjacent to the control room. The load sequencers shed loads on the 4.16-kV AC buses and allow the diesel generator to reach rated speed and voltage before loads are re-applied to the bus. The load sequencers then sequence the ESF loads back onto the buses. A potential failure mode for a load sequencer is for it to send a continuous load-shed signal to the associated ESF bus, effectively preventing loading of the ESF loads onto the bus. Continuous load-shed following a reactor trip can lead to core damage unless the ESF loads can be restored to the bus.

The existing PRA stated that load sequencers will fail when room temperatures exceed $120^{\circ} \mathrm{F}$. This information was derived from vendor-supplied information and appears to be the best available. The following accident scenarios were constructed and appear to the most limiting scenarios for loss of control room cooling:

- Accidental dropping of the HVAC dampers could block all airflow to the control room. Based on thermal calculations, operators would have approximately 12 hours to provide cooling to the room. Operators would be relied upon to detect the temperature increase and implement corrective measures, which may include propping open doors and installing portable fans and blowers to circulate air. The closed dampers could also be opened, but this requires a long time to complete.

- The loss of AHU fans would result in the same loss of airflow to the control rooms as dropping the dampers. Heatup will occur in approximately 15 hours. Recovery actions for this scenario are the same as for dropped dampers.

The CDFs associated with these control room scenarios are included in the quantification process described in Section 4. Response to these scenarios is similar to the response to the grouped transients, except that the dependencies of ESF components on the load sequencers are considered when the cut sets are generated. In other words, assuming control room ventilation is failed and not recovered, potential failure of load sequencers is considered as a means of failing the ESF components needed in response to transients.

\subsection{BABCOCK AND WILCOX PRESSURIZED WATER REACTOR (PWR)}

\subsubsection{Plant and Site Description}

The representative Babcock and Wilcox (B\&W) PWR contains three nuclear power plant units. The nuclear steam supply system (NSSS) for each unit consists of two reactor-coolant-system loops and two once-through steam generators (OTSGs). OTSGs are vertical straight-itube units that produce steam at constant pressure. In commercial operation since 1974, Unit 3, the representative B\&W PWR, produces 2568 MWt full power, generating about 860 MWe. 


\subsubsection{Safety System Description and Systems Analysis}

This section presents a brief description and simplified schematic diagrams of the principal safety systems at the representative B\&W PWR. There are 17 safety systems included in the plant's existing PRA; however, only seven of these systems are affected by this issue.

The following subsections describe the representative plant's safety systems, including dependencies on other systems, and the fault trees for those systems that are related and dependent upon the cooling function. This section focuses on the systems exhibiting some dependency on HVAC/room cooling systems. Additional information, including schematic diagrams of each safety system, is presented in Appendix E.

The safety-related systems identified as having a dependency on HVAC/room cocler systems are listed below:

- Low-pressure injection/recirculation (LPI/R pump room coolers)

- Reactor Building spray system (RBSS pump room cooler)

- Emergency AC power system (Auxiliary Building HVAC)

- Standby shutdown facility (SSF HVAC system)

- Control room.

An important system not 1 isted above is the high pressure injection (HPI) system. Operation of the HPI pumps is independent of HVAC systems because the pumps have been qualified to operate in much higher ambient temperatures than the HPI pumps at the other representative plants. HPI pumps are located in a relatively large room connected to a separate large room outside the HPI pump room through open hatches at either end. This allows air circulation through the HPI pump room, further reducing the need for active room cooling systems. In addition, AFW pumps (referred to as Emergency Feedwater or EFW pumps at the representative B\&W PWR) are located in large, open areas that will not rapidly heat up. Operation of the EFW pumps was judged to be independent of HVAC.

\subsubsection{Low-Pressure Injection/Recirculation System}

The low-pressure injection/recirculation (LPI/R) system is designed to perform both normal and emergency functions in several modes of operation.

Under normal conditions, the most frequently used function is decay-heat removal (DHR), after a shutdown. In this mode of operation, the system removes fission-product decay heat during the later stages of cooldown, after the temperature and pressure of the reactor-coolant system (RCS) have been reduced by heat removal via the SGs. The system is also used to supply water for auxil- 
iary spray to the pressurizer, maintain the proper reactor coolant temperatures for refueling, and provide a means for filling and draining the fueltransfer canal.

The emergency functions are LPI and LPR. In the LPI mode, the system provides two flow paths for injecting borated water from the borated-water storage tank (BWST) into the reactor vessel after a loss-of-coolant accident (LOCA). It is designed to cool the core after the core-flood tanks have exhausted their supp?y of cooling water after a LOCA. In the LPR mode, it also provides two flow paths for recirculating the reactor coolant spilled in a LOCA from the reactor-building emergency sump back to the reactor vessel. The LPR mode can also be coupled with high-pressure pumps to provide HPR capabilities.

A simplified diagram of the LPI system is presented in Appendix E. The LPI system is a high-capacity, low-head system with appropriate separation and a sufficient number of components to provide two-train redundancy for the safeguards mode of operation. It includes three low-pressure centrifugal pumps, of which two, pumps $3 A$ and $3 B$, are normally available and aligned for LPI operation; pump $3 C$ is valved out and would be load-shed. For operation in the DHR mode, the system includes two decay-heat coolers.

Loss of HVAC will have an effect on the LPI/LPR systems. The LPI pumpmotor rooms are cooled by the HVAC system; therefore, the LPI system will fail if HVAC fails.

Separate fault trees, developed for the LPI, LPR, and DHR modes, are shown in Appendix E. Brief summaries of the fault trees and the HVAC/room cooler contributions to these fault trees are provided below.

Low-Pressure Injection. LPI failure, top gate LP-1, represents failure to deliver flow to the core-flooding nozzles from one of two LPI trains. The fault trees for each train, top gates LP-3 and LP-4, are essentially identical. Top event LP-1 is an OR gate and has two inputs:

- Failure to deliver flow from one of two LPI trains

- LPI system failure through human error.

The latter event is a basic event named LPABH and represents a human interaction whereby the operator inhibits the entire LPI system.

The failure of a single train will occur if the pump in that train fails to start or fails to continue running for the LPI mode; or if any valve in the flow path from the BWST to the reactor vessel fails to open, was left in the closed position after maintenance or testing, or was inadvertently closed and not reopened. In addition, if valves $3 L P-41,3 L P-42$, and $3 L P-40$ in Train $A$ were all left in the open position after testing or maintenance, the diversion of this flow from the main flow path back to the BWST was considered a failure of Train A. For Train B, failure would result from leaving valve $3 L P-40$ in 
the open position. For certain types of fallures, success for Trains $A$ or $B$ could be achieved by using one of the other LPI pumps and opening the necessary crossover valves, $3 L P-9$ and $3 L P-10$.

For injection, the BWST suction source is the same for HPI and requires the BWST development, while the reactor-building spray pumps may be able to draw suction from the discharge side of the LPI pumps.

Low-Pressure Recirculation. LPR failure, top gate LP-60 in Appendix E, represents failure to deliver recirculated coolant to the core-flooding nozzles from one of two LPR trains. As in low-pressure injection, the fault trees for each train, gates LP-216 and LP-217, are essentially identical. Moreover, the fault tree for LPR is similar to that for LPI, but it includes the following additional failures:

- Failure to provide low-pressure service water to a DHR cooler was considered a failure of the corresponding LPR train when the cooling was included in the success requirements.

- A failure of the DHR-cooler bypass valve (LP-93, LP-92) in the open position was considered a failure of the corresponding LPR train when cooling of the recirculation water was required.

- Failure to manually realign suction from the BWST to the Reactor Building emergency sump was considered a failure of the train in which this failure occurred. Using Train A as an example, failure to open $3 L P-19$ would be a failure to realign Train A for recirculation. The decision to initiate recirculation is included in the top logic for the event trees.

- If the LPI pumps were intentionally stopped during the injection mode to prevent overheating, failure to manually restart these pumps in the recirculation mode would be a failure of the train in which this occurred.

Other LPI/LPR Model Developments. The Reactor Building spray system interfaces with the LPI system. The fault-tree developments needed to support the spray fault tree are illustrated in Appendix E. Gate LP-50 and LP-51 support the spray-injection mode. Gates LP-88 and LP-9L are used when cooling of the spray water in the decay-heat coolers is require. Finally, gates LP-901 and LP-902 describe system operation when direct cooling of the spray water is not required.

Decay-heat removal requires operator action to manually start the LPI pumps and open the appropriate valves to enter this mode of operation. Failure to open either valve $3 L P-1,3 L P-2$, or $3 L P-3$ in the reactor-coolant outlet line would prevent entering the DHR mode. These failures, along with failure to provide coolant to the core-flooding nozzles as modeled in the LPR tree, were included in the DHR top event for SGTR. 


\subsubsection{High-Pressure Injection/Recirculation Systems}

The high-pressure injection (HPI) system performs three functions that are important with respect to the event sequences of interest in evaluating the likel thood of core melt. The normal makeup/letdown system (MU/LDS), a portion of the HPI system, maintains the volume of the RCS within acceptable limits during most modes of plant operation. It also recirculates reactor coolant for purification; addition of chemicals for the control of RCS corrosion; and control of soluble-boron concentration for long-term reactivity contro1. The MU/LDS function, which is described here and for which a faulttree model was constructed, is that of maintaining sufficient RCS volume for transient events. RCP seal cooling is provided by the seal-injection portion of the HPI system operating with the component cooling system (CCS). These seals serve to prevent the leakage of reactor coolant between the shaft and the housing of the RCPs, and when the RCS is at a high temperature the seals must be cooled to keep them from warping; to keep the seal faces from becoming cracked or eroded; and to prevent the 0-rings from extruding. The interruption of cooling flow can result in seal damage, leading to increased RCS leakage or small-break LOCA conditions. Most important, the HPI system is designed to provide a high-pressure flow of water to maintain a adequate inventory in the RCS after small-break LOCAs and can be used to remove heat from the reactor core should the normal path of heat removal, through the SGs, not be available.

The HPI system consists of three motor-driven, high-pressure centrifugal pumps, with two primary suction and discharge paths. The system configuration is shown in Appendix E. The design features relevant to each of the system's three functions are described below in more detail.

Makeup/Leitown System. The makeup function is achieved primarily by a portion of the HPI system and the coolant storage and chemical addition systems. Makeup flow is supplied by either pump HP-P3A or HP-P3B and is controlled automatically to balance normal leakage. Letdown flow from the RCS accommodates small increases in RCS volume due to inleakage from the seals of the RCPS and variations in RCS temperature. A diagram of the letdown and suction supply portions of the MU/LDS is provided in Appendix E.

RCP Seal Cooling Systems. Seal-injection flow is provided by the HPI pump that is operating to supply normal RCS makeup. A simplified flow diagram of the seal injection and return portion of the HPI system is presented in Appendix E. The injection flow is controlled by air-operated valve 3HP-31. It enters each RCP at the face of the lower seal and then separates such that some flow passes to the upper seal chamber while the remainder flows downward across a recirculation device and into the RCS. Approximately $40 \mathrm{gpm}$ is circulated through the lower seal chamber and an external heat exchanger, where heat is rejected to the CCS. This configuration is illustrated for a typical RCP in Appendix E. The portion of the seal-injection flow that does not leak into the RCS is returned to the letdown storage tank (LDST) after being cooled by one of the two heat exchangers. 
The configuration of the CCS is shown in Appendix E. The CCS operates continuously to supply cooling flow to several components inside the Reactor Building in addition to the RCP seal heat exchangers. It is a closed-loop system with two electric pumps, one of which is normally operating. The pumps are interlocked: one starts if the other trips. The two pumps are also interlocked with containment-isolation valves $3 C C-7$ and $3 C C-8$ so that they trip if these valves are closed. The valves are closed upon actuation of engineered safeguards channels 5 and 6 , respectively, on high containment pressure. Cqoling for the $C C$ flow is provided by the flow of low-pressure service water (LPSW) through one of two parallel heat exchangers.

Emergency Injection Mode of the HPI System. The HPI system provides emergency core cooling in the event of a small-break LOCA, and it also provides an alternative means of core heat removal if the ability to cool via the steam generators is lost. The initiation of the HPI system requires the opening of at least one of the suction valves, $3 H P-24$ and $3 H P-25$, that isolate the HPI pumps from the emergency suction source, the BWST. All three pumps receive actuation signals on low RCS pressure and/or high Reactor Butlding pressure, although the signal is only confirmatory for the normally operating pump. Discharge valves 3HP-26 and $3 \mathrm{HP}-27$ also receive signals to open, although valve $3 \mathrm{HP}-27$ is normally left open. For most event sequences, flow from one pump is sufficient; for special cases, two pumps may be required to function. The HPIS is capable of supplying flow at a relatively high RCS pressure, with a shutoff head of 2900 psig.

The HPI and CC systems are designed to operate without support from any of the plant HVAC systems. The utility indicated that pump motor cooling was all that was required to ensure pump operability. The HPSI pumps are qualified to operate in much higher ambient temperature conditions $\left(212^{\circ} \mathrm{F}\right)$ than most other plants' ESF pumps (104 to 120\% F).

The existing PRA constructed and discussed a fault tree for each mode of operation of interest. The following fault trees are analyzed in the PRA:

- Makeup/letdown system fault tree

- Cooling systems for RCP seals fault tree

- High-pressure injection fault tree

- Success criterion of two of three pumps fault tree.

The fault trees listed above are not interfaced with HVAC systems; therefore, modifications were made to the minimal cut sets from the existing PRA to incorporate potential failures of room cooling functions.

High-Pressure Recirculation (HPR). The HPR mode is designed to be initiated on depletion of the BWST supply if no other form of core-heat removal has been established. HPR is initiated by opening the two Reactor 
Building emergency sump valves (valves 3 LP-19 and 3 LP-20), starting at least one LPI pump, closing valves $3 L P-21$ and $3 L P-22$ from the BWST, and opening valves $3 L P-15$ and $3 L P-16$ to the suction of the HPI pumps.

The recirculation mode is designed the same as the injection mode, but instead of using the BWST as the suction source, it is provided by the LPI system. As discussed before, HVAC fallure will cause LPI system fallures; therefore, HPR will fall if LPI pump room cooling is unsuccessful.

The failure of HPR was modeled as shown in Appendix $E$. The failure modes are nearly identical to those for HPI, except that suction flow to the HPI pumps must be provided from the LPI pumps.

\subsubsection{Reactor Butlding Spray System}

The Reactor Building spray system (RBSS) is designed to cool the atmosphere of the Reactor Building (RB) after an accident, thereby maintaining peak pressure below the RB design pressure and eventually reducing the pressure to nearly atmospheric. Together with the Reactor Building cooling system (RBCS) the sprays provide a redundant and diverse means of RB pressure reduction. The RBSS is an engineered safeguards sy'stem and performs no normal operating function.

The RBSS, shown in Appendix E, is a once-through, two-train system taking suction from the LPI system suction header and discharging into the RB atmosphere. The RBSS operates during both the injection and the recirculation modes of LPI system operation. It sprays borated water into the RB atmosphere to remove post-accident energy from the atmosphere and transfer the energy through the decay-heat coolers to the low-pressure service-water (LPSW) system.

Each of the independent RBSS trains consists of a pump, a discharge header, spray headers, associated piping, valves, instrumentation, and controls. The RBSS pumps take suction from the LPI system headers upstream of the LPI pumps: pump A from the header of LPI system Train A and pump B from the header of LPI system Train B. During the injection mode, the LPI suction headers are aligned to the BWST; during the recirculation mode, they are aligned to the RB emergency sump. The RBSS pumps are capable of taking suction from either source without the LPI pumps running. From the LPI suction header, the borated water passes through a 10-inch RBSS suction header to the RBSS pump. Each RBSS suction line contains a check valve and a normally open motor-discharge header into the Reactor Building. The discharge header contains a check valve, a ocked-open manual valve, and a normally closed MOV that is automatically upened when the RBSS is initiated.

The RBSS pumps and MOVs require AC power from the emergency electrical power supply system. The engineered safeguards (ES) activation system supplies signals to the pumps and the MOVs on the discharge headers. The pump motors are air-cooled and required AHUs located in the pump rooms for longterm operation. The RBSS requires the LPI suction headers as a water source. 
Therefore, fallure of LPI will cause RBSS to fatl to function, because the LPI pumps requitre room cooling in order to operate successfully. Hence, the RBSS is dependent upon successful operation of the LPI pump room cooler system.

Three fault trees were developed for the RBSS, one for the injection mode and two for the recirculation mode. The detalled fault tree shown in Appendix $E$ include the recirculation mode fault tree and the injection mode fault tree.

The top event of the fault trees is the fallure of one of the two RBSS trains to operate. This corresponds to a loss of flow through both the $A$ and $B$ train spray headers, nodes $J$ and $A$, respectively, in Appendix $E$. Note that loss of flow into the pump-suction nodes, $C$ and $L$, is treated as a transfer to the LFI fault trees.

\subsubsection{Reactor Building Cooling System}

The Reactor Building cooling system (RBCS) is used to remove heat form the atmosphere of the RB. During normal operation, the RBCS serves as the principal means of controlling the temperature of the RB atmosphere. In an accident resulting in a failure of the reactor-coolant-system pressure boundary, the RBCS provides protection for the integrity of the RB. It cools the post-accident RB atmosphere, condensing steam, and reduces an overpressurization challenge to the RB structure.

Post-accident RB integrity protection is also provided by the RBSS. Together the RBCS and the RBSS provide redundant and diverse means of postaccident. RB pressure control.

The RBCS consists of three fan-and-cooler assemblies and the associated distribution-duct network. The RBCS fans are two-speed air-cooler fans, each drawing air from the upper half of the RB atmosphere and pushing it through an air cooler. The RBCS coolers are air-to-water heat exchangers, with LPSW serving as the tube-side coolant. The LPSW system piping associated with the RBCS is schematically diagrammed in Appendix $E$. The remainder of the RBCS consists of a two-train distribution-duct network. The ducting directs the cooled-air flow from each fan-and-cooler assembly, through an electric-motoroperated flow damper into a common header, and then into each of the SG cavities of the containment and also into the reactor vessel cavity.

The RBCS fans, coolers and LPSW valves are designed to operate in the post-accident containment atmosphere; they do not require HVAC.

The existing PRA developed one fault tree for the RBCS with the top event "3 RBC units fail to provide RB cooling." Because the RBCS is not dependent upon HVAC systems, the RBCS fault tree is not addressed.

\subsubsection{Emergency Feedwater System}

The emergency feedwater (EFW) system is used to supply feedwater to the SGs when the MFW system is not available. The function of the EFW system is 
to remove energy stored in the core and primary coolant. The EFW system provides a sufficient secondary-side SG heat sink for cooling down the reactor-coolant system (RCS) from a reactor trip at power operction to conditions at which the low-pressure decay-heat removal system may be ut 111 zed (i.e., 350 psia and $250^{\circ} \mathrm{F}$ ).

The EFW system is diagrammed in Appendix E. It takes suction from either the upper surge tanks (USTS) or the condenser hotwell and delivers flow to both SGs through the EFW nozzles. The EFW system is equipped with three pumps: two MDPs powered by the emergency $A C$ power system and one steam-driven pump supplied from both the main and auxilitary steam systems. The primary sources of water for the EFW system are the upper surge tanks-two 36,000gallon tanks valved together to make one 72,000-gallon tank. The condenser hotwell can also serve as the source of suction to the EFW pumps and has a 142,000-gallon capacity. To take suction from the hotwell with the MDPs, the condenser vacuum must be broken, because a net positive suction head (NPSH) must be established. The steam-driven pump takes suction from the bottom of the hotwel1. Vacuum does not need to be broken to operate the steam-driven pump when aligned to the hotwell.

The EFW system mechanical components are designed to operate without support from the HVAC system. EFW pumps are located in open areas in the lower level of the Turbine Building. A large open area allows for effective dissipation of heat generated during pump operation.

The existing PRA developed a fault tree for the EFW system with the top level of the fault tree being the fallure of both EFW headers to deliver flow to the SGs. Because the EFW system is not dependent upon HVAC system for successful long-term operation, the fault troe is not addressed in this study.

\subsubsection{Engineered Safequards System}

The engineered safeguards (ES) system is designed to detect failures in the integrity of the reactor-coolant system (RCS) and to provide digital trip signals that initiate automatic protective actions in the event of such failures.

The ES-actuated plant-protection systems provide the following function:

- Removal of decay heat from the core

- Protection of Reactor Building (RB) integrity

- Removal of radionuclides from the atmosphere of the RB and from any air leaking from the RB.

The first function is provided by the HPI and/or LPI systems; the second via RB isolation in conjunction with the RBCS or RBSS systems. The third ES-actuated function is provided by the RB penetration-room ventilation system. 
A general schematic diagram of the ES system is provided in Appendix E. As shown in the diagram, the ES system consists of two major subsystems, analog and digital. The analog subsystem consists of three redundant channels, designated A, B, and C. Each channel continuously monitors RCS and RB pressure. If either is observed to deviate from a preselected pressure setpoint, the channel that is associated with that setpoint is designed to trip. The trip signal from an analog channel is transmitted to the digital channel assoclated with the particular pressure parameter. In the digital channel, the trip signals from the three analog channels are combined in a 2-of-3 logic configuration to trip that digital channel.

This system is located within the control room and the control room cooling function is not discussed in the existing PRA. This dependency will be modeled in the CDF calculations (see Section 4).

The existing PRA developed several fault trees for the ES system. Each top gate represents a failure of ES to accurate a specific valve, pump, or other piece of plant safety equipment. Because the fault trees were modeled without HVAC failure they are not shown here. However, as mentioned previously, the dependency of the ES system on control room cooling will be modeled in the CDF quantification process.

\subsubsection{The AC Power System}

The AC power system supplies electric power to the plant's external power grid during normal operation and to the unit auxiliaries under normal and accident conditions.

The representative B\&W PWR's AC power system is an interconnected set of several subsystems. In addition to the three 850-MWe generators at the site, and the external power grid, it contains the following subsystems:

- The 230- and 525-kV switchyards.

- The auxiliary electric power systems, including the main transformer (T3), the auxiliary transformer (3T), the startup transformer (CT3), the emergency power underground transformer (CT4), and a 100-kV transformer (CT5).

- Emergency $A C$ power from a nearby hydropower station.

- Two combustion turbines at a nearby power station, the associated transmission line, and a $100-k V$ switchyard.

The layout of the $A C$ power system, including a simplified schematic and oneline diagram, is presented in Appendix E.

The external grid consists of 230-, 525-, and 100-kV transmission lines and their interconnections with the remainder of the utility's system or other 
interconnected systems. During normal operation, the units supply power to this external power grid. When the units are not operating, the external grid may supply power to the unit auxiliary electrical loads.

The unit generators are connected to the external power grid through their respective main step-up transformers, and the 230- and 525-kV switchyards at the site.

The AC power system is the one used in normal operation. It supports other plant systems under both normal and accident conditions and is, in turn, supported by the DC power system and the ES system. The systems supported by $A C$ power include the HVAC system and the safety-related pump room coolers.

HVAC fan motors require DC power to operate. Power for Train A fan motors is supplied by 208-V MCC $3 \times L$ bus, and power for Train B fan motors is supplied by 208-V MCC $3 \times N$ bus. Loss of power from both of these buses will cause the HVAC system to fail.

The effect of HVAC failure on the operability of AC power is not addressed in the existing PRA. However, as discussed for the other representative plants, HVAC and room cooling systems are needed to support operation of MCCs that supply power to small fan motors and to the 4.16-kV AC power system that provides power to the ESF pump motors.

The fault tree models for 208-V MCC 3XL and 208-V MCC 3 XN bus failure are shown in Appendix $E$. As shown, no dependencies on HVAC or room cooler systems are modeled in the fault tree. These dependencies will be included in the CDF calculations in Section 4.

\subsubsection{DC Power System}

The representative B\&W PWR is provided with two separate DC power systems. One is the 125-V DC vital instrumentation and control (I\&C) power system; the other is a separate $125 / 250-V$ DC station power system that supplies large power loads. In addition to the DC power systems associated with the site, there are the 125-V DC switching power system for the 230- and 525KV switchyards and a 125-V DC station power system for each of the two emergency power units.

The $125-V$ DC vital I\&C power system, the $120-V$ vital AC I\&C power system, the $120-V A C$ integrated control system (ICS) power system, and the 240/120-V AC computer-power system were examined in this study and are collectively called the $D C$ power system in the remainder of the discussion. The 120-V AC auxiliary power panelboard $(K X)$, which is not required to support any of the systems that were modeled, was excluded from this analysis. A portion of the 240/120-V AC regulated-power system is also included in the analysis because it provides an interface between the $D C$ power system and the $600-V$ auxiliary power system.

The DC power system, shown in Appendix $E$, consists of two distribution centers, two control-power batteries, three control-power battery chargers, 
four vital DC power panelboards, four vital AC power panelboards, an ICS power panelboard, and a computer-power panelboard. The typical schematic component chain is shown for Channel A; Channels B, C, and D are identical. The vital power systems provide continuous power for safety-related control and instrumentation required for the startup, normal operation, and orderly shutdown of the plant.

Loss of HVAC will have an effect on the DC power system. High temperatures can be responsible for common-cause failures of inverters, chargers, and breakers in the cable rooms and equipment rooms. However, the existing PRA does not consider this effect and does not discuss HVAC failures in the DC power sec ion. This dependency will be added to the DC power system models in this study.

\subsubsection{Service Water Systems}

Service-water systems are used to remove waste heat generated in the plant. The specific needs for service water as a support system are identified at the component level in the fault trees of other systems.

Service water is supplied by four systems: 1) the low-pressure service water (LPSW) system, 2) the condenser circulating-water (CCW) system, 3) the high-pressure service-water (HPSW) system, and 4) the recirculating cooling water (RCW) system.

The LPSW system supplies cooling for many emergency and nonemergency needs throughout the plant. The important functions of this system include the following:

- Cooling the motors of electric EFW pumps.

- Cooling the turbines and bearing oil of the steam-driven EFW pumps.

- Cooling the motors of HPI pumps.

- Decay-heat removal through the heat exchangers of the LPI system.

- Supplying the ventilation cooling units of the RB.

- Cooling the motors of reactor-coolant pumps.

- Supplying the ventilation units for the Auxiliary Building and LPI pump room.

The condenser circulating-water system supplies the large-volume cooling required by the main condensers for the normal operation of the turbine. Additional loads are also attached to the condenser circulating water, the most important being the oil cooler of the steam-driven EFW pump and the. suction source for the LPSW and HPSW systems. 
The HPSW system supplies fire-protection systems throughout the plant. The system is also available as a backup source for LPSW if all LPSW pumping capability is lost.

The RCW system services the seal-return coolers of the reactor-coolant pumps (RCPs) and the spent-fuel cooling system.

Diagrams in Appendix $E$ show the relationships among the various servicewater systems. The LPSW was identified as being the most important with respect to safety and, in addition, it is the only system related to the HVAC/room cooler systems. Hence, only the LPSW system will be discussed in more detail.

The LPSW system for Unit 3 is shown in Appendix E. Two 15,000-gpm pumps take suction from the CCW crossover. Because of the large volume of water available in the crossover lines, CCW flow is not required to maintain suction. The LPSW flow is delivered to the loads through two main headers, $A$, and $B$. The headers are normally cross-connected through normally open valve LPSW-132. Either pump is sufficient to supply loads during normal or emergency conditions. The pumps are fitted with suction strainers and a backwash header for cleaning the strainers.

The LPSW flow for the AHUS 3-1 and 3-2 is obtained from header B as indicated in 'Appendix E. These AHUs are required to provide cooling for the LPI pump room.

The LPSW system operates without support from HVAC, but cooling to AHUs $3-1$ and 3-2 of the HVAC system is provided from header B of the LPSW system. Therefore, service water system failure has an effect on the room cooling to the LPI pump room cooling.

HVAC requires LPSW from header $B$. Therefore, Gate SW16, "No flow from LPSW header $B$," developed in the existing PRA, is included in Appendix $E$ to provide more detail.

\subsubsection{Standby Shutdown Facility}

The standby shutdown facility (SSF) is a separate, bunkered installation that is constructed to provide a secure means for attaining and maintaining a hot shutdown condition in all three units. The SSF was designed principaliy to provide core cooling for incidents of industrial sabotage, fires, and flooding.

The SSF consists of two systems: the SSF auxiliary service-water (ASW) system, which provides a backup supply of water to the steam generators, and the reactor coolant volume control system (RCVCS, also referred to as the reactor coolant makeup (RCM) system), which is designed to maintain sufficient inventory in the reactor coolant system to sustain natural circulation. All electrically operated equipment in the SSF can be powered from plant ES buses backed up by a diesel generator in the SSF. 
The RCM system consists of three equipment trains, each housed within the reactor building of the unit being served and powered and controlled through the SSF. Diagrams in Appendix E illustrate the major components of this system. The ASW system contains one pump that is capable of providing lake water to the SGs of any or all of the three units. The isolation and control valves are located within the units being served and are controlled and powered through the SSF. The key components of this system are illustrated in Appendix E.

The SSF requires HVAC to operate; however, the SSF HVAC system is not analyzed in the existing PRA. This dependency will be added during the CDF quantification process.

The SSF is an independent facility: it does not require support from the HVAC systems in the plant, but has its own HVAC system, which is divided into five subsystems:

1) SSF Constant Ventilation Subsystem: The SSF constant ventilation subsystem is designed to supply outside air to and exhaust air from the switchgear room, pump room, HVAC room, and diesel generator room, and to exhaust air from the battery room, the toilet, and the stair-well. The supply and exhaust fans and their controls are located in the HVAC room at elevation 817. This subsystem provides continuous ventilation, using dampers and heaters to maintain the design temperature for those rooms that are serviced by the SSF constant ventilation subsystem, including maintaining these rooms above a minimum temperature of $60^{\circ} \mathrm{F}$.

2) SSF On-Line Ventilation Subsystem: The SSF on-line ventilation subsystem is designed to provide additional outside air to and exhaust air from the HVAC, switchgear, and pump rooms when the ASW pump is energized. The supply fan and the interlocked exhaust fans and their controls are located in the HVAC room. This subsystem is used to maintain those rooms below $104^{\circ} \mathrm{F}$.

3) SSF Summer Ventilation Subsystem: The SSF summer ventilation subsystem is designed to provide additional outside air to and exhaust air from the switchgear room, pump room, HVAC room, and diesel generator room. When the outside air temperature rises above the designed set point, the supply and exhaust fans are energized to provide additional ventilation to these rooms. The supply and exhaust fans and their controls are located in the HVAC room. This subsystem is used to maintain these rooms below $104^{\circ} \mathrm{F}$.

4) SSF Diesel Generator Enqine Ventilation Subsystem: The EDG engine ventilation exhaust fan, in conjunction with its inlet and exhaust dampers and interlocks from the EDG start switch and fire protection system, provide intake and exhaust air flow for the EDG when it is running. The exhaust fan is controlled by a three-position switch and a purge push-button switch located on vendor control panel $\mathrm{CP}-1$ in the HVAC room. 
5) SSF Air Conditioning (AC) Subsystem: The SSF AC subsystem is designed to maintain the central alarm station, SSF control room, computer room, response room, and battery rooms within their design temperature range. The AC, with its two compressors and fan with normal and standby motor and controls, is located in the HVAC room with condenser water supplied from the HVAC service water subsystem. This subsystem is used to maintain the temperature between 60 and $85^{\circ} \mathrm{F}$ during normal and accident conditions. The SSF HVAC service water subsystem is designed to provide condenser water to the $A C$ unit. Two pumps, one in operation and one in standby, provide condenser water to the 'AC via a common line. These pumps are alternated periodically to allow for balanced run time and maintenance. The pumps are located in the pump room at elevation 745 with the controls in the HVAC room at elevation 817 .

There are two top events in the SSF fault tree model, which is shown in Appendix E: one is failure of SSF ASW system to provide secondary side heat removal, and the other is failure of SSF RCM system to provide RCP seal injection. For successful secondary side heat removal, the SSF ASW flow must reach either SG. However, SSF RCM flow must reach all four RCPs. Failure of RCM flow to any one RCP, when needed, can lead to an RCP seal LOCA and is considered system failure. The complete SSF fault tree is shown in Appendix E.

Failure of the SSF ASW system to provide secondary side heat removal is modeled as an OR gate with inputs from 1) failure to provide sufficient flow, 2) three different human errors (i.e., operators fail to deploy to the standby shutdown facility in time, SSF ASW System left unavailable after test or maintenance, and operators fail to align the SSF ASW system for operation), and 3) failure of SSF HVAC. Failure to provide sufficient flow is modeled as an OR gate with inputs from 1) valve failures, 2) SSF ASW pump failure, and 3) failure of the pump suction source. Failure of the SSF ASW pump is modeled as an OR gate with inputs from 1) pump mechanical failures, 2) loss of electrical power, and 3) failure of the pump bearing cooling line.

Failure of the SSF RCM system to provide RCP seal injection is modeled as an OR gate with inputs from 1) failure to provide sufficient flow, 2) three different human errors (i.e., operator fail to deploy to the standby shutdown facility in time, SSF RCM system left unavailable after test or maintenance, and operators fail to align the SSF RCM system for operation), and 3) failure of SSF HVAC. Failure to provide sufficient flow is modeled as three different OR gates: one represents failure of pump discharge MOV HP-398, one represents failure of any RCP injection line check valve, and one represents failure of flow up to and through the RCM pump. Failure of flow up to and through the RCM pump is modeled as an OR gate with inputs from 1) mechanical pump failures, 2) failures of valves in the flow path and 3) failure of electrical power to the pump motor.

Failure of the SSF electric power system is modeled as loss of power to the switchgear and MCCs supplying power to the pumps and valves within the SSF ASW and SSF RCM systems. Since the electric power system supports these front-1ine systems, it has no top event of its own. Loss of power to the required switchgear and MCCS is modeled as an OR gate with inputs from breaker 
and bus failures and from failure of the appropriate power source(s). Failure of power from the SSF diesel generator is modeled as an OR gate with inputs from loss of DC control power, breaker failures, failure of service water cooling to the diesel engine jacket, maintenance unavailability on the diesel, and failures of the diesel itself. Special events have been used to represent failure of normal plant power without transferring to the AC power system fault tree. When plant power is available, the probabilities assigned to the special events' represent independent hardware failures. When plant power is not available, the special events represent flags that are set to TRUE (probability of 1.0$)$.

Failure of the SSF HVAC AC system is modeled as an OR gate with inputs from 1) failure of the AHU, 2) failure of the refrigerant compressors and condensers, 3) failure of HVAC service water to the condensers, and 4) failure of electrical power. Failure of the refrigerant portion is modeled as an OR gate because both compressor/condenser pairs are needed. Failure of HVAC service water cooling is modeled as an AND gate because both pump trains must fail for the function to fail.

\subsubsection{Heating, Ventilating, and Air Conditioning System}

The heating, ventilating, and air conditioning (HVAC) functions at the representative B\&W PWR are performed by several independent systems, including

- The control area ventilation system (CAVS)

- The Auxiliary Building ventilation system (ABVS)

- The spent fuel cooling system

- The Reactor Building purge

- The Administration Building ventilation system

- The AHUs that serve individual areas in the plant.

The existing PRA covers the systems that function as support systems in important accident sequences, including the CAVS, the ABVS, and AHUS $3 A H U-1$ and $3 A H U-2$, which serve the LPR and RBSS pump rooms. Of these HVAC systems, only $3 A H U-1$ and $3 A H U-2$ appear explicitly in the accident sequences.

Control Area Ventilation System (CAVS). The CAVS heats, cools, and ventilates the control area as required. The control area, which is located in the Auxiliary Building, ccissists of the control room, the cable room, and the electrical equipment room. Although most of the air is recirculated, some filtered outside air is provided to maintain a positive pressure for radioactivity control. The CAVS is a full-time-running system. The IPE identified the CAVS as the most important HVAC system, and because it provides cooling to equipment such as inverters and battery chargers that are expected fail earl- 
ier than other equipment under high temperature conditions, it was the only HVAC system analyzed in the IPE. The other HVAC systems 1 isted above are described for completeness but are not modeled.

The CAVS consists of three separate, nearly identical equipment trains for the control room, the electrical equipment room, and the cable room. They share redundant outside-air booster fans and trains of high-efficiency particulate air (HEPA) filters, which provide fresh air and positive pressure in the control area. They also share a common smoke-purge exhaust fan and a cooling water supply from the station's chilled water system.

The electrical equipment room and the control room are served by two $100 \%$-capacity AHUs. The AHUs are supplied with chilled water by the chilled water (WC) system. The WC system consists of two $100 \%$-capacity chillers arranged in parallel and two $100 \%$-capacity pumps also in parallel. A crossconnector is available so that either pump can be used with either chiller. Makeup water to the WC system is supplied from the plant drinking water (PDW) system. Simplified diagrams for the HVAC systems are shown in Appendix E.

One AHU operates in each of the cable, equipment, and control rooms under normal conditions. The AHUs run continuously with WC flowing through the coils to control temperature. In the case of leakage, the WC system is replaced by the PDW system, which delivers makeup water on a demand-only basis. If the operating AHU equipment fails, the standby AHU equipment can be started manually.

HVAC system dependencies and interfaces include the following:

- Instrument air. One AHU per room requires instrument air for operation. Loss of instrument air pressure causes the WC minimum flow valve to open, starving the AHUs of their supply of WC.

- Low-pressure service water. LPSW is required by the chiller condensers.

- Electrical power supply. Power supplies are required by the following components: chilled water pumps, chiller compressor controls, AHUs, chillers, temperature controls, and chiller condenser pumps.

The fault tree logic model describing failure of the CAVS to cool the electrical equipment room and the control room are developed and addressed in the IPE and presented in Appendix E. There are two separate top events, one is the normal control room cooling failure which is labeled as "VCR", and the other is Unit 3 electrical equipment room cooling failure, which is labeled as "VER." The modeling for these two rooms is very similar, with differing AHUs, dampers, and valves. One AHU for each room is assumed to be operating with the other in standby. Failure of normal control room cooling is modeled as an AND gate with inputs from 1) AHU 3-13 fails to provide control room cooling, 2) AHU 4-14 fails to provide control room cooling, and 3) operators fail to provide alternate means of room cooling. Failure of Unit 3 electrical equipment room cooling is modeled as an AND gate with inputs from 1) Unit 3 
equipment room cooling via AHU 3-15 fails, 2) AHU 3-16 falls to cool Unit 3 equipment room, and 3 ) operators fail to provide alternate means of room cooling.

Auxiliary Building Ventilation System (ABVS). The ABVS heats, cools, and ventilates, as required, all areas of the Auxiliary Building that are not serviced by the CAVS. The ABVS is a once-through system with no recirculation; it is a full-time-running system.

The Auxiliary Building has no isolation between units, even though the ABVS for Unit 3 is separate from the ABVS for Units 1 and 2. Numerous singlearea recirculating AHUs serve portions of the Auxiliary Building, particularly where significant cooling capacity is required, but these units are not considered part of the ABVS.

The unit 3 ABVS consists of two supply-fan trains, ductwork to various areas and rooms in the Auxiliary Building, and two sets of exhaust-fan trains. Each of the supply trains contains two fans; each of the exhaust trains contains three fans. Each area of the Auxiliary Building is served by one of the supply trains and one of the exhaust trains. The system is balanced to maintain a negative pressure in the Auxiliary Building. The ABVS fans are not redundant and are all normally running.

Cooling water is supplied to each supply fan by the LPSW system, and heating is supplied to each supply fan by the auxiliary steam system. Instrument air is required to control heating, cooling, and damper positioning.

Air-Handling Units for LPI and RBS Pump Rooms. The pump rooms in the Auxiliary Building are served not only by the ABVS but al so by individual AHUs. These units cool the pump rooms, particularly during pump operation, and are necessary to prevent the pumps from overheating. Air-handling unit $3 A H U-1$ serves the room containing LPI pump 3B, LPI pump $3 C$, and RBS pump $3 B$; $3 A H U-2$ serves the room containing LPI pump $3 A$ and RBS pump $3 A$. For each AHU, ventilation is provided by fans, and cooling is provided by LPSW. The LPSW cooling flow is controlled by air-operated valves.

The HVAC systems described here are all normally operating systems. Each of the CAVS subsystems in the control room, the cable room, and the equipment room has one of two redundant AHUs operating. These AHUs are not load-shed on loss of power from transformer CT3. On loss of instrument air, one of the two AHUS, 3AHU-13, will function with cooling provided.

The four supply fans and six exhaust fans of the ABVS are all normally operating. Power to these fans would be interrupted on loss of power from transformer CT3. It is essential that adequate exhaust fan capability be restored and maintained to keep a negative pressure in the Auxiliary Building for radioactivity control. Loss of instrument air would cause loss of LPSW cooling and ventilation. 
The $3 A H U-1$ and $3 A H U-2$ room units operate automatically when the pumps are operating. On loss of instrument air, the valves fail open to permit LPSW cooling. On loss of normal power, the power for these units is not load-shed.

Malfunction of HVAC equipment in any system would not be alarmed or indicated in the control room. Equipment malfunction or personnel discomfort would be the first indication of system problems. In the Auxiliary Building, the loss of negative pressure would be alarmed, indicating a possible ABVS problem.

These are the HVAC system dependencies:

- Each of the HVAC systems described above requires $A C$ power for its operation.

- All AHUs, regardless of the system, also use instrument air for the control of dampers and cooling water as described above.

- The CAVS requires the WC system for cooling water, while the ABVS and the room AHUs require LPSW for cooling.

Several components in the plant require HVAC, particularly the cooling function, for proper operation. To prevent hydrogen buildup and to prevent rapid deterioration of batteries from high temperature, proper ABVS operation is required for the battery rooms. To prevent overheating and damage to LPI and RBS pumps during their operation, pump room AHUs must operate. Electrical equipment, particularly in the control room, cable room, and equipment room, requires proper CAVS operation. These component and human interfaces were taken into account when modeling accident sequences and evaluating initiating events.

The HVAC system provides support for numerous plant systems. However, the important interfaces modeled in the IPE are

- Low-pressure injection

- Low-pressure recirculation

- High-pressure recirculation

- Reactor Building spray systems.

In all cases, the AHUs are required for pump room cooling to prevent pump failure.

\subsubsection{Event Tree Analysis}

This section provides an overview of the event tree analysis in the representative B\&W plant's IPE (Duke Power Company 1990). In addition, all accident sequences in the event trees that relate to the room cooler failure elements are also addressed and discussed. 
There are 21 initiating events analyzed in the IPE and summarized in Table 3.4-1. The table also provides the nomenclature for the event trees presented in this section. Because every transient requires the same safety functions, a single event tree is constructed for all transient initiating events. The IPE developed six event trees for internal initiating events that are listed below:

- Transient

- Small LOCA

- Medium LOCA

- Large LOCA

- Steam generator tube rupture

- Anticipated transient without SCRAM.

These event trees are described in separate subsections. In addition, new event trees were developed in this study to evaluate accident sequences initiated by loss of control room and electrical equipment room cooling. Each subsection briefly describes the accident sequences that may involve room cooler failures.

\subsubsection{Transient Event Tree}

The transient event tree shown in Figure 3.4-1 applies to all transients that result in reactor trip. Given a transient event, the first concern is reactivity cohtrol; i.e., does the reactor protection system trip the reactor (event $K$ )? If event $K$ succeeds, the status of secondary side heat removal is determined (event $B$ ). The occurrence of event $B$ indicates a failure to maintain heat removal from the RCS. The operators must then resort to HPI cooling to remove decay heat. The PRVs are addressed whether or not the secondary side heat removal has succeeded. If event B succeeds, PRVs can still be challenged by overcooling transients and inadvertent ESAS actuation. If event $B$ fails, the PRVs will be challenged, because they are the remaining path for heat removal from the RCS. Should the PRVs close after opening (event Qr succeeds), RCS integrity can still be violated by the RCS pump seal failure (event Qs). Successful HPI (event $U$ ) is required if event $B$ occurs or if RCS integrity is lost. The recirculation phase (event $X$ ) is attached if event $U$ is successful. Given that event $X$ succeeds, the core will remain in a safe, stable state.

Event Tree Sequences. The IPE presented the following discussion of the transient sequences:

- Sequence TQsX. Sequence TQSX is a transient with failure of RCP seal integrity and a failure of high-pressure makeup during the recirculation phase. A recovery is applied to those cut sets where letdown flow to 
IABLE 3,4-1. Final List of Internal Initiating Events

\begin{tabular}{|l|l|}
\hline Identifier & \multicolumn{1}{|c|}{ Definition } \\
\hline B & Secondary heat removal \\
D1 & Depressurize with pressurizer sprays \\
HVAC & Depressurize with PORVs \\
$K$ & Loss of HVAC \\
LL & Reactor protection system \\
ML & Large-break LOCA \\
MTC & Medium-break LOCA \\
$P$ & Moderator temperature coefficient \\
Qr & Power-operated relief valves close \\
QS & Pressurizer safety valves close \\
$R$ & RCP seal integrity \\
RPV & Decay heat removal systems \\
SL & Reactor pressure vessel rupture \\
T1 & Small-break LOCA \\
T2 & Reactor/turbine trip \\
T3 & Loss of main feedwater \\
T4 & Fault on bus 3TC \\
T5F & Loss of condenser vacuum \\
T5S & Loss of offsite power: electrical grid \\
T5W & Loss of offsite power: switchyard \\
T6 & Loss of offsite power: severe weather \\
T7 & Loss of instrument air \\
T8 & Excessive feedwater \\
T9 & Spurious engineered safeguards signal \\
T10 & Steaml ine break \\
T11 & Feedwater/condensate line break \\
T12 & Loss of power from bus 3kI \\
Tt & Loss of low-pressure service water \\
$U$ & Turbine trip \\
$V$ & High-pressure injection \\
$X$ & Interfacing systems loca \\
$Y$ & Long-term decay heat removal \\
\hline & Steam generator tube rupture \\
\hline
\end{tabular}




\begin{tabular}{|c|c|c|c|c|c|c|c|c|}
\hline $\begin{array}{l}\text { Transient } \\
\text { Initiating } \\
\text { Event }\end{array}$ & $\begin{array}{l}\text { RPS trips } \\
\text { reactor }\end{array}$ & $\begin{array}{l}\text { Secondary } \\
\text { Heat } \\
\text { Removal }\end{array}$ & $\begin{array}{l}\text { Pressurizer } \\
\text { Safety Valves } \\
\text { Reclose }\end{array}$ & $\begin{array}{l}\text { RCP Seal } \\
\text { Integrity } \\
\text { Maintained }\end{array}$ & $\begin{array}{l}\text { HPI Es- } \\
\text { tabl ished }\end{array}$ & $\begin{array}{l}\text { Long-term } \\
\text { Heat Removal } \\
\text { Established }\end{array}$ & & \\
\hline$T$ & $K$ & B & $Q R$ & QS & U & $x$ & Sequence & Core \\
\hline
\end{tabular}

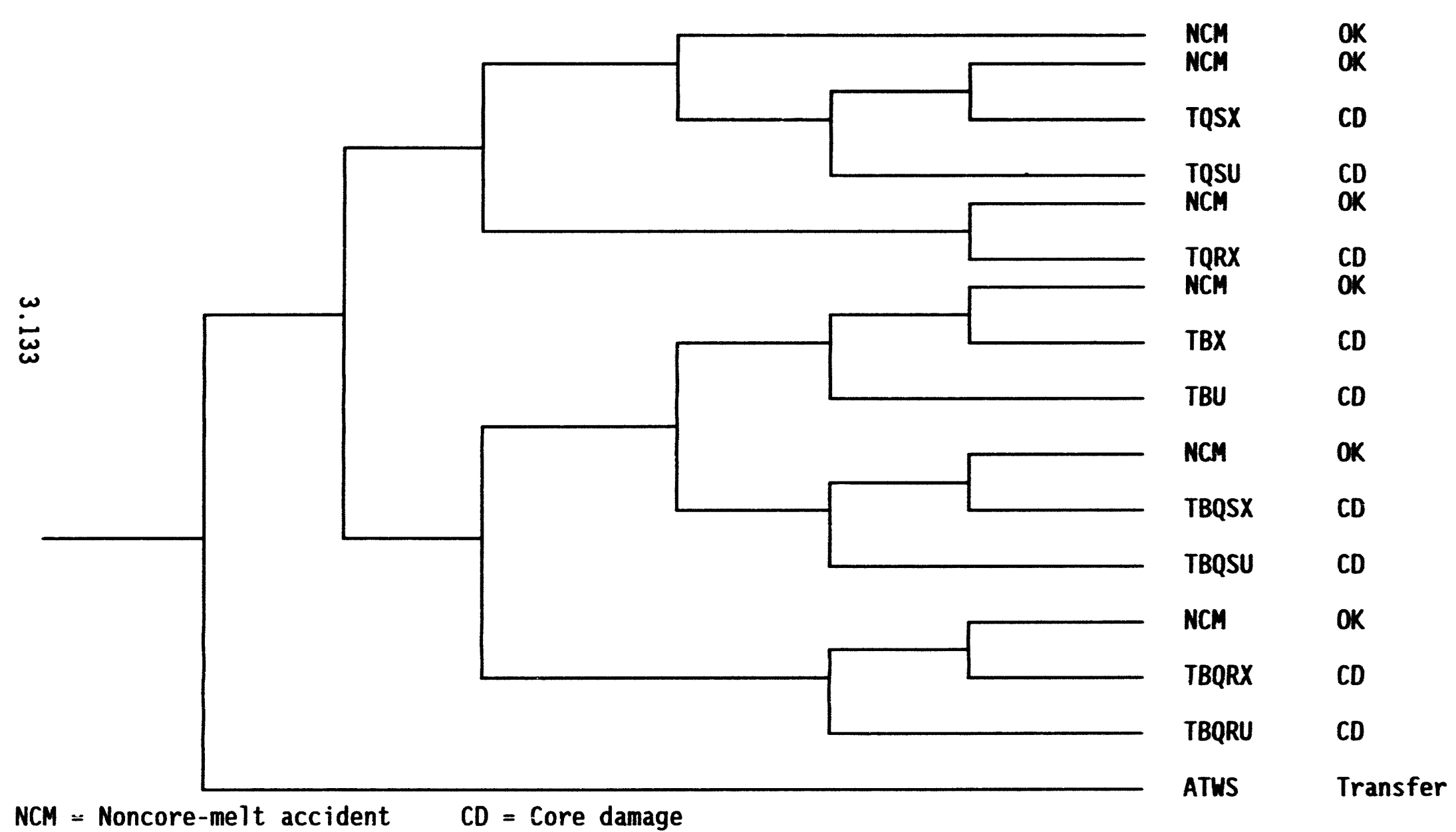

FIGURE 3.4-1. Transient Event Tree 
the letdown storage tank is cut off, causing the tank to empty due to cont inued makeup suction. The operators can manually open HP-24 to take suction from the BWST before the letdown storage tank goes dry.

- Sequence TQsU. Sequence TQsU is a transient with fallure of RCP seal integrity and a fallure of high-pressure makeup in the injection phase. Reactor coolant makeup (RCM) from the SSF is applied as a recovery to those cut sets where hardware failures cause high-pressure seal injection and component cooling to fall. LPSW from Units 1 and 2 is applled as a recovery to those cut sets where Unit 3's LPSW falls as cooling to component cooling and the HPI pump motors. If LPSW is lost due to the CCW pumps being load-shed and fallure of the syphons, the reloading of CCW pumps onto emergency power is applied as a recovery. When the loss of RCP seal cooling is due to a loss of all power, recovertes involve breakering in the $100-k V$ grid through CT5, aligning the emergency AC power unit through CT4, and powering RCM from the SSF diesel generator.

- Sequence TQrX. Sequence TQrX is a transient with a stuck-open pressurizer SRV and fallure of high-pressure makeup in the recirculation phase. The stuck-open safety relief valve (SRV) produces the equivalent of a medium LOCA leakage rate. Throttling HPI flow before challenging a rellef valve is applied as a recovery. Secondary side heat removal succeeds, but the release out of the rellef valve will cause containment pressure to reach the Reactor Building spray system set point (10 psig).

- Sequence TBX. Sequence TBX is a transient with failure of secondary side heat removal and failure of HPI cooling in the recirculation phase. A recovery is applied to cut sets with MFW fallures due to hardware failures. EFW from other units is applied as a recovery to cut sets involving failure of all three Unit 3 pump trains. Aligning the motordriven EFW pumps to the hotwell is applied as a recovery to those cut sets where the upper surge tanks cannot be refilled, and the turbinedriven EFW pump cannot be aligned to the hotwell. The release out the PRV will cause containment pressure to reach the Reactor Building spray system set point (10 psig).

- Sequence TBU. Sequence TBU is a transient with failure of secondary side heat removal and failure of HPI cooling in the injection phase. Loss-of-all-power cut set recoveries involve breakering in the 100-kV grid (and subsequently the backup combustion turbines) through CT5, aligning the backup hydroelectric power unit through CT4 and powering ASW from the SSF diesel generator. Those cut sets not involving loss of all power had secondary side heat removal recoveries applied in the same manner as Sequence TBX. The failure of events $B$ and $U$ leads to an early core melt.

- Sequence TBQsX. Sequence TBQsX is a transient with fallure of secondary side heat removal, failure of RCP seal integrity, and failure of HPI cooling in the recirculation phase. The recoveries applied to this sequence are combinations of those applied to Sequences TQSX and TBX. The release out of the PRV will cause containment pressure to reach the 
Reactor Buflding spray system set point (10 psig). The timing of core melt (early or late) will depend on whether spray injection succeeds and draws down the BWST.

- Sequence TBQsU. Sequence TBQsU is a transtent with fallure of secondary side heat removal, fallure of RCP seal integrity, and fallure of HPI cooling in the injection phase. Since loss-of-all-power cut sets dominate this sequence, the recoveries applied involve breakering in the 100-kV grid (and subsequently the backup combustion turbines) through CT5, aligning the backup hydroelectric unit through CT4, and powering both ASW and RCM from the SSF diesel generator. The fallure of both events $B$ and $U$ leads to a early core melt.

- Sequence TBQrX. Sequence TBQrX is a transient with fallure of secondary side heat removal, a stuck-open pressurizer SRV, and fallure of HPI cooling in the recirculation phase. The recoveries applied to these cut sets are the same as those applied to Sequence TBX with one difference: secondary side heat removal must be recovered before the SRV is challenged by liquid relief. The release out of the SRV will cause containment pressure to reach the Reactor Bullding spray system set point (10 psig). The timing of core melt (early or late) will depend on whether spray injection succeeds and draws down the BWST.

- Sequence TBQrU. Sequence TBQrU is a transient with fallure of secondary side heat removal, a stuck-open pressurizer SRV, and fallure of HPI cooling in the injection phase. The recoveries applied to these cut sets are the same as those applied to sequence TBU with one difference: secondary side heat removal must be covered before the SRV is challenged by liquid relief. The failure of both events $B$ and $U$ leads to an early core melt.

\subsubsection{Small LOCA Event Tree}

The small LOCA (SL) event tree presented in Figure 3.4-2 applies to all breaks from $3 / 8$ inch to 1.5 inches in diameter. The occurrence of a small LOCA will result in a demand for a reactor trip. Event $K$ was included in the event tree to permit the definition of core-melt sequences that include failure to trip. The next event is the secondary side heat removal (event $B$ ). Given that SSHR succeeds, it will slow the blow-down rate and lead to sequences involving late core melts. The RCS pressurizes to the PORV and SRV set points if SSHR fails. If a SRV fails to reseat (event Qr), water will be relleved through the SRV, which leads to medium LOCA. Given that SSHR fails and RCS relief valves fail to reseat, a core melt will be prevented if injection (event $U$ ) and long-term heat removal (event $X$ ) succeed.

\subsubsection{Medium LOCA Event Tree}

The medium LOCA event tree shown in Figure 3.4-3 includes ali breaks from 1.5 inches up to 4 inches in diameter. The first event addressed in the medium LOCA event tree is the avallability of HPI (event $U$ ); core melt will result if injection fails. Given that HPI succeeds, HPR must be established 


\begin{tabular}{|c|c|c|c|c|c|c|c|}
\hline $\begin{array}{l}\text { Smal1 LOCA } \\
\text { Occurs }\end{array}$ & $\begin{array}{l}\text { RPS SCRAMS } \\
\text { Reactor }\end{array}$ & $\begin{array}{l}\text { Secondary } \\
\text { Heat } \\
\text { Removal }\end{array}$ & $\begin{array}{l}\text { RCS Relief } \\
\text { Valves } \\
\text { Reclose }\end{array}$ & $\begin{array}{l}\text { HPI } \\
\text { Available }\end{array}$ & $\begin{array}{l}\text { Long-term } \\
\text { Heat Removal } \\
\text { Established }\end{array}$ & & \\
\hline$S$ & K & B & $Q r$ & U & $x$ & Sequence & Core \\
\hline
\end{tabular}

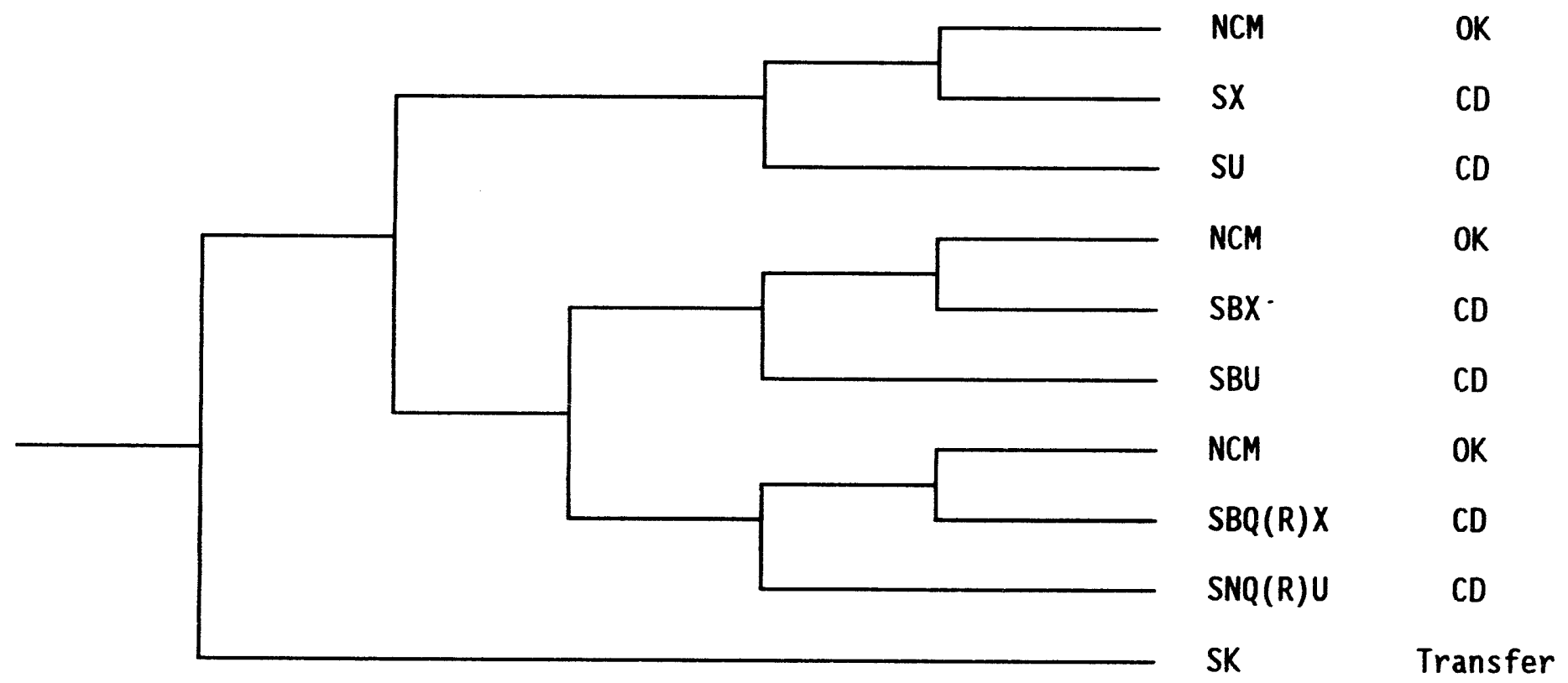

NCM = Non-core-melt accident $\quad C D=$ Core damage

FIGURE 3.4-2. Smal1 LOCA Event Tree 


\begin{tabular}{|c|c|c|c|c|}
\hline $\begin{array}{l}\text { Medium } \\
\text { LOCA } \\
\text { Occurs }\end{array}$ & $\begin{array}{l}\text { HPI } \\
\text { Available }\end{array}$ & $\begin{array}{l}\text { Long-term } \\
\text { Heat Removal } \\
\text { Established }\end{array}$ & \multicolumn{3}{|c}{} \\
\hline$M$ & $U$ & $X$ & Sequence & Core \\
\hline
\end{tabular}

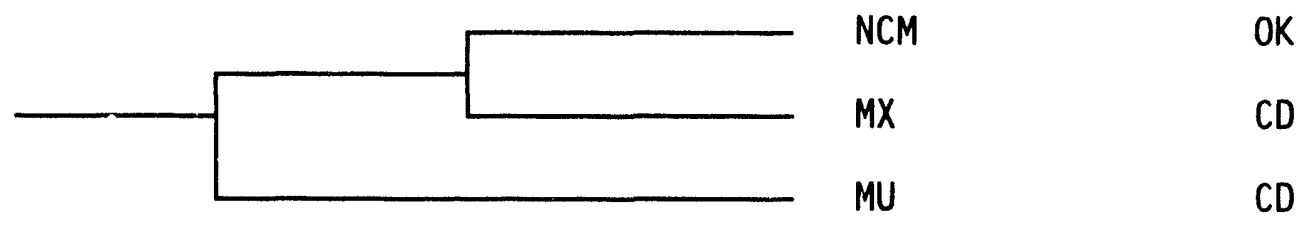

$N C M=$ Non-core-melt accident $\quad C D=$ Core damage

FIGURE 3.4-3. Medium LOCA Event Tree

for long-term decay heat removal (event $X$ ). To achieve HPR lasting until 24 hours after the occurrence of the LOCA, the following are required:

1) injection flow from a HPI pump train, 2) one LPI pump train drawing suction from the Reactor Building emergency sump arid pumping it to the HPI pump suctions, and 3) cooling of the recirculated water by the LPI cooler in the running pump train or Reactor Building cooling by a RBCU. Event $X$ failure will result in a core melt.

\subsubsection{Large LOCA Event Tree}

The large LOCA event tree shown in Figure 3.4-4 includes all breaks from 4 inches in diameter up to a double-ended guillotine of a hot-leg pipe. The

\begin{tabular}{|c|c|c|c|c|}
\hline $\begin{array}{l}\text { Large } \\
\text { LOCA } \\
\text { Occurs }\end{array}$ & $\begin{array}{l}\text { Coolant } \\
\text { Injection } \\
\text { Available }\end{array}$ & $\begin{array}{c}\text { Long-term } \\
\text { Heat Removal } \\
\text { Established }\end{array}$ & \multicolumn{4}{|l}{} \\
\hline$L$ & $U$ & $X$ & Sequence & Core \\
\hline
\end{tabular}

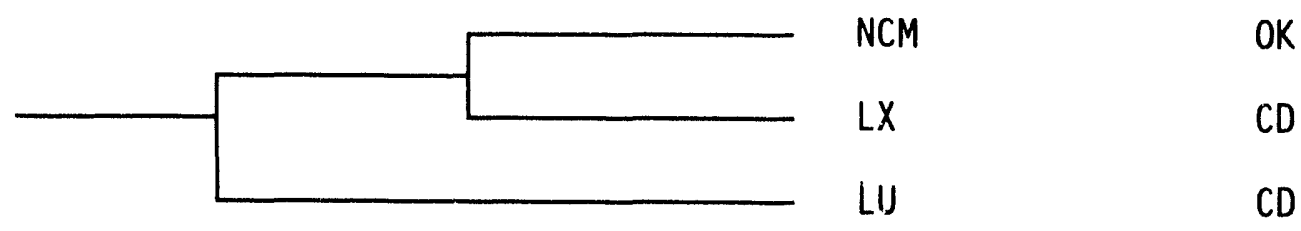
NCM $=$ Non-core-melt accident
$C D=$ Core damage

FIGURE 3.4-4. Large LOCA Event Tree 
first event addressed in the large LOCA event tree is the availability of core coolant injection (event $U$ ), which is determined by the success or failure of LPI. Success for event $U$ requires 1) at least one core flood tank dumps to cool the core while LPI is being started, and 2) at least one LPI pump train pumps the BWST water into the core until the BWST supply is depleted and sufficient water is in the RB emergency sump to initiate LPR. If LPI succeeds, long-term cooling must be available (event $X$ ) whether HPR is established or not. Success for event $X$ is sustained decay heat removal. It requires the following conditions: 1) at least one LPI pump train taking suction from the RB emergency sump and injecting into the reactor vessel; 2) cooling of the recirculation flow by the LPI cooler in the running pump train or Reactor Building cooling by a RBCU.

\subsubsection{Steam Generator Tube Rupture (SGTR) Event Tree}

The SGTR event tree is presented in Figure 3.4-5. The first event addressed in the event tree is the RPS (event $K$ ). Given that event $K$. succeeds, consideration is turned to HPI (event $U$ ) which is providing reactor coolant makeup. The core is assumed to be uncovered, which would result in core damage without reactor coolant makeup.

Given event $U$ failure, the status of secondary side heat removal (event $B$ ) is questioned to determine core melt timing needed for consequence analysis. Event $B$ success places the core melt in a late core-melt bin, and Event B failure places this accident sequence in an early core-melt bin.

Given that event $U$ succeeds, the status of event $B$ is then considered. If event $B$ fails, operators proceed to primary feed-and-bleed. Feed-and-bleed uses the PORV as a bleed path (event P) to remove coolant and heat. Event $D$ failure results in a core melt. HPR (event $X$ ) is needed in feed-and-bleed to supply long-term heat removal if event $P$ succeeds. A core melt is assumed to occur given event $X$ failure.

Given success of events $U$ and $B$, RCS integrity is considered. If the operators fail to throttle HPI flow, an overpressurization of the RCS may occur, which leads to a possibility of lifting a SRV or nonblocked PORV. The valve may not reclose given sufficient overpressurization. This results in a loss of RCS integrity (event Q1 failure) with primary coolint eleascd into the containment. If event $X$ succeeds, released coolant $c a$; ircolia's back into the RCS. If event $X$ fails, a core melt will occur.

Given event Q1 success, RCS depressurization is perforget wsing the pressurizer spray (event Dl). If event Dl succeeds, on? th the daray heat removal system (event $R$ ) success is needed in establising $h o n g-t$ erin decay heat removal. Event $R$ failure is assumed to result in a ras? mel $t$.

Given that event Dl fails, depressurization is accomping the PORV (event D2). If event D2 fails, the RCS is assumed to reirain at high pressure for a sufficient length of time to uncover the core, resulting in a core melt. 


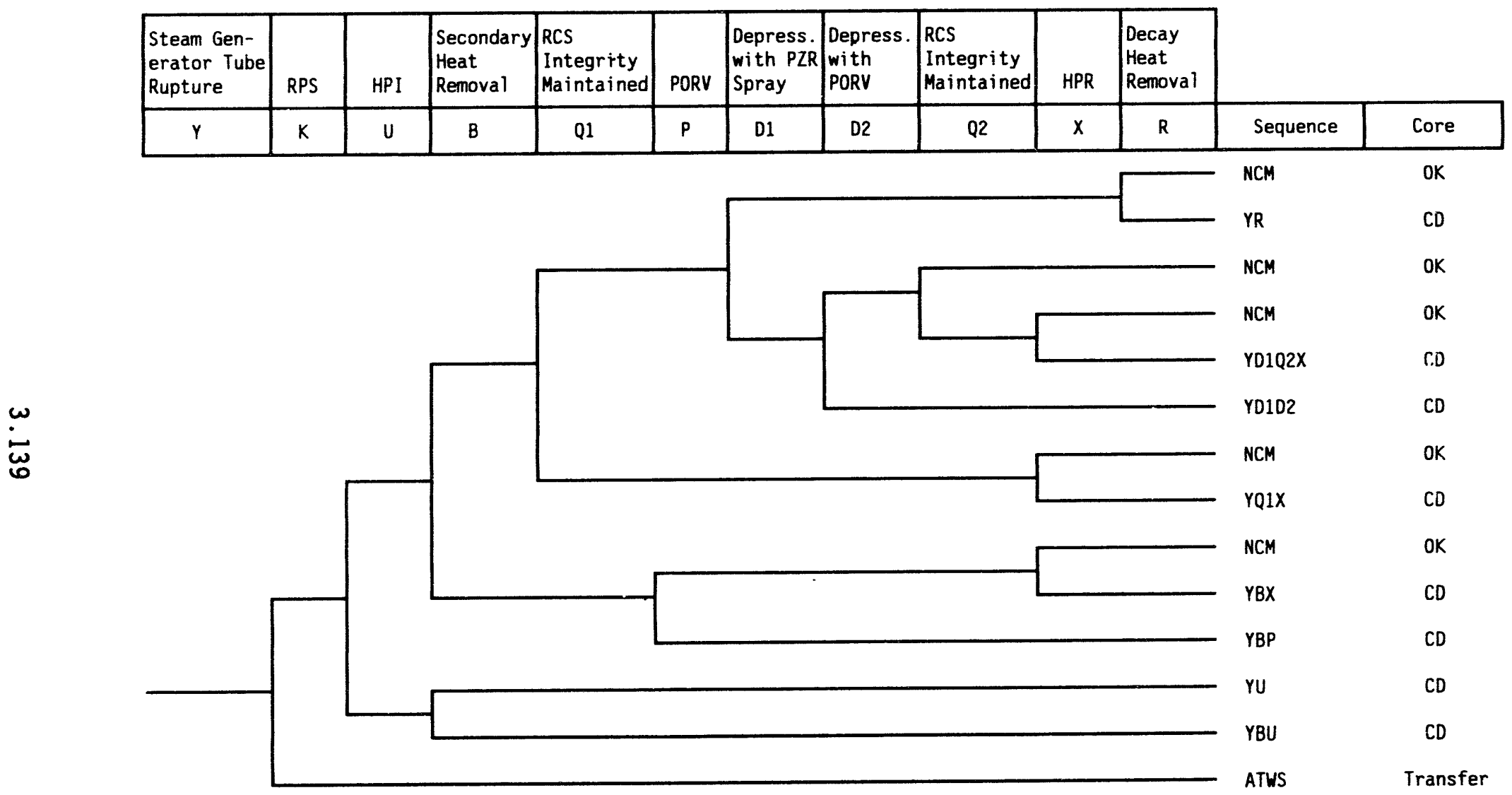

FIGURE 3.4-5. Steam Generator Tube Rupture Event Tree 
Given that event D2 succeeds, failure of RCS integrity (event Q2) which is caused by the PORV opening after depressurization, is considered. A failure of event $Q 2$ challenges event $X$ with a failure of event $X$ leading to a core melt.

\subsubsection{Anticipated Transient without SCRAM Event Tree}

An anticipated transient without SCRAM (ATWS) event is a failure of the reactor protection system (RPS). The ATWS event tree, presented in Figure 3.4-6, illustrates the combinations of successful actions and failed actions that lead to ATWS event mitigation or core melt. The ATWS (event A) is the LOFW transient concurrent with the failure to drop control rods before overpressurization occurs. LOFW comprises both loss of MFW and loss of condenser vacuum events. Success of the RPS for ATWS is defined as dropping either of the safety groups or the regulating groups of control rods.' Moderator temperature coefficient (event E) is the possibility that the MTC is more positive than the value shown to be adequate by analysis. Ninety percent was used in the IPE to allow for the possibility of core reload design changes. When the MTC is inadequate, an ATWS is assumed to lead to a core melt.

The turbine trip (event TT) addresses the possibility that the turbine will fail to trip after a LOFW. Tripping the main turbine failure/delay will subsequently delay the primary to secondary heat transfer mismatch, but a much faster primary pressure rise will occur when the SGs dry out due to a more severe primary temperature rise. Event TT will result in overpressurization. Event $B$ is addressed as the possibility to provide cooling from the EFW pump. EFW is necessary to reverse the heat transfer imbalance so that RCS tempera. ture will begin to decrease. One EFW pump is capable of supplying enough water to carry away reactor decay heat plus the heat generated by reactor coolant pumps. Event P, "Primary Safety Relief Valve," addresses the

\begin{tabular}{|c|c|c|c|c|}
\hline $\begin{array}{l}\text { ATWS } \\
\text { Occurs }\end{array}$ & $\begin{array}{l}\text { RCS Not } \\
\text { Overpres- } \\
\text { surized }\end{array}$ & $\begin{array}{c}\text { HPI } \\
\text { Successful }\end{array}$ & \multicolumn{2}{|c|}{} \\
\hline A & E/TT/B/P & $U$ & Sequence & Core \\
\hline
\end{tabular}

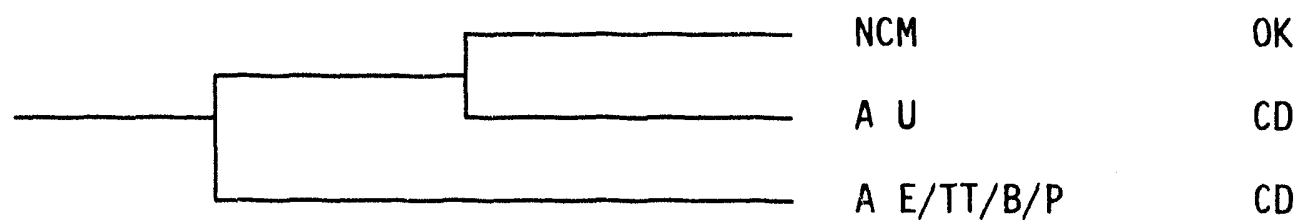

NCM $=$ Non-core-melt accident $\quad C D=$ Core damage

FIGURE 3.4-6. Anticipated Transient Without SCRAM Event Tree 
condition in which an SRV fails to open during an ATWS. Injection (event U) is the failure of HPI such that additional boron cannot be added to the RCS to establish core shutdown margin.

\subsubsection{Event Tree for Loss of Electrical Equipment Room Cooling}

The event tree for a loss of electrical equipment room cooling (TEER) is shown in Figure 3.4-7. This event tree was developed for the completeness of this study (i.e., was not developed in the existing Oconee IPE). The B\&W plant's IPE considers a loss of HVAC to the electrical equipment rooms is enveloped by the plant trip initiating event (T1) based on the following information: 1) failure of the HVAC system will allow the temperature in the electrical equipment rooms to increase, and 2) inverters and the battery chargers located in the electrical equipment rooms are the most sensitive to high temperature. High temperature can result in a common-cause failure of all the battery chargers. This would require the batteries to support the $D C$ power loads. Common cause failure of vital inverters DIA, DIB, DIC and DID also occur due to high temperature.

High-temperature-induced failure of the vital inverters will cause the unit to trip and will remove the dominant DC load from the batteries. The vital inverters can fail if the battery voltage drops below 90 volts. Once again, this trips the unit and removes the dominant DC load from the batteries. Furthermore, some noncritical instrumentation would be lost upon inverter failure, because power to the $120-V$ AC vital instrumentation power panelboards KVIA, KVIB, KVIC, and KVID will not be available. The electrical equipment room cooling event tree was developed exactly as the transient event tree discussed in Subsection 3.4.3.1. The description of accident sequences following loss of electrical equipment room cooling is similar to the description of accident sequences in the transient event tree section and will not be repeated here. The initiating event and basic event probabilities were modified to include the effects of the loss of HVAC. The modification is discussed in Section 4.0 .

\subsubsection{Event Tree for Loss of Control Room Cooling}

The event tree for a loss of control room cooling (TCR) is shown in Figure 3.4-8. This event tree was developed for the completeness of this study (i.e., was not developed in the IPE). The IPE does not consider a loss of HVAC to the control room as a potential initiating event that could lead to core damage. This conclusion in the IPE was based on the following observations:

- Portable cooling can be used to make up for temporary losses of cooling to the control room. The concern with maintaining cooling to electrical components is from a component length-of-life standpoint and not from a concern of inducing immediate failure. 


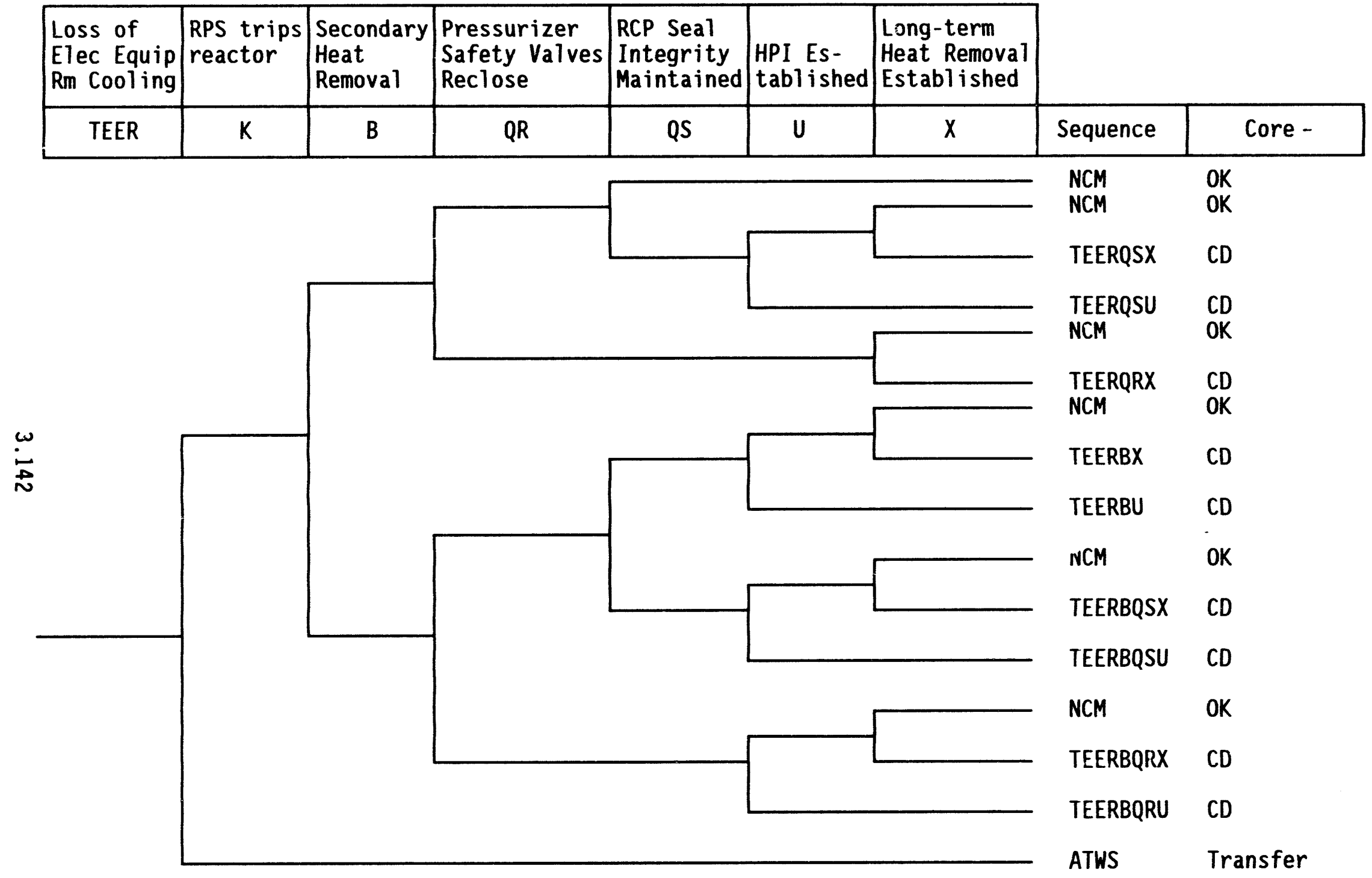

NCM $=$ Non-core-melt accident $\quad C D=$ Core damage

FIGURE 3.4-7. Loss of Electrical Equipment Room Cooling Event Tree 


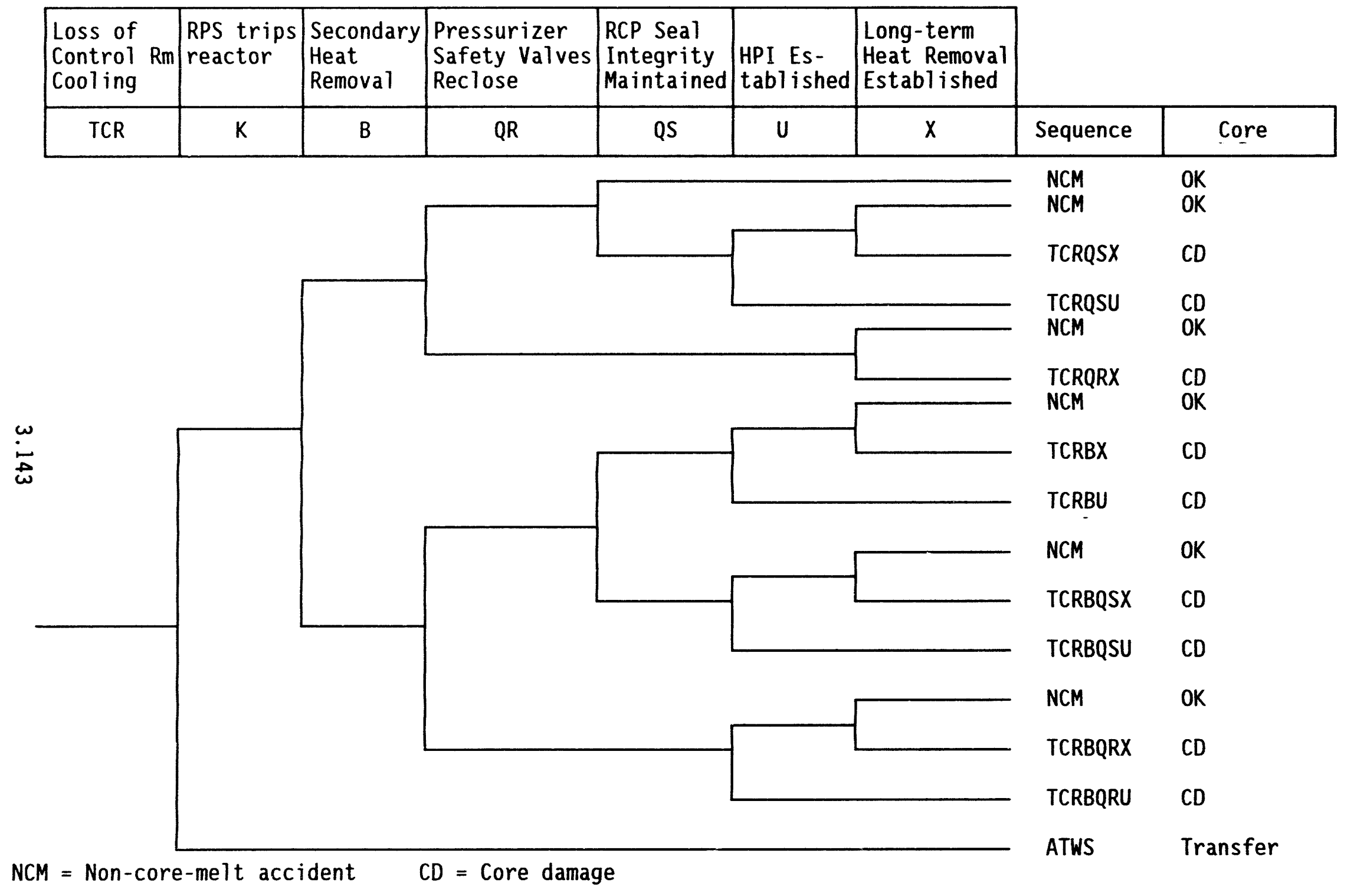

FIGURE 3.4-8. Loss of Control Room Cooling Event Tree 
- The auxiliary shutdown panel (ASP) can be used to shut down the reactor if the control room was actually lost due to overheating.

- The SSF has enough instrumentation and controls to shut down the reactor, and the facility has its own HVAC system.

The probability of a core melt due to loss of control room cooling is not negligible. The loss of control room event tree was constructed based on the transient event trees with initiating event TCR. The first event, RCR "Recovery," addresses the probability of control room cooling recovery. If loss of room cooling continues for a sufficient period of time, the temperature will rise within the switchgear room to the point at which the equipment within the rooms may fail. However, because of long heatup times, there is a significant amount of time available to recover from this initiating event. Given that event RCR fails, event ASP (Auxiliary Shutdown Panel) is addressed. As mentioned above, the ASP can be used to shut down the reactor. Should loss of control room cooling occur, and operators fail to recover, it does not matter whether the ASP is available; the plant would be required by technical specifications to begin an orderly shutdown. All core damage sequences generated for the transient event tree were modified to incorporate the contribution of control room cooling recovery and the auxiliary shutdown panel. These modifications will be discussed in Section 4 . 


\subsection{QUANTIFICATION OF AFFECTED CORE DAMAGE FREOUENCY AND PUBLIC RISKS FROM INTERNAL EVENTS}

This section contains the results of the core damage frequency (CDF) and public risk calculations performed in this study. These results form the basis for the value-impact calculations. Separate subsections are presented for each of the four representative plants examined in this study, including a W PWR (Section 4.1) and BWR (Section 4.2), ACE PWR (Section 4.3), and a B\&W PWR (Section 4.4).

\subsection{ANALYSIS OF THE AFFECTED CDF AND PUBLIC RISKS AT THE REPRESENTATIVE WESTINGHOUSE PWR}

This section presents the affected CDF and public risk calculations for the representative W PWR. Separate discussions are presented for 1) room cooler failures as initiating events that could ultimately lead to core damage and 2) room cooler failures as contributing events to other types of plant transients.

\subsubsection{Loss of Room Cooling as an Initiator}

A simplified approach was applied to the event trees developed in this study to model room cooler failures as initiating events. As discussed in Section 2, the approach involved developing of new event trees, developing new accident sequences using cut set information from the existing PRAs, modifying the component unavailabilities to account for prior failure of the room cooling function, and quantifying the new accident sequences using the modified safety system unavailabilities.

\subsubsection{Initiator Frequency}

Each accident sequence is initiated by a loss of room cooling function followed by failure to recover that room cooler in a specified time frame. The initiating event frequencies were developed by reviewing Licensee Event Reports (LERs) involving room cooler failures and then calculating the initiating event frequency using the number of LERs and the number of reactoryears (RYS) of operation over the time period for which LERs were reviewed. This was done by dividing the number of operating failures by the number of reactor hours of operation over the seven-year period from 1985 to 1991. Plant operating data in Nuclear Safety $(1986,1988,1991)$ were used to calculate this value, which are presented in Table 4.1-1. As shown, the average plant availability over this period was $68.5 \%$. A total of 512.7 RYs of operation have occurred over this period for an average of $73.3 \mathrm{RY} / \mathrm{yr}$.

The room-cooler LERs were reviewed to determine the total number of engineered safety features (ESF) switchgear, control room, high pressure injection/recirculation (HPI/HPR) pump, and low-pressure injection/ recirculation (LPI/LPR) room cooler failures that occurred over the 
IABLE 4.1-1. Nuclear Power Plant Operational Data for 1985 to 1991

\begin{tabular}{|c|c|c|c|}
\hline Year & $\begin{array}{c}\text { Number } \\
\text { of Plants }\end{array}$ & $\begin{array}{c}\text { Average } \\
\text { Availability }\end{array}$ & $\begin{array}{c}\text { Number of } \\
\text { Reactor-yr }\end{array}$ \\
\hline 1985 & 97 & 0.685 & 66.5 \\
\hline 1986 & 102 & 0.655 & 68.8 \\
\hline 1987 & 105 & 0.672 & 68.5 \\
\hline 1988 & 107 & 0.698 & 74.7 \\
\hline 1989 & 110 & 0.685 & 75.4 \\
\hline 1990 & 112 & 0.711 & 79.6 \\
\hline 1991 & $112^{(a)}$ & 0.711 & 79.6 \\
\hline Total & & 0.685 & 512.7 \\
\hline (a) Data are not yet available for $1991 ;$ they are \\
assumed to be identical to 1990 data.
\end{tabular}

1985 to 1991 time frame. Initially, all room cooler failures were included in the database, including failures that occurred while the plant was in shutdown or refueling modes (see Appendix A). A second sort was performed to identify LERs that occurred while the plant was in an operating mode. Failures that occurred during shutdown were not a concern, because the control rods have already been inserted and plant decay heat levels are low. Therefore, during plant shutdowns, reactor coolant system pressure and temperature levels are very low relative to operational modes. This allows a much longer time to diagnose and correct room cooler failures during shutdown conditions than while the plant is operating. For this reason, it is believed very unlikely that loss of a room cooler during shutdown conditions could lead to a core damage scenario. Table 4.1-2 presents the results of this analysis, including the total LERs observed for the four components, the total LERs observed during plant operating conditions, and the annual initiating event frequency for each room cooler system.

Recovery from loss of room coolers may be a relatively simple procedure and in most cases can be accomplished using equipment on hand. For example, fan belts often break and require replacement to repair the problem. Most utilities carry replacement fan belts in their spare parts programs. Most utilities are also provided with portable fans that may be used to blow cool air from one room to another, thus providing room cooling to a room in which room coolers are failed. The portable fans may be supplemented by flexible, portable ductwork to facilitate the flow of air from one room to another. A third possibility may be to simply open room doors or cabinets to facilitate the flow of air. 
TABLE 4.1-2. Room Cooler Initiating Event Frequencies

\begin{tabular}{|l|c|c|c|}
\hline Room Cooler & $\begin{array}{c}\text { Number } \\
\text { of Failures, } \\
\text { All Modes }\end{array}$ & $\begin{array}{c}\text { Number } \\
\text { of Failures, } \\
\text { Operating }\end{array}$ & $\begin{array}{c}\text { Initiator } \\
\text { Frequency, } \\
\text { per RY }\end{array}$ \\
\hline LPI/LPR pump room cooler (a) & 25 & 12 & $2.34 E-02$ \\
\hline HPI/HPR pump room cooler & 45 & 19 & $3.71 E-02$ \\
\hline Control room HVAC system & 41 & 23 & $4.49 E-02$ \\
\hline ESF switchgear room cooler & 18 & 10 & $1.95 E-02$ \\
\hline (a) Includes failures of RHR systems, LPI/LPR at PWRs, and BWR low- \\
pressure core spray and low-pressure coolant injection systems \\
(LPCS/LPCI). \\
(b) Included failures of PWR HPI/HPR systems, and BWR reactor core \\
isolation cooling systems, high-pressure core spray, and high- \\
pressure coolant injection systems (HPCS/HPCI).
\end{tabular}

The probability of recovery from room cooler initiating events was evaluated separately based on room heatup times and backup room cooling capabilities. The nonrecovery probability was calculated using the methodology described in NUREG/CR-4834 (Weston, Whitehead, and Graves 1987). The probabilities of failure of the following actions were assessed:

- Detection of room cooler failures by high room temperature indications in the control room, HVAC alarms in the control room, and daily operator walkthrough inspections in safety-related equipment rooms to read and record room temperatures.

- Probable maintenance staff actions to open doors and/or install portable fans in rooms containing failed room coolers.

- A total of 24 hours was estimated to be required to diagnose the failure and then reach ECCS pump room equipment prior to exceeding the design basis ambient temperature values. This time frame is based on room heatup calculations following a total loss of room cooling (see Appendix F).

- A total 'of 12 hours was estimated to be required to diagnose control room and switchgear room equipment failures prior to exceeding the design basis ambient temperature values following a total loss of room cooling. 
The formula used to calculate the recovery failure probability for ESF switchgear and control room cooling was taken from NUREG/CR-4834, as shown below:

$$
\begin{array}{ll}
P(N R)= & P(N D)+P(N A)-P(N D) P(N A) \\
\text { where: } \quad & P(N R)=\text { Probability of failure to recover } \\
& P(N D)=\text { Probability of failure to diagnose appropriate action } \\
& P(N A)=\text { Probability of failure to reach appropriate area of } \\
& \text { plant and accomplish action. }
\end{array}
$$

$P(N D)$ was taken directly from Table 4.2-1 of NUREG/CR-4834. Normally, the maximum time to accomplish the recovery activity $\left(T_{M}\right)$ is the sum of the time to diagnose $\left(T_{p}\right)$ and time to reach the area and accomplish the activity $\left(T_{A}\right)$. However, in this instance, there is a substantial amount of time available to effect repairs. Therefore, it was assumed that diagnosis time requirements are one hour, and the time to reach the appropriate rooms makes up the remainder of the maximum recovery time. Therefore, if a recovery action must be performed within 12 hours, it was assumed that the time required to diagnose the problem is one hour, and the time required to accomplish the recovery action is 11 hours. The probability of failure to diagnose $P(N D)$ within one hour was found to be $0.0011 /$ demand.

$P(N A)$ was estimated using Human Reliability Analysis (HRA) techniques, as described by Weston, Whitehead, and Graves (1987) and Swain and Guttman (1983). In this case, an operator must direct a plant maintenance person to restart room coolers; e.g., the specific room cooler that is not functioning and the appropriate procedural references for restarting room coolers, providing augmented cooling capabilities, etc. An HRA event tree was drawn to model the action phase of this recovery action, as shown in Figure 4.1-1. The HRA event tree, along with human error probabilities given by Swain and Guttman (1983, chapters 20 and 21 ), provide the means of calculating $P(N A)$.

From the HRA event tree, the probability of failing to accomplish the action of restoring or providing backup room cooling is found by

$$
\begin{aligned}
P(N A) & =F_{1}+F_{2}+F_{3}+F_{4} \\
& =0.0+(0.003)(0.04)+(0.003)(0.04)+(0.001)(0.003) \\
& =2.4 E-04
\end{aligned}
$$

$P(N R)$ may now be calculated as follows:

$$
\begin{aligned}
P(N R) & =P(N D)+P(N A)-P(N D) P(N A) \\
& =(0.011)+(2.4 E-04)-(0.011)(2.4 E-04) \\
& =1.34 E-03
\end{aligned}
$$

A hardware failure probability of $3 E-3 /$ demand was included to account for the possibility that backup fans and other equipment may not function properly. Therefore, the total probability of nonrecovery from ESF switchgear and control room cooling was calculated to be $4.3 \mathrm{E}-3 /$ demand. 


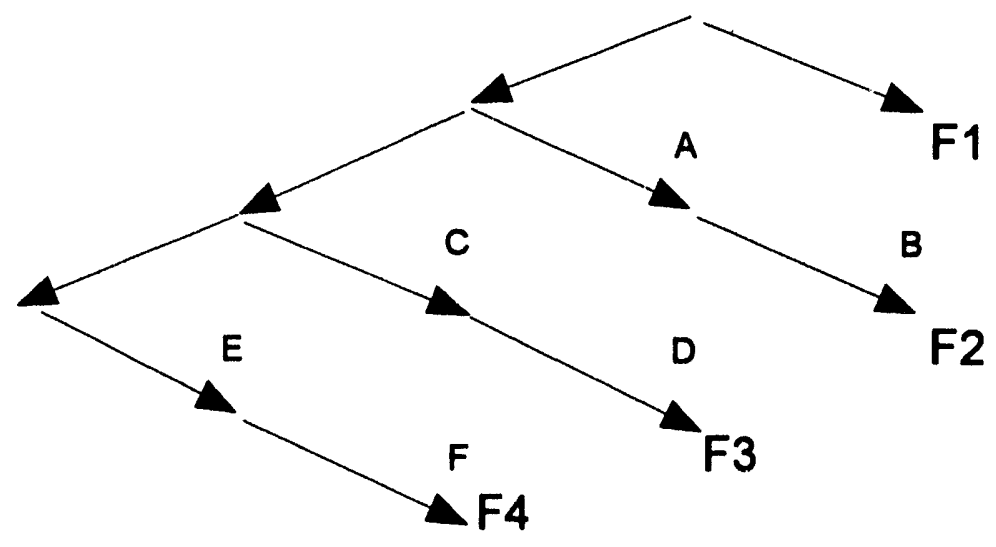

\begin{tabular}{|c|c|c|}
\hline Event & $\begin{array}{l}\text { Human Error } \\
\text { Probability }\end{array}$ & Source ${ }^{(a)}$ \\
\hline $\begin{array}{l}\text { A. Error in message from operator } \\
\text { B. Operator fails to monitor feedback } \\
\text { C. HVAC man misunderstands message } \\
\text { D. Operator fails to monitor feedback } \\
\text { E. HVAC man fails to restore cooling } \\
\text { F. Operator fails to monitor feedback }\end{array}$ & $\begin{array}{l}0.04 \\
0.003 \\
0.04 \\
0.003 \\
0.001 \\
0.04 \\
\end{array}$ & $\begin{array}{l}\text { Table } 20-8 \text { p. } \\
20-13 \\
\text { Table } 20-8 \\
\text { p. } 20-13 \\
\text { Table } 21-2 \\
\text { p. } 20-13 \\
\end{array}$ \\
\hline \multicolumn{3}{|c|}{$\begin{array}{l}\text { This column presents the table or page number in Swain and } \\
\text { Guttman (1983) that contains the referenced human error } \\
\text { probabilities (HEPs). }\end{array}$} \\
\hline
\end{tabular}

FIGURE 4.1-1. HRA Event Tree for Recovery from Room Cooler Initiators

The probability of nonrecovery from failure of HPI/HPR and LPI/LPR room cooling failures was taken directly from Bertucio and Brown (1990, p. 4.8-9). The recovery factor (designated RA5 by Bertucio and Brown) was calculated to be 0.16 , based on a $P(N D)$ of $0.027, P(N A)$ of 0.08 , and hardware failure probability of 0.05 .

\subsubsection{Core Damage Frequency Quantification}

The next step in the analysis was establishing core damage accident sequences based on the new event trees and quantifying the affected accident sequences and minimal cut sets. A list of affected events was developed, representing the safety system components required to respond to the loss of room cooling function in the specified room. Bertucio and Brown provided the cut sets and values for the unmodified parameters. These parameter values were then modified to take into account the prior failure of the room cooling function. 
Four new event trees were developed in Section 3 to model the loss of room cooling function as an initiating event: 1) loss of ESF switchgear room cooling, 2) loss of control room cooling, 3) loss of HPI/R pump room cooling, and 4) loss of LPI/R pump room cooling. A fifth event tree for loss of room cooling to vital DC equipment was based on loss of a vital DC bus (see Figure 3.1-21 for event $\left.T_{D C X}\right)$. The four former event trees were developed based on the original event tree for a transient with MFW initially available. Success criteria for these event trees are presented in Table 4.1-3. The three safety functions required in response to these events include reactor subcriticality, SG makeup for core heat removal, and RCS integrity. Success criteria for the $D C$ equipment room cooling event tree are the same as for the other four except that MFW and condensate booster trains are unavailable as a result of the DC bus failure. Loss of a DC bus could cause main steam isolation valve (MSIV) closure, which results in loss of the power conversion system capabilities to remove decay heat. This is further discussed in Section 4.3.

The quantification process for the new event trees began by obtaining the original cut sets from existing PRAs for a transient with MFW initially available (Bertucio and Brown 1990). Each of these cut sets was examined to determine which basic events, if any, would be affected by a loss of room cooling function. Obvious examples include failure of HPI/HPR pumps, failure of LPI/LPR pumps, failure of control circuitry and/or ESF actuation circuitry in the control room, and failure of emergency core cooling system (ECCS) related motor-operated values ( $10 \mathrm{Vs})$ to function properly.

TABLE 4.1-3. Success Criteria for Loss of Room Cooling Function Initiators

\begin{tabular}{|c|c|c|c|c|}
\hline $\begin{array}{l}\text { Reactor } \\
\text { Subcriti- } \\
\text { cality }\end{array}$ & $\begin{array}{c}\text { Core Heat } \\
\text { Removal, Early }\end{array}$ & $\begin{array}{l}\mathrm{RCS} \\
\text { Integrity }\end{array}$ & $\begin{array}{l}\text { Core Heat } \\
\text { Removal, Late }\end{array}$ & $\begin{array}{c}\text { Containment } \\
\text { Pressure } \\
\text { Suppression, Late }\end{array}$ \\
\hline RPS & $\begin{array}{c}1 / 3 \text { AFS, } \\
- \text { OR - } \\
1 \text { MFW or } \\
\text { condensate } \\
\text { booster train, } \\
- \text { OR - } \\
1 / 4 \mathrm{HPI} \text { and } 2 / 2 \\
\text { PORV (in feed- } \\
\text { and-bleed) }\end{array}$ & $\begin{array}{c}\text { Any open PORVs } \\
\text { reclose } \\
\text { RCP seal } \\
\text { integrity } 1 / 2 \\
\text { CCP in } \\
\text { injection mode, } \\
\text { - OR - } \\
1 \text { CCW train to } \\
\text { thermal } \\
\text { barriers }\end{array}$ & $\begin{array}{c}1 / 4 \mathrm{HPR} \text { and } \\
1 / 2 \mathrm{LPR}\end{array}$ & $\begin{array}{l}1 / 2 \text { CSS w/heat } \\
\text { exchanger, } \\
- \text { OR - } \\
1 / 2 \text { LRP w/heat } \\
\text { exchanger }\end{array}$ \\
\hline \multicolumn{5}{|c|}{$\begin{array}{l}\text { (a) Based on success criteria for a transient with MFW initially available. } \\
\text { (b) Early containment pressure suppression is not required. }\end{array}$} \\
\hline
\end{tabular}


The affected parameters and their values were then modified to account for the possibility of prior failure of room coolers. The unaffected parameters remained unchanged. Assumptions used to modify the affected parameter values are presented below.

\section{LosS of ESF Switchgear Room Cooling.}

- Failure probabilities for motor-operated power-operated relief values (PORV) block valves were set equal to 0.5 , the approximate probability that an operator would be able to restore power to a valve actuator, given failure of one train of ESF switchgear.

- Failure of PORVs to open on demand is assumed to be unaffected by loss of switchgear room cooling.

- Failure of AFW motor-driven pumps (MDP) to start and run was set equal to 0.5 to account for the possibility that one train of ESF switchgear is unavailable. This includes the contribution from the operator being unable to restore cooling to AFW MCCS located in ESF switchgear room, given loss of cooling in one train of switchgear.

- AFW turbine-driven pump (TDP) failure probabilities were assumed unaifected because the pump is provided with backup DC control power, and the AFW TDP room cooler is provided with backup DC power. Therefore, failure of the AFW TDP was assumed to be unaffected by failure of one train of ESF switchgear room cooling.

- All air-operated valves (AOVs) are unaffected by failure of ESF switchgear room cooling. The safety-related air compressor may be inoperable as a result of failure of ESF switchgear; however, a limited supply of pressurized air remains available following loss of the air compressor.

- Failure of operators to switch to feed-and-bleed cooling were set equal to 1.0 , reflecting the high probability that loss of switchgear room cooling could affect control room indications as well as operability of components required to respond to a transient.

- AFW actuation circuitry failure probability was set equal to 0.5 to reflect the probability that an operator will be able to restore cooling to the appropriate shutdown board areas, given loss of room cooling to one train of switchgear.

- Failure probabilities for HPI/HPR and LPI/LPR pumps to start and run were set equal to 0.5 if only one pump appeared in a cut set. If two pumps appeared in the same cut set, the failure probability of the first was set to 1.0 and the failure probability of the second was unaffected. This reflects the separation between trains of switchgear (i.e., failure of one train of switchgear room cooling affects the operability of only that specific train). 
- Unavailabilities of pumps and valves due to test and maintenance were assumed to be unaffected.

- The failure probabilities for $125-V$ vital buswork was set equal to 1.0 since this equipment is located in the ESF switchgear room.

\section{Loss of Control Room Cooling.}

- Failure probabilities for motor-operated PORV block valves were set equal to 0.5. This is the approximate probability that an operator would be able to restore power to a valve actuator, given failure of one train of control room cooling.

- Failure of PORVs to open on demand is assumed to be unaffected by loss of control room cooling.

- Failure of AFW MDPs to start and run was set equal to 0.5 to account for the possibility that valve and pump controls in the control room are unavailable. This includes the contribution from the operator being unable to restore cooling to AFW panels located in the control room, given loss of one train of control room HVAC. For sequences in which two AFW MDPs fail simultaneously, both pump failure probabilities were set to 0.5 .

- AFW TDP failure probabilities were assumed unaffected, because the pump, is provided with backup DC control power, and the AFW TDP room cooler is provided with backup DC power. Therefore, failure of the AFW TDP was assumed to be independent of failure of one train of control room cooling.

- All AOVs are unaffected by failure of control room cooling (see above).

- Failure of operators to switch to feed-and-bleed cooling was set equal to 1.0. This reflects the high probability that loss of control room cooling could affect control room indications as well as operability of components required to respond to a transient.

- AFW actuation circuitry failure probability is independent of loss of control room cooling.

- Unavailabilities of pumps and valves due to test and maintenance were assumed to be unaffected.

- Failure probabilities for HPI/HPR and LPI/LPR pumps were treated in the same manner as loss of switchgear room cooling.

Loss of HPI/HPR Pump Room Cooling.

- Failure probabilities for motor-operated PORV block valves, PORVs, and all AFW-related valves, pumps, and actuation circuitry are unaffected by failure of HPI pump room cooling. 
- All AOVs are unaffected by failure of HPI room cooling (see above).

- Unavailabilities of pumps and valves due to test and maintenance were assumed to be unaffected.

- Failure of operators to switch to feed-and-bleed cooling were set equal to 1.0 to reflect the prior failure of HPI pump room cooling, which causes failure of the LIPI/HPR pump to start on demand or to run for the required period of time. LPI/LPR pump operability is not affected.

LOSS of LPI/LPR Pump Room Cooling.

- Failure probabilities for motor-operated PORV block valves, PORVs, and all AFW-related valves, pumps, and actuation circuitry are unaffected by failure of LPI pump room cooling.

- All AOVs are unaffected by failure of LPI room cooling (see above).

- Unavailabilities of pumps and valves due to test and maintenance were assumed to be unaffected.

- Failure of operators to switch to feed-and-bleed cooling is not affected by operability of LPI room coolers, because only HPI is required for early core heat removal via feed-and-bleed cooling.

- Failure probabilities for LPI/LPR pumps were set equal to 1.0 to reflect the prior failure of LPI pump room cooling, which causes failure of the LPI/LPR pump to start on demand or to run for the required period of time. HPI/HPR pump operability is not affected.

Loss of Vital DC Equipment Room Cooling.

- Loss of a vital DC bus was assumed to cause MSIV closure and turbine trip. Loss of the power conversion system (PCS) was assumed to be unrecoverable.

- Loss of the vital DC bus was assumed to result in failure of vital control power to ESF pumps and valves powered from this bus. The other vital $D C$ bus was assumed to be unaffected by loss of room cooling to the affected $D C$ equipment.

- The vital DC bus affected by loss of room cooling was assumed to the most heavily loaded bus.

Table 4.1-4 summarizes the affected parameters and their values for each room cooling event tree.

The procedure used to calculate the affected CDF involved downloading the minimal cut sets from the SARA computer code into a spreadsheet and then performing the parameter modifications described above. For the loss of 
TABLE 4.1-4. Affected Parameters and Values for Basic Events in Room Cooler Initiator Event Trees

\begin{tabular}{|c|c|c|c|c|c|c|c|}
\hline \multirow{2}{*}{\multicolumn{2}{|c|}{$\begin{array}{l}\text { Parameter } \\
\text { Designation }\end{array}$}} & \multirow{2}{*}{$\begin{array}{l}\text { Original } \\
\text { Value, per } \\
\text { Demand }\end{array}$} & \multicolumn{5}{|c|}{ Modified Values, per demand $(C)$} \\
\hline & & & $T S W^{(D)}$ & $T C R^{(D)}$ & $\mathrm{TH}^{(0)}$ & $T L P(0)$ & $T D C^{(0)}$ \\
\hline \multicolumn{2}{|c|}{ HPI -XHE-FO-FDBLD } & $2.2 \mathrm{E}-02$ & 1.0 & 1.0 & 1.0 & $2.2 E-02$ & $2.2 E-02$ \\
\hline \multicolumn{2}{|c|}{ HPI - MDP-FS-1AA } & $3.0 E-03$ & $0.5^{(c)}$ & 0.5 & 1.0 & $3.0 E-03$ & 3. $0 E-03$ \\
\hline \multicolumn{2}{|c|}{ HPI-MDP-FS-1BB } & $3.0 E-03$ & 0.5 & 0.5 & 1.0 & $3.0 E-03$ & $3.0 E-03$ \\
\hline \multicolumn{2}{|c|}{ HPI - MDP-FR-1AAGH } & $5.4 E-04$ & 0.5 & 0.5 & 1.0 & $5.4 E-04$ & $5.4 E-04$ \\
\hline \multicolumn{2}{|c|}{$H P I-M D P-F R-1 B B 6 H$} & $5.4 E-04$ & 0.5 & 0.5 & 1.0 & $5.4 E-04$ & $5.4 E-04$ \\
\hline \multicolumn{2}{|c|}{ LPI-MDP-FS-1AA } & $3.0 E-03$ & $0.5^{(d)}$ & 0.5 & $3.0 E-03$ & 1.0 & $3.0 E-03$ \\
\hline \multicolumn{2}{|c|}{ LPI - MDP-FS-1BB } & $3.0 E-03$ & 0.5 & 0.5 & $3.0 E-03$ & 1.0 & $3.0 E-03$ \\
\hline \multicolumn{2}{|c|}{ LPI-MDP-FR-1AAGH } & $5.4 E-04$ & 0.5 & 0.5 & $5.4 E-04$ & 1.0 & $5.4 E-04$ \\
\hline \multicolumn{2}{|c|}{ LPI -MDP-FR-1BB6H } & $5.4 E-04$ & 0.5 & 0.5 & $5.4 E-04$ & 1.0 & $5.4 E-04$ \\
\hline \multicolumn{2}{|c|}{ PPS-MOV-FT-332 } & $3.0 E-03$ & 0.5 & $3.0 E-03$ & $3.0 E-03$ & $3.0 E-03$ & 3. $O E-03$ \\
\hline \multicolumn{2}{|c|}{ PPS-MOV-FT-333 } & $3.0 E-03$ & 0.5 & $3.0 E-03$ & $3.0 E-03$ & $3.0 E-03$ & $3.0 E-03$ \\
\hline \multicolumn{2}{|c|}{$D C P-B D C-S T-I$} & $3.1 E-06$ & $0.5^{(d)}$ & 0.5 & $3.1 E-06$ & $3.1 E-06$ & $3.1 E-06$ \\
\hline \multicolumn{2}{|c|}{$D C P-B D C-S T-11$} & $3.1 E-06$ & 0.5 & 0.5 & $3.1 E-05$ & $3.1 E-06$ & $3.1 E-06$ \\
\hline \multicolumn{2}{|c|}{$A F W-M D P-F S-1 A A$} & $3.0 E-03$ & $0.5^{(d)}$ & 0.5 & $3.0 E-03$ & $3.0 E-03$ & $3.0 E-03$ \\
\hline \multicolumn{2}{|c|}{$A F W-M D P-F S-18 B$} & $3.0 E-03$ & 0.5 & 0.5 & $3.0 E-03$ & $3.0 E-03$ & $3.0 E-03$ \\
\hline \multicolumn{2}{|c|}{$A F W-M D P-F R-1 A A 6 H$} & $1.8 E-04$ & 0.5 & 0.5 & $1.8 E-04$ & $1.8 \mathrm{E}-$ & $1.8 E-04$ \\
\hline \multicolumn{2}{|c|}{$A F W-M D P-F S-1 B B 6 H$} & $1.8 \mathrm{E}-04$ & 0.5 & 0.5 & $1.8 E-04$ & $1.8 E-04$ & $1.8 E-04$ \\
\hline \multicolumn{2}{|c|}{ AFW-ACT-FA-TRNA } & $1.6 E-03$ & 0.5 & 0.5 & $1.6 E-03$ & $1.6 E-03$ & 1. $6 \mathrm{E}-03$ \\
\hline \multicolumn{2}{|c|}{ AFW-ACT-FA-TRNB } & $1.6 E-03$ & 0.5 & 0.5 & $1.6 E-03$ & $1.6 \mathrm{E}-03$ & $1.6 \mathrm{E}-03$ \\
\hline \multicolumn{2}{|c|}{$A C P-B A C-S T-1 A A$} & $3.1 E-06$ & $0.5^{(d)}$ & 0.5 & $3.1 E-06$ & $3.1 E-06$ & 3.1E-06 \\
\hline \multicolumn{2}{|c|}{$A C P-B A C-S T-1 B B$} & $3.1 E-06$ & 0.5 & 0.5 & $3.1 E-06$ & $3.1 E-06$ & 3.1E-06 \\
\hline \multicolumn{2}{|c|}{ AFW-TDP-FS-1AS } & $3.0 \mathrm{E}-02$ & 0.5 & 0.5 & $3.0 E-03$ & $3.0 E-03$ & $1.0^{(e)}$ \\
\hline \multicolumn{2}{|c|}{$A F W-T D P-F R-1 A S 6 H$} & $3.0 E-02$ & 0.5 & 0.5 & $1.8 \mathrm{E}-04$ & $1.8 E-04$ & 1.0 \\
\hline \multicolumn{2}{|c|}{ AFW-TDP-TM-1AS } & $1.0 \mathrm{E}-02$ & 0.5 & 0.5 & $1.8 \mathrm{E}-04$ & $1.8 E-04$ & 1.0 \\
\hline \multicolumn{8}{|c|}{$\begin{array}{l}\text { (a) Bertucio and Brown (1990). } \\
\text { (b) TSW = Loss of Switchgear room cooling initiator: TCR = Loss of control room cooling initiator: } \\
T H=\text { LOSS of HPI pump room cooling initiator: TLP = Loss of LPI pump room cooling initiator: } \\
T D C=\text { Loss of DC equipment room cooling initiator. } \\
\text { (c) Separate columns are provided for basic event probabilities used in each room cooler initiator } \\
\text { event tree. } \\
\text { (d) The value used in cut sets involving failure of a single pump, valve, or DC shutdown board was } \\
0.5 \text {. For cut sets involving failure of two pumps, two similar valves in different trains, or } \\
\text { two trains of DC shutdown board buswork, the probability of failure of the first component was } \\
\text { set to } 1.0 \text { and that for the second pump was set equal to the original value. } \\
\text { (e) Failure of DC bus results in loss of AFW TOP due to failure of steam inlet valves to open. One } \\
\text { motor-driven AFW train is also assumed to be unavailable due to loss of one division of vital DC } \\
\text { power. The other AFW pump train was assumed to be unaffected, and original parameter values } \\
\text { were used. }\end{array}$} \\
\hline
\end{tabular}

control room, switchgear room, and ESF pump room cooling initiating events, the cut sets for a transient with PCS unavailable were downloaded and modified to incorporate the loss of HVAC initiator and an event for failure to restore HVAC. Subsequent events or parameters in each cut set were then reviewed in light of the prior failure of the particular HVAC system. If the loss of HVAC 
affects the subsequent failure events, the modifications described previousiy were made to the parameter values. Unaffected events were left unchanged.

An example to illustrate this process follows: One original cut set from the SARA code involved a transient, followed by failure of both motordriven AFW pumps (Trains A and B) to start, failure of the turbine-driven AFW pump to start, and failure of operators to initiate feed-and-bleed cooling. Modifications made to this cut set consisted of the following:

- The original transient initiating event was changed to loss of control room cooling and failure to restore cooling.

- The failure probabilities for the MD AFW pumps were changed to 0.5 to reflect the prior failure of control room cooling, which will affect the ESF actuation system equipment located in the control room.

- Main feedwater was secured when AFW was initiated. Operators will attempt to restore MFW following loss of all AFW sources. The probability for operator failure to restore MFW given loss of control room cooling was assessed to be 0.1 demand.

- The probability for operator failure to initiated feed-and-bleed cooling was changed to 1.0 (i.e., always fails) because the loss of cooling in the control room renders operators "blind" due to malfunctions of instrumentation and control equipment.

The modification process for this minimal cut set is illustrated below:

\begin{tabular}{|c|c|c|}
\hline \multicolumn{2}{|r|}{ Original Cut Set Elements } & Probability \\
\hline T3 & Turbine trip with MFW available & $6.3 E+00$ \\
\hline$A F W-M D P-F S-1 A A$ & Train A AFW MDP fails to start & $3.0 E-03$ \\
\hline$A F W-M D P-F S-1 B B$ & Train B AFW MDP fails to start & $3.0 E-03$ \\
\hline AFW-TDB-FS-1AS & AFW TDP fails to start & $3.0 E-02$ \\
\hline M & Failure to recover MFW & $4.0 E-03$ \\
\hline HPI-XHE-FO-FDBLD & $\begin{array}{c}\text { Operator fails to initiate feed-and-bleed } \\
\text { Original cut set frequency }\end{array}$ & $\begin{array}{l}2.2 E-02 \\
1.5 E-10\end{array}$ \\
\hline \multicolumn{2}{|r|}{ Modified Cut Set Elements } & Probability \\
\hline TCR & Loss of control room cooling & $4.5 E-02$ \\
\hline RCR & Failure to recover loss of cooling & 4. $3 E-03$ \\
\hline AFW-MDP-FS-1AA & Train A AFW MDP fails to start & $5.0 E-01$ \\
\hline$A F W-M D P-F S-1 B B$ & Train B AFW MDP fails to start & $5.0 E-01$ \\
\hline AFW-TDB-FS-1AS & AFW TDP fails to start & $3.0 E-02$ \\
\hline M & Failure to recover $\mathrm{MFW}$ & $1.0 E-01$ \\
\hline HPI - XHE - FO-FDBLD & $\begin{array}{l}\text { Operator fails to initiate feed-and-bleed } \\
\text { Modified cut set frequency }\end{array}$ & $\begin{array}{l}1.0 E+00 \\
1.5 E-07\end{array}$ \\
\hline
\end{tabular}


These modified cut sets and the cut set frequency calculations, which were facilitated by a spreadsheet, are presented in Appendix B.

The mean total from room cooler initiators was calculated to be 2.04E-06/RY. The cumulative distribution function for the CDF is shown in Figure 4.1-2. The important statistical parameters of the CDF distribution are listed below; they were generated using Lat in Hypercube sampling techniques.

$\begin{array}{ll}\text { Mean: } & 2.04 \mathrm{E}-06 / \mathrm{RY} \\ 95 \% \text { upper confidence bound: } & 4.3 \mathrm{E}-06 / \mathrm{RY} \\ \text { Median: } & 1.1 \mathrm{E}-06 / \mathrm{RY} \\ 5 \% \text { lower confidence bound: } & 7.6 \mathrm{E}-07 / \mathrm{RY}\end{array}$

The mean cut set frequencies for each of the four room cooler initiators are presented in Table 4.1-5. Figure 4.1-3 presents a pie chart illustrating the contributions of each room cooler initiator to the total CDF associated with room cooler initiating events. As shown, $54 \%$ of the CDF from room cooler initiators result from failure of the ESF switchgear room coolers. Failure of the control room coolers contributes approximately $36 \%$, and failure of DC equipment room cooling contributed about $8 \%$ of the affected CDF. Approximately $2 \%$ of the CDF arises from HPI/HPR pump room cooler initiators, and less than $1 \%$ arises from failure of LPI/LPR pump room coolers.

This study resulted in the identification of 32 minimal cut sets with frequencies greater than 1E-08/RY. Of these 32 presented in Table 4.1-6, seven have frequencies greater than IE-07/RY. The 32 cut sets shown in the table account for approximately $95 \%$ of the total CDF due to room cooler initiators. The values shown in the table are point estimates, based on mean values for each event. The cut sets are briefly described below.

The top four cut sets in Table 4.1-6 are very similar; they involve loss of control room cooling and nonrecovery in sufficient time to prevent a reactor SCRAM, failure of AFW pumps, failure of MFW, and failure of feed-and-bleed cooling due to operator error. The differences among the top four cut sets arise from different combinations of both trains of AFW MDPs to start and/or run and failure of the AFW TDP to start and/or run. The effects of loss of control room cooling on the operability of the AFW pumps and the operator's ability to initiate feed-and-bleed cooling were incorporated into the quantification process.

The next four highest frequency cut sets are similar to the top four, except that the initiator is failure of the ESF switchgear room coolers. As with the top four cut sets, these four involve failure of AFW pumps, failure of MFW, and failure of feed-and-bleed cooling due to operator error. 


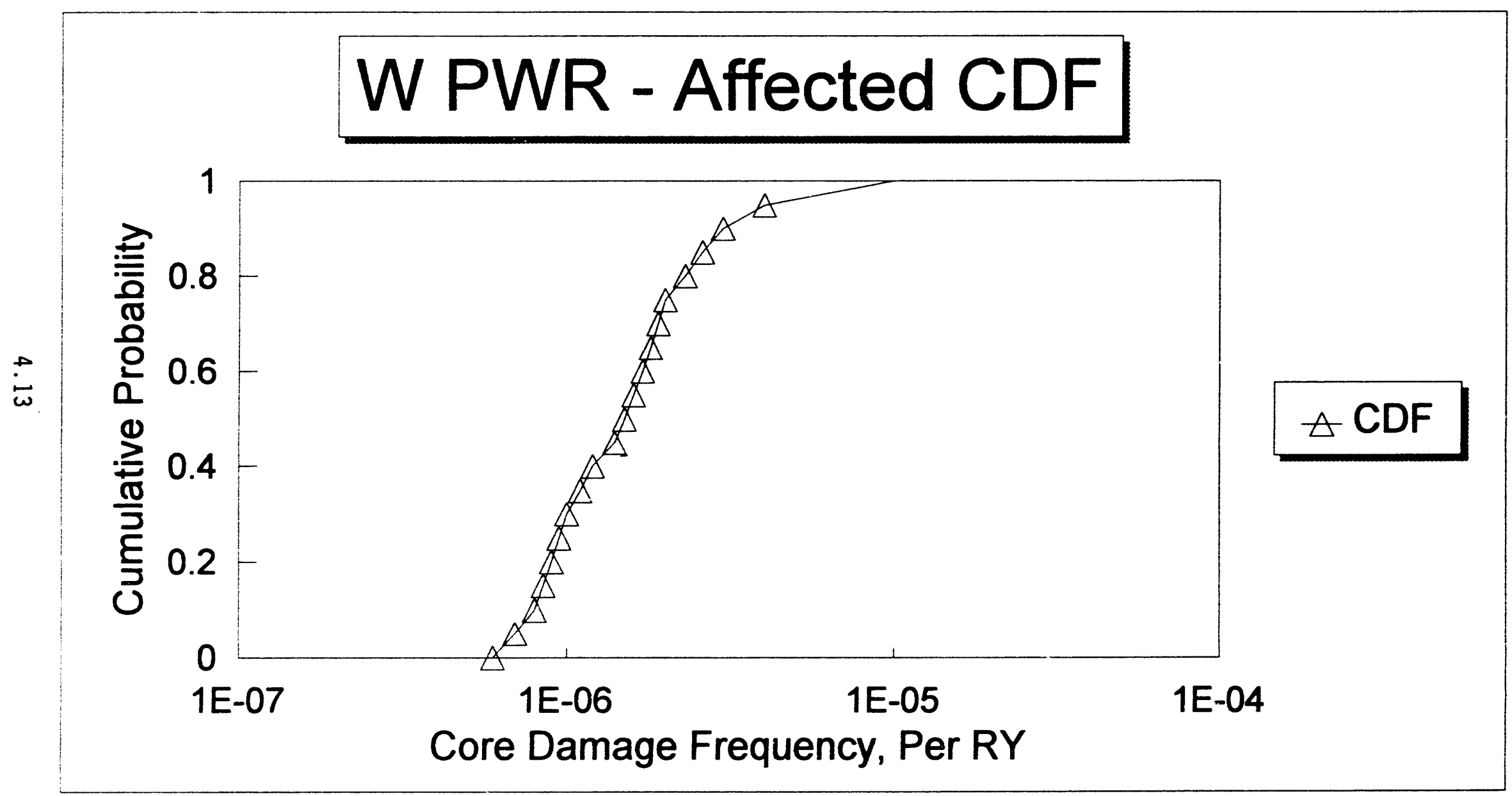

FIGURE 4.1-2. Total Room Cooler Initiator Core Damage Frequency Distribution 
TABLE 4.1-5. Assessed Mean Frequencies of Room Cooler Initiator Sequences (point estimates)

\begin{tabular}{|c|c|}
\hline Initiator & $\begin{array}{c}\text { Frequency } \\
\text { Per RY }\end{array}$ \\
\hline TSW & $1.1 \mathrm{E}-06$ \\
\hline TCR & $7.3 \mathrm{E}-07$ \\
\hline TH & $4.1 \mathrm{E}-08$ \\
\hline TLP & $2.9 \mathrm{E}-09$ \\
\hline TDC & $1.6 \mathrm{E}-07$ \\
\hline Totai & $2.0 \mathrm{E}-06$ \\
\hline
\end{tabular}

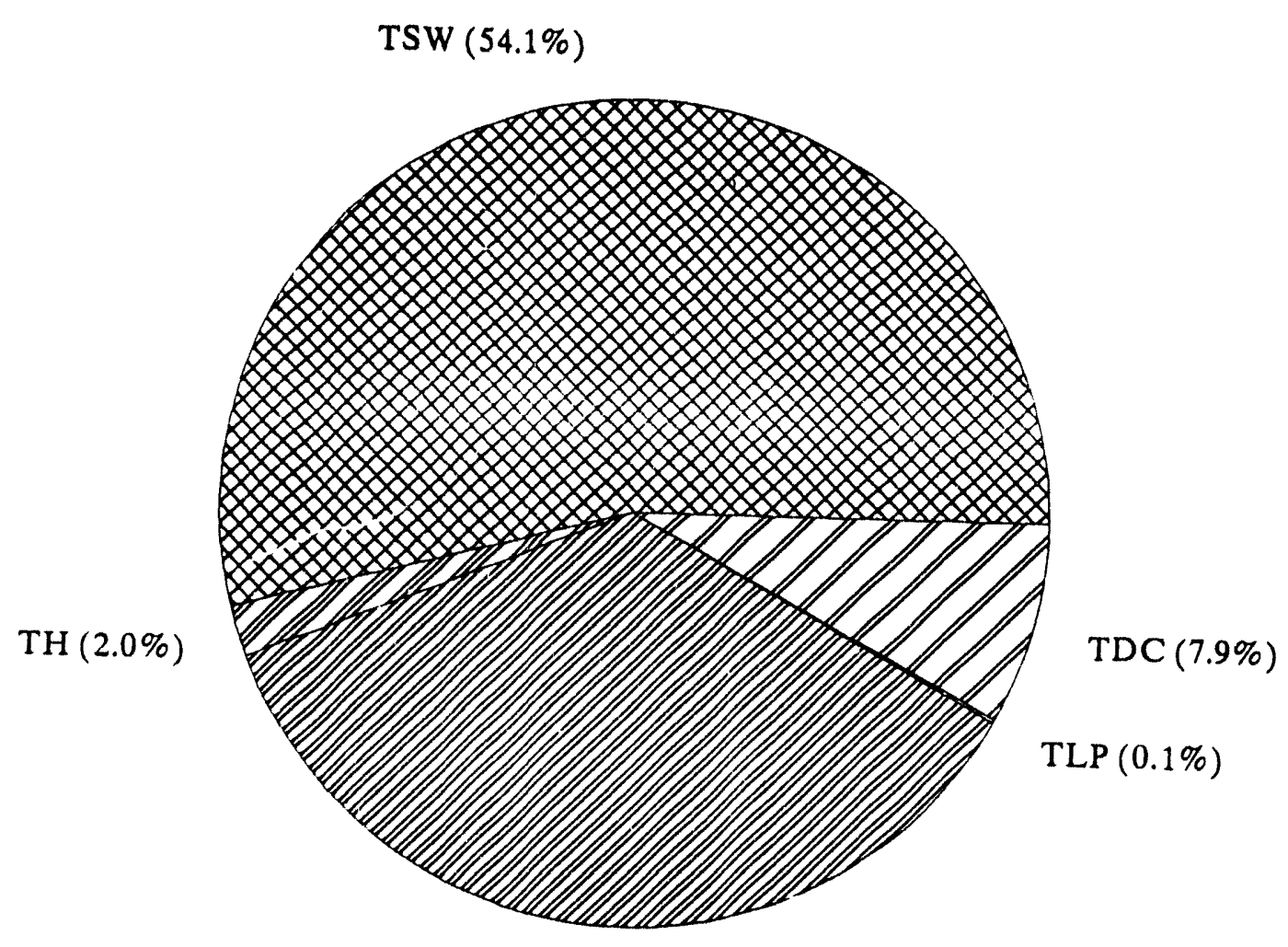

$\operatorname{TCR}(35.9 \%)$

EIGURE 4.1-3. Pie Chart Illustrating Contributions of Each Initiator to the CDF from Room Cooler Initiating Events 
IABLE 4.1-6. Summary of Minimal Cut:Sets with Frequencies Greater Than IE-08/RY (point estimates)

\begin{tabular}{|c|c|c|}
\hline $\begin{array}{l}\text { Cut Set } \\
\text { Number }\end{array}$ & Cut Set & $\begin{array}{l}\text { Frequency, } \\
\text { per RY }\end{array}$ \\
\hline TCR-39 & TCR, RCR, AFW-MDP-FS-1AA，AFW-MDP-FS-18B，AFW-TDP-FR-1AS6H， HPI-XHE-FO-FDBLD，M & $1.593 \mathrm{E}-07$ \\
\hline TCR-40 & TCR, RCR, AFW-MDP-FS-1AA, AFW-MDP-FS-1RB, AFW-TDP-FS-1AS, HPI-XHE-FO-FDBLD, M & $1.593 \mathrm{E}-07$ \\
\hline TCR-62 & TCR, RCR, AFW-MDP-FR-1AA24，AFW-MDP-FS-1BB，AFW-TDP-FR-1AS6H， HPI-XHE-FO-FDBLD, M & $1.593 \mathrm{E}-07$ \\
\hline TCR-63 & TCR, RCR, AFW-MDP-FR-1BB24, AFW-MDP-FS-1AA, AFW-TDP-FR-1AS6H, HP1-XHE-FO-FDBLD, M & $1.593 E-07$ \\
\hline TSW-45 & TSW, R'SW, AFW-MDP-FS-1AA，AFW-MDP-FS-18B，AFW-TDP-FR-1AS6H， HFI-XHE-FO-FDBLD, M & $1.384 \mathrm{E}-07$ \\
\hline TSW-46 & TSW, RSW, AFW-MDP-FS-1AA, AFW-MDP-FS-1BB, AFW-TDP-FS-1AS, HPI-XHE-FO-FDBLD, M & $1.384 E-07$ \\
\hline TSW-78 & TSW, RSW, AFW-MDP-FR-1AA24, AFW-MDP-FS-1BB, AFW-TDP-FR-1AS6H, HPI-XHE-FO-FDBLD, M & $6.918 \mathrm{E}-08$ \\
\hline TSW-79 & TSW, RSW, AFW-MDP-FR-1BB24, AFW-MDP-FS-1AA, AFW-TDP-FR-1AS6H, HPI-XHE-FO-FDBLD，M & $6.918 E-08$ \\
\hline TSW-88 & TSW, RSW, AFW-MDP-FS-1BB, AFW-TDP-FS-1AS, DCP-BDC-ST-1, M & $6.918 \mathrm{E}-08$ \\
\hline TSW-89 & TSW, RSW, AFW-MDP-FS-1AA, AFW-TDP-FR-1AS6H, DCP-BDC-ST-11, M & $6.918 \mathrm{E}-08$ \\
\hline TSW-90 & TSW, RSW, AFW-MDP-FS-1BB, AFW-TDP-FR-1AS6H, DCP-BDC-ST-I, M & $6.918 \mathrm{E}-08$ \\
\hline TSW-91 & TSW, RSW, AFW-MDP-FS-1AA, AFW-TDP-FS-1AS, DCP-BDC-ST-II, M & $6.918 E-08$ \\
\hline TSW- 108 & TSW, RSW, AFW-MDP-FR-1BB24, AFW-TDP-FS-1AS, DCP-BDC-ST-1, M & $6.918 E-08$ \\
\hline TSW-109 & TSW, RSW, AFW-MDP-FR-1AA24, AFW-TDP-FR-1AS6H, OCP-BDC-ST-II, M & $6.918 E-08$ \\
\hline TSW-110 & TSW, RSW, AFW-MDP-FR-1BB24, AFW-TDP-FR-1AS6H, OCP-BDC-ST-I, M & $6.918 E-08$ \\
\hline TSW-111 & TSW, RSW, AFW-MDP-FR-1AA24, AFW-TDP-FS-1AS, DCP-BDC-ST-11, M & $6.918 E-08$ \\
\hline TCR-22 & TCR, RCR, AFW-ACT-FA-TRNA, AFW-ACT-FA-TRNB, HPI-XHE-FO-FDBLD, M & 3. $398 E-08$ \\
\hline TOC -21 & $T D C, R D C, A F W-M D P-F S, A F W-T D P-F R-1 A S 6 H, B E T A-A F W$ & $2.688 \mathrm{E}-08$ \\
\hline TSW-106 & TSW, RSW, AFW-MDP-FS-1AA, AFW-TDP-TM-IAS, DCP-BDC-ST-1I, M & $2.306 \mathrm{E}-08$ \\
\hline TSW-107 & TSW, RSW, AFW-MDP-FS-1BB, AFW-TDP-TM-1AS, DCP-BDC-ST-1, M & $2.306 \mathrm{E}-08$ \\
\hline$T H-01$ & TH, RH, AFW-AOV-CC, BETA-BAOV, HP1-XHE-FO-FDBLD, M & $2.233 \mathrm{E}-08$ \\
\hline TCR-18 & TCR, RCR, AFW-MDP-FS, AFW-TDP-FS-1AS, BETA-AFW, HPI-XHE-FO-FDBLD, M & $1.784 \mathrm{E}-08$ \\
\hline TCR-19 & TCR, RCR, AFW-MDP-FS, AFW-TDP-FR-1AS6H, BETA-AFW, HPI-XHE-FO-FDBLD, M & $1.784 \mathrm{E}-08$ \\
\hline$T D C-23$ & TDC, RDC, AFW-MDP-FS-1AA, AFW-TDP-FR-1AS6H, RA17 & $1.776 \mathrm{E}-08$ \\
\hline TOC- 24 & TDC, RDC, AFW-MDP-FS-1AA, AFW-TDP-TM-1AS, RA17 & $1.776 \mathrm{E}-08$ \\
\hline TDC -25 & TDC, RDC, AFW-MDP-FS-1AA, AFW-TDP-FS-1AS, RA17 & $1.776 \mathrm{E}-08$ \\
\hline TSW-24 & TSW, RSW. AFW-ACT-FA-TRNA, AFW-ACT-FA-TRNB, HPI-XHE-FO-FDBLD, M & $1.476 \mathrm{E}-08$ \\
\hline$T S W-47$ & TSW, RSW, AFW-MDP-FS-1AA, AFW-MDP-FS-1BB, AFW-FAN-FS-TDPD, HPI-XHE-FO-FDBLD, M & $1.384 E-08$ \\
\hline TSW-112 & TSW, RSW, ACP-BAC-ST-1BB, AFW-MDP-FS-1AA, AFW-TDP-FR-1AS6H, PPS-MOV-FC-332, M & $1.384 E-08$ \\
\hline TSW-113 & TSW, RSW, ACP-BAC-ST-1AA, AFW-MDP-FS-18B，AFW-TDP-FR-1AS6H，PPS-MOV-FC-333，M & $1.384 \mathrm{E}-08$ \\
\hline TDC -26 & TDC, RDC, AFW-MDP-TM-1AA, AFW-TDP-FR-1AS6H, RA17 & $1.184 E-08$ \\
\hline TOC -27 & TDC, RDC, AFW-MDP-TM-1AA, AFW-TDP-FS-1AS, RA17 & $1.384 \mathrm{E}-08$ \\
\hline \multicolumn{3}{|r|}{$1.90 \mathrm{E}-06$} \\
\hline
\end{tabular}

The next eight cut sets, numbers 9 to 16, are initiated by loss of ESF switchgear room cooling and represent failure of the AFW TDP, failure of one train of AFW MDPs, and failure of the $125-\mathrm{V}$ vital bus supplying power to the other train of AFW MDPs. The effects of prior failure of switchgear room cooling on the values for the MDPs and the $125-V$ vital bus were incorporated into the analysis. 
Cut set 'number 17 is initiated by loss of control room cooling. Subsequent events include failure of both trains of AFW actuation signais, failure of MFW, and operator failure to switch to feed-and-bleed cooling. Cut set number 23 is similar but is initiated by loss of ESF switchgear room cooling. The effect of prior failure of control room cooling on the actuation circuitry was incorporated into the quantification process.

Cut set number 18 is the highest-frequency cut set initiated by loss of cooling to DC equipment. Core damage results from failure to provide secondary cooling via a motor-driven AFW pump train that is powered from the linfailed division of vital DC power.

Cut sets are similar to 9 through 16, except that the cause of failure of the AFW TDP was due to test/maintenance activities.

Cut set number 21 is initiated by failure of an HPI pump room cooler. Subsequent events that lead to core damage include failure of an AFW AOV to open, common-cause failure of eight AOVs leading to failure of AFW, and operator failure to initiate feed-and-bleed cooling. This is the only cut set in the top 26 that is initiated by loss of HPI pump room cooling.

Cut sets number 22 and 23 are initiated by loss of control room cooling, followed by failure of the AFW MDP to start, common-cause failure of both AFW MDPs, failure of the AFW TDP to start and/or run, and operator failure to initiate feed-and-bleed cooling.

Cut sets 24 to 26 are initiated by loss of DC equipment room cooling. Core damage results from failure of the AFW system to provide secondary heat removal.

Cut set 27 is initiated by loss of ESF switchgear room cooling. Subsequent events include failure of both trains of AFW MDPs to start, failure of the AFW TDP room cooler, failure to initiate feed-and-bleed cooling, and failure of MFW. The failure probability for the AFW room cooler was set to 1.0 to incorporate the effects of ESF switchgear room cooling on the operability of the AFW room cooler.

The next three cut sets in Table 4.1-6 are also initiated by loss of switchgear room cooling. Subsequent events include failure of one train of the 6.9-kV shutdown board buswork, located in the switchgear room, failure of the AFW MDP fed by the other train of 6.9-kV shutdown board buswork, failure of MFW, and failure of feed-and-bleed cooling. In these two cut sets, feedand-bleed cooling is unsuccessful because of prior closing of a PORV.

The final two cut sets in Table 4.1-6 are initiated by loss of DC equipment room cooling. Subsequent events include failure of the unaffected motor-driven AFW train and failure of the AFW TDP. The third AFW train, a motor-driven pump train, was assumed to be unavailable following loss of the vital DC power division cooled by the failed DC equipment room coolers. 


\subsubsection{Public Risk Calculations}

The next step in the analysis was to calculate the public risk associated with the core damage sequences discussed in the previous section. The minimal cut sets were grouped into plant damage states (PDSs). Each PDS provides simflar initial conditions for the subsequent accident progression analysis. Accident progression analysis uses large event trees to determine the possible ways in which an accident might evolve. The many paths through the accident progression event tree are then grouped into accident progression bins (APBs) which provide similar initial conditions for the subsequent source term analysis. The results of the accident progression analysis are probabilities for each APB, given the occurrence of a PDS. A source term is then computed for each APB which defines the quantities of radioactive materiai released to the environment. Consequence calculations are then performed for each source term. The accident progression, source term, and consequence analyses described by Gregory et al. (1990) form the basis for the present analysis.

For the analysis of room cooler initiators, the APBs and conditional probabilities were extracted from Gregory et al. (1990, Table 2.5-10). This table, which is reproduced in this report as Table 4.1-7, provides the APBs

IABLE 4.1-7. Conditional Probabilities of APBs Resulting from Transient Initiators

\begin{tabular}{|l|c|}
\hline \multicolumn{1}{|c|}{ Accident Progression Bin (APB) } & Conditional \\
Probability
\end{tabular}


resulting from transient initiators and the conditional probabilities of occurrence of each APB. The conditional probabilities given in the table were multiplied by the total CDF from room cooler initiators to calculate the accident frequency associated with each APB. A spreadsheet was used to perform these calculations.

The next step was to determine the source terms associated with each APB in Table 4.1-7. Gregory et a1. (1990) was used to partition the APBs into similar source term groups. The following observations presented by Gregory were used to perform this partitioning activity:

- About one-third of the source terms in source term group SEQ-14 are from early containment failures. Therefore, SEQ-14 was used to approximate the source term from the APB involving containment failure during core damage.

- Source term groups SEQ-16, SEQ-17, and SEQ-18 are dominated by late containment failures. These source term groups do not arise from accidents that result in bypass or early containment failure. These source term groups were assigned to the last three APBs shown in Table 4.1-7.

- The five most probable APBs for transients have no vessel break (VB) and no containment failure (Gregory et a1. 1990, p. 2.77). Therefore, it is likely that the APB for no VB will result in a relatively small source term. This APB was assigned to source term group SEQ-01.

- Source term group SEQ-04 was dominated by event V (interfacing LOCA). Event $V$, in turn, is characterized by a high probability of VB. CF is of little interest because of a direct leakage path from the reactor building to the auxiliary building. Therefore, the APB involving VB but no CF at VB was assigned to source term group SEQ-04.

Based on the previous discussion, the APB assignments to source term groups and the conditional probabilities of the various source term groups were developed. The results of this step are summarized in Table 4.1-8. The mean consequences, in terms of the integrated population dose within 50 miles of the representative plant, are also shown in the table.

The formula used to calculate public risk is

$$
\text { RISK }=\sum_{i, j}\left(C D F * A P B_{i} * S T G_{i, j} * C_{i, j}\right)
$$

where: $\quad A P B_{i}=$ Conditional probability of accident progression bin " $j$ " $S T G_{i, j}=$ Conditional probability for each source term group " $j$ " for each accident progression bin " $i$ "

$c_{i, j}=$ Consequences for source term group " $j$ " associated with each accident progression bin 
IABLE 4.1-8. Partitioning of APBs into Source Term Groups

\begin{tabular}{|c|c|c|c|}
\hline APB & $\begin{array}{l}\text { Source Term } \\
\text { Group }\end{array}$ & $\begin{array}{l}\text { Conditional } \\
\text { Probability }\end{array}$ & $\begin{array}{l}\text { Consequences } \\
\text { person-rem }\end{array}$ \\
\hline CF during CD & $\begin{array}{l}\text { SEQ-14-1 } \\
\text { SEQ } \\
\text { SEQ } 14-2 \\
\text { SEQ } 14\end{array}$ & $\begin{array}{l}0.039 \\
0.359 \\
0.602\end{array}$ & $\begin{array}{l}1.13 E+07 \\
2.96 E+04 \\
8.20 E+06\end{array}$ \\
\hline No VB & SEQ-01-02 & 1.0 & $3.19 E+04$ \\
\hline CF at VB & SEQ-07-03 & 1.0 & $1.49 E+06$ \\
\hline VB, no $C F$ at $V B$ & $\begin{array}{l}\text { SEQ-04-01 } \\
\text { SEQ-04-01 }\end{array}$ & $\begin{array}{l}0.002 \\
0.998\end{array}$ & $\begin{array}{l}7.71 E+05 \\
6.82 E+05\end{array}$ \\
\hline CF - late burn & $\begin{array}{l}\text { SEQ-16-01 } \\
\text { SEQ-16-02 }\end{array}$ & $\begin{array}{l}0.99 \\
0.01\end{array}$ & $\begin{array}{l}1.38 E+02 \\
1.98 E+03\end{array}$ \\
\hline$C F$ - very late $O P$ & $\begin{array}{l}\text { SEQ-17-01 } \\
\text { SEQ-17-02 }\end{array}$ & $\begin{array}{l}0.999 \\
0.001\end{array}$ & $\begin{array}{l}1.14 E+03 \\
8.09 E+03\end{array}$ \\
\hline CF - very late BMT & $\begin{array}{l}\text { SEQ-18-01 } \\
\text { SEQ-18-02 }\end{array}$ & $\begin{array}{l}0.888 \\
0.112\end{array}$ & $\begin{array}{l}1.06 E+05 \\
3.06 E+05\end{array}$ \\
\hline \multicolumn{4}{|c|}{$\begin{array}{l}\text { (a) Integrated radiation dose to the population with } 50 \text { miles of the } \\
\text { representative plant (Gregory et al. 1990, Table } 4.3-1 \text { ). } \\
\text { (b) Source term groups are further subdivided into three subgroups } \\
\text { based on evacuation timing. In subgroup 1, evacuation starts at } \\
\text { least } 30 \text { minutes prior to the release. In subgroup } 2 \text {, evacua- } \\
\text { tion starts between } 30 \text { minutes before and one hour after the } \\
\text { release. In subgroup } 3 \text {, evacuation starts more than one hour } \\
\text { after the release. The possible subgroups and their proba- } \\
\text { bilities were taken from Gregory et al. (1990, Table 3.4-4). }\end{array}$} \\
\hline
\end{tabular}

To illustrate the calculation process, the public risk from accident sequence TSW is described below. The frequency of this sequence was calculated to be $1.1 \mathrm{E}-06 / \mathrm{RY}$. This frequency was then multiplied by the conditional probabilities of each potential APB to calculate the APB frequencies for this sequence. For example, the frequency of TSW core damage sequences that leads to an APB characterized by containment failure during core damage is $\left(1.1 \mathrm{E}-06 / \mathrm{RY} * 0.002^{(\mathrm{a})}\right)=2.2 \mathrm{E}-09 / \mathrm{RY}$. The resulting accident sequence/APB frequency was then multiplied by the conditional probabilities of the source term groups applicable to this APB. For example, Table 4.1-8 shows that the $A P B$ "CF During CD" is split among three source term groups: SEQ-14-1, SEQ-14-2, and SEQ-14-3. The frequency of TSW sequences that progress to this $A P B$ and then release radioactive materials in quantities and types represented by source term group SEQ-14-1 was calculated to be $(1.1 \mathrm{E}-06 / \mathrm{RY} * 0.002$ * $0.039)=8.5 E-11 / R Y$. The next step was to combine the frequency of the

(a) See Table 4.1-7 for APB probabilities. 
sequence involving "TSW/CD During CD/SEQ-14-1" with the consequences of a SEQ-14-1 release to calculate the public risk value associated with this sequence. Therefore, the risk associated with "TSW/CD During CD/SEQ-14-1" was calculated to be $(8.5 \mathrm{E}-11 / \mathrm{RY} * 1.13 \mathrm{E}+07$ person-rem) $=9.7 \mathrm{E}-04$ person-rem $/ \mathrm{RY}$. This procedure was then repeated for all source-term groups and APBs associated with TSW core damage sequences. Then, the same procedure was applied to the other accident sequences, TCR, TSW, TLP, and TH. A spreadsheet was developed to facilitate the calculations. The data used in the spreadsheet were taken from Tables 4.1-7 and 4.1-8.

The mean public risk associated with room cooler initiators at the representative W PWR was calculated to be 4.0E-01 person-rem/RY. The cumulative distribution function for public risks is shown in Figure 4.1-4. The important statistical parameters are listed below; these were generated using Latin Hypercube Sampling techniques.

\section{Mean:}

95\% upper confidence bound:

Median:

$5 \%$ lower confidence bound:
4.0E-01/person-rem/RY

9.7E-01/person-rem/RY

$3.2 E-01 /$ person-rem/RY

$1.6 \mathrm{E}-01 /$ person-rem/RY

\subsubsection{Room Cooler Failure Contributions to Other Accident Sequences at the Representative W PWR}

This section presents the results of the calculations performed using data taken from the SARA computer code. These calculations were performed to quantify the contributions to the CDF that result from safety system failures due to inoperable or malfunctioning room coolers. In this part of the analysis, room cooler failures are considered as contributors to core damage sequences initiated by events other than room cooler failures. Subsection 4.1.2.1 contains a discussion of the initiating event frequencies, subsection 4.1.2.2 discusses the quantification of the CDF, and subsection 4.1.2.3 presents the public risk calculations.

\subsubsection{Initiating Event Frequency}

Initiating event frequencies were taken directly from Bertucio and Brown (1990). No additional analyses were needed to develop initiator frequencies for this part of the analysis.

\subsubsection{Core Damage Frequency Quantification}

The main source of data for this part of the analysis was the SARA code data files developed from Bertucio and Brown (1990). SARA data files were obtained from the NRC. Then the cut sets containing room cooler failure events were identified, and the remaining cut sets were deleted because they are not affected by this issue. This is applicable to all cut sets except 


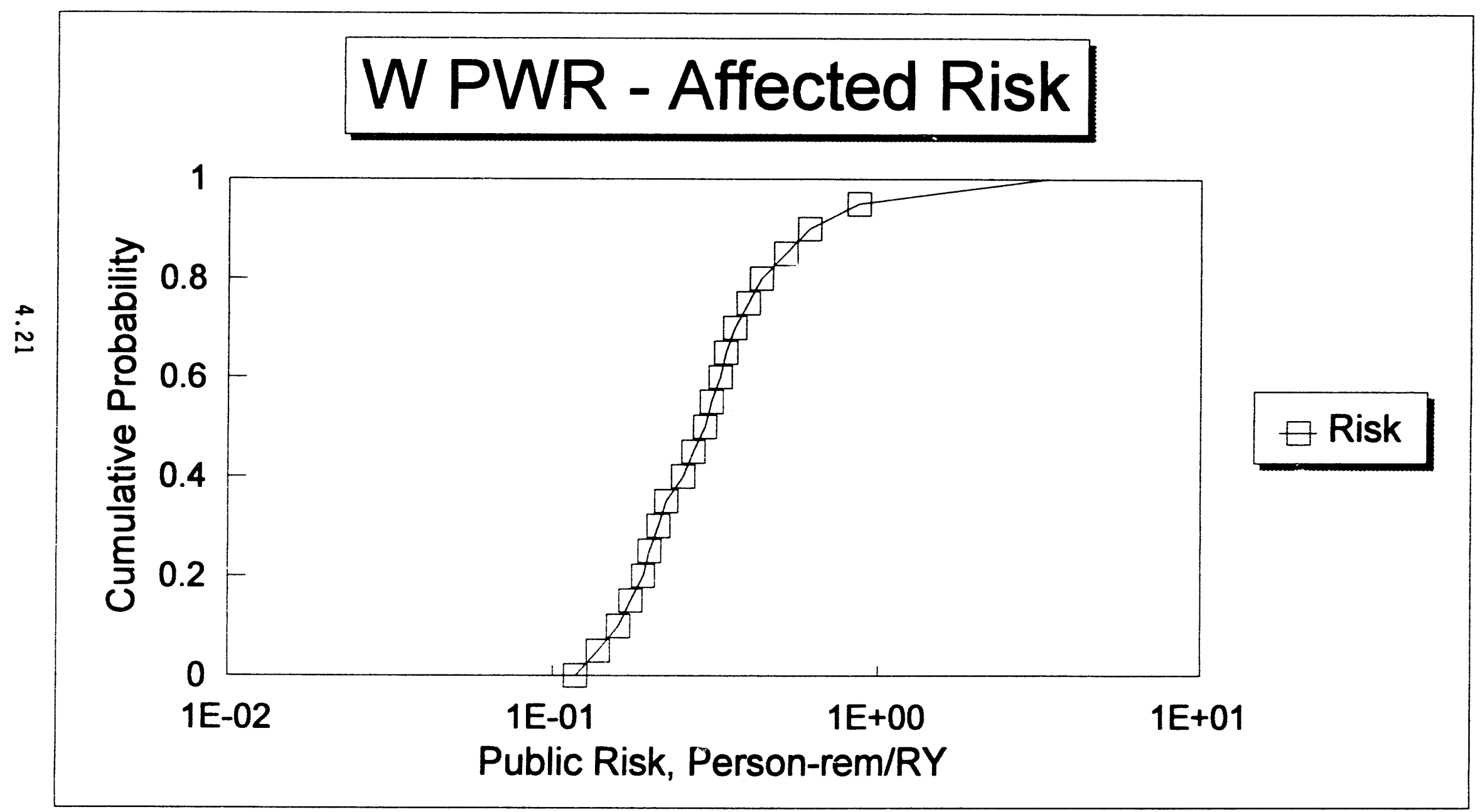

FIGURE 4.1-4. Total Room Cooler Initiator Public Risk Distribution 
those initiated by a loss of offsite power (LOOP). The LOOP cut sets and other cut sets involving emergency diesel generator (EDG) failures were retained for further analys is because the EDG room cooler failures were not included in the SARA data files. Since it was desirable to include EOG room cooling in this analysis, the LOOP cut sets were modified to incorporate EDG room cooler failures.

Modifications to the LOOP minimal cut sets, i.e., those that included EDG failures, consisted primarily of creating additional cut sets that incorporated EDG ventilation system failures. EDG ventilation system failures were considered functionally equivalent to failures of the EDGs to start, since there is little time, perhaps only about 15 minutes, to restore ventilation prior to failure of the cabinets and electrical switchgear equipment in the EDG rooms. Based on this observation, recovery from EDG ventilation failure is considered unlikely.

As an example of this modification process, consider a cut set that involves the following basic events:

1. T1S - Loss of offsite power

2. AFW-XHE-OPNVALVE - Failure to open AOVs between SGs and AFW TDP

3. DG-REC - Recovery of EDGs within one hour

4. NOT-SGI - Secondary side integrity retained

5. NOTQ - Successful closure of PORV

6. NRACIHR - Failure to recover offsite power within one hour

7. OEP-DGN-FS-1AA - Failure of EDG 1A to start

8. OEP-DGN-FS-1BB - Failure of EDG 1B to start

This cut set was modified to generate three new cut sets containing EOG ventilation system failures. These new cut sets are

1. T1S - Loss of offsite power

2. AFW-XHE-OPNVALVE - Failure to open AOVs between SGs and AFW TDP

3. EDG-REC - Recovery of EDGs within one hour

4. NOT-SG1 - Secondary side integrity retained

5. NOTQ - Successful closure of PORV

6. NRACIHR - Failure to recover offsite power within one hour

7A. OEP-DGN-FS-1AA - Failure of EDG 1A to start

8A. DGN-FAN-FS-1BB - Failure of Train B of the EDG ventilation system

and

1. T1S - Loss of offsite power

2. AFW-XHE-OPNVALVE - Failure to open AOVs between SGs and AFW TDP

3. EDG-REC - Recovery of EDGs within one hour

4. NOT-SGI - Secondary side integrity retained

5. NOTQ - Successful closure of PORV

6. NRACIHR - Failure to recover offsite power within one hour

7B. OEP-DGN-FS-1BB - Failure of EDG 1B to start

8B. DGN-FAN-FS-1AA - Failure of Train A of the EDG ventilation system 
and

1. T1S - Loss of offsite power

2. AFW-XHE-OPNVALVE - Failure to open AOVs between SGs and AFW TDP

3. EDG-REC - Recovery of EDGs within one hour

4. NOT-SGI - Secondary side integrity retained

5. NOTQ - Successful closure of PORV

6. NRACIHR - Failure to recover offsite power within one hour

7C. DGN-FAN-FS-1AA - Failure of Train A of the EDG ventilation system

8D. DGN-FAN-FS-1BB - Fallure of Train B of the EDG ventilation system

Additional cut sets were developed to include other EDG failure modes, such as failure of the EDG "A" to run for six hours combined with failure of the EDG "B" ventilation system, and so on.

The new EDG ventilation system-r lated cut sets were programmed into a spreadsheet that now includes cut sel; for the following accident sequences:

- SIH4 - SI = Medium LOCA; H4 = Failure of LPI in miniflow mode ( $1 / 2$ trains) or LPR (1/2 trains) or hot-leg recirculation in the long term. Includes cut sets with failure of LPR pump room coolers as well as cut sets with EDG failures that were modified in this study to incorporate EDG ventilation failures)

- $\mathrm{S} 2 \mathrm{H3}-\mathrm{S2}=\mathrm{Smal1}$ LOCA; H3 = Failure of LPI in miniflow mode ( $1 / 2$ trains) or LPR ( $1 / 2$ trains) (hot-leg recirculation not required)

- S30CH3 - $S 3=$ Very small LOCA $O C=$ Operator not able to control containment sprays during S3 LOCA; H3 (see above)

- S3W1H3 - S3 = Very small LOCA; W1 = Failure to provide 1/2 RHR trains during shutdown cooling mode; $\mathrm{H} 3$ (see above)

- $\mathrm{AHI} \quad-\mathrm{A}=$ Large LOCA; $\mathrm{Hl}=$ Failure of LPR with $1 / 2$ trains or failure to switch to hot leg (includes cut sets with EDG failures modified to incorporate EDG ventilation failures)

- SBO-BATT - Station blackout (SBO) sequences with battery depletion (includes cut sets with EDG failures modified to incorporate EDG ventilation failures)

- SBO-SLOCA - SBO sequences with RCP seal LOCA (includes cut sets with EDG failures modified to incorporate EDG ventilation failures)

- SBC-L - SBO sequences with failure of AFW (includes cut sets with AFW TDP room cooler failures as well as cut sets with diesel EDG failures modified to incorporate EDG ventilation failures) 
- SBO-Q - Station blackout sequences with stuck open PORV (includes cut sets with EDG failures modified to incorporate EDG ventilation failures)

As a result of the previous analyses, approximately 160 minimal cut sets were developed to model room cooler failures as contributing events. These cut sets are presented in Appendix $C$.

The basic event probability data presented by Bertucio and Brown (1990) were then input to the spreadsheet, and the CDF was calculated. The mean total CDF from room cooler contributors was calculated to be $2.6 \mathrm{E}-06 / \mathrm{RY}$. The cumulative distribution function for the CDF is shown in Figure 4.1-5. The important statistical parameters of the CDF distribution are listed below. These statistics were generated using Lat in Hypercube sampling techniques.
Mean:
$2.62 E-06 / R Y$
95\% upper confidence bound:
5.0E-06/RY
Median:
7.0E-07/RY
5\% lower confidence bound:
$1.0 \mathrm{E}-07 / \mathrm{RY}$

The mean cut set frequencies for each of the accident sequences containing room cooler failures are presented in Table 4.1-9. Figure 4.1-6 presents a pie chart illustrating the contributions of each room cooler initiator to the total CDF associated with room cooler initiating events. As shown, $49 \%$ of the CDF from room cooler failure contributing events results from SBO-RCP Seal LOCA sequences. The next highest fraction results from SBO sequences involving loss of AFW. Very small LOCA sequences with HPR and LPR failure results in about $8 \%$ of the total CDF due to room cooler contributing events.

This part of the analysis resulted in identifying 23 minimal cut sets containing room cooler contributing events that had frequencies greater than 1E-08 per RY. Of these 23 cut sets, three have frequencies greater than 1E-07 per RY. These cut sets are presented in Table 4.1-10. The 23 cut sets shown in the table account for approximately $75 \%$ of the total CDF due to room cooler contributors. The values shown in the table are point estimates, based on mean values for each event. These cut sets are briefly described below.

The first two cut sets are SBO-SLOCA sequences in which failures of Unit 1 EDGs and the $A C$ power connection from Unit 2 occur. The sequence also includes recovery of the Unit 1 EDGs, failure to recover offsite power within 216 minutes, and failure of the EDG ventilation system. This results in a seal vulnerable condition and ultimately core damage due to RCP seal LOCA.

The next four cut sets are SBO-AFW failure sequences. AFW failure is due to failure to open AOVs between the SGs and the AFW TDP, resulting in failure of $S G$ heat removal. The cut sets also involve common cause failure of the EDGs, recovery of EDG failures, and subsequent failure of the EDG ventilation system. Cut set numbers seven and eight are similar to cut set three except AFW system failure results from failure of the AFW TDP to start and from failure of the AFW TDP room cooler to start, respectively. 


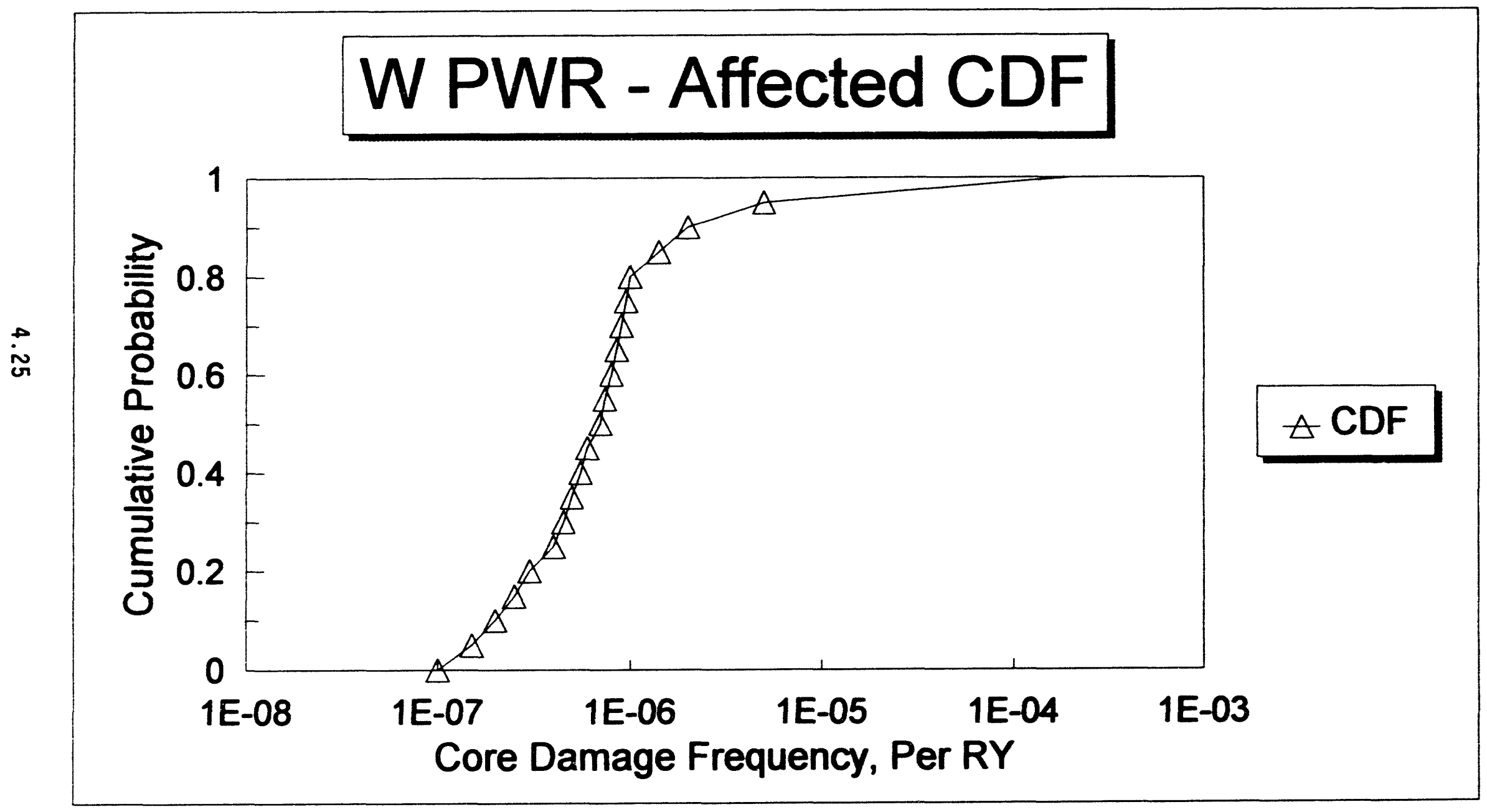

FIGURE 4.1-5. Total Room Cooler Contributing Event Core Damage Frequency Distribution 
IABLE 4.1-9. Affected Accident Sequences and Base-Case Frequenctes (point estimates)

\begin{tabular}{|l|c|}
\hline Sequence & $\begin{array}{c}\text { Frequency, } \\
\text { per RY }\end{array}$ \\
\hline S1H4 & $1.1 \mathrm{E}-09$ \\
S2H3 & $1.6 \mathrm{E}-08$ \\
S3OCH3 & $8.0 \mathrm{E}-08$ \\
S3W1H3 & $1.7 \mathrm{E}-07$ \\
AH1 & $4.7 \mathrm{E}-12$ \\
SBO-BATT & $8.2 \mathrm{E}-09$ \\
SBO-L & $7.3 \mathrm{E}-07$ \\
SBO-Q & $4.0 \mathrm{E}-08$ \\
SBO-SLOCA & $1.0 \mathrm{E}-06$ \\
\hline TOTAL & $2.1 \mathrm{E}-06$ \\
\hline
\end{tabular}

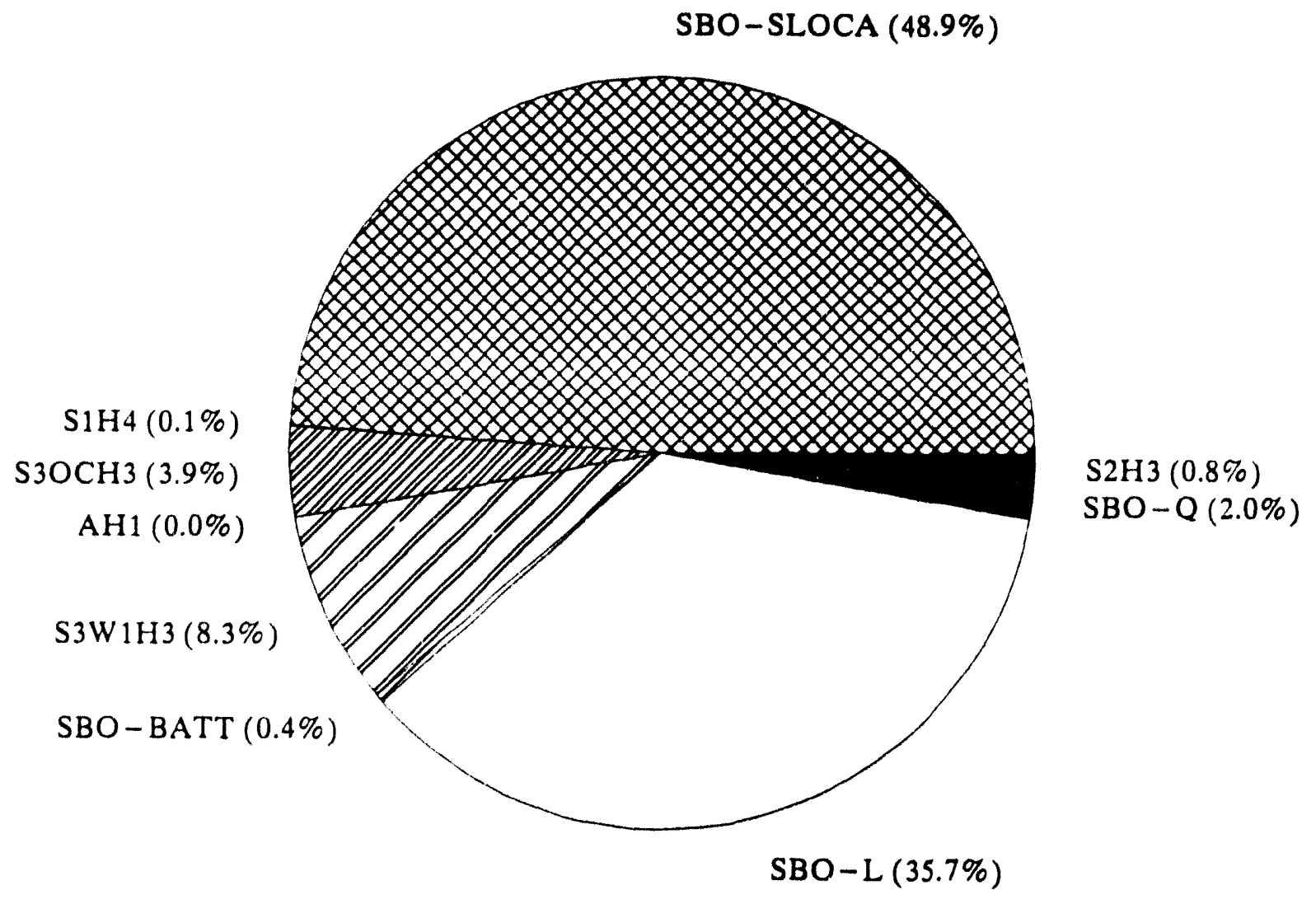

FIGURE 4.1-6. Pie Chart Illustrating Contributions of Each Initiator to the CDF from Room Cooler Contributing Events 


\section{TABLE 4.1-10. Minimal Cut Sets with Frequencies Greater Than 1E-8/RY}

\begin{tabular}{|c|c|c|}
\hline $\begin{array}{l}\text { Cut Set } \\
\text { Number }\end{array}$ & Cut Set Elements & $\begin{array}{l}\text { Frequency, } \\
\text { per RY }\end{array}$ \\
\hline SL.OCA-1 & $\begin{array}{l}\text { T1S, ACP-DGN-RC-U2, BETA-2DG, DCP-U2, DG-REC2, NOTL, NOTQ, NRAC-216MIN, /0D3, } \\
\text { DGN-FAN-FS, RCP-LOCA-100OGPM, /SGI }\end{array}$ & $3.883 E-07$ \\
\hline SLOCA-2 & $\begin{array}{l}\text { T1S, ACP-DGN-RC-U2, BETA-2DG, DCP-U2, OG-REC2, NOTL, NOTQ, NRAC-216MIN, } / 0 D 3 \text {, } \\
\text { DGN-FAN-FR, RCP-LOCA-1000GPM, /SG1 }\end{array}$ & $3.883 E-07$ \\
\hline$S B 0-L-21$ & T1S, AFW-XHE-OPNVALVE, BETA-2DG, DG-REC, NOT-SGI, NOTQ, NRAC1HR, OGN-FAN-FS, & $1.081 E-07$ \\
\hline$S B O-L-22$ & $\begin{array}{l}\text { T1S, AFW-XHE-OPNVALVE, DG-REC, NOT-SGI, NOTQ, NRACIHR, OEP-DGN-FS-1AA, } \\
\text { DGN-FAN-FS-1BB }\end{array}$ & $8.532 E-08$ \\
\hline$S B O-L-23$ & $\begin{array}{l}\text { T1S, AFW-XHE-OPNVALVE, DG-REC, NOT-SGI, NOTQ, NRAC1HR, OEP-DGN-FS-1BB, } \\
\text { DGN-FAN-FS-1AA }\end{array}$ & $8.532 E-08$ \\
\hline$S B O-L-26$ & $\begin{array}{l}\text { TIS, AFW-XHE-OPNVALVE, DG-REC, NOT-SGI, NOTQ, NRACIHR, OEP-DGN-FS-1BB, } \\
\text { DGN-FAN-FR-IAA }\end{array}$ & $8.532 \mathrm{E}-08$ \\
\hline$S B O-L-24$ & T1S, AFW-TDP-FS-1AS, BETA-2DG, DG-REC, NOT-SGI, NOTQ, NRACIHR, DGN-FAN-FS & $5.066 \mathrm{E}-08$ \\
\hline$S B O-L-1$ & T1S, AFW-FAN-FS-TDPD, BETA-2DG, DG-REC, NOT-SGI, NOTQ, NRACIHR, OEP-DGN-FS, & $5.066 \mathrm{E}-08$ \\
\hline$S B O-L-2$ & $\begin{array}{l}\text { T1S, AFW-FAN-FS-TDPD, UG-REC, NOT-SGI, NOTQ, NRACIHR, OEP-DGN-FS-1AA, } \\
\text { OEP-DGN-FS-1BB }\end{array}$ & $3.999 E-08$ \\
\hline$S B O-L-25$ & $\begin{array}{l}\text { T1S, AFW-TDP-FS-1AS, DG-REC, NOT-SGI, NOTQ, NRAC1HR, OEP-DGN-FS-1AA, } \\
\text { DGN-FAN-FS-1BB }\end{array}$ & $3.999 \mathrm{E}-08$ \\
\hline$S B O-L-27$ & $\begin{array}{l}\text { TIS, AFW-XHE-OPNVALVE, DG-REC, NOT-SGI, NOTQ, NRACIHR, OEP-DGN-FR-1BBG, } \\
\text { DGN-FAN-FS-1AA }\end{array}$ & $3.413 E-08$ \\
\hline$S B O-L-28$ & $\begin{array}{l}\text { TIS, AFW-XHE-OPNVALVE, DG-REC, NOT-SGI, NOTQ, NRAC1HR, OEP-DGN-FR-1AA6, } \\
\text { DGN-FAN-FS-1BB }\end{array}$ & $3.413 \mathrm{E}-08$ \\
\hline SLOCA-3 & $\begin{array}{l}\text { T1S, ACP-DGN-RC-U2, DCP-U2, DG-REC2, NOTL, NOTQ, NRAC-216MIN, /0D3, } \\
\text { OEP-DGN-FS-1AA, DGN-FAN-FS-1BB, RCP-LOCA-100OGPM, /SG1 }\end{array}$ & $3.066 \mathrm{E}-08$ \\
\hline SLOCA-4 & $\begin{array}{l}\text { T1S, ACP-DGN-RC-U2, DCP-U2, DG-REC2, NOTL, NOIQ, NRAC-216MIN, /OD3, } \\
\text { OEP-DGN-FS-1AA, DGN-FAN-FS-1BB, RCP-LOCA-100OGPM, /SG1 }\end{array}$ & $3.066 \mathrm{E}-08$ \\
\hline$S B O-L-3$ & $\begin{array}{l}\text { TIS, AFW-FAN-FS-TDPD, DG-REC, NOTQ, NRACIHR, OEP-DGN-FR-1AAG, OEP-DGN-FS-1BB, } \\
\text { ISGI }\end{array}$ & $1.600 E-08$ \\
\hline$S B O-L-4$ & $\begin{array}{l}\text { T1S, AFW-FAN-FS-TDPD, OG-REC, NOT-SGI, NOTQ, NRACIHR, OEP-DGN-FR-1AAG, } \\
\text { OEP-DGN-FS-1BB }\end{array}$ & $1.600 E-08$ \\
\hline$S B O-L-5$ & $\begin{array}{l}\text { I1S, AFW-FAN-FS-TDPD, DG-REC, NOT-SGI, NOTD, NQRAC1HR, OEP-DGN-FR-1BBG, } \\
\text { OEP-DGN-FS-IAA }\end{array}$ & $1.600 E-08$ \\
\hline SLOCA-12 & $\begin{array}{l}\text { T1S, ACP-DGN-RC-U2, OCP-U2, NOTL, NOTQ, NRAC-216MIN, /OD3, OEP-DGN-FR-IAA6, } \\
\text { DGN-FAN-FS-1BB, RCP-LOCA-1000GPM, /SG1 }\end{array}$ & $1.533 E-08$ \\
\hline SLOCA-13 & $\begin{array}{l}\text { T15, ACP-DGN-RC-U2, DCP-U2, NOTL, NOTQ, NRAC-216MIN, /003, OEP-DGN-FR-1BB6, } \\
\text { DGN-FAN-FS-1AA, RCP-LOCA-1000GPM, /SG1 }\end{array}$ & $1.533 E-08$ \\
\hline SLOCA-5 & $\begin{array}{l}\text { T1S, ACP-DGN-RC-U2, DCP-U2, DG-REC2, NOTL, NOTQ, NRAC-216MIN, /0D3, } \\
\text { OEP-DGN-FR-1AA6, DGN-FAN-FS-1BB, RCP-LOCA-1000GPM, /SG1 }\end{array}$ & $1.226 \mathrm{E}-08$ \\
\hline SLOCA-6 & $\begin{array}{l}\text { T1S, ACP-DGN-RC-U2, DCP-U2, OG-REC2, NOTL, NOTQ, NRAC-216MIN, /0D3, } \\
\text { OEP-DGN-FR-1BB6, DGN-FAN-FS-1AA, RCP-LOCA-1000GPM, /SG1 }\end{array}$ & $1.226 E-08$ \\
\hline SLOCA-17 & $\begin{array}{l}\text { I1S, ACP-DGN-RC-U2, /OCP-U2, NOTL, NOTQ, NRAC-216MIN, /0D3, DEP-DGN-FR-IAA6, } \\
\text { DGN-FAN-FS-1BB, RCP-LOCA-1000GPM, /SGI }\end{array}$ & $1.094 E-08$ \\
\hline SLOCA- 18 & $\begin{array}{l}\text { T1S, ACP-DGN-RC-U2, /OCP-U2, NOTL, NOTQ, NRAL-216MIN, /OD3, OEP-DGN-FR-1BB6, } \\
\text { DGN-FAN-FS-1AA, RCP-LOCA-100OGPM, /SG1 }\end{array}$ & $1.094 E-08$ \\
\hline & Total & \\
\hline
\end{tabular}


Cut sets number 9 and 10 are similar to cut set number 4 except AFW fallure results from fallure of the AFW TDP to start.

Cut sets number 11 and 12 are similar to cut set number 3 . The only difference is in the fallure mode for one of the two EDGs; i.e., fallure to run for six hours in cut sets 11 and 12 versus fallure to start in cut set 3 .

Cut sets number 13 and 14 are seal LOCA sequences; they are identical except for the causes of failure of the two separate EDG trains. In one, the Train A EDG fails to start, and the Train B EDG ventilation system fails. In the other cut set, Train A EDG ventilation fails, and Train B EDG fails to start.

Cut sets 15 through 17 are SBO-L sequences in which AFW fails due to fallure of the AFW TDP room cooler, which results in failure of the AFW TDP. These cut sets also include fallure of the EDGs and failure to recover offsite power.

The remaining six cut sets (18 through 23) are all RCP seal LOCA sequences and include failure to connect to Unit 2 EDGs through the shutdown utility bus. The connection to the Unit 2 batteries also falls, followed by various combinations of failures of the EDGs to start and/or run and EDG ventilation system fallures.

\subsubsection{Public Risk Calculations}

Public risk calculations were performed for room cooler contributing events using the same approach as that for room cooler initiators (see Section 4.1.3). The main difference is in the conditional probabilities of the various accident progression bins (APBs). Two plant damage states, LOCAs and LOOP, are required to model the progression of the accident sequences 1 isted in Table 4.1-9. The conditional probabilities for the seven APBs in each plant damage state grouping were taken from Gregory et al. (1990), and are presented in Table 4.1-11. The source terms and consequences associated with each APB are the same as those presented in Table 4.1-8.

The mean public risk associated with room cooler contributors at the representative W PWR was calculated to be $1.7 E+00$ person-rem/RY. The cumulative distribution function for public risks is shown in Figure 4.1-7. The important statistical parameters are listed below. These statistics were generated using Lat in Hypercube Sampling techniques.

Mean:

95\% upper confidence bound: Median:

5\% lower confidence bound:
1.7E+00/person-rem/RY

3. $2 E+00 /$ person-rem/RY

4.3E-01/person-rem/RY

1.3E-01/person-rem/RY 
IABLE 4.1-11. Conditional Probabilities of APBs Resulting From
LOCA and LOOP PIant Damage State Groupings $(a)$

\begin{tabular}{|l|l|l|}
\hline \multicolumn{1}{|c|}{ Accident Progression Bin (APB) } & \multicolumn{2}{c|}{$\begin{array}{c}\text { Conditional } \\
\text { Probability }\end{array}$} \\
\cline { 2 - 3 } & LOOP & LOCA \\
\hline Fraction with containment failure (CF) during core damage (CD) & 0.055 & 0.004 \\
\cline { 2 - 3 } $\begin{array}{l}\text { Fraction with no reactor vessel breach (VB) } \\
\text { Fraction with CF at VB }\end{array}$ & 0.576 & 0.367 \\
\cline { 2 - 4 } Fraction with VB but no CF at VB & 0.089 & 0.05 \\
\hline Fraction with CF by late hydrogen burn & 0.335 & 0.363 \\
Fraction with CF by very late overpressure & 0.096 & 0.001 \\
\hline Fraction with CF by very late base-mat melt through (BMT) & 0.004 & 0.22 \\
\hline (a) Gregory et al (1990) Table 2.5-8 for LOOP sequences, and pages 2.75 \\
and 2.77 for LOCA sequences. & 0.041 & 0.04 \\
\hline
\end{tabular}

\subsubsection{Iotal Affected CDF and Public Risks for the Representative W PWR}

The total affected CDF and public risk values are the sum of the room cooler initiator (see Section 4.1.1) and room cooler contributing events (see Section 4.1.2). The affected CDF and public risks for the representative W PWR, based on their mean values, are shown below:

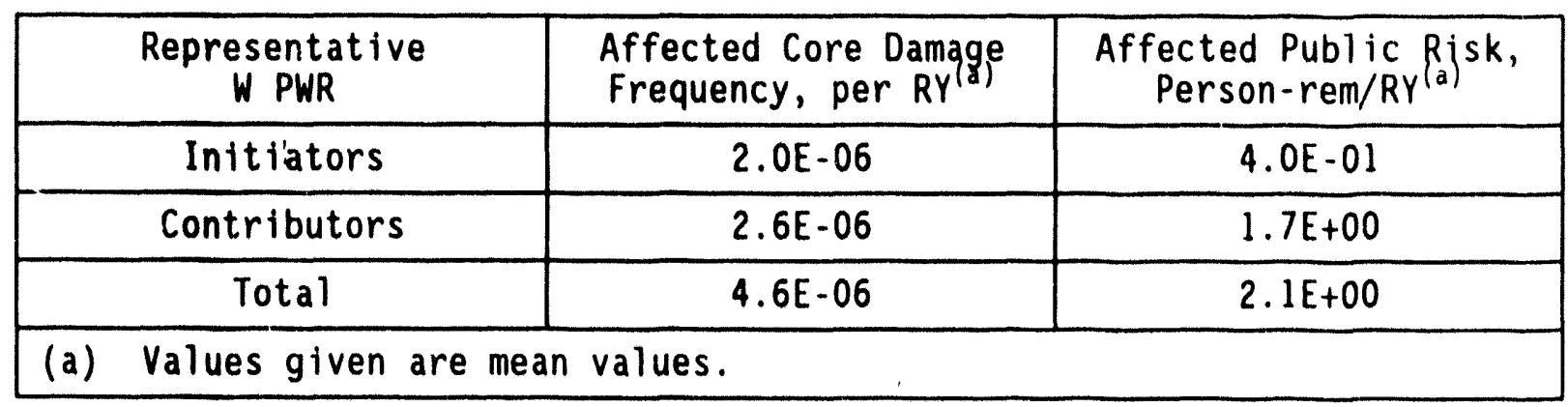




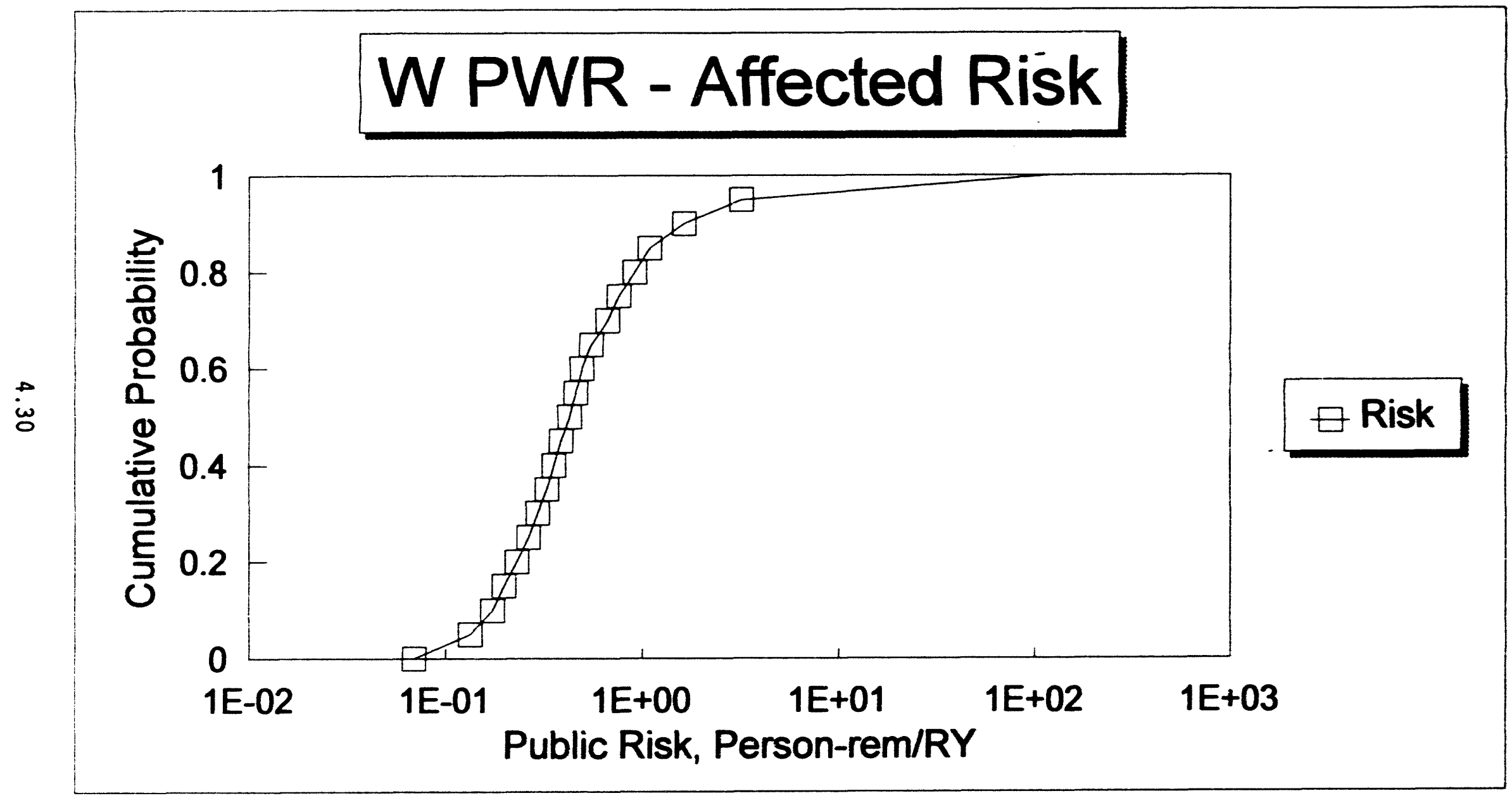

FIGURE 4.1-7. Total Room Cooler Contributing Event Public Risk Distribution 


\subsection{ANALYSIS OF AFFECTED CDF AND PUBLIC RISKS FOR THE REPRESENTATIVE BWR}

This section presents the affected CDF and public risk calculations for the representative BWR. Separate discussions are presented for 1) room cooler failures as initiating events that could ultimately lead to core damage and 2) room cooler failures as contributing events to ott.er types of plant transients.

\subsubsection{Loss of Room Cooling as an Initiator}

A simplified approach was applied to the event trees developed in this study to model room cooler failures as initiating events. As discussed in Section 2, the approach involved development of new event trees and new accident sequences using cut set information from the existing PRAs, modification of the component unavailabilities to account for prior failure of the room cooling function, and quantification of the new accident sequences using the modified safety system unavailabilities.

\subsubsection{Initiator Frequency}

HVAC and room cooler failure initiating event frequencies for the representative BWR are the same as those determined in Section 4.1.1.1 for the W PWR.

\subsubsection{Core Damage Frequency Calculations}

The next step in the analysis was establishing CD accident sequences based on the new event trees and quantifying the affected accident sequences and minimal cut sets. A list of affected events was developed, representing the safety system components required to respond to the loss of room cooling function in the specified room. Druin et al. (1989) provided the cut sets and values for the unmodified parameters. These parameter values were then modified to take into account the prior failure of the room cooling function discussed in subsection 4.1.1.2.

Three event trees were developed to model the loss of room cooling function as an initiating event for the representative BWR. Five room cooler initiator sequences were developed for the representative $W$ PWR, but two, loss of high-pressure ECCS pump room cooling and loss of low-pressure ECCS pump room cooling, were shown to be insignificant relative to the other three. Therefore, only three room cooler-initiated accident sequences were examined for the representative BWR: 1) loss of ESF switchgear room cooling, 2) loss of control room cooling, and 3) loss of DC equipment room cooling. Event trees for these sequences were developed based on the existing PRA for the representative BWR. These event trees are modeled after the event trees given by Druin et al. (1989) for a plant transient with the power conversion system (PCS) initially available. Success criteria for these event trees are presented in Table 4.2-1. The safety functions required in response to these events include reactor subcriticality, RCS overpressure protection, emergency core cooling, and containment overpressure protection. 
TABLE 4.2-1. Success Criteria for Loss of Room Cooling Function Initiators ${ }^{(a)}$

\begin{tabular}{|c|c|c|c|}
\hline $\begin{array}{l}\text { Reactor } \\
\text { Subcriti- } \\
\text { cality }\end{array}$ & $\begin{array}{c}\text { RCS } \\
\text { Overpressure } \\
\text { Protection }\end{array}$ & Emergency Core Cooling & $\begin{array}{l}\text { Containment } \\
\text { Overpressure } \\
\text { Protector }\end{array}$ \\
\hline $\begin{array}{c}\text { RPS } \\
-O R- \\
\text { ARI AND RPT } \\
\text {-OR- } \\
\text { Manual Rods } \\
\text { AND RPT } \\
\text {-OR- } \\
\text { Timely SLC } \\
\text { AND RPT }\end{array}$ & $\begin{array}{c}\text { PCS } \\
-O R- \\
\text { SRVs open } \\
\text { and close }\end{array}$ & 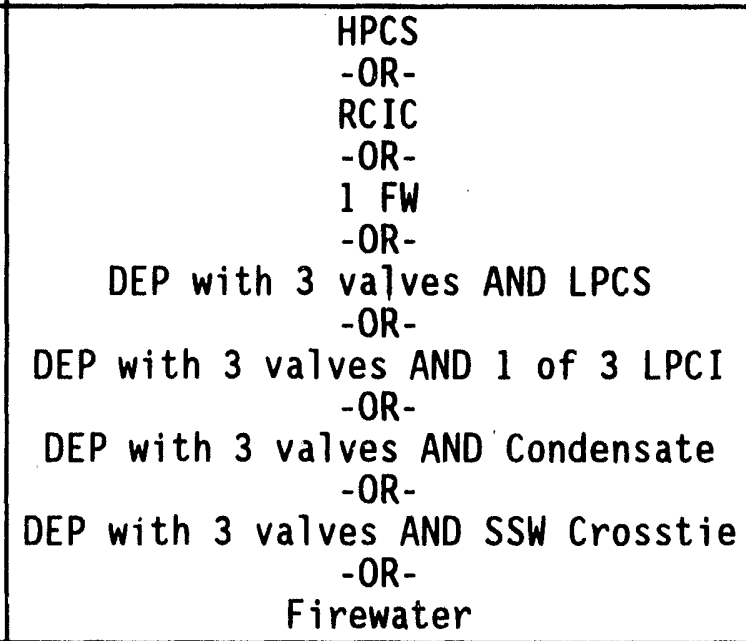 & $\begin{array}{c}\text { 1/2 RHR and } \\
\text { heat exchanger } \\
\text { (SDC, SPC } \\
\text { Spray mode) } \\
\text {-AND- } \\
\text { Associated SSW } \\
\text {-OR- } \\
\text { PCS } \\
\text {-OR- } \\
\text { Containment } \\
\text { Venting }\end{array}$ \\
\hline \multicolumn{4}{|c|}{$\begin{array}{l}\text { (a) Based on success criteria for a transient with PCS initially } \\
\text { available. } \\
\text { (b) Early containment pressure suppression is not required. }\end{array}$} \\
\hline \multicolumn{4}{|c|}{$\begin{array}{ll}\text { RPS }=\text { Reactor protection system } & \text { PCS }=\text { Power conversion system } \\
\text { ARI }=\text { Alternate rod insertion } & \text { RPT }=\text { Recirculation pump trip } \\
\text { SPC = Suppression pool cooling } & \text { SLC = Standby liquid control } \\
\text { SSW = Standby service water } & \text { RHR = Residual heat removal } \\
\text { SDC = Shutdown cooling } & \text { HPCS = High-pressure core spray } \\
\text { LPCS = Low-pressure core spray } & \text { RCIC = Reactor core isolation cooling } \\
\text { DEP = Depressurization } & \text { SRV }=\text { Safety relief valve }\end{array}$} \\
\hline
\end{tabular}

The quantification process for the new event trees began by obtaining the original cut sets from the existing PRA (Druin et a1. 1989) for a transient with PCS initially available. Each of these cut sets was examined to determine which basic events, if any, would be affected by a loss of room cooling function. Obvious examples include failure of RCIC, HPCI, and LPCI pumps, failure of control circuitry and/or ESF actuation circuitry in the control room, and failure of DC equipment to function properly. The affected parameters and their values were then modified to account for the possibility of prior failure of room coolers. The unaffected parameters remained unchanged. Assumptions used to modify the affected parameter values are presented below: 
Loss of ESF Switchgear Room Cooling.

- Failure probabilities for MOVs set equal to 0.5 . This is the approximate probability that an operator would be able to restore power to a valve actuator, given failure of one train of ESF switchgear.

- Failure of SRVs to open on demand is assumed to be unaffected by loss of switchgear room cooling.

- Failure of ECCS MDPs to start and run was set equal to 1.0 to account for the failed switchgear room cooling.

- $\mathrm{RCIC}$ turbine-driven pump does not require $A C$ power to operate, so failure of the RCIC TDP was assumed to be unaffected by failure of ESF switchgear room cooling.

- All AOVs are unaffected by failure of ESF switchgear room cooling. The safety-related air compressor may be inoperable as a result of failure of ESF switchgear; however, a limited supply of pressurized air remains available following loss of the air compressor.

- Actuation circuitry failure probability was set equal to 0.5 to reflect the probability that an operator will be able to restore cooling to the appropriate shutdown board areas, given loss of room cooling to one train of switchgear.

- Failure probabilities for HPCI and LPCI pumps to start and run were set equal to 1.0 if only one pump appeared in a cut set. This assumes that the pump is powered from the failed emergency switchgear. If two pumps from redundant trains appeared in the same cut set, the failure probability of the first was set to 1.0 , and the failure probability of the second was unaffected. This reflects the separation between trains of switchgear (i.e., failure of one train of switchgear room cooling affects the operability of only that specific train).

- Failure of operators to initiate manually injection was set equal to 1.0 to reflect a loss of operator control of ECCS systems.

- Unavailabilities of pumps and valves due to testing and maintenance were assumed to be unaffected.

Loss of Control Room Cooling.

- Failure probabilities for MOVs were set equal to 1.0. This is the approximate probability that an operator would be able to restore power to a valve actuator, given failure of one train of control room cooling.

- Failure of SRVs to open on demand is assumed to be unaffected by loss of control room cooling. 
- Failure of ECCS MDPs to start and run was set equal to 1.0 to account for the possibility that valve and pump controls in the control room are unavailable. This includes the contribution from the operator being unable to restore cooling to ECCS control panels located in the control room, given loss of one train of control room HVAC.

- The RCIC TDP failure probabilities were assumed to be unaffected by loss of control room cooling. The probability that operators cannot restore RCIC, given loss of control room cooling, was set equal to 1.0 to account for possibly failed RCIC actuation and control equipment in the control room.

- Failure of operators to initiate manually injection was set equal to 1.0 to reflect a loss of operator control of ECCS systems.

- All AOVs are unaffected by failure of control room cooling (see above).

- ECCS actuation circuitry and logic failure probability was set equal to 1.0 to reflect loss of control of ECCS systems. The probabilities of manual actuation of ECCS systems were al so assumed to be zero (i.e., the probability that operators fail to actuate LPCI, HPCI, RCIC systems was set to 1.0$)$.

- Unavailabilities of pumps and valves due to test and maintenance were assumed to be unaffected.

- Failure probabilities for HPI/HPR and LPI/LPR pumps were treated in the same manner as described for loss of switchgear room cooling.

Loss of DC Equipment Room Cooling.

- Failure of DC equipment results in closure of MSIVs and loss of PCS for decay heat removal and RCS overpressure protection.

- Failure probabilities of operators to manually initiate injection systems were set equal to 1.0 to reflect a loss of vital DC control power to ECCS systems.

- ECCS actuation circuitry and logic failure probability was set equal to 1.0 to reflect loss of control of ECCS systems.

- All AOVs are unaffected by failure of DC equipment room cooling (see above).

- Unavailabilities of pumps and valves due to testing and maintenance were assumed to be unaffected.

- Failure probabilities for HPI/HPR and LPI/LPR pumps were treated in the same manner as described for loss of switchgear room cooling. 
Table 4.2-2 summarizes the affected parameters and their values for each room cooling event tree.

The affected and unaffected values for the basic events were substituted into the cut sets that were developed from the event trees shown in Section 3, and the affected CDF was calculated. These calculations are presented in Appendix $C$.

The mean total CDF from room cooler initiators at the representative BWR was calculated to be $4.71 \mathrm{E}-07 / \mathrm{RY}$. The cumulative distribution function for the CDF is shown in Figure 4.2-1. The important statistical parameters of the

TABLE 4.2-3. Affected Parameters and Values for Basic Events in Room Cooler Initiator Event Trees

\begin{tabular}{|c|c|c|c|c|}
\hline \multirow{2}{*}{$\begin{array}{l}\text { Parameter } \\
\text { Designation }\end{array}$} & \multirow{2}{*}{$\begin{array}{l}\text { Original } \\
\text { Value, per } \\
\text { Demand }\end{array}$} & \multicolumn{3}{|c|}{ Modified Values, per demand ${ }^{(b)}$} \\
\hline & & TSW & TCR & TDC \\
\hline ESF-CCF-MC-VSLVL & $6.8 E-05$ & $6.8 \mathrm{E}-05$ & $6.8 E-05$ & $6.8 E-05$ \\
\hline ESF-CCF-MC-DEPRES & $6.8 E-05$ & $6.8 \mathrm{E}-05$ & $6.8 E-05$ & $6.8 E-05$ \\
\hline HCS-ICC-FT-MV12 & $1.0 E-04$ & 1.0 & 1.0 & 1.0 \\
\hline HCS-LOG-NO-HPCS & $1.6 E-03$ & 1.0 & 1.0 & 1.0 \\
\hline HCS-MPD-FS-MDP1 & $3.0 E-03$ & 1.0 & 1.0 & 1.0 \\
\hline HCS-MDP-MA-MDP1 & $2.0 E-03$ & 1.0 & 1.0 & 1.0 \\
\hline HCS-MDP-FR-MDP1 & $7.2 E-04$ & 1.0 & 1.0 & 1.0 \\
\hline HCS-MOV-CC-MV12 & $3.0 E-03$ & 1.0 & 1.0 & 1.0 \\
\hline HCS-MOV-00-MV1 & $3.0 \mathrm{E}-03$ & 1.0 & 1.0 & 1.0 \\
\hline HCS - ICC - FT-MV12 & $1.25 E-04$ & 0.5 & $3.0 E-03$ & $3.0 E-03$ \\
\hline HCS - XHE - RE-HPCS & $5.5 E-04$ & 0.5 & $3.0 E-03$ & $3.0 E-03$ \\
\hline$R A-I N J-1 H R$ & $4.5 E-02$ & $4.5 E-02$ & $4.5 E-02$ & $4.5 E-02$ \\
\hline SSW-HTX-PG-HXIC & $1.4 E-04$ & $1.4 \mathrm{E}-04$ & $1.4 \mathrm{E}-04$ & $1.4 \mathrm{E}-04$ \\
\hline SSW-MOV-MA-MV11 & $8.0 E-04$ & $8.0 E-04$ & 1.0 & 1.0 \\
\hline RXINJ-XHE-ADS & 1.0 & 1.0 & 1.0 & 1.0 \\
\hline RCI - TDP-FR-TDP1 & $1.2 \mathrm{E}-01$ & $1.2 E-01$ & $1.2 \mathrm{E}-01$ & 1.0 \\
\hline RCS-TFP-FS-TDP1 & $3.0 E-02$ & $3.0 E-02$ & $3.0 \mathrm{E}-02$ & 1.0 \\
\hline CRD-XHE-FO-MDPB & 1.0 & 1.0 & 1.0 & 1.0 \\
\hline (a) Drouin et al. & & Di & $r$ & \\
\hline
\end{tabular}




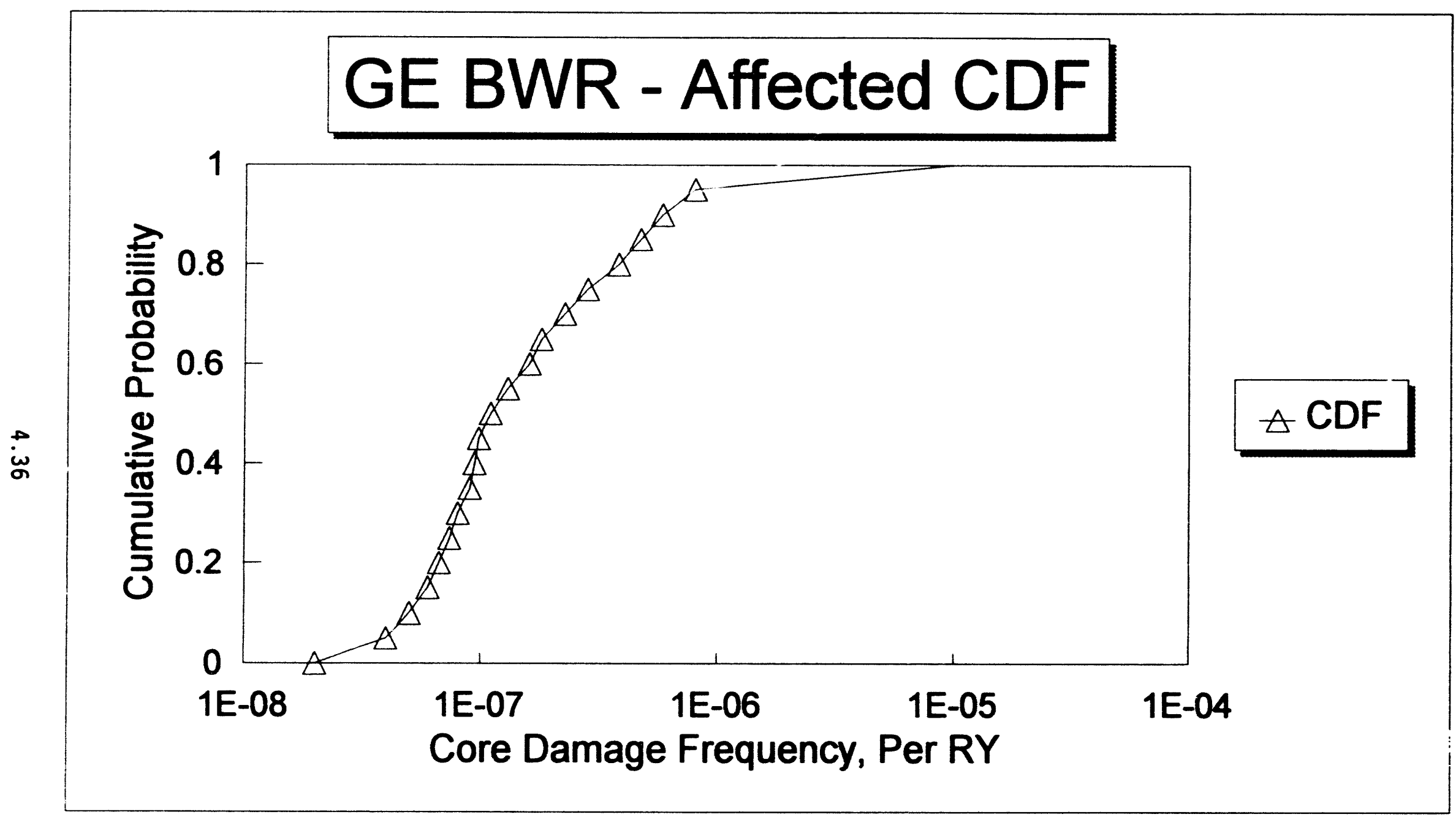

FIGURE 4.2-1. Total Room Cooler Initiator Core Damage Frequency Distribution 
CDF distribution are listed below; these statistics were generated using Latin Hypercube sampling techniques.
Mean:
95\% upper confidence bound:
4.71E-07/RY
Median:
8.0E-07/RY
$5 \%$ lower confidence bound:
$1.1 E-07 / R Y$
4.0E-08/RY

The mean cut set frequencies for each of the three room cooler initiators are presented in Table 4.2-3. Figure 4.2-2 presents a pie-chart illustrating the contributions of each room cooler initiator to the total CDF associated with room cooler initiating events. As shown, 54\% of the CDF from room cooler initiators result from failure of the control room cooling systems. Failure of the emergency switchgear room coolers contributes approximately $30 \%$ of the CDF. Approximately $8 \%$ of the CDF arises from failure of DC equipment room cooling initiating events.

This study resulted in the identification of one minimal cut set with frequency greater than 1E-08 per RY. An additional 27 cut sets were identified with frequencies greater than 5E-09/RY. These 28 cut sets are presented in Table 4.2-4.

The single cut set with frequency greater than 1E-08/RY is initiated by a loss of control room cooling, followed by failure to manually depressurize, failure to initiate CRD pump, common cause miscalibration of reactor level sensors, failure of operators to initiate injection given failure of automatic systems, failure to recover to PCS, operator failure to initiate RCIC, and failure of the SSW system heat exchanger due to plugging. These failures in combination result in failure of ECCS injection and decay heat removal functions, leading to core damage.

TABLE 4.2-3. Calculated Frequencies of Room Cooler Initiator Sequences (point estimates)

\begin{tabular}{|c|c|}
\hline Initiator & $\begin{array}{c}\text { Frequency } \\
\text { Per RY }\end{array}$ \\
\hline TSW & $1.3 \mathrm{E}-07$ \\
TCR & $1.8 \mathrm{E}-07$ \\
TOC & $2.8 \mathrm{E}-08$ \\
\hline Total & $3.4 \mathrm{E}-07$ \\
\hline
\end{tabular}




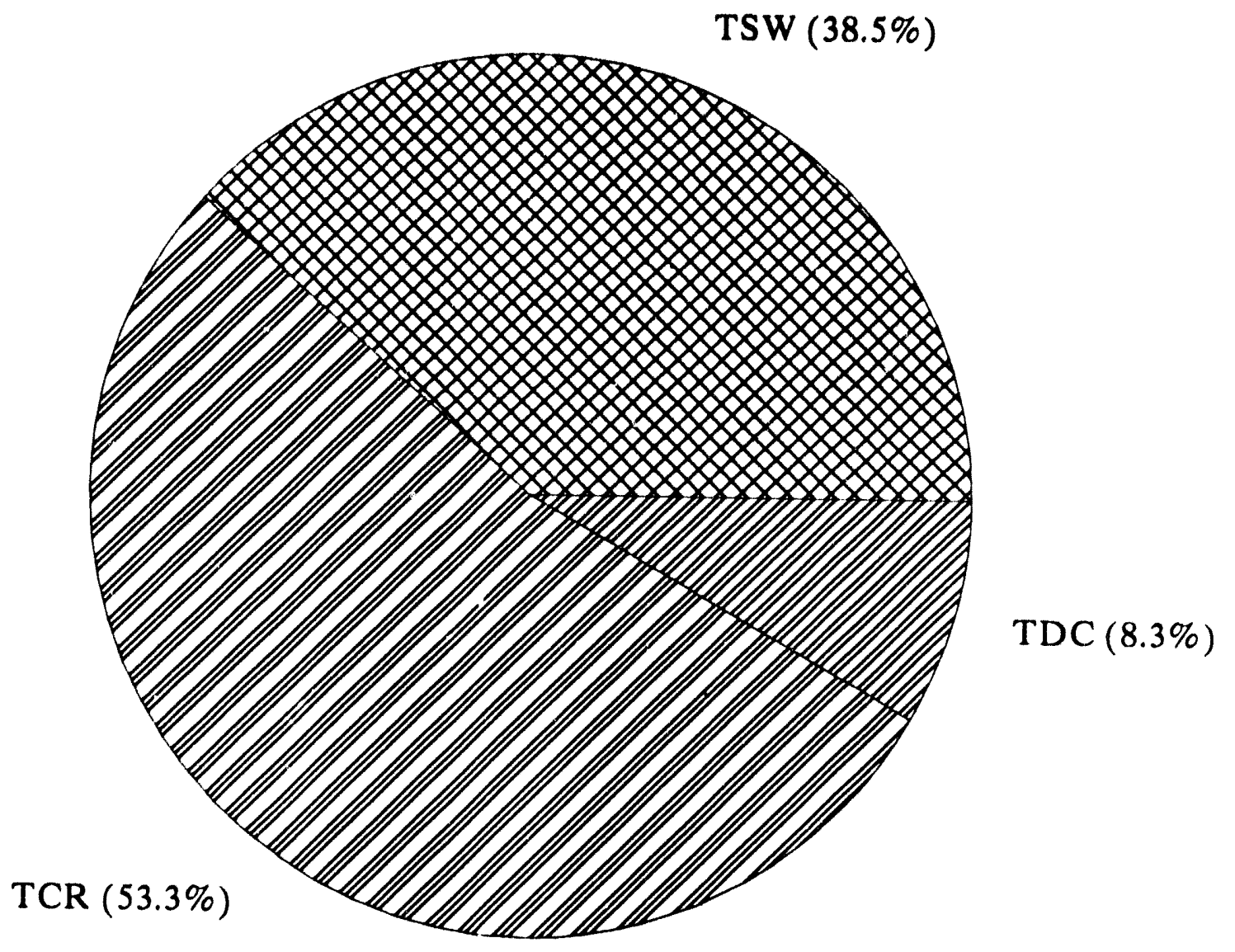

FIGURE 4.2-2. Pie Chart Illustrating Contributions of Each Initiator to the CDF from Room Cooler Initiating Events

The remaining 27 cut sets shown in Table 4.2-4 are initiated by loss of switchgear room cooling. None of the cut sets initiated by failure of DC equipment room cooling at the representative BWR was calculated to have frequencies greater than 5E-09/RY.

All 27 TSW cut sets include failure of HPI systems and failure of operators to depressurize the RCS to permit usage of LPI. Operator failure to depressurize the RCS is common to all 27 cut sets. All 27 cut sets also include failure of automatic actuation of ESF functions due to common-cause miscalibration of reactor vessel level instrumentation. Various causes of HPI failures are included in the cut sets, including

- failure to initiate CRD systems manually

- failure of the RCIC system, including failure to manually actuate RCIC, and failures of various RCIC system valves and the turbine-driven RCIC pump

- failures of various HPI system valves and the motor-driven HPI pump. 
TABLE 4.2-4. Summary of Minimal Cut Sets with Frequencies Greater Than 5E-09/RY

\begin{tabular}{|c|c|c|}
\hline $\begin{array}{c}\text { Cut Set } \\
\text { Number }\end{array}$ & Cut Set Elements & $\begin{array}{c}\text { Frequency } \\
\text { per RY }\end{array}$ \\
\hline TSW-26 & TSW. RSW. ADS-XHE-ACT-MAN, CRD-XHE-FO-MDPB, ESF-CCF-MC-VSLVL, RA-INJ-1HR, RA-PCS-1HR, RXINJ-XHE-ADS, RXINJ-XHE-RCIC, SSW-HTX-PG-HXIC & $5.702 E-08$ \\
\hline TCR-9 & TCR, RCR, ADS-XHE-ACT-MAN, CRD-XHE-FO-MDPB, ESF-CCF-MC-VSLVL, HCS-ICC-FT-MVI2, RA-INJ-IHR, RA-PCS-1HR, RXINJ-XHE-ADS-RXINJ-XHE-RCIC & 5.908E-09 \\
\hline TCR-11 & TCR, RCR, ADS-XHE-ACT-MAN, CRD-XHE-FO-MDPB, ESF-CCF-MC-VSLVL, HCS-LOG-MO-HPCS, RA-INJ-IHR, RA-PCS-IHR, RXINJ-XHE-ADS, RXINJ-XHE-RCIC & $5.908 E-09$ \\
\hline TCR-12 & TCR, RCR. ADS-XHE-ACT-MAN, CRD-XHE-FO-MDPB. ESF-CCF-MC-VSLVL. HCS-MDP-FR-MDP1, RA-INJ-1HR, RA-PCS-1HR, RXINJ-XHE-ADS, RXINJ-XHE-RCIC & $5.908 E-09$ \\
\hline TCR-14 & TTCR, RCR, ADS-XHE-ACT-MAN, CRD-XHE-FO-MDPB, ESF-CCF-MC-VSLVL, HCS-MDP-FS-MDP1, RA-INJ-1HR, RA-PCS-1HR, RXINJ-XHE-ADS, RXIMJ-XHE-RCIC & 5.908E-09 \\
\hline TCR-16 & TCR, RCR, ADS-XHE-ACT-MAN, CRD-XHE-FO-MDPB, ESF-CCF-MC-VSLVL, HCS-MDP-MA-MDP1, RA-INJ-1HR, RA-PCS-1HR, RXIMJ-XHE-ADS, RXINJ-XHE-RCIC & $5.908 E-09$ \\
\hline TCR-18 & TTCR, RCR, ADS-XHE-ACT-MAN, CRD-XHE-FO-MDPB, ESF-CCF-MC-VSLVL, HCS-MOV-CC-MV12, RA-IMJ-IHR, RA-PCS-1HR, RXINJ-XHE-ADS, RXIMJJ-XHE-RCIC & F.908E-09 \\
\hline TCR-20 & TTCR, RCR, ADS-XHE-ACT-MAN, CRD-XHE-FO-MDPB, ESF-CCF-MC-VSLVL, HCS-MOV-CC-MV4, RA-INJ-1HR, RA-PCS-1HR, RXINJ-XHE-ADS, RXINJ-XHE-RCIC & $5.908 E-09$ \\
\hline TCR-21 & TCR, RCR, ADS-XHE-ACT-MAN, CRD-XHE-FO-MDPB, ESF-CCF-MC-VSLVL. HCS-MOV-MA-MV12, RA-INJ-1HR, RA-PCS-1HR, RXINJ-XHE-ADS, RXINJ-XHE-RCIC & F.908E-09 \\
\hline TCR-22 & TCR, RCR, ADS-XHE-ACT-MAN, CRD-XHE-FO-MDPB, ESF-CCF-MC-VSLVL. HCS-MOV-MA-MV4, RA-INJ-1HR, RA-PCS-1HR, RXINJ-XHE-ADS, RXINJ-XHE-RCIC & 5.908E-09 \\
\hline TCR-24 & TCR, RCR, ADS-XHE-ACT-MAN, CRD-XHE-FO-MDPB, ESF-CCF-MC-VSLVL, HCS-MOV-00-MVI, RA-INJ-IHR, RA-PCS-1HR, RXINJ-XHE-ADS, RXINJ-XHE-RCIC & $5.908 E-09$ \\
\hline TCR-25 & FCR, RCR, ADS-XHE-ACT-MAN, CRD-XHE-FO-MDPB, ESF-CCF-MC-VSLVL. HCS-XHE-RE-HPCS, RA-INJ-1HR, RA-PCS-1HR, RXIMJ-XHE-ADS, RXIMJ-XHE-RCIC & B.908E-09 \\
\hline TCR-26 & TCR, RCR, ADS-XHE-ACT-MAN, CRD-XHE-FO-MDPB, ESF-CCF-MC-VSLVL, RA-INJ-1HR, RA-PCS-1HR, RXINJ-XHE-ADS, RXINJ]-XHE-RCIC, SSW-HTX-PG-HXIC & 5.908E-09 \\
\hline TCR-27 & TCR, RCR, ADS-XHE-ACT-MAN, CRD-XHE-FO-MDPB, ESF-CCF-MC-VSLVL, RA-INJ-1HR, RA-PCS-1HR, RXINJ-XHE-ADS, RXINJ-XHE-RCIC, SSH-MDP-FS-MDPZC & $5.908 E-09$ \\
\hline TCR-28 & TCR, RCR, ADS-XHE-ACT-MAN, CRD-XHE-FO-MDPB, ESF-CCF-MC-VSLVL, RA-INJ-IHR, RA-PCS-IHR, RXINJ-XHE-ADS, RXINJ-XHE-RCIC, SSW-MOV-MA-MVII & $5.908 E-09$ \\
\hline TCR-37 & TCR, RCR, ADS-XHE-ACT-MAN, ESF-CCF-MC-VSLVL, HCS-ICC-FT-MV12, LOCA-SIGNAL, RA-INJ-IHR, RA-PCS-1HR, RXIMJ-XHE-ADS, RXINJ-XHE-RCIC & $5.908 E-09$ \\
\hline TCR-39 & TCR, RCR, ADS-XHE-ACT-MAN, ESF-CCF-MC-VSLVL, HCS-LOG-NO-HPCS, LOCA-SIGNAL, RA-INJ-1HR, RA-PCS-1HR, RXINJ-XHE-ADS, RXINJ-XHE-RCIC & $5.908 E-09$ \\
\hline TCR -40 & TCR, RCR, ADS-XHE-ACT-MAN, ESF-CCF-MC-VSLVL, HCS-MDP-FR-MDP1. LOCA-SIGNAL, RA-INJ-1HR, RA-PCS-1HR, RXIMJ-XHE-ADS, RXIMJ-XHE-RCIC & $5.908 E-09$ \\
\hline TCR-42 & TCR, RCR, AOS-XHE-ACT-MAN, ESF-CCF-MC-VSLVL, HCS-MDP-FS-MDP1. LOCA-SIGMAL, RA-INJ-1HR, RA-PCS-1HR, RXIMJ-XHE-ADS, RXIMJ-XHE-RCIC & 5.908E-09 \\
\hline TCR-44 & TCR, RCR, ADS-XHE-ACT-MAN, ESF-CCF-MC-VSLVL, HCS-MDP-MA-MDP1, LOCA-SIGNAL, RA-INJ-1HR, RA-PCS-1HR, RXIMJ-XHE-ADS, RXINJ-XHE-RCIC & $5.908 E-09$ \\
\hline TCR-46 & TCR, RCR, ADS-XHE-ACT-MAN, ESF-CCF-MC-VSLVL, HCS-MOV-CC-MV12, LOCA-SIGMAL, RA-INJ-1HR, RA-PCS-1HR, RXINJ-XHE-ADS, RXINJJ-XHE-RCIC & $5.908 E-09$ \\
\hline TCR-48 & TCR, RCR, ADS-XHE-ACT-MAN, ESF-CCF-MC-VSLVL, HCS-MOV-CC-MV4, LOCA-SIGNAL, RA-INJ-IHR, RA-PCS-1HR, RXIMJ-XHE-ADS, RXINJ-XHE-RCIC & 5.908E-09 \\
\hline TCR-49 & TCR. RCR, ADS-XHE-ACT-MAN, ESF-CCF-MC-VSLVL, HCS-MOV-MA-MV12, LOCA-SIGNAL, RA-INJ-1HR, RA-PCS-1HR, RXINJ-XHE-ADS, RXIMJ-XHE-RCIC & $5.908 E-09$ \\
\hline TCR-50 & TCR, RCR. ADS-XHE-ACT-MAN, ESF-CCF-MC-VSLVL, HCS-MOV-MA-MV4, LOCA-SIGNAL, RA-INJ-1HR, RA-PCS-1HR, RXINJ-XHE-ADS, RXINJ-XHE-RCIC & 5.908E-09 \\
\hline TCR-52 & TCR, RCR, ADS-XHE-ACT-MAN, ESF-CCF-MC-VSLVL, HCS-MOV-00-MVI, LOCA-SIGNAL, RA-INJJ-IHR, RA-PCS-1HR, RXINJ-XHE-ADS, RXINJ-XHE-RCIC & $5.908 E-09$ \\
\hline TCR-53 & TCR, RCR, ADS-XHE-ACT-MAN, ESF-CCF-MC-VSLVL, HCS-XHE-RE-HPCS, LOCA-SIGNAL, RA-INJ-1HR, RA-PCS-1HR, RXINJ-XHE-ADS, RXIMJ-XHE-RCIC & $5.908 E-09$ \\
\hline TCR-54 & TCR, RCR, ADS-XHE-ACT-MAN, ESF-CCF-MS-VSLVL, LOCA-SIGNAL, RA-INJ-1HR, RA-PCS-IHR, RXINJ-XHE-ADS, RXINJ-XHE-RCIC. SSH-HTX-PG-HXI & $5.908 E-09$ \\
\hline TCR-55 & TCR, RCR, ADS-XHE-ACT-MAN, ESF-CCF-MS-VSLVL, LOCA-SIGMAL, RA-INJ-1HR, RA-PCS-IHR, RXINJ-XHE-ADS, RXINJ-XHE-RCIC, SSH-MDP-FS-MDP & 5.908E-09 \\
\hline 0.00 & Total & 2.16E-07 \\
\hline
\end{tabular}


Failure to restore the PCS to operable status and failure to restore injection systems within one hour are also included in the cut sets.

\subsubsection{Public Risk Calculations}

The calculation procedure used in this section is the same as that described in subsection 4.1.1.3 for the representative W PWR, including grouping the cut sets into plant damage states (PDSs), grouping the PDSs into accident progression bins (APBs), calculating source terms and defining source term groups for each APB, calculating the consequences of each source term group, and then calculating public risk values. The accident progression, source term, and consequence analyses presented by Brown et al. (1990) form the basis for this analysis.

Brown et a1. (1990) indicated that the PDS represented by short-term SBO scenarios, designated PDS-1, dominated the CDF from internal events at the representative BWR. PDS-1, contributing $92 \%$ of the total CDF, involves station blackout sequences in which the LOOP is recoverable. Coolant injection capabilities are lost early in POS-1 such that core damage occurs in the short term and with the RCS at high pressure, because depressurization does not prevent core damage. The accident sequences initiated by room cooler failures in many cases result in LOOP or similar conditions. For example, loss of switchgear and $D C$ equipment room cooling scenarios result in recoverable loss of motive and control power, respectively, to one division of ESF equipment. Loss of control room cooling leads to spurious actuation and equipment malfunctions that could mislead or "blind" operators to actual plant conditions. These conditions are similar to those that may occur in a station blackout. Therefore, all of the HVAC- and room cooler-initiated sequences were assigned to PDS-1 because of these similarities and because PDS-1 is the dominant plant damage state for the representative BWR.

The next step was to partition PDS-1 into different APBs. This was done using Table 2.5-7 of Brown et al. (1990), reproduced as Table 4.2-5 in this report. This table indicates the conditional probabilities of eight APBs given the occurrence of PDS-1. The values in this table are multiplied by the frequencies of core damage sequences initiated by HVAC/room cooler failures to calculate the frequency of each $A P B$.

Next each APB was assigned to an appropriate source term group. The source term group must be representative of the release quantities anticipated to result from each $A P B$. For example, the source term group for the first APB in Table 4.2-5 must be representative of the release quantities anticipated to result should the containment fail early, containment sprays fail, and suppression pool bypass occur early. A relatively large release will occur if these conditions arise following a core damage accident. Much smaller releases are anticipated if vessel breakthrough occurs, but containment failure does not occur. Assignment of the source term groups to the APBs determines the consequences of the releases, which are taken directly from Table 4.3-1 of Brown (1990). The source term groups assigned to represent each PDS and the consequences of each source term group are presented in Table 4.2-6. 
IABLE 4.2-5. Conditional Probabjlities of APBs Resulting from HVAC/Room Cooler Initiators

\begin{tabular}{|l|c|}
\hline \multicolumn{1}{|c|}{ Accident Progression Bin (APB) } & $\begin{array}{c}\text { Conditional } \\
\text { Probability }\end{array}$ \\
\hline Vessel break (VB), early containment fałlure (CF), early & 0.168 \\
suppression pool bypass (SPB), no containment sprays (CS) & \\
VB, early CF, early SPB, CS & 0.031 \\
VB, early CF, late SPB & 0.006 \\
VB, early CF, no SPB & 0.182 \\
VB, late CF & 0.308 \\
VB, venting & 0.032 \\
VB, no CF & 0.053 \\
No VB & 0.201 \\
\hline (a) Brown et al. (1990) \\
\hline
\end{tabular}

The final step was combining the accident sequence frequencies, conditional probabilities of each APB, conditional probabilities of each source term group, and the consequences of each source term group to calculate the public risk value associated with HVAC/room cooler initiators. An example was presented in subsection 4.1.1.3 to illustrate the calculation process. A spreadsheet was developed to facilitate the calculations and to perform the Lat in Hypercube sampling analyses.

The mean public risk associated with room cooler initiators at the representative BWR was calculated to be $2.3 E-01$ person-rem/RY. The public risk based on point estimates for each parameter value was calculated to be 1.6E-02 person-rem/RY. The cumulative distribution function for public risks is shown in Figure 4.2-3. The important statistical parameters are listed below. These statistics were generated using Lat in Hypercube sampling techniques.

Mean:

95\% upper confidence bound:

Median:

$5 \%$ lower confidence bound:

2.3E-01/person-rem/RY

$1.0 \mathrm{E}+00 /$ person-rem/RY

6.7 E-02/person-rem/RY

2.2E-02/person-rem/RY

\subsubsection{Room Cooler Failure Contribution to Accident Sequences at the Representative BWR}

This section presents the contribution of room cooler failures to the CDF of the representative BWR. The results were calculated using the SARA computer code developed by EG\&G Idaho (Stewart et al. 1989). The data files were provided by the NRC and were based on the PRA results of NUREG-1150. This section considers room coolers as contributors to the core damage accident sequences and not as initiators, as discussed in Section 4.1. 
IABLE 4,2-6. Partitioning of APBs into Source Term Groups

\begin{tabular}{|c|c|c|c|}
\hline APB & $\begin{array}{l}\text { Source Term } \\
\text { Group }\end{array}$ & $\begin{array}{l}\text { Conditional } \\
\text { Probability }\end{array}$ & $\begin{array}{l}\text { Consequencess, } \\
\text { person-rem }\end{array}$ \\
\hline VB, early CF, early SPB, no CS & $\begin{array}{l}G G-13-011^{10} \\
G G-13-02\end{array}$ & $\begin{array}{l}0.635 \\
0.365\end{array}$ & $\begin{array}{l}1.88 E+06 \\
2.01 E+06\end{array}$ \\
\hline & $\begin{array}{l}G G-12-01 \\
G G-12-02\end{array}$ & $\begin{array}{l}0.387 \\
0.613\end{array}$ & $\begin{array}{l}4.03 E+05 \\
4.18 E+05\end{array}$ \\
\hline VB, early CF, late SPB & $\begin{array}{l}G G-10-01 \\
G G-10-02\end{array}$ & $\begin{array}{l}0.981 \\
0.019\end{array}$ & $\begin{array}{l}2.58 E+05 \\
2.30 E+05\end{array}$ \\
\hline VB, early CF, no SPB & $\begin{array}{l}G G-10-01 \\
G G-10-02\end{array}$ & $\begin{array}{l}0.981 \\
0.019\end{array}$ & $\begin{array}{l}2.58 E+05 \\
2.30 E+05\end{array}$ \\
\hline VB, late CF & $\begin{array}{l}G G-05-01 \\
G G-05-02\end{array}$ & $\begin{array}{l}0.593 \\
0.407\end{array}$ & $\begin{array}{l}1.82 E+05 \\
1.61 E+05\end{array}$ \\
\hline VB, venting & $\begin{array}{l}G G-03-01 \\
G G-03-02\end{array}$ & $\begin{array}{l}0.673 \\
0.327\end{array}$ & $\begin{array}{l}6.99 E+04 \\
8.00 E+04\end{array}$ \\
\hline VB, no CF & $\begin{array}{l}G G-02-01 \\
G G-02-02\end{array}$ & $\begin{array}{l}0.499 \\
0.501\end{array}$ & $\begin{array}{l}4.18 E+02 \\
4.18 E+02\end{array}$ \\
\hline No VB & $\begin{array}{l}G G-01-01 \\
G G-01-02\end{array}$ & $\begin{array}{l}0.999 \\
0.001\end{array}$ & $\begin{array}{l}3.47 E+01 \\
1.17 E+02\end{array}$ \\
\hline \multicolumn{4}{|c|}{$\begin{array}{l}\text { (a) Integrated radiation dose to the population within } 50 \text { miles of the } \\
\text { representative plant (Brown et al. 1990, Table } 4.3-1 \text { ). } \\
\text { (b) Source term groups are further subdivided into subgroups based on } \\
\text { evacuation timing. In subgroup 1, evacuation starts at least } \\
30 \text { minutes prior to the release. In subgroup } 2 \text {, evacuation starts } \\
\text { between } 30 \text { minutes before and one hour after the release. In subgroup } \\
3 \text {, evacuation starts more than one hour after the release. The } \\
\text { possible subgroups and their probabilities were taken from Brown et al. } \\
\text { (1990, Table } 3.4-4 \text { ). The conditional probabilities of subgroup } 3 \text { were } \\
\text { a11 assessed to be } 0.0 \text {. }\end{array}$} \\
\hline
\end{tabular}

\subsubsection{Initiating Event Frequency}

Due to memory limitations of the SARA computer model, only the top seven significant accident sequences developed under the PRA are analyzed. These sequences make up over $99 \%$ of the CDF. Each sequence is initiated by one of three events. The initiating events and their frequency are shown in Table 4.2-7.

\subsubsection{Core Damage Frequency Calculations}

The SARA data files were reviewed and compared to the fault trees of Section 3.2 to identify the basic events potentially affected by this issue (Table 4.2-8). The data files were complete with no further additions necessary. The events marked with an asterisk (*) are cut set members of a significant accident sequence. The events not marked with an asterisk were el iminated from further analysis. 


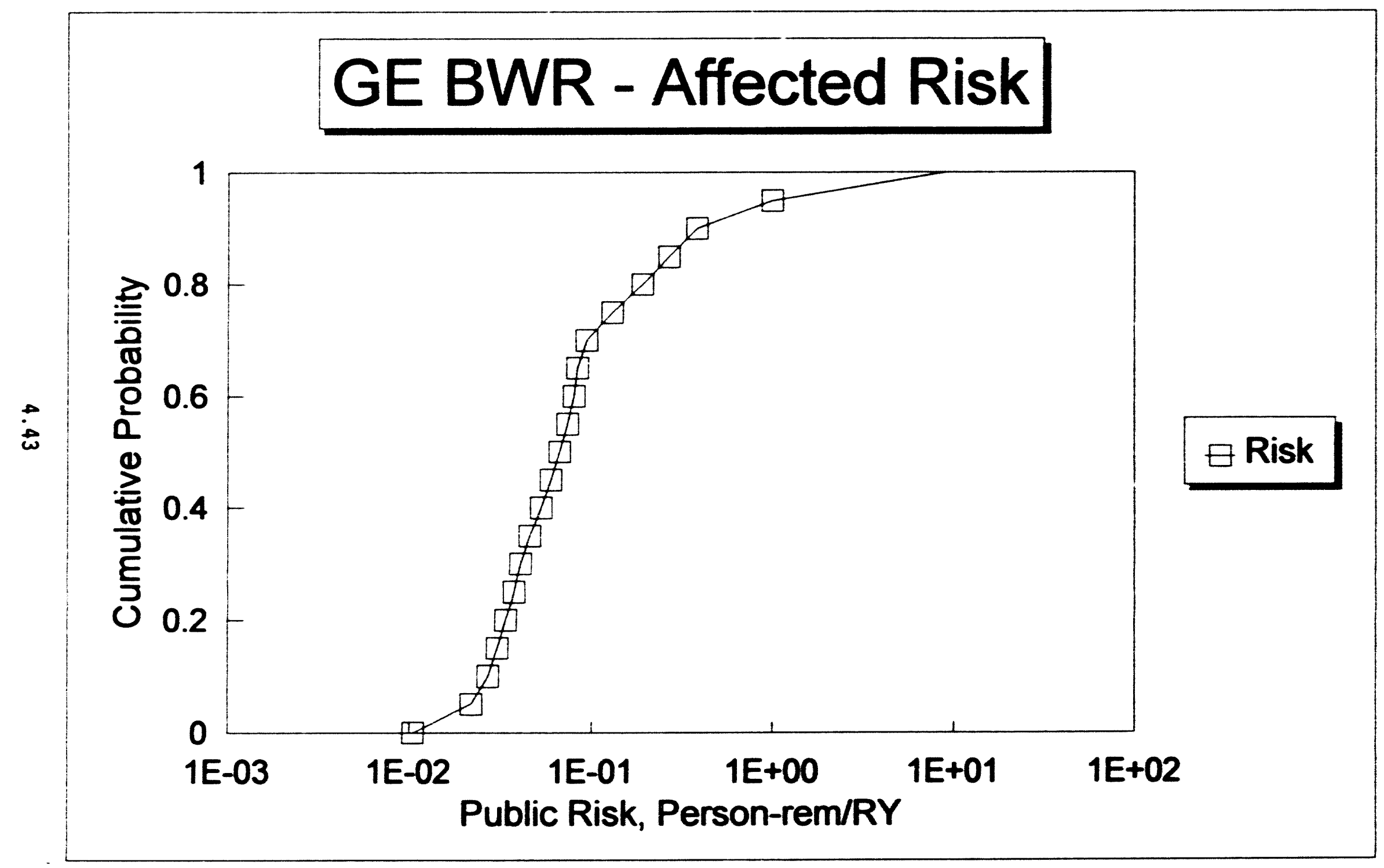

FIGURE 4.2-3. Total Room Cooler Initiator Public Risk Distribution for the Representative BuR 
IABLE 4.2-7. Initiating Events and Frequencies

\begin{tabular}{|l|c|}
\hline \multicolumn{1}{|c|}{ Initiating Event } & $\begin{array}{c}\text { Frequency (per } \\
\text { reactor year) }\end{array}$ \\
\hline Total Transtents & 7.13 \\
Loss of Power Conversion System Transient (PCSLOS) & 1.62 \\
Station Blackout (STABLA) & 0.11 \\
\hline
\end{tabular}

\section{IABLE 4,2-8. Basic Events Potentially Affected By GI 143 at the Representative BWR}

\begin{tabular}{|c|c|c|c|}
\hline Bevic Event & Description & Basic Event & Description \\
\hline 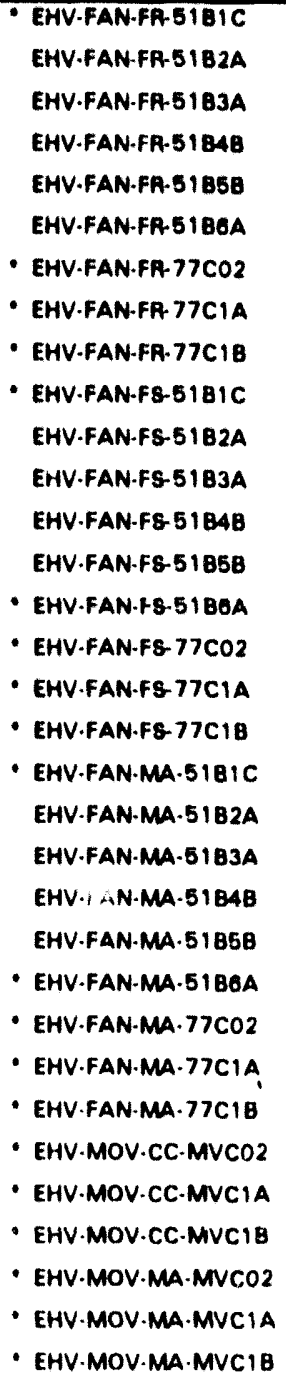 & 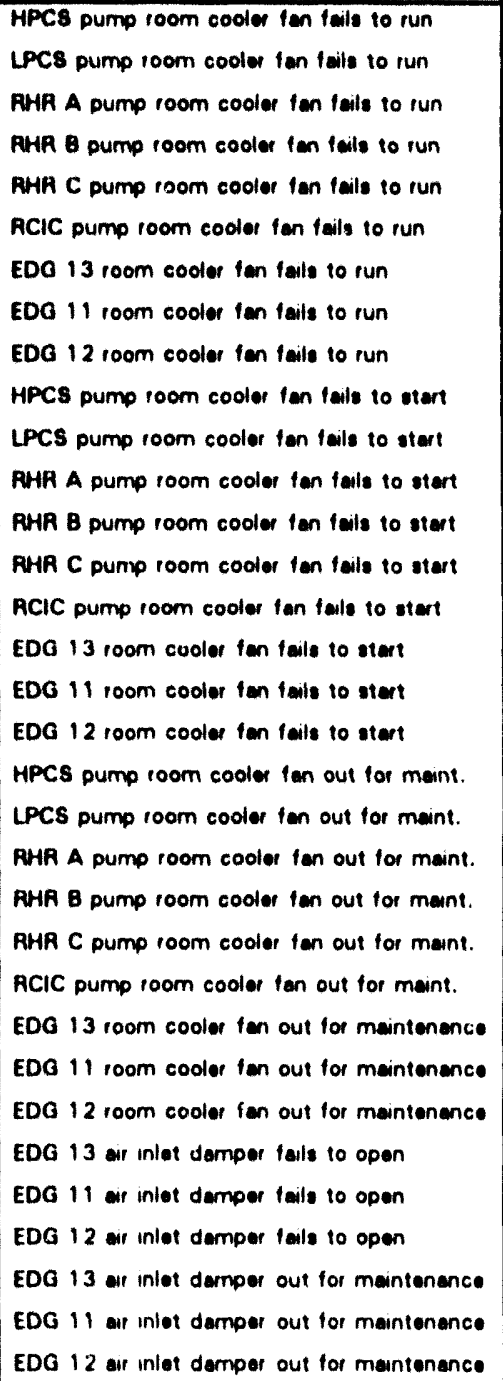 & 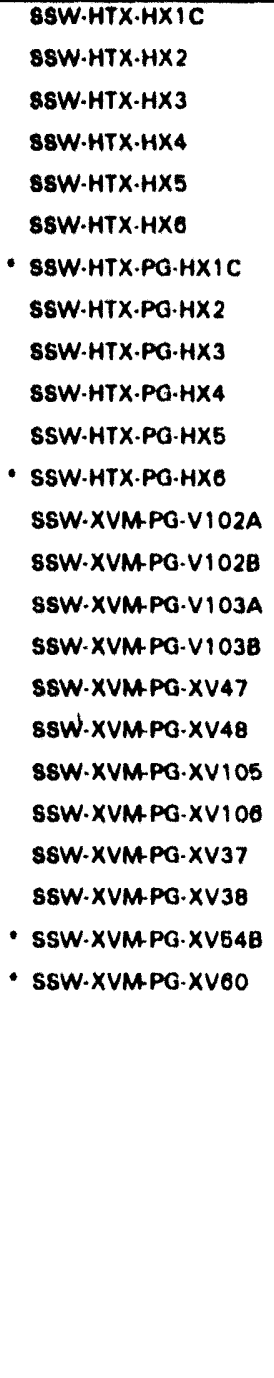 & 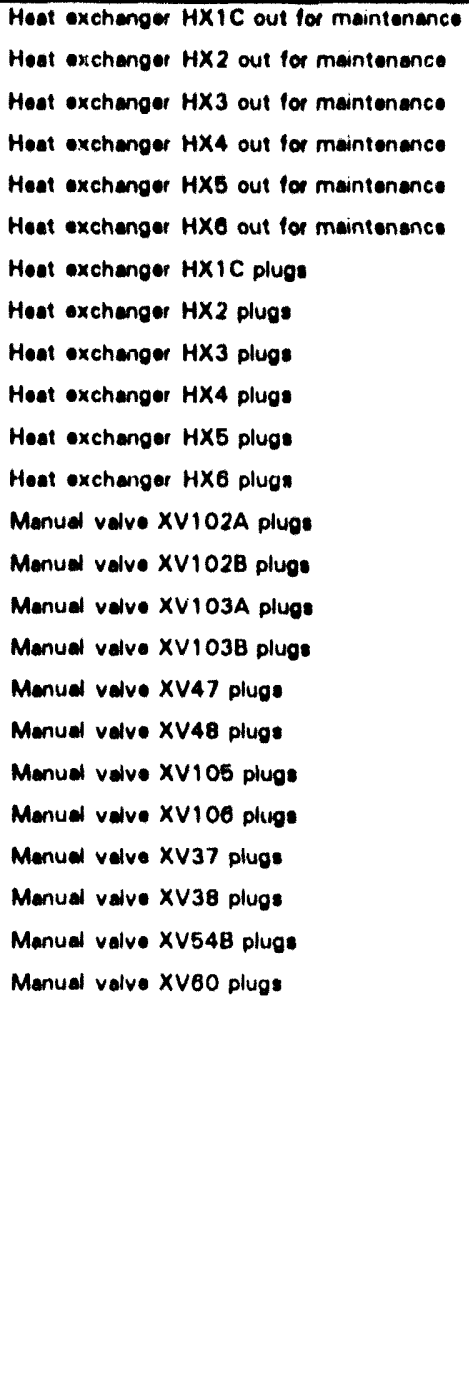 \\
\hline
\end{tabular}


The cumulative cut set frequency was calculated for the remaining events. The event probability, number of affected cut sets, and the cumulative cut set frequency for core damage are 1isted in Table 4.2-9. Events contributing to a total cumulative cut set frequency greater than $1.0 \mathrm{E}-09 / \mathrm{RY}$ are marked with an asterisk $(*)$. The only events to remain are related to the HPCS room cooler and diesel generator ventilation.

Each cut set entered into SARA was assigned to an accident sequence and plant damage state. The affected CDF was determined by totaling the frequencies of all the cut sets containing one or more of the affected parameters (i.e., basic events). The results are presented in Table 4.2-10. Only those sequences and plant damage states with an affected frequency higher than 1.0E-09 are retained for further analysis.

\section{IABLE 4.2-9. Basic Event Cumulative Cut Set Frequency}

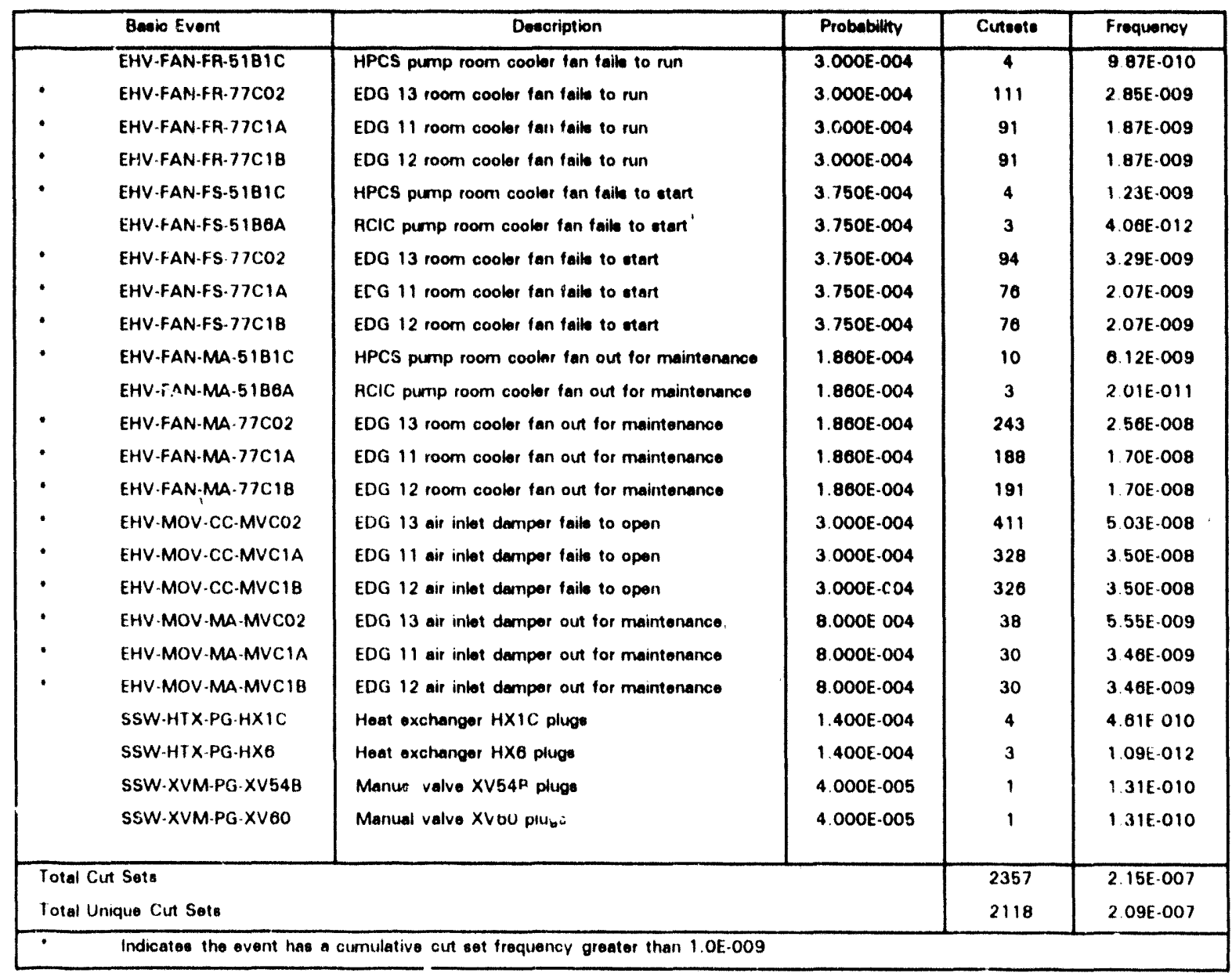


TABLE 4.2-10. Affected Sequences and Plant Damage States

\begin{tabular}{|c|c|c|c|c|c|c|c|c|}
\hline $\begin{array}{l}\text { Initiating } \\
\text { Event }\end{array}$ & $\begin{array}{l}\text { Sequence } \\
\text { Number }\end{array}$ & $\begin{array}{c}\text { Plant } \\
\text { Damage } \\
\text { State }\end{array}$ & $\begin{array}{l}\text { Total } \\
\text { Cut } \\
\text { Sets }\end{array}$ & $\begin{array}{l}\text { Affected } \\
\text { Cut Sets }\end{array}$ & $\begin{array}{l}\text { Mincut } \\
\text { CDF }\end{array}$ & $\begin{array}{l}\text { Affected } \\
\text { CDF }\end{array}$ & $\begin{array}{l}\text { Minimum } \\
\text { CDF } \\
(\text { Prob }=0)\end{array}$ & $\begin{array}{c}\text { Maximum } \\
\text { CDF } \\
(\text { Prob }=1)\end{array}$ \\
\hline \multirow{16}{*}{$\begin{array}{c}\text { Station } \\
\text { Blackout } \\
\text { (STABLA) }\end{array}$} & 13 & 8 & 1159 & 467 & $3.14 E-008$ & 5.03E-009 & $2.64 E-008$ & $1.44 E-004$ \\
\hline & \multirow{3}{*}{14} & 4 & 829 & 347 & 2.03E-008 & $3.56 E-012$ & $1.67 E-008$ & 3.81E-005 \\
\hline & & 5 & 107 & 1 & 5.91E-010 & 7.3OE-012 & 5.84E-010 & 3.01E-009 \\
\hline & & 6 & 3 & 0 & $1.92 E-009$ & 0 & $1.92 E-009$ & $1.92 \mathrm{E}-009$ \\
\hline & \multirow{4}{*}{16} & 1 & 946 & 273 & $1.23 E-006$ & $1.81 E-007$ & $1.05-006$ & $9.67 E-004$ \\
\hline & & 2 & 39 & 2 & $1.33 E-008$ & $5.20 \mathrm{E}-010$ & $1.28-008$ & $1.84 E-007$ \\
\hline & & 3 & 25 & 0 & $1.56 E-007$ & 0 & $1.56-007$ & $1.56 \mathrm{E}-007$ \\
\hline & & 7 & 1 & 0 & 4.00E-007 & 0 & $4.00 E-007$ & $4.00 F \cdot 007$ \\
\hline & \multirow{4}{*}{17} & 1 & 1487 & 693 & $1.08 E-008$ & 2.19E-009 & 8.63E-009 & $9.61 E-005$ \\
\hline & & 2 & 136 & 21 & 2.65E-010 & $1.12 \mathrm{E}-011$ & 2.54E-010 & 4.60E-009 \\
\hline & & 3 & 62 & 1 & $1.08 \mathrm{E}-009$ & $<1.00 E-012$ & $1.08 E-009$ & $1.23 E-009$ \\
\hline & & 7 & 1 & 0 & 5.20E-010 & 0 & $5.20 E-010$ & 5.20E-010 \\
\hline & \multirow{4}{*}{21} & 1 & 978 & 273 & $4.92 E-008$ & $7.26 \mathrm{E}-009$ & $4.20 E-008$ & $3.89 \mathrm{E}-005$ \\
\hline & & 2 & 39 & 2 & $5.32 \mathrm{E}-010$ & $2.06 E-011$ & $5.12 \mathrm{E}-010$ & $7.38 \mathrm{E}-009$ \\
\hline & & 3 & 25 & 0 & $6.23 E-009$ & 0 & $6.23 E-009$ & $6.23 E-009$ \\
\hline & & 7 & 1 & 0 & $1.60 \mathrm{E}-008$ & 0 & $1.60 E-008$ & $1.60 \mathrm{E}-008$ \\
\hline \multirow{2}{*}{ PCSLOS } & \multirow{2}{*}{56} & 11 & 190 & 5 & $1.41 \mathrm{E}-008$ & $<1.00 E-011$ & $1.41 E-008$ & $3.32 E-008$ \\
\hline & & 12 & 101 & 12 & $3.06 \mathrm{E}-010$ & $2.90 E-011$ & 2.77E-010 & $5.71 E-008$ \\
\hline \multirow{2}{*}{ ATWS } & \multirow{2}{*}{74} & 9 & 39 & 5 & 5.33E-008 & $1.00 E-011$ & $5.33 E-008$ & 5.66E-008 \\
\hline & & 10 & 20 & 2 & $6.48 E-008$ & 7.33E-009 & $5.75 E-008$ & $1.97 E-005$ \\
\hline \multicolumn{3}{|l|}{ Total } & b,188 & 1,708 & $2.07 E-006$ & 2.0E-007 & $1.86 E-006$ & $1.30 \mathrm{E}-003$ \\
\hline
\end{tabular}

A summary of the remaining events and accident sequences is presented in Table 4.2-11. There are two initiating events and five sequences that remain. These sequences have a combined total of 1,708 affected cut sets and are listed in Appendix C. There are no affected cut sets with a frequency greater than $1.0 \mathrm{E}-08 / \mathrm{RY}$.

As discussed above, there are five affected accident sequences, including four SBO sequences (sequences 13,16, 17, and 21) and one ATWS (anticipated transient without SCRAM) sequence (sequence 74). Discussions of each affected accident sequence are presented in the following paragraphs. 
TABLE 4.2-11. Affected Cut Set Allocation Summary(a)

\begin{tabular}{|c|c|c|c|c|c|c|c|}
\hline \multirow[b]{3}{*}{ Basic Event } & \multicolumn{4}{|c|}{ Station Blackout } & \multirow{3}{*}{$\begin{array}{l}\text { ATWS } \\
\text { Seq. } 74 \\
\text { PDS } 10\end{array}$} & \multirow{2}{*}{\multicolumn{2}{|c|}{ Total }} \\
\hline & \multirow{2}{*}{$\frac{\text { Soq. } 13}{\text { PDS } 8}$} & \multirow{2}{*}{$\frac{\text { Seq. } 16}{\text { PDS } 1}$} & \multirow{2}{*}{$\frac{\text { Seq. } 17}{\text { PDS } 1}$} & \multirow{2}{*}{$\frac{\text { Seq. } 21}{\text { PDS } 1}$} & & & \\
\hline & & & & & & Cut Set & Freq. \\
\hline $\begin{array}{l}\text { Diesel Generator I: } \\
\text { EHV-FAN-FS-77C1A } \\
\text { EHV-FAN-FR-77C1A } \\
\text { EHV-FAN-MA-77C1A } \\
\text { EHV-MOV-CC-MVC1A } \\
\text { EHV-MOV-MA-MVC1A }\end{array}$ & $\begin{array}{r}21 \\
29 \\
36 \\
75 \\
4\end{array}$ & $\begin{array}{r}5 \\
7 \\
27 \\
45 \\
3\end{array}$ & $\begin{array}{r}29 \\
32 \\
69 \\
108 \\
16\end{array}$ & $\begin{array}{r}5 \\
7 \\
27 \\
45 \\
3\end{array}$ & & $\begin{array}{r}60 \\
75 \\
159 \\
273 \\
26\end{array}$ & $\begin{array}{l}2.01 \mathrm{E}-9 \\
1.83 \mathrm{E}-9 \\
1.67 \mathrm{E}-8 \\
3.44 \mathrm{E}-8 \\
3.38 \mathrm{E}-9\end{array}$ \\
\hline $\begin{array}{l}\text { Diesel Generator } 11: \\
\text { EHV-FAN-FS,77C1B } \\
\text { EHV-FAN-FR-77C1B } \\
\text { EHV-FAN-MA-77C1B } \\
\text { EHV-MOV-CC-MVC1B } \\
\text { EHV-MOV-MA-MVC1B }\end{array}$ & $\begin{array}{r}21 \\
29 \\
36 \\
75 \\
4\end{array}$ & $\begin{array}{r}5 \\
7 \\
27 \\
43 \\
3\end{array}$ & $\begin{array}{r}29 \\
32 \\
72 \\
106 \\
16\end{array}$ & $\begin{array}{r}5 \\
7 \\
27 \\
43 \\
3\end{array}$ & & $\begin{array}{r}60 \\
75 \\
162 \\
267 \\
26\end{array}$ & $\begin{array}{l}2.01 E-9 \\
1.83 E-9 \\
1.67 E-8 \\
3.39 E-8 \\
3.38 E-9\end{array}$ \\
\hline $\begin{array}{l}\text { Diesel Generator } 111: \\
\text { EHV-FAN-FS-77CO2 } \\
\text { EHV-FAN-FR-77CO2 } \\
\text { EHV-FAN-MA-77CO2 } \\
\text { EHV-MOV-CC-MVCO2 } \\
\text { EHV-MOV-MA-MVCO2 }\end{array}$ & $\begin{array}{r}25 \\
35 \\
41 \\
94 \\
5\end{array}$ & $\begin{array}{r}7 \\
9 \\
37 \\
62 \\
4\end{array}$ & $\begin{array}{r}35 \\
38 \\
85 \\
114 \\
19\end{array}$ & $\begin{array}{r}7 \\
9 \\
37 \\
62 \\
4\end{array}$ & & $\begin{array}{r}74 \\
91 \\
200 \\
332 \\
32\end{array}$ & $\begin{array}{l}3.21 \mathrm{E}-9 \\
2.79 \mathrm{E}-9 \\
2.52 \mathrm{E}-8 \\
4.95 \mathrm{E}-8 \\
5.43 \mathrm{E}-9\end{array}$ \\
\hline $\begin{array}{l}\text { HPCS Room Cooler: } \\
\text { EHV-FAN-FS-51B1C } \\
\text { EHV-FAN-MA-5i1B1C }\end{array}$ & 1 & & & & $\begin{array}{l}5 \\
2\end{array}$ & $\begin{array}{l}1 \\
1\end{array}$ & $\begin{array}{l}1.23 \mathrm{E}-9 \\
6.10 \mathrm{E}-9\end{array}$ \\
\hline $\begin{array}{l}\text { Total Unique Cut Sets } \\
\text { Cumulative Mean Frequency }\end{array}$ & $\begin{array}{r}467 \\
5.03 E-9\end{array}$ & $\begin{array}{r}275 \\
1.82 E-7\end{array}$ & $\begin{array}{r}715 \\
2.20 E-9\end{array}$ & $\begin{array}{r}275 \\
7.28 \mathrm{E}-9\end{array}$ & $\begin{array}{r}7 \\
7.334-9\end{array}$ & & $\begin{array}{l}1,708 \\
2.0 E-7\end{array}$ \\
\hline $\begin{array}{l}\text { Numbers in columns } \\
\text { set element. }\end{array}$ & 8 & & $80 \mathrm{r}$ & & me & One & d cut \\
\hline
\end{tabular}

Station Blackout Sequence 16 . This sequence is initiated by a LOOP (T1). The reactor SCRAMS (/C) and the SRVs successfully cycle and reclose (/P1*/P2), but Divisions 1,2 , and 3 EDGs fail (B*B1). The only available coolant injection system is RCIC, but it fails to function (U2). A11 coolant makeup is lost and the core uncovers, resulting in core damage. This sequence contributes approximately $89 \%$ to the total CDF. The sequence has 1,011 cut sets, an original mean frequency of $3.6 \mathrm{E}-06 / \mathrm{RY}$, and original point estimate frequency of $1.8 \mathrm{E}-06 / \mathrm{RY}$.

Failure of the EDG room ventilatic systems fails the control panels of the EDGs in approximately 15 minutes. This affects the value of $B * B 1$ of the accident sequence. There is no practical recovery action available in that time. There are 275 cut sets out of the original 1,011 that are potentially affected by this issue. The affected cumulative cut set frequency is $1.82 E-07 / R Y$, about $88 \%$ of the total affected CDF.

Station Blackout Sequence 21. This sequence is initiated by a LOOP (T1) followed by a successful reactor SCRAM (/C) and a subsequent loss of Division 1,2 , and 3 EDGs $(B * B 1)$. The SRVs cycle, but one SRV fails to reclose (P1). 
RCIC is demanded but fails to function (U2). A11 coolant makeup is lost and the core uncovers, resulting in core damage. This sequence contributes approximately $4 \%$ to the total CDF. The sequence has 1,043 cut sets, an original mean frequency of $1.6 \mathrm{E}-07 / \mathrm{RY}$, and original point estimate of $6.6 \mathrm{E}-08 / \mathrm{RY}$.

Failure of the EDG room ventilation systems fails the control panels of the EDG in approximately 15 minutes. This affects the value of $B * B 1$ of the accident sequence. There is no practical recovery action available in that time. There are 275 cut sets out of the original 1,043 that are potentially affected by this issue. The affected cumulative cut set frequency is 7.28E-09/RY, about $3.5 \%$ of the total affected CDF.

ATWS Sequence 74. This sequence is initiated by an ATWS followed by a subsequent closure of the MSIVs $(Q)$. The operator is unable to SCRAM the reactor, because the RPS failed due to mechanical faults (CM). The recirculation pumps trip (/D), which reduces core power. The operator then fails to initiate the SLC system either early or late during the transient $\left(C^{\prime}{ }^{*} C^{\prime \prime}\right)$, and the HPCS system fails to function when demanded (UI). The operator fails to depressurize (X1) and all coolant makeup is lost. The core uncovers and core damage resuits. This sequence contributes approximately $3 \%$ to the total CDF. The sequence has 59 cut sets, an original mean frequency of $1.1 E-07 / R Y$, and original point estimate of $1.2 \mathrm{E}-07 / \mathrm{RY}$.

Failure of the HPCS room cooler is expected to fail the HPCS pump in approximately 12 hours, according to Druin et al. (1989). Similar time estimates are presented in Appendix F. This affects the value of U1 of the accident sequence. The probability of recovery action within 12 hours was estimated at 4.3E-03. There are seven cut sets out of the original 59 that are potentially affected by this issue; the affected cumulative cut set frequency is $7.34 \mathrm{E}-09 / \mathrm{RY}$, about $3.5 \%$ of the total affected CDF.

Station Blackout 13. This sequence is initiated by a LOOP (T1), followed by a successful reactor SCRAM $(/ C)$. The SRVs successfully open to relieve system pressure and then reclose $\left(/ P_{1 *} / P_{2}\right)$. However, al1 three EDGs fail to operate $(B * B 1)$. The RCIC system initially functions to provide coolant to the vessel; however, without the capacity to remove heat from the containment, the containment pressurizes, resulting in a high turbine exhaust pressure trip of the RCIC turbine. The reactor is subsequently depressurized $(/ X 1)$, and the firewater system is actuated $(/ V 5)$. Without $A C$ power, the batteries eventually deplete, and the SRVs close. The reactor pressurizes above the shutoff head of the firewater system. The operator fails to depressurize the reactor via the RCIC steam line. With no coolant injection, the core uncovers and damage occurs. This sequence contributes approximately $2 \%$ to the total CDF. The sequence has 1,159 cut sets, an original mean frequency of $6.6 \mathrm{E}-08 / \mathrm{RY}$, and an original point estimate of $3.1 \mathrm{E}-08 / \mathrm{RY}$.

Failure of the EDG room ventilation system fails the control panels of the EDGs in approximately 15 minutes. This affects the value of $B * B 1$ of the accident sequence. There is no practical recovery action available in that time. There are 467 cut sets out of the original 1,161 that are potentially 
affected by this issue. The affected cumulative cut set frequency is $5.03 E-09 / R Y$, about $2.4 \%$ of the total affected CDF.

Station Blackout Sequence 17. This sequence is initiated by LOOP (T1), followed by a successful reactor SCRAM $(/ C)$. All three EDGs fail to function $(B * B 1)$, and two SRVs stick open (P2) after relieving system pressure. The only operating: coolant injection system is RCIC, but the capacity of this system is not sufficient to make up the coolant lost out of two open SRVs. Eventually, the core uncovers and damage occurs. This sequence contributes approximately $1 \%$ of the original CDF. The original mean frequency was about $3.7 \mathrm{E}-08 / \mathrm{RY}$; the original point estimate waS $1.27 \mathrm{E}-08 / \mathrm{RY}$; and the original sequence included 1,686 cut sets.

Failure of the EDG room ventilation systems fails the control panels of the EDGs in approximately 15 minutes, affecting the value of $B \star B l$ of the accident sequence. There is no practical recovery action available in that time. There are 715 cut sets out of the original 1,686 that are potentially affected by this issue. The affected cumulative cut set frequency was calculated $2.20 E-09 / R Y$, about $1 \%$ of the total affected CDF.

The affected CDF at the representative BWR was calculated using the SARA computer mode1. The mean affected CDF was calculated to be $2.59 E-07 / R Y$. Table 4.2-12 presents the contribution of each accident sequence to the total affected CDF. A pie chart illustrating the contributions of each sequence to the total affected CDF is presented in Figure 4.2-4. Sequence 16 is the highest contributor with $88 \%$ of the affected CDF. The EDG ventilation system

TABLE 4.2-12. Affected Accident Sequences and Frequencies for Room Cooler Contributing Events at the Representative BWR (point estimates)

\begin{tabular}{|c|c|}
\hline Sequence & Frequency Per RY \\
\hline Station Blackout & $5.02 \mathrm{E}-09$ \\
- Sequence 13 & $1.81 \mathrm{E}-07$ \\
- Sequence 16 & $2.19 \mathrm{E}-09$ \\
- Sequence 17 & $7.26 \mathrm{E}-09$ \\
- Sequence 21 & $1.96 \mathrm{E}-07$ \\
\hline Subtotal & $7.33 \mathrm{E}-09$ \\
\hline TotwS & $2.03 \mathrm{E}-07$ \\
\hline
\end{tabular}


and the HPCS room cooler are the only significant events affected by this issue. The important statistical parameters of the CDF distribution were generated using Latin Hypercube sampling techniques; the results are presented below:

$\begin{array}{ll}\text { Mean: } & 2.59 E-07 / R Y \\ 95 \% \text { upper confidence bound: } & 1.2 E-06 / R Y \\ \text { Mean: } & 5.0 E-08 / R Y \\ 5 \% \text { lower confidence bound: } & 5.0 E-09 / R Y\end{array}$

The cumulative distribution function for the CDF is shown in Figure 4.2-5.

\subsubsection{Public Risk Calculations}

The calculational approach used in this section is the same as that described in subsection 4.1.1.3. This included assignment of the affected accident sequences to specified plant damage states (PDSs), partitioning of the PDSs into APBs, correlation APBs with appropriate source term categories and associated release consequences, and then completion of risk calculations. The accident progression and consequence analyses described by Brown et al. (1990) were used as the principal bases for the calculations in this section.

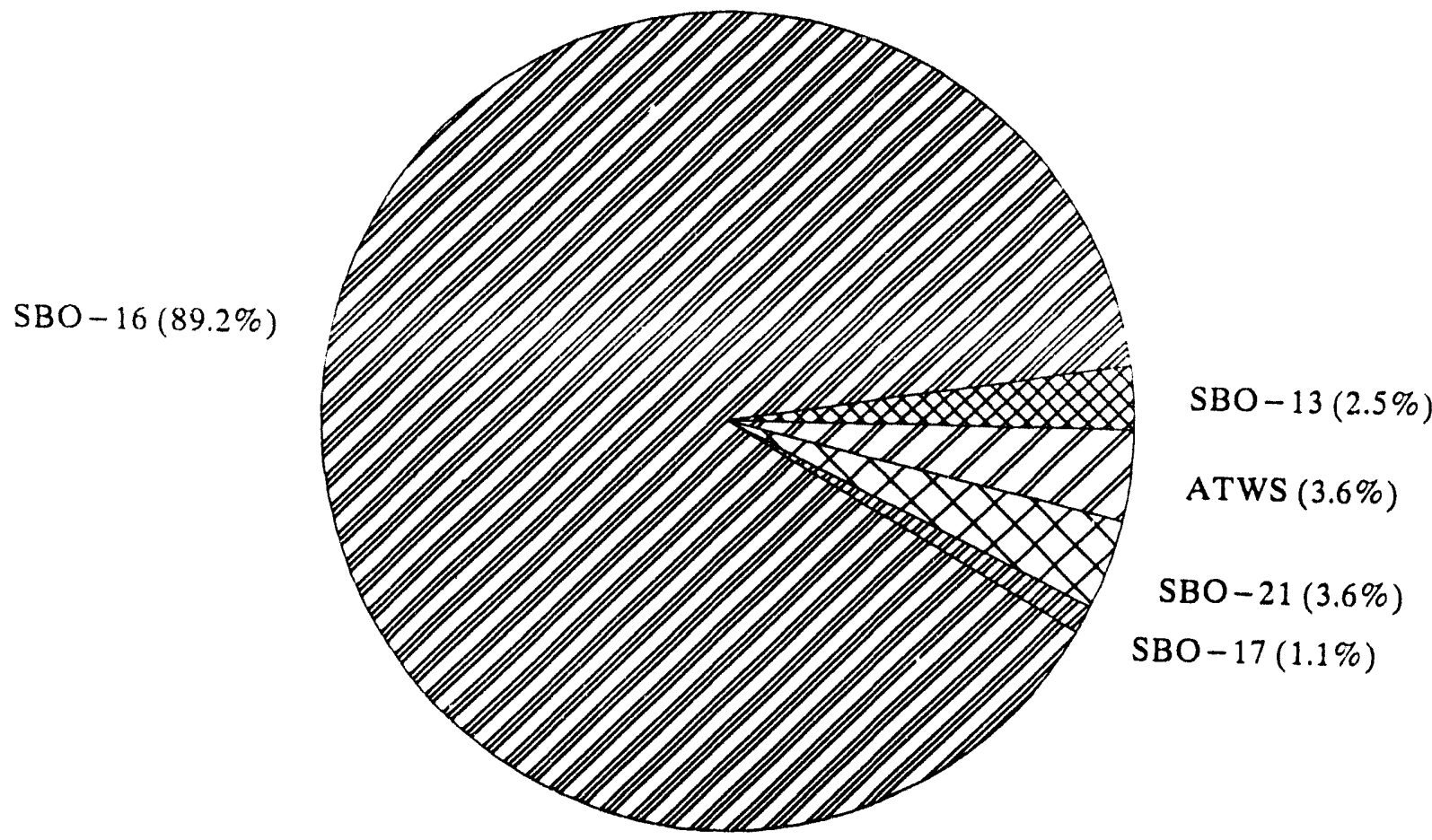

FIGURE 4.2-4. Sequence Contributions to Total Affected CDF for the Representative BWR - Iniernal Contributors 


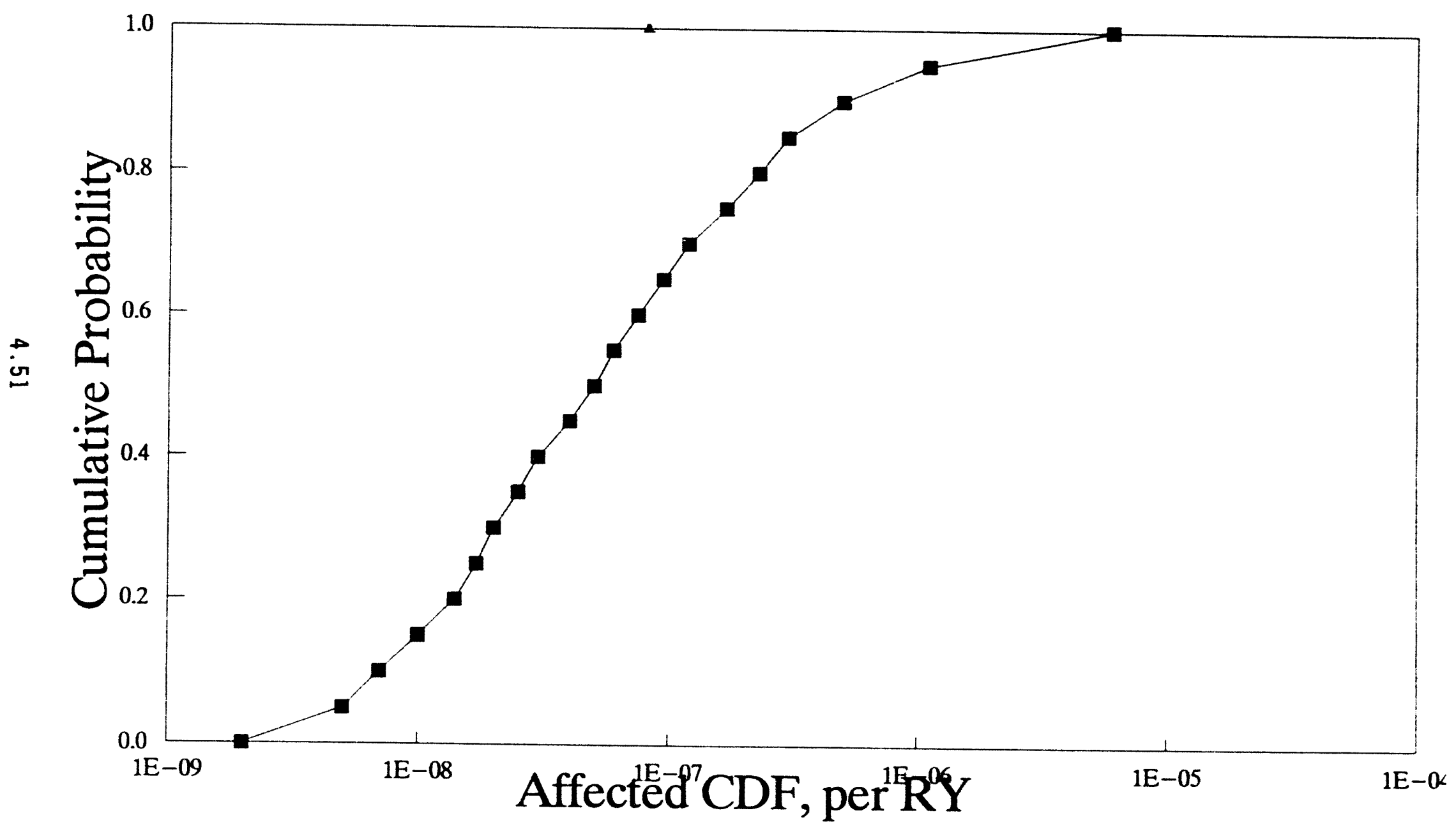

FIGURE 4.2-5. Cumulative Affected CDF Distribution for Internal Contributors at the Representative BWR 
In subsection 4.2.3.2, it was observed that the affected accident sequences were assigned to three plant damage states: PDS-1, PDS-8, and PDS-10. These three PDS categories constitute $98 \%$ of the affected CDF. The largest contributor is PDS-1, with $92 \%$ of all affected categories.

The PDS categories were partitioned into APBs as defined in Brown; the conditional probabilities of each APB were taken directly from Table 2.5-7 of that document, and source term category probabilities and consequence estimates for each source term category were taken from Tables 3.4-4 and 4.3-1. The calculations performed for each PDS are discussed in the following paragraphs.

Plant Damage State PDS-1 (B2-P3-I5-H2-M2-ST). This PDS involves SBO scenarios where LOOP is recoverable (B2). Coolant injection is lost early such that core damage occurs in the short term and with the vessel at high pressure (P3), because depressurization did not have an effect in the prevention of core damage. If offsite power is restored, the following functions are available: either HPI or LPI or both (I5); heat removal via the sprays (H2); and the miscellaneous systems, venting, SBGT, CI, and H2I (M2).

This PDS also includes cut sets with either one or two stuck-open relief values (SORVs). With the restoration of offsite power, the following coolant injection systems are recoverable: HPCS, condensate, LPCI and LPCS. In some cases, HPCS and LPCS are recoverable, but only for around 12 hours; they are then lost on room heatup. The firewater system is available in every cut set; for those cut sets with two SORVs, the RCIC system is available.

This PDS contributes $94 \%$ of the affected CDF with a point estimate of $1.90 \mathrm{E}-07 / \mathrm{RY}$ and a mean of $2.50 \mathrm{E}-07 / \mathrm{RY}$. The largest cut set has a mean frequency of $7.09 E-09 / R Y$. The APB probabilities for this bin were assumed to fall under the super-group short-term SBO (STSB). The public risk value calculated for this bin was 1.1E-01 person-rem/RY (Table 4.2-13).

Plant Damage State PDS-8 (B1-P1-I1-H1-MI-LT). This PDS involves SBO (without any $D C$ power) scenarios where LOOP is not recoverable (B1). Cool ant injection is lost late such that core damage occurs in the long term and with the vessel at high pressure (P1); depressurization is not possible. Since offsite power is not recoverable, functions (i.e., injection [I1], heat removal [HI] and the miscellaneous systems [MI]) are not available.

This PDS contributes $2.5 \%$ of the affected CDF with a point estimate of $5.03 E-09 / R Y$ and a mean of $1.01 E-08 / R Y$. The largest cut set has a mean frequency of 2.1E-10/RY. The APB probabilities for this bin are assumed to fall under the super-group long-term SBO (LTSB). The risk value calculated for this PDS was 7.4E-03 Person-rem/RY (Table 4.2-14).

Plant Damage State PDS-10 (TC-P2-I4-H3-M3-Lt). This PDS involves ATWS transient scenarios. Coolant injection is lost late such that core damage occurs in the long term and with the vessel at high pressure, because the operator failed to depressurize (P2). Low-pressure injection is recoverable 
IABLE 4.2-13. PDS-1 Risk Calculation

\begin{tabular}{|c|c|c|c|c|c|c|c|}
\hline $\begin{array}{l}\text { Accident } \\
\text { Progreation Bin }\end{array}$ & $\begin{array}{l}\text { Conditional } \\
\text { Probability }\end{array}$ & $\begin{array}{c}\text { APQ } \\
\text { Frequenoy }\end{array}$ & $\begin{array}{l}\text { Source.Torm } \\
\text { Group }\end{array}$ & $\begin{array}{l}\text { Conditional } \\
\text { Probubility }\end{array}$ & $\begin{array}{l}\text { Source-Torm } \\
\text { Group Frequency }\end{array}$ & $\begin{array}{l}\text { Consequences } \\
\text { Person-tem/Event }\end{array}$ & $\begin{array}{c}\text { Risk } \\
\text { Pereon-rem/AY }\end{array}$ \\
\hline \multirow{2}{*}{$\begin{array}{l}\text { VB, earty CF, } \\
\text { carty SPE, no CS }\end{array}$} & \multirow{2}{*}{0.188} & \multirow{2}{*}{ 4.21E.00 } & GQ-13-1 & 0.635 & 2.07E-08 & $1.88 E+\infty$ & $5.02 E-02$ \\
\hline & & & $a Q-13-2$ & 0.365 & 1.54E.08 & $2.01 E+00$ & $3.00 E .02$ \\
\hline \multirow{2}{*}{$\begin{array}{l}\text { VE, earty CF, } \\
\text { ourly SPB, CS }\end{array}$} & \multirow{2}{*}{0.031} & \multirow{2}{*}{$7.70 E-00$} & 00.12 .1 & 0.387 & $3.00 E-00$ & $4.03 E+00$ & $1.21 E-03$ \\
\hline & & & $90.12 \cdot 2$ & 0.613 & 4.76E-09 & $4.18 E+06$ & 1.00E-03 \\
\hline \multirow{2}{*}{$\begin{array}{c}\text { VE, ourty CF, lato } \\
\text { SPB }\end{array}$} & \multirow{2}{*}{0.006} & \multirow{2}{*}{$1.50 E-\infty 0$} & GQ.10.1 & 0.881 & 1.47E-09 & $2.58 E+0.5$ & $3.80 \mathrm{E}-04$ \\
\hline & & & $0 \mathrm{a}-10-2$ & 0.010 & $2.86 \mathrm{E}-11$ & $2.30 E+03$ & 6.57E-06 \\
\hline \multirow{2}{*}{$\begin{array}{c}\text { VB, earty CF, no } \\
\text { SPB }\end{array}$} & \multirow{2}{*}{0.182} & \multirow{2}{*}{$4.56 E-08$} & aQ.10-1 & 0.981 & 4.47E-08 & $2.58 E+0 s$ & 1.15E.02 \\
\hline & & & GG.10-2 & 0.019 & $8.68 \mathrm{E} \cdot 10$ & $2.30 E+0.5$ & $1.89 E-04$ \\
\hline \multirow{2}{*}{ Ve, late CF } & \multirow{2}{*}{0.308} & \multirow{2}{*}{$7.71 E-00$} & 60.05.1 & 0.503 & 4.57E.08 & $1.82 E+05$ & 8.33E.03 \\
\hline & & & GQ-0s-2 & 0.407 & 3.14E-08 & $1.61 E+05$ & S.06E-03 \\
\hline \multirow{2}{*}{ VB, Venting } & \multirow{2}{*}{0.032} & \multirow{2}{*}{ 8.02E-00 } & GQ.03-1 & 0.673 & $5.30 E-00$ & $6.09 E+04$ & 3.77E.04 \\
\hline & & & 0Q.03-2 & 0.327 & 2.62E-09 & $6.00 E+04$ & $2.10 E \cdot 04$ \\
\hline \multirow{2}{*}{ VB, no CF } & \multirow{2}{*}{0.053} & \multirow{2}{*}{$1.33 \mathrm{E}-08$} & GG.02.1 & 0.480 & 6.62E-09 & $4.18 E+02$ & 2.77E-08 \\
\hline & & & $0 Q .02 .2$ & 0.501 & 6.65E-09 & $4.18 E+02$ & $2.78 \mathrm{E}-08$ \\
\hline \multirow{2}{*}{ No VB } & \multirow{2}{*}{0.201} & \multirow{2}{*}{ 5.03E-00 } & GG-15-1 & 0.009 & 5.03E-08 & $3.47 E+01$ & $1.76 E-00$ \\
\hline & & & $0 Q \cdot 15 \cdot 2$ & 0.001 & $5.03 E-11$ & $1.17 E+02$ & 5.89E-09 \\
\hline \multicolumn{2}{|c|}{ Note: PDS.1 Frequency } & \multicolumn{2}{|l|}{$2.50 E-07$} & & & Total & 1.10E-01 \\
\hline
\end{tabular}

IABLE 4.2-14. PDS-8 Risk Calculation

\begin{tabular}{|c|c|c|c|c|c|c|c|}
\hline $\begin{array}{c}\text { Accident } \\
\text { Progreselion Bin }\end{array}$ & $\begin{array}{l}\text { Conditional } \\
\text { Probability }\end{array}$ & $\begin{array}{c}\text { APB } \\
\text { Frequency }\end{array}$ & $\begin{array}{l}\text { Source-Term } \\
\text { Group }\end{array}$ & $\begin{array}{l}\text { Conditional } \\
\text { Probability }\end{array}$ & $\begin{array}{l}\text { Source-Term } \\
\text { Group Frequency }\end{array}$ & $\begin{array}{l}\text { Consequences } \\
\text { Person-rem/Event }\end{array}$ & $\begin{array}{c}\text { Plisk } \\
\text { Porson-tem/faY }\end{array}$ \\
\hline \multirow{2}{*}{$\begin{array}{l}\text { VB, early CF. } \\
\text { early SPB, no CS }\end{array}$} & \multirow{2}{*}{0.292} & \multirow{2}{*}{ 2.85E-00 } & GQ.13-1 & 0.635 & 1.87E-09 & $1.88 E+08$ & 3.52E-03 \\
\hline & & & $G G-13-2$ & 0.385 & $1.08 E-00$ & $2.01 E+08$ & 2.17E-03 \\
\hline \multirow{2}{*}{$\begin{array}{l}\text { VB, earty CF, } \\
\text { early SPB, CS }\end{array}$} & \multirow{2}{*}{0.017} & \multirow{2}{*}{$1.72 E-10$} & GQ.12.1 & 0.387 & $6.65 E \cdot 11$ & $4.03 E+03$ & 2.69E-05 \\
\hline & & & $60.12 \cdot 2$ & 0.813 & $1.05 E \cdot 10$ & $4.18 E+0 s$ & 4.40E-05 \\
\hline \multirow{2}{*}{$\begin{array}{c}\text { VB, early CF, late } \\
\text { SPB }\end{array}$} & \multirow{2}{*}{0.005} & \multirow{2}{*}{ 5.00E-11 } & GG.10.1 & 0.861 & $4.88 E \cdot 11$ & $2.56 E+05$ & $1.28 E-05$ \\
\hline & & & $Q Q \cdot 10-2$ & 0.018 & $9.60 E-13$ & $2.30 E+05$ & 2.21E.07 \\
\hline \multirow{2}{*}{$\begin{array}{c}\text { VB, oarly CF, no } \\
\text { SPB }\end{array}$} & \multirow{2}{*}{0.531} & \multirow{2}{*}{$5.37 E-09$} & GQ-10-1 & 0.881 & $5.27 \mathrm{E}-00$ & $2.58 E+05$ & $1.36 \mathrm{E} \cdot 03$ \\
\hline & & & $G Q \cdot 10-2$ & 0.018 & $1.02 E-10$ & $2.30 E+05$ & 2.35E-05 \\
\hline \multirow{2}{*}{ VB, late CF } & \multirow{2}{*}{0.120} & \multirow{2}{*}{$1.30 E-00$} & GG-0s-1 & 0.593 & $7.73 E-10$ & 1. $82 E+05$ & $1.41 \mathrm{E} \cdot 04$ \\
\hline & & & GG.05.2 & 0.407 & 5.31E.1. & $1.01 E+05$ & 6.5SE.05 \\
\hline \multirow{2}{*}{ VB, Venting } & \multirow{2}{*}{0.003} & \multirow{2}{*}{$3.03 E-11$} & Ga.03.1 & 0.673 & $2.04 E-11$ & $6.90 E+04$ & $1.43 E-08$ \\
\hline & & & GG-03-2 & 0.327 & $9.82 \mathrm{E}+12$ & $6.00 E+04$ & 7.93E-07 \\
\hline \multirow{2}{*}{ VB, no CF } & \multirow{2}{*}{0.003} & \multirow{2}{*}{$3.03 E \cdot 11$} & G0.02.1 & 0.499 & $1.51 E-11$ & $4.18 E+02$ & 6.33E-00 \\
\hline & & & GG.02-2 & 0.501 & $1.52 \mathrm{E} \cdot 11$ & $4.18 E+02$ & 6. 35E.00 \\
\hline \multirow{2}{*}{ No VB } & \multirow{2}{*}{0.015} & \multirow{2}{*}{$1.52 E-10$} & GG.15.1 & 0.098 & 1.51E-10 & $3.47 E+01$ & $5.28 E-00$ \\
\hline & & & GG-15.2 & 0.001 & 1.S2E-13 & $1.17 E+02$ & $1.77 \mathrm{E}-11$ \\
\hline \multicolumn{2}{|c|}{ Note: PDS-8 Frequency } & \multicolumn{2}{|l|}{$1.01 E-09$} & & & Total & 7.36E-03 \\
\hline
\end{tabular}


with reactor depressurization (14). Heat removal via the sprays is avallable (H3), and the miscellaneous systems (venting, SBGT, Cl, and H2I) are avallable (M3).

This PDS contributes $3.6 \%$ of the affected CDF with a point estimate of $7.34 \mathrm{E}-09 / \mathrm{RY}$ and a mean of 6.96E-09/RY. The largest two cut sets were calculated to have frequencies of 6.10E-09/RY and 1.23E-09/RY. The APB probabilities for this bin are assumed to fall under the super-group anticipated transient without SCRAM (ATWS). The public risk value calculated for this PDS was 1.8E-03 person-rem/RY (Table 4.2-15).

The public risk value associated with room cooler contributors at the representative BWR was calculated to have a point estimate of $8.3 \mathrm{E}-02$ person$\mathrm{rem} / \mathrm{RY}$ and a mean of $1.2 \mathrm{E}-01$ person-rem/RY. The final results and uncertainty analysis are presented below. The cumulative distribution is shown is Figure 4.2-6.
Point Estimate:
8.3E-02 person-rem/RY
Mean:
1.2E-01 person-rem/RY
95\% upper confidence bound:
5.3E-01 person-rem/RY
Median:
2.3E-02 person-rem/RY
$5 \%$ lower confidence bound:
2.3E-03 person-rem/RY

\subsubsection{Iotal Affected Core Damage Frequency and Public Risks}

The total affected CDF and public risk values are the sum of the room cooler initiator (see Section 4.2.1) and room cooler contributing events (see Section 4.2.2). The affected CDF and public risks for the representative BWR, based on their mean values, are shown below:

\begin{tabular}{|c|c|c|}
\hline $\begin{array}{c}\text { Representative } \\
\text { General Electric } \\
\text { BWR }\end{array}$ & $\begin{array}{c}\text { Affected } \\
\text { Core Damage } \\
\text { Frequency, } \\
\text { per RY }\end{array}$ & $\begin{array}{c}\text { Affected } \\
\text { Public Risk, } \\
\text { Person-rem/RY(a) }\end{array}$ \\
\hline Initiators & $4.7 E-07$ & $2.3 E-01$ \\
\hline Contributors & $2.6 E-07$ & $1.2 E-01$ \\
\hline Total & $7.3 E-07$ & $3.5 E-01$ \\
\hline (a) Values given are mean values.
\end{tabular}




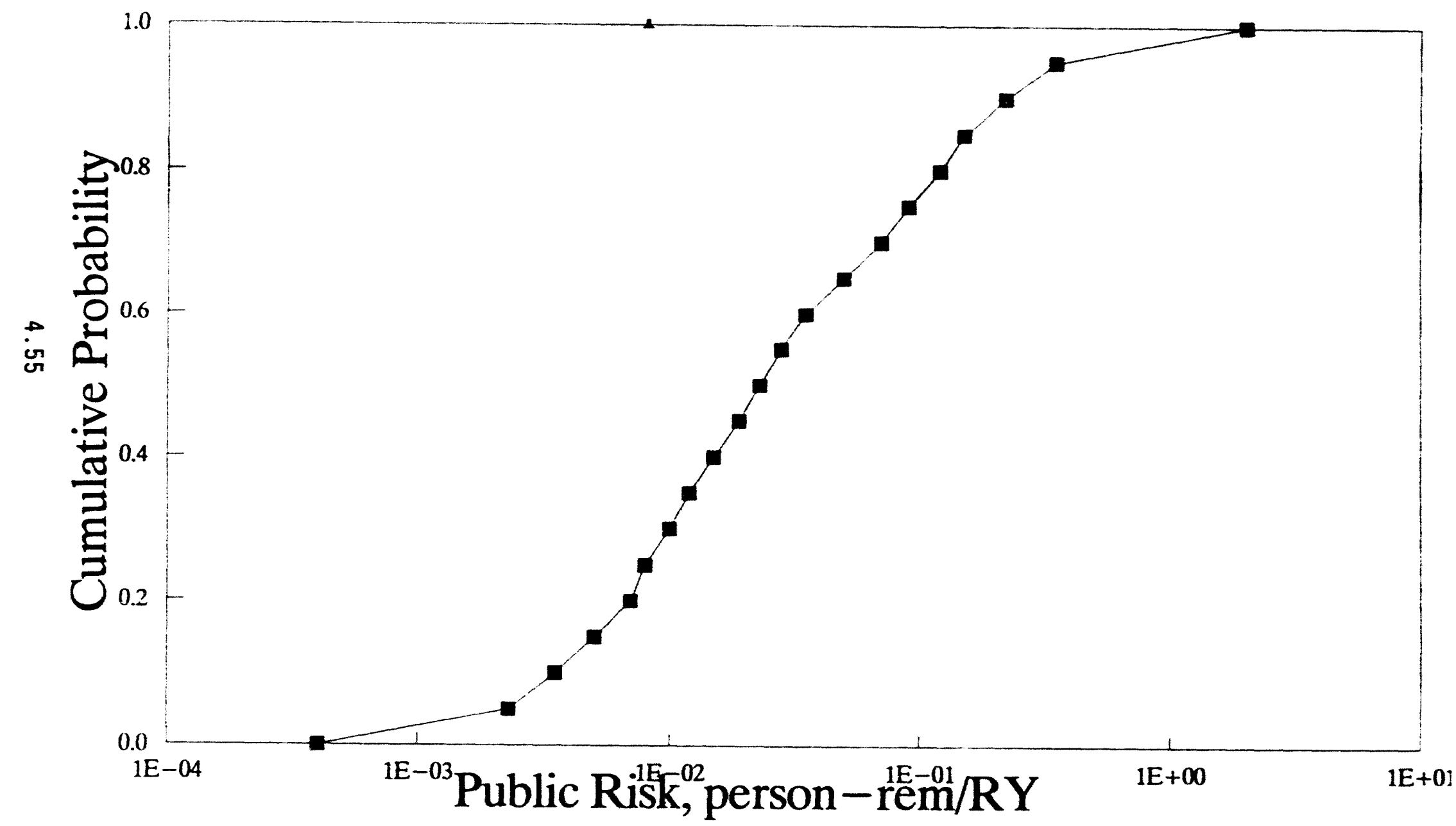

FIGURE 4.2-6. Affected Public Risk Distribution for Internal Contributors - Representative BUR 
IABLE 4,2-15. POS-10 Risk Calculation

\begin{tabular}{|c|c|c|c|c|c|c|c|}
\hline $\begin{array}{c}\text { Aocident } \\
\text { Prognvion un }\end{array}$ & $\begin{array}{l}\text { Conditional } \\
\text { Probabiliny }\end{array}$ & $\begin{array}{c}\text { APG } \\
\text { Erequency }\end{array}$ & $\begin{array}{l}\text { Soures.Torm } \\
\text { Orowp }\end{array}$ & $\begin{array}{l}\text { Conditional } \\
\text { Probability }\end{array}$ & $\begin{array}{c}\text { Soures-Tem } \\
\text { Broup Freacunoy }\end{array}$ & $\begin{array}{l}\text { Concequences } \\
\text { Pereon-rem/Event }\end{array}$ & $\begin{array}{c}\text { Rivk } \\
\text { Pomon-romar }\end{array}$ \\
\hline \multirow{2}{*}{$\begin{array}{l}\text { VB, earty CF. } \\
\text { sarty sPe, no CS }\end{array}$} & \multirow{2}{*}{0.000} & \multirow{2}{*}{$4.17 \mathrm{E} .11$} & QQ.13-1 & 0.098 & $2.608+11$ & $1.805+00$ & $4.00=00$ \\
\hline & & & $00.13-2$ & 0.306 & $1.82 E-11$ & $2.01 E+00$ & $3.00 E-08$ \\
\hline \multirow{2}{*}{$\begin{array}{l}\text { Va, earty CF, } \\
\text { canty spa, Ce }\end{array}$} & \multirow{2}{*}{0.237} & \multirow{2}{*}{1.08500} & 00.12 .1 & 0.397 & $0.358+10$ & $4.03 E+00$ & 2.07E-04 \\
\hline & & & Go.12.2 & 0.613 & $1.01 E-00$ & $4.10 E+00$ & $4.205-04$ \\
\hline \multirow{2}{*}{$\begin{array}{c}\text { VB, eary CF, late } \\
\text { 9PQ }\end{array}$} & \multirow{2}{*}{0.000} & \multirow{2}{*}{2.000 .11} & CQ:10-1 & 0.001 & $2.085-11$ & $2.4 E+00$ & $5.248-09$ \\
\hline & & & $00-10-2$ & 0.010 & $3.006-13$ & $2.30 \mathrm{E}+00$ & $0.12 E-00$ \\
\hline \multirow{2}{*}{$\begin{array}{c}\text { VB, carty CF, no } \\
\text { gape }\end{array}$} & \multirow{2}{*}{0.000} & \multirow{2}{*}{$3.81 E-00$} & $00.10-1$ & 0.091 & 3.45500 & $2.605+6 s$ & c.ece-04 \\
\hline & & & 00.10 .2 & 0.010 & $0.07 \mathrm{E}+11$ & $2.30 \mathrm{E}+00$ & $1.04 E-\infty$ \\
\hline \multirow{2}{*}{ Va, I CF } & \multirow{2}{*}{0.074} & \multirow{2}{*}{ 6. $16 E \cdot 10$} & $00.00-1$ & 0.803 & $3.00=-10$ & $1.865+00$ & 6.60800 \\
\hline & & & GQ-0s.2 & 0.407 & $2.10 c \cdot 10$ & $1.01 E+00$ & $3.37 E-06$ \\
\hline \multirow{2}{*}{$\mathrm{VB}$, Vonting } & \multirow{2}{*}{0.100} & \multirow{2}{*}{$7.805 \cdot 10$} & $00-08-1$ & 0.673 & 6. $10 E-10$ & $0.00 E+04$ & $3.07 E-\infty$ \\
\hline & & & $00-03-2$ & 0.327 & $2.45 \cdot 10$ & $0.00 E+04$ & $1.005-00$ \\
\hline \multirow{2}{*}{ VE, no Cf } & \multirow{2}{*}{0.030} & \multirow{2}{*}{$2.00 \mathrm{E} \cdot 10$} & $00-02.1$ & 0.400 & $1.28 E-10$ & $4.10 E+\infty$ & $8.205-00$ \\
\hline & & & $00-02 \cdot 2$ & 0.801 & $1.26 E-10$ & $4.18 E+\infty 2$ & $5.24 E-00$ \\
\hline \multirow{2}{*}{ No Ve } & \multirow{2}{*}{0.018} & \multirow{2}{*}{$1.74 E \cdot 10$} & GC.1B-1 & 0.000 & $1.74 E-10$ & 3.47E+01 & $0.035-00$ \\
\hline & & & $00.15 \cdot 2$ & 0.001 & $1.74 E \cdot 13$ & $1.17 E+\infty 2$ & $2.00 E-11$ \\
\hline \multicolumn{2}{|c|}{ Note: PD8-10 Frequency } & \multicolumn{2}{|l|}{ 6.00E-9 } & & & Total & $1.01 E-\infty$ \\
\hline
\end{tabular}

\subsection{ANALYSIS OF AFFECTED CDF AND PUBLIC RISKS FOR THE REPRESENTALIVE COMBUSTION ENGINEERING PWR}

This section presents the affected CDF and public risk calculations for the representative CE PWR. The analysis of the CE PWR was based on the plant's IPE (APSC 1992), which was performed using a slightly different approach and presented in a different format than the NUREG-1150 PRAs (NRC 1990). As a result, the format of the information presented in the following subsections is somewhat different from the format of Sections 4.1 and 4.2, although an effort was undertaken to follow the previous format as closely as possible. One effect of the differences between the CE PWRS IPE and the NUREG-1150 PRAs was that the analysis of HVAC/room cooler initiators and contributing events were combined into a single analysis to develop estimates of the affected CDF and public risks for the CE PWR. The CDF calculations are presented in Section 4.3.1, and the affected public risk calculations are presented in Section 4.3.2.

\subsubsection{Core Damage Frequency Calculations}

The affected CDF and public risks associated with HVAC and room cooler failures at the representative CE PWR were calculated from minimal cut set data provided in the existing PRA (APSC 1992). A total of 200 minimal cut sets were presented in the existing PRA, which were then examined to remove' unaffected cut sets; i.e., cut sets that did not contain elements that exhibit a room cooling dependency. The remaining cut sets were then reviewed in detail to determine whether they should be used directly (cut sets that 
included explicit HVAC/room cooler fallures) or should be modifted to incorporate HVAC/room cooler fallures. Cut sets were modified for the following reasons:

- An ESF component fallure was included in the cut set and had a probability that was much more likely than failure of the associated room cooler and fallure to restore room cooling (this may have resulted in the cut set being eliminated based on a low frequency value). A new cut set was created to replace the ESF component fallure with a room cooler fallure, as illustrated in Section 2.4 .

- The cut set contained failure of an ESF component in a room for which no room cooler dependencies were modeled. For example, modifications to cut sets were made to incorporate failure of the diesel generator ventilation systems that were not modeled in the existing PRA.

This process resulted in the minimal cut sets shown in Appendix D. Each modified cut set was then reviewed to remove duplicates.

A list of the affected cut set elements is provided in Table 4.3-1. The values used to quantify the cut sets and their bases are also shown in the table; the bases for the values indicated in the table are discussed below. Note that the rest of the parameters in the cut sets shown in Appendix $D$ are unchanged from the values given in the existing PRA.

AFW-ABN-FAN: This event is a common-cause failure of room cooling in all three AFW pump room coolers combined with failure to restore room cooling in time to prevent secondary cooling failure. A common-cause fallure probability of 1E-04/demand is used here, based on common-cause failure of both EW pumps as given in the representative plant's PRA. This value was used to represent the room coolers because it tends to present a limiting case for a three-outof-three system and because the room coolers are nearly identical units, similar to the EW pumps. The recovery failure probability is $4 \mathrm{E}-03$ (see Section 4.1) for failure to restore room cooling to at least one AFW pump within 12 hours. The probability for this event is therefore $(1 E-04) *(4 E-03)=$ 4E-07/demand. This cut set element was substituted for AFW pump start/run failures in the existing PRA cut sets.

AFAPO1-FAN-FR24 and AFBPO1-FAN-FR24: These cut set elements represent failure of the Train A and Train B AFW pump room coolers to start and run for 24 hours. Failure of these room coolers would result in failure of the respective AFW pumps within 12 hours. The room cooler fallure probability was calculated from information in the existing PRA as shown below:
Local fault in air handling unit
$2.7 \mathrm{E}-03$
Unavailable due to maintenance
4.0E-04
EW cooling water inlet valve fails to open
9.8E-06
$3.1 \mathrm{E}-03 /$ demand 

IABLE 4,3-1. List of Affected Cut Set Elements and Values
for the Representative CE PWR

\begin{tabular}{|c|c|c|c|}
\hline Desigiation & Description & Value & Basis \\
\hline$A F W-A B N-F A N$ & $\begin{array}{l}\text { Common cause fallure of all room cooling to AFW pumps (Train } \\
A, B \text {, and } N \text { ) and fallure to restore room cooling within } 12 \\
h r\end{array}$ & $4.0 E-07 / 0$ & $\begin{array}{l}\text { Sec } 4.3 \\
\text { this study }\end{array}$ \\
\hline AFAPO1-FAN-FR24 & $\begin{array}{l}\text { Fallure of Train A AFW pump (turbine-driven) room cooler to } \\
\text { run for } 24 \mathrm{hr}\end{array}$ & $3.1 E-03 / 0$ & $\begin{array}{l}\text { Sec } 4.3 \\
\text { this study }\end{array}$ \\
\hline AFBPOI-FAN-FR24 & $\begin{array}{l}\text { Fallure of Train B AFW pump (motor-driven) room cooler to } \\
\text { run for } 24 \mathrm{hr}\end{array}$ & $3.1 E-03 / D$ & $\begin{array}{l}\text { Sec } 4.3 \\
\text { this study }\end{array}$ \\
\hline DG1-FAN-FR24 & Fallure of $D G 1$ ventilation fan to run for $24 \mathrm{hr}$ & $5.9 E-04 / D$ & $\begin{array}{l}\text { Sec } 4.3 \\
\text { this study }\end{array}$ \\
\hline DG2-FAN-FR24 & Fallure of $D G 1$ ventllation fan to run for $24 \mathrm{hr}$ & $5.9 E-04 / 0$ & $\begin{array}{l}\text { Sec } 4.3 \\
\text { this study }\end{array}$ \\
\hline$D G 12-F A N-C C$ & $\begin{array}{l}\text { Common cause failure of both } D G \text { room ventilation fans to } \\
\text { start and run }\end{array}$ & $3.5 E-05 / 0$ & $\begin{array}{l}\text { Sec } 4.3 \\
\text { this study }\end{array}$ \\
\hline DG12-DAMP-CC & $\begin{array}{l}\text { Common cause failure of air supply dampers in } D G \text { ventllation } \\
\text { system to open on demand }\end{array}$ & $2.3 E-06 / 0$ & $\begin{array}{l}\text { Sec } 4.3 \\
\text { this study }\end{array}$ \\
\hline CRAC-FR-NREC & $\begin{array}{l}\text { Fallure of control room air conditioning system and fallure } \\
\text { to restore cooling within } 12 \mathrm{hr}\end{array}$ & $4.7 E-06 / 0$ & $\begin{array}{l}\text { Sec } 4.3 \\
\text { this study }\end{array}$ \\
\hline CSSA-FAN-FRI & $\begin{array}{l}\text { Containment spray pump A essential atr conditioning unit } \\
\text { fails to run }\end{array}$ & $3.4 E-04 / D$ & PRA \\
\hline CSSB-FAN-FRI & $\begin{array}{l}\text { Containment spray pump B essential air conditioning unit } \\
\text { fails to run }\end{array}$ & $3.4 \mathrm{E}-04 / 0$ & PRA \\
\hline ISAB-LOADSEQB-CM & Load sequencer 8 unavallable due to maintenance & $4.7 E-06 / 0$ & $\begin{array}{l}\text { Sec } 4.3 \\
\text { this study }\end{array}$ \\
\hline ISA-AFASI2 - -CC & $\begin{array}{l}\text { Common cause failure of AFAS-1 and AFAS-2 (level indication } \\
\text { fails) }\end{array}$ & $4.7 \mathrm{E}-06 / 0$ & $\begin{array}{l}\text { Sec } 4.3 \\
\text { this study }\end{array}$ \\
\hline IEPKBM42 - HVAC & Loss of Channel B DC equipment room HVAC - initiating event & $1.6 \mathrm{E}-04 / \mathrm{RY}$ & $\begin{array}{l}\text { Sec } 4.3 \\
\text { this study }\end{array}$ \\
\hline IEPKAM41-HVAC & Loss of Channel $A$ DC equipment room HVAC & $1.6 \mathrm{E}-04 / \mathrm{RY}$ & $\begin{array}{l}\text { Sec } 4.3 \\
\text { this study }\end{array}$ \\
\hline 1CRHVC-COOL12OHL & $\begin{array}{l}\text { Control room operator falls to shut off essential fan and } \\
\text { open door within } 12 \mathrm{hr}\end{array}$ & $2.0 \mathrm{E}-03 / 0$ & PRA \\
\hline 1ECBE01-ARHFS & $\begin{array}{l}\text { Train B essential chiller fails to start laffects ESF } \\
\text { component, control room, and switchgear room HVAC }\end{array}$ & $3.7 E-04 / D$ & PRA \\
\hline
\end{tabular}

These cut set elements were substituted in place of AFW Train A and train pump start/run failures to model the effects of AFW pump room coolers.

DG1-FAN-FR24 and DG2-FAN-FR24: These cut set elements represent failure to supply ventilation air to diesel generators 1 and 2 , respectively. These elements comprised three potent:al failures that will result in loss of airflow to the diesel generator (DG) room. These faults and their respective probabilities were taken from the existing PRA:
Local fault, exhaust fan
$3.4 \mathrm{E}-04$
Damper fails to open
Actuation circuitry (relay) fails
$2.4 E-04$
$8.6 \mathrm{E}-06$
$5.9 \mathrm{E}-04 /$ demand 
These cut set elements were substituted in place of DG start/run failures to model the effects of DG ventilation failure on CDFs and plant risks. Recovery of DG ventilation fallures was not included, because there is insufficient time to perform recovery actions.

DG12-FAN-CC: This parameter represents common-cause failure of both DG ventilation systems to start, resulting in fallure of the DGs. The commoncause failure probability for these systems was assumed to be approximately equal to the common-cause fallure rates for both control room HVAC fans to start, 3.5E-05/demand. This was believed to be representative of the DG HVAC system because in both room cooling systems, the component designs are identical, both represent fallures of fans, and both are two-out-of-two systems. This cut set element was substituted into existing PRA cuts sets in place of DG start/run failures to model the effects of fallure of the DG ventilation system.

DG12-DAMP-CC: This parameter is for conmon cause failure of motor-operated dampers in the diesel generator ventilation systems. Failure of these dampers results in a loss of airflow into the DG rooms and will cause failure of the DGs to perform their intended function. The value for this parameter was derived using the common-cause fault rates for control room HVAC fans and the random failure rate for a single control room fan. It was assumed that the ratio of common-cause fault rates for the two-out-of-two control room HVAC fans to the random fallure rate for a single fan will be the same for the DG room dampers. This ratio was calculated to be 0.1 for the control room fans. The random failure rate for motor-operated dampers in the existing PRA was given as 2.4E-07/hour. Using an exposure time of 0.25 months (this was used for other dampers in the existing PRA), the demand failure probability for a single DG motor-operated damper was calculated to be $2.3 \mathrm{E}-05 /$ demand. The common-cause fault rate is 0.1 times this value, or $2.3 E-06 /$ demand. This cut set element was substituted into existing PRA cuts sets in place of DG start/ run failures to model the effects of failure of the DG ventilation system.

CRAC-FR-NREC: This parameter represents failure of control room air conditioning systems and failure to recover within 12 hours to prevent overheating of temperature-sensitive cabinets. The first part of this parameter represents failure of the control room HVAC system. This probability was based on the failure of the control room AHUs to operate, $1.1 \mathrm{E}-03 /$ demand, as given in the existing PRA. The probability of failure to restore cooling, from Section 4.1 of this study, amounts to $4.3 \mathrm{E}-03 /$ demand. The probability of failure of control room HVAC and failure to restore is the product of these two terms, or 4.7E-06/demand. This event was substituted into cut sets containing failure of auxiliary feedwater actuation system (AFAS) logic channels and ESF load sequencers. Cabinets for both AFAS logic and load sequencers are located in rooms cooled by the essential control room HVAC system.

CSSB-FAN-FR1 and CSSA-FAN-FR1: These parameters represent failure of the containment spray (CS) pump room coolers leading to failure of the CS pumps. The probability of failure of these components, as given in the existing PRA, was 3.4E-04/demand. This event was substituted into the cut sets taken from the existing FrA that contained CS pump failures. 
1SAB-LOADSEOB-CM: This parameter represents failure of the load sequencers located in the control room due to random equipment faults. To model the HVAC reliability concern expressed in this study, this parameter was replaced by failure of control room HVAC and failure to recover in time to prevent failure. A value of 4.7E-06/demand was used to represent the probability of failure of these components due to loss of room cooling. The cut set element involving failure of control room air conditioning (CRAC-FR-NREC discussed above) was substituted into existing PRA cut sets in place of all events involving failure of the ESF load sequencers, including 1LSA--LDSHED-2SA, 1LSA1-LDSHD-2SA, 1LSB--LDSHED-2SA, and 1LSB1-LDSHD-2SA).

IEPKBM42-NR and IEPKAM41-NR: These cut set elements represent failure of the DC equipment room HVAC system to remove heat from sensitive components located in the rooms (Channel $A$ and $B$, respectively) and failure to restore cooling within 45 minutes to prevent component failures. These are initiating events. The probabilities of these events consist of two parts: loss of DC equipment room HVAC and failure to restore room cooling. The annual frequency of DC equipment room HVAC failures was calculated in the existing PRA to be 2E-02/RY based on plant-specific data. The second part was developed in this study using the quantification process for operator recovery actions described in Section 4.1 . The formula for the nonrecovery probability is

$$
P(N R)=P(N D)+P(N A)-P(N D) P(N A)
$$

where: $P(N R)=$ Probability of failure to recover

$P(N D)=$ Probability of failure to diagnose appropriate action

$P(N A)=$ Probability of failure to reach appropriate area of plant and accomplish action

$P(N D)$ was taken directly from Table 4.2-1 of NUREG/CR-4834. The maximum time to accomplish the recovery activity $\left(T_{M}\right)$ is the sum of the time to diagnose $\left(T_{D}\right)$ and time to reach the area and accomplish the activity $\left(T_{A}\right)$. In this instance, the recovery actions must be accomplished within 45 minutes to prevent equipment overheating. The time required to accomplish the necessary actions; i.e., travel time from control room plus time to open doors and establish airflow into the room, was estimated to be 15 minutes. Therefore, a maximum of 30 minutes is available to detect and diagnose the failure. As a result, $P(N D)$ is 0.008 .

P(NA) was estimated using Human Reliability Analys is (HRA) techniques, as described by Weston, Whitehead, and Graves (1987) and Swain and Guttman (1983). In this case, an operator must direct a plant maintenance person in the actions required to establish airflow into the DC equipment room. An HRA event tree was drawn to model the action phase of this recovery action, as shown previously in Figure 4.1-1. The HRA event tree, along with human error probabilities given by Swain and Guttman (1983, Sections 20 and 21), provide the means of calculating $P(N A)$, as shown below: 


\begin{tabular}{|c|c|c|}
\hline \multicolumn{1}{|c|}{ Event } & $\begin{array}{c}\text { Human Error } \\
\text { Probability }\end{array}$ & $\begin{array}{c}\text { HRA Handbook } \\
\text { Reference }\end{array}$ \\
\hline A. Error in message from operator & 0.04 & Table 20-8 \\
B. Operator fails to monitor feedback & 0.003 & p. 20-13 \\
C. HVAC man misunderstands message & 0.04 & Table 20-8 \\
D. Operator fails to monitor feedback & 0.003 & p. 20-13 \\
E. HVAC man fails to restore cooling & 0.001 & Table 21-2 \\
F. Operator fails to monitor feedback & 0.04 & p. 20-13 \\
\hline
\end{tabular}

From the HRA event tree (Figure 4.1-1), the probability of failing to accomplish the action of restoring DC equipment room cooling is found by:

$$
\begin{aligned}
P(N A) & =F_{1}+F_{2}+F_{3}+F_{4} \\
& =0.0+(0.003)(0.04)+(0.003)(0.04)+(0.001)(0.003) \\
& =2.4 E-04
\end{aligned}
$$

$P(N R)$ may now be calculated as follows:

$$
\begin{aligned}
P(N R) & =P(N D)+P(N A)-P(N D) P(N A) \\
& =(0.008)+(2.4 E-04)-(0.008)(2.4 E-04) \\
& =8.2 E-03 / \text { demand }
\end{aligned}
$$

The frequensy of DC equipment room HVAC failures is the product of the terms for failure of the $D C$ equipment room c0oling (2E-02/RY) and failure to restore cooling (8.2E-03/demand), or 1.6E-04/RY.

Cut sets in the existing PRA that were initiated by loss of the $125-V D C$ buses were retained for further analysis. The cut set element described here was substituted directly for the loss of $125-V$ DC bus initiator.

1CRVC-COOL12DHL: This cut set element represents failure of the control room HVAC system due to failure of operators to: shut down one essential fan and open doors to circulate air within a 12-hour period. The probability used here is the same as that derived in the existing PRA, 2.0E-03/demand. Cut sets involving this element were retained without modification.

1ECBE01-ARHFS: This parameter represents Train B essential chiller failures to start. Failure of the essential chiller affects ESF component, control room, and switchgear room HVAC systems and is an important contributor to failure of all three room cooling systems. The value derived in the existing PRA, 3.7E-04/demand, was used in this study. Cut sets involving this element were retained without modification.

The next step in the analysis was to quantify the cut sets and sum them to calculate the total affected CDF. As shown in Appendix D, the total affected CDF for the representative CE PWR, based on point estimates, was calculated to be $1.3 \mathrm{E}-06 / \mathrm{RY}$. The important statistical parameters of the CDF distribution are listed below. These statistics were generated using Latin Hypercube sampling techniques. 
Mean:

95\% upper confidence bound:

Median:

$5 \%$ lower confidence bound:
$1.4 \mathrm{E}-06 / \mathrm{RY}$

3.0E-06/RY

9.0E-07/RY

3. $0 \mathrm{E}-07 / \mathrm{RY}$

The cumulative distribution function for the affected CDF at the representative CE PWR is shown in Figure 4.3-1.

A breakdown of the total CDF by accident sequence is quantified in Table 4.3-2 and illustrated in Figure 4.3-2. As shown, approximately 50\% of the affected CDF arises from LOOP initiators and failure to provide secondary side cooling to SGS. SBOB sequences, characterized by SBO initiators followed by failure to recover offsite power within three hours, contributes about $23 \%$ of the affected CDF, followed by smaller fractions for the remaining sequences. The sum of the frequencies of room cooler initiator sequences (i.e., CRHVC, 42PKB, and 41PKA) was calculated to be $8.8 E-8 / R Y$ or about $7 \%$ of the total.

The CDF quantification resulted in identification of two cut sets with frequencies greater than 1E-07/RY and six additional cut sets with frequencies greater than 5E-08/RY. These eight cut sets are shown in Table 4.3-3 and are briefly described in the following paragraphs.

The top eight cut sets are all LOOP sequences followed by failure to provide secondary cooling. The top two cut sets involve failure of the Train A spray pond pumps (event 1SPAP01--CX5FS) resulting in loss of cooling to Train A of the EC and EW systems. Two other events fail Train B AFW pump room cooling, namely local faults of AFW Train B pump room AHU (event IHABHVACAFW-2OP) and failure of the Train B essential chiller (event 1ECBE01--AR7CM), respectively. The other event, 1AFBP01-NOBAC20P, represents AFW Train B (motor-driven) pump failure due to failure of the pump room AHUs. Based on an analysis performed by the utility, the probability of AFW MDP failure given loss of all room cooling is 0.5 .

The third and fourth highest sequences include LOOP, failure to isolate high-pressure from low-pressure nitrogen (1GAN2BACKUP--2HR), and failure of AFW Train B pump (1AFBPO1-NOBAC2OP) given failure of the Train B essential chiller (control circuit faults, event 1CBE01--CX8FS). The last evants in the third and fourth cut sets result in failure to provide steam to the AFW Train A TDP. Event 1SGAUV0134ASV-F0 represents failure of the solenoid-operated steam bypass valve used during turbine startup, and event 1AFAHV054-MV9CM represents failure of the steam turbine/throttle valve leading to the turivine.

The fifth and sixth highest cut sets include LOOP and failure of AFW Train B pump (1AFBP01-NOBAC2OP) given failure of the Train B essential chiller (control circuit faults, event 1CBE01--CX8FS). The remaining events in these two cut sets represent failure of Train A essential spray pond cooling. 'Event 1SPAHV049A-MV9CM represents failure (in closed position) of the Train A spray pond return line due to unscheduled maintenance and 1PKAF11--BX-PW represents failure of the Train A battery that provides $125-V$ DC control power to the spray pond pumps. 


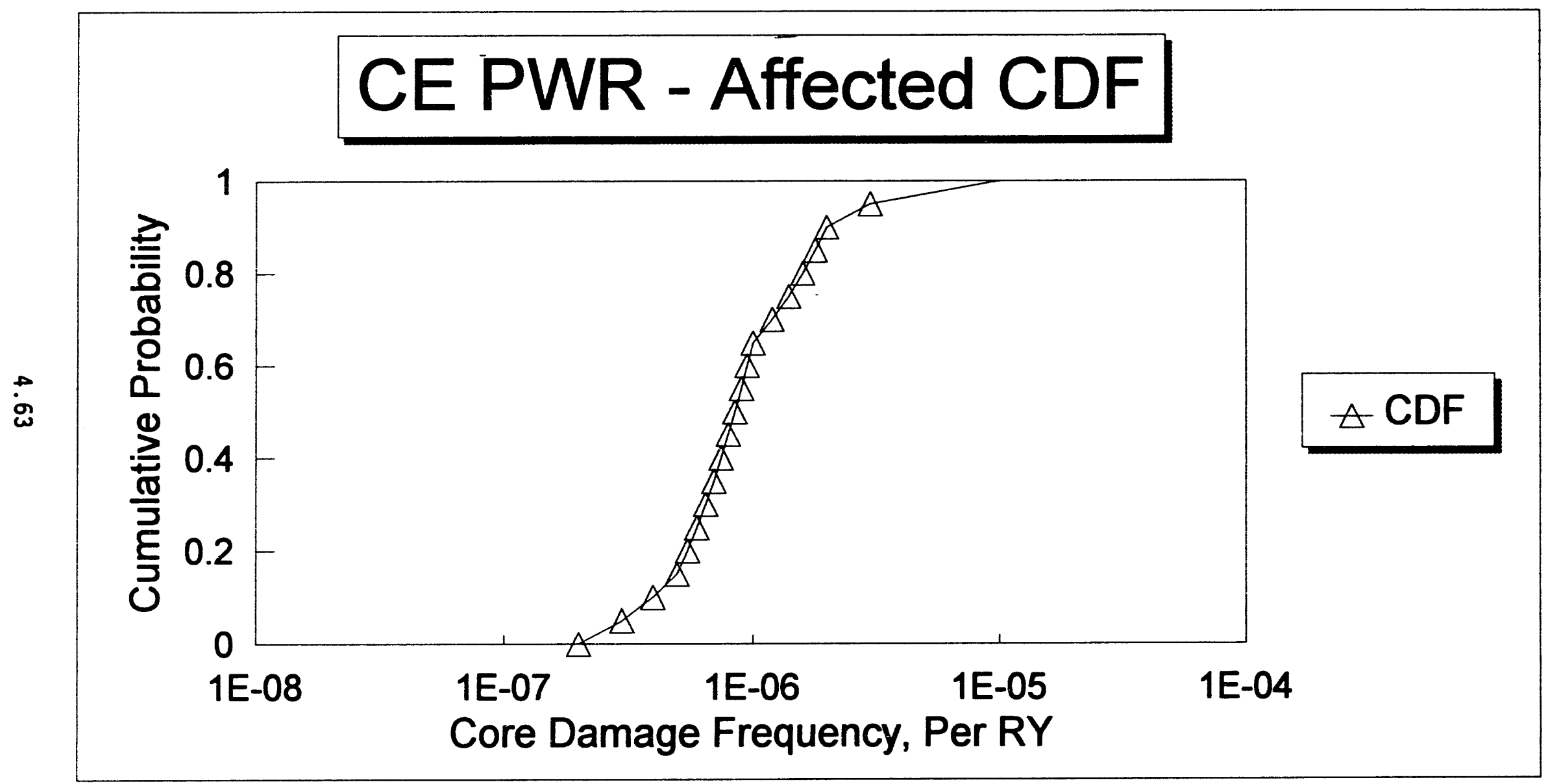

FIGURE 4.3-1. Affected CDF Distribution for the Representative CE PWR 
IABLE 4,3-2. Affected Accident Sequences and Calculated Frequencies for the Representative CE PWR (point estimates)

\begin{tabular}{|l|l|c|}
\hline $\begin{array}{l}\text { Accident } \\
\text { Sequence }\end{array}$ & \multicolumn{1}{|c|}{ Description } & $\begin{array}{c}\text { CDF, } \\
\text { per RY }\end{array}$ \\
\hline SBOB & Station blackout, fail to recover offsite power in 3 hr & $3.1 \mathrm{E}-07$ \\
\hline MISC & Misc, reactor trip, fail to provide SG cooling & $5.7 \mathrm{E}-08$ \\
\hline LOOP & Loss of offsite power, failure to provide SG cooling & $6.7 \mathrm{E}-07$ \\
\hline IAS & Loss of instrument air, fail to cool SG & $2.8 \mathrm{E}-08$ \\
\hline TCW & Loss of turbine cooling water, fail to cool SG & $1.4 \mathrm{E}-08$ \\
\hline IT & Turbine trip. fail to cool SG & $4.6 E-08$ \\
\hline 42PKB & Loss of 125-V DC Channel B (HVAC), fail to cool SG & $7.1 \mathrm{E}-09$ \\
\hline SBOA & Station blackout, fail AFW turbine pump, fail to recovery in 1 hr & $4.3 \mathrm{E}-08$ \\
\hline CRHVC & Loss of all HVAC, fail to recover HVAC & $7.8 \mathrm{E}-08$ \\
\hline LCONV & Loss of condenser vacuum, fail to cool SG & $3.2 \mathrm{E}-08$ \\
\hline MLOCA & Medium LOCA & $1.6 \mathrm{E}-08$ \\
\hline LMFWP & Loss of main feedwater pump. fail to cool SG & $2.3 \mathrm{E}-08$ \\
\hline 41PKA & Loss of 125-V DC Channel A (HVAC). fail to cool SG & $6.4 \mathrm{E}-10$ \\
\hline & Total & $1.3 E-06$ \\
\hline
\end{tabular}

$$
\text { CRHVC }(5.9 \%) \quad \text { IAS }(2.1 \%)
$$

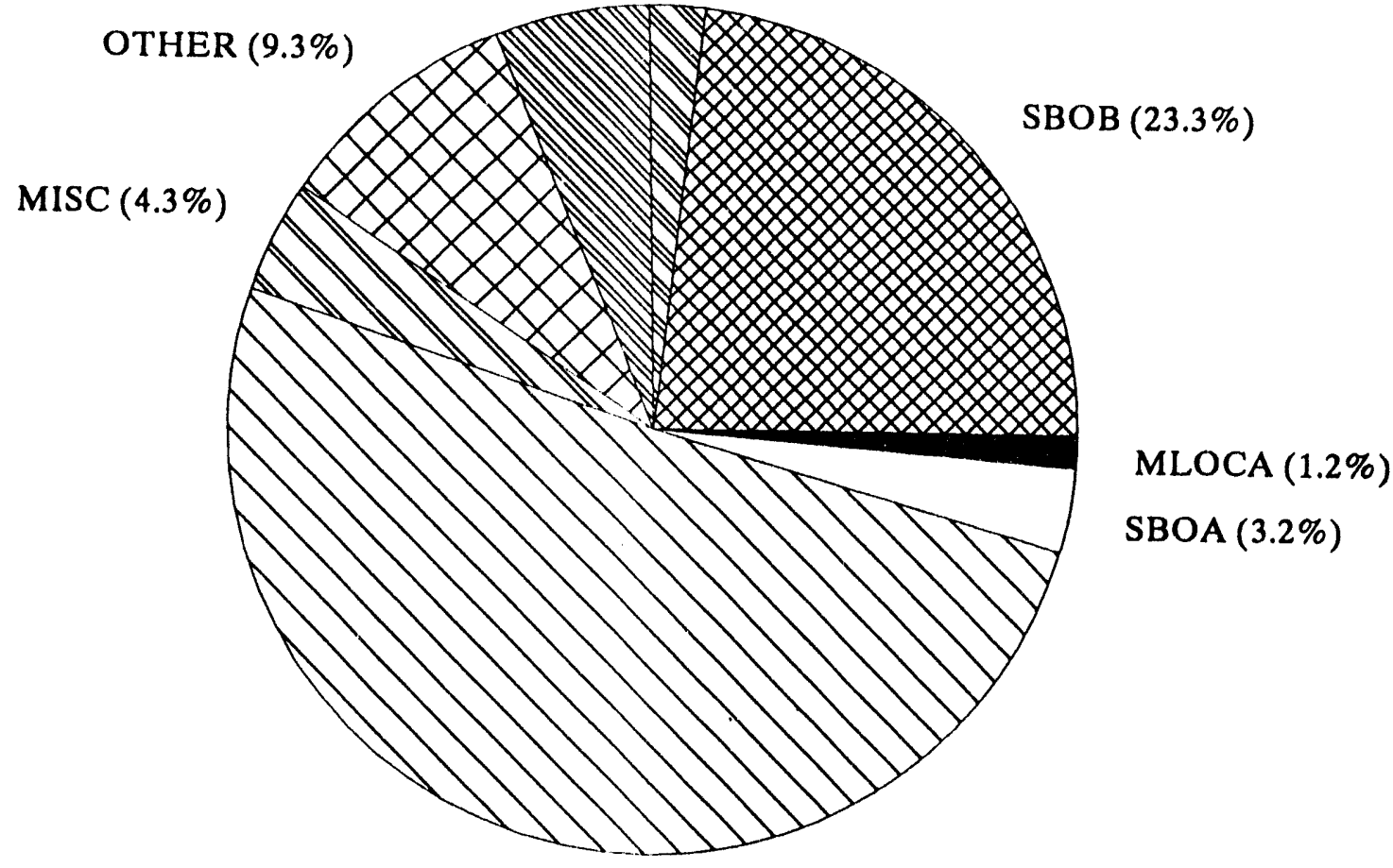

$\operatorname{LOOP}(50.6 \%)$

FIGURE 4.3-2. Pie Chart Illustrating Contributions of Affected Accident Sequences to Total CDF for the Representative CE PWR 
IABLE 4.3-3. Cut Sets with Frequencies Greater Than $E_{-}^{-08 / R Y}$

\begin{tabular}{|c|c|c|}
\hline No. & Cut Set Elements & $\begin{array}{c}\text { Frequency } \\
\text { Per RY }\end{array}$ \\
\hline 58 & IELOOP, IAFBPO1-NOBAC2OP, IECBE01---AR7CM, 1SPAPO1---CX5FS & $1.158 \mathrm{E}-07$ \\
\hline 59 & IELOOP, 1AFBPO1-NOBAC2OP, IHABHVACAFW--20P, 1SPAPO1---CX5FS & $1.158 E-07$ \\
\hline 78 & IELOOP, 1GAN2BACKUP--2HR, IAFBPO1-NOBAC2OP, 1ECBE01---CX8FS, ISGAUVO134ASV-FO & $8.564 \mathrm{E}-08$ \\
\hline 86 & IELOOP, IGAN2BACKUP--2HR, IAFBPO1-NOBAC2OP, IECBEO1--.-CX8FS, IAFAHV054-MV9CM & $8.284 E-08$ \\
\hline 87 & IELOOP, IAFBPO1-NOBAC2OP, IECBE01----CX8FS, ISPAHVO49A-MV9CM & $8.284 E-08$ \\
\hline 89 & IELOOP, 1AFBP01-NOBAC2OP, 1ECBE01---CX8FS, 1PKAF11---BX-PW & $8.003 E-08$ \\
\hline 4 & IELOOP，LOOP-RECOVR3-2PW， IPEBG02-DG---2FR, DGA-FAN-FR24 & $6.277 E-08$ \\
\hline 5 & IELOOP，LOOP-RECOVR3-2PW， IPEAGO1-DG---2FR，DGB-FAN-FRZ4 & $6.277 E-08$ \\
\hline
\end{tabular}

The final two cut sets in Table 4.3-3 include LOOP, fail to recover offsite power in three hours (LOOP-RECOVR3-2PW), failure of one diesel generator to run for 24 hours (1PEAGO1-DG-2FR and 1PEBGO1-DG-2FR), and failure of the DG ventilation fan of the opposite train (DGB-FAN-FR24 and DGA-FAN-FR-24). This effectively fails all onsite sources of $A C$ power and, if not recovered within three hours, will result in battery depletion and subsequent failure of DC control power to the AFW TDP, leading to core damage.

\subsubsection{Public Risk Calculations}

Affected public risk for the representative CE PWR was calculated in much the same manner as that for the representative W PWR (see Section 4.1). For the CE PWR, each accident sequence was examined in the existing PRA to determine the progression of each sequence following core damage through containment failure and release to the environment. Unfortunately, the existing CE plant's PRA did not calculate the consequences of potential releases of radioactive materials. Therefore, this study used the consequence analysis results from the W PWR plant's PRA as a surrogate for the consequences of releases from the representative CE PWR, because the population near both plants is relatively sparse, and a relatively large population center is located 50 to $60 \mathrm{~km}$ away. Although this approach results in significant uncertainties for the representative CE PWR, the public risks for the CE PWR would tend to be overstated; i.e., based on a comparison of the population distributions around both sites, the consequence analysis for the representative W PWR would result in higher values than would an analys is of the representative CE PWR.

The CE plant's PRA presentation of accident progression, containment analysis, and source term analysis results made it possible to combine these three steps into a single calculation. Table 11.7-2 in the existing PRA presented the accident sequences and their contribution to the frequency of each source term category (STC). Twenty-two STCs were established, each representing a particular containment failure mode. For example, STC-1 and STC-18 represent no containment failure and STC-4 to STC-7 represent early containment failure with in-vessel injection available. This table also made it 
relatively easy to match the source term release quantities calculated in the CE PRA with those calculated in the W plant's existing PRA.

As stated above, the existing PRA presented the contributions of each accident sequence to the frequencies of each STC. The next step in the present study was to assign each minimal cut set shown in Appendix $D$ to its appropriate accident sequence. For most cut sets this was straightforward, involving only matching the initiating event to the appropriate accident sequence initiator (e.g., there was only one accident sequence associated with loss of 125-V DC Channel B, turbine trip, etc.). For accident sequences that involved the same initiator but progressed differently to core damage, a review of the cut set events was necessary to assign the cut set to its appropriate sequence. For example, there are two SBO sequences, SBOA (SBO followed by failure of the AFW TDP and failure to recover offsite power in one hour) and SBOB (SBO followed by failure to recover offsite power in three hours). A review of the cut set elements was necessary to assign cut sets to appropriate accident sequences.

The next step was assigning each accident sequence to its associated STC. Each accident sequence progresses differently depending upon the specific ESFs that have failed. As a result, containment failure may result from one of several different modes, resulting in different size radioactive material releases. Table 11.7-2 of the existing PRA presented the contribution of each accident sequence to each of the 22 STCs and made it possible to partition the affected accident sequences and frequencies (see Table 4.3-2) into their respective STCS. The underlying assumption is that the relative contribution of each accident sequence to the specified STC is the same in this study as it was in the existing PRA. For example, the existing PRA stated that the frequency of accident sequence SBOB partitioned into STC-1 was $5.8 E-06 / R Y$. The total frequency of SBOB was calculated in the existing PRA to be about $1.7 E-05 / R Y$. Thus, about $35 \%$ of the SBOB frequency was partitioned into STC-1. This fraction was assumed in this study to be the same. Similar calculations were performed for all the affected accident sequences in this study, resulting in a frequency being calculated for each combination of affected accident sequence and STC.

Each STC has its associated release quantities, but the existing PRA did not calculate the consequences of the potential releases. Thus, it was necessary to use the consequence analys is in the existing $W$ plant's PRA as a surrogate. This was done by matching the release quantities given in Table 3.4-4 of the W PRA (NUREG/CR-4551, Vol. 5) with those given in Table 11.7-8 of the CE plant's existing PRA. The mean consequence results given in the $W$ PRA (Table 4.3-1 of NUREG/CR-4551, Vol. 5) were then used as surrogates for the CE plant's release consequences.

The affected public risk calculations for the representative CE PWR are presented in Table 4.3-4. This table shows the partitioning of each affected accident sequence into appropriate STCS as well as the risk calculations, which are the product of the STC frequency and STC consequences. 
The total affected public risk for the representative CE PWR was calculated to be 7.2E-01 person-rem/RY. The important statistical parameters are listed below. These statistics were generated using Lat in Hypercube sampling techniques.

\author{
Mean: \\ 95\% upper confidence bound: \\ Median: \\ 5\% lower confidence bound:
}

7.2E-01/person-rem/RY
$1.8 \mathrm{E}+00 /$ person-rem/RY
4.5E-01/person-rem/RY
$1.6 \mathrm{E}-01 /$ person-rem/RY

The cumulative distribution function for the affected risks at the representative CE PWR is shown in Figure 4.3-3.

The affected risks associated with each accident sequence are shown in Table 4.3-5 and illustrated in Figure 4.3-4. As shown, the affected public risk value is dominated by the risks associated with LOOPs and failure to provide SG cooling. Over $70 \%$ of the affected public risk results from LOOP sequences. Other significant contributors included SBO (about $8 \%$ for the sum of SBOA and SBOB sequences) and loss of control room HVAC (14\%). Failure of $D C$ equipment room cooling contributed less than $1 \%$ of the total affected public risk. The public risk associated with room cooler initiators was calculated to be 1.1E-01 person-rem/RY or about $15 \%$ of the total risk.

Room cooling systems are an important contributor to failure of the AFW pumps. In general, the AFW system is an important ESF to the representative CE PWR and is relied upon for core heat removal following almost all initiators. A key difference between the representative CE PWR and other PWRs is the inability of the CE plants to establish feed-and-bleed cooling in the event that secondary cooling is lost, which is a result of insufficient primary system pressure relief capacity to remove core decay heat. Thus the representative CE PWR must establish some means of removing heat through the SGs.

\subsection{ANALYSIS OF AFFECTED CDF AND PUBLIC RISKS FOR THE REPRESENTATIVE BABCOCK AND WILCOX PWR}

This section presents the affected CDF and public risks associated with HVAC and room cooler failures at the representative Babcock and Wilcox (B\&W) PWR. The results were calculated using the information and the minimal cut set data provided in the existing Individual Plant Examination (IPE) (Duke Power Company 1990). Assessments of the affected CDF for accident sequences initiated by room cooler failures are presented in Section 4.4.1. Section 4.4 .2 presents the assessment of transient-initiated accident sequences that contain room cooler failures as contributing events. A summary of the results is presented in Section 4.4.3. 


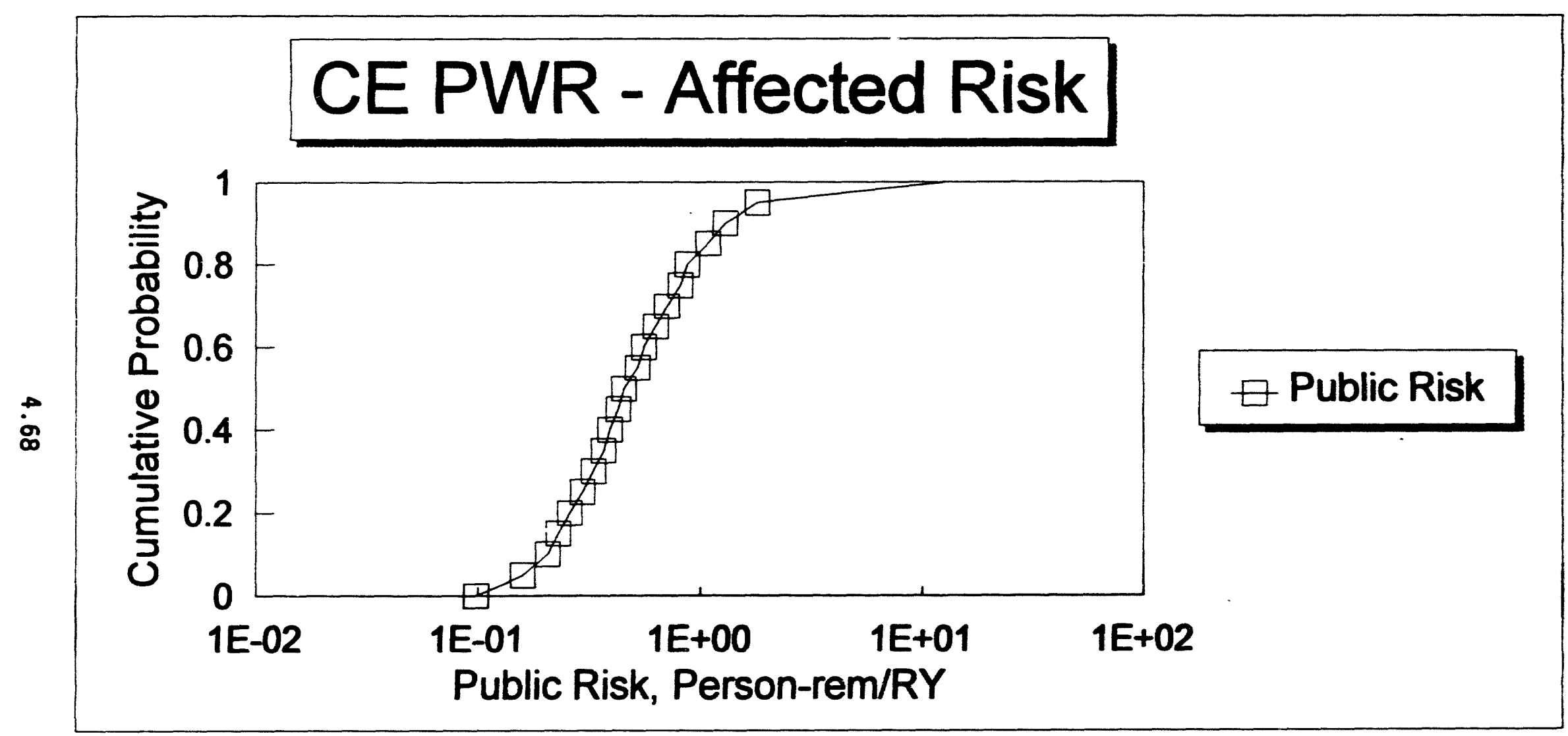

FIGURE 4.3-3. Affected Public Risk Distribution for the Representative CE PWR 
TABLE 4.3-4. Affected Public Risk Calculations for the Representative CE PWR

\begin{tabular}{|c|c|c|c|c|c|c|}
\hline Initiator & $\begin{array}{c}\text { Source Term } \\
\text { Category }\end{array}$ & Frequency & $\begin{array}{c}\text { Fraction of } \\
\text { Frequency in Source } \\
\text { Term Category }\end{array}$ & $\begin{array}{c}\text { Release Category } \\
\text { Frequency }\end{array}$ & $\begin{array}{c}\text { Release Category } \\
\text { Consequences, } \\
\text { Person-rem }\end{array}$ & $\begin{array}{c}\text { Public Risk } \\
\text { Person-rem/ } \\
\text { Reactor-yr }\end{array}$ \\
\hline \multirow[t]{14}{*}{ SBOB } & 1 & $5.800 \mathrm{E}-06$ & $3.49 \mathrm{E}-01$ & $1.068 \mathrm{E}-07$ & $8.090 E+03$ & 8.644E-04 \\
\hline & 2 & $2.600 \mathrm{E}-08$ & $1.56 E-03$ & 4.790E-10 & $3.060 E+05$ & $1.466 \mathrm{E}-04$ \\
\hline & 5 & $1.400 \mathrm{E}-09$ & 8.42E-05 & $2.579 E-11$ & $1.260 E+05$ & $3.250 E-06$ \\
\hline & 6 & $1.800 E-10$ & $1.08 E-05$ & $3.316 \mathrm{E}-12$ & $1.260 E+05$ & 4.178E-07 \\
\hline & 9 & $1.100 E-08$ & $6.62 E-04$ & $2.026 \mathrm{E}-10$ & $1.970 E+06$ & $3.992 E-04$ \\
\hline & 10 & $2.300 \mathrm{E}-08$ & $1.38 E-03$ & 4.237E-10 & $1.970 E+06$ & 8.347E-04 \\
\hline & 11 & $3.600 E-08$ & 2.17E-03 & $6.632 E-10$ & $8.320 E+05$ & $5.518 E-04$ \\
\hline & 12 & $3.400 E-08$ & $2.05 E-03$ & $6.263 E-10$ & $1.080 E+06$ & $6.764 E-04$ \\
\hline & 13 & $5.900 E-08$ & 3.55E-03 & $1.087 E-09$ & $1.490 E+06$ & $1.619 E-03$ \\
\hline & 15 & $2.200 E-06$ & 1.32E-01 & 4.053E-08 & $8.090 E+03$ & $3.279 E-04$ \\
\hline & 17 & $4.900 E-08$ & 2.95E-03 & $9.026 \mathrm{E}-10$ & $1.090 E+06$ & 9.839E-04 \\
\hline & 18 & 8.100E-06 & 4.87E-01 & $1.492 E-07$ & $8.090 E+03$ & $1.207 E-03$ \\
\hline & 22 & $2.800 E-07$ & $1.68 E-02$ & 5.158E-09 & $8.200 E+06$ & 4.230E-02 \\
\hline & SUM & $1.662 E-05$ & $1.00 E+00$ & & & 4.991E-02 \\
\hline \multirow[t]{11}{*}{ SBOA } & 1 & $9.300 \mathrm{E}-07$ & $3.72 E-01$ & $1.592 \mathrm{E}-08$ & $8.090 E+03$ & $1.288 E-04$ \\
\hline & 2 & $4.800 E-09$ & $1.92 E-03$ & $8.215 E-11$ & $3.060 E+05$ & 2.514E-05 \\
\hline & 9 & $1.100 \mathrm{E}-08$ & 4.40E-03 & $1.883 E-10$ & $1.260 E+05$ & 2.372E-05 \\
\hline & 11 & 2.500E-09 & $1.00 \mathrm{E}-03$ & $4.279 E-11$ & $8.320 E+05$ & $3.560 \mathrm{E}-05$ \\
\hline & 12 & 2.300E-09 & $9.21 E-04$ & $3.936 E-11$ & $1.080 E+06$ & 4.251E-05 \\
\hline & 13 & 7.900E-09 & $3.16 E-03$ & $1.352 E-10$ & $1.490 E+06$ & $2.015 E-04$ \\
\hline & 15 & 3.900 E-07 & $1.56 \mathrm{E}-01$ & 6.675E-09 & $8.090 E+03$ & $5.400 E-05$ \\
\hline & 17 & 8.000E-09 & $3.20 E-03$ & $1.369 \mathrm{E}-10$ & $1.090 \mathrm{E}+06$ & $1.492 E-04$ \\
\hline & 18 & $1.100 \mathrm{E}-06$ & 4.40E-01 & $1.883 E-08$ & $8.090 E+03$ & $1.523 E-04$ \\
\hline & 22 & $4.200 E-08$ & $1.68 \mathrm{E}-02$ & $7.188 \mathrm{E}-10$ & $8.200 E+06$ & 5.894E-03 \\
\hline & SUM & 2.499E-06 & $1.000 E+00$ & & & 6.707E-03 \\
\hline \multirow[t]{2}{*}{ MISC } & 1 & $4.300 E-06$ & $2.65 \mathrm{E}-01$ & $1.502 E-08$ & $8.090 E+03$ & $1.215 \mathrm{E}-04$ \\
\hline & 13 & $2.000 E-07$ & $1.23 E-02$ & 6.986E-1\%, & $1.490 E+06$ & $1.041 E-03$ \\
\hline
\end{tabular}


TABLE 4.3-4. (contd)

\begin{tabular}{|c|c|c|c|c|c|c|}
\hline Initiator & $\begin{array}{c}\text { Source Term } \\
\text { Category }\end{array}$ & Frequency & $\begin{array}{l}\text { Fraction of } \\
\text { Frequency in Source } \\
\text { Term Category }\end{array}$ & $\begin{array}{l}\text { Release Category } \\
\text { Frequency }\end{array}$ & $\begin{array}{l}\text { Release Category } \\
\text { Consequences, } \\
\text { Person-rem }\end{array}$ & $\begin{array}{l}\text { Public Risk } \\
\text { Person-rem/ } \\
\text { Reactor-yr }\end{array}$ \\
\hline & $\begin{array}{c}15 \\
17 \\
18 \\
22 \\
\text { SUM }\end{array}$ & $\begin{array}{l}4.800 \mathrm{E}-07 \\
1.200 \mathrm{E}-08 \\
1.100 \mathrm{E}-05 \\
2.600 \mathrm{E}-07 \\
1.625 \mathrm{E}-05\end{array}$ & $\begin{array}{l}2.95 E-02 \\
7.38 E-04 \\
6.77 E-01 \\
1.60 E-02 \\
1.000 E+00\end{array}$ & $\begin{array}{l}1.677 E-09 \\
4.192 E-11 \\
3.843 E-08 \\
9.082 E-10\end{array}$ & $\begin{array}{l}8.090 E+03 \\
1.090 E+06 \\
8.090 E+03 \\
8.200 E+06\end{array}$ & $\begin{array}{l}1.356 E-05 \\
4.569 E-05 \\
3.109 E-04 \\
7.448 E-03 \\
8.980 E-03\end{array}$ \\
\hline LCONV & $\begin{array}{c}1 \\
13 \\
15 \\
17 \\
18 \\
22 \\
\text { SUM }\end{array}$ & $\begin{array}{l}4.100 E-07 \\
1.900 E-08 \\
4.700 E-08 \\
1.100 E-09 \\
1.100 E-06 \\
2.500 E-08 \\
1.602 E-06\end{array}$ & $\begin{array}{l}2.56 E-01 \\
1.19 E-02 \\
2.93 E-02 \\
6.87 E-04 \\
6.87 E-01 \\
1.56 E-02 \\
1.000 E+00\end{array}$ & $\begin{array}{l}8.299 E-09 \\
3.846 E-10 \\
9.514 E-10 \\
2.227 E-11 \\
2.227 E-08 \\
5.061 E-10\end{array}$ & $\begin{array}{l}8.090 E+03 \\
1.490 E+06 \\
8.090 E+03 \\
1.090 E+06 \\
8.090 E+03 \\
8.200 E+06\end{array}$ & $\begin{array}{l}6.714 E-05 \\
5.731 E-04 \\
7.697 E-06 \\
2.427 E-05 \\
1.801 E-04 \\
4.150 E-03 \\
5.002 E-03\end{array}$ \\
\hline 42PKB & $\begin{array}{c}1 \\
10 \\
13 \\
15 \\
17 \\
18 \\
22 \\
\text { SUM }\end{array}$ & $\begin{array}{l}3.300 E-07 \\
1.500 E-06 \\
1.500 E-08 \\
3.800 E-08 \\
9.500 E-09 \\
8.500 E-07 \\
4.600 E-08 \\
2.789 E-06\end{array}$ & $\begin{array}{l}1.18 E-01 \\
5.38 E=01 \\
5.38 E-03 \\
1.36 E-02 \\
3.41 E-03 \\
3.05 E-01 \\
1.65 E-02 \\
1.000 E+00\end{array}$ & $\begin{array}{l}8.436 E-10 \\
3.834 E-09 \\
3.834 E-11 \\
9.714 E-11 \\
2.428 E-11 \\
2.173 E-09 \\
1.176 E-10\end{array}$ & $\begin{array}{l}8.090 E+03 \\
1.970 E+06 \\
1.490 E+06 \\
8.090 E+03 \\
1.090 E+06 \\
8.090 E+03 \\
8.200 E+06\end{array}$ & $\begin{array}{l}6.824 E-06 \\
7.554 E-03 \\
5.713 E-05 \\
7.858 E-07 \\
2.647 E-05 \\
1.758 E-05 \\
9.642 E-04 \\
8.627 E-03\end{array}$ \\
\hline LMFWP & $\begin{array}{c}1 \\
13 \\
15 \\
17 \\
18 \\
22 \\
\text { SUM }\end{array}$ & $\begin{array}{l}2.800 E-07 \\
1.300 E-08 \\
3.200 E-08 \\
7.600 E-10 \\
7.200 E-07 \\
1.700 E-08 \\
1.063 E-06\end{array}$ & $\begin{array}{l}2.63 E-01 \\
1.22 E-02 \\
3.01 E-02 \\
7.15 E-04 \\
6.77 E-01 \\
1.60 E-02 \\
1.000 E+00\end{array}$ & $\begin{array}{l}5.944 E-09 \\
2.760 E-10 \\
6.793 E-10 \\
1.613 E-11 \\
1.528 E-08 \\
3.609 E-10\end{array}$ & $\begin{array}{l}8.090 E+03 \\
1.490 E+06 \\
8.090 E+03 \\
1.090 E+06 \\
8.090 E+03 \\
8.200 E+06\end{array}$ & $\begin{array}{l}4.809 E-05 \\
4.112 E-04 \\
5.495 E-06 \\
1.759 E-05 \\
1.236 E-04 \\
2.959 E-03 \\
3.565 E-03\end{array}$ \\
\hline
\end{tabular}


TABLE 4.3-4. (contd)

\begin{tabular}{|c|c|c|c|c|c|c|}
\hline Initiator & $\begin{array}{c}\text { Source Term } \\
\text { Category }\end{array}$ & Frequency & $\begin{array}{c}\text { Fraction of } \\
\text { Frequency in Source } \\
\text { Term Category }\end{array}$ & $\begin{array}{c}\text { Release Category } \\
\text { Frequency }\end{array}$ & $\begin{array}{l}\text { Release Category } \\
\text { Consequences, } \\
\text { Person-rem }\end{array}$ & $\begin{array}{l}\text { Public Risk } \\
\text { Person-rem/ } \\
\text { Reactor-yr }\end{array}$ \\
\hline$\pi T$ & $\begin{array}{c}1 \\
13 \\
15 \\
17 \\
18 \\
22 \\
\text { SUM }\end{array}$ & $\begin{array}{l}9.100 \mathrm{E}-07 \\
4.100 \mathrm{E}-08 \\
1.000 \mathrm{E}-07 \\
2.500 \mathrm{E}-09 \\
2.300 \mathrm{E}-06 \\
5.600 \mathrm{E}-08 \\
3.410 \mathrm{E}-06\end{array}$ & $\begin{array}{l}2.67 E-01 \\
1.20 E-02 \\
2.93 E-02 \\
7.33 E-04 \\
6.75 E-01 \\
1.64 E-02 \\
1.000 E+00\end{array}$ & $\begin{array}{l}1.219 E-08 \\
5.492 E-10 \\
1.340 E-09 \\
3.349 E-11 \\
3.081 E-08 \\
7.50 E-10\end{array}$ & $\begin{array}{l}8.090 E+03 \\
1.490 E+06 \\
8.090 E+03 \\
1.090 E+06 \\
8.090 E+03 \\
8.200 E+06\end{array}$ & $\begin{array}{l}9.862 E-05 \\
8.183 E-04 \\
1.084 E-05 \\
3.650 E-05 \\
2.493 E-04 \\
6.151 E-03 \\
7.365 E-03\end{array}$ \\
\hline CRHVC & $\begin{array}{c}7 \\
14 \\
17 \\
18 \\
22 \\
\text { SUM }\end{array}$ & $\begin{array}{l}1.300 E-08 \\
8.100 E-07 \\
1.900 E-09 \\
1.600 E-06 \\
4.500 E-08 \\
2.470 E-06\end{array}$ & $\begin{array}{l}5.26 E-03 \\
3.28 E-01 \\
7.69 E-04 \\
6.48 E-01 \\
1.82 E-02 \\
1.000 E+00\end{array}$ & $\begin{array}{l}4.090 E-10 \\
2.541 E-08 \\
5.977 E-11 \\
5.033 E-08 \\
1.416 E-09\end{array}$ & $\begin{array}{l}1.260 E+05 \\
3.370 E+06 \\
1.090 E+06 \\
8.090 E+03 \\
8.200 E+06\end{array}$ & $\begin{array}{l}5.153 E-05 \\
8.587 E-02 \\
6.515 E-05 \\
4.072 E-04 \\
1.161 E-02 \\
9.801 E-02 \\
\end{array}$ \\
\hline IAS & $\begin{array}{c}1 \\
13 \\
15 \\
17 \\
18 \\
22 \\
\text { SUM }\end{array}$ & $\begin{array}{l}1.500 \mathrm{E}-06 \\
6.900 \mathrm{E}-08 \\
1.700 \mathrm{E}-07 \\
4.100 \mathrm{E}-09 \\
3.900 \mathrm{E}-06 \\
9.300 \mathrm{E}-08 \\
5.736 \mathrm{E}-06\end{array}$ & $\begin{array}{l}2.62 E-01 \\
1.20 E-02 \\
2.96 E-02 \\
7.15 E-04 \\
6.80 E-01 \\
1.62 E-02 \\
1.000 E+00\end{array}$ & $\begin{array}{l}7.249 E-09 \\
3.334 E-10 \\
8.215 E-10 \\
1.981 E-11 \\
1.885 E-08 \\
4.494 E-10\end{array}$ & $\begin{array}{l}8.090 E+03 \\
1.490 E+06 \\
8.090 E+03 \\
1.090 E+06 \\
8.090 E+03 \\
8.200 E+06\end{array}$ & $\begin{array}{l}5.864 E-05 \\
4.968 E-04 \\
6.646 E-06 \\
2.160 E-05 \\
1.525 E-04 \\
3.685 E-03 \\
4.421 E-03\end{array}$ \\
\hline TCW & $\begin{array}{c}1 \\
13 \\
15 \\
17 \\
18 \\
22 \\
\text { SUM }\end{array}$ & $\begin{array}{l}1.500 E-06 \\
6.800 E-08 \\
1.700 E-07 \\
4.000 E-09 \\
3.800 E-06 \\
9.100 E-08 \\
5.633 E-06\end{array}$ & $\begin{array}{l}2.66 E-01 \\
1.21 E-02 \\
3.02 E-02 \\
7.10 E-04 \\
6.75 E-01 \\
1.62 E-02 \\
1.000 E+00\end{array}$ & $\begin{array}{l}3.788 E-09 \\
1.717 E-10 \\
4.293 E-10 \\
1.010 E-11 \\
9.597 E-09 \\
2.298 E-10\end{array}$ & $\begin{array}{l}8.090 E+03 \\
1.490 E+06 \\
8.090 E+03 \\
1.090 E+06 \\
8.090 E+03 \\
8.200 E+06\end{array}$ & $\begin{array}{l}3.065 E-05 \\
2.559 E-04 \\
3.473 E-06 \\
1.101 E-05 \\
7.764 E-05 \\
1.885 E-03 \\
2.263 E-03\end{array}$ \\
\hline
\end{tabular}


TABLE 4.3-4. (contd)

\begin{tabular}{|c|c|c|c|c|c|c|}
\hline Initiator & $\begin{array}{l}\text { Source Term } \\
\text { Category }\end{array}$ & Frequency & $\begin{array}{l}\text { Fraction of } \\
\text { Frequency in Source } \\
\text { Term Category }\end{array}$ & $\begin{array}{l}\text { Release Category } \\
\text { Frequency }\end{array}$ & $\begin{array}{l}\text { Release Category } \\
\text { Consequences, } \\
\text { Person-rem }\end{array}$ & $\begin{array}{l}\text { Public Risk } \\
\text { Person-rem/ } \\
\text { Reactor-yr }\end{array}$ \\
\hline \multirow[t]{9}{*}{ MLOCA } & 1 & 5.900E-07 & $2.29 \mathrm{E}-01$ & $3.690 E-09$ & $8.090 E+03$ & $2.985 E-05$ \\
\hline & 3 & 8.400E-07 & 3.27E-01 & 5.254E-09 & $1.090 E+06$ & 5.727E-03 \\
\hline & 4 & $1.200 E-10$ & 4.67E-05 & $7.506 E-13$ & $1.260 E+05$ & $9.457 E-08$ \\
\hline & 10 & 2.600E-07 & $1.01 E-01$ & $1.626 \mathrm{E}-09$ & $1.970 E+06$ & $3.204 E-03$ \\
\hline & 13 & $3.500 E-08$ & $1.36 \mathrm{E}-02$ & $2.189 E-10$ & $1.490 E+06$ & $3.262 E-04$ \\
\hline & 15 & 7.600E-08 & $2.96 E-02$ & $4.754 \mathrm{E}-10$ & $8.090 E+03$ & $3.846 E-06$ \\
\hline & 17 & $7.700 \mathrm{E}-10$ & $2.99 E-04$ & $4.816 E-12$ & $1.090 E+06$ & $5.250 E-06$ \\
\hline & 18 & $7.700 \mathrm{E}-07$ & $2.99 \mathrm{E}-01$ & $4.816 E-09$ & $8.090 E+03$ & 3.896E-05 \\
\hline & SUM & $2.572 E-06$ & $1.000 E+00$ & & & $9.335 E-03$ \\
\hline \multirow[t]{4}{*}{ 41PKA } & 1 & $1.500 \mathrm{E}-07$ & $2.79 E-01$ & $1.784 \mathrm{E}-10$ & $8.090 E+03$ & $1.443 E-06$ \\
\hline & 13 & $6.800 E-09$ & $1.27 E-02$ & $8.087 E-12$ & $1.490 E+06$ & $1.205 E-05$ \\
\hline & 18 & 3.800E-07 & 7.08E-01 & $4.519 E-10$ & $8.090 E+03$ & $3.656 \mathrm{E}-06$ \\
\hline & SUM & 5.368E-07 & $1.000 E+00$ & & & $1.715 E-05$ \\
\hline \multirow[t]{14}{*}{ LOOP } & 1 & $1300 E-06$ & $8.28 E-02$ & $5.516 \mathrm{E}-08$ & $8.090 E+03$ & $4.462 E-04$ \\
\hline & 3 & 8.000E-06 & $5.09 E-01$ & $3.394 \mathrm{E}-07$ & $1.090 E+06$ & $3.700 E-01$ \\
\hline & 4 & 3.800E-09 & $2.42 E-04$ & $1.612 E-10$ & $1.260 E+05$ & $2.032 E-05$ \\
\hline & 5 & $1.400 \mathrm{E}-09$ & 8.91E-05 & $5.940 E-11$ & $1.260 E+05$ & $7.485 E-06$ \\
\hline & 6 & 5.700E-09 & $3.63 E-04$ & $2.418 E-10$ & $1.260 E+05$ & $3.047 E-05$ \\
\hline & 10 & 8.300E-07 & $5.28 \mathrm{E}-02$ & $3.522 E-08$ & $1.970 E+06$ & $6.938 E-02$ \\
\hline & 11 & $3.500 E-07$ & $2.23 E-02$ & $1.485 E-08$ & $8.320 E+05$ & $1.236 E-02$ \\
\hline & 12 & $3.000 \mathrm{E}-07$ & $1.91 E-02$ & $1.273 E-08$ & $1.080 E+06$ & $1.375 E-02$ \\
\hline & 13 & $1.000 \mathrm{E}-07$ & $6.37 E-03$ & $4.243 E-09$ & $1.490 E+06$ & $6.322 E-03$ \\
\hline & 15 & $1.800 E-07$ & $1.15 E-02$ & 7.637E-09 & $8.090 E+03$ & $6.179 E-05$ \\
\hline & 17 & 7.500E-09 & 4.77E-04 & $3.182 E-: 0$ & $1.090 E+06$ & $3.469 E-04$ \\
\hline & 18 & 4.500E-06 & $2.86 E-01$ & $1.909 E-07$ & $8.090 E+03$ & $1.545 E-03$ \\
\hline & 22 & 1.300E-07 & 3.28E-03 & $5.516 E-09$ & $8.200 E+06$ & 4.523E- 02 \\
\hline & SUM & $1.571 E-05$ & $1.000 E+00$ & & & $5.195 E-01$ \\
\hline
\end{tabular}


IABLE 4,3-5. Affected Accident Sequences and Calculated Public Risk for the Representative CE PWR (point estimates)

\begin{tabular}{|c|c|c|}
\hline $\begin{array}{l}\text { Accident } \\
\text { Sequence }\end{array}$ & Description & $\begin{array}{l}\text { Public Risk, } \\
\text { person-rem/RY }\end{array}$ \\
\hline SBOB & $\begin{array}{l}\text { Station blackout, fail to recover offsite power } \\
\text { in } 3 \mathrm{hr}\end{array}$ & $5.0 E-02$ \\
\hline MISC & Misc. reactor trip, fail to provide SG cooling & $9.0 \mathrm{E}-03$ \\
\hline LOOP & $\begin{array}{l}\text { Loss of offsite power, failure to provide SG } \\
\text { cooling }\end{array}$ & $5.2 E-01$ \\
\hline IAS & Loss of instrument air, fail to cool SG & $4.4 E-03$ \\
\hline TCW & Loss of turbine cooling water, fail to cool SG & $2.3 E-03$ \\
\hline TT & Turbine trip, fail to cool SG & $7.4 E-03$ \\
\hline 42PKB & $\begin{array}{l}\text { Loss of 125-V DC Channel B (HVAC), fail to cool } \\
\text { SG }\end{array}$ & $8.6 \mathrm{E}-03$ \\
\hline SBOA & $\begin{array}{l}\text { Station blackout, fail AFW turbine pump, fail } \\
\text { to recover in } 1 \mathrm{hr}\end{array}$ & $6.7 E-03$ \\
\hline CRHVC & Loss of all HVAC, fail to recover HVAC & $9.8 \mathrm{E}-02$ \\
\hline LCONV & Loss of condenser vacuum, fail to cool SG & $5.0 \mathrm{E}-03$ \\
\hline MLOCA & Medium LOCA & $9.3 E-03$ \\
\hline LMFWP & Loss of main feedwater pump, fail to cool SG & $3.6 E-03$ \\
\hline 41PKA & $\begin{array}{l}\text { Loss of } 125-V \text { DC Channel A (HVAC), fail to cool } \\
\text { SG }\end{array}$ & $1.7 E-05$ \\
\hline & Total & $7.2 E-01$ \\
\hline
\end{tabular}




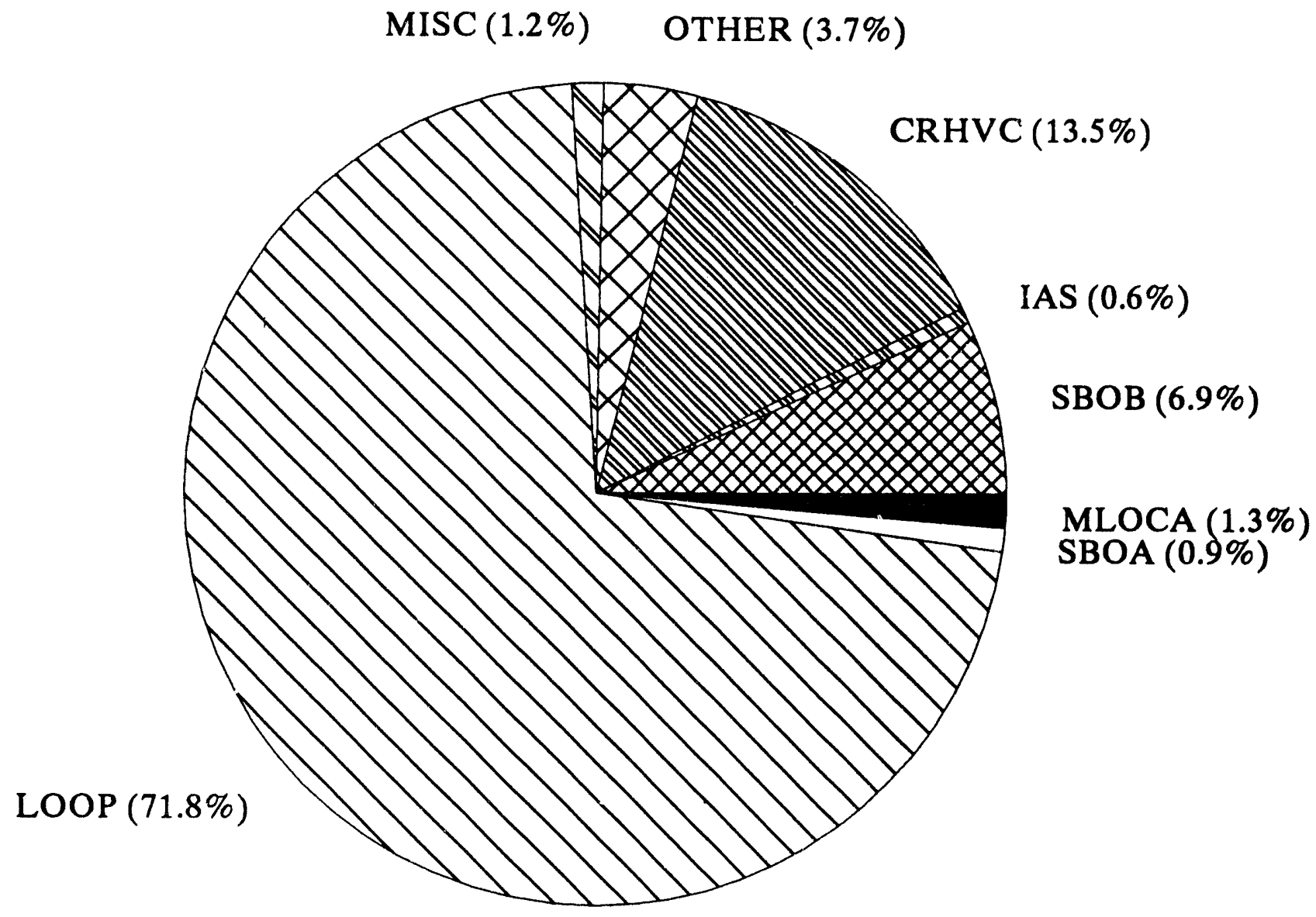

FIGURE 4.3-4. Pie Chart Illustrating Relative Contributions of Accident Sequences to Affected Public Risk for the Representative CE PWR

\subsubsection{Loss of Room Cooling As An Initiator}

The approach used to estimate the affected CDF and public risks for accident sequences initiated by losses of room coolers at the representative B\&W PWR is approximately the same as the approach described in section 2 . The process used to quantify the affected CDF due to loss of room cooling initiators included the following:

- Development of new event trees

- Development of modified cut set information from the existing IPE (Duke Power 1990)

- Modification of the component unavailabilities to account for prior failure of room cooling functions 
- Quantification of the new accident sequences using the modified safety system unavailabilities.

One additional activity was performed in support this assessment; it involved development of the unavailability of the standby shutdown facility (SSF) HVAC system. The fault tree for this system was taken from the IPE and quantified using the IRRAS computer code, because the complexity of the SSF HVAC fault tree made it much more difficult to quantify using the handcalculation methods that were used for the other representative plants. Quantification of this fault tree is discussed in subsection 4.4.1.2.

\subsubsection{Initiator Frequency}

Appendix $E$ in this study shows the fault tree logic models that were developed in the IPE describing failure of the control area ventilation system (CAVS) to cool the electrical equipment room and the control room. The room cooler initiating event frequencies were derived directly from these fault trees. The frequencies of these initiating events were found to be

- VCR "Normal Control Room Cooling Fails" = 3.28E-05/demand

- VER "Unit 3 Equipment Room Cooling Fails" = 3.28E-05/demand.

The IPE converted these numbers to an annual frequency and applied a capacity factor of 0.74. Based upon this, the results were

- Loss of control room cooling $=1.1 \mathrm{E}-03 / \mathrm{RY}$

- Loss electrical equipment room cooling $=1.1 \mathrm{E}-03 / \mathrm{RY}$.

The plant-specific capacity factor was found based on the information provided in the NUREG-0020. The IPE assumes that the total PWR operating experience is about 469.6 RY. The operating experience at the representative B\&W PWR site is given as $30.3 \mathrm{RY}$. The total calendar years since each unit started to operate is 40.9 years. Based on these numbers, the capacity factor of 0.74 was used. For consistency with room cooler initiator analyses for the other representative plants in this study, the frequency of loss of control room cooling was set to $4.49 \mathrm{E}-02 / \mathrm{RY}$ (see Section 4.1.1).

\subsubsection{Core Damage Frequency Quantification}

The next steps in the analysis were to establish core damage accident sequences based on the room-cooler-initiated event trees (see Section 3.4) and then to quantify the frequencies of the affected minimal cut sets and affected accident sequences. A list of affected events was developed, representing the safety system components required to respond to the loss of room cooling function in the specified room. The IPE (Duke Power Co. 1990) provided the original cut sets and values for the unmodified parameters. These parameter values were then modified to take into account the prior failure of the room cooling function.

New event trees were developed in Section 3.4 to model the loss of room cooling function as an initiating event. These are 1) loss of electrical 
equipment (ESF switchgear) room cooling and 2) loss of control room cooling. These event trees were developed based on the original event tree from the IPE for a transient with MFW initially available.

The original cut sets for transients with MFW available were obtained from the IPE and then reviewed to identify areas in which modifications were necessary to incorporate losses of room cooling functions into the cut sets. The key issue related to the representative B\&W PWR involves failure of the SSF HVAC system. The SSF provides backup reactor coolant makeup (RCM) and steam generator feedwater capabilities (referred to as the auxiliary service water (ASW) system) in addition to the normal ECCS functions (HPI, LPI, etc.). Failure of the SSF HVAC system, which the IPE treated as functionally identical to failure of the SSF ASW and SSF RCM functions, was therefore substituted into the cut sets in place of the events for failure of the SSF RCM and ASW systems. This effectively incorporates this important HVAC system into the representative B\&W plant's core damage models. Quantification of the SSF HVAC unavailability is discussed below.

Appendix $E$ of this study shows that the two top gates, ASW001, "SSF ASW Fails to Provide Secondary Side Heat Removal," and RCMO0l, "SSF RCM Fails to Provide RCP Seal Injection," were modeled as "OR" gates with failure of the SSF HVAC system as input. This means that SSF HVAC system failure has a direct effect on the SSF unavailability. Failure of the SSF HVAC system can be caused by

- Mechanical failures of the fan and compressors/condensers within the AHU and refrigerant portions of the subsystem

- Loss of HVAC service water cooling to the condensers due to

- HVAC service water pump failures

- Valve failures in the HVAC service water pump trains, which block flow

- Loss of electrical power to the HVAC service water pump motors

- Loss of electrical power to the fan and compressors within the HVAC subsystem.

The unavailability of the SSF HVAC system cannot be obtained directly from the existing IPE documentation. As a result, the SSF HVAC fault tree developed in the IPE was entered into the IRRAS (Version 2.6) software to perform the calculations necessary to determine the system unavailability. Table 4.4-1 provides the event names, descriptions, and associated probabilities that were used to estimate SSF HVAC system failure (see Appendix E for SSF HVAC fault tree). Approximately 87 dominant minimal cut sets were generated from the IRRAS software; these are presented in Appendix $E$. The mean failure probability of the SSF HVAC system was calculated to be 1.57E-02. 
TABLE 4.4-1. SSF HVAC System Reliability Data

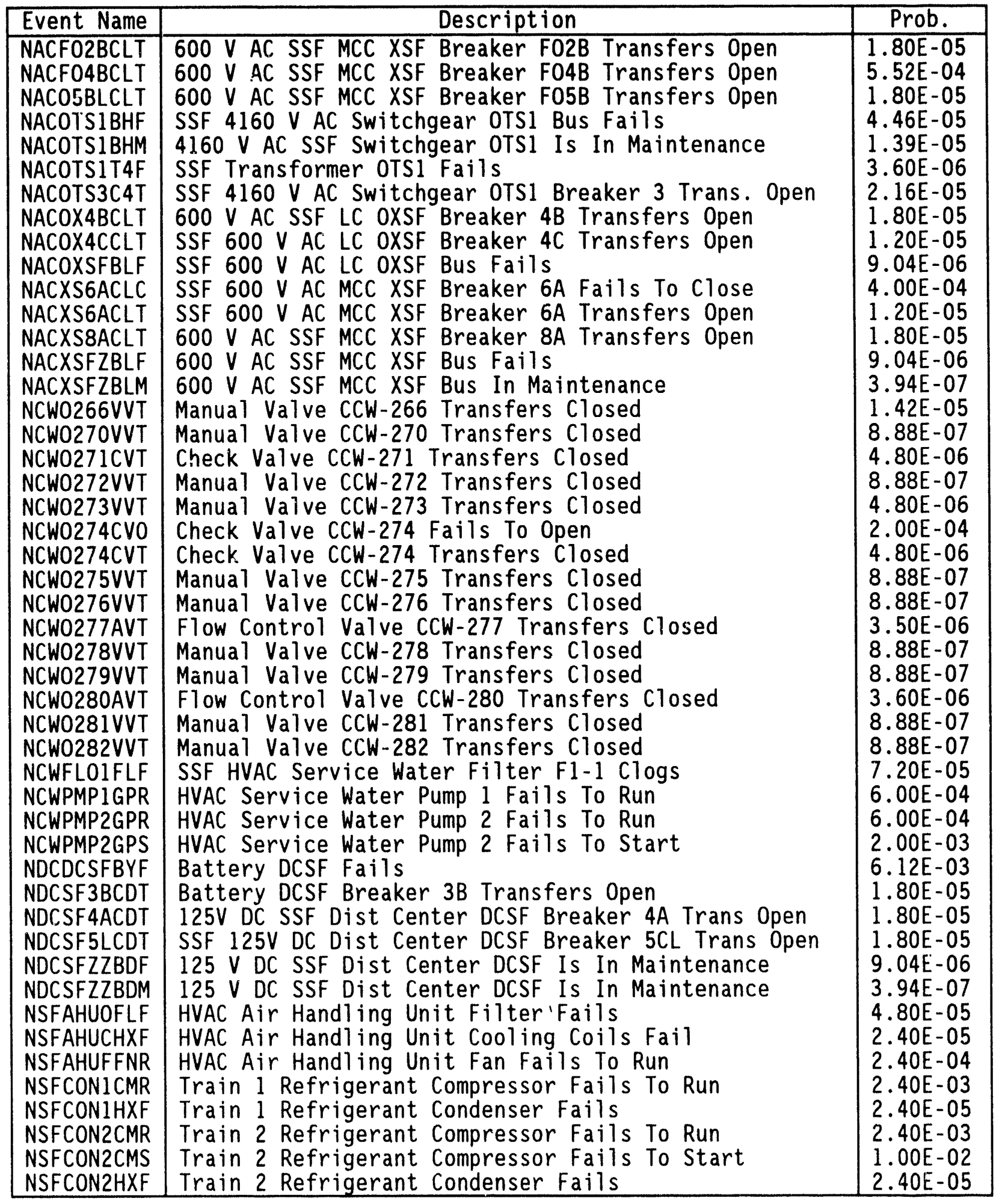


The percentage contributed from SSF HVAC failure to the failure of SSF RCM without plant power available (event probability $2.54 \mathrm{E}-01 /$ demand) was calculated to be about $6.2 \%$, and the percentage contributed to the failure of SSF ASW without plant power available (probability 2.56E-01/demand) was also calculated to be about $6.2 \%$. Therefore, failure of SSF HVAC contributes only small fraction of the total failure probability of these important SSF functions. Based on the dominant cut sets provided in Appendix $E$, the failure of the basic event NSFCON2CMS, "Train 2 Refrigerant Compressor Fails to Start," represents approximately $63.8 \%$ of the failure probability of the SSF HVAC system. In addition, basic events NSFCON2CMR, "Train 2 Refrigerant Compressor Fails to Run," and NSFCONICMR, "Train 1 Refrigerant Compressor Fails to Run," contribute approximately $15.3 \%$ each to the SSF HVAC system failure. These are the three dominant causes of failure of the SSF HVAC system.

The results of the SSF HVAC unavailability assessment were incorporated into the cut sets, where appropriate, to replace events involving failure of the SSF RCM and ASW functions. The modified cut sets were then used to calculate the affected CDF from room cooler initiators.

The next step in the analysis was to establish core damage accident sequences based on the new event trees and to quantify the affected accident sequences and minimal cut sets. All of the affected events were identified and modified to account for the possibility of prior failure of the room cooling function. These modifications are discussed later.

There are two new event trees that were developed to model the loss of cooling function as an initiating event (see Section 3.4): Loss of Electrical Equipment Room Cooling and Loss of Control Room Cooling. These event trees were developed based upon the original IPE (Duke Power 1990) transient event tree, similar to the event trees developed for the other representative plants. Quantification of the affected CDF for each of these initiators is discussed below.

Loss of Electrical Equipment Room Cooling. In the existing IPE, loss of HVAC to the electrical equipment rooms was treated as an initiating event and was enveloped by the plant trip initiating event (TI). Therefore, the quantification process for loss of electrical equipment room cooling begins with obtaining the original Tl cut sets. For each of these cut sets, the initiating event $\mathrm{Tl}$ was replaced by loss of room cooling initiating event; and they were examined to determine which basic events, if any, would be affected by a loss of room cooling function. These affected parameters and their values were then modified to account for the possibility of prior failure of room coolers. The unaffected parameters remained unchanged. Assumptions used to modify the affected parameter values associated with loss of electrical equipment room cooling are presented below:

- All AOVs are unaffected by failure of electrical equipment room cooling.

- Loss of MFW was assumed to be unaffected. 
- Operator failure to initiate HPR was set equal to 0.5. This reflects the high probability that HPI/HPR pumps fail to start on demand or to run due to loss of electrical equipment room cooling.

- Operator failure to recover MFW was assumed to be unaffected.

- Operator failure to throttle emergency feedwater (EFW) pump flow was assumed to be unaffected.

- Operator failure to align EFW from another unit was not considered. It is assumed to be an innovative recovery action.

- Common-cause failure of breakers E1 and E2 to close/open was assumed to equal 1.0, since these components are located in the electrical equipment room.

- Operator failure to close/open breakers E1 and E2 within four hours was assumed to be unaffected.

- Operator failure to close/open breakers E1 and E2 within 40 minutes was assumed to be unaffected.

- Operator failure to align the SSF RCM.and SSF ASW systems for operation were assumed to be unaffected due to loss of electrical equipment room cooling because SSF is an independent facility, and it is provided with a backup diesel generator.

- Instrument air system major leakage and operator failure to find the leaks are unaffected by failure of electrical equipment room cooling.

- Operator failure to switch EFW TDP suction to hot well was assumed to be unaffected.

- 100-kV AC overhead line from to transformer CT5 is not affected.

- Unavailability of both emergency $A C$ power units due to maintenance was assumed to be unaffected.

- Transformer CT3 failure and/or maintenance unavailability values were assumed to be unaffected.

- Unavailability of the TDEFW train due to maintenance was assumed to be unaffected.

- Drain valves 3PR-23, 3PR-25, and 3PR-68, left open due to human error, were assumed to be unaffected.

Loss of control room cooling. The loss of control room cooling event tree shown in Section 3.4 was used to estimate the CDF from control room cooler initiators. The quantification process for the control room event trees is the same as for the electrical equipment room. The original cut sets 
from the existing IPE for plant transient were used, modified to account for the effects of recovery of room cooling functions and use of the auxiliary shutdown panel (ASP). All affected parameters and their values were modified and substituted. The probability of nonrecovery from loss of control room cooling given in Section 4.1.1 is used; this number was found to be 4.3E-03/ demand. As discussed in Section 3.4, the ASP, located outside the control room, can be used to shut down the reactor, so credit may also be given for this ASP. The probability that operators will unsuccessfully recover the plant from the ASP is 7.4E-02; this number was taken directly from Table 5.14 of NUREG/CR-4550, Vol.3, Rev. 1, Part 3. Assumptions that were used to modify the affected control room parameter values are presented below:

- The total probability of nonrecovery from loss of control room cooling was calculated to be 4.3E-03/demand (see Section 4.1.1).

- All AOVs are unaffected by failure of control room cooling.

- Loss of MFW was assumed to be unaffected.

- Operator failure to recover MFW was assumed to be unaffected.

- Operator failure to initiate HPR was set equal to 0.5. This reflects the high probability that HPI/HPR pumps fail to start on demand or to run due to loss of control room cooling.

- Operator failure to throttle EFW pump flow was set equal to 1.0. To throttle flow, the flow control valves FDW-315 and FDW-316 and pneumatic valves operated from the control room would be used. The electrical panel or cabinet containing controls for these valves may not function properly if control room cooling is lost for a sufficient period of time. Therefore, these valves were assumed to fail given loss of control room cooling.

- Operator failure to align EFW from another unit was set equal to 0.1 by assuming that the control room was disabled due to the loss of HVAC (e.g., vital electrical circuits). The instrumentation indications and/or the necessary process monitors are not available given the loss of these vital electrical buses.

- Common-cause failure of breaker El and E2 to close is unaffected due to loss of control room cooling.

- Operator failure to close/open breakers E1 and E2 within four hours and/or 40 minutes are unaffected due to loss of control room cooling.

- Operator failure to align the SSF RCM and SSF ASW systems for operation were assumed to be unaffected due to loss of control room cooling.

- Instrument air system major leakage and operator failure to find them are unaffected due to failure of control room cooling. 
- Operator fallure to switch TDEFW pump suction to hotwell was estimated to be 0.1 . To align this pump to the hotwell, the valves that must be manipulated are motor-operated and controlled from the control room. These valves were assumed to be failed given loss of and failure to restore control room cooling.

- 100-kV AC overhead line providing backup AC power to transformer CT5 is unaffected.

- Unavailabilities of both emergency $A C$ power units due to maintenance were assumed to be unaffected.

- Transformer СТ3 failure and/or maintenance unavailability values are not affected.

- Unavailability of the TDEFW train due to maintenance was assumed to be unaffected.

- The event involving drain valves 3PR-23, 3PR-25, and 3PR-68 being left open due to human error were assumed to be unaffected.

For basic events that were assumed to be unaffected, the failure probability is the same as the probability given in the existing PRA. According to plant operators, the HPI pumps can be controlled from the ASP. Therefore, for the cut sets with the ASP available, the original probability $(1.0 \mathrm{E}-03)$ was used for basic event TTRHPRIDHE, "Operators Fail to Initiate High-Pressure Recirculation." Table 4.4-2 summarizes the affected parameters and their values for each room-cooling-initiated event tree.

The affected and unaffected values for the basic events were substituted into the cut sets that were generated from the loss of electrical equipment room and control room cooling event trees shown, and the affected CDF was calculated. The calculations are presented in Table 4.4-3 for loss of electrical equipment room cooling and in Table 4.4-4 for loss of control room cooling (assuming no credit for the ASP). These tables present the dominant cut sets and parameter values that were used to calculate the CDF associated with accident sequences initiated by losses of electrical equipment room cooling and control room cooling, respectively.

A special case was performed to determine the effects of the ASP on the affected CDF for loss of control room cooling. Although the operator can establish and maintain a hot shutdown condition from the auxiliary shutdown panel, the instrumentation and controls available on this panel are limited. On another hand, there are some common cause failures (e.g., loss of power, loss of chilled water system) that will fail both control room cooling system and auxiliary shut down panel room cooling system at the same time. Furthermore, based on conversations with representatives of B\&W plant's staff, the ASP does not satisfy the Appendix R fire protection requirements (the SSF provides a reliable means of shutting down the plant from outside the control room). For these reasons, the ASP event does not appear in Table 4.4-4. To determine the effects of the ASP on the control room cooling CDF, an event 
IABLE 4.4-2. Affected Parameters and Values for Room Cooler Inttiator Minimal Cut Sets

\begin{tabular}{|c|c|c|c|}
\hline Parameter & Original & \multicolumn{2}{|c|}{ Modified } \\
Designation & Probability & TEER & TCR \\
\cline { 3 - 4 } & Prity \\
\hline TRCSRVODEX & $9.00 E-01$ & $9.00 E-01$ & $9.00 E-01$ \\
TLOMFATDEX & $6.00 E-02$ & $6.00 E-02$ & $6.00 E-02$ \\
TTRHPRIDHE & $1.00 E-02$ & $5.00 E-01$ & $5.00 E-01$ \\
FEFEFW2DHE & $5.00 E-03$ & $5.00 E-03$ & $1.00 E-01$ \\
FEFEFW1REC & $5.00 E-02$ & $5.00 E-02$ & $1.00 E-01$ \\
TMFFDW2REC & $9.00 E-02$ & $9.00 E-02$ & $9.00 E-02$ \\
PACE1E2COM & $8.90 E-05$ & $1.00 E-00$ & $8.90 E-05$ \\
PACE3E4REC & $1.00 E-03$ & $5.00 E-01$ & $1.00 E-03$ \\
NSFORCMDHE & $1.00 E-01$ & $1.00 E-01$ & $1.00 E-01$ \\
AIA0LEKDEX & $1.20 E-03$ & $1.20 E-03$ & $1.20 E-03$ \\
AIA0LEKDHE & $1.00 E-01$ & $1.00 E-01$ & $1.00 E-01$ \\
FEFSWCHDHE & $5.00 E-02$ & $5.00 E-02$ & $1.00 E-01$ \\
NSF0ASWDHE & $1.00 E-01$ & $1.00 E-01$ & $1.00 E-01$ \\
PACLINEDEX & $7.80 E-03$ & $7.80 E-03$ & $7.80 E-03$ \\
PACKE0SHYM & $1.93 E-02$ & $1.93 E-02$ & $1.93 E-02$ \\
PACXCT3THF & $3.62 E-04$ & $3.62 E-04$ & $3.62 E-04$ \\
PACE1E2REC & $5.00 E-02$ & $1.00 E-01$ & $5.00 E-02$ \\
FEFTDFPTRM & $9.40 E-03$ & $9.40 E-03$ & $9.40 E-03$ \\
PACN1N2COM & $3.00 E-05$ & $1.00 E-01$ & $3.00 E-05$ \\
PACN3N4REC & $1.00 E-03$ & $1.00 E-01$ & $1.00 E-03$ \\
PACXCT3THM & $1.74 E-04$ & $1.74 E-04$ & $1.74 E-04$ \\
LPR0025LHE & $3.00 E-03$ & $3.00 E-03$ & $3.00 E-03$ \\
LPRPN60LHE & $3.00 E-03$ & $3.00 E-03$ & $3.00 E-03$ \\
\hline
\end{tabular}


TABLE 4.4-3. Loss of Electrical Equipment Room Cooling Cut Sets

\begin{tabular}{|c|c|c|c|c|}
\hline $\begin{array}{l}\text { Seq. } \\
\text { Name }\end{array}$ & Event Name & Event Description & Probability & $\begin{array}{c}\text { Cut Set } \\
\text { Frequency }\end{array}$ \\
\hline TBX & $\begin{array}{l}\text { TEER } \\
\text { TRCSRVODEX } \\
\text { TLOMFATDEX } \\
\text { TTRHPRIDHE } \\
\text { FEFEFW2DHE } \\
\text { FEFEFWIREC } \\
\text { TMFFDW2REC }\end{array}$ & $\begin{array}{l}\text { Loss Of Electrical Equipment Room Cooling } \\
\text { RCS Safety Relief Valve Does Not Stick Open After } \\
\text { Relieving } \\
\text { Loss Of Main Feedwater Following A Turbine Trip } \\
\text { Operators Fail To Initiate High Pressure Recirculation } \\
\text { Operators Fail To Throttle EFW Pump Flow } \\
\text { Operators Fail To Align EFW From Another Unit } \\
\text { Operators Fail To Recover Main Feedwater Within } 45 \\
\text { Minutes }\end{array}$ & $\begin{array}{l}1.10 \mathrm{E}-03 \\
9.00 \mathrm{E}-01 \\
6.00 \mathrm{E}-02 \\
5.00 \mathrm{E}-01 \\
5.00 \mathrm{E}-03 \\
5.00 \mathrm{E}-02 \\
9.00 \mathrm{E}-02\end{array}$ & $6.68 \mathrm{E}-10$ \\
\hline TQsU & $\begin{array}{l}\text { TEER } \\
\text { PACE1E2COM } \\
\text { PACE3E4REC } \\
\text { NSFORCMDHE }\end{array}$ & $\begin{array}{l}\text { Loss of Electrical Equipment Room Cooling } \\
\text { Common Cause Failure Of Breakers E1 And E2 To Close } \\
\text { Operators Fail To Close Breakers E1 And E2 Within } 4 \\
\text { Hours } \\
\text { Operators Fail To Align The SSF RCM System For } \\
\text { Operation }\end{array}$ & $\begin{array}{l}1.10 \mathrm{E}-03 \\
1.00 \mathrm{E}+00 \\
1.00 \mathrm{E}-03 \\
1.00 \mathrm{E}-01\end{array}$ & $1.10 \mathrm{E}-07$ \\
\hline TBX & $\begin{array}{l}\text { TEER } \\
\text { AIAOLEKDEX } \\
\text { AIAOLEKDHE } \\
\text { FEFSWCHDHE } \\
\text { TTRHPRIDHE } \\
\text { NSFOASWDHE }\end{array}$ & $\begin{array}{l}\text { Loss of Electrical Equipment Room Cooling } \\
\text { Instrument Air System Major Leakage } \\
\text { Operators Fail To Find Instrument Air System Leak } \\
\text { Operators Fail To Switch TDEFW Pump Suction To Hotwell } \\
\text { Operators Fail To Initiate High Pressure Recirculation } \\
\text { Operators Fail To Align The SSF ASW System For } \\
\text { Operation }\end{array}$ & $\begin{array}{l}1.10 \mathrm{E}-03 \\
1.20 \mathrm{E}-03 \\
1.00 \mathrm{E}-01 \\
5.00 \mathrm{E}-02 \\
5.00 \mathrm{E}-01 \\
1.00 \mathrm{E}-01\end{array}$ & $3.30 E-10$ \\
\hline TQsU & $\begin{array}{l}\text { TEER } \\
\text { PACLINEDEX } \\
\text { PACKEO2HYM } \\
\text { PACXCT3THF } \\
\text { NSFORCMDHE }\end{array}$ & $\begin{array}{l}\text { Loss of Electrical Equipment Room Cooling } \\
100 \mathrm{kV} \text { AC Overhead Line to CT5 Fails } \\
\text { Both Emergency AC Units Are In Maintenance } \\
\text { Transformer CT3 Fails } \\
\text { Operators Fail To Align The SSF RCM System For } \\
\text { Operation }\end{array}$ & $\begin{array}{l}1.10 \mathrm{E}-03 \\
7.80 \mathrm{E}-03 \\
1.93 \mathrm{E}-02 \\
3.62 \mathrm{E}-04 \\
1.00 \mathrm{E}-01\end{array}$ & $\begin{array}{l}\text { Negligi- } \\
\text { ble }\end{array}$ \\
\hline TBU & $\begin{array}{l}\text { TEER } \\
\text { TRCSRVODEX }\end{array}$ & $\begin{array}{l}\text { Loss of Electrical Equipment Room Cooling } \\
\text { RCS Safety Relief Valve Does Not Stick Open After } \\
\text { Relieving }\end{array}$ & $\begin{array}{l}1.10 \mathrm{E}-03 \\
9.00 \mathrm{E}-01\end{array}$ & $4.65 E-08$ \\
\hline
\end{tabular}


IABLE 4.4-3. (contd)

\begin{tabular}{|c|c|c|c|c|}
\hline $\begin{array}{l}\text { Seq. } \\
\text { Name }\end{array}$ & Event Name & Event Description & Probability & $\begin{array}{c}\text { Cut Set } \\
\text { Frequency }\end{array}$ \\
\hline \multirow[b]{2}{*}{ TQsU } & $\begin{array}{l}\text { PACE1E2COM } \\
\text { PACE1E2REC } \\
\text { NSFOASWDHE } \\
\text { FEFTDFPTRM }\end{array}$ & $\begin{array}{l}\text { Common Cause Failure of Breakers E1 And E2 To Close } \\
\text { Operators Fail To Close Breakers E1 And E2 Within } 40 \\
\text { Min. } \\
\text { Operators Fail To Align The SSF ASW System For } \\
\text { Operation } \\
\text { Turbine-Driven EFW Pump Is In Maintenance }\end{array}$ & $\begin{array}{l}1.00 \mathrm{E}+00 \\
5.00 \mathrm{E}-02 \\
1.00 \mathrm{E}-01 \\
9.40 \mathrm{E}-03\end{array}$ & \multirow[b]{2}{*}{$1.1 \mathrm{E}-07$} \\
\hline & $\begin{array}{l}\text { TEER } \\
\text { PACiN1N2COM } \\
\text { PACN3N4REC } \\
\text { NSFORCMDHE }\end{array}$ & $\begin{array}{l}\text { Loss Of Electrical Equipment Room Cooling } \\
\text { Common Cause Failure Of Breakers N1 And N2 To Open } \\
\text { Operators Fail To Open Breakers N1 And N2 Within } 4 \\
\text { Hours } \\
\text { Operators Fail To Align The SSF RCM System For } \\
\text { Operation }\end{array}$ & $\begin{array}{l}1.10 \mathrm{E}-03 \\
1.00 \mathrm{E}+00 \\
1.00 \mathrm{E}-03 \\
1.00 \mathrm{E}-01\end{array}$ & \\
\hline TQsU & $\begin{array}{l}\text { TEER } \\
\text { PACLINEDEX } \\
\text { PACKEOSHYM } \\
\text { PACXCT3THM } \\
\text { NSFORCMDHE }\end{array}$ & $\begin{array}{l}\text { Loss of Electrical Equipment Room Cooling } \\
100 \text { kV AC Overhead Line To CT5 Fails } \\
\text { Both Emergency AC Units Are In Maintenance } \\
\text { Transformer CT3 Is In Maintenance } \\
\text { Operators Fail To Al ign The SSF RCCM System For } \\
\text { operation }\end{array}$ & $\begin{array}{l}1.10 \mathrm{E}-03 \\
7.80 \mathrm{E}-03 \\
1.93 \mathrm{E}-02 \\
1.74 \mathrm{E}-04 \\
1.00 \mathrm{E}-01\end{array}$ & $\begin{array}{l}\text { Negligi- } \\
\text { ble }\end{array}$ \\
\hline TQsU & $\begin{array}{l}\text { TEER } \\
\text { PACE1E2COM } \\
\text { PACE3E4REC } \\
\text { NSFORCMDHE } \\
\text { LPR0025LHE }\end{array}$ & $\begin{array}{l}\text { Loss of Electrical Equipment Room Cool ing } \\
\text { Common Cause Failure of Breakers E1 And E2 To Close } \\
\text { Operators Fail To Close Breakers E1 And E2 Within } 4 \\
\text { Hours } \\
\text { Operators Fail To Align The SSF RCM System For } \\
\text { operation } \\
\text { Drain Valve 3PR-25 Is Left Open: Latent Human Error }\end{array}$ & $\begin{array}{l}1.10 \mathrm{E}-03 \\
1.00 \mathrm{E}+00 \\
1.00 \mathrm{E}-03 \\
1.00 \mathrm{E}-01 \\
3.00 \mathrm{E}-03\end{array}$ & $3.30 E-10$ \\
\hline TQsU & $\begin{array}{l}\text { TEER } \\
\text { PACE1E2CON } \\
\text { PACE3H4REC } \\
\text { NSFORCMDHE } \\
\text { LPRPN60LHE }\end{array}$ & $\begin{array}{l}\text { Loss of Electrical Equipment Room Cooling } \\
\text { Common Cause Failure of Breakers E1 And E2 To Close } \\
\text { Operators Fail To Close Breakers E1 and E2 Within } 4 \\
\text { Hours } \\
\text { Operators Fail To Align The SSF RCM System For } \\
\text { Operation } \\
\text { Drain Valve 3PR-23 or 3PR- } 68 \text { Left Open: Latent Human }\end{array}$ & $\begin{array}{l}1.10 \mathrm{E}-03 \\
1.00 \mathrm{E}+00 \\
1.00 \mathrm{E}-03 \\
1.00 \mathrm{E}-01 \\
3.00 \mathrm{E}-03\end{array}$ & $3.30 E-10$ \\
\hline & & $\begin{array}{lll} & \text { Total } \\
\end{array}$ & & $2.68 \mathrm{E}-07$ \\
\hline
\end{tabular}


TABLE 4.4-4. LoSs of Control Room Cooling Cut Sets (without auxiliary shutdown panel)

\begin{tabular}{|c|c|c|c|c|}
\hline $\begin{array}{l}\text { Seq. } \\
\text { Name }\end{array}$ & Event Name & $\begin{array}{l}\text { Event Description } \\
\end{array}$ & Probability & $\begin{array}{c}\text { Cut Set } \\
\text { Frequency }\end{array}$ \\
\hline TBX & $\begin{array}{l}\text { TCR } \\
\text { RCR } \\
\text { TRCSRVODEX } \\
\text { TLOMFATDEX } \\
\text { TTRHPRIDHE } \\
\text { FEFEFW2DHE } \\
\text { FEFEFW1REC } \\
\text { TMFFDW2REC }\end{array}$ & $\begin{array}{l}\text { Loss Of Control Room Cooling } \\
\text { Nonrecovery From Control Room Cooling } \\
\text { RCS Safety Relief Valve Does Not Stick Open After Relieving } \\
\text { Loss Of Main Feedwater Following A Turbine Trip } \\
\text { Operators Fail To Initiate High Pressure Recirculation } \\
\text { Operators Fail To Throttle EFW Pump Flow } \\
\text { Operators Fail To Align EFW From Another Unit } \\
\text { Operators Fail To Recover Main Feedwater Within } 45 \text { Minutes }\end{array}$ & $\begin{array}{l}4.49 \mathrm{E}-02 \\
4.30 \mathrm{E}-03 \\
9.00 \mathrm{E}-01 \\
6.00 \mathrm{E}-02 \\
5.00 \mathrm{E}-01 \\
1.00 \mathrm{E}+00 \\
1.00 \mathrm{E}-01 \\
9.00 \mathrm{E}-02\end{array}$ & $4.69 \mathrm{E}-08$ \\
\hline TQsU & $\begin{array}{l}\text { TCR } \\
\text { RCR } \\
\text { PACE1E2COM } \\
\text { PACE3E4REC } \\
\text { NSFORCMDHE }\end{array}$ & $\begin{array}{l}\text { Loss of Control Room Cooling } \\
\text { Nonrecovery From Control Room Cooling } \\
\text { Common Cause Failure of Breakers E1 And E2 To Close } \\
\text { Operatcrs Fail To Close Breakers E1 And E2 Within } 4 \text { Hours } \\
\text { Operators Fail To Align The SSF RCM System For Operation }\end{array}$ & $\begin{array}{l}4.49 \mathrm{E}-02 \\
4.30 \mathrm{E}-03 \\
8.90 \mathrm{E}-05 \\
1.00 \mathrm{E}-03 \\
1.00 \mathrm{E}-01\end{array}$ & Negligible \\
\hline TBX & $\begin{array}{l}\text { TCR } \\
\text { RCR } \\
\text { AIAOLEKDEX } \\
\text { AIAOLEKDHE } \\
\text { FEFSWCHDHE } \\
\text { TTRHPRIDHE } \\
\text { NSFOASWDHE }\end{array}$ & $\begin{array}{l}\text { Loss of Control Room Cooling } \\
\text { Nonrecovery From Control Room Cooling } \\
\text { Instrument Air System Major Leakage } \\
\text { Operators Fail To Find Instrument Air System Leak } \\
\text { Operators Fail To Switch TDEFW Pump Suction To Hotwell } \\
\text { Operators Fail To Initiate High Pressure Recirculation } \\
\text { Operators Fail To Align The SSF ASW System For Operation }\end{array}$ & $\begin{array}{l}4.49 \mathrm{E}-02 \\
4.30 \mathrm{E}-03 \\
1.20 \mathrm{E}-03 \\
1.00 \mathrm{E}-01 \\
1.00 \mathrm{E}-01 \\
5.00 \mathrm{E}-01 \\
1.00 \mathrm{E}-01\end{array}$ & Negligible \\
\hline TQSU & $\begin{array}{l}\text { TCR } \\
\text { RCR } \\
\text { PACLINEDEX } \\
\text { PACKEO2HYM } \\
\text { PACXCT3THF } \\
\text { NSFORCMDHE }\end{array}$ & $\begin{array}{l}\text { Loss of Control Room Cooling } \\
\text { Nonrecovery From Coritrol Room Cooling } \\
100 \mathrm{kV} \text { AC Overhead Line To CT5 Fails } \\
\text { Both Emergency AC Units Are In Maintenance } \\
\text { Transformer CT3 Fails } \\
\text { Operators Fail To Align The SSF RCM System For Operation }\end{array}$ & $\begin{array}{l}4.49 \mathrm{E}-02 \\
4.30 \mathrm{E}-03 \\
7.80 \mathrm{E}-03 \\
1.93 \mathrm{E}-02 \\
3.62 \mathrm{E}-04 \\
1.00 \mathrm{E}-01\end{array}$ & \\
\hline TBU & $\begin{array}{l}\text { TCR } \\
\text { RCR } \\
\text { TRCSRVODEX }\end{array}$ & $\begin{array}{l}\text { Loss of Control Room Cooling } \\
\text { Nonrecovery From Control Room Cooling } \\
\text { RCS Safety Relief Valve Does Not Stick Open After Relieving }\end{array}$ & $\begin{array}{l}4.49 E-02 \\
4.30 E-03 \\
0.00 E-01\end{array}$ & Negligible \\
\hline
\end{tabular}


TABLE 4.4-4. (contd)

\begin{tabular}{|c|c|c|c|c|}
\hline $\begin{array}{l}\text { Seq. } \\
\text { Name }\end{array}$ & Event Name & Event Description & Probability & $\begin{array}{l}\text { Cut Set } \\
\text { Frequency }\end{array}$ \\
\hline & $\begin{array}{l}\text { PACEIE2COM } \\
\text { PACEIE2REC } \\
\text { NSFOASWDHE } \\
\text { FEFTDFPTRM }\end{array}$ & $\begin{array}{l}\text { Common Cause Failure of Breakers E1 And E2 To Close } \\
\text { Operators Fail To Close Breakers E1 And E2 Within } 40 \text { Min. } \\
\text { Operators Fail To Align The SSF ASW System For Operation } \\
\text { Turbine-Driven EFW Pump Is In Maintenance }\end{array}$ & $\begin{array}{l}8.90 \mathrm{E}-05 \\
5.00 \mathrm{E}-02 \\
1.00 \mathrm{E}-01 \\
9.40 \mathrm{E}-03\end{array}$ & \\
\hline TQsU & $\begin{array}{l}\text { TCR } \\
\text { RCR } \\
\text { PACN1N2COM } \\
\text { PACN3N4REC } \\
\text { NSFORCMDHE }\end{array}$ & $\begin{array}{l}\text { Loss of Control Room Cooling } \\
\text { Nonrecovery From Control Room Cool ing } \\
\text { Common Cause Failure Of Breakers N1 And N2 To Open } \\
\text { Operators Fail To Open Breakers N1 And N2 Within } 4 \text { Hours } \\
\text { Operators Fail To Align The SSF RCM System For Operation }\end{array}$ & $\begin{array}{l}4.49 \mathrm{E}-02 \\
4.30 \mathrm{E}-03 \\
3.00 \mathrm{E}-05 \\
1.00 \mathrm{E}-03 \\
1.00 \mathrm{E}-01\end{array}$ & Negligible \\
\hline TQSU & $\begin{array}{l}\text { TCR } \\
\text { RCR } \\
\text { PACLINEDEX } \\
\text { PACKEOSHYM } \\
\text { PACXCT3THF } \\
\text { NSFORCMDHE }\end{array}$ & $\begin{array}{l}\text { Loss Of Control Room Cooling } \\
\text { Nonrecovery From Control Room Cooling } \\
100 \mathrm{kV} \mathrm{AC} \mathrm{Overhead} \mathrm{Line} \mathrm{To} \mathrm{CT5} \mathrm{Fails} \\
\text { Both Emergency AC Units Are In Maintenance } \\
\text { Transformer CT3 Is In Maintenance } \\
\text { Operators Fail To Align The SSF RCCm System For Operation }\end{array}$ & $\begin{array}{l}4.49 \mathrm{E}-02 \\
4.30 \mathrm{E}-03 \\
7.80 \mathrm{E}-03 \\
1.93 \mathrm{E}-02 \\
1.74 \mathrm{E}-04 \\
1.00 \mathrm{E}-01\end{array}$ & Negligible \\
\hline TQsU & $\begin{array}{l}\text { TCR } \\
\text { RCR } \\
\text { PACE1E2COM } \\
\text { PACE3E4REC } \\
\text { NSFORCMDHE } \\
\text { LPRO025LHE }\end{array}$ & $\begin{array}{l}\text { Loss of Control Room Cooling } \\
\text { Nonrecovery From Control Room Cooling } \\
\text { Common Cause Failure Of Breakers El And E2 To Close } \\
\text { Operators Fail To Close Breakers E1 And E2 Within } 4 \text { Hours } \\
\text { Operators Fail To Align The SSF RCM System For Operation } \\
\text { Drain Valve 3PR-25 Is Left Open: Latent Human Error }\end{array}$ & $\begin{array}{l}4.49 E-02 \\
4.30 E-03 \\
8.90 E-05 \\
1.00 E-03 \\
1.00 E-01 \\
3.00 E-03\end{array}$ & Negligible \\
\hline TQSU & $\begin{array}{l}\text { TCR } \\
\text { RCR } \\
\text { PACE1E2CON } \\
\text { PACE3H4REC } \\
\text { NSFORCMDHE } \\
\text { LPRPN60LHE }\end{array}$ & $\begin{array}{l}\text { Loss of Control Room Cooling } \\
\text { Nonrecovery From Control Room Cool ing } \\
\text { Common Cause Failure Of Breakers E1 And E2 To Close } \\
\text { Operators Fail To Close Breakers E1 and E2 Within } 4 \text { Hours } \\
\text { Operators Fail To Align The SSF RCM System For Operation } \\
\text { Drain Valve 3PR-23 Or 3PR-68 Left Open: Latent Human Error }\end{array}$ & $\begin{array}{l}4.49 \mathrm{E}-02 \\
4.30 \mathrm{E}-03 \\
8.90 \mathrm{E}-05 \\
1.00 \mathrm{E}-03 \\
1.00 \mathrm{E}-01 \\
3.00 \mathrm{E}-03\end{array}$ & Negligible \\
\hline & & $\begin{array}{rr} & \text { Total }\end{array}$ & & $4.70 E-08$ \\
\hline
\end{tabular}


representing fallure of the ASP was incorporated into the appropriate cut sets, and the affected CDF was recalculated. The minimal cut sets and frequencies for this sequence are presented in Table 4.4-5.

The total affected CDF from room cooler inttiators, based on the point estimates given in Tables 4.4-3 and 4.4-4, was calculated to be 3.15E-07/RY. This number excludes potential recovery from the ASP. Approximately $85 \%$ of this value results from loss of electrical equipment room cooling, and $15 \%$ results from loss of control room cooling. The total represents about $0.28 \%$ of the total original CDF (1.1E-04/RY) that was calculated in the IPE.

Table 4.4-6 presents the contributions of each room cooler initiator to the total affected CDF.

The total affected CDF due to electrical equipment room cooling failure was calculated to be about $2.68 \mathrm{E}-07 / \mathrm{RY}$. This study resulted in identification of only two minimal cut sets with frequencies greater than 1E-07/RY. Those cut sets involve breaker failures that are located in the equipment room and operator fallure to reset these breakers. Loss of control room cooling contributes about 4.7E-08/RY. This is a relatively small value, because credit was taken for recovery actions. If credit is also given for the ASP, the CDF due to loss of control room cooling is reduced by about a factor of 10 $(4.4 E-09 / R Y)$.

The total affected CDF from room cooler initiators, based on point est $i$ mates for each parameter value, was calculated to be about $3.2 E-07 / R Y$. The important statistical parameters of the CDF distribution are 1isted below. These statistics were generated using Lat in Hypercube sampling techniques.

Mean:

95\% upper confidence bound:

Median:

$5 \%$ lower confidence bound:
$5.8 E-08 / R Y$

2. $0 \mathrm{E}-07 / \mathrm{RY}$

1. $0 \mathrm{E}-09 / \mathrm{RY}$

$3.0 \mathrm{E}-11 / \mathrm{RY}$

\subsubsection{Public Risk Calculations}

The next step in the analys is was calculating the public risk associated with the core damage sequences discussed in the previous section. The minimal cut sets were assigned to plant damage states (PDSs). The PDSs associated with each cut set were provided in Appendix D of the IPE (Duke Power Co.; 1990). Each PDS provides similar initial conditions for the subsequent accident progression analysis. Each cut set was assigned to a specific PDS depending upon the timing of core damage (early, late), the availability of ECCS systems (including HPI, I.PI, and EFW) systems, and the availability of consequence-mitigating features (e.g., containment overpressure protection, containment isolation), and other parameters. Each PDS is further partitioned into specific release categories. Release categories define the quantities of each radionuclide that would be released to the environment if the specific PDS occurs. The IPE also provided the conditional probabilities of each release-category, conditional upon the occurrence of each PDS (see Table 4.4-7). Detailed accident progression analyses, including solution of 
TABLE 4.4-5. Loss of Control Room Cooling Cut Sets (with auxiliary shutdown panel)

\begin{tabular}{|c|c|c|c|c|}
\hline $\begin{array}{l}\text { Seq. } \\
\text { Name }\end{array}$ & Event Name & Event Description & Probability & $\begin{array}{l}\text { Cut Set } \\
\text { Frequency }\end{array}$ \\
\hline TBX & $\begin{array}{l}\text { TCR } \\
\text { RCR } \\
\text { ASP } \\
\text { TRCSRVODEX } \\
\text { TLOMFATDEX } \\
\text { TTRHPRIDHE } \\
\text { FEFEFW2DHE } \\
\text { FEFEFW1REC } \\
\text { TMFFDW2REC }\end{array}$ & $\begin{array}{l}\text { Loss Of Control Room Cooling } \\
\text { Nonrecovery From Control Room Cooling } \\
\text { Auxiliary Shut Down Panel unavailable } \\
\text { RCS Safety Relief Valve Does Not Stick Open After Relieving } \\
\text { Loss Of Main Feedwater Following A Iurbine Trip } \\
\text { Operators Fail To Initiate High Pressure Recirculation } \\
\text { Operators Fail To Throttle EFW Pump Flow } \\
\text { Operators Fail To Align EFW From Another Unit } \\
\text { Operators Fail To Recover Main Feedwater Within } 45 \text { Minutes }\end{array}$ & $\begin{array}{l}\text { 4. 49E-02 } \\
4.30 \mathrm{E}-03 \\
7.40 \mathrm{E}-02 \\
9.00 \mathrm{E}-01 \\
6.00 \mathrm{E}-02 \\
5.00 \mathrm{E}-01 \\
1.00 \mathrm{E}+00 \\
1.00 \mathrm{E}-01 \\
9.00 \mathrm{E}-02\end{array}$ & $3.74 E-09$ \\
\hline TBX & $\begin{array}{l}\text { TCR } \\
\text { RCR } \\
\text { ASP } \\
\text { AIAOLEKDEX } \\
\text { AIAOLEKDHE } \\
\text { FEFSWCHDHE } \\
\text { TTRHPRIDHE } \\
\text { NSFOASWDHE }\end{array}$ & $\begin{array}{l}\text { Loss Of Control Room Cooling } \\
\text { Nonrecovery From Control Room Cooling } \\
\text { Auxiliary Shut Down Panel unavailable } \\
\text { Instrument Air System Major Leakage } \\
\text { Operators Fail To Find Instrument Air System Leak } \\
\text { Operators Fail To Switch TDEFW Pump Suction To Hotwell } \\
\text { Operators Fail To Initiate High Pressure Recirculation } \\
\text { Operators Fail To Align The SSF ASW System For Operation }\end{array}$ & $\begin{array}{l}4.49 \mathrm{E}-02 \\
4.30 \mathrm{E}-03 \\
7.40 \mathrm{E}-02 \\
1.20 \mathrm{E}-03 \\
1.00 \mathrm{E}-01 \\
1.00 \mathrm{E}-01 \\
5.00 \mathrm{E}-01 \\
1.00 \mathrm{E}-01\end{array}$ & Negligible \\
\hline TBX & $\begin{array}{l}\text { TCR } \\
\text { RCR } \\
\text { TRCSRVODEX } \\
\text { TLOMFATDEX } \\
\text { TTRHPRIDHE } \\
\text { FEFEFW2DHE } \\
\text { FEFEFW1REC } \\
\text { TMFFDW2REC }\end{array}$ & $\begin{array}{l}\text { Loss Of Control Room Cooling } \\
\text { Nonrecovery From Control Room Cooling } \\
\text { RCS Safety Relief Valve Does Not Stick Open After Relieving } \\
\text { Loss Of Main Feedwater Following A Turbine Trip } \\
\text { Operators Fail To Initiate High Pressure Recirculation } \\
\text { Operators Fail To Throttle EFW Pump Flow } \\
\text { Operators Fail To Align EFW From Another Unit } \\
\text { Operators Fail To Recover Main Feedwater Within } 45 \text { Minutes }\end{array}$ & $\begin{array}{l}4.49 \mathrm{E}-02 \\
4.30 \mathrm{E}-03 \\
9.00 \mathrm{E}-01 \\
6.00 \mathrm{E}-02 \\
1.00 \mathrm{E}-02 \\
1.00 \mathrm{E}+00 \\
1.00 \mathrm{E}-01 \\
9.00 \mathrm{E}-02\end{array}$ & $9.38 \mathrm{E}-10$ \\
\hline TQsU & $\begin{array}{l}\text { TCR } \\
\text { RCR }\end{array}$ & $\begin{array}{l}\text { Loss of Control Room Cooling } \\
\text { Nonrecovery From Control Room Cooling }\end{array}$ & $\begin{array}{l}4.49 \mathrm{E}-02 \\
4.30 \mathrm{E}-03\end{array}$ & Negligible \\
\hline
\end{tabular}


TABLE 4.4-5. (contd)

\begin{tabular}{|c|c|c|c|c|}
\hline $\begin{array}{l}\text { Seq. } \\
\text { Name }\end{array}$ & Event Name & Event Description & Probability & $\begin{array}{l}\text { Cut Set } \\
\text { Frequency }\end{array}$ \\
\hline & $\begin{array}{l}\text { PACEIE2COM } \\
\text { PACE3E4REC } \\
\text { NSFORCMDHE }\end{array}$ & $\begin{array}{l}\text { Common Cause Failure of Breakers E1 And E2 To Close } \\
\text { Operators Fail To Close Breakers E1 And E2 Within } 4 \text { Hours } \\
\text { Operators Fail To Align The SSF RCM System For Operation }\end{array}$ & $\begin{array}{l}8.90 \mathrm{E}-05 \\
1.00 \mathrm{E}-03 \\
1.00 \mathrm{E}-01\end{array}$ & \\
\hline \multirow[t]{7}{*}{ TBX } & TCR & Loss of Control Room Cooling & 4.49E-02 & Negligible \\
\hline & & Nonrecovery From Control Room Cooling & 4.30E-03 & \\
\hline & AIAOLEKDEX & Instrument Air System Major Leakage & $1.20 E-03$ & \\
\hline & AIAOLEKDHE & Operators Fail To Find Instrument Air System Leak & $1.00 \mathrm{E}-01$ & \\
\hline & FEFSWCHDHE & Operators Fail To Switch TDEFW Pump Suction To Hotwell & $1.00 E-01$ & \\
\hline & TTRHPRIDHE & Operators Fail To Initiate High Pressure Recirculation & $1.00 \mathrm{E}-02$ & \\
\hline & NSFOASWDHE & Operators Fail To Align The SSF ASW System For Operation & $1.00 \mathrm{E}-01$ & \\
\hline \multirow[t]{6}{*}{ TQsU } & TCR & Loss of Control Room Cooling & 4.49E-02 & Negl igible \\
\hline & & Nonrecovery From Control Room Cooling & $4.30 \mathrm{E}-03$ & \\
\hline & PACLINEDEX & 100 kV AC Overhead Line To CT5 Fails & $7.80 \mathrm{E}-03$ & \\
\hline & PACKE02HYM & Both Emergency AC Units Are In Maintenance & $1.93 \mathrm{E}-02$ & \\
\hline & РАСХСТЗТTHF & Transformer CT3 Fails & $3.62 \mathrm{E}-04$ & \\
\hline & NSFORCMDHE & Operators Fail To Align The SSF RCM System For Operation & $1.00 \mathrm{E}-01$ & \\
\hline \multirow[t]{7}{*}{ TBU } & TCR & Loss of Control Room Cooling & 4.49E-02 & Negligible \\
\hline & & Nonrecovery From Control Room Cooling & 4.30E-03 & \\
\hline & TRCSRVODEX & RCS Safety Relief Valve Does Not Stick Open After Relieving & $9.00 \mathrm{E}-01$ & \\
\hline & PACE1E2COM & Common Cause Failure of Breakers E1 And E2 To Close & $8.90 \mathrm{E}-05$ & \\
\hline & PACE1E2REC & Operators Fail To Close Breakers E1 And E2 Within 40 Min. & $5.00 E-02$ & \\
\hline & NSFOASWDHE & Operators Fail To Align The SSF ASW System For Operation & $1.00 \mathrm{E}-01$ & \\
\hline & FEFTDFPTRM & Turbine-Driven EFW Pump Is In Maintenance & $9.40 E-03$ & \\
\hline \multirow{4}{*}{ TQsU } & TCR & Loss of Control Room Cooling & $4.49 \mathrm{E}-02$ & Negligible \\
\hline & RCR & Nonrecovery From Control Room Cooling & $4.30 \mathrm{E}-03$ & \\
\hline & PACN1N2COM & Common Cause Faiiure of Breakers N1 And N2 To Open & $3.00 \mathrm{E}-05$ & \\
\hline & PAACN3N4REC & Operators Fail To Open Breakers N1 And N2 Within 4 Hours & $1.00 \mathrm{E}-03$ & \\
\hline
\end{tabular}


TABLE 4.4-5. (contd)

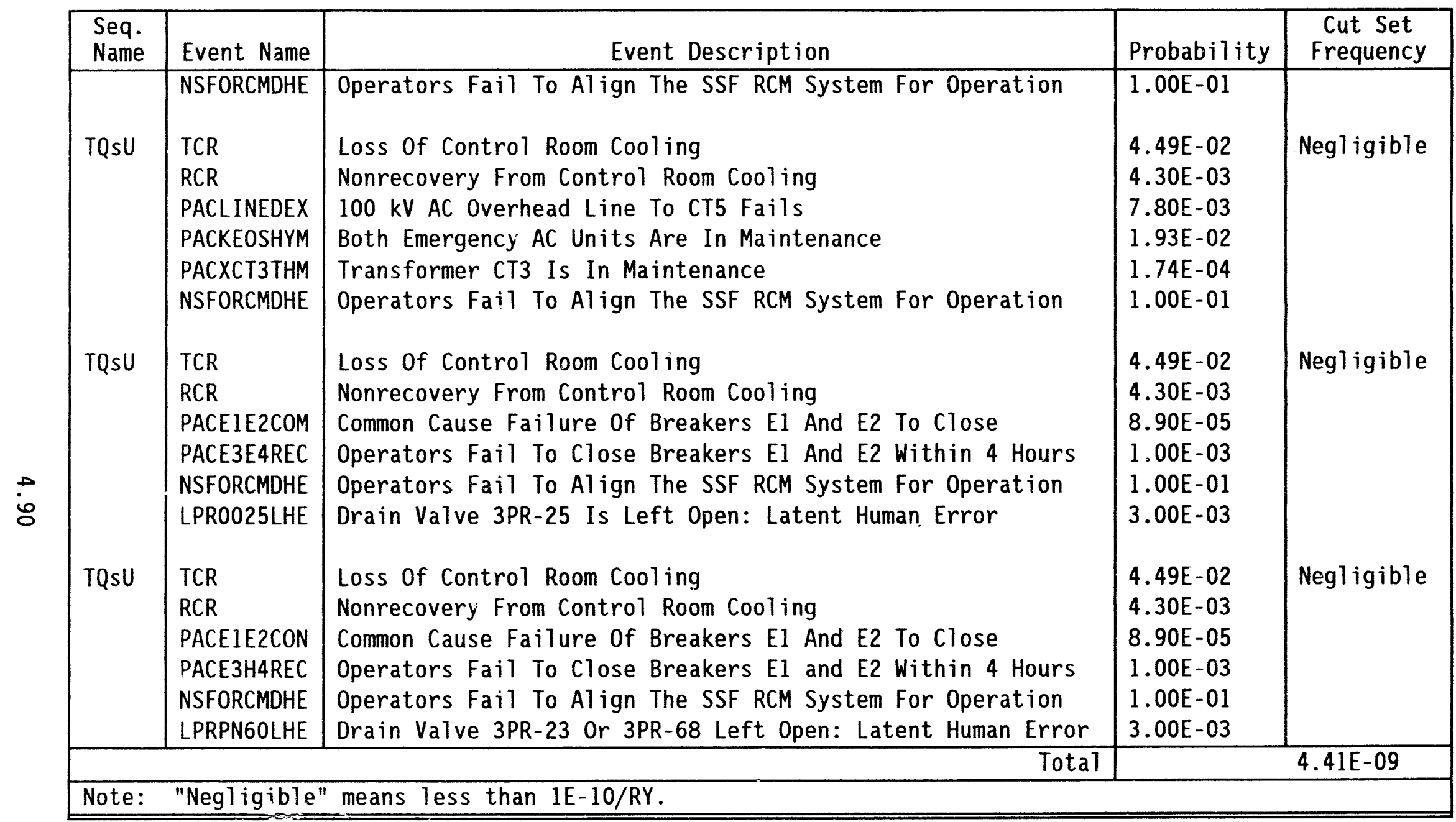


IABLE 4.4-6. Core Damage Frequency and Percentage Contribution

\begin{tabular}{|c|c|c|}
\hline Initiating Event & $\begin{array}{c}\text { Core Damage } \\
\text { Frequency, } \\
\text { per RY }\end{array}$ & $\begin{array}{l}\text { Percentage } \\
\text { Contribution }\end{array}$ \\
\hline $\begin{array}{l}\text { Loss of electrical equipment room } \\
\text { cooling }\end{array}$ & $2.68 \mathrm{E}-07$ & $0.24 \%$ \\
\hline Loss of control room cooling (w/o ASP) & $4.70 E-08$ & $0.04 \%$ \\
\hline Loss of control room cooling (W ASP) & $4.41 E-09$ & $0.004 \%$ \\
\hline Total (W/o ASP) & $3.15 \mathrm{E}-07$ & $0.28 \%$ \\
\hline Total (W/ ASP) & $2.72 E-07$ & $0.25 \%$ \\
\hline $\begin{array}{l}\text { (a) Represents percent of total oric } \\
\text { representative B\&W PWR. }\end{array}$ & $\mathrm{F}(1.1 \mathrm{E}-04)$ & for the \\
\hline
\end{tabular}

the containment event tree, were performed in the IPE to develop these conditional probabilities. A source term (release quantity) was then developed for each release category, and consequence calculations were performed for each source term. The accident progression, source term, and consequence analyses described in the IPE (Duke Power Co. 1990) form the basis for the present analysis.

For the analysis of room cooler initiators, the conditional probabilities of all plant release categories, conditional upon the occurrence of each damage state, were extracted from the release category matrix provided in the IPE (Duke Power Co. 1990, Table 6.3-23). Each cut set in Tables 4.4-3 and 4.4-4 was assigned to the same PDS given in the IPE. Risk calculations were not performed for loss of control room cooling cut sets with the ASP recovery actions (i.e., Table 4.4-5) because of the potential deficiencies described previousiy. The frequencies of the cut sets in each PDS were then summed to calculate the PDS frequencies. The conditional probabilities given in there lease category matrix were multiplied by the appropriate PDS frequencies to calculate the frequencies of each release category. Finally, the consequences associated with each release category were taken from the IPE (Duke Power Co. 1990, Table 7.3-1) to calculate the public risk associated with each PDS. Then, the PDS risk values were summed to calculate the total affected public risk from room cooler initiators. This calculation process is similar to that described in subsection 4.1.1.3. A spreadsheet was used to perform these calculations.

The results of the affected public risk calculations for room cooler initiator sequences are presented in Table 4.4-7. This table presents the plant damage states each cut set was assigned to, the conditional probabilities of each release category given the occurrence of the specific PDSs, the consequences associated with each release category, and the resulting public risk values. The affected public risk value, calculated using the point estimates for the equipment failure and human error probabilities and conditional probabilities of each release category, was calculated to be $1.3 \mathrm{E}-01$ 
IABLE 4.4-7. Public Risk Calculations for Room Cooler Initiator Sequences

\begin{tabular}{|c|c|c|c|c|c|c|}
\hline PDS & $\begin{array}{c}\text { Cut Set } \\
\text { Numbers }\end{array}$ & $\begin{array}{c}\text { Core Damage } \\
\text { Frequency, } \\
\text { per RY }\end{array}$ & $\begin{array}{l}\text { Release } \\
\text { Category }\end{array}$ & $\begin{array}{c}\text { Release } \\
\text { Category } \\
\text { Probability }(\mathrm{b}) \\
\end{array}$ & $\begin{array}{c}\text { Release } \\
\text { Consequencess, } \\
\text { person-rem }\end{array}$ & $\begin{array}{l}\text { Public Risk } \\
\text { person-rem/RY }\end{array}$ \\
\hline \multirow[t]{7}{*}{$13 \mathrm{H}$} & $1,3,10,12$ & $4.80 E-08$ & $\mathrm{RC} 5.01$ & $6.73 \mathrm{E}-04$ & $1.25 \mathrm{E}+07$ & $4.04 \mathrm{E}-04$ \\
\hline & & & $\mathrm{RC} 5.02$ & $5.51 E-04$ & $1.26 \mathrm{E}+07$ & $3.33 E-04$ \\
\hline & & & RC 4.05 & $1.43 E-03$ & $1.52 E+06$ & $1.04 E-04$ \\
\hline & & & $\mathrm{RC} 4.06$ & $1.41 E-01$ & $1.52 E+06$ & $1.03 E-02$ \\
\hline & & & $\mathrm{RC} 4.07$ & $8.56 E-03$ & $2.16 E+06$ & $8.88 E-04$ \\
\hline & & & RC 4.08 & $8.47 E-01$ & $2.80 E+06$ & $1.14 \mathrm{E}-01$ \\
\hline & & & & & & $1.26 \mathrm{E}-01$ \\
\hline \multirow[t]{9}{*}{$7 F$} & $2,4,6-9,11$ & $2.21 E-07$ & RC 9.04 & $7.29 E-01$ & $5.05 E+03$ & $8.12 E-04$ \\
\hline & $13,15-19$ & & $\mathrm{RC} 8.01$ & $2.47 \mathrm{E}-01$ & $3.40 E+04$ & $1.85 \mathrm{E}-03$ \\
\hline & & & $\mathrm{RC} 7.01$ & $4.41 E-03$ & $4.27 E+05$ & $4.16 E-04$ \\
\hline & & & RC 7.04 & $1.67 \mathrm{E}-02$ & $4.27 E+05$ & $1.57 \mathrm{E}-03$ \\
\hline & & & $\mathrm{RC} 6.02$ & $2.47 E-04$ & $1.40 E+06$ & $7.63 E-05$ \\
\hline & & & $\mathrm{RC} 6.04$ & $2.42 E-04$ & $8.73 E+06$ & $4.66 \mathrm{E}-04$ \\
\hline & & & $\mathrm{RC} 6.06$ & $9.38 \mathrm{E}-04$ & $1.42 E+06$ & $2.94 E-04$ \\
\hline & & & $\mathrm{RC} \quad 6.08$ & $9.17 \mathrm{E}-04$ & $8.75 E+06$ & $1.77 \mathrm{E}-03$ \\
\hline & & & & & & $7.26 \mathrm{E}-03$ \\
\hline \multirow[t]{7}{*}{$12 \mathrm{~F}$} & 5,14 & $4.65 E-08$ & RC 9.04 & $7.29 E-01$ & $5.05 E+03$ & $1.71 E-04$ \\
\hline & & & $\mathrm{RC} 8.01$ & $2.47 E-01$ & $3.40 E+04$ & $3.91 E-04$ \\
\hline & & & RC 7.02 & $4.41 E-03$ & $4.27 E+05$ & $8.76 E-05$ \\
\hline & & & RC 7.04 & $1.30 E-02$ & $4.27 E+05$ & $2.58 E-04$ \\
\hline & & & $\mathrm{RC} 6.02$ & $2.47 E-04$ & $1.40 E+06$ & $1.61 E-05$ \\
\hline & & & RC 6.04 & $2.42 \mathrm{E}-04$ & $8.73 E+06$ & $9.83 E-05$ \\
\hline & & & & & & $1.02 \mathrm{E}-03$ \\
\hline $\begin{array}{l}\text { (a) } \\
\text { (b) } \\
\text { (c) }\end{array}$ & $\begin{array}{l}\text { Cut sets } 1 \text { to } \\
\text { Duke Power Co. } \\
\text { Product of PDS }\end{array}$ & 1990. & 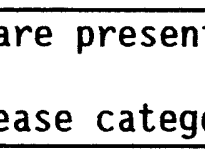 & nunhohilitu & 3 and $4.4-4, r$ & ectively. \\
\hline
\end{tabular}


person-rem/RY. Latin Hypercube sampling was performed on these cut sets to determine the uncertainty associated with the public risk values. The results of the uncertainty calculations are as follows:
Mean:
1.5E-01 person-rem/RY
95\% l:pper confidence bound:
2.0E-06 person-rem/RY
Median:
$1.0 \mathrm{E}-04$ person-rem/RY
5\% lower confidence bound:
3.2E-02 person-rem/RY

\subsubsection{Room Cooling Failure as a Contributing Event to Other Accident Sequences at the Representative B\&W PWR}

The results of the SSF HVAC analys is were incorporated into the models used to calculate the CDF and public risks for a B\&W PWR. The calculations are based on the IPE for the B\&W plant (Duke Power Co. 1990). The affected portion of the CDF associated with SSF HVAC contributors to accidents not initiated by loss of HVAC systems is calculated from the transient-initiated minimal cut sets that were provided in the IPE. Where necessary, the cut sets were modified to incorporate HVAC/room cooler failures.

As discussed in Section 3.4, the SSF is a stand-alone, bunkered facility constructed at the representative B\&W PWR to provide a secure means for attaining and maintaining a hot shutdown condition in all three units at the site. The SSF, designed principally to provide core cooling for incidents of industrial sabotage, fires, and flooding, was also designed to provide an alternative means of cooling after failure of normal and emergency plant systems. This is why the SSF was applied as a recovery action to the transient-initiated minimal cut sets.

The first step in this analysis of transient-initiated sequences with room cooler contributing events was performing a detailed review of the minimal cut sets in the IPE to identify SSF-related parameters. Cut sets incorporating SSF-related parameters are defined as being affected by this analysis through failure of the SSF HVAC system (see Appendix E for transientinitiated minimal cut sets). The second step was quantifying the affected CDF by coding the affected minimal cut sets into a spreadsheet; the cut sets were grouped into the five transient accident sequences described in the following paragraphs.

The resulting affected CDF values for each affected sequence are listed in Table 4.4-8 and are illustrated in Figure 4.4-1. The total affected CDF due to those sequences involving SSF HVAC failure was calculated to be about $8.89 \mathrm{E}-07 / \mathrm{RY}$. This is about $0.8 \%$ of the total CDF associated with the representative B\&W PWR (1.1E-04/RY). Derivation of the values in Table 4.4-8 is discussed in the descriptions of the transient sequences. 


\section{TABLE 4.4-8. Summary of Affected CDF for HVAC/Room Cooler Contributor Accident Sequences (point estimates)}

\begin{tabular}{|c|c|}
\hline $\begin{array}{c}\text { Transient } \\
\text { Sequence }\end{array}$ & $\begin{array}{c}\text { Affected Core Damage } \\
\text { Frequency, per RY }\end{array}$ \\
\hline TBX & $3.60 \mathrm{E}-07$ \\
\hline TQSU & $3.27 \mathrm{E}-07$ \\
\hline TBU & $6.59 \mathrm{E}-08$ \\
\hline TBQrX & $3.54 \mathrm{E}-08$ \\
\hline TBQsU & $1.00 \mathrm{E}-07$ \\
\hline Total & $8.89 \mathrm{E}-07$ \\
\hline
\end{tabular}

Sequence TBX. This sequence is initiated by a transient event followed by failure of secondary side heat removal and failure of HPI cooling in the recirculation phase. The SSF ASW function is applied as a recovery action in this sequence. Failure of the SSF ASW function results in core damage. Minimal cut sets involving the SSF ASW system failures were identified and modified to reflect the probability of failure of the SSF HVAC system. As shown in Appendix E, the SSF fault tree was modeled as an OR gate with failure of SSF HVAC feeding into it. Therefore, the calculation was done by substituting the SSF HVAC failure probability (see subsection 4.4.1.2) into the affected minimal cut sets to replace the parameters involving failure of SSF equipment. The failure probability for the SSF HVAC system was calculated in subsection 4.4.1.2 to be $1.57 \mathrm{E}-02 /$ demand. This value was substituted into the minimal cut sets for the TBX sequence. Each modified cut set was then requantified and summed to calculate the affected CDF shown in Table 4.4-8.

Sequence TQSU. This sequence is initiated by a transient event followed by failure of the RCP seals and a failure of high-pressure makeup in the injection phase. The SSF RCM function was used as a recovery for this sequence. The procedure discussed above was repeated for 37 affected minimal cut sets (see Appendix E); and from this the affected CDF for this sequence was calculated to be $3.27 \mathrm{E}-07 / \mathrm{RY}$.

Sequence TBU. This sequence is initiated by a transient event followed by failure of all secondary side heat removal and failure of HPI cooling in the injection phase. The SSF ASW function was applied as a recovery action in this sequence; therefore, the approach to calculating the affected CDF for this sequence is the same as the above procedure. After repeating this procedure for nine affected minimal cut sets (see Appendix E), the affected CDF for this sequence was calculated to be $6.59 \mathrm{E}-08 / \mathrm{RY}$. 


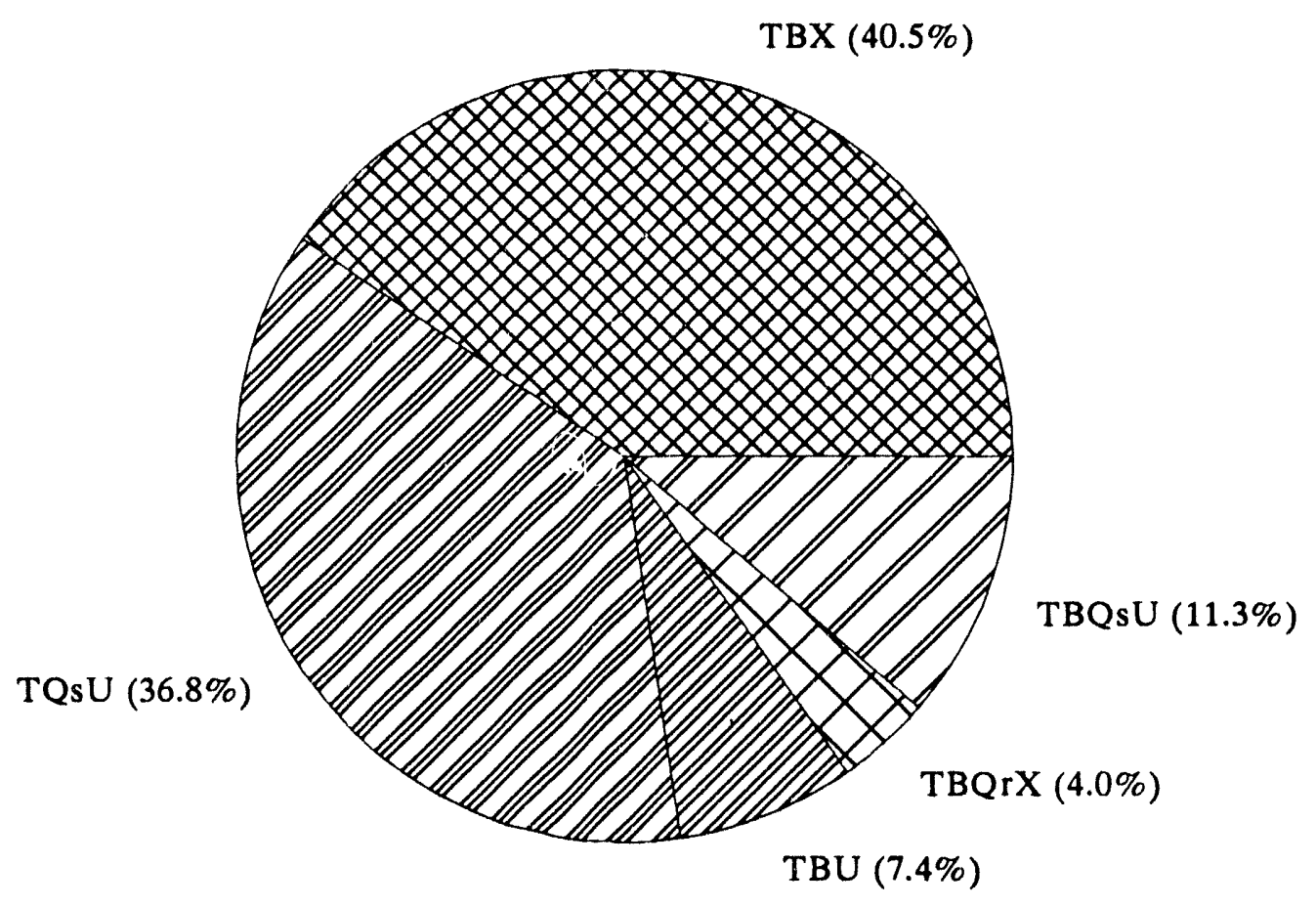

FIGURE 4.4-1. Pie Chart Illustrating Relative Contributions of Affected Accident Sequences to Affected CDF

Sequence TBQrX. This sequence is initiated by a transient event followed by failure of all secondary side heat removal, failure of the pressurizer SRV, and failure of HPI cooling in the recirculation phase. The SSF ASW function was used as a recovery for this sequence. Therefore, the approach to calculating the affected CDF for this sequence is identical to the approach used for sequence TBX. After applying this procedure on four affected dominant minimal cut sets (see Appendix E), the affected CDF for this sequence was calculated to be $3.54 E-08 / R Y$.

Sequence TBOSU. This sequence is initiated by a transient event followed by failure of all secondary side heat removal, failure of RCP seal integrity, and failure of HPI cooling in the injection phase. Because loss of all power cut sets dominate this sequence, the recoveries applied involve breakering in the 100-kV grid, connecting the backup emergency $A C$ power units, and powering both ASW and RCM from the SSF EDG. The approach to calculating the affected CDF for this sequence is substituting the SSF HVAC failure probability into the cut sets that involve EDG events and requantifying. After applying these modifications to the 14 affected dominant minimal cut sets shown in Appendix $E$, the affect CDF for this sequence was calculated to be $1.00 E-07 / R Y$.

To illustrate the calculational procedure, the following minimal cut set was taken from the IPE: 


\begin{tabular}{|l|l|l|}
\hline Event Name & Prob. & \multicolumn{1}{|c|}{ Event Description } \\
\hline T6 & $3.30 E-02$ & Loss Of Compressed Air System Pressure Init. Event \\
TRCSRVODEX & $9.00 E-01$ & RCS SRV Does Not Stick Open After Relieving \\
TTRHPRIDHE & $1.00 E-02$ & Operators Fail To Initiate HPR \\
FEFSWCHDHE & $5.00 E-02$ & Opers. Fail To Switch TDEFW Pump Suction To Hotwe11 \\
NSFOASWDHE & $1.00 E-01$ & Opers. Fail To Align The SSF ASW Sys. For Operation \\
\hline Frequency & \multicolumn{2}{|l}{$1.48 \mathrm{E}-06 /$ RY } \\
\hline
\end{tabular}

This cut set was modified as follows by replacing the failure of the SSF ASW function with failure of the SSF HVAC function.

\begin{tabular}{|l|c|l|}
\hline Event Name & Pro. & \multicolumn{1}{|c|}{ Event Description } \\
\hline T6 & $3.30 E-02$ & Loss Of Compressed Air System Pressure Init. Event \\
TRCSRVODEX & $9.00 E-01$ & RCS SRV Does Not Stick Open After Relieving \\
TTRHPRIDHE & $1.00 E-02$ & Operators Fail To Initiate HPR \\
FEFSWCHDHE & $5.00 E-02$ & Opers. Fail To Switch TDEFW Pump Suction To Hotwe11 \\
SSF-HVAC & $1.57 E-02$ & SSF HVAC System Failure \\
\hline Frequency & \multicolumn{2}{|c|}{$2.33 \mathrm{E}-07 /$ RY } \\
\hline
\end{tabular}

This procedure was repeated for the other affected cut sets (see Appendix E) in this accident sequence, TBX, as well as the other four affected sequences. The cut sets for all five sequences are presented in Appendix E.

The total affected CDF from room cooler contributors, calculated using point estimates for each parameter value, was calculated to be about $8.9 \mathrm{E}-07 / \mathrm{RY}$. The important statistical parameters of the CDF distribution are listed below. These statistics were generated using Latin Hypercube sampling techniques.
Mean :
95\% upper confidence bound:
Median:
5\% lower confidence bound:
1. $6 \mathrm{E}-07 / \mathrm{RY}$
5. $6 \mathrm{E}-07 / \mathrm{RY}$
2.8E-09/RY
8. $5 \mathrm{E}-11 / \mathrm{RY}$ 


\subsubsection{Public Risk Calculations}

Public risk calculations were performed for room cooler contributing events using the same approach as for room cooler initiators (see subsection 4.4.1.3). The main differences are in the PDSs to which each cut set was assigned (see Appendix E) and the conditional probabilities of each release category, given the PDS. Similar to the process used to calculate the public risks associated with room cooler initiators, the IPE was used to assign each cut set to an appropriate PDS. The conditional probabilities of each release category were taken from the release category matrix in the IPE, which also provided the consequence values for each release category. The public risks associated with each rilease category were calculated by first calculating the sum of the frequencies of all cut sets assigned to a given PDS. The resulting PDS frequency was then multiplied by the conditional probabilities of each release category associated with the PDS, and then by the consequence value for each release category. The resulting product is the public risk value associated with each PDS: release category combination. The sum of these values is the total affected CDF. These calculations are presented in Table 4.4-9. The relative contributions of each affected accident sequence to the total affected public risk is illustrated in Figure 4.4-2.

The mean public risk associated with room cooler contributors at the representative B\&W PWR, based on the point estimates for each parameter value, was calculated to be 3.5E-02 person-rem/RY. The important statistical parameters are listed below. These statistics were generated using Latin Hypercube Sampling techniques.

Mean:

95\% upper confidence bound:

Median:

$5 \%$ lower confidence bound:
3.8E-02 person-rem/RY

$1.8 \mathrm{E}-01$ person-rem/RY

2.6E-05 person-rem/RY

1.1E-08 person-rem/RY

\subsubsection{Total Affected Core Damage Frequency and Public Risks for the Representative B\&W PWR}

The total affected CDF and public risk values are the sum of the room cooler initiator (see Section 4.4.1) and room cooler contributing events (see Section 4.4.2). The affected CDF and public risks for the representative $B \& W$ PWR, based on their mean values, are shown below:

\begin{tabular}{|c|c|c|}
\hline $\begin{array}{c}\text { Representative } \\
\text { B\&W PWR }\end{array}$ & $\begin{array}{c}\text { Affected } \\
\text { Core Damage } \\
\text { Frequency, } \\
\text { per RY }\end{array}$ & $\begin{array}{c}\text { Affected } \\
\text { Public Risk, } \\
\text { Person-rem/RY (a) }\end{array}$ \\
\hline Initiators & $5.8 \mathrm{E}-08$ & $1.5 \mathrm{E}-01$ \\
\hline Contributors & $1.6 \mathrm{E}-07$ & $3.8 \mathrm{E}-02$ \\
\hline Total & $2.2 \mathrm{E}-07$ & $1.9 \mathrm{E}-01$ \\
\hline (a) Values given are mean values. \\
\hline
\end{tabular}


TABLE 4.4-9. Affected Public Risk Calculations for the Representative B\&W PWR

\begin{tabular}{|c|c|c|c|c|c|c|}
\hline PDS & $\begin{array}{l}\text { Cut Set } \\
\text { Numbers }\end{array}$ & $\begin{array}{l}\text { Core Damage } \\
\text { Frequency, } \\
\text { per RY }\end{array}$ & $\begin{array}{l}\text { Release } \\
\text { Category }\end{array}$ & $\begin{array}{c}\text { Release } \\
\text { Category } \\
\text { Probability(b) }\end{array}$ & $\begin{array}{l}\text { Release } \\
\text { Corisequencess } \\
\text { person-rem }\end{array}$ & $\begin{array}{l}\text { Püblic Risk } \\
\text { person-rem/RY }\end{array}$ \\
\hline $13 B$ & 1 to 21 & $3.59 \mathrm{E}-07$ & $\begin{array}{ll}\mathrm{RC} & 9.01 \\
\mathrm{RC} & 9.02 \\
\mathrm{RC} & 9.04 \\
\mathrm{RC} & 8.01 \\
\mathrm{RC} & 5.01 \\
\mathrm{RC} & 5.02\end{array}$ & $\begin{array}{l}1.43 E-03 \\
1.41 E-01 \\
8.46 E-06 \\
8.56 E-01 \\
6.73 E-04 \\
5.51 E-04\end{array}$ & $\begin{array}{l}2.31 E+02 \\
4.90 E+03 \\
5.05 E+03 \\
3.40 E+04 \\
1.25 E+07 \\
1.26 E+07\end{array}$ & $\begin{array}{l}1.18 \mathrm{E}-07 \\
2.48 \mathrm{E}-04 \\
1.54 \mathrm{E}-08 \\
1.05 \mathrm{E}-02 \\
3.02 \mathrm{E}-03 \\
2.49 \mathrm{E}-03 \\
\end{array}$ \\
\hline & & & & & Total & $1.62 \mathrm{E}-02$ \\
\hline $13 \mathrm{H}$ & 22 to 25 & $7.34 \mathrm{E}-10$ & $\begin{array}{ll}\mathrm{RC} & 5.01 \\
\mathrm{RC} & 5.02 \\
\mathrm{RC} & 4.05 \\
\mathrm{RC} & 4.06 \\
\mathrm{RC} & 4.07 \\
\mathrm{RC} & 4.08\end{array}$ & $\begin{array}{l}6.73 E-04 \\
5.51 E-04 \\
1.43 E-03 \\
1.41 E-01 \\
8.56 E-03 \\
8.47 E-01\end{array}$ & $\begin{array}{l}1.25 E+07 \\
1.26 E+07 \\
1.52 E+06 \\
1.52 E+06 \\
2.16 E+06 \\
2.80 E+06\end{array}$ & $\begin{array}{l}6.18 E-06 \\
5.10 E-06 \\
1.60 E-06 \\
1.57 E-04 \\
1.36 E-05 \\
1.74 E-03\end{array}$ \\
\hline & & & & & Total & $1.93 \mathrm{E}-03$ \\
\hline $7 F$ & 26 to 57 & $3.25 E-07$ & $\begin{array}{ll}\mathrm{RC} & 9.04 \\
\mathrm{RC} & 8.01 \\
\mathrm{RC} & 7.02 \\
\mathrm{RC} & 7.04 \\
\mathrm{RC} & 6.02 \\
\mathrm{RC} & 6.04 \\
\mathrm{RC} & 6.06 \\
\mathrm{RC} & 6.08 \\
\end{array}$ & $\begin{array}{l}7.29 \mathrm{E}-01 \\
2.47 \mathrm{E}-01 \\
4.41 \mathrm{E}-03 \\
1.67 \mathrm{E}-02 \\
2.47 \mathrm{E}-04 \\
2.42 \mathrm{E}-04 \\
9.38 \mathrm{E}-04 \\
9.17 \mathrm{E}-04\end{array}$ & $\begin{array}{l}5.05 E+03 \\
3.40 E+04 \\
4.27 E+05 \\
4.27 E+05 \\
1.40 E+06 \\
8.73 E+06 \\
1.42 E+06 \\
8.75 E+06\end{array}$ & $\begin{array}{l}1.20 \mathrm{E}-03 \\
2.74 \mathrm{E}-03 \\
6.14 \mathrm{E}-04 \\
2.32 \mathrm{E}-03 \\
1.13 \mathrm{E}-04 \\
6.89 \mathrm{E}-04 \\
4.34 \mathrm{E}-04 \\
2.62 \mathrm{E}-03\end{array}$ \\
\hline & & & & & Total & $1.07 \mathrm{E}-02$ \\
\hline
\end{tabular}


TABLE 4.4-9. (contd)

\begin{tabular}{|c|c|c|c|c|c|c|}
\hline PDS & $\begin{array}{l}\text { Cut Set } \\
\text { Numbers }\end{array}$ & $\begin{array}{l}\text { Core Damage } \\
\text { Frequency, } \\
\text { per RY }\end{array}$ & $\begin{array}{l}\text { Release } \\
\text { Category }\end{array}$ & $\begin{array}{c}\text { Release } \\
\text { Category } \\
\text { Probability }\end{array}$ & $\begin{array}{c}\text { Release } \\
\text { Consequences } \\
\text { person-rem }\end{array}$ & $\begin{array}{l}\text { Public Risk } \\
\text { person-rem/RY }\end{array}$ \\
\hline $7 \mathrm{~L}$ & 58 to 62 & $8.72 E-10$ & $\begin{array}{ll}\mathrm{RC} & 6.04 \\
\mathrm{RC} & 4.01 \\
\mathrm{RC} & 4.02 \\
\mathrm{RC} & 4.03 \\
\mathrm{RC} & 4.04\end{array}$ & $\begin{array}{l}1.13 E-03 \\
4.41 E-03 \\
4.90 E-04 \\
8.96 E-01 \\
9.95 E-02\end{array}$ & $\begin{array}{l}8.73 E+06 \\
3.54 E+05 \\
5.34 E+05 \\
5.34 E+05 \\
1.73 E+06\end{array}$ & $\begin{array}{l}8.60 \mathrm{E}-06 \\
1.36 \mathrm{E}-06 \\
2.28 \mathrm{E}-07 \\
4.17 \mathrm{E}-04 \\
1.50 \mathrm{E}-04\end{array}$ \\
\hline & & & & & Total & $5.78 \mathrm{E}-04$ \\
\hline $12 \mathrm{~F}$ & 63 to 71 & $6.59 \mathrm{E}-08$ & $\begin{array}{ll}\mathrm{RC} & 9.04 \\
\mathrm{RC} & 8.01 \\
\mathrm{RC} & 7.02 \\
\mathrm{RC} & 7.04 \\
\mathrm{RC} & 6.02 \\
\mathrm{RC} & 6.04\end{array}$ & $\begin{array}{l}7.29 E-01 \\
2.07 E-01 \\
4.41 E-02 \\
1.30 E-02 \\
2.47 E-03 \\
2.42 E-03\end{array}$ & $\begin{array}{l}5.05 E+03 \\
3.40 E+04 \\
4.27 E+05 \\
4.27 E+05 \\
1.40 E+06 \\
8.73 E+06\end{array}$ & $\begin{array}{l}2.43 E-04 \\
4.65 E-04 \\
1.24 E-03 \\
3.67 E-04 \\
2.28 E-04 \\
1.40 E-03\end{array}$ \\
\hline & & &. & & Total & $3.94 E-03$ \\
\hline $5 B$ & 72 to 75 & $3.54 E-08$ & $\begin{array}{ll}R C & 9.01 \\
R C & 9.02 \\
R C & 8.01 \\
R C & 5.01 \\
R C & 5.02 \\
\end{array}$ & $\begin{array}{l}1.01 E-03 \\
1.00 E-01 \\
8.98 E-01 \\
1.28 E-04 \\
5.28 E-04\end{array}$ & $\begin{array}{l}2.30 E+02 \\
4.90 E+03 \\
3.40 E+04 \\
1.25 E+07 \\
1.26 E+07 \\
\end{array}$ & $\begin{array}{l}8.23 E-09 \\
1.74 E-05 \\
1.08 E-03 \\
5.67 E-05 \\
2.36 E-04 \\
\end{array}$ \\
\hline & & & & & Total & $1.39 \mathrm{E}-03$ \\
\hline $9 \mathrm{~F}$ & 76 to 86 & $1.00 \mathrm{E}-07$ & $\begin{array}{ll}\mathrm{RC} & 9.04 \\
\mathrm{RC} & 8.01 \\
\mathrm{RC} & 7.02 \\
\mathrm{RC} & 7.04 \\
\mathrm{RC} & 6.02 \\
\mathrm{RC} & 6.04 \\
\end{array}$ & $\begin{array}{l}7.29 E-01 \\
2.07 E-01 \\
4.41 E-02 \\
1.30 E-02 \\
2.47 E-03 \\
2.42 E-03\end{array}$ & $\begin{array}{l}5.05 E+03 \\
3.40 E+04 \\
4.27 E+05 \\
4.27 E+05 \\
1.40 E+06 \\
8.73 E+06\end{array}$ & $\begin{array}{l}3.69 E-04 \\
8.42 E-04 \\
1.89 E-04 \\
5.56 E-04 \\
3.47 E-05 \\
2.12 E-04 \\
\end{array}$ \\
\hline & & & & & Total & $2.20 \mathrm{E}-03$ \\
\hline \multicolumn{7}{|c|}{$\begin{array}{l}\text { (a) Cut set numbers are provided in Appendix E. } \\
\text { (b) Duke Power Co. } 1990 \text {. } \\
\text { (c) Product of PDS frequency, release category }\end{array}$} \\
\hline
\end{tabular}


TBX (52.6\%)

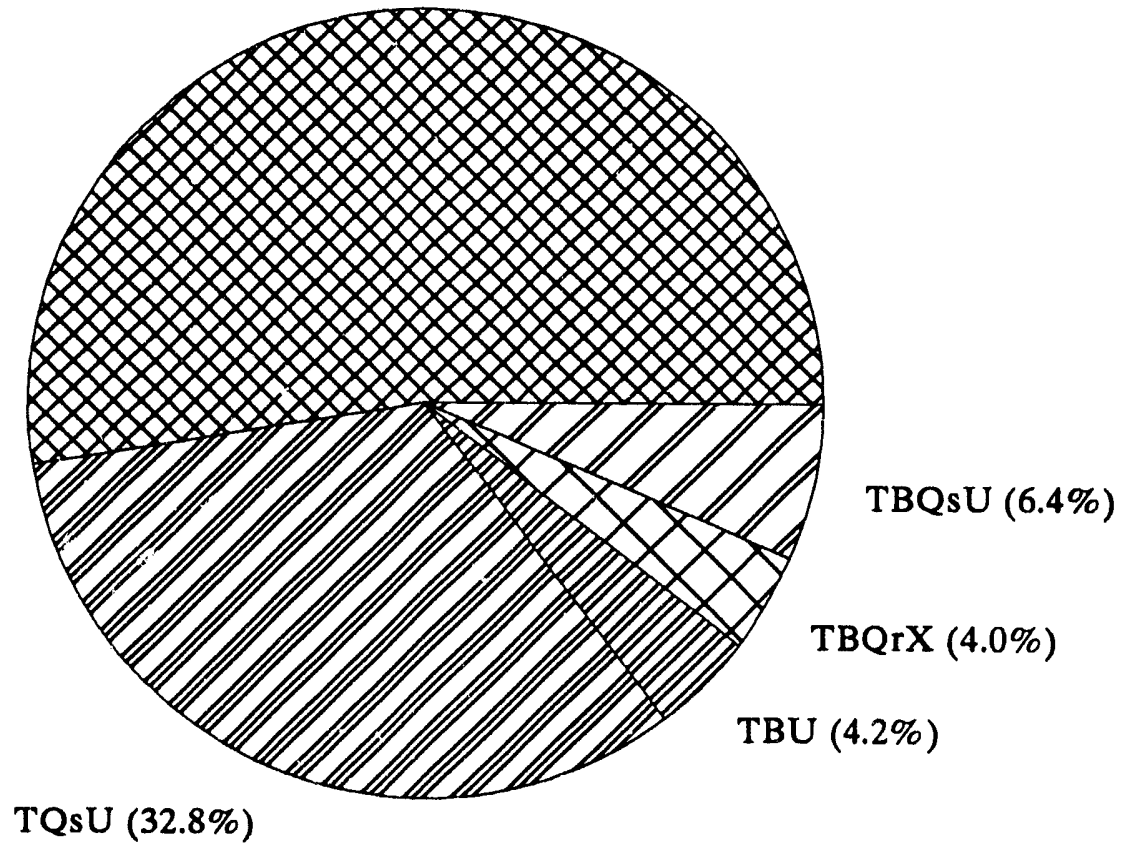

FIGURE 4.4-2. Pie Chart Illustrating Relative Contributions of Affected Accident Sequences to Affected Public Risk 


\subsection{EXTERNAL EVENTS}

This section contains an evaluation of evaluates the effects of HVAC and room cooling failures on the core damage frequency (CDF) resulting from events such as earthquakes, fires, and floods, referred to as "external events." The principal sources of information for this analysis were the detailed external events analyses in NUREG/CR-4550, Volumes 3 and 4 (Bohn et al. 1990; Lambright et al. 1990). These documents provided detailed assessments of plant CDFs arising from external events. Additional key information sources included the Oconee IPE (Duke Power Co. 1990) and the Surry IPE (VEPCO 1990). The material in this section identifies and quantifies the external event accident sequences involving failures of HVAC and room cooling systems.

The approach used by Bohn et al. and Lambright et al. consisted of three major activities. The first was a comprehensive external event screening process in which negligible contributors to external event CDF were el iminated from further analysis. The screening analyses performed by Bohn and Lambright eliminated all external events except seismic events and fires. Thus, the affected CDF from seismic events and fires are examined in detail in this section. For completeness, analyses of the affected CDF due to floods and tornadoes were also performed. The affected seismic CDF calculations are presented in Section 5.1, and the affected fire CDF calculations are presented in Section 5.2. Floods are addressed in Section 5.3; Section 5.4 addresses tornadoes. The total affected CDF and public risk estimates resulting from external events are discussed in Section 5.5.

\subsection{ASSESSMENT OF AFFECTED CDF DUE TO SEISMIC EVENTS}

Bohn et al. (1990) and Lambright et al. (1990) provided detailed seismic risk assessments for a W PWR and GE 8WR, respectively. The major steps in the seismic risk assessment included

- Seismic Hazard Characterization - development of seismic hazard curves for the plant site.

- Initiating Events and Event Trees - event trees developed for internal events analyses to model the progression of seismic accident sequences from initiating event through core damage. The analys is included LOCAs (small, medium, large, and reactor vessel ruptures), transients with the power conversion system (PCS) unavailable, and transients with the PCS initially available.

- Fault Trees - fault trees developed for the internal events analyses with modifications to incorporate basic events for seismic failure modes. 
- Component and Structure Failure Descriptions - development of component and structure fragility functions which define and quantify vulnerabilities to seismic-induced failures. Generic and plant-specific fragility functions were utilized.

- Seismic Response of Structures and Components - estimated building and component responses to seismic events. The effects of local geology and component/building design details were included in the analysis.

- Probabilistic Failure and Core Damage Calculations - the frequencies of cut sets and accident sequences calculated using the information deve1oped in the previous steps. Uncertainty analyses were also performed.

The approach used in this study to estimate the affected seismic CDF due to HVAC and room cooler failures is described in the next subsection.

\subsubsection{Approach to Calculation of Seismic-Induced HVAC and Room Cooler Failures}

The approach that was used to calculate the affected portion of the seismic event CDF was to incorporate seismic-induced HVAC and room cooler failures into the Boolean expressions for each seismic accident sequence. It was observed that air handling units (AHUS), fans, and room coolers were not directly included in the Boolean expressions given by Bohn and Lambright for the seismic accident sequences. In fact, the references indicated that the dominant seismic failure modes for most emergency core cooling system (ECCS) subsystems included failure of suction sources (e.g., condensate storage tank, refueling water storage tank) and loss of $A C$ power due to seismic-induced failures of switchgear. Thus it was necessary to modify the expressions to incorporate HVAC and room cooling functional failures into the Boolean expressions.

Seismic accident sequences consist of a seismic initiating event and the subsequent safety system failures that are necessary to lead to core damage. The frequencies of seismic accident sequences are the product of a seismic initiating event frequency and conditional safety system failure probabilities. This can be written:

$$
\begin{aligned}
& \Phi=\lambda_{\text {seismic }} P_{1} P_{2} \ldots P_{n} \\
& \text { where } \Phi=\text { seismic accident sequence frequency } \\
& \lambda_{\text {seismic }}=\text { seismic initiating event frequency } \\
& P_{n}=\text { failure probability of safety system " } n \text { " given } \\
& \text { occurrence of a seismic event. }
\end{aligned}
$$

In actual practice, $\lambda_{\text {seismic }}$ is a statistical distribution of seismic event frequencies as a function of seismic intensity. The values of $p_{n}$ are a function of the seismic event intensity. This study will used median values for these parameters to perform the CDF calculations. 
The unavailabilities of safety systems following seismic events were assumed to be dominated by single failures. This assumption is appropriate for single-train systems and single trains of redundant systems, but not for a multiple-train redundant system that may be dominated by seismic-induced common-cause failures. Therefore, for a single train, all individual components are assumed connected in series (i.e., the system fault tree contains only OR gates). It was also assumed that the failure probabilities are all small enough that the arithmetic sum of the failure probabilities is a good approximation to their Boolean sum. Therefore, for single train systems, the unavailability is approximately the sum of the failure probabilities of individual components in that system. That is, the unavailability of one train of high pressure injection (HPI) is the sum of the failure probabilities of the HPI pump, various HPI valves, motor control center (MCC), actuation circuitry, etc. This can be written as

$$
P_{f} \text { (safety system) } \approx \sum_{i} P_{f, i}
$$

where $i$ denotes individual safety system components.

To illustrate this assumption, the auxiliary feedwater (AFW) system at the representative W PWR was observed to include the following individual components or categories of components: switchgear, MCC, pump, valves, pipes, room cooler, and condensate storage tank (CST) (suction source). The above formula can be rewritten:

$$
\begin{gathered}
P_{f}(1 \text { train }) \approx P_{f} \text { (switchgear) }+P_{f}(M C C)+P_{f} \text { (pump) }+P_{f} \text { (valve) } \\
+P_{f}(\text { room cooler })+P_{f}(C S T)
\end{gathered}
$$

This formula forms the basis for modifications to the conditional probabilities of safety system failures given a seismic event.

Component-level fragility data were used to separate the HVAC-related seismic CDF from the total seismic CDF. The median fragility values for individual components represent the median seismic acceleration $(\mathrm{g})$ required to fail the component. The failure probability of a given component is a function of its median fragility value, as fo'lows:

$$
\begin{aligned}
& P_{f, i}=f\left(m_{f, i}\right) \\
& \text { where } P_{f, i}^{\prime}=\text { failure probability of component } i \\
& m_{f, i}=\text { median fragility for component } i
\end{aligned}
$$

Combining the previous equations, the failure probability of a single train is a function of the median fragility values of the components in that system:

$$
\begin{aligned}
P_{f}(1 \text { train }) \approx & f\left[m_{f} \text { (switchgear) }\right]+f\left[m_{f}(M C C)\right]+f\left[m_{f}(\text { pump })\right]+ \\
& f\left[m_{f}(\text { valve })\right]+f\left[m_{f}(\text { room cooler })\right]+f\left[m_{f}(C S T)\right] .
\end{aligned}
$$


Substituting these expressions into the expression for seismic sequence frequency produces the following formula:

$$
\begin{aligned}
& \Phi=\lambda_{\text {seismic }} P_{1} P_{2} \ldots P_{n} \\
& =\lambda_{\text {seismic }} P_{f}\left(1 \text { train) } P_{i} \ldots P_{n}\right.
\end{aligned}
$$

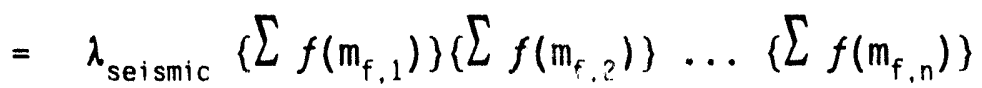

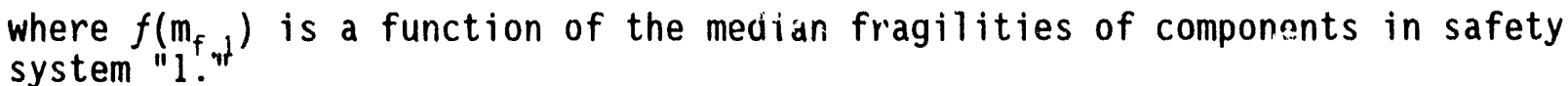

The affected portion of a seismic accident sequence that contains HVAC/ room cooler failures was approximated using the ratio of the seismic failure probabilities of HVAC components to the sum of the seismic failure probabilities of all components in the safety system. That is,

$$
R_{\text {affected }}=\left[P_{f}(1 \text { train })-P_{f}(\text { train } w / 0 H V A C)\right] / P_{f}(1 \text { train })
$$

where $R_{\text {affected }}$ is the affected portion of the conditional failure probability of a safety system that is attributable to seismic-induced failure of HVAC equipment. Therefore,

$$
\begin{aligned}
\Phi_{\text {affected }} & =\lambda_{\text {seismic }}\left(R_{1, \text { affected }} P_{1}\right) \ldots\left(R_{n, \text { affected }} P_{n}\right) \\
& =\lambda_{\text {seismic }}\left(P_{1} \ldots P_{n}\right)\left(R_{1, \text { affected }} \ldots R_{n, \text { affected }}\right) \\
& =\Phi_{\text {original }}\left(R_{1, \text { affected }} \ldots R_{n, \text { affected }}\right)
\end{aligned}
$$

The affected frequency is therefore the original frequency times an adjustment factor, $R$, which is represented by the ratio of HVAC failure probabilities to the failure probability of the safety system supported by HVAC.

Use of the above formula requires the seismic failure probabilities of each individual component in a safety system. The seismic failure probabilities were previously shown to be a function of the median fragility values. Median fragility values given by Bohn and Lambright were used. Table 5.1-1 presents the median fragility values for each type of component considered in this analysis.

Seismic failure probabilities for specific components are functions of the component fragility, structural response, and corresponding random variabilities. The formula given by Bohn for calculating seismic failure probabilities is shown below:

$$
\begin{aligned}
& P_{f}=F\left\{\left[\ln \left(m_{R} / m_{f}\right)\right] /\left[\left(\beta_{F R}^{2}+\beta_{R R}^{2}\right)^{0.5}\right]\right\} \\
& \text { where } P_{f} \quad=\text { seismic failure probability } \\
& \mathrm{F}^{\mathrm{f}} \quad=\text { standard normal cumulative distribution function } \\
& \mathrm{m}_{r}, \mathrm{~m}_{\mathrm{f}}=\text { medians of response and fragility } \\
& \beta_{F R}^{r}, \beta_{R R}=\text { corresponding random variabilities. }
\end{aligned}
$$


IABLE 5.1-1. Median Fragility and Response Values Used in Analysis ${ }^{(a)}$

\begin{tabular}{|c|c|c|}
\hline Component & $\begin{array}{c}\text { Median } \\
\text { Fragility }\end{array}$ & $\begin{array}{c}\text { Median }^{(\mathrm{b})} \\
\text { Response }^{(\mathrm{s})}\end{array}$ \\
\hline Switchgear & 21.33 & 0.48 \\
\hline Pump & 3.19 & 0.52 \\
\hline Valve 1 & 12.5 & 0.52 \\
\hline Room Cooler & 4.42 & 0.52 \\
\hline Motor control centers (MCCS) & 7.63 & 0.48 \\
\hline Condensate storage tank (CST) & 0.45 & 0.40 \\
\hline Refueling water storage tank (RWST) & 0.46 & 0.40 \\
\hline Air handling unit (AHU) & 6.9 & 0.52 \\
\hline Power-operated relief valve (PORV) & 8.9 & 0.32 \\
\hline \multicolumn{3}{|c|}{$\begin{array}{l}\text { (a) Sources: Bohn et al. (1990) and Lambright et al. (1990). } \\
\text { (b) Median response values for the approximate locations of } \\
\text { these components were taken from Bohn et al. PORVs were } \\
\text { assumed to be located in the Reactor Building at the } 27-\mathrm{ft} \\
\text { elevation, the CST and RWST in the outdoor yard, MCCs and } \\
\text { switchgear in the Auxiliary Building at the } 17 \text { - } \mathrm{ft} \\
\text { elevation, and all other components were assumed to be } \\
\text { located on the ground floor of the Auxiliary Building. } \\
\text { Response values for a } 0.4 \mathrm{~g} \text { seismic event are provided in } \\
\text { the Table. }\end{array}$} \\
\hline
\end{tabular}

The cumulative normal distribution for " $x$ " with mean $\mu$ and standard deviation $\sigma$ is

$$
F(x)=\int_{-\infty}^{x}\left\{\left[1 /(2 \pi \sigma)^{0.5}\right] \exp \left\{-0.5[(x-\mu) / \sigma]^{2}\right\}\right\} d x
$$

In this case,

$$
x=\ln \left(m_{r} / m_{f}\right) /\left[\left(\beta_{F R}^{2}+\beta_{R R}^{2}\right)^{0.5}\right]
$$

The preceding formulae provide expressions for the failure probability $\left(P_{f}\right)$ of a component as a function of its median fragility $\left(m_{f}\right)$ and median response $\left(m_{r}\right)$ values. This appears to be realistic in that the failure probability increases with decreasing median fragilities (i.e., the higher the fragility value, the lower the failure probability given a seismic event). Components with low values of $m_{f}$ are more likely to fail given a seismic 
event. Based on these observations and the formula given above, the failure probabilities for safety systems are related to the median fragilities of the components composing that system using the following formula:

$$
P_{f} \text { (safety system) } \propto \sum_{i} F\left(x_{i}\right)
$$

where $i=$ variable representing components of the safety system

Combining this equation with the expression for $R_{\text {affected }}$ produces the following formula:

$$
\begin{aligned}
R_{\text {affected }} & =\left(P_{f, \text { safety system }}-P_{f, \text { safety system w/o HVAC }}\right) / P_{f, \text { safety system }} \\
& =\left[\sum_{i} F\left(x_{i}\right)-\sum_{i} F\left(x_{i, w / O H V A C}\right)\right] / \sum_{j} F\left(x_{j}\right)
\end{aligned}
$$

This expression can be substituted into the expression for the affected seismic sequence frequency, as follows:

$$
\begin{aligned}
\Phi_{\text {affected }} & =\Phi_{\text {original }}\left(R_{1, \text { affected }} \cdots R_{n, \text { affected }}\right) \\
& =\Phi_{\text {original }}\left\{\left[\sum_{i} F\left(x_{i}\right)-\sum_{i} F\left(x_{i, w / O H V A C}\right)\right] / \sum_{i} F\left(x_{i}\right)\right\}
\end{aligned}
$$

This equation was used to estimate the affected portion of a given seismic accident sequence that could contain HVAC-related failures. This formula is applicable to core damage sequences that involve only one safety system failure. For core damage sequences that involve two or more safety system failures, additional values of $R$ are calculated for each safety system. Then, all values of $R_{n}$ are multiplied together to obtain $R_{\text {affected }}$ for that particular sequence. "This formula is analogous to the nonseismic failure probabilities of safety systems (at least individual trains of a given safety system) in which a first-order approximation of the unavailability of a given train of an ESF system can be approximated by the sum of the unavailabilities of all components in that train of the safety system.

The affected seismic CDF calculations are complicated by the fact that most of the safety-related equipment served by HVAC and room cooler systems is likely to fail given a seismic event that fails the HVAC/room cooler components. To illustrate this, assume that a severe seismic event occurs, resulting in a demand for HPI. There are three possible scenarios:

- The seismic event directly fails the HPI system (pump, motor, valve, pipe failure, etc.) but not the HPI room cooler.

- The seismic event directly fails both the HPI system components and the HPI room cooler.

- The seismic event fails the HPI room cooler but leaves the HPI system intact. 
All three scenarios are assumed to be addressed in the system failure probability model described previously. The third scenario, the only one of interest to this study, fails the HPI room cooler, resulting in heatup of the HPI pump room. The first two scenarios directly fail the HPI function; failure to start and run the HPI system successfully is independent of the operability status of the HPI room cooler. Since the median fragilities of room coolers and AHUS are somewhat larger than fragilities for pumps and switchgear needed to provide the HPI function, and since time would be available in the third scenario to restore some form of HPI room cooling, the failure probability associated with the third scenario will be smaller than the failure probabilities associated with the first two scenarios in which the HPI function is directly affected.

The method for quantifying the seismic-induced safety system failure probabilities due to HVAC and room cooler equipment failures was to develop a multiplication factor to be applied to the safety system failure probabilities. This factor, defined as $Z$, is incorporated into the expression for the affected CDF as follows:

$$
\Phi_{\text {affected }}=\Phi_{\text {original }} Z R_{\text {affected }}
$$

The value for the factor $Z$ is related to the probabilities of component failures given a seismic event, and thus is a function of the median fragilities of HVAC/room cooler components relative to the median fragilities of the more seismic-sensitive components of the ESF systems. An approximation for the value of $Z$ would be the ratio of the failure probabilities of HVAC/room cooler components to the failure probability of the safety system. Therefore,

$$
\begin{aligned}
Z & =P_{f, H V A C} / P_{f, \text { safety system }} \\
& \left.=F\left(x_{\text {HVAC }}\right) / \sum_{j} F\left(x_{i}\right)\right] .
\end{aligned}
$$

Median fragilities and median response values for the safety system components were used to estimate $Z$ (see Table 5.1-1). This factor represents the fraction of safety system failures that are attributable to seismic-induced failures of HVAC/room cooling components only. This factor is expected to be a small value because, according to the fragility data, the probability that a tank will fail given a seismic event is much larger than the probability of a room cooler or HVAC failure. Therefore, all conditions being equal, it is not likely that a given seismic event will fail a room cooler and not fail a pump or other safety system compcnent.

The value of $Z$ was computed by substituting into the equation the values of $m_{f}$ and $m_{r}$ for the various components and solving for $Z$, as follows:

$$
\begin{aligned}
Z= & \left.F\left(x_{H V A C}\right) / \sum_{i} F\left(x_{i}\right)\right] \\
= & F\left(x_{H V A C}\right) /\left[F\left(x_{\text {switchgear }}\right)+F\left(x_{\text {pump }}\right)+F\left(x_{\text {valve }}\right)+F\left(x_{\text {HVAC }}\right)\right. \\
& \left.+F\left(x_{M C C}\right)+F\left(x_{\text {tank }}\right)\right]
\end{aligned}
$$




$$
\begin{aligned}
= & F(-3.74) /[F(-1.91)+F(-3.83)+4 * F(-3.32)+F(-3.74) \\
& +F(-3.09)+F(-0.32) .
\end{aligned}
$$

The value of 4 in the above formula accounts for the four different valves in the HPI system that must be open to allow coolant injection into the reactor vessel. Lookup tables were used to determine the appropriate values of the cumulative normal distribution function, $F$. For negative values, the value of $F(-x)$ equals $1-F(x)$. The value of $Z$ was calculated to be 0.002 . Therefore, it was estimated that approximately $0.2 \%$ of the HVAC contribution to safety system failure probabilities are due to failures of the room coolers themselves in seismic events that do not fail the safety system directly. This value rias multiplied by the HVAC/room cooler contribution to safety system failure probabilities from seismic events to calculate the contributions from seismic-induced HVAC/room cooler failures to the total original seismic CDF.

Because the value of $Z$ is so small, it appears that the affected seismic CDF will be insignificant relative to the other external and internal event CDF values. Therefore, this factor will not be used in further calculations, because it tends to overstate the CDF and public risks associated with seismic-induced HVAC system failures.

\subsubsection{Affected Seismic CDF Calculations for a Representative $W$ PWR}

The approach and observations discussed above were applied to the seismic accident sequence frequency calculations presented by Bohn et al. (1990). Descriptions of the important accident sequences and the CDF calculations performed in this study to estimate the contributions of HVAC and room cooler systems to seismic CDF at a W PWR are presented in this section. The results are summarized in Table 5.1-2 and illustrated in Figure 5.1-1.

There is substantial uncertainty in the affected CDF presented in Table 5.1-2, much of which results from the inability to directly calculate the HVAC failure contributions from the original cut sets developed by Bohn et al. (1990). Another source of uncertainty is the simplified approach taken here to compute the fractional contributions of seismic-induced HVAC failures to safety system failure probabilities. However, the approach taken here models ESF dependencies on HVAC functions, and even though the approach is not complex nor as rigorous as the approach taken by Bohn et al. (1990), the results are believed to reasonably approximate the contributions of HVAC failures to seismic CDF.

Regardless of the uncertainty, the data indicate that HVAC equipment is less vulnerable to seismic-induced failures than many other components. Based on the fragility data in Table 5.1-1, AHUs are less sensitive to seismic events than water storage tanks, pumps, and electrical switchgear. Therefore, 
IABLE 5.1-2. Summary of Affected Seismic CDF for a Representative PWR

\begin{tabular}{|l|l|l|l|}
\hline Sequence & $\begin{array}{c}\text { Original } \\
\operatorname{CDF}^{(a)}\end{array}$ & $\begin{array}{c}\text { HVAC } \\
\text { Fraction }\end{array}$ & $\begin{array}{c}\text { Affected } \\
\text { CDF, per RY }\end{array}$ \\
\hline T1-6 & $5.12 \mathrm{E}-05$ & $5.11 \mathrm{E}-04$ & $2.61 \mathrm{E}-08$ \\
T1-5 & $7.19 \mathrm{E}-06$ & $2.64 \mathrm{E}-04$ & $1.90 \mathrm{E}-09$ \\
$\mathrm{~T} 1-1$ & $2.50 \mathrm{E}-05$ & $5.11 \mathrm{E}-04$ & $1.28 \mathrm{E}-08$ \\
T3-1 & $4.55 \mathrm{E}-06$ & $5.11 \mathrm{E}-04$ & $2.32 \mathrm{E}-09$ \\
SLOCA-7 & $8.08 \mathrm{E}-06$ & $2.11 \mathrm{E}-03$ & $1.71 \mathrm{E}-08$ \\
ALOCA-3 & $4.67 \mathrm{E}-06$ & $2.11 \mathrm{E}-03$ & $9.88 \mathrm{E}-09$ \\
RVR & $3.17 \mathrm{E}-06$ & 0.0 & 0.0 \\
MLOCA-4 & $1.82 \mathrm{E}-06$ & $2.11 \mathrm{E}-03$ & $3.85 \mathrm{E}-09$ \\
ALOCA-2 & $4.35 \mathrm{E}-06$ & $2.11 \mathrm{E}-03$ & $9.20 \mathrm{E}-09$ \\
T3-6 & $2.05 \mathrm{E}-06$ & $5.11 \mathrm{E}-04$ & $1.05 \mathrm{E}-09$ \\
\hline TOTAL & $1.12 \mathrm{E}-04$ & \multicolumn{3}{|l}{$8.42 \mathrm{E}-08$} \\
\hline (a) Based on the CDF calculated using the LLNL hazard \\
(b) Purves.
\end{tabular}

$\mathrm{T} 1(48.5 \%)$

T3 $(4.0 \%)$

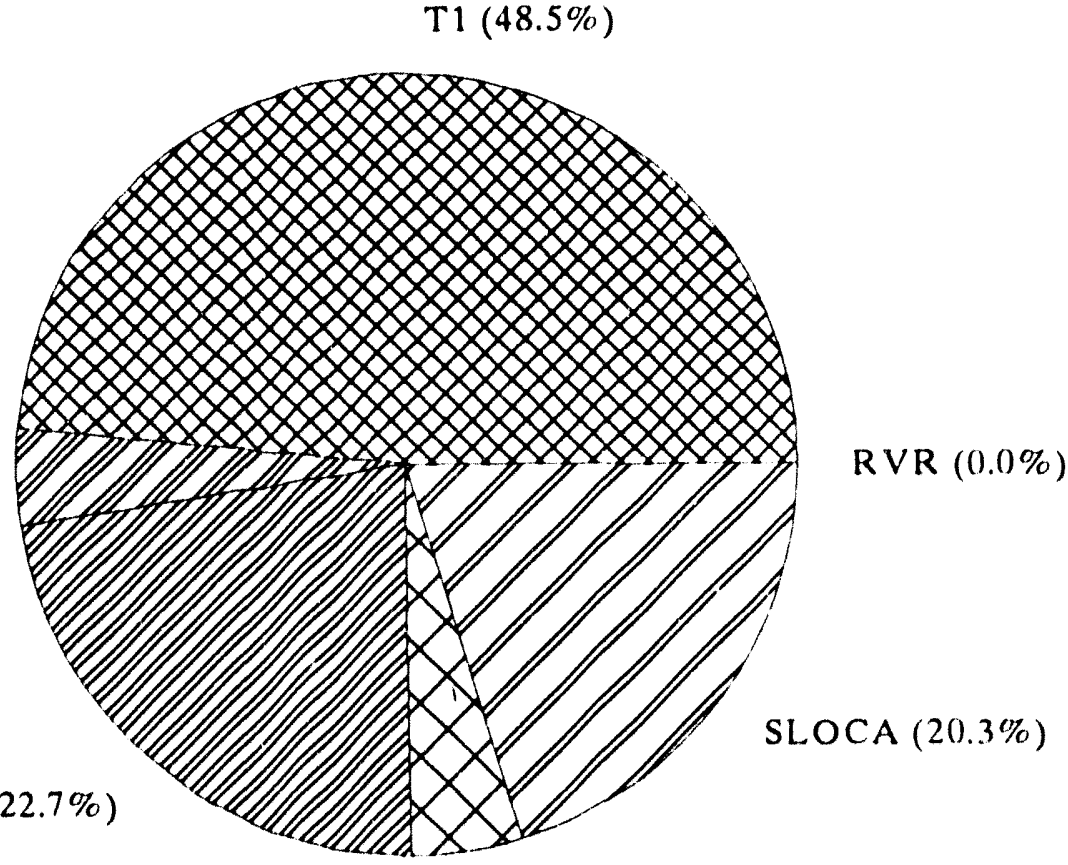

MLOCA $(4.6 \%)$

FIGURE 5.1-1. Affected Seismic CDF by Initiator for a W PWR 
the latter components are more likely to cause ESF malfunctions or fallures in seismic events than are HVAC components. As was observed for internal events, HVAC failures may not result in a sudden loss of ESF function following a seismic event. Rather, time is available to restore HVAC capabilities following their loss in a seismic event. Failures of other equipment in ESF systems are more likely to cause loss of an ESF function than failure of HVAC equipment. Therefore, it is expected that a large fraction of the dominant cut sets in a seismic analysis will not contain HVAC fallures. This is borne out by the results in Table 5.1-1, which indicate the affected CDF is about $0.2 \%$ of the original seismic CDF calculated by Bohn et al. (1990).

The rest of this section describes the seismic accident sequences and quantifies the HVAC/room cooler contribution to each sequence.

\subsubsection{Sequence $I_{1}-6$}

This is a loss of offsite power (LOOP) sequence in which both AFW and HPI systems fail. AFW failure is dominated by failure of the CST, which is not directly related to failure of HVAC and room cooler systems. HPI failure is dominated by failure of the RWST or loss of emergency AC power. The failure of emergency $A C$ power is dominated by failure of the switchgear (seismicinduced failures of anchorages), or failure of diesel generators to start given a seismic event. There were no important instances of HVAC and room cooler failures in this sequence.

The affected CDF calculations for this sequence incorporated room cooler failures into the expression for the HPI and AFW failures. Based on the formula given previously, the probability of seismic failure of the HPI system is a function of the median fragilities of the components in the HPI system. The HPI system was assumed to consist of switchgear, pumps, valves, the RWST, and the HVAC system (represented by the AHU fragility value given in Table 5.1-1). The affected portion of the T,6 sequence frequency attributable to the HPIrelated HVAC/room cooler failures was calculated as follows:

$$
\Phi_{\text {affected }}=\Phi_{\text {original }} R_{\text {affected,AFW }} R_{\text {affected,HPI }} \text {. }
$$

The original sequence frequency, $\Phi_{\text {ociginal }}$ was $5.12 E-05 / R Y$. The factor $Z$ was not incorporated into the formula. "The value of $R_{\text {affected,AFW }}$ was calculated as follows:

$$
R_{\text {affected,AfW }}=(A-B) / A
$$

where $A=$ Failure probability of AFW including $H V A C$

$B=$ Failure probability of AFW not including HVAC.

The value of $A$ in the above formula was calculated to be

$$
\begin{aligned}
A_{A F W}= & F\left(x_{\text {switchgear }}\right)+F\left(x_{\text {pump }}\right)+F\left(x_{\text {valve }}\right)+F\left(x_{H V A C}\right)+F\left(x_{\text {MCC }}\right) \\
& +F\left(x_{C S T}\right) \\
= & 0.4050
\end{aligned}
$$


Similarly, the value of $B$ was calculated as follows:

$$
\begin{aligned}
B_{\text {AFW }} & \left.=F\left(x_{\text {switchgear }}\right)+F\left(x_{\text {pump }}\right)+F\left(x_{\text {valve }}\right)+F\left(x_{\text {MCC }}\right)\right]+F\left(x_{\text {CST }}\right) \\
& =0.4049
\end{aligned}
$$

The value of $R_{a f f e c t e d, A F W}$ is then:

$$
\begin{aligned}
R_{\text {affected,AFW }} & =(0.4050-0.4049) / 0.4050 \\
& =2.47 \mathrm{E}-04 .
\end{aligned}
$$

Standard lookup tables were used to evaluate the values of the cumulative normal distribution. Excess significant figures are retained for calculation purposes.

The values of $A$ and $B$ for the HPI system were calculated after making appropriate adjustments to reflect the HPI system design differences from the AFW system. The values of $A_{H P 1}$ and $B_{H P I}$ were calculated to be 0.3792 and 0.3791 , respectively. Using these values, $R_{\text {affected,HPI }}$ was calculated to be $2.64 \mathrm{E}-04$.

The value of $R_{\text {affacted }}$ for this sequence is the combination of $R_{A F W}$ and $R_{H P I}$. The sequence value of $R_{\text {affected }}$ was calculated as follows:

$$
\begin{aligned}
R_{\text {affected }} & =\left\{\left(A_{A F W} A_{H P I}\right)-\left(B_{A F W} B_{H P I}\right)\right\} /\left(A_{A F W} A_{H P I}\right) \\
& =[(0.4050 * 0.3792-(0.4049 * 0.3791)] /(0.4050 * 0.3792) \\
& =5.11 E-04 .
\end{aligned}
$$

This value reflects the fraction of the frequency of seismic sequence $T_{1}-6$ that includes seismic-induced HVAC/room cooler failures.

Based on the preceding discussion, the affected frequency for the $T_{1} 6$ seismic sequence was calculated to be

$$
\begin{aligned}
\Phi_{\text {affected }} & =\Phi_{\text {original }} * R_{\text {affected }} \\
& =5.12 E-05 * 5.11 \mathrm{E}-04 \\
& =2.6 \mathrm{E}-08 / \mathrm{RY} .
\end{aligned}
$$

\subsubsection{Sequence $T_{1}=1$}

This sequence involves a LOOP sequence leading to a loss of reactor coolant pump (RCP) seal cooling and subsequent RCP seal loss of coolant accident (LOCA). In this sequence, the AFW system is successful but the HPI and condenser circulating water (CCW) systems fail, leading to a loss of RCP seal cooling. The dominant failure causes for these systems are due to failure of the RWST and failure of the emergency onsite power system. Assuming that the 
CCW system is roughly simflar to the HPI system (1.e., switchgear, pumps, valves, etc.), the affected portion of the CDF was calculated using the same fraction that was calculated for sequence $T_{1}-6$ (1.e., 5.11E-04). Therefore, the affected CDF was calculated to be $(5.11 \mathrm{E}-04 * 2.50 \mathrm{E}-05)=1.3 \mathrm{E}-08 / \mathrm{RY}$.

\subsubsection{Sequence $\mathrm{T}_{3}=1$}

This sequence is identical to sequence $T_{1}-1$ except that there is no LOOP; i.e., the transient is caused by some other failure leading to plant shutdown. The most important contributing event to this sequence is a loss of the 4.16-kV emergency switchgsar, leading to a loss of emergency power. The affected portion of the CDP was calculated using the same fraction that was calculated for sequence $\left.T_{1}-1\right)$. Therefore, the affected CDF was calculated to be $(5.11 \mathrm{E}-04 * 4.55 \mathrm{E}-06)=2.3 \mathrm{E}-09 / \mathrm{RY}$.

\subsubsection{Sequence SLOCA-7}

This sequence is a small LOCA followed by failure of the HPI system. The predominant causes of HPI failure are failure of the RWST or of onsite power sources.

The fraction of the original CDF that includes HPI failures is different than the previous sequences, because only one affected ESF system is involved: the HPI system. Previously, two ESF systems were modeled, including the HPI and AFW systems or the HPI and CCW systems. The affected fraction, therefore, was calculated using only the failure probabilities of the HPI system components. The resulting fraction was calculated to be $2.11 \mathrm{E}-03$. Therefore, the affected portion of this accident sequence was calculated to be $(2.11 \mathrm{E}-03$ * $8.08 \mathrm{E}-06)=1.7 \mathrm{E}-08 / \mathrm{RY}$.

\section{1 .2 .5 Sequence $T_{1}-5$}

This is the fifth most important sequence given by Bohn et al. (1990). This sequence is initiated by LOOP, followed by failure of the AFW system and feed-and-bleed cooling. Feed-and-bleed cooling fails primarily due to failure of PORVs and their associated block valves. The affected portion of this sequence was then determined by incorporating PORV seismic failure probabilities into the equation used to calculate the fraction due to AFW failures. The resulting fraction was calculated to be 2.64E-04. This fraction is smaller than the others because PORV operation is not directly affected by HVAC system failures. Therefore, the affected accident sequence frequency was calculated to be $(2.64 \mathrm{E}-04 * 7.19 \mathrm{E}-06)=1.9 \mathrm{E}-09 / \mathrm{RY}$.

\subsubsection{Sequence $\mathrm{T}_{3}-6$}

This sequence is the same as sequence $T_{1}-6$ except that offsite power is initially available. Subsequent ESF failures include AFW and HPI systems, which are caused primarily by failure of the water sources (CST and RWST, 
respectively). Therefore, the affected portion of this sequence was calculated using the fraction of the original CDF that was calculated for sequence $T_{1}-6$. Thus, the affected CDF for sequence $T_{3}-6$ is $(5.11 \mathrm{E}-04 * 2.05 \mathrm{E}-06)=$ $1.1 \mathrm{E}-09 / \mathrm{RY}$.

\subsubsection{Sequences ALOCA-3 and ALOCA-2}

These sequences are initiated by a large LOCA. In the former sequence, the accumulators function properly, but the LPI systeri fails due primarily to AC power failures. In ALOCA-2, the accumulators and LPI function properly, but core damage results from failure of long-term low-pressure injection (LPI). In bath sequences, the affected portion was calculated assuming that only one ESF system contributes to the core damage sequence (see SLOCA-7). Therefore, the affected portion of sequence ALOCA-3 was calculated to be

$$
(2.11 \mathrm{E}-03 * 4.67 \mathrm{E}-06)=9.9 \mathrm{E}-09 / \mathrm{RY}
$$

and for ALOCA-2 was calculated to be

$$
(2.11 E-03 * 4.35 E-06)=9.2 E-09 / R Y \text {. }
$$

\subsubsection{Sequence RVR}

The reactior vessel rupture (RVR) sequence is dominated by failures of the RCP and steam generator (SG) supports. No additional safety system failures are necessary to cause core damage. HVAC and room cooling functions are not required for RCP and SG support integrity. Therefore, there is no affected portion of this sequence; i.e., the affected $C D F=0$.

\subsubsection{Sequence MLOCA-4}

This is a medium LOCA sequence that occurs primarily due to failure of the HPI system. HPI failures are dominated by the loss of power and failure of the RWST, similar to sequence ALOCA-2. Therefore, the affected CDF was calculated to be $(2.11 \mathrm{E}-03 * 1.82 \mathrm{E}-06)=3.9 \mathrm{E}-09 / \mathrm{RY}$.

\subsubsection{Affected Seismic CDF Calculations for a GE BWR}

The approach to calculating the affected CDF due to seismic events that was described in Section 5.1.1 was applied to the results given by Lambright et al. (1990) for a GE BWR. As was observed for the W PWR, component fragility data indicated that HVAC components are less likely to fail given a seismic event than other components of safety-related systems (e.g., pumps, switchgear). In addition, HVAC failures were not mentioned by Lambright et al. (1990) as being dominant contributors to seismic accident sequences.

The results of the affected seismic CDF calculations for a GE BWR that were obtained in this study are presented in Table 5.1-3 and illustrated in Figure 5.1-2. As shown, the affected CDF is about 2.6E-07/RY, which is about 
TABLE 5.1-3. Affected Seisnic CDF for a GE BWR

\begin{tabular}{|l|c|c|c|}
\hline \multicolumn{1}{|c|}{ Sequence } & $\begin{array}{c}\text { Original } \\
\text { CDF }^{(a)}\end{array}$ & $\begin{array}{c}\text { HVAC } \\
\text { Fraction }^{(b)}\end{array}$ & Affected CDF \\
\hline RVR-1 & $8.92 \mathrm{E}-06$ & 0.00 & 0.00 \\
ALOCA-17 & $1.23 \mathrm{E}-07$ & $5.28 \mathrm{E}-04$ & $6.49 \mathrm{E}-11$ \\
ALOCA-30 & $1.84 \mathrm{E}-05$ & $2.64 \mathrm{E}-04$ & $4.86 \mathrm{E}-09$ \\
SILOCA-25 & $2.02 \mathrm{E}-08$ & $5.28 \mathrm{E}-04$ & $1.07 \mathrm{E}-11$ \\
SILOCA-70 & $6.67 \mathrm{E}-06$ & $2.64 \mathrm{E}-04$ & $1.76 \mathrm{E}-09$ \\
SILOCA-80 & $6.72 \mathrm{E}-07$ & $2.64 \mathrm{E}-04$ & $1.77 \mathrm{E}-10$ \\
S2!OCA-2-44 & $2.86 \mathrm{E}-07$ & $7.91 \mathrm{E}-04$ & $2.26 \mathrm{E}-10$ \\
S2LOCA-42 & $1.20 \mathrm{E}-06$ & $5.28 \mathrm{E}-04$ & $6.33 \mathrm{E}-10$ \\
RWT-1 & $2.76 \mathrm{E}-06$ & $5.28 \mathrm{E}-04$ & $1.46 \mathrm{E}-09$ \\
RWT-2 & $2.94 \mathrm{E}-07$ & $5.28 \mathrm{E}-04$ & $1.55 \mathrm{E}-10$ \\
RWT-3 & $6.26 \mathrm{E}-09$ & $5.28-\mathrm{E} 04$ & $3.30 \mathrm{E}-12$ \\
RWT-4 & $6.26 \mathrm{E}-10$ & $5.28 \mathrm{E}-04$ & $3.30 \mathrm{E}-13$ \\
T1-25 & $2.98 \mathrm{E}-07$ & $1.32 \mathrm{E}-03$ & $3.93 \mathrm{E}-10$ \\
T1-32 & $1.18 \mathrm{E}-10$ & $7.91 \mathrm{E}-04$ & $9.34 \mathrm{E}-14$ \\
T1-33 & $3.69 \mathrm{E}-05$ & $2.64 \mathrm{E}-04$ & $9.74 \mathrm{E}-09$ \\
T1-36/S2-41 & $2.86 \mathrm{E}-08$ & $1.32 \mathrm{E}-03$ & $3.77 \mathrm{E}-11$ \\
T1-36/S2-42 & $1.11 \mathrm{E}-11$ & $5.28 \mathrm{E}-04$ & $5.86 \mathrm{E}-15$ \\
T1-40/S1-70 & $1.27 \mathrm{E}-10$ & $7.91 \mathrm{E}-04$ & $1.00 \mathrm{E}-13$ \\
T1-40/S1-80 & $5.67 \mathrm{E}-13$ & $2.64 \mathrm{E}-04$ & $1.50 \mathrm{E}-16$ \\
T1-43/AL0-30 & $2.53 \mathrm{E}-07$ & $5.28 \mathrm{E}-04$ & $1.33 \mathrm{E}-10$ \\
T3A-1/T2-29 & $1.45 \mathrm{E}-09$ & $5.28 \mathrm{E}-04$ & $7.65 \mathrm{E}-13$ \\
T3A-1/T2-36 & $4.48 \mathrm{E}-10$ & $5.28 \mathrm{E}-04$ & $2.36 \mathrm{E}-13$ \\
\hline TOTAL & $7.68 \mathrm{E}-06$ & & $1.97 \mathrm{E}-08$ \\
\hline (a) Based on the & CDF calcu1ated using the LLNL hazard curves \\
(b) Product of $\mathrm{R}_{\text {affected }}$ for app1 icable safety systems \\
\hline
\end{tabular}

0.3 to $0.4 \%$ of the original seismic CDF calculated by Lambright et a1. (1990). This is consistent with the $0.2 \%$ value calculated for the W PWR in Section 5.1-3. The following paragraphs discuss the dominant seismic accident sequences listed in Table 5.1-3 and the modifications made to the sequences to separate out the HVAC/room cooler contributions to each sequence.

\subsubsection{Sequence $\mathrm{T}_{1}=33$}

This sequence is a LOOP. Subsequently, onsite power fails; highpressure coolant injection (HPCI) systems initially function successfully (HPCI is steam-driven and independent of AC motive power) but eventually fail due to battery depletion or loss of room cooling. No times were given by Lambright; however, Drouin et al. (1989) estimated that 12 hours without room cooling would cause failure of HPCI at a BWR. Failure temperatures for a 


\section{$\mathrm{T} 1(52.4 \%)$}

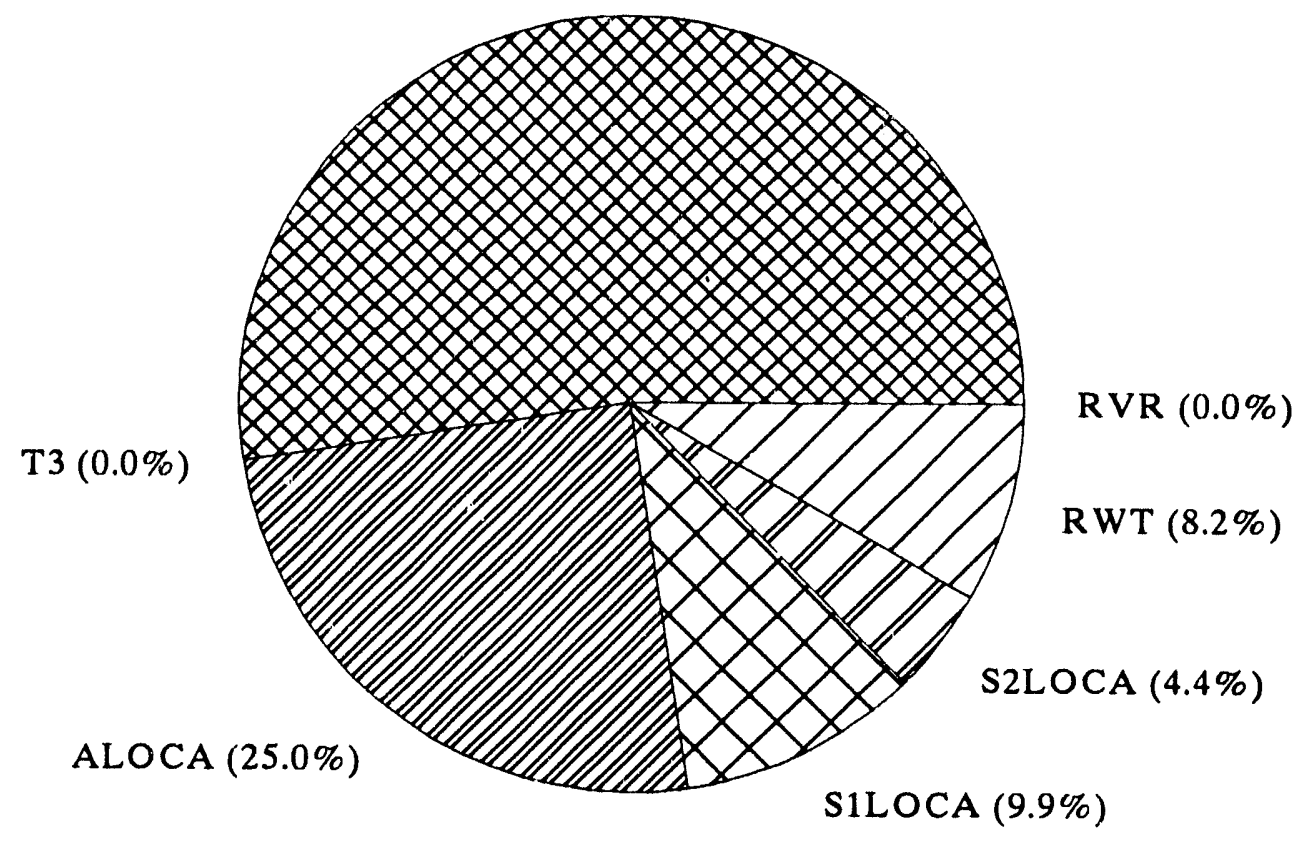

FIGURE 5.1-2. Affected Seismic CDF by Initiator for a GE BWR

steam-driven pump at a PWR were reached in about two hours. Therefore, it appears that at least two hours and as many as 12 hours are available following loss of room cooling for operators to restore room cooling before steamdriven HPCI pumps fail due to extreme room temperatures.

The dominant failures in this sequence involve loss of the emergency service water (ESW) system. ESW is provided to the HPCI room coolers to cool the HPCI pump room and to the emergency diesel generators (EDGs) to remove heat from the engine coolant system (does not remove heat from the EDG room). The fractional contribution of the HPCI room cooler to this sequence, $R_{\text {affected }}$, was calculated to be 2.64E-04. The value of $Z$ was again neglected in this analysis; therefore, the affected CDF for sequence $T_{1}-33$ is $(2.64 \mathrm{E}-04$ * $3.69 \mathrm{E}-05)=9.7 \mathrm{E}-09 / \mathrm{RY}$.

\subsubsection{Sequence ALOCA-30}

This sequence is a large LOCA with simultaneous LOOP and loss of the low pressure coolant injection (LPCI) and low pressure core spray (LPCS) systems. This accident sequence is dominated by failure of the ESW system, which results in failure of the EUGs. Together with the LOOP event, this sequence results in a station blackout (SBO). As such, this sequence is similar to $T_{1}-33$, except for the initiator. Another difference is that room cooler failures are not included in the dominant cut sets. Because the safety system failures are similar to those in sequence $T_{1}-33$, the fractional contribution 
of HVAC/room cooler failures to the sequence frequency is al so approximately the same. Therefore, the affected CDF was calculated to be (2.64E-04 * $1.84 \mathrm{E}-05)=4.9 \mathrm{E}-09 / \mathrm{RY}$.

\subsubsection{Sequence RVR-1}

Sequence RVR-1 consists of a failure of the reactor vessel (RV) supports, which leads to failure of the ECCSs to provide coolant inventory makeup and decay heat removal functions. As with the reactor vessel rupture (RVR) sequence for the W PWR, no additional safety system failures are needed to result in core damage. Since the occurrence of the seismic-induced RV support failures are independent of HVAC and room cooling functions, and no mitigation system failures are required to result in core damage, this sequence will have no HVAC/room cooler contributions. Therefore, the affected CDF is 0.

\subsubsection{Sequence S1 LOCA-70}

This sequence is an intermediate-size LOCA with LOOP. HPCI succeeds to the point at which the RCS has depressurized to a level at which the lowpressure ECCS systems can be used. However, because of the SBO condition, there is no motive power for the LPI systems, resulting in core damage.

As with the previous seismic sequences, the frequency of the S1 LOCA-70 sequence is dominated by failures of the ESW system. Failure of the ESW system eventually results in failure of the HPCI system. LPCI and LPCS systems are dependent upon HPCI, so the low-pressure systems also fail as a result of a loss of ESW. Consequently, the contribution of HVAC and room-cooler-related cut sets to this sequence was calculated using the fraction calculated for sequence $T_{1}-33$. The affected CDF is then $(2.64 \mathrm{E}-04 * 6.67 \mathrm{E}-06)=1.8 \mathrm{E}-09 / \mathrm{RY}$.

\subsubsection{Sequence RWT-1}

Sequence RWT-1 is a transient sequence that results from failure of the Radwaste/Turbine Building at the GE BWR. HPCI and the reactor core isolation cooling (RCIC) high-pressure systems fail as a result of failure to provide actuation and control power to the pumps (SBO).

In this sequence, two separate safety systems must fail to cause core damage. Therefore, the fractional contribution of HVAC/room cooler-related cut sets is different than the fraction calculated previously. In this case, two safety systems dependent upon room cooling systems must fail simultaneously. In this case, the fraction was calculated by multiplying the seismic failure probability for the RCIC system, with room coolers included, by the seismic failure probability of the HPCI system, including the room cooler, and then dividing by the product of the safety system failure probabilities without the room coolers. This fraction represents the fractional contribution of room cooler failures to the failure probabilities of the two independent safety systems. The value of $R_{\text {affected }}$ for this sequence was calculated in the same manner as for previous sequences and, in this case, was calculated to be 5.28E-04. Therefore, the affected CDF for this accident sequence was calculated to be $(5.28 \mathrm{E}-04 * 2.76 \mathrm{E}-06)=1.5 \mathrm{E}-09 / \mathrm{RY}$. 


\subsubsection{Sequence S2 LOCA-42}

This sequence is initiated by a small-break LOCA and LOOP. Additional safety system failures include both HPCI and RCIC as well as failure to depressurize due to seismic-induced failure of the RWT. Because two separate safety systems must fail simultaneously (HPCI and RCIC), the fractional contribution of HVAC and room cooler failures to this sequence was calculated using the fraction calculated for the RWT-1 sequence. Therefore, the affected CDF was calculated to be $(5.28 \mathrm{E}-04 * 1.20 \mathrm{E}-06)=6.3 \mathrm{E}-10 / \mathrm{RY}$.

\subsubsection{Sequence S1 LOCA-80}

The final dominant seismic sequence is S1 LOCA-80, which consists of an intermediate break LOCA in conjunction with LOOP, failure of HPCI, and failure to depressurize the RCS. The dominant cut sets causing failure of the HPCI and depressurization system include seismic-induced failure of the Radwaste/ Turbine Building. HVAC and room cooler systems are not related to the seismic-induced failure of the Radwaste/Turbine Building. Therefore, HVAC and room cooler failures only appear in nondominant cut sets. Because there is only one HVAC-dependent ESF function (HPCI) in these cut sets, the fractional contribution of HVAC and room cooler failures to this sequence is the same as for sequence $T_{1}-33$, or 2.64E-04. The affected CDF for this sequence is therefore $\left(2.64 \mathrm{E}-04^{1} * 6.72 \mathrm{E}-07\right)=1.8 \mathrm{E}-10 / \mathrm{RY}$.

\subsection{ASSESSMENT OF AFFECTED CDF DUE TO INTERNAL FIRES}

The objective of this section is to develop estimates of the CDF from internal fires that contain HVAC or room cooler system failures. Bohn et al. (1990) and Lambright et al. (1990) provided detailed assessments of the CDF from internal fires. As with the seismic analyses, a screening activity was performed to identify the risk-significant locations in the plant in which fires could occur. This was accomplished by identifying fire zones in which safety-related equipment or control cables are located, quantifying fireinduced initiating event frequencies in these zones, and then screening each zone on the initiating event frequency as well as on the order and frequency of cut sets leading to core damage. A detailed quantification process was then applied to the fire zones surviving the screening process.

Fire-induced scenarios involving HVAC-related failures did not survive the screening processes performed by Bohn or Lambright. The scenarios remaining after screening included fires in the control room, emergency switchgear room, and cable spreading room at the BWR (Lambright et al. 1990) and control room, cable vault/tunnel, Auxiliary Building, emergency switchgear room, and charging pump service water pump room at the W PWR (Bohn et al. 1990). The assessment of HVAC-related, fire-induced CDF in this study will build upon and modify the analyses presented in these references.

Detailed CDF analyses were performed for the probabilistically significant accident sequences resulting from the screening activity. The steps in the detailed quantification methodology are the following: 
- Determine temperature response in each fire zone. The COMPBRN fire growth code was used to calculate fire propagation and equipment damage. No additional COMPBRN modeling was done in the present analys is. Results obtained by Bohn and Lambright were incorporated directly into this analysis.

- Estimate fire barrier failure probabilities. These data were used to evaluate adjacent fire zones.

- Perform recovery analysis. Recovery of nonfire-related random failures was allowed, similar to the internal events analysis.

- Perform uncertainty calculations.

The results of these four quantification steps form the basis of the present study's quantification of the HVAC-related portion of the fire-induced CDF. A more detailed discussion of the approach used in the present study is provided later.

HVAC and room cooling systems are provided at many diverse locations within a nuclear power plant. For this analysis, the following plant configuration information was used to incorporate HVAC-related failures into the detailed fire scenario frequency calculations presented by Bohn and Lambright.

- The Auxiliary Building emergency HVAC system is a centralized system that provides conditioned air to several safety-related rooms. The representative Auxiliary Building emergency HVAC system consists of an AHU, chiller package, controls, and ductwork necessary to supply conditioned air to numerous locations, including emergency switchgear rooms and DC equipment rooms. One train of Auxiliary Building HVAC is provided for each redundant train of switchgear and DC equipment.

- ECCS pumps (AFW, HPI, LPI, CS, etc.) are located in small cubicles that are cooled by $A C$-powered local room coolers.

- The emergency control room HVAC system is a redundant system consisting of two independent trains of HVAC equipment. Each train consists of an AHU, chiller package, controls, and ductwork necessary to supply conditioned air to the control room and adjacent safety-related electrical/ control equipment areas.

These representative configurations will be used to modify the existing fire scenarios given by Bohn and Lambright to incorporate HVAC-related events. Because these representative configurations are applicable to both BWRs and PWRs, separate CDF calculations for both plant types were not developed. The CDF calculations presented in the following sections are believed to be applicable to both types of plants. Precise estimates of the CDF due to internal fires are possible only on a plant-specific basis, because the details of the fire zones, fire barriers, cable routes, and the like, are plant-specific. However, because the generic HVAC configurations listed above are relatively 
common at nuclear power plants, the fire-induced CDF calculated in the following sections is a reasonable representation for most nuclear power plants.

As indicated above, the two most fire-sensitive areas in the plant are the emergency switchgear rooms and the main control room. A third scenario involving a fire in the $D C$ equipment room was also developed due to the relatively large contributions of random $D C$ equipment fallures to the internal event CDF calculated in Section 4 . These three fire scenarios are described and quantified in the following sections, and the results are summarized in Table 5.2-1.

\subsubsection{Fire Causes Loss of Emergency Switchgear Room Cooling}

A common fire-induced accident scenario involved loss of emergency switchgear and subsequent loss of power to ESF components. The specific scenario examined here involves the followinc sequence of events:

- A fire occurs in Auxiliary Building HVAL equipment room, causing a loss of switchgear room HVAC function.

- Failure of switchgear room cooling causes room temperature to rise and, unless cooling can be restored, it is postulated that the offsite power trunks located in the switchgear room will fail. This effectively fails offsite power feed to the plant and one train of emergency $A C$ power, also located in the same room.

IABLE 5.2-1. Affected CDF from Internal Fires

\begin{tabular}{|c|c|c|c|c|}
\hline \multirow[b]{2}{*}{ Fire Location } & \multicolumn{2}{|c|}{$\begin{array}{l}\text { Original } \\
\text { CDF, per RY(a) }\end{array}$} & \multicolumn{2}{|c|}{$\begin{array}{l}\text { Affected } \\
\text { CDF, per RY }\end{array}$} \\
\hline & PWR & BWR & PWR & BWR \\
\hline Control Room & $1.58 \mathrm{E}-06$ & $6.29 E-06$ & $1.92 E-06$ & $1.92 E-06$ \\
\hline $\begin{array}{l}\text { Emergency Switchgear } \\
\text { Room }\end{array}$ & $6.09 \mathrm{E}-06$ & $1.30 E-05$ & $3.70 E-06$ & $3.70 E-06$ \\
\hline DC Equipment Room & Not Evaluated & Not Evaluated & $1.49 E-06$ & $1.49 E-06$ \\
\hline TOTAL $^{(b)}$ & $1.13 E-05$ & $2.00 E-05$ & $7.11 E-06$ & $7.11 \mathrm{E}-06$ \\
\hline \multicolumn{5}{|c|}{$\begin{array}{l}\text { (a) Bohn et al. (1990) and Lambright et al. (1990) for PWRs and BWRs, } \\
\text { respectively. Mean values are given in the table. } \\
\text { (b) The original cDFs include contributions from fires in the cable } \\
\text { vault/tunnel and charging pump service water pump room (that are not } \\
\text { affected by this generic issue) as well as the locations listed in } \\
\text { the table. The original CDFs for the BWR include contributions from } \\
\text { fires in the cable spreading room that are not affected by this } \\
\text { generic issue as well as fires in the locations listed in the table. }\end{array}$} \\
\hline
\end{tabular}


- The second train of emergency $A C$ power is postulated to fall due to a random (fire-independent) fallure of the ESW system to provide cooling water to remove heat from an EDG OR random fallure of the redundant EDG (fallure of EDG ventilation is a potential cause of EDG fallure). This results in an SBO condition. Due to separation of the two switchgear rooms and separate HVAC systems for each switchgear room, it was determined that no probabilistically significant scenarios involving fireinduced failures of both HVAC equipment rooms or of redundant trains of switchgear existed.

- HPCI is actuated and operates unt 11 station batteries are depleted or the HPCI pump fails because there is no $A C$-independent room cooler system for the HPCI pump room. Fallure of the HPCI system under station blackout conditions results in core damage.

Basec on this uccident scenario and the information in Bohn et al. (1990) and Lambright et al. (1990), the following formula was derived to develop the affected CDF $\$$

$$
\Phi=\lambda_{A U X} f_{A} Q\left(\tau_{g}\right)\left[Q_{E S W}+Q_{E D G-H V A C}\right]
$$

where

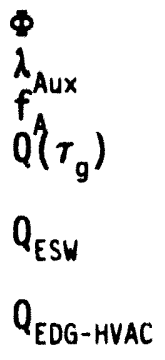

- Core damage frequency

- Frequency of Auxiliary Building fires

- Area fraction (HVAC equipment room/Auxiliary Building area)

- Percentage of fires not suppressed before critical damage to components in fire zones occurs.

= Random unavallability of ESW system to provide cooling water to EDGs

$Q_{\text {EDG-HVAC }}=$ Random unavailability of EDG HVAC system to remove heated air from EDG cubicles

The values given in Bohn et al. for $\lambda_{A y x}(0.066 / R Y), Q\left(\tau_{q}\right)(0.8)$ were used directly in this analysis. Development of the values for the other parameters is described below.

The parameter $\left(f_{A}\right)$ represents the fractional area of the HVAC equipment room with respect to the entire Auxiliary Building. Floor plan drawings for the representative W PWR described in Sections 3 and 4 were used to calculate this fraction. According to the drawings, the floor area of the HVAC equipment room was calculated to be about $532 \mathrm{ft}^{2}$. The floor area of the Auxiliary Building, including four entire floors, was calculated to be about $23,300 \mathrm{ft}^{2}$. Therefore, the area fraction was calculated to be about 0.0228 .

The random failure probabilities for the ESW system, which is not dependent on HVAC or room coolers to function properly, and for the EDG-HVAC system were calculated using the following Boolean expressions:

$$
\begin{aligned}
Q_{E S W}= & E S W-C K V-C 515 A+E S W-C C F-L F-A O V S+A C P-D G N-F R-E D G B \\
& \star A C P-D G N-F R-E D G C * \text { DGHWNR16H (Bohn et al. 1990) }
\end{aligned}
$$




$$
\begin{aligned}
Q_{E D G-H V A C}= & A C P-B A C-S T+A C P-C R B-C O+D G N-F A N-F R+D G N-D A M P-F O \\
& + \text { ESF-ACT-FA (developed in this study). }
\end{aligned}
$$

The values for each of these terms and their sources are presented in Table 5.2-2. The calculated value of $Q_{E S W}$ is $8.1 \mathrm{E}-04 /$ demand and the fallure probability for $Q_{E D G-H V A C}$ is $2.25 E-03 /$ demand.

Based on the preceding discussion, the affected CDF for a fire scenario involving fallure of emergency switchgear room cooling is

$$
\begin{aligned}
\Phi & =\lambda_{A u x} f_{A} Q\left(\tau_{g}\right)\left[Q_{E S W}+Q_{E D G-H V A C}\right] \\
& =(0.066 / R Y)(0.023)(0.8)(8.1 E-04+2.25 E-03) \\
& =3.7 E-06 / R Y .
\end{aligned}
$$

Note that no credit was given for recovery of the emergency switchgear room cooiling fallure. This is because no credit was allowed by Bohn et al. for recovery of fire-induced fallures. It may be possible to provide supple-

\begin{tabular}{|c|c|c|}
\hline Parameter & Description & $\begin{array}{l}\text { Fallure } \\
\text { Probability }\end{array}$ \\
\hline ESW-CKV-C515A & ESW check valve fails to open & $1.0 \mathrm{E}-04^{(0)}$ \\
\hline ESW-CCF-LF-AOVS & $\begin{array}{l}\text { Common cause failure of ESF air-operated } \\
\text { valves to open on demand }\end{array}$ & $1.0 \mathrm{E}-04^{(\mathrm{a})}$ \\
\hline$A C P-D G N-F R-E D G B$ & Failure of EDG-B to run & $3.2 E-02^{(a)}$ \\
\hline$A C P-D G N-F R-E D G C$ & Failure to EDG-C to run & $3.2 E-02^{(a)}$ \\
\hline DGHWNR16H & $\begin{array}{l}\text { Failure to restore failed EDG within } 16 \\
\text { hours }\end{array}$ & $6.0 E-01^{(b)}$ \\
\hline$A C P-B A C-S T$ & 6.9 kV shutdown board bus fails & $3.1 E-06^{(a)}$ \\
\hline ACP-CRB-CO & Spurious transfer of feeder breaker & $2.9 E-054^{(a)}$ \\
\hline DGN-FAN-FR & Fallure of EDG ventilation fan to run & $5.9 E-04^{(c)}$ \\
\hline DGN-DAMP-FO & $\begin{array}{l}\text { Failure of EDG ventilation damper to open } \\
\text { on demand }\end{array}$ & $2.3 E-05^{(c)}$ \\
\hline ESF-ACT-FA & No actual signal from logic train & $1.6 \mathrm{E}-03^{(\mathrm{a})}$ \\
\hline \multicolumn{3}{|c|}{$\begin{array}{l}\text { (a) Table 4.9-5 of Bertucio and Brown (1990). } \\
\text { (b) Based on probability of nonrecovery of failed EDG within seven hours } \\
\text { (event DG-REC3) given on } \mathrm{p} \text {. 4.9-21 of Bertucio and Brown }(1990) \text {. } \\
\text { (c) See Table 4.4-1 of this document. }\end{array}$} \\
\hline
\end{tabular}
mentary cooling to this room by opening doors and installing portable fans. However, under station blackout conditions, no AC power is avallable to operate the redundant HVAC trains or to operate portable fans, so not allowing

IABLE 5.2-2. Parameter Values for Calculating $Q_{E S W}$ and $Q_{E D G-H V A C}$ 
HVAC recovery under conditions is reasonable. Recovery of EDGs following loss of room cooling is also unlikely given the small amount of time avallable for such an action, as discussed in Appendix F.

\subsubsection{Eire Causes Loss of DC Equipment Room Cooling}

This scenario was developed primarily due to the potentially high internal CDF from a loss of DC equipment room HVAC, which was discussed in Section 4.4. This scenario is initiated by a fire in the HVAC equipment room for the adjacent $D C$ equipment room. The fire fails the HVAC equipment, resulting in a loss of cooling to the DC equipment room. The air temperature in this room heats up due to a loss of cooling and ultimately fails the inverter, battery charger, or vital DC bus in this room. It was assumed that the falled vital DC bus is the most heavily-loaded bus in the DC power system, and results in a reactor SCRAM followed by failure of four of five feedwater sources. Alternatively, if this analysis were for a BWR, the fire could fail control power to four of five sources of coolant injection, including one or more trains of HPCI and RCIC. The only remaining feedwater source, which is powered from a separate DC bus, is a motor-driven AFW pump train (or a motordriven HPCI pump for a BWR). Core damage results if the remaining AFW (or HPCI) pump train fails due :0 random (i.e., not fire-related) causes.

The following formula was derived to develop the affected CDF:

$$
\Phi=\lambda_{\text {Aux }} f_{A} Q\left(\tau_{g}\right) Q_{A F W} R_{o p}
$$

where $\Phi \quad$ = Core damage frequency

$\lambda_{\text {Aux }}=$ Frequency of Auxiliary Butlding fires

$f_{A}^{A u x}=$ Area fraction (DC equipment HVAC room/Auxiliary Building area)

$Q\left(\tau_{g}\right)=$ Percentage of fires not suppressed before critical damage to components in fire zones occurs

$Q_{A F W}=$ Random unavailability of motor-driven AFW pump train to provide secondary cooling to steam generator

$R_{o p} \quad$ Operator fails to install supplementary cooling in DC equipment room.

The values given in Bohn et al. for $\lambda_{A y x}(0.066 / R Y), Q\left(\tau_{q}\right)(0.8)$ were used directly in this analysis. Development of the values for the other parameters is described below.

The value for $f_{A}$ was assumed to be the same as the value used for the emergency switchgear room HVAC fire discussed previously $(0.023)$, because the area of the DC equipment room HVAC room is nearly the same (but less than) the area of the Auxiliary Butlding HVAC equipment room. In some plants, there is no separate HVAC system for the DC equipment room, which, in this case, is cooled by the Auxiliary Building HVAC system.

The value for $Q_{A F W}$ was calculated using the following Boolean expression, which was developed in this study: 


$$
\begin{aligned}
Q_{A F W}= & A F W-A C T-F A+A F W-A O V-C C+(2 \star A F W-C K V-C C)+A F W-M D P-F S+ \\
& A F W-M D P-F R+A F W-M D P-T M+A F W-C C F-F T-A O V .
\end{aligned}
$$

The values for these parameters are shown in Table 5.2-3. The total fallure probability for $Q_{A F W}$ was calculated to be $7.65 E-03 /$ demand.

The parameter $R_{\text {p }}$ represents the probability that operators do not restore cooling to the $D C$ equipment room prior to fallure of the vital $D C$ equipment. For plants in which the $D C$ equipment room cooling is separate from the Auxiliary Building HVAC system, AC power should be avallable to operate the Auxiliary Building HVAC equipment or supplementary cooling equipment, at least initially, to prevent a rapid heatup of the $D C$ equipment room to equipment failure temperatures. In the event that the $D C$ equipment room is cooled by the Auxiliary Building general area HVAC (rather than a separate HVAC system), a fire-induced fallure of the Auxiliary Building HVAC system could cause simultaneous failure of the $D C$ equipment room and emergency switchgear room cooling function. In this case, the loss of cooling to the DC equipment room will result in fallure of a vital DC power division well before the emergency switchgear equipment fails due to high room temperature (the Palo Verde IPE estimated that fallure of DC equipment room cooling would cause room temperatures to exceed equipment qual ification temperatures in about 45 minutes; information obtained from another plant indicated that emergency switchgear room temperatures will not exceed equipment qualification temperatures for 24 hours or more following loss of room cooling). Therefore, fallure of DC equipment room cooling will lead to core damage much faster than failure of switchgear room cooling.

\begin{tabular}{|c|c|c|}
\hline Parameter & Description & $\begin{array}{c}\text { Failure } \\
\text { Probability }\end{array}$ \\
\hline AFW-ACT-FA & AFW actuation signal fails on demand & $1.6 \mathrm{E}-03$ \\
\hline$A F W-A O V-C C$ & $\begin{array}{l}\text { Failure of AFW air-operated valves to open } \\
\text { on demand }\end{array}$ & $1.0 E-04$ \\
\hline AFW-CKV-CC & AFW check valve fails closed & $1.0 E-04$ \\
\hline$A F W-C C F-F T-A O V$ & $\begin{array}{l}\text { Common-cause failure of AFW AOVs to open on } \\
\text { demand }\end{array}$ & $3.4 E-05$ \\
\hline AFW-MDP-FS & AFW motor-driven pump fails to start & $3.0 E-03$ \\
\hline AFW-MDP-FR-24 & $\begin{array}{l}\text { AFW motor-driven pump fails to run for } 24 \\
\text { hours }\end{array}$ & $7.2 E-04$ \\
\hline AFW-MDP-TM & $\begin{array}{l}\text { AFW motor-driven pump fails due to } \\
\text { test/maintenance }\end{array}$ & $2.0 E-03$ \\
\hline$A C P-B A C-S T$ & 6.9-kV shutdown board bus fails & $3.1 E-06$ \\
\hline$A C P-C R B-C O$ & Spurious transfer of feeder breaker & $2.9 E-05$ \\
\hline
\end{tabular}

IABLE 5,2-3. Parameter Values for Calculating $Q_{A F W}$ 
Based on the preceding discussion, up to 45 minutes may be available for operators to restore DC equipment room cooling or install portable cooling capabilities before DC equipment falls due to extreme room temperatures. For this study, the probability given by Bertucio and Brown (1990) for fallure to establish alternate room cooling using portable fans was used to represent the failure to perform similar activities in the $D C$ equipment rooms. This nonrecovery probability was 0.16 .

Based on the parameter values discussed above, the affected CDF for fire-induced fallures of DC equipment room HVAC systems is

$$
\begin{aligned}
\Phi & =\lambda_{A U X} f_{A} Q\left(\tau_{g}\right) Q_{A F Y} R_{O P} \\
& =(0.066)(0.023)(0.8)(7.65 E-03)(0.16) \\
& =1.49 E-06 / R Y .
\end{aligned}
$$

\subsubsection{Eire Causes Loss of Control Room Cooling}

The third and final fire scenario involves fire-induced fallure of the control room emergency HVAC (CRAC) system. The CRAC system equipment is normally located in the Control or Auxiliary Buildings, often in rooms adjacent to the main control room. It was assumed that the fire occurs in the CRAC equipment room and results in fallure of all trains of emergency control room cooling. The CRAC equipment is safety-related and subject to technical specifications and limiting conditions for operation. A reactor shutdown is required when a total loss of CRAC occurs. Therefore, once it has been determined that all CRAC trains have been disabled by the fire, plant operators must manually shut down the plant. An automatic shutdown is not anticipated, because the manual shutdown would be called for by technical specifications before an automatic trip setpoint would be reached.

Failure of the CRAC system results in a loss of control room cooling, which causes room temperatures to rise in the control room. Spurious alarms and equipment actuations and incorrect readings on instrumentation and control (I\&C) equipment could result if the control room temperatures exceed equipment qualification temperatures. Operators may elect to abandon the control room and control the plant from the remote shutdown panel. At all the plants visited in this study, the remote shutdown panel room was cooled by a separate safety-related HVAC system (i.e., NOT the CRAC system). Therefore, it is possible for operators to shut down and provide limited control of plant systems from the remote shutdown panel if the control room should become uninhabitable or if main control room equipment malfunctions due to the fire in the CRAC equipment room.

The CRAC equipment room fire scenario consists of the following basic events. First, a fire occurs in the CRAC equipment room, resulting in a total loss of control room emergency ventilation systems. Control room equipment then begins to heat up, and at equipment qualification temperatures, the equipment begins to malfunction and/or fail. Operators will notice the rise in room temperature, because it becomes obviously uncomfortable, and will 
Initiate actions to restore cooling to the control room and/or directly to equipment cabinets. Actions taken by operators in actual loss of control room cooling events have included installation of portable fans and ductwork (AC power is still available) and opening doors to adjacent cooled rooms. As an example, one plant that experienced a total loss of control room emergency HVAC opened the doors separating the control room and the computer room. Loss of the CRAC system did not affect the nonsafety-related computer room cooling system, which was still functioning properly. With this in mind, plant operators installed portable fans to circulate cool air from the computer room to the main control room, which helped to provide time for the operators to stabilize the plant while the CRAC system was being restored. If recovery actions falled, control room equipment cabinets would begin to overheat and malfunction, forcing operators to abandon the control room and stabilize the plant from the remote shutdown panel. Fallure to stabllize the plant from the remote shutdown panel is assumed to result in core damage.

The formula used to calculate the CDF resulting from CRAC equipment room fires is

$$
\Phi=\lambda_{C R} R_{C R} f_{R} R_{O P}
$$

where $\Phi$ - Core damage frequency

$\lambda_{C R}=$ Frequency of CRAC equipment room fires

$R_{C R}^{C R}=$ Probability that operators unsuccessfully restore the CRAC system ( $A C$ power avallable)

$f_{R}=$ Probability that heat will force control room abandonment

$R_{o p}^{R}=$ Probability that operators fail to recover plant from the remote shutdown panel.

The value for $\lambda_{C R}$ was assumed to be equal to the frequency of control room fires given by Bohn et al. (1990) and Lambright et al. (1990). These values were given as $1.8 \mathrm{E}-03 / \mathrm{RY}$ and 2.3E-03/RY, respectively. Thus, a value of $2 E-03 / R Y$ will reasonably approximate the frequency of control room $\mathrm{HVAC}$ equipment fires.

The parameter $R_{C R}$ represents the probability that operators do not restore some form of room cooling, either the CRAC system or supplemental cooling, to the main control room. The probability of this event was estimated based on the HRA results presented in Section 4.1.1. The probability of failing to accomplish the necessary recovery actions was assessed at 0.08 . Added to this is the probability of hardware failure (e.g., portable fans), given to be about 0.05 (Bertucio and Brown 1990). The total probability for $R_{C R}$ is therefore 0.13 .

The probability that heat will force operators to abandon the control room, $f_{i}$, was taken directly from Bohn et al. (1990). An event was described and evaluated by Bohn for operators being forced to abandon the control room because of smoke. Smoke is a much harsher environment to tolerate than excessive room temperatures, so it is likely that smoke would force control room abandonment sooner than high room temperatures. Consequently, the probability that smoke forces control room abandonment is likely to be higher than the 
probability that high room temperatures force control room abandonment. Therefore, the value of 0.1 that was calculated by Bohn tends to overstate the probability of control room abandonment due a loss of room cooling.

The probability that operators fail to recover the plant from the remote shutdown panel, $R_{\text {op }}$, was taken directly from Bohn et al. (1990). The best estimate value given by Bohn was 0.074 . This probability accounts for opera. tor errors in activating and operating remote shutdown equipment given that main control room equipment is not functioning. This is a very similar situation to that resulting from a fire in the CRAC equipment room that causes control room cabinets to overheat and malfunction.

Based on the parameter values discussed above, the affected CDF for fire-induced fallures of the control room emergency HVAC systems is

$$
\begin{aligned}
\Phi & =\lambda_{C R} R_{C R} f_{R} R_{O P} \\
& =(2 E-03 / R Y)(0.13)(0.1)(0.074) \\
& =1.92 E-06 / R Y .
\end{aligned}
$$

\subsection{ASSESSMENT OF AFFECTED CDF DUE TO FLOODS}

The third potential external event considered in this study is a flood, which may produce multiple component fallures when vital areas of the plant are submerged in water. Floods may arise from external or internal sources. Examples of externally initiated floods include dam failures, highprecipitation events, high-runoff events, or severe weather such as hurricanes. Internally initiated floods may be caused by ruptures of pipes, valves, pumps, or water storage tanks. NRC regulations related to flood protection are contained in 10 CFR 50 and 10 CFR 100.

Two flood analyses were performed in this study: The first is based on the supporting documentation for the flood analyses performed for the NUREG-1150 PRA program. Sufficient detail was not readily available to directly calculate the HVAC/room cooler contributions to the flood-induced CDF calculated in the NUREG-1150 PRAs. The results of this analysis (see Section 5.3.1) are generic and are used to represent the affected CDF and public risks associated with $W$ and CE PWRs as well as BWRs. The second flood analysis in this study was based on the IPE for a B\&W plant. This IPE provided a sufficient basis (i.e., listing of cut sets) to directly calculate HVAC/room cooler contributions to the flood-induced CDF for this plant. The results of this analysis (see Section 5.3.2) are used to represent the affected CDF and public risk for B\&W PWRs.

\subsubsection{Analysis of Floods for $W$ and CE PWRs and BWRS}

The methods and data used in this section to estimate the affected CDF from floods involving HVAC and room cooler systems were derived primarily from Bohn et a1. (1990), Lambright et al. (1990), and the Surry IPE (VEPCO 1992). 
The approach consisted of developing and evaluating event trees initiated by floods. The CDF from external floods was eliminated from both IPEs on the basis that the frequencies of externally initiated floods are low (on the order of 1E-05/RY or lower) and that the conditional probabilities that the flood affects the site and results in core damage cause the flood-induced CDF contribution to be negligible to total plant CDF. Therefore, this study focuses on internally initiated floods, which are more likely sources of core damage than external floods.

The first step in the flood analysis was to identify the critical areas of the plant in terms of flood-induced fallures. It has already been shown that the critical areas of this analysis are the HVAC equipment rooms serving the switchgear, DC equipment, and control rooms. Room coolers in ESF pump rooms were eliminated from this analysis on the basis that they are located above the floors and, in most cases, well above the elevations of the ESF pumps. If a flood should occur in these rooms, it would reach a level that fails the pump before it reaches a level that would cause the room cooler to fail. The rest of this section describes the event tree analyses performed for tlood-induced failures of emergency switchgear room, DC equipment room, and control room HVAC systems. The results of this assessment are summarized in Table 5.3-1.

\subsubsection{Flood-Induced Failure of Emergency Switchgear Room HVAC}

An event tree was developed to model the progression of events and safety system failures in potential flood accident sequences. The event tree shown in Figure 5.3-1 is initiated by a flood in the Auxiliary Building HVAC equipment room that disables one division of emergency switchgear room cooling. The temperature in the switchgear room will begin to rise and, if not restored, will reach failure temperatures for the electrical equipment in the room. If the switchgear equipment (e.g., MCCs for ESF pumps) should begin to overheat, one entire division of ESF equipment may malfunction or fail due to loss of AC power to the ESF pumps and valves. Manual shutdown of the reactor, which is not modeled in the event tree, will occur, and the plant must then be cooled and stabilized using the remaining division of ESF equipment. Removal of decay heat from the reactor may be accomplished either through providing AFW to the steam generators in combination with providing reactor coolant

TABLE 5.3-1. Summary of Flood-Induced Affected CDF Results for $W$ and CE PWRs and GE BWRs

\begin{tabular}{|l|c|}
\hline \multicolumn{1}{|c|}{ Flood Location } & $\begin{array}{c}\text { Affected } \\
\text { CDF, per RY }\end{array}$ \\
\hline Emergency Switchgear Room HVAC & $5.15 \mathrm{E}-07$ \\
\hline Control Room HVAC & $4.23 \mathrm{E}-07$ \\
\hline DC Equipment Room HVAC & $5.71 \mathrm{E}-08$ \\
\hline TOTAL & $9.95 \mathrm{E}-07$ \\
\hline
\end{tabular}




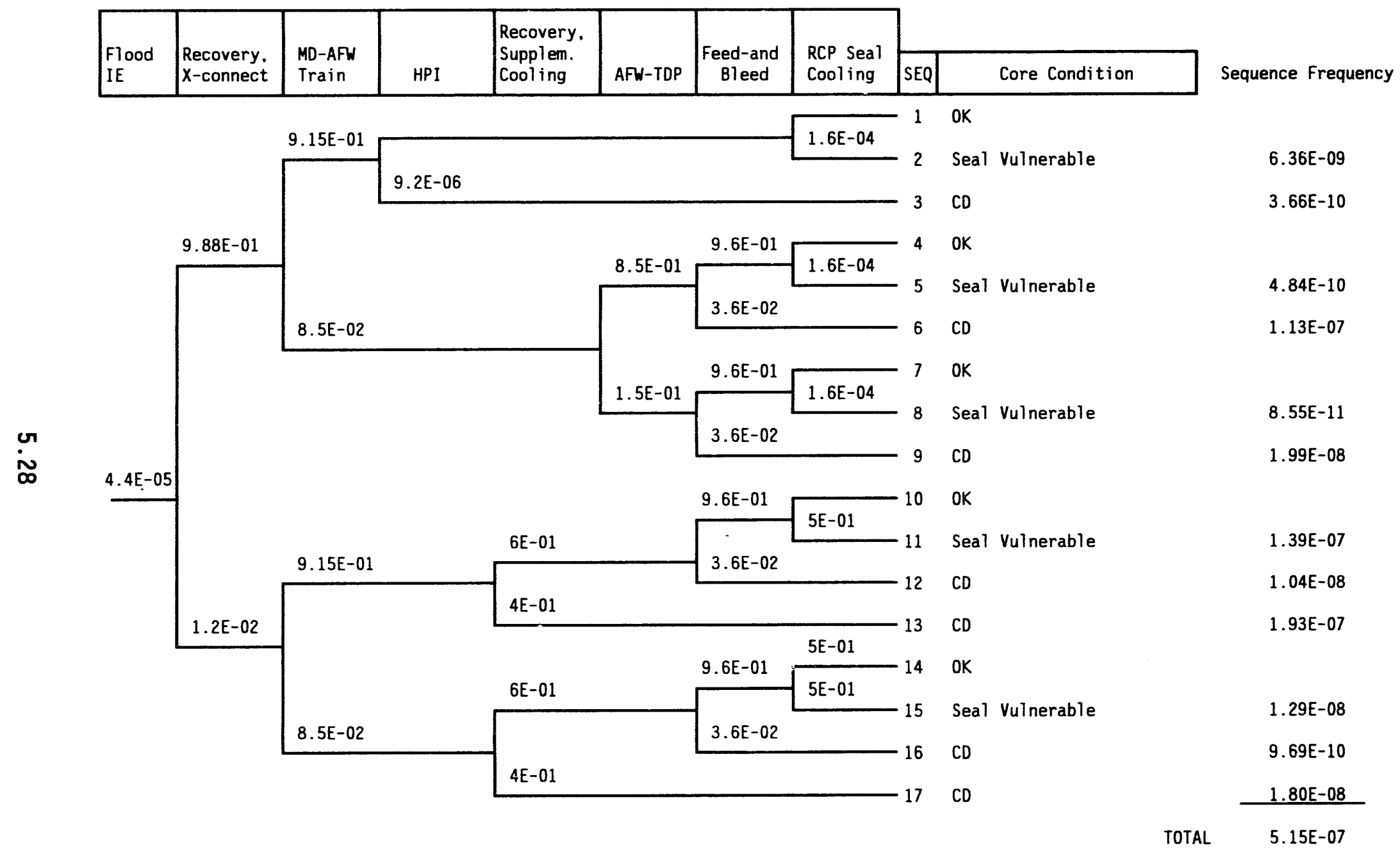

FIGURE 5.3-1. Event Tree for Flood-Induced Failure of Emergency Switchgear Room HVAC 
makeup using the HPI system or through feed-and-bleed cooling using the HPI system and PORVs. RCP seal cooling must also be maintained to prevent an RCP-seal LOCA. Of course, operability of the ESF functions required to recover from the flood is affected by the unavailability of cooling to the emergency switchgear room.

The supporting logic used in developing the event tree shown in Figure $5.3-1$ is as follows:

- Initial recovery from the flood consists of installing a cross-connect from the failed Auxiliary Building HVAC equipment to the unaffected train of HVAC equipment, effectively allowing the unaffected HVAC train to cool both divisions of emergency switchgear. This recovery action, if successful, terminates the loss of cooling to the switchgear rooms and terminates the threat of loss of ESF functions due to overheating switchgear rooms. Subsequent ESF failures were treated as independent of the flooded HVAC equipment room.

- Failure to recover from the HVAC failures resulting from the flood results in an SBO condition due to failure of emergency switchgear and offsite power buses due to overheating. This results in failure of HPI, AFW, and CCW room cooling, resulting in unrecoverable loss of these ESF functions and leads directiy to core damage. The AC-independent AFW TDP train will function until DC power fails due to battery depletion or the pump fails due to high ambient temperatures in the pump room.

- Following the flood and failure to cross-connect the essential HVAC systems, AC power is still available to one motor-driven AFW pump train served by the redundant division of emergency switchgear. The AFW TDP can be operated without onsite or offsite $A C$ power.

- Successful recovery through implementation of the cross-connect between the affected and unaffected trains of essential HVAC terminates the loss of cooling to the emergency switchgear rooms. If recovery is successful, core damage sequences can occur due to random (i.e., floodindependent) failures of ESF systems.

- Failure of secondary heat removal (i.e., failure of both available AFW pump trains, including one turbine-driven and one motor-driven pump train) leads to demand for feed-and-bleed cooling. The HPI pumps required for feed-and-bleed cooling were assumed to function only if one of the recovery actions is successful.

As shown in Figure 5.1-1, 17 accident sequences were developed to model the flood-induced switchgear room cooling failure scenario. Each of these sequences is described below.

Sequence 1 represents successful mitigation of the flood through recovery of switchgear room cooling and successful initiation and operation of one AFW MDP train and one train of HPI. RCP seal cooling is also successful in sequence 1. Sequence 2 represents a vulnerable seal condition in which AFW 
and HPI are successful, but RCP seal cooling fails. Sequence 3 results in core damage due to failure of the HPI system to inject water into the reactor core to make up for shrinkage and any leakage present before the accident.

Sequences 4 through 9 include recovery of the switchgear room cooling via the cross-connecting capabilities; which are then followed by floodindependent failures of the AFW MDP train. Sequence 4 represents successful operation of the AFW TDP train, successful feed-and-bleed cooling, and successful RCP seal cooling so core damage does not occur. In sequence 5, RCP seal cooling fails, resulting in core damage due to an RCP seal LOCA. In sequence 6 , core damage occurs due to failure of feed-and-bleed cooling. In sequences 7 and 8 , the AFW TDP train fails, resulting in a demand for feedand-bleed cooling. Sequence 7 does not result in core damage, due to successful feed-and-bleed cooling as well as successful RCP seal cooling. In sequences 8 and 9, core damage occurs due to failure of RCP seal cooling and feed-and-bleed, cooling, respectively.

In the remaining accident sequences shown in Figure 5.3-1, the initial recovery action involving the cross-connecting capabilities fails. Emergency switchgear room temperatures continue to rise and may begin to reach equipment failure temperatures. It was assumed that the MD AFW pump train will be initially available because of the time required to reach equipment failure temperatures, but the AFW train will eventually fail when MCCs or other electrical equipment in the switchgear room fail.

In sequence 10, core damage does not occur because supplementary cooling capabilities in the switchgear room allow successful recovery. Sequence 11 is similar to sequence 10 , except that core damage occurs as a result of failure of the RCP seal cooling function (this event is conditional upon failure to recover through the cross-connect capabilities and successful installation of supplemental cooling). Sequence 12 is similar to sequence 10 , except that core damage occurs as a result of failure of feed-and-bleed cooling. Sequence 13 proceeds to core damage because of unsuccessful recovery through the crossconnects and the supplemental cooling capabilities.

Sequences 14 through 17 are similar to sequences 10 through 13 except that the MD AFW pump train fails due to random (i.e., flood-independent) causes in the former sequences.

The initiating event frequency and conditional safety-system failure probabilities used to quantify the affected CDF from this event were presented in Figure 5.3-1. As shown, the affected CDF for this initiating event was calculated to be 5E-07/RY. Derivation of the parameter values used to develop this estimate are discussed in the following paragraphs.

Event "Flood IE": The initiating event is a flood in the Auxiliary Building HVAC equipment room that results in failure of one division of HVAC equipment (a second division is not affected because the HVAC equipment is located in a separate room). Failure of one division of HVAC equipment results in failure to provide cooling to one division of emergency switchgear, 
which, if not restored successfully, causes one division of emergency switchgear to malfunction or fail. This results in loss of $A C$ power to one division of ESF equipment, including HPI, LPI, AFW, and CCW.

The frequency of floods in the Auxiliary Building HVAC equipment room was derived from information in the 0conee IPE. Because these rooms are typically located well above ground level, external flooding (such as flooding caused by dam breaks or high precipitation/runoff events) is not a major concern. This leaves the possibility that a flood could occur due to ruptures of water lines that serve the chillers or heat exchangers. Ruptures of piping, valves, and expansion joints in these lines were examined in this study.

The flood analysis in the Oconee IPE used empirical relationships given by Thomas (1981) to calculate the frequency of pipe ruptures in the HVAC equipment room. This method considers the leakage probabilities for pipes, valves, and expansion joints, as well as the numbers of valves and expansion joints and the length of pipe, number of pipe segments/welds and pipe age, in a specific area. The flood frequency given in the Oconee IPE was developed for the Turbine Building, which contains many more pipe loops and valves than an HVAC equipment room. Therefore, only selected elements of the 0conee Turbine Building flood frequency were included in this analysis. The specific elements included in the HVAC equipment room flood frequency and their rupture frequencies are presented below:

Only gross ruptures of piping and valves were considered in this analysis because the HVAC equipment rooms are provided with floor drain systems, and the HVAC equipment was observed to be raised off the floor on approximately $20-\mathrm{cm}(8-\mathrm{in}$.$) -high pads or was surrounded by similar size con-$ crete curbs. Smaller ruptures would not release enough water to overwhelm the floor drains and fill the room with enough water to overflow the $20-\mathrm{cm}-\mathrm{high}$ flood barriers. As shown above, the total flood frequency for the assumed HVAC equipment room configuration was calculated to be $4.4 E-05 / R Y$.

\begin{tabular}{|c|l|l|}
\hline $\begin{array}{c}\text { Element } \\
\text { No. }\end{array}$ & \multicolumn{1}{|c|}{ Element Name } & Frequency \\
\hline 1 & Gross rupture of chiller inlet lines & $1.5 E-05 / R Y$ \\
2 & Gross rupture of chiller outlet lines & $5.4 E-06 / R Y$ \\
3 & Gross rupture of ESW inlet line & $2.2 E-06 / R Y$ \\
4 & Gross rupture of ESW discharge piping & $1.2 E-05 / R Y$ \\
5 & Gross rupture of 18 outlet valves & $1.6 E-06 / R Y$ \\
6 & Gross rupture of 18 inlet valves & $4.7 E-06 / R Y$ \\
7 & Gross rupture of ESW inlet valves & $6.1 E-07 / R Y$ \\
8 & Gross rupture of ESW outlet valves & $3.5 E-07 / R Y$ \\
9 & Rupture of chilled water pump & $1.7 E-06 / R Y$ \\
\hline
\end{tabular}


Recovery, $X$-Connect. This is the first recovery action operators would attempt following a loss of one division of HVAC equipment. This action consists of diverting water from a separate chilled water loop (e.g., service building chillers or the redundant switchgear room chiller) or between the affected and unaffected switchgear room chiller systems. The probability of failing to successfully implement this cross-connect capability was taken directly from the Surry IPE (Bohn et al. 1990, p. 3-261) for the identical event. The failure probability amounts to 0.012 per demand, including a hardware failure contribution of 3.14E-04/demand and human error probability of $0.0117 /$ demand.

MD-AFW Pump Train. This event represents failure of the motor-driven AFW train that is powered from the unaffected division of emergency switchgear. Since this event appears early in the event tree, sufficient time has not elapsed to allow the temperature to rise in this area to the point at which pump failure could occur. Therefore, only random (i.e., floodindependent) failure modes need be considered for this event.

The probability for this event was derived from analyses presented by Bertucio and Brown (1990) of the failure probability of a AFW TDP train. Adjustments were made to the failure probability for an event involving failure of the AFW TDP to supply water to two of four steam generators. Bertucio and Brown stated the probahility of this event is dominated by single failures in the AFW TDP train. Similarly, it was assumed here that failure of the AFW MDP train is dominated by single failures of components in the AFW MDP train. This is reasonable because the second AFW MDP train was already assumed failed as a result of failure of the HVAC division serving the room containing the switchgear for the second AFW pump train.

The failure probability of the AFW TDP train to provide water to two of four steam generators was calculated by Bertucio and Brown (1990) to be $0.15 /$ demand. The AFW TDP train is very similar to a AFW MDP train except for the pump and associated control systems. Adjustments were made to the value given by Bertucio and Brown to account for the difference in pump failure probabilities between MDPs and TDPs by subtracting the failure probabilities given by Bertucio and Brown for the TDP from the overall TDP train failure probability and then adding the probabilities of MDP failures to the result. The probability of failure of a single AFW MDP train was estimated to be $0.085 /$ demand.

HPI. This event represents failure of the HPI system to provide coolant injection to the reactor vessel to replace shrinkage and any pre-existing leakage resulting from a plant shutdown. Successful initiation of AFW and HPI results in successful termination of this accident.

Successful initiation of HPI depends on the success or failure of the preceding recovery actions. Failure to recover some form of switchgear room cooling was assumed to result in failure of the HPI system due to loss of AC power to the HPI pumps. If recovery was successful, the HPI system failure probability was calculated using random, flood-independent component failure probabilities. A value of 9.2E-06/demand was taken from Bertucio and Brown 
(p. D-94, for event $D_{1}$, "failure of HPI with one of four charging or safety injection trains). Assuming that recovery is unsuccessful, $A C$ power to the safety injection and charging pumps will be unavailable. The failure probability for the HPI system was assigned a value of 1.0 under these conditions.

Recovery - Supplemental Cooling. This event involves recovery of switchgear room cooling by such actions as opening doors and installing portable fans and ductwork to supply air to the affected switchgear equipment. This event is the second potential recovery action involved in restoring cooling to the switchgear room. Unsuccessful recovery is the combination of failure to implement the cross-connect capabilities described previously AND failure to provide supplemental cooling. The failure probability for this event, when multiplied by the failure probability for implementing the crossconnect capabilities ( 0.012 /demand) yields the failure probability calculated in Section 4 for restoring cooling to emergency switchgear rooms (4.3E-03) demand). The probability for the this recovery event was calculaied to be $4.3 \mathrm{E}-03 / 0.012=0.36 /$ demand.

AFW-TDP. This event represents unsuccessful operation of the AFW TDP train to supply cooling water to steam generators. The AFW TDP is available only under conditions in which cooling has been successfully restored to the emergency switchgear room because of the dependence on an $A C$-powered room cooler to remove heat from the AFW TDP room. Under conditions in which switchgear room cooling is available, the failure probability for this event is independent of the flood and will be dominated by single failures in the AFW TDP train. The failure probability for such an event was calculated by Bertucio and Brown to be 0.15 /demand.

Feed-and-Bleed. Failure of AFW systems to remove decay heat from the steam generators results in a need for feed-and-bleed cooling. Under conditions in which switchgear room HVAC systems have not been restored, the HPI pumps were assumed to fail due to a loss of $A C$ power. If switchgear room cooling has been restored, the HPI pumps will have AC power available, and feed-and-bleed cooling is possible.

The failure probability for feed-and-bleed cooling, given that the emergency switchgear room cooling has been restored, was taken from Bertucio and Brown. Feed-and-bleed cooling requires that one of four HPI systems is available to inject water into the reactor vessel AND that both PORVs open and close successfully when needed. Therefore, failure to provide feed-and-bleed cooling could result from either failure of one of two PORVs or failure of four of the four HPI pump trains (two safety injection trains and two charging trains). The approximate failure probability of feed-and-bleed cooling is then the sum of the failure probabilities for the PORVs and HPI pump trains. These values were given by Bertucio and Brown to be $3.6 \mathrm{E}-02$ /demand and 9.2E-06/demand, respectively. The total failure probability for feed-andbleed cooling was estimated to be 3.6E-02/demand, dominated by the failure probability for one of two PORVs.

RCP Seal Cooling. RCP seal cooling is provided by one of two charging pumps in seal injection mode or one of two CCW trains providing water to the 
RCP thermal barriers. Fallure of both the charging pump trains and both CCW trains is required to cause fallure to remove heat from the RCP seals.

As with most of the previous events involving safety system failures, fallure of the RCP cooling systems is conditional upon prior success or fallure to restore emergency switchgear room cooling functions. If switchgear room cooling is avallable, the RCP seal cooling fallure probability reverts to the values calculated by Bertucio and Brown. Since fallure of both charging AND CCW systems are necessary to result in failure of all RCP seal cooling, the RCP seal cooling failure probability is the product of the failure probabilities of the charging and CCW systems. Since one train of switchgear may be unavailable, adjustments were made to the failure probabilities given by Bertucio and Brown for these systems. It was observed that the seal injection and CCW systems are two-100p systems, with each loop identical to the other. Assuming there are not common-cause failures that could disable both trains of each system simultaneously, and there should not be because of single-failure criteria for safety systems, the failure probability for each loop is the square root of the failure probability for the systems. The probability of failing to provide RCP seal injection flow via the charging trains was calculated by Bertucio and Brown to be 3.7E-04/demand. Therefore, the failure probability for a single-seal injection train is $(3.7 \mathrm{E}-04)^{1 / 2}=1.9 \mathrm{E}-02$. The probability of failure of the CCW system to provide cooling water to the RCP thermal barriers was calculated by Bertucio and Brown to be 7.0E-05/demand, so the failure probability for a single $C C W$ loop is $(7.0 E-05)^{1 / 2}=8.4 E-03$. Therefore, the total failure probability for the RCP seal cooling system, on the condition that one train of switchgear room cooling be available, was estimated to be $(1.9 \mathrm{E}-02) *(8.4 \mathrm{E}-03)=1.6 \mathrm{E}-04 /$ demand.

Under the condition in which switchgear room cooling is unavailable, the RCP seal cooling systems are vulnerable to loss of power failure modes. A failure probability of 0.5 /demand was developed in the Palo Verde IPE for a similar situation involving loss of AFW MDPs during a room cooler failure sequence. This value was used for the failure probability of RCP seal cooling conditional upon failure of the switchgear room cooling system.

\subsubsection{Flood-Induced Failure of DC Equipment Room HVAC}

A flood may occur in the HVAC equipment room for the DC equipment room. The sequence of events following the flood is similar to that described in Section 5.2.2, except for the different initiating event. The flood is postulated to fail the HVAC equipment, resulting a loss of cooling to the DC equipment room. If cooling is not restored, the ambient temperature in the $D C$ equipment room will reach equipment failure temperatures, resulting in a loss of one division of vital DC power. Assuming, as with previous DC equipment room scenarios, that the affected division of vital DC power is heavilyloaded, a plant trip will occur, followed by failure of control power to four of five AFW pump trains and failure of one entire division of ESF equipment. The remaining ESF equipment capable of stabilizing the plant includes one train of AFW, one train of HPI/HPR, and one train of LPI/LPR. Although it is possible at some plants to remove decay heat from the primary coolant system through feed-and-bleed cooling, this is assumed to be prevented in this 
instance due to loss of $D C$ control power to the relief valves that are needed to vent reactor coolant to remove decay heat. Thus, feed-and-bleed cooling is not possible under these conditions.

The event tree developed to model the progression of events from the flood inttiator to core damage is presented in figure 5.3-2. As shown, the total affected CDF for DC equipment room HVAC floods was calculated to be 5.4E-08/RY. The accident sequences depicted in the event tree are described in the following paragraphs.

Sequence 1 represents successful recovery from the initiating event. Operators are able to successfully restore cooling to this room either through a cross-connect to an unaffected HVAC circuit or installation of supplementary cooling capabilities (e.g., opening doors, installing portable fans). Although this does not necessarily prevent core damage, additional safety system failures would have to occur for the plant to proceed to core damage. Since the additional safety system failures would be independent of the flood, inclusion of the safety system failures in the event tree would reduce the CDF to insignificant levels. Therefore, no further analyses are necessary.

Recovery fails in sequences 2 through 7 , resulting in overheating and failure of one division of vital DC power. As discussed above, if this occurs, only one train of AFW is available for secondary heat removal. Sequence 7 represents a core damage sequence resulting from failure of AFW (feed-and-bleed cooling was assumed to be unavailable due to failure of the DC power division). Should AFW successfully operate, HPI or LPI would be initiated to inject water into the primary system. LPI could not be initiated until operators depressurize the primary system. Sequence 2 represents successful mitigation of this scenario through successful HPI, operator depressurization,

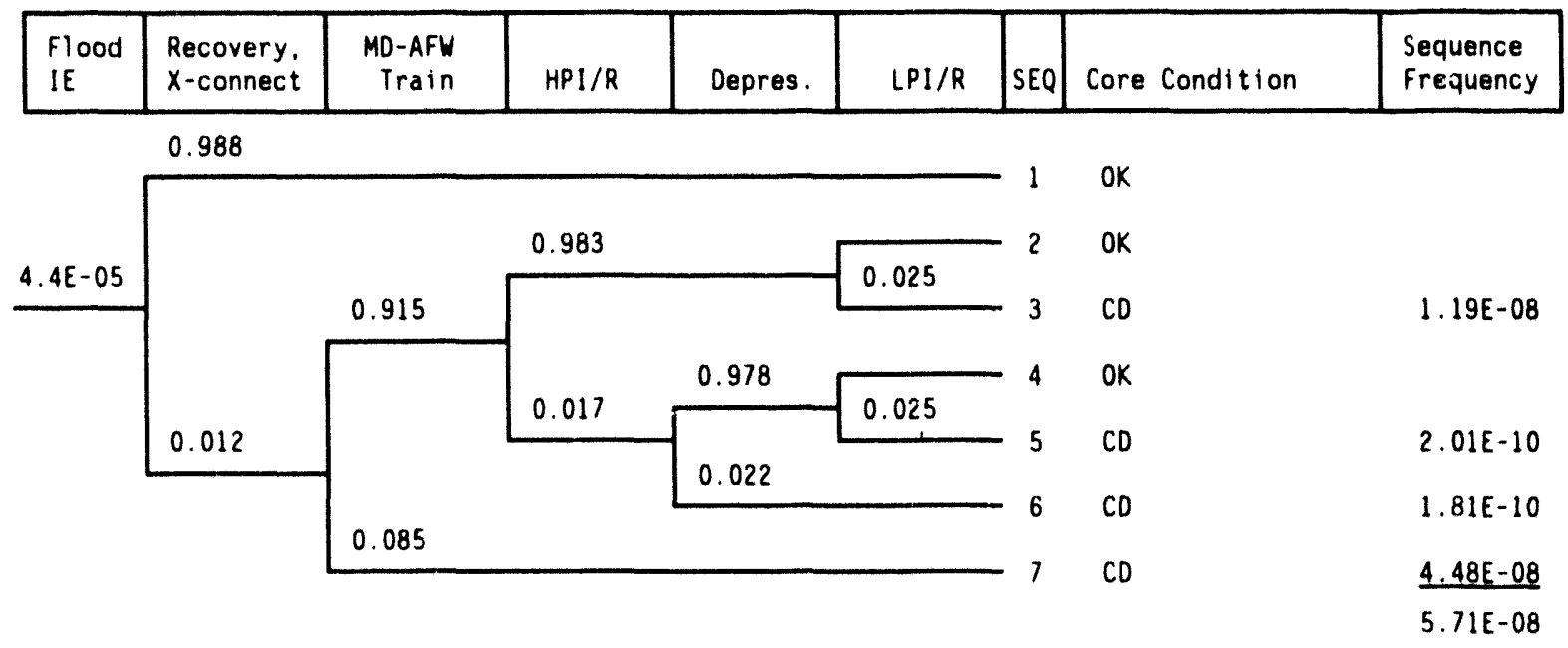

EIGURE 5,3-2. Event Tree for Flood-Induced Loss of DC Equipment Room HVAC 
and LPI. Sequence 3 represents core damage due to fallure of long-term cooling using LPI system. Unsuccessful switchover to LPR is included in the analysis.

Sequences 4 through 6 include fallure of HPI. Sequence 4 represents successful mitigation though successful depressurization of the primary system and successful operation of LPI/R. Sequences 5 and 6 lead to core damage resulting from failure to depressurize the primary system and failure of $L P I / R$, respectively.

The parameter values that were used to quantify the event tree are discussed in the following paragraphs.

Elood - IE. This parameter represents the frequency of internally initiated fluods that occur in the HVAC equipment room for the vital DC equipment. The initiating event frequency given for the switchgear room HVAC equipment room flooding event (see Section 5.3.1) was used here. This value is most likely an overestimate, based on the smaller HVAC requirements for the $D C$ equipment room relative to the switchgear room. Smaller pipes and shorter pipe lengths are needed to provide cooling, water to the HVAC equipment room HVAC systems. The initiating event frequency was estimated to be $4.4 E-05 / R Y$.

Recovery - Cross-connect. This is the same recovery action addressed in the switchgear room HVAC flood analysis. The nonrecovery probability was assessed to be $0.012 /$ demand.

MD-AFW Train. This is the same event described previously for the switchgear room HVAC flood analysis. The failure probability was calculated to be $0.085 /$ demand.

$H P I / R$. This event represents failure of one train of HPI/R equipment, given prior fallure of HVAC to the vital DC equipment that provides $D C$ control power to the redundant HPI train. This event is dominated by single failures in the functional HPI train. It was assumed that both HPI and HPR must function successfully to terminate the accident sequence.

The system diagram for the HPI system (see Figure 3.1-1) was reviewed to develop a Boolean equation for fallure of one train of HPI/R. This equation includes failure of operators to manually switch over to recirculation and pump and valve failures in the HPI/R system. The resulting Boolean equation is

$$
\begin{aligned}
H P I / R= & \text { (HPI pump failure }+ \text { (Flow Control Valve Failures) }+ \text { (Check } \\
& \text { Valve Failures) }+ \text { (Operator Failure to successfully switch over } \\
& \text { to recirculation) } \\
= & \text { (HPI-MDP-FS }+ \text { HPI-MDF-FR }+ \text { HPI-MDP-TM) }+(H P I-F C V-63-5 \\
& + \text { HPI-FCV-63-48 + HPI-FCV-63-153) }+(H P I-C V-63-510) \\
& +(\text { OP-FAIL-RECIRC). }
\end{aligned}
$$


where MDP = Motor-driven pump

$T M=$ Test/maintenance

CV = Check valve
$F S=F a i l s$ to start

FCV - Flow control valve

$F R=$ Fails to run

The parameter values that were used to develop the fallure probability for event HPI/R in the $D C$ equipment room HVAC flood event tree are shown in Table 5.3-2. The failure probability was calculated to be $1.73 E-02 /$ demand.

Depressurization. This event represents failure of operators to depressurize the primary coolant system. The value calculated by Bertucic and Brown for this event was used here. The fallure probability was assessed to be $0.022 /$ demand.

LPI/R. This event represents failure of a single train of LPI/R. The redundant train of LPI/LPR was assumed to fail as a result of failure of cooling to the vital DC equipment ronm. The same approach that was uied to develop an estimate of the failure probability for event HPI/R was used to develop the fallure probability for LPI/R.

As with the HPI/R failure probability, the failure probability for event LPI/R will be dominated by single failures in the unaffected LPI/R system train. The Boolean equation developed for this event is

$$
\begin{aligned}
\text { LPI } / R= & (\text { LPI-MDP-FS + LPI-MDF-FR }+ \text { LPI-MDP-TM) + (LPI-FCV-63-1 } \\
& + \text { LPI-FCV-74-21 + LPI-FCV-74-28 + LPI-FCV-74-32) } \\
& +(\text { LPI-CV-74-515) }+(\text { OP-FAIL-RECIRC) }
\end{aligned}
$$

The parameters that were used to derive the failure probability for this event are shown in Table 5.3-2. The resulting probability of event LPI/R was calculated to be $2.46 \mathrm{E}-02 /$ demand.

\subsubsection{Flood-Induced Failure of Control Room HVAC}

An internally initiated flood may occur in the control room essential HVAC equipment room, effectively eliminating one train of this system. The control room is provided with a redundant system which is also assumed to be unavailable throughout this scenario. It is not likely that a single flood could disable both trains of control room HVAC, because the trains are either separated by flood barriers or located in separate rooms. Nonetheless, it is assumed for this evaluation that both trains of control room HVAC fail as a result of the flood.

The accident scenario is initiated by control room HVAC equipment room flooding and subsequent failure to provide cooling to the control room. Subsequent events in this scenario are similar to what would occur in a fire situation, including an attempt to recover cooling to the control room. It was assumed that no cross-connecting capabilities to an unaffected HVAC circuit are available for the main control room. Therefore, opening doors and installing portable fans are the only possible recovery actions. If these. recovery actions fail, the main control room will begin to heat up until 
IABLE 5.3-2. Parameter Values Used To Evaluate HPI/R and LPI/LPR

\begin{tabular}{|c|c|c|}
\hline Parameter & Description & $\begin{array}{c}\text { Fallure } \\
\text { Probability }\end{array}$ \\
\hline HPI-MDP-FS & HPI MDP falls to start & $3 E-03$ \\
\hline HPI -MDF - FR & HPI MDP falls to run for $18 \mathrm{hr}$ & $5.4 E-04$ \\
\hline HPI - MDP-TM & Test/maintenance faults of HPI MDP & $2 E-03$ \\
\hline HPI -FCV -63-5 & HPI FCV $63-5$ fatls to open & 3E-03 \\
\hline HPI - FCV - $63-48$ & HPI FCV $63-48$ unavatlable & $1.1 \mathrm{E}-04$ \\
\hline HPI - FCV - 63-153 & HPI FCV 63-153 unavatlable & 6.6E-04 \\
\hline HPI - CV - 63-510 & HPI check valve falls to open & $1 E-03$ \\
\hline OP-FAIL-RECIRC & $\begin{array}{l}\text { Operator falls to switch over to } \\
\text { recirculation }\end{array}$ & $6.95 \mathrm{E}-03^{(\mathrm{a})}$ \\
\hline LPI-MDP-FS & LPI MDP falls to start & $3 E-03$ \\
\hline LPI -MDF - FR & LPI MDP falls to run for $18 \mathrm{hr}$ & $5.4 E-04$ \\
\hline LPI - MDP-TM & Test/maintenance faults of LPI MDP & $2 E-03$ \\
\hline LPI-FCV-63-1 & LPI FCV 63-1 falls to open & $3 E-03$ \\
\hline LPI -FCV-74-21 & LPI FCV 74-21 fatls to open & $3 E-03$ \\
\hline LPI-FCV-74-28 & LPI FCV $74-28$ fatls to open & $3 E-03$ \\
\hline LPI -FCV -74-32 & LPI FCV $74-32$ fatls to open & $3 E-03$ \\
\hline LPI -CV-74-515 & LPI check valve fails to open & $1 E-04$ \\
\hline \multicolumn{3}{|c|}{$\begin{array}{l}\text { (a) Includes the following individual operator errors: operator falls to } \\
\text { open safety injection mint-flow to RWST (2.85E-03/demand), operator } \\
\text { falls to open flow control valves } 63-6 \text { and } 63-7 \text { (2.05E-03/demand), and } \\
\text { operator fails to open flow control valves } 63-8 \text { and } 63-11 \quad(2.05 \mathrm{E}-03 / \\
\text { demand). The total failure probability is the sum of the probabili- } \\
\text { ties of these three events or } 6.95 \mathrm{E}-03 / \text { demand. }\end{array}$} \\
\hline
\end{tabular}

equipment failure temperatures are reached and I\&C equipment begins to malfunction and fail. At this time, operators are assumed to abandon the main control room and activate the remote shutdown panel. From the remote shutdown panei, operators are capable of bringing the plant to hot shutdown conditions, effectively terminating the accident.

The approach used to estimate the CDF associated with internal flooding of the control room HVAC equipment room is similar to that used in the fire analysis (see Section 5.2.3). The equation used to develop this estimate is shown below:

$$
=\lambda_{C R} R_{C R} R_{o p}
$$


where $\$$ - Core damage frequency

$\lambda_{C R}=$ Frequency of control room HVAC equipment room floods

$R_{C R}^{C R}$ - Probability that operators unsuccessfully restore the control room HVAC system (AC power available)

$R_{o p}=$ Probability that operators fall to recover plant from the remote shutdown panel.

The value for $\lambda_{\text {ce }}$ was assumed to be equal to the frequency of switchgear room floods developed in Section 5.3.1, or 4.4E-05/RY. This is a reasonable approximation, given that the control room HVAC system is similar in many respects to the switchgear room HVAC system (1.e., the Auxiliary Building HVAC system). Both systems have relatively large-capacity ESW and chilled water piping leading to and from a chiller package; pumps may be located in the same room; and each room contains many valves. Due to these similarities, the initiating frequency appears to be approximately the same for both the control room and switchgear room HVAC equipment rooms.

The parameter $R_{C R}$ represents the probability that operators do not restore some form of room cooling, either the control room HVAC system or supplemental cooling, to the main control room. The probability of this event was estimated based on the HRA results presented in Section 4.1.1. The probability of failing to accomplish the necessary recovery actions was assessed at 0.08. Added to this is the probability of hardware failure (e.g., portable fans), given to be about 0.05 (Bertucio and Brown 1990). The total probabil ity for $R_{C R}$ is therefore 0.13 .

The probability that operators fall to recover the plant from the remote shutdown panel, $R_{\text {op }}$, was taken directly from Bohn et al. (1990). The best estimate value given by Bohn was $0.074 /$ demand. This probability accounts for operator errors in activating and operating remote shutdown equipment given that main control room equipment is not functioning. This is a very similar situation to that resulting from a fire in the control room HVAC equipment room that causes control room cabinets to overheat and malfunction.

Based on the parameter values discussed above, the affected CDF for flood-induced fallures of the control room emergency HVAC systems is

$$
\begin{aligned}
\Phi & =\lambda_{C R} R_{C R} R_{O P} \\
& =(4.4 E-05 / R Y)(0.13)(0.074) \\
& =4.23 E-07 / R Y .
\end{aligned}
$$

\subsubsection{Analys is of Floods for a B\&W PWR}

This section presents the analys is of the flood-induced affected CDF and public risks for a B\&W PWR. This analysis was performed to determine if design differences between vendors result in significant differences in floodinduced CDF and public risk values. The results also provide some confirmation of the "generic" results presented in Section 5.3.1. 
The IPE for the B\&W plant (Duke Power Co. 1990) forms the bas is for the calculations in this section. The affected portion of the flood-induced CDF for the B\&W PWR calculated directly from the flood-initiated minimal cut sets that were provided in the IPE. The first step was to perform a detailed review of the minimal cut sets to identify HVAC and room cooler related parameters. Cut sets incorporating HVAC-related parameters are defined as being affected by this issue. As discussed in Section 4.4, the most prevalent HVACrelated parameters for this plant involve failure of the standby shutdown facility (SSF) HVAC system. Other HVAC and room cooling-related parameters were shown to be less significant than the SSF HVAC system, partly because the plant can be brought to a shutdown condition using only the equipinent in the SSF. Therefore, failure of HVAC to cool important safety-related pumps is less risk-significant at this plant relative to other plants because of the independent backup feedwater, reactor coolant makeup, and RCP seal cooling capabilities provided by the SSF. As a result, the rest of the analysis in this section focuses on the SSF HVAC contributions to flood-induced accident sequences.

The second step in this analysis was to quantify the affected CDF. These three event trees were developed in the IPE:

- Auxiliary Building equipment room, which contains load centers, MCCs, and other vital $A C$ and $D C$ equipment

- Auxiliary Building HPI pump room

- Turbine Building.

Other areas of the plant, including the control room, LPI, and Reactor Building spray pump rooms, component cooling water pump room, and cable spreading room, were also examined in the IPE and were determined not to contribute significantly to the plant's CDF.

Two of the event trees given in the IPE were not complex and could easily be quantified using hand calculation techniques: floods in the equipment room and floods in the HPI pump room (Figures 5.3-3 and 5.3-4). Modifications were made to these two event trees to incorporate SSF HVAC system failures that can cause the SSF functions to fail. For the equipment room flood event tree, the SSF reactor coolant makeup (RCM) function was replaced with the SSF HVAC failure event. For the HPI pump room flood event tree, the SSF auxiliary service water (ASW) function failure was replaced by the SSF HVAC failure. Derivation of the failure probability for the SSF HVAC function was discussed in Section 4.4. No modifications to the SSF HVAC failure probability are required to incorporate the prior floods in the equipment and HPI pump rooms, as the SSF equipment is independent of the equipment in these rooms.

The CDFs calculated using these event trees are shown in Figures 5.3-3 and 5.3-4. As shown, the total affected CDF from flooding the HPI pump room was calculated to be $4.0 E-09 / R Y$. The affected CDF from flooding of the equipment room was calculated to be about $1 E-12 / R Y$. The latter CDF is 


\begin{tabular}{|l|c|c|c|c|}
\hline $\begin{array}{l}\text { Equipment room } \\
\text { Flood Initiating } \\
\text { Event }\end{array}$ & $\begin{array}{l}\text { Turbine-Driven } \\
\text { EFW Pump Falls }\end{array}$ & $\begin{array}{l}\text { SSF HVAC } \\
\text { fails to cool } \\
\text { SSF ASW pump }\end{array}$ & $\begin{array}{l}\text { HPI Cool ing } \\
\text { Fatls }\end{array}$ & $\begin{array}{l}\text { Sequence } \\
\text { Frequency } \\
\text { per RY }\end{array}$ \\
\hline FEQUIP & TDEFWP & SSF-HVAC & HPI & \\
\hline
\end{tabular}

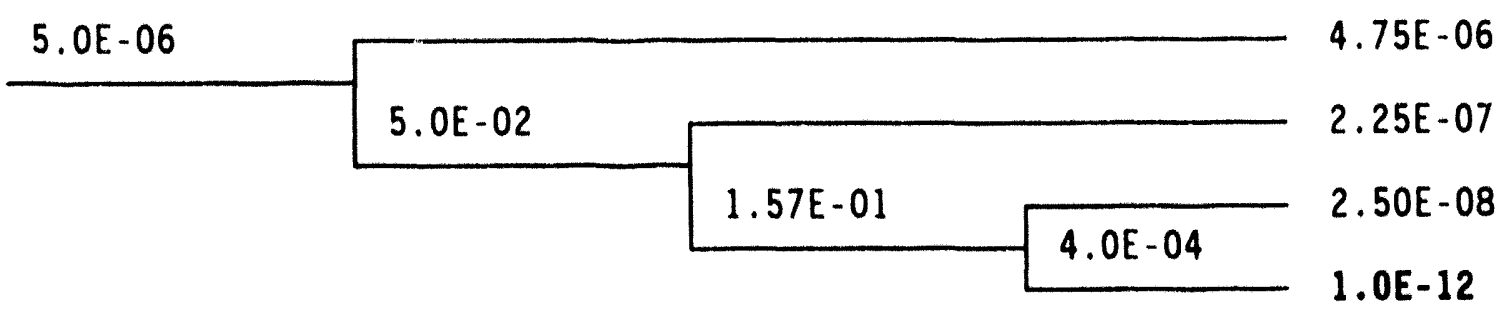

Note: Affected accident sequence is in bold.

FIGURE 5.3-3. Event Tree for Equipment Room Flooding

\begin{tabular}{|l|c|c|c|}
\hline $\begin{array}{l}\text { HPI Pump Room } \\
\text { Flood Initiating } \\
\text { Event }\end{array}$ & $\begin{array}{l}\text { Failure of } \\
\text { Component cool- } \\
\text { ing to RCP Seal }\end{array}$ & $\begin{array}{l}\text { SSF HVAC } \\
\text { fails to cool } \\
\text { SSF ASW pump }\end{array}$ & $\begin{array}{l}\text { Sequence } \\
\text { Frequency } \\
\text { per RY }\end{array}$ \\
\hline FHPI & CC & SSF-HVAC & \\
\hline
\end{tabular}

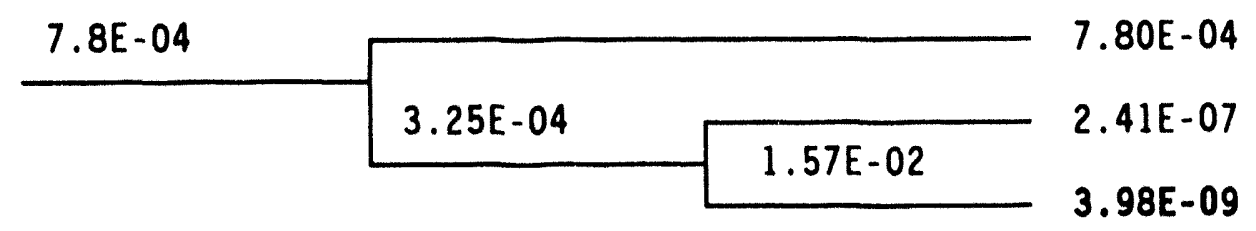

Note: Affected accident sequence is in bold.

EIGURE 5.3-4. Event Tree for HPI Pump Room Flooding

negligible relative to the CDF from flooding of the HPI pump room. This value is very small because flooding of the equipment room does not affect the operability of the SSF and an HPI pump. Thus, backup feedwater, injection, and RCP seal cooling capabilities are not affected by the equipment room flood.

The third event tree involved floods in the Turbine Building. This is a much more complex event tree, as shown in Figure 5.3-5. The minimal cut sets presented in Appendix D of the IPE were used to quantify the affected CDF from Turbine Building floods. The first step was to code the affected minimal cut 


\begin{tabular}{|c|c|c|c|c|c|c|}
\hline $\begin{array}{l}\text { Turbine } \\
\text { Building } \\
\text { Flood } \\
\text { Initiator }\end{array}$ & $\begin{array}{l}\text { RPS trips } \\
\text { the } \\
\text { Reactor }\end{array}$ & $\begin{array}{l}\text { Secondary } \\
\text { Side Heat } \\
\text { Removal } \\
\text { Maintained }\end{array}$ & $\begin{array}{l}\text { Pressurizer } \\
\text { Relief Valves } \\
\text { Close After } \\
\text { Opening }\end{array}$ & $\begin{array}{l}\text { RC Pump } \\
\text { Seal } \\
\text { Integrity } \\
\text { Maintained }\end{array}$ & $\begin{array}{l}\text { High } \\
\text { Pressure } \\
\text { Injection } \\
\text { Established }\end{array}$ & $\begin{array}{l}\text { Long-term } \\
\text { Core Heat } \\
\text { Removal } \\
\text { Established }\end{array}$ \\
\hline FL & K & B & QR & QS & U & $X$ \\
\hline
\end{tabular}

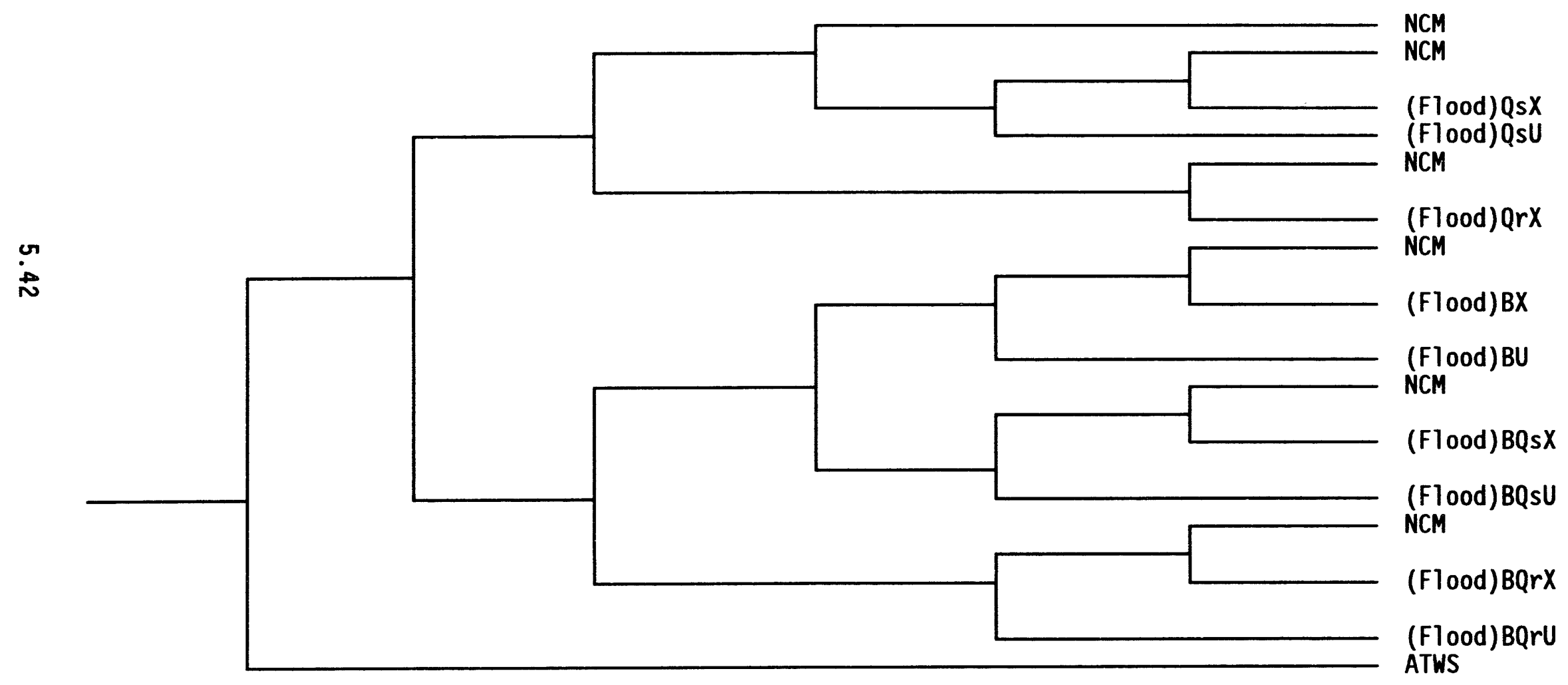

NCM = Non-core-melt accident sequence.

FIGURE 5.3-5. Event Tree for Turbine Building Flood 
sets into a spreadsheet. As shown in Figure 5.3-5, the Turbine Building flood cut sets in the IPE were separated into flood-induced accident sequences. The affected sequences were determined by reviewing the cut set elements to identify potential HVAC-related parameters. There were no HVAC-related parameters in the cut sets, so a modification process was performed to incorporate HVACrelated events into the cut sets. This involved primarily identifying cut sets with events involving failures of SSF functions and then substituting an event for failure of the SSF HVAC system. This modification process is described below for each flood-induced accident sequence.

The resulting affected CDF values for each sequence are summarized in Table 5.1-9. As shown, the total affected CDF due to floods was calculated to be about 2.4E-06/RY. This value is only about a factor of 2 higher than the CDF calculated for a "generic" plant in Table 5.3-1, increasing confidence that the results are reasonable.

Derivation of the Turbine Building flood CDF values shown in Table 5.3-3 is discussed in the following paragraphs.

(Flood)QsX: This sequence is initiated by a flood in the Turbine Building, followed by failure of the RCP seals and a failure of the HPI system during recirculation. The SSF reactor coolant makeup (RCM) function was applied as a recovery to these cut sets.

Failure of the SSF RCM function in these sequences results in core damage. Minimal cut sets involving the SSF RCM system failures were modified to reflect the probability of failure of the SSF HVAC system by substituting the SSF HVAC failure probability into the affected cut sets to replace parameters involving failure of equipment cooled by the SSF HVAC system. The failure probability for the SSF HVAC system was calculated in Section 4.4 to be $0.0157 /$ demand. This value was substituted into the minimal cut sets for the (Flood) QsX sequence, each modified cut set was then requantified, and the modified cut set values were summed to calculate the affected CDF.

TABLE 5.3-3. Summary of the Affected Flood-Induced CDF for a B\&W PWR

\begin{tabular}{|l|c|}
\hline $\begin{array}{c}\text { Flood } \\
\text { Sequence }\end{array}$ & $\begin{array}{c}\text { Affected Core Damage } \\
\text { Frequency, per RY }\end{array}$ \\
\hline Equip. Rm. & $1.00 \mathrm{E}-12$ \\
HPI Room & $3.98 \mathrm{E}-09$ \\
(Flood)BX & $1.14 \mathrm{E}-06$ \\
(Flood)QsU & $4.46 \mathrm{E}-08$ \\
(Flood)QsX & $1.12 \mathrm{E}-06$ \\
(Flood)BU & $8.54 \mathrm{E}-08$ \\
\hline TOTAL & $2.39 \mathrm{E}-06$ \\
\hline
\end{tabular}


As an example, the following minimal cut set was taken from the IPE. This cut set is from sequence (Flood)QSU.

\begin{tabular}{|l|c|l|}
\hline Event Name & Probability & Event Description \\
\hline FLN & $3.4 E-04$ & Large, nonisolable Turbine Building flood \\
WSFORCMDHE & $1.0 \mathrm{E}-01$ & $\begin{array}{l}\text { Operators fail to align the SSF RCM system } \\
\text { Wlevated water storage tank unavailable due to } \\
\text { latent human error }\end{array}$ \\
\hline Frequency & $3.0 \mathrm{E}-03$ & $1.02 \mathrm{E}-07 / \mathrm{RY}$ \\
\hline
\end{tabular}

This cut set was modified as follows:

\begin{tabular}{|c|c|c|}
\hline Event Name & Probability & Event Description \\
\hline FLW & $3.4 \mathrm{E}-04$ & Large, nonisolable Turbine Building flood \\
\hline SSF_HVAC & $1.57 \mathrm{E}-02$ & Failure of SSF HVAC fails the SSF RCM system \\
\hline WHSEWSTLHE & $3.0 \mathrm{E}-03$ & $\begin{array}{l}\text { Elevated water storage tank unavailable due to } \\
\text { latent human error }\end{array}$ \\
\hline Frequency & \multicolumn{2}{|l|}{$1.60 E-08 / R Y$} \\
\hline
\end{tabular}

This procedure was repeated for all the affected cut sets in this accident sequence. The affected CDF for this sequence was calculated to be $1.12 \mathrm{E}-06 / \mathrm{RY}$.

(Flood)BX: This sequence is a Turbine Building flood with failure of secondary-side heat removal and failure of the HPI system during recirculation. The SSF ASW function was applied as a recovery action in this sequence. Therefore, the approach to calculating the affected CDF for this sequence is identical to the approach used for (Flood)QSX; i.e., substituting the SSF HVAC failure probability into the affected cut sets to replace parameters involving failure of equipment cooled by the SSF HVAC system. The modified cut sets were then requantified and summed to calculate the affected CDF for this sequence. The resulting affected CDF for sequence (Flood)BX was calculated to be $1.14 \mathrm{E}-06 / \mathrm{RY}$.

(Flood)BU: Sequence (Flood)BU is a flood in the Turbine Building followed by failure of a11 secondary side heat removal and failure of HPI cooling in the injection phase. As with the (Flood)BX sequence, the SSF ASW function was applied as a recovery action in this sequence. Therefore, the approach to calculating the affected CDF for this sequence consisted of substituting the SSF HVAC failure probability into the affected cut sets to replace parameters involving failure of equipment cooled by the SSF HVAC system. The modified cut sets were then requantified and summed to calculate the affected CDF for this sequence. The resulting affected CDF for sequence (Flood)BU was calculated to be $8.54 E-08 / R Y$. 
(Flood)OsU: This sequence is initiated by a Turbine Building flood followed by failure of the RCP seals and failure of HPI in the injection phase. Secondary-side heat removal is successful so core damage, if it occurs, will occur late. The SSF RCM function was used as recovery for this sequence. Following the same procedure outlined above, the affected CDF for this sequence was calculated to be $4.46 \mathrm{E}-08 / \mathrm{RY}$.

Several other flood sequences were examined in the IPE. Flooding of the HPI pump room and equipment rooms located in the Auxiliary Building was evaluated and found to be negligible relative to the Turbine Building flood scenarios. Other areas evaluated in the IPE included the main control room, cable-spreading room, cable shaft, component cooling pump room, and other Auxiliary Building pump rooms. These rooms cause little or no concern related to flooding for various reasons:

- Detection: some rooms are occupied at all times and operators would immediately detect a flood in these areas.

- Timing: some flood source are so small that operators would have a significant amount of time to take mitigating actions.

- Elevation: the elevations of some rooms and the elevations of important equipment within rooms to prevent contact with floodwater.

- Flood control: some equipment is located in areas that are open to corridors that would dissipate the flood.

For these reasons, the IPE focused on floods in the Turbine Building.

\subsection{ASSESSMENT OF AFFECTED CDF DUE TO TORNADOES}

The effects of tornadoes on nuclear power plant structures, systems, and components are considered in plant design and siting decisions in accordance with 10 CFR 50 and 10 CFR 100, respectively. The basic premise is that plants must be designed to withstand a design-basis tornado whose characteristics (including wind speed, rotational velocity, and pressure drop) are specified in NRC Regulatory Guide 1.76 (NRC 1974). This regulatory guide specifies the design basis tornado characteristics for three regions of the country (see Table 5.4-1 and Figure 5.4-1). Thus, for a tornado to damage HVAC or room cooler systems, the characteristics of the tornado would have to exceed those specified in the regulatory guide.

Tornadoes may damage nuclear power plant structures, systems, and components through one of three mechanisms:

- mechanical loadings caused by the impact of winds on structures

- tornado-generated missile impacts

- ambient pressure drop. 
TABLE 5.4-1. Design Basis Tornado Characteristics

\begin{tabular}{|c|c|c|c|c|c|c|c|}
\hline & $\begin{array}{c}\text { Max. } \\
\text { Wind } \\
\text { Region }\end{array}$ & $\begin{array}{c}\text { Rota- } \\
\text { tional } \\
\text { mph }\end{array}$ & $\begin{array}{c}\text { Speed, } \\
\text { mph }\end{array}$ & $\begin{array}{c}\text { Translational } \\
\text { Speed, mph }\end{array}$ & $\begin{array}{c}\text { Radius } \\
\text { of Max. } \\
\text { Rotational } \\
\text { Speed, feet }\end{array}$ & $\begin{array}{c}\text { Pressure } \\
\text { Drop, } \\
\text { psi }\end{array}$ & $\begin{array}{c}\text { Rate of } \\
\text { Pressure } \\
\text { Drop, } \\
\text { psi/sec }\end{array}$ \\
\hline I & 360 & 290 & 70 & 5 & 150 & 3.0 & 2.0 \\
\hline II & 300 & 240 & 60 & 5 & 150 & 2.25 & 1.2 \\
\hline III & 240 & 190 & 50 & 5 & 150 & 1.5 & 0.6 \\
\hline
\end{tabular}

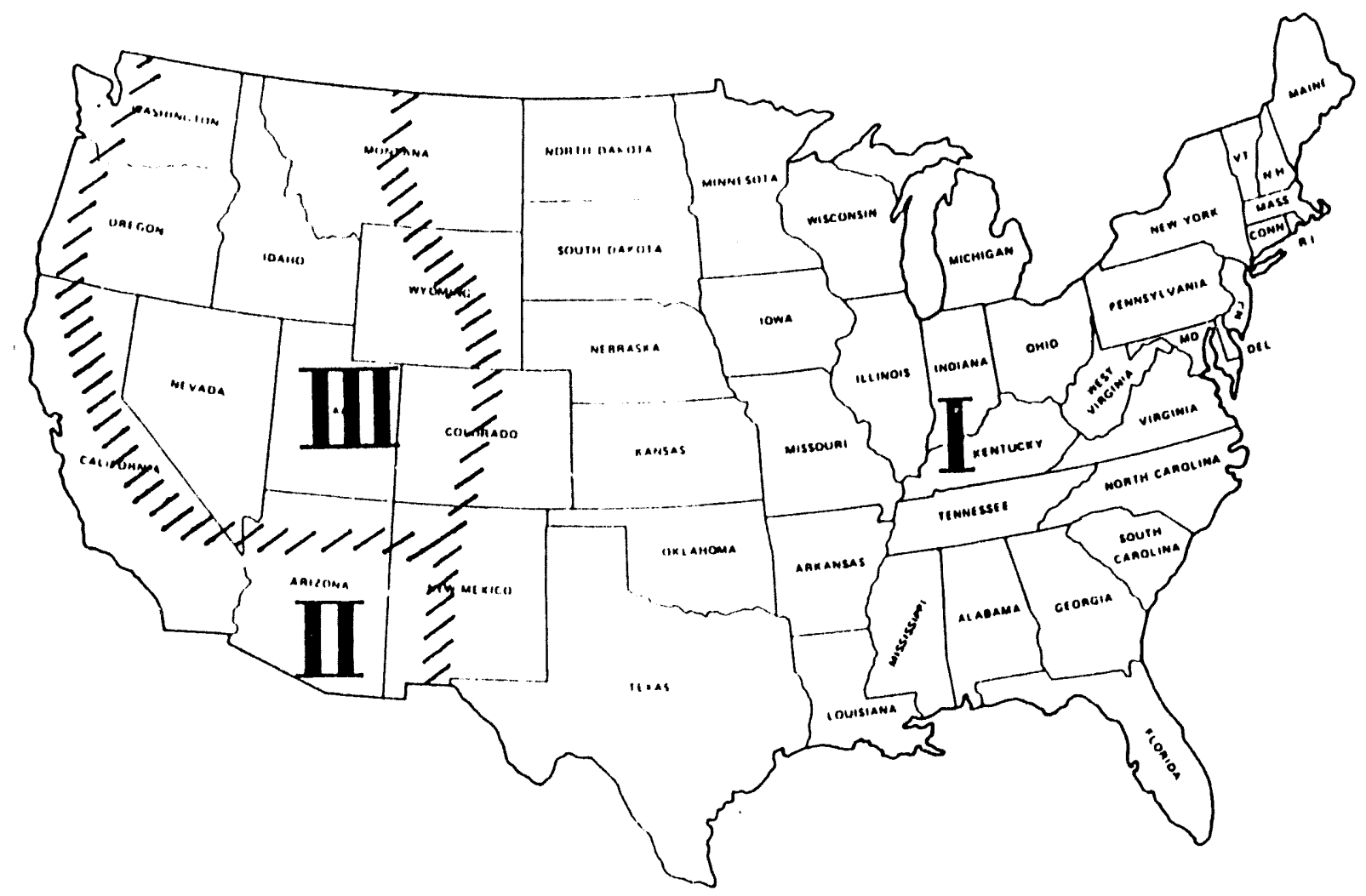

FIGURE 5.4-1. Tornado Intensity Regions

The effects of each of these damage mechanisms on HVAC and room cooler system equipment are addressed in this section.

Tornadoes produce high winds that may impact directly on external structures. The frequencies of tornadoes of sufficient intensity to produce significant structural damage at a nuclear power $p l a n t$ site are a function of the region in which the plant is located. Ramsdell and Andrews (1986) divided the United States into two regions: Eastern Region (east of the 
$105^{\circ}$ longitude near the Rocky Mountains) and Western Region (west of $105^{\circ}$ longitude). Tornado strike probabilities and intensities depend upon the region being considered. In general, tornado strike probabilities and intensities are much greater in the Eastern Region than the Western Region. The tornado strike probability for the West was estimated by Ramsdell and Andrews to be approximately 3.5E-06/yr and in the East to be approximately 2.3E-04/yr (p. 44). These values represent the expected frequencies of all tornadoes of all intensities in the specific regions.

The effects of tornado-induced high winds may include structural failures of buildings, including the Auxiliary Building, Control Building, Turbine Building, and Diesel Generator Building, as well as failure of outdoor switchyards, overhead lines, transformers, and storage tanks. Buildings containing safety-related HVAC equipment (Auxiliary, Diesel Generator, and Control Buildings) are generally Seismic Category I structures constructed of reinforced concrete frames. Features that provide protection from structural damage during seismic events also provide substantial protection from tornado damage. Only high-intensity tornadoes will produce significant wind damage to these structures. A single tornado will not impact all of these structures simultaneously, because one structure will shield one or more other structures from the high winds (Kimura and Budnitz 1987).

Tornado intensities vary with the region under consideration. Table 5.4-1 presents the distribution of tornado intensities in two regions of the United States that was developed by Ramsdell and Andrews. The Eastern Region includes Tornado Region I as defined in Regulatory Guide 1.76, and the Western Region includes Tornado Regions II and III. The table also shows the wind speeds associated with each tornado intensity classification. Critical intensities in terms of the classification of tornadoes that could cause serious damage to nuclear power plant buildings (i.e., not including outdoor tanks, switchyards, and overhead lines) are those tornadoes exceeding F3 intensities, which are characterized by wind speeds from 158 to $206 \mathrm{mph}$. The Oconee IPE (Duke Power Co. 1990) stated that a tornado of F4 intensity or greater may cause the reinforced-concrete-framed exterior walls of the Auxiliary Building to fail. It was concluded that the exterior siding of the steel-framed Turbine Building, also provided with concrete floors, would be destroyed by a tornado, but the frame and floors are expected to be largely undamaged. Thus, it appears that the an F3 tornado could cause failure of the Turbine Building and other steel-framed, concrete-floored buildings. The reinforced-concrete-framed walls of the Control and Auxiliary Buildings would likely survive an F3 intensity tornado but could fail in tornadoes with an F4 or greater intensity. The Oconee IPE further stated that the outdoor borated water storage tank (BWST) will fail at wind speeds slightly above $150 \mathrm{mph}$, or the upper end of the F2 intensity classification. With this in mind, the Oconee IPE (Duke Power Co. 1990) assumed that tornadoes will fail all outdoor switchyards, gverhead lines, and transformers, rendering all AC power supplies unavailable. (a)

(a) An underground power cable protected by a reinforced concrete enclosure was assumed to be available. 
Most safety-related HVAC and room cooling equipment is located in the Control and Auxiliary Buildings, which are typically Seismic Category I buildings of reinforced-concrete construction. Diesel generator butldings are also constructed of reinforced concrete for seismic protection. As a result, it is likely that these three types of buildings will survive tornadoes up through F3 intensity. Based on this observation and the tornado strike probabilities shown in Table 5.4-2, it is concluded that the frequencies of tornadoes severe enough to fail HVAC equipment due to wind loadings on the structures in which they are housed is, at most, 3.6E-05/yr in the Eastern United States and less than 1.2E-07/yr in the West. Therefore, on this basis, it was concluded that the CDF attributable to tornado-induced failures of HVAC/room coolers in western plants is insignificant relative to other external and internal events.

The frequency of tornadoes severe enough to result in failure of buildings housing HVAC/room cooler equipment, about 3.6E-05/yr for Eastern Region plants, may cause equipment other than HVAC/room coolers to fail, including safety-related ECCS pumps, valves, and switchgear that are served by HVAC and room cooler systems. It is likely that any tornado severe enough to cause an HVAC or room cooler component to fail will also fail the equipment served by that HVAC and room cooler system. No information in the literature was found to indicate that HVAC/room cooler equipment is more vulnerable to tornadoinduced wind loadings than other safety-related components. This conclusion was derived through reviews of the Oconee IPE (Duke Power Co. 1990) and from synopses of 12 plant-specific PRAs containing tornado analyses that were reviewed by Kimura and Budnitz (1987). In none of these assessments did HVAC and room cooling equipment contribute to tornado risk. The main reason for

TABLE 5.4-2. Tornado Strike Probabilities

\begin{tabular}{|c|c|c|c|}
\hline \multirow[b]{2}{*}{ Intensity } & \multirow{2}{*}{$\begin{array}{l}\text { Wind } \\
\text { Speed, mph }\end{array}$} & \multicolumn{2}{|c|}{$\begin{array}{c}\text { Tornado Strike } \\
\text { Frequency, per year }\end{array}$} \\
\hline & & East & West \\
\hline FO & 40 to 72 & $2.26 \mathrm{E}-04$ & $3.54 E-06$ \\
\hline $\mathrm{F} 1$ & 73 to 112 & $2.23 E-04$ & $3.04 E-06$ \\
\hline $\mathrm{F} 2$ & 113 to 157 & $1.89 E-04$ & $2.01 E-06$ \\
\hline F3 & $156: 0206$ & $1.07 E-04$ & $1.16 E-07$ \\
\hline F4 & 207 to 260 & $3.56 E-05$ & (a) \\
\hline F5 & $>261$ & $4.97 E-06$ & (a) \\
\hline \multicolumn{4}{|c|}{$\begin{array}{l}\text { Due to the relatively sparse historical tornado data } \\
\text { (1954 to 1983) for the West, and to only } 11 \text { torna- } \\
\text { does in the database for this region listed as F3 } \\
\text { intensity, these probabilities were not calculated } \\
\text { by Ramsdeil and Andrews (1986). }\end{array}$} \\
\hline
\end{tabular}


this observation appears to be that the conditional probability of a tornadoinduced fallure of HVAC and room cooling equipment is equal to or substantially smaller than the conditional probability of tornado-induced failure of the components served by the HVAC/room cooler. Furthermore, the conditional probability that a tornado falls an HVAC component but does not also fail the component served by the HVAC system is small relative to the probability that the tornado directly causes the safety-related pump, valve, or switchgear, to fail.

To illustrate the above observation, assume that a tornado-induced LOOP occurs. The tornado is also assumed to fail the EOG Building, resulting in loss of the emergency AC power system, or SBO. At PWRs, this results in a demand for the AFW TDP, which is located in a room cooled by a safety-related room cooler. The AFW pump room is typically located in the reinforced-

concrete Auxiliary Building. The high winds are assumed to be severe enough to fail the Auxiliary Building walls. Three possible scenarios involving the AFW pump room are possible:

- The tornado fails the turbine-driven AFW pump but not the AFW pump room cooler.

- The tornado fails the AFW pump room cooler and the AFW pump.

- The tornado fails the AFW pump room cooler but not the AFW pump.

In the first two possible scenarios, the AFW TDP train is immediately unavailable to perform its function. In the third scenario, assuming no other failures in the AFW pump train, the AFW pump will function initially, but room cooling must be restored to ensure continued operation of the TD AFW pump train. Therefore, in the third scenario, which is the scenario of interest to this study, time is available to restore the room cooler to operable status (if $A C$ power is available; some plants have a DC-powered backup room cooler) or implement recovery actions (e.g., open doors, install portable fans). It is apparent that the third scenario is less likely than the first two because of the possibility that some form of cooling can be restored to the AFW pump room.

It was concluded that tornado-induced CDFs due to high winds that involve HVAC and room cooler failures is insignificant. The frequencies of tornadoes severe enough to fail structures housing HVAC and room cooling components were shown to be less than $1 \mathrm{E}-07 / \mathrm{yr}$ in the West and about 3.6E$05 / \mathrm{yr}$ in the East. These initiating events must be followed by safety system failures to lead to a core damage accident. A single tornado is not likely to fail redundant trains of ECCS cooling because of the abilities of buildings containing safety-related components to withstand high wind loadings. Buildings also can provide protection to other buildings against tornado winds because they provide intervening shielding. A single tornado is not likely to fail one or more entire ESF systems because of the diversity and separation of redundant trains of ESF equipment. Furthermore, the probabilities that HVAC/ room cooler components fail as a result of the tornado high winds were shown to be less likely than failure of the components served by the HVAC/room 
cooler systems due to the time available to restore some form of room cooling. The conditional probabilities of safety system failures and low tornado frequencies will therefore result in insignificant CDF levels from tornadoinduced high winds.

The second tornado damage mechanism is the tornado-induced missile. Missiles may be generated when the high winds of tornadoes interact with objects at a nuclear power plant site. Examples of missiles include trees, pipes, cars, telephone/power poles, and fence posts. Typically, computerized Monte Carlo analyses are performed using site-specific characteristics to determine the conditional probabilities of missile-induced damage to structures. Core damage frequencies from tornado-generated missiles are, in general, insignificant contributors to total CDFs. This observation has been made in a number of tornado risk assessments:

- Plant-specific tornado-missile analyses were performed in the Oconee IPE (Duke Power Co. 1990). It was concluded that the risk of tornadomissile-induced core damage is insignificant.

- Results of case studies described by Twisdale, Dunn, and Chu (1978) indicated that the annual frequencies of missile-induced core damage are on the order of 1E-07/yr or less in the East and 1E-08/yr in the West. The highest frequency sequences involved direct failures of ESF components due to missile damage. The CDF associated with tornado-missile damage to HVAC/room cooling equipment would be a fraction of these values.

- Lambright et al. (1990) concluded that the CDF from tornado missile impacts to plant structures at a BWR results in negligible CDFs, primarily because the thicknesses of exterior walls of safety-related structures were shown to be adequate to prevent structural failures.

- Bohn et al. (1990) concluded that the risk of core damage from tornado winds and tornado missile impacts at a W PWR are negligible, because there were no metal-sided walls or roofs on safety-related structures, and the concrete walls of these buildings were at least 18 in. thick.

Core damage frequencies associated with tornado-generated missile damage to HVAC and room cooler systems would be a fraction of the total CDF from tornado-generated missiles, because direct missile impacts to safety-related components are at least as likely as impacts on HVAC/room cooler equipment. As with tornado winds examined above, the likelihood of safety system fallures due to missile impacts would be dominated by the direct missile impact on the ESF component and not by indirect failure of the ESF component due to missileinduced failure of HVAC/room cooler systems. Therefore, the CDF from tornadogenerated missile damage to $\mathrm{HVAC} / \mathrm{room}$ cooler systems is also insignificant.

The third potential tornado-induced failure mechanism is related to the ambient pressure changes caused by passage of the tornado. Regulatory Guide 1.76 (NRC 1974) specifies the design-basis pressure changes ranging from 1.5 
to 3.0 psi in tornado regions III and I, respectively. Furthermore, Regulatory Guide 1.117 (NRC 1978) requires tornado protection for the following HVAC and room cooler systems:

- "Systems or portions of systems that are required for ... supporting the above systems, e.g., cooling water, ultimate heat sink, air supply, auxiltary feedwater, and ventilation."

- "The control room, including all equipment needed to maintain the control room within safe habitability limits for personnel and safe environments for tornado-protected equipment."

- "Systems or portions of systems that are required for monitoring, actuating, and operating tornado-protected portions of systems listed in items ..."

- "Those portions of the long-term ECCS system that would be required to maintain the plant in a safe condition for an extended time after a LOCA."

- "The Class $1 E$ electric systems, including the auxiliary systems for the onsite electric power supplies, ..."

These requirements effectively include the short-term and long-term room cooling functions for all ESF systems. Therefore, the effects of tornadoinduced pressure drops on HVAC and room cooler systems are addressed in plant design activities. On this basis, only a tornado with characteristics more severe than those listed in Table 5.3-3 will cause any significant damage to safety-related HVAC/room cooler equipment. It was previously shown that the frequencies of such tornadoes are about 1E-07/yr in the West and about $4 E-05 / y r$ in the Eastern United States (see Table 5.4-1).

Assuming that a tornado-induced pressure drop fails the tornado protection systems for HVAC and room cooler components such as tornado damper on inlet and outlet ventilation fans, an interruption of HVAC functions may occur due to fan fallure or other causes. If this occurs, time is available to recover ventilation airflow capabilities to safety-related equipment rooms. Cross-connect capabilities to unfailed systems exist and, if the cross-connect fails or does not exist, supplementary room cooling provisions are available. Consequently, it was concluded that ambient pressure changes caused by tornadoes will contribute negligibly to the affected CDF due to HVAC and room cooler failures.

In conclusion, this discussion has demonstrated that the CDF associated with tornado-induced HVAC and room cooler system failures is negligible. This was based primarily on the low frequencies of tornadoes severe enough to exceed the design basis tornado characteristics, the physical protection from high winds and missiles provided by safety-related structures, and the redundancy and diversity of ESF functions. 


\subsection{IOTAL CORE DAMAGE FREOUENCY AND PUBLIC RISKS DUE TO EXTERNAL EVENTS}

The total CDF due to external events that involves loss of room cooling functions is the sum of the CDF due to seismic events, fires, and floods. Table 5.5-1 summarizes the results developed in this section. As shown in Table 5.5-1, the affected CDF (sum of seismic-, flood-, and fire-induced CDFs) was calculated to be about 8E-06/RY for PWRs and 8E-06/RY for BWRs. These values represent about 5 to $6 \%$ of the total external event CDF for both plant types.

\section{IABLE 5.5-1. Summary of Affected Core Damage Frequency Due to External Events}

\begin{tabular}{|c|c|c|c|c|c|c|c|}
\hline \multirow[b]{2}{*}{ External Event } & \multicolumn{2}{|c|}{$\begin{array}{l}\text { Original } \\
\text { COF. per RY (a) }\end{array}$} & \multicolumn{2}{|c|}{$\begin{array}{l}\text { Affected } \\
\text { COF, per RY }\end{array}$} & \multicolumn{2}{|c|}{$\begin{array}{l}\text { Fraction, } \\
\text { Affected: Total }\end{array}$} & \multirow[b]{2}{*}{$\begin{array}{l}\text { Report } \\
\text { Section }\end{array}$} \\
\hline & PUR & BWP & PWR & BWR & PWR & BWR & \\
\hline Seismic & 1.12E-04 & $7.68 \mathrm{E}-05$ & $8.42 E-08$ & $1.97 E-08$ & 0.0008 & 0.0003 & 5.1 \\
\hline $\begin{array}{l}\text { Fire } \\
\text { - Control room } \\
\text { - } \text { DC equipment } \\
\text { room } \\
\text { - Emergency } \\
\text { switchgear room }\end{array}$ & $\begin{array}{l}\text { 1. } 58 E-06 \\
\quad \text { Not } \\
\text { Evaluated } \\
6.09 E-06\end{array}$ & $\begin{array}{l}6.20 E-06 \\
\text { Not } \\
\text { Evaluated } \\
1.30 E-05\end{array}$ & $\begin{array}{l}1.92 E-06 \\
1.49 E-06 \\
3.70 E-06\end{array}$ & $\begin{array}{l}1.92 E-06 \\
1.49 E-06 \\
3.70 E-06\end{array}$ & (g) & (g) & $\begin{array}{l}5.2 .3 \\
5.2 .2 \\
5.2 .1\end{array}$ \\
\hline Total fire & $1.13 E-05^{(C)}$ & $1.92 \mathrm{E}-05^{(T)}$ & $7.11 E-06$ & $7.11 E-06$ & 0.63 & 0.36 & \\
\hline $\begin{array}{l}\text { Flood } \\
\text { - Control room } \\
\text { - DC equipment } \\
\text { room } \\
\text { - Emergency } \\
\text { switchgear room } \\
\end{array}$ & $\begin{array}{c}\text { Not } \\
\text { Evaluated }\end{array}$ & $\begin{array}{c}\text { Not } \\
\text { Evaluated }\end{array}$ & $\begin{array}{l}4.23 E-07 \\
5.71 E-08 \\
5.15 E-07\end{array}$ & $\begin{array}{l}4.23 E-07 \\
5.71 E-08 \\
5.15 E-07\end{array}$ & $\cdots$ & $\cdots$ & $\begin{array}{l}5.3 .1 .3 \\
5.3 .1 .2 \\
5.3 .1 .1\end{array}$ \\
\hline $\begin{array}{l}\text { Total Floop } \\
\text { "Generic" } \\
\text { B\&W PWR }\end{array}$ & $2.80 E-05^{(d)}$ & $2.80 E-0.5(d)$ & $\begin{array}{l}9.95 E-07 \\
2.39 E-06\end{array}$ & $9.95 E-07$ & $\begin{array}{l}0.036 \\
0.085\end{array}$ & $\begin{array}{c}0.036 \\
\ldots\end{array}$ & 5.3 .2 \\
\hline Tornadoes & $9.70 E-06^{(E)}$ & $9.70 E-06$ (e) & $\mathrm{Neg}$. & Neg. & $\cdots$ & $\cdots$ & 5.3 .3 \\
\hline $\begin{array}{l}\text { Total External } \\
\text { Event CDF }\end{array}$ & $1.61 E-04$ & 1. $34 E-04$ & 8. $19 E-06$ & $8.12 E-06$ & 0.05 & 0.06 & \\
\hline \multicolumn{8}{|c|}{$\begin{array}{l}\text { Note: Neg. = Negligible. CDF less than IE-08/RY. Excess significant figures are retained for } \\
\text { calculation purposes. } \\
\text { (a) Bohn et al. (1990) and Lambright et al. (1990) for PWRs and BWRs, respectively. Mean values are } \\
\text { given in the table. } \\
\text { (b) "Generic" values were calculated in Section } 5.3 .1 \text { and are assumed to be applicable to CE and } W \\
\text { PWRs and GE BWRs. An additional value was calculated for a BQW PWR. } \\
\text { (c) Includes contributions from fires in the cable vault/tunnel and charging pump service water pump } \\
\text { room that are not affected by this generic issue as well as the locations listed in the table. } \\
\text { (d) Oconee IPE (Ouke Power Co. 1990). Sum of CDF from internal and external floods. } \\
\text { (e) Oconee IPE (Duke Power Co. 1990). } \\
\text { (f) Includes contributions from fires in the cable spreading room that are not affected by this } \\
\text { generic issue as well as the locations listed in the table. } \\
\text { (g) The affected portions of the individual fire sequence frequencies are not calculated because a } \\
\text { combined PWR and BWR fire-induced CDF was calculated. This appears to be reasonable given that } \\
\text { the difference between the total fire-induce CDF for PWRs and BWRs are approximately equal. }\end{array}$} \\
\hline
\end{tabular}


For both PWRs and BWRs, the affected seismic CDF is dominated by a few accident sequences. The dominant accident sequences primarily involve SBO situations, although the exact causes of SBO differ among plant types. For example, at the representative BWR, the most important cause of fallure of the emergency $A C$ power system was fallure to provide cooling water to the EDGs. Fallure of the ESW and emergency cooling water systems were the most important causes of EDG fallure. At the representative PWR, the dominant accident sequences were LOOP transient sequences. The most dominant sequence involved a LOOP transient followed by fallure of the AFW and HPI systems either due to failure of the CST or fallure of emergency AC power. The second most dominant sequence involves a LOOP transient followed by failure of both the HPI and CCW systems, leading to a reactor coolant pump seal LOCA.

Another observation from Table 5.5-1 is that the affected fire-induced CDF is a much larger fraction of the total fire-induced CDF than the corresponding fraction of the seismic-induced CDF. The main reason for this is that the HVAC and room cooling equipment is much less vulnerable to seismic-induced failures than other safety system components, such as pumps and valves (see Table 5.1-1). Consequently, dominant seismic accident sequences were observed to involve losses of equipment and components that are more vulnerable to seismic failures.

Safety injection system fallures in dominant accident sequences were not HVAC-dependent (e.g., suction sources such as the CST and RWST). This tends to minimize the contributions of HVAC failures to seismic accident sequences. On the other hand, HVAC equipment is as vulnerable to fire-induced failures as other safety-related components, and fire accident sequences do not tend to be dominated by HVAC-independent equipment failures such as the suction sources listed above. As a result, the HVAC and room cooler system contributions to fire-induced core damage sequences are much more significant than their contributions to seismic-induced core damage sequences.

HVAC/room cooler contributions to the CDF from seismic and tornado accident sequences were, in general, relatively small compared with the contributions from flood-and fire-induced CDF. A key reason for this is that HVAC and room cooler components are as vulnerable to seismic and tornado hazards as the components they serve but are less likely to fail under tornado and seismic conditions. Seismic events and tornadoes can simultaneousiy affect the operability of room coolers and HVAC equipment in addition to the ESF equipment they protect. Therefore, the relative unavailabilities of HVAC/room coolers and ESF functions, given the occurrence of a seismic event or tornado, are a function of the equipment vulnerabilities to these events. It has been shown previously that the failure probabilities of room coolers and HVAC equipment, given a seismic event, are substantially smaller than the failure probabilities of certain components of the systems they support. On the other hand, floods and fires affect only limited portions of the plant. Since HVAC equipment is generally located in different rooms than the switchgear, $D C$ equipment, and control room equipment, the likelihood is low that a flood or fire will simultaneously fail both the HVAC systems and the ESF 
systems served by the HVAC system. This is one reason why the fractional contributions of HVAC and room cooler system fallures are smaller for seismic events and tornadoes than for floods and fires.

One other important observation related to modeling of the HVAC/room cooler fallures is related to the above observation. Because the HVAC and room cooler equipment appear to be less vulnerable to failure under external event conditions, it is unlikely that an external event will cause failure of the HVAC/room cooler components and not the ESF component supported by HVAC/ room coolers. For example, a seismic event is much less likely to fail an HPI pump room cooler than the HPI pump. Based on the median fragility data presented in Table 5.1-1, a seismic event severe enough to fail a room cooler will also fail the HPI pump. Therefore, it is even less likely that a seismic event will fail the room cooler and not fail the HPI pump. Obviously, failure of the HPI pump is a more critical fallure than a room cooler failure because of the possibility of restoring some form of HPI pump room cooling. On the other hand, if an external event fails the HPI pump, it becomes immediately unavailable and is not likely to be recovered in time to prevent core damage. Therefore, under external event conditions, failures of the ESF system components are more critical, and tend to dominate the CDF, than failures of HVAC and room cooling equipment. This is illustrated in Table 5.5-1 by the relatively small contributions of HVAC/room cooler failures to the total external event CDF.

The affected public risks associated with external event-induced HVAC/room cooler failures were calculated using the same approach described in Sections 4.1 and 4.2. The accident progression analyses described by Gregory et al. (1990) and Brown et al. (1990) were used to assign the external event sequences to appropriate accident progression bins (APBs) and to establish source term categories for the respective APBS. The conditional probabilities of the APBS and source term categories were taken from these documents, as were the release consequences for the respective source term categories. The public risk calculations were performed in the same manner as the calculation process described in Section 4.1.3.

The public risk calculations and results are presented in Table 5.5-2 for the representative $W$ and CE PWRs and in Table 5.5-3 for the representative BWR. The results indicate that the affected public risk values are 5.6 person-rem/RY and 3.9 person-rem/RY for the representative $W / C E$ PWR and GE BWR, respectively.

A separate analysis was performed to calculate the affected floodinduced public risk for a B\&W PWR. This was done as a check on the adequacy of the risk calculations shown in Tables 5.5-2 and 5.5-3. The B\&W flood risk calculations are based on the accident progression and consequence analyses in the plant's IPE (Duke Power Co. 1990). Each minimal cut set in the IPE was assigned to a plant damage state, as was done for the other plants. Each plant damage state corresponded to specific release categories that were presented in Table 6.3-23 of Duke Power Co. (1990). Each release category has an associated probability of occurrence, given the prior occurrence of the specific plant damage state. In addition, each release category has associated 
TABLE 5.5-2. External Event Public Risk Calculations for the Representative $W$ and CE PWRs

\begin{tabular}{|c|c|c|c|c|c|c|c|}
\hline $\begin{array}{l}\text { Accident Pro- } \\
\text { gression Bin }\end{array}$ & $\begin{array}{l}\text { Conditional } \\
\text { Probability }\end{array}$ & Frequency & $\begin{array}{l}\text { Source Term } \\
\text { Group }\end{array}$ & $\begin{array}{l}\text { Conditional } \\
\text { Probability }\end{array}$ & $\begin{array}{l}\text { Source Term Group } \\
\text { Frequency }\end{array}$ & $\begin{array}{l}\text { Consequences, } \\
\text { Person-ren/Event }\end{array}$ & $\begin{array}{l}\text { Risk. } \\
\text { Person-rem/RY }\end{array}$ \\
\hline $\begin{array}{l}\text { CF during CD } \\
\text { No VB } \\
C F \text { at VB } \\
\text { VB. no CF at VB } \\
\text { CF by late burn } \\
\text { CF by very late OP } \\
\text { CF by very later BMT }\end{array}$ & $\begin{array}{l}0.002 \\
0.798 \\
0.021 \\
0.181 \\
0.001 \\
0.016 \\
0.023\end{array}$ & $\begin{array}{l}1.64 E-08 \\
6.53 E-06 \\
1.72 E-07 \\
1.48 E-06 \\
8.19 E-09 \\
1.31 E-07 \\
1.88 E-07\end{array}$ & $\begin{array}{l}\text { SEQ-14-1 } \\
\text { SEQ-14-2 } \\
\text { SEQ-14-3 } \\
\text { SEQ-01-02 } \\
\text { SEQ-07-03 } \\
\text { SEQ-04-01 } \\
\text { SEQ-04-03 } \\
\text { SEQ-16-01 } \\
\text { SEQ-16-02 } \\
\text { SEQ-17-01 } \\
\text { SEQ-17-02 } \\
\text { SEQ-18-01 } \\
\text { SEQ-18-02 }\end{array}$ & $\begin{array}{l}0.039 \\
0.359 \\
0.602 \\
1.000 \\
1.000 \\
0.002 \\
0.998 \\
0.990 \\
0.010 \\
0.999 \\
0.001 \\
0.888 \\
0.112\end{array}$ & $\begin{array}{l}6.39 E-10 \\
5.88 E-09 \\
9.86 E-09 \\
6.53 E-06 \\
1.72 E-07 \\
2.96 E-09 \\
1.48 E-06 \\
8.11 E-09 \\
8.19 E-11 \\
1.31 E-07 \\
1.31 E-10 \\
1.67 E-07 \\
2.11 E-08\end{array}$ & $\begin{array}{l}1.13 E+07 \\
2.96 E+04 \\
8.20 E+06 \\
3.19 E+04 \\
1.49 E+06 \\
7.71 E+05 \\
6.82 E+05 \\
1.38 E+02 \\
1.98 E+03 \\
1.14 E+03 \\
8.09 E+03 \\
1.06 E+05 \\
3.06 E+05\end{array}$ & $\begin{array}{l}7.22 E-03 \\
1.74 E-04 \\
3.09 E-02 \\
2.08 E-01 \\
2.56 E-01 \\
2.29 E-03 \\
1.01 E+00 \\
1.12 E-06 \\
1.62 E-07 \\
1.49 E-04 \\
1.06 E-06 \\
1.77 E-02 \\
6.46 E-03\end{array}$ \\
\hline
\end{tabular}

TABLE 5.5-3. External Event Public Risk Calculations for the Representative BWR

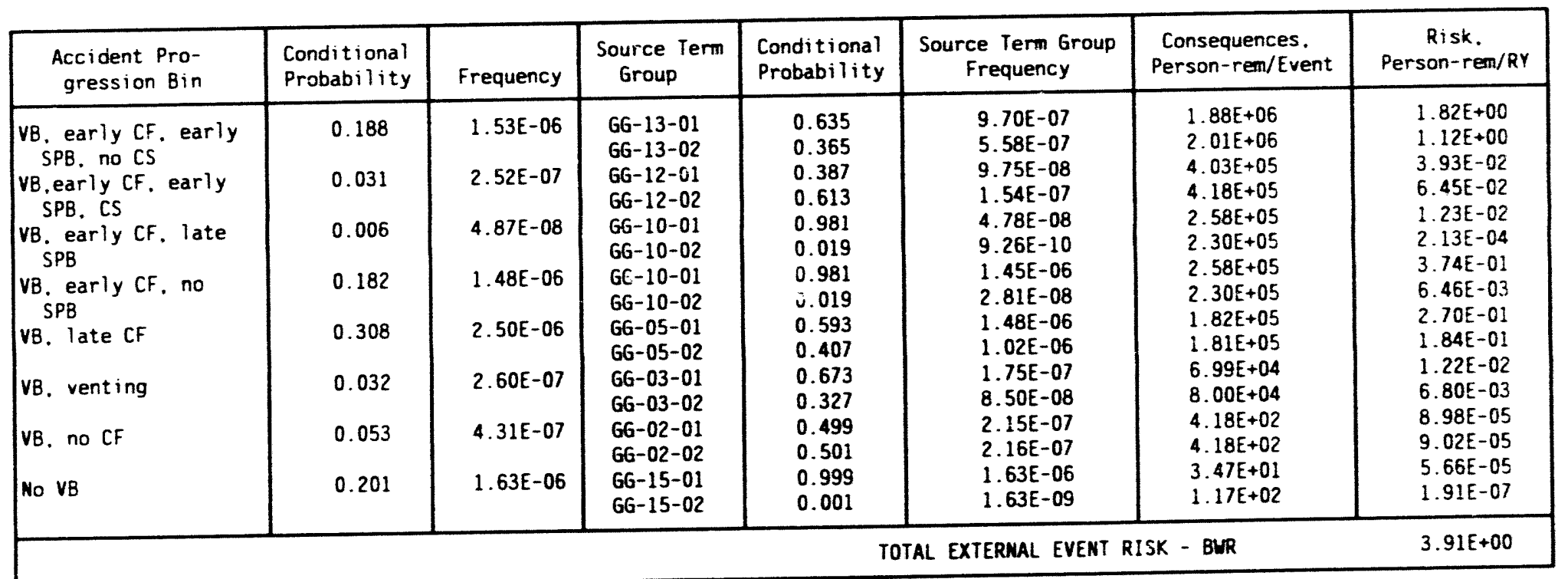


consequences, including integrated population doses (see Table 7.3-1 of Duke Power Co. 1990). The affected public risk is calculated by multiplying together the affected CDF, corresponding release category probability, and release consequences.

As an example of the risk calculation procedure, consider floodinitiated accident sequence (Flood) QsX. Table D-4 of the IPE provided a minimal cut set listing for the flood-initiated accident sequences. This table also provided the plant damage state (PDS) associated with each cut set. All of the affected cut sets in this sequence were stated to have been assigned to PDS 8F. A matrix was prepared for the IPE (Table 6.3-23 of Duke Power Co. 1990) that provided the corresponding release categories and conditional probabilities for each release category. The table indicated the following release categories and probabilities are relevant to PDS 8F:

\begin{tabular}{|c|c||c|c|}
\hline Release Category & Probability & Release Category & Probability \\
\hline RC 9.02 & $7.53 E-02$ & RC 8.01 & $8.55 E-01$ \\
RC 7.02 & $2.03 E-02$ & RC 7.04 & $4.92 \mathrm{E}-04$ \\
RC 6.02 & $1.14 \mathrm{E}-03$ & RC 5.01 & $4.80 \mathrm{E}-03$ \\
RC 5.02 & $4.09 \mathrm{E}-02$ & & \\
\hline
\end{tabular}

The release category probabilities are multiplied by the affected CDF for this flood sequence to calculate the PDS frequency. In this case, since all of the cut sets were indicated to be assigned to a single PDS, the affected CDF being assigned to PDS $8 F$ is the total affected (Flood)QsX sequence frequency or $1.12 \mathrm{E}-06 / \mathrm{RY}$. Other flood sequences were partitioned into two or more PDSs so care must be taken to ensure that the cut set frequencies are placed in the correct PDS bin and summed accordingly. As an example, the frequency calculated for sequence (Flood)QsX that leads to release category $\mathrm{RC} 9.02$ is

Sequence: (Flood)QsX

PDS 8F

$$
\begin{aligned}
\mathrm{RC} 9.02 \text { frequency } & =1.12 \mathrm{E}-06 / \mathrm{RY} * 7.53 \mathrm{E}-02 \\
& =8.4 \mathrm{E}-08 / \mathrm{RY}
\end{aligned}
$$

Similar calculations were performed for other release categories in this sequence, and similar procedures were followed for other flood sequences.

The next step was to multiply the release category frequencies by the consequences (population exposures) of the release. This creates a risk value for each release category in each sequence. Consequence calculations were performed in the IPE for each release category and the results were presented 
in Table 7.3-1 of Duke Power Co. (1990). These values were multiplied by the corresponding release category frequencies to calculate the release category risk value. Continuing on with the previous example,

Sequence: (Flood)QsX

PDS 8F

$R C 9.02$ frequency $=8.4 \mathrm{E}-08 / \mathrm{RY}$

$\mathrm{RC} 9.02$ consequences $=4.90 \mathrm{E}+03$ person - rem

Risk $=4.14 E-04$ person-rem/RY

After the risk associated with each release category was calculated, the release category risk values in each flood sequence were summed to calculate the affected public risk value for each sequence. The sequence risk values were then summed to calculate the total affected public risks. These results are presented in Table 5.5-4.

The public risk results are summarized in Table 5.5-5. As shown, the affected public risk values ranged from about 4 person-rem/RY for a GE BWR to about 6 person-rem/RY for a B\&W PWR. 
TABLE 5.5-4. Flood Risk Calculations for the Representative B\&W PWR

\begin{tabular}{|c|c|c|c|c|c|}
\hline $\begin{array}{c}\text { Plant } \\
\text { Damage } \\
\text { State } \\
\end{array}$ & $\begin{array}{c}\text { Affected } \\
\text { CDF }\end{array}$ & $\begin{array}{l}\text { Release } \\
\text { Category }\end{array}$ & $\begin{array}{c}\text { Release } \\
\text { Category } \\
\text { Probability }\end{array}$ & $\begin{array}{c}\text { Release } \\
\text { Consequences } \\
\text { Person-rem }\end{array}$ & $\begin{array}{l}\text { Public Risk } \\
\text { Person-rem/RY }\end{array}$ \\
\hline \multirow[t]{9}{*}{$13 \mathrm{~F}$} & $5.09 E-07$ & RC 9.02 & $7.53 \mathrm{E}-02$ & $4.90 E+03$ & $1.88 \mathrm{E}-04$ \\
\hline & & RC 8.01 & $8.15 E-01$ & $3.40 E+04$ & $1.41 E-02$ \\
\hline & & RC 7.02 & $5.40 E-02$ & $4.27 E+05$ & $1.17 E-02$ \\
\hline & & RC 7.04 & $7.93 E-04$ & $4.27 E+05$ & $1.73 E-04$ \\
\hline & & $\mathrm{RC} 6.02$ & $3.03 E-03$ & $1.40 E+06$ & $2.16 \mathrm{E}-03$ \\
\hline & & $\mathrm{RC} 6.04$ & $2.97 E-03$ & $8.73 E+06$ & $1.32 \mathrm{E}-02$ \\
\hline & & RC 5.01 & $7.55 E-03$ & $1.25 E+07$ & $4.81 E-02$ \\
\hline & & RC 5.02 & $4.09 E-02$ & $1.26 E+07$ & $2.63 E-01$ \\
\hline & & & & TOTAL & $3.52 E-01$ \\
\hline \multirow[t]{9}{*}{$13 E$} & $6.26 E-07$ & RC 9.01 & $7.61 E-04$ & $2.31 E+02$ & $1.10 \mathrm{E}-07$ \\
\hline & & RC 9.02 & $7.53 \mathrm{E}-02$ & $4.90 E+03$ & $2.31 E-04$ \\
\hline & & RC 8.01 & $8.15 E-01$ & $3.40 E+04$ & $1.73 E-02$ \\
\hline & & RC 7.02 & $5.40 E-02$ & $4.27 E+05$ & $1.44 E-02$ \\
\hline & & RC 6.02 & $3.03 E-03$ & $1.40 E+06$ & $2.66 \mathrm{E}-03$ \\
\hline & & RC 6.04 & $2.97 E-03$ & $8.73 E+06$ & $1.62 E-02$ \\
\hline & & RC 5.01 & $7.55 E-03$ & $1.25 E+07$ & $5.91 E-02$ \\
\hline & & RC 5.02 & $4.09 E-02$ & $1.26 E+07$ & $3.23 E-01$ \\
\hline & & & & TOTAL & $4.33 E-01$ \\
\hline \multirow[t]{8}{*}{$7 E$} & $4.46 E-08$ & RC 9.01 & $8.01 E-04$ & $2.31 E+02$ & $8.25 E-09$ \\
\hline & & RC 9.02 & $7.93 E-02$ & $4.90 E+03$ & $1.73 E-05$ \\
\hline & & RC 8.01 & $8.96 E-01$ & $3.40 E+04$ & $1.36 \mathrm{E}-03$ \\
\hline & & RC 7.02 & $2.10 \mathrm{E}-02$ & $4.27 E+05$ & $4.00 E-04$ \\
\hline & & RC 7.04 & $4.98 E-04$ & $4.27 E+05$ & $9.48 E-06$ \\
\hline & & RC 6.02 & $1.18 E-03$ & $1.40 E+06$ & $7.37 E-05$ \\
\hline & & RC 6.04 & $1.15 E-03$ & $8.73 E+06$ & $4.48 E-04$ \\
\hline & & & & TOTAL & $2.31 E-03$ \\
\hline \multirow[t]{8}{*}{$8 \mathrm{~F}$} & $1.12 \mathrm{E}-06$ & RC 9.02 & $7.53 E-02$ & $4.90 E+03$ & $4.14 E-04$ \\
\hline & & RC 8.01 & $8.55 E-01$ & $3.40 E+04$ & $3.26 \mathrm{E}-02$ \\
\hline & & RC 7.02 & $2.03 E-02$ & $4.27 E+05$ & $9.73 E-03$ \\
\hline & & RC 7.04 & $4.92 E-04$ & $4.27 E+05$ & $2.36 \mathrm{E}-04$ \\
\hline & & RC 6.02 & $1.14 E-03$ & $1.40 E+06$ & $1.79 E-03$ \\
\hline & & RC 5.01 & $4.80 E-03$ & $1.25 E+07$ & $6.73 E-02$ \\
\hline & & RC 5.02 & 4.09E-02 & $1.26 E+07$ & $5.78 \mathrm{E}-01$ \\
\hline & & & & TOTAL & $6.91 E-01$ \\
\hline \multirow[t]{8}{*}{$12 F$} & $8.54 E-08$ & RC 9.04 & $7.29 E-01$ & $5.05 E+03$ & $3.14 E-04$ \\
\hline & & RC 8.01 & $2.07 E-01$ & $3.40 E+04$ & $6.01 E-04$ \\
\hline & & RC 7.02 & 4. $41 E-02$ & $4.27 E+05$ & $1.61 E-03$ \\
\hline & & RC 7.04 & $1.13 \mathrm{E}-02$ & $4.27 E+05$ & $4.12 E-04$ \\
\hline & & RC 6.02 & $2.47 E-03$ & $1.40 E+06$ & $2.95 E-04$ \\
\hline & & RC 6.04 & $2.42 E-03$ & $8.73 E+06$ & $1.80 E-03$ \\
\hline & & & & TOTAL & $5.03 E-03$ \\
\hline & & & & GRAND TOTAL & $1.48 E+00$ \\
\hline
\end{tabular}


IABLE 5.5-5. Summary of Affected Public Risk Values from External Events

\begin{tabular}{|l|c|c|c|c|}
\hline \multirow{2}{*}{$\begin{array}{l}\text { External } \\
\text { Event }\end{array}$} & \multicolumn{4}{|c|}{ Affected Public Risk, person-rem/RY } \\
\cline { 2 - 5 } & W PWR & CE PWR & GE BWR & B\&W PWR \\
\hline Seismic & $1.6 \mathrm{E}-02$ & $1.6 \mathrm{E}-02$ & $9.5 \mathrm{E}-03$ & $3.8 \mathrm{E}-03$ \\
Fire & $1.4 \mathrm{E}+00$ & $1.4 \mathrm{E}+00$ & $3.4 \mathrm{E}+00$ & $1.4 \mathrm{E}+00$ \\
Flood & $1.9 \mathrm{E}-01$ & $1.9 \mathrm{E}-01$ & $4.8 \mathrm{E}-01$ & $1.5 \mathrm{E}+00$ \\
Tornado & $\mathrm{Neg}^{(\mathrm{a})}$ & $\mathrm{Neg}$ & $\mathrm{Neg}$ & $\mathrm{Neg}$ \\
\hline TOTAL (b) & $1.6 \mathrm{E}+00$ & $1.6 \mathrm{E}+00$ & $3.9 \mathrm{E}+00$ & $2.9 \mathrm{E}+00$ \\
\hline (a) Neg $=$ Negligible & \\
(b) Values in columns may not add to totals due to \\
rounding.
\end{tabular}




\subsection{GENERIC INSIGHTS}

The purpose of this section is to provide insights on the ability of the four representative plants to represent the entire population of commercial light water reactors (LWRs) relative to the availability of HVAC and room cooling functions. As discussed in Section 2, the designs and configurations of room cooling and HVAC systems are plant-specific and do not appear to follow any discernible pattern based on climate, location, vendor, water source type, or other variable. Thus, the question to be answered is, "Do the plant configurations and designs and the affected core damage frequencies (CDFs) calculated for the representative plants adequately represent other plants?"

This section attempts to answer this question using the following rationale. Separate subsections are provided for assessments of each.

- Design Differences and Similarities: Information was collected from plant visits and Facility Safety Analys is Reviews (FSARs) to determine whether design differences between room cooling systems at different LWRs represent generic vulnerabilities.

- Identification of Plant-Specific Accident Sequences: Somewhat related to potential design differences are specific accident sequences that have relatively high CDFs. Assessments are provided to determine if these sequences are representative of the entire population of LWRs because of unique design and/or operational vulnerabilities.

- Assessment of Core Damage Frequencies at Other LWRs: Limited-scope Probabilistic Risk Assessment (PRA) calculations were performed to develop estimates of CDFs at LWRs other than the representative plants used in this study. These calculations are less rigorous than the calculations described in Sections 3 and 4 for the representative plants but yield estimates that are suitable for comparison purposes. This was done to further illustrate the ability of the representative plants to adequately represent the CDFs due to room cooler failures that may arise in other PRAs.

Based on assessments of these three rationale, conclusions were derived on the abilities of the four representative plants to represent the room cooling system designs and CDFs associated with room cooler failures for the entire population of commercial LWRs. These key conclusions, which are based on the discussions in this section, are

- HVAC/room cooler system designs were reviewed for ten plants. It was determined that one relatively common design vulnerability is related to placement of vital DC equipment in small rooms. Small rooms heat up more quickly than large rooms and are therefore more vulnerable to loss of room cooling events. It was also shown that location of emergency diesel generator (EDG) control equipment in rooms separate from the 
diesel engine is more favorable from a room cooling perspective than collocating the diesel engines and control equipment in the same room.

- Three generic vulnerabilities to losses of HVAC/room cooling systems were identified: 1) ventilation/fire damper failures that resulted in loss of room cooling functions to safety-related equipment rooms were observed at numerous plants; 2) numerous instances of inspection, test, and maintenance errors were cited as causes of HVAC/room cooler failures; and 3) electrical cabinet cooling failures were observed to result in a significant number of events involving spurious readings and equipment malfunctions.

- A sensitivity study was performed using the representative W PRA models developed in this study to evaluate the effects of cross-connecting vital DC power systems between units at a two-unit site. This was done to determine the extent to which single-unit sites are more vulnerable to loss of room cooling than multi-unit sites. It was shown that approximately a $33 \%$ increase in the affected CDF results from eliminating the cross-connect capability between units. An approximate affected CDF of $3 E-06 / R Y$ was calculated for single-unit sites.

- Accident sequence frequencies as high as 2E-02/RY involving HVAC failures have been estimated (see Section 6.2.5). Most of these highfrequency sequences have been reduced in importance as a result of enhanced test/maintenance programs and/or hardware changes. However, the effects of losses of HVAC systems are sometimes not readily apparent and often have indirect effects on safety-related equipment. Consequently, high-frequency, plant-specific accident sequences may exist and are not likely to be uncovered until detailed plant-specific analyses, such as Individual Plant Examinations (IPEs) or engineering studies, are completed.

- The four representative plants used in this study were judged to adequately represent the population of nuclear power plants in terms of the CDFs attributable to HVAC/room cooler failures.

- The arithmetic mean affected CDF from internal events for all nine plants addressed in this study (four representative plants addressed in Sections 3 and 4 plus five additional plants addressed in Section 6.3) was about 4E-06/RY. The affected CDFs for the nine plants were shown to fall within a factor of 6 higher and factor of 18 lower than the arithmetic mean of the calculated CDFs (the lowest affected CDF was removed from this calculation because it was not possible to make all modifications to the plant's existing PRA necessary for a valid comparison). The highest affected CDF value calculated was shown to overstate the actual CDF due to conservatisms applied in the PRA.

The bases for these conclusions are developed in the following subsections. 


\subsection{DESIGN DIFFERENCES AND SIMILARITIES}

This section discusses design differences and similarities among the room cooling and HVAC systems at several LWRs, including the representative plants evaluated in this study. In general, there are wide variations in the sizes of rooms and capacities of room cooler systems. Major differences were also found in the designs of water systems used to cool essential chillers and engineered safety feature (ESF) pump room coolers. However, some significant similarities were also found. These differences and similarities are discussed as they relate to PRA-based systems analyses and CDF calculations for ESF pump room, control room, EDG room, and ESF switchgear room cooling functions in the following subsections. In addition, a sensitivity study using the representative W PWR was performed to examine the effects of an important design feature; i.e., having the capability of cross-connecting an important safety-related function between two units at the same site.

All HVAC design calculations reviewed in this study were conservative. Typically, the plant designers used conservative steady-state heat balance equations to determine the sizes and capacities of HVAC and room cooling equipment. Conservative assumptions were also made to estimate heat dissipation requirements, such as assuming that all of the energy supplied to a pump motor was converted to heat; i.e., neglecting the electrical energy expended to pump fluids or the energy lost heating up the fluid being pumped. Another example was assuming that $100 \%$ of the electrical energy supplied to a transformer or motor control center (MCC) was converted to heat, and that no electrical energy output was produced. These conservative assumptions result in oversized HVAC equipment that should be capable of providing adequate cooling capabilities under conditions more severe than the design bases.

\section{1 .1 ESF Pump Rooms}

ESF pumps, including high-pressure injection (HPI), low-pressure injection (LPI), containment spray (CS), auxiliary feedwater (AFW), essential raw cooling water (ECW), component cooling water (CCVi), etc., are typically located in relatively small cubicles in the auxiliary buildings at LWRs. At most plants, a separate cubicle is provided for each pump and, in almost all cases, separate cubicles are provided for pumps in different redundant trains of the same system. The most common ESF room configuration was found to include separate rooms for each ESF pump such that only one pump was located in each room. below:

Some notable variations from this typical plant are briefly described

- Separate small rooms were provided for HPI, LPI, and CS pumps; and separate rooms were provided for the redundant trains. A small room was a) so provided for the turbine-driven AFW pump. However, two motordriven AFW pumps were located in a large, open room that also contained the CCW pumps. Location of the pumps in large, open rooms reduces the vulnerability to room cooler failures, because heatup times are much slower than for small enclosed rooms. 
- One plant configuration had all HPI pumps located in the same room. This room was relatively large compared with the small rooms provided for sing?e pumps, and was al so provided with air circulation pathways that communicated with a large, open room outside the HPI pump rooms. The size and air circulation pathways result in longer room heatup times relative to the small pump enclosures.

- One plant located three ESF pumps in one train in a relatively large, open room. This room contained the HPI, LPI, and CS pumps. A separate room was provided for the HPI, LPI, and CS pumps in the other train. Although fallure of room cooling in one of these rooms could potentially disable one entire train of three ECCS subsystems, the large, open nature of the room minimizes the heatup rate following loss of room cooling.

- Motor-driven AFW pumps were located in the Turbine Building at one plant. The pumps were located in a large, open area where air circulation communicated with all levels of the building. Therefore, low heatup rates would be expected to result from loss of the HVAC system in this building.

The ESF pump rooms varied in size, but most are in the $30 \times 30 \times 25$ to $50 \times 50 \times 25 \mathrm{ft}$ range. Some pump rooms were also found to be two levels in height, or about $50 \mathrm{ft}$; however, most ESF pump cubicles were one level high. Walls and floors were typically constructed of concrete. Nearly all the ESF pump rooms were provided with local ambient temperature indicators, but few were provided with remote temperature indications that could be accessed from the control room.

A11 ESF pump room coolers in these relatively small rooms were of the same general design, although capacities varied from plant to plant. The typical ESF pump room cooler consisted of a belt-driven fan that blew air over a set of cooling coils that carried either raw service water, CCW (intermediate 100p), or chilled water to remove heat from the room air. These room coolers are normally standby systems that are interlocked to start when the pumps start. Typically, plants are provided with remote indications in the control room that the ESF room coolers are running. Little variation was observed arnong plants in these general characteristics.

ESF pump room coolers are referred to as "attendant" equipment and are tested in accordance with the requirements imposed on the pumps; i.e., they must start during normal surveillance tests of the ESF pumps. If a room cooler is declared inoperable, the ESF pump in that room is also considered inoperable. This was a common characteristic of most plants.

ESF pumps in large open areas are typically cooled by a safety-related portion of the Control Building or Auxiliary Building HVAC system. The typical configuration of these HVAC systems consists of a relatively large air handling unit (AHU) and cooling coils, similar to the ESF pump room coolers for smaller rooms. The capacities of these room coolers are proportionally larger than the small cubicle coolers. The larger coolers are also normally 
provided with inlet air filters, which are not provided on the smaller coolers. The cooling coils are provided with water from a safety-grade service water, chilled water, or CCW system. The cooled outlet air from the fans is ducted to separate areas within the room to provide adequate airflow to cool safety-related components. The room coolers may be located in the same room as the ESF components themselves or may be located in a separate room.

A final ttem related to ESF pump room cooling capabilities is related to the temperature sensitivities of the ESF pumps. At almost all plants, the design ambient temperatures for the pumps were in the range from $104^{\circ} \mathrm{F}$ to $120^{\circ} \mathrm{F}$. The ESF pumps were qualified to operate at these temperatures, and room coolers were sized to dissipate heat such that the maximum temperature expected in the rooms was maintained below these levels. However, at one plant, the equipment qualification test requirements for the HPI, LPI, and Reactor Building spray pump motors were found to be $212 \circ \mathrm{F}$, or about $100 \circ \mathrm{F}$ higher than the typical equipment qualification temperatures found at most other plants. This plant would be less vulnerable to loss of room cooling in the ESF pump rooms, because much more time would be required to heat up the rooms to ambient temperatures at which pump failures would be expected.

\subsubsection{Control Room HVAC Systems}

Control room coo?ing systems among plants were observed to have many commonalities. The essential control room HVAC systems are normally standby systems that are automatically actuated during accident conditions. A normally operating system is also provided that is isolated when the essential system starts up. The essential system cools not only the control room but also adjacent cable spreading and relay rooms and electrical equipment rooms containing plant protection system, auxiliary relay, nuclear steam supply system, and other control and monitoring cabinets.

The specific design configuration and features of the essential control room cooling systems vary from plant to plant, but some significant commonalities exist. The typical control room HVAC system consists of one-out-oftwo, fully redundant and separate HVAC trains. Each train is capable of providing $100 \%$ of the airflow necessary to accomplish its intended function. Each train is provided with a 100\%-capacity chiller package, AHU, ductwork, and necessary controls. The chiller package is typically a centrifugal chiller using freon as the cooling medium. Heat is rejected to a circulating water system using either raw service water or intermediate CCW loops.

The essential control room HVAC system is relatively complex. The systems are designed to isolate the control room under accident conditions to protect control room operators from potential airborne hazardous materials or radioactive materials, and to maintain a comfortable working environment. As such, these systems are provided with $100 \%$ air recirculation capabilities as well as numerous detectors (radiation, combustible gas, chlorine detectors) that function to automatically actuate the recirculation mode. The essential control room HVAC systems are safety-related and are subject to technical specifications, surveillance/test requirements, and 1 imiting conditions for operation that further increase system complexity. This complexity has been 
blamed, at least in part, for the unreliability of some control room HVAC systems (McDougald and Christie 1992). In Appendix A, it is stated that there were numerous LERs involving inadvertent switchover of essential control room HVAC systems to recirculation mode and spurious or malfunctioning detectors. This is further evidence of the problems that have resulted from the complexity of the essential control room HVAC systems.

Although there are examples of unreliable systems, personnel from the four representative plants in this study indicated they have had no significant reliability problems with their essential control room HVAC systems. The HVAC staff at these plants indicated that experience with the system and use of properly trained maintenance personnel has resulted in relatively reliable systems. Most of the plant personnel indicated there were significant startup problems associated with these systems, but once they had gained a few years experience operating and maintaining the equipment, they had experienced much higher system reliabilities. All of the plant personnel indicated that aggressive preventive maintenance programs have minimized equipment failures and downtime.

\subsubsection{Diesel Generator Room Cooling}

Emergency diesel generator room cooling system configurations were found to be approximately the same at all the plants examined in this study. A typical EDG room cooling system consists of large exhaust fans that pull outside air into the room and past the diesel engine, and then exhaust the heated air to the outside environment. No air-cooling capabilities are provided, so there is no dependence upon a circulating water system to remove heat; heat is simply exhausted to the environment. Normally closed dampers are provided at the inlet, outlet, or both locations, that must open to allow airflow through the room. No plant was observed to have remote temperature sensors that could be monitored in the control room. However, all plants provided positive indications in the control room that the EDG ventilation fans were operating. These room cooling systems are very simple and seem to operate reliably, based on the data in Appendix $A$.

Most often, EDG room cooling is provided by only a safety-related exhaust air system that is automatically actuated when the diesel engines are started. However, at some plants, a relatively low-capacity, normally operating system is also provided. The normal system is isolated when the EDGs are started. The capacities of the normal system are so low that it is doubtful that they would provide much cooling capability when the diesel engines are running.

A significant design difference was identified in the EDG rooms at different plants. Some plants located all EDG control and monitoring equipment in a room adjacent to the EDG enclosuie. This effectively isolated the temperature-sensitive equipment from the high heat source represented by the diesel engine., This design is less vulnerable to the effects of EDG room cooler failures because it will take significantly longer for the isolated EDG control room temperatures to exceed the equipment failure temperatures. 
The effects on CDF of the different EDG room cooler systems was judged to be negligible. The CDF calculations described in Section 4 assumed there would be no recovery from EDG room cooler fallures. That is, it was assumed that fallure of the EDG room ventilation systems resulted in unrecoverable failure of the associated emergency $A C$ power train. This assumption was applied to both EDG room designs (with and without control and monitoring equipment in the same room). Calculations in Appendix $F$ and other sources (including NUREG/CR-4550) indicated that, although there is additional time to recover EDG failures for situations in which the EDG control and monitoring equipment is not located in the same room as the diesel engine, there is not enough time to diagnose and repair the ventilation system.

\subsubsection{ESF Switchgear and DC Equipment Room Cooling}

The ESF switchgear rooms contain MCCs for large and small ESF pump motors and valve actuators. DC equipment rooms contain the vital DC buses, $A C$ inverters, and battery chargers necessary to provide control power to pump motors and valves. In these rooms is temperature-sensitive electrical equipment that will malfunction or fail under relatively high ambient temperature conditions $\left(-120^{\circ} \mathrm{F}\right)$. Thus, these rooms are typically provided with a normally operating nonsafety-grade HVAC system as well as a normally standby safety-grade HVAC system.

The essential HVAC systems were typically a part of the Control Building or Auxiliary Building essential HVAC systems. Most of these systems were observed to be cooled by an AHU/chiller-condenser package that provided chilled air to the rooms. Another common system involved an AHU/Cooling coil system, similar to but larger than those serving the ESF pump rooms. Safetygrade service water or CCW systems were pumped through the cooling coils to cool the passing air. At all plants, the ESF switchgear rooms were cooled using centralized systems that also cooled other safety-related areas in the buildings. No cooling systems dedicated to only the ESF switchgear rooms were observed. Separate and redundant ESF switchgear room cooling systems are provided for each train of ESF switchgear (e.g., Train A ESF switchgear room HVAC cools the Train A ESF switchgear room, and Train B HVAC cools the Train B ESF switchgear room).

ESF switchgear is housed in cabinets that are typically not provided with internal cooling means such as internal fans. Some ventilated cabinets were observed, but most were provided with louvered cabinet walls and doors to promote air circulation through the cabinets, which are cooled by natural convection. The rooms are typically large open areas, on the order of $80 \times 40 \times$ $25 \mathrm{ft}$. This size room provides a large heat sink that minimizes room heatup rates (should room cooling fai?! relative to smaller ESF pump rooms.

DC equipment may be Coloc:ced with the ESF switchgear or placed in a separate smaller room adjacent to the switchgear. Both design configurations were found to be common. When separate rooms are provided, the DC equipment is located in a small room, approximately $20 \times 20 \times 15 \mathrm{ft}$. Because these rooms are small, they heat up much faster than the ESF switchgear rooms following a loss of cooling. Some plants with separate DC equipment rooms 
provide supplemental cooling to augment the normal and essential HVAC system that cools the ESF switchgear rooms. These supplemental cooling systems are relatively small, with capacities similar to those of ESF pump room coolers.

Battery rooms are typically about the same size as DC equipment rooms. Loss of battery room cooling is of much less concern than loss of switchgear or $D C$ equipment room cooling, because batteries are not especially vulnerable to high ambient temperatures. The purposes of the HVAC systems in battery rooms are more to prevent hydrogen gas buildup and to provide heating than to provide cooling. Batteries are less sensitive to high ambient temperatures than to low temperatures.

It was concluded from this review that switchgear room cooling systems are not significantly different operationally nor in general design configurations among the different plants reviewed. One significant difference was found relative to $D C$ equipment room designs, and it appears that, due to the small sizes of separate DC equipment rooms, they are more vulnerable to room cooler failures than plants that have collocated DC equipment in the large, open ESF switchgear rooms. These differences were accounted for in the PRA calculations in Section 4.

\subsubsection{Shared Capabilities Between Two Units at the Same Site}

A sensitivity study was performed to examine the effects on the affected CDF for a single-unit site. The minimal cut sets and accident sequence analyses described in Sections 3 and 4 for the W PWR took credit for the capability of providing $D C$ power from a second unit at the same site following failure of $D C$ power at the first unit. This event appeared in a number of dominant cut sets for the representative W PWR, so a sensitivity study was performed to evaluate the effects of not having this capability. The sensitivity study represents situations in which a site contains only a single unit or more than one unit but no cross-connect capabilities.

The sensitivity study was performed by removing the potential for a cross-connect between DC power supplies between two units at the same site. The calculations were performed by substituting a value of 1.0 (i.e., always failed) into the cut sets containing the event "DCP-U2" (see Appendix C). The cut sets and affected CDF were then requantified.

The results of this sensitivity case are shown in Table 6.1-1. Accident sequence frequencies for the base-case and sensitivity study are shown in the table. The total affected CDF for the sensitivity study was calculated to be 2.8E-06/RY, approximately 33\% higher than the base-case affected CDF calculated in Section 4 . Two dominant accident sequences were shown to increase by about 70\%, including the highest frequency sequence (SBO-SLOCA sequences). However, no changes were observed in the frequencies for the other accident sequences ( $D C$ power from Unit 2 was not included in the other sequences). 
IABLE 6.1-1. Results of Sensitivity Study

\begin{tabular}{|l|c|c|c|}
\hline Sequence & $\begin{array}{c}\text { Affected } \\
\text { CDF, } \\
\text { per RY }\end{array}$ & $\begin{array}{c}\text { Sensitivity } \\
\text { Study CDF, } \\
\text { per RY }\end{array}$ & $\begin{array}{c}\text { Percent } \\
\text { change }\end{array}$ \\
\hline S1H4 & $1.1 \mathrm{E}-09$ & $1.1 \mathrm{E}-09$ & $\cdots$ \\
S2H3 & $1.6 \mathrm{E}-08$ & $1.6 \mathrm{E}-08$ & $\cdots$ \\
S3OCH3 & $8.0 \mathrm{E}-08$ & $8.0 \mathrm{E}-08$ & $\cdots$ \\
S3W1H3 & $1.7 \mathrm{E}-07$ & $1.7 \mathrm{E}-07$ & $\cdots$ \\
AH1 & $4.7 \mathrm{E}-12$ & $4.7 \mathrm{E}-12$ & $\cdots$ \\
SBO-BATT & $8.2 \mathrm{E}-09$ & $1.4 \mathrm{E}-08$ & $+71 \%$ \\
SBO-L & $7.3 \mathrm{E}-07$ & $7.3 \mathrm{E}-07$ & $\cdots$ \\
SBO-Q & $4.0 \mathrm{E}-08$ & $4.0 \mathrm{E}-08$ & - \\
SBO-SLOCA & $1.0 \mathrm{E}-06$ & $1.7 \mathrm{E}-06$ & $+70 \%$ \\
\hline TOTAL & $2.1 \mathrm{E}-06$ & $2.8 \mathrm{E}-06$ & $+33 \%$ \\
\hline
\end{tabular}

\subsection{EYALUATION OF PLANT-SPECIFIC ACCIDENT SEQUENCES}

A review and evaluation of potential high-frequency accident sequences involving room cooler fatlures was performed to determine whether a number of high-frequency sequences described in the literature are plant-specific outlyers or are generic vulnerabilities applicable to several LERs. The potential high-frequency accident sequences are described in separate subsections. Each subsection contains an explanation of the specific vulnerability encountered as well as an assessment of the generic or plant-specific nature of the vulnerability.

The vulnerabilities identified in this section range from design inadequacies to deficient operating, maintenance, and test procedures. The vulnerabilities identified in the following subsections include

- Installation errors during $p l a n t$ construction or modification could disable water systems that remove heat from ESF pump rooms and essential chillers.

- Test and maintenance errors, particularly failure to return safetyrelated HVAC components to service properly, could disable one or more trains of HVAC.

- Inadequate test procedures could also result in failure to return HVAC components to service properly. 
- Falled or malfunctioning ventilation and fire dampers can result in a total loss of room cooling to safety-related equipment rooms.

- Inadequate attention to test, inspection, and preventive maintenance of HVAC and room cooling system components significantly degrades their reliabllity.

- Design errors have resulted in inadequate ventilation airflow to certain rooms and to certain areas within rooms. One design error involving location of one train of vital DC equipment in a switchgear room for the other train was identified.

- Fire protection system designs and reviews have resulted in identification of inadequate separation between electrical cables feeding redundant trains of HVAC systems.

- Heavy loading of individual divisions of vital DC control power, whose components are sensitive to elevated room temperatures, may result in failure of significant portions of safety-related systems if HVAC systems should fail.

- Inadequate cooling of electrical cabinets has resulted in spurious readings and equipment malfunctions.

In most cases, these vulnerabilities appear to be plant-specific concerns. However, three potential generic vuinerabilities were identified. The first is related to failures and/or malfunctions of dampers in HVAC ductwork that have resulted in interrupted airflow to rooms containing safetyrelated equipment. Numerous examples are described in the following subsections as well as in Appendix A.

The second potential generic vulnerability is related to inadequate cooling of electrical cabinets. Several examples are described in the following subsections. A sufficient number of events were identified or discussed with plant personnel to indicate that vulnerabilities to inadequate cabinet cooling exist at a significant fraction of plants.

The third potential generic vulnerability involves inadequate inspection and test/maintenance programs for HVAC and room cooling equipment. Although this did not appear to be especially applicable to the plants visited in this project, a sufficient number of inspection, test, maintenance errors, and instances of inadequate attention to this equipment, were identified to warrant categorizing these errors as generic vulnerabilities.

Detalled discussions of these generic vulnerabilities are presented in the following subsections. Other vulnerabilities to HVAC/room cooler fallures are shown in the following subsections to be plant-specific concerns. 


\subsubsection{Electrical Switchgear Room Cooling Failures at a W PWR}

Lois (1992) presented information on a potential accident sequence involving loss of electrical switchgear room cooling at a W PWR. This accident sequence was identified from the plant's IPE. The event described by Lois involves a loss of one train of switchgear room cooling during a loss of offsite power (LOOP) with one EDG inoperable. The inoperable EDG was designed to provide power to the other train of switchgear. This accident sequence results in a total loss of $A C$ power to the emergency core cooling systems (ECCS). Such a sequence would lead to core damage.

Lois (1992) estimated the CDF from the following event: the frequency of LOOP was given by the licensee as 3.84E-02/RY, and the probability of ESF switchgear room cooling failures was given as $3.44 E-02 /$ demand. The CDF estimated by Lois was given as $1.3 \mathrm{E}-03 / \mathrm{RY}$. The licensee estimated the frequency of this sequence at $9.85 E-07 / R Y$, a difference of over three orders of magnitude.

The difference between the CDF calculated by Lois and the licensee calculations was in the application of recovery factors. Lo is allowed no recovery from the loss of switchgear room cooling, whereas the licensee took credit for about a 1E-03 nonrecovery probability. Room heatup calculations presented in Appendix $F$ indicate that switchgear room temperatures would not exceed $120^{\circ} \mathrm{F}$ for approximately 20 hours following loss of cooling under nonloss of coolant accident (LOCA) conditions. Equipment failure data in Appendix $G$ indicates switchgear equipment should not fail until a room temperature of $130^{\circ} \mathrm{F}$ is reached. Therefore, based on the long heatup rates for large, open areas that are typical for switchgear rooms, a nonrecovery probability of $1 \mathrm{E}-03$ seems reasonable in relative agreement with the nonrecovery probability of $4.3 \mathrm{E}-03$ calculated in Section 4 . Based on these results, it is concluded that no generic vulnerabilities exist in this instance. However, Lois correctly points out that PRAs traditionally neglect room cooling systems as potentially important ESF system dependencies and thus may overlook significant accident sequences. Although no generic vulnerability to core damage was uncovered, this example illustrates that loss of room cooling functions should not be dismissed offhand in plant-specific PRAs.

\subsubsection{Electrical Switchgear Room Cooling Failures at a BWR}

An event at a BWR occurred [Licensee Event Report (LER) 86-016] in which it was found that both trains of the electrical switchgear room cooling system were inoperable. The event occurred during a performance verification test when an operator error caused a water regulating valve to fail to open, resulting in failure of emergency service water (ESW) flow into the switchgear room cooler's condenser. An operator repositioned the valve from $100 \%$ to $0 \%$, and the valve opened. Similar results occurred when the other train of switchgear room cooling was tested. Such failures could render one or both of the switchgear room cooling systems inoperable. If a LOCA had occurred simultaneously, the plant's low-pressure ECCS systems could fail. 
The LER noted that the circulating air in the switchgear rooms is cooled during normal operations by the Reactor Building chilled water (RBCW) system. During a LOCA, the RBCW system is isolated, and the switchgear room cooling units are automatically started. The water regulating valve automatically opens to allow ESW flow into the room cooler. Without ESW flow, the room cooler units would trip, causing a loss of cooling to the emergency switchgear and emergency load center rooms. Although the fans would also trip, it is possible to restart the fans from the control room, which would circulate air and partially remove the heat generated by the electrical components in the rooms. The maximum room temperature the components are qualified to operate at is $104^{\circ} \mathrm{F}$. If the temperature should rise above this value, it is uncertain what ie effects on the electrical components would be, although Appendix $G$ indicates actual failure temperatures may be somewhat higher than $104^{\circ} \mathrm{F}$. If the electrical components had failed, AC power to the low-pressure coolant injection (LPCI) and core spray (CS) systems would have failed.

This event appears to be a plant-specific anomaly that was caused, in part, by a valve installation error. Operators were able to avoid an overheat condition in the rooms even under these misleading conditions. Because of the low heatup rates in these rooms, there would be a relatively long time available to diagnose this problem and implement a short-term fix or longerterm repair. It is concluded that no generic vulnerabilities exist in this instance. Similar installation errors were not observed in the LER data in Appendix $A$ or in the plant visits conducted in this study.

\subsubsection{Electrical Switchgear Room Cooling Failures at a W PWR}

At a W PWR (different plant than that described in Section 6.2.1), it was determined that a loss of cooling in a Train B emergency switchgear room will result in loss of cooling to Train $A$ inverters and battery chargers. This could result in a common mode failure affecting both trains of vital control power. During a root cause analysis, it was observed that cooling to two battery board rooms was reversed. Consequently, failure of Train B switchgear room cooling could result in inoperability of Train A and Train B equipment. At the time, the Train B chiller for the switchgear rooms was inoperabie, but both AHUs were operable. The Train A chiller and both AHUs were operable.

The licensee responded to these observations by performing thermal analysis calculations to determine the temperature rise within the switchgear rooms following loss of room cooling. It was determined that the ambient temperature within the room would reach the $104^{\circ} \mathrm{F}$ maximum design temperature in 27 to 44 hours. At this point, the equipment in the room would technically be inoperable, and the plant would enter a technical specification requirement to bring it to hot shutdown in one hour. The calculations al so showed that, at an initial temperature of $100^{\circ} \mathrm{F}$, it would take about 10 hours to reach the $104^{\circ} \mathrm{F}$ maximum temperature. As a result, the licensee implemented requirements to monitor room temperatures every two hours following loss of the room chillers and would be required to shut down if the temperature in either room exceeded $100^{\circ} \mathrm{F}$. The licensee al so implemented a requirement that, following 
loss of Train B cooling, the door between the Train A and B switchgear rooms will be opened to circulate cooled air from the Train A room to the Train B room. The licensee also installed portable ventilation ducts and fans to circulate the cooled air.

This event identified a potential plant condition in which failure of one train of switchgear room cooling could cause failure of one train of ESF switchgear and, simultaneously, a separate train of DC equipment. This would result in loss of motive power to one division of ECCS pump motors and loss of vital DC control power to the other division, which was stated by the licensee to be a design error. Other plant designs were examined for similar types of design errors, and none were found; such errors were not observed at the other plants visited in this project.

\subsubsection{Equipment Room Cooling Failures at a CE PWR}

A potential accident sequence was discovered at a CE PWR that could be initiated by loss of cooling to the DC equipment room (Arizona Public Service Co. 1992). The potential accident was initiated by loss of one essential chiller, causing the ambient temperature in the DC equipment room to rise. Electro-thermal links are provided to allow fire dampers to close in the ventilation ductwork for this room, effectively halting all ventilation airflow. After the room temperature had risen to equipment qualification temperatures, a vital AC inverter was postulated to fail, which would actuate ESFs, close main steam isolation valves (MSIVs) (effectively failing main feedwater [MFW]), and cause a turbine trip and reactor SCRAM. At the same time, one train of nonsafety AFW and alternate feedwater (AltFW) from condensate pumps would fail due to loss of control solenoids for feedwater downcomer isolation valves. The safety-related steam-driven AFW pump would also fail following battery depletion, because the control power for the pump comes from this bus. A motor-driven AFW pump is powered from a second bus and would be available. Therefore, this transient effectively fails four of five potential AFW sources. In addition, one EDG control and field flashing system is powered from this bus, so failure of this equipment also results in blackout of one EDG. The CDF associated with this accident sequence was in the 1E-04 to 1E-03/RY range. This accident, sequence was uncovered during the IPE process.

The vulnerabilities that were uncovered in this sequence are as follows:

- Failure of fire dampers effectively isolates the $D C$ equipment room from all room cooling systems. These small rooms will heat up rapidly when the equipment is operating and all airflow is interrupted. Therefore, little time is available to diagnose the failures and implement recovery actions.

- One of the four divisions of vital DC power was loaded much more heavily than the other three divisions. The IPE uncovered the fact that failure of this particular division of DC power causes failure of four of five sources of feedwater to the plants' steam generators. 
The licensee indicated that plant modifications were made that resulted in a significant reduction of the CDF associated with loss of DC equipment room HVAC. The modifications included installing remote room temperature instrumentation in the $D C$ equipment room that is monitored and alarmed in the control room; changing DC power supplied for several loads to avoid the overloading problem on one DC bus; and modifying downcomer feedwater isolation valve logic to fail open on loss of DC power (prevents failure of MFW). The CDF for this sequence for the modified plant was estimated to be less than $1 E-07 / R Y$, based on the observation that loss of DC equipment room HVAC accident sequences did not appear on the list of sequences with frequencies greater than $1 E-07 / R Y$ for the modified plant.

It is possible that vulnerability to loss of HVAC caused by fire dampers is a generic concern. Given the prevalence of the fire protection systems and the fact that many HVAC systems serve more than one room and must be isolated from fires in adjacent rooms, it is likely that similar situations exist at nearly all LWRs. The tradeoff between the vulnerability to loss of HVAC and to a fire in an adjacent room appears to be one of timing. A fire threatens equipment in adjacent rooms much more rapidly than failure of HVAC and room cooling systems. Thus, it seems prudent to protect against fire vulnerability at the expense, in part, of the reliability of HVAC systems.

The vulnerability to a heavily loaded division of $D C$ power may also be a generic concern but appears to affect a small number of plants relative to the fire damper vulnerability. This type of vulnerability did not appear at the other representative plants in this study, but this is insufficient evidence to state that it does not occur at other plants. It is difficult for nonplant personnel to examine the DC power divisions to determine if one division of DC power is more heavily loaded than others in terms of failing safety systems. It is known that due to single-failure criteria, redundant ESF systems are powered from separate divisions of vital DC power. Therefore, at least one division of ESF systems should be available following loss of one division of $D C$ power. However, the example described above indicates that, even though the $D C$ power system met the single-failure criteria, this did not preclude relatively high CDFs.

\subsubsection{Loss of RHR Pump Room Cooling at a W PWR}

Information on residual heat removal (RHR) pump room cooling from the Zion Probabilistic Safety Study (ZPSS) was discussed at a meeting of the Advisory Committee on Reactor Safeguards (ACRS) (McKinley 1986). The information presented indicated that the RHR pumps were assumed to fail in the recirculation mode following loss of room cooling. This is consistent with the data presented in this study, which indicate that room cooling is not necessary during the injection mode but is required to prevent pump failures during recirculation. This is a matter of timing in that injection is normally accomplished rather quickly, but recirculation may continue for a long period of time. Thus, RHR pumps may operate for short periods of time following loss of room cooling and accomplish injection but may fail during recirculation because of high ambient temperatures. 
The CDF estimated for this accident sequence was given as $2 E-02 / R Y$, based on an estimated unavailability of the room coolers over the plant lifetime of 0.6 (based on no inspection or testing). This estimate is very conservative for four reasons: first, even though there was no explicit inspection or testing procedures for the RHR pump room coolers, they are, in fact, interlocked to start when the pumps start and so are tested each time the pumps are tested. Even though the room coolers are not explicitly called out in test procedures, it is unlikely that test personnel would fail to detect a malfunctioning room cooler during an RHS pump test. Second, the RHR system is the preferred means of decay heat removal during shutdown conditions, and this system has thousands of hours of service since the plant began operating. A significant degradation in RHR room cooler performance would likely have been detected during normal operator rounds. Third, the RHR room cooler systems are not extremely complex, are used in many other industries, and were not mentioned by personnel at the plants visited during this study to be unreliable systems. It seems that the 0.6 unavailability value is a high estimate. Fourth, no recovery factor was applied to the initial unavailability of the room coolers. This study shows that several hours are available to detect and implement corrective actions to cool ESF pump rooms.

The identified vulnerability in this instance was a lack of inspection and testing of the room cooling function. The licensee implemented new requirements to test this function, thus reducing the probability of room cooler failure. The plants visited in this study were questioned about testing and inspection of room coolers, and all indicated that room coolers were considered "attendant" equipment and must be demonstrated to be operable during the testing of the ESF components in the rooms. Based on these limited observations, this vulnerability appears to be plant-specific.

\subsubsection{Common-Cause Failure of Control Room and Relay Room HVAC}

A potential design deficiency was identified at a BWR that couid result in a common-cause failure of the control room and relay room HVAC system. The potential vulnerability involves a fire that could disable electrical cables, rendering bothitrains of the HVAC system inoperable. The cables were stated to not meet fire separation criteria. The potential generic vulnerability is, therefore, to potential common-cause failures due to fire. Furthermore, a related vulnerability that may also be generic is common-cause failures due to seismic events.

The specific vulnerability was discovered during a fire protection review at a BWR. It was discovered that an electric power feeder cable for a 600-V AC MCC was routed through a fire zone through which equipment from the same $A C$ power division required for safe shutdown was routed. The two MCCS provide $A C$ power to the main control room and relay room HVAC equipment. It was possible that a fire could cause a loss of power to the HVAC emergency ventilation fans for these rooms. Engineering evaluations indicated that the temperature in the control/relay room could rise to $130^{\circ} \mathrm{F}$ without HVAC, far in excess of the $104^{\circ} \mathrm{F}$ maximum temperature for the components in the room. Should this equipment fail, the equipment for controlling and monitoring the safe shutdown process would be rendered inoperable. 
To determine if the vulnerability to fire and seismic events affects a large number of plants, the LER data in Appendix A was reviewed. It was determined that a significant number of plants had reported seismic and fire vulnerabilities that were uncovered in various plant reviews and reported to the NRC. However, only two LERs involving common-cause failures of separate trains of HVAC due to fire and eight LERs involving seismic design inadequacies were in the database, small fractions of the total LERs involving fire protection system and seismic design inadequacies for all areas of the plant. Based on this information, it would appear that the vulnerabilities of HVAC systems to inadequate fire protection separation and seismic design are not a significant generic concern. This conclusion is somewhat "soft" in that the number of plants that have examined these potential vulnerabilities in sufficient detail to identify these problems is not known.

\subsubsection{Various HVAC Deficiencies at a BWR}

A letter from R. E. Beedle to the NRC (a) responding to an NRC Diagnostic Evaluation Team (DET) identified the following four HVAC system deficiencies that were evaluated here for potential generic implications:

- The temperature in the reactor water cleanup (RWCU) heat exchanger room exceeded the entry condition of $119^{\circ} \mathrm{F}$. The excessive temperature was caused by degraded performance of the room cooler and loose or missing insulation on the RWCU heat exchanger. Although this temperature does not significaritly degrade the RWCU heat exchanger performance, the continued existence of the high temperature and the requirement to enter an Emergency Operating Procedure on a daily basis demonstrated a lack of adequate attention to this room cooler.

- Temperature-related operability criteria for the low-pressure coolant injection (LPCI) LPI motor-operated valve (MOV) uninterruptible power supply batteries did not exist. Safety-related temperature sensors did exist for the station battery rooms but none were provided for the LPCI MOV batteries. The plant information computer does provide temperature indications for the LPCI MOV battery area, including high and low alarm setpoints. The potential vulnerability is related to a possible lack of control room temperature indication coverage of some safety-related areas of the plant.

- Emergency service water system water. hammer damage to essential chiller condensers had occurred, and the safety significance of the events had not been adequately assessed. The "fix" applied to this system was to install a "keep-full" system to make up for back-leakage through the ESF injection valies into the chiller condenser. The potential vulnerability involves water-hammer-type failures of essential chillers.

(a) Beedle, R. E. 1992. Letter JPH-92-024 to T. E. Murley, U.S. Nuclear Regulatory Commission. New York Power Authority, White Plains, New York. 
- An EDG fan had failed to start upon a loss of a 115-kV 1ine. Recent modifications to the fan had resulted in incorrect installation of the fan starter cubicle into the MCC. The potential vulnerability identified here was the inadequate instructions to HVAC maintenance and test personnel.

Two main potential generic vulnerabilities are indicated by these events. The first is inadequate preventive maintenance, inspection, and testing of HVAC and room cooler systems. The general feeling is that HVAC and room cooler systems are relatively reliable systems that do not use "magic" technologies. This function is performed by equipment that has been around for many years and exists in some form in nearly every building in the U.S. Operating experience for these systems is extensive, and any major unreliability problems should have been identified and corrected long before they were installed in the plant. While this is true, operating experience also indicates that preventive maintenance practices and maintenance staff training is also very important to the reliability of chillers and HVAC systems. Therefore, although the systems are relatively common and do not use complicated technologies, they are susceptible to failure if not adequately maintained. This appears to be a problem with some other plants, given the numbers and types of failures presented in Appendix A. However, some plants have implemented aggressive preventive maintenance, inspection, and testing programs for HVAC systems that appear to have a positive effect on system reliability.

The second potential vulnerability is related to water hammer of essential chiller condensers. The events described above were the only waterhammer-related failures of chiller condensers found in the literature. The licensees visited in this study indicated ESW lines are normally kept filled, which prevents water hammer when ESW is pumped into the chillers. This does not appear to be a generic concern, although the number of plants for which this was verified is small.

\subsubsection{Ventilation and Fire Damper Errors at Four Plants}

Ventilation and fire damper failures have occurred at many plants. Four significant events are described briefly below:

- At a W PWR, an EDG tripped on overspeed during an operability test. The trip was attributed to low governor oil temperatures caused by an open ventilation supply damper. The damper had been found to be failed during a previous inspection and had then been locked open to ensure adequate room cooling for the EDG enclosure. However, low outside temperatures adversely affected the governor oil temperature, causing the EDG trip. This EDG failure mode was not considered previously.

- At a W PWR, a charging pump became inoperable due to a bearing oil leak. The standby charging pump was started and became technically inoperable when a ventilation damper failed to open. The damper was inadvertently left in a position following a test procedure in which it could not open when the charging pump was started. The failure was blamed on inade- 
quate training of test personnel and inadequate test procedures, which did not address the proper procedure for returning the damper to service.

- At a BWR, a ventilation exhaust fan serving a room containing two RHR service water pumps and one ESW pump tripped on thermal overload. The apparent cause of the failure was closed fire dampers in the supply duct to the room. Fire dampers in the redundant RHRSW/ESW pump room were also found to be closed. Calculations indicated that with all three pumps operating and the fire dampers closed, the room temperature would increase from 70 to $240^{\circ} \mathrm{F}$ in ten minutes, likely causing the pumps to fail.

- At a BWR, control room outside air exhaust isolation dampers were closed to perform maintenance on the ESF system and an MCC. After the MCC cleaning was completed, the circuit breakers for the damper motors were closed, which caused the dampers to open. Later, an operator reopened the breakers to complete the ESF maintenance, which resulted in a condition in which the dampers and the breakers were both open, meaning that the dampers could not close under accident conditions. This constituted a threat to control room habitability if an accident had occurred.

These four events, along with the accident sequence described in Section 6.2.4, illustrate the hidden and potentially serious consequences of disabled or malfunctioning dampers in HVAC systems. Events involving fire dampers have occurred rather frequently, indicating the possibility that vulnarabilities to disabled or malfunctioning fire dampers may be a generic concern. Other possible generic vulnerabilities addressed by these four events include inadequate management attention to HVAC systems, inadequate test procedures, inadequate training of test/maintenance personnel, and inadequate consideration of fire dampers in the designs of room ventilation systems.

\subsubsection{Loss of Control Room Cooling at a W PWR}

An event involving failure of control room eniergency HVAC (CRAC) systems at a W PWR (Chiramal 1986), pointed out the potential for spurious actuations of equipment and spurious readings and alarms on control panels. The event involved failure of all control room ventilation resulting in an increase. in control room ambient temperature. The control room ventilation system is a two-train system; Train A had been removed from service for maintenance, and the Train $B$ chiller tripped due to low oil level. Efforts to restart the Train B chiller failed, initiating the loss of control room cooling event.

A short time (45 minutes) after the initial Train B chiller trip, the control room received numerous alarms including high average temperature in a reactor coolant loop and high pressurizer level. At approximately two hours into the event, the control room operators started to reduce power as required by plant specifications. Operators also opened instrument cabinet doors, which allowed cool air to circulate from the air conditioned computer room. 
Portable fans and ducts were installed to move cool air from the computer room door to the cabinets. At approximately three hours into the event, the control room ventilation system was returned to service and declared operable. Due to previous experience with overheating instrumentation and control (I\&C) systems, the plant operators were able to anticipate the problem alarms and respond correctly to the spurious alarms.

During the event, operators recalled the maximum ambient temperature near the cabinets as being about $90^{\circ} \mathrm{F}$, well below the technical specification limit of $120 \circ \mathrm{F}$. Design bases for the I\&C cabinet indicated a temperature rise of $20^{\circ} \mathrm{F}$ above room ambient temperature so the maximum expected temperature in the cabinet should have been approximately $110^{\circ} \mathrm{F}$. However, following the event, temperature measurements indicated that internal cabinet air temperatures ranged from $73^{\circ} \mathrm{F}$ near the bottom to a maximum of $109^{\circ} \mathrm{F}$ near the top under ambient temperature conditions of $72^{\circ} \mathrm{F}$, resulting in a maximum temperature rise of about $37 \circ \mathrm{F}$. Thermocouples placed directly on the instrument racks measured $115^{\circ} \mathrm{F}$ at the middle and $125^{\circ} \mathrm{F}$ at the top rack. Based on these measurements, the temperature at the top rack during the event may have been as high as $143^{\circ} \mathrm{F}$, exceeding the card performance test of $140^{\circ} \mathrm{F}(12$-hour cycle). Based on this observation, it is concluded that electronic components inside cabinets can be exposed to potentially damaging temperatures at ambient temperatures significantly below control room technical specification limits.

The potential generic vulnerability in this instance is related to the assumption that cabinet temperatures are approximately $20^{\circ} \mathrm{F}$ higher than ambient temperatures. Obviously, this assumption did not hold true in this case, and it is likely that most, not all, plants have used this or a similar assumption in designing I\&C equipment. During the plant visits in this study, requests were made for actual temperature measurements inside cabinets, and none could be provided. Therefore, it appears that this is a concern for most plants and should be considered as a generic vulnerability.

\subsubsection{ESFAS Cabinet Failure at a CE PWR}

An electronic failure in an ESF actuation system (ESFAS) cabinet resulted in spurious actuation of several ESF signals at a CE PWR (Chiramal 1986). A spurious automatic start of an EDG, operation of the ESF load sequencer, and a load-shed signal in one safety-related bus were experienced. The cause of the event was traced to an overheated ESF load sequencer cabinet (a fan had failed), which caused the ESF load sequencer module to overheat and malfunction. The malfunction resulted in the load sequencer sending a continuous load-shed signal to an emergency bus, preventing automatic and manual loading of electrical loads onto the safety-related bus and EDG.

To clear the load-shed signal, the ESFAS cabinet was deenergized, the normal supply breaker for the bus was closed, undervoltage relays were jumpered, and the leads of the load-shed relays were lifted. Control fuses for one train of high-pressure safety injection (HPSI), low-pressure safety injection (LPSI), and containment spray pumps were removed prior to deenergizing the cabinet to prevent automatic starting of the pumps. During the initial phase of the event, the Train B essential chiller had tripped (low 
refrigerant level), rendering all Train B equipment inoperable. Because both trains of HPSI, LPSI, and containment spray were inoperable, the plant entered into a technical specification condition which required the plant to be brought to hot shutdown within one hour.

The vulnerability in this instance is similar to that described in Section 6.2.9, i.e., inadequate cabinet cooling.

\subsubsection{Less of Switchgear Room Cooling at a W PWR}

Loss of emergency switchgear room cooling at a W PWR was found in an IPE (VEPCO 1991) to have a CDF of $1.6 E-05 / R Y$. The vulnerable equipment in the switchgear room includes 4.16-kV and DC power supplies. If room cooling is interrupted and not restored, the room will heat up and eventually fail the vital AC or DC power supplies. The IPE established that opening the doors of the room is not sufficient to mitigate room heatup. At this particular plant, switchgear room cooling may be restored by cross-connecting chilled water from a central air conditioning systems or cross-connecting to the switchgear room cooling system of the second unit at the site to provide airflow. Procedures exist to accomplish these recovery actions before the vital $A C$ or $D C$ power supplies are lost due to elevated temperatures in the switchgear room.

The frequency of the loss of switchgear room cooling initiating event was calculated to be 5.86E-04/RY, based on fault tree modeling performed in support of the IPE. The dominant contributors to the CDF associated with this initiating event were found to be failure of operators to cross-connect the central chillers and failure of either one of two cross-connect valves to open.

The CDF associated with loss of switchgear room cooling depends on the ability of the operators to detect the switchgear room cooling failure and the ability to cross-connect the central chillers (VEPCO 1991). Time is available to accomplish the recovery actions, although no time limits were specified in the IPE. Additional time can be made available by shedding nonessential loads or shedding loads on redundant load center transformers that are located in the switchgear room and that generate the highest heat loads. The available time can be increased by deenergizing one train of decay heat removal, provided the other train can be established. Credit was not taken in the IPE for this recovery action. However, the W PWR is modifying the procedures in the event of a loss of switchgear room cooling such that, in an emergency situation, it will be possible to shed a large portion of the heat load in the switchgear room and still maintain one complete train of ESF equipment in operable status. The effects of this procedure on the CDF associated with loss of switchgear room cooling were not quantified; however, this recovery action would apply to all switchgear room cooler-initiated accident sequences. Therefore, the CDF would be reduced by multiplying the existing CDF by the nonrecovery probability associated with the new procedure. Therefore, if the nonrecovery probability was calculated to be 0.1 (i.e., operators would be successful only nine times out of ten in performing the load-shedding actions), the CDF would be reduced to about $1.3 \mathrm{E}-06 / \mathrm{RY}$. 


\subsubsection{Loss of Control Room Cooling at a CE PWB}

An event occurred at a CE PWR in which both independent trains of control room emergency ventilation system air conditioning (CR HVAC) were declared inoperable. One train was determined to be inoperable, while the other train was removed from service for routine maintenance. At this plant, one train is normally operating and the second is in standby.

Failure of the operating train of CR HVAC resulted from insufficient refrigerant level to support compressor start at extremely low outside temperatures (the outside temperature at the time of the event was $16^{\circ} \mathrm{F}$ ). The low temperature caused the refrigerant to migrate to the HVAC system condenser, causing low compressor suction pressure, which resulted in a compressor trip during starting. This occurrence, during the time when the standby train was removed from service for maintenance, resulted in both trains of CR HVAC being inoperable. The plant entered into a 1 imiting condition for operation (LCO). The plant recovered by restoring the train down for maintenance to operable status. Subsequently, modifications were made to the CR HVAC breakers (which were discovered to be faulty) and troubleshooting procedures. The failed train was subsequently tested and declared operable. Additional actions were taken to revise maintenance procedures to specify the appropriate amount of refrigerant.

The LER associated with event indicated that the event was initially detected by control room personnel who noticed that control room air temperature was rising. Operators then opened outside air dampers to reduce air temperatures. No additional measures such as opening doors were necessary to maintain control room temperatures below their maximum values. Control room equipment apparently continued to function normally despite the temperature rise. It is not known to what temperatures the control room had risen.

\subsection{COMPARISONS OF REPRESENTATIVE PLANT-AFFECTED CDFS TO OTHER PLANTS}

To add some perspective to the affected CDFs calculated for the representative plants, a review and limited-scope quantitative evaluation of other PRAs was performed. The quantification of other plants' CDFs was much less rigorous than that presented in Section 4. However, the affected CDFs quantified in this section are believed to be acceptable for comparison with the CDFs calculated in this study. The plants evaluated in this section include

- CE PWR (Payne 1984), designated plant CE-2

- B\&W PWR (Garcia et al. 1981), designated plant BW-2

-W PWR (Bertucio and Julius 1990), designated plant W-2

- BWR (Amico 1983), designated plant BWR-2

- BWR (Kolaczkowski et al. 1989), designated plant BWR-3.

The affected CDFs for these $p l a n t s$ are calculated in the following subsections. A subsection comparing the CDFs calculated in this section with the affected CDFs for the four representative plants is provided in the final subsection. 


\subsubsection{Affected CDF for Plant CE-2}

The PRA for a second CE plant (Payne 1984) was reviewed to identify accident sequences and cut sets that included HVAC and room cooler failures. HVAC and room cooling functions were explicitly modeled in this PRA, including ESF pump room, switchgear room, DC equipment room, and EDG ventilation systems. Therefore, the approach to developing estimates of the affected CDFs consisted of the following general steps:

- For each accident sequence, review cut set parameter definitions to identify affected parameters. This assessment was 1 imited to the dominant cut sets, with the exceptions of the modifications described in the fourth step, below.

- Review cut sets to identify those containing affected parameters.

- Retain cut sets involving explicit fan or room cooler failures. No modifications are necessary for these cut sets.

- Retain cut sets involving ESF pump, diesel generator, DC power, and inverter failures. Modify the parameters to account for fallure of the safety-related components given fallure of the HVAC system serving the area (Step 4).

- Some cut sets were observed to involve two affected parameters. New cut sets were created under these conditions, as follows:

- For cut sets containing one fan or room cooler failure $(X)$ and 1 inverter or pump failure $(Y)$, the original cut set was retained and a second cut set was created, as follows:

New Cut Set $=$ (Initiating Event) * (0ther events) $* X * Y^{\prime}$ where $Y^{\prime}$ represents the modified parameter to account for room cooling failures (see Step 4)

- For cut sets containing two ESF pumps, EDG, DC power, and/or inverter failures ( $Y$ and $Z$ ), three modified cut sets were created as follows:

$$
\begin{aligned}
& i \text { (Initiating even * (Other Events) * }(Y) *\left(Z^{\prime}\right) \\
& \text { if (Initiating event) * (Other Events) * }\left(Y^{\prime}\right) *(Z) \\
& \text { iii (Initiating event) * (0ther Events) * }\left(Y^{\prime}\right) *\left(Z^{\prime}\right)
\end{aligned}
$$

where $Y^{\prime}$ and $Z^{\prime}$ represent the modified parameters (see Step 4).

- Quantify modified cut set frequencies and add to unmodified cut set frequencies in each accident sequence.

- Sum accident sequence frequencies to calculate the affected CDF. 
Table 6.3-1 summarize: the results of the CDF calculations for plant CE-2. The results indicate that the affected CDF for plant CE-2 may be as high as 1.5E-05/RY. The key reason for the high affected CDF for plant CE-2 was that recovery factors were not applied to key cut sets in sequences $S_{2} H$ (small-small LOCA, fallure of HPSR) and S,FH (small-small LOCA, fatlure of HPSR and CSSR). These two accident sequences contributed $88 \%$ of the affected CDF for plant CE-2. Many of the affected dominant cut sets in these sequences included failures of ESF pump room cooling with no recovery applied. It is shown in Appendix $G$ that hours may be available to implement recovery actions to restore cooling to these rooms so a recovery factor is warranted. Because cut sets containing ESF room coolers dominate the affected $\mathrm{S}_{2} \mathrm{H}$ and $\mathrm{S}_{2} \mathrm{FH}$ sequence frequencies, application of a recovery factor will reduce the total affected CDF by an amount approximately equal to the recovery factor; 1.e., if the probability of nonrecovery were assessed at 0.1 , the affected accident sequence frequency would be reduced to $10 \%$ of the value calculated in Section 6.3.1. Because no recovery factor was applied to the dominant cut sets and one is warranted, it appears that the assessment performed for plant CE-2 tends to overstate the actual affected CDF.

A second reason for the high affected CDF is that the component fallure data were developed in the early 1980s. The data were generic in nature, which normally tends to produce conservative results. In the NUREG-1150 PRAs and IPE submittals, plant-specific failure data was used to some extent and a inore reliable and extensive cominorient failure data base was available. The overall result is that the failure data used in the more recent PRAs is lessconservative, yet more accurate, than the data avallable in the early 1980s.

The calculations performed for each accident sequence are described briefly in the following paragraphs. The affected CDF for each accident sequence is also presented.

TABLE 6.3-1. Affected Core Damage Frequency for Plant CE-2

\begin{tabular}{|l|c|}
\hline Accident Sequence & $\begin{array}{c}\text { Core Damage } \\
\text { Frequency, per RY }\end{array}$ \\
\hline$T_{D C} L^{\prime}$ & $5.8 \mathrm{E}-07$ \\
$S_{2} H$ & $4.7 \mathrm{E}-06$ \\
$S_{2} F H$ & $8.1 \mathrm{E}-06$ \\
$\mathrm{~T}_{4} \mathrm{ML}$ & $9.1 \mathrm{E}-08$ \\
$T_{1} Q-D^{\prime}{ }^{\prime} C C^{\prime}$ & $4.9 \mathrm{E}-07$ \\
$T_{1} \mathrm{~L}$ & $3.5 \mathrm{E}-07$ \\
$\mathrm{~T}_{3} \mathrm{ML}$ & $1.3 \mathrm{E}-07$ \\
$T_{1} L C C^{\prime}$ & $1.1 \mathrm{E}-07$ \\
$\mathrm{~T}_{2} \mathrm{~L}$ & $1.3 \mathrm{E}-07$ \\
\hline TOTAL AFFECTED CDF & $1.5 \mathrm{E}-05$ \\
\hline
\end{tabular}




\section{Accident Sequence $I_{D C}$}

This accident sequence, fallure of a DC bus, leads to a trip of the reactor and fallure of the power conversion system. Safety systems are also degraded. A successful SCRAM occurs, but auxiliary feedwater subsequently fails. The core inventory eventually bolls off due to a lack of secondary heat removal. No credit for feed-and-bleed cooling is given. The original frequency for this accident sequence was $2.1 E-05 / R Y$.

Modifications were made to this accident sequence to determine the portion affected by HVAC and room cooling systems. The modifications were made to the initiating event frequency to incorporate the frequency of a loss of DC bus due to loss of HVAC to the DC equipment room. Previousiy, the .nitiating event frequency included all possible causes of DC bus fallure, including hardware, control circuitry, etc. The frequency of the modified initiating event was calculated as follows:

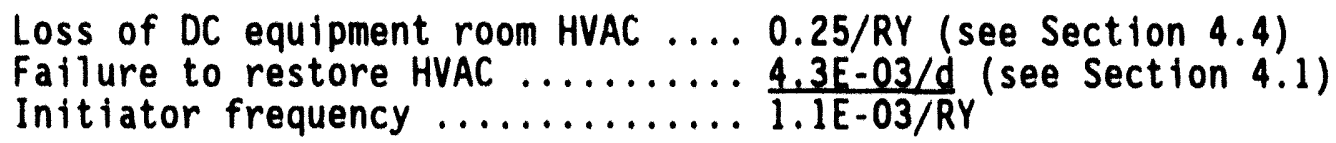

This new value was substituted for the initiating event frequency given by Payne (1984, p. 8-7) that included fallure of a DC bus from all causes and a new accident sequence frequency was calculated. Since the initiating event frequency is a part of all cut sets, the modified accident sequence frequency was calculated by multiplying the original accident sequence frequency (2.1E-05/RY) times the ratio of the (modified initiator frequency):(original initiator frequency) or 1.1E-03/3.6E-02. The modified accident sequence frequency was calculated to be 5.8E-07/RY.

\section{Accident Sequence $S_{2}$ H}

This accident sequence is initiated by a small-small LOCA $\left(S_{2}\right)$. Successful SCRAM occurs followed by successful operation of the AFW and HPSI systems providing secondary heat removal and primary system makeup. When the refueling water tank (RWT) is depleted, switchover to recirculation occurs and HPSR (H) fails. The original sequence frequency was calculated to be $1.4 E-05 / R Y$.

The dominant cut sets composing this accident sequence were observed to include failures of ESF pump room coolers due to AC power cable failures, failure to provide service water to the cooling coils, breaker faults, local faults of fans, and fan maintenance. The cut sets including these failures were identified and their frequencies summed to arrive at the affected CDF for this accident sequence. The affected CDF for sequence $\mathrm{S}_{2} \mathrm{H}$ was calculated to be $4.7 E-06 / R Y$. 


\section{Accident Sequence $S_{2} \underline{F H}$}

This accident sequence is similar initially to $\mathrm{S}_{2} \mathrm{H}$. However, after switchover to recirculation occurs, both HPSR $(H)$ and the containment spray recirculation (CSSR) system (F) fails. The original sequence frequency was $1.1 E-05 / R Y$.

As with $\mathrm{S}_{2} \mathrm{H}$, the dominant cut sets in this sequence included HPSR pump room cooling system failures. The $S_{2} F H$ sequence al so include failure of CSSR pump room cooling systems. The sum of the frequencies of the cut sets involving the HPSR and CSSR pump room cooling failures was calculated to be 8.1E-06/RY.

\section{Accident Sequence $\mathrm{T}_{4} \underline{M L}$}

This sequence is initiated by a transient other than loss of offsite power followed by loss of PCS (M) and failure of AFW (L). The original frequency of this sequence was estimated to be $6.3 E-06 / R Y$.

The affected parameters in this sequence included failure of an AFW turbine-driven pump (TDP). This parameter was modified to incorporate failure of the AFW pump due to loss of room cooling. The modified parameter value was calculated as follows:

Failure of AFW pump room cooler: 5.4E-04/d (Payne 1984, P. 8-18)

Failure of pump given failure of fan: $\underline{0.5}$

Total Failure probability:

$$
2.7 E-04 / d
$$

The modified probability was substituted into the cut sets containing this affected parameter, and the cut sets were then quantified. The affected accident sequence frequency was estimated to be $9.1 E-08 / R Y$.

\section{Accident Sequence $\mathrm{T}_{2} \mathrm{~L}$}

This sequence is initiated by a loss of the PCS $\left(T_{2}\right)$ and is followed by a loss of AFW $(L)$. Core damage occurs due to failure to remove heat from the secondary side of the steam generators. The original sequence frequency was calculated to be $7.1 \mathrm{E}-06 / \mathrm{RY}$.

Affected parameters in this sequence included failure of the AFW TDP and failure of the AFW motor-driven pump (MDP). The dominant cut sets were modified to incorporate failure of the pumps due to loss of room cooling. The modified parameter value for the TDP was the same as that given for sequence $\mathrm{T}_{4} \mathrm{ML}$. The AFW MDP was indicated to have approximately a $20 \%$ lower failure probability than the MDP pump. This percentage was applied to the value given above for the AFW TDP to calculate the failure probability of the i.e., $0.8 \times$ $2.7 \mathrm{E}-04=2.2 \mathrm{E}-04$. These values were substituted into tha affected cut sets. The affected CDF was calculated to be $1.3 E-07 / R Y$. 


\section{Accident Sequence $\mathrm{T}_{4} \mathrm{Q}-\mathrm{D}^{\prime \prime} \mathrm{CC} \mathrm{C}^{\prime}$}

This sequence is initiated by a LOOF followed by a transient-induced LOCA (Q). AFW is successful but HPSI, CS, containment air recirculation, and cooling systems fail. The frequency of this sequence was estimated to be about 5.3E-06/RY.

The affected parameters for this accident sequence included four separate faults that could cause failure of the EDG ventilation system: local faults to power breakers for the ventilation fans and three different damper failures. These faults could occur in either EDG ventilation system train. The frequencies of the cut sets involving these parameters were added together to obtain the affected accident sequence frequency, which was calculated to be 4.9E-07/RY.

\section{Accident Sequence $\mathrm{T}_{1} \underline{\underline{L}}$}

This sequence is initiated by a L.OP $\left(T_{1}\right)$ followed by failure of AFW (L) to provide secondary cooling. As with all other sequences involving failure of AFW, no credit was given for feed-and-bleed cooling. The original sequence frequency was calculated to be $4.9 \mathrm{E}-06 / \mathrm{RY}$.

The affected parameters in this sequence included failures of the AFW TDP, AFW MDP, and the EDG ventilation system. Modifications to these parameters were discussed previously. The affected accident sequence frequency was calculated to be $3.5 \mathrm{E}-07 / \mathrm{RY}$.

\section{Accident Sequence $\mathrm{T}_{3} \underline{\mathrm{ML}}$}

This sequence is initiated by a transient requiring primary pressure relief $\left(T_{3}\right)$ followed by loss of the PCS (M) and AFW (L). The original sequence frequency was calculated to be $1.7 \mathrm{E}-06 / \mathrm{RY}$.

The affected parameters in the dominant cut sets for this sequence included failure of the AFW TDP and failure of an AC inverter. Failure of the $A C$ inverter results in failure of the AFW actuation system to start the AFW MDP and the steam admission valves for one of the two AFW TDPs. A series of other valve failures eventually causes a trip of the MFW pumps. As a result, failure of the AC inverter results in failure of the PCS and two of three AFW trains. The original failure probability for the inverter, ivhich includes all failure modes, was given as 2.4E-03. Calculations presented in Section 4.5 indicate that failure of the inverter due to room cooler failures was estimated to be $1.6 \mathrm{E}-04$. This value was substituted into the cut sets containing the inverter failure. The AFW TDP failure probability was modified as discussed previously. The affected CDF was estimated to be $1.3 E-07 / R Y$.

\section{Accident Sequence $\underline{T}_{1} \underline{L C C^{\prime}}$}

This sequence is initiated by a LOOP $\left(T_{1}\right)$. Subsequent safety system failures include AFW $(L)$, CSSI $(C)$, and CARCS $\left(C^{\prime}\right)$. The original sequence frequency was calculated to be $1.0 \mathrm{E}-06 / \mathrm{RY}$. 
The affected parameters include failure of the AFW TDP, failure of the vital $A C$ inverter, and failures of the EDG ventilation system. The modifications to these parameters were discussed previously. The affected CDF for this accident sequence was estimated to be 1.1E-07.

\subsubsection{Affected CDF for Plant BW-2}

The PRA for a second B\&W plant (Garcia et a1. 1981) was reviewed to identify accident sequences and cut sets that included HVAC and room cooler failures. HVAC and room cooling functions were explicitly modeled for ESF pump rooms, control room, and switchgear rooms in this PRA. However, failures of EDG ventilation systems were not included. Loss of ventilation as a potential cause of failure of the EDGs was added to the cut sets where applicable. The basic approach to developing estimates of the affected CDFs with the exception of the EDG ventilation failures, was the same as the approach described in Section 6.3.1. The affected accident sequences, affected parameters, and affected CDF values are discussed in the following paragraphs.

Table 6.3-2 summarizes the results of the affected CDF calculations for plant $B W-2$. As shown, the affected CDF was calculated to be $5.4 E-06 / R Y$.

\section{Accident Sequence $\mathrm{B}_{4} \underline{\mathrm{S}}_{23}$}

This sequence is initiated by a small-small LOCA $\left(B_{4}\right)$ followed by failure of emergency coolant injection (ECI) and Reactor Building spray (RBS) systems. Similar sequences exist for small, medium, and large LOCAs $\left(B_{3}, B_{2}\right.$, and $B_{1}$, respectively). The original sequence frequencies were calculated to be

$-\mathrm{B}_{4} \mathrm{~S}_{23}-6.5 \mathrm{E}-05 / \mathrm{RY}$
$-\mathrm{B}_{3} \mathrm{~S}_{23}-5.1 \mathrm{E}-06 / \mathrm{RY}$
$-\mathrm{B}_{2} \mathrm{~S}_{23}-5.0 \mathrm{E}-06 / \mathrm{RY}$
$-\mathrm{B}_{1} \mathrm{~S}_{23}-5.0 \mathrm{E}-06 / \mathrm{RY}$

TABLE 6.3-2. Affected Core Damage Frequency for Plant BW-2

\begin{tabular}{|l|c|}
\hline Accident Sequence & $\begin{array}{c}\text { Affected Core Damage } \\
\text { Frequency, per RY }\end{array}$ \\
\hline $\mathrm{B}_{4} \mathrm{~S}_{23}$ & $2.3 \mathrm{E}-07$ \\
$\mathrm{~B}_{3} \mathrm{~S}_{23}$ & $1.8 \mathrm{E}-08$ \\
$\mathrm{~B}_{2} \mathrm{~S}_{23}$ & $1.8 \mathrm{E}-08$ \\
$\mathrm{~B}_{1} \mathrm{~S}_{23}$ & $1.8 \mathrm{E}-08$ \\
$\mathrm{~T}_{2 \mathrm{~T}_{10}} \mathrm{~T}_{10}$ & $2.3 \mathrm{E}-06$ \\
$\mathrm{~T}_{2 \mathrm{~A}} \mathrm{~T}_{9}$ & $4.7 \mathrm{E}-08$ \\
$\mathrm{~T}_{2 \mathrm{~A}} \mathrm{~T}_{8}$ & $8.0 \mathrm{E}-07$ \\
$\left(\mathrm{~T}_{2}-\mathrm{T}_{2 \mathrm{~A}}\right) \mathrm{T}_{8}$ & $196 \mathrm{E}-06$ \\
\hline Total Affected CDF & $5.4 \mathrm{E}-06$ \\
\hline
\end{tabular}


These four sequences were observed to be dominated by one cut set each. This cut set involved an operator switching over to recirculation prematurely, resulting in pump failure due to insufficient water in the sump. This particular parameter is not dependent upon room cooling, so a new cut set was created to incorporate the effects of failure of room cooling in ESF pump rooms. The new cuts included failure of the ESF pump in one train and failure of the ESF pump room cooler in the other train, or failure of both trains of ESF pump room cooling. This created three new cut sets, as shown below:

- $B_{4}$ * (ESF Pump A) * (ESF Fan B)

- $B_{4}^{4}$ * (ESF Pump B) * (ESF Fan A)

- $B_{4}^{4}$ * (ESF Fan $\left.A\right) *(E S F$ Fan B)

The failure probabilities for the ESF pumps and fans were calculated using the following procedure. For [:SF pumps, three failure modes were included:

- Failure to start .......... 3E-03

- Failure to run for $24 \mathrm{hr} \ldots$ 3E-04

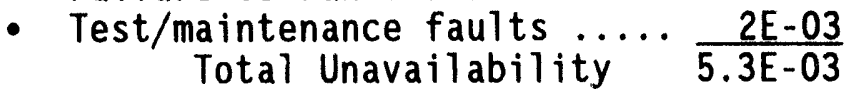

The failure probabilities for these failure modes were taken from Bertucio and Brown (1990).

The failure probability for the ESF room coolers included the three failure modes used for the pumps as well as failure of a service water valve to open to allow cooling water flow into the room coolers (both failing to open and plugging were included), failure of $A C$ power due to failure of either the ESF pump MCC or AC feeder breaker, and failure of the vital DC bus. The failure probabilities for these failure modes were also taken from Bertucio and Brown (1990). Recovery of the room coolers was not included for conservatism. The total unavailability of the room coolers was calculated as follows:

- Failure to start ........... 3E-03

- Failure to run for $24 \mathrm{hr} \ldots . .3 \mathrm{E}-04$

- Test/maintenance faults ......2E-03

- ESW valve failure - plugged .. 6.6E-04

- ESW valve failure to open .... 3E-04

- Failure of AC MCC ........... 1E-04

- Failure of feeder breaker ...2.2.9E-05

- Failure of DC bus ........... $\frac{1.3 E-07}{9.1 E-03}$
Total Unavailability

These values were substituted into the three new cut sets shown previously. 'The affected CDFs for all three accident sequences were calculated to be 
- $\mathrm{B}_{4} \mathrm{~S}_{23}-2.3 \mathrm{E}-07 / \mathrm{RY}$

- $B_{3}^{4} S_{23}^{23}-1.8 E-08 / R Y$

- $\mathrm{B}_{2} \mathrm{~S}_{23}^{23}-1.8 \mathrm{E}-08 / \mathrm{RY}$

- $B_{1}^{2} S_{23}^{23}-1.8 E-08 / R Y$

\section{Accident Sequence $T_{2 A} I_{10}$}

This sequence is initiated by a LOOP. Subsequent safety system failures include AFW, HPI (feed-and-bleed mode), RBS and Reactor Building cooling systems. The original sequence frequency was $5.4 \mathrm{E}-05 / \mathrm{RY}$.

The affected parameters in this sequence included failure of the EDG to start/run (modified to failure of EDG ventilation), fail re of the AFW TDP (modified to failure of the AFW pump due to room cooling failure), and failure of a st ion battery (modified to failure of $D C$ equipment room cooling). The failure obability values for the affected parameters were derived as

follows:

- Failure of EDG ventilation: 5.9E-04 (see Section 4.4)

- Failure of turbine-driven AFW pump room cooling: 3.1E-03 (see Section 4.4)

- Failure of DC equipment room cooling: failure rate $=0.25 / \mathrm{yr}$ (APSC 1992), mission time $=1 \mathrm{yr}$. Failure probability $=5.7 \mathrm{E}-05 /$ demand.

New cut sets were developed from the dominant cut sets for this sequence using the approach discussed in Section 6.3.1 for cut sets involving one or more affected parameters. The appropriate failure probabilities were then substituted into the cut set. The affected CDF for this accident sequence was calculated to be 2.3E-06/RY.

\section{Accident Sequence $\mathrm{B}_{4} \underline{S}_{6}$}

This sequence is initiated by a small-small LOCA followed by successful operation of the RBS and HPI systems in the injection mode. Following successful injection, the HPI and RBS systems fail in the recirculation mode. The original sequence frequency was calculated to be $3.9 E-06 / R Y$, which is similar to the $\mathrm{B}_{4} \mathrm{~S}_{23}$ sequence described previously except recirculation fails because operators fail to initiate recirculation in time to prevent depletion of the RWST and slibsequent failure of HPI pumps. Modifications to this accident sequence to include room cooler failures result in identical modified cut sets to $\mathrm{B}_{4} \mathrm{~S}_{23}$ and thus are not included to avoid double-counting the same cut sets.

\section{Accident Sequence $I_{2 A} I_{9}$}

This accident sequence is initiated by a LOOP followed by failure of AFW, HPI (feed-and-bleed mode), and RBS systems. The original sequence frequency was given to be $2.5 \mathrm{E}-06 / \mathrm{RY}$. 
Affected parameters in the dominant cut sets composing this accident sequence included failures of the EDG to start and failure of the AFW TDP. Modifications to the affected parameters and to the dominant cut sets to include room cooling concerns were the same as described previously for accident sequence $T_{2 A} T_{10}$. The affected CDF for accident sequence $T_{2 A} T_{9}$ was estimated to be $9.6 \mathrm{E}-08 / \mathrm{RY}$.

\section{Accident Sequence $\mathrm{T}_{2 A} \mathrm{I}_{8}$}

This accident sequence is initiated by a LOOP followed by failure of AFW and HPI (feed-and-bleed mode) systems. RBS systems function successfully to reduce containment pressures and radioactivity releases. The original sequence frequency was given to be $1.4 \mathrm{E}-05 / \mathrm{RY}$.

The affected parameters in this accident sequence included failures of the EDG to start run, failure of the AFW TDP, and failure of the HPI pump (modified to incorporate failure of HPI room coolers). Modifications to the affected parameters and to the dominant cut sets to include room cooling concerns were the same as described previously for accident sequence $T_{2 A} T_{10}$ (for EDG ventilation and AFW pump failures) and $B_{4} S_{23}$ (for HPI pump/room cooler failures). The affected CDF for accident sequence $T_{2 A} T_{8}$ was estimated to te $8.0 \mathrm{E}-07 / \mathrm{RY}$.

\section{Accident Sequence $\left(T_{2}-T_{2 A}\right) T_{8}$}

This accident sequence is initiated by a loss of the PCS not caused by a loop $\left(T_{2}-T_{2 A}\right)$. Subsequent safety system failures include AFW and HPI (feedand-bleed mode) systems. RBS systems function successfully to reduce containment pressures and radioactivity releases. The original sequence frequency was given to be $8.6 \mathrm{E}-06 / \mathrm{RY}$.

The affected parameters in this sequence are somewhat different than those affected previously. Potentially affected parameters included failure of the AFW TDP train (see above), as well as failure of a AFW MDP train, and failure of auto-actuation systems for the AFW system. Modifications were made to the latter two parameters to incorporate room cooler failures. The modifications to the motor-driven AFW train failure were the same as those described for the turbine-driven AFW train, resulting in a modified failure probability of 3.1E-03. The failure of the AFW auto-actuation systems was modified to incorporate failure of the control room HVAC system and failure to recover, resulting in a failure probability of 4.7E-06 (see Section 4.4). Using these modified parameters, the affected CDF for this accident sequence was calculated to be $1.9 \mathrm{E}-06 / \mathrm{RY}$.

\subsubsection{Affected CDF for Plant $W-2$}

The PRA for a second W plant (Bertucio and Brown 1990) was reviewed to identify HVAC and room cooler failures that may contribute to the overall plant CDF. HVAC and room cooling functions were not modeled in this PRA. It was stated that room cooling requirements were evaluated, and none of the systems required rcom cooling. However, based on the system analyses and plant 
design features, this plant is similar in design to the representative $W$ PWR. Therefore, it was decided to incorporate HVAC and room cooler failures into the accident sequence analyses for plant $W-2$.

The results of the accident sequence frequency calculations and the affected sequence frequencies for plant $W-2$ are shown in Table 6.3-3. The table also shows the sequence designators for the representative plant and the designators for similar sequences for plant $W-2$. The total affected CDF for non-HVAC initiated sequences at plant $W-2$ is also shown in the table. The total affected CDF for plant $W-2$ represents about $64 \%$ of the total original $\operatorname{CDF}(4.0 \mathrm{E}-05 / \mathrm{RY})$, which is somewhat higher than the $43 \%$ of the original CDF estimated for the representative W PWR. The dominant accident sequences for plant $W-2$ also differ from the representative $W$ PWR. For plant W-2, station blackout sequences (SBO) contribute $68 \%$ of the affected CDF while SBO sequences contribute on ly about $20 \%$ of the affected CDF for the representative W PWR. LOCA sequences contribute about $62 \%$ of the affected CDF for the representative W PWR and only abnut 19\% of the affected CDF for plant W-2.

Because the assessment described in this section is not as rigorous or comprehensive as the assessment of affected CDF for the representative plants, a simplified quantification procedure was used to develop estimates of the affected accident sequence frequencies for $p l a n t W-2$. Similar safety systems are provided at plant $W-2$ as at the representative $W$ PWR. These included:

- Component cooling water (CCW) - closed-cycle system with one-out-of-two pump trains, each with its own heat exchanger

- Auxiliary feedwater (AFW) - one TDP and two MDP trains

- Containment spray system (CSS) - two 100\%-capacity spray injection trains

- Emergency $A C$ power - one dedicated EDG and one shared EDG per unit plus two $4160-V$ AC buses, four $480-V$ AC buses, four $120-V$ AC vital instrumentation buses, two $125-V$ DC buses.

- High-pressure injection/recirculation (HPI/HPR); two-out-of-three charging pump train system injecting to cold legs.

- Low-pressure injection/recirculation (LPI/LPR); two $100 \%$-capacity pump trains

- Emergency service water (ESW); gravity flow system at plant $W-2$ versus an open-cycle system requiring two-out-of-four pumps to function under accident conditions. 


\section{TABLE 6.3-3. Assessment of Affected Core Damage Frequency for Plant W-2}

\begin{tabular}{|c|c|c|c|c|c|c|c|}
\hline \multirow[b]{2}{*}{ Accident Sequence Description } & \multicolumn{4}{|c|}{ Representative W PWR } & \multicolumn{3}{|c|}{ Plant $\mathrm{W}-2$} \\
\hline & $\begin{array}{l}\text { Accident } \\
\text { Sequence }\end{array}$ & $\begin{array}{l}\text { Affected } \\
\text { Frequency }\end{array}$ & $\begin{array}{l}\text { Original } \\
\text { Frequency }\end{array}$ & Fraction & $\begin{array}{l}\text { Accident } \\
\text { Sequence }\end{array}$ & $\begin{array}{l}\text { Original } \\
\text { Frequency }\end{array}$ & $\begin{array}{l}\text { Affected } \\
\text { Frequency }\end{array}$ \\
\hline Medium LOCA, HPR fail & S1H4 & $1.10 E-09$ & $1.90 \mathrm{E}-06$ & $5.79 \mathrm{E}-04$ & S1HI & $1.70 E-06$ & $9.84 \mathrm{E}-10$ \\
\hline Small LOCA. LPR fails & $\mathrm{S} 2 \mathrm{H} 3$ & $1.60 E-08$ & $1.70 \mathrm{E}-06$ & $9.41 \mathrm{E}-03$ & $\mathrm{~S} 2 \mathrm{HI}$ & $2.40 \mathrm{E}-09$ & $2.26 \mathrm{E}-11$ \\
\hline Very small LOCA, LPR fails & $\mathrm{S} 30 \mathrm{CH} 3$ & $8.00 E-08$ & $5.00 E-06$ & $1.60 \mathrm{E}-02$ & S3ODHI & 4.60E-09 & $7.36 \mathrm{E}-11$ \\
\hline Very small LOCA, RHR, LPR fail & S3W1H3 & $1.70 E-07$ & $6.30 E-07$ & $2.70 E-01$ & S3W3HI & $5.90 E-10$ & $1.59 \mathrm{E}-10$ \\
\hline Large LOCA, LPR fails & AH1 & $4.70 \mathrm{E}-12$ & $1.00 E-06$ & $4.70 E-06$ & AH1 & $8.20 \mathrm{E}-07$ & $3.85 E-12$ \\
\hline Station blackout, battery depletion & SBO-BATT & $8.20 E-09$ & $3.10 E-07$ & $2.65 \mathrm{E}-02$ & SBO-BATT & $1.10 \mathrm{E}-05$ & $2.91 \mathrm{E}-07$ \\
\hline Station blackout, AFW fails & SBO-L & $7.30 \mathrm{E}-07$ & $9.60 \mathrm{E}-06$ & $7.60 E-02$ & $S B O-L$ & $4.70 \mathrm{E}-06$ & $3.57 \mathrm{E}-07$ \\
\hline Station blackout, stuck open PORV & SBO-Q & 4.00E-08 & $3.90 E-07$ & $1.03 E-01$ & SBO-Q & $2.20 \mathrm{E}-06$ & $2.26 \mathrm{E}-07$ \\
\hline Station blackout. RCP seal LOCA & SBO-SLOCA & $1.00 \mathrm{E}-06$ & $4.30 E-06$ & $2.33 \mathrm{E}-01$ & SBO-SLOCA & $5.30 E-06$ & $1.23 \mathrm{E}-06$ \\
\hline \multicolumn{2}{|l|}{ Total Affected Core Damage Frequency } & $2.05 E-06$ & & & & & $2.11 \mathrm{E}-06$ \\
\hline
\end{tabular}


These safety systems are very similar, with the exception of the ESW system, to the safety systems provided at the representative W PWR. Of course, there are differences in piping and valve arrangements and other details of the system; however, for this limited assessment, these differences were assumed to be insignificant with respect to their failure probabilities under accident conditions.

The basic approach to estimating the affected CDF for plant $W-2$ assumes that the ratios of the affected accident sequence frequencies to the original sequence frequencies for the representative W PWR are equal to the ratios for plant W-2. Accident sequences developed by Bertucio and Julius (1990) closely followed the accident sequences developed for the representative plant, although nomenclature was different. The formula used to calculate the affected CDF for each accident sequence for plant $W-2$ is

CDF due to

HVAC for $=\operatorname{CDF}($ Total, $W-2) *$ CDF (HVAC at representative plant) plant W-2

CDF (total at representative plant)

This approach seems reasonable because of the many similarities in the safety systems between the representative W PWR and plant W-2.

\subsubsection{Affected CDF for Plant BWR-2}

The PRA for a BWR plant (Amico 1983) was reviewed to identify HVAC and room cooler failures that may contribute to the overall plant CDF. HVAC and room cooling functions were not modeled in this PRA. Therefore, it was decided to incorporate HVAC and room cooler failures into the accident sequence analyses for plant BWR-2.

Table 6.3-4 summarizes the results of the affected CDF calculations for plant BWR-2. As shown, the total affected CDF for plant BWR-2 was calculated to be $5.3 E-06 / R Y$.

The basic approach to estimating the affected CDF for plant BWR-2 is the same as that described in Section 6.3.1. However, for BWR-2, there are dominant cut sets containing HVAC or room cooling failures. Therefore, modifications to incorporate these failures were applied to all of the accident sequences and dominant cut sets. The modifications made in this assessment are described in the following paragraphs.

\section{Accident Sequence $\mathrm{T}_{4} \underline{\mathrm{JCD}}$}

This sequence is initiated by a loss of normal $A C$ power $\left(T_{4}\right)$. Subsequent safety system failures include failure of the safety relief valve to reseat after opening (J), failure of HPI (C), and failure of operators to depressurize the primary coolant system to allow LPI systems to operate (D). Containment cooling systems operate successfully to delay containment failure and mitigate consequences. The original frequency of this accident sequence was estimated to be $7 E-05 / R Y$. 
IABLE 6.3-4. Affected CDF for Plant BWR-2

\begin{tabular}{|l|c|c|}
\hline $\begin{array}{l}\text { Accident } \\
\text { Sequence }\end{array}$ & $\begin{array}{c}\text { Original } \\
\text { Frequency, per RY }\end{array}$ & $\begin{array}{c}\text { Affected } \\
\text { Frequency, per RY }\end{array}$ \\
\hline $\mathrm{T}_{4}$ JCD & $7 \mathrm{E}-05$ & $1.1 \mathrm{E}-06$ \\
$\mathrm{~T}_{4} J C E F G$ & $4 \mathrm{E}-05$ & $2.2 \mathrm{E}-07$ \\
$\mathrm{~T}_{4}$ KCD & $3 \mathrm{E}-05$ & $1.1 \mathrm{E}-06$ \\
$\mathrm{~T}_{4}$ KCEFG & $3 \mathrm{E}-05$ & $8.7 \mathrm{E}-07$ \\
$\mathrm{~T}_{4} \mathrm{LCD}$ & $3 \mathrm{E}-05$ & $5.4 \mathrm{E}-07$ \\
$\mathrm{~T}_{4} \mathrm{LCEDG}$ & $2 \mathrm{E}-05$ & $1.7 \mathrm{E}-07$ \\
$\mathrm{~T}_{4}$ JCMG & $2 \mathrm{E}-05$ & $2.6 \mathrm{E}-06$ \\
$\mathrm{~T}_{4} \mathrm{LCMG}$ & $1 \mathrm{E}-05$ & $1.4 \mathrm{E}-07$ \\
$\mathrm{~T}_{4}$ KCEDG & $1 \mathrm{E}-05$ & $7.3 \mathrm{E}-07$ \\
$\mathrm{~T}_{4}$ KCMG & $9 \mathrm{E}-06$ & $1.7 \mathrm{E}-07$ \\
\hline TOTAL & $2.7 \mathrm{E}-04$ & $5.3 \mathrm{E}-06$ \\
& & $(2 \%)$ \\
\hline
\end{tabular}

The affected parameters in the dominant cut sets for this accident sequence and the modifications made to incorporate HVAC failures include

- AC-GTG-LOF: failure of the gas turbine generator (GTG) (0.06). Modified to failure of GTG to start/run as a result of HVAC failures (5.9E-04 based on analysis in Section 4.4).

- FW-LOGIC-FAIL: failure of relays that initiate feedwater coolant injection system (same as HPI). Modified to failure of safety injection actuation system logic cabinets located in control room (4.7E-06 based on analysis in Section 4.4).

These modified parameter values were substituted into the cut sets containing the original parameters. The affected CDF was calculated to be $1.1 E-06 / R Y$.

\section{Accident Sequence $\mathrm{T}_{4}$ JCEFG}

This accident sequence is initiated by a LOOP followed by failure of a safety relief valve (SRV) to reseat after opening (J), failure of the HPI 
system (C), successful depressurization of the primary coolant system, and failure of the LPI and CS systems ( $E$ and F, respectively). This sequence also includes failure of the containment cooling system $(G)$. The original accident sequence frequency was $4 E-05 / R Y$.

The affected parameters in this sequence include AC-GTG-LOF (see above) and failure of the emergency diesel generator (EDG), AC-EDGN-LOF. Since the failure probability for the GTG was stated to be identical to failure probability of the EDG, the modified value, to take into account failure of the EDG ventilation system, was assumed to be the same as the modified AC-GTG-LOF value. The affected CDF for this sequence was calculated to be $2.2 E-07 / R Y$.

\section{Accident Sequence $\mathrm{T}_{4} \mathrm{KCD}$}

This sequence is initiated by a loss of normal $A C$ power $\left(T_{4}\right)$. Subsequent safety system failures include failure of the isolation condenser (IC) system to remove decay heat from the reactor coolant system (K), failure of HPI (C), and failure of operators to depressurize the primary coolant system to allow LPI systems to operate (D). Containment cooling systems operate successfully to delay containment failure and mitigate consequences. This sequence is similar to $T_{4} J C D$ with the exception that, in this instance, cooling is lost through failure of the IC system, and in $T_{4} J C D$, coolant is lost through a stuck-open SRV. The original frequency of this accident sequence was estimated to be $3 E-05 / R Y$.

The affected parameters in the dominant cut sets for this accident sequence and the modifications made to incorporate HVAC failures include the modification discussed previously for AC-GTG-LOF and the following:

- IC-RELAY-CONTACTS: failure of isolation condenser initiation logic relay contacts (3.6E-03). Modified to failure of IC actuation system logic cabinets located in control room (4.7E-06 based on analys is in Section 4.4).

- SWS-MECH-FAIL: mechanical failure of service water system (SWS) to provide cooling water to HPI pumps (5.8E-02). Modified to failure of SWS train pumps due to failure of room cooling to pump rooms (9.1E-03 based on analysis of ESF pump failure due to HVAC failure in Section 6.3.2)

After substituting these modified parameter values into the dominant cut sets for this accident sequence, the affected CDF was calculated to be 1.1E-06/RY.

\section{Accident Sequence $\mathrm{T}_{4}$ KCEFG}

This accident sequence is initiated by a LOOP followed by failure of the IC system to remove decay heat from the primary coolant system (K), failure of the HPI system (C), successful depressurization of the primary coolant system, and failure of the LPI and CS systems ( $E$ and $F$, respectively). This sequence 
also includes failure of the containment cooling system (G). The original accident sequence frequency was $3 E-05 / R Y$.

The affected parameters in this accident sequence included AC-GTG-LOF and AC-EDGN-LOF described previously and the following parameter:

- DC-BATT-A-FAIL: failure of DC battery "A" (7.5E-04). Modified to failure of $D C$ equipment room cooling and subsequent failure of one division of vital DC power (5.7E-05, see analysis in Section 6.3.2).

The modified parameter values were then substituted into the affected dominant cut sets. New cut sets were developed for cases in which two of the affected parameters were found in the same original cut set (see approach described in Section 6.3.1). The affected CDF was calculated to be 8.7E-07/RY.

\section{Accident Sequence $\mathrm{T}_{4} \underline{\mathrm{LCD}}$}

This accident sequence is initiated by a LOOP followed by failure to supply cooling water to the shell side of the IC system to remove decay heat from the primary coolant system (L), failure of the HPI system (C), and failure to depressurize the primary coolant system to allow coolant makeup via the LPI system. The original sequence frequency was $3 E-05 / R Y$.

The affected parameters in this accident sequence included AC-GTG-LOF and SWS-MECH-FAIL which were described previously. After substituting the modified parameter values into the affected cut sets, the affected accident sequence frequency was calculated to be $5.4 \mathrm{E}-07 / \mathrm{RY}$.

\section{Accident Sequence $\mathrm{T}_{4}$ JCDG}

This accident sequence is initiated by a LOOP followed by failure of a safety relief valve (SRV) to reseat after opening (J), failure of the HPI system (C), failure of the primary coolant system to depressurize (D), and failure of the containment cooling system $(G)$. The original accident sequence frequency was $2 E-05 / R Y$.

The affected parameters in this accident sequence included AC-GTG-LOF and $A C-E D G N-L O F$ described previously and the following parameter:

- $A C-I A C-A B T-L O F:$ failure of vital instrument $A C$ power bus transfer results in failure of LPI pump cooling (0.3). Modified to failure of LPI pump due to room cooler failure OR failure of DC equipment room cooling $(9.1 \mathrm{E}-03+5.7 \mathrm{E}-05=9.2 \mathrm{E}-03$; 'see Section 6.2.3).

- INSTRUMENT-AC: failure of breaker/transformer that fails vital instrument power $(0.4)$. Same modification as for AC-IAC-ABT-LOF. 
These modified parameter values were substituted into the dominant cut sets that make up this accident sequence. Additional cut sets were developed for original cut sets that contained more than one of the affected parameters. The affected accident sequence frequency was calculated to be $1.7 \mathrm{E}-07 / \mathrm{RY}$.

\section{Accident Sequence $\mathrm{T}_{4} \mathrm{JCMG}$}

This accident sequence is initiated by a LOOP followed by failure of an SRV to reseat after opening (J), failure of the HPI system (C), successful depressurization of the primary coolant system, and failure of the shutdown cooling system to remove decay heat (M). Failure of the containment cooling system $(G)$ is also included. The original accident sequence frequency was $2 \mathrm{E}-05 / \mathrm{RY}$.

The affected parameters in this accident sequence included AC-GTG-LOF, INSTRUMENT-AC, and AC-IAC-ABT-LOF that were described previously. The modified parameter values were substituted into the dominant cut sets for this accident sequence. Additional cut sets were developed for original cut sets that contained more than one of the affected parameters. The affected accident sequence frequency was calculated to be $2.6 \mathrm{E}-07 / \mathrm{RY}$.

\section{Accident Sequence $\mathrm{T}_{4} \underline{L C M G}$}

This accident sequence is initiated by a LOOP. Subsequent safety system failures include failure to provide shell-side cooling to the isolation condenser (L), failure of the HPI system (C), successful depressurization of the primary coolant system, and failure of the shutdown cooling system to remove decay heat (M), and failure of the containment cooling system (G). The original accident sequence frequency was $1 E-05 / R Y$.

The affected parameters in this accident sequence included AC-GTG-LOF, INSTRUMENT-AC, and AC-IAC-ABT-LOF that were described previousiy. The modified parameter values were substituted into the dominant cut sets for this accident sequence. Additional cut sets were developed for original cut sets that contained more than one of the affected parameters. The affected accident sequence frequency was calculated to be $1.4 \mathrm{E}-07 / \mathrm{RY}$.

\section{Accident Sequence $\mathrm{T}_{4} \underline{\mathrm{KCDG}}$}

This accident sequence is initiated by a loss of normal $A C$ power followed by failure of the IC system (K), failure of the HPI system to provide coolant at high pressure (C), failure of operators to manually depressurize the primary coolant system (D), and failure of containment cooling (G). The original accident sequence frequency was $1 E-05 / R Y$.

The affected parameters in the dominant cut sets for this sequence include AC-GTG-LOF, AC-EDGN-LOF, AC-ABT-LOF, IC-RELAY-CONTACTS, and INSTRUMENT-AC. Modifications were also made to the dominant cut sets to include parameter AC-IAC-ABT-LOF, which is similar to INSTRUMENT-AC. 
Modifications to these parameters to reflect failure of HVAC and room cooling systems were discussed previously. The affected accident sequence frequency was calculated to be $7.3 \mathrm{E}-07 / \mathrm{RY}$.

\section{Accident Sequence $\mathrm{T}_{4} \underline{\mathrm{KCMG}}$}

This accident sequence is initiated by a loss of normal AC power. The loss of power transient is followed by failure of the IC system (K), failure of the HPI system to provide coolant at high pressure (C), successful depressurization of the primary coolant system, failure of the shutdown cooling system to provide long-term cooling $(M)$, and failure of containment cooling $(G)$. The original accident sequence frequency was $1 E-05 / R Y$.

The affected parameters in the dominant cut sets for this sequence include AC-GTG-LOF, AC-IAC-ABT-LOF, IC-RELAY-CONTACTS, and INSTRUMENT-AC. Modifications to these parameters to reflect failure of HVAC and room cooling systems were discussed previously. The affected accident sequence frequency was calculated to be $1.7 E-07 / R Y$.

\subsubsection{Affected CDF For Plant BWR-3}

The PRA for a third BWR (Kolaczkowski et a1. 1989), designated BWR-3, was reviewed to identify HVAC and room cooler failures that contribute to the overall CDF. Room cooling functions were modeled by the emergency ventilation system (EVS) and the essential service water (ESW) system. The affected CDF of plant BWR-3 was determined from the risk reduction analys is in the PRA and then compared to the representative BWR.

The main CDF contribution from HVAC and room cooler failures results from failure of the EDG room ventilation system. The EVS provides room cooling to four EDG rooms that are shared between units at the multi-unit BWR-3 site. The EDG rooms are similar to the representative BWR except that there are four EDG rooms instead of three and a one-out-of-two fan train instead of a one-out-oftone for each room. These differences provide more redundancy for BWR-3 and are key to the low affected CDF for plant BWR-3 that was calculated to be $8.0 E-08 / R Y$. The point estimate affected CDF for the representative BWR was slightly higher at 2.0E-07/RY.

The BWR-3 PRA modeled room cooling functions in the HPCI, RHR, RCIC, and LPCS pump rooms. The model included the valves, heat exchangers, coils, and fans for the room coolers. No cut sets involving HVAC or room cooler failures were identified as contributing significantly to the original BWR-3 CDF given by Kolaczkowski et al. (1989). The representative BWR had similar results, with only two significant cut sets having a combined frequency of $7.3 E-09 / R Y$.

The only significant room cooler failures affecting the CDF for BWR-3 and the representative BWR are those in the EDG rooms. As a result, only sequences involving a LOOP are affected. Important quantitative differences between the affected CDF of plant BWR-3 and the representative BWR were due to 
initiating event frequencies and redundancies in the EDG room cooler designs. The value for initiating event LOOP was $0.079 / R Y$ for plant BWR-3 and $0.11 / R Y$ for the representative BWR.

The risk reduction analysis presented by Kolaczkowski was used to estimate the affected CDF for BWR-3. The calculations were performed by setting the probabilities of affected events, such as failure of the EDG EVS, to zero. This results in setting all cut sets containing the events to a value of 0.0 . The difference in CDF that results from eliminating the affected cut sets is the affected CDF associated with failures of HVAC and room cooling equipment. Plant BWR-3 had only three events affected by this issue that had any significance in reducing the CDF. The affected CDF was calculated to be 8.0E-08/RY. The results are summarized in Table 6.3-5.

\subsubsection{Comparisons Between Affected CDF for Representative Plants and Other Plants Analyzed}

This section presents the insights gained about the abilities of the four representative plants analyzed in Sections 3 and 4 to represent the population of LWRs in terms of the quantified contributions of HVAC and room cooler failures to a plant's CDF. This section compares the affected CDFs for the representative LWRs to the affected CDFs calculated in Sections 6.3.1 to 6.3.5. Overal1, the HVAC and room cooler contributions to the CDF from internal events were calculated for nine different plants. Detailed evaluations were performed for representative plants from each vendor (i.e., CE PWR, W PWR, B\&W PWR, and a GE BWR). In addition, less comprehensive calculations were performed for an additional plant from each PWR vendor and two additional GE BWR plants. The affected CDFs for each of these plants are presented in Table 6.3-6 and illustrated in Figure 6.3-1.

As shown, the affected CDFs calculated in this study ranged from about $1 E-07 / R Y$ to $1 E-05 / R Y$. Except for the highest and lowest frequency plants, all the affected CDFs were in a more narrow range from $1 E-06$ to $5 E-06 / R Y$.

The arithmetic mean across all nine plants is about $4 E-06 / R Y$. Thus, the mean is within about a factor of 4 higher and a factor of 18 lower relative to maximum and minimum affected CDFs, respectively (the affected CDF for plant BWR-3 was neglected from this calculation because it was not possible to make all modifications to the plant's existing PRA necessary for a valid comparison). This range is not a large variation.

\subsection{EXTERNAL EVENTS}

The affected CDF and public risk values associated with external events were quantified in Section 5 . The affected CDF due to external events was estimated to be about $8 E-06 / R Y$ for both PWRs and BWRs. The external event CDF was found to be about 2 to 40 times higher, depending upon the plant, than the affected CDF due to internal events. 
IABLE 6.3-5. Affected CDF for Plant BWR-3

\begin{tabular}{|llccc|}
\hline Event & \multicolumn{1}{c}{ Description } & Occur. & Prob. & $\begin{array}{c}\text { Risk } \\
\text { Reduction }\end{array}$ \\
\hline EHV-AOV-CC-CCF & $\begin{array}{l}\text { Common cause failure of } \\
\text { EDG room AOVs to open }\end{array}$ & 25 & $1.0 E-03$ & $6.35 E-08$ \\
EHV-SRV-CC-RV3 & $\begin{array}{l}\text { Relief damper 3 fails to } \\
\text { open }\end{array}$ & 40 & $3.0 E-04$ & $8.13 E-09$ \\
EHV-SRV-CC-RV2 & $\begin{array}{l}\text { Relief damper 2 fails to } \\
\text { open }\end{array}$ & 40 & $3.0 E-04$ & $8.13 E-09$ \\
\hline
\end{tabular}

TABLE 6.3-6. Comparison of Affected CDFs for Nine LWRs (internal events)

\begin{tabular}{|l|c|}
\hline Plant Designation & $\begin{array}{c}\text { Affected } \\
\text { CDF, per RY }\end{array}$ \\
\hline Representative W PWR & $4.1 \mathrm{E}-06$ \\
Representative GE BWR & $5.4 \mathrm{E}-07$ \\
Representative CE PWR & $1.3 \mathrm{E}-06$ \\
Representative B\&W PWR & $1.2 \mathrm{E}-06$ \\
Plant CE-2 & $1.5 \mathrm{E}-05$ \\
Plant BW-2 & $5.4 \mathrm{E}-06$ \\
Plant W-2 & $2.1 \mathrm{E}-06$ \\
Plant BWR-2 & $5.3 \mathrm{E}-06$ \\
Plant BWR-3 & $8.0 \mathrm{E}-08$ \\
\hline
\end{tabular}

Conclusions derived from the external events analyses:

- Fires were found to dominate the affected external event CDF, partly because fires in HVAC equipment rooms are not likely to directly affect the operability of the equipment supported by the HVAC equipment due to separation requirements, fire protection requirements, etc. Fires affecting HVAC equipment are an indirect effect; $i . e .$, the fire-induced loss of HVAC causes rooms to heat up, but since the safety-related equipment is located in separate rooms from the HVAC equipment, it is not likely that a fire will cause failure of both the HVAC equipment and the safety-related equipment. On the other hand, the effects of seismic events are not limited to a few rooms. The seismic event will affect the entire plant to some degree, so there is no reason to believe that a seismic event will fail HVAC equipme.it and not equipment supported by the HVAC components. This observation, in conjunction with the observation that room coolers are less susceptible to seismic-induced failures than other plant components such as pumps, switchgear, and water storage 


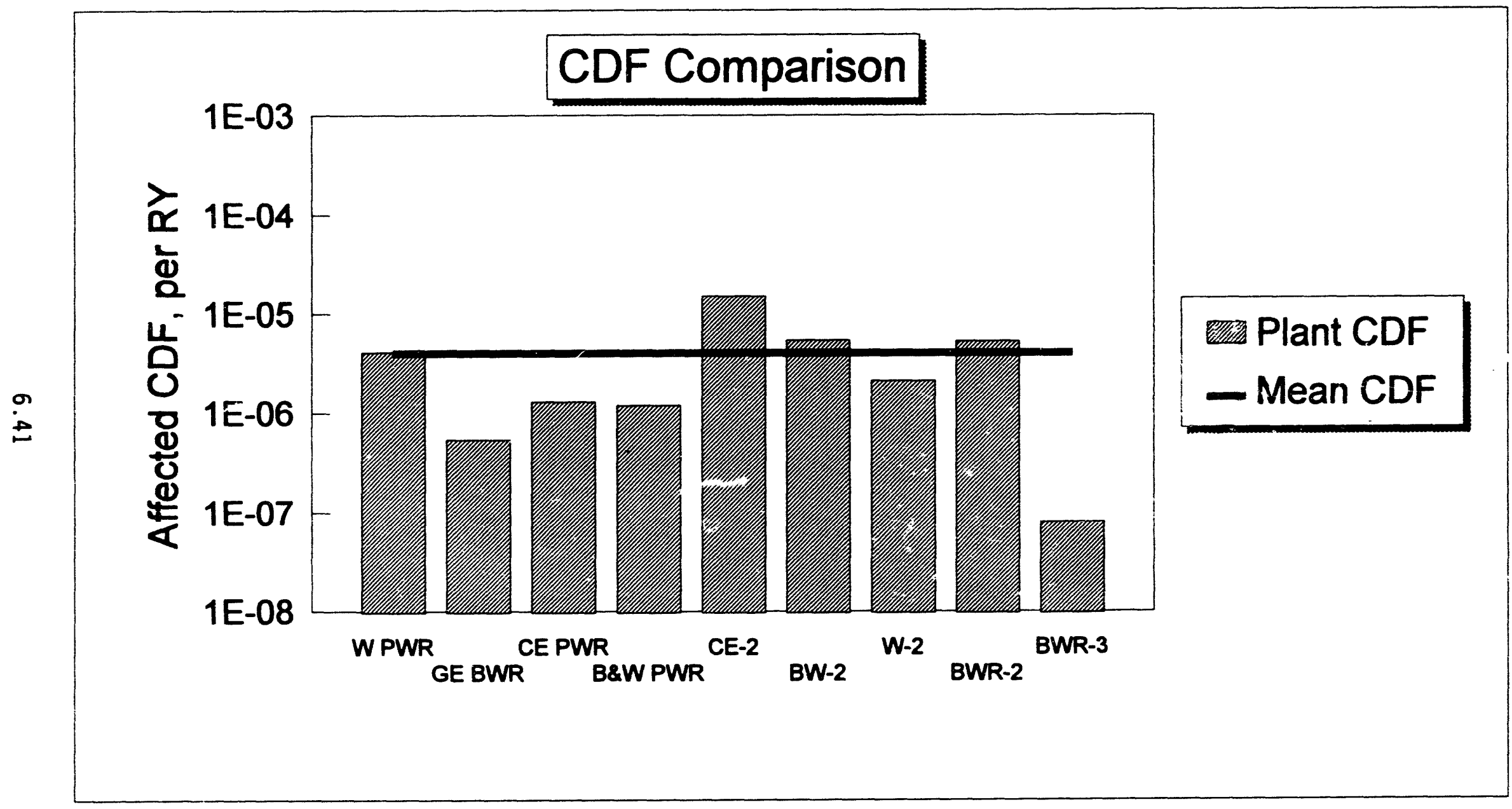

FIGURE 6.1. Comparison of Affected Core Damage Frequency for Eight LWRs 
tanks, leads to the conclusion that HVAC equipment is more vulnerable to fires than to other external events. This tends to minimize the contributions of seismic events to the affected CDF.

- It was observed that the affected fire-induced CDF is a much larger fraction of the total fire-induced CDF than the corresponding fraction of the se'ismic-induced CDF. The main reason for this is that the HVAC and room cooling equipment is much less vulnerable to seismic-induced failures than other safety system components such as pumps.

- For both PWRs and BWRs, the affected seismic CDF is dominated by a few accident sequences. The dominant accident sequences primarily involve SBO situations, although the exact causes of SBOs differ somewhat among plant types.

- Tornadoes were demonstrated to contribute insignificantly to the affected external event CDF because of the protection provided by plant structures and buildings from tornado-induced high winds and missiles. Tornadoes have effects on HVAC components similar to seismic events; i.e., it is unlikely that a tornado will fail HVAC equipment and not the safety-related equipment supported by the HVAC system (i.e., the effects of a tornado are not likely to be localized in the HVAC equipment room). Therefore, failures of components other than HVAC equipment will dominate the tornado-induced CDF.

- Flood-induced accident sequences were observed to contribute a small fraction of the affected CDF due to internal events. Similar to fires, flood effects are likely to be concentrated in a certain area of the plant. Therefore, it is possible that a flood could cause failure of HVAC equipment and not directly affect the operability of the equipment supported by the HVAC function.

It is believed that these conclusions are generically applicable to all U.S. nuclear power plants. The external events analyses noted no significant plant-specific anomalies that would lead one to believe that the HVAC/room cooler systems at the plants examined in this study are any more or less vulnerable than other plants to external events that may fail HVAC and room cooler equipment. It was shown that the failure probabilities for HVAC/room coolers subjected to the various external events are lower than for other safety-system components. 


\subsection{DESCRIPTION OF ALTERNATIVE RESOLUTIONS}

The alternative resolution strategies for GIN-143 are described in this section. As mentioned previously, the alternative resolutions are composed of several elements, each designed to prevent or mitigate one or more of the vulnerabilities identified in Section 6.0. The first part of this section describes each individual resolution element and indicates which vulnerability(ies) that the specific element addresses. The second part combines one or more of the elements into comprehensive resolution strategies.

\subsection{DESCRIPTION OF RESOLUTION ELEMENTS}

This section describes the resolution elements designed to address one or more of the vulnerabilities described in Section 6.0. Table 7.1-1 summarizes the resolution elements and indicates the vulnerabilities addressed by each element.

\subsubsection{Perform Room Heatup Calculations and Thermal "Fragility" Analyses}

The objective of this element is to determine the amount of time available following loss of room cooling before safety-related equipment will begin to malfunction or fail due to high room temperatures. Each plant would need to perform its own analyses to accommodate plant-specific design configurations, room geometries and dimensions, materials, initial temperatures, and heat loads. Two main activities are needed: The first is to perform transient thermal calculations for various rooms to determine the rate of temperature rise following loss of room cooling. Sensitivity studies should also be performed to evaluate the effects of potential heatup mitigation tactics, such as opening doors and installing portable fans. The second activity consists of searching for and compiling relevant temperature-dependent failure information. Sources include Environmental Qualification documents, vendors, and documents prepared in support of station blackout (SBO), fire protection, and other analyses.

The benefits derived from this resolution element include identification of temperature-sensitive equipment in areas that may heat up rapidly. This will indicate to plant operators which locations may be most vulnerable to loss of HVAC/room cooling and guide implementation of subsequent measures designed to prevent or mitigate failures of safety-related equipment due to high room temperatures. In addition, this study will indicate the amount of time available for operators to recover from a loss of room cooling, information that would be useful for developing the most successful preventive/ mitigative strategies. For example, if it is determined that only 15 minutes is available following loss of room cooling before a safety-related equipment item is predicted to fail, it is probably not possible to successfully install portable cooling equipment after a room cooler failure. On the other hand, this option may be successful if several hours is available. A further benefit of this study is that it can identify rooms or specific locations that would benefit from installation of remote temperature monitoring/alarm 


\section{IABLE 7.1-1. Matrix of Vulnerabilities Versus Resolution Elements}

\begin{tabular}{|c|c|c|c|c|c|c|c|c|c|c|c|}
\hline \multirow[b]{2}{*}{ Vulnerability } & \multicolumn{11}{|c|}{ Resolution Element Addressing Specific Vulnerability } \\
\hline & 1 & 2 & 3 & 4 & 5 & 6 & 7 & 8 & 9 & 10 & 11 \\
\hline Spurious actuation of control room components inside cabinets & $x$ & & & & & $x$ & $x$ & $x$ & & & $x$ \\
\hline Temperature sensitivity of DC equipment (inverter. battery charger) & $x$ & & & & $x$ & $x$ & $x$ & $x$ & & & \\
\hline Loss of EDG ventilation system rapidly fails EDG control equipment & $x$ & & & & & & $x$ & $x$ & $x$ & & \\
\hline Installation errors disable HVAC-related water systems & & $x$ & & & & & & & & & \\
\hline Inadequate test/maintenance procedures & & & $x$ & & & & & & & & \\
\hline Inadequate PM program for HVAC/room cool ing equipment (a) & & & $x$ & & & & & & & & \\
\hline Failed/mal functioning ventilation and fire dampers & $x$ & $x$ & $x$ & & $x$ & & $x$ & $x$ & & & \\
\hline Design errors lead to inadequate airflow & $x$ & $x$ & & & $x$ & & & & & & $x$ \\
\hline Electrical cabinets overheat due to fan failures & $x$ & & $x$ & $x$ & & $x$ & $x$ & $x$ & & $x$ & $x$ \\
\hline Electrical cabinet heat rejection capabilities overestimated & $x$ & $x$ & & & & $x$ & & & & $x$ & $x$ \\
\hline Actual room temperatures not monitored in control rooms & & $x$ & & $x$ & $x$ & & & & & & \\
\hline Essential chiller design not optimized & & $x$ & & & & & & & & & \\
\hline Inadequate separation between electrical cables & & $x$ & & & & & & & & & \\
\hline Heavily loaded vital OC buses & & $x$ & & & & & & & & & \\
\hline Inadequate emergency procedures to cope with loss of room cooling & & & & $x$ & $x$ & & & & & & \\
\hline Small room versus large room & $x$ & $x$ & & & & $x$ & $x$ & $x$ & & & \\
\hline Fires and floods dominated afferted CDF due to external events & $x$ & $x$ & & $x$ & & $x$ & $x$ & $x$ & & & \\
\hline $\begin{array}{l}\text { (a) } \mathrm{PM}=\text { preventive maintenance } \\
\text { Resolution element titles are as follows. See text to complete desc } \\
\text { 1) Perform room heatup calculations and thermal fragility analyses: } \\
\text { program: 4) Improve emergency procedures; 5) Install remote room tem } \\
\text { qualification requirements: 7) Install portable air cool ing equipmen } \\
\text { 9) Install thermal barriers between heat-producing components and th } \\
\text { tests: and 11) Airflow test program. }\end{array}$ & 8) & & & & & $\left\{\begin{array}{l}\text { En } \\
\text { In } \\
\text { kup }\end{array}\right.$ & & & & & \\
\hline
\end{tabular}


capabilities. The remote temperature monitoring/alarm equipment would effectively alert operators of potential HVAC failures and the threat of associated equipment malfunctions.

\subsubsection{HVAC/Room Cooler System Design Review}

The purpose of this element is to identify design vulnerabilities and develop recommendations on ways to eliminate or minimize them. The important design vulnerabilities that were identified in this study included the following:

- Small ESF pump room versus large, open ESF pump room

- Heavily loaded vital DC buses

- Inadequate cooling water flow to safety-related chillers and room coolers

- Electrical cabinet cooling capabilities overestimated

- Inadequate separation of electrical cables

- Inadequate ventilation airflow (i.e., dead spots) in safety-related equipment rooms (inadequate airflow enhanced by array of cabinets).

The design review should focus on the HVAC/room cooler system configuration and the support systems needed to make the HVAC/room cooler system function, such as service water, $A C$ and $D C$ power, and instrument air systems.

\subsubsection{Enhanced Preventive Maintenance and Testing Program}

A potential generic vulnerability involving the priorities related to maintenance and testing of various HVAC and room cooler system components has been identified. Although the HVAC personnel at the plants visited did not specifically mention that the priorities are low, it was apparent from the LER review conducted in this study that numerous maintenance errors and preventive maintenance-related failures have occurred in the past. For example, numerous instances were found in the LERs dealing with failures of fan belts on room coolers and failure of essential chillers due to low refrigerant levels. Therefore, it is believed that an enhanced preventive maintenance (PM), inspection, and testing program would increase the availability of the HVAC and room cooler systems.

The enhanced PM program could be tailored to meet plant-specific needs. Plants keep comprehensive records on failures and maintenance of HVAC equipment, and HVAC and systems engineers at the plants are aware of specific maintenance-related problems. Therefore, the basis exists to establish a plant-specific PM program that focuses efforts on the most unreliable HVAC equipment. As a minimum, the enhanced PM program should evaluate the reliability of the essential chiller, ventilation/fire dampers, and AHUs (including the fans and associated heat exchangers). 
An additional aspect of the enhanced PM program should include improvements to maintenance procedures. Instances of failure to restore safetyrelated HVAC equipment to operable status following test and maintenance activities were observed in the LERs and other relevant documentation. Failure to restore this equipment to operable status is a potential cause of losing one train of HVAC equipment and may contribute to common-cause failures of redundant HVAC trains. It is important to ensure that test/maintenance procedures are clear and explicit and that operators are well-trained to implement the procedures. Part of this resolution element will therefore include a review of test/maintenance procedures for HVAC equipment and improvements to the procedures judged to be faulty. Training operators and maintenance personnel in the new procedures is also needed.

\subsubsection{Improve Emergency Procedures}

The purpose of this resolution element is to ensure that emergency procedures addressing loss of HVAC/room cooling functions are available and operators are trained in their implementation. Based on discussions witn plant operators, emergency procedures exist, at least at the plants visited in this study, to cope with loss of HVAC/room cooling. However, there were indications in the literature reviewed that some plants do not have such emergency procedures. These plants should examine their existing emergency procedures and develop new procedures to cope with loss of HVAC/room cooling systems and room temperature rises.

An important aspect of the PRA calculations performed in this study involves operator recovery of loss of HVAC/room cooling function. Where procedures exist, there is a technical basis for allowing recovery actions, because operators would be familiar with necessary actions following a loss of room cooling and would also be trained in their implementation. This resolution element would benefit from performing thermal analyses, because the "critical" equipment and HVAC systems identified in would be the most critical in terms of preparing new emergency procedures or improving existing procedures.

\subsubsection{Install Remote Room Temperature Monitors/Alarms}

One of the vulnerabilities described in Section 7.1 was the inability of operators to monitor actual room temperatures. It was stated that operators may have an indirect means of detecting a rise in room temperature (e.g., fan start/run indicators), but few plants are provided with instrumentation allowing control room operators to monitor room temperatures. This may result in operators not being aware of current plant parameters that could adversely affect a decision such as selecting the appropriate AFW pump to start manually, or could cause an operator to inadvertently secure a safety system from operation. In addition, the absence of real-time room temperature monitoring could delay implementation of backup cooling or other recovery actions, which could allow a room to heat up to equipment failure temperatures before operators are aware a problem exists. 
An example of a successful implementation of this element was observed at one of the plants visited and was also discussed in the plant's (IPE). The IPE determined that the CDF associated with loss of DC equipment room cooling was a large contributor to the total CDF. It was also determined thai equipment failure temperatures would be reached rapidly, in about 45 minutes, following loss of cooling to this room. In response, plant staff installed a remote temperature monitoring/alarm system for this room, which is continuously displayed in the control room. Alarm setpoints were established at well below the equipment failure temperatures. Emergency procedures were then developed to deal with a rising temperature in this room. This increases the probability that operators will be able to quickly detect a failure in the room cooling system for this room and then perform emergency actions necessary to restore cooling or otherwise mitigate the effects of high temperatures in this room.

This element does not seek to install remote temperature monitoring/ alarm systems for every safety-related room at the plant, for it is believed that operators would not benefit from such a large array of new plant information on top of the already complex control room environment. Instead, this element seeks to provide operators prompt warning of equipment failures that could affect the operability of ESF functions that may be needed in accident conditions. As a result, it may not be necessary to install remote temperature indicating systems for rooms that are not judged to be "critical" in terms of room heatup rate and the temperature "fragility" of safety-related equipment. The results from performing thermal analyses would provide important guidance on which rooms are most critical in terms of room heatup rates and the temperature-sensitivity of equipment on the rooms. Only the most critical rooms would need remote temperature sensors.

\subsubsection{Increase Environmental Qual ification Requirements}

The purpose of this resolution element is to increase the reliability of safety-related equipment exposed to a higher-than-anticipated room temperature environment. Almost all of the safety-related equipment in the scope of this study is located in the Control or Auxiliary Buildings. Consequently, most of the equipment is not qualified for "harsh" environments, such as the environmental conditions expected inside containment following a steam-line-break accident. Typical environmental qualification temperatures for ESF pumps outside containment are approximately $120^{\circ} \mathrm{F}$, and operating the pumps in a $120^{\circ} \mathrm{F}$ temperature environment can rapidly degrade their reliability. However, if a pump were to be qualified to operate at temperatures approaching $212 \circ \mathrm{F}$, as has been done for HPI pumps at one plant, the failure rate for these pumps would be much smaller at $120^{\circ} \mathrm{F}$ than that for the original pump qualified at $120^{\circ} \mathrm{F}$. It may be possible to eliminate the dependencies of these pumps on room cooling if it can be shown that the rooms will not heat up to equipment qualification temperatures following loss of room cooling and under design-basis accident conditions such as LOCAs or steam-line breaks. 


\subsubsection{Install Portable Air Cooling Equipment}

It has been observed that portable room cooling equipment intended to be used under loss of room cooling conditions as not always located conveniently and may not be available when needed for various reasons. The purpose of this element is to ensure that portable room cooling equipment, such as portable fans and ductwork, is available when needed in emergency situations. Plants may benefit from having portable room cooling equipment avallable at all times near the "critical" rooms identified using a program such as described in subsection 7.1.1. It may be necessary to purchase additional equipment to install near critical locations. Battery-powered equipment may also be advisable, because some of the important accident sequences involving loss of room cooling may also involve an SBO condition.

\subsubsection{Install Permanent Backup Room Cooling Systems}

One way to increase the reliability of a system is installing a redundant backup system to perform the same function. The way in which HVAC systems are designed typically involves providing each train of safety-related equipment with its own train of HVAC/room cooling equipment. For example, some plants are provided with two separate, redundant residual heat removal (RHR) pump trains. A single room cooler is provided for each RHR train that receives motive and control power from the same train of equipment providing motive and control power for the RHR pumps. That is, the Train A RHR pump is cooled by the Train A room cooler, and the Train B RHR pump is cooled by the Train $B$ room cooler. Failure of either room cooler could lead to loss of the RHR pump served by that room cooler. Backup room cooling capabilities are typically not provided in these cases.

This resolution element involves installation of redundant room cooling systems in "critical" areas. Again, a program such as Element 1 could provide the basis for identification of "critical" rooms. The redundant room cooling equipment could be powered from the other equipment train, or it could be $D C$-powered and thus remove any dependence on motive power from the potentially affected equipment train. Such a system has been installed in the AFW pump rooms of a W PWR. The backup systems could be automatically or manually actuated, depending upon the type of system desired.

\subsubsection{Install Thermal Barriers Between Heat-Producing Components and Thermally Sensitive Components}

This resolution element was established to protect EDG control equipment from the effects of the heat generated by the diesel engine. One of the generic findings from this study was that EDG enclosures in which EDG control equipment was located in a separate room from the diesel engine had significantly more time available to effect EDG room ventilation recovery or restoration activities than those in which the diesel engine and EDG control equipment is located in the same room. Since the diesel engine is not particularly vulnerable to room temperature excursions, protecting the EDG control from the diesel engine could increase the available time needed to implement recovery actions (the probability of recovery from an EDG ventilation systein failure 
was assumed to be 0.0$)$. This wc ild increase the likelihood that recovery of EDG ventilation functions could be completed before the EDG fails due to control system overheating.

The thermal barrier should consist of low-heat-transfer material. It is assumed that an enclosure could be constructed around the diesel engine or around the control enuipment to prevent rapid heatup of the air around the control cabinets. The design of the thermal barrier needs to consider the amount of heat being generated by the operating diesel engine and the airflow patterns in the rooms to ensure that the barrier effectively isolates the EDG control equipment from the heat generated by the diesel engine. It is not necessary to design a barrier that will totally isolate the control systems from the diesel engines; however, the barrier should be designed to protect the EDG control systems from the diesel engine for a sufficient length of time to ensure that offsite power or other onsite power sources can be restored.

\subsubsection{Electrical Cabinet Tests}

A generic vulnerability was related to inadequate cooling of electrical cabinets. The current design basis temperatures for cabinet components are based on a maximum internal cabinet temperature that is obtained by adding $20^{\circ} \mathrm{F}$ to the maximum ambient temperature. Therefore, if the control room maximum temperature is set at $104^{\circ} \mathrm{F}$, the components in control room cabinets are designed to withstand $124^{\circ} \mathrm{F}$ internal cabinet temperatures. This has been shown in some cases to be an inadequate basis for establishing temperature qualification requirements for electrical cabinets.

One way of resolving this potential vulnerability is to perform actual cabinet temperature tests. The tests would involve placement of thermocouples or other temperature-measuring devices at selected locations inside the cabinet (e.g., on an instrument rack, at the airflow outlet), powering up the cabinet, and measuring the temperatures. Room ambient temperatures would also be measured so the difference between the cabinet and room temperatures can be measured. The information gained from this test program would be used to identify cabinets requiring additional cooling capabilities, to recommend potential cabinet modifications to enhance airflow (e.g., eliminating dead spots inside the cabinet), and to identify critical cabinets that may be more susceptible to overheating than others.

\subsubsection{Airflow Test Program}

A vulnerability was identified related to potentially inadequate airflow balance in safety-related equipment rooms, particularly those containing arrays of cabinets, such as switchgear rooms. Since these cabinets are primarily cooled by convection, airflow around the cabinets is important to dissipate heat. Dead spots, or pockets with little or no airflow, can reduce the convective heat transfer to the point at which less heat is being dissipated than is being produced in the cabinets. 
The purpose of this resolution element is to identify and fix airflow problems that may cause cabinets to overheat. At least one utility, responding to a previous event, has identified airflow difficulties through a program of airflow measurements. Computer modeling techniques may al so be used to predict airflow patterns. Deficiencies identified using either technique may be resolved by changing the flow balances, installing deflectors to direct airflow to appropriate locations, rearranging cabinets to correct the deficiencies, or installing additional equipment (fans, ductwork).

\subsection{DESCRIPTION OF ALTERNATIVES TO RESOLUTION OF GI-143}

Three alternatives were developed to bound the range of possible costs and benefits resulting from resolution of GIN-143. The first is the minimum improvement alternative and combines plant evaluation elements and procedural/ maintenance improvements to prevent or mitigate potential losses of room cooling. The second alternative combines the elements of the first with relatively minor hardware changes designed to improve detection and recovery capabilities. The third alternative results in maximum improvement to HVAC/ room cooler reliability and combines the elements of the second with additional testing programs and hardware changes. Each alternative addresses, to some extent, all of the vulnerabilities identified in Section 7.1. The three alternatives are summarized in Table 7.2-1 and described below.

\subsubsection{Improve Detection and Recovery Capabilities}

This is the minimum cost, minimum benefit alternative. It consists of Elements 1, 2, 3, and 4 from Table 7.2-1. Elements 1 and 2 are studies designed to define, evaluate, and prioritize, on a plant-specific basis, potential vulnerabilities to loss of HVAC and room cooling functions. The results of the studies will be used to identify specific rooms and areas susceptible to rapid heatup rates, identify thermally sensitive components in these rooms/ areas, determine possible mechanisms that could cause losses of cooling in these rooms/areas, and prioritize the areas of most concern to plant safety. These studies can also form the basis for suggesting ways to improve the reliability of HVAC/room cooler systems and suggest the most effective areas for improved hardware, maintenance, or procedures.

Elements 3 and 4 are designed to improve procedural and maintenance/test programs. Element 3 seeks to improve the reliability of HVAC/room cooler sys tems through enhanced preventive maintenance and testing programs. Element 4 involves a review and enhancement of emergency procedures designed to cope with or recover from losses of HVAC/room cooling. This should improve the likelihood that operators will successfully detect and recover from losses of these functions. The results of the studies conducted under resolution Elements 1 and 2 would be used to focus improvements on the most vulnerable areas. 
IABLE 7.2-1. Summary of Alternative Resolutions to GI-143

\begin{tabular}{|c|c|}
\hline Alternative & Resolution Elements \\
\hline 1 & $\begin{array}{l}\text { 1. Perform room heatup calculations and thermal fragility } \\
\text { analyses. } \\
\text { 2. Perform design review } \\
\text { 3. Enhanced PM and testing program } \\
\text { 4. Improve emergency procedures }\end{array}$ \\
\hline 2 & $\begin{array}{l}\text { 1. Perform room heatup calculations and thermal fragility } \\
\text { analyses. } \\
\text { 2. Perform design review } \\
\text { 3. Enhanced PM and testing program } \\
\text { 4. Improve emergency procedures } \\
\text { 5. Install remote temperature monitors/alarms } \\
\text { 7. Install portable room cooling equipment } \\
\end{array}$ \\
\hline 3 & $\begin{array}{l}\text { 1. Perform room heatup calculations and thermal fragility } \\
\text { analyses. } \\
\text { 2. Perform design review } \\
\text { 3. Enhanced PM and testing program } \\
\text { 4. Improve emergency procedures } \\
\text { 5. Install remote room temperature monitors/alarms } \\
\text { 6. Increase environmental qualification requirements } \\
\text { 7. Install portable air cooling equipment } \\
\text { 8. Install permanent backup room cooling systems } \\
\text { 9. Install thermal barriers between heat-producing } \\
\text { 10. Electrical cabinet tests } \\
\text { 11. Airflow test program }\end{array}$ \\
\hline
\end{tabular}

\subsubsection{Hardware Changes}

Alternative 2 includes all of the elements of Alternative 1 plus Elements 5 and 7 . Element 5 involves installation of remote temperature monitoring systems in the plant's most vulnerable areas (i.e., areas that heat up rapidly following loss of room cooling and that contain temperaturesensitive equipment). The remote temperature-monitoring systems should be designed to continuously measure room temperatures, read out in the control room, and alarm when temperatures rise to the point at which safe operating limits begin to be threatened. This equipmerit has been installed in at least one plant to continuously monitor room temperatures in their DC equipment rooms. Alarm setpoints were established at a temperature below which the DC equipment should not be susceptible to failure and which would allow operators sufficient time to implement temporary cooling, if needed.

Element 7 involves purchasing and installing portable cooling equipment to improve the likelihood that operator recovery actions are successful. A satisfactory example of a portable system would be one consisting of portable fans and possibly flexible ductwork. The fans are envisioned to be located in 
strategic locations throughout the plant, such as near the control room and DC equipment rooms and outside ESF pump rooms. Because many of the core damage accident scenarios examined in this study are initiated by loss of offsite power or can evolve into an SBO situation, it may be prudent to provide portable DC-powered fans.

\subsubsection{Additional Testing and Hardware Changes}

This alternative is the highest-cost, highest-benefit alternative examined in this study. It involves all of the elements of Alternative 2 plus the addition of Elements 8, 9, 10, and 11. This alternative involves all of the resolution elements described in Section 7.1 except increasing environmental qualification temperature requirements. This element was judged to be impractical to implement at operating plants due to the obviously large expense involved in the design, procurement, installation, and testing of new or modified ESF pumps that would be required. Advanced plants and plants now under construction may consider this a viable option for increasing the reliability of room cooling systems.

Resolution Element 8 involves installing permanent backup HVAC/room cooling capabilities for vulnerable rooms and areas. This is a more costly and more effective method of improving room cooling reliability than installing portable room cooling equipment. A backup room cooling system would be installed to remove heat from ESF pump rooms and possibly DC equipment rooms, switchgear rooms, and control rooms. However, it is most likely that this element would be applied to ESF pump rooms becaise of difficulties in installing redundant centralized HVAC systems for the latter rooms (e.g., space needed for additional equipment and ductwork, numerous penetrations need to be made in existing seismic Category I structures). Some plants are already provided with backup room coolers in, for example, turbine-driven AFW pump rooms. One of the plants visited in this study was provided with a backup, DC-powered room cooler in their turbine-driven auxiliary feedwater (TD-AFW) pump room. The others were not equipped in this manner.

Element 9 addresses vulnerabilities related to failure of the EDG ventilation system. Because there is no practical recovery from loss of the EDG ventilation system because the timing is too short, a method of insulating the EDG control equipment from the diesel engine could increase the time available to effect recovery actions or return the EDG ventilation system to operable status. A thermal barrier, if practical, could effectively reduce the room heatup rate in the vicinity of the EDG control equipment. It is believed that this plant modification could be performed without major redesign of the EDG enclosures, although at some plants this may be impossible due to the proximity of the control equipment to the diesel engine or a lack of available space in the EDG enclosure.

Element 10 involves performing actual temperature measurements on electrical cabinets. The goal of these tests is to determine the actual difference between internal cabinet temperatures and outside room ambient temperatures. The test results will provide insights on whether improvements are needed to the heat rejection capabilities of potentially vulnerable 
cabinets. Fixes to potentially overheating cabinets include installing portable or permanent backup cooling equipment to cope with potential overheating situations or replacing existing cabinet components with components that are less sensitive to temperature.

The objective of Element 11 is to identify areas that are not receiving sufficient airflow to remove heat generated by electrical cabinets. Relatively simple airflow detection equipment can be used to perform tests to identify dead spots or areas where there is little or no air circulation. If dead spots are detected, relatively simple fixes can be implemented including installing airflow deflectors to redirect airflow past dead spots, installirig additional fans in the rooms to enhance air circulation, or modifying airflow balances. 


\subsection{VALUE-IMPACT ASSESSMENT}

This section contains the value-impact assessment for the alternative resolutions to GI-143, to provide sufficient supporting information for NRC staff to determine the cost-effectiveness of the proposed resolutions that were developed in Section 7. An alternative is considered to be cost-effective if the benefits (i.e., averted consequences) outweigh the costs. Benefits are expressed in terms of person-rem averted and the costs are expressed in dollars. If the dollars spent divided by the averted person-rem exceed $\$ 1,000 /$ person-rem, the alternative is not cost-effective. Otherwise, the alternative is considered to be cost-effective.

This section is divided into three subsections. The first describes the changes in core damage frequency (CDF) and public risks anticipated to result from implementing the three alternatives. The second subsection describes the cost estimates developed for each resolution element. The per-plant implementation costs and annual operation maintenance costs for each alternative are then calculated from the elemental costs. The final subsection combines the cost and risk information and presents the value-impact ratios for each alternative.

\subsection{CALCULATION OF BENEFITS}

The approach to this analysis was to modify the risk calculation models used in the probabilistic risk assessment (PRA) calculations performed in this study. Modifications made to the models at the cut set level represent potential improvements in HVAC/room cooler system reliability and the abilities of operators to, recover from the loss of one of these functions that is anticipated to result from implementing the resolution alternatives. These modifications and the resulting changes in CDF and public risks are described in the following paragraphs.

The spreadsheets developed in previous tasks of this study were used to facilitate the calculations. The basic event probabilities programmed into the spreadsheets were modified from the values used in the "basecase," which represents the current situation at nuclear power plants, to reflect the implementation of the various elements of this alternative. After all of the basic event parameter modifications were completed, the affected CDF and public risk values were recalculated. The affected CDF and public risks resulting from implementing the alternatives were then subtracted from the basecase results to determine the reductions in CDF and public risks that will result. The modifications described in the following subsections were applied to the affected CDF and public risk calculations for both internal and external events.

This analysis focuses on the risk reduction achievable at a pressurized water reactor (PWR). Risk reduction at other plant types should not be appreciably different. A summary of the affected CDF and public risk values that were calculated for each alternative is presented in Table 8.1-1. The 
TABLE 8.1-1. Summary of Affected Core Damage Frequency and Public Risks of Alternative Resolutions ${ }^{(a)}$

\begin{tabular}{|l|c|c|}
\hline Alternative & $\begin{array}{c}\text { Affected } \\
\text { CDF, per RY }\end{array}$ & $\begin{array}{c}\text { Affected Public } \\
\text { Risk, person-rem/RY }\end{array}$ \\
\hline \hline Base-Case & $2.04 \mathrm{E}-06$ & $3.95 \mathrm{E}-01$ \\
Initiators & $2.05 \mathrm{E}-06$ & $1.31 \mathrm{E}+00$ \\
Contributors & $8.19 \mathrm{E}-06$ & $1.59 \mathrm{E}+00$ \\
External & $1.23 \mathrm{E}-05$ & $3.30 \mathrm{E}+00$ \\
\hline Total & & \\
\hline \hline Alternative 1 & & $2.49 \mathrm{E}-01$ \\
Initiators & $1.22 \mathrm{E}-06$ & $7.55 \mathrm{E}-01$ \\
Contributors & $1.28 \mathrm{E}-06$ & $1.45 \mathrm{E}+00$ \\
External & $7.40 \mathrm{E}-06$ & $2.45 \mathrm{E}+00$ \\
\hline Total & $9.90 \mathrm{E}-06$ & \\
\hline \hline Alternative 2 & & $1.25 \mathrm{E}-01$ \\
Initiators & $6.43 \mathrm{E}-07$ & $6.15 \mathrm{E}-01$ \\
Contributors & $9.83 \mathrm{E}-07$ & $1.21 \mathrm{E}+00$ \\
IXternal & $6.20 \mathrm{E}-06$ & $1.95 \mathrm{E}+00$ \\
\hline Total & $7.83 \mathrm{E}-06$ & $1.53 \mathrm{E}-03$ \\
\hline \hline Alternative 3 & $7.89 \mathrm{E}-09$ & $3.14 \mathrm{E}-01$ \\
Initiators & $5.14 \mathrm{E}-07$ & $9.95 \mathrm{E}-01$ \\
Contributors & $5.10 \mathrm{E}-06$ & $1.31 \mathrm{E}+00$ \\
\hline External & $5.62 \mathrm{E}-06$ & \\
\hline Total & \\
\hline \hline (a) All values are point estimates. \\
\hline
\end{tabular}

table shows the results of the calculations performed for internal events initiated by room cooler failures, internal events initiated by plant transients and loss of coolant accidents (LOCAs) that involve room coolers as contributing events, and external events.

The detailed changes in the affected CDF for each alternative are presented in Table 8.1-2. The table presents the affected CDF values for each accident sequence included in the calculations, including sequences initiated by losses of HVAC/room cooling, sequences in which HVAC/room cooler failures are contributing events, and external event sequences. The key reductions in CDF are discussed below.

In Alternative 1 , a relatively large reduction in CDF (72\%) was observed for SBO-SLOCA (station blackout leading to reactor coolant pump seal LOCA). This is primarily due to the improved reliability of component cooling water (CCW) pump room coolers and the enhanced 'abilities of operators to recover 
IABLE 8.1-2. Detailed Core Damage Frequency Results for This Value-Impact Assessment

\begin{tabular}{|c|c|c|c|c|c|c|c|}
\hline Sequence & $\begin{array}{c}\text { Base- } \\
\text { Case } \\
\text { CDF }\end{array}$ & $\begin{array}{l}\text { Alt. } \\
\operatorname{CDF}^{\prime}(a)^{\prime}\end{array}$ & $\begin{array}{l}\text { Fraction } \\
\text { Reduction }\end{array}$ & ${ }_{\text {CDFla }}^{\text {Alt. }}{ }^{2}$ & $\begin{array}{l}\text { Fraction } \\
\text { Reduction }\end{array}$ & 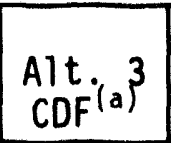 & $\begin{array}{l}\text { Fraction } \\
\text { Reduction }\end{array}$ \\
\hline TSW & $1.1 E-06$ & $6.9 E-07$ & 0.37 & $3.5 \mathrm{~F}-07$ & 0.68 & $7.4 \mathrm{E}-10$ & 1.00 \\
\hline TCR & $7.3 E-07$ & $4.6 E-07$ & 0.37 & $2.3 E-07$ & 0.68 & $2.8 E-09$ & 1.00 \\
\hline TH & $4.1 E-08$ & $2.6 E-08$ & 0.37 & $1.4 E-08$ & 0.66 & $3.0 E-10$ & 0.99 \\
\hline TLP & $2.9 E-09$ & $1.8 E-09$ & 0.38 & $1.0 \mathrm{E}-09$ & 0.66 & $2.4 \mathrm{E}-10$ & 0.92 \\
\hline TDC & $1.6 \mathrm{E}-07$ & $1.0 \mathrm{E}-07$ & 0.38 & $5.2 E-08$ & 0.68 & $3.8 E-09$ & 0.98 \\
\hline S30CH3 & $8.0 E-08$ & $7.3 E-08$ & 0.09 & $5.0 E-08$ & 0.38 & $3.4 E-08$ & 0.58 \\
\hline S3W1H3 & $1.7 \mathrm{E}-07$ & $1.6 \mathrm{E}-07$ & 0.06 & $1.1 \mathrm{E}-07$ & 0.35 & $7.2 E-08$ & 0.58 \\
\hline SBO-BATT & 8.2E-09 & $7.4 E-09$ & 0.10 & $7.4 E-09$ & 0.10 & $2.0 E-09$ & 0.76 \\
\hline SBO-L & $7.3 E-07$ & $6.5 E-07$ & 0.11 & $4.9 E-07$ & 0.33 & $2.4 E-07$ & 0.67 \\
\hline SBO-Q & $4.0 E-08$ & $3.6 E-08$ & 0.10 & $3.6 E-08$ & 0.10 & $1.8 \mathrm{E}-08$ & 0.55 \\
\hline SBO-SLOCA & $1.0 \mathrm{E}-06$ & $2.8 E-07$ & 0.72 & $2.8 \mathrm{E}-07$ & 0.72 & $1.4 E-07$ & 0.86 \\
\hline other LOCA & $1.7 \mathrm{E}-08$ & $1.6 \mathrm{E}-08$ & 0.06 & $1.0 \mathrm{E}-08$ & 0.41 & $6.7 E-09$ & 0.61 \\
\hline Seismic & $8.4 E-08$ & $7.6 E-08$ & 0.10 & $5.9 E-08$ & 0.30 & $4.2 E-08$ & 0.50 \\
\hline Fire & $7.1 E-06$ & $6.6 \mathrm{E}-06$ & 0.07 & $5.6 E-06$ & 0.21 & $4.8 E-06$ & 0.32 \\
\hline Flood & $9.9 \mathrm{E}-07$ & $7.3 E-07$ & 0.26 & $5.0 \mathrm{E}-07$ & 0.49 & $3.0 \mathrm{E}-07$ & 0.70 \\
\hline Total & $1.2 \mathrm{E}-05$ & $9.9 \mathrm{E}-06$ & 0.19 & $7.8 E-06$ & 0.36 & $5.7 E-06$ & 0.54 \\
\hline Initiators & $2.0 \mathrm{E}-06$ & $1.3 E-06$ & 0.37 & $6.5 E-07$ & 0.68 & $7.9 \mathrm{E}-09$ & 1.00 \\
\hline Contributor & $2.0 \mathrm{E}-06$ & $1.2 E-06$ & 0.40 & $9.8 \mathrm{E}-07$ & 0.52 & $5.1 \mathrm{E}-07$ & 0.75 \\
\hline External & $8.2 E-06$ & $7.4 E-06$ & 0.09 & $6.2 E-06$ & 0.25 & $5.1 \mathrm{E}-06$ & 0.37 \\
\hline Total & $1.2 \mathrm{E}-05$ & $9.9 E-06$ & 0.19 & $7.8 \mathrm{E}-06$ & 0.36 & $5.7 \mathrm{E}-06$ & 0.54 \\
\hline $\begin{array}{l}\text { (a) The f } \\
\text { case }\end{array}$ & ctional & reductio & & & & ve to th & \\
\hline
\end{tabular}

from failed room cooling systems. This reduction lead to a total change in CDF for HVAC/room cooler contributors of about $40 \%$. An approximately $40 \%$ reduction in CDF was also observed for sequences initiated by loss of room cooling. All five sequences (TSW, TCR, TDC, TH, and TL) experienced approximately a $40 \%$ reduction, due primarily to enhanced procedures for coping with loss of room cooling. The CDF associated with external events was reduced by only about $10 \%$. This illustrates the reliative inability to simply resolve HVAC/room cooler vulnerabilities to external events. Overall, the affected CDF was reduced by about $19 \%$ as a result of Alternative 1 , which translates to approximately a $1 \%$ reduction in the total CDF for this plant. (a)

(a) This was calculated by dividing the reduction in CDF for this alternative (2.4E-06/RY; see Table 8.1-1) by the original CDF (2.2E-04/RY) that was calculated by adding the original CDFs resulting from external events $(1.6 \mathrm{E}-04 / \mathrm{RY})$ and internal events $(5.7 \mathrm{E}-05 / \mathrm{RY})$. 
The affected CDF for Alternative 2 was observed to be about $36 \%$ lower than the basecase affected CDF. HVAC/room cooler initiator sequences were reduced by about $68 \%$, and the contributors were reduced by about $50 \%$. As with Alternative 1, the smallest reduction in CDF for Alternative 2 results from external events (i.e., about a $25 \%$ reduction in the affected external event CDF). Overall, the reduction in CDF for Alternative 2 amounts to about a $2 \%$ reduction in, the original CDF.

The affected CDF for Alternative 3 was observed to be about $54 \%$ lower than the basecase affected CDF. HVAC/room cooler initiator sequences were reduced to insignificant levels, and the contributors were reduced by about $75 \%$. The affected CDF from external events was reduced by $37 \%$. Overall, the reduction in CDF for Alternative 3 amounts to about a $3 \%$ reduction in the original CDF.

\subsubsection{Risk Reduction Resulting From Alternative 1}

This alternative involves improvements to the probability that operators recover from a loss of HVAC/room cooling (resolution Element 4, improve emergency procedures) and improvements to the reliability of HVAC systems [resolution Element 3, improved preventive maintenance (PM) and testing programs]. Elements 1 and 2 are designed primarily to identify the potential problems that can be resolved through their implementation and do not directly result in improvements to plant safety.

Enhanced PM and testing programs would increase the reliability of HVAC/ room cooler systems to function when needed. This reduces the frequencies of $\mathrm{HVAC} /$ room cooler initiating event frequencies. A $10 \%$ reduction in $\mathrm{HVAC} / \mathrm{roOm}$ cooler initiator frequencies was assumed to result from this element. Implementing Element 3 reduces the operator nonrecovery probability by ensuring that operators are aware of, and trained to implement, procedures specifically designed to respond to losses of various HVAC and room cooler systems. A $30 \%$ reduction in human error probabilities was assumed to result from this element.

\subsubsection{Risk Reduction Resulting from Alternative?}

This alternative involves all the elements of Alternative 1 plus Elements 5 and 7 . Element 5 involves installation of remote temperature monitors/alarms for vulnerable areas. This results in an improved detection capability, which will increase the probability that a failed HVAC/room cooling function is detected, reduce the time necessary to isolate the faulted condition, and improve the probability that operators will be able to correctly diagnose and restore the disabled room cooling function.

Element 7 involves installing portable fans and ductwork to help plant operators restore cooling to rooms affected by loss of HVAC/room cooler functions. In many cases, it has been shown that simply increasing airflow into a room will improve heat rejection capabilities enough to delay or prevent component failures. In other words, this will provide temporary backup 
cooling capabilities that will increase the probability that operators can successfully recover from failed HVAC/room cooling systems.

These improvements are applicable to the operator recovery probabilities in the CDF and public risk models. A $50 \%$ reduction in the human error probabilities associated with nonrecovery probabilities was taken to represent implementation of Element 5 . Element 7 was assumed to remove $100 \%$ of the hardware failure probabilities in the recovery terms.

\subsubsection{Risk Reduction Resulting from Alternative 3}

Alternative 3 involves all the elements of Alternative 2 plus Elements $8,9,10$, and 11 . Elements 10 and 11 are primarily diagnostic activities designed to identify potential cooling deficiencies and provide recommendations for the most cost-effective areas to implement the procedural and hardware modification described in the other elements. However, minor hardware modifications, such as installing cabinet fans, may result from imnlementing Elements 10 and 11 . To model these improvements, a $30 \%$ reduction in failure probabilities for ESF actuation systems was assumed.

Element 8 involves installing permanent backup room coolers in four ESF pump rooms, increasing the probability that some form of room cooling is available to these pump rooms. The improvement was translated into an additional basic event that must fail to cause a total loss of ESF pump room c001ing. The failure probability for this additional event was set equal to $0.1 /$ demand. This is conservative in that the failure probabilities for room coolers are on the order of 0.001 per demand. However, a probability of 0.1 demand should adequately account for the possibilities of common-cause failures affecting both the existing and backfit room coolers.

Element 9 involves designing and installing a permanent thermal barrier between the emergency diesel generator (EDG) engine and the EDG control equipment sometimes located in the same enclosure. Installation of this barrier should increase the time between EDG ventilation failure and diesel engine failure by isolating the EDG control equipment from the large heat source represented by the diesel engine. The improvements were modeled by adding an event representing operator recovery from a loss of EDG ventilation. The probability of this event was estimated to be about $0.5 /$ demand, based on the fact that the recovery actions will likely be performed in stressful situations under severe time pressures and in noisy areas.

\subsection{CALCULATION OF COSTS}

This section describes the cost calculations performed in this study. The methods and data for this analysis were taken primarily from Heaberlin and Burnham (1983). The following paragraphs develop estimates of the onsite conseyuences of the three resolution alternatives, including increased occupational exposures due to implementation, operation, and maintenance activities. Also in this section are the averted occupational doses and economic consequences associated with reduced accidents. These latter costs are treated as 
cost offsets and are deducted from the total implementation, operation, and maintenance costs calculated in subsection 7.3.2.2.

\subsubsection{Onsite Consequences}

Four categories of onsite consequences are estimated in this section, including 1) increased occupational exposures, 2) averted occupational exposures due to reduced accidents, 3) averted onsite property damage due to reduced accidents, and 4) averted offsite property damage due to reduced accidents.

\subsubsection{Occupational Exposures}

This cost category deals with the increased occupational exposures that are required to implement, operate, and maintain the resolution alternatives. This cost category includes such items as increased occupational exposures resulting from installing, for instance, redundant pump room coolers; and the increased occupational exposures required to test, inspect, and maintain the redundant room cooler.

The increased occupational exposures are a function of the labor requirements in radiation zones and the average radiation dose rate in the area under consideration. For example, it was estimated that it would require approximately $42 \mathrm{staff}$ weeks/cooler to install and test a redundant pump room cooler. This corresponds to about 1680 staff hours in radiation zones. The average dose rate in a safety injection pump room for a PWR was given to be 8 $\mathrm{mrem} / \mathrm{hr}$ (Sciacca 1992). This dose rate was rounded to $10 \mathrm{mrem} / \mathrm{hr}$ to account for potentially higher dose rates in some pump rooms. The total occupational dose to install a redundant room cooler is therefore:

$$
\text { Dose }=(1680 \mathrm{man}-\mathrm{hr} / \text { cooler })(0.01 \mathrm{rem} / \mathrm{hr})=16.8 \mathrm{person}-\mathrm{rem} / \mathrm{cooler}
$$

Similar calculations were performed for the other elements of the resolution alternatives, based on the implementation, operation, and maintenance labor requirements provided in Section 8.2.2. A summary of the total resource requirements, radiation dose rates, and total occupational exposures for each resolution alternative are presented in Table 8.2-1.

TABLE 8.2-1. Estimated Occupational Exposures for Implementation, Operation, and Maintenance of Resolution Alternatives

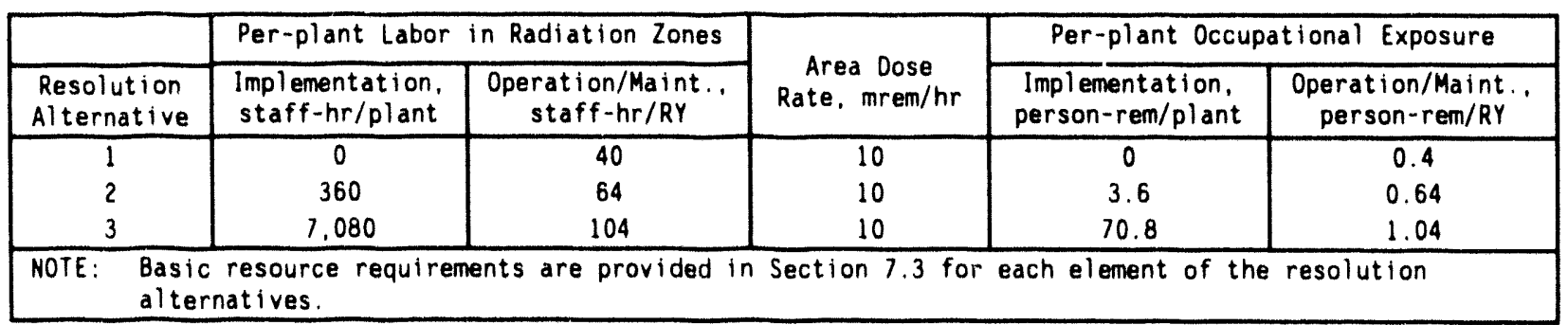


The total occupational exposures over the remaining reactor lifetimes were calculated by multiplying the per-plant implementation doses by the total number of plants (110), and then adding the result to the product of the operation/maintenance dose, number of plants' (110), and average remaining lifetime ( 24 years). The results are as follows:

- Resolution Alternative 1:

Total Dose $=(0.4$ person - rem/RY $)(110$ plants $)(24$ yr $)$

$=\quad 1.1 E+03$ person-rem

- Resolution Alternative 2

Total Dose $=$ ( 3.6 person-rem/plant $)(110$ plants $)$

$+(0.64$ person-rem/RY) (110 plants) (24 yr)

$=\quad 2.1 E+03$ person-rem

- Resolution Alternative 3

Total Dose $=(70.8$ person - rem $/$ plant $)(110$ plants $)$

$+(1.04$ person-rem/RY) (110 plants) (24 yr)

$=\quad 1.1 E+04$ person-rem

The radiation exposure values were converted to economic impacts using $\$ 1000 /$ person-rem conversion factor Heaberl in and Burnham 1983, p. 3.24. The resulting economic impacts are $\$ 1.1 E+06, \$ 2.1 E+06$, and $\$ 1.1 E+07$ for resolution alternatives 1,2 , and 3 , respectively.

\subsubsection{Averted Occupational Exposures Due to Accidents}

Averted occupational exposures due to accidents result from the reduced CDF (and thus fewer accidents) that would result if the resolutions were implemented at the plants. The equation used to calculate the averted occupational exposures is

Averted Dose $=\triangle \bar{F} N \bar{T} D_{0}$ where:

$$
\begin{aligned}
& \Delta \bar{F}=\text { reduction in CDF } \\
& \frac{N}{T}=\text { number of affected plants (110) } \\
& D_{0}=\text { average remaining } 1 \text { ifetimes of affected plants }(24 \mathrm{yr})
\end{aligned}
$$

The values of $\Delta \bar{F}$ for each alternative were shown in Table 8.1-1. The value of $D_{0}$ includes both immediate and long-term doses; immediate doses occur at the time of the accident and during the immediate management of the emergency, and long-term doses result from cleanup and refurbishment or decommissioning of the damaged facility. The value of $D_{0}$ used in this analysis was 
taken from Grant and Harris (1989, p. 4.12) and amounts to about 21,000

person-rem/accident averted. The results of the calculations are as follows:

- Resolution Alternative 1:

Total Dose $=(2.4 E-06 / R Y)(110$ plants $)(24 \mathrm{yr})(2.1 E+04$ person-rem/event $)$

= 133 person-rem

- Resolution Alternative 2:

Total Dose $=(4.5 E-06 / R Y)(110$ plants $)(24 \mathrm{yr})(2.1 E+04$ person - rem/event $)$

$=249$ person-rem

- Resolution Alternalive 3:

Total Dose $=(6.7 E-06 / R Y)(110$ plants $)(24 \mathrm{yr})(2.1 \mathrm{E}+04$ person-rem/event $)$

= 371 person-rem

\subsubsection{Averted Onsite Property Damage}

Onsite property damage costs from an accident are the economic costs to plant, equipment, land, and materials within the boundary of the affected site. Onsite costs can be broken into three categories: property interdiction or decontamination costs, replacement power costs, and capital costs of damaged plant equipment. The averted onsite damage costs are calculated using the following formula taken from Heaberlin and Burnham (1983, p. 3.29):

$$
V_{O P}=\Delta \bar{F} N U
$$

where:

$$
\begin{aligned}
V_{\rho P}= & \text { impact of averted onsite property damage }(\$) \\
N^{\prime}= & \text { number of affected plants } \\
\Delta \bar{F}= & \text { reduction in CDF (event/RY) } \\
U= & \text { present value of property damage, conditional on occurring } \\
& (\text { (\$/event) }
\end{aligned}
$$

Generic estimates for cleanup, repair, refurbishment, and replacement power costs were taken from Andrews et al. (1983). The values from this study are those for a major LOCA in which the emergency core cooling system (ECCS) is delayed. The cost for cleanup of the reactor was estimated to be $\$ 373$ million. Repair and refurbishment costs were estimated to be $\$ 106$ million. Replacement power costs were estimated to be $\$ 1072$ million, spread equally over a ten-year period. The total generic costs, in 1983 dollars, were estimated to be $\$ 1650$ million. This value was escalated to 1993 dollars using the Federal Reserve Implicit Price Deflator for Gross Domestic Product (formerly Gross National Product); the total generic cost for onsite property damage was calculated to be about $\$ 2260$ million in 1993 dollars.

\section{8}


The generic cost estimate was discounted at 5 and $10 \%$ rates to 1993 . The present value of onsite property damage, $U$, was calculated as follows:

$$
U=\left[\frac{\left(C_{C}+C_{x}+C_{r p}\right)}{m}\right] \frac{\left(e^{-r t 1}\right)}{r^{2}}\left[1-e^{-r(t f-t i)}\right]\left(1-e^{-r m}\right)
$$

where:

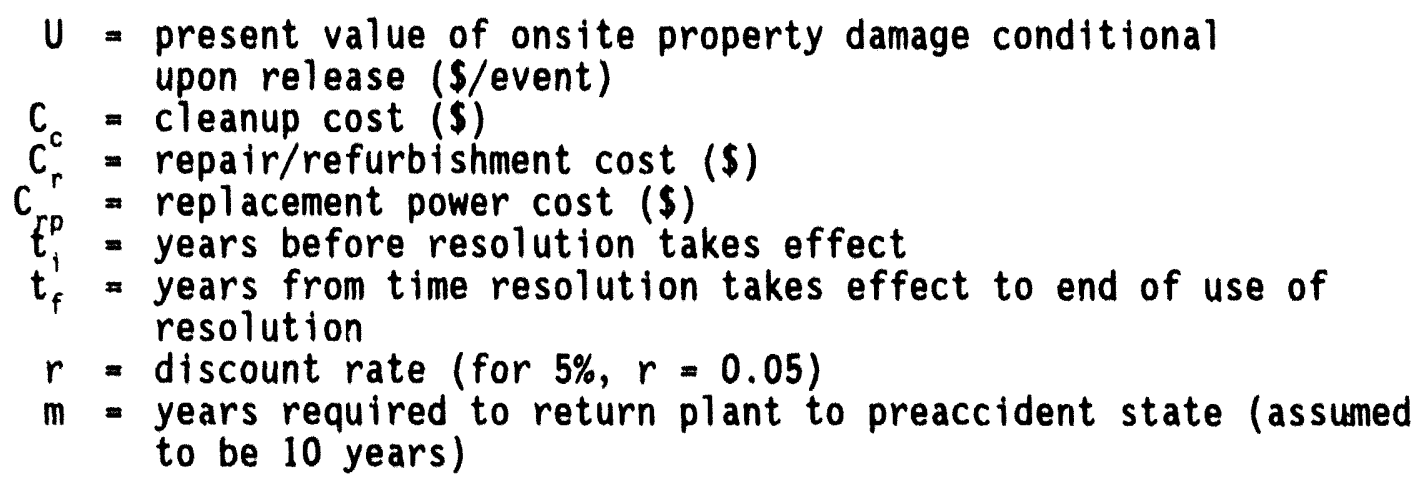
costs.

Table 8.2-2 presents the values of $\Delta \bar{F}, N$, and $U$ as well as the generic

\subsubsection{Averted Public Property Damage}

Averted public, or offsite, property damage represents the discounted costs associated with reduced accidents that may affect offsite property. The impact of averted public property damage can be calculated as follows Heaberlin and Burnham 1983,

IABLE 8.2-2. Summary of Averted Onsite Property Damage Costs

\begin{tabular}{|c|c|c|c|c|c|}
\hline $\begin{array}{l}\text { Resolution } \\
\text { Alternative }\end{array}$ & $\begin{array}{l}\text { Discount } \\
\text { Rate, \% }\end{array}$ & $\begin{array}{c}\Delta \mathrm{F}, \\
\text { events/RY }\end{array}$ & N & $\begin{array}{c}\text { U, } \\
\text { S/event }\end{array}$ & $v_{\rho p}$. \\
\hline 1 & $\begin{array}{c}5 \\
10\end{array}$ & $\begin{array}{l}2.4 E-06 \\
2.4 E-06\end{array}$ & $\begin{array}{l}110 \\
110\end{array}$ & $\begin{array}{l}2.03 E+10 \\
1.01 E+10\end{array}$ & $\begin{array}{l}5.4 E+06 \\
2.7 E+06\end{array}$ \\
\hline 2 & $\begin{array}{r}5 \\
10\end{array}$ & $\begin{array}{l}4.5 \mathrm{E}-06 \\
4.5 \mathrm{E}-06\end{array}$ & $\begin{array}{l}110 \\
110\end{array}$ & $\begin{array}{l}1.60 E+10 \\
7.64 E+09\end{array}$ & $\begin{array}{l}7.9 \mathrm{E}+06 \\
3.8 \mathrm{E}+06\end{array}$ \\
\hline 3 & $\begin{array}{c}5 \\
10\end{array}$ & $\begin{array}{l}6.7 \mathrm{E}-06 \\
6.7 \mathrm{E}-06\end{array}$ & $\begin{array}{l}110 \\
110\end{array}$ & $\begin{array}{l}1.39 E+10 \\
6.53 E+09\end{array}$ & $\begin{array}{l}1.0 E+07 \\
4.8 E+06\end{array}$ \\
\hline
\end{tabular}




$$
V_{F P}=\Delta F N E_{D G}
$$

where:

$$
\begin{aligned}
V_{F P}= & \text { value of averted offsite property damage }(S) \\
\Delta F= & \text { number of affected plants } \\
\Delta F= & \text { reduction in CDF (events/RY) } \\
D_{G}= & \text { present value of offsite property damage conditional upon } \\
& \text { release ( } \$ \text { /event) }
\end{aligned}
$$

Estimates of the generic present value of offsite property damage were taken from Grant and Harris (1989, p. 4.16) and escalated to 1993 dollars using the Federal Reserve Implicit Price Deflator for Gross Domestic Product. The escalated generic cost estimate amounted to $\$ 2.35 \mathrm{E}+09 /$ event.

The generic cost value was discounted at 5 and $10 \%$ discount rates to 1993. The present value of offsite property damage, $E_{D G}$, was calculated as follows Heaberl in and Burnham 1983,

$$
D_{G}=C \times B
$$

where:

$$
\begin{aligned}
c & =\frac{e^{(-r t)}-e^{(-r t f)}}{r} \\
r & =\text { discount rate (for } 10 \%, r=0.10) \\
t_{1} & =\text { years before implementation complete } \\
t_{f} & =\text { years from time implementation complete to end of resolution } \\
B & =\text { operation/maintenance }
\end{aligned}
$$

Table 8.2.3 presents the values of $\Delta \bar{F}, N, C$, and $E_{D G}$ for all three potential resolutions as well as the generic costs.

\subsubsection{Cost Calculations}

This section presents the estimated costs for each resolution element and then combines the elemental costs to develop the total costs for implementation, operation, and maintenance of each alternative resolution. Only the industry portion of the costs are shown; NRC costs are in addition to the estimates developed in this section.

\subsubsection{Resolution Element Costs}

The cost estimates for each resolution element are presented in this subsection. It was judged that all of the resolution alternatives can be performed during normal operations or during scheduled outages. There appears to be no need to extend an outage to accommodate these resolution strategies, so no additional replacement power costs are required. Table 8.2-4 presents a summary of the cost estimates developed for each resolution element. 
IABLE 8.2-3. Summary of Averted Offsite Property Damage Costs

\begin{tabular}{|c|c|c|c|c|c|c|}
\hline $\begin{array}{l}\text { Resolution } \\
\text { Alternative }\end{array}$ & $\begin{array}{l}\text { Discount } \\
\text { Rate, \% }\end{array}$ & C & $\begin{array}{c}\Delta F, \\
\text { events/RY }\end{array}$ & $N$ & $\begin{array}{c}D_{G} \\
\text { S/event }\end{array}$ & $V_{\text {EP }}$ \\
\hline 1 & $\begin{array}{c}5 \\
10\end{array}$ & $\begin{array}{c}11.4 \\
7.1\end{array}$ & $\begin{array}{l}2.4 E-06 \\
2.4 E-06\end{array}$ & $\begin{array}{l}110 \\
110\end{array}$ & $\begin{array}{l}2.69 E+10 \\
1.67 E+10\end{array}$ & $\begin{array}{l}7.1 E+06 \\
4.4 E+06\end{array}$ \\
\hline 2 & $\begin{array}{r}5 \\
10\end{array}$ & $\begin{array}{l}9.0 \\
5.4\end{array}$ & $\begin{array}{l}4.5 E-06 \\
4.5 E-06\end{array}$ & $\begin{array}{l}110 \\
110\end{array}$ & $\begin{array}{l}2.12 E+10 \\
1.26 E+10\end{array}$ & $\begin{array}{l}1.1 E+07 \\
6.2 E+06\end{array}$ \\
\hline 3 & $\begin{array}{r}5 \\
10\end{array}$ & $\begin{array}{l}7.8 \\
4.6\end{array}$ & $\begin{array}{l}6.7 E-06 \\
6.7 E-06\end{array}$ & $\begin{array}{l}110 \\
110\end{array}$ & $\begin{array}{l}1.84 E+10 \\
1.07 E+10\end{array}$ & $\begin{array}{l}1.4 E+07 \\
7.9 E+06\end{array}$ \\
\hline
\end{tabular}

IABLE 8.2-4. Summary of Cost Estimates for Each Resolution Element

\begin{tabular}{|l|r|r|}
\hline Resolution Element & $\begin{array}{c}\text { Implementatio } \\
\text { n Costs, \$ } \\
\text { Per plant }\end{array}$ & $\begin{array}{c}\text { Operation/ } \\
\text { Maintenanc } \\
\text { e Costs, } \\
\text { S/RY }\end{array}$ \\
\hline 1. Heatup, fragility analysis & 150,000 & 0 \\
2. $\quad$ Design review & 54,500 & 0 \\
3. Enhanced PM and testing & 20,000 & 2,270 \\
4. Improve emergency procedures & 16,620 & 0 \\
5. Remote temperature monitors & 100,000 & 908 \\
6. Increased equipment qualification & \multicolumn{2}{|c|}{ Not Practical } \\
7. Install portable coolers & 10,000 & 454 \\
8. Install permanent coolers & 626,400 & 2,270 \\
9. Install thermal barriers & 63,000 & 0 \\
10. Electrical cabinet tests & 61,480 & 0 \\
11. Airflow measurements & 61,480 & 0 \\
\hline
\end{tabular}

Element 1: Thermal Calculations. This element was broken onto three major tasks: 1) room heatup calculations, 2) temperature "fragility" analysis, and 3 ) integration of heatup and fragility results. Labor costs were calculated using basic labor rates amounting to $\$ 100,000$ per person-yr(\$2270/staffwk). Hardware costs were estimated based on discussions with vendors. The costs for each activity were estimated as follows:

Room Heatup Calculations

Software development/application

Interpret results

Documentation/review/approval

$\begin{aligned} 24 & \text { staff-wk } \\ 4 & \text { staff-wk } \\ 6 & \text { staff-wk }\end{aligned}$ 


$\begin{array}{lr}\text { Temperature "Fragility" Analysis } & \\ \text { Data collection } & 12 \text { staff-wk } \\ \text { Interpret results } & 4 \text { staff-wk } \\ \text { Documentation/review/approval } & 4 \text { staff-wk } \\ \text { Integration } & 12 \text { staff-wk } \\ \text { Total } & 66 \text { staff-wk } \\ \text { COST }=(66 \text { staff-wk }) *(\$ 2270 / \text { staff-wk })+\$ 150,000 / p l a n t\end{array}$

Element 2: Design Review. The scope of the design review would be limited to reviewing the design calculations and equipment qualification documentation related to HVAC and room cooler systems. The design review was assumed to be performed by plant personnel, including HVAC engineers, system engineers, maintenance personnel, and operations staff to achieve the best overall efficiency. It was estimated that this design review could be accomplished for approximately 24 staff-weeks of utility labor. This amounts to $(24$ staff-wk $) *(\$ 2270 /$ staff-wk $)=\$ 54500 /$ plant .

Element 3: Enhanced Preventive Maintenance and Testing. This element was assumed to increase the preventive maintenance and testing programs for 10 HVAC/room cooler systems that were determined by Elements 1 and 2 to present the most significant vulnerabilities. For each system, an additional 0.5 $d /$ reactor-yr were estimated to be required to perform the enhanced programs relative to HVAC/room coolers. This amounts to about five staff-days of work per $R Y$ for the entire plant. The cost for these activities amounts to about $\$ 2270 /$ RY.

New PM/testing procedures are also needed. According to Sciacca (1989), the approximate cost for developing new procedures and implementing on-the-job training for operators and maintenance staff amounts to about $\$ 2000 /$ procedure. Based on the need for 10 new procedures, the total cost for the new procedures was estimated to be $\$ 20,000 / \mathrm{plant}$.

Element 4: Improve Emergency Procedures. The basic cost for developing a new emergency procedure is about $\$ 1000 /$ procedure (Sciacca 1989). It was assumed that each plant would develop three new emergency procedures, for a total cost of about $\$ 3000 / \mathrm{plant}$. Training will also be required; training costs were estimated to be applied to approximately 30 operators. An eighthour classroom training session was judged to be adequate. This amounts to about 240 staff-hours of additional resources needed for the training, or about 6 staff-weeks, which costs about $\$ 13,620 / \mathrm{p}$ lant. The total cost for this element was estimated to be $\$ 16,620 / \mathrm{pl}$ ant.

Element 5: Remote Temperature Monitors/Alarms. This element involves a backfit of additional instrumentation in rooms vulnerable to loss of room cooling. This element was assumed to be applied to four rooms at each plant. The estimated cost of providing this equipment includes design, hardware costs, installation labor, and testing, as follows: 
Design:

Equipment costs:

Installation/test labor:

Total :

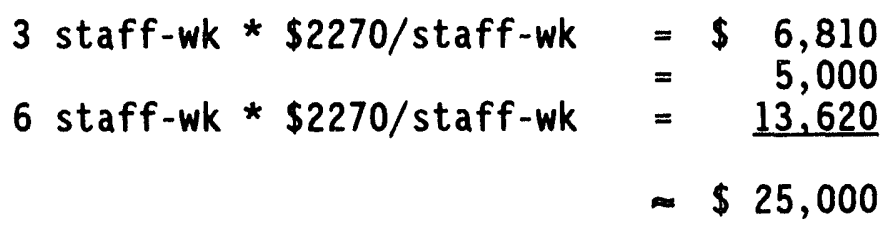

The total cost for each room was estimated to be about $\$ 25,000 /$ system for a total cost of about $\$ 100,000 / p 1$ ant. Routine testing and maintenance of this equipment was estimated to require an additional two staff-days/RY for a total annual cost of $\$ 908 / R Y$.

Element 6: Increase Equipment Qualification Requirements. This resolution element was judged to be impractical at existing plants.

Element 7: Install Portable Room Cooling Equipment. This element involves procuring and installing portable fan systems to serve as backups in areas vulnerable to loss of room cooling. Ten fan systems, which include a DC-powered fan, batteries, battery charger, and portable ductwork, are estimated to be required to fulfill the intent of this element. Each fan system was estimated to cost about $\$ 1000$, including installation costs (a wallmounted fan system was assumed). The total cost for this equipment was calculated to be about $\$ 10,000$ per plant. Maintenance and periodic testing of this equipment was estimated to amount to about one staff-day/RY for an annual cost of about \$454/RY.

Element 8: Install Permanent Backup Cooling Equipment. This element involves a major effort to design, purchase, install, maintain, and test permanent backup room cooling equipment. This element was assumed to be applicable to only ESF pump rooms, because space requirements will likely prevent installing backup centralized HVAC systems and the associated ductwork, controls, and equipment. Therefore, this element was limited to installing redundant backup room cooler systems for the LPI, HPI, AFW, and containment spray pump rooms. Only one train of each system was assumed to receive the additional protection; four additional permanent room coolers will be needed.

The cost estimate for this element was derived as follows:

Design (16 staff-wk/cooler o \$2270/staff-wk):

Purchase room coolers and associated piping, valves and instrumentation:

Installation labor, including needed penetrations, piping, valves, and control systems (40 staff-wk per cooler):

Test (2 staff-wk/cooler * $\$ 2270 /$ staff-wk):

Total

Annual test/maintenance labor ( 1 staff-wk/RY):
$\$ 36,400 /$ cooler

$\$ 25,000 /$ cooler

$\$ 90,800 /$ cooler $\$ 4,540 /$ cooler

$\$ 156,600 /$ cooler $\times 4$ coolers/plant $\$ 626,400 /$ plant

$\$ 2,270 / R Y$ 
Element 9: Install Thermal Barrier. This element involves designing and installing a thermal barrier to separate heat-sensitive components from heat-generating equipment. The most important area for this improvement was judged to be the EDG enclosures. The thermal barrier is anticipated to consist of a double-walled enclosure around the EDG control equipment to thermally separate the controls from the diesel engine. Two EDG enclosures per plant were assumed to be needed. Design costs for this element were estimated to amount to about 16 staff-weeks of utility labor or about $\$ 36,000$ / plant, including computer time for structural analyses, thermal analyses, etc. This effort includes designs for both enclosures since the enclosures for each EDG are approximately identical. Materials for construction of the walls were estimated to cost about $\$ 9,000$ /enclosure. Installation of the enclosures was estimated to require approximately 16 staff-weeks/enclosure or about $\$ 36,000 /$ enclosure. Total installation costs were therefore estimated to be about $\$ 45,000$ /enclosure. Since two enclosures are required, the total material and installation costs are about $\$ 90,000 / \mathrm{plant}$. Adding the design costs, the total costs for this element is about $\$ 126,000 / p l a n t$.

It was assumed that about one-half of the nuclear-power-plant EDG enclosures contain separate areas for the control equipment. These plants would not need to install the thermal barriers. Therefore, the total effective per-plant cost for this element is about one-half of $\$ 126,000 / p 1$ ant or about $\$ 63,000 / \mathrm{p} 1$ ant.

\section{Element 10: Electrical Cabinet Tests}

This resolution element consists of conducting actual temperature measurements on electrical cabinets. The element provides input to decisions on which cabinets, if any, are in need of additional cooling capabilities.

The per-plant costs for this element were derived as follows:

Develop test plan (4 staff-wk):

Purchase equipment:

Conduct tests (12 staff-wk):

Interpret results (4 staff-wk):

Document/review/approve (4 staff-wk):

TOTAL
$\$ 9,080 /$ plant $5,000 /$ plant

$27,240 / \mathrm{plant}$ $9,080 /$ plant

9,080/plant

$\$ 59,480 /$ plant

The study results indicate that four electrical cabinets will require some form of additional cooling, such as a cabinet fan. The cost for this modification was estimated to be about $\$ 500 /$ cabinet or $\$ 2000 / \mathrm{plant}$. The total cost for this element was estimated to be $\$ 61,480 / \mathrm{pl}$ ant.

Element 11: Airflow Tests. This element also involves a testing program. The estimated costs for this program were assumed to be equal to the costs of Element 10, or about $\$ 61,480 / \mathrm{plant}$. 


\subsubsection{Total Industry Costs for Safety Issue Resolution Alternatives}

The total costs of implementing, operating, and maintaining the three alternative resolutions to this issue were calculated by combining the elemental costs discussed in subsection 7.3.2.1 for each alternative and then multiplying by the number of plants and average remaining lifetimes. The cost estimates were then discounted in accordance with guidance in NUREG/ CR-3568 (Heaberl in and Burnham, 1983). The results are the nuclear industry total 1 ife-cycle costs for each alternative. The current values for the number of plants and average remaining lifetimes are $110 \mathrm{plants}$ and 24 years, respectively. (a) These values incorporate all plants, including all PWRs and BWRs. There are no distinctions made between elements best applied to one plant type or the other. Therefore, the costs of each alternative were assumed to be app'icable to both plant types.

Resolution Alternative 1. This alternative combines Elements $1,2,3$, and 4 into a comprehensive, yet relatively noncomplex program to increase HVAC/room cooler reliability and improve response to losses of this equipment. Implementation costs for these elements total about \$241,120 per plant, in constant 1993 dollars. Annual operation and maintenance costs, also in constant 1993 dollars, total \$2,270, per reactor-year.

The next' step in the analysis was to discount the cost estimates presented above because some of the costs will be incurred in the future. Discounting was performed using methods described in Heaberl in and Burnham (1983). The costs estimates will be discounted at $5 \%$ and $10 \%$ discount rates. The implementation phase for this resolution alternative was assumed to start in 1993 and extend to 1995. Therefore, implementation costs were assumed to be discounted over a two-year period. The operation/maintenance costs were discounted over the remaining 22 years of average reactor operating 1 ifetime. The discounting calculations were performed using the following equation:

$$
P V_{i m p}=F_{i m p} * D F
$$

where:

$$
\begin{aligned}
P V_{i m p} & =\text { Present value of implementation costs } \\
F_{i m p} & =\text { Implementation costs, constant dollars (assumed to occur in } \\
D F & =\text { Discount factor }
\end{aligned}
$$

(a) Weakley, S. A. October 7, 1992. Memorandum to R. H. V. Gallucci. "Updating of Nuclear Power Plants Average Remaining Lifetime for Backfit VIA Calculations." Pacific Northwest Laboratory, Richland, Washington. Revised April 9, 1993. 
The values of DF are a function of the discount rate (5\% and $10 \%$ ) and the number of years in the future in which the costs will incur $(1995-1993$ $=2 \mathrm{yr}$ ). The values of DF were found to be 0.907 and 0.827 for $5 \%$ and $10 \%$ discount rates, respectively (Heaberl in and Burnham, 1983). Therefore, the discounted implementation costs were calculated to be

- $5 \%$ discount rate case:

$$
P V_{\text {imp }}=\$ 241,120 / p l \text { ant } * 0.907=\$ 218,700 / p l \text { ant }
$$

- $10 \%$ discount rate case:

$$
P V_{\text {imp }}=\$ 241,120 / \text { plant } * 0.827=\$ 199,400 / \mathrm{plant}
$$

The operation/maintenance costs are an annual recurring cost and are discounted differently than the implementation costs. The formula for discounting recurring costs is

$$
P V_{o / m}=F_{o / m} * A D F * D F
$$

where:

$$
\begin{aligned}
P_{0 / m} & =\text { Present value of operating/maintenance costs } \\
F^{\circ / m} & =\text { Operating/maintenance costs, constant dollars } \\
A D F & =\text { Annuity discount factor } \\
D F & =\text { Discount factor }
\end{aligned}
$$

The first two terms on the right side of this equation discount the annual costs from the end of the operating lifetimes of the reactors to the beginning of the operating/maintenance period of the resolution element. Operation/maintenance occurs over a 22-year period beginning in the year 1995. The values of ADF for the assumed 22-year period were taken from Heaberlin and Burnham (1983, Table A.2) and amount to 13.3 years and 8.78 years for the $5 \%$ and $10 \%$ discount rate cases, respectively. The third term in the equation discounts the costs in 1995 dollars to the year 1993. The resulting discounted operation/maintenance costs are

- $5 \%$ discount rate case

$$
P V_{o / m}=\$ 2270 / R Y * 13.3 y r * 0.907=\$ 27,400 / p l a n t
$$

- $10 \%$ discount rate case

$$
P V_{o / m}=\$ 2270 / R Y * 8.78 \mathrm{yr} * 0.827=\$ 16,500 / \mathrm{plant}
$$

The total present value of this resolution element, on a per-plant basis, is the sum of the discounted implementation and operation/maintenance costs. The total present value is the per-plant cost times the total number of affected plants. These calculations are shown below:

- $5 \%$ discount rate case: 
Total present value $=(\$ 218,700+27,400) * 110$ plants $=\$ 2.71 E+07$

- $10 \%$ discount rate case:

Total present value $=(\$ 199,400+16,500) * 110$ plants $=\$ 2.37 E+07$

Resolution Alternative 2. This alternative consists of resolution Elements $1,2,3,4,5$, and 7 . The sum of the implementation costs for these elements was calculated to be about $\$ 351,120$ per plant in constant 1993 dollars. Operation/maintenance costs total about \$3,632 per RY (constant 1993 dollars). The implementation period for this alternative was estimated to require four years, and the operating/maintenance period covers the remaining 20 years of reactor operating lifetimes. Discounting was performed using the same equations shown above. The discount factors and cost calculations for this resolution alternative are shown below:

- $5 \%$ discount rate case

$$
\begin{aligned}
& \begin{array}{lll}
P V_{1 m p}=\$ 351,120 / \mathrm{plant} * 0.823 & = & \$ 289,000 / \mathrm{plant} \\
P V^{1}= & \$ 3632 / R Y * 12.5 \mathrm{yr} * 0.823= & \$ 37,400 / \mathrm{plant}
\end{array} \\
& \text { Per-Plant Total (5\%) \$326,400/plant } \\
& \times \quad 110 \text { plants } \\
& \text { Total Present Value }=\$ 3.59 \mathrm{E}+07
\end{aligned}
$$

- $10 \%$ discount rate case

$$
\begin{aligned}
& \begin{array}{llll}
P V_{i m p}=\$ 351,120 / \mathrm{plant} * 0.683 & = & \$ 239,800 / \mathrm{pl} \text { ant } \\
P V^{\text {im }}=\$ 3632 / \mathrm{RY} * 8.51 \text { yr } * 0.683 & = & \$ 21,100 / \mathrm{plant}
\end{array} \\
& \text { Per-Plant Total (10\%) \$260,900/plant } \\
& \mathrm{x} \quad 110 \text { plants } \\
& \text { Total Present Value }=\$ 2.87 \mathrm{E}+07
\end{aligned}
$$

Resolution Alternative 3 . This alternative consists of resolution Elements 1 through 11 (with the exception of Element 6 , which was judged to be impractical). The sum of the implementation costs for these elements was calculated to be about $\$ 1,163,500$ per plant in constant 1993 dollars. Operation/maintenance costs in 1993 constant dollars total about \$5,900 per RY. Implementation is assumed to require up to five years and the operation/ maintenance period last for 19 years. Therefore, the total discounted costs for this resolution element are

- $5 \%$ discount rate case

$$
\begin{aligned}
& P V_{\text {imp }}=\$ 1,163,500 / \text { plant } * 0.784=\$ 912,200 / \mathrm{pl} \text { ant } \\
& \mathrm{PV}_{\mathrm{o} / \mathrm{m}}^{i \mathrm{mp}}=\$ 5900 / \mathrm{RY} * 12.1 \mathrm{yr} * 0.784=\$ 56,000 / \mathrm{plant} \\
& \text { Per-Plant Total (5\%) \$968,200/plant }
\end{aligned}
$$


- $10 \%$ discount rate case

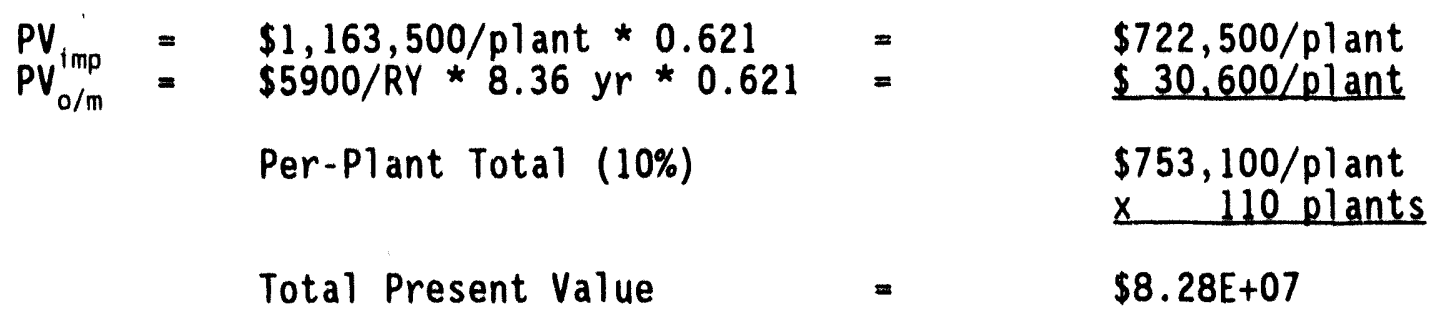

\subsubsection{NRC Costs}

NRC costs'include costs for development and implementation of each resolution alternative. The costs to develop and issue appropriate guidance for Alternatives 1 and 2 were estimated to be about $\$ 11,000 / p$ lant (a public hearing was judged to be unnecessary, so this relatively low value was chosen). NRC costs to develop and issue guidance for Alternative 3 were estimated to be about $\$ 21,000 / \mathrm{plant}$, reflecting the more complicated resolution elements in Alternative 3 relative to Alternatives 1 and 2 . These cost estimates were taken from Kohut et a1. (1991, p. 95), discounted using the approach discussed in subsection 8.2.2.2, and illustrated below:

- Alternatives 1 and 2

$\begin{aligned}(5 \% \text { case }) \text { NRC costs } & =(\$ 11,000 / \mathrm{plant}) *(110 \mathrm{plants}) * 0.952 \\ (10 \% \text { case }) \text { NRC costs } & =\$ 1.15 \mathrm{E}+06 \\ & =(\$ 11,000 / \mathrm{plant}) *(110 \mathrm{plants}) * 0.909 \\ & =\$ 1.10 \mathrm{E}+06\end{aligned}$

- Alternative 3

$\begin{aligned}(5 \% \text { case }) \text { NRC costs } & =(\$ 21,000 / \mathrm{plant}) *(110 \text { plants }) * 0.952 \\ & =\$ 2.20 \mathrm{E}+06 \\ (10 \% \text { case }) \text { NRC costs } & =(\$ 21,000 / \mathrm{plant}) *(110 \text { plants }) * 0.909 \\ & =\$ 2.10 \mathrm{E}+06\end{aligned}$

The NRC will also incur additional annual operating costs for periodic inspections, to ensure compliance with the proposed requirements. For Alternatives 1 and 2, the incremental NRC labor requirements were estimated to be about two staff-day/RY, which amounts to about \$908/RY. NRC operation labor requirements for Alternative 3, which is much more complicated that Alternatives 1 and 2, were estimated to be about 1 staff-wk/RY. This amounts to about $\$ 2,270 / R Y$. These costs were discounted, assuming the costs will begin in 1994, as follows: 
- Alternatives 1 and 2

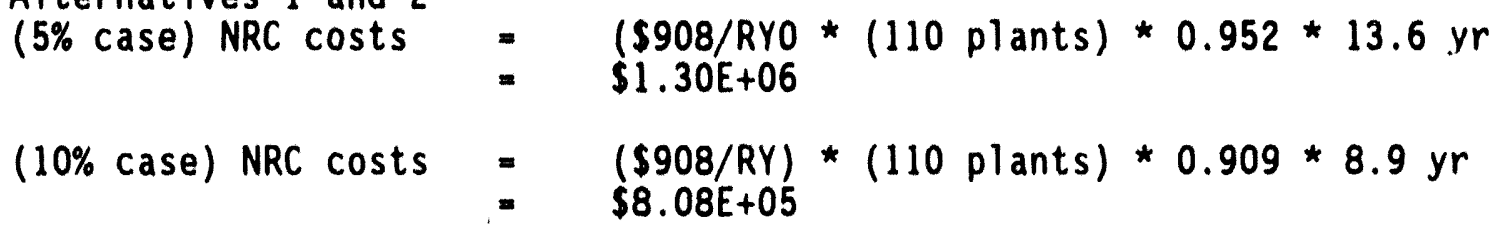

- Alternative 3

$(5 \%$ case $)$ NRC costs $=(\$ 2,270 / R Y) *(110 \mathrm{plants}) * 0.952 * 13.6 \mathrm{yr}$

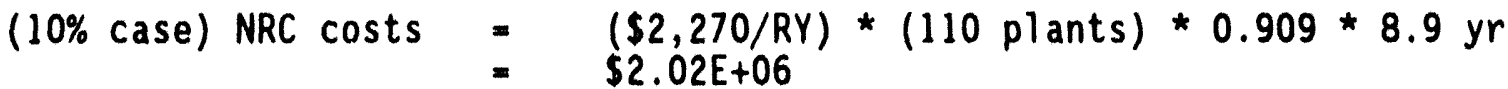

\subsection{VALUE-IMPACT ASSESSMENT}

The value-impact assessment combines the results of the cost calculations presented in Section 8.2 and the risk calculations presented in Section 7.2. These results of the public risk reduction calculations, or the benefits of the alternative resolutions to GI-143, are summarized in

Table 8.3-1. The table shows the per-plant reductions in CDF and public risks associated with implementation of each of the alternatives and the total $1 \mathrm{ife}$ cycle public risk reduction. The total public risk reduction is defined as the per-plant risk integrated over all current plants and the average remaining lifetimes of these plants.

The costs of each alternative resolution are presented in Table 8.3-2. This table shows the implementation, operation/maintenance, NRC, onsite consequences, onsite property damage, and offsite property damage costs for each alternative resolution. The top half of the table presents the per-plant costs and the bottom half presents the total integrated costs. All costs are discounted to 1993 dollars.

IABLE 8.3-1. Summary of Benefits of Alternative Resolutions to GI 143

\begin{tabular}{||l|c|c|c|}
\hline \multicolumn{1}{|c|}{ Parameter } & \multicolumn{3}{|c|}{ GI-143 Resolution A1 ternative } \\
\hline \multicolumn{1}{|c|}{} & 1 & 2 & 36 \\
\hline $\begin{array}{l}\text { Per-plant reduction in core damage } \\
\text { frequency (per RY) }\end{array}$ & $2.4 \mathrm{E}-06$ & $4.5 \mathrm{E}-06$ & $6.7 \mathrm{E}-06$ \\
$\begin{array}{l}\text { Per-plant reduction in public risks } \\
\text { (person-rem/RY) }\end{array}$ & $8.4 \mathrm{E}-01$ & $1.3 \mathrm{E}+00$ & $2.0 \mathrm{E}+00$ \\
$\begin{array}{l}\text { Total integrated risk reduction } \\
\text { (person-rem) }\end{array}$ & $2.2 \mathrm{E}+03$ & $3.6 \mathrm{E}+03$ & $5.2 \mathrm{E}+03$ \\
\hline
\end{tabular}


TABLE 8.3-2. Summary of Per-Plant and Total Costs for Each Resolution Alternative

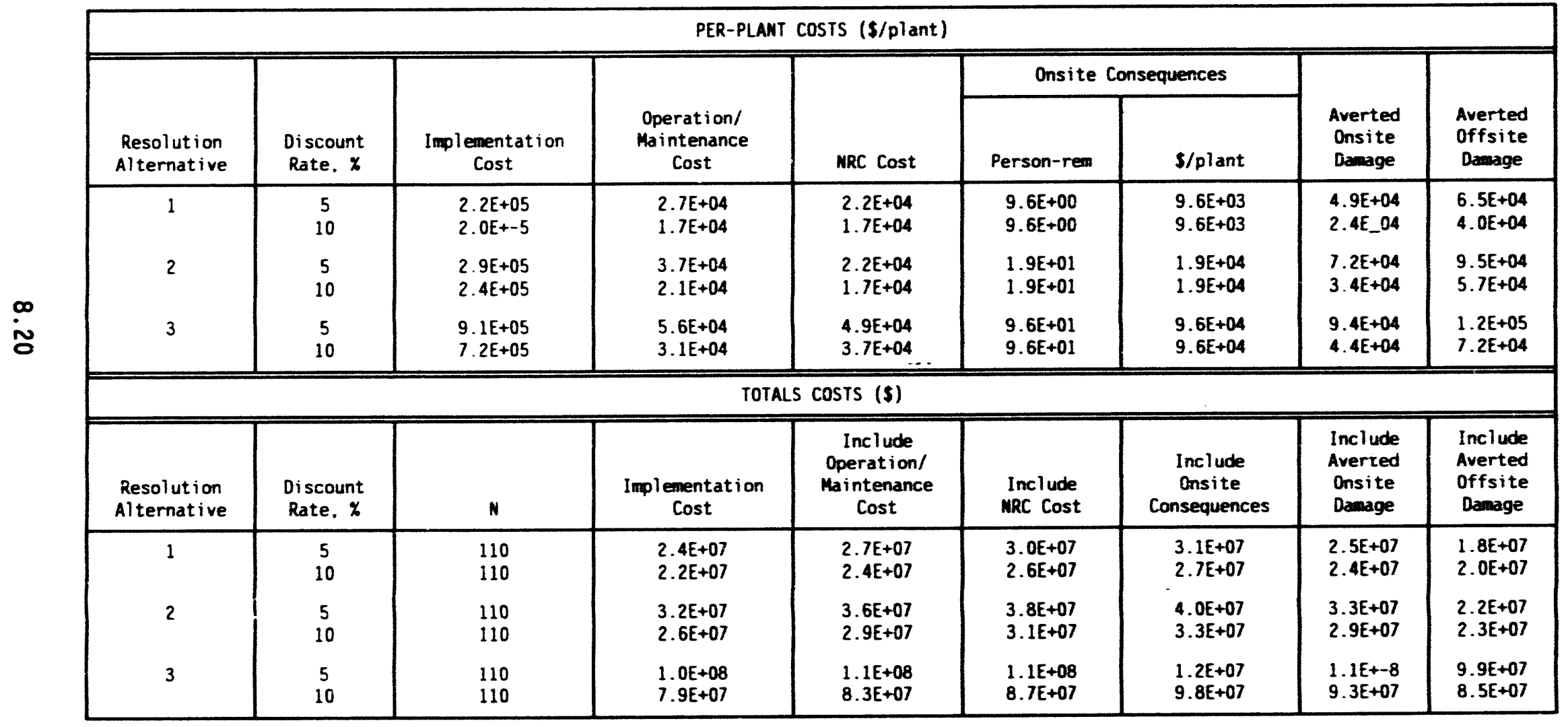


Table 8.3-3 shows the value-impact ratios for each alternative. The ratios are calculated by dividing the total discounted costs by the total public risk reduction. The table shows the net value:impact ratio, calculated without the cost offsets for onsite and public property damage, as well as the net value: impact ratio (includes costs offsets). These value:impact ratios are illustrated in Figure 8.1-1 relative to the value of $\$ 1000 /$ person-rem used for a cost-effectiveness measure. As shown, all of the resolution alternatives exceed the $\$ 1000 /$ person-rem cost-effectiveness ratio, both in terms of the net and total value:impact ratto.

IABLE 8,3-3. Best Estimate Value:Impact Ratios (\$/person-rem)

\begin{tabular}{|c|c|c|c|}
\hline $\begin{array}{c}\text { Resolution } \\
\text { Alternative }\end{array}$ & $\begin{array}{c}\text { Discount } \\
\text { Rate, } \%\end{array}$ & $\begin{array}{c}\text { Net } \\
\text { Cost: Benefit }\end{array}$ & $\begin{array}{c}\text { Total } \\
\text { Cost: Benefit }\end{array}$ \\
\hline 1 & 5 & $8.2 E+03$ & $1.4 E+04$ \\
& 10 & $8.8 E+03$ & $1.2 E+04$ \\
2 & 5 & $6.2 E+03$ & $1.1 E+04$ \\
& 10 & $6.4 E+03$ & $9.2 E+03$ \\
3 & 5 & $1.9 E+04$ & $2.3 E+04$ \\
& 10 & $1.6 E+04$ & $1.9 E+04$ \\
\hline
\end{tabular}



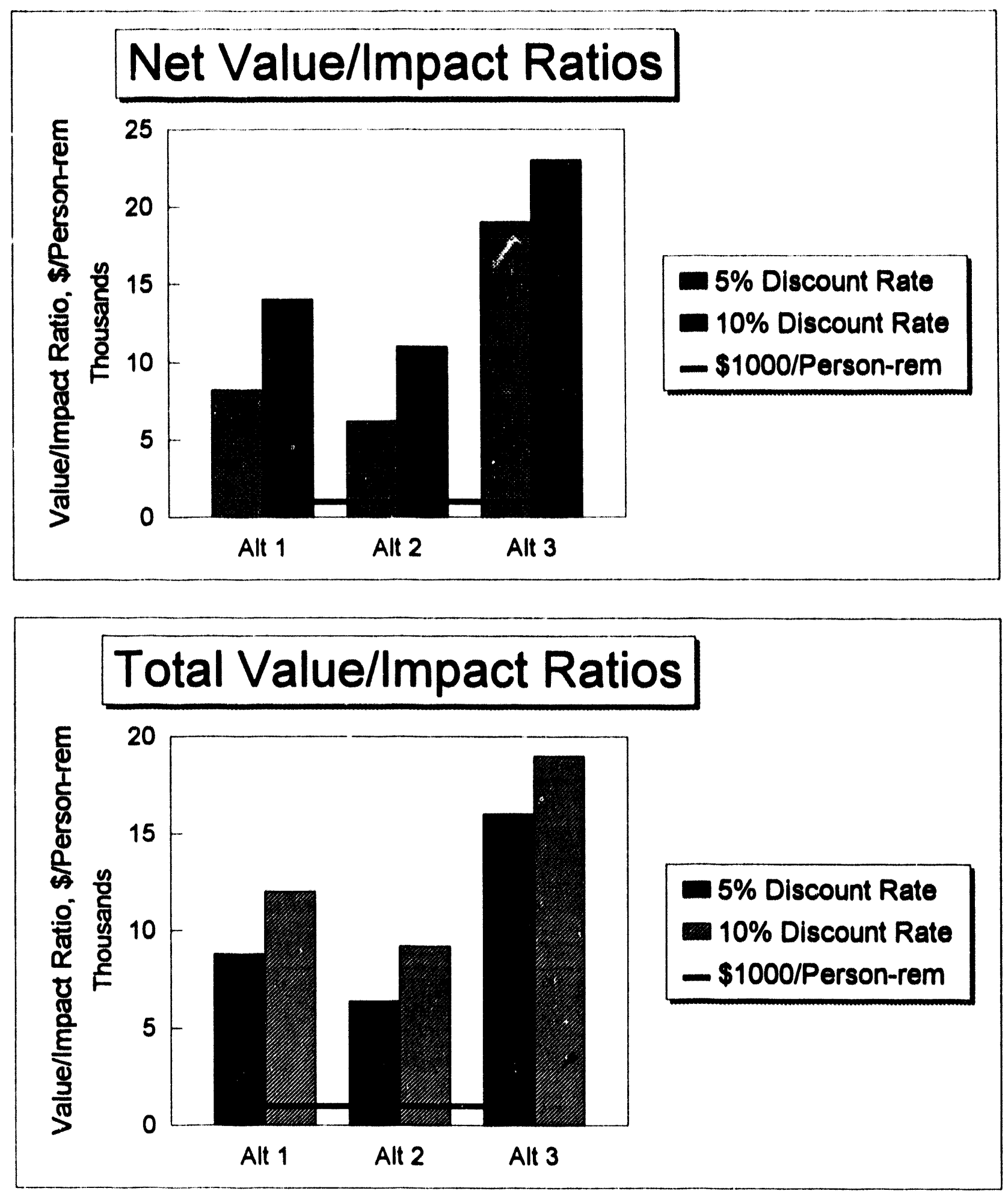

EIGURE 8.1-1. Illustration of Value: Impact Ratios Relative to $\$ 1000 /$ Person-Rem Cost-Effectiveness Measure 


\subsection{REFERENCES}

Amico, P. J. 1983. Interim Reliability Evaluation Programi Analys is of the Millstone Point Unit 1 Nuclear Power Plant. NUREG/CR-3085/2 APP, SAND82-7212. Sandia National Laboratories, Albuquerque, New Mexico.

Andrews, W. B., R H. V. Galluccl, S. W. Heaberl in, W. E. Bickford,

G. J. Konzek, D. L. Strenge, R. I. Smith, and S. A. Weakley, 1983. Guideline for Nuclear Power Plant Safety issue Prioritization Information Develooment. NUREG/CR-2800 (PNL-4297), prepared by Pacific Northwest Laboratory for the U.S. Nuclear Regulatory Commission, Washington, D.C.

Arizona Public Service Co, 1992. Pale Verde Nuclear Generating Station Individual Plant Examination. Docket No. 50528, 50529, and 50530. Submitted to U.S. Nuclear Regulatory Commission, Washington D.C.

Bertucio, R. C., and J. A. Julius. 1990. Analys is of Core Damage Frequency: Surry Unit I Internal Events. NUREG/CR-4550, Vol. 3 Reg. 1, Sandia National Laboratories, Albuquerque, New Mexico.

Bertucio, R. C., and S. R. Brown. 1990. Analys is of Core Damage Frequency: Sequoyah Unit 1 Internal Events. NUREG/CR-4550, Vol. 5, Rev. 1, Sandia National Laboratories, Albuquerque, New Mexico.

Bohn, M. P., J. A. Lambright, S. L. Daniel, J. J. Johnson, M. K. Ravindra, P. 0. Hashimoto, M. J. Mraz, W. H. Tong. 1990. NUREG/CR-4550 Vol. 1 (SAND862084), prepared by Sandia National Laboratories for the U.S. Nuclear

Regulatory Commission, Washington, D.C.

Brown, T. D., R. J. Breeding, H. N. Jow, S. J. Higgins A. W. Shiver, and J. C. Helton. 1990. Evaluation of Severe Accident Risks: Grand Gulf Unit 1. NUREG/CR-4551, Vol. 6, Rev. 1, Sandia National Laboratories, Albuquerque, New Mexico.

Chirama1, M. 1986. Effects of Ambient Temperatures on Electronic Components in Safety-Related Instrumentation and Control Systems. AEOD/C604. Office for Analysis and Evaluation of Operational Data, U.S. Nuclear Regulatory Commission, Washington D.C.

Drouin, M. T. et al. 1989. Analysis of Core Damage Frequency: Grand Gulf Unit 1 Internal Events. NUREG/CR-4550, Vol. 6, Reg. 1, Sandia National Laboratories, Albuquerque, New Mexico.

Duke Power Company. 1990. Oconee Nuclear Station Unit 3 Probabilistic Risk Assessment, Yol. 1, Duke Power, Company, Charlotte, North Carolina.

Garcia, A. A. 1981. Crystal River-3 Safety Study. NUREG/CR-2515 (SANDIA-7229), Sandia National Laboratories, Albuquerque, New Mexico. 
Gertman, D. I., B. G. Gilbert, W. E. Gilmore, and W. J. Galyean. Nuclear Computerized Library for Assessing Reactor Rel lability (NUCLARR). NUREG/ CR-4639 (EGG-2458) Vol. 5, prepared by the Idaho National Engineering Laboratory for the U.S. Nuclear Regulatory Commission, Washington, D.C.

Goodman, T. C. 1964. "Application of Integral Methods to Transient, NonLinear, Heat Transfers." Advances in Heat Transfer, Volume 1. Academic Press, New York.

Grant, T. F., and M. S. Harris. 1989. Value-Impact Assessment of Candidate Qperating Procedure Update Program. NUREG/CR-5458, U.S. Nuclear Regulatory Commission Division of Systems Research, Washington, D.C.

Gregory, J. J., S. J. Higgins, R. J. Breeding, A. W. Shtver, W. P, Murfin, and J.C. Helton. 1990. Evaluation of Severe Accident Risks: Sequevah Unit 1. NUREG/CR-4551, Vo1. 5, Rev. 1, Sandia National Laboratories, ATbuquerque, New Mexico.

Heaberlin, S. W., and J. B. Burnham. 1983. Handbook for Value-Impact Assessment. NUREG/CR-3568, Pacific Northwest Laboratory, Richland, Washington.

Kimura, C. Y., and R. J. Budnitz: 1987. Evaluation of External Hazards to Nuclear Power Plants in the United States. NUREG/CR-5042, prepared by Lawrence Livermore National Laboratory for the U.S. Nuclear Regulatory Commission, Washington, D.C.

Kohut, P., Z. Musicki, and R. Fitzpatrick. 1991. Analysis of Risk Reduction Measures Apolied to Shared Essential Service Water Systems at Multi-Unit Sites. NUREG/CR-5526, prepared by the Brookhaven National Laboratory for the U.S. Nuclear Regulatory Commission, Washington, D.C.

Kolaczkowski, W. R., T. T. Cramond, K. J. Maloney, T. A. Wheeler, and S. L. Danie1. 1989. Analys is of Core Damage Frequency: Peach Bottom Unit 2 Internal Events. NUREG/CR-4550 Vol 4, Part 1 (SAND86-2084), prepared by Sandia National Laboratories for the U.S. Nuclear Regulatory Commission, Washington, D.C.

Lambright, J. A., M. P. Bohn, S. L. Daniel, J. J. Johnson, M. K. Ravindra, P. O. Hashimoto, M. J. Mraz, W. H. Tong, and D. A. Brosseau. 1990. Analysis of Core Damage Frequency: Peach Bottom, Unit 2 External Events. NUREG/CR-4550 Vo1. 4, Part 3 (SAND86-2084), prepared by Sandia National Laboratories for the U.S. Nuclear Regulatory Commission, Washington, D.C.

Mackowiak, D. P., C. D. Gentillon, and K. L. Smith. 1985. Develooment of Iransient Initiating Event Frequencies for Use in Probabilistic Risk Assessments. EG\&G Idaho, Inc., Idaho Falls, Idaho.

McDougald, W., and R. Christie. 1992. "Impact of Safety Requirements on Component Availability." ANS Transactions, Volume 65. American Nuclear Society, LaGrange Park, Illinois. pp 303-305. 
McKinley, J. C. 1986. Summary and minutes of the June 27, 1986, Joint Meeting of the ACRS Subcommittees on "Occupational and Environmental Protection Systems" and "Auxillary Systems." U.S. Nuclear Regulatory Commission, Washington D.C.

Nuclear Safety. Oct-Dec 1986. "Operating Experiences." Vo1. 27, No. 4, p. 530 .

Nuclear Safety. Jul-Sept 1988. "Operating Experiences." Vol. 29, No. 3.

Payne, A. C. 1984. Interim Reliability Evaluation Program: Analysis of the Calvert Cliffs Unit 1 Nuclear Power Plant. NUREG/CR-3511 (SANDIA-2086), Sandia National Laboratories, Albuquerque, New Mexico.

Ramsde 11, J. V., and G. L. Andrews. 1986. Tornado Climatology of the Contiquous United States. NUREG/CR-4461 (PNL-5697), prepared by Pacific Northwest Laboratory for the U.S: Nuclear Regulatory Commission, Washington, D.C.

Russel, K., and M. Sattison. 1990. Integrated Reliability and Risk Analysis Software (IRRAS) User's Guide, Version 2.6. NUREG/CR-5111. EG\&G Idaho, Inc. Idaho Falls, Idaho.

Sciacca, F. 1992. Generic Cost Estimates. NUREG/CR-4627, prepared for the U.S. Nuclear Regulatory Commission by Science and Engineering Associates, Inc. U.S. NRC, Washington, DC.

Stewart, H. D., K. D. Russell, M. B. Sattison, W. W. Tullock, A. M. Espinosa, and M. A. Lenhart. 1989. Systems Analysis and Risk Assessment System (SARA) - Reference Manual Version 4.0. NUREG/CR-5022 (EGG-2522), EG\&G Idaho Inc., Idaho Falls, Idaho.

Sugnet, W. R., G. J. Boyd, S. R. Lewis, et al. 1984. Oconee PRA, A Probabilistic Risk Assessment of Oconee Unit 3 . NSAC-60, Electric Power Research Institute, Palo Alto, California.

Swain A. D., and H. E. Guttman. 1983. Handbook and Human Rel lability Analysis with Fimplias is on Nuclear Power Plant Application. NUREG/CR-1278, SAND80-0200. Siandia National Laboratory, Albuquerque, New Mexico.

Thomas, H. M. 1981. "Pipe and Vessel Failure Probability." Rellability Engineering. Vol. 2, pp. 83 to 124.

Twisdale, L. A., W. L. Dunn, and J. Chu. 1978. Tornado Missile Risk Analysis. Carolina Power and Light Company, Raleigh, North Carolina.

U.S. Nuclear Regulatory Commission (NRC). 1989. Severe Accident Risks: An Assessment for Five U.S. Nuclear Power Plants. NUREG-1150, U.S. NRC, Washington, D.C. 
U.S. Nuclear Regulatory Commission (NRC). 1974. "Design Basis Tornado for Nuclear Power Plants." Regulatory Guide 1.76, U.S. NRC, Washington, D.C.

U.S. Nuclear Regulatory Commission (NRC). 1978. "Tornado Design Classification." Regulatory Guide 1.117, U.S. NRC, Washington, D.C.

Virginia Electric and Power Company (VEPCO). 1991. Probabilistic Risk Assessment for the Individual Plant Examination Final Report. VEPCO, Richmond, Virginia.

Weston, L. M., and D. W. Whitehead. 1987. Recovery Actions in PRA for the Risk Methods Integration and Evaluation Program (RMIEP). NUREG/CR-4834, Sandia National Laboratories, Albuquerque, New Mexico. 
APPENDIX A

REVIEW OF LICENSEE EVENT REPORT DATA

INVOLVING HVAC AND ROOM COOLER FAILURES - 1980 to 1991 
APPENDIX A

REVIEW OF LICENSEE EVENT REPORT (LER) DATA

INVOLVING HVAC AND ROOM COOLER FAILURES - 1980 to 1991

This appendix describes a review of NRC Licensee Event Reports (LERs) involving HVAC and room cooler failures during the period 1980 to 1991. The Nuclear Documents System/Advanced Design (NUDOCS/AD) computerized database system was used to search for LERs involving the following key words:

\begin{tabular}{|l|l|l|}
\hline 1 & HVAC or LER & 1115 records \\
\hline
\end{tabular}

As shown, a total of 1115 records were identified.

A preliminary review of these records indicated that there were many records that did not represent failure of the HVAC or room coolers to remove heat from safety-related equipment rooms. A large number of these records involved failure/malfunction of toxic gas (chlorine and ammonia) detectors and radiation monitors which caused the control room HVAC system to shift to emergency recirculation mode. As a result, additional searches were performed to eliminate these non-applicable failures, as follows:

\begin{tabular}{|c|l|c|}
\hline 2 & Radiation detectors or radiation monitors & 3228 records \\
\hline 3 & Gas detectors or gas monitors & 1024 records \\
\hline 4 & Chlorine or ammonia & 1233 records \\
\hline 5 & Toxic gas or gas analyzer & 876 records \\
\hline
\end{tabular}

A combined Boolean search was performed to remove the records from search 1 that were also in searches 2 to 5 . This was done as follows:
6
1 and not 2 and not 3 and not 4 and not 5
702 records

These 702 potentially-applicable records were reviewed individually for applicability to this analysis.

The first step in the review of these 702 records was to identify and eliminate duplicate records (a single event may be represented by two or more records; e.g., LER 86-029 included the original LER plus 12 followup reports). The remaining records were then reviewed to identify actual component or system failures of interest to this study. This involved eliminating those 
LERs that did not represent an actual HVAC or room cooler failure to remove heat from a safety-related area of a plant. The most common of these nonapplicable failures are shown below:

- Malfunctions resulting in low ambient temperatures were eliminated.

- Violations of technical specifications were eliminated unless the violation resulted in uncovery of an undetected HVAC or room cooler system failure.

- Procedural errors and test/maintenance errors during outages were eliminated unless the error was indicated to result in inoperability of an HVAC or room cooler system component if undetected.

- LERs involving failure of the fuel storage area HVAC system were eliminated unless they were accompanied by failures of reactor or auxiliary building HVAC systems or were indicated to involve failure of cooling functions in areas within the fuel handling building that are occupied by components of interest to this study.

- LERs involving successful switchover of the control room HVAC system to recirculation mode when demanded to do so as a result of failures in other systems. Recirculation mode is implemented during emergency conditions to prevent potentially contaminated outside air from entering the control room. For example, failures of one division of $A C$ power requires control room HVAC to automatically shift to recirculation mode. This type of LER is reportable to the NRC because it involves actuation of an engineered safety feature (i.e., the control room HVAC system), regardless of whether or not the original failure is reportable. If a successful shift to recirculation mode was indicated, the LER was eliminated because there was no failure of a room cooling function.

- LERs involving deficiencies of fire protection requirements (i.e., 10 CFR 50, Appendix R) or seismic design requirements were el iminated because they do not necessarily result in HVAC or room cooler failures. These were retained separately for use in future efforts.

- Failures of electric heaters or filters in exhaust air trains (e.g., standby gas treatment system filter or charcoal adsorber failures or failures of filters in control room HVAC systems) were eliminated because they do not represent failure of a cooling function.

The LERs that remained after this elimination process are presented in Table A.1. The results of a review of these LERs are described on the following pages. 
TABLE A.1. Licensee Event Reports Involving HVAC and Room Cooler Failures

\begin{tabular}{|c|c|c|c|c|c|}
\hline ISSUED & PLANT & MICROFICHE & REFERENCE & POWER & DESCRIPTION \\
\hline $02-11-80$ & Brunswick 2 & $04025 / 283-283$ & LER-324/80-001 & $95 \%$ & $\begin{array}{l}\text { LER } 80-001 / 03 \mathrm{~L}-0 \text { : on } 800117 \text {. during attempt to start RHR room cooler } 2 \mathrm{~A} \text {, } \\
\text { breaker tripped on magnetics. Cause could not be determined due to } \\
\text { inoperable room cooler } 28 \text {. Breaker reset } \& \text { closed. }\end{array}$ \\
\hline $06-10-80$ & Browns Ferry 1 & $05393 / 331-332$ & LER-259/80-042 & $99 \%$ & $\begin{array}{l}\text { LER } 80-042 / 03 L-0: \text { on } 800512 \text {, w/unit at } 96 \% \text { power, core spray sys } 1 \text { rcom } \\
\text { cooler failed. Caused by apparent malfunction of check valves in header. } \\
\text { Check valves removed, inspected \& reinstalled. }\end{array}$ \\
\hline $07-30-80$ & Edwin Hatch 1 & $06110 / 325-326$ & LER-321/80-082 & $10 \%$ & $\begin{array}{l}\text { LER } 80-082 / 03 L-0: \text { on } 800711 \text {, during startup, cooling water to LPCI inverter } \\
\text { room cooler was isolated on two occasions. LPCIB inverter tripped, making } \\
\text { loop B of RHR inoperable. Caused by high ambient temp in inverter room. } \\
\text { Inverter re-energized. }\end{array}$ \\
\hline $08-29-80$ & Edwin Hatch 1 & $06442 / 312-313$ & LER-321/80-092 & $99 \%$ & $\begin{array}{l}\text { LER } 80-092 / 03 L-0: \text { on } 800731 \text {, while at steady state power, cooling water to } \\
\text { LPCI inverter room cooler was isolated resulting in high ambient temp in } \\
\text { inverter room. Caused by high ambient temp causing B loop of RHR to be } \\
\text { inoperable. }\end{array}$ \\
\hline $09-19-80$ & Brunswick 2 & $06625 / 187-187$ & LER-324/80-033 & $10 \%$ & $\begin{array}{l}\text { Updated LER } 80-033 / 03 L-1 \text {; on } 800215 \text {, while attempting to start } 2 A \text { RHR room } \\
\text { cooler. cooler blower motor tripped on magnetics. Caused by low breaker } \\
\text { magnetics setting. Breaker magnetics reset \& breaker satisfactorily tested. }\end{array}$ \\
\hline $09-30-80$ & Peach Bottom 2 & $15320 / 353-353$ & LER-277/80-017 & $100 \%$ & $\begin{array}{l}\text { LER } 80-017 / 03 L-0 \text { : on } 800906 \text {, during surveillance test at full power. RHR B } \\
\text { subsystem pump room cooler failed to start automatically. Caused by improper } \\
\text { adjustment of cell switch on pump breaker. Breaker replaced \& test } \\
\text { completed. }\end{array}$ \\
\hline $12-01-80$ & Browns Ferry 3 & $07148 / 259-260$ & LER-296/80-047 & $88 \%$ & $\begin{array}{l}\text { LER } 80-047 / 03 L-0 \text { : on } 801108 \text {, during normal operation, difficulties } \\
\text { encountered while trying to determine EECW flow to } 3 B \text { \& } D \text { core spray room } \\
\text { cooler. Caused by biofouling. sitt accumulation \& corrosion. }\end{array}$ \\
\hline $07-22-81$ & Browns Ferry 2 & $09220 / 093-094$ & LER-260/81-031 & $99 \%$ & $\begin{array}{l}\text { LER } 81-03 \mathrm{i} / 03 \mathrm{~L}-0 \text { : on } 810701 \text {. RHR pump room cooler } 3-\mathrm{A} \text { developed water leak. } \\
\text { Caused by broken Sil'fos joint on } 1 / 4-\text { inch vent } 1 \text { ine. Joint resoldered. }\end{array}$ \\
\hline $12-17-81$ & Browns Ferry 2 & $11390 / 063-064$ & LER-260/81-063 & $100 \%$ & $\begin{array}{l}\text { LER } 81-063 / 03 L-0 \text { : on } 811117 \text {. northwest core spray room cooler found } \\
\text { inoperable. Caused by trip of CR124 overload relays. Relays reset \& stated } \\
\text { current verified. }\end{array}$ \\
\hline $03-03-82$ & Sequoyah 1 & $12333 / 261-261$ & LER-327/82-020 & $30 \%$ & $\begin{array}{l}\text { LER } 82-020 / 03 L-0 \text { : on } 820203 \text {, emergency gas treatment sys room cooler } \\
\text { declared inoperable due to fuses blowing in coolers control circuitry. } \\
\text { Caused by shorted solenoid coil of } 2-\text { FSV-67-338. Coil replaced. }\end{array}$ \\
\hline $05-05-82$ & Peach Bottom 3 & $13085 / 038-038$ & LER-278/82-004 & $100 \%$ & $\begin{array}{l}\text { LER } 82-004 / 03 L-0: \text { on } 820410 \text {, while performing surveillance tests on } D \text { core } \\
\text { spray \& D RHR pumps, room cooler fans failed to start w/control switches in } \\
\text { auto or run position. Caused by de-energized control circuit. Circuit } \\
\text { re-energized. }\end{array}$ \\
\hline $05-12-82$ & LaSalle 1 & $13223 / 027-028$ & LER-373/82-005 & $0 \%$ & $\begin{array}{l}\text { LER } 82-005 / 03 L-0 \text { : on } 820426 \text {. OB control room HVAC emergency makeup train } \\
\text { found inoperable. Caused by binding limit switch on damper OVCO2YB. Limit } \\
\text { switch adjusted. }\end{array}$ \\
\hline $06-10-82$ & LaSalle 1 & $13533 / 189-189$ & LER-373/82-022 & $0 \%$ & $\begin{array}{l}\text { LER } 82-022 / 03 L-0 \text { : on } 820523 \text {. emergency makeup train heater temp switch for } \\
\text { control room HVAC tripped. Caused by inadvertent closure of tornado damper } \\
\text { which blocked all suction to train thus raising temp \& tripping switch. }\end{array}$ \\
\hline
\end{tabular}


TABLE A.1. (contd)

\begin{tabular}{cccccc}
\hline ISSUED & PLANT & MICROFICHE & REFERENCE & POWER & DESCRIPTION \\
\hline 06-16-82 & LaSalle 1 & $13631 / 316-318$ & LER-373/82-023 & $0 \%$ & $\begin{array}{l}\text { LER 82-023/03L-0: on 820524, piston seal on damper actuator failed to } \\
\text { operate in control room emergency HVAC sys. Caused by personnel failure to } \\
\text { adequately review degraded equipment log. Other HVAC train repaired \& parts } \\
\text { ordered for damper }\end{array}$ \\
& & & &
\end{tabular}

08-03-82 Edwin Hatch $2 \quad 14326 / 359-360$ LER-366/82-067

09-09-82 Brunswick 2

$14905 / 083-083$

LER-324/82-102

09-07-82

Quad-Cities 1

14973/165-165

LER-254/82-023

02-17-83

Pal isades

$17309 / 332-332$

LER-255/83-007

$17452 / 275-275$

LER-255/83-008

$05-10-83$

Quad-Cities 1

18548/195-196

LER-254/83-017

05-24-83

Sequoyah 1

18674/068-069

LER-327/83-065

06-24-83

Calvert $\mathrm{Cl}$ iffs 1

$19382 / 265-267$

LER-317/83-034

$07-25-83$

Grand Gulf

19882/072-073

LER-416/83-080

08-23-83

Browns Ferry 2

$20210 / 186-188$

LER-260/83-049

$08-26-83$

Grand Gulf

20263/084-085

LER-416/83-110
$96 \%$

ordered for damper.

LER 82-067/03L-0: on 820705. A \& B SVC water supply valves to RHR \& core spray pump room cooler failed to pass core spray operability procedure requirements. Caused by lack of lubrication. Valves lubricated $\&$ reassembled.

0\% LER 82-102/03L-0: on 820810. attempt to operate A loop core spray subsystem room cooler determined that svc water discharge valve $2-S W-V 128$ would not operate properly. Caused by grease on valve due to moisture from air lines.

57\% LER 82-023/03L-0: on 820824, RHR sys sve water pump 1-1001-65A removed from svc to repack room cooler isolation valve. Pump removed for preventive maint on associated room cooler isolation valve. Maint completed \& pump returned to sve.

100\% LER 83-007/01T-0: on 830204, during review of SEP topics following LOCA $w /$ concurrent loss of either diesel generator. determined only one fan in each engineering safeguards room cooler would operate. Caused by design deficiency.

100\% LER 83-008/01T-0: on 830209. thermal overload for one engineered safeguards room cooler fan tripped based on evaluation \& testing activities. Cause not stated. Tripped overload reset.

100\% LER 83-017/03L-0: on 830412. RHR sve water pump 1-1001-65C taken out of sve to facilitate repair of broken coupling on RHR sve water vault room cooler 1-5745-C drain line. Caused by overpressurization of piping. W/830510 $\mathrm{itr}$.

$100 \%$ LER 83-065/03L-0: on 830502, during performance of Surveillance Instruction 166. 21. train A emergency gas treatment sys room cooler declared inoperable. Caused by short in solenoid valve coil. Coil replaced. W/830524 $1 \mathrm{tr}$.

100\% LER 83-034/03L-0: on 830525. ECCS pump room cooler 12 taken out of sve for maint \& declared inoperable, rendering ECCS subsystem inoperable. Caused by debris in saltwater supply piping \& strainer. Piping \& strainer cleaned. $W / 830624 \mathrm{ltr}$.

0\% LER 83-080/03L-0: on 830626, control room operators experienced problems W/HVAC sys involving inadequate cooling capacity \& sys losses. Partially caused by malfunctioning condenser cooling water flow control valve. W/830725 itr.

95\% LER 83-049/03L-0: on 830725, while performing Surveillance Instruction 4. 2. B-60. core spray NE room cooler fan would not operate. Caused by tripped overload relays in full voltage nonreversing magnetic. starter. Relays replaced. W/830823 itr.

0\% LER 83-110/03L-0: on 830728, control room HVAC loop A shutdown to repair freon shutoff valve. Tests $\&$ insps revealed three compressor inlet strainers $\&$ two pistons damaged. Cause not determined. Compressor rebuilt. W/830826 Itr. 
TABLE A.1. (contd)

\begin{tabular}{|c|c|c|c|c|c|}
\hline ISSUED & PLANT & MICROFICHE & REFERENCE & POWER & DESCRIPTION \\
\hline $08-18-83$ & Edwin Hatch 1 & $20276 / 161-164$ & LER-321/83-082 & $100 \%$ & $\begin{array}{l}\text { LER } 83-082 / 03 L-0 \text { : on } 830729 \text {, during control room panel walkdown. HPCI pump } \\
\text { room cooler indicator light on control room panel not lit, indicating cooler } \\
\text { inoperable. Caused by electrical poor circuit being in off position. } \\
W / 830818 \mathrm{itr} \text {. }\end{array}$ \\
\hline
\end{tabular}

09-21-83 Brunswick 2 20590/340-342 LER-324/83-069

07-24-84 Arkansas

$12-20-84$ WPPSS 2

03-01-85 Sequoyah 1

$29247 / 337-339$

LER-327/85-007

03-05-85 Dresden 3

29393/078-080

LER-249/85-003

in

$03-04-85$

$03-15-85$

Callaway 1

$03-25-85$

Donald C. Cook 2 29668/109-124

LER-315/85-007

04-03-85 Dresden 3

08-16-85 Callaway 1

$32302 / 001-007$

LER-483/85-034

08-12-85

Quad-Cities 1

$32333 / 118-120$

LER-254/85-009

$08-26-85$

32447/274-277 LER-341/85-045
$100 \%$

LER 83-069/03L-0: on 830825, while attempting to place RHR room coolers $2 \mathrm{~A}$ $2 B$ into svc, neither room cooler would start. Cased by fan start switch of $2 A$ out of adjustment w/airflow dampers of 28 mechanically binding. $W / 830921$ $1 \mathrm{tr}$.

180\% Updated LER 80-026/03X-1: on 800514. control room emergency air conditioner compressor trip occurred on freeze protection. Cased by insufficient load when providing cooling from core protection calculator room. W/840724 itr.

1/96\% LER 84-123-00: on 841202. normal Div I critical switchgear room cooling lost due to manual shutdown caused by vibration of fan unit. All Div I equipment declared inoperable. Fan shaft replaced \& bearings instalied. W/841220 $\mathrm{itr}$.

1/100\% LER 85-007-00: on 850131. while performing Surveillance Instruction 166. 21. Train B emergency gas treatment sys room cooler would not start. Caused by blown control fuse. Fuse replaced. W/850301 $1 \mathrm{tr}$

N/91\% LER 85-003-00: on 850206. HPCI room cooler fan belts fell off, rendering sys inoperable. Cause not stated. Belts replaced \& cooler fans ran properly. W/850305 itr.

4/96\% LER 85-004-00: on 850208. HPCI room cooler fan tripped. Caused by grounded motor windings. HPCI declared inoperable. Tech Spec surveillances initiated Fan motor replaced. HPCI returned to svc. W/850304 itr.

1/100\% LER 85-009-00: on 850215. Train A of control room emergency vent 1 lation sys declared inoperable due to absence of flow restricting orifice. Caused by discrepancy between Tech Spec flow \& design flow. W/850315 $7 \mathrm{tr}$

1/100\% LER 85-007-00: on 850222. controlled shutdown initiated. Caused by inoperable control room emergency ventilation sys. Analysis of potential radiological consequences of operation at higher flow rates performed. Room radiological consequences
balanced. W/850325 $\mathrm{itr}$.

N/100\% LER 85-006-01: on 850222 sve water leading to HPCi room cooler discovered valved out, causing SVC water \& HPCI sys to be inoperable. Caused by

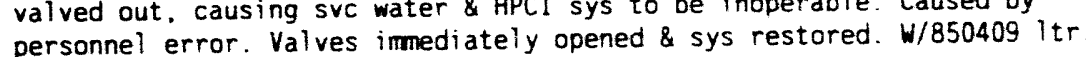

1/100\% LER 85-034-00: on 850718. trip occurred as result of power range high negative flux rate signal. Caused by inadequate cooling of rod drive power cabinet. Caution tag added to handswitch controlling room cooler. W/850815 $1 \mathrm{tr}$.

4/88\% LER 85-009-00: on 850725, broken fan belt on room cooler for RHR pumps C \& D discovered. Caused by component failure. Belt replaced \& fan housing adjustments made. W/850812 itr.

4/0\% LER 85-045-00: on 850727. reactor bidg HVAC sys tripped. Caused by erratic operation of freezestat $T 41-N 054 B$. Freezestat switch replaced $w / l i k e-f o r-1$ ike switch. W/850826 ltr. 
IABLE A.1. (contd)

\begin{tabular}{|c|c|c|c|c|c|}
\hline ISSUED & PLANT & MICROFICHE & REFERENCE & POWER & $\begin{array}{l}\text { DESCRIPTION } \\
\end{array}$ \\
\hline $08-26-85$ & Enrico Fermi 2 & $32446 / 331-335$ & LER-341/85-043 & $3 / 0 \%$ & $\begin{array}{l}\text { LER 85-043-00: on } 850724 \text {. Div } 1 \text { core spray mode inoperable due to } \\
\text { deenergization of RCIC room cooler I41-8021. Caused oy cooler room control } \\
\text { switch in off position. Cooier returned to normal. W/850826 itr. }\end{array}$ \\
\hline $09-04-85$ & Enrico Fermi 2 & $32525 / 280-284$ & LER-341/85-044 & $2 / 4 \%$ & $\begin{array}{l}\text { LER 85-044-00: on 850726. Div II control ctr HVAC supply fan shut down for } \\
\text { insp. Fan not returned to sve until } 2 \text { days after expiration of } 7 \text {-day } \\
\text { limiting condition for operation due to failure to log condition. W/850904 } \\
\text { ltr. }\end{array}$ \\
\hline $09-05-85$ & Enrico Fermi 2 & $32602 / 030-033$ & LER-341/85-048 & $3 / 0 \%$ & $\begin{array}{l}\text { LER 85-048-00: on } 850724 \text {, reactor bldg HVAC failed to start after planned } \\
\text { trip. HVAC exhaust isolation damper reopened when isolation signal reset } \\
\text { despite exhaust fan trip. Response procedure revised. } \forall / 8509051 \mathrm{tr} \text {. }\end{array}$ \\
\hline $09-23-85$ & Dresden 3 & $32809 / 201-203$ & LER-249/85-016 & $N / 95 \%$ & $\begin{array}{l}\text { LER 85-016-00: on } 850826 \text {, equipment attendant observed HPCI room cooler fan } \\
\text { breaker emitting smoke. Caused by shorted motor contactor coil. Coil \& } \\
\text { auxiliary contacts replaced \& Maint Procedure DMP } 7300-5 \text { performed. W/850923 } \\
\text { Itr. }\end{array}$ \\
\hline $10-04-85$ & Browns Ferry 1 & $32934 / 348-351$ & LER-259/85-045 & $\mathrm{N} / 0 \%$ & $\begin{array}{l}\text { LER 85-045-00: on } 850904 \text {, during performance of Technical Instruction- } 33 \text {. } \\
\text { emergency equipnent cool ing water flow verification found inadequate. } \\
\text { Possibly caused by silt accumulation, biofoul ing \& corrosion. W/851004 Itr. }\end{array}$ \\
\hline $10-08-85$ & Byron 1 & $33053 / 322-326$ & LER-454/85-089 & $1 / 47 \%$ & $\begin{array}{l}\text { LER 85-089-00: on } 850913 \text {, both trains of control room ventilation } \\
\text { inoperable. Caused by workers misreading HVAC ductwork drawings. Froject } \\
\text { const dept will review HVAC drawing conventions w/personnel responsible. } \\
\text { W/851008 itr. }\end{array}$ \\
\hline $11-14-85$ & Calvert Cliffs 2 & $33584 / 138-141$ & LER-318/85-009 & & $\begin{array}{l}\text { LER } 85-009-00 \text { : on } 851015 \text {. sve water subsystem } 21 \text { declared inoperable. Caused } \\
\text { by partial blockage of saltwater sys flow through sve water } \mathrm{HX} 21 \text {. HX } \\
\text { cleaned \& returned to svc. W/851114 } 1 \mathrm{tr} \text {. }\end{array}$ \\
\hline $11-18-85$ & Callaway 1 & $33641 / 345-349$ & LER-483/85-047 & $1 / 100 \%$ & $\begin{array}{l}\text { LER 85-047-00: on } 851018 \text {. plant continued operations w/centrifugal charging } \\
\text { pumps inoperable. violating Tech Specs. Plump B failure caused by broken room } \\
\text { cooler drive belts. Belts replaced. Pump A maint completed. W/851118 itr. }\end{array}$ \\
\hline $03-12-86$ & Sequoyah 1 & $35128 / 285-289$ & LER-327/86-002 & $5 / 0 \%$ & $\begin{array}{l}\text { LER 86-002-00: on } 860212 \text {, during calibr of control bldg HVAC sys. isolation } \\
\text { of Train B of main control room ventilation sys occurred. Caused by } \\
\text { personnel error. Overtemp switch (OTS)-311-5B calibr \& returned to sve. } \\
w / 860313 \text { ltr. }\end{array}$ \\
\hline $05-06-86$ & Quad-Cities 2 & $35989 / 290-293$ & LER-265/86-007 & $4 / 100 \%$ & $\begin{array}{l}\text { LER } 86-007-00 \text { : on } 860409 \text {. discovered that core spray rocm cooler } 28 \\
\text { inoperable. Caused by pitting \& burning of contacts on motor control ctr } \\
\text { contactor that supplies power to room cooler motor. Contactor replaced. } \\
W / 860506 \text { itr. }\end{array}$ \\
\hline $06-20-86$ & Quad-Cities 2 & $36792 / 051-058$ & LER-265/86-008 & $4 / 92 \%$ & $\begin{array}{l}\text { LER 86-008-00: on } 860525 \text {. core spray } 2 A \& 2 B \text { room coolers declared } \\
\text { inoperable due to frayed belts on core spray sys room cooler } 2-5748 \mathrm{\&} \& \\
\text { diesel generator trip. Caused by normal belt wear. Belts replaced. W/860620 } \\
\text { ltr. }\end{array}$ \\
\hline $07-02-86$ & Perry 1 & $36928 / 212-215$ & LER-440/86-021 & $5 / 0 \%$ & $\begin{array}{l}\text { LER 86-021-00: on } 860602 \text {. discovered that five recirculation damper } \\
\text { actuators in diesel generator bldg ventilation sys inoperable due to seal } \\
\text { failures. Caused by expiration of seallife \& improper storage } 8 \text { maint. Seals } \\
\text { replaced. }\end{array}$ \\
\hline
\end{tabular}


TABLE A.1. (contd)

\begin{tabular}{|c|c|c|c|c|c|}
\hline ISSUED & PLANT & MICROFICHE & REFERENCE & POWER & DESCRIPTION \\
\hline $07-18-86$ & Peach Bottom 2 & $37216 / 323-327$ & LER-277/86-014 & $N / 100 \%$ & $\begin{array}{l}\text { LER 86-014-00: on } 860618 \text {, shutdown initiated due to potential loss of } \\
\text { emergency sve water (ESW). Caused by need to repair ES pipe leak occurring } \\
\text { in inlet to RHR room cooler 2A. Pipe temporarily repaired \& ultrasonically } \\
\text { tested. W/860718 } \mathrm{itr} \text {. }\end{array}$ \\
\hline $07-16-86$ & Quad-Cities 2 & $37274 / 309-313$ & LER-265/86-009 & $4 / 92 \%$ & $\begin{array}{l}\text { LER 86-009-00: on } 860626 \text {. drive belts on core spray room cooler } 2 B \text { broke } \\
\text { remaining belt came off pulleys. Caused by normal operational wear. Beits } \\
\text { replaced. Verification of belts performed daily. W/860718 ltr. }\end{array}$ \\
\hline $08-25-86$ & Limerick 1 & $37687 / 328-332$ & LER-352/86-040 & $1 / 100 \%$ & $\begin{array}{l}\text { LER } 86-040-00 \text { : on } 860723 \text {. RUCU sys isolated twice as result of regenerative } \\
\text { HX room temp exceeding } 122 \mathrm{~F} \text { setpoint. Caused by vent ilation sys being } \\
\text { removed from sve \& failure of pressure safety relief valve. } W / 860825 \mathrm{Itr} \text {. }\end{array}$ \\
\hline $10-06-86$ & 3 Mile Island 1 & $38271 / 027-031$ & LER-289/86-012 & $1 / 100 \%$ & $\begin{array}{l}\text { LER 86-012-00: on } 860904 \text {. exhaust duct grill in Switchgear Room } 10 \text { found } \\
\text { blanked off. blocking air flow from room. Caused by personnel error. Fire } \\
\text { watches established. W/861006 } 1 \text { tr. }\end{array}$ \\
\hline $10-20-86$ & Grand Gulf 1 & $38348 / 210-214$ & LER-416/86-029 & $3 / 0 \%$ & $\begin{array}{l}\text { LER 86-029-01: on } 860826 \text {, use of incorrect instrument fiow coefficient in } \\
\text { establishing coolant flow to ESF electrical switchgear room coolers in Fall } \\
1985 \text {. discovered. Caused by fouled supply pipes. Pipes flushed. } W / 861020 \\
\text { itr. }\end{array}$ \\
\hline $10-30-86$ & Pal isades & $38464 / 224-227$ & LER-255/86-036 & N/0\% & $\begin{array}{l}\text { LER 86-036-00: on } 860930 \text {. discovered that sve water sys pumps incapable of } \\
\text { meet ing flow/head values of } 8.000 \mathrm{gpm} \text { per FSAR. Caused by installation of } \\
\text { incorrect pump impellers. Periodic testing will be implemented. } W / 861030 \\
\text { itr. }\end{array}$ \\
\hline $11-24-86$ & Susquehanna 2 & $38738 / 286-290$ & LER-388/86-016 & $2 / 1 \%$ & $\begin{array}{l}\text { LER } 86-016-00 \text { : on } 861024 \text {. DX unit valve } A^{-} \text {discovered mispositioned. Caused } \\
\text { by procedure incorrectiy stating that valve } A \text { be placed at zero position. } \\
\text { Procedure revised to reflect correct repositioning. } W / 861121 \mathrm{itr} \text {. }\end{array}$ \\
\hline $12-08-86$ & Palo Verde 1 & $38949 / 351-354$ & LER-528/86-055 & $1 / 100 \%$ & $\begin{array}{l}\text { LER 86-055-01: on } 861105 \text {, Surveillance Test } 365 \mathrm{ST}-9 \mathrm{SA02} \text { identified as } \\
\text { incomplete. per Tech Spec 4.0.2. Caused by inability to position control } \\
\text { room intake damper due to actuator malfunction. Actuator adjusted. W/861208 } \\
\text { itr. }\end{array}$ \\
\hline $12-08-86$ & Rancho Seco & $39084 / 165-169$ & LER-312/86-023 & N/O\% & $\begin{array}{l}\text { LER 86-023-00: on } 861111 \text {. inadequate voltage supplies sent to control } \\
\text { room/technical support center HVAC under certain "worst case" conditions. } \\
\text { Caused by inadequate engineering review. ECN R-0911 written. W/861208 itr. }\end{array}$ \\
\hline $01-23-87$ & Brunswick 1 & $39436 / 035-046$ & LER-325/86-033 & $1 / 96 \%$ & $\begin{array}{l}\text { LER 86-033-00: on } 861104 \text {. during developnent of PRA model. diesel generator } \\
\text { bldg ventilation design deficiency identified. Caused by failed close design } \\
\text { of supply dampers. Supply plenum damper linkages wired open. W/870123 itr. }\end{array}$ \\
\hline $02-03-87$ & Oconee 1 & $39555 / 067-073$ & LER-269/86-012 & $5 / 0 \%$ & $\begin{array}{l}\text { LER 86-012-00: on } 861015 \text {. water supply available to standby shutdown } \\
\text { facility (SSF) insufficient to enable SSF to accompli ish function. Caused by } \\
\text { failure to define design bases of SSF. Listed plant mods completed. } \mathbf{W / 8 7 0 2 0 3} \\
\text { ltr. }\end{array}$ \\
\hline $02-05-87$ & LaSalle 1 & $39650 / 254-259$ & LER-373/87-006 & $1 / 89 \%$ & $\begin{array}{l}\text { LER 87-006-00: on } 870106 \text {. Div } 11 \text { de distribution panels } 212 X \text { \&212Y became } \\
\text { inoperable but not declared inoperable. Caused by personnel error. Battery } \\
\text { test procedures will be revised \& personnel counseled. } W / 870205 \text { itr. }\end{array}$ \\
\hline $02-11-87$ & River Bend 1 & $39685 / 310-313$ & LER-458/86-018 & $1 / 34 \%$ & $\begin{array}{l}\text { LER 86-018-01: on } 860207 \text {. RCIC sys isolited on high differential temp } \\
\text { between main steam tunnel inlet } 8 \text { outlet vent lilation. Caused by conflicting } \\
\text { functions of unit cooler operation. Standing order issued. W/870211 } \mathrm{ltr} \text {. }\end{array}$ \\
\hline
\end{tabular}




\section{TABLE A.1. (contd)}

\begin{tabular}{|c|c|c|c|c|c|}
\hline ISSUED & PLANT & MICROFICHE & REFERENCE & POWER & DESCRIPTION \\
\hline $02-26-87$ & Sequoyah 1 & $39872 / 254-257$ & LER-327/87-008 & $5 / 0 \%$ & $\begin{array}{l}\text { LER 87-008-00: on } 870126 \text {. determined survelllance instruction e ERCV valves } \\
\text { servicing safety-related equipment did not ensure compliance w/Tech Spec } \\
\text { surveillance requirement. Caused by personnel error. Instruction revised. } \\
\text { w/870226 ltr. }\end{array}$ \\
\hline $04-21-87$ & Grand Gulf 1 & $40688 / 228-252$ & LER-416/86-029 & $3 / 0 \%$ & $\begin{array}{l}\text { LER 87-029-06: on } 860826 \text {. standby sve flow rates to Div } 1 \text { \& } 2 \text { ESF switchgear } \\
\text { room coolers found below design values. Caused by piping blockage due to } \\
\text { sedimentation. Hydrolazing \& flushing of piping conducted. W/870421 itr. }\end{array}$ \\
\hline $05-12-87$ & Susquat:inna 2 & $40955 / 190-193$ & LER-388/87-005 & $1 / 100 x$ & $\begin{array}{l}\text { LER 87-005-00: on 870412. RUCU sys isolation occurred due to high } \\
\text { differential temp signal from RUCU penetration room. Cause unknown. Wo } \\
\text { corrective actions planned. W/870512 itr. }\end{array}$ \\
\hline $05-29-87$ & H. B. Robinson 2 & $41239 / 037-039$ & LER-261/87-006 & N/OK & $\begin{array}{l}\text { LER 87-006-00: on } 870501 \text {. while Unit } 2 \text { in refueling shutdown. diesel } \\
\text { generator room damper failure on loss of instrument air identified. Fail } \\
\text { position of louvres \& dampers revised. W/870529 itr. }\end{array}$ \\
\hline $05-19-87$ & Quad-Cities 2 & $41267 / 101-105$ & LER-265/87-009 & $1 / 100 \%$ & $\begin{array}{l}\text { LER 87-009-01: on } 860626 \text {, core spray room cooler } 28 \text { fcund w/ broken fan } \\
\text { belt. Caused by variable-pitch sheave on motor shaft causing accelerated } \\
\text { wear. Fixed pitch sheave installed \& tested by } 870120 \text {. W/870519 } \mathrm{ltr} \text {. }\end{array}$ \\
\hline $06-09-87$ & J. M. Farley 1 & $41298 / 103-106$ & LER-348/87-009 & $1 / 100 \%$ & $\begin{array}{l}\text { LER 87-009-00: on } 870510 \text {, during performance of sve water (SW) flowpath } \\
\text { verification. RHR pump } 1 B \text { room cooler SW isolation valves found closed. } \\
\text { Caused by personnel not ensuring that valves repositioned. Personnel } \\
\text { counseled. } W / 8706091 \mathrm{tr} \text {. }\end{array}$ \\
\hline $06-08-87$ & Clinton 1 & $41334 / 317-320$ & LER-461/87-027 & $2 / 1 x$ & $\begin{array}{l}\text { LER 87-027-00: on } 870513 \text {. automatic isolation of RUCS on } H X \text { room high temp } \\
\text { isolation signal occurred. Caused by flow control valve malfunction. Caution } \\
\text { tag placed on valve. } W / 870608 \mathrm{itr} \text {. }\end{array}$ \\
\hline $06-12-87$ & Palo Verde 2 & $41427 / 209-212$ & LER-529/86-044 & $3 / 0 x$ & $\begin{array}{l}\text { LER 86-044-00: on } 870515 \text {. discovered that both independent trains of control } \\
\text { room essential filtration sys inoperable on } 870423-25 \text { due to maint on one } \\
\text { train. Caused by design flaw. Isolation dampers will be installed. } \mathbf{W} 870612 \\
\text { itr. }\end{array}$ \\
\hline $06-19-87$ & Turkey Point 3 & $41474 / 026-030$ & LER-250/87-015 & $6 / 0 \%$ & $\begin{array}{l}\text { LER 87-015-00: on } 870522 \text {. design basis reconstitution, revealed potential } \\
\text { loss of HWAC in inverter \& battery rooms. Caused by mods to original plant } \\
\text { design. Maint \& insp procedures implemented for air conditioning units. } \\
\text { W/870619 ltr. }\end{array}$ \\
\hline $06-26-87$ & Dresden 2 & $41634 / 179-183$ & LER-237/87-018 & $N / 88 \%$ & $\begin{array}{l}\text { LER } 87-018-00 \text { : on } 870606 \text {. W/unit at } 88 \text {. } 7 \% \text { rated thermal power. HPCI sys } \\
\text { room cooler found inoperative. Caused by broken drive belts resulting from } \\
\text { wear \& age. Work Request } 065782 \text { initiated to replace room cooler belts. } \\
W / 870626 \mathrm{itr} \text {. }\end{array}$ \\
\hline $07-17-87$ & Clinton 1 & $41828 / 247-250$ & LER-461/87-031 & $1 / 20 \%$ & $\begin{array}{l}\text { LER } 87-031-00 \text { : on } 870617 \text {. RUCU sys pumps tripped \& in-board containaent } \\
\text { isolation vaives shut. On } 870705 \text {. spurious signal received isolating RMCU } \\
\text { sys. Caused by failed differential temp point module. Hodule replaced. } \\
\text { W/870717 itr. }\end{array}$ \\
\hline $07-23-87$ & Braidwood 1 & $42022 / 294-297$ & LER-456/87-033 & $3 / 0 \%$ & $\begin{array}{l}\text { LER 87-033-00: on } 870702 \text {. control room ventilation return \& makeup fans } \\
\text { tripped during monthly surveillarice test. Caused by inadvertent power } \\
\text { shutoff to dampers by nonlicensed personnel. Fans restarted. W/870723 itr. }\end{array}$ \\
\hline
\end{tabular}


TABLE A.1. (contd)

\begin{tabular}{cccccc}
\hline ISSUED & PLANT & MICROFICHE & REFERENCE & POUER & DESCRIPTION \\
\hline 08-21-87 & Alvin Vogtle 1 & $42376 / 174-179$ & LER-424/87-049 & $1 / 100 \%$ & LER 87-049-00: on 870722. Tech Spec Limiting rondition for Operation 3. O. 3 \\
& & & & $\begin{array}{c}\text { entered because temp switch failed on Train B ESF chiller wile train A ESF } \\
\text { room cooler unit out of sve for preventive maint. Temp switch replaced. }\end{array}$
\end{tabular}
room cooler unit out of svc for preventive maint. Tenp switch replaced. $\psi / 870821 \mathrm{itr}$.

08-25-87 Edwin Hatch 2 42400/081-089 LER-366/87-006

08-27-87 Sequoyah

10-02-87 Susquehanna 2

42952/2E2-265

LER-388/87-009

$10-02-87$

J. M. Farley 2

$43001 / 177-180$

LER-364/87-002

$11-02-87$

$12-10-87$

Sequoyah 1

$12-21-87$

South Texas 1

43886/016-022

LER-498/87-015

12-22-87 Callaway 1

43920/041-051

LER-483/87-013

12-24-87 Hope Creek 1

43961/058-062

LER-354/87-048

$12-28-87$

Susquehanna 1

$43960 / 151-154$

LER-387/87-034

$02-29-88$
River Bend 1
44612/339-343 LER-458/87-028
1/89\% LER 87-006-00: on 870726. reactor scram occurred due to loss of power. Caused by equipnent failure due to inadequate HVAC design. Inverter refurbished \& returned to sve. W/870825 $\mathrm{itr}$

5/0\% LER 87-037-00: on 870728. capacity of ESF safety features equipment coolers determined inadequate for LOCA conditions. Caused by calculation errors due to use of wrong heat load data. Surveillance procedure will be revised. to use of wrong

1/100\% LER 87-009-00: on 870902. Div II RHCU isolation occurred. Caused by tenp element location \& design temp setpoint selection for RUCU differential temp trip. Evaluation of temp leak detection requirements will be made. $W / 871002$ Itr

100\% LER 87-002-00: on 870903, determined that Train A \& B svc wastebattery changer roon coolers water supplies crossed. Caused by design error. Design change will be implemented \& complete during refueling outage in Oct 1987. $W / 871002 \mathrm{itr}$.

6/0\% LER 87-023-00: on 871001, control roon ventilation/chillied water Trains A \& B chillers declared inoperable. Train A trip caused by blown fuse. Train 8 trip caused by failure of actuator microswitch. Fuse replaced. W/871102 itr..

5/0\% LER 87-072-00: on 871110. ESF equipment room coolers inadequate to maintain temps within environ qualification profiles. Caused by inadequate design control program. Duct work to be revised \& filtration sys installed. W/871210 itr.

4/0\% LER 87-015-00: on 871121. cooldown initiated due to inoperability of essential chiller units $11 C \& 12 \mathrm{~A}$. Caused by inadequate protection of equipment controls. Caution tags posted \& operator logs revised. W/871221 itr.

1/100\% LER 87-013-02: on 870608. control room emergency ventilation sys inoperabie due to pressure boundary breach Caused by personnel error. Mispositioned due to pressure boundary penetrations sealed \& personrel counseled. W/871222 damper $1 \mathrm{tr}$

1/100\% LER 87-048-00: on 871125 trip of safety aux 17 lary c00ling sys(SACS) pumps $B$ $\& D \&$ automatic start of pump A occurred. Caused by lack of precautions in SACS venting procedure. Procedure for venting room coolers revised. W/871224 Itr.

1/80\% LER 87-034-00: on 871129. HPCI inboard steam isolation valve inadvertently closed. Caused by personnel error. HPCI isolation reset \& vaive reopened. States links will be installed inside cabinet. W/871228 itr

N/0\% LER 87-028-01: on 871106. RHR pump A tripped Caused by high differential temp from RHR pump A room leak detection sys due to natural convective air flow through unit cooler. Cooler \& RHR loop A returned to sve. W/880229 itr. 


\section{IABLE A.1. (contd)}

\begin{tabular}{|c|c|c|c|c|c|}
\hline ISSUED & PLANT & MICROFICHE & REFERENCE & PONER & DESCRIPTION \\
\hline $03-09-88$ & WPPSS 2 & $44716 / 207-212$ & LER-397/88-005 & $1 / 72 x$ & $\begin{array}{l}\text { LER 88-005-00: on 880208, control room emergency filtration sys. Train } 8 . \text {. } \\
\text { bypass flow was greater than } 0 \text {. 05x allowed by Tech Specs. Cause unknown. } \\
\text { Flow restrictor installed to restore proper balanced condition to sys. } \\
\text { w/880309 ltr. }\end{array}$ \\
\hline
\end{tabular}

03-17-88 Sequoyah $1 \quad 44787 / 135-143 \quad$ LER-327/87-001

4/0\% LER 87-001-01: on 870106. trip setpoints for cont inuous overcurrent incorrect for feeder breakers supplying power to three control \& auxiliary bldg ventilation boards. Caused by inadequate design calculations. $W / 880317$ itr.

03-10-88 Quad-Cities 2 44961/079-083 LER-265/88-002

4/97\% LER 88-002-00: on 880223. HPCI inoperable due to room cooler loss from short circuit of control relay. Caused by short circuit in control relay causing transformer to overheat \& short. Control relay \& transformer replaced. W/880310 itr.

$45046 / 142-152-1 E R-325 / 88-008$

1/100\% LER 88-008-01: on 880302, determined that generic failure mechanism existed for supply fans of comonon diesel generator bldg ventilation sys. Caused by cracks due to frequent stop \&start. A B rotors replaced. $\mathbf{W} 880331$ itr.

04-08-88 Perry i 45184/033-036 LER-440/88-010

1/100\% LER 88-010-00: on 880310 \& 11. RUCU containment isolations occurred due to pump room high differential temp. Caused by inadequate instructions. Roughing filters in WNAC sys $A B$ replaced. $W / 880408$ Itr.

05-12-88 Rancho Seco 45624/263-268 LER-312/88-006

N/25\% LER 88-006-00: on 880414, potential deviation from quality initiated to rept spurious actuations of control room technical support ctr essential HVAC sys. Caused by high temp indications. Temp switch changed. W/880512 $1 \mathrm{tr}$.

?

LER 87-049-01: on 870806. thermal overload protection devices incorrectly sized. Caused by nonconservative assumptions in design calculations 8 lack of coordination between design maint. Calculations revised. W/880524 itr.

06-03-88 Perry

45800/182-184 LER-440/88-016

$1 / 100 \%$

LER 88-016-00: on 880504. unexpected RUCU contaiment isolation occurred due to pump room high differential temp. Caused by personnel error. Caution added to repetitive task for cal ibr of time delay for fan A trip relay.

06-14-88 Braidwood $2 \quad 46109 / 226-229 \quad$ LER-457/88-009

07-15-88 South Texas 1 46327/106-111 iER-498/88-039

LER 38-009-00: on 880530, manual reactor trip due to inoperable rod control sys. Caused by failure of miscellaneous electric room (MER) ventilation fan. Temporary cooling fans installed in MER. $H / 8806231 \mathrm{tr}$.

1/25\% LER 88-039-00: on 880616. Tech Spec 3. 0. 3 entered on two occasions when min number of operable essential chillers not met. Cause of pimp seal failure under investigation. Load ctr feederbreaker trip caused by personnel error. W/880715 itr.

09-09-88 Quad-Cities $1 \quad 46992 / 353-359 \quad$ LER-254/88-013

4/60\% LER 88-013-00: on 880822. discovered core spray room cooler inoperable due to broken fan belts. Caused by insufficient preventive maint. belts replaced $\&$ procedure revised to require belt replacenent during refuel outages. W/880909 itr.

09-29-88 Palo Verde $1 \quad 47111 / 345-357 \quad$ LER-528/88-017

1/100\% LER 88-017-01: on 880529. Trains A \& B essential chillers discovered inoperable due to shut root isolation valves for transmitter. Caused by personnel errors while affixing warning labels near vaives. w/880929 $\mathrm{itr}$. 
IABLE A.1. (contd)

\begin{tabular}{cccccc}
\hline ISSUED & PLANT & MICROFICHE & REFERENCE & POWER & DESCRIPTION \\
\hline 10-05-88 & Brunswick 2 & $47173 / 054-059$ & LER-324/88-016 & $1 / 100 \%$ & LER $88-016-00:$ on 880908 . Div 2 sVC water vital header leak resulted in \\
manual isolation of associated header. Caused by excessive corrosion of
\end{tabular}
manual isolation of associated header. Caused by excessive corrosion returned to sve. W/881005 itr.

11-25-88 Perry 1

47667/202-204 LER-440/88-043

12-01-88 Oconee 1

$47783 / 234-240 \quad$ LER-269/88-008

12-15-88 Catamba

47925/351-357

LER-413/88-025

01-26-89 Grand Gulf 1

48359/346-010

LER-416/86-029

02-06-89

South Texas 2

48484/014-018

LER-499/89-001

$\stackrel{D}{\square}$

$02-08-89$

South Texas 2

$48520 / 336-340$

LER-499/89-002

$02-17-89$

Alvin Vogtle 1

$48633 / 109-113$

LER-424/89-003

03-14-89

South Texas 1

$48982 / 064-068$

LER-498/89-008

03-20-89

Cooper

49080/359-001

LER-298/89-006

$03-20-89$

Cooper

49081/002-005

LER-298/89-007

$03-20-89$

Cooper

49081/012-015 LER-298/89-010
$4 / 0$

LER 88-043-00: on 881030. HPCS pump room cooler inadvertently started duri performance of breaker retest. Caused by procedural deficiency. Retest guidelines will be added to generic electrical instructions for maint. W/881125 $\mathrm{itr}$.

N/100\% LER 88-008-00: on 880301. testing of standby shutdown facility HVAC sve water sys revealed max sys flow capacity below design value for worst case water sys revealed max sys flow capacity below design value for wo positively confirmed. $\mathrm{W} / 881201 \mathrm{tr}$.

196\% LER 88-025-00: on 881113, one auxiliary bldg ventilation sys train inoperable for greater than 7-day period, contrary to Tech Spec 3. 7. 7. Caused by personnel errors \& design deficiency. W/881215 itr.

3/0\% LER 86-029-10: on 860826. discovered that incorrect instrument flow coefficient used in establishing coolant flow to ESF. Caused by accumulation of matls in varying degrees from sve water. Flow improved to coolers by

5/0\% LER 89-001-00: on 890106. partial loss of offsite power occurred on Trains $B$ \& C due to fire protection sys actuation. Caused by inadvertent actuation of transformer deluge sys. Procedure developed. $\mathbf{H} / 890206 \mathrm{ltr}$.

5/0\% LER 89-002-00: on 890107. train C did not function properly during performance of surveillance test to verify operability of control room envelope HVAC sys. Caused by inadequate test procedure. Bullet in issued. W/890208 itr.

3/0\% LER 89-003-00: on 890119. ESF Train B chiller removed from sve for calibr. resulting in entering Limiting Condition for Operation 1-89-032. Caused by personnel calibr wrong train. Train B restored to operable status. W/890217 personn.

5/0\% LER 89-008-00: on 890212. discovered that inverter IV-1203 which supplies uninterruptible power to distribution panel DP-123 overheating. causing uninterruption of control room \& fuel handling bldgs HVAC sys. Transformer actuation of control rocm
replaced. $H / 890314 \mathrm{itr}$.

N/100\% LER 89-006-00. control bldg HVAC design concerns identified during MRC insp on 870511-0619. Caused by inadequate design. Steps to install permanent essential equipment that will provide acceptable room temps being pursued.

N/100\% LER 89-007-00: on 890217 sve water sys flowrate concerns associated w/ original sys design identified during MRC insp on 870511-0619. Caused by inadequate design. Reduction of diesel generator room temps being pursued.

N/100\% LER 89-010-00: diesel generator room ambient temp control inadequacies identified during NRC insp on 870511-0619. Caused by error in original plant design. Design Change 87-132 provided permanent mod to el iminate deficiency. 
IABLE A.1. (contd)

\begin{tabular}{|c|c|c|c|c|c|}
\hline ISSUED & PLANT & MICROFICHE & REFERENCE & POWER & DESCRIPTION \\
\hline $05-24-89$ & Edwin Hatch 1 & $49987 / 339-347$ & LER-321/87-011 & $1 / 100 \%$ & $\begin{array}{l}\text { LER } 87-011-01: \text { on } 870723 \text {. reactor water level decreased to reactor } \\
\text { protection sys actuation setpoint reactor scram occurred. Caused by } \\
\text { equipment failure due to inadequate ventilation design. Inverter } \\
\text { refurbished. W/890524 itr. }\end{array}$ \\
\hline $05-24-89$ & Edwin Hatch 2 & $49982 / 017-025$ & LER-366/87-006 & $1 / 89 \%$ & $\begin{array}{l}\text { LER 89-006-00: on } 870726 \text {. inadequate design for inverter cooling caused } \\
\text { power failure resulting in reactor scram. Caused by equipment fallure due to } \\
\text { inadequate HVAC design. Inverter refurbished. W/890524 itr. }\end{array}$ \\
\hline $06-21-89$ & Browns Ferry 2 & $50366 / 051-055$ & LER-260/89-015 & N/Ox & $\begin{array}{l}\text { LER 89-015-00: on } 890523 \text {. discovered no air flow in RHR } 2 C \text { pump room cooler } \\
\text { fan duct. Caused by personnel error. Proper fan rotation established } 8 \\
\text { verified. Min qualification for personnel performing const test initiated. } \\
\text { w/890621 itr. }\end{array}$ \\
\hline $07-09-89$ & Zion 1 & $50544 / 165-167$ & LER-295/89-008 & $1 / 99 \%$ & $\begin{array}{l}\text { LER } 89-008-00 \text { : on } 890609 \text {. identified that potential problem exists re sve } \\
\text { water sys ability to supply both room coolers w/current piping } \\
\text { configuration. Caused by design deficiency. Safety significance for subj } \\
\text { room cooler being evaluated. }\end{array}$ \\
\hline $08-31-89$ & Alvin Vogtle 2 & $51150 / 193-199$ & LER-425/89-025 & $1 / 100 \%$ & $\begin{array}{l}\text { LER 89-025-00: on 890801. entry into limiting condition for operation } 3.0 \text {. } \\
3 \text { occurred when ESF room cooler tripped on themal overload. Cause not } \\
\text { determined. Thermal overload trip setpoints for ESF room coolers increased. } \\
\text { W/890831 itr. }\end{array}$ \\
\hline $09-22-89$ & Dresden 2 & $51342 / 131-135$ & LER-237/89-022 & $N / 93 \%$ & $\begin{array}{l}\text { LER 89-022-00: on 890827. discovered that HPC! room cooler drive belts } \\
\text { broker: \& HPCI sys declared inoperable. Caused by increased frequency of room } \\
\text { cooler operation due to recent elevated ambient room temps. Belts replaced. } \\
W / 890922 \mathrm{ltr} \text {. }\end{array}$ \\
\hline $10-18-89$ & Palisades & $51607 / 347-351$ & LER-255/89-021 & $N / 80 \%$ & $\begin{array}{l}\text { LER 89-021-00: on } 890918 \text {, identii ed possibility for single relay failure } \\
\text { leaving control room HVAC train in normal mode when energency mode would be } \\
\text { desired. Switchover circuitry not designed to meet single failure criteria. } \\
W / 891018 \mathrm{itr} \text {. }\end{array}$ \\
\hline $11-20-89$ & Dresden 3 & $51872 / 185-188$ & LER-249/89-004 & $N / 93 \%$ & $\begin{array}{l}\text { LER } 89-004-00 \text { : on } 891022 \text {. determined that HPCI sys room cooler drive belts } \\
\text { had failed rendering sys inoperable in accordance w/station policy. Caused } \\
\text { by component failure of drive belts. Drive belts replaced. W/891120 itr. }\end{array}$ \\
\hline $12-28-89$ & WPPSS 2 & $52202 / 063-068$ & LER-397/89-044 & $1 / 100 \%$ & $\begin{array}{l}\text { LER 89-044-00: on } 891128 \text {. discovered six incorrectly sized thermal overload } \\
\text { heaters that could have prevented HPCS from performing safety function. } \\
\text { Caused by inadequate design. Procedures revised. W/891228 } 1 \text { tr. }\end{array}$ \\
\hline $01-08-90$ & Virgil Sumer 1 & $52336 / 020-027$ & LER-395/88-008 & $3 / 0 \%$ & $\begin{array}{l}\text { LER 88-008-01: on 880607. AE (Gilbert Assoc) notified util of desion defect } \\
\text { yielding potential for steam propagation path which could affect safe } \\
\text { shutdown equipment. Caused by design error. Also reportable per Part } 21 \text {. } \\
\text { W/900108 itr. }\end{array}$ \\
\hline $01-17-90$ & Clinton 1 & $52424 / 270-275$ & LER-461/89-041 & $1 / 61 \%$ & $\begin{array}{l}\text { LER 89-041-00: on } 891122 \text {, unit entered Tech Spec } 3.0 .3 \text { when RCIC \& HPCS } \\
\text { sys inoperable simultaneously for } 37 \text { minutes. Chiller condensing unit } \\
\text { tripped due to low refrigerant pressure. Refrigerant in chiller recharged. } \\
\text { W/900117 itr. }\end{array}$ \\
\hline $01-19-90$ & Perry 1 & $52425 / 036-040$ & LER-440/89-032 & $1 / 100 \%$ & $\begin{array}{l}\text { LER 89-032-00: on } 891228 \& 900105 \text {. HPCS sys declared inoperable due to } \\
\text { inoperability of Div } 3 \text { battery. Caused by low pilct cell voltage. cell } \\
\text { w/slow electrolyte leak \& blown power fuse. Fuse \& hydronotor pump replaced. } \\
W / 900119 \mathrm{ltr} \text {. }\end{array}$ \\
\hline
\end{tabular}


TABLE A.1. (contd)

\begin{tabular}{|c|c|c|c|c|c|}
\hline ISSUED & PLANT & MICROFICHE & REFERENCE & POWER & DESCRIPTION \\
\hline $02-02-90$ & Perry 1 & $52598 / 100-103$ & LER-440/90-002 & $1 / 100 \%$ & $\begin{array}{l}\text { LER } 90-002-00: \text { on } 900107 \text {. RCIC sys isolated due to high differential temp } \\
\text { signal detected across RCIC room cooler following reactor scram due to loss } \\
\text { of feedwater flow. Caused by design deficiency. Procedures re flow rate } \\
\text { revised. }\end{array}$ \\
\hline
\end{tabular}

12-18-89 Waterford $3 \quad 52829 / 227-230 \quad$ LER-382/89-021

3/0\% LER 89-021-00: on 891116, emergency diesel generator A declared inoperable when essential svcs chiller A declared inoperable w/o verifying availability of offsite ac power. Caused by personnel error. Supervisor counseled. W/891218 $1 \mathrm{tr}$.

03-30-90 9 Mile Point 1 53338/050-056 LER-220/90-002

N/0\% LER 90-002-00: on 900228, design deficiency discovered in reactor bldg closed loop cooling water sys. Caused by inadequate evaluation for single failure when original sys design reviewed against GDC-44. W/900330 $1 \mathrm{tr}$.

04-05-90 Clinton $1 \quad 53405 / 078-092 \quad$ LER-461/90-002

1/100\% LER 90-002-00: on 900124, inappropriate acceptance criteria used in pre-operational test of shutdown svc water sys. Cause under investigation. Flow condition of components measured. W/900405 $1 \mathrm{tr}$.

04-20-90 J. M. Farley 1 53589/127-135 LER-348/89-004

1/100\% LER 89-004-01: on 890616, determined that calculations unavailable to demonstrate that sve water sys capable of maintaining design flow to safety-related loads. Documentation found teficient. W/900420 $1 \mathrm{tr}$.

04-19-90 Peach Bottom 2 53625/077-081 LER-277/90-004

N/0\% LER 90-004-00: on 900321, discovered potentially inoperable safety sys due to inadequate emergency svc water cooling flow through room coolers. Caused by gradual buildup of corrosion \& silt. Mod completed. W/900419 $1 \mathrm{tr}$.

LER 90-012-00: on 900411, during routine review of emergency diesel generator loading sequence, design engineering group identified that manual actions necessary to start fans. Caused by error in plant design. Design changed. W/900511 $1 \mathrm{tr}$.

LER 90-010-00: on 900427, discovered that annulus ventilation control room ventilation sys headers would not operate, as designed, under postulated operating conditions. Caused by design deficiency. Change submitted. W/900613 itr.

06-15-90 Wolf Creek

$06-28-90$

Dresden 3

$54580 / 015-018$

LER-249/

08-06-90

Palisades

$54904 / 253-256$

LER-255/90-012

$08-03-90$

$54905 / 006-010 \quad$ LER-416/90-010
$1 / 30 \%$

-00: on 900516, discovered that insp access door for motor driven auxiliary feedwater pump $B$ room cooler had been removed. Caused by personnel error. Maint personnel informed of necessity of doors being in place. W/900615 $1 \mathrm{tr}$.

N/93\% Forwards LER 89-004-01 correcting error identified by Corporate Nuclear Safety Review Group. Rev clarifies that lubrication of HPCI room cooler bearings currently quarterly surveillance activity \& updates corrective actions.

N/80\% LER 90-012-00: on 900705, sve water to control room HVAC found to be inadequate to support control room HVAC design temp due to incorrect heat load assumption. Caused by personnel error. Svc water flow rates rebalanced. W/900806 $1 \mathrm{tr}$.

1/100\% LER 90-010-00: on 900706, error discovered in evaluation used to demonstrate adequacy of sve water flow to HPCS pump room cooler. Matls nonconformance rept generated to document discrepancy. W/900803 itr. 
IABLE A.1. (contd)

\begin{tabular}{|c|c|c|c|c|c|}
\hline ISSUED & PLANT & MICROFICHE & REFERENCE & POWER & DESCRIPTION \\
\hline $08-06-90$ & Limerick 1 & $54952 / 354-358$ & LER-352/90-014 & $1 / 90 \%$ & $\begin{array}{l}\text { LER 90-014-00: on } 900705 \text {, group III primary containment \& reactor vessel } \\
\text { isolation control sys isolation signal occurred, initiating RWCU sys } \\
\text { isolation. Causes included high outside air temp. Normal ventilation } \\
\text { restored. W/900806 itr. }\end{array}$ \\
\hline $08-24-90$ & Trojan & $55073 / 217-224$ & LER-344/90-012 & $5 / 0 \%$ & $\begin{array}{l}\text { LER 90-012-01: on } 900409 \text {, identified that manual actions necessary to start } \\
\text { fans that provide cooling air flow in ESFs electrical switchgear rooms. } \\
\text { Caused by design error. Condition reportable per Part } 21 \text {. W/900824 } 1 \text { tr. }\end{array}$ \\
\hline $08-29-90$ & Trojan & $55136 / 265-273$ & LER-344/90-018 & $5 / 0 \%$ & $\begin{array}{l}\text { LER } 90-018-01 \text { : on } 900529 \text {, discovered that up to } 13 \% \text { of equipment spray pump } \\
\text { room cooler tubes blocked by river silt \& clam shell fragments. Caused by } \\
\text { lack of cooler insp \& cleaning program. Coolers inspected. W/900829 } 1 \mathrm{tr} \text {. }\end{array}$ \\
\hline $10-15-90$ & Peach Bottom 2 & $55605 / 187-192$ & LER-277/90-026 & N/82\% & $\begin{array}{l}\text { LER 90-026-00: on } 900913 \text {. HPCI sys declared inoperable due to low emergency } \\
\text { svc water flow through room coolers. W/901015 } \mathrm{tr} \text {. }\end{array}$ \\
\hline $11-20-90$ & H. B. Robinson 2 & $55969 / 338-346$ & LER-261/90-013 & $\mathrm{N} / 0 \%$ & $\begin{array}{l}\text { LER 90-013-00: on 900911, freon leak resulted in emergency action level } \\
\text { classification alert. W/901120 } 1 \text { tr. }\end{array}$ \\
\hline $11-20-90$ & Catawba 1 & $55996 / 278-285$ & LER-413/90-030 & $1 / 100 \%$ & $\begin{array}{l}\text { LER } 90-030-00 \text { : on } 901023 \text {. TS } 3.0 .3 \text { entered due to two inoperable trains of } \\
\text { control room area ventilation sys. W/ } 901120 \mathrm{ltr} \text {. }\end{array}$ \\
\hline $12-17-90$ & JA FitzPatrick & $56245 / 216-224$ & LER-333/90-035 & $N / 100 \%$ & $\begin{array}{l}\text { LER 90-025-00: on } 901115, \text { three } 3 \text {-inch swing check valves failed to close } \\
\text { during testing due to corrosion \& silt accumulation in hinge pin mechanism. } \\
\text { Valve internals replaced w/stainless steel components. W/901217 ltr. }\end{array}$ \\
\hline $01-18-91$ & Salem 2 & $56540 / 169-174$ & LER-311/90-042 & $1 / 100 \%$ & $\begin{array}{l}\text { LER 90-042-00: on } 901220 \text {. SWS through wall leak on inlet pipe to component } \\
\text { cooling pump room cooler occurred. Caused by equipment failure } \& \text { internal } \\
\text { corrosion. Carbon steel pipe will be painted for protection. W/910118 itr. }\end{array}$ \\
\hline $02-20-91$ & Salem 1 & $55897 / 308-313$ & LER-272/91-002 & $1 / 100 \%$ & $\begin{array}{l}\text { LER 91-002-00: on } 910117 \text {, RHR pump } 11 \text { room cooler leakage noted on metal } \\
\text { weld of inlet control valve. On } 910124 \text {. Teakage noted on SI pump room cooler } \\
\& \text { auxiliary feedwater pump cooler. Caused by equipment failure. W/910220 } \\
\text { itr. }\end{array}$ \\
\hline $02-28-91$ & Waterford 3 & $56897 / 263-274$ & LER-382/90-019 & $1 / 100 \%$ & $\begin{array}{l}\text { LER 90-019-01: on } 901212 \text {, both trains of control room heating ventilation \& } \\
\text { air conditioning sys inoperable due to breach in control room envelope. } \\
\text { Caused by air flow past retaining angle. Leakage paths repaired. W/910228 } \\
\text { litr. }\end{array}$ \\
\hline 03-08-91 & Wolf Creek & 56989/005-011 & LER-482/91-004 & $1 / 100 \%$ & $\begin{array}{l}\text { LER 91-004-00: on } 910206 \text {, EDG bldg ventilation sys caused EDGs } A \text { or } B \text { to be } \\
\text { inoperable. Caused by personnel error. Administrative guidance revised. } \\
\text { W/910308 itr. }\end{array}$ \\
\hline $03-15-91$ & W. B. McGuire 1 & $57126 / 229-237$ & LER-369/91-002 & $1 / 100 \%$ & $\begin{array}{l}\text { LER 91-002-00: on } 910213 \text {, trains A \& B of control area ventilation sys } \\
\text { inoperable due to unknown causes. OPS personnel Tech Spec } 3.0 .3 \text { on both } \\
\text { units on } 910213 \text { \& PERF personnel exited flow balance test. W/910315 itr. }\end{array}$ \\
\hline $04-10-91$ & Salem 2 & 57485/093-098 & LER-311/91-003 & $1 / 100 \%$ & $\begin{array}{l}\text { LER 91-003-01: on } 910225 \text {. ASME Code } 3 \text { piping leakage occurred. Caused by } \\
\text { equipment failure. Repair of affected components completed in accordance } \\
\text { w/ASME Code \& addl insp being reviewed \& modified. W/910410 itr. }\end{array}$ \\
\hline $04-29-91$ & Virgil Surmer 1 & $57687 / 267-271$ & LER-395/90-009 & $1 / 100$ & $\begin{array}{l}\text { LER 90-009-01: on 901026, design defect noted in chilled watersys. Caused by } \\
\text { inadequate sys design. Nonessential header isolation valves closed \& } \\
\text { permanent mods in progress. Also reported per Part } 21 \text {. W/910429 } 1 \mathrm{tr} \text {. }\end{array}$ \\
\hline
\end{tabular}


TABLE A.1. (contd)

\begin{tabular}{rcccc}
\hline ISSUED & PLANT & MICROFICHE & REFERENCE & POWER \\
\hline $06-20-91$ & Peach Bottom 2 & $58226 / 176-180$ & LER-277/91-017 & N/0\%
\end{tabular}

LER 91-017-00: on 910521, discovered HPCI sys unknowingly rendered inoperable during performance of surveillance test. Caused by procedural inadequacy, inadequate design review \& subsequent sys reviews. Mod initiated. W/910620 $\mathrm{ltr}$.

07-15-91 Calvert Cliffs 2 58500/194-198 LER-318/91-006

07-18-91 Callaway 1

$58628 / 038-044$

LER-483/91-002

09-19-91 Wolf Creek

59212/037-041 LER-482/91-013

09-23-91 Palo Verde 1

59292/210-217 LER-528/91-007

09-23-91 Peach Bottom 3

$59263 / 290-293$

LER-278/91-013

in

10-07-91 Wolf Creek

10-08-91

Peach Bottom 3

$59407 / 120-123$

LER-278/91-015

$10-08-91$

South Texas 1

$59441 / 129-136$

LER-498/91-007

$10-28-91$

Indian Point 2

$59652 / 067-071$

LER-247/91-020

11-07-91 Catawba 1

59801/245-256 LER-413/91-024

11-11-91 Wolf Creek

$59801 / 145-150 \quad$ LER-482/87-061
1/100\% LER 91-006-00: on 910615. loss of control room emergency ventilation occurred causing plant shutdown. Caused by lack of adequate procedural guidance. Establishing-task force to identify problems. W/910715 $\mathrm{ltr}$.

1/100\% LER 91-002-00: on 910619, tech spec violation occurred re blown fuse for ultimate heat sink cooling tower fan causing inoperability of both trains of safety injection pumps. Fuses replaced. W/910718 $\mathrm{ltr}$.

1/86\% LER 91-013-00: on 910821, inoperability of certain safety related equipment occurred due to potential of fault in non-safety related circuit propagating. Cause unknown. Addl insp of conduit \& cable performed. W/910919 propaga.

1/100\% LER 91-007-00: on 910822, evaluation determined that normal HVAC sys cooling to various ESF pump roms inadial cooling loads. Cause by inconsistency in design. Administrative guidance issued. W/910923 itr.

N/96\% LER 91-013-00: on 910825. high pressure coolant injection sys discovered in inmediately reset thermal overloads. W/910923 $1 \mathrm{tr}$.

1/86\% LER 91-015-00: on $910907 \& 09$, discovered that dirty. temporary filter in place on intake to RHR pump room \& air flow for room coolers could not be obtained. Caused by procedural inadequacy. Workers counseled. W/911007 $1 \mathrm{tr}$

N/89\% LER 91-015-60: on 910908, core spray pump found to be inoperable. Caused by room cooler not being available due to personnel error. No actual safety consequences occurred. Room cooler switch placed in manual position. W/911008 Itr.

5/0\% LER 91-007-01: on 910309. switchyard breaker experienced phase-to-ground flashover, resulting in loss of offsite power to ESF buses. Caused by dislodged connecting pin in linkage mechanism. Modified pin installed. W/911008 $1 \mathrm{tr}$.

N/99\% LER 91-020-00: on 910927, determined that 480-volt switchgear room temp could exceed max temp recommended by safeguards equipment switchgear mfgs. Caused by erroneous room design. Power supplies will be separated. W/911028 Caused

1/100\% LER 91-024-00: on 911009, TS 3. 0. 3 entered when both trains of control room area ventilation \& chilled water sys declared inoperable. Caused by room area ventilations $\&$ problems wactuator. Actuator to be replaced. W/911107 itr.

1/100\% LER 87-061-00: on 870312, motor to emergency diesel generator ventilation supplan inoperable. On 880717 \& 900428, air damper clamped in nonsafeguards position. Caused by personnel error. 
IABLE A.1. (contd)

\begin{tabular}{|c|c|c|c|c|c|}
\hline ISSUED & PLANT & MICROFICHE & REFERENCE & POWER & DESCRIPTION \\
\hline $11-11-91$ & Wolf Creek & $59801 / 151-156$ & LER-482/91-004 & $1 / 100 \%$ & $\begin{array}{l}\text { LER 91-004-01: on } 870312 \text {, motor to emergency diesel generator supply fan } \\
\text { removed, rendering fan inoperable. On } 880717 \text { \& } 900428 \text {. recirculation air } \\
\text { damper clamped in nonsafeguards position. Caused by personnel error. } \\
\text { Guidance revised. }\end{array}$ \\
\hline $12-04-91$ & Quad-Cities 1 & $59983 / 192-196$ & LER-254/91-022 & $4 / 100 \%$ & $\begin{array}{l}\text { LER 91-022-00: on } 911104 \text {, " } B \text { " Train CR HVAC emergency filtration unit failed } \\
\text { to attain proper differential temp due to unknown cause. Train declared } \\
\text { inoperable. Supplemental rept will be submitted. W/911202 ?tr. }\end{array}$ \\
\hline $12-12-91$ & Catawba 1 & $60097 / 162-170$ & LER-413/91-020 & $1 / 98 \%$ & $\begin{array}{l}\text { LER } 91-020-00 \text { : on } 910915 \text {, discovered that breaker } 1 \text { EKPG } 22 \text {. Train A control } \\
\text { room area/ventilation \& chilled water sys open. Caused by inappropriate } \\
\text { operator actions. Breaker closed\& task force formed. W/9:1212 1tr. }\end{array}$ \\
\hline $12-20-91$ & Enrico Fermi 2 & $60139 / 237-242$ & LER-341/91-019 & $1 / 100 \%$ & $\begin{array}{l}\text { LER 91-019-00: on } 911120 \text {, two ESF actuations of RWCU sys occurred. Caused by } \\
\text { high pump room differential pressure \& personnel error during sys } \\
\text { restoration. Pump room cooler controller placed in manual. W/911220 } 1 \mathrm{tr} \text {. }\end{array}$ \\
\hline $12-17-91$ & Catawba 1 & $60212 / 132-137$ & LER-413/91-023 & $1 / 100 \%$ & $\begin{array}{l}\text { LER } 91-023-00 \text { : on } 911117 \text {, discovered that suction isolation damper for } A \\
\text { train CR air handiling unit had failed to close. Caused by equipment } \\
\text { failure/malfunction due to failed hydromotor. Work request initiated. } \\
\text { W/911217 ltr. }\end{array}$ \\
\hline $12-20-91$ & Enrico Fermi 2 & $60212 / 228-233$ & LER-341/91-019 & $1 / 100 \%$ & $\begin{array}{l}\text { LER } 91-019-00: \text { on } 911120 \text {, reactor water cleanup sys isolation occurred due } \\
\text { to high pump room differential temp \& personnel error during sys } \\
\text { restoration. Caused by failure of nonsafety temp switch. Temp switch } \\
\text { recalibrated. W/911220 itr. }\end{array}$ \\
\hline
\end{tabular}


Table A.2 presents the number of LER failures involving room coolers and HVAC systems by year from 1980 to 1991. As shown, the total number of LERs ranged from one in 1984 to 28 in 1987 for an average of about 14 per year. The LER data were noted to be somewhat lacking for the years 1980 to 1984 , most likely because the LER reporting requirements in those years were less comprehensive than the requirements from 1985 to present. As a result, LER data for the period 1985 to 1991 were separated from the older LER data, as shown in the table. For the period 1985 to 1991, the average number of LERs per year involving room cooler and/or HVAC fallures was about 20 per year. This is substantially larger that the 14/yr over the 1980 to 1991 time period, illustrating the apparent enhanced LER reporting requirements from 1985 to present. These data are illustrated in Figure A.1.

Table A.2 tabulates the numbers of LERs by year in which each of the rooms/areas served by HVAC or chilled water systems were listed as having failed to perform its intended function. More than one room cooler may be listed in a single LER so the total number of affected coolers is greater than the total number of LERs. The data from which the failure rates will be derived for this study include failures that occurred during all plant operating modes, including normal power operations, shutdown, and refueling outages. Therefore, the failure rate calculations are somewhat conservative because they will be used for core damage frequency calculations and core damage accidents are less likely to occur during plant shutdowns and at low power levels than at full power and cannot occur during refueling outages when fuel has been removed from the reactor vessel.

The key safety-related pump and electrical equipment rooms are listed in Table A.2 and are illustrated in Figure A.2. As shown, no particular room/ area appears more frequently in LERs than others, with the possible exception of the control room HVAC system. From 1980 to 1981, about four LERs/year were reviewed that involved failure of one or more trains of the control room emergency HVAC system. Since 1985, control room HVAC failures appeared in about six LERs/year. Taken together, control room HVAC failures represent approximately $18 \%$ of the room/area cooler failures listed in LERs (see Figures $A .3$ and A.4). The next most likely room cooler failures are HPCI/HPCS pump room coolers (9.8\% of the LERs) and RHR pump room coolers $(9.1 \%$ of the LERs). Therefore, control room HVAC failures were found to occur at approximately twice the frequency of the next most likely room cooler failures.

Table A.3 presents a breakdown of the room/area coolers listed in Table A.2 as "other" coolers. These "other" coolers include such rooms/areas as emergency gas treatment system rooms, centrifugal charging pump rooms, containment coolers and spray pump rooms, battery rooms, essential service water pump rooms, and essential chillers. The average number of LERs per year in which these room coolers were indicated to have failed ranged from about $0.1 / y r$ (control rod drive power supply room) to about $1.3 / \mathrm{yr}$ (essential chiller failures). Other room/area coolers which fail relatively frequently inciuded reactor water cleanup (RWCU) room and auxiliary feedwater pump 
TABLE A.2. Number of LERs in Which HVAC and/or Room Cooler Failures Appeared - 1980 to 1991

\begin{tabular}{|c|c|c|c|c|c|c|c|c|c|c|c|c|c|c|c|c|}
\hline \multirow[b]{2}{*}{ Room/Area } & \multirow[b]{2}{*}{1980} & \multirow[b]{2}{*}{1981} & \multirow[b]{2}{*}{1982} & \multirow[b]{2}{*}{1983} & \multirow[b]{2}{*}{1984} & \multirow[b]{2}{*}{1985} & \multirow[b]{2}{*}{1986} & \multirow[b]{2}{*}{1987} & \multirow[b]{2}{*}{1988} & \multirow[b]{2}{*}{1989} & \multirow[b]{2}{*}{1990} & \multirow[b]{2}{*}{1991} & \multicolumn{2}{|c|}{1980 to 1991 DATA } & \multicolumn{2}{|c|}{1985 to 1991 DATA } \\
\hline & & & & & & & & & & & & & TOTAL & AVERAGE & TOTAL & AVERAGE \\
\hline Number of LERs & 8 & 2 & 8 & 10 & 1 & 17 & 18 & 28 & 15 & 20 & 19 & 21 & 167 & 13.92 & 138 & 19.71 \\
\hline RHR Pump Room & 3 & 1 & 3 & 1 & & 2 & 2 & 3 & 1 & 2 & 3 & 2 & 23 & 1.92 & 15 & 2.14 \\
\hline Core Spray Pump Room & 2 & 1 & 3 & 1 & & 1 & 4 & 1 & 2 & 1 & 2 & 1 & 19 & 1.58 & 12 & 1.71 \\
\hline LPCI/LPCS Room & 2 & & & 1 & & 1 & 1 & 1 & 1 & 1 & 2 & 3 & 13 & 1.08 & 10 & 1.43 \\
\hline RCIC Pump Room & & & & & & 1 & 2 & & & 3 & 3 & & 9 & 0.75 & 9 & 1.29 \\
\hline $\begin{array}{l}\text { Control Room HVAC - } \\
1 \text { Train }\end{array}$ & & & 3 & 3 & & 2 & 4 & 4 & 3 & 4 & 3 & 5 & 31 & 2.58 & 25 & 3.57 \\
\hline $\begin{array}{l}\text { Control Room HVAC - } \\
2 \text { Trains }\end{array}$ & & & & 1 & & 2 & 1 & -2 & & 3 & 3 & 5 & 17 & 1.42 & 16 & 2.29 \\
\hline ESF Switchgear Room & & & & 4 & 1 & & 4 & 5 & 2 & 2 & 2 & 3 & 23 & 1.92 & 18 & 2.57 \\
\hline HPCI/HPCS Room & & & & 1 & & 4 & & 3 & 2 & 6 & 5 & 4 & 25 & 2.08 & 24 & 3.43 \\
\hline $\begin{array}{l}\text { Emergency Diesel } \\
\text { Generator HVAC }\end{array}$ & & & & & & & 2 & 4 & 1 & 3 & 2 & 3 & 15 & 1.25 & 15 & 2.14 \\
\hline $\begin{array}{l}\text { Other Room Coolers, } \\
\text { HVAC Subsystems }\end{array}$ & 0 & 0 & 1 & 1 & 0 & 7 & 1 & 26 & 8 & 7 & 11 & 8 & 70 & 5.83 & 68 & 9.70 \\
\hline
\end{tabular}




\section{Licensee Event Report Data}

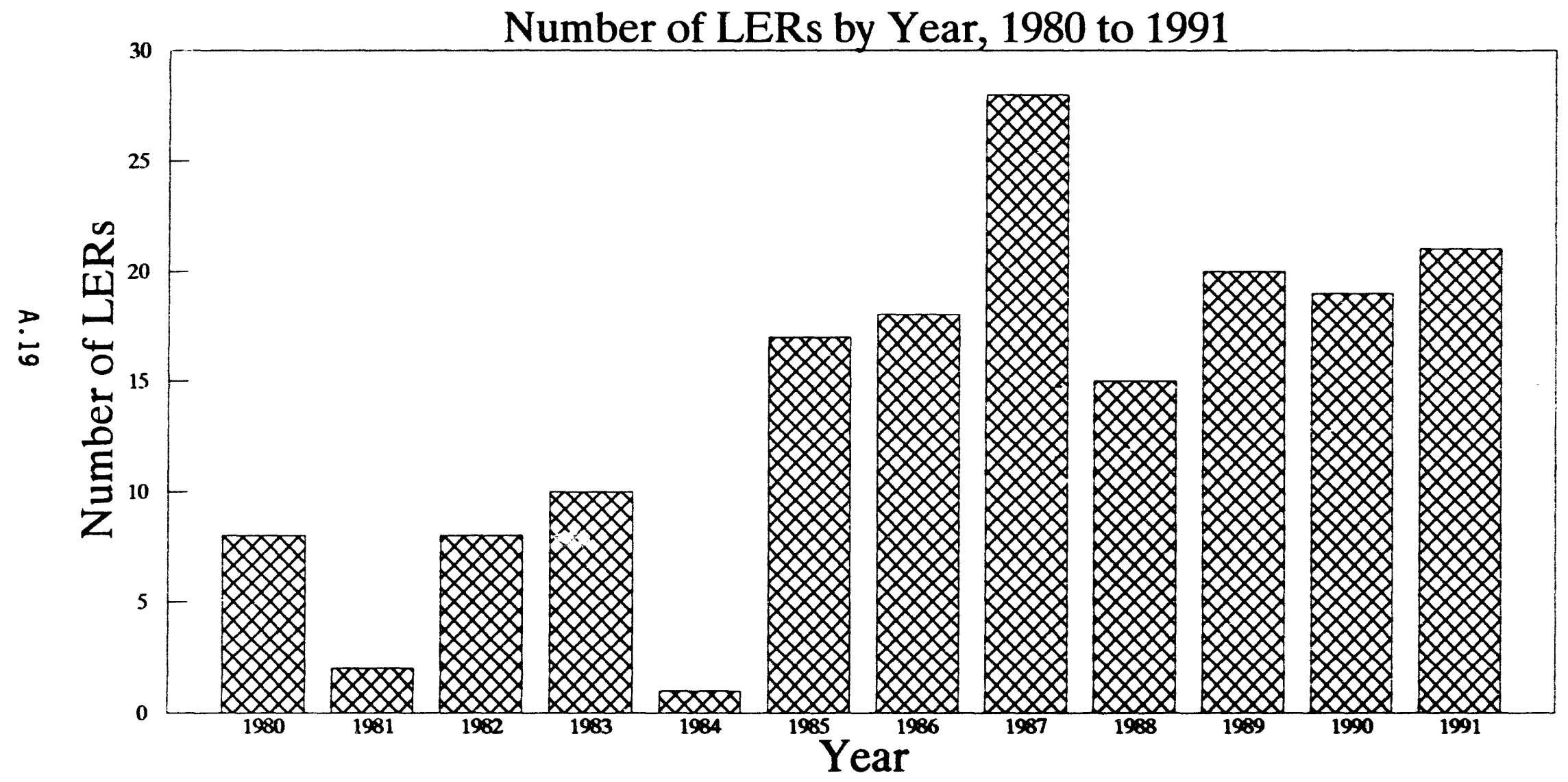

FIGURE A.1. Annual Numbers of LERs Involving HVAC and Room Cooler Failures 


\section{Licensee Event Report Data}

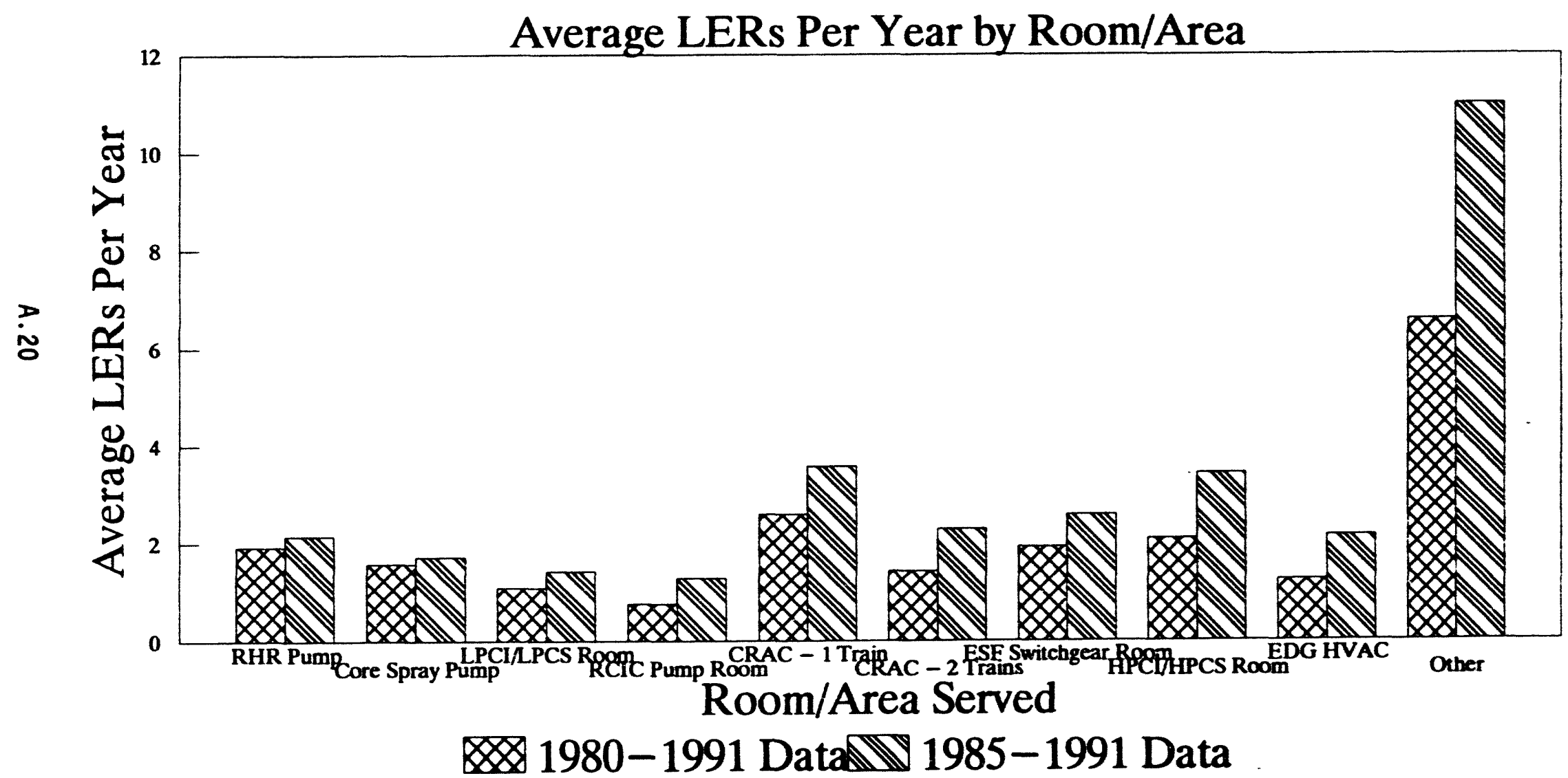

FIGURE A.2. Average Annual Numbers of LERs in Which Various HVAC and Room Cooler Failures Are Noted 


\section{Licensee Event Report Data}

\section{Fraction of LERs by Room/Area, 1980-1991}

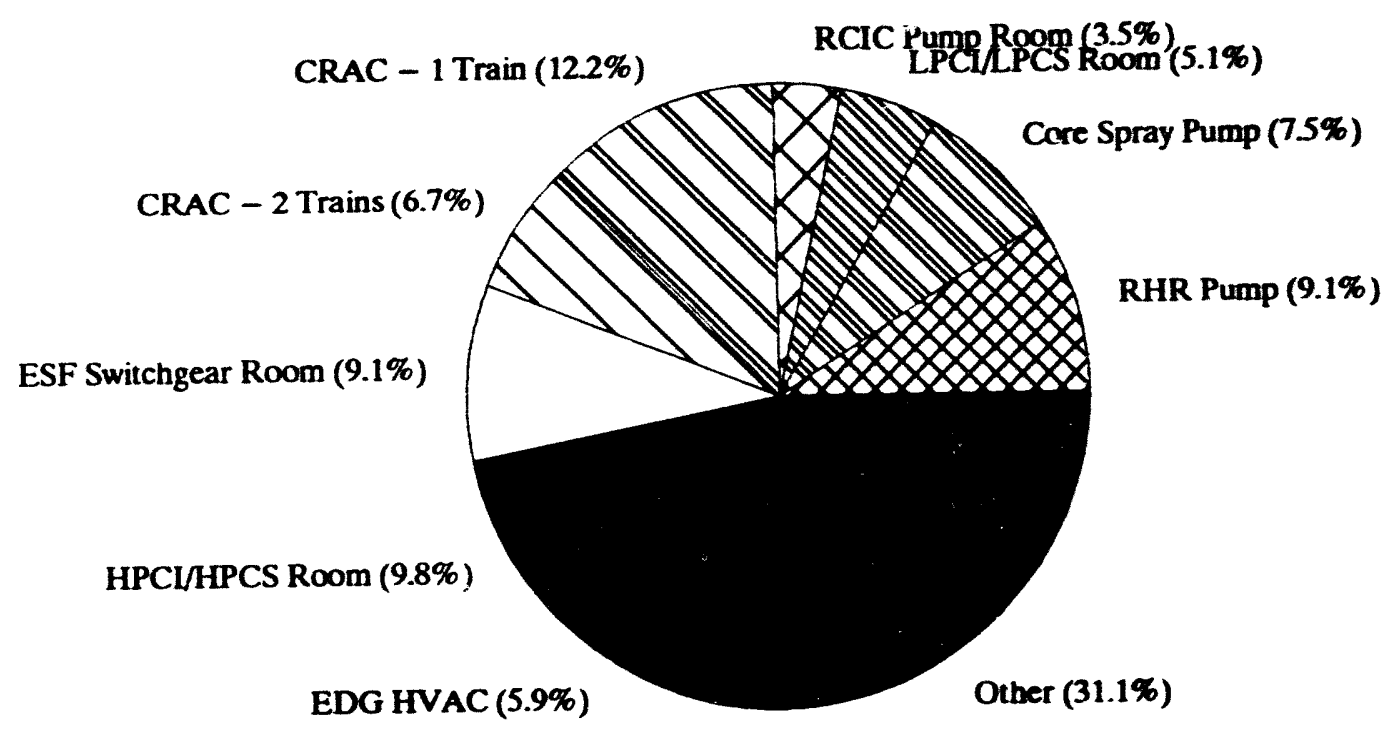

FIGURE A.3. Pie Chart Illustrating Fractions of Annual Average LERs in Which Various HVAC and Room Cooler Failures Are Identified - 1980 to 1991 Data 


\section{Licensee Event Report Data}

Fraction of LERs by Room/Area, 1985-1991

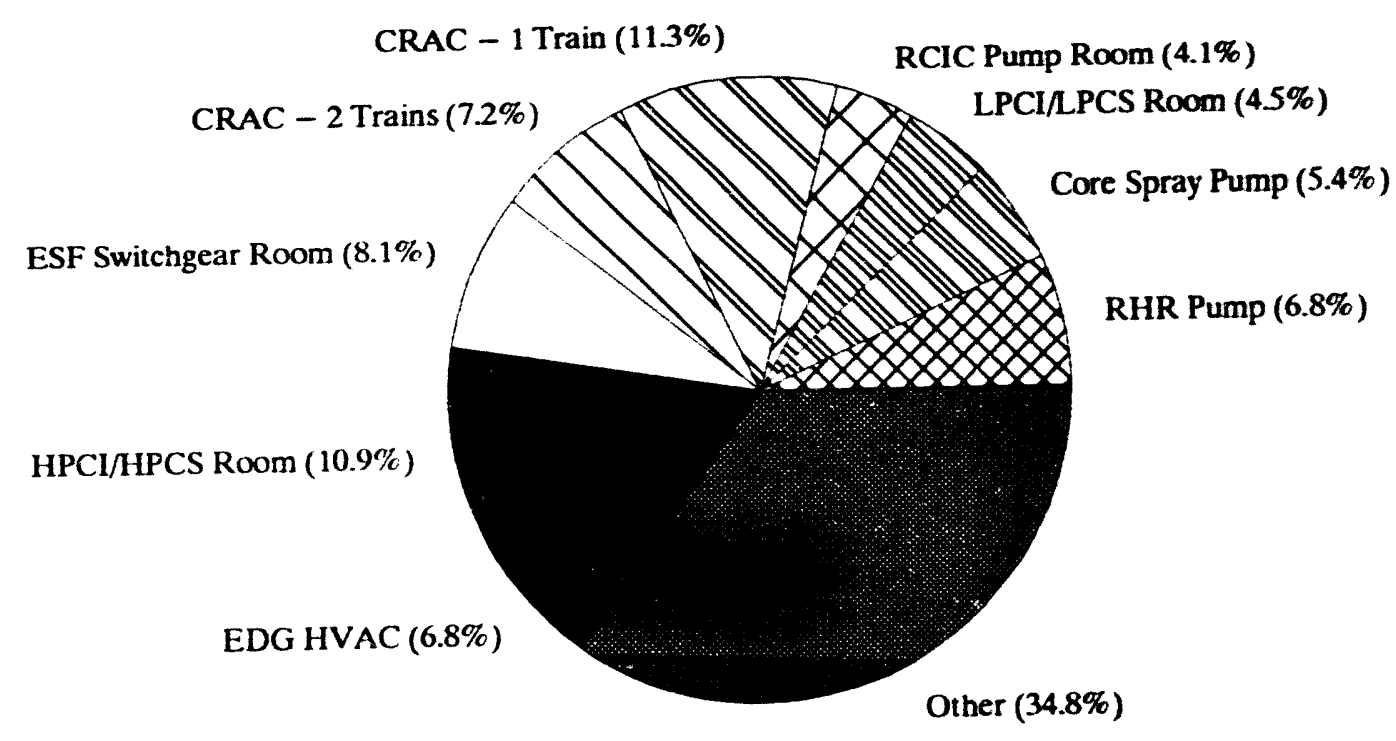

FIGURE A.4. Pie Chart Illustrating Fractions of Annual Average LERs in Which Various HVAC and Room Conler Failures Are Identified - 1985 to 1991 Data 
TABLE A.3. LER Data for Room Cooler and HVAC Failures Designated as "Other"

\begin{tabular}{|c|c|c|c|c|c|c|c|c|c|c|c|c|c|c|c|c|}
\hline \multirow[b]{2}{*}{ Room/Area } & \multirow[b]{2}{*}{1980} & \multirow[b]{2}{*}{1981} & \multirow[b]{2}{*}{1982} & \multirow[b]{2}{*}{1983} & \multirow[b]{2}{*}{1984} & \multirow[b]{2}{*}{1985} & \multirow[b]{2}{*}{1986} & \multirow[b]{2}{*}{1987} & \multirow[b]{2}{*}{1988} & \multirow[b]{2}{*}{1989} & \multirow[b]{2}{*}{1990} & \multirow[b]{2}{*}{1991} & \multicolumn{2}{|c|}{1980 to 1991 DATA } & \multicolumn{2}{|c|}{1985 to 1991 DaTA } \\
\hline & & & & & & & & & & & & & TOTAL & AVERAGE & TOTAL & AVERAGE \\
\hline $\begin{array}{l}\text { Emergency Gas } \\
\text { Treatment System } \\
\text { Room }\end{array}$ & & & 1 & 1 & & 1 & & 1 & & & 1 & & 5 & 0.42 & 3 & 0.43 \\
\hline $\begin{array}{l}\text { Control Rod Drive } \\
\text { Power Supply Room } \\
\end{array}$ & & & & & & 1 & & & & & & & 1 & 0.08 & 1 & 0.14 \\
\hline $\begin{array}{l}\text { Reactor Building } \\
\text { HVAC }\end{array}$ & & & & & & 2 & & & & & & & 2 & 0.17 & 2 & 0.29 \\
\hline $\begin{array}{l}\text { Centrifugal Charging } \\
\text { Pump Room }\end{array}$ & & & & & & 1 & & 2 & & & 1 & 1 & 5 & 0.42 & 5 & 0.71 \\
\hline Containment Coolers & & & & & & 1 & & & & & & & 1 & 0.08 & 1 & 0.14 \\
\hline $\begin{array}{l}\text { Containment Spray } \\
\text { Pump Room }\end{array}$ & & & & & & 1 & & 2 & & 2 & 1 & 1 & 7 & 0.58 & 7 & 1.00 \\
\hline $\begin{array}{l}\text { Component Cooling } \\
\text { Hater Pump Room }\end{array}$ & & & & & & & & 1 & & 1 & 1 & & 3 & 0.25 & 3 & 0.43 \\
\hline $\begin{array}{l}\text { Vital AC Inverter } \\
\text { Room }\end{array}$ & & & & & & & & 2 & & 1 & 1 & & 4 & 0.33 & 4 & 0.57 \\
\hline Battery Room & & & & & & & & 3 & & & & 1 & 4 & 0.33 & 4 & 0.57 \\
\hline Essential Chiller & & & & & & & & 3 & 2 & 3 & 1 & & 9 & 0.75 & 9 & 1.29 \\
\hline $\begin{array}{c}\text { Essential Service } \\
\text { Water Pump Room } \\
\end{array}$ & & & & & & & & 2 & 2 & & 2 & 1 & 7 & 0.58 & 7 & 1.00 \\
\hline $\begin{array}{l}\text { Electrical } \\
\text { Penetration Rooms }\end{array}$ & & & & & & & & 3 & & & & & 3 & 0.25 & 3 & 0.43 \\
\hline $\begin{array}{c}\text { Regenerat ive Heat } \\
\text { Exchanger Room }\end{array}$ & & & & & & & 1 & 1 & & & 1 & & 3 & 0.25 & 3 & 0.43 \\
\hline $\begin{array}{l}\text { Reactor Water } \\
\text { Cleanup Pump Room }\end{array}$ & & & & & & & & 3 & 2 & & 1 & 2 & 8 & 0.67 & 8 & 1.14 \\
\hline $\begin{array}{l}\text { Auxiliary Feedwater } \\
\text { Pump Room }\end{array}$ & & & & & & & & 3 & 2 & & 1 & 2 & 8 & 0.67 & 8 & 1.14 \\
\hline
\end{tabular}


coolers at $1.1 / y r$ and containment spray pump room coolers at about $1 / y r$. These data are 11lustrated in Figures A.5 (1980 to 1991 data) and A.6 (1985 to 1991 data). Note that there are no major changes in the fractions of "other" room/area cooler fallures when comparing the two data sets, even though the total LERs per year are substantially higher from 1985 to 1991 (9.7/yr; see "other" in Table A.2.) that they were in the 1980 to 1991 data sets (5.8/yr).

The causes of the room cooler fallures were identified through reviews of the LERs summarized in Table A.1. Many of the causes of fallures are listed below:

- frayed belts on room cooler fans

- pitting/burning of contacts on room cooler or fan motor control center (MCC) contactor

- seal fallures on recirculation dampers

- low refrigerant (freon) level in chiller

- inadequate $A C$ power or power tripped by personnel

- faults on DC distribution panels

- ESW flow blocked by debris or inadequate due to design errors

- inadequate thermal overload protection devices

- procedural errors result, for example, in inoperable essential chilled water system pumps

- inadequate air flow rates.

The LER data were reviewed to identify potential common cause fallures which could result in simultaneous disabling or failure of more than one entire cooling train or more than one room cooler. These LERs involved failures that may lead to inoperability of an entire division of HVAC or room cooling functions. The types of common cause fallures that were identified were placed in four categories, as shown in Table A.4. These four categories of common cause failures are:

- design errors

- failure/blockage of essential service water

- personnel error

- equipment fallure (other than ESW; e.g., fallure of power sources or failure of the essential chiller). 


\section{Licensee Event Report Data}

\section{"Other" Failures by Room/Area, 1980-1991}

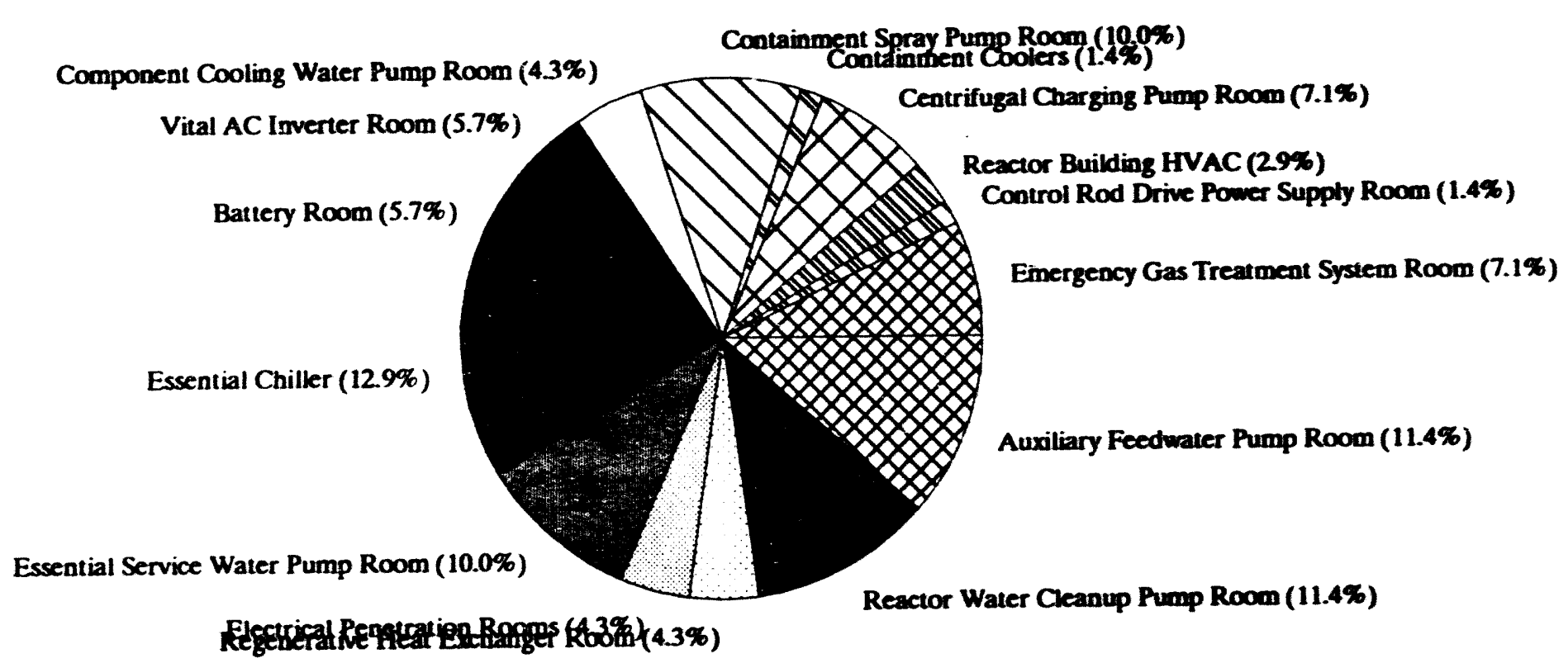

FIGURE A.5. Pie Chart Illustrating Fractions of Annual Average LERs in which "Other" HVAC and Room Cooler Failures Are Identified - 1980 to 1991 Data 


\section{Licensee Event Report Data}

"Other" Failures by Room/Area, 1985-1991

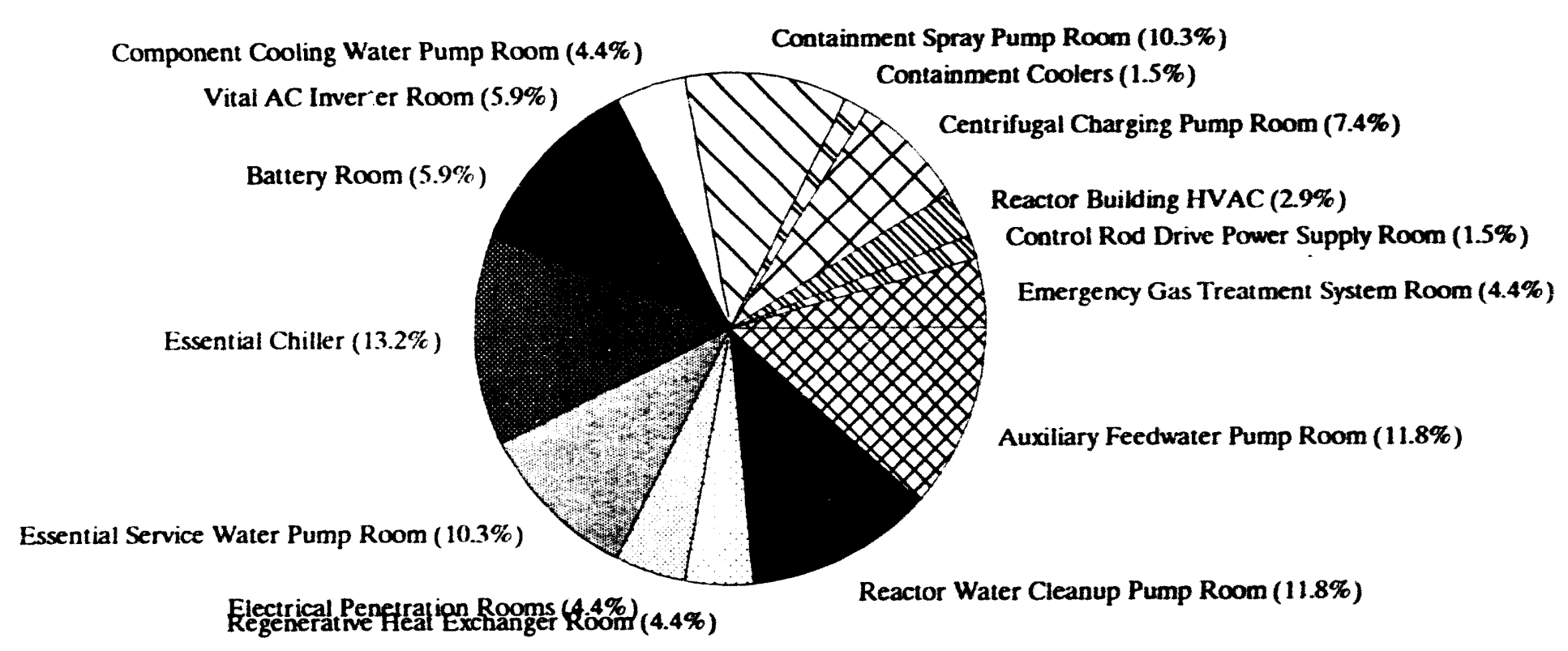

FIGURE A.6. Pie Chart Illustrating Fractions of Annual Average LERs in Which "Other" HVAC and Room Cooler Failures Are Identified - 1985 to 1991 Data 
TABLE A.4. Common-Cause Failure Data from LER Reviews of HVAC and Room Cooler Failures

\begin{tabular}{|c|c|c|c|c|c|c|c|c|c|c|c|c|c|c|c|c|}
\hline \multirow[b]{2}{*}{$\begin{array}{l}\text { Potential Common- } \\
\text { Cause Failure }\end{array}$} & \multirow[b]{2}{*}{1980} & \multirow[b]{2}{*}{1981} & \multirow[b]{2}{*}{1982} & \multirow[b]{2}{*}{1983} & \multirow[b]{2}{*}{1984} & \multirow[b]{2}{*}{1985} & \multirow[b]{2}{*}{1986} & \multirow[b]{2}{*}{1987} & \multirow[b]{2}{*}{1988} & \multirow[b]{2}{*}{1989} & \multirow[b]{2}{*}{1990} & \multirow[b]{2}{*}{1991} & \multicolumn{2}{|c|}{1980 to 1991 DATA } & \multicolumn{2}{|c|}{1985 to 1991 DATA } \\
\hline & & & & & & & & & & & & & TOTAL & AVERAGE & TOTAL & AVERAGE \\
\hline Design Errors & & & 1 & & & 1 & 6 & 6 & 3 & 8 & 4 & 2 & 31 & $2: 58$ & 30 & 4.29 \\
\hline ESW Blockage & 1 & & i & & & 4 & 1 & 3 & 3 & 1 & 2 & 1 & 17 & 1.42 & 15 & 2.14 \\
\hline Personnel Error & & & & & & & - & 2 & 2 & & & & 4 & 0.33 & 4 & 0.57 \\
\hline Equipment Failure & & 1 & & 1 & & & & & 1 & 1 & & 1 & 5 & 0.42 & 3 & 0.43 \\
\hline TOTAL & 1 & 1 & 2 & 1 & 0 & 5 & 7 & 11 & 9 & 10 & 6 & 4 & 57 & 4.75 & 52 & 7.43 \\
\hline
\end{tabular}


The common cause failure data by year are plotted in Figure A.7. As shown, in 1987, a total of 11 LERs involving common cause failures were identified. The average over the period 1985 to 1991 was calculated to be about 7.4/yr (see Table A.4). The average annual LERs involving common cause failures are plotted by failure category in Figure A.8. As shown, the most likely types of common cause failures are design errors, such as errors made in the design of the ESW system that result in inadequate flow rates through safetyrelated room coolers. ESW blockage is the next most likely common cause type failure. The most frequent example of these types of common cause failures resulted from accumulations of mud, silt, corrosion products, and biofouling (e.g., clam shells, oyster shells) in ESW heat exchangers and piping systems.

The data in the preceding tables and figures were used to develop reliability data for the HVAC and room cooler systems. The LER failures were first categorized as either failure of an operating component to continue running or fajlure of a normally standby (or normally alternating) component to start. A total of $91 \mathrm{room} /$ area cooler failures were determined to be normally operating components and 121 were determined to be normally standby or alternating components. Normally operating components included CRAC systems, and HVAC/chilled water systems to the vital AC inverter room, essential chiller room, battery room, electrical equipment rooms, relay room, RWCU room, centrifugal charging pump room, cable spreading room, ESW pump room, and CCW pump room. Normally standby components included various ECCS pump rooms (including RCIC, HPCI/HPCS, LPCI/LPCS, core spray, containment spray, and RHR pump rooms), emergency diesel generator rooms, and AFW pump rooms.

The next step was to calculate the likelihood of HVAC and room cooler failures for normally operating and standby components. For normally operating components, this was done by dividing the numbers of operating failures by the number of reactor-hours of operation over the seven-year period from 1985 to 1991. Plant operating data in Nuclear Safety (1986, p. 530 ; 1988, p. 370 ; and 1991, p. 282) were used to calculate this value (see Table A.5). As shown, the average plant availability over this period was 68.8\%. A total of 512.7 reactor-yr (RY) of operation have occurred over this period for an average of $73.3 \mathrm{RY} / \mathrm{yr}$.

Failure rates for normally standby components were calculated by dividing the total number of standby failures over the seven-year period by the total number of demands for these components to start over the same period. According to data in NUREG/CR-3862 (Mackowiak, Gentillon, and Smith 1985, pp. 44-47), a total of 5406 transients at PWRs and BWRs were catalogued over a certain time period representing 674.2 RY of operation. This results in an average transient frequency of $8.02 / R Y$. Assuming that this transient frequency is applicable to the time period of this LER review (1985 to 1991 representing $513 \mathrm{RY}$ of operation), a total of 4112 transients occurred. Each transient is assumed to represent a demand for normally standby HVAC system components and room coolers to start. This results in normally standby HVAC/room cooler system failure rates of $2.9 E-2 /$ demand. Individual rocm cooler failure rates are shown in Table A.6. Individual 


\section{Licensee Event Report Data}

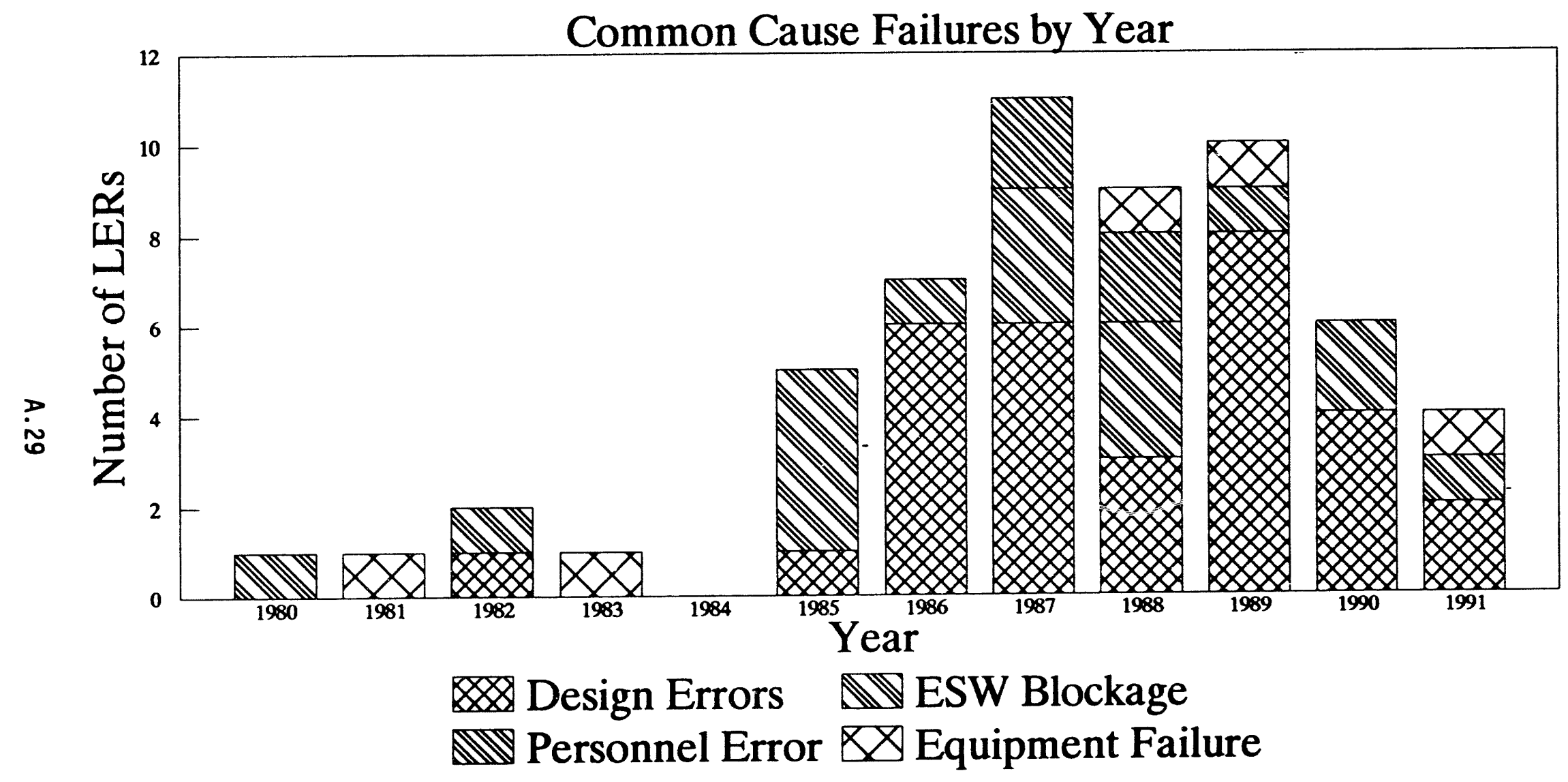

FIGURE A.7. Common-Cause Failures by Year in which HVAC and Room Cooler Failures Are Identified 


\section{Licensee Event Report Data}

\section{Common Cause Failures by Cause}

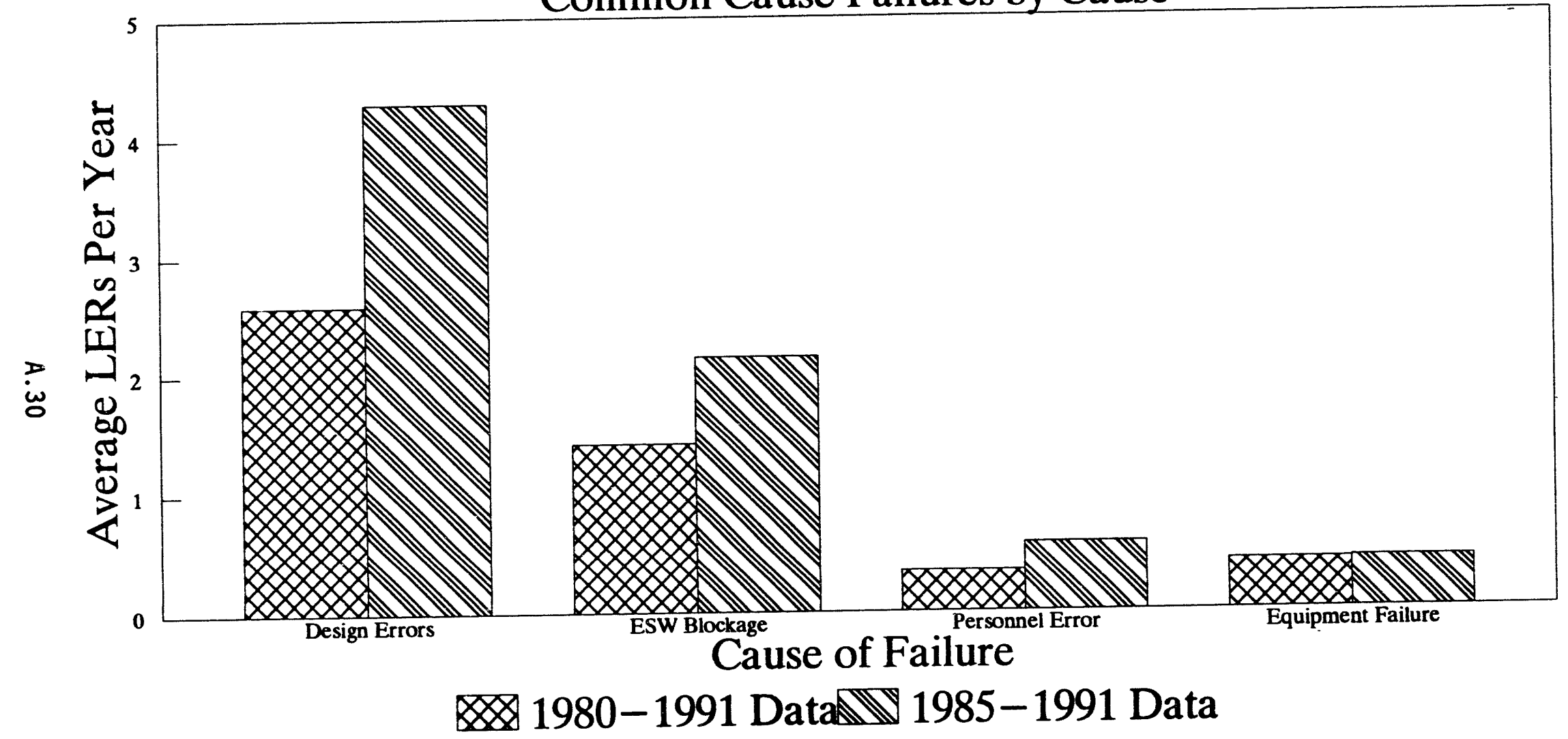

FIGURE A.8. Average Annual Numbers of Common-Cause Failures by Category 
TABLE A.5. Nuclear Power Plant Operational, Data for 1986 to 1991

\begin{tabular}{|c|c|c|c|}
\hline Year & $\begin{array}{c}\text { Number } \\
\text { of Plants }\end{array}$ & $\begin{array}{c}\text { Average } \\
\text { Availability }\end{array}$ & $\begin{array}{c}\text { Number of } \\
\text { Reactor-yr }\end{array}$ \\
\hline 1985 & 97 & 0.685 & 66.5 \\
\hline 1986 & 102 & 0.655 & 68.8 \\
\hline 1987 & 105 & 0.672 & 68.5 \\
\hline 1988 & 107 & 0.698 & 74.7 \\
\hline 1989 & 110 & 0.685 & 75.4 \\
\hline 1990 & 112 & 0.711 & 79.6 \\
\hline 1991 & $112^{\text {(a) }}$ & 0.711 & 79.6 \\
\hline TOTAL & & 0.685 & 512.7 \\
\hline (a) Data is not yet available for 1991.0 It \\
was assumed to be identical to 1990 data. \\
\hline
\end{tabular}

component demand failure rates range from about $6 \mathrm{E}-3 /$ demand for HPCI/HPCS pump room coolers to about $2 \mathrm{E}-4$ /demand for containment cooler units.

The failure rates for normally operating components were calculated by dividing the total number of failures by the total number of RY of operation over the seven-year period and then by $8760 \mathrm{hr} / \mathrm{yr}$. The results of these calculations for each individual room/area cooler type are presented in Table A.6. The failure rates range from about $6 \mathrm{E}-6 / \mathrm{hr}$ for failure of one train of the control room HVAC system to about $2 \mathrm{E}-7 / \mathrm{hr}$ for control rod drive power supply room coolers. These appear to be reasonably within the ranges of component failure rates that were published in the NUCLARR database (Gertman et al. 1988).

Four new event trees were developed for this study to model room cooler failures as initiating events. These are

- loss of control room HVAC

- loss of ESF switchgear room cooling

- loss of HPI/HPR pump room cooling

- loss of LPI/LPR pump room cooling. 
IABLE A.6. Reliability Data for Area/Room Coolers Based on LER Data

\begin{tabular}{|c|c|c|c|}
\hline Room/Area Cooler & $\begin{array}{l}\text { No. of } \\
\text { Failures }\end{array}$ & \multicolumn{2}{|c|}{$\begin{array}{l}\text { Failure to Start } \\
\text { Per Demand }\end{array}$} \\
\hline \multicolumn{4}{|l|}{ Normally-Standby Components } \\
\hline $\begin{array}{l}\text { RHR Pump Room } \\
\text { Core Spray Pump Room } \\
\text { LPCI/LPCS Room } \\
\text { RCIC Pump Room } \\
\text { Emergency Gas Treatment System Room } \\
\text { Containment Coolers } \\
\text { ESF Switchgear Room } \\
\text { HPCI/HPCS Room } \\
\text { Emergency Diesel Generator HVAC } \\
\text { Essential Service Water Pump Room } \\
\text { Containment Spray Pump Room }\end{array}$ & $\begin{array}{r}15 \\
12 \\
10 \\
9 \\
3 \\
1 \\
18 \\
24 \\
15 \\
7 \\
7\end{array}$ & \multicolumn{2}{|c|}{$\begin{array}{l}3.6 \mathrm{E}-03 \\
2.9 \mathrm{E}-03 \\
2.4 \mathrm{E}-03 \\
2.2 \mathrm{E}-03 \\
7.3 \mathrm{E}-04 \\
2.4 \mathrm{E}-04 \\
4.4 \mathrm{E}-03 \\
5.8 \mathrm{E}-03 \\
3.6 \mathrm{E}-03 \\
1.7 \mathrm{E}-03 \\
1.7 \mathrm{E}-03\end{array}$} \\
\hline \multirow[t]{3}{*}{ TOTAL } & 121 & \multicolumn{2}{|c|}{$2.9 \mathrm{E}-02$} \\
\hline & \multirow{2}{*}{$\begin{array}{l}\text { No of } \\
\text { Failures }\end{array}$} & \multicolumn{2}{|c|}{ Failure Rate } \\
\hline & & Per RY & Per hr \\
\hline \multicolumn{4}{|l|}{ Normally-Operating Components } \\
\hline $\begin{array}{l}\text { Control Rod Drive Power Supply Room } \\
\text { Reactor Building HVAC } \\
\text { Centrifugal Charging Pump Room } \\
\text { Control Room HVAC - } 1 \text { Train } \\
\text { Control Room HVAC - } 2 \text { Trains } \\
\text { Component Cooling Water Pump Room } \\
\text { Vital AC Inverter Room } \\
\text { Battery Room } \\
\text { Essential Chiller } \\
\text { Auxiliary Feedwater Pump Room } \\
\text { Electrical Penetration Rooms } \\
\text { Regenerative Heat Exchanger Room } \\
\text { Reactor Water Cleanup Pump Room }\end{array}$ & $\begin{array}{r}1 \\
2 \\
5 \\
25 \\
16 \\
3 \\
4 \\
4 \\
9 \\
8 \\
3 \\
3 \\
8\end{array}$ & $\begin{array}{l}2.0 \mathrm{E}-03 \\
3.9 \mathrm{E}-03 \\
9.8 \mathrm{E}-03 \\
4.9 \mathrm{E}-02 \\
3.1 \mathrm{E}-02 \\
5.9 \mathrm{E}-03 \\
7.8 \mathrm{E}-03 \\
7.8 \mathrm{E}-03 \\
1.8 \mathrm{E}-02 \\
1.6 \mathrm{E}-02 \\
5.9 \mathrm{E}-03 \\
5.9 \mathrm{E}-03 \\
1.6 \mathrm{E}-02\end{array}$ & $\begin{array}{l}2.2 \mathrm{E}-07 \\
4.5 \mathrm{E}-07 \\
1.1 \mathrm{E}-06 \\
5.6 \mathrm{E}-06 \\
3.6 \mathrm{E}-06 \\
6.7 \mathrm{E}-07 \\
8.9 \mathrm{E}-07 \\
8.9 \mathrm{E}-07 \\
2.0 \mathrm{E}-06 \\
1.8 \mathrm{E}-06 \\
6.7 \mathrm{E}-07 \\
6.7 \mathrm{E}-07 \\
1.8 \mathrm{E}-06\end{array}$ \\
\hline TOTAL & 91 & $1.8 \mathrm{E}-01$ & $2.0 \mathrm{E}-05$ \\
\hline
\end{tabular}


The frequencies of these initiating events were calculated by dividing the number of LERs related to these components by the total number of operating years (i.e., 512.7 reactor-years). Only the LERs that occurred during plant operations were included in these calculations. The room cooler LERs were reviewed to determine the total number of ESF switchgear, control room, HPI/HPR pump, and LPI/LPR room cooler failures that occurred over the 1985 to 1991 time frame. Initially, all room cooler failures were included in the database, including failures that occurred while the plant was in shutdown or refueling modes (see Table A.2). A second sort was performed to identify LERs that occurred while the plant was in an operating mode. Failures that occurred during shutdown were not a concern because the control rods have already been inserted and plant decay heat levels are low. Therefore, during plant shutdowns, reactor coolant system pressure and temperature levels are very low relative to operational modes. This allows a much longer time to diagnose and correct room cooler failures during shutdown conditions than while the plant is operating. For this reason, it is believed very unlikely that loss of a room cooler during shutdown conditions could lead to a core damage scenario. Table A.7 presents the results of this analysis, including the total LERs observed for the four components, the total LERs observed during plant operating conditions, and the annual initiating event frequency for each room cooler sysitem.

TABLE A.7. Room Cooler Initiating Event Frequencies

\begin{tabular}{|c|c|c|c|}
\hline Room Cooler & $\begin{array}{l}\text { Number of } \\
\text { Failures, } \\
\text { All modes }\end{array}$ & $\begin{array}{l}\text { Number of } \\
\text { Failures, } \\
\text { Operating }\end{array}$ & $\begin{array}{l}\text { Initiator } \\
\text { Frequency, } \\
\text { per RY }\end{array}$ \\
\hline LPI/LPR pump room cooler (a) & 25 & 12 & $2.34 \mathrm{E}-02$ \\
\hline HPI/HPR pump room cooler & 45 & 19 & $3.71 E-02$ \\
\hline Control room HVAC system & 41 & 23 & $4.49 E-02$ \\
\hline ESF switchgear room cooler & 18 & 10 & $1.95 E-02$ \\
\hline \multicolumn{4}{|c|}{$\begin{array}{l}\text { (a) Includes failures of RHR systems, LPI/LPR at PWRs, and BWR } \\
\text { low-pressure core spray and low pressure coolant injection } \\
\text { systems (LPCS/LPCI). } \\
\text { (b) Included failures of PWR HPI/HPR systems, and BWR reactor } \\
\text { core isolation cooling systems, high-pressure core spray, } \\
\text { and high-pressure coolant injection systems (HPCS/HPCI). }\end{array}$} \\
\hline
\end{tabular}




\section{REFERENCES}

Gertman, D. I., B. G. Gilbert, W. E. Gilmore, and W. J. Galyean. Nuclear Computerized Library for Assessing Reactor Reliability (NUCLARR).

Mackowiak, D. P., C. D. Gentillon, and K. L. Smith. 1985. Development of Transient Initiating Event Frequencies for Use in Probabilistic Risk Assessments. EG\&G Idaho, Inc., Idaho Falls, Idaho.

Nuclear Safety. Oct-Dec. 1986. Vol. 27, No. 4. "Operating Experiences." Office of Scientific and Technical Information, U.S. Department of Energy Washington D.C. p. 530.

Nuclear Safety. 1988. "Operating Experiences." Office of Scientific and Technical Information, U.S. Department of Energy Washington D.C. pp. 370.

Nuclear Safety. 1991. "Operating Experiences." Office of Scientific and Technical Information, U.S. Department of Energy Washington D.C. pp. 282.

NUREG/CR-4639 (EGG-2458) Vol. 5, prepared by the Idaho National Engineering Laboratory for the U.S. Nuclear Regulatory Commission, Washington, D.C. 
APPENDIX B

SYSTEMS ANALLYSIS AND MINIMAL CUT SETS

FOR THE REPRESENTATIVE WESTINGHOUSE

PRESSURIZED WATER REFICTOR 
APPENDIX B

SYSTEMS ANALYSIS AND MINIMAL CUT SETS

FOR THE REPRESENTATIVE WESTINGHOUSE

PRESSURIZED WATER REACTOR

This appendix presents the fault tree analyses and 1ists the minimal cut sets, the values of each parameter in each cut set, and the cut set frequencies for accident sequences initiated by HVAC/room cooler failures and for accident sequences initiated by other plant transients that contain HVAC/room cooler failures as contributing events. These cut sets were developed based on the event trees presented in Section 3 of the main report and the fault tree analyses summarized in this appendix. Assumptions used in the quantification of affected parameters were presented in Section 4.1. Values for parameters not affected by this issue were taken from Bertucio and Brown (1990, Table 4.9-5).

\section{B.1 WESTINGHOUSE PRESSURIZED WATER REACTOR PLANT DESCRIPTION}

This pressurized water reactor (PWR) contains two nuclear power plant units. Each unit is a four-10op Westinghouse (W) PWR capable of producing $1128 \mathrm{MW}$ of electrical power (MWe) per unit. Unit 1 entered commercial operation in July 1981, and Unit 2 in June 1982.

\section{B.2 SAFETY SYSTEM DESCRIPTION AND SYSTEMS ANALYSIS}

This section contains summary-level descriptions and simplified schematic diagrams of the principal safety systems and presents the fault tree analyses performed by Bertucio and Brown (1990) on these systems. This information was necessary to identify the elements of the minimal cut sets in the existing plant probabilistic risk assessment (PRA) that involve failure to provide room cooling functions to safety systems. A secondary, but no less important, objective was to develop modifications to the systems analyses to model room cooler failures in important systems that were dismissed by Bertucio and Brown as insignificant contributors. The most relevant example is one involving room cooler failures in the diesel generator and electrical switchgear rooms. Bertucio and Brown stated that these failures were not modeled because it was decided that "... the combinations of fan failures and SWS (service water system) failures were of low enough probability to be of minimal contribution to loss of power to components." Nonetheless, such failures were modeled here to develop comprehensive models of the dependencies of safety system operability on room coolers.

The following subsections describe the safety systems, including dependencies on other systems; present the fault trees for the systems that are dependent upon room cooling; and identify the cut set elements that represent 
fallures of one or more trains of room cooling equipment. For completeness, all of the safety systems included in the existing PRA (Bertucio and Brown) are reviewed. However, fault trees and relevant cut set telements are presented for only the systems that are dependent upon room cooling.

The following safety-related systems are identified in this section as having a dependency on room cooling functions:

- Safety injection system (SI pump room cooler)

- Charging system (CS pump room cooler)

- Low-pressure injection/recirculation system (LPI/R pump room cooling)

- Auxiliary feedwater system (AFW pump room coolers)

- Containment spray system (CSS pump room coolers)

- Component cooling water (CCW) system

- Electric power system (emergency diesel generator [EDG] enclosure ventilation system, engineered safety feature [ESF] switchgear room HVAC, DC equipment room HVAC).

As shown, room coolers are provided for the SI pump, CS pump, LPI/R pump, turbine-driven AFW pump, and CSS pump rooms. Centralized HVAC systems are provided for cooling the general area in which motor-driven AFW pumps and CCW pumps are located. A dedicated ventilation system is provided for each diesel generator enclosure. In addition, a safety-related control room emergency HVAC system is provided for the mail control room.

\section{B.2.1 Cold Leg Accumulators}

The function of the cold leg accumulator system is to deliver borated water to reflood the reactor core following a large loss-of-coolant accident (LOCA). This system consists of four pressure vessels filled with borated water and pressurized with nitrogen gas. One accumulator is connected to each of the four reactor coolant system (RCS) cold legs. During normal operation, the accumulators are isolated from the RCS by two check valves in series. A normally open motor-operated valve (MOV) is also present in each accumulator line. In the event of a large LOCA, the primary RCS pressure falls below the accumulator pressure, the check valves open, and borated water is injected into a cold leg of the RCS.

The accumulator system is passive in that no pumps are required and the check valves change position when accumulator pressure exceeds RCS pressure. The accumulators are dependent upon nitrogen gas to maintain pressure in the accumulator vessels. The normally open MOVs in each accumulator 1 ine receive an ESF signal to open in the event they have been inadvertently left closed. Neither the dependencies of the accumulators on the nitrogen system or the ESF actuation system (ESFAS) were developed in detail in the existing PRA. 
Furthermore, there are no dependenctes on HVAC/room cooler systems. Therefore, operability of the accumulator system is not affected by the reliability of the HVAC and chilled water systems so the accumulator system is not analyzed further.

\section{B.2.2 Safety Injection System}

The safety injection (SI) system, together with the charging system (see Section B.2.3) perform the high-pressure coolant injection (HPI) and recirculation (HPR) functions. The SI system is initiated upon loss of RCS coolant or steam line break conditions. The SI system is automatically actuated by the ESFAS but can also be actuated manually if the ESFAS fails.

The SI system shown in Figure B.1 includes two redundant, 100\%-capacity trains. Upon receipt of an ESF signal, the two SI pumps start automatically, drawing suction from the refueling water storage tank (RWST). Room coolers in the SI pump room are interlocked to start automatically when the pumps start. Suction is taken from the RWST from a single line containing a normally open MOV and check valve in series. The two pumps discharge to a common line, which delivers flow to all four RCS cold legs. This configuration constitutes the injection mode of the SI system.

Changeover from injection to recirculation mode of the SI system requires operator intervention. In this mode, the SI pumps take suction from the discharge of the low pressure recirculation (LPR) pumps, which have taken suction from the containment pump. Operator action is required to open the MOVs (see FCV 63-8, FCV 63-11, FCV 63-6, and FCV 6307 in Figure B.1) which permit SI suction to be taken from the discharge of the LPR pumps.

SI system dependencies are listed below:

- It shares the RWST as a common suction source with the low-pressure injection (LPI) system and the containment spray (CS) system.

- There is a physical and functional interface with the charging system in that the SI and charging system jointly make up the high pressure emergency core cooling system (ECCS) function.

- Injection Mode: RWST provides fluid inventory; AC power system provides motive power for pumps; DC power system provides pump control power; ESFAS provides pump actuation; the service water system (SWS) and component cooling water (CCW) system provide pump lube oil and seal cooling, respective:y. No dependency is apparent on HVAC and chilled water systems for pump room cooling.

- Recirculation Mode: LPR system is a fluid source; AC power, DC power, SWS and CCW systems perform the same functions as injection mode. Room cooling is needed for long-term operation of SI pumps in recirculation mode. 


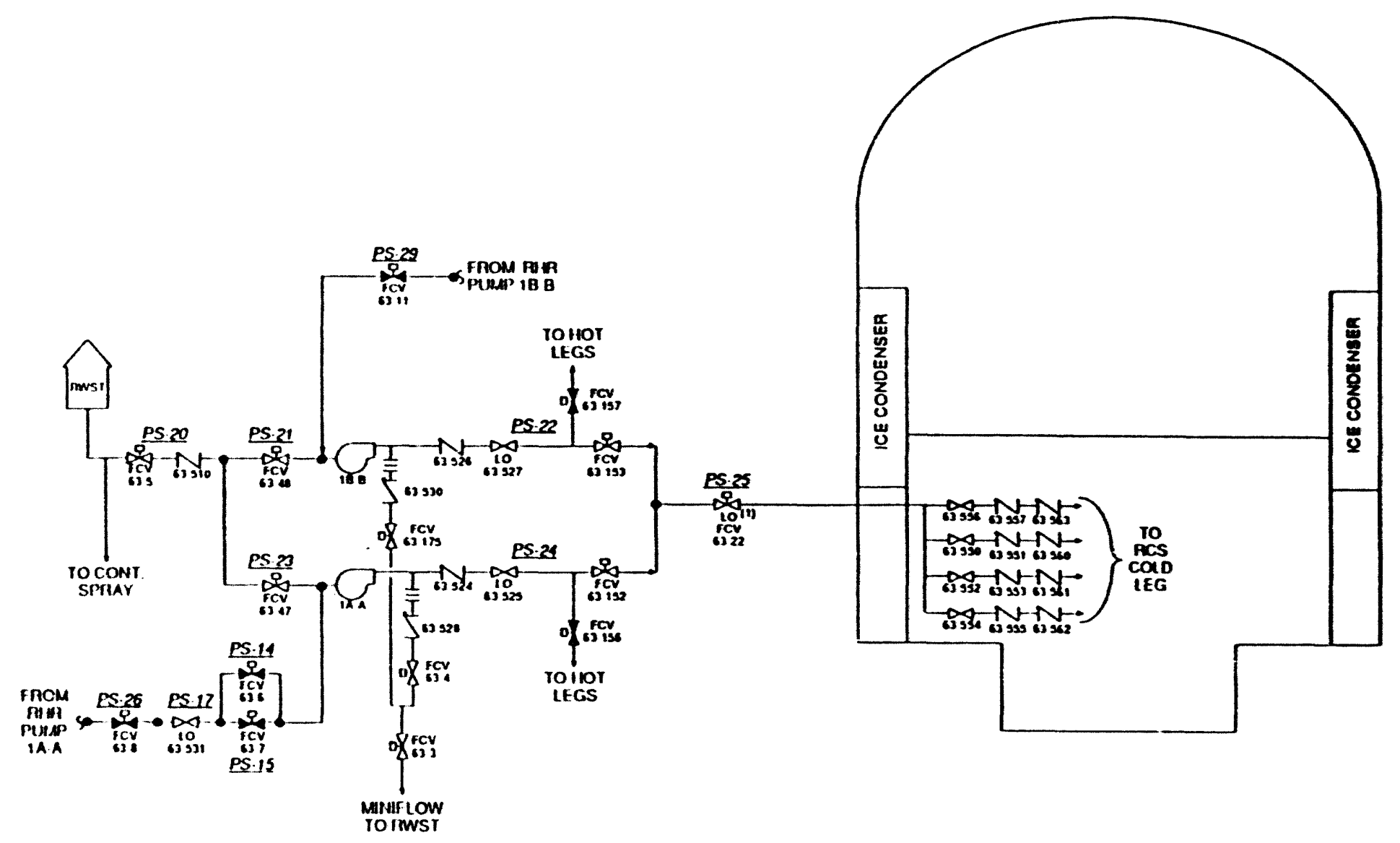

MOIF. (1) BREAKEF RACKED OUT AT POWER SUPPIY

FIGURE B.1. Simplified Schematic of the Safety Injection System 
Bertucio and Brown (1990) developed these three separate fault trees for the SI system:

- SI System - Injection Mode (designated fault tree SIINJ)

- SI System - Recirculation Mode (SIREC)

- SI System - Charging Mode (SICH).

A detalled review of all three of these fault trees indicated that room cooling is necessary only during the recirculation mode. It was indicated by Bertucio and Brown that room cooling is not necessary during the injection phase, because the pumps can operate without room cooling for the short time required to complete injection. Room cooling is required, however, for the much longer time frames assoclated with recirculation. As a result, only fault tree SIREC was examined further in this analysis.

A simplified fault tree for the SI system in the recirculation mode is shown in Figure B.2. This tree was simplified by "pruning" branches that did not contain basic events involving room cooler fallures. These "pruned" branches are retained on the figure as undeveloped events. Some events are intermediate events that were developed further by Bertucio and Brown yet do not contain HVAC/room cooler dependencies. These intermediate events are labeled, "Not developed further in this study." Figure B.2 aids in identifying of basic events involving room cooler failures.

As shown in Figure B.2, failure of HPI fan 1B-B contributes to failure to provide sufficient flow through pipe segment 22 (PS 22), representing failure of PHI Train B. Not shown in the fault tree is failure of HPI fan 1A-A, which contributes to failure to provide sufficient flow through PS 24 (Train A). The branch of the fault tree involving PS 24 is identical to the branch involving PS 22 except for differences in specific pipe segment and valve numbers (Train A vs. Train B) and is not shown for brevity. Because the PHI fan failures are connected to the intermediate event, "Insufficient Flow Through PS 22 (Recirculation)," through logical "OR" gates, these fan failures are functionally equivalent to all the other basic events shown on the figure, including HPI pump failures, plugged/mispositioned valves, and the HPI actuation signal failures. Although not shown in the figure, it was observed that HPI fans $1 A-A$ and $1 B-B$ are completely separate; i.e., they are actuated by separate actuation logic channels, powered from separate AC buses, and are controlled through separate $125-V$ vital buses. Motor control centers (MCCS) for Train A and B are also located in separate ESF switchgear rooms.

\section{B.2.3 Charging System}

The charging pumps, together with the SI pumps, perform the highpressure coolant injection and recirculation (HPI/R) functions at the representative $W$ PWR. The charging system consists of two centrifugal charging pumps (CCP) and one positive displacement charging pump (PDP) (Figure B.3). Neglecting the P.DP because of leakage and reliability problems, the charging system consists of two $100 \%$ redundant pump trains, which share a common RWST suction line and common injection line into the RCS cold legs. The PDP is not shown in Figure B.3. 
Safety Injection SystemRecirculation Mode (SIREC)
Insufficient

Flow Through

PS25

(Recirculation)

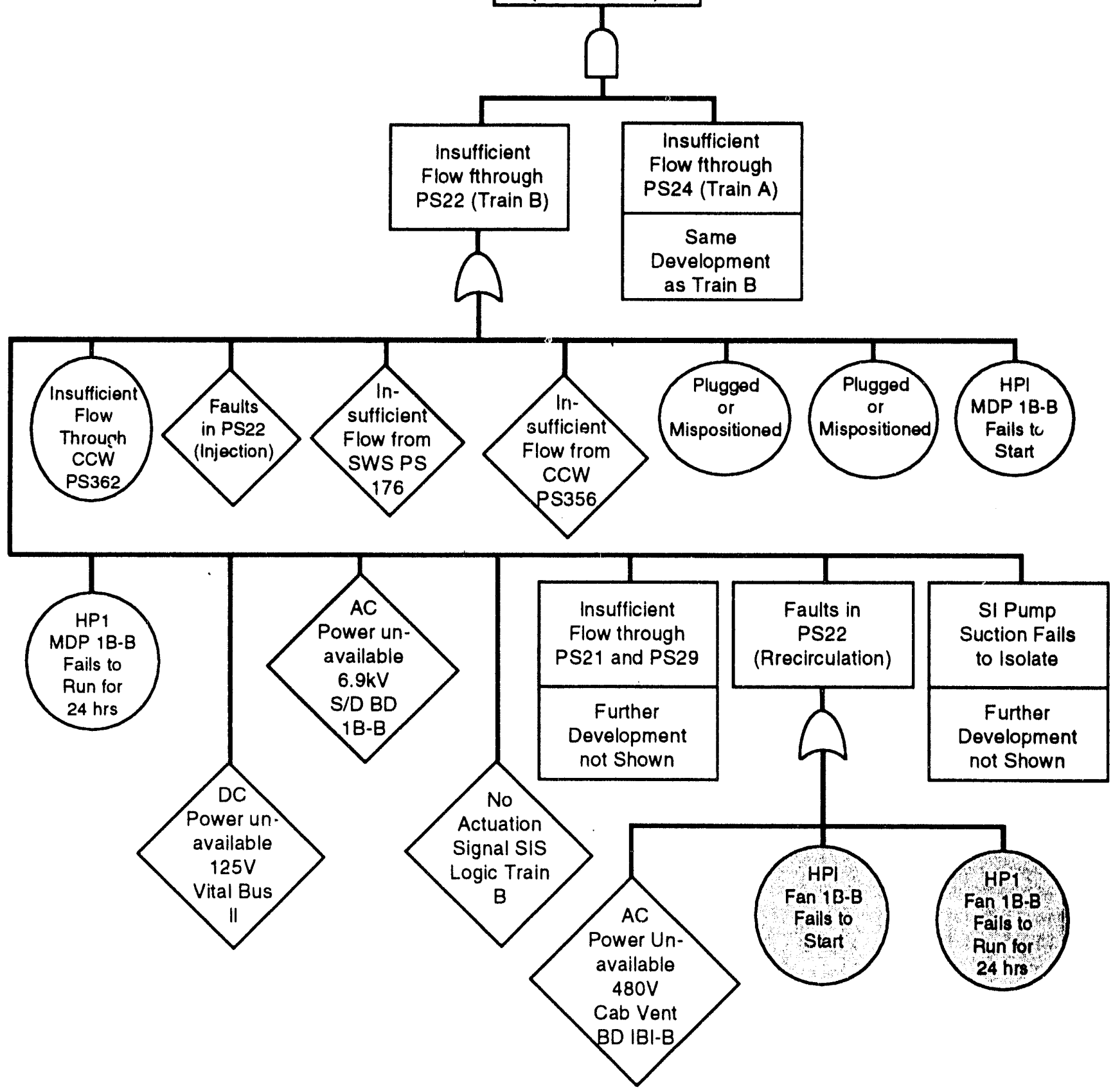

FIGURE B.2. Simplified Fault Tree for the SI System 


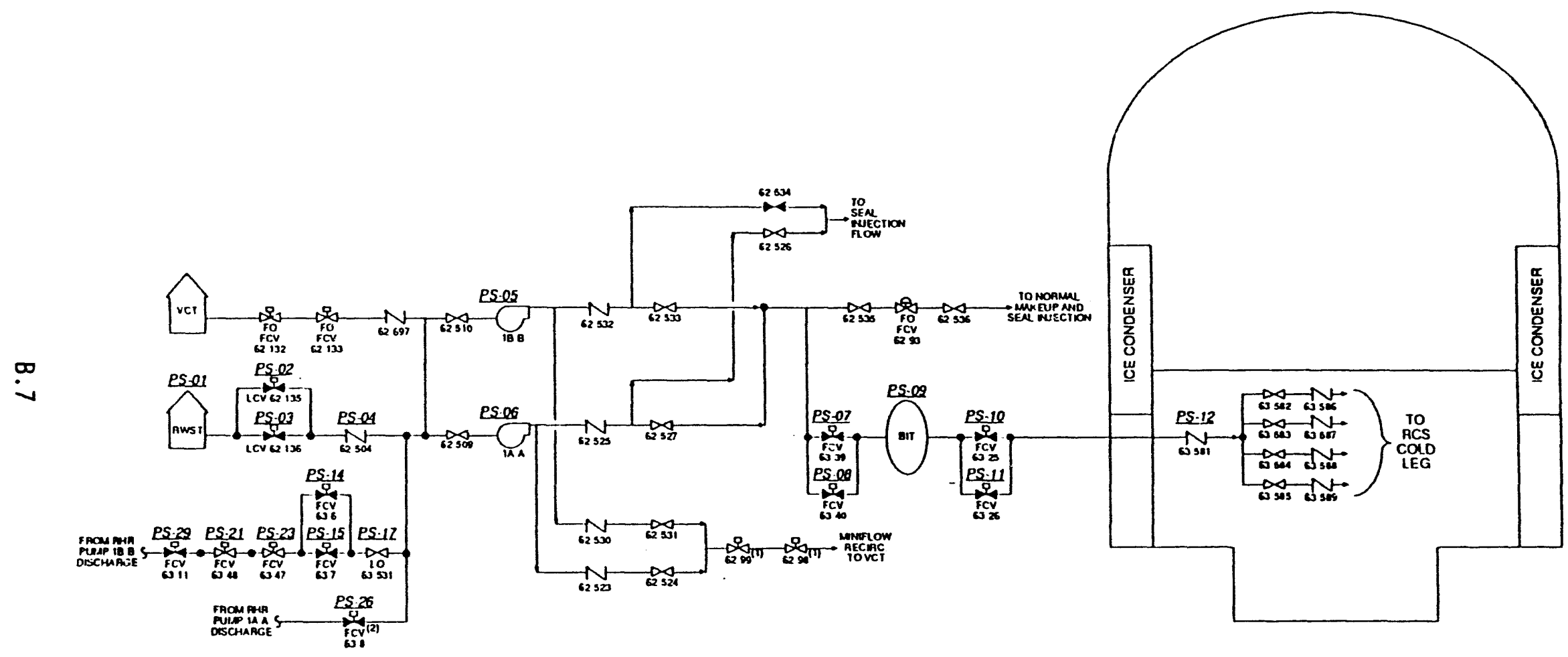

NOTES: (IINOAMALLY OPEN. POWEA REMOVED

(2) WILL NOT OPEN UNLESS THANEO SUMP ISO. VALVE (FCV 63.73 OR 63.72) IS FULLY OPEN, ANO SI MNFFL OW VALVE 633 IS FULLY CL OSED OR BOTH SI MNIFLCW VALVES 63-175 AND 63. 4 AAE FUL LY CLOSED

FIGURE B.3. Simplified Schematic of the Charging System 
Under normal operations, one CCP is operating to provide reactor coolant inakeup. In this mode, the CCP takes suction from the volume control tank and delivers makeup flow through two normally open MOVs in series. The charging pumps also provide seal injection flow to the reactor coolant pump (RCP) seals.

Under accident conditions, the ESFAS automatically initiates charging system operation in the injection mode. The second CCP is started, the RWST isolation valves are opened, and the MOVs on either side of the boron injection tank are opened, allowing flow to be delivered to the RCS cold legs. Should automatic actuation fail to occur, or if feed-and-bleed cooling were required, the system may be operated manually. Room coolers are interlocked to start automatically when the pumps start.

In the recirculation mode, the charging pumps take suction from the LPR pump discharge. It is necessary to manually accomplish this switchover by opening MOVs that permit charging system and SI system suction to be taken from the LPR pump discharges.

Charging system dependencies and interfaces include the following:

- RWST as suction source shared with SI, residual heat removal (RHR), and containment spray systems.

- Physical and functional interface with the SI system in that the SI and charging system jointly make up the high-pressure ECCS function.

- Injection Mode: RWST for fluid inventory; AC power system for pump and MOV motive force; DC power system for control power; ESF for component activation; and SWS for room cooling and lube oil cooling. Room cooling is required only during the recirculation phase because of the short duration of the injection phase.

- Recirculation Mode: RHR system as a fluid source; AC power, DC power, and SWS systems for same functions as injection mode; room cooling.

Two fault trees were developed by Bertucio and Brown (1990) for the charging system: one for the injection mode and one for the recirculation mode. Only the recirculation mode fault tree, designated CSR, contain d b: ic events involving room cooler failures. A simplified CSR fault tree $i i I_{1}$ ting the dependencies of the charging system on room cooling is shown in Figure B.4.

Basic events that represent room cooler failures are shown on $r$ agos : and 3 of Figure B.4. Note that failure of charging fans $1 A-A$ and in $B$ io functionally equivalent to failure of charging pumps $1 A-A$ and $1 B-B$, res ittively. Also, it was assumed by Bertucio and Brown (1990) that charyin. lim. $1 A-A$ and fan IA-A are normally running, so a basic event for failure $\therefore$, equipment to START is not included in the fault tree. Failure to RUN fry it hours is included. Finally, note that the room coolers for the Trains $A$ and $B$ charging pumps are completely separate from each other; i.e., they receive 


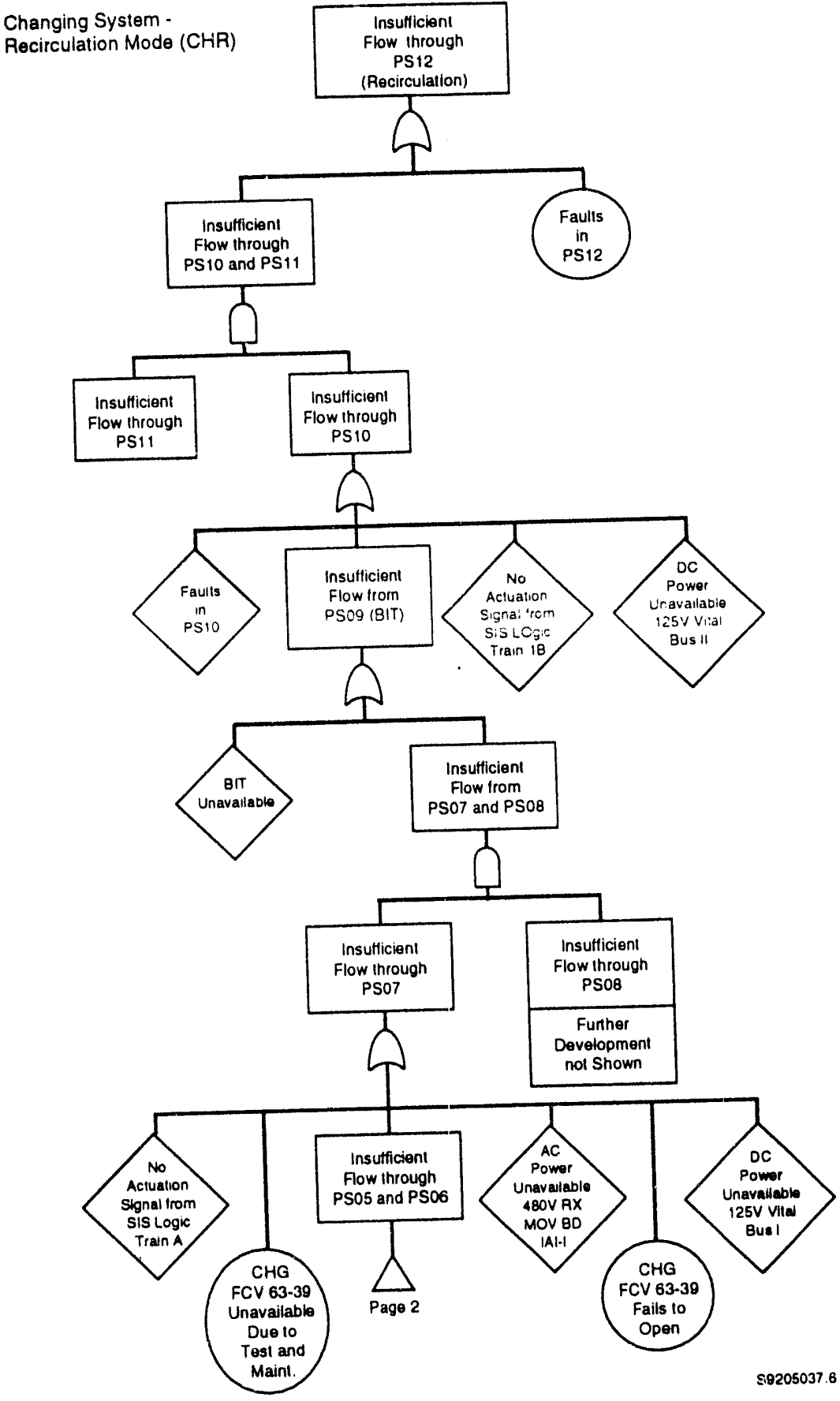

FIGURE B.4. Simplified Fault Tree for the Charging System - Recirculation Mode 


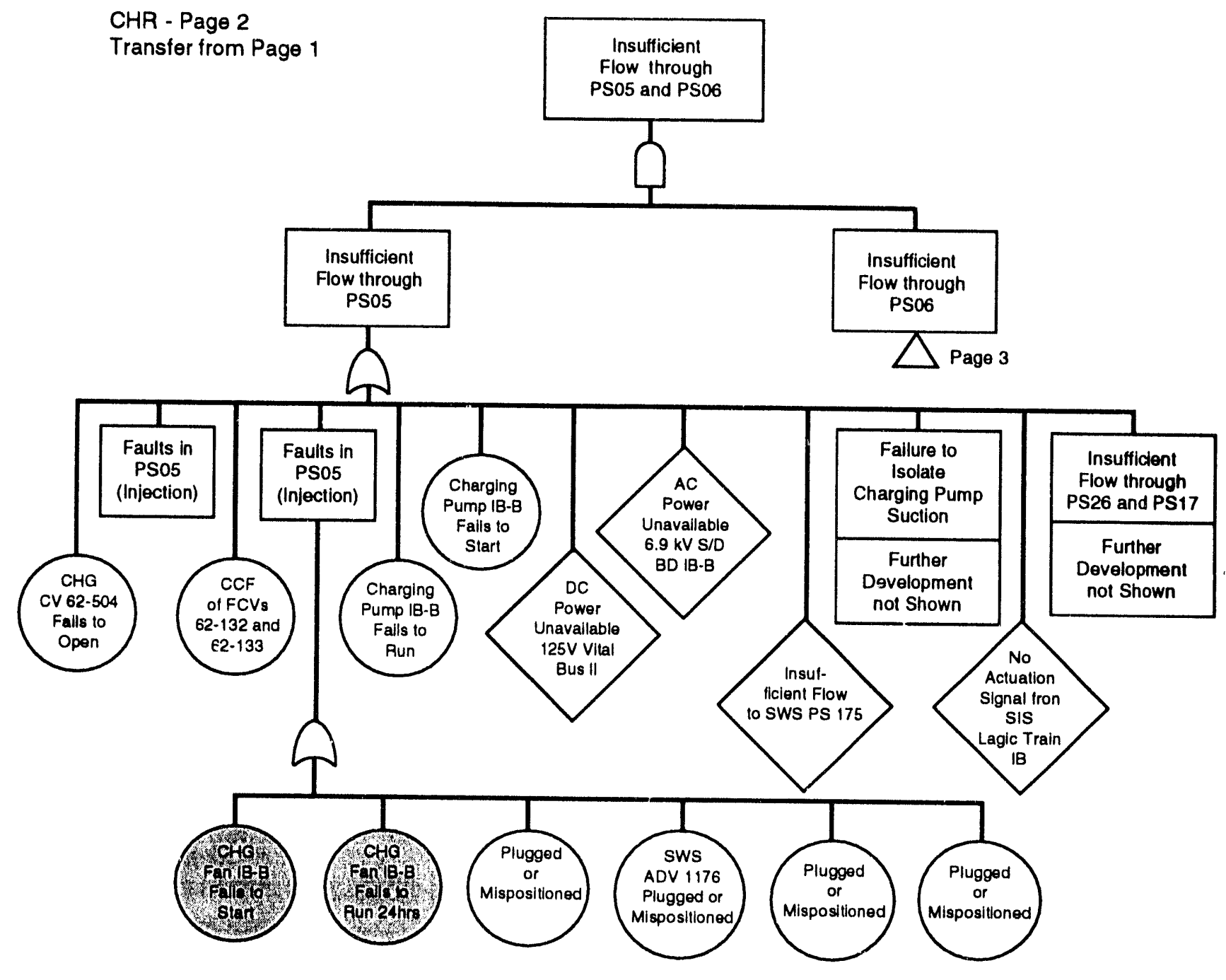

$\$ 9205037.7$

FIGURE B.4. (contd) 


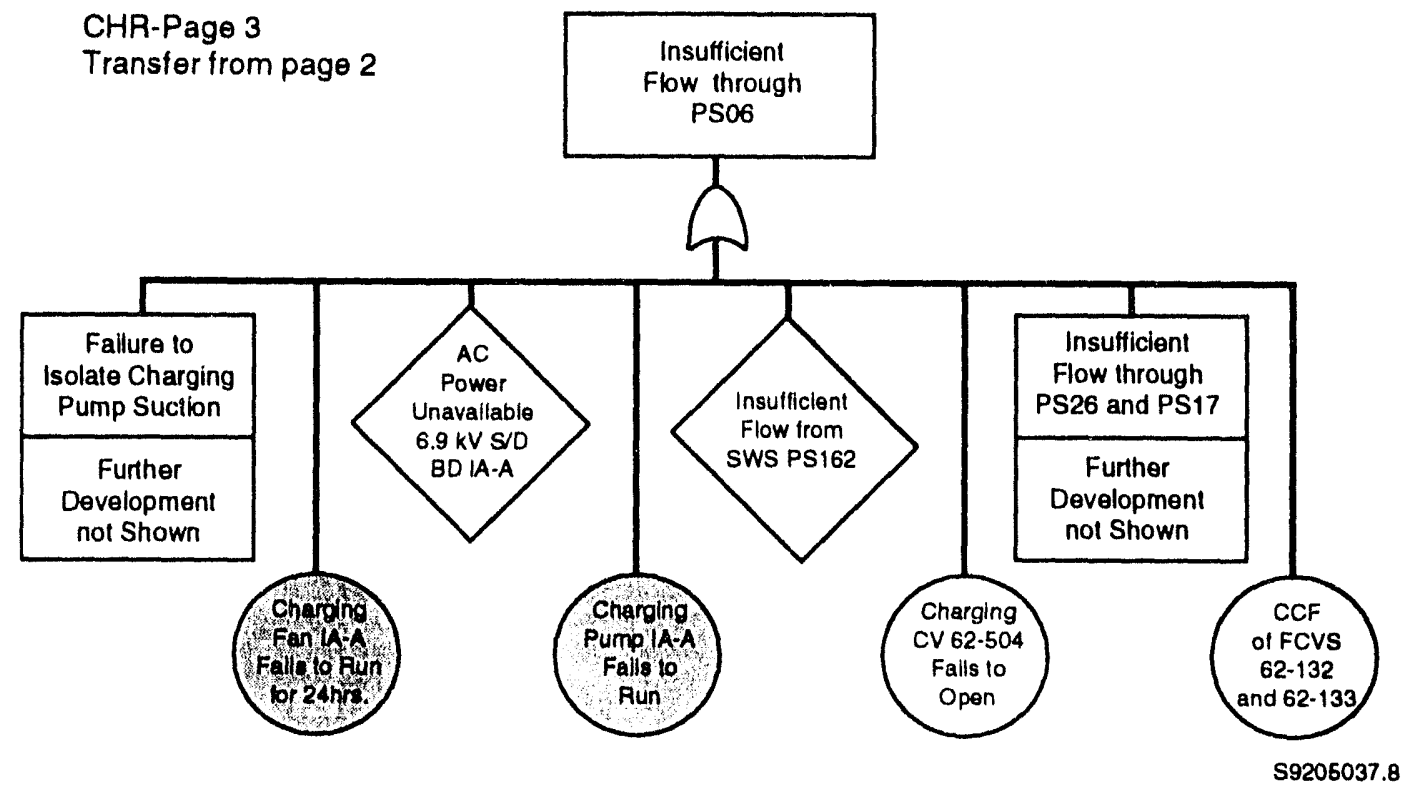

FIGURE B.4. (contd)

separate actuation signals and are powered from different 6.9-kV shutdown boards. Basic event data for the charging fans were presented in Table B.1.

\section{B.2.4 Low-Pressure Injection/Recirculation System}

The residual heat removal (RHR) system provides emergency coolant injection and recirculation following LOCAs in which the primary system has been depressurized. Under these conditions, the RHR system is referred to as the LPI or LPR system. The RHR system also provides the shutdown cooling function. In addition, LPI/LPR provides primary containment overpressure protection by delivering low-pressure sprays to the containment atmosphere.

The LPI/LPR system comprises two 100\%-capacity, redundant pump trains (see Figure B.5). During the injection mode, LPI pumps take suction from the RWST and discharge through a check valve, two locked-open manual valves, the RHR heat exchanger, an air-operated valve (AOV), and an MOV, all arranged in series, into the RCS cold legs. Each of the lines to the RCS cold legs contain two check valves to isolate the LPI system from the high-pressure RCS. LPI/LPR room coolers start automatically when the pumps start.

In recirculation mode, the LPR pump trains take suction from the containment sump. Discharge into the RCS cold legs follows the same path as the injection mode. Opening of the sump suctionivalves occurs automatically upon reaching low (29\%) RWST level. 


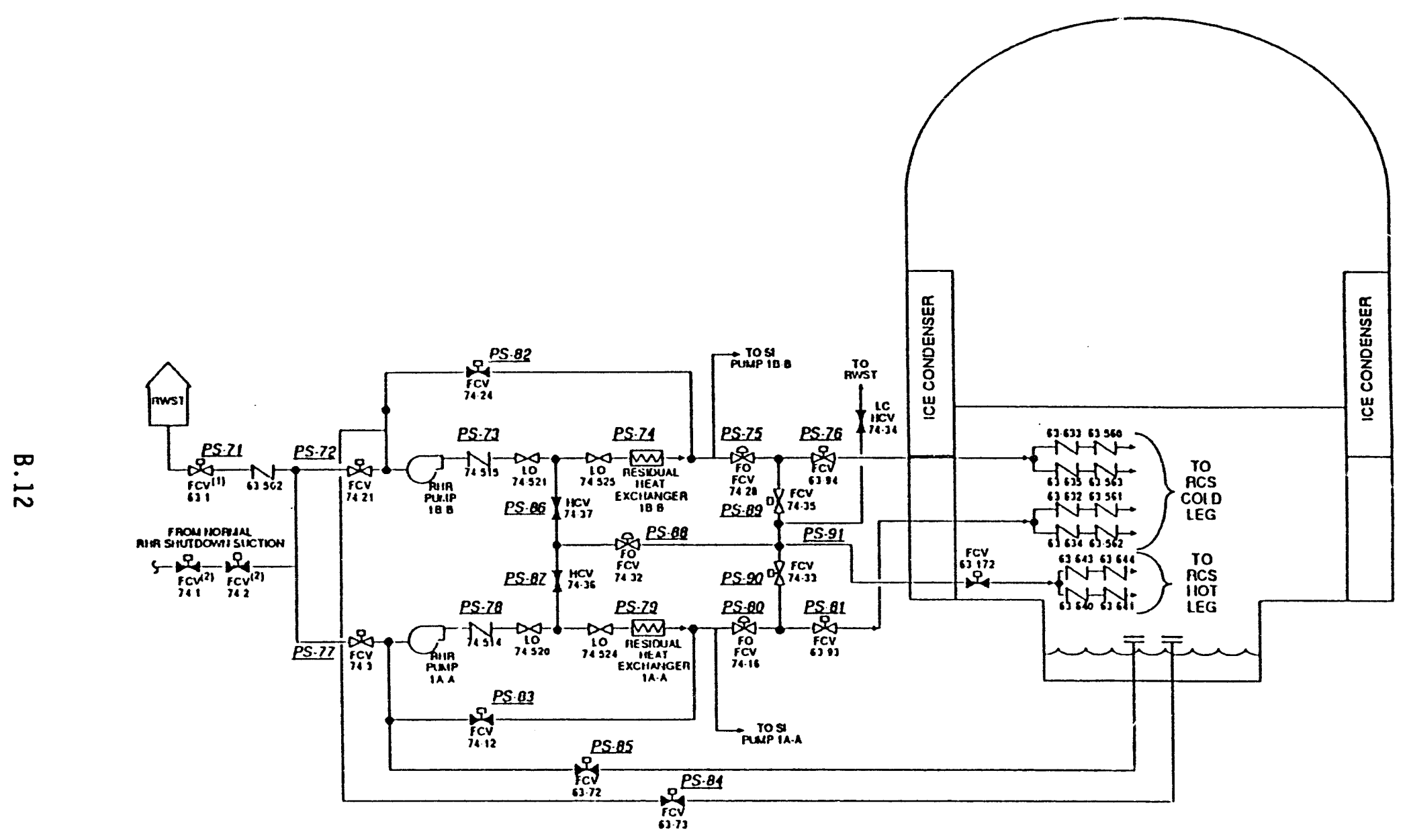

NOTES: (1) HORMALLY OPEN. POWER REAIOVED

(2) LOCKED CLOSED. PRESSUIRE INIERLOCKED VALVES

FIGURE B.5. Simplified Schematic of the LPI/LPR System 
LPI/LPR system interfaces and dependencies include

- LPI interfaces with containment spray and charging systems at the common RWST

- LPR interfaces with charging and SI systems at their respective suction valves

- Injection Mode: dependencies include the RWST as a fluid source; $A C$ power system for pump and MOV motive power; DC power system for pump control power; ESFAS for system actuation; CCW system for pump cooling. CCW is required to provide pump cooling during both injection and recirculation phases; pump room cooling is required only during recirculation mode because of the short duration of the injection mode.

- Recirculation Mode: containment sump as fluid source; AC power, DC power, CCW, and SWS systems as described above for injection mode. ESF required to switch from injection to recirculation modes. Room cooling is required during recirculation mode. Room cooling is required during recirculation mode.

These three fault trees were developed by Bertucio and Brown (1990) for the LPI/LPR system:

- Low-pressure system - injection mode (LPI)

- Low-pressure system - cold leg recirculation mode (LPCHR)

- Low-pressure system - hot leg recirculation mode (LPHOT)

Only the cold leg recirculation mode fault tree, designated LPCHR, contained basic events involving room cooler failures. A simplified LPCHR fault tree illustrating the dependencies of the LPI/LPR system on room cooling is shown in Figure B.6.

Failures of the LPR fans are functionally equivalent to failures of the LPI/LPR pumps. Neither LPR pumps $1 A-A$ and $1 B-B$ nor their attendant room coolers are normally operating components, so the fault tree includes separate events for failure of the pumps (and fans) to start as well as failure to run for 24 hours. Unavailability of the fans due to test and maintenance is also included. Note that failure of LPR requires failures of both Train A (insufficient flow through PS 81) and Train B (insufficient flow through PS 76). Development of the fault tree branch for Train $A$ is not shown in Figure B. 6 but is similar to the branch for Train B, except for obvious differences in valve numbers, power sources, specific pipe segments, and other separate and redundant equipment.

\section{B.2.5 Auxiliary Feedwater System}

The function of the auxiliary feedwater (AFW) system is to provide feedwater to the steam generators (SGs) to allow continued heat removal from the primary system when main feedwater (MFW) is not available. The AFW system consists of three trains (see Figure B.7). Two trains are provided with 


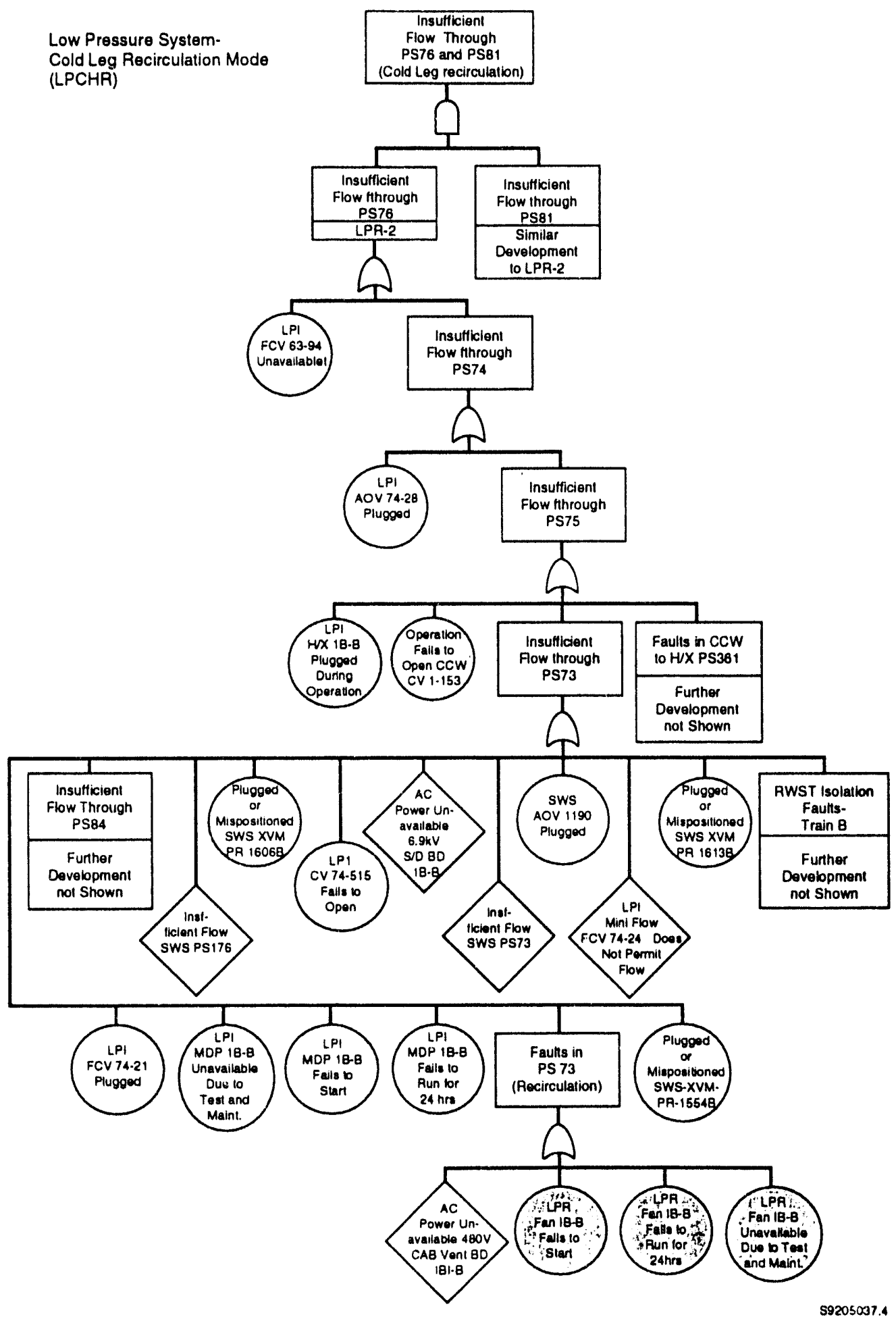

FIGURE B.6. Simplified Fault Tree for the LPI/LPR System - Cold Leg Recirculation Mode 


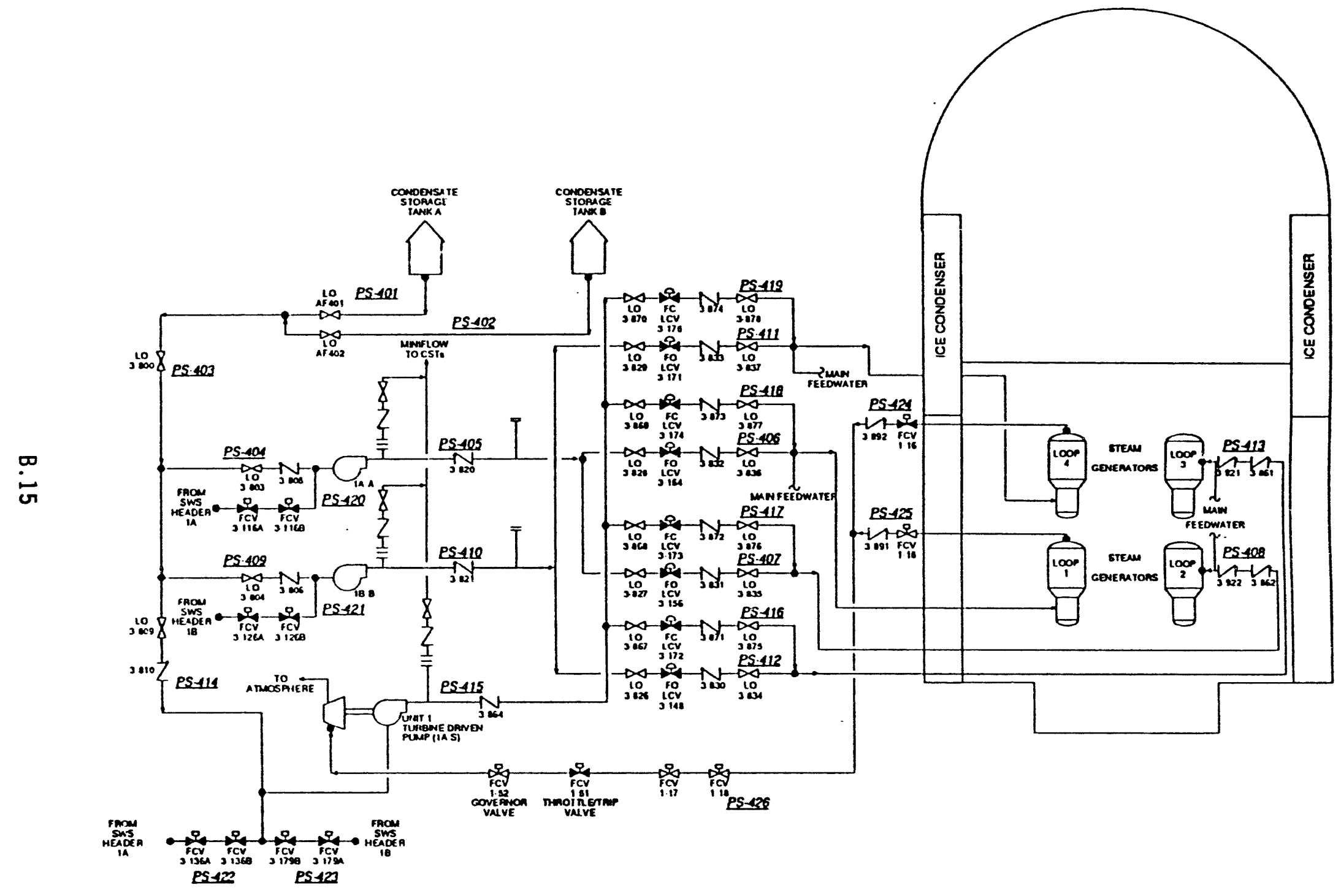

FIGURE B.7. Simplified Schematic of the Auxiliary Feedwater System 
motor-driven pumps (MDPs) and the third is provided with a turbine-driven pump (TDP). Each MDP discharges to two of the four SGs. The TDP, which is twice the capacity of each MDP, is capable of discharging to all four SGs. Each pump takes suction through a common header from the condensate storage tank (CST) or from one of two SWS headers.

The two MDPs automatically start and the TDP throttle/trip valve opens automatically to start the TDP upon receipt of an AFW actuation signal. The signal also causes the normally closed AOVs in the AFW supply lines to the SGs to open automatically. TDP room coolers are interlocked and start automatically when the pump starts. Automatic switchover to the SWS supply headers is accomplished upon receipt of a low AFW pump suction pressure, which indicates that the CST water supply is becoming depleted. This is done by automatically opening the SWS header isolation valves.

AFW system dependencies and interfaces include the following:

- $A C$ power for motive power for the MDPS; DC power for control power for the MDPS, TDPs, and AOVs; and ESFAS for automatic actuation.

- Instrument air system for operation of the AOVs.

- HVAC system for TDP room cooling.

- Room cooling is required for the TDP but is not required for MDPs, which are located in open rooms and are environmentally qualified for highenergy line break conditions, which are postulated to be more severe than loss of room cooling conditions.

- AFW interfaces with the SWS for a backup water supply.

Three AFW fault trees were developed by Bertucio and Brown (1990).

- Failure to provide AFW to at least two of four SGs (AFW2)

- Failure to provide AFW to at least three of four SGS (AFW3)

- Failure of one of three AFW pumps to provide AFW to two of three SGs (for steam generator tube rupture sequences - L-SGTR)

A review of these fault trees indicated that only AFW2 and L-SGTR fault trees contained room cooler failures. Simplified versions of these two fault trees are presented in Figures $B .8$ and B.9, respectively.

(a) Room heatup calculations for the AFW MDP room were performed by the utility in support of a 10 CFR 50, Appendix $R$ (fire protection) submittal to the NRC. The results of these calculations confirmed a high-energy line break in this room produces more severe ambient temperature conditions than a loss of room cooling. 


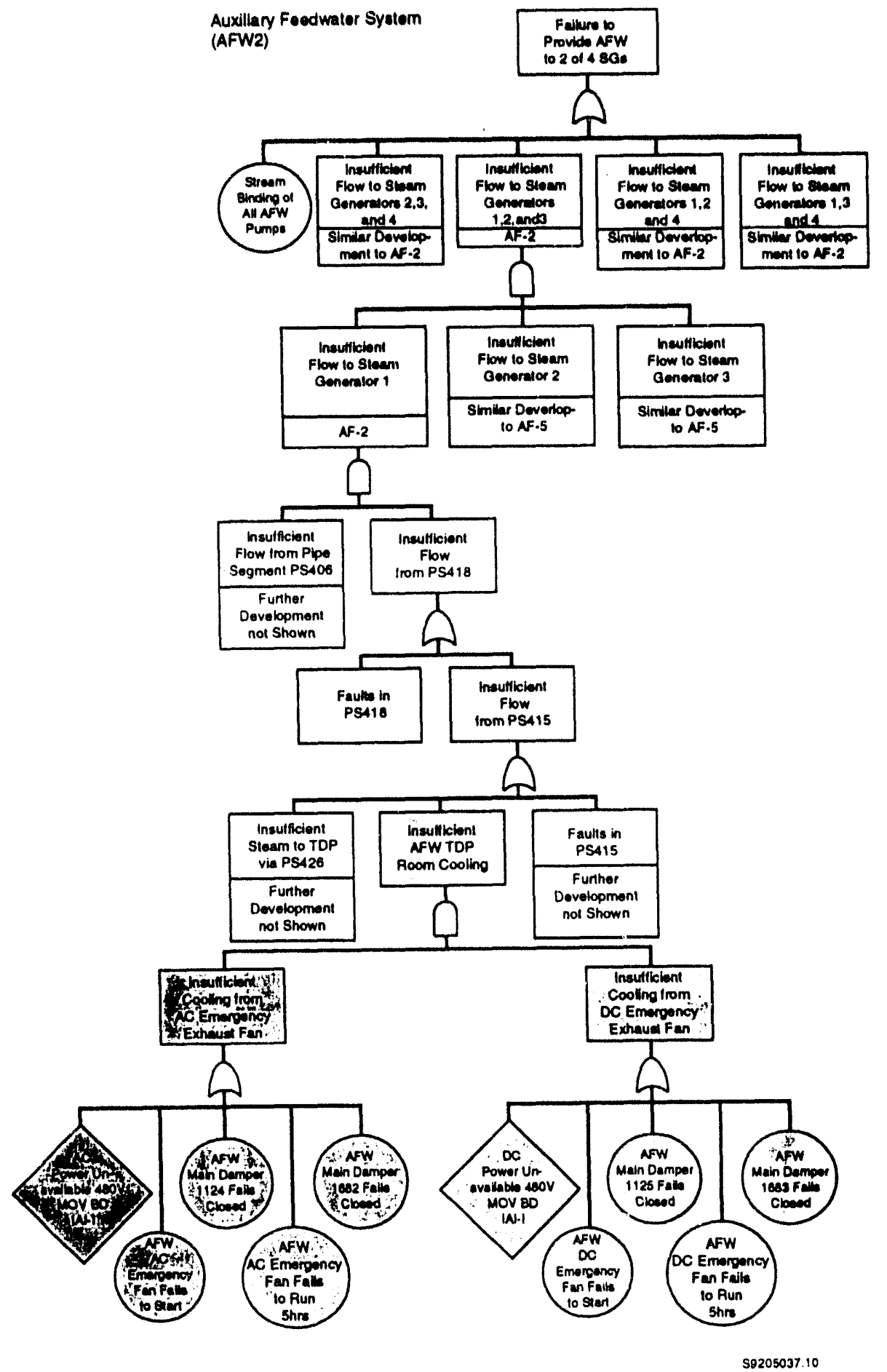

FIGURE B.8. Simplified Fault Tree for AFW System Failure to Provide AFW to Two of Four Steam Generators 


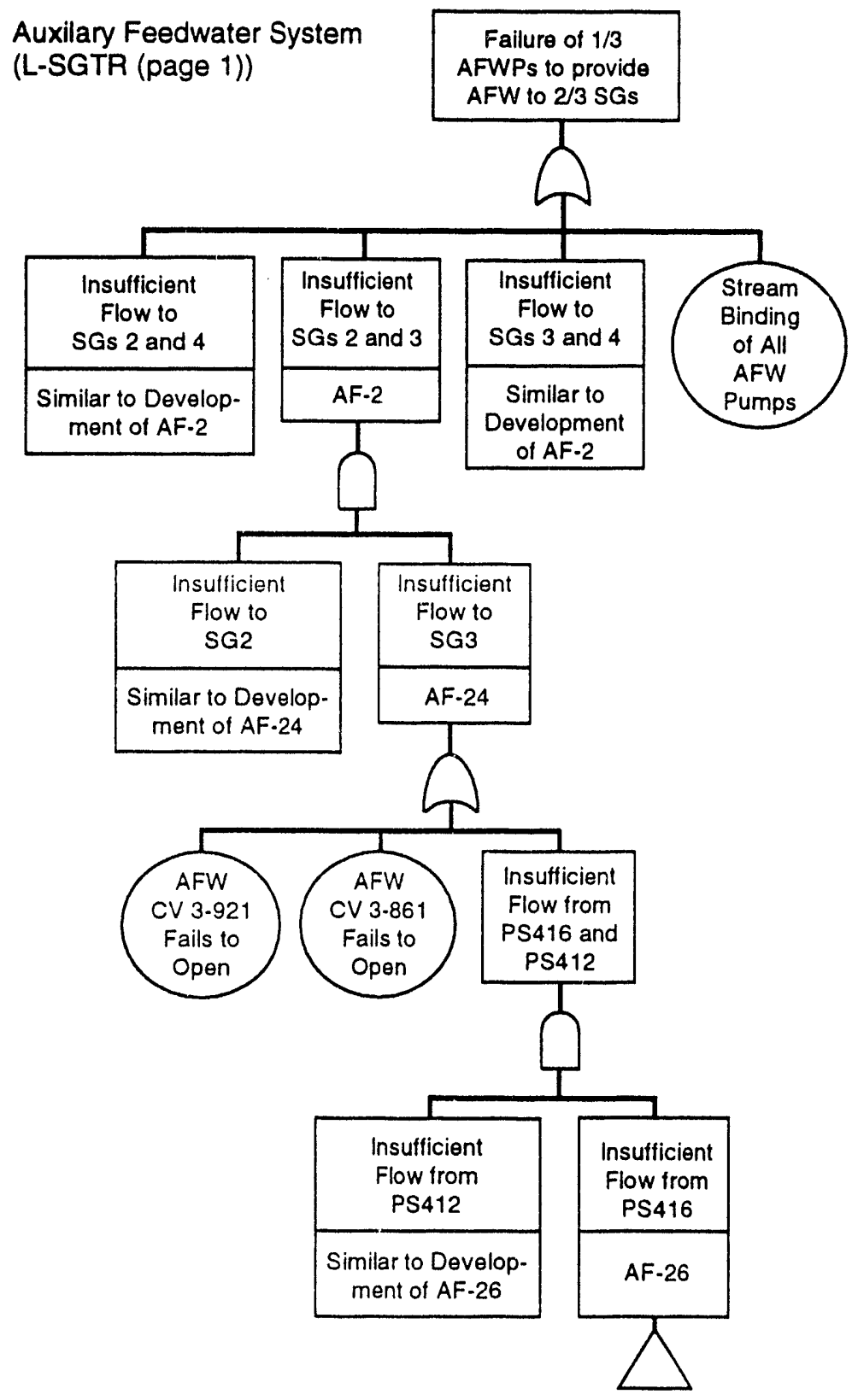

59205037.1

FIGURE B.9. Simplified Fault Tree for Failure of One of Three AFW Pumps to Provide AFW to Two of Three Steam Generators 
As shown in Figure B.8, TDP room cooling may be provided either by an $A C$-powered fan or a DC-powered fan. Failure of both fans is required to result in failure of TDP room cooling. These fans are simply exhaust fans and are not provided with chilled water to cool the room. Heat is exhausted to the large open general area outside the TDP room at the plant. Again, as with previous safety systems, failure of the TDP room coolers is functionally equivalent to failure of the purnp. Failure of the MDP room coolers was not included in the fault trees, because the MDPs are expected to function adequately under loss of room cooling conditions.

\section{B.2.6 Primary Pressure Relief System}

The function of the primary pressure relief system (PPRS) is to provide overpressure protection for the primary system. The PPRS also provides a means to lower RCS pressure if necessary for such situations as feed-and-bleed cooling. The system consists of three safety-relief valves (SRVs) and two power-operated relief valves (PORVs). All relief valves discharge to the pressurizer relief tank. The PORVs automatically open upon high RCS pressure or may be manually opened from the control room. Normally open motor-operated block valves are also provided with each PORV. The PORVs provide RCS pressure relief at a set point below the SRVs.

The PPRS is dependent upon DC power for control power to the PORVs and $A C$ power for motive power to the PORV block valves. The PORVs are not dependent on any other plant system and the SRVs have no dependencies. No dependencies on HVAC or room cooling functions were identified.

\section{B.2.7 Containment Spray System}

The containment spray system (CSS) provides part of the capability for containment pressure suppression during the injection phase of a LOCA and containment heat removal capabilities during the recirculation phase following a LOCA. Pressure suppression is accomplished by spraying cool water from the RWST to condense steam in the containment, referred to as the containment spray injection (CSI) mode. When the RWST is depleted, the CSS is switched to containment spray recirculation (CSR) mode. In the CSR mode, containment heat removal is accomplished by drawing water from the containment sump and circulating through heat exchangers before being discharged to the containment. The switchover from CSI to CSR modes is made through a combination of automatic and manual actions.

The CSS, shown in Figure B.10, contains two 100\%-capacity pump trains. Each train includes a centrifugal pump, heat exchanger, and associated piping and valves. Both CSS pumps are normally in a standby condition. The pumps start automatically when signalled to do so by the ESFAS upon receipt of a high differential pressure signal between the lower containment compartment and the annulus between the ice condenser and the outer containment wall.

This signal also causes an automatic opening of the normally open CSS MOVs in the CSS pump suction lines and the normally closed MOVs in the CSS pump discharge lines. 


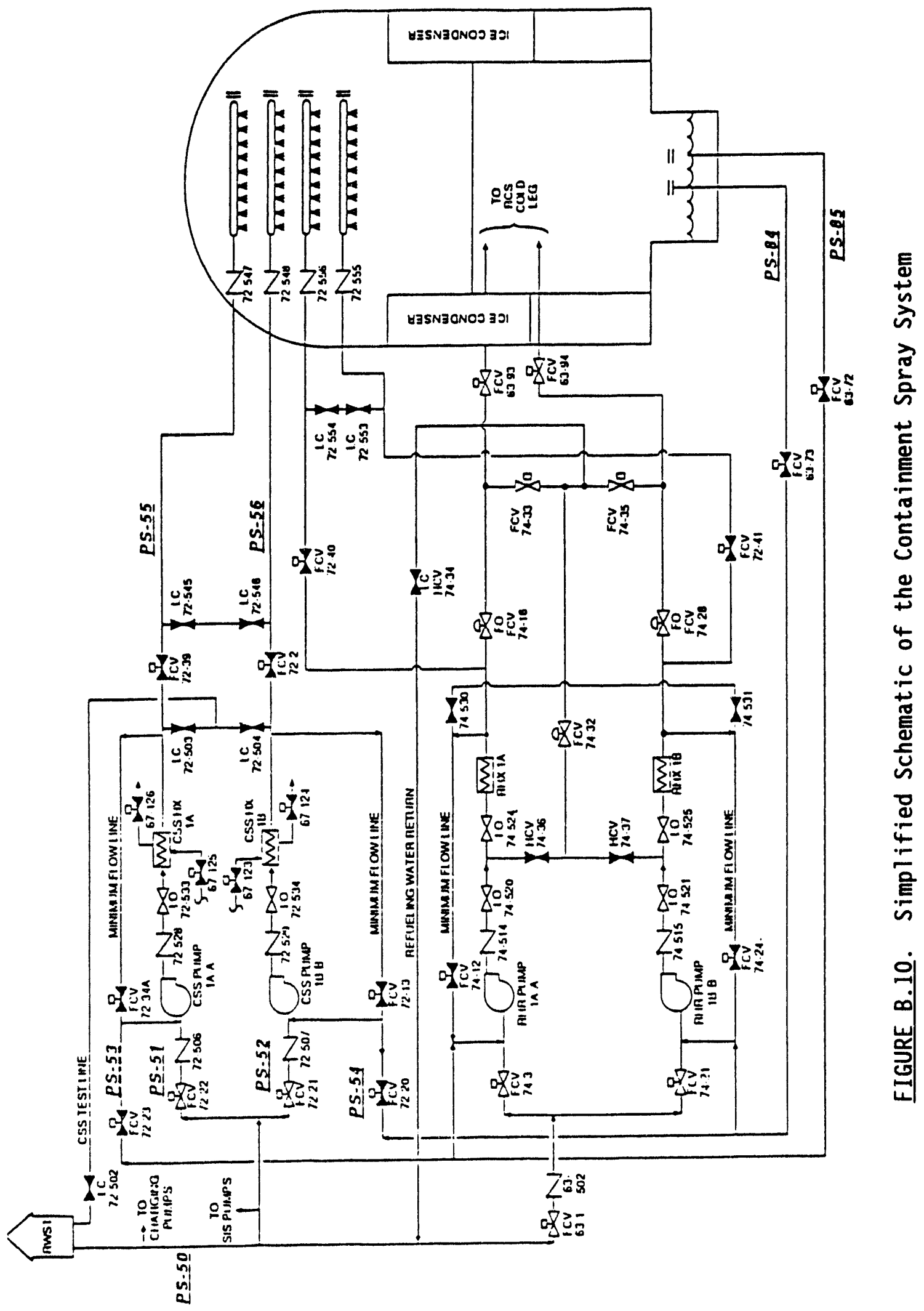

B. 20 
CSS dependencies include

- electric power for motive power for the CSS pumps and MOVs

- ESFAS for automatic actuation

- ESW system for cooling water to the CSS heat exchangers and CSS pump room coolers

- CCW system for cooling to CSS pump oil and bearing coolers

- CSS pump room cooling.

Two fault trees were developed by Bertucio and Brown (1990) for the CSS, one for the injection mode and one for the recirculation mode. Only the recirculation mode fault tree, designated CHR, contained basic events involving room cooler failures. A simplified CHR fault tree illustrating the dependencies of the containment spray system on room cooling is shown in Figure B.11.

As show in Figure B.11, failure of CSS room coolers is functionally equivalent to failure of the CSS pumps. This system is not normally operating, so the fault trees include basic events for failure of the room coolers to START, failure to RUN, and failure due to TEST/MAINTENANCE. The CSS room coolers start automatically when the CSS pumps start.

\section{B.2.8 Component Cooling Water System}

The component cooling water (CCW) system provides cooling water to various ESF components. Systems cooled by CCW include RHR, SI, and CSS. The $C C W$ system also provides cooling water to the reactor coolant pump (RCP) thermal barriers.

The CCW system at the representative $W$ PWR is a closed cooling system, as shown in Figure B.12, that is shared by both reactor units at the site. The CCW system includes five centrifugal pumps and three heat exchangers (HXs). Normal alignment of the CCW system is as follows:

Unit 1

Train 1A ESF equipment

CCW Pump 1A-A, CCW HX A RCP thermal barrier

Train 1B ESF equipment

CCW Pump C-S, CCW HX C

Unit 2

Train 2A ESF equipment RCP thermal barrier

CCW Pump 2A-A, CCW HX B

Train 2B ESF equipment

CCW Pump C-S, CCW HX C

The remaining pumps (i.e., CCW pumps $1 B-B$ and $2 B-B$ ) are normally standby and serve as backups to the normally running pumps during normal operation. The backup pumps start automatically upon receipt of a low-pressure signal in 


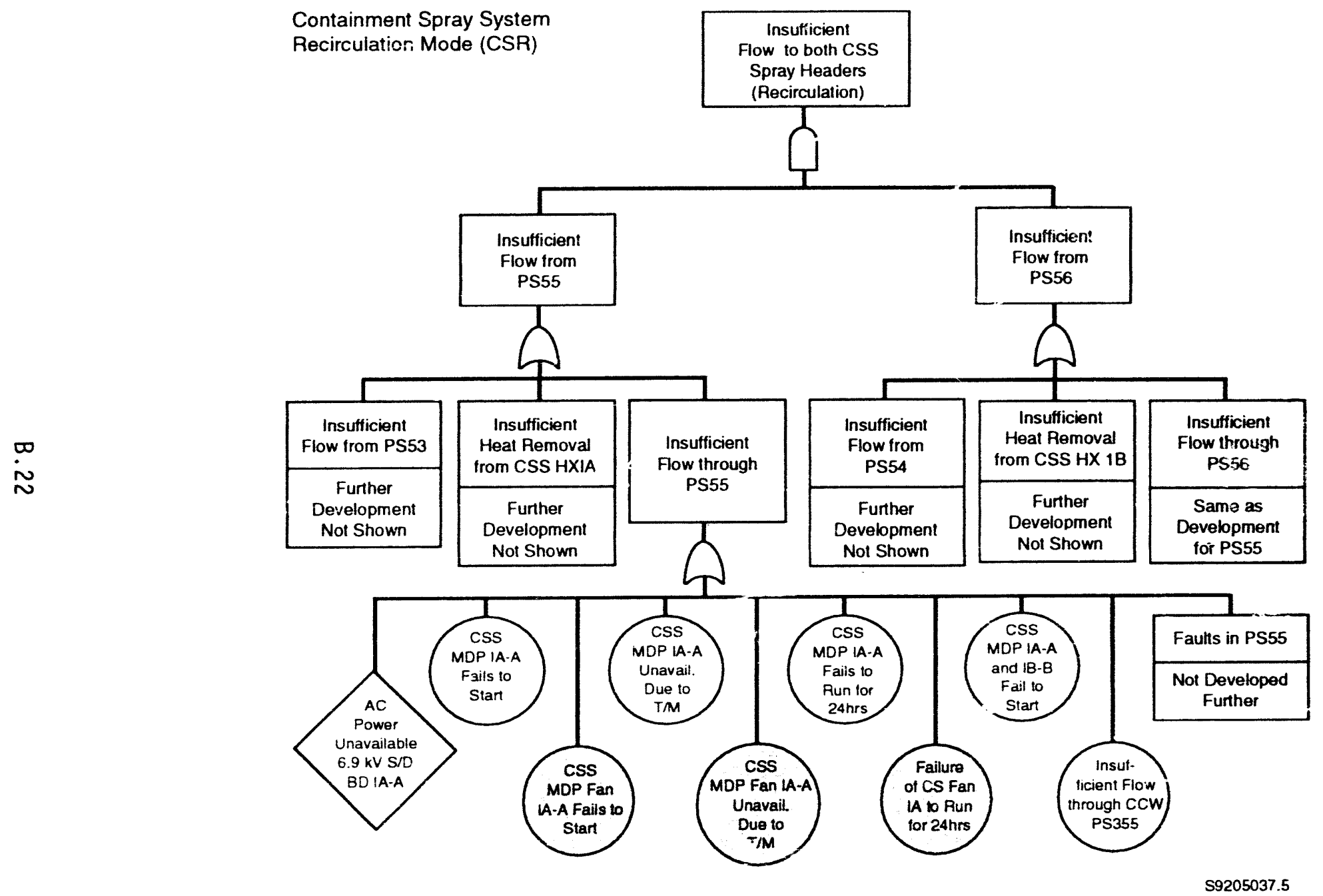

FIGURE B.11. Simplified Fault Tree for Containment Spray System Recirculation Mode 


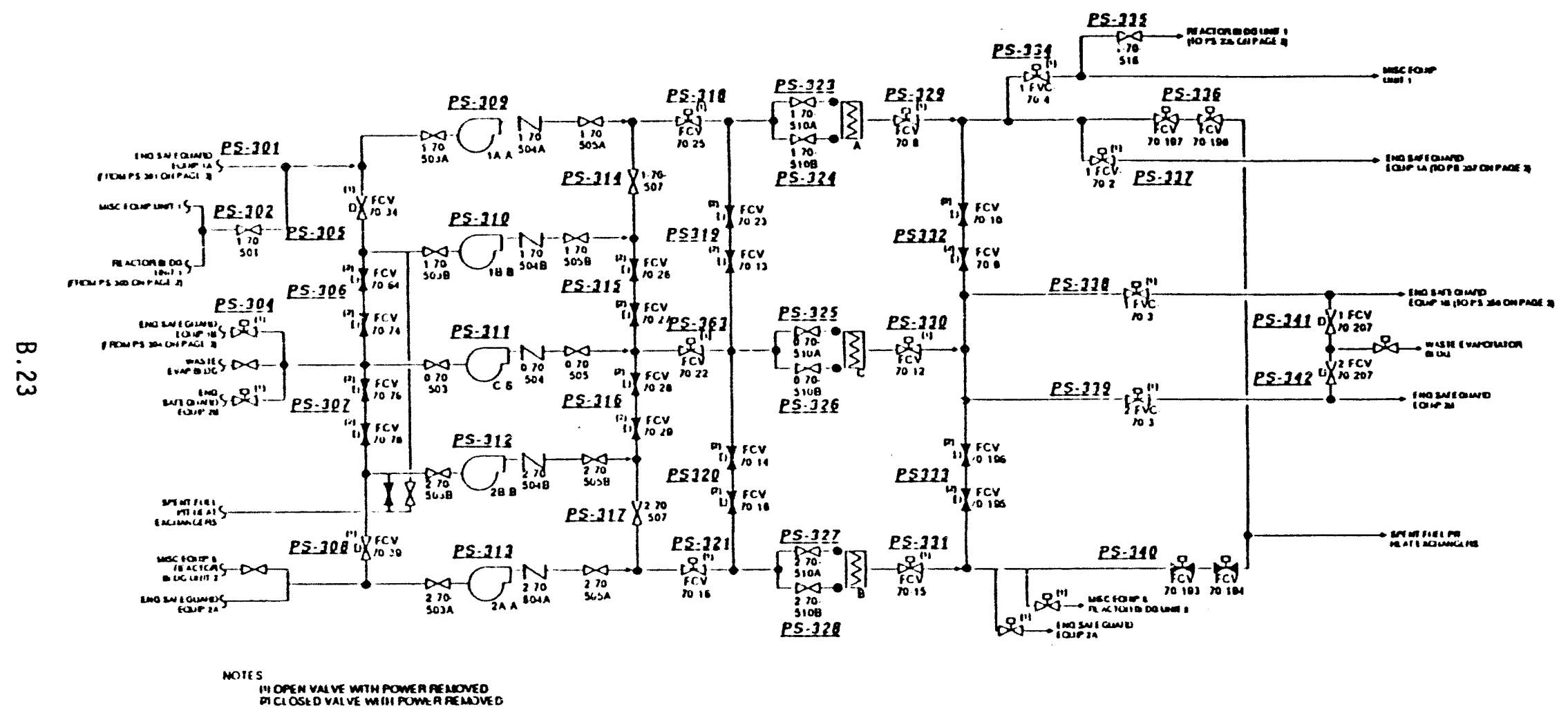

FIGURE B.12. Simplified Schematic of the Component Cooling Water System 


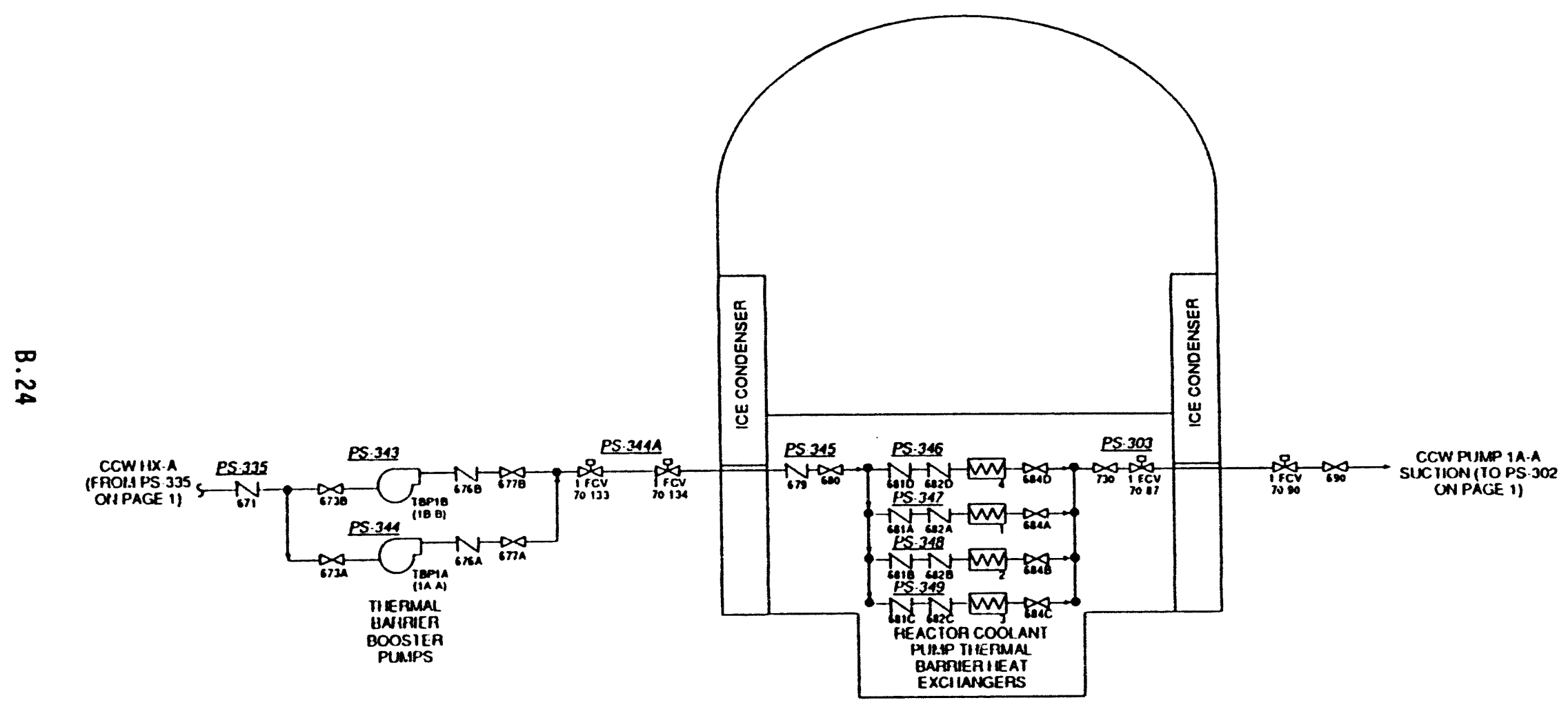

FIGURE B.12. (contd) 


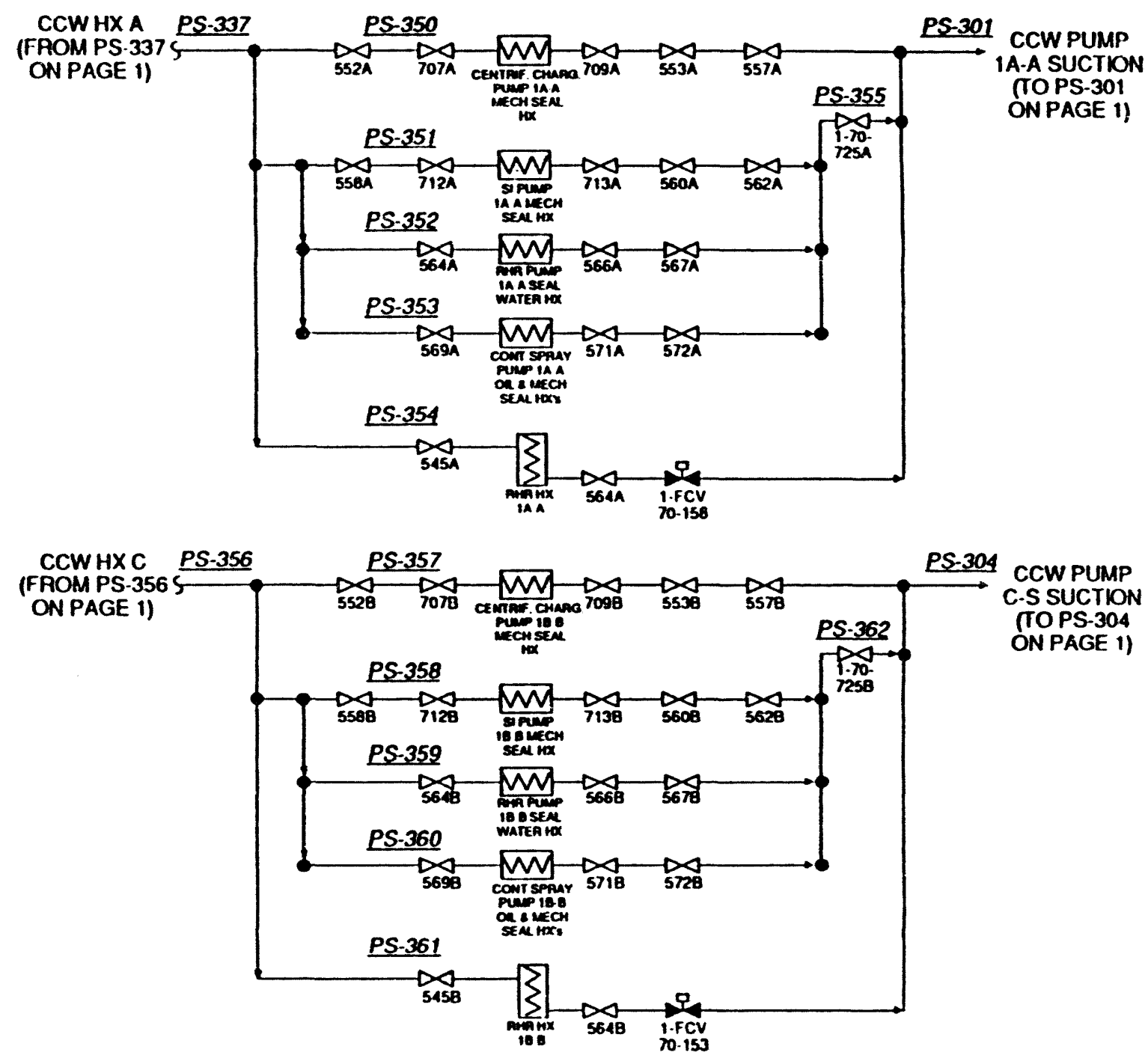

ALI COMPONENTS OUTSHOE CONTAMMENT

FIGURE B.12. (contd) 
the discharge header. In addition, each pump receives an automatic start signal from the corresponding train of ESFAS.

The CCW pumps take suction from the CCW return lines from the ESF equipment they serve. They discharge through the CCW HXs to the CCW supply lines to the ESF equipment they serve. A fraction of the flow from CCW pumps $1 A-A$ or $1 B-B$ is routed through the RCP thermal barrier booster pumps to the Unit 1 RCP thermal barriers and is returned to the suction header for the CCW pumps.

CCW system interfaces and dependencies are as follows:

- Interfaces with electric power system, ESFAS, and ESW systems.

- CCW/AFW pump space is common to both systems. This space is cooled by space coolers which are cooled by the SWS. The pump motors are environmentally qualified to meet high-energy line break criteria, which are more severe than conditions produced in the event of a loss of room cooling. This assumption was confirmed through a review of room heatup calculations performed in support of a 10 CFR 50, Appendix $R$, submittal to the NRC. Therefore, because of the environmental qualification and the open nature of the CCW/AFW room, it was assumed by Bertucio and Brown (1990, p. 4.6-51) that the CCW pumps do not require room cooling for continued operation.

- LPI/LPR depends on CCW for heat removal from the RHR HXs and pump seal water HXs. HPI/HPR system depends on CCW for heat removal from the SI pump. CSS depends on CCW for heat removal from CSS pump oil and mechanical seal HXs. CCW is also needed to remove heat from the RCP thermal barriers.

Since there are no dependencies on room cooling, the CCW system is not considered further in this analysis.

\section{B.2.9 Essential Service Water System}

The essential service water (ESW) system (referred to as the essential raw cooling water system at the representative W PWR) provides cooling water to various front-line safety-related components, including HPI, LPI, and CSS. The ESW system also provides cooling water to the CCW and electric power systems (EPS) and serves as an alternate water supply source for the AFW system. This system, in general, provides cooling water to the various chillers that are used to remove heat from rooms containing safety-related equipment.

The ESW system, an open-cycle system that serves both units at the site (see Figure B.13), draws water from a river. It contains a total of eight pumps: four are normally in operation (two per unit), and the remaining four are started automatically by the ESFAS. Separate supply headers are provided for each ESF train ( $i . e$. , Trains $1 A$ and $1 B$ at Unit 1 and $2 A$ and $2 B$ at Unit 2) for a total of four supply headers. Water flows from the supply headers into branch lines serving the various components listed as follows: 


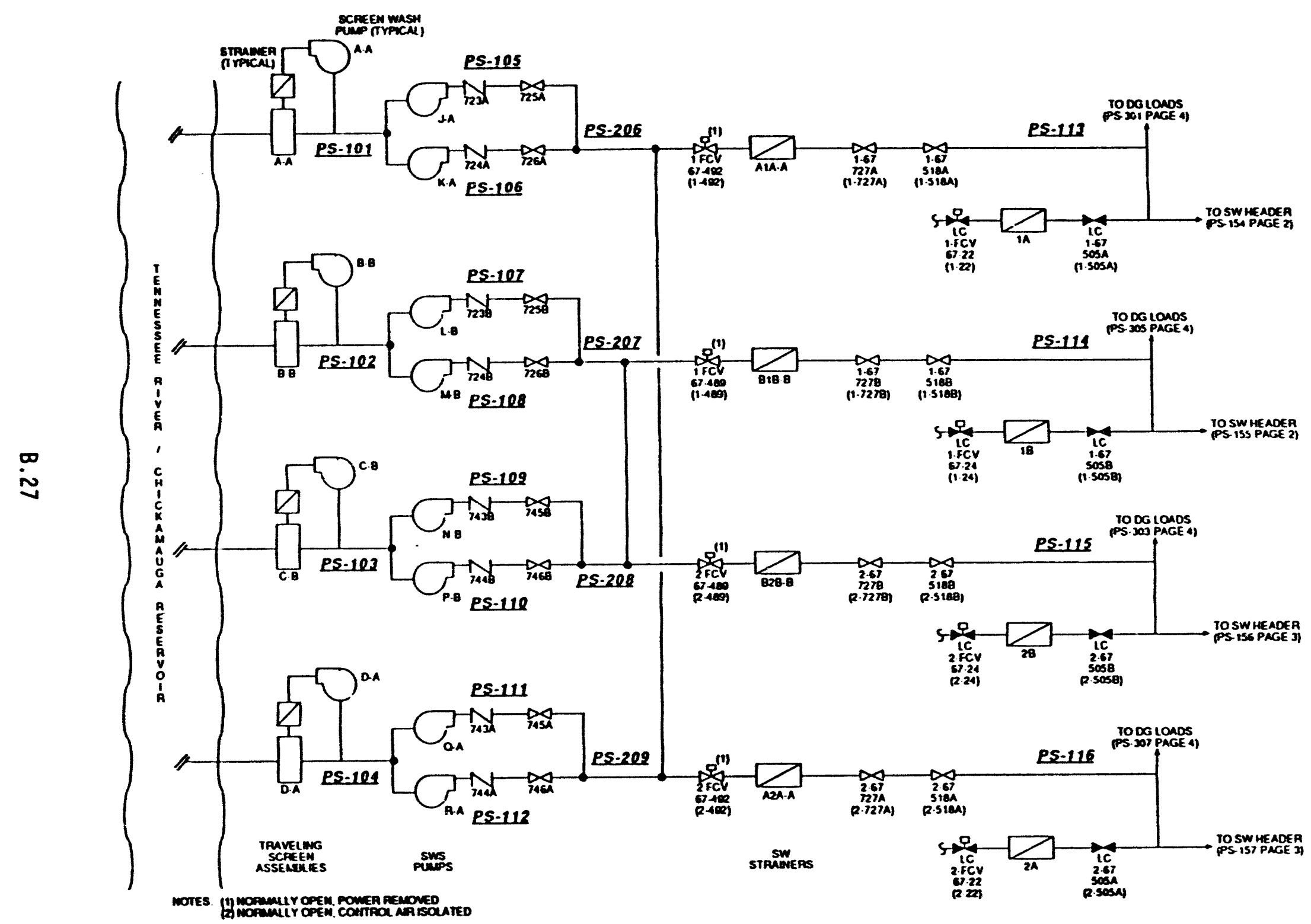

FIGURE B.13. Simplified Schematic of the Essential Service Water System 


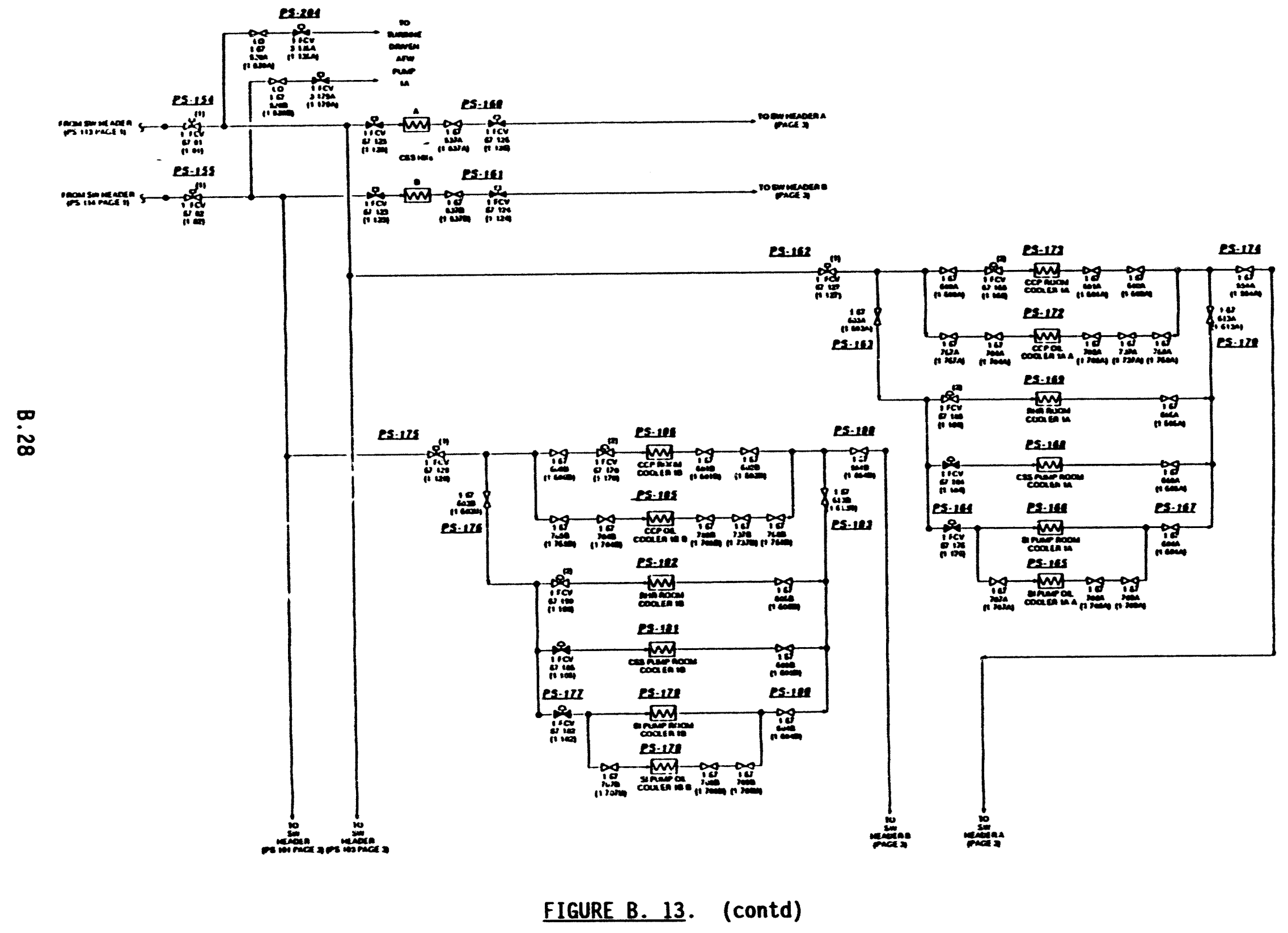




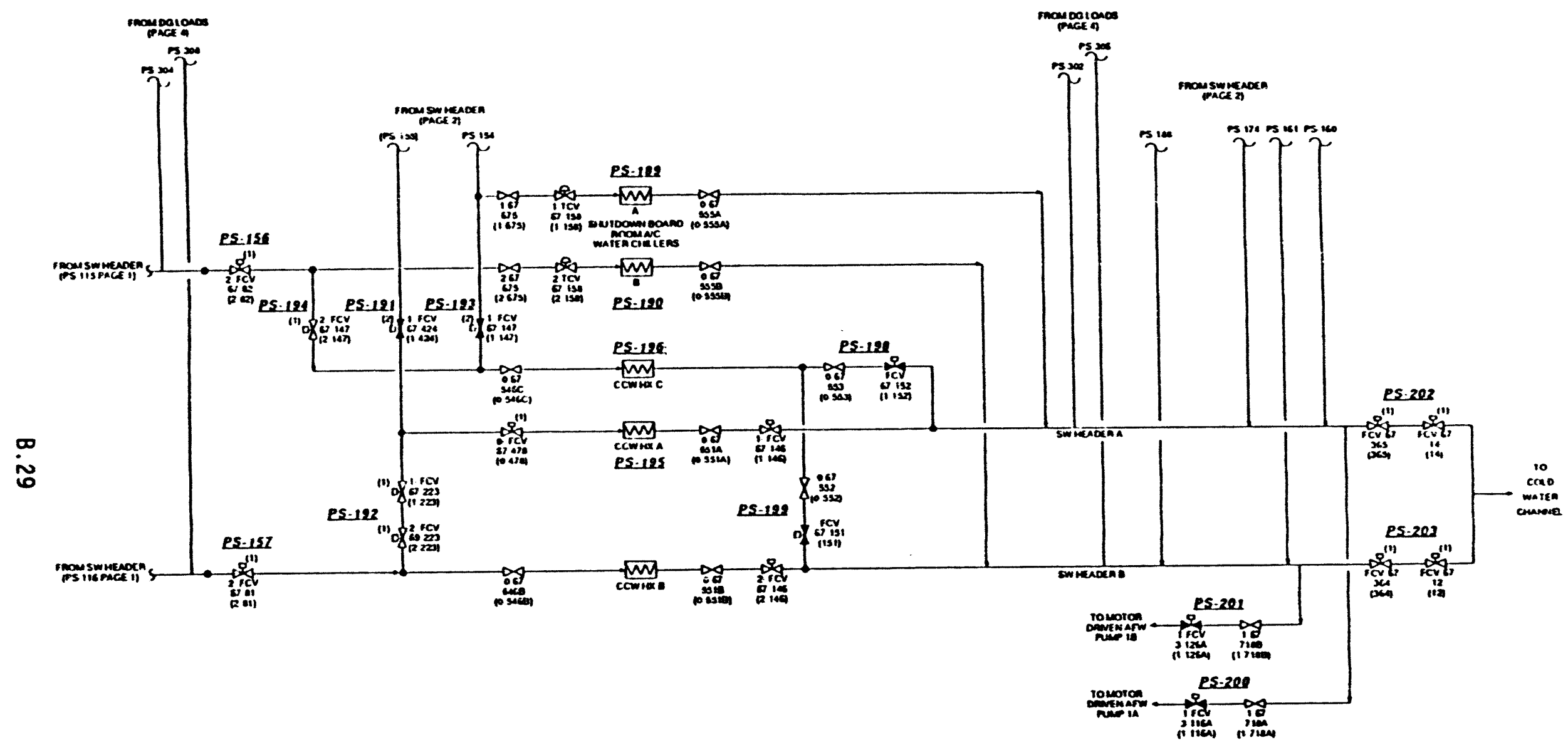

FIGURE B. 13 . (contd) 


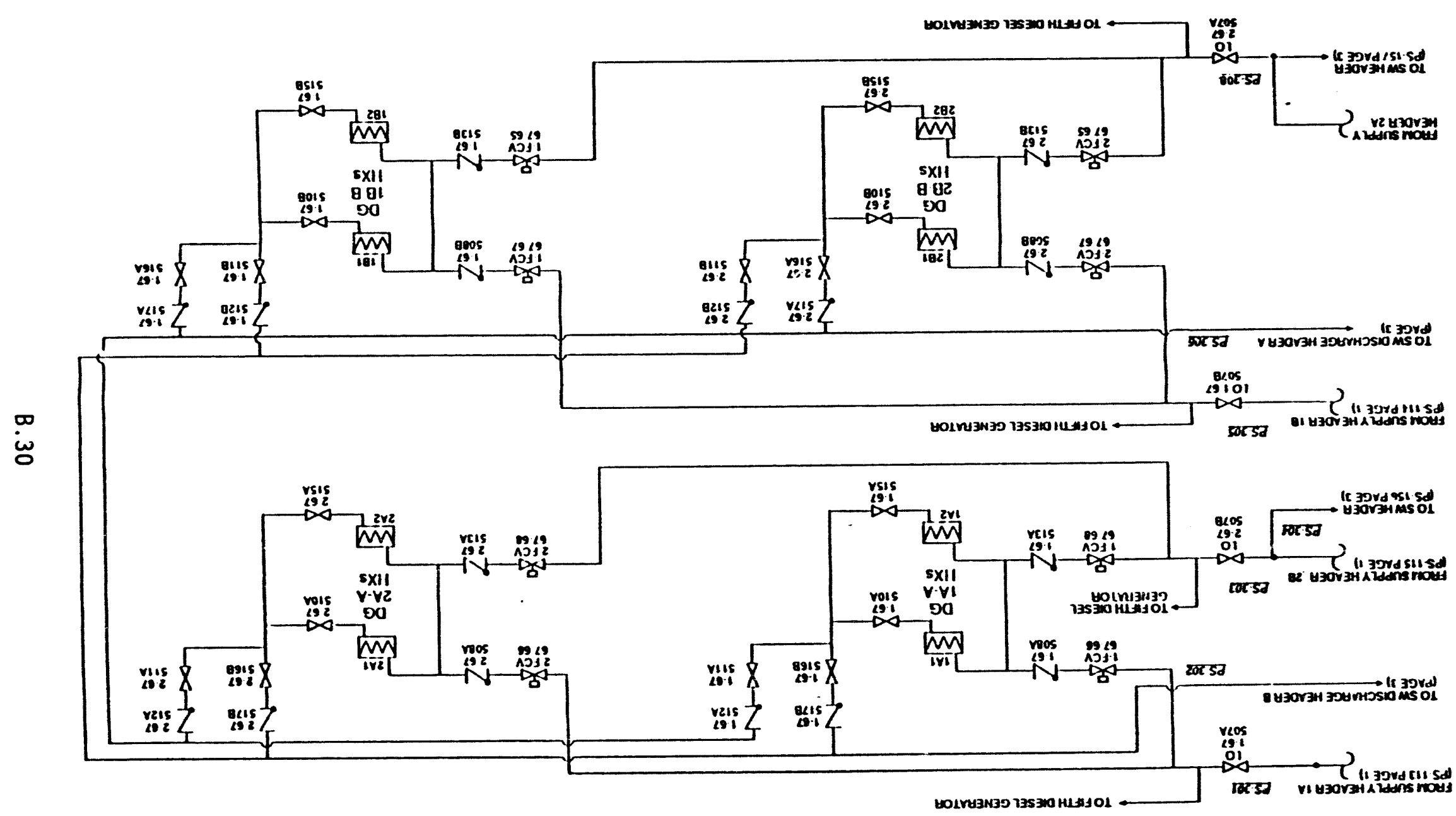

FIGURE B. 13 . (contd) 
- SI and charging pump oil coolers and room coolers

- RHR pump room coolers

- CSS heat exchangers

- Emergency diesel generator (EDG) unit coolers

- Turbine-driven AFW pump

- CSS heat exchangers

- Emergency switchgear (also known as shutdown board) room air conditioner water chillers

- CCW heat exchangers

- Other nonessential loads.

ESW dependencies include $A C$ power for motive power for the pump motors and for motive and control power to valve motors; DC power for control power for the MDPS, TDP, and air-operated valves; and ESFAS for automatic actuation. The pumps are self-cooled and require no room cooling for continued operation. Interfaces include the components listed above. In addition, the AFW system may be aligned to draw water from the ESW system. No dependencies on ESW pump room cooling were identified.

\section{B.2.10 Electric Power System}

The function of the electric power system (EPS) is to provide $A C$ and $D C$ power to safety-related components. The EPS, illustrated in Figure B.14, includes separate $A C$ and $D C$ subsystems. Each subsystem is divided into four trains serving the two reactor units.

$A C$ Trains $1 A$ and $1 B$ serve Unit 1 , and Trains $2 A$ and $2 B$ serve Unit 2. Each $A C$ train includes one 6.9-kV AC shutdown board and two 480-V AC shutdown boards. Each of the 6.9-kV shutdown boards is normally supplied by the offsite power grid or by the plant's main generator. Each board also has an EDG unit that automatically starts upon loss of the normal power supply.

DC Trains I and II generally serve Unit I, and Trains III and IV generally serve Unit 2 . Some DC loads, such as the turbine-driven AFW pump, are cross-connected between units. Each 125-V DC battery board supplies two 120-V AC vital instrument power boards through $120-V$ AC vital inverters. The 120-V AC vital instrument power boards can alternatively be supplied from the 480-V AC shutdown boards through 50-kVA instrument power transformers.

During normal operation, the EPS is dependent upon offsite power. In general, however, operation of the EPS is not dependent on other plant systems. A notable dependency that was not modeled by Bertucio and Brown was the ESW system, which is used to remove heat from EDGs and for cooling of the 


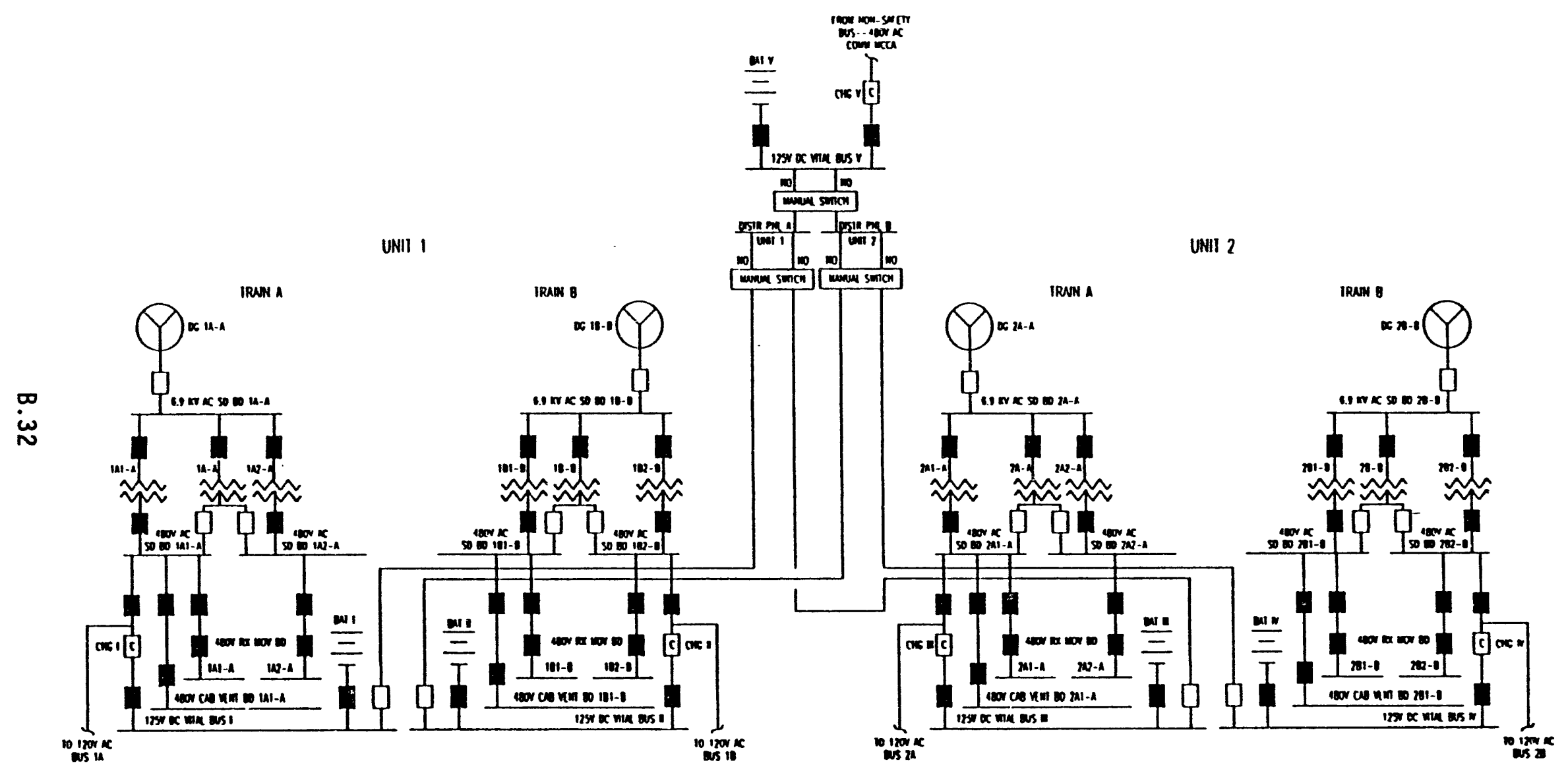

FIGURE B.14. Simplified Schematic of the Electric Power System 


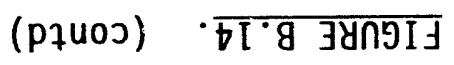
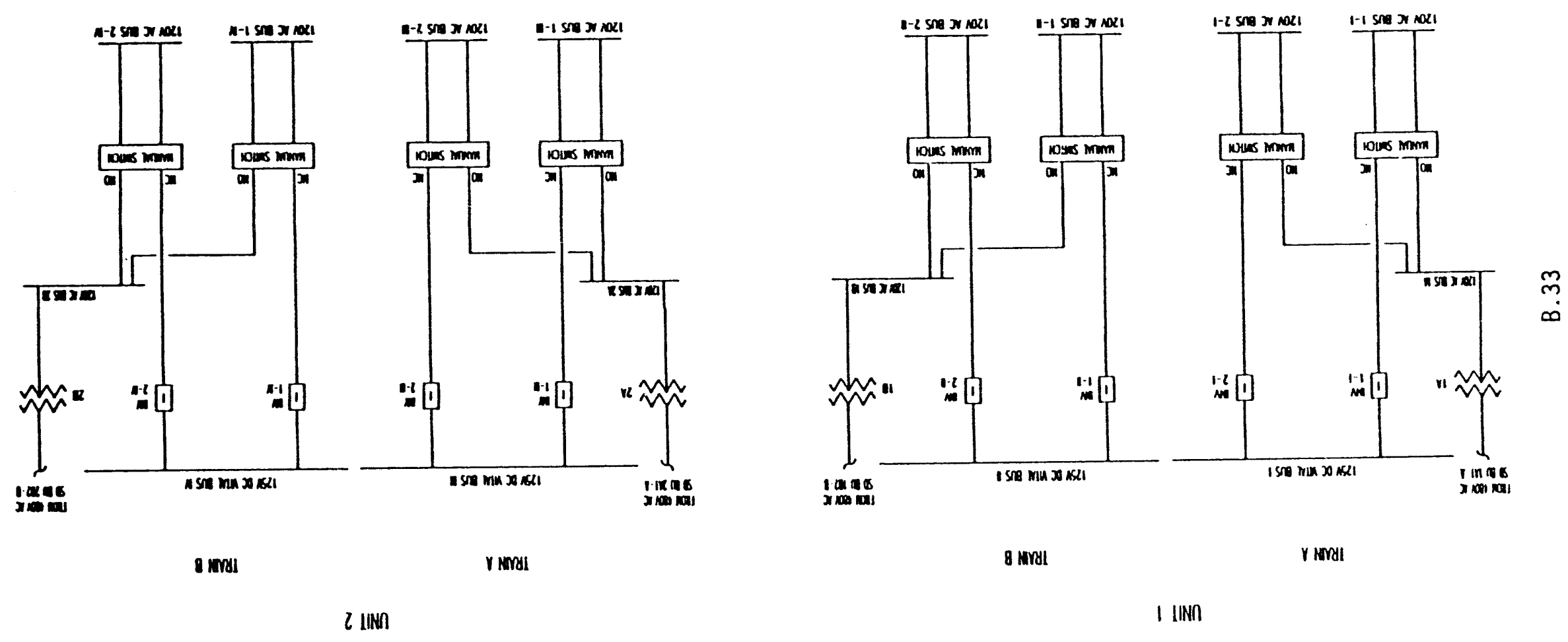
shutdown board rooms (also referred to as emergency switchgear rooms). It was stated that the probability of failure of the doubly redundant ESW system to provide EDG cooling was far less than the probability of EDG failure and did not merit further attention. In the case of the switchgear room, the combinations of fan failures and ESW failures were of low enough probability that their contribution to EPS failure was insignificant. However, because of potential vulnerabilities of multiple ESF components to failure of switchgear room cooling, an analysis of switchgear room cooler failures as potential initiating events was performed in this study (see Section 4 of the main report).

Failure of the fans to cool the EDG rooms are functionally equivalent to failure of an EDG to start or run. The EDG enclosures are cooled by large exhaust fans that remove heated air from the enclosure and exhaust to the atmosphere. No cooling water is provided to cool the air. Room heatup calculations shown in Appendix $F$ indicate that room temperatures will exceed the failure temperatures for electrical equipment (EDG controls) and switchgear located in the EDG enclosure in less than 30 minutes if the ventilation system malfunctions. This allows insufficient time to repair the ventilation system and prevent failure of backup AC power. Possible causes of failure of the ventilation system include failure of an exhaust fan and failure of an air damper to open in each EDG enclosure.

Dependencies of battery rooms on room cooling were also examined in this study. Discussions with plant personnel indicated that overheating is not a concern with regard to battery operability. Low ambient temperatures may affect battery operability, but heating systems are not in the scope of this study. High temperatures can affect the operability of $A C$ inverters and battery chargers, and room cooling to these areas is addressed. The EPS fault trees, simplified as with previous fault trees, are shown in Figures B.15 and B. 16 .

\section{B.2.11 Instrument Air System}

The instrument air system was not examined in detail by Bertucio and Brown (1990). Faults in the instrument air system were incorporated into the fault trees for the systems they support. No dependencies on room cooling or chilled water systems were identified.

\section{B.2.12 Engineered Safety Features Actuation System}

The engineered safety features actuation system (ESFAS) is designed to sense plant parameters, determine whether predetermined safety limits are being exceeded, and, if they are, to determine which ESF components are required to respond to the condition that exists. The ESFAS then sends actuation signals to the required ESF components.

The ESFAS consists of both analog and digital circuitry. The analog portion of the ESFAS provides redundant channels that monitor various plant parameters. The digital circuitry portion provides two redundant logic trains that receive inputs from the analog channels and provide the necessary logic to actuate required ESF colnponents. 


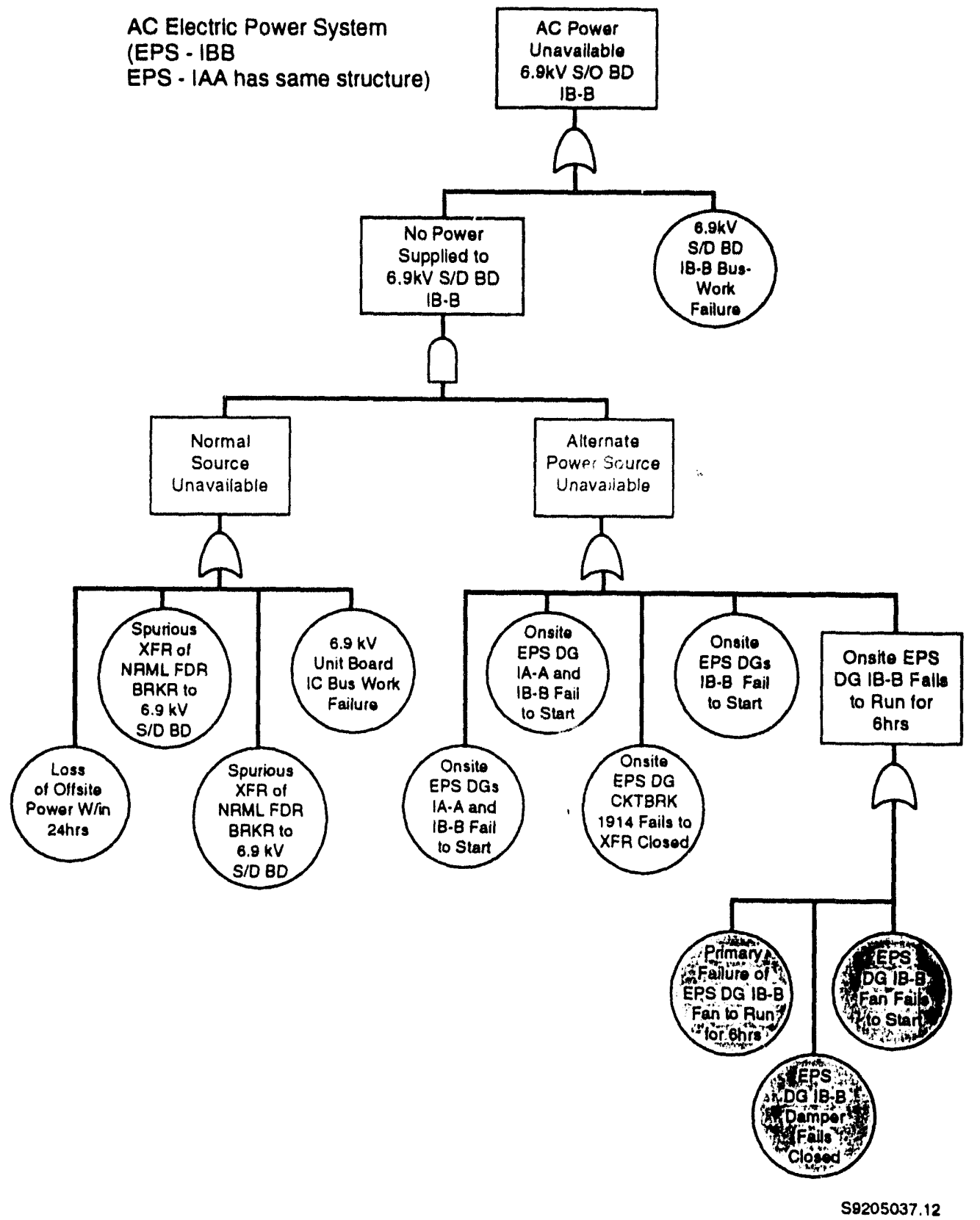

FIGURE B.15. Simplified Fault Tree for the AC Electric Power System 


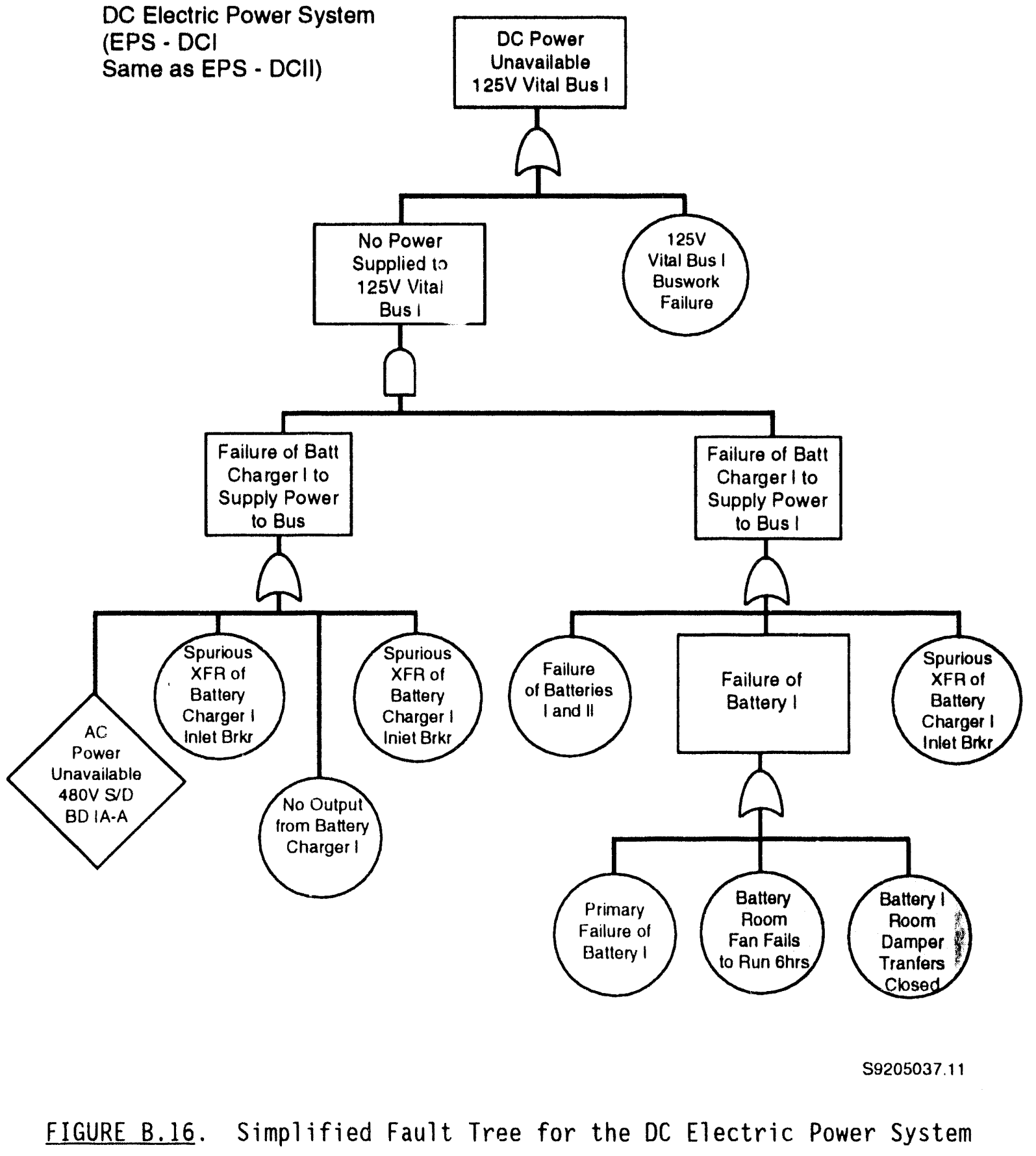


The ESFAS is dependent on the $A C$ power subsystem to provide $125-V A C$ for instrumentation and the $D C$ power subsystem to provide power for instrumentation and logic circuits. Interfaces witn the specific functions that rely on the ESFAS for actuation include

- Reactor trip, if not provided by the reactor protection system

- Proper sequencing of ESF power loads, including cold leg injection isolation valves, charging pumps, SI pumps, LPI pumps and associated valving, and motor-driven AFW pumps

- Phase A containment isolation

- Steam line isolation

- Main feedwater isolation

- Starting EDGs to ensure backup power supr y

- Containment spray actuation

- Phase B containment isolation

- ESW and CCW pump start

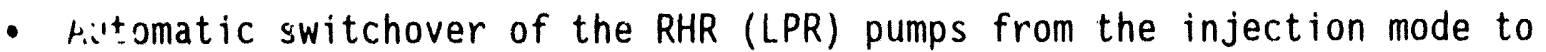
the recirculation mode.

No additional dependencies were modeled by Bertucio and Brown (1990). However, the present study examined a possible dependency of the ESFAS on room cooling in safety-related rooms containing ESFAS components.

\section{B.2.13 Power Conversion System}

The power conversion system (PCS) provides MFW to the SGs. The PCS can be used to remove heat from the RCS through the SGs following a transient and loss of AFW systems. The PCS consists of the MFW pumps, the condensate booster pumps, the hotwell inventory, and the main steam supply to the MFW pumps. Operation of the PCS is dependent upon $A C$ and $D C$ power systems and instrument air. No dependencies on room coolers or HVAC systems were identified.

\section{B.2.14 Reactor Protection System}

The reactor protection system (RPS) is designed to insert control rods into the reactor core after receiving a reactor trip signal. The reactor trip signal may be initiated manually or automatically as a result of detection of adverse reactor parameters or receipt of SI or turbine trip signals. No dependencies on room coolers were considered in the existing PRA. 


\section{B.2.15 Ice Condenser System}

The ice condenser system (ICS) is provided for containment pressure suppression during the initial stages of a LOCA. The ICS is a passive heat sink in the air/steam flow path between the lower and upper containment compartments. The ice condenser, located in the annulus formed by the containment vessel wall and crane wall, is essentially a cold storage room in which borated ice flakes are maintained in vertical cylindrical columns. Following a LOCA, rising pressure in the lower compartment forces steam and air through the space between the columns and into the upper compartment. The ice condenser is normally isolated from the containment bullding by inlet and out let doors that are spring-loaded to open on differential pressure. Air return fans are provided to promote mixing between the upper and lower compartments for long-term operation.

The ICS is a completely passive system during a LOCA and has no dependencies or interfaces. During normal plant operation, the ice is maintained by an ice condenser refrigerant system. No dependencies or interfaces with room cooling functions were identified.

\section{B.2.16 Heating, Ventilation, and Air Conditioning System}

The plant heating, ventilation, and air conditioning (HVAC) system was not modeled as a distinct system by Bertucio and Brown (1990). It was addressed, however, in the fault tree models in which room cooling functions were required. For example, room cooling is required for operation of LPI/LPR pumps during the recirculation mode: therefore, the LPR fault trees contained the various segments of the HVAC system that serve the LPI/LPR pump rooms. The HVAC functions were included through the ESF system interfaces with the ESW system, which is the heat sink for the ESF pump areas, and through room cooling fans, which are required for room cooling. Specific events involving failures of room cooling functions were addressed in Section 3.1.3 of the main report.

\section{B.3 MINIMAL CUT SETS FOR THE REPRESENTATIVE W PWR}

This section presents the minimal cut sets used to quantify the affected core damage frequency (CDF) for the representative W PWR. A spreadsheet was developed to facilitate calculation of the affected CDF and public risks for this plant. The affected cut sets and their calculated frequencies are presented in Figures B.1 to B.6. The total affected CDF is presented at the end of the table for each initiator. Because the cut sets were entered into a spreadsheet for calculation purposes, some "cells" contain values of 1.0 and are not associated with an event designation. The calculations are shown in the following tables: 
Iable Ne.

Table B.1. Loss of ESF Switchgear Room Cooling

Table B.2 Loss of Control Room Cooling

Table B.3 Loss of HPI/HPR Pump Room Cooling

Table B.4 Loss of LPI/LPR Pump Room Cooling

Table B.5 Loss of DC Equipment Room Cooling

Table B.6

Title
No.

B. 41

B. 47

B. 52

B. 57

B. 62

HVAC/Room Cooler Contributions to Accident

Sequences Initiated by Other Plant Transients

B.64

\section{B.4 REEERENCES}

Bertucto, R. C., and S. R. Brown. 1990. Analys is of Core Damage Freauency: Sequoyah 'nit 1 Internal Events. NUREG/CR-4550 Vol. 5, Rev. 1. Sandia National i.aboratories, Albuquerque, New Mexico. 
IABLE B.1. Loss of HPI Pump Room Cooling

\begin{tabular}{|c|c|c|c|c|c|c|c|}
\hline & & & Cut sot & Element: & & & $\begin{array}{l}\text { Cut } 8 \text { ot } \\
\text { Froquency }\end{array}$ \\
\hline $1 \mathrm{TsW}$ & AsW & AFW AOV CC & BETA.BAOV & HPI XHE FO FDALO & & $M$ & $3.164 E-10$ \\
\hline $2 \mathrm{Tsw}$ & REW & AFW-AOV.CC & BETA-BAOV & MPI MOP.FS IAA & HPI MDP F8.188 & M & $9.403 E \quad 13$ \\
\hline $3 \mathrm{TsW}$ & A8 $W$ & AFW.AOV.CC & BETA BAOV & HPI MOPFS IAA & HPIFAN FE $18 B$ & $M$ & $0.463 E-13$ \\
\hline $4 \mathrm{TgW}$ & AsW & AFW.AOV.CC & BETA.BAOV & HPI MDPFS.18B & HPIFAN.FB IAA & $M$ & $0.463 E-13$ \\
\hline b tsw & ค8พ & a1 & AWT XHE MSCAL & & & & 6. $108 \mathrm{E} 13$ \\
\hline$\theta \mathrm{TSW}$ & ค8W & a1 & BETA.2MOV & IPR MOV CC & & & $3.642 E \times 13$ \\
\hline $1 \mathrm{TSW}$ & Asw & al & BETALPI & CSS XHE.FO CBR & LPI MDP F & & $4.649 E 14$ \\
\hline TSW & RsW & al & BETA LPI & C8B.XHE.FO CBA & LPI MOP FAN FS & & $4.649 E \cdot 14$ \\
\hline 9 TsW & ค8W & ai & LPR MDP.FS.1AA & LPA.MDP.FS 188 & & & $1201 E \cdot 14$ \\
\hline $10 \mathrm{rgw}$ & RsW & 01 & LPA.MDP FS. IAA & LPR.FANFB $18 B$ & & & $1.207 E \cdot 14$ \\
\hline $11 \mathrm{rsw}$ & RSW & a1 & IPA MOP.FS IBB & LPAFAN FS IAA & & & $1.207 E-14$ \\
\hline $12 \mathrm{TSW}$ & RSW & HPI XHE FO-FOBLD & STEAM-GINDINO & & & $M$ & Q.223E-11 \\
\hline $13 \mathrm{TSW}$ & RSW & STEAM BINDING & HPI MDP.FS IAA & HPIMDP.FS IBB & & $M$ & $2.767 \mathrm{E} \cdot 13$ \\
\hline $14 \mathrm{rsw}$ & RSW & STEAM-BINDINO & HPI.MOP.F 8 & HPIFAN FS 1BB & & $M$ & $2.707 \mathrm{E} \cdot 13$ \\
\hline $16+5 W$ & RSW & STEAM-BINDING & HPI.MOP.FS & HPIFAN FS.IAA & & $M$ & $2.707 \mathrm{E} 13$ \\
\hline 16 TSW & RSW & AFW.AOV CC & BETA BAOV & PPS SOV FT 340A & & $M$ & $1.087 \mathrm{E} 12$ \\
\hline $17 \mathrm{TSW}$ & RSW & AFW AOV CC & BETA.HAOV & PPS.8OV FT.334 & & $M$ & $1.98 / E 12$ \\
\hline 18 TSW & AsW & AFW.MOP.FS & AFW TDP.FS.1AS & BETA.AFW & HPI.XHE.FO FDBLD & $M$ & $1.748 E 09$ \\
\hline $19 \mathrm{TSW}$ & RsW & AFW.MDP.FS & AFW TDP.FA IASEH & BETA AFW & HPI XHE FO FDBLD & $M$ & $7.746 E \cdot 09$ \\
\hline $20 \mathrm{rgw}$ & RsW & AFW-MDPFS & AFW FANFS TDPD & BETA.AFW & HPI XHE FO FDBLO & $M$ & $7.148 E \cdot 10$ \\
\hline $21 \mathrm{rsw}$ & RSW & AFW MDPFS & AFW-FAN-FA-TDPDB & BETA.AFW & HPI XHE FO FDBLD & $M$ & $3.8 / 4 E \cdot 11$ \\
\hline $22 \mathrm{TSW}$ & RSW & PPS. SOV FT 334 & STEAM BINDINO & & & $M$ & $6.811 E 13$ \\
\hline $23 \mathrm{TSW}$ & RSW & PPS-SOV FT 340A & STEAM-BINDING & & & $M$ & $6.811 E 13$ \\
\hline $24 \mathrm{TSW}$ & RSW & AFW ACT FA TRNA & AFW ACT FA. TANB & HPI XHE FO FDBLO & & $M$ & $1.476 E \cdot 08$ \\
\hline $26 \mathrm{TSW}$ & RSW & AFW MDPFS & AFW TOP TM IAS & BETA.AFW & HPI.XHE.FO FDBLD & $M$ & $2.603 E .09$ \\
\hline $28 \mathrm{TSW}$ & RSW & AFW.MOP.FS & AFW TDP.FR IASGH & BETA.AFW & PPS SOV FT 340A & $M$ & 4.881E 11 \\
\hline $21 \mathrm{TsW}$ & AsW & AFW.MDP.FS & AFW TDPFS IAS & BETA AFW & PPS SOV.FT 334 & $M$ & 4.881E.II \\
\hline $28 \mathrm{TSW}$ & RSW & AFW MDPFS & AFW-FAN FS TDPD & BETA AFW & PPS SOV FT 340A & M & 4.881E.12 \\
\hline $29 \mathrm{TSW}$ & RSW & AFW MOP FS & AFW FAN FR TDPDB & BETA.AFW & PPS SOV.FT 334 & $M$ & $2.441 E \cdot 13$ \\
\hline $30 \mathrm{rsw}$ & RSW & AFW MOPFS & AFW TOP.FS.1AS & BETA.AFW & PPS SOV FT $340 \mathrm{~A}$ & $M$ & 4.881E.11 \\
\hline $31 \mathrm{rsw}$ & RSW & AFW MDP FS & AFW TDP.FR-1ASBH & BETA.AFW & PPS SOV.FT 334 & $M$ & $4.881 E \cdot 11$ \\
\hline $32 \mathrm{TSW}$ & FSW & AFW MDPFS & AFW FAN FS TDPD & BETA.AFW & PPS SOV.FT $340 A$ & $M$ & $4.881 E 12$ \\
\hline 33 TSW & RSW & AFW MOP FS & AFW FAN-FR TDPDB & BETA AFW & PPS SOV FT 334 & $M$ & $2.441 E 13$ \\
\hline $34 \mathrm{TSW}$ & RSW & AFW AOV CC & BETA BAOV & PPS $190 \mathrm{~V}$ FC 332 & PPS.MOV.FT 332 & $M$ & $3.164 E 11$ \\
\hline $36 \mathrm{TSW}$ & RSW & AFW AOV.CC & BETA BAOV & PPS MOV FC 333 & PPS MOV FT 333 & $M$ & 3.16AE 11 \\
\hline $36 \mathrm{TSW}$ & RSW & AFW ACT FA TANA & AFW ACT FA TRNB & PPS soV FT 334 & & $M$ & $9.297 \mathrm{E} 11$ \\
\hline 3) TSW & RSW & AFW ACT FA TRNA & AFW ACT FA TRNB & PPS SOV FT $340 A$ & & $M$ & $9.297 \mathrm{E} 11$ \\
\hline $3 \mathrm{HTSW}$ & RSW & AFW AOV CC & BETA BAOV & BETA SAV & PPS SOVFT & $M$ & $1.381 E 1 \mathrm{~s}$ \\
\hline $39 \mathrm{TSW}$ & RSW & AFW MDPFS & AFW. MOV CC. 161 & BETA AFW & HPI.XHE-FO FDBLD & $M$ & $1 / 4 \mathrm{BE} 10$ \\
\hline $40 \mathrm{TSW}$ & RSW & AFW HDV LF 152 & AFW.MDP.FS & BETA AFW & HPI.XHE FO FDBLD & $M$ & $0.148 E \cdot 10$ \\
\hline 41 TSW & RSW & AFW MDP FS & AFW TDP.TM IAS & BETA AFW & PPS.SOV FT 340A & $M$ & $1.621 \mathrm{E} \|$ \\
\hline $42 \mathrm{TSW}$ & RSW & AFW MDFFS & AFW TDP TM-1AS & BETA AFW & PPS SOV FT 334 & $M$ & I.A2IE 11 \\
\hline $43 \mathrm{TSW}$ & RSW & PPS MOV FC 332 & PPS.MOV FT 332 & STEAM BINDING & & $M$ & 9 $223 \mathrm{E} \quad 12$ \\
\hline $44 \mathrm{TSW}$ & RSW & PPS MOV FC 333 & PPS MOV FT 333 & STEAM BINDING & & $M$ & $922.1 E 12$ \\
\hline 4s TSW & RSW & AFW MOP FS IAA & AFW MDPFS $1 B B$ & AFW TDPFA 1 ASGH & HPI XHE FO FOBLD & $M$ & $1.384 E O /$ \\
\hline $40 \mathrm{TSW}$ & RSW & AFW MDP FS IAA & AFW MDPFS $1 B B$ & AFIV TOP FS IAS & HPI XHE FO FDBLD & $M$ & $1.384 \mathrm{E} \mathrm{O} /$ \\
\hline 4/ TSW & RSW & AFW MOP FS IAA & AFW MDP.FS IBB & AFW.FAN FS TOPD & HPI. XHE.FO FDBLD & $M$ & $1.364 \mathrm{E} O 8$ \\
\hline $48 \mathrm{TSW}$ & RSW & AFW MDPFS IAA & AFW MDP FS $1 B B$ & AFW FAN FR TDPDS & HPI.XHE.FO FDBLD & $M$ & 6.818E 10 \\
\hline
\end{tabular}


IABLE B.1. (contd)

Cut set Elemente

Cut set

Frequency

\begin{tabular}{|c|c|c|c|c|c|c|c|c|}
\hline 40 TSW & Row & BETA.8AV & PPs.soV-FT & ITEAM BINDINO & & & $M$ & $4.068 E \cdot 14$ \\
\hline 60 rew & AsW & AFW.MOP.FS. 188 & AFW.MDP.TM-IAA & AFW-TOP-FA.IASBH & HPI-XHE-FO.FOALD & & M & $2.767 E \cdot 10$ \\
\hline 61 Tow & nsw & AFW.MDP.PS-IAA & AFW.MDP.TM-18B & AFW.TOP.FS.1AB & HPI.XHE-FO.FDBLO & & $M$ & $2.767 E \cdot 10$ \\
\hline 52 TOW & Rew & AFW.MOP.FS $18 B$ & AFW.MDP.TM-IAA & AFW.FAN.F8-TOPO & HPI.XHE.FO.FDOLO & & M & $2.7078 \cdot 11$ \\
\hline 63 Tow & Rsw & AFW-MDP.FS IAA & AFW.MDP.TM-18B & AFW-FAN.FA.TOPOE & HPI XHE FO-FDBLD & & $M$ & $1.384 E \cdot 12$ \\
\hline 64 TSW & คดพ & AFW.MOP.FS & AFW.MOV.CC.161 & DETA.AFW & PPS.8OV.FT.340A & & $M$ & $4.881 E \cdot 12$ \\
\hline 65 Tow & A8W & AFW.MOR.FS & AFW.MOV.CC. 161 & BETA-AFW & PMg.soV.FT.334 & & & Q.136E. 10 \\
\hline $56 \mathrm{TSW}$ & new & AFW.HOV.LF.162 & AFW.MDP.FS & DETA.AFW & PPS.8OV.FT-340A & & $M$ & $4.881 E \cdot 12$ \\
\hline $67 \mathrm{rsw}$ & Rsw & AFW.HDV.LF.162 & AFW.MDP.FS & BETA.AFW & PPS. SOV.FT. 334 & & $\mathbf{M}$ & $4.681 E \cdot 12$ \\
\hline $68 \mathrm{TSW}$ & RsW & AFW.MOP.Fs & AFW.TDP.FB:1A8 & BETA.AFW & PPS.MOV.FC. 333 & PPS.MOV.FT.333 & $M$ & $7.748 E \cdot 10$ \\
\hline $60 \mathrm{rsw}$ & AsW & AFW.MDP.FB & AFW.TOP.FR-1ASBH & DETA AFW & PPS.MOV.FC. 332 & PPS.MOV.FT-332 & $M$ & $7.748 E \cdot 10$ \\
\hline $60 \mathrm{TSW}$ & ค8 W & AFW-MDP.FS & AFW.FAN-FB.TDPO & BETA.AFW & PPS.MOV.FC.333 & PP8.MOV.FT.333 & $M$ & $7.748 E \cdot 11$ \\
\hline a1 raw & Row & AFW.MDP.FB & AFW-FAN-FR-TDPOE & BETA.AFW & PPS.MOV.FC. 332 & PP8-MOV.FT- 332 & $M$ & $3.874 E \cdot 12$ \\
\hline a2 TSW & AsW & AFW'MDP.F8 & AFW.TDP.FB.1A8 & BETA-AFW & PPS.MOV.FC. 332 & PPS.MOV.FT-332 & $M$ & $7.7488 \cdot 10$ \\
\hline 63 TsW & Row & AFW.MDP.Fs & AFW.TOP.FA.1ASBH & DETA.AFW & PPB-MOV.FC.333 & PPS-MOV.FT-333 & $M$ & $7.748 E \cdot 10$ \\
\hline 64 TSW & ค8) & AFW.MDP.FS & AFW.FAN-FB.TOPO & EETA.AFW & PPB.MOV.FC. 332 & PPB.MOV-PT-332 & $M$ & $7.748 E \cdot 11$ \\
\hline 66 TSW & R8W & AFW.MDP.F8 & AFW.FAN-FR-TOPOE & BETA.AFW & PPS.MOV.FC. 333 & PPB.MOV.FT. 333 & $M$ & $3.674 E \cdot 12$ \\
\hline $68 \mathrm{TsW}$ & RsW & AFW-MDP.FS & AFW.TDP.FB.1AB & BETA.AFW & BETA.SAV & PPo-8OV.FT & $M$ & $3.417 E \cdot 12$ \\
\hline o7 ToW & nsw & AFW.MDP.F 8 & AFW.TDP.FA.1ASEH & BETA.AFW & Beta.sav & PPS.8OV.FT & $M$ & $3.417 E \cdot 12$ \\
\hline 68 TaW & R8W & AFW-MDP.FB & AFW.FAN-FE-TOPO & EETA.AFW & DETA.sav & PPs-soV.FT & $M$ & $3.417 E \cdot 13$ \\
\hline $68 \mathrm{TSW}$ & R8W & AFW'MDP-F8 & AFW.FAN-FA.TOPOG & BETA.AFW & BETA.8AV & PPS.8OV.FT & $M$ & $1.708 E \cdot 14$ \\
\hline $70 \mathrm{TsW}$ & AsW & AFW.AOV.CC. 3168 & AFW.MDP.FB.18B & AFW-TOP-FA-1A88H & HPI.XHE-FO-FDQLD & & $M$ & $1.384 E \cdot 10$ \\
\hline 71 TaW & RsW & AFW.AOV.CC.3171 & AFW.MDP.FB.1AA & AFW-TDP-FA-1A88H & HPI.XHE.FO-FDBLD & & $M$ & $1.384 E \cdot 10$ \\
\hline 72 TSW & RsW & AFW.AOV.CC.314B & AFW.MDP.FS-1AA & AFW.TDP.FA.1A8EM & MPI.XHE-FO-FOELD & & $M$ & $1.384 E \cdot 10$ \\
\hline 73 TSW & AsW & AFW.AOV.CC.3164 & AFW.MOP.F8.18B & AFW-TDP-FA-1ASBH & HPI.XHE.FO-FDELD & & $M$ & $1.384 E \cdot 10$ \\
\hline $74 \mathrm{TsW}$ & Row & AFW.MDP.F8-1AA & AFW-MDP-FS-18B & AFW.TDP.F8-1AS & PP8.8OV.FT.340A & & $M$ & $4.358 E \cdot 10$ \\
\hline 76 TSW & R8W & AFW-MDP-FS+1AA & AFW-MDP.FE-18B & AFW-TDP.FA-1ASBH & PPS.soV.FT.334 & & $M$ & $4.358 E \cdot 10$ \\
\hline $76 \mathrm{TSW}$ & RSW & AFW.MDP-FS-1AA & AFW.MDP.FB-1BB & AFW.TDP-FS.1AS & PPg.80V.FT.334 & & $M$ & $4.358 E \cdot 10$ \\
\hline 77 TSW & AsW & AFW.MDP.FS.1AA & AFW.MDP.F8.18B & AFW-TDP-FR-1ABBH & PPS-8OV.FT.340A & & $M$ & $4.358 \varepsilon \cdot 10$ \\
\hline $78 \mathrm{TSW}$ & A8W & AFW-MDP-FR-1AA24 & AFW.MDP.F8.18B & AFW-TOP.FA-1A8BH & HPI.XHE.FO-FDBLD & & $M$ & $6.918 E .08$ \\
\hline $70 \mathrm{TSW}$ & RsW & AFW.MDP.FA- 18824 & AFW.MDP-FB.1AA & AFW-TOP.FA-1ASGH & HPI.XHE-FO.FOBLD & & $\mathbf{M}$ & $0.918 \varepsilon .08$ \\
\hline $80 \mathrm{TgW}$ & A8W & AFW.AOV.CC. 3168 & AFW-MDP.TM-18B & AFW-TDP.FA-1A88H & HPI.XHE.FO.FDBLD & & $M$ & $6.634 E \cdot 13$ \\
\hline $81 \mathrm{TSW}$ & RsW & AFW.AOV.CC. 3148 & AFW-MDP.TM-1AA & AFW-TDP.FA-1ASGH & HPI.XHE-FO-FDQLD & & $M$ & $6.6348 \cdot 13$ \\
\hline 82 TSW & R8W & AFW.AOV.CC.3164 & AFW-MDP-TM-1BB & AFW-TOP-FA-1ASEH & HPI.XHE.FO-FDBLD & & $M$ & 6.634E.13 \\
\hline $83 \mathrm{TsW}$ & RsW & AFW.AOV.CC.3171 & AFW.MDP.TM-1AA & AFW-TDP-FA-1 AS6H & HPI.XHE-FO.FDELD & & $M$ & 6.E34E.13 \\
\hline B4 TSW & RsW & AFW-MDP.F 8.1BB & AFW-MDP-TM-IAA & AFW. TDP.FA.1A86H & PPS-80V-FT-340A & & M & $1.743 E \cdot 12$ \\
\hline $86 \mathrm{TSW}$ & คs W & AFW-MDP.FS-IAA & AFW-MDP.TM-18B & AFW-TDP-FA-1 1 ABEH & PPB.8OV-FT-340A & & $M$ & $1.743 E \cdot 12$ \\
\hline 86 TSW & RSW & AFW.MDP.FS.IAA & AFW-MDP-TM-1BB & AFW.TDP.FA-1 $A 8 B H$ & PP8.8OV.FT.334 & & $M$ & $1.743 E-12$ \\
\hline $87 \mathrm{TSW}$ & R\&W & AFW.MDP-FS-18B & AFW-MDP.TM-1AA & AFW-TDP-FR-1ASOH & PPS.80V-FT.334 & & $M$ & $1.743 E-12$ \\
\hline $88 \mathrm{TSW}$ & Row & AFW MDP-F8-1B8 & AFW.TDP.F8.1A8 & DCP-BDC-8T.1 & & & M & $6.818 E .08$ \\
\hline $89 \mathrm{TSW}$ & ค8พW & AFW.MDP.FB.1AA & AFW.TDP-FA-1A8BH & DCP.BDC.8T-11 & & & $M$ & $0.018 E .08$ \\
\hline $90 \mathrm{TSW}$ & Row & AFW.MDP.FS-1BB & AFW.TDP-FA-1 1ABEH & DCP.8DC.8T.1 & & & $M$ & $0.918 \varepsilon-08$ \\
\hline 91 TSW & RsW & AFW.MDP-F8-IAA & AFW.TDP.FB.1A8 & DCP.BDC.8T-11 & & & $M$ & $0.918 E \cdot 08$ \\
\hline 92 TSW & REW & AFW.MDP.TM-1BB & AFW.TOP.F8.1AS & DCP.BDC.8T-1 & & & $M$ & $2.767 E \cdot 10$ \\
\hline 93 TSW & R8W & AFW-MDP.TM-18B & AFW-TDP-FR-1A8BH & DCP.8DC.8T.1 & & & $M$ & $2.767 E \cdot 10$ \\
\hline 94 T8W & R8W & AFW.MDP.TM-IAA & AFW-TDP-FR-1A8BH & DCP.BDC.8T.1I & & & $M$ & $2.767 E \cdot 10$ \\
\hline O6 TSW & RSW & AFW-MDP-TM-IAA & AFW.TDP.FS-1AS & DCP.8OC.8T.11 & & & $M$ & $2.787 E \cdot 10$ \\
\hline Ba TSW & RSW & AFW.AOV.CC & BETA.BAOV & DCP.BOC.8T.I & & & $M$ & $1.677 \mathrm{E}-10$ \\
\hline 97 T8W & RSW & AFW.AOV.CC & BETA.BAOV & DCP.BDC.8T.11 & & & $\mathbf{M}$ & $1.677 E \cdot 10$ \\
\hline
\end{tabular}




\section{IABLE B.1. (contd)}

\begin{tabular}{|c|c|c|}
\hline Tow & Aew & AFW.AOV.CC.3160 \\
\hline & new & AFW.AOV.CC.3164 \\
\hline $100 \mathrm{TsW}$ & now & AFW.AOV.CC.3171 \\
\hline $101 \mathrm{TSW}$ & Rew & AFW.AOV.CC.3150 \\
\hline $102 \mathrm{~T} / \mathrm{W}$ & คอพ & $A F W \cdot A O V \cdot C C \cdot 3148$ \\
\hline $103 \mathrm{TeW}$ & new & AFW.AOV.CC.3171 \\
\hline $104 \mathrm{TgW}$ & now & $A F W \cdot A O V \cdot C C \cdot 3148$ \\
\hline 106 TsW & nsw & AFW-AOV.CC-3184 \\
\hline $108 \mathrm{TeW}$ & คow & AFW.MOP.FS-1AA \\
\hline 107 Tew & naw & AFW-MOP.FS-18D \\
\hline 108 TeW & new & AFW-MOP.FR. 18024 \\
\hline 109 TeW & Raw & AFW-MOP-FR-1AA24 \\
\hline $110 \mathrm{TsW}$ & Aew & AFW-MDP.FA-18024 \\
\hline $111 \mathrm{TsW}$ & Aew & AFW-MDP.FA-1AA24 \\
\hline $112 \mathrm{TsW}$ & Aอพ & АСР.BAC.8T. $18 B$ \\
\hline $113 \mathrm{TsW}$ & คaw & АСР-ВАС-BT-1АA \\
\hline $114 \mathrm{TBW}$ & Asw & АСР.AC-8T.IAA \\
\hline $116 \mathrm{~T} 8 \mathrm{~W}$ & Asw & АCP-BAC-8T-18B \\
\hline
\end{tabular}

AFW.TOP.PA.1ASOH DCP.BDC.8T.II AFW.TOP.FS.1AS DCP.BDC.8T.II AFW.TOP.FS.IAS AFW.TOP.PE-1AB AFW.TOP.PE.1AS AFW.TOP.FR.1ABEH AFW.TDP.FA.1ABGH AFW.TOP.PR.1ABEH AFW-TOP.TM-1AS AFW.TOP.TM-1AS AFW.TOP.FE-1AS AFW.TDP.FR-1ABEH AFW-TOP.FA-1ABOH AFW.TOP.FE-1AB AFW.MDP.FB.1AA AFW.MOP.FS.180 AFW.MDP.TM-188 AFW.MDP.TM.1A

\section{DCP.EDC.}

DCP.BDC.AT."I

DCP.EDC.8T.1

OCP.8OC-8T.1

DCP.80C.8T.1

DCP.eDC.8T.11

DCP-BDC-8T-11

DCP.ED. 8 . 1

DCP.DOC-8T.1

DCP.BOC.8T.11

DCP.BDC.8T.I

DCP-BDC.8T. II
AFW.TOP.FA-1ASOH PPS.MOV.FC.332

AFW.TOP.FA.IAS6H PPS.MOV.PC.333 AFW.TDP.FA.1A8BH PPS.MOV.FC.333 AAFW.TDP.FA-1A8OH PPE.MOV.FC.332
M 1.304E 10

M 1.384E.10

$M \quad 1.384 E \cdot 10$

M $1.384 E \cdot 10$

M 1.384E. 10

M 1.384E.10

M 1.384E.10

$M \quad 1.3845 \cdot 10$

M 2.3006.08

M 2.3006 .08

M $\quad 0.0186 .08$

M $\quad 0.018 E-08$

M $0.018 E .08$

M 6.218E.08

M 1.384E.08

M $1.384 E .08$

M $6.634 E \cdot 11$

M $1.000 E+\infty 0$ 


\section{IABLE B.2. Loss of Control Room Cooling}

\begin{tabular}{|c|c|c|c|c|c|c|c|}
\hline & & & Cut 801 & Eloments & & & $\begin{array}{l}\text { Cut set } \\
\text { Frequency }\end{array}$ \\
\hline $1 \mathrm{TCA}$ & ACA & AFW.AOV.CC & BETA-BAOV & HPI XHE.FO.FDQLD & & $M$ & $7.203 E \cdot 10$ \\
\hline 2 TCA & RCA & AFW.AOV.CC & BETA.BAOV & HPI.MDP.FP IAA & HPI.MOP.FE- $18 B$ & $M$ & $2.179 E-12$ \\
\hline 3 TCR & คCA & AFW.AOV.CC & DETA-GAOV & HPI.MDP.FS.1AA & HPI.FAN-F8. 188 & $M$ & $2.170 E \cdot 12$ \\
\hline 4 TCA & ACA & AFW.AOV.CC & DETA-BAOV & HPI-MDP.F8-18B & HPI.FAN.F8.1AA & $M$ & $2.179 E \cdot 12$ \\
\hline 5 TCA & ACA & a1 & AWT-XHE-MBCAL & & & & $1.646 E \cdot 12$ \\
\hline - TCA & RCA & 01 & BETA.2MOV & LPA-MOV.CC & & & 8.165E.13 \\
\hline 7 TCR & RCA & a1 & BETA.LPI & C8S.XHE.FO.CBA & LPI.MDP.F8 & & $1.070 E \cdot 13$ \\
\hline B TCR & RCR & ai & EETA-LPI & CS8.XHE-FO.CBA & LPI.MDP.FAN.Fs & & $1.0706 \cdot 13$ \\
\hline Q TCA & ACA & 01 & LPA.MOP.FS-1AA & LPA.MDP.FS. 188 & & & $2.780 E \cdot 14$ \\
\hline $10 \mathrm{TCA}$ & ACR & Q1 & LPA.MDP.FB. IAA & LPA.FAN.F8.186 & & & $2.780 t \cdot 14$ \\
\hline \|TCA & RCA & a1 & LPA-MDP.FS-188 & LPA.FAN.F8.1AA & & & $2.780 E \cdot 14$ \\
\hline 12 TCA & ACA & HPI.XHE.FO-FDELO & STEAM-BINDINO & & & $M$ & $2.124 E-10$ \\
\hline $13 \mathrm{TCA}$ & ACA & STEAM-BINDINO & HPI-MDP.FS-1AA & HPI-MDP-FS-18B & & $M$ & 6. $371 E-13$ \\
\hline $14 \mathrm{TCA}$ & ACA & STEAM-BINDINO & HP1.MDP.FS & HPIFAN-F8.1BB & & $M$ & 6.371E-13 \\
\hline $16 \mathrm{TCA}$ & ACA & OTEAM-ONDINO & HPI.MDP.Fs & HPI-FAN.F8.1AA & & $M$ & $0.371 E \cdot 13$ \\
\hline $10 \mathrm{TCA}$ & ACA & AFW.AOV.CC & EETA-BAOV & PPS-8OV-FT-340A & & $M$ & $4.576 E-12$ \\
\hline 17 TCA & ACA & AFW.AOV.CC & BETA.BAOV & PPS.8OV.FT.334 & & $M$ & $4.676 E-12$ \\
\hline $18 \mathrm{TCA}$ & RCR & AFW.MDP.FS & AFW.TOP-FS-1AS & BETA.AFW & HPI.XHE.FO.FDQLD & $M$ & $1.784 E .08$ \\
\hline $10 \mathrm{TCA}$ & ACR & AFW.MOP.FS & AFW-TDP-FR-1A86H & BETA.AFW & HPI.XHE.FO.FDQLO & $M$ & $1.784 E .08$ \\
\hline $20 \mathrm{TCA}$ & ACR & PPS.8OV.FT.334 & STEAM-EINOING & & & $M$ & $1.338 \varepsilon .12$ \\
\hline 21 TCA & ACA & PPS-80V.FT-340A & STEAM-BINDINO & & & $\mathbf{M}$ & $1.3388 \cdot 12$ \\
\hline $22 \mathrm{TCR}$ & ACA & AFW.ACT.FA-TANA & AFW-ACT.FA.TRNB & HPI.XHE-FO.FDBLD & & $M$ & $3.398 E .08$ \\
\hline 23 TCA & RCA & AFW-MDP-Fs & AFW-TUP.TM-1AS & BETA-AFW & HPI.XHE.FO.FDQLD & $M$ & 6.847E.co \\
\hline 24 TCR & RCA & AFW.MOP.FS & AFW-TOP.FA-1ASBH & BETA.AFW & PP8.8OV.FT.340A & $\mathbf{M}$ & $1.124 E \cdot 10$ \\
\hline 26 TCR & RCA & AFW-MOP.FS & AFW-TDP-F8-1AB & BETA.AFW & PP8.9OV.FT.334 & $M$ & $1.124 E-10$ \\
\hline 26 TCR & RCA & AFW.MDP.FB & AFW-TOP.FS-1AS & BETA-AFW & PPS-8OV.FT-340A & $M$ & $1.124 E \cdot 10$ \\
\hline 27 TCR & RCA & AFW.MDP.F8 & AFW-TOP-FR-1ASEH & BETA.AFW & PPS-80V-FT.334 & $\mathbf{M}$ & $1.124 E \cdot 10$ \\
\hline $28 \mathrm{TCA}$ & RCA & AFW-AOV-CC & BETA.BAOV & PPQ-MOV-FC. 332 & PP8.MOV.FT.332 & $\mathbf{M}$ & $4.368 E-13$ \\
\hline $29 \mathrm{TCR}$ & RCA & AFW.AOV.CC & BETA-BAOV & PP8.MOV.FC. 333 & PPS.MOV.FT-333 & $\mathbf{M}$ & $4.368 E \cdot 13$ \\
\hline $30 \mathrm{TCA}$ & RCA & AFW-ACT.FA.TRNA & AFW-ACT-FA-TRNB & PP8-80V-FT-334 & & $M$ & $2.141 E-10$ \\
\hline 31 TCR & RCA & AFW.ACT'FA-TRNA & AFW-ACT.FA.TRNB & PPS.8OV.FT-340A & & $M$ & $2.141 E \cdot 10$ \\
\hline 32 TCR & RCA & AFW.AOV.CC & BETA-BAOV & BETA-SRV & PPS.soV.FT & $M$ & $3.203 E \cdot 13$ \\
\hline 33 TCR & RCA & AFW.MOP.FB & AFW.MOV.CC.161 & BETA.AFW & HPI.XHE.FO-FDBLD & $M$ & $1.784 E .09$ \\
\hline $34 \mathrm{TCR}$ & ACA & AFW.HDV-LF-162 & AFW-MDP.Fs & BETA-AFW & HPI.XHE.FO-FOBLD & $M$ & $1.784 E .09$ \\
\hline 36 TCA & RCR & AFW-MDP.F8 & AFW.TOP.TM-1AB & BETA.AFW & PPB-8OV-FT-340A & $M$ & $3.746 E \cdot 11$ \\
\hline 36 TCA & RCR & AFW MOH.Fs & AFW-TOP-TM-1A8 & BETA.AFW & PP8-8OV.FT-334 & $M$ & $3.746 E-11$ \\
\hline 37 TCA & RCA & PPS MOV.FC-332 & PPS-MOV.FT.332 & STEAM-BINDINO & & $M$ & $2.124 E-11$ \\
\hline $38 \mathrm{TCR}$ & RCA & PPS-MOV-FC-333 & PPS.MOV.FT.333 & STEAM-BINDINO & & $\mathbf{M}$ & $2.124 E \cdot 11$ \\
\hline 39 TCR & RCR & AFW-MDP-F8.1AA & AFW-MDP.FS-1BB & AFW-TDP-FR-1ASBH & HPI-XHE-FO-FDBLD & $M$ & $1.683 E .07$ \\
\hline $40 \mathrm{TCR}$ & RCR & AFW-MOP-FB-1AA & AFW-MDP.F8.188 & AFW.TDP-FS-1AS & HPI-XHE-FO-FDBLD & $M$ & $1.683 E+07$ \\
\hline $41 \mathrm{TCA}$ & RCR & BETA.SAV & PP8.8OV.fT & 8TEAM-BINDINO & & $M$ & $9.360 E \cdot 14$ \\
\hline $42 \mathrm{TCA}$ & ACA & AFW-MDP.FS-1BB & AFW-MUP-TM-1AA & AFW.TOP.FR-1ASEH & HPI-XHE-FO-FDBLD & $\mathbf{M}$ & 6.371E-10 \\
\hline $43 \mathrm{TCA}$ & ACA & AFW.MDP.FS-1AA & AFW-MOP.TM-18B & AFW-TOP-FA-1ASEH & HPI-XME-FO-FDBLD & M & $6.371 E \cdot 10$ \\
\hline 44 TCP & ACR & AFW-MDP.FS & AFW.MOV.CC.161 & BETA.AFW & PP8.SOV.FT.340A & M & $1.873 E .08$ \\
\hline
\end{tabular}


IABLE B.2. (contd)

\begin{tabular}{|c|c|c|c|c|c|c|c|c|}
\hline & & & Cut Bot & Elemente & & & & $\begin{array}{l}\text { Cut sot } \\
\text { Froquency }\end{array}$ \\
\hline $46 \mathrm{TCA}$ & ACR & AFW'MDP.F8 & AFW-MOV-CC.161 & BETA-AFW & PP8.8OV.FT.334 & & $M$ & $1.873 \mathrm{E}-09$ \\
\hline $46 \mathrm{TCA}$ & RCR & AFW.HDV.LF. 162 & AFW-MDP.FS & BETA.AFW & PPS-8OV.FT.340A & & $M$ & $1.124 E-11$ \\
\hline 47 TCA & RCA & AFW.HDV.LF. 152 & AFW-MDP-FS & BETA.AFW & PP8-8OV.FT.334 & & $M$ & $1.124 E-11$ \\
\hline $48 \mathrm{TCA}$ & RCA & AFW.MDP.FB & AFW-TDP-F8.1AS & BETA.AFW & PPS-MOV.FC-333 & PPS-MOV-FT-333 & $M$ & $1.070 E-11$ \\
\hline $40 \mathrm{TCA}$ & ACR & AFW-MDP.FS & AFW-TDP-FA-1AS8H & BETA-AFW & PP8-MOV.FC.332 & PPS.MOV.FT. 332 & $M$ & $1.070 E-11$ \\
\hline $60 \mathrm{TCA}$ & RCR & AFW.MDP.F8 & AFW-TDP.FS.1AB & BETA.AFW & PPS-MOV-FC-332 & PPS-MOV-FT-332 & $M$ & $1.070 E-11$ \\
\hline $61 \mathrm{TCR}$ & RCR & AFW-MDP.FS & AFW-TDP-FA-1 1 A8BH & BETA.AFW & PP8.MOV.FC-333 & PPS-MOV-FT-333 & $M$ & $1.0708-11$ \\
\hline 62 TCR & ACR & AFW-MDP.FS & AFW.TOP.F8.1AS & BETA.AFW & BETA.SRV & PPS.SOV.FT & $M$ & 7.867E-12 \\
\hline 63 TCR & ACR & AFW'MDP.FB & AFW-TDP.FA-1 ASBH & BETA-AFW & BETA.SAV & PPS.SOV.FT & $M$ & $7.867 E-12$ \\
\hline $64 \mathrm{TCA}$ & RCR & AFW-AOV.CC-3156 & AFW-MDP-FS-1BB & AFW-TDP.FA.1ASGH & HPI.XHE.FO.FDBLD & & $M$ & 3.186E.10 \\
\hline 65 TCA & RCA & AFW.AOV.CC.3171 & AFW-MDP.FS-1AA & AFW-TDP.FR-1A86H & HPI-XHE-FO-FDBI.D & & $M$ & $3.186 E-10$ \\
\hline $66 \mathrm{TCR}$ & ACR & AFW-AOV.CC.3148 & AFW-MDP-FS-1AA & AFW-TOP-FR-1ASBH & HPI-XHE-FO-FDBLD & & $M$ & $3.186 E \cdot 10$ \\
\hline 67 TCR & RCR & AFW.AOV.CC.3104 & AFW-MDP-F8.1BB & AFW-TDP.FR-1ASBH & HPI.XHE-FO-FDBLD & & $M$ & 3. $186 E \cdot 10$ \\
\hline 68 TCR & RCA & AFW-MDP.F8-1AA & AFW-MDP.F8-18B & AFW.TDP-FS.1AS & PPB.8OV.FT.340A & & $M$ & $1.003 E .09$ \\
\hline $68 \mathrm{TCR}$ & RCR & AFW.MDP.FS-1AA & AFW-MDP.F8-18B & AFW-TOP-FA-1A98H & PPS-8OV.FT.334 & & $M$ & $1.003 E .00$ \\
\hline $60 \mathrm{TCR}$ & RCR & AFW-MDP-FS.1AA & AFW-MDP.FS-1BB & AFW.TDP.FS-1AS & PPS.80V.FT-334 & & $M$ & $1.003 E-00$ \\
\hline $61 \mathrm{TCR}$ & RCA & AFW.MDP.FB.1AA & AFW-MDP-F8.188 & AFW-TDP.FR-IASBH & PPB.8OV.FT-340A & & $M$ & $1.003 E .09$ \\
\hline 62 TCR & RCR & AFW-MDP-FR-1AA24 & AFW-MDP.F8-1BB & AFW-TOP-FR-1A88H & HPI-XHE-FO-FDBLD & & $M$ & $1.683 E .07$ \\
\hline 63 TCR & RCA & AFW-MDAFA-1B824 & AFW.MDP.FS-1AA & AFW.TDP.FA.1A88H & HPI-XHE-FO-FDBLD & & $M$ & $1.693 E-07$ \\
\hline 64 TCR & RCR & AFW-AOV-CC-3166 & AFW-MDP.TM-18B & AFW-TDP-FR-1A88H & HPI-XHE-FO-FDBLD & & $M$ & $1.274 E \cdot 12$ \\
\hline $66 \mathrm{TCR}$ & RCA & AFW.AOV.CC.3148 & AFW-MDP-TM-IAA & AFW-TDP-FR-1A86H & HPI-XHE-FO-FDBLD & & $M$ & $1.274 E \cdot 12$ \\
\hline $66 \mathrm{TCR}$ & RCR & AFW.AOV.CC-3164 & AFW-MDP-TM-18B & AFW-TDP-FA-1ASGH & HPI-XHE-FO-FDBLD & & $M$ & $1.274 E-12$ \\
\hline 67 TCR & RCR & AFW.AOV.CC.3171 & AFW-MDP.TM-1AA & AFW-TDP-FR-1ASBH & HPI-XHE.FO-FDBLD & & $M$ & $1.274 E \cdot 12$ \\
\hline $68 \mathrm{TCA}$ & RCR & AFW-MDP.FS-1BB & AFW-MDP.TM-1AA & AFW-TOP-FR-1A8BH & PP8-80V-FT-340A & & $M$ & $4.014 E-12$ \\
\hline 69 TCR & RCA & AFW-MOP-F8-1AA & AFW-MDP-TM-18B & AFW-TDP-FR-1AS6H & PP8.8OV.FT.340A & & $M$ & $4.014 E-12$ \\
\hline $70 \mathrm{TCR}$ & RCA & AFW.MDP-FS-1AA & AFW-MDP-TM-18B & AFW-TDP-FR-1ASBH & PPS-SOV-FT-334 & & $M$ & $4.014 E-12$ \\
\hline $71 \mathrm{TCR}$ & RCA & AFW:-MDP.FB-18B & AFW-MDP-TM-1AA & AFW-TDP-FR-1ASBH & PPS-80V-FT-334 & & $M$ & $4.014 E-12$ \\
\hline 72 TCR & RCA & AFW.MOP.F8.188 & AFW-TDP-FB-1AS & DCP-BDC-ST-1 & & & $M$ & $9.87 \theta E-13$ \\
\hline $73 \mathrm{TCA}$ & RCA & AFW-MDP.FS-1AA & AFW-TDP-FR-1A86H & DCP-BDC-8T-11 & & & $M$ & $9.876 E-13$ \\
\hline $74 \mathrm{TCR}$ & ACA & AFW.MDP.F8-1BB & AFW-TDP-FR-1ASBH & DCP-BDC-ST-I & & & $M$ & $9.878 E \cdot 13$ \\
\hline 76 TCA & RCA & AFW-MDP-FS-1AA & AFW-TDP-FB.1AS & DCP-BDC-8T-11 & & & $M$ & $8.876 E-13$ \\
\hline $76 \mathrm{TCR}$ & RCA & AFW-MDP.TM-18B & AFW-TDP.FB-1AS & DCP-BDC-8T-I & & & $M$ & $3.85 J E-16$ \\
\hline 77 TCR & RCR & AFW-MDP-TM-1BB & AFW-TDP-FR-1A8BH & DCP-BDC.ST-I & & & $M$ & $3.950 E \cdot 16$ \\
\hline $78 \mathrm{TCR}$ & RCA & AFW.MDP-TM-1AA & AFW-TDP-FR-1ASBH & DCP-BDC-ST-II & & & $M$ & 3.960E-16 \\
\hline 70 TCR & RCA & AFW.MDP.TM-1AA & AFW.TDP-FS-1AS & DCP-BDC-ST-II & & & $M$ & $3.850 E-16$ \\
\hline $80 \mathrm{TCR}$ & RCA & AFW-AOV.CC & BETA.BAOV & DCP.BDC.8T.I & & & $M$ & $2.262 E-16$ \\
\hline 81 TCA & RCR & AFW.AOV.CC & BETA.BAOV & DCP-BDC-ST-11 & & & $M$ & $2.262 E-16$ \\
\hline 82 TCA & RCR & AFW.AOV.CC.3166 & AFW-TDP-FR-1A8BH & DCP-BDC-8T-11 & & & $M$ & $1.976 E-16$ \\
\hline 83 TCR & RCA & AFW.AOV.CC.3184 & AFW-TDP-F8-1AS & DCP-BDC-ST-\|I & & & $M$ & $1.876 E-16$ \\
\hline 84 TCA & RCR & AFW-AOV.CC.3171 & AFW-TDP-FS-1AS & DCP.BDC.8T.1 & & & $M$ & $1.876 E \cdot 16$ \\
\hline $86 \mathrm{TCA}$ & RCA & AFW.AOV.CC.316B & AFW.TDP-FS-1AS & DCP.BDC.8T-11 & & & $M$ & $1.876 E \cdot 16$ \\
\hline $8 \theta \mathrm{TCA}$ & RCA & AFW-AOV.CC-3148 & AFW-TDP-FB.1A8 & DCP-BDC-8T-1 & & & $\mathbf{M}$ & $1.876 E \cdot 16$ \\
\hline 87 TCR & RCA & AFW.AOV.CC.3171 & AFW-TDP-FR-1ASBH & DCP.BDC-ST-1 & & & $M$ & $1.876 E \cdot 16$ \\
\hline
\end{tabular}




\section{IABLE B.2. (contd)}

\begin{tabular}{|c|c|c|}
\hline $88 \mathrm{TCA}$ & RCA & AFW-AOV.CC.3148 \\
\hline $89 \mathrm{TCA}$ & ACA & AFW-AOV-CC-3164 \\
\hline OO TCR & RCA & AFW-MDP-FS-1AA \\
\hline 91 TCR & RCR & AFW-MDP.F8-1BB \\
\hline O2 TCA & RCA & AFW-MDP-FR-1BB24 \\
\hline 93 TCR & ACA & AFW-MOP-FR- 1 AA2 2 \\
\hline 94 TCA & RCA & AFW-MDP-FR-18824 \\
\hline 06 TCR & ACR & AFW-MDP-FR-1AA2 \\
\hline $98 \mathrm{TCA}$ & RCR & АCP-BAC'8T-1BB \\
\hline 97 TCA & RCR & ACP.BAC.8T.1AA \\
\hline & RCR & ACP-BAC-8T-1AA \\
\hline OO TCR & RCR & ACP-BAC-8T-1BB \\
\hline
\end{tabular}

AFW.TOP-FR-1ABQH DCP-BDC-8T. AFW-TOP.FR-1A86H DCP.BDC-8T-II AFW-TDP.TM-1AS DCP.BDC-8T-11 AFW.TOP.TM.1A8 DCP.BDC-8T-I AFW.TDP-F8.1A8 DCP-BDC-8T.I AFW-YOP-FR-1ABEh DCP-BDC-8T-II AFW-TDP.FR.1A86H DCP-BOC-8T-I AFW-TOP.F8-1AS DCP-BDC-8T-II AFW-MDP-F8.1AA AFW-TDP-FR-1A86H PP8-MOV-FC.332 AFW-MDP-F8-18B AFW-TDP-FA-1A86H PP8-MOV-FC.333 AFW-MDP.TM-1BB AFW-TDP-FR-1A86H PPS-MOV.FC.333 AFW-MDP-TM-1AA AFW-TDP-FA-1A8EH PPE-MOV-FC.332
M 1.975E-16

M 1.976E.16

M $3.202 E+13$

M $3.292 \mathrm{E} \cdot 13$

M $9.876 E-13$

M 0.8705 .13

M 0.8765.13

M 9.876E.13

M 1.075E-13

M 1.976E.13

M 7.900E.16

M 7.000E-16

TCR subtotal 7.287E.07 


\section{TABLE B.3. Loss of HPI Pump Room Cooling}

\begin{tabular}{|c|c|c|c|c|c|c|c|}
\hline & & & Cut $\mathbf{s}$ & t Elements & & & $\begin{array}{l}\text { Cut Set } \\
\text { Frequency }\end{array}$ \\
\hline $1 \mathrm{TH}$ & RH & AFW-AOV-CC & BETA-BAOV & HPI-XHE-FO-FDBLD & & $M$ & $2.233 \mathrm{E}-08$ \\
\hline $2 T H$ & $\mathbf{R H}$ & AFW-AOV-CC & BETA-BAOV & HPI-MDP-FS-IAA & HPI-MDP-FS-1BB & $M$ & $6.689 \mathrm{E}-11$ \\
\hline $3 \mathrm{TH}$ & $\mathbf{R H}$ & AFW-AOV-CC & BETA-BAOV & HPI-MDP-FS-1AA & HPI-FAN-FS-1BB & $M$ & 6.699E-11 \\
\hline $4 \mathrm{TH}$ & $\mathbf{R H}$ & AFW-AOV-CC & BETA.BAOV & HPI-MDP-FS-1BB & HPI-FAN-FS-1AA & $M$ & $6.699 \mathrm{E}-11$ \\
\hline $6 \mathrm{TH}$ & $\mathbf{R H}$ & Q1 & RWT-XHE-MSCAL & & & & $4.749 E-11$ \\
\hline $6 \mathrm{TH}$ & $\mathbf{R H}$ & Q1 & BETA-2MOV & LPR-MOV-CC & & & 2.607E-11 \\
\hline $7 \mathrm{TH}$ & RH & 01 & BETA-LPI & CSS-XHE-FO-CSR & LPI-MDP-FS & & $3.281 E-12$ \\
\hline $8 \mathrm{TH}$ & $\mathbf{R H}$ & 01 & BETA-LPI & CSS-XHE-FO-CSR & LPI-MDP-FAN-FS & & $3.281 E-12$ \\
\hline $9 \mathrm{TH}$ & RH & 01 & LPR-MDP-FS-1AA & LPR-MDP-FS-1BB & & & $8.648 E-13$ \\
\hline $10 \mathrm{TH}$ & $\mathbf{R H}$ & Q1 & LPR-MDP-FS-1 AA & LPR-FAN-FS-1BB & & & $8.648 E-13$ \\
\hline $11 \mathrm{TH}$ & $\mathbf{R H}$ & 01 & LPR-MDP-FS-1BB & LPR-FAN-FS-1AA & & & $8.648 E-13$ \\
\hline $12 \mathrm{TH}$ & $\mathbf{R H}$ & HPI-XHE-FO-FDBLD & STEAM-BINDING & & & $M$ & $6.630 E-09$ \\
\hline $13 \mathrm{TH}$ & $\mathbf{R H}$ & STEAM-BINDING & HPI-MDP-FS-1AA & HPI-MDP-FS-18B & & $M$ & $1.969 E-11$ \\
\hline $14 \mathrm{TH}$ & $\mathbf{R H}$ & STEAM-BINDING & HPI-MDP-FS & HPI-FAN-FS-1BB & & $M$ & $1.959 \mathrm{E}-11$ \\
\hline $16 \mathrm{TH}$ & $\mathbf{R H}$ & STEAM-BINDING & HPI-MDP-FS & HPI-FAN-FS-1AA & & $M$ & $1.969 E-11$ \\
\hline $16 \mathrm{TH}$ & RH & AFW-AOV-CC & BETA.8AOV & PPS-SOV-FT-340A & & $M$ & $1.407 E-10$ \\
\hline $17 \mathrm{TH}$ & $\mathbf{R H}$ & AFW-AOV-CC & BETA-BAOV & PPS-SOV-FT-334 & & $M$ & $1.407 E-10$ \\
\hline $18 \mathrm{TH}$ & RH & AFW-MDP-FS & AFW-TDP-FS-1AS & BETA-AFW & HPI-XHE-FO-FDBLD & $M$ & $3.291 \mathrm{E}-09$ \\
\hline $19 \mathrm{TH}$ & $\mathbf{R H}$ & AFW-MDP-FS & AFW-TDP-FR-1AS6H & BETA-AFW & HPI-XHE-FO-FDBLD & $M$ & $3.291 E-0 \theta$ \\
\hline $20 \mathrm{TH}$ & RH & PPS-SOV-FT-334 & STEAM-BINDING & & & $M$ & 4.114E-11 \\
\hline $21 \mathrm{TH}$ & $\mathbf{R H}$ & PPS-SOV-FT-340A & STEAM-BINDING & & & $M$ & $4.114 E-11$ \\
\hline $22 \mathrm{TH}$ & $\mathbf{R H}$ & AFW-ACT-FA-TRNA & AFW-ACT-FA-TRNB & HPI-XHE-FO-FDBLD & & $M$ & $1.672 E-09$ \\
\hline $23 \mathrm{TH}$ & $\mathbf{R H}$ & AFW-MDP-FS & AFW-TDP-TM-1AS & BETA-AFW & HPI-XHE-FO-FDBLD & $\mathbf{M}$ & $1.097 \mathrm{E}-09$ \\
\hline $24 \mathrm{TH}$ & $\mathbf{R H}$ & AFW-MDP-FS & AFW-TDP-FR-1AS6H & BETA-AFW & PPS-SOV-FT-340A & $M$ & $2.073 E-11$ \\
\hline $25 \mathrm{TH}$ & RH & AFW-MDP-FS & AFW-TDP-FS-1AS & BETA-AFW & PPS-SOV-FT-334 & $M$ & $2.073 E-11$ \\
\hline $26 \mathrm{TH}$ & $\mathbf{R H}$ & AFW-MDP-FS & AFW-TDP-FS-1AS & BETA-AFW & PPS-SOV-FT-340A & $M$ & 2.073E-11 \\
\hline $27 \mathrm{TH}$ & $\mathbf{R H}$ & AFW-MDP-FS & AFW-TDP-FR-1ASBH & BETA-AFW & PPS-SOV-FT-334 & $M$ & $2.073 E-11$ \\
\hline $28 \mathrm{TH}$ & $\mathbf{R H}$ & AFW-AOV-CC & BETA-BAOV & PPS-MOV-FC-332 & PPS-MOV-FT-332 & $M$ & $1.340 E-11$ \\
\hline $29 \mathrm{TH}$ & $\mathbf{R H}$ & AFW-AOV-CC & BETA-8AOV & PPS-MOV-FC-333 & PPS-MOV-FT-333 & $M$ & $1.340 E-11$ \\
\hline $30 \mathrm{TH}$ & $\mathbf{R H}$ & AFW-ACT-FA-TRNA & AFW-ACT-FA-TRNB & PPS-SOV-FT-334 & & $M$ & $1.063 E-11$ \\
\hline $31 \mathrm{TH}$ & $\mathbf{R H}$ & AFW-ACT-FA-TRNA & AFW-ACT-FA-TRNB & PPS-SOV-FT-340A & & $M$ & $1.063 E-11$ \\
\hline $32 \mathrm{TH}$ & $\mathbf{R H}$ & AFW-AOV-CC & BETA-BAOV & BETA-SRV & PPS-SOV-FT & $M$ & $9.848 \mathrm{E}-12$ \\
\hline $33 \mathrm{TH}$ & RH & AFW-MDP-FS & AFW-MOV-CC-151 & BETA-AFW & HPI-XHE-FO-FDBLD & $M$ & $3.291 E-10$ \\
\hline $34 \mathrm{TH}$ & $\mathbf{R H}$ & AFW-HDV-LF-152 & AFW-MDP-FS & BETA-AFW & HPI-XHE-FO-FDBLD & $M$ & $3.291 E-10$ \\
\hline $35 \mathrm{TH}$ & $\mathbf{R H}$ & AFW-MDP-FS & AFW-TDP-TM-1AS & BETA-AFW & PPS-SOV-FT-340A & $M$ & $6.811 E-12$ \\
\hline $36 \mathrm{TH}$ & $\mathbf{R H}$ & AFW-MDP-FS & AFW-TDP-TM-1AS & BETA-AFW & PPS-SOV-FT-334 & $M$ & $6.911 \mathrm{E}-12$ \\
\hline $37 \mathrm{TH}$ & $\mathbf{R H}$ & PPS-MOV-FC-332 & PPS-MOV-FT-332 & STEAM-BINDING & & $M$ & $3.918 \mathrm{E}-12$ \\
\hline $38 \mathrm{TH}$ & $\mathrm{RH}$ & PPS-MOV-FC-333 & PPS-MOV-FT-333 & STEAM-BINDING & & $M$ & $3.918 E-12$ \\
\hline $39 \mathrm{TH}$ & $\mathbf{R H}$ & AFW-MDP-FS-1AA & AFW-MDP-FS-1BB & AFW-TDP-FR-1AS6H & HPI-XHE-FO-FOBLD & $M$ & $1.763 E-10$ \\
\hline $40 \mathrm{TH}$ & $\mathbf{R H}$ & AFW-MDP-FS-1AA & AFW-MDP-FS-1BB & AFW-TDP-FS-1AS & HPI-XHE-FO-FDBLD & $M$ & $1.763 \mathrm{E}-10$ \\
\hline $41 \mathrm{TH}$ & $\mathbf{R H}$ & BETA-SRV & PPS-SOV-FT & STEAM-BINDING & & $M$ & $2.880 E-12$ \\
\hline $42 \mathrm{TH}$ & $\mathbf{R H}$ & AFW-MDP-FS-1BB & AFW-MDP-TM-1AA & & & & \\
\hline $43 \mathrm{TH}$ & $\mathbf{R H}$ & AFW-MDP-FS-1AA & AFW-MDP-TM-1BB & AFW-TDP-FR-1AS6H & HPI-XHE-FO-FDBLD & $M$ & $1.176 \mathrm{E}-10$ \\
\hline $44 \mathrm{TH}$ & RH & AFW-MDP-FS & AFW-MOV-CC-151 & BETA-AFW & PPS-SOV-FT-340A & $M$ & $2.073 E-12$ \\
\hline $46 \mathrm{TH}$ & RH & AFW-MDP-FS & AFW-MOV-CC-151 & BETA-AFW & PPS-SOV-FT-334 & $M$ & $2.073 E-12$ \\
\hline
\end{tabular}


TABLE B.3. (contd)

\begin{tabular}{|c|c|c|c|c|c|c|c|c|}
\hline \multicolumn{7}{|c|}{ Cut Set Elements } & \multirow[b]{2}{*}{$M$} & \multirow{2}{*}{$\frac{\begin{array}{c}\text { Cut Set } \\
\text { Frequency }\end{array}}{2.073 E-12}$} \\
\hline $46 \mathrm{TH}$ & RH & AFW-HDV-LF-152 & AFW-MDP-FS & BETA-AFW & PPS-SOV-FT-340A & & & \\
\hline $47 \mathrm{TH}$ & $\mathbf{R H}$ & AFW-HDV-LF-15: & AFW-MDP-FS & BETA-AFW & PPS-SOV-FT-334 & & $M$ & $2.073 E-12$ \\
\hline $48 \mathrm{TH}$ & RH & AFW-MDP-FS & AFW-TDP-FS-1AS & BETA-AFW & PPS-MOV-FC-333 & & $M$ & $1.97 E-12$ \\
\hline $49 \mathrm{TH}$ & RH & AFW-MD:-FS & AFW-TDP-FR-1ASGH & BETA-AFW & PPS-MOV-FC-332 & PPS-MOV-FT-332 & $M$ & $1,976 \mathrm{E}-12$ \\
\hline $60 \mathrm{TH}$ & $\mathbf{R h}^{\prime}$ & AFW-iMDP-FS & AFW-TDP-FS-1 AS & BETA-AFW & PPS-MOV-FC-332 & PPS-MOV-FT-332 & $M$ & $1.976 \mathrm{E}-12$ \\
\hline $61 \mathrm{TH}$ & RH & AFW-MDP-FS & AFW-TDP-FR-1 AS6H & BETA-AFW & PPS-MOV-FC-333 & PPS-MOV-FT-333 & $M$ & $1.975 \mathrm{E}-12$ \\
\hline $52 \mathrm{TH}$ & RH & AFW-MDP-FS & AFW-TDP-FS-1 AS & BETA-AFW & BETA-SRV & PPS-SOV-FT & $M$ & $1.461 \mathrm{E}-12$ \\
\hline $63 \mathrm{TH}$ & $\mathbf{R H}$ & AFW-MDP-FS & AFW-TDP-FR-1 AS6H & BETA-AFW & BETA-SRV & PPS-SOV-FT & $M$ & $1.461 E-12$ \\
\hline $64 \mathrm{TH}$ & RH & AFW-AOV-CC-3156 & AFW-MDP-FS-1BB & AFW-TDP-FR-1AS6H & HPI-XHE-FO-FDBLD & & $M$ & $6.877 \mathrm{E}-11$ \\
\hline $65 \mathrm{TH}$ & RH & AFW-AOV-CC-3171 & AFW-MDP-FS-1AA & AFW-TDP-FR-1ASGH & HPI-XHE-FO-FDBLD & & $M$ & $6.877 E-11$ \\
\hline $66 \mathrm{TH}$ & $\mathbf{R H}$ & AFW-AOV-CC-3148 & AFW-MDP-FS-1AA & AFW-TDP-FR-1 ASBH & HPI-XHE-FO-FDBLD & & $M$ & $6.877 E-11$ \\
\hline $57 \mathrm{TH}$ & RH & AFW-AOV-CC-3164 & AFW-MDP-FS-1BB & AFW-TDP-FR-1AS6H & HPI-XHE-FO-FDBLD & & $M$ & 6.877E-11 \\
\hline $58 \mathrm{TH}$ & RH & AFW-MDP-FS-1AA & AFW-MDP-FS-1BB & AFW-TDP-FS-1AS & PPS-SOV-FT-340A & & $M$ & $1.111 E-12$ \\
\hline $59 \mathrm{TH}$ & RH & AFW-MDP-FS-1AA & AFW-MDP-FS-1BB & AFW-TDP-FR-1 ASGH & PPS-SOV-FT-334 & & M & $1.111 E-12$ \\
\hline $60 \mathrm{TH}$ & RH & AFW-MDP-FS- 1 AA & AFW-MDP-FS-1BB & AFW-TDP-FS-1AS & PPS-SOV-FT-334 & & $M$ & $1.111 \mathrm{E}-12$ \\
\hline $61 \mathrm{TH}$ & RH & AFW-MDP-FS-1AA & AFW-MDP-FS-1BB & AFW-TDP-FR-1AS6H & PPS-SOV-FT-340A & & $M$ & $1.111 E-12$ \\
\hline $62 \mathrm{TH}$ & RH & AFW-MDP-FR-1AA24 & AFW-MDP-FS-1BB & AFW-TDP-FR-1AS6H & HPI-XHE-FO-FDBLD & & $M$ & $4.231 E-11$ \\
\hline $63 \mathrm{TH}$ & RH & AFW-MDP-FR-1BB24 & AFW-MDP-FS-1AA & AFW-TDP-FR-1ASGH & HPI-XHE-FO-FDBLD & & $M$ & $4.231 E-11$ \\
\hline $64 \mathrm{TH}$ & RH & AFW-AOV-CC-3156 & AFW-MDP-TM-1BB & AFW-TDP-FR-1AS6H & HPI-XHE-FO-FDBLD & & $M$ & $3.918 \mathrm{E}-11$ \\
\hline $66 \mathrm{TH}$ & RH & AFW-AOV-CC-3148 & AFW-MDP-TM-1 AA & AFW-TDP-FR-1AS6H & HPI-XHE-FO-FDBLD & & $M$ & $3.918 E-11$ \\
\hline $66 \mathrm{TH}$ & $\mathbf{R H}$ & AFW-AOV-CC-3164 & AFW-MDP-TM-1BB & AFW-TDP-FR-1 ASEH & HPI-XHE-FO-FDBLD & & $M$ & $3.918 \mathrm{E}-11$ \\
\hline $67 \mathrm{TH}$ & $\mathrm{RH}$ & AFW-AOV-CC-3171 & AFW-MDP-TM-1AA & AFW-TDP-FR-1ASGH & HPI-XHE-FO-FDBLD & & $M$ & $3.918 \mathrm{E}-11$ \\
\hline $68 \mathrm{TH}$ & RH & AFW-MDP-FS-1BB & AFW-MDP-TM-1AA & AFW-TDP-FR-1AS6H & PPS-SOV-FT-340A & & $M$ & $7.406 E-13$ \\
\hline $69 \mathrm{TH}$ & $\mathbf{R H}$ & AFW-MDP-FS-1AA & AFW-MDP-TM-1BB & AFW-TDP-FR-1ASEH & PPS-SOV-FT-340A & & $M$ & $7.406 \mathrm{E}-13$ \\
\hline $70 \mathrm{TH}$ & $\mathbf{R H}$ & AFW-MDP-FS-1AA & AFW-MDP-TM-1BB & AFW-TDP-FR-1 AS $6 H$ & PPS-SOV-FT-334 & & $M$ & $7.406 \mathrm{E}-13$ \\
\hline $71 \mathrm{TH}$ & RH & AFW-MDP-FS-1BB & AFW-MDP-TM-1AA & AFW-TDP-FR-1AS6H & PPS-SOV-FT-334 & & $M$ & $7.406 \mathrm{E}-13$ \\
\hline $72 \mathrm{TH}$ & RH & AFW-MDP-FS-1BB & AFW-TDP-FS-1AS & DCP-BDC-ST-1 & & & $M$ & $1.822 \mathrm{E}-13$ \\
\hline $73 \mathrm{TH}$ & RH & AFW-MDP-FS-1AA & AFW-TDP-FR- 1 AS $6 \mathrm{H}$ & DCP-BDC-ST-II & & & $M$ & $1.822 \mathrm{E}-13$ \\
\hline $74 \mathrm{TH}$ & RH & AFW-MDP-FS-1BB & AFW-TDP-FR-1AS6H & DCP-BDC-ST-I & & & $\mathbf{M}$ & $1.822 \mathrm{E}-13$ \\
\hline $75 \mathrm{TH}$ & RH & AFW-MDP-FS-1AA & AFW-TDP-FS-1AS & DCP-BDC-ST-II & & & $M$ & $1.822 \mathrm{E}-13$ \\
\hline $76 \mathrm{TH}$ & $\mathbf{R H}$ & AFW-MDP-TM-1BB & AFW-TDP-FS-1AS & DCP-BDC-ST-I & & & M & $1.216 \mathrm{E}-13$ \\
\hline $77 \mathrm{TH}$ & RH & AFW-MDP-TM-1BB & AFW-TDP-FR-1AS6H & DCP-BDC-ST-I & & & $M$ & $1.216 \mathrm{E}-13$ \\
\hline $78 \mathrm{TH}$ & $\mathbf{R H}$ & AFW-MDP-TM-1AA & AFW-TDP-FR-1AS6H & DCP-BDC-ST-\| & & & $\mathbf{M}$ & $1.216 \mathrm{E}-13$ \\
\hline $79 \mathrm{TH}$ & $\mathbf{R H}$ & AFW-MDP-TMI-1AA & AFW-TDP-FS-1AS & DCP-BDC-ST-II & & & $M$ & $1.216 \mathrm{E}-13$ \\
\hline $80 \mathrm{TH}$ & $\mathbf{R H}$ & AFW-AOV-CC & BETA-BAOV & DCP-BDC-ST-I & & & $M$ & $6.923 E-14$ \\
\hline $81 \mathrm{TH}$ & RH & AFW-AOV-CC & BETA-BAOV & DCP-BDC-ST-II & & & $\mathbf{M}$ & $6.923 E-14$ \\
\hline $82 \mathrm{TH}$ & RH & AFW-AOV-CC-3156 & AFW-TDP-FR-1AS6H & DCP-BDC-ST-\| & & & $M$ & $6.073 E-14$ \\
\hline $83 \mathrm{TH}$ & RH & $A F W-A O V-C C-3164$ & AFW-TDP-FS-1AS & DCP-BDC-ST-II & & & $M$ & $6.073 E-14$ \\
\hline $84 \mathrm{TH}$ & RH & $A F W-A O V-C C-3171$ & AFW-TDP-FS-1AS & DCP-BDC-ST-1 & & & $\mathbf{M}$ & 6.073E-14 \\
\hline $85 \mathrm{TH}$ & $\mathbf{R H}$ & AFW-AOV-CC-3160 & AFW-TDP-FS-1AS & DCP-BDC-ST-II & & & $M$ & $6.073 E-14$ \\
\hline $86 \mathrm{TH}$ & RH & AFW-AOV-CC-3148 & AFW-TDP-FS-1AS & DCP-BDC-ST-I & & & M & $6.073 E \cdot 14$ \\
\hline $87 \mathrm{TH}$ & $\mathrm{RH}$ & $A F W-A O V-C C-3171$ & AFW-TDP-FR-1ASGH & DCP-BDC-ST-I & & & $M$ & $6.073 E-14$ \\
\hline $88 \mathrm{TH}$ & RH & $A F W-A O V-C C-3148$ & AFW-TDP-FR-1AS6H & DCP-BDC-ST-1 & & & $\mathbf{M}$ & 6.073E-14 \\
\hline $89 \mathrm{TH}$ & RH & AFW-AOV-CC-3164 & AFW-TDP-FR-1AS6H & DCP-BDC-ST-II & & & $M$ & $6.073 E-14$ \\
\hline $90 \mathrm{TH}$ & $\mathbf{R H}$ & AFW-MDP-FS-1AA & AFW-TDP-TM-1AS & DCP-BDC-ST-11 & & & M & 6.073E-14 \\
\hline $91 \mathrm{TH}$ & RH & AFW-MDP-FS-1BB & AFW-TDP-TM-1AS & DCP-BDC-ST-I & & & $M$ & $6.073 E-14$ \\
\hline $92 \mathrm{TH}$ & RH & AFW-MDP-FR- 1 BB 24 & AFW-TDP-FS-1AS & DCP-BDC-ST-1 & & & $\mathbf{M}$ & $4.372 E-14$ \\
\hline
\end{tabular}




\section{TABLE B.3. (contd)}

\begin{tabular}{|c|c|c|c|c|c|c|c|}
\hline \multicolumn{7}{|c|}{ Cut Sot Eloments } & \multirow{2}{*}{$\begin{array}{c}\begin{array}{c}\text { Cut Sot } \\
\text { Frequency }\end{array} \\
4.372 E-14\end{array}$} \\
\hline $93 \mathrm{TH}$ & RH & AFW-MDP-FR-1 AA24 & AFW-TDP-FR-1ASBH & DCP-BDC-ST-11 & & $M$ & \\
\hline $84 \mathrm{TH}$ & RH & AFW-MDP-FR-1BB24 & AFW-TDP-FR-1ASBH & DCP-BDC-ST-I & & $M$ & $4.372 E-14$ \\
\hline $85 \mathrm{TH}$ & RH & AFW-MDP-FR-1 AA24 & AFW-TDP-FS-1AS & DCP-BDC-ST-II & & $M$ & $4.372 E-14$ \\
\hline $96 \mathrm{TH}$ & RH & ACP-BAC-ST-1BB & AFW-MDP-FS-1AA & AFW-TDP-FR-1AS6H & PPS-MOV-FC-332 & $M$ & $3.644 E-14$ \\
\hline $97 \mathrm{TH}$ & $\mathbf{R H}$ & ACP-BAC-ST-1AA & AFW-MDP-FS-1BB & AFW-TDP-FR-1ASBH & PPS-MOV-FC-333 & $M$ & $3.644 E-14$ \\
\hline $98 \mathrm{TH}$ & RH & ACP-BAC-ST-1AA & AFW-MDP-TM-1BB & AFW-TDP-FR-1AS6H & PPS-MOV-FC-333 & $M$ & $2.428 E-14$ \\
\hline $99 \mathrm{TH}$ & RH & ACP-BAC-ST-1BB & AFW-MDP-TM-1AA & AFW-TDP-FR-1ASBH & PPS-MOV-FC-332 & $M$ & $2.428 E-14$ \\
\hline
\end{tabular}


TABLE B.4. Loss of LPI/LPR Pump Room Cooling

\begin{tabular}{|c|c|c|c|c|c|c|c|}
\hline \multicolumn{7}{|c|}{ Cut Sot Eloments } & \multirow{2}{*}{$\begin{array}{c}\begin{array}{c}\text { Cut Set } \\
\text { Froquency }\end{array} \\
3.098 \mathrm{E}-10\end{array}$} \\
\hline $1 \mathrm{TLP}$ & RLP & AFW-AOV-CC & BETA-BAOV & HPI-XHE-FO-FDBLD & & $M$ & \\
\hline 2 TLP & RLP & $A F W \cdot A O V \cdot C C$ & BETA.BAOV & HPI-MDP-FS-1AA & HPI-MDP-FS-1BB & $\mathbf{M}$ & $1.268 E-13$ \\
\hline 3 TLP & RLP & AFW-AOV-CC & BETA-BAOV & HPI-MDP-FS-1AA & HPI-FAN-FS-1BB & $M$ & $8.461 E-14$ \\
\hline 4 TLP & RLP & AFW-AOV-CC & BETA-8AOV & HPI-MDP-FS-1BB & HPI-FAN-FS-1AA & $M$ & $8.461 \mathrm{E}-14$ \\
\hline 5 TLP & RLP & Q1 & RWT-XHE-MSCAL & & & & $2.896 \mathrm{E}-11$ \\
\hline $6 \mathrm{TLP}$ & RLP & 0.1 & BETA-2MOV & LPR-MOV-CC & & & $1.681 \mathrm{E}-11$ \\
\hline 7 TLP & RLP & 01 & BETA-LPI & CSS-XHE-FO-CSR & LPI-MDP.FS & & $6.810 E-10$ \\
\hline 8 TLP & RLP & Q1 & BETA-LPI & CSS-XHE-FO-CSR & LPI-MDP-FAN-FS & & $6.819 E-10$ \\
\hline 9 TLP & RLP & Q1 & LPR-MDP-FS-1AA & LPR-MDP-FS-1BB & & & $1.797 \mathrm{E}-10$ \\
\hline $10 \mathrm{TLP}$ & RLP & Q1 & LPR-MD F FS-1AA & LPR-FAN-FS-1BB & & & $1.787 \mathrm{E}-10$ \\
\hline $11 \mathrm{TLP}$ & RLP & Q1 & LPR-ME,P-FS-1BB & LPR-FAN-FS-1AA & & & $1.797 \mathrm{E}-10$ \\
\hline 12 TLP & RLP & HPI-XHE-FO-FDBLD & STEAM-BINDING & & & $M$ & $9.060 E-11$ \\
\hline 13 TLP & RLP & STEAM-BINDING & HPI-MDP-FS-1AA & HPI-MDP-FS-1BB & & $M$ & $3.707 E-14$ \\
\hline $14 \mathrm{TLP}$ & RLP & STEAM-BINDING & HPI-MDP-FS & HPI-FAN-FS-1BB & & $M$ & $2.471 E-14$ \\
\hline 16 TLP & RLP & STEAM-BINDING & HPI-MDP-FS & HPI-FAN-FS-1AA & & $M$ & $2.471 E-14$ \\
\hline $16 \mathrm{TLP}$ & RLP & AFW-AOV-CC & BETA-BAOV & PPS-SOV-FT-340A & & $M$ & $8.874 E-11$ \\
\hline $17 \mathrm{TLP}$ & RLP & AFW-AOV-CC & BETA-8AOV & PPS-SOV-FT-334 & & $M$ & $8.874 E-11$ \\
\hline $18 \mathrm{TLP}$ & RLP & AFW-MDP-FS & AFW-TDP-FS-1AS & BETA-AFW & HPI-XHE-FO-FDBLD & $M$ & $4.566 \mathrm{E}-11$ \\
\hline $19 \mathrm{TLP}$ & RLP & AFW-MDP-FS & AFW-TDP-FR-1 ASBH & BETA-AFW & HPI-XHE-FO-FDBLD & $M$ & $4.666 \mathrm{E}-11$ \\
\hline 20 TLP & RLP & PPS-SOV-FT-334 & STEAM-BINDING & & & $M$ & $2.596 E-11$ \\
\hline $21 \mathrm{TLP}$ & RLP & PPS-SOV-FT-340A & STEAM-BINDING & & & $M$ & $2.696 E-11$ \\
\hline 22 TLP & RLP & AFW-ACT-FA-TRNA & AFW-ACT-FA-TRNB & HPI-XHE-FO-FDBLD & & $M$ & $2.318 \mathrm{E}-11$ \\
\hline 23 TLP & RLP & AFW-MDP-FS & AFW-TDP-TM-1AS & BETA-AFW & HPI-XHE-FO-FDBLD & $M$ & $1.622 E-11$ \\
\hline 24 TLP & RLP & AFW-MDP-FS & AFW-TDP-FR-1 ASGH & BETA-AFW & PPS-SOV-FT-340A & $M$ & $1.308 E-11$ \\
\hline 25 TLP & RLP & AFW-MDP.FS & AFW-TDP-FS-1AS & BETA-AFW & PPS-SOV-FT-334 & $M$ & $1.308 E-11$ \\
\hline 26 TLP & RLP & AFW-MDP-FS & AFW-TDP-FS-1AS & BETA-AFW & PPS-SOV-FT-340A & $M$ & $1.308 \mathrm{E}-11$ \\
\hline 27 TLP & RLP & AFW-MDP-FS & AFW-TDP-FR-1ASGH & BETA-AFW & PPS-SOV-FT-3.34 & $M$ & $1.308 E-11$ \\
\hline $28 \mathrm{TLP}$ & RLP & AFW-AOV-CC & BETA-8AOV & PPS-MOV-FC-332 & PPS-MOV-FT-332 & $M$ & $8.461 E-12$ \\
\hline 29 TLP & RLP & AFW-AOV-CC & BETA-8AOV & PPS-MOV-FC-333 & PPS-MOV-FT-333 & $M$ & $8.461 \mathrm{E}-12$ \\
\hline 30 TLP & RLP & AFW-ACT-FA-TRNA & AFW-ACT-FA-TRNB & PPS-SOV-FT-334 & & $M$ & $6.642 E-12$ \\
\hline $31 \mathrm{TLP}$ & RLP & AFW-ACT-FA-TRNA & AFW-ACT-FA-TRNB & PPS-SOV-FT-340A & & $M$ & $6.642 \mathrm{E}-12$ \\
\hline 32 TLP & RLP & $A F W \cdot A O V \cdot C C$ & BETA-BAOV & BETA-SRV & PPS-SOV-FT & $M$ & $6.211 E-12$ \\
\hline 33 TLP & RLP & AFW-MDP-FS & AFW-MOV-CC-161 & BETA-AFW & HPI-XHE-FO-FDBLD & $M$ & $4.686 E-12$ \\
\hline 34 TLP & RLP & AFW-HDV-LF- 162 & AFW-MDP-FS & BETA.AFW & HPI-XHE-FO-FDBLD & $M$ & $4.666 \mathrm{E}-12$ \\
\hline 35 TLP & RLP & AFW-MDP-FS & AFW-TDP-TM-1AS & BETA-AFW & PPS-SOV-FT-340A & $M$ & $4.369 \mathrm{E} \cdot 12$ \\
\hline $36 \mathrm{TLP}$ & RLP & AFW-MDP.FS & AFW-TDP-TM-1AS & BETA-AFW & PPS-SOV-FT-334 & $M$ & $4.369 \mathrm{E}-12$ \\
\hline 37 TLP & RLP & PPS-MOV-FC-332 & PPS-MOV-FT-332 & STEAM-BINDING & & $M$ & $2.471 E-12$ \\
\hline 38 TLP & RLP & PPS-MOV-FC-333 & PPS-MOV-FT-333 & STEAM-BINDING & & $M$ & $2.471 E-12$ \\
\hline 39 TLP & RLP & AFW-MDP-FS-1AA & AFW-MDP-FS-1BB & AFW-TDP-FR-1AS6H & HPI-XHE-FO-FDBLD & $M$ & $2.446 E-12$ \\
\hline 40 TLP & RLP & AFW-MDP-FS-1AA & AFW-MDP-FS-1BB & AFW-TDP-FS-1AS & HPI-XHE-FO-FDBLD & $M$ & $2.446 E-12$ \\
\hline 41 TLP & RLP & BETA-SRV & PPS-SOV-FT & STEAM-BINDING & & $M$ & $1.81 \theta E-12$ \\
\hline 42 TLP & RLP & AFW-MDP-FS-1BB & AFW-MDP-TM-1AA & AFW-TDP-FR-1AS6H & HPI-XHE-FO-FOBLD & $M$ & $1.631 \mathrm{E}-12$ \\
\hline 43 TLP & RLP & AFW-MDP-FS-1AA & AFW-MDP-TM-1BB & AFW-TDP-FR-1AS6H & HPI-XHE-FO-FDBLD & $M$ & $1.631 E \cdot 12$ \\
\hline 44 TLP & RLP & AFW-MDP-FS & AFW-MOV-CC-151 & BETA-AFW & PPS-SOV-FT-340A & $M$ & $1.308 E-12$ \\
\hline 46 TLP & RLP & AFW-MDP-FS & AFW-MOV-CC-161 & BETA-AFW & PPS-SOV-FT-334 & $M$ & $1.308 E \cdot 12$ \\
\hline
\end{tabular}




\section{TABLE B.4. (contd)}

\begin{tabular}{|c|c|c|c|c|c|c|c|c|}
\hline & & & Cut Se & Elements & & & & $\begin{array}{l}\text { Cut Sot } \\
\text { Frequency }\end{array}$ \\
\hline $46 \mathrm{TLP}$ & RLP & AFW-HDV-LF- 152 & AFW-MDP-FS & BETA-AFW & PPS-SOV-FT-340A & & $M$ & $1.308 E-12$ \\
\hline 47 TLP & RLP & AFW-HDV-LF- 162 & AFW-MDP.FS & BETA-AFW & PPS.SOV-FT-334 & & $M$ & $1.308 E-12$ \\
\hline $48 \mathrm{TLP}$ & RLP & AFW-MDP.FS & AFW.TDP.FS-1AS & BETA-AFW & PPS.MOV.FC. 333 & PPS.MOV-FT. 333 & $M$ & $1.245 \mathrm{E} \cdot 12$ \\
\hline 49 TLP & RLP & AFW-MDP-FS & AFW-TDP-FR-1ASEH & BETA-AFW & PPS-MOV-FC- 332 & PPS-MOV-FT- 332 & $M$ & $1.245 E-12$ \\
\hline 50 TLP & RLP & AFW-MDP-FS & AFW-TDP-FS-1AS & BETA-AFW & PPS-MOV-FC-332 & PPS.MOV-FT- 332 & $M$ & $1.246 \mathrm{E}-12$ \\
\hline 51 TLP & RLP & AFW-MOP-FS & AFW-TDP-FR-1ASBH & BETA-AFW & PPS.MOV-FC. 333 & PPS-MOV-FT-333 & $M$ & $1.245 \mathrm{E} \cdot 12$ \\
\hline 52 TLP & RLP & AFW-MDP-FS & AFW-TDP-FS-1AS & BETA-AFW & BETA-SRV & PPS.SOV-FT & $M$ & $9.154 E \cdot 13$ \\
\hline 63 TLP & RLP & AFW-MDP-FS & AFW-TDP-FR-1ASGH & BETA.AFW & BETA-SRV & PPS-SOV-FT & $M$ & $8.154 \mathrm{E}-13$ \\
\hline 64 TLP & RLP & AFW-AOV-CC-3156 & AFW-MDP-FS-1BB & AFW-TDP-FR-1ASGH & HPI-XHE-FO-FDBLD & & $M$ & $8.154 E-13$ \\
\hline 55 TLP & RLP & AFW-AOV-CC-3171 & AFW-MDP-FS-1AA & AFW-TDP-FR-1ASGH & HPI-XHE-FO-FDBLD & & $M$ & $8.154 E \cdot 13$ \\
\hline 56 TLP & RLP & AFW-AOV-CC. 3148 & AFW-MDP-FS-1AA & AFW-TDP-FR-1ASGH & HPI-XHE-FO-FDBLD & & $M$ & $8.164 E-13$ \\
\hline 57 TLP & RLP & AFW-AOV-CC-3164 & AFW-MDP-FS-1BB & AFW-TDP-FR-1ASGH & HPI-XHE-FO-FDBLD & & $M$ & $8.154 \mathrm{E} \cdot 13$ \\
\hline 58 TLP & RLP & AFW-MDP-FS-IAA & AFW-MDP-FS-1BB & AFW-TDP-FS-1AS & PPS-SOV-FT-34OA & & $M$ & $7.005 E-13$ \\
\hline 69 TLP & RLP & AFW-MDP-FS-IAA & AFW-MDP-FS-1BB & AFW-TDP-FR-1ASBH & PPS.SOV.FT-334 & & $M$ & $7.005 E \cdot 13$ \\
\hline $60 \mathrm{TLP}$ & RLP & AFW-MDP-FS-1AA & AFW-MDP-FS-1BB & AFW-TDP-FS-1AS & PPS.SOV.FT-334 & & $M$ & $7.005 E-13$ \\
\hline 61 TLP & RLP & AFW-MDP.FS-1AA & AFW-MDP-FS-1BB & AFW-TDP-FR-1AS6H & PPS-SOV.FT-340A & & $M$ & $7.005 E-13$ \\
\hline 62 TLP & RLP & AFW-MDP-FR-1AA24 & AFW-MDP-FS-1BB & AFW-TDP-FR-1ASBH & HPI-XHE-FO-FDBLD & & $M$ & $5.871 E-13$ \\
\hline 63 TLP & RLP & AFW-MDP-FR-1BB24 & AFW-MDP-FS-1AA & AFW-TDP-FR-1ASGH & HPI-XHE-FO-FDBLD & & $M$ & $5.871 E-13$ \\
\hline $64 \mathrm{TLP}$ & RLP & AFW-AOV.CC-3156 & AFW-MDP-TM-1BB & AFW-TDP-FR- 1 AS $6 \mathrm{H}$ & HPI-XHE-FO-FDBLD & & $M$ & $5.436 \mathrm{E} \cdot 13$ \\
\hline 66 TLP & RLP & $A F W \cdot A O V \cdot C C \cdot 3148$ & AFW-MDP-TM-1AA & AFW-TOP-FR-1ASGH & HPI-XHE-FO-FOBLD & & $M$ & $5.436 \mathrm{E}-13$ \\
\hline $66 \mathrm{TLP}$ & RLP & AFW-AOV-CC-3164 & AFW-MDP-TM-1BB & AFW-TDP-FR-1 ASGH & HPI-XHE-FO-FDBLD & & $M$ & $5.438 E-13$ \\
\hline 67 TLP & RLP & AFW-AOV-CC.3171 & AFW-MDP-TM-1AA & AFW-TDP-FR-1ASGH & HPI.XHE-FO-FDBLD & & $M$ & $5.436 E-13$ \\
\hline $68 \mathrm{TLP}$ & RLP & AFW-MDP-FS-1BB & AFW-MDP-TM-1AA & AFW-TDP-FR-1ASGH & PPS-SOV-FT-340A & & $M$ & $4.870 \mathrm{E} \cdot 13$ \\
\hline 69 TLP & RLP & AFW-MDP.FS-1AA & AFW-MDP.TM-1B8 & AFW-TDP.FR-1AS6H & PPS-SOV-FT-340A & & $M$ & $4.670 E-13$ \\
\hline $70 \mathrm{TLP}$ & RLP & AFW-MDP-FS-1AA & AFW-MDP-TM-1BB & AFW-TDP-FR-1ASGH & PPS-SOV-FT-334 & & $M$ & $4.670 E-13$ \\
\hline 71 TLP & RLP & AFW-MDP-FS-1BB & AFW-MDP-TM-1AA & AFW-TDP-FR-1AS6H & PPS-SOV-FT- 334 & & $M$ & $4.670 E-13$ \\
\hline 72 TLP & RLP & AFW-MDP-FS-1BB & AFW-TDP.FS-1AS & DCP-BDC-ST-I & & & $M$ & $1.149 \mathrm{E}-13$ \\
\hline 73 TLP & RLP & AFW-MDP-FS-1AA & AFW-TDP-FR-1ASGH & DCP-BDC-ST-II & & & $M$ & $1.149 \mathrm{E}-13$ \\
\hline 74 TLP & RLP & AFW-MDP-FS-1BB & AFW-TDP-FR-1ASGH & DCP-BDC-ST-I & & & $M$ & $1.149 \mathrm{E}-13$ \\
\hline 75 TLP & RLP & AFW-MDP-FS-1AA & AFW.TDP.FS-1AS & DCP-BDC-ST-11 & & & $M$ & $1.149 \mathrm{E}-13$ \\
\hline $76 \mathrm{TLP}$ & RLP & AFW-MDP-TM-1BB & AFW-TDP-FS-1AS & DCP-BDC-ST-1 & & & $M$ & 7.660 E- 14 \\
\hline 77 TLP & RLP & AFW-MDP-TM-1BB & AFW-TDP-FR-1ASGH & DCP.BDC.ST-I & & & $M$ & 7.660 E- 14 \\
\hline 78 TLP & RLP & AFW-MDP-TM-1AA & AFW-TDP-FR-1AS6H & DCP-BDC-ST-\|I & & & $M$ & $7.660 E-14$ \\
\hline 79 TLP & RLP & AFW-MDP-TM-1AA & AFW-TDP-FS-1AS & DCP-BDC-ST-II & & & $M$ & $7.660 E \cdot 14$ \\
\hline $80 \mathrm{TLP}$ & RLP & $A F W \cdot A O V \cdot C C$ & BETA-BAOV & DCP-BDC-ST-I & & & $M$ & $4.366 E-14$ \\
\hline 81 TLP & RLP & $A F W \cdot A O V \cdot C C$ & BETA-BAOV & DCP-BDC-ST.II & & & $M$ & $4.366 \mathrm{E} \cdot 14$ \\
\hline 82 TLP & RLP & AFW-AOV-CC.3156 & AFW-TDP.FR-1AS6H & DCP-BDC.ST-\| & & & $M$ & $3.830 E \cdot 14$ \\
\hline 83 TLP & RLP & AFW.AOV.CC. 3164 & AFW-TDP-FS-1AS & DCP-BDC-ST-II & & & $M$ & $3.830 E-14$ \\
\hline 84 TLP & RLP & AFW-AOV-CC-3171 & AFW-TDP-FS- 1 AS & DCP.BDC.ST.I & & & $M$ & 3. $830 E \cdot 14$ \\
\hline 85 TLP & RLP & AFW-AOV-CC. 3156 & AFW-TDP.FS-1AS & DCP-BDC-ST-II & & & $M$ & $3.830 E \cdot 14$ \\
\hline $86 \mathrm{TLP}$ & RLP & AFW-AOV-CC. 3148 & AFW-TDP.FS. 1 AS & DCP-BDC.ST-I & & & $M$ & $3.830 E-14$ \\
\hline 87 TLP & RLP & AFW-AOV-C'C-3171 & AFW-TDP.FR-1ASGH & DCP-BDC-ST-I & & & $M$ & $3.830 E \cdot 14$ \\
\hline 88 TLP & RLP & AFW-AOV.CC. 3148 & AFW-TDP-FR-1AS6H & DCP.BDC.ST-I & & & $M$ & $3.830 \mathrm{E} \cdot 14$ \\
\hline $89 \mathrm{TLP}$ & RLP & AFW.AOV.CC. 3164 & AFW-TDP.FR-1ASGH & DCP.BDC.ST-II & & & $M$ & $3.830 E \cdot 14$ \\
\hline 90 TLP & RLP & AFW-MDP.FS-1AA & AFW-TDP.TM-1AS & DCP.BDC.ST-II & & & $M$ & $3.830 \mathrm{E} \cdot 14$ \\
\hline $91 \mathrm{TLP}$ & RLP & $A F W \cdot M D P-F S \cdot 1 B B$ & AFW-TDP-TM-1AS & DCP.BDC.ST-I & & & $M$ & $3.830 E \cdot 14$ \\
\hline 92 TLP & RLP & $A F W \cdot M D P \cdot F R \cdot 1 B B 24$ & AFW-TDP-FS-1AS & DCP.BDC.ST-I & & & $M$ & $2.758 E_{14}$ \\
\hline
\end{tabular}




\section{IABLE B.4. (contd)}

Cut Set Elements

$\begin{array}{lll}93 \text { TLP } & \text { RLP } & \text { AFW-MDP-FR-1AA24 } \\ 94 \text { TLP } & \text { RLP } & \text { AFW-MDP.FR-1BB24 } \\ 96 \text { TLP } & \text { RLP } & \text { AFW-MDP.FR-1AA24 } \\ 96 \text { TLP } & \text { RLP } & \text { ACP-BAC-ST-1B8 } \\ 97 \text { TLP } & \text { RLP } & \text { ACP-BAC-ST-1AA } \\ 98 \text { TLP } & \text { RLP } & \text { ACP-BAC-ST-1AA } \\ 99 \text { TLP } & \text { RLP } & \text { ACP-BAC-ST-1BB }\end{array}$

$\begin{array}{lll}\text { AFW-TDP.FR-1AS6H } & \text { DCP.BDC.ST-II } & \\ \text { AFW-TDP-FR.1AS6H } & \text { DCP-BDC.8T-1 } & \\ \text { AFW-TDP-FS-1AS } & \text { DCP-BDC-ST-11 } & \\ \text { AFW-MDP-FS-1AA } & \text { AFW-TDP-FR-1AS6H } & \text { PPS-MOV-FC.332 } \\ \text { AFW-MDP-FS-1BB } & \text { AFW-TDP.FR-1AS6H } & \text { PPS.MOV-FC.333 } \\ \text { AFW-MDP-TM-1BB } & \text { AFW-TDP-FR-1AS6H } & \text { PPS-MOV-FC-333 } \\ \text { AFW-MDP-TM-1AA } & \text { AFW-TDP-FR-1AS6H } & \text { PPS-MOV-FC.332 }\end{array}$

Cut Set Frequency

M 2.768E.14

M 2.768E-14

M 2.768E.14

M 2.298E-14

M 2.298E-14

M 1.532E-14

M 1.532E-14

TLP Subtotal $2.876 E \cdot 08$

B. 51 
IABLE B.5. Loss of DC Equipment Room Cooling

\begin{tabular}{|c|c|c|c|c|}
\hline \multicolumn{4}{|c|}{ Cut set Elemente } & \multirow{2}{*}{$\begin{array}{l}\begin{array}{l}\text { Cut sot } \\
\text { frequency }\end{array} \\
1.600 \text { E.08 }\end{array}$} \\
\hline 1 TDC & STEAM-BINDING & & & \\
\hline $2 \pi D C$ & ACP-BAC-8T-1AA & AFW-TDP-FR-1A8EH & & $4.860 E \cdot 10$ \\
\hline 3 TDC & AFW.AOV.CC & BETA.BAOV & & $6.440 E-08$ \\
\hline 4 TOC & AFW-TDP-FR-1ASGH & DCP-BDC-8T-1 & & $4.320 E-10$ \\
\hline 6 TDC & AFW-AOV.CC.3160 & AFW-TDP-FR-1A86H & RA17 & 6.820E.09 \\
\hline B TDC & AFW.AOV.CC.3168 & AFW-TDP-FS-1AS & RA17 & 6.820E-08 \\
\hline $7 \mathrm{TDC}$ & AFI-AOV-CC-3160 & AFW-TDP-TM-1AS & RA17 & 6.920E-09 \\
\hline 8 TDC & AFW.AOV-CC-3164 & AFW-TDP-FR-1A8BH & RA 17 & $6.820 E .00$ \\
\hline $8 \mathrm{TDC}$ & AFW.AOV.CC-3164 & AFW-TDP-F8-1A8 & RA17 & 6.820E.08 \\
\hline $10 \mathrm{TDC}$ & AFW-AOV-CC-3164 & AFW-TDP-TM-1AS & RA 17 & $6.920 E \cdot 09$ \\
\hline 11 TDC & AFW-CKV-CC-3820 & AFW-TDP-FR-1ASGH & RA17 & $6.820 E \cdot 10$ \\
\hline 12 TOC & AFW-CKV-CC-3831 & AFW-TUP-FR-1ASBH & RA17 & $6.820 E \cdot 10$ \\
\hline 13 TOC & AFW.CKV.CC-3832 & AFW-TDP-FR-1ASBH & RA 17 & $6.920 E \cdot 10$ \\
\hline 14 TDC & AFW.CKV.CC. 3862 & AFW-TDP-FR-1ASBH & RA17 & $6.820 E-10$ \\
\hline 16 TDC & AFW-CKV.CC.3922 & AFW-TDP-FR-1ASGH & RA17 & $6.820 E \cdot 10$ \\
\hline $18 \mathrm{TDC}$ & AFW'HDV.LF-162 & AFW-MDP-FS-1AA & RA17 & $6.328 E-11$ \\
\hline 17 TDC & AFW-HDV-LF-162 & AFW-MDP-TM-1AA & RA17 & $3.662 \mathrm{E}-11$ \\
\hline $18 \mathrm{TOC}$ & AFW-MDP.FR-1 AA24 & AFW-TDP-FR-1ASGH & RA17 & $4.262 E-09$ \\
\hline 10 TDC & AFW-MDP-FR-1AA24 & AFW-TDP-FS.1AS & RA17 & $4.282 E-09$ \\
\hline $20 \mathrm{TDC}$ & AFW-MDP-FR-1 AA24 & AFW-TDP-TM-1AS & RA17 & $4.262 E-08$ \\
\hline $21 \mathrm{TDC}$ & AFW-MDP-FS & AFW-TDP-FA-1ASBH & BETA-AFW & $2.688 E-08$ \\
\hline 22 TOC & AFW-MDP-FS-1AA & AFW-MOV-CC-161 & RA 17 & $6.328 E \cdot 11$ \\
\hline $23 \mathrm{TDC}$ & AFW-MDP-FS-1AA & AFW-TDP-FR-1ASGH & RA17 & $1.778 E-08$ \\
\hline 24 TDC & AFW-MDP-FS-IAA & AFW-TDP-FS-1AS & RA 17 & $1.776 E-08$ \\
\hline 26 TDC & AFW-MDP-FS-1AA & AFW-TDP-TM-1AS & RA17 & $1.776 E-08$ \\
\hline 28 TDC & AFW-MDP-TM-1AA & AFW-MOV-CC-161 & RA17 & $3.652 \mathrm{E} \cdot 11$ \\
\hline 27 TDC & AFW-MDP-TM-1AA & AFW-TDP-FR-1ASBH & RA17 & $1.184 E \cdot 08$ \\
\hline $28 \mathrm{TDC}$ & AFW-MDP-TM-1AA & AFW-TDP-FS-1AS & RA17 & $1.184 \mathrm{E}-08$ \\
\hline & & & TOTAL TDC & $1.633 \mathrm{E}-07$ \\
\hline
\end{tabular}


TABLE B.6. Minimal Cut Sets for HVAC/Room Cooler Contributing Events

Cur Ser Eloments

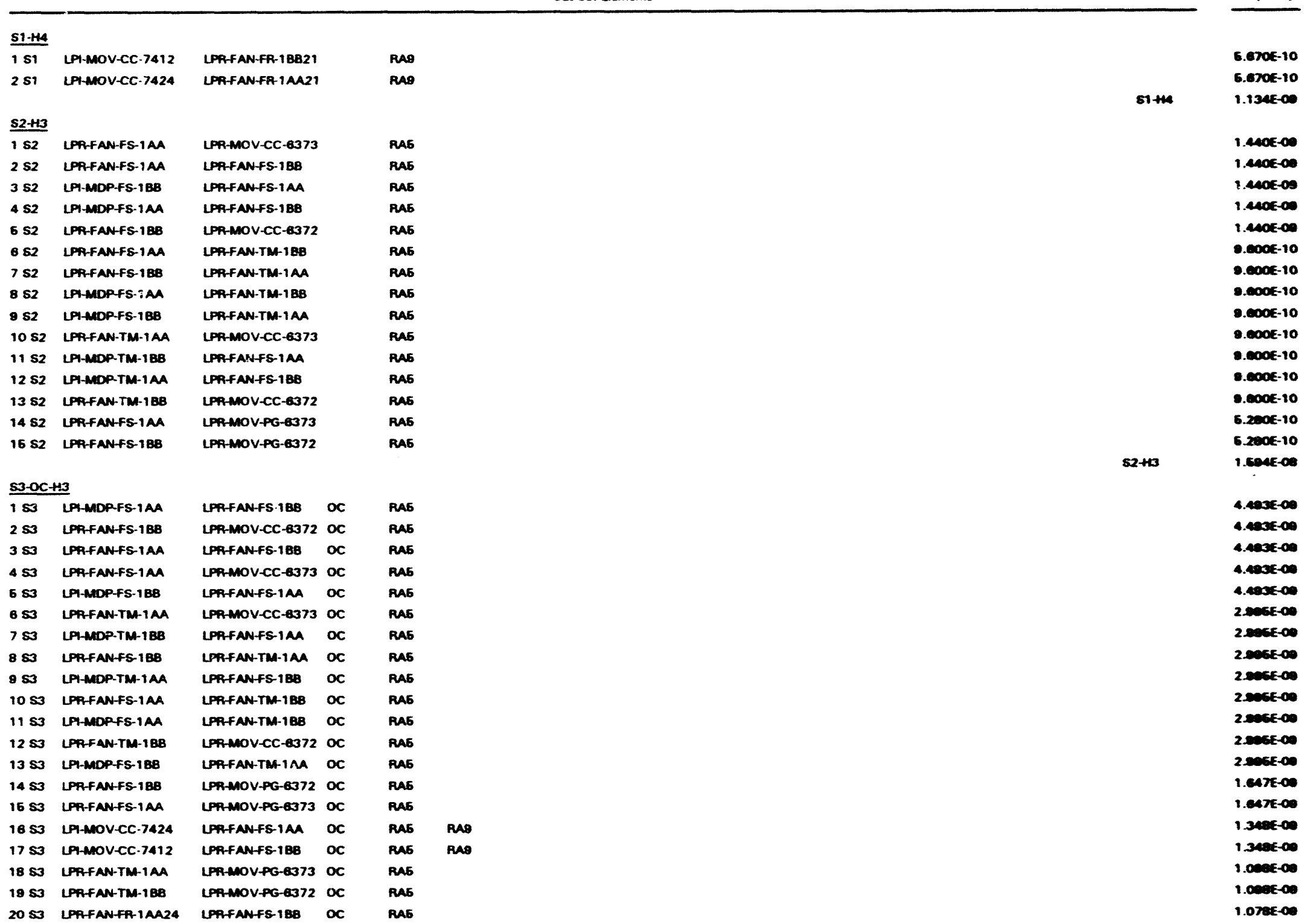




\section{IABLE B.6. (contd)}

Cur Ser Etromente

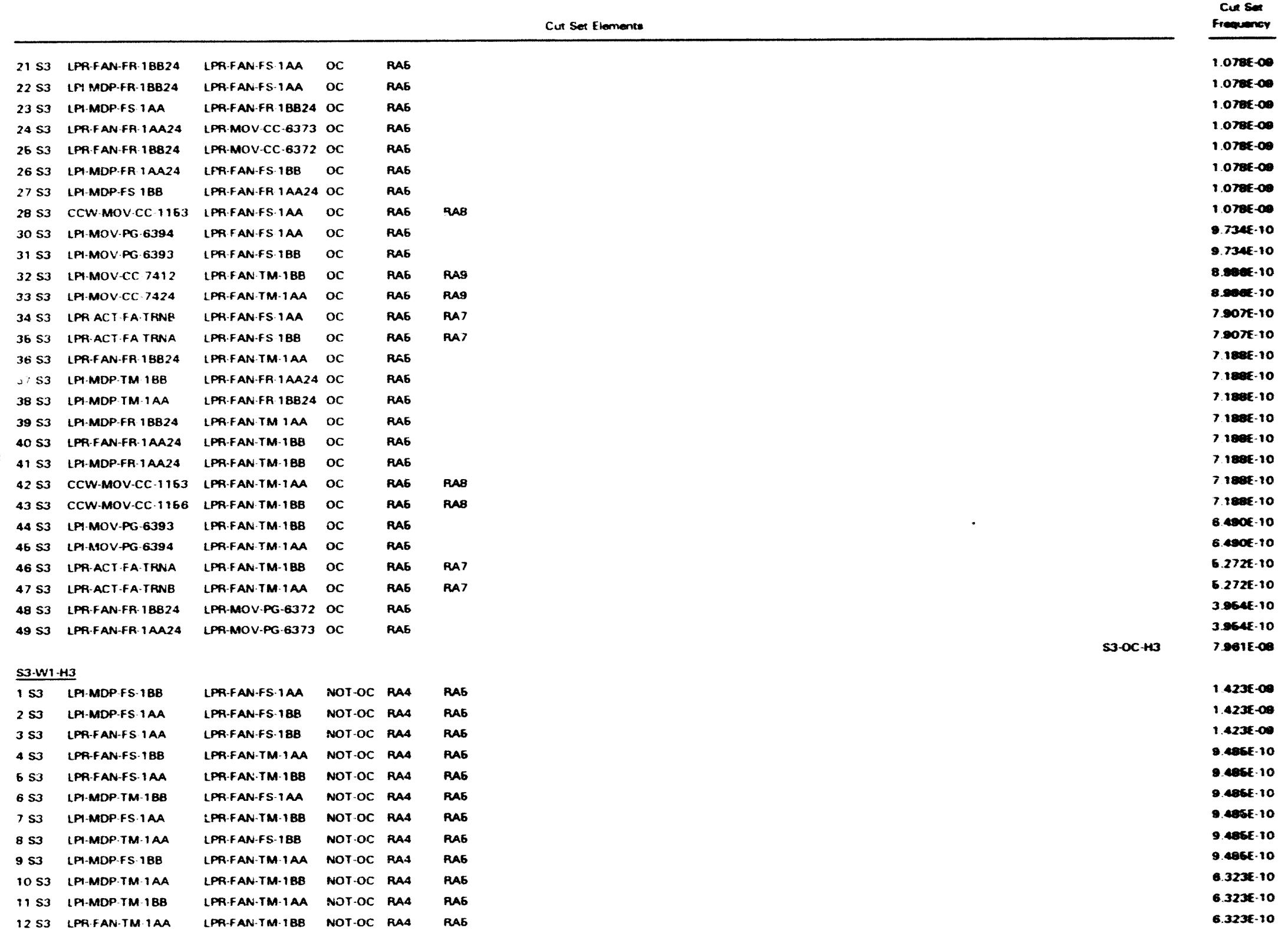


IABLE B.6. (contd)

Cur Ser Elomentes

DIESE GENGRATOR RELATED SEOUENCES

Lerge LOCA Sequence with Dresed Generstors

IA OEP.BAC.ST IC DGN.FAN.FS.18B

$4.0506-12$

Modium LOCA Sequences with Dised Generators

IS1 OFP.CRB-CO.1722 DGN.FAN-FS-18B

$\begin{array}{lll}1 \mathrm{~S} 1 & \text { OFP-CRB-CO.1722 } & \text { DGN.FAN-FS 1BB } \\ 2 \mathrm{~S} 1 & \text { OEP.BAC ST IC } & \text { DGN.FAN-FS.1BB }\end{array}$

3 S1 OEP.BAC-ST.IC DGN-FAN-FR.1BBG

SBO-BATT SEOUENCE

111S ACPDON

GN-AC U

BETA 2DG

DCP.U2 DG-REC3 NOTL NOTO NFAC 7HR

DCP.U2 DG-REC3 NOTL NOTO NRAC 7 HR

DCP.U2 DG-REC3 NOTL NOTO NPAC THA

3 TIS ACP-DGN-RC-U2

4 IIS ACP-DGN-AC-U2

DCP.U2 DG-REC3 NOTL NOTO NRAC7HR

NSLOCA

nsLOCA

1003

003 OEP.DGNFSIMA DGNFANFS-18B

6 TIS ACP.DGN

OCPU2

DG-REC3

NOTL NOTO NRACTHA

NSLOCA

OEP-OGN-FS-18B

1003

DGN-FMN-FS-1MA

Den-Fan-FS-1Be

1003

OEP.DGMFS-1BB DGN+MNFS-1M

Q.700e-11

9.3006-12

$4000-13$

-67e-11

1 TIS AFW-FAN-FS.TOPO BETA-20G

DG-REC NOT-SGI

NOTO NRACIHR

OEP-DGN-FS

DG-REC NOT-SG

NOTO NRACIHR

OEP-DGN-FS-1MA OEP.DGN-FS-188

NOTO NPACIHA

G 3 TIS AFW-FAN-FS-TDPD

4 TIS AFW-FAN-FS-TDPO

6 TIS AFW.FAN-FS.TDPD

DG-PEC

OEP-DGN-FS-180

NOTO NPACIHA OEP.DGN-FA.1MA OEP-DGNFS.180

OEP-DGN-FA 1 BBE OEP.DCNFS-1MA

OEP-DGN-FS-IAM OEP-DGN-MA-1BB

NOTO NRACIHR

DG-AEC NOT-SG

7 TIS AFW.FAN.FS.TDPD

8 TIS AFW-FAN-FS-TOPD

9 TIS AFW-FAN.FS-TDPD

10 IIS AFW-FAN.FS-TDPD

11 IIS AFW-FAN-FS.TDPD

12 TIS AFW-FAN-FS TDPD

13 TIS AFW.FAN.FS.TDPD

14 IIS AFW-FAN-FS.TDPD

16 TIS AFW-FAN-FS TDPD

16 TIS AFW-FAN-FS-TOPD

17 TIS AFW.FAN-FS-YDPD

18 TIS AFW.FAN.FS-TOPO

19 TIS AFW.FAN-FS TDPD

NOTO NaACiHR

OEP-DGN-FS-18B OEP-DGNAMA-1AA

NOTO NRACIHR OEP-DGN-FR-1AMG OEP-DGN-FR-18BG

OEP-CAB-FT-1912 OEP-DGN-FS-18B

OEP-CRB-FT-1912 OEP-DGN-FS-18

OEP.DGN-FR 1 BB6 OEP.DGNMAM-1M

NOTO NPACIHR

DG-REC NOT.SGI

DG-REC NOT.SGI

NOTO MRACIHA

NOTO NRACIHA

NOTO NRACIHR

DG-REC

OEP-DGN-FA.1AMG OEP.DGN-MA-18B

OEP-DGN-FS

DG-PEC NOT.SG NOTO NPACIHP

OEP-DGN-FS-1AA OEP-DGN-FS. $18 B$

OEP-CFB-FT. 1912 OEP.DGN-FA.18B6

NOTO NPACIHR OEP.CRB-FT-1914 OEP-DGN-FR.1MAG

OEP.DGN-FR. 1 BBE OEP-DGN.FS.IAA

NOTO NPAC1HR

DG.REC

OEP-DGN-FA-IMAG OEP-DGN-FS-16B

OEP-CPB-FT-1914 OEP-DGN-MA-1MA

NOTO NPACIHR

DG.AEC NOT-SG

20 TIS AFW-FAN.FS-TDPD

DG-AEC NOT-SG

NOTO NPAC1HR OEP-CPB-FT-1912 OEP-DGN-MA-1BB

DGN-FAN-FS

21 IIS AFW-XHE-OPNVAIVE BETA-ZDG DG-AEC NOT-SG

22 IIS AFW-XHE-OPNVALVE

23 TIS AFW.XHE-OPNVALVE

24 TIS AFW.TDP.FS.1AS BETA.2DG

DG-AEC NUTSG

DG-REC NOT-SGI

DG-REC NOT-SGI

26 TIS AAW.TDP.FS.1AS

26 TIS AFW-XHE-OPNVAIVE

NOTO NRACIHR

NOTO MPACIHR

OEP-DGN-FS-1AA DGN-FAN-FS-1BB

OEP-DGN-FS-1BB DGNFANFSIA

NOTO NRAC:HR DGN-FAN-FS

DG-REC NOT-SGI

DG-REC NOT-SGi

NOTO NPACIHA

OEP-DGN-FS-1AA DCN-FAN-FS-1BB

NOTO NRACIHR

DEPGNFS1Aa DGN-Fan-FS-1BB

OEP-DGN-FA-1BBG DGN-FANFS-IM

cose- $-\infty$

4. .01E-11

4. .01E-11

6.623E-10

6.623E-10

8.120E-00

$6.080 \times-00$

3.0006-08

$1.000 k-00$

$1.0006-\infty$

$1.0006-0$

7.000

$1.0005-\infty$

$7.1106-00$

$3.2006-\infty$

3 rase -20

3. $1006-00$

$3.1006-00$

$2.000-\infty$

$2.1056-0$

$1.7770-\infty$

$1.2776-00$

B.419E-10

8.419E-10

$7.000 \mathrm{e}-10$

$7.9006-10$

I.01E-0?

. $.6325-08$

$8.5325-00$

$6.0000-00$

3.000t-0

8.6325.08

DG-REC NOT-SG

NOTO NRACIHA

$3.413 \times 00$ 


\section{IABLE B.6. (contd)}

Cur Sar Elememe

\begin{tabular}{|c|c|c|c|c|c|c|c|}
\hline $28 \mathrm{TIS}$ & AFW-XHE-OPNVALVE & & DG-FEC & NOT-SG & мото & MPUC1HA & OEP-DGNFA-11 \\
\hline $29 \mathrm{Tis}$ & AFW-ANFE-TDPA & BETA-2DG & DG-REC & NOT-8GA & мото & MRACIHA & DGNFANFS \\
\hline $30 \mathrm{TIS}$ & AFW-FAN-FS-TDPA & & DG-PEC & NOT-8G & мото & MRACIHA & OEP-DGUFS- \\
\hline 31 Tis & AFWFANFS-TDPA & & DG-AEC & NOT-\$GI & Noto & MRACithe & OEP-DCNFS \\
\hline 32 TIS & AFW-FAN-FS-TDPA & & DG-AEC & NOT-SG & Noro & MPACIHA & OEPDCWFA \\
\hline $33 \mathrm{rIs}$ & AFW-FAN-FS-TDPA & & DG-REC & NOT-SGI & Nota & MPACIHA & OEPDGNFA \\
\hline $34 \mathrm{TIS}$ & AFW-AOV-CC-3172 & BETA-2DG & DG-REC & & Noto & MRACIHA & DGNFANFE \\
\hline $36 \mathrm{TIS}$ & AFW-AOV-CC-3174 & BETA-2DG & DG-REC & & moto & MPACIHA & DENFANFE \\
\hline \multicolumn{8}{|c|}{ SBO-O SEQUENCES } \\
\hline $1 \mathrm{TIS}$ & BETA-2DG & DearsBo & DG-AEC & NOT-SGI NOTL & & NRAciten & DGNFANFE \\
\hline 2 T1S & BETA-2DG & DEM-S80 & DG-AEC & NOT-SGI MOTL & & MRACIHA & DENFANFS \\
\hline 3 TIS & DEM-SBO & & DG-PECC & NOT-8GI & MOTL & & Macith \\
\hline $4 \mathrm{TIS}$ & DEM-SBO & & DG-AEC & NOT-8GI & NOTL & & Mracikn \\
\hline $6 \mathrm{TIS}$ & DEM-SBO & & DG-AEC & NOT-SGI & NOTL & & Narcitm \\
\hline 6 TIS & DEMA-SBO & & DG-AEC & NOT-sa & NOTL & & Mracikn \\
\hline $7 \pi 15$ & DEM-SBO & & DGREC & MOT-8G & Nort & & MPACIth \\
\hline $8 \mathrm{TIS}$ & DEM-SBO & & DG-AREC & NOT-EGI & NOTL & & MPAC 11Fer \\
\hline 9 Tis & DEM-SBo & & DG-AEC & NOT-SGI & Norl & & Maraciker \\
\hline $10 \mathrm{TIS}$ & DEM-SBO & & DG-FEC & NOT-8GI & MOTL & & MRAcith \\
\hline
\end{tabular}

of SBo-SLOCA SEOUENCES

ITIS ACP-DGN-AC-U2

$2 T 1 S$ ACP-DGN-AC-U2

3 TIS ACPDONAC-AL

BETA-20G

BETA-2DG

DCP.U2

4 IIS ACP-DGN-AC-U2

DCP-U2

6 TIS ACP-DGNAC-U2 DCPU2

CTIS ACP-DGNAC-U2 OCP-U2

7 T1S ACP-DGNAC-U2 TOCPU2

8 T1S ACP-DGNAC-U2 DCP.U2

9 TIS ACPDGNAC-U2 BETA-2DG

10 TIS ACP-DGNAC-U2 BETA-2DG

11 TIS ACPDOENAC-U2 DCPU2

12 T1S ACP-DGNAC-U2 DCP-U2

13 TIS ACPDONAC-U2 DCPU2

14 TIS ACP-DGNAC-U2 DCPU2

16 TIS ACPDDENAC-U2 DCP-U2

16 TIS ACP-DGNAC-U2 DOP-U2

17 TIS ACPDGNAC-U2 DCPUV

$18 \mathrm{TIS}$ ACP-DGNAC-U2 IOCP-U2

19 T1S ACP-DGNAC-U2 TOCPU2

20 IIS ACP-DGNAC-U2 NOCPU2

21 TIS ACPDDENAC-U2 DCPU2

22 TIS ACP-DGNAC-U2 DCPU2

23 TIS ACP-DGNAC-U2 DCPUI

24 TIS ACP-DGNAC-U2 DCPU2

DCP-U2 DGFEC2 NOTL MOTO NPAC-21 Gamn 1003

DCPU2 DG-REC2 NOTL NOTO MRAC-21 DG-FEC2 NOTL MOTO MPAC-21EMan 1003 OSPEC 2 MOTL NOTO NPAC-21EAMN 003 DG-FEC2 NOTL NOTO MPAC-21 ENON 1003 DG-FEC2 NOTL NOTO MPAC-21Emen 000 DG-REC2 NOTL NOTO MRAC-21Em 1003 DG-AEC2 NOTL NOTO NPAC-21EMnN 1003

DCPU1 DGFEC2 NOTL NOTO MPAC-252m 1003 DCPU2 DGAEC2 NOTL NOTO MRAC-2621m 1003 DGFEC2 NOTL NOTO MAC-262man 1000 NOTL NOTO MPAC-21Ean 003 NOTL NOTO MRAC-21eam 1003 DG-REC2 MOTL NOTO MPAC-21EAm 1003

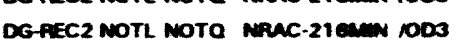
DG-FEC2 NOTL NOTO MaC-262nm 1003 MOTL NoTO Mruc-21 10003 NOTL Noto Nrac-216um 1003 DGFEC2 MOTL NOTO MPAC-21 10003 DGFEC2 NOTL NOTO MRAC-21Emin 1003 DG-FEC2 MOTL NOTO MPUC-21EMm 1003 DG-REC2 MOTL NOTO MARC-21EMN 1003 DGAEC2 NOTL NOTO NRAC-2621m DG-PEC2 NOTL MOTO NRAC-262MUN 1003
Cuesents $3.413 x-6$ $5.000=00$ 3.000e-

35encen

$1.000 \times-00$

$1.000 \mathrm{e}-0$

-

a.ext-11

$7.2716-07$

-.2notor

c.200e-00

4. enxea

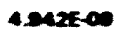

- senze-0

4enze-

$1977-00$

$19776-\infty$

$1077 \in-\infty$

$1.0776-\infty$

4.01ex-a

3.

3.

3.0001-0

$3.007-6$

$1220-0$

$1.22 x=-\infty$

$-213 x=0$

- 213e-0

7 sente-

s.enter

- . 2015e-

$1.0005-00$

1.000000

C.13TE-00

-. I31E-

$4.7225-0$

1.00050

1.00uken

$4.007-00$

4.00\%-a

3.000e-00

$3.000<-\infty$

$2.6145-00$

$2.6145-0$ 


\section{TABLE B.6. (contd)}

Cue sen Elemenee

26 T18 ACP-DGNAC-U2 DCPU2 DGFC2 NOTI NOTO NMC-21 1000

26 TIS ACP-DGNAC-U2

26 T1S ACPDENAC-U2

27 T18 ACPDCNAC-U2

28 T1S ACPDOANAC-U2

20 TIS ACPDENAC-U2

30 T1S ACPDGNAC-U2

31 T1S ACRDGNAC-U2

32 T1S ACP-DGNAC-U2

DCPU2

DCPU2

DCPU2

CPPU2

DCPU2

DCPU2

DCPU2

DCPU2

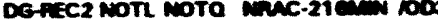
DG-REC2 MOTL Noto mac-2100m 1003

Derec2 MotL nото muc-21emm 1000

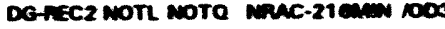

DENEC2 MOTL moto Manc-21 emen 1000

Derec2 mort moto muc-2100m 1000

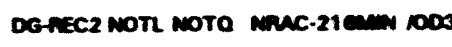

DefREC2 MOTL NOTO Mruc-21 1000

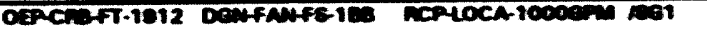

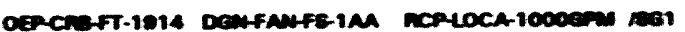

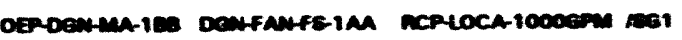

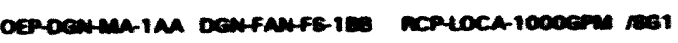

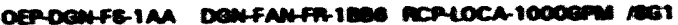

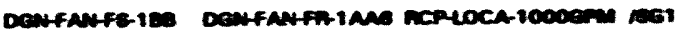

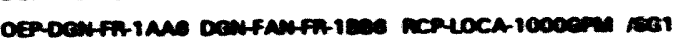

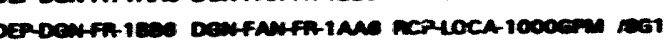

Cin sac

230006

$2.3006-00$

230900

.131E-

a.1315-0

$1.5000-10$

$1.030 \times 10$

C.131E-10

e.131E-10

1.000500 
APPENDIX C

SYSIEMS ANALYSIS AND MINIMAL CUT SETS

FOR THE REPRESENTATIVE BOILING WATER REACTOR 


\section{APPENDIX C \\ SYSTEMS ANALYSIS AND MINIMAL CUT SETS \\ FOR THE REPRESENTAIIVE BOILING WATER REACTOR (BWR)}

This appendix presents the systems analysis and the affected minimal cut sets for the representative BWR. The information in this section supplements the HVAC/room-cooler-related systems analyses presented in Section 3.2 and provides the basis for the core damage frequency (CDF) and public risk calculations in Section 4.2 of the main report.

\section{C.1 PLANT DESCRIPTION}

The representative BWR contains a single unit producing 1250 MWe. The General Electric (GE) reactor is housed in a Mark III containment. The station began commercial operation in July 1985.

\section{C.2 PLANT SYSTEMS}

This section presents a brief description and simplified schematics of the systems important to providing safety functions (e.g., core cooling, containment cooling) in preventing core damage. The summary descriptions are taken from the NUREG-CR/4550 (Drouin et al. 1989) and include each system's design characteristics, functions, dependencies, and their applicability to room cooling or HVAC failure. There are 23 systems described; however, only eight of the systems are affected by this issue.

The following safety-related systems were identified as systems having a dependency on room cooling functions:

- High-pressure core spray (HPCS) system

- Reactor core isolation cooling (RCIC) system

- Low-pressure core spray (LPCS) system

- Low-pressure coolant injection (LPCI) system

- Residual heat removal (RHR): suppression pool cooling (SPC) system

- Residual heat removal (RHR): shutdown cooling (SDC) system

- Residual heat removal (RHR): containment spray (CS) system

- Emergency power system (EPS)

The two primary systems that provide room cooling for the above systems are the standby service water (SSW) system and the emergency ventilation system (EVS). Table C.I estimates the time to failure for equipment susceptible to failure without room cooling. Appendix $F$ provides the basis for these values. 
IABLE C.1. Estimated Time to Failure for Room Cooling Sensitive Equipment

\begin{tabular}{|c|c|}
\hline EQUIPMENT & IIME TO FAILURE \\
\hline $\begin{array}{l}\text { DG A } \\
\text { DG B } \\
\text { DG C } \\
\text { RHR A Pump } \\
\text { RHR B Pump } \\
\text { RHR C Pump } \\
\text { HPCS Pump } \\
\text { LPCS Pump } \\
\text { RCIC Pump }\end{array}$ & $\begin{array}{r}15 \text { minutes } \\
15 \text { minutes } \\
15 \text { minutes } \\
4 \text { hours } \\
4 \text { hours } \\
4 \text { hours } \\
12 \text { hours } \\
4 \text { hours } \\
12 \text { hours }\end{array}$ \\
\hline
\end{tabular}

\section{C.2.1 High-Pressure Core Spray (HPCS) System}

The HPCS system provides coolant to the reactor vessel during accidents in which pressure remains high. The system consists of a single train with motor-operated valves (MOVs) and a motor-driven pump (MDP). Suction is taken from either the condensate storage tank (CST) or the suppression pool. Injection to the reactor vessel is via a spray ring mounted inside the core shroud. Most of the HPCS system is located in a separate room in the Auxiliary Building with fire/flood doors. A simplified schematic of the HPCS system is provided in Figure C.1.

The HPCS system is automatically initiated and controlled or may be manually started. Operator intervention is required to throttle flow to prevent the HPCS injection valve from opening and closing in response to the reactor vessel level.

The HPCS dependencies include DC control power for initiating the actuation relay logic and HPCS pump breaker, AC power for operating the HPCS pump and valves, and HPCS pump room cooling. Division 3 (AC and DC power) is dedicated to the HPCS system and its supports. Room cooling to the HPCS pump is provided by the emergency ventilation system (EVS). The HPCS pump was assumed by Drouin et al. (1989) to fail in 12 hours without room cooling. Room heatup calculations following loss of room cooling presented in Appendix G confirm that the room will heat up to the maximum operating temperature of the pump within about 12 hours. Failure rate data also presented in Appendix G indicate that the pump will continue to operate at temperatures up to about $250^{\circ} \mathrm{F}$; however, the pump failure rate increases significantly at higher ambient temperatures.

The fault tree diagram developed for the HPCS system was simplified by "pruning" the branches that did not include room cooling failure. The "pruned" branches were left as undeveloped events. The simplified HPCS fault tree diagram is shown in Figure C.2. 


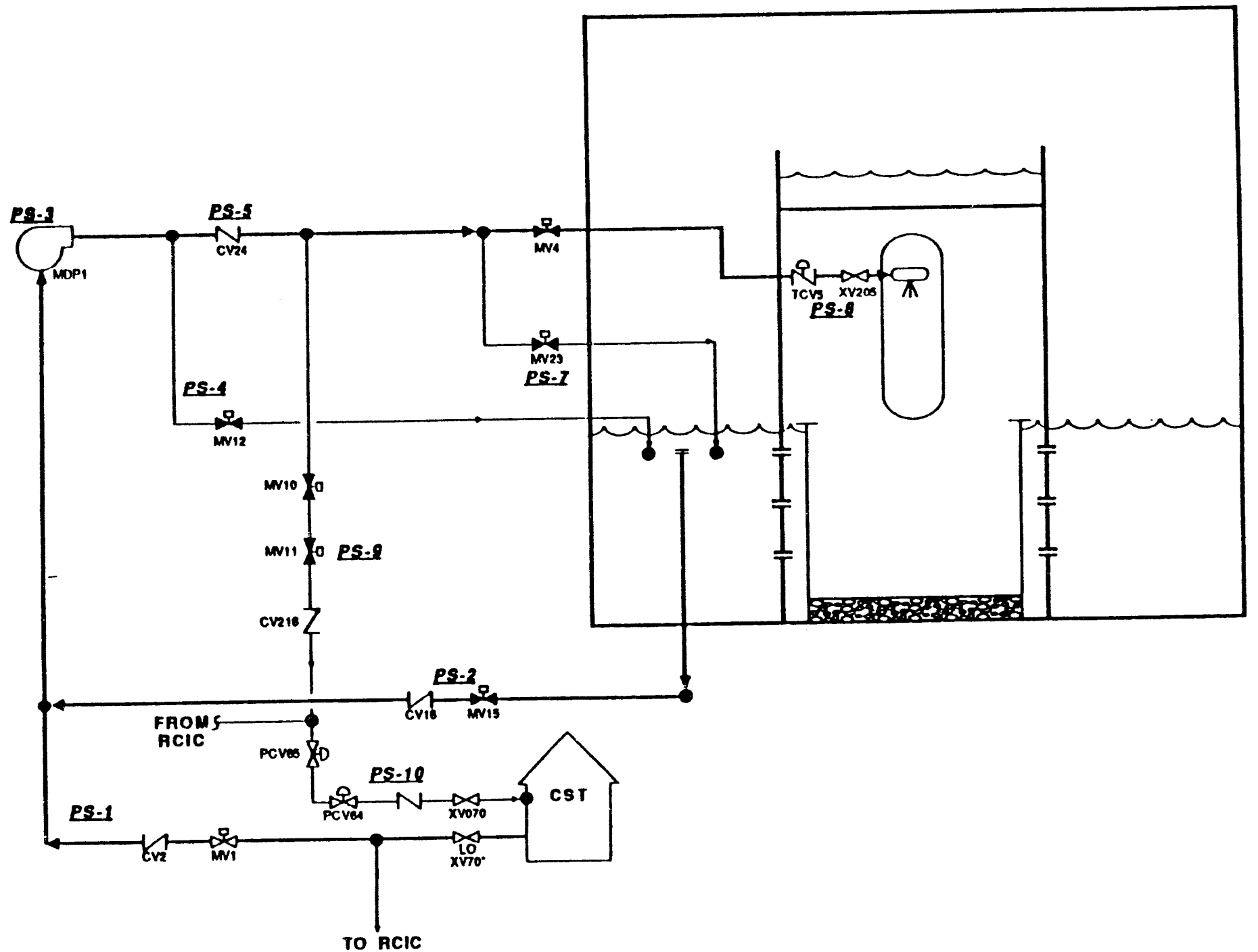

VNLVE POSTTIONS ARE GHOWW W THEIR STANDBY MODE - VAL VE ALSO LOCATED ON RCIC SCHEMUTKC

FIGURE C.1. High-Pressure Core Spray System Schematic 


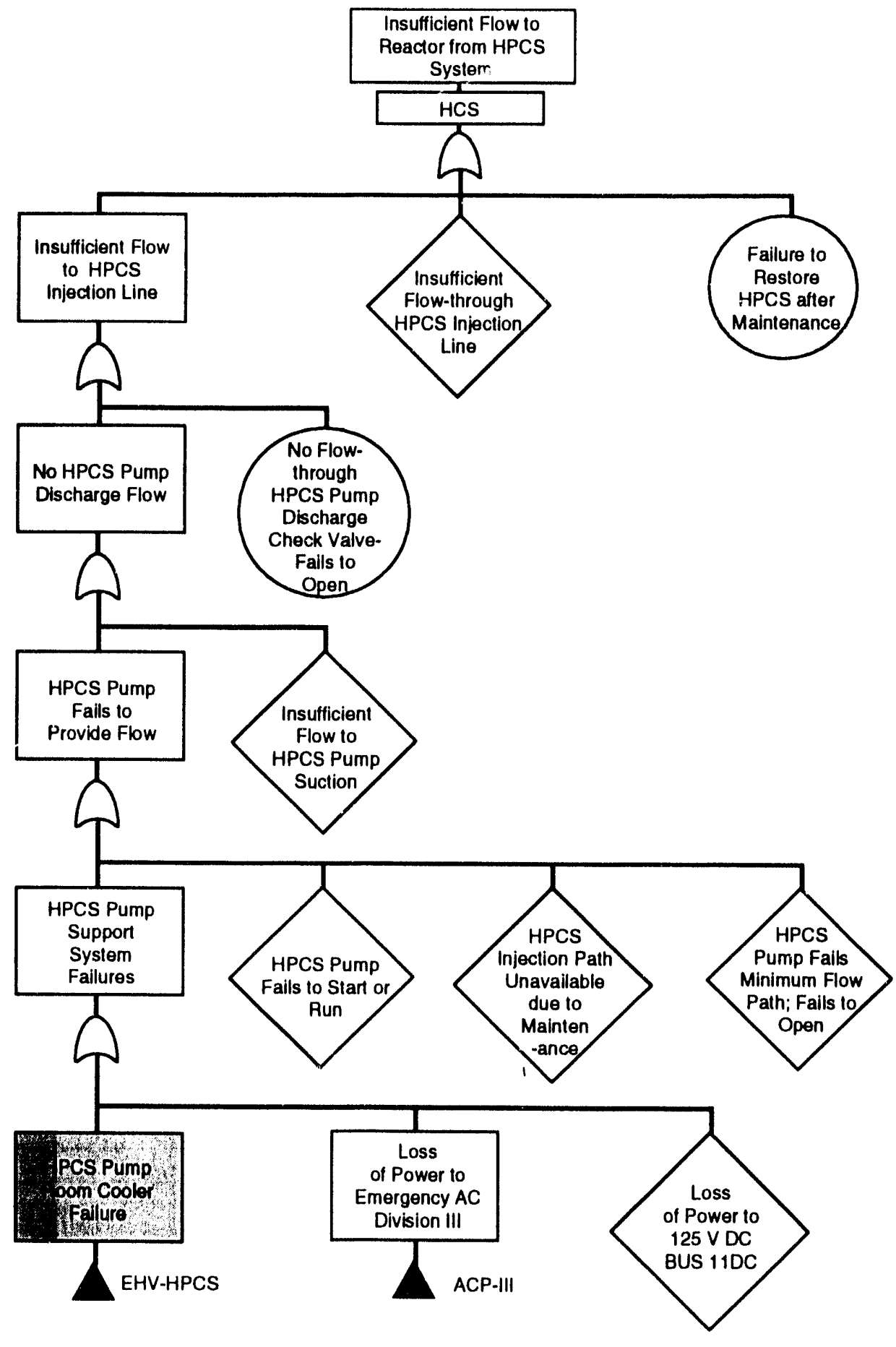

$\$ 9205093.2$

FIGURE C.2. High-Pressure Core Spray Fault Tree

C. 4 
As shown in Figure C.2, HPCS room cooling failure is functionally equivalent to failure of the HPCS pumps. This is the same dependence exhibited by the W PWR emergency core cooling system (ECCS). Failure of the HPCS pumps and failure of the HPCS room cooler both lead to failure of the HPCS system to provide coolant to the reactor vessel. The main difference is in the timing of HPCS functional failure. While failure of the pumps results in immediate loss of the HPCS, time is available following loss of HPCS room cooling before HPCS functional failure occurs.

\section{C.2.2 Reactor Core Isolation Cooling (RCIC) System}

The RCIC system provides coolant to the reactor vessel during accidents in which system pressure remains high. The system consists of a single train with MOVs and a turbine-driven pump (TDP). Suction is taken from either the CST or the suppression poo1. The RCIC pump discharges the water to the "B" RHR system header which discharges to the "B" feedwater line. Part of the flow is recirculated through the turbine lube oil cooler. Most of the RCIC system is located in a separate room in the Auxiliary Building. The RCIC system is physically located in a different quadrant of the building than the HPCS system. A simplified schematic of the RCIC system is provided by Figure C.3.

The RCIC system is automatically initiated and controlled or may be manually started. Operator intervention is required to prevent either vessel overfill or continuous system trip/restart cycles, and to set up the system for continuous operation when battery depletion is imminent.

The RCIC dependencies include DC power for short-term operation, and room cooling for long-term operation (requires $A C$ power). $D C$ power is required from Division 1 and 2 buses. Room cooling is provided by the EVS. Room cooling failure was assumed by Drouin et al. (1989) to fail the RCIC pump in 12 hours. The RCIC and HPCS systems share a common CST valve which is normally open.

Steam fon the RCIC pump turbine comes from the "A" main steam line. The RCIC system is the only steam-driven system. Temperature sensors are located in the RCIC equipment room and steam-line tunnel. Sensors trip at $185^{\circ} \mathrm{F}$ in case of a pipe break. A RCIC turbine trip occurs on high turbine exhaust pressure, high reactor water level, low pump suction pressure, low steam pressure, or an auto isolation signal.

The fault tree diagram developed for the RCIC system was simplified by "pruning" the branches that did not include room cooling failure. The "pruned" branches were left as undeveloped events. The simplified RCIC fault tree diagram is shown in Figure C.4. Similar to the W PWR, failure of the RCIC room cooling system is functionally equivalent to failure of the RCIC pump. The main difference is that failure of the RCIC room cooler does not immediately result in failure of the system to provide coolant to the reactor vessel. 


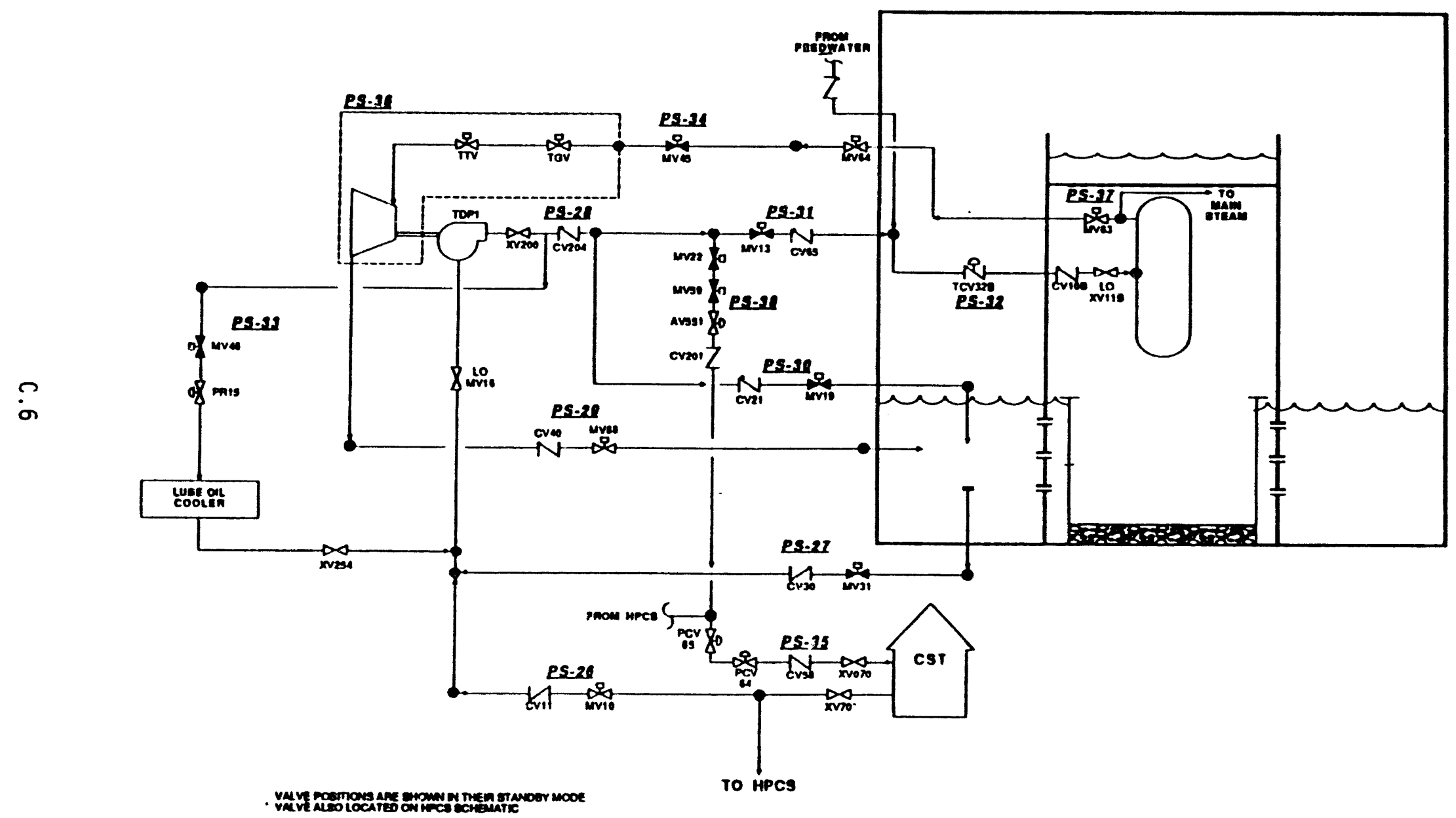

FIGURE C.3. Reactor Core Isolation Cooling System Schematic 


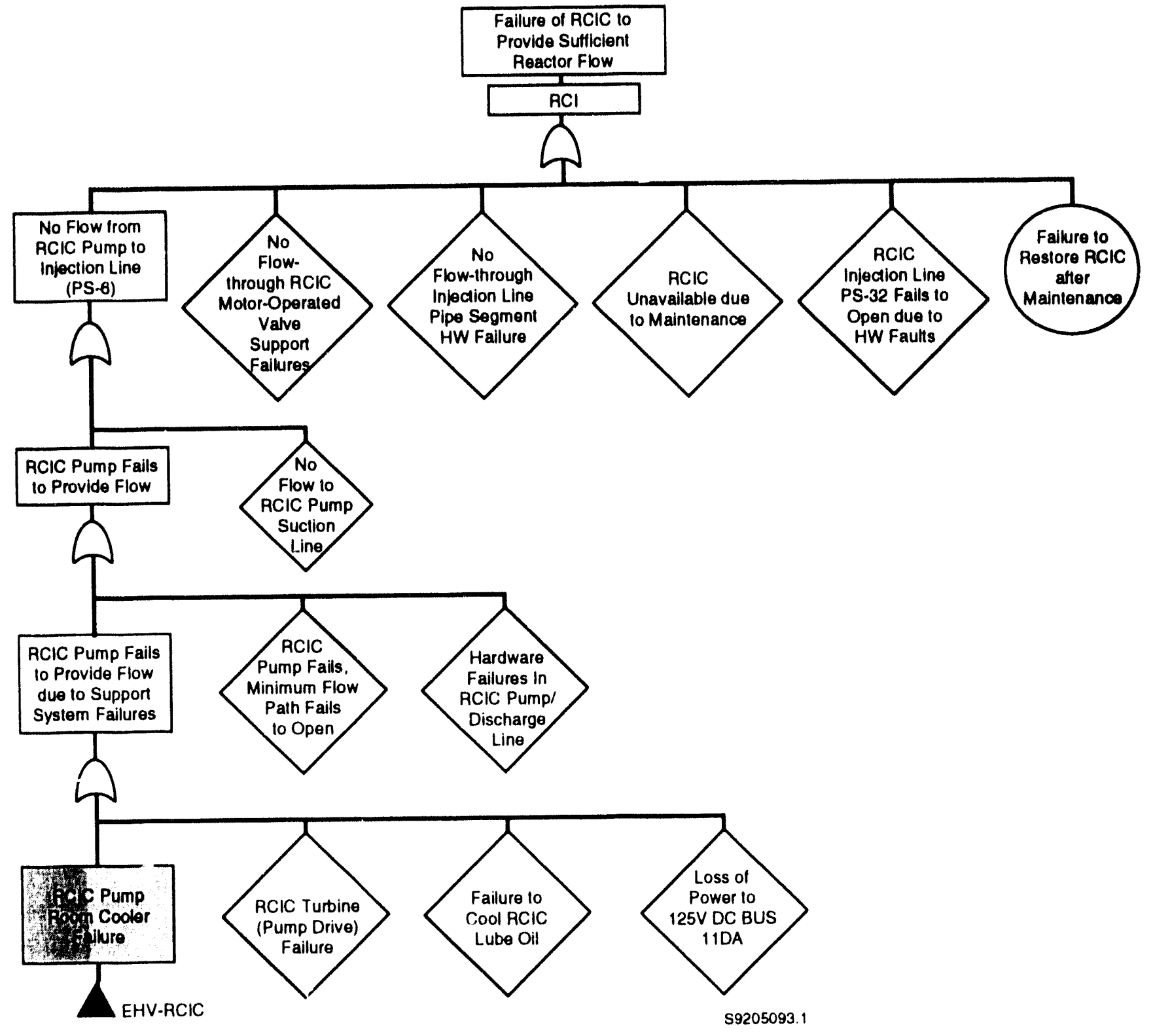

FIGURE C.4. Reactor Core Isolation Cooling System Fault Tree

\section{C.2.3 Control Rod Drive (CRD) System}

The CRD system is a backup source for high pressure injection (HPI). The CRD pumps take suction from the condenser hotwell makeup/reject 1 ine provided by the CST. Excess condensate from the condenser is rejected to the CST by the condensate system. Two pumps provide pressure to two different discharge paths. The first path is through the hydraulic control units' (HCUs) cooling header. Flow is controlled by one of two air-operated control 
valves. The second path is through the HCU charging headers. Most of the CRD system is located in the Auxiliary Building. A simplified schematic of the CRD system is provided in Figure C.5.

Both CRD pumps are required at the start of an accident when the CRD system is the only makeup source. The first discharge path fails closed, while the second path fails open on a loss of the instrument air system (IAS). However, the secondary path to the HCU charging headers is restricted and is not sufficient to provide adequate cooling requirements by itself.

The CRD pump $A$ is powered by $A C$ Division 1 with control and actuation power supplied by DC Division 1. The CRD pump $B$ is powered by AC Division 2 with control and actuation power supplied by DC Division 2. Instrument air is required for operating the flow control valves. Manual actuation is required for the system. However, CRD pump A is normally operating.

The CRD pumps are cooled by the component cooling water (CCW) system and room cooling. Room cooling and pump motor cooling failures are assumed not to fail CRD pumps during short-term operation. The demand for CRD is a shortterm action and must be accomplished quickly following a transient or L.OCA. Sufficient time is available following loss of CRD room cooling to complete the CRD function before room temperatures could result in CRD pump failure. Therefore, fault trees were not developed in this study for the CRD system.

\section{C.2.4 Standby Liquid Control (SLC) System}

The SLC system provides a backup method (redundant and independent) to establish and maintain the reactor subcritical. Two paralle1, positive displacement pumps can inject sodium pentaborate solution from the SLC ta: $\therefore$. Each pump contains a normally closed MOV. Two parallel explosive valves are downstream of the pump discharge. Downstream of the explosive valves, the system combines to a common discharge line that enters the reactor through the HPCS sparger. A simplified schematic of the SCL system is provided in Figure C.6.

The SLC system is activated manually with two keylock switches on the control room console. Each keylock switch operates a different train of the system. Most of the SLC system is located in the containment outside of the drywe 11 .

The SLC tank outlet valves are powered by AC Divisions 1 and 2, respectively. The liquid temperature in the SLC tank must be maintained above $59^{\circ} \mathrm{F}$ to prevent the sodium pentaborate from precipitating out of the solution. Two heaters are installed in the tank in case heating should be required. Normally, ambient temperature is adequate to maintain the temperature. There are no dependencies on any room cooling functions. Therefore, fault trees were not developed for the SLC system. 


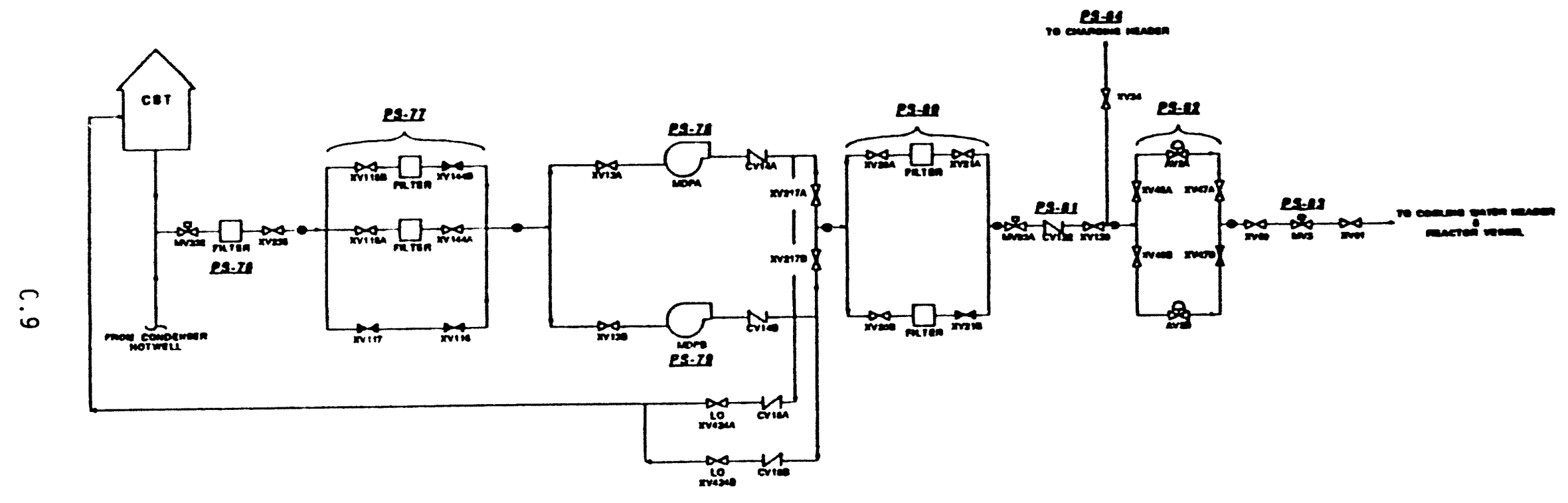

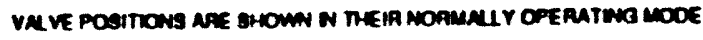

FIGURE C.5. Control Rod Drive System Schematic 


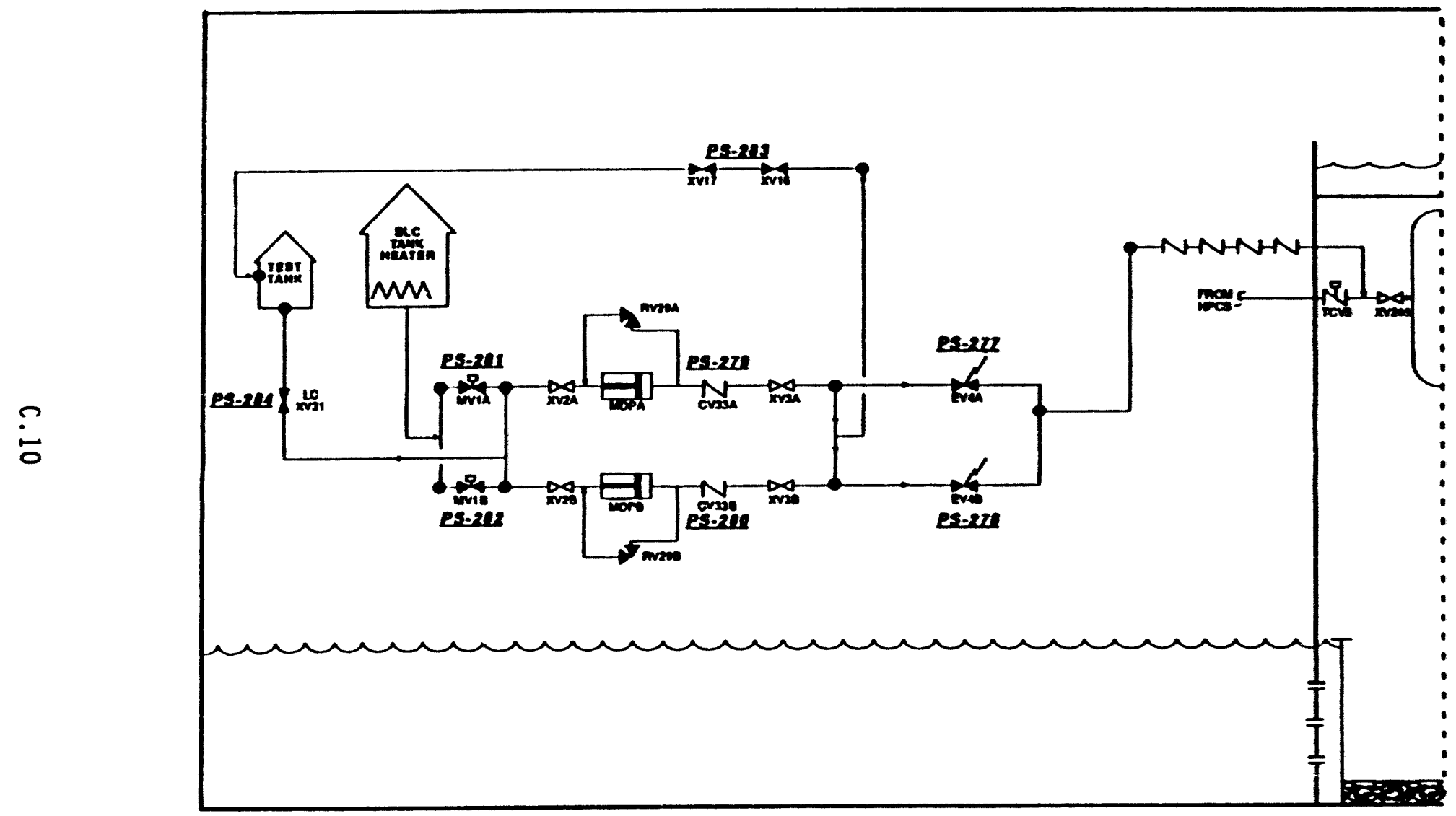

VALV VOSTIONS AFE GHOWN W THEFA STAMDOY MOOE

FIGURE C.6. Standby Liquid Control System Schematic 


\section{C.2.5 Suppression Pool Makeup (SPMU) System}

The SPMU system provides water from the upper containment pool to the suppression pool following a LOCA. The system consists of two lines that penetrate the side walls in the separator storage area of the upper containment pool. These lines are routed down to the suppression pool on either side of the steam tunnel. Each line has two normally closed, butterfly MOVs in series. The upper pool is dumped by gravity flow when the valves receive a simultaneous signal to open. The pools and valves are located in the containment building. A simplified schematic of the SPMU system is provided in Figure C.7.

The SPMU system requires electrical power for operation. The Train A valves are powered by emergency $A C$ Division 1, while Train $B$ valves are powered by $A C$ Division 2. The initiation logic for Trains $A$ and $B$ are powered by $D C$ Divisions 1 and 2, respectively. There appear to be no dependencies on any room cooling functions. Therefore, fault trees were not developed for the SPMU system.

\section{C.2.6 Automatic Depressurization System (ADS)}

The ADS is designed to depressurize the reactor vessel to a pressure at which the LPI systems can inject coolant to the reactor vessel. The ADS consists of eight relief valves capable of being manually opened. Each valve is located inside the drywell and discharges into the suppression pool. A simplified schematic of the SPMU system is provided by Figure C.8.

The ADS is automatically initiated or may be manually initiated. Depressurization may also be achieved by using the twelve safety relief valves (SRVs) that are not connected to the ADS logic.

The ADS depends upon the IAS and two DC power sources. Successful operation requires three of the eight valves to open to depressurize the reactor. There are no dependencies on any room cooling functions. Therefore, fault trees were not developed for the SPMU system.

\section{C.2.7 Condensate System}

The condensate system may be used as an LPI system. The system has three main condenser units, three condensate pumps, three condensate booster pumps, three strings of four low-pressure heaters, a condensate drain tank and associated valves, piping, instrumentation, and controls to supply to reactor feed pumps with heated feedwater at the necessary net positive suction head. The condensate system also supplies water to. the reactor vessel during low pressure conditions such as startups, shutdowns, and in emergency situations, through the feedwater startup valve. A simplified schematic of the condensate system is provided by Figure C.9.

The condensate system is operating during normal plant conditions. The operator can establish condensate flow to the reactor vessel by opening the air-operated feedwater startup valve. Long-term operation of the system as a 


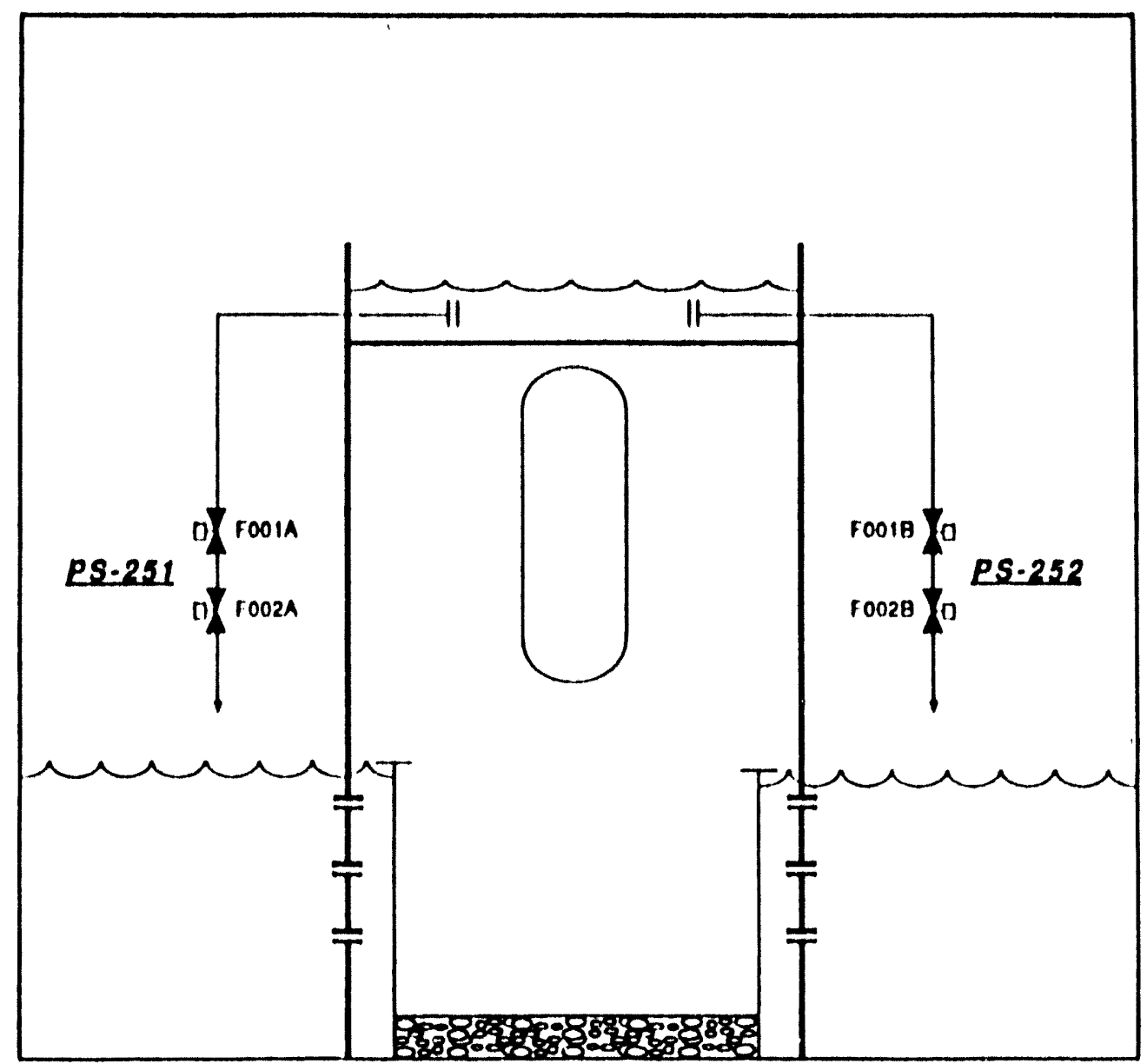

VALVE POSIIIONS ARE SHOWN IN THEIP SIANDBY MODE

\section{FIGURE C.7. Suppression Pool Makeup System Schematic}

LPI system would require that makeup water be supplied to the condenser. Flow from any of the six pumps will result in successful reactor vessel cooling.

The condensate pumps are powered by nonsafety buses. Power to the MOVs is also provided by nonsafety buses. The IAS is required to supply air to the condenser makeup valve and also to open the feedwater startup valve. Makeup to the condenser is provided by the condensate and refueling water storage and transfer system. There are no dependencies on any room cooling functions. Therefore, fault trees were not developed for the condensate system.

\section{C.2.8 Low-Pressure Core Spray (LPCS) System}

The LPCS system is to provide coolant to the reactor vessel during accidents in which vessel pressure is low. The ADS can be used in conjunction with the LPCS to attain a low enough system pressure for injection to occur. 


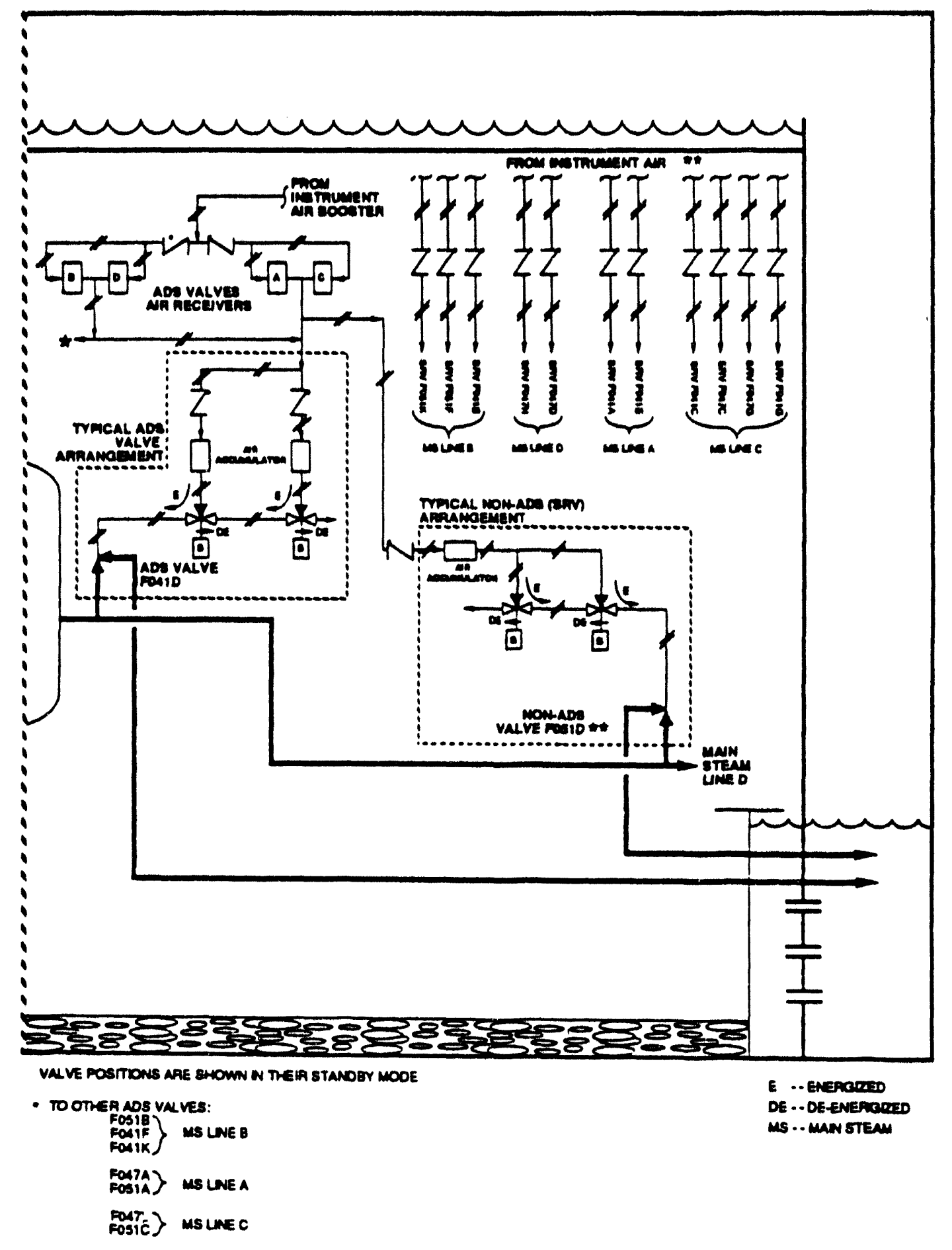

CHONADS SAV FOSTD RECENES TS AP SLPPLY FFOM THE AOS VAVES AA AECENERS MO

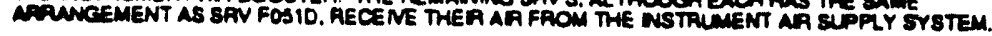

EIGURE C.8. Automatic Depressurization System Schematic 


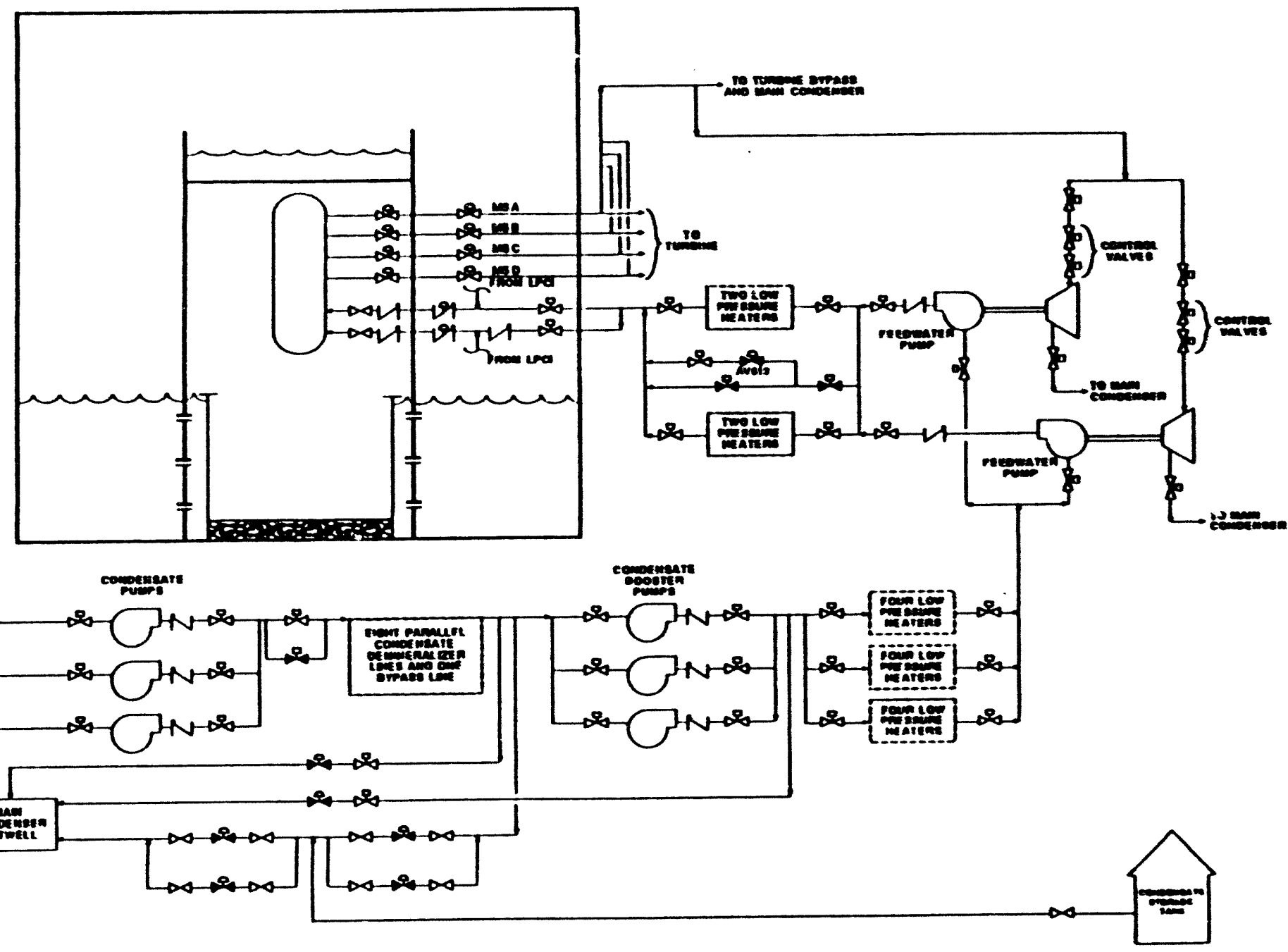

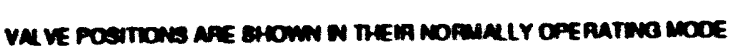

FIGURE C.9. Condensate System Schematic 
The system is a single train system consisting of motor-operated and manual valves and a MDP. The LPCS pump takes water from the suppression pool through strainers. Most of the LPCS system is located in the Auxiliary Butlding. The LPCS is automatically initiated and controlled or may be started manualiy. A simplified schematic of the condensate system is provided by figure C.10.

The LPCS system major dependencies are DC control power for initiating the actuation relay logic and LPCS pump breaker, AC power for operating the LPCS pump and valves, and LPCS pump room cooling. DC and AC power is provided by Division 1. Room cooling is provided by the emergency ventilating system (EVS). Room cooling fallure was assumed by Drouin et al. (1989) to fatl the LPCS pump in four hours.

The fault tree diagram developed by Drouin et al. (1989) for the LPCS system was simplified in this study by "pruning" the branches that did not include room cooling fallure. The "pruned" branches were left as undeveloped events. The simplified LPCS fault tree diagram is shown in Figure C.11. As shown, failure of LPCS pumps and failure of LPCS pump room cooling are either the LPCS pump or the LPCS room cooler results in fallure of the associated LPCS division to provide coolant to the reactor vessel.

\section{C.2.9 Low Pressure Coolant Injection (LPCI) System}

The LPCI system provides coolant to the reactor vessel during accidents in which system pressure is low. The ADS can be used in conjunction with the LPCI system to attain a low enough RCS pressure for injection to occur. The LPCI system is but one mode of the RHR system and, as such, shares components with other modes.

The LPCI system is a three-train system consisting of MOVs and MDPs. Trains $A$ and $B$ each have two heat exchangers in series downstream of the pump. Train $C$ is dedicated to injection and has no heat exchangers. Cooling water flow to the heat exchangers is not required for the LPCI mode. The LPCI pump suction source is the suppression pool. Most of the LPCI system is located in the Auxiliary Building. The LPCS is automatically initiated and controlled or may be started manualiy. A simplified schematic of the LPCI system is provided by Figure C.12.

The LPCI system major dependencies are DC control power for initiating the actuation relay logic and RHR pump breakers, AC power for operating the RHR pumps and valves, RHR pump cooling, and RHR pump room cooling. DC power is provided by Division 1 to the Train $A$ and Division 2 to Trains $B$ and $C$. $A C$ power is provided by Division 1 to RHR $A$ pump and Division 2 to the RHR $B$ and LPCI pumps. All pumps require pump cooling and room cooling. Room cooling failure was assumed by Drouin et al. (1989) to fail the RHR pumps in four hours.

Many components of the LPCI system are shared with the different modes of the RHR system. These commonalities are as follows: 1) the RHR pumps A and $B$ are common to LPCI, suppression pool cooling (SPC), shutdown cooling 


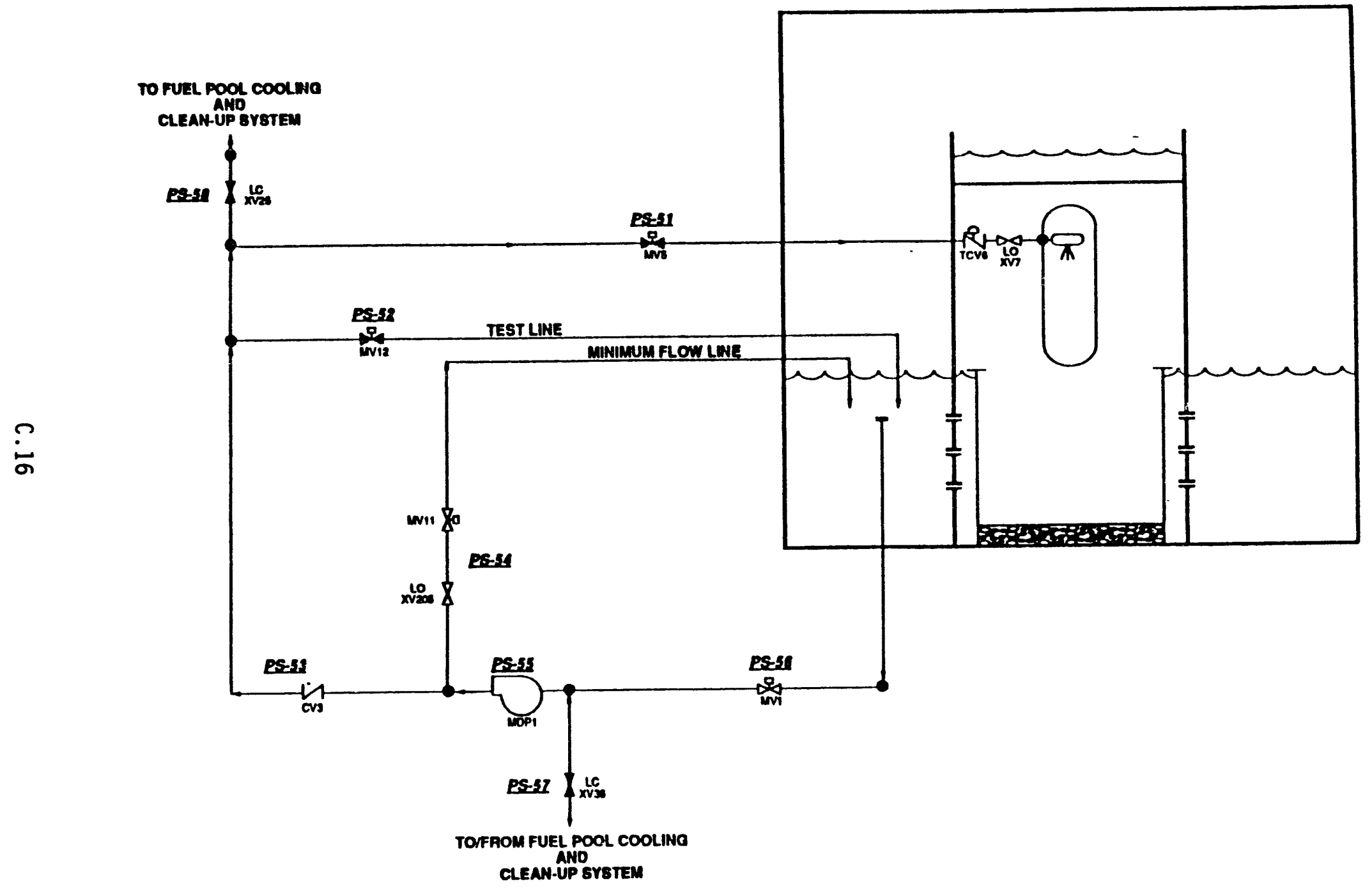

VALVE POSTIONS ARE GHOWN W THEIA STANDBY MODE

FIGURE C.10. Low-Pressure Core Spray System Schematic 


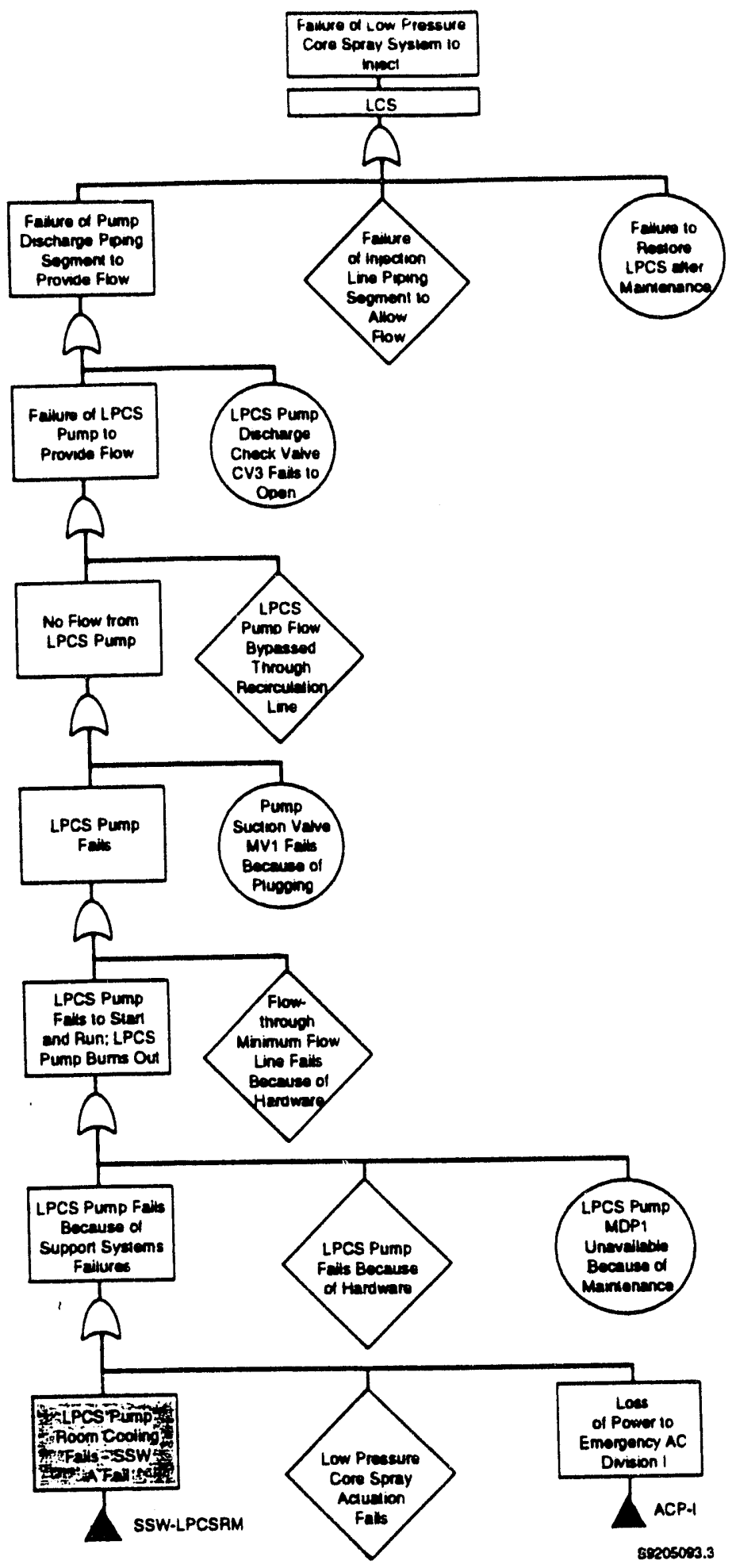

FIGURE C.11. Low-Pressure Core Spray System Fault Tree 


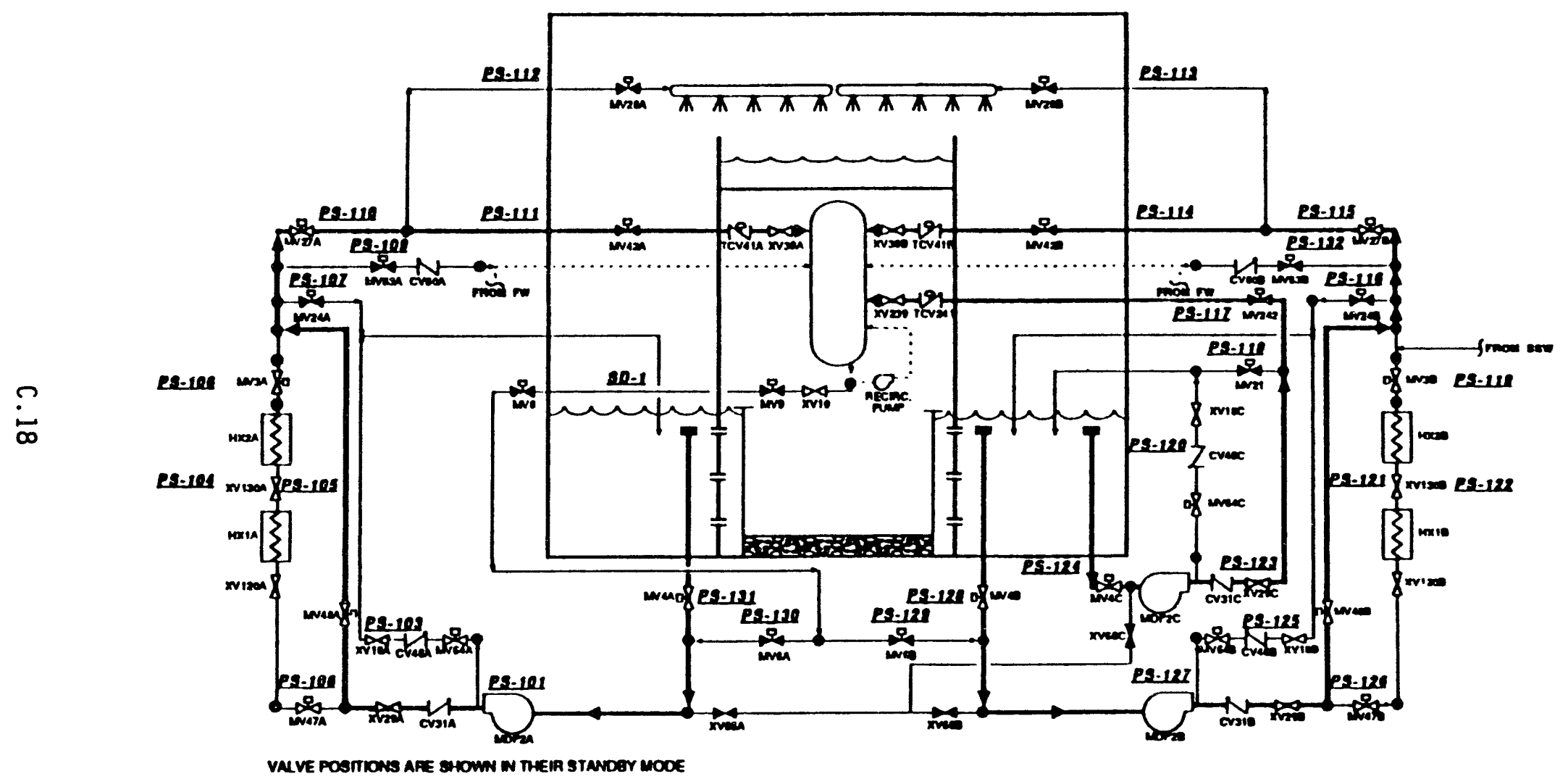

FIGURE C.12. Low-Pressure Coolant Injection System Schematic 
(SDC), and containment spray (CS) modes; and 2) the suppression pool suction valve for pump Trains $A$ and $B$ is common to the LPCI, SPC, and CS modes.

The fault tree diagram developed for the LPCI was simplified by "pruning" the branches that did not include room cooling failure. The "pruned" branches were left as undeveloped events. The simplified LPCI fault tree diagram is shown in Figure C.13. Again, as with LPCS and other ECCS systems, failure of PPCI pump room cooling is functionally equivalent to failure of the LPCI pumps.

\section{C.2.10 Standby Service Water (SSW) Cross-Tie System}

The SSW cross-tie system provides a coolant makeup source to the reactor vessel during accidents in which normal sources of emergency injection have failed. The SSW cross-tie system comprises Train B of the SSW and Train B of the LPCI systems.

The SSW cross-tie system uses SSW pump B to inject water into the reactor via the LPCI system Train B injection lines. The SSW cross-tie system has no automatic actuation, but must be manually aligned and actuated. A simplified schematic of the SSW cross-tie system is provided in Figure C.14.

The dependencies for the SSW cross-tie system are the same as those for SSW Train B and LPCI Train B. Both B trains of the SSW and LPCI require power from DC Division 1, while the SSW pump $B$ and RHR pump B require power from $A C$ Division 2. The SSW pump $B$ is self-cooled. There is no room cooling dependency mentioned for the RHR pump B during the SSW cross-tie mode. Therefore, fault trees were not developed for the SSW cross-tie system.

\section{C.2.11 Firewater System}

The firewater system, a backup source for LPI, is a three-train system consisting of one MDP and two diesel-driven pumps. The pumps feed into a common header that supplies water to the fire hoses. The pumps take suction from two 300,000-galion water storage tanks. Any pump can take water from either tank. The fire hoses are connected, via an adapter, to various test connections in the Auxiliary Building. These connections feed into various injection systems and water can then be injected through the systems' injection valve. The pumps are located in the firewater pump house. A simplified schematic of the firewater system is provided in Figure C.15.

The firewater system, when used for injection, must be manually initiated and controlled. The operator is required to align the system and to start the pumps.

The two diese1-driven firewater pumps have no outside interfaces or dependencies. Each pump has self-contained batteries that provide it with starting power. The electric MDP requires AC power. No dependencies on room cooling were identified. Therefore, fault trees were not developed for the firewater system. 


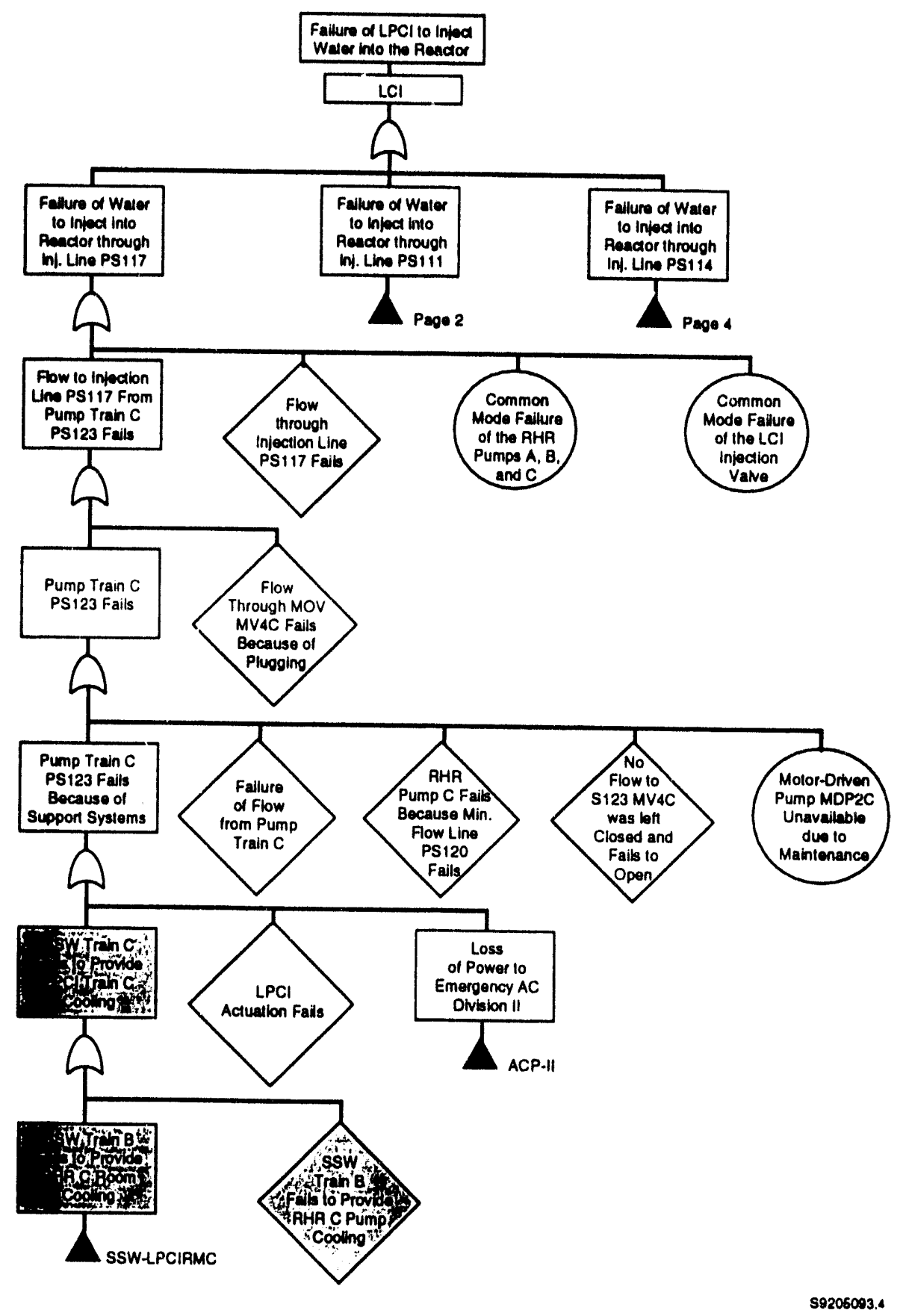

FIGURE C.13. Low-Pressure Coolant Injection System Fault Tree 


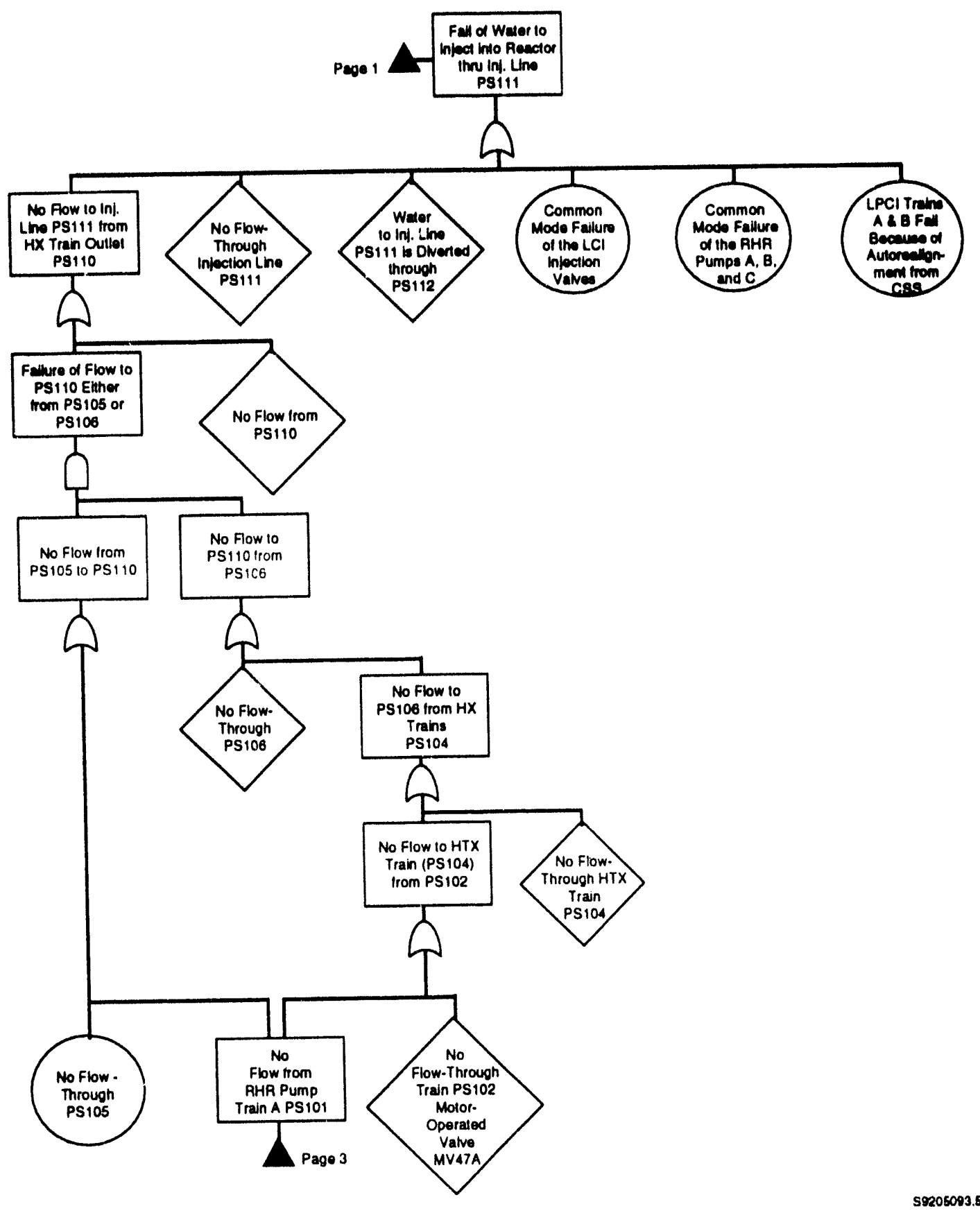

FIGURE C.13. (contd) 


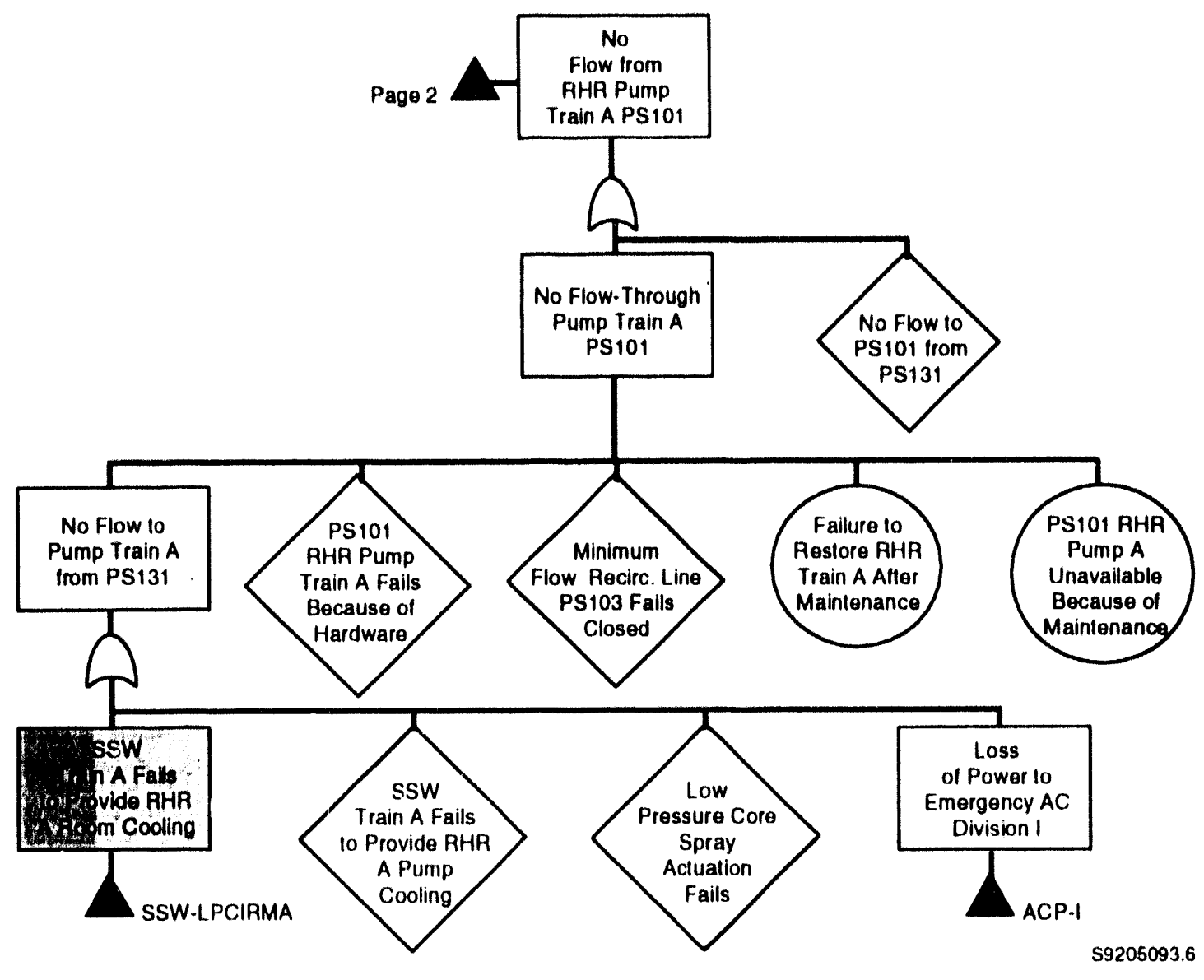

FIGURE C.13. (contd) 


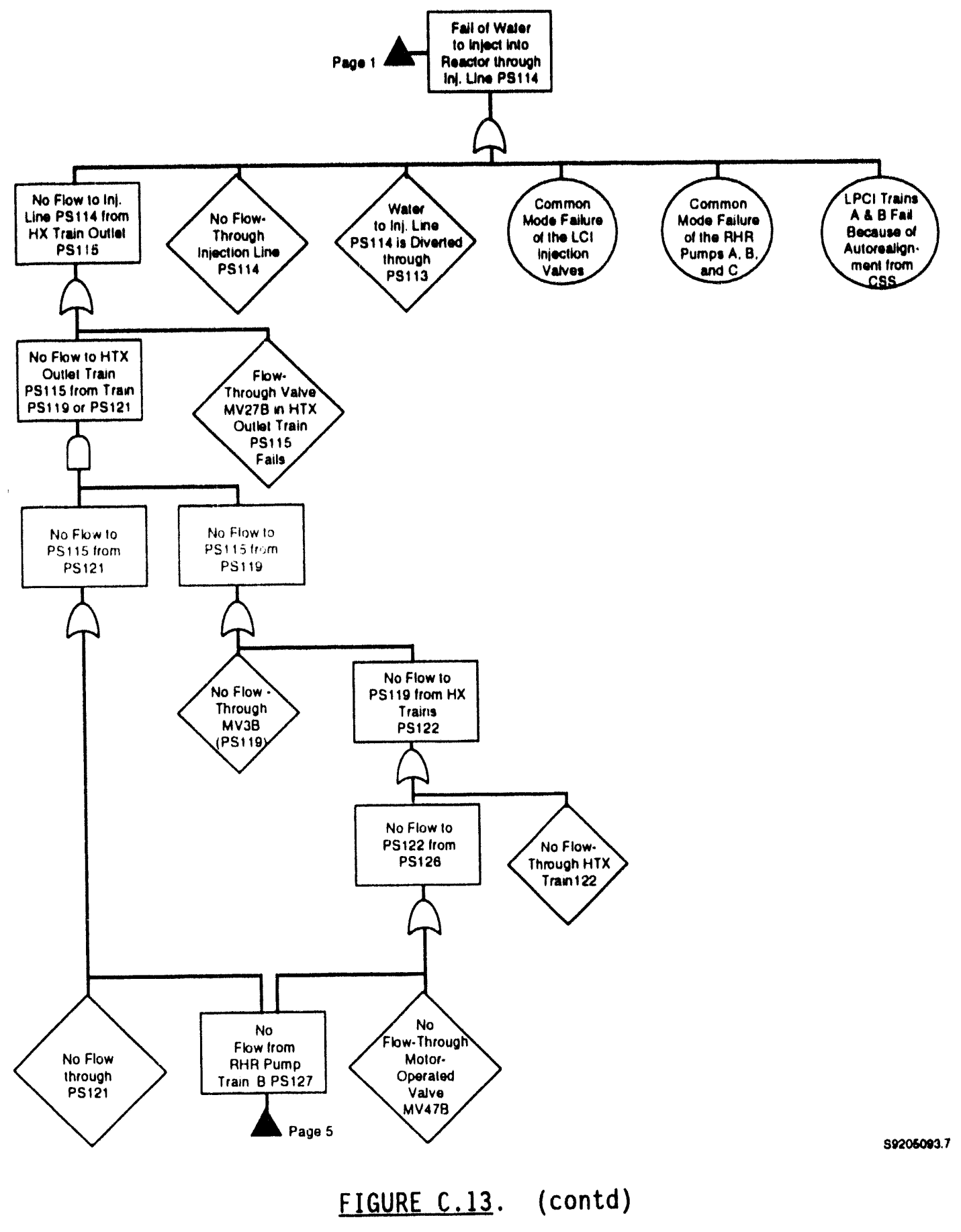




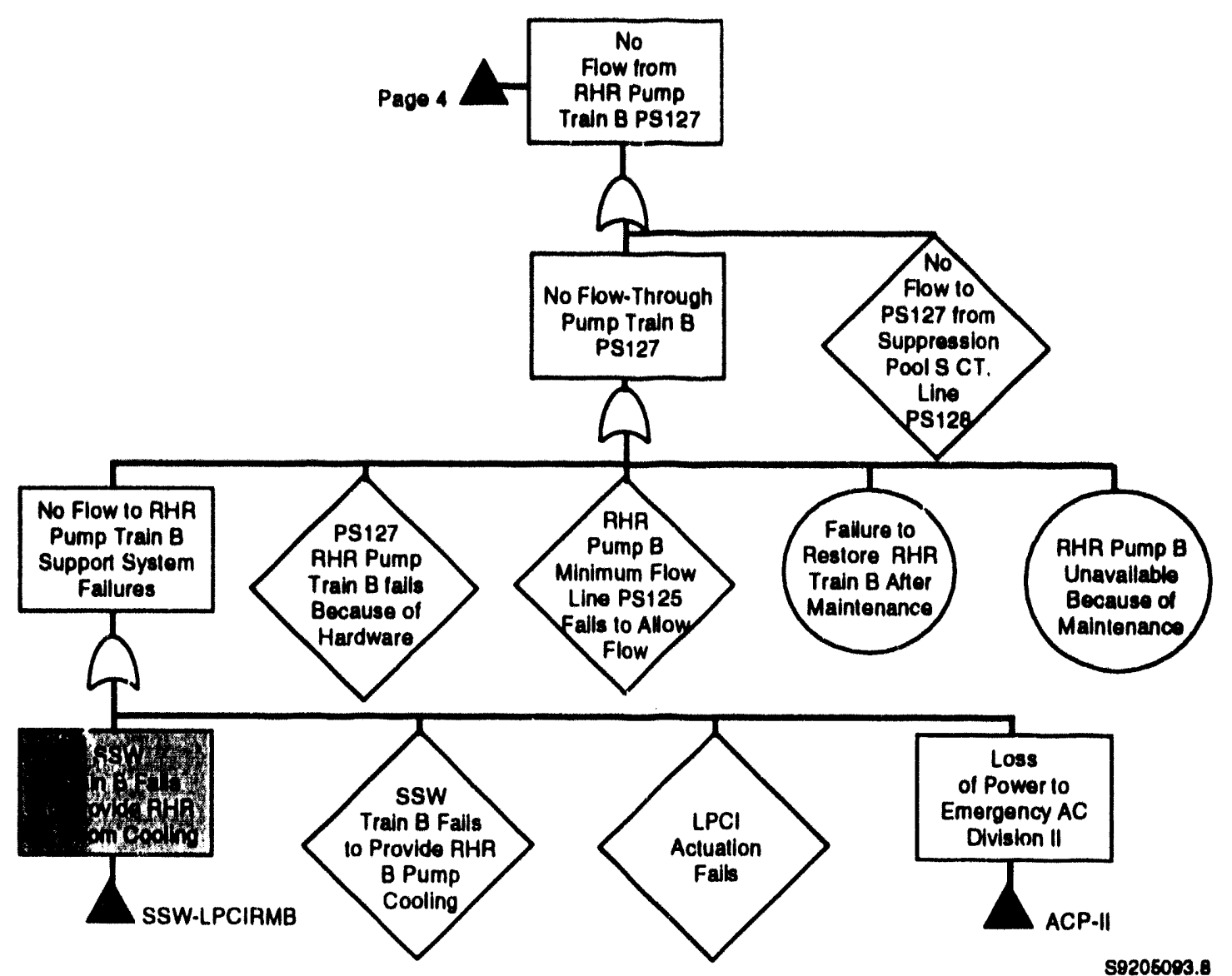

FIGURE C.13. (contd)

\section{C.2.12 Residual Heat Removal (RHR): Suppression Pool Cooling (SPC) System}

The SPC system removes decay heat from the suppression pool during accidents. The SPC system is one mode of the RHR system and, as such, shares components with other modes.

The SPC system is a two-train system consisting of MOVs and MDPs. Both trains have two heat exchangers in series downstream of the pump. Cooling water flow to the heat exchanger is required for the SPC mode. The SPC suction source is the suppression pool. The pumps are located in the Auxiliary Building in an enclosed room with fire/flood doors. A simplified schematic of the SPC system is provided by Figure C.16.

The SPC system is manually initiated and controlled. The operator is required to align the system and to start the pumps. Injection flow from either pump/heat exchanger train to the suppression pool is sufficient to accomplish the SPC function. 


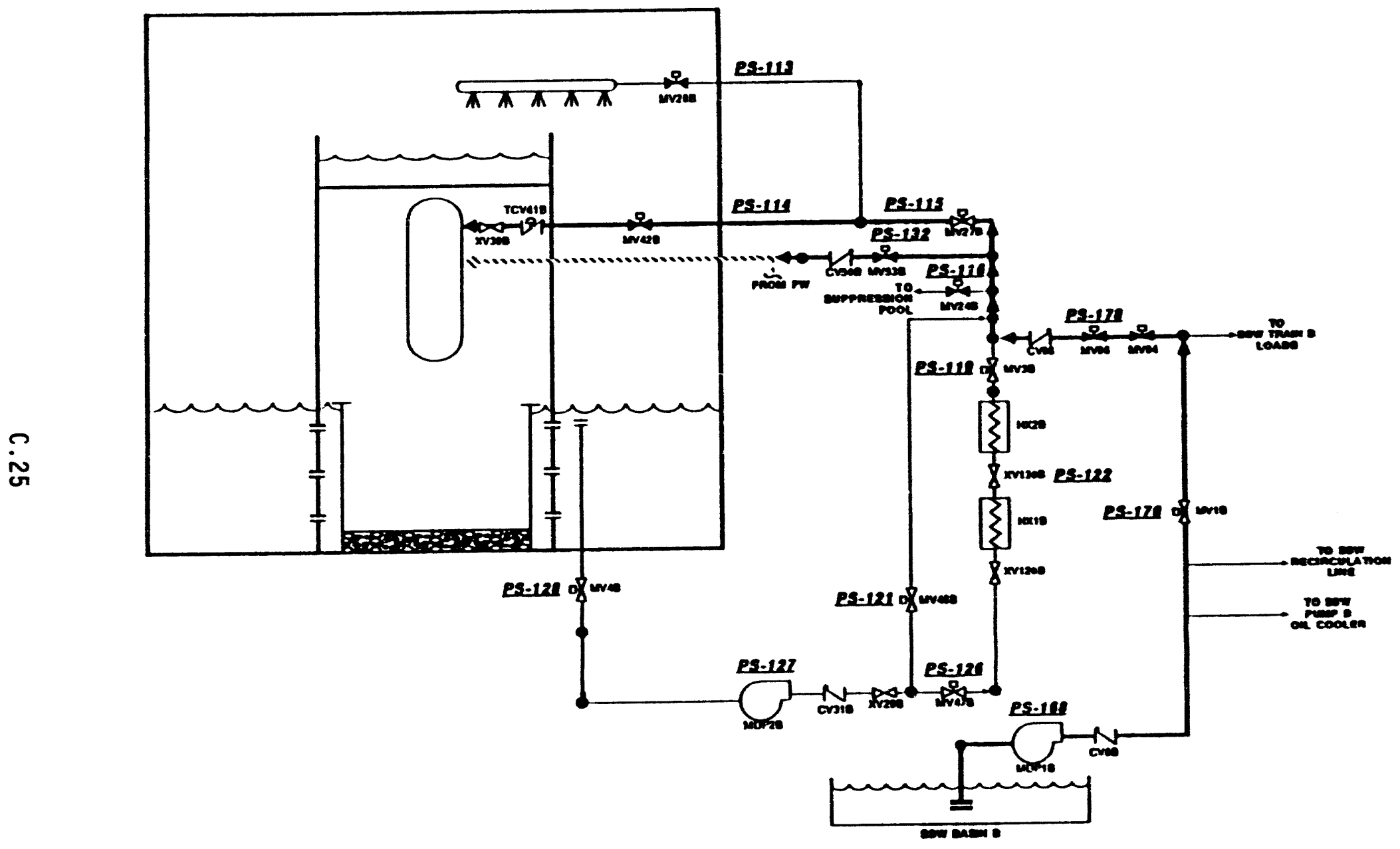

VALV POSITONS AFE BHOWW WW TEEA BTANDOY MOOE

FIGURE C.14. Standby Service Water Cross-Tie System Schematic 


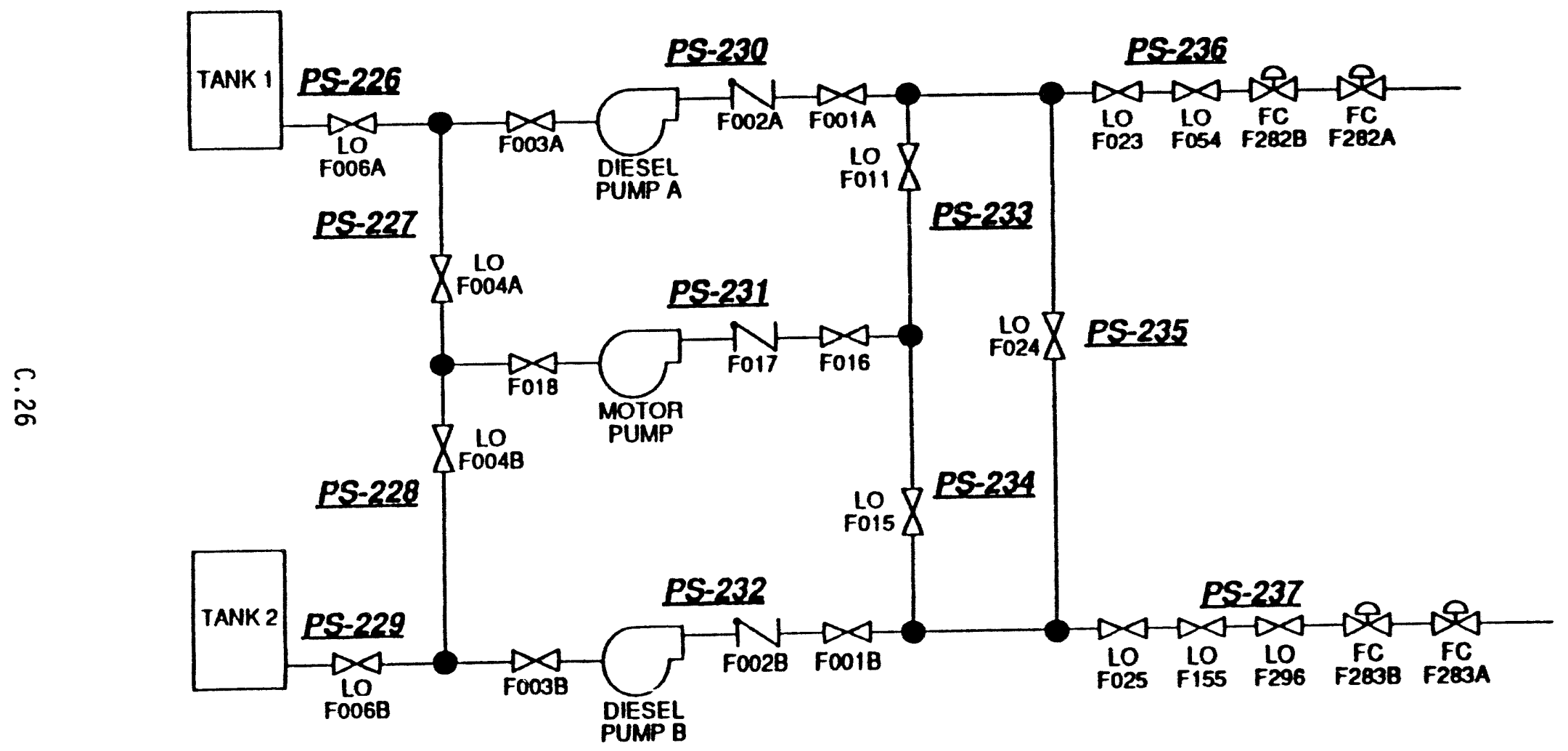

FIGURE C.15. Firewater System Schematic 


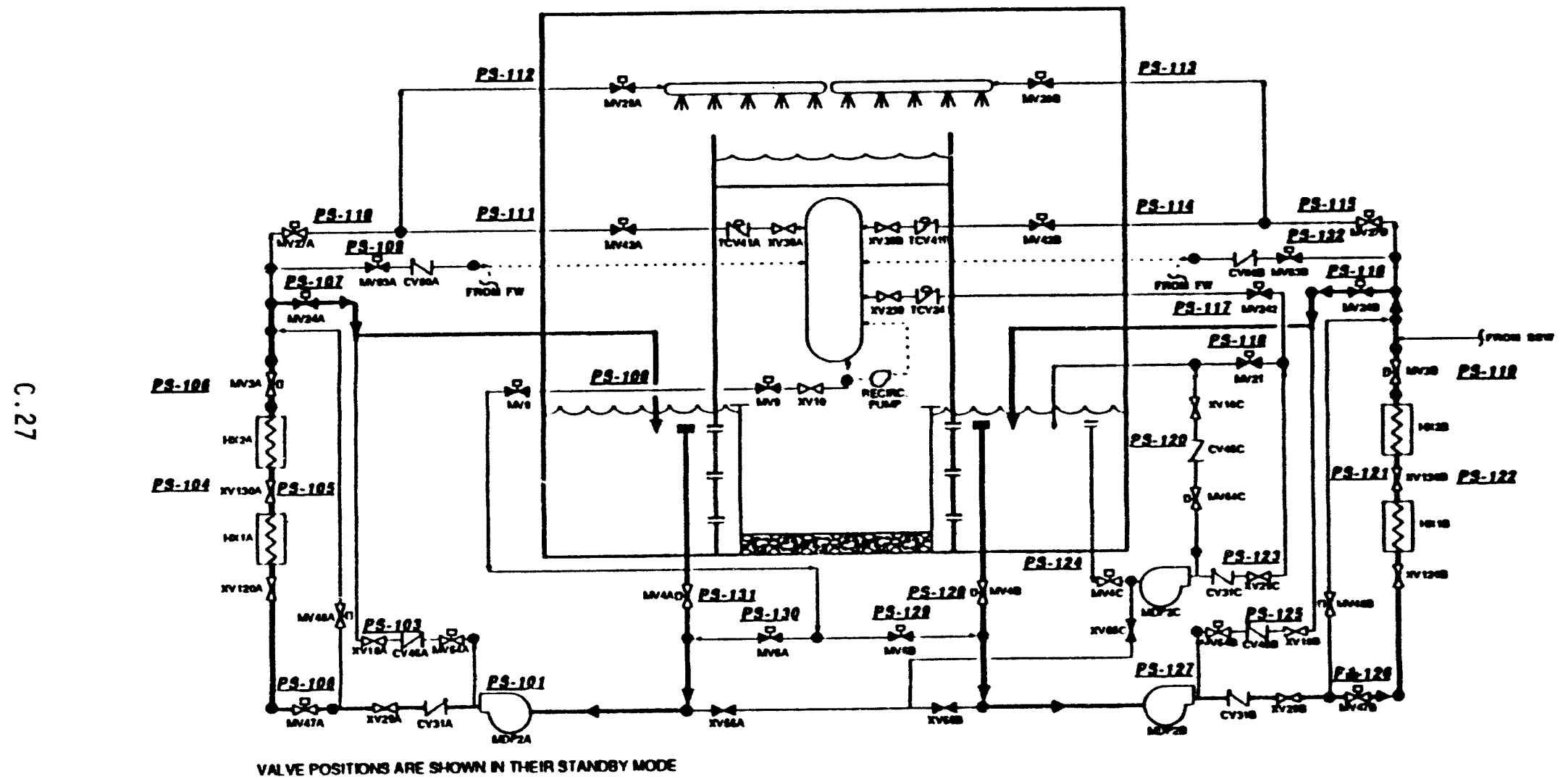

FIGURE C.16. Suppression Pool Cooling System Schematic 
The SPC system major dependencies are DC control power for actuation, $A C$ power for operating the RHR pumps and valves, RHR pump cooling, and RHR pump room cooling. DC power is pruwided by Division 1 to the $A$ Train and Division 2 to the B Train. AC power is provided by Division 1 to RHR $A$ pump and Division 2 to the RHR B pump. Both pumps require pump cooling and room cooling. Room cooling failure was assumed by Drouin et al. (1989) to fall the RHR pumps in four hours (see Appendix F).

Many components of the SPC system are shared with the different modes of the RHR system. These commonalities are as follows: 1) the RHR pumps $A$ and $B$ are common to LPCI, SPC, SDC, and CS modes; 2) the suppression pool suction valve for pump Trains $A$ and $B$ is common to the LPCI, SPC, and CS modes.

The fault tree diagram developed for the SPC was simplified by "pruning" the branches that did not lead to room cooling failure. The "pruned" branches were left as undeveloped events. The simplified SPC fault tree diagram is shown in Figure C.17.

\section{C.2.13 Residual Heat Removal (RHR): Shutdown Cooling (SDC) System}

The SDC system removes decay heat during accidents in which reactor vessel integrity is maintained. The SDC is one mode of the RHR system and, as such, shares components with other modes.

The SDC system is a two-train system consisting of MOVs and MDPs. Each train has two heat exchangers in series downstream of the pump. Cooling water flow to the heat exchanger is required for the SDC mode. The SDC system suction source is one recirculation pump's suction line. The SDC pumps are located in the Auxiliary Building in an enclosed room with fire/flood doors. A simplified schematic of the SDC system is provided in Figure C.18.

The SDC system is manually initiated and controlled. The operator is required to align the system and to start the pumps.

The SDC system major dependencies are $D C$ control power for actuation, $A C$ power for operating the RHR pumps and valves, RHR pump cooling, and RHR pump room cooling. DC power is provided by Division 1 to the $A$ Train and Division 2 to the B Train. AC power is provided by Division 1 to RHR A pump and Division 2 to the RHR B pump. Both pumps require pump cooling and room cooling. Room cooling failure was assumed by Drouin et al. (1989) to fail the RHR pumps in four hours (see Appendix F).

Many components of the SDC system are shared with the different modes of the RHR system. These commonalities are as follows: 1) the RHR pump flow paths are common to LPCI, SPC, SDC, and CS modes; 2 ) the heat exchangers are common to the LPCI, SPC, SDC, and CS modes.

The fault tree diagram developed for the SDC was simplified by "pruning" the branches that did not lead to room cooling failure. The "pruned" branches were left as undeveloped events. The simplified SDC fault tree diagram is shown in Figure C.19. 


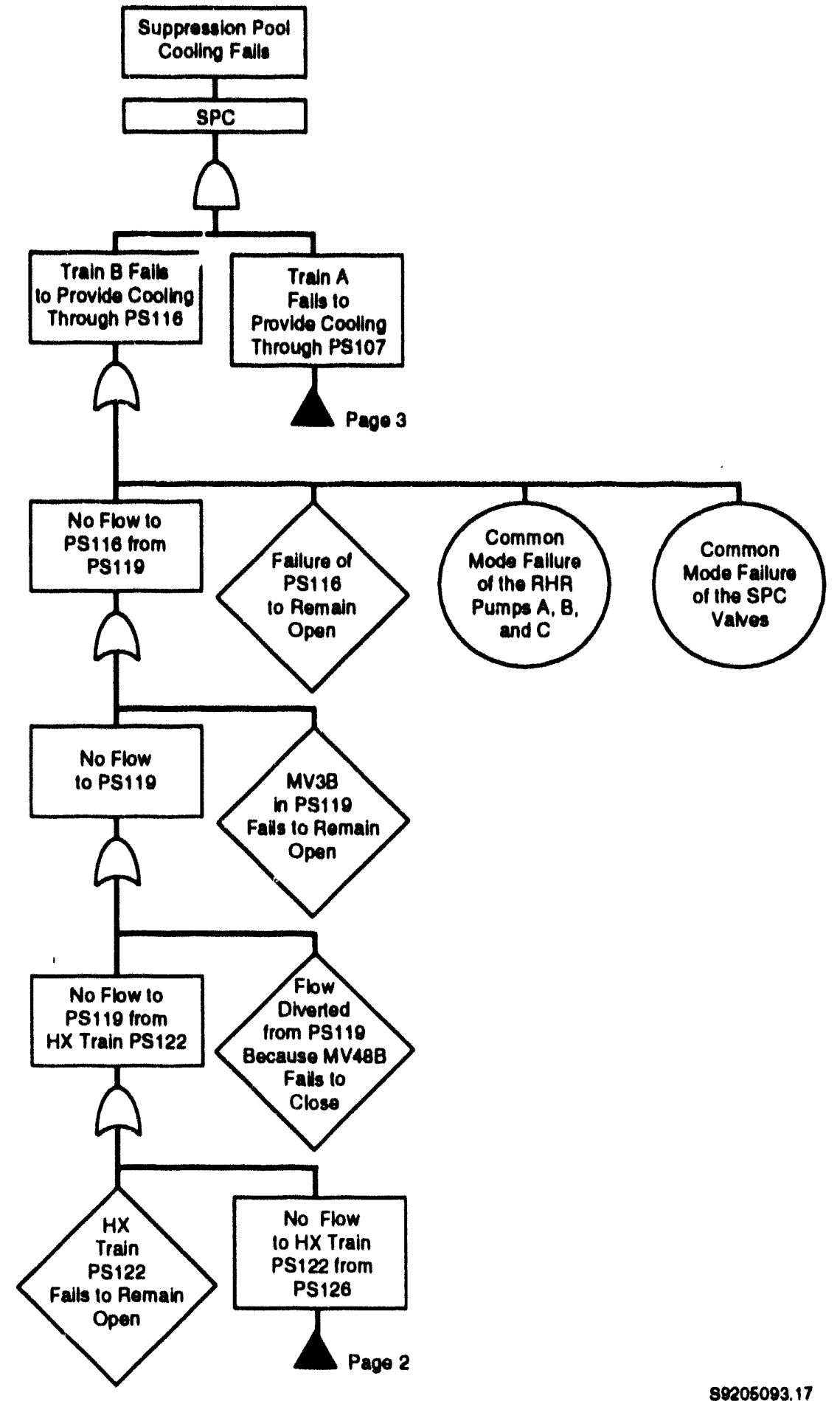

EIGURE C.17. Suppression Pool Cooling System Fault Tree 


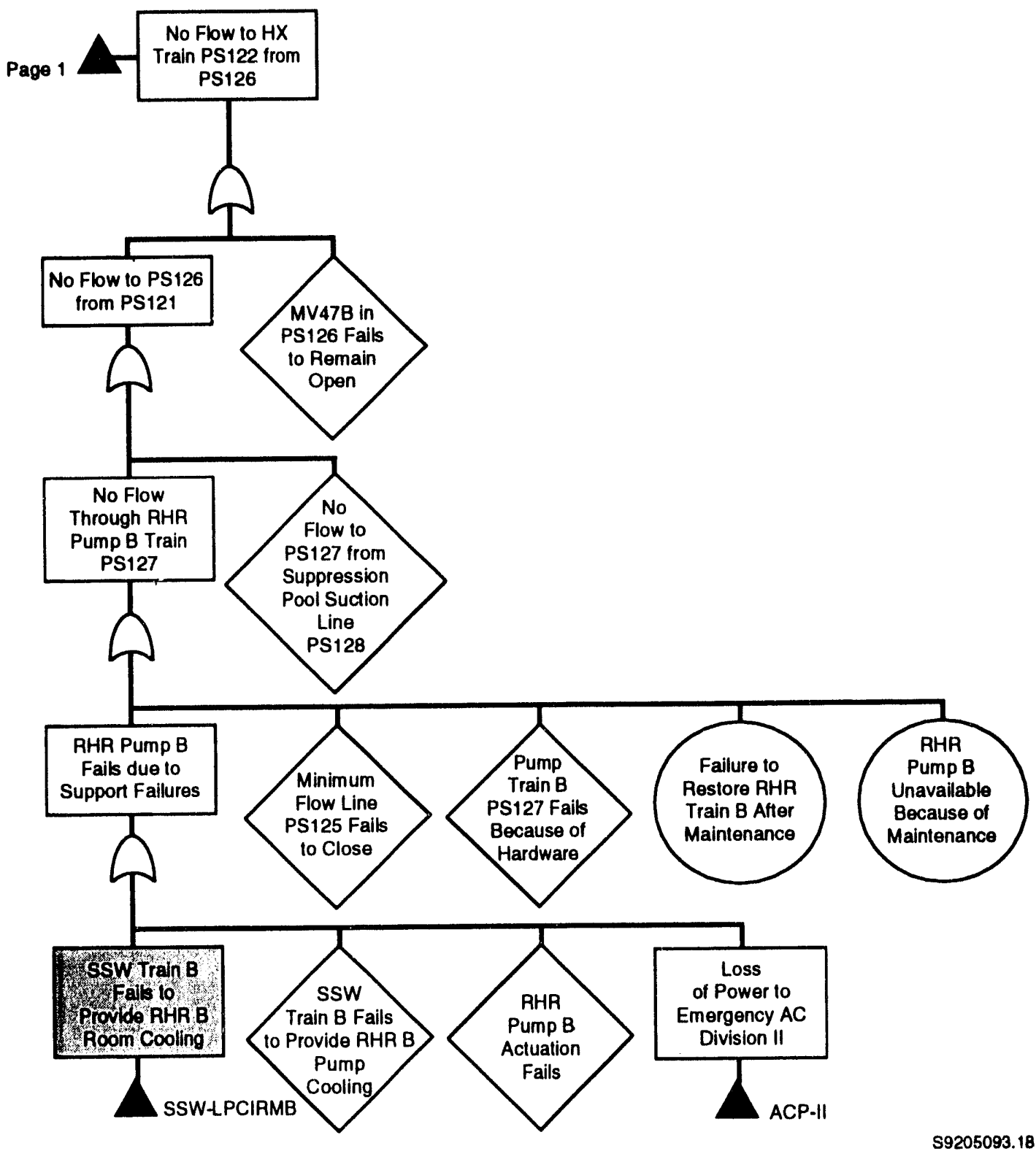

FIGURE C.17. (contd) 


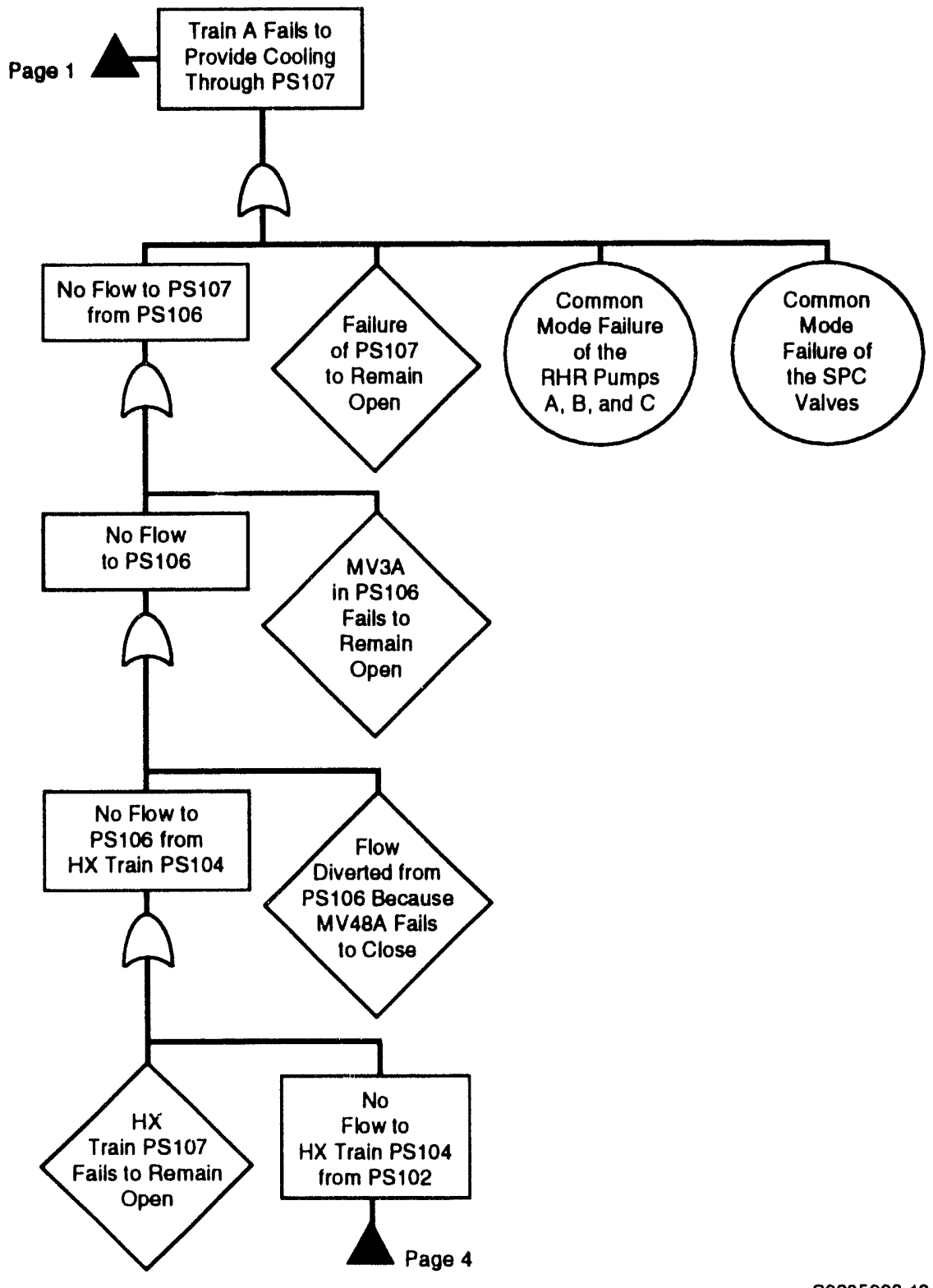

59205093.19

FIGURE C.17. (contd) 


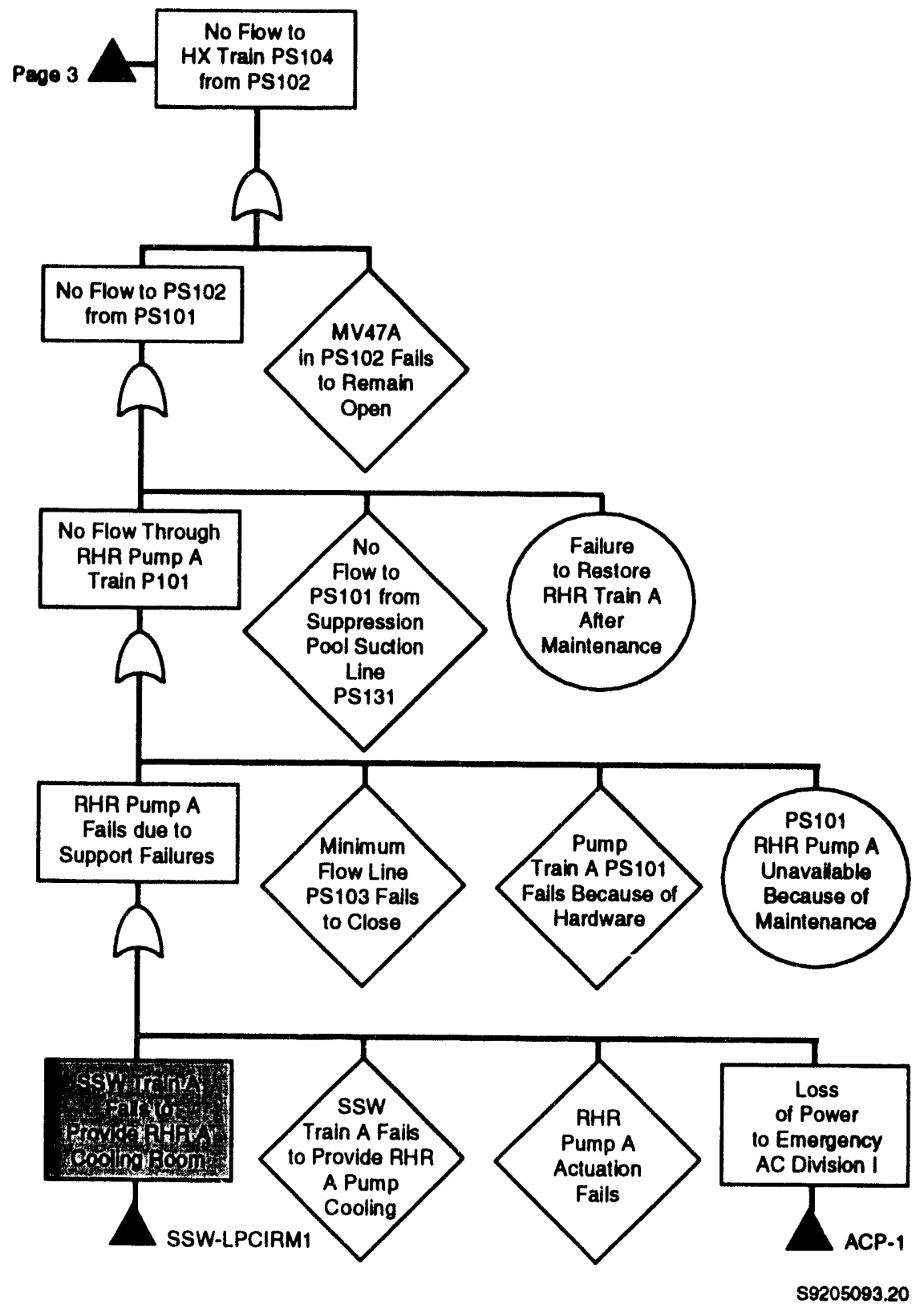

FIGURE C.17. (contd) 


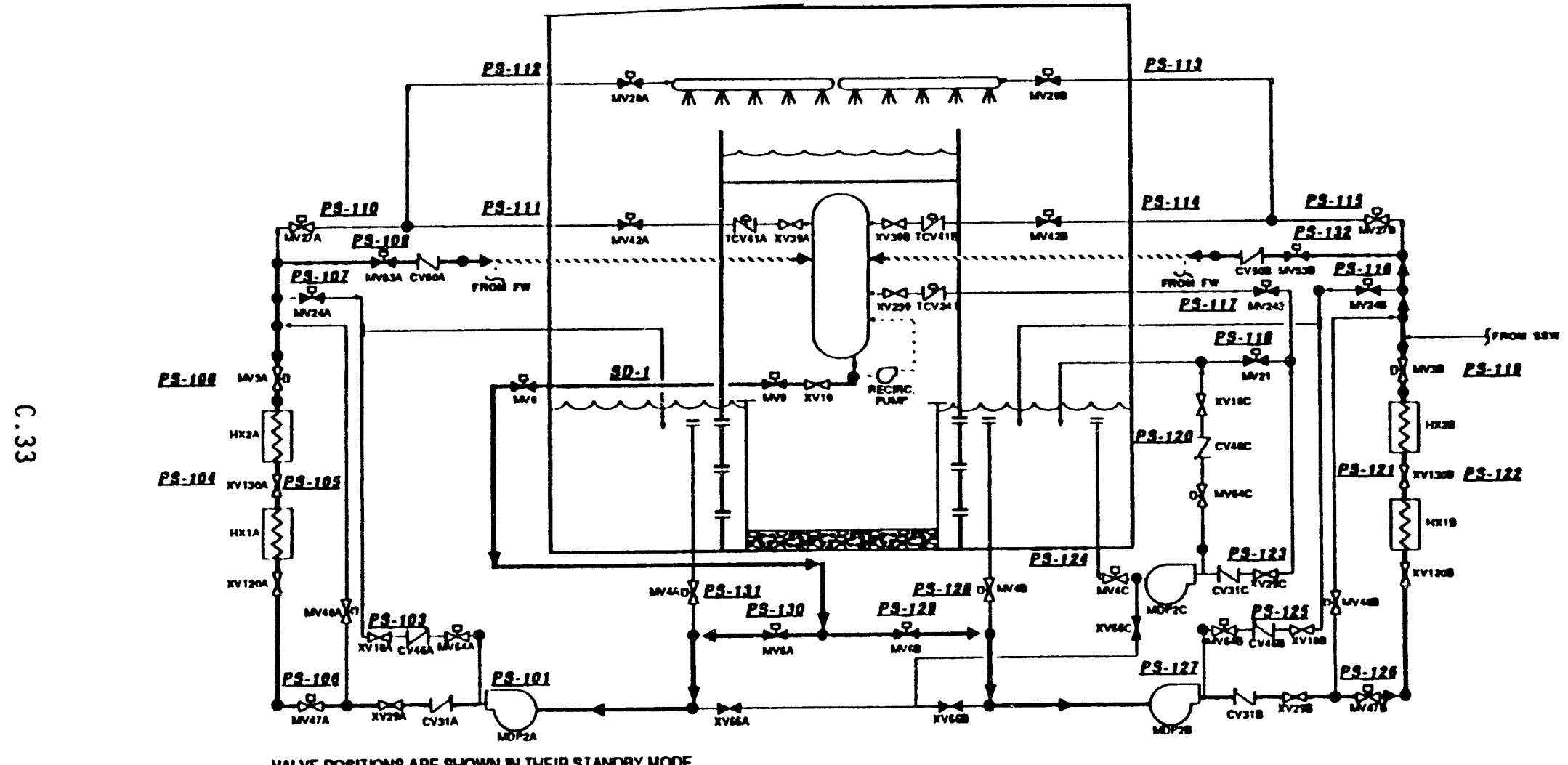

FIGURE C.18. Shutdown Cooling System Schematic 


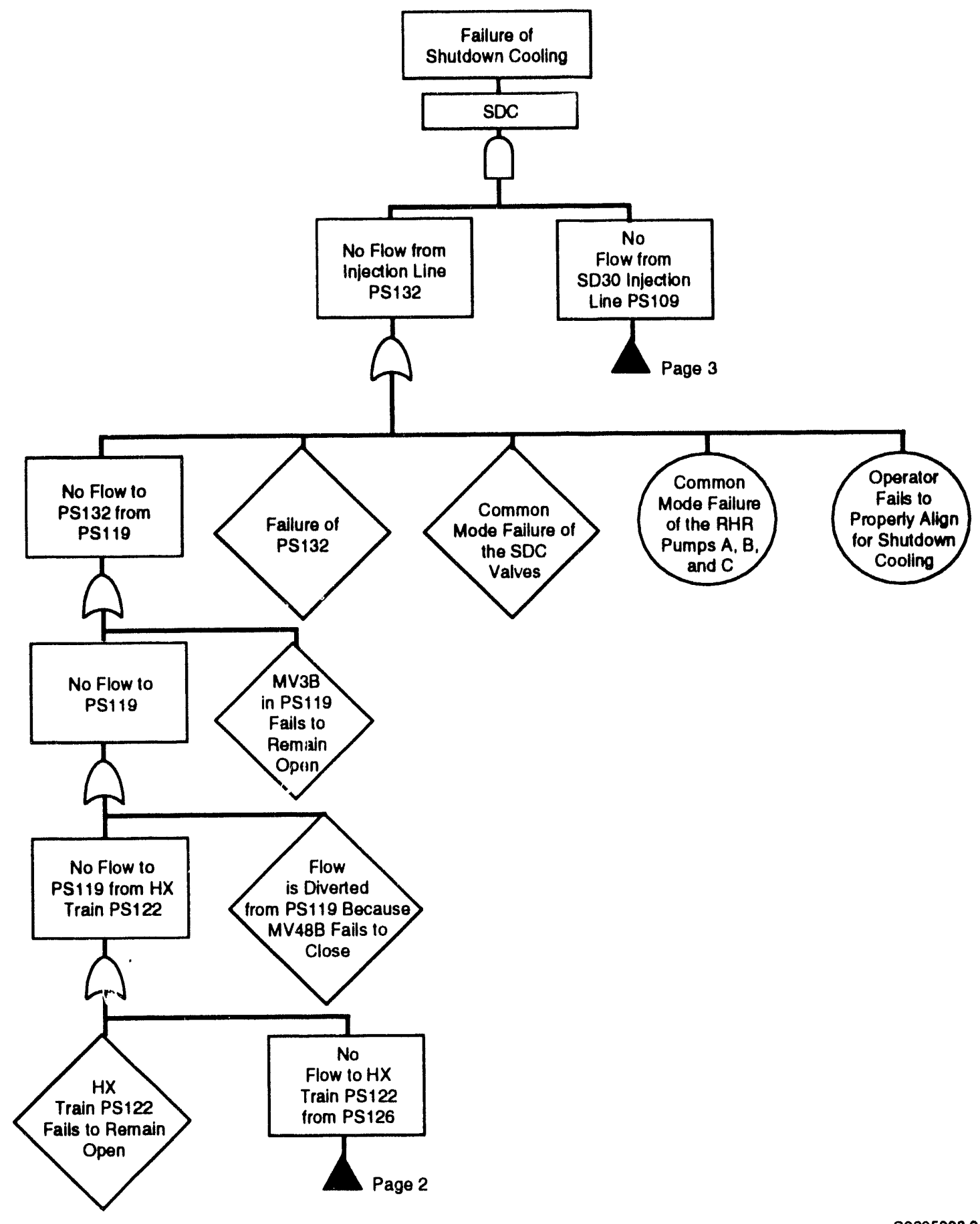

FIGURE C.19. Shutdown Cooling System Fault Tree 


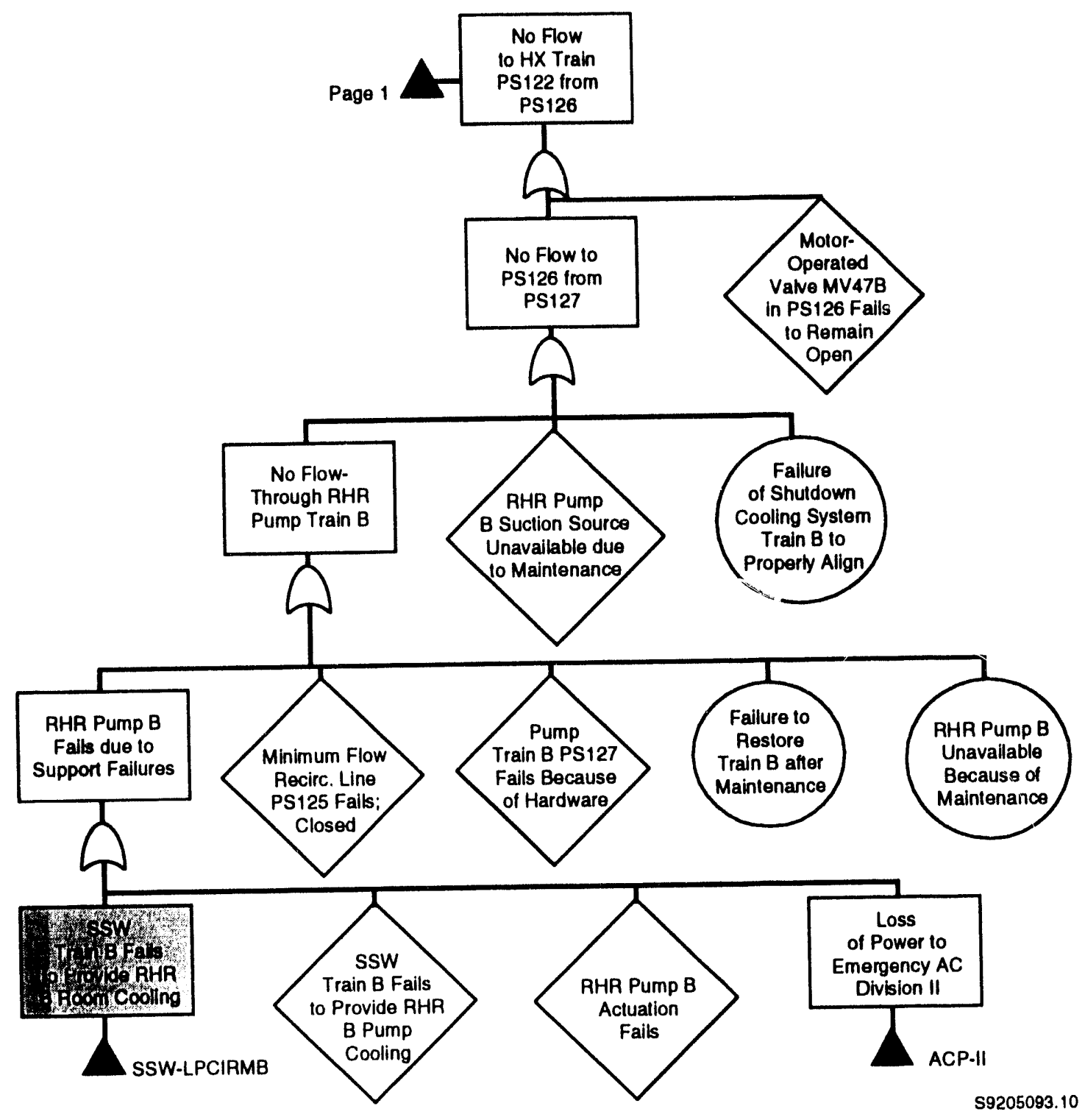

FIGURE C.19. (contd) 


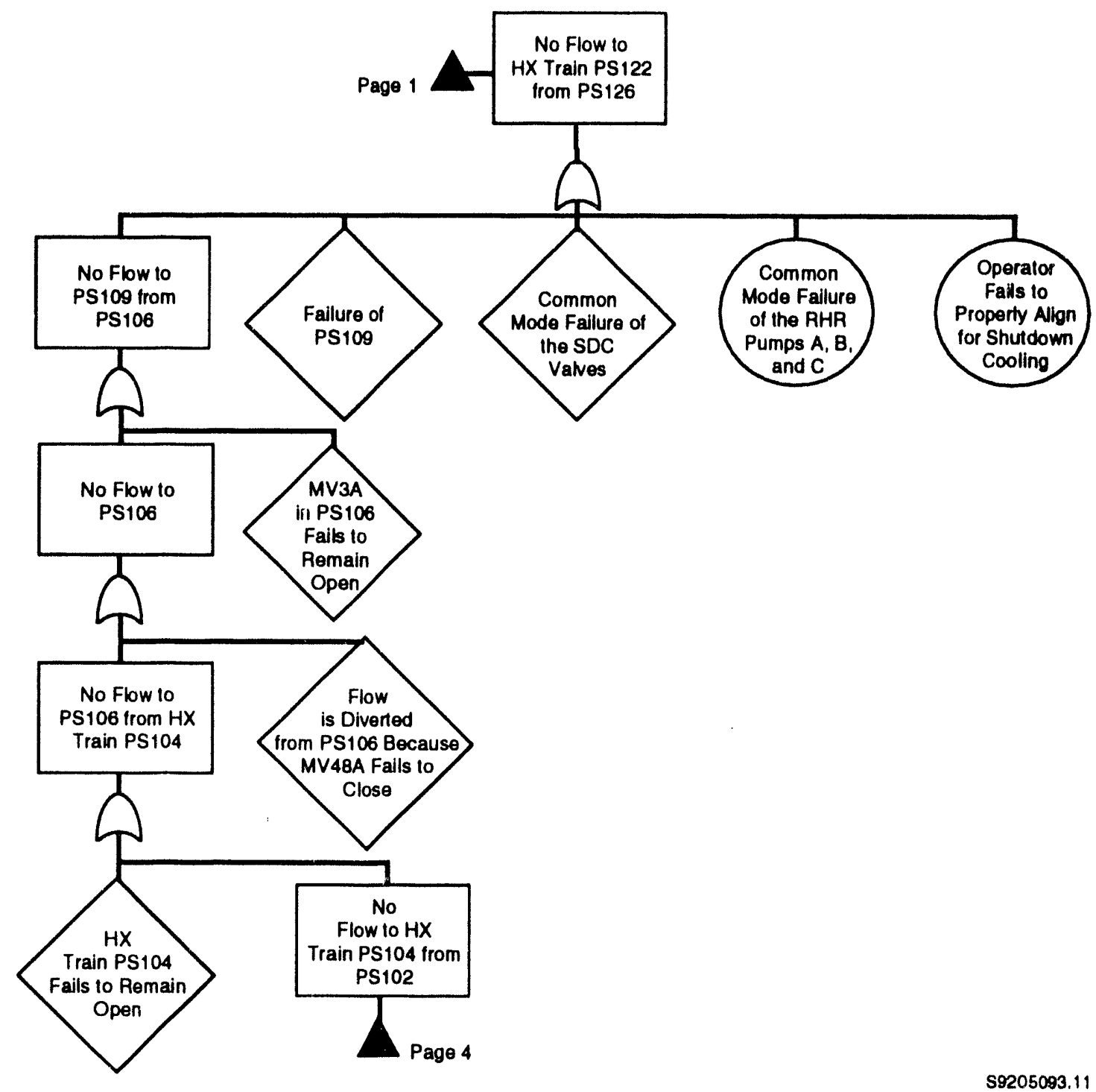

FIGURE C.19. (contd) 


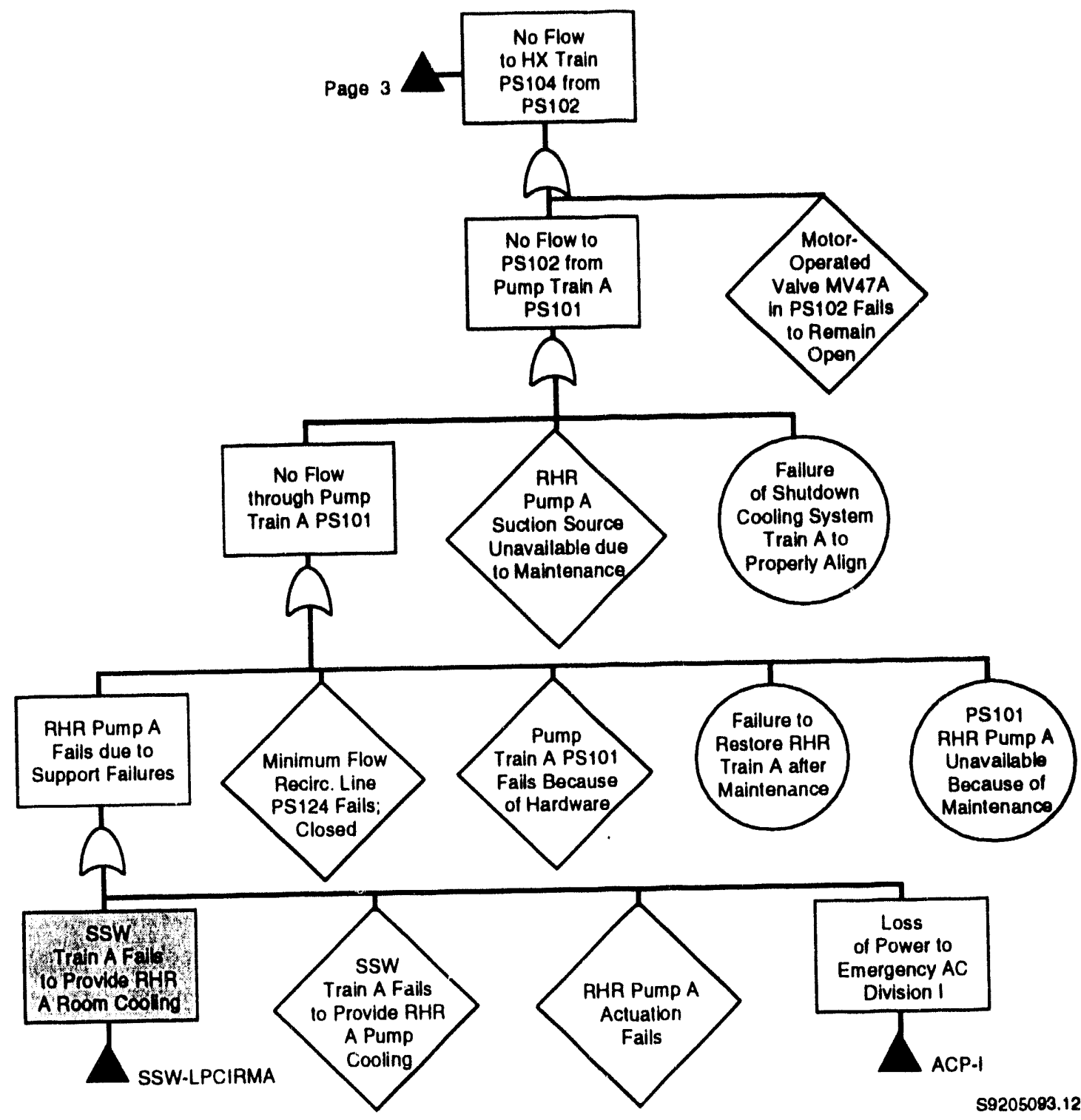

FIGURE C.19. (contd)

\section{C.2.14 Residual Heat Removal (RHR): Containment Spray (CS) System}

The CS system suppresses pressure in the containment during accidents. The CS system is one mode of the RHR system and, as such, shares components with other modes.

The CS system is a two-loop system consisting of MOVs and MDPs. There are two heat exchangers in series per loop. Cooling water flow to the heat exchanger is required for CS mode. The CS suction source is the suppression pool. The pumps are located in the Auxiliary Building in an enclosed room 
with fire/flood doors. The CS system is automatically initiated and controlled or may be manually initiated. A simplified schematic of the CS system is provided by Figure C.20.

The CS system major dependencies are DC control power for actuation, $A C$ power for operating the RHR pumps and valves, RHR pump cooling, and RHR pump room cooling. DC power is provided by Division 1 to the $A$ Train and Division 2 to the B Train. AC power is provided by Division 1 to RHR $A$ pump and Division 2 to the RHR B pump. Both pumps require pump cooling and room cooling. Room cooling fallure was assumed by Drouin et al. (1989) to fail the RHR pumps in four hours (see Appendix F).

Many components of the CS system are shared with the different modes of the RHR system. These commonalities are as follows: 1) the RHR pumps are common to the LPCI, SPC, SDC, and CS modes; 2) the suppression pool suction valve for each pump train is common to the CS, SPC, and LPCI modes; and 3) the heat exchangers are common to the LPCI, SPC, SDC, and CS modes.

The fault tree diagram developed for the CS was simplified by "pruning" the branches that did not lead to room cooling failui'e. The "pruned" branches were left as undeveloped events. The simplified CS tault tree diagram is shown in Figure C.21.

\section{C.2.15 Containment Venting System (CVS)}

The CVS prevents the primary containment pressure limit from being exceeded when the SPC and CS systems have failed. The vent path used is a 20 -inch-diameter purge exhaust line that is part of the containment ventilation and filtration system. This line includes four air-operated dampers that are normally closed. All four fail closed on loss of air. Two of the dampers are closed by a containment isolation signal. The other two are closed by the standby gas treatment system initiation. The CVS discharges to the roof of the Auxiliary Building. A schematic of the CVS is shown in Figure C.22.

The venting procedure requires containment venting when the pressure exceeds 17.25 psig. Venting requires that the operator jumper the isolation relays for each damper (which are located on back panels in the control room), and then open them. The actual venting procedure can be initiated only by order of the Emergency Director.

Containment venting requires instrument air for opening the air-operated dampers. The dampers also require power from emergency AC Divisions 1 and 2 for operation of the solenoids. No dependencies on any room cooling functions were identified; however, containment venting affects the probability of containment failure and thus affects public risks. Therefore, the CVS will be considered in the public risk calculations but not in the assessment of CDF. Consequently, fault trees were not developed for the CVS. 
$\underset{\omega}{\omega}$

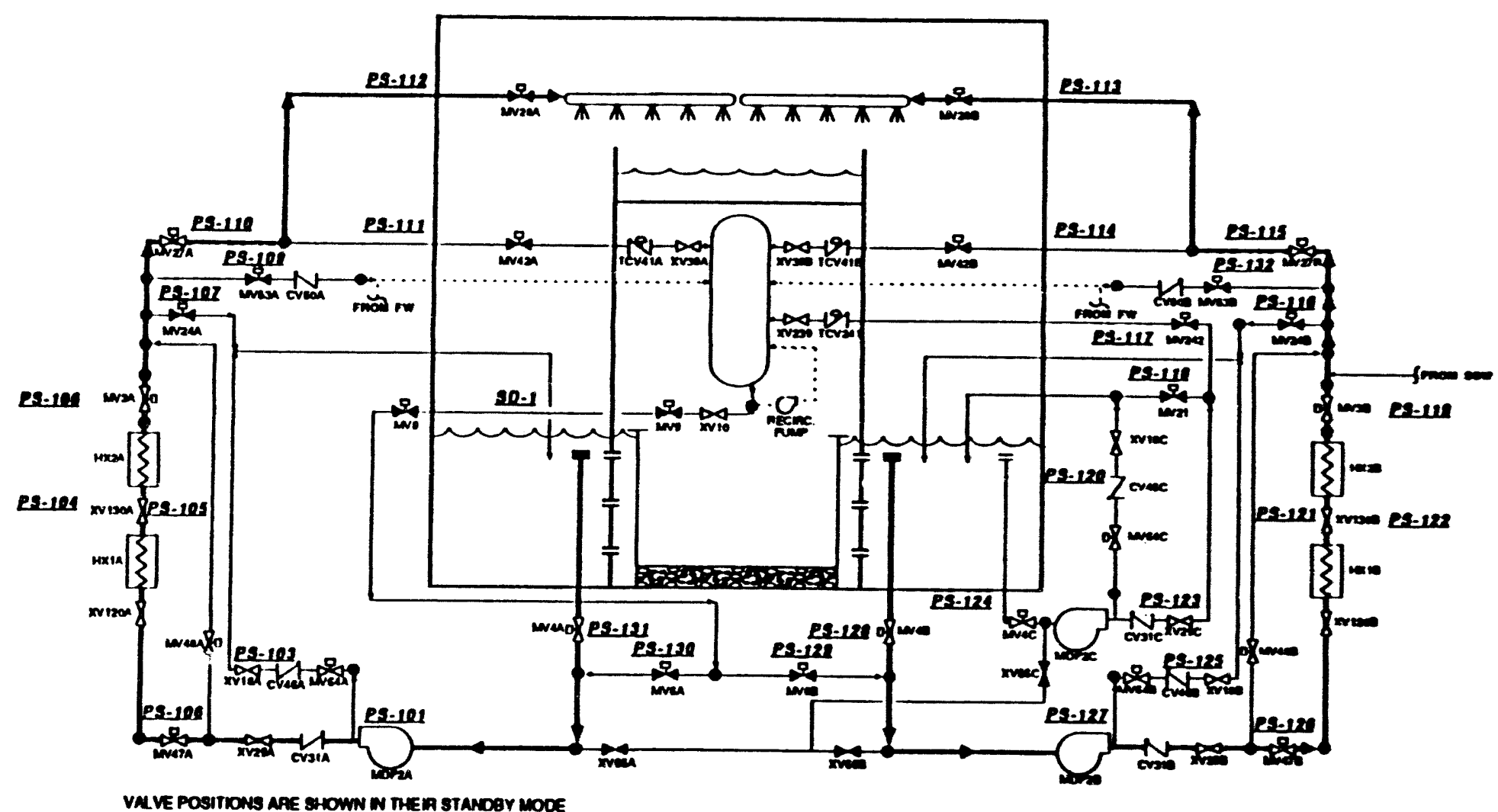

FIGURE C.20. PHR: Containment Spray System Schematic 


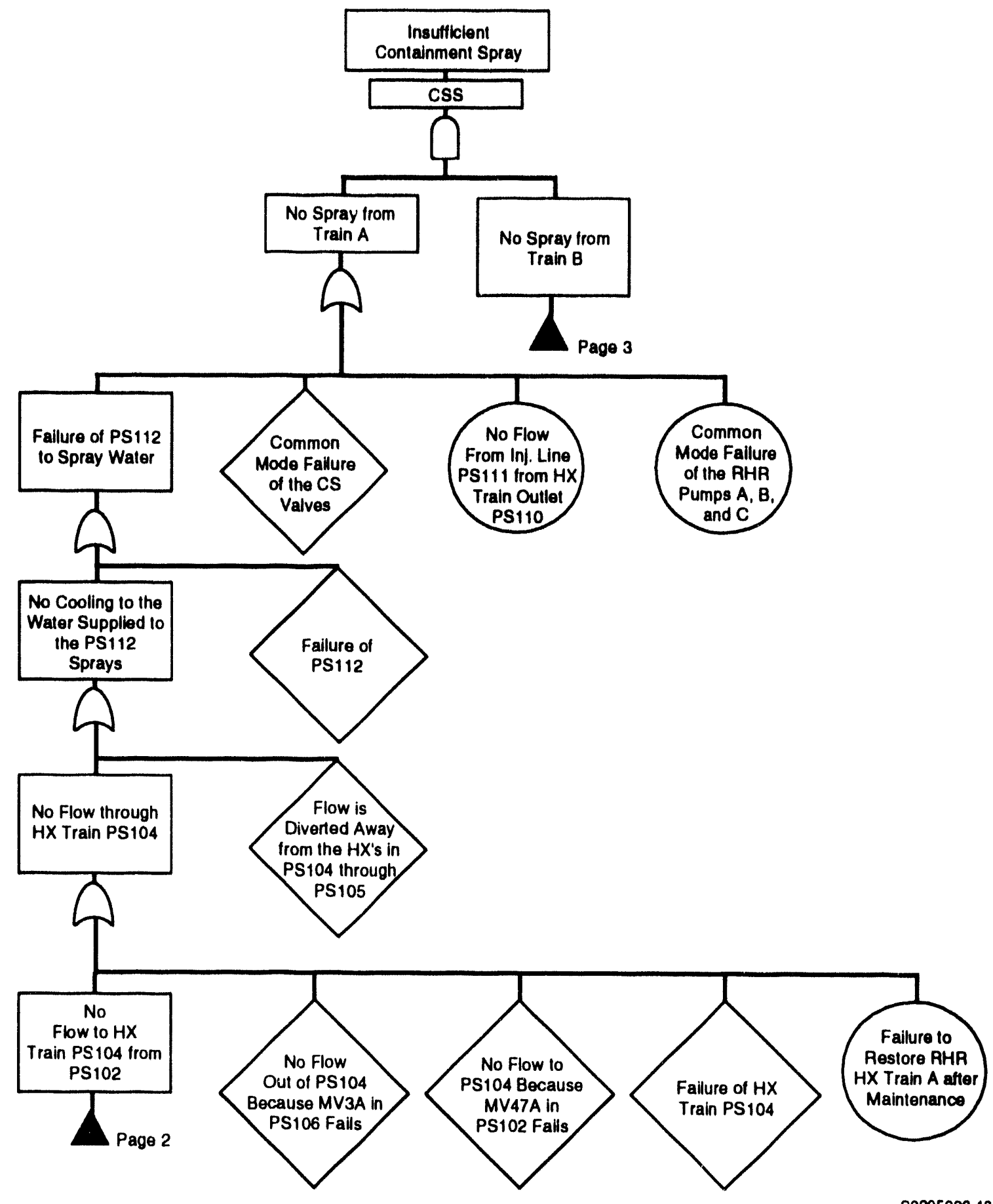

$\$ 9205093.13$

FIGURE C.21. Containment Spray System Fault Tree 


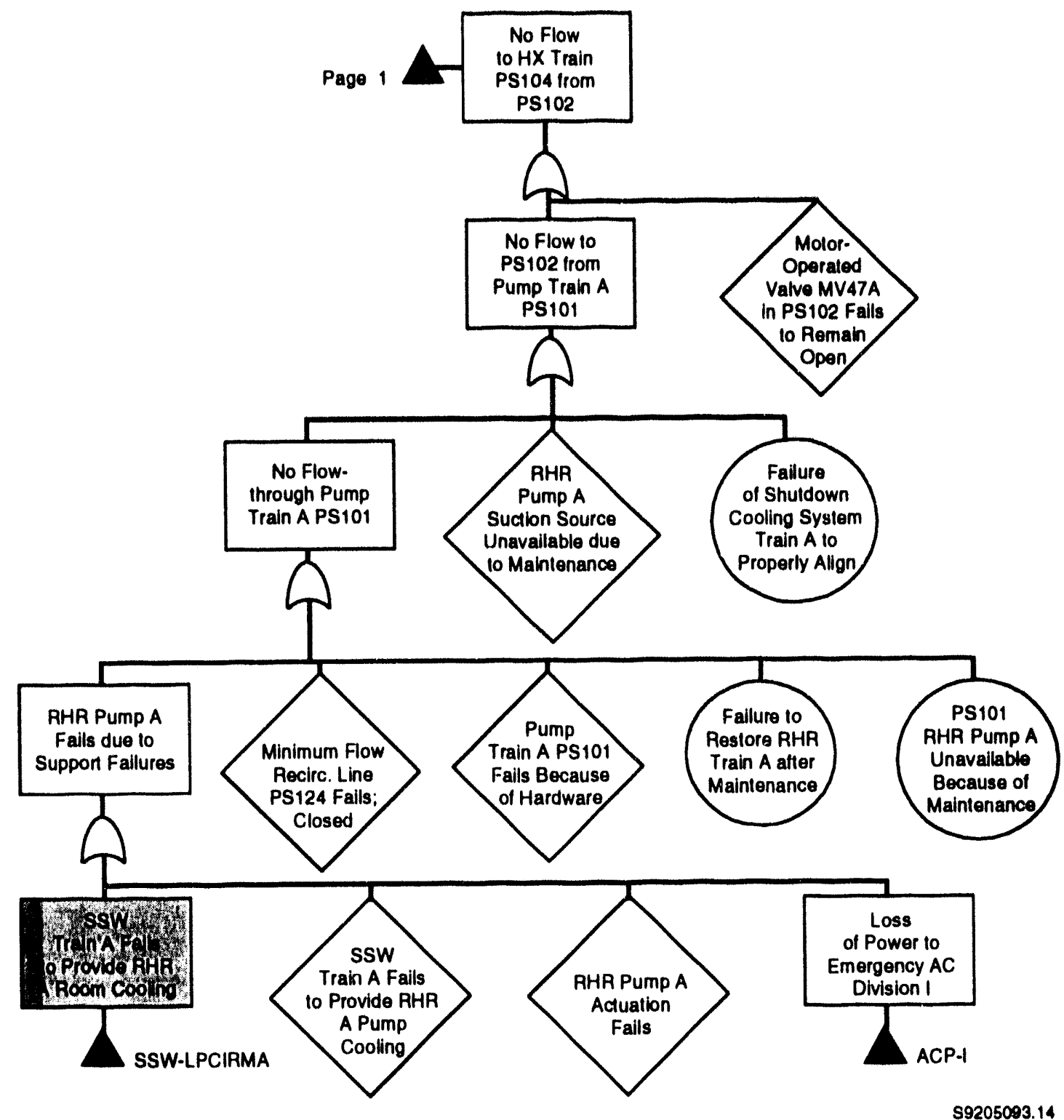

FIGURE C.21. (contd) 


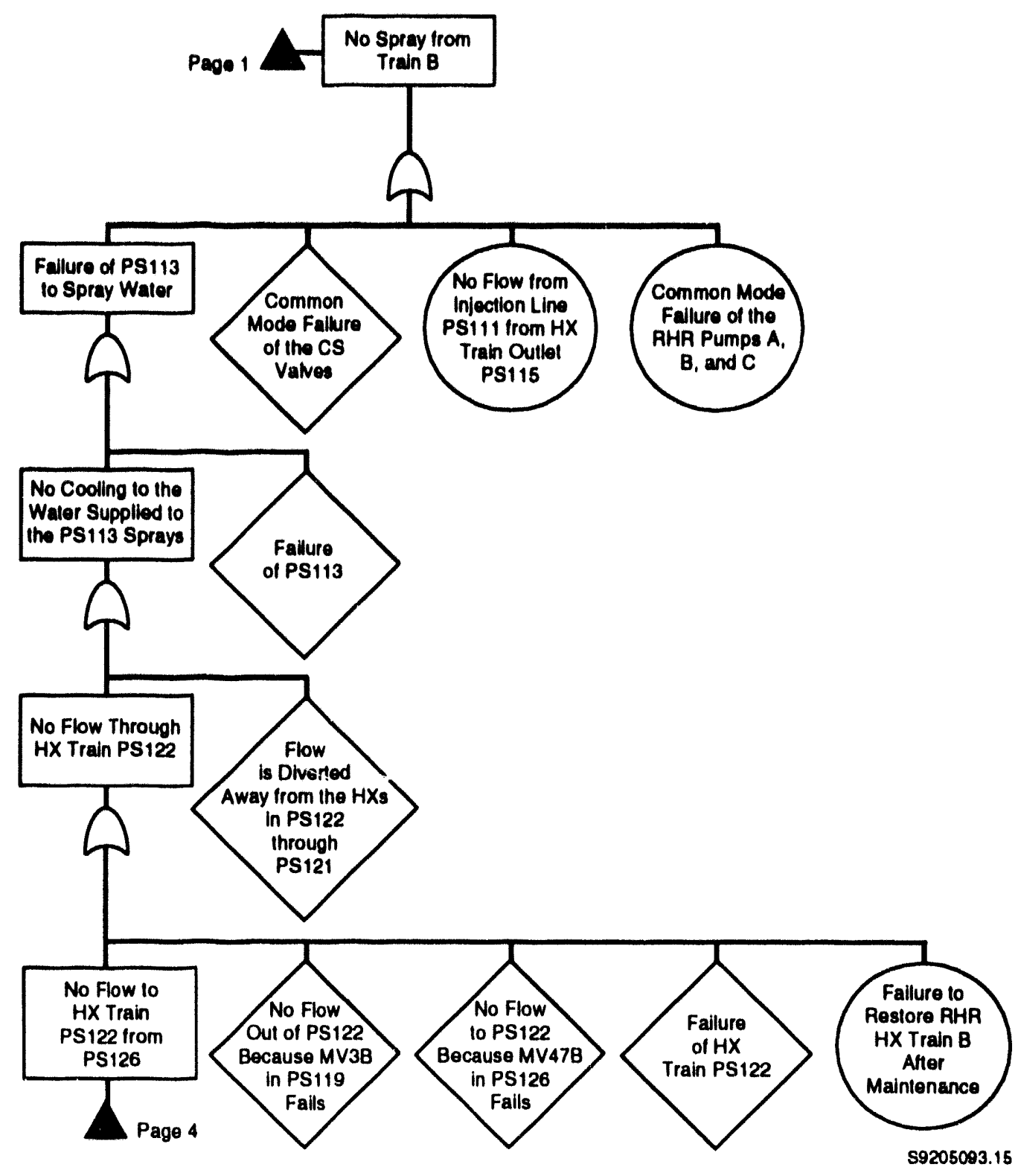

FIGURE C.21. (contd) 


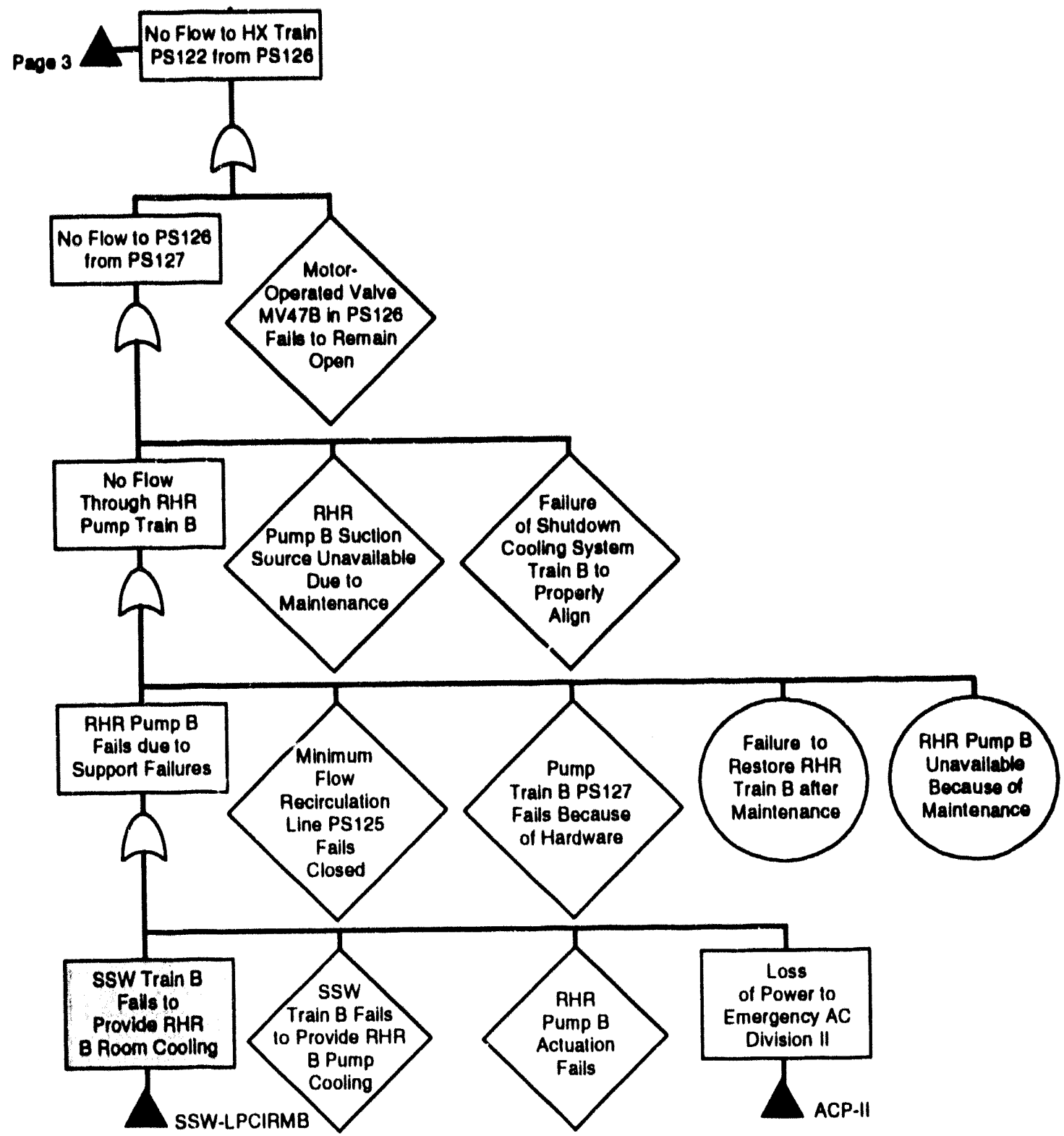

$\mathbf{5 9 2 0 5 0 9 3 . 1 6}$

FIGURE C.21. (contd) 


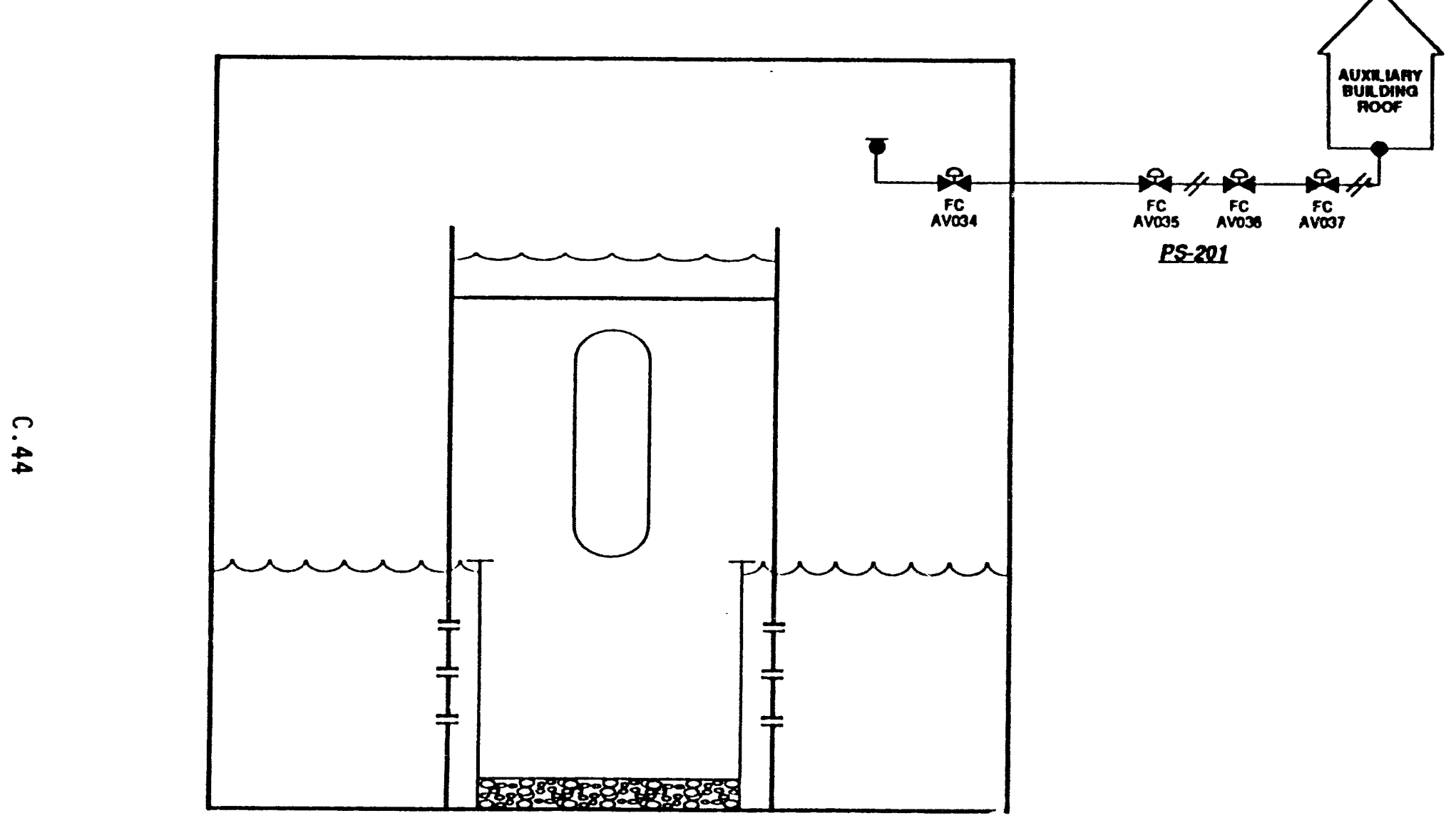

DAMPEA POSTIONS ARE SHOWN W THEIA STANDEY MODE

FIGURE C.22. Containment Venting System Schematic 


\section{C.2.16 Emergency Power System (EPS)}

The EPS consists of the $A C$ and $D C$ power divisions required by the ESF to safely shut down the plant. Both $A C$ and $D C$ power are divided into three separate divisions, two of which ( 1 and 2) are for the majority of the ESF and the third 3 ) is dedicated to the HPCS system and its required support systems. A schematic of the EPS is shown in Figure C.23.

The ESF AC divisions normally receive power from one of three offsite sources through ESF transformers. Each ESF bus has a standby diesel generator which is available to supply bus loads upon a loss of normal AC power. These diesels may be started manually or automatically. Each ESF DC division consists of two battery chargers, which normally supply the load, and a bank of batteries that function as backup.

Each diesel generator has six subsystems required for its operation:

- fuel oil subsystem

- air starting subsystem

- lube oil subsystem

- jacket water cooling subsystem

- combustion air intake, exhaust, and crankcase ventilation

- standby generator excitation subsystem.

With the exception of the combustion air subsystem, all of these subsystems are normally treated as part of the diesel generator. However, some of these other subsystems are dependent on operation of other systems.

The ESF AC divisions require DC power from the associated ESF DC buses for circuit breaker control power, diesel generator field flashing, and the diesel fuel oil booster pump. The SSW system is required to supply cooling water to the diesel generation jacket water coolers.

There is a limitation as to which loads can be supported by the Division 3 HPCS diesel generator when cross-tied to either Division 1 or 2 . The following loads on either Division 1 or 2 can be supplied by the Division 3 diesel generator:

- RHR pump

- SSW pump

- MOVs

- Control room emergency fan

- Battery charger

- Drywell coolers

- Fuel pool cooling and recirculation pump 


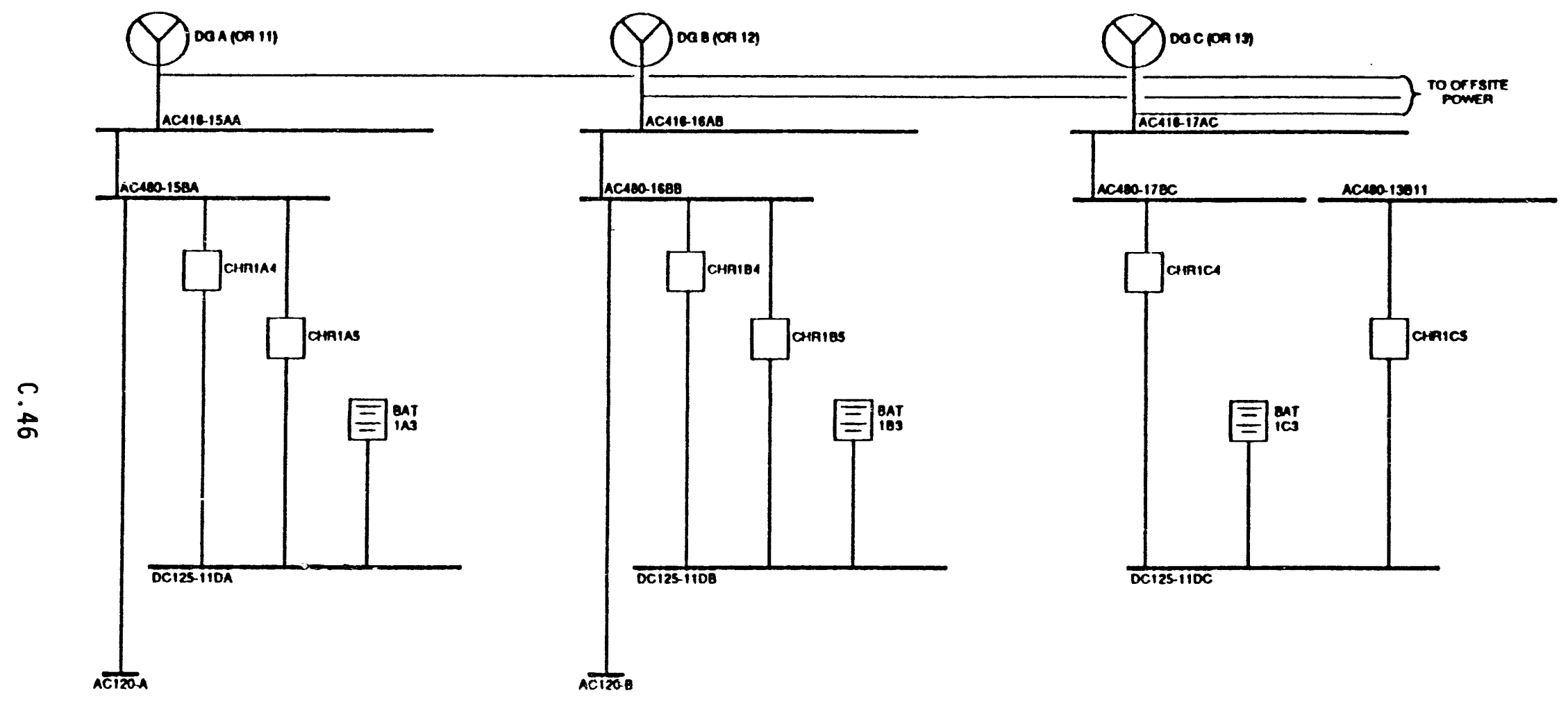

AC DIvision 1

A.C DIVISION 2

AC DIVISION 3

FitiviRE C.23. Emergency Power System Schematic 
- SSW pump fan

- Control room air conditioning system, including chiller, chilled water pump, piping, valves, fan, and air duct

- SSW cooling tower fans

- ESF electrical room cooler fan

- Instrument air compressor

- Safeguards switchgear and battery room fans

- ECCS pump room cooler

- HPCS diesel generator accessories cooling water pumps, supply fan and auxiliaries.

Most of the EPS is located in the Diesel Building and in compartmentalized rooms within the Auxiliary Building. Room cooling is required for the diesel generator rooms. Diesel generators were assumed by Drouin et al. (1989) to fail in fifteen minutes without room cooling. Appendix $F$ indicates a temperature rise of about $60^{\circ} \mathrm{F} / \mathrm{hr}$ will result if room cooling fails and the EDGs are running. EPS failure will result from failure of control systems and switchgear located in the EDG enclosure. Depending upon the initial temperature of the EDG room, 15 minutes is a reasonable approximation for the amount of time following loss of room cooling and failure of electrical equipment in the room.

The battery and switchgear rooms were assumed to by Drouin et al. (1989) to not require room cooling during accident conditions. This is similar to the representative W PWR, although a safety-related area cooler is provided for these rooms. As shown in Appendix $F$, the heat loads are relatively small in these large, open rooms such that the heatup rates following loss of room cooling are low; perhaps as much as 24 hours are needed to reach the room design maximum temperature. As discussed in Section 3.7 of the main report, batteries are not particularly sensitive to high ambient temperatures. The rooms are required to be ventilated to prevent hydrogen gas buildup and are also heated, but room cooling is not necessary.

The fault tree diagram developed for the EPS was broken up into three trees, each corresponding to a different division $(1,2$, or 3$)$. The EPS fault trees were simplified by "pruning" the branches that did not lead to room cooling failure: the "pruned" branches were left as undeveloped events. The simplified EPS fault tree diagrams are shown in Figures C.24, C.25, and C.26.

\section{C.2.17 Standby Service Water (SSW) System}

The SSW system provides heat removal from plant auxiliaries that require cooling water during an emergency shutdown of the plant. The system is made 


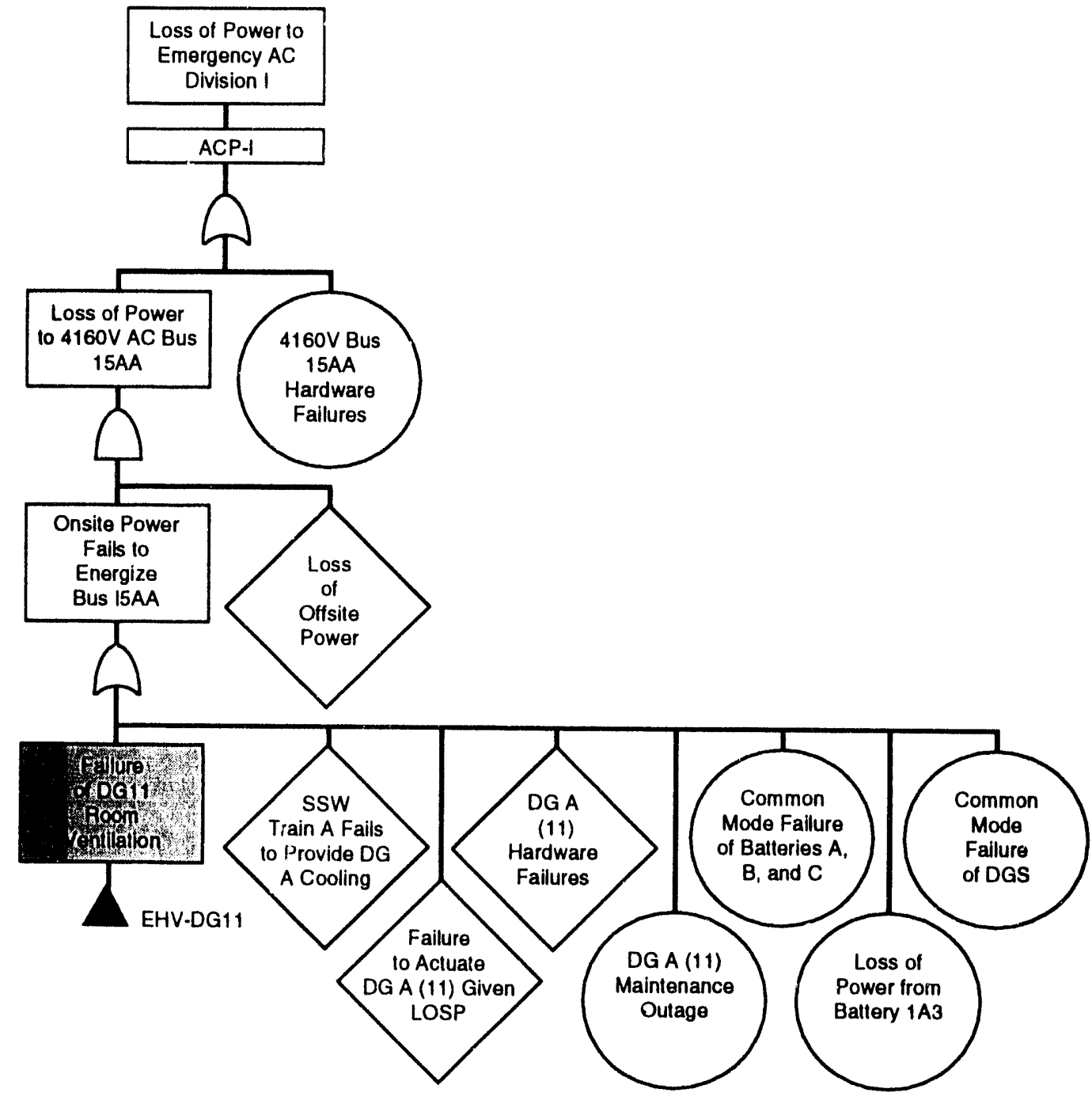

59205093.21

\section{FIGURE C.24. Emergency AC Division 1 System Fault Tree}

up of three independent trains, each consisting of an MDP, MOVs, and heat exchangers. Train $C$ is dedicated to the HPCS system.

Each SSW pump takes water from the cooling tower basins, circulates it through the HXs for each load, and returns it to the towers through a motoroperated discharge valve. Each train has its own discharge valve. A schematic of the SSW system is shown in Figure C.27.

The SSW system major dependencies are $D C$ control power for initiating the actuation relay logic and AC power for operating the SSW pumps and valves. The pumps are self-cooled. The $A C$ and $D C$ power requirements are provided by Divisions 1, 2, and 3 to Trains A, B, and C, respectively. 


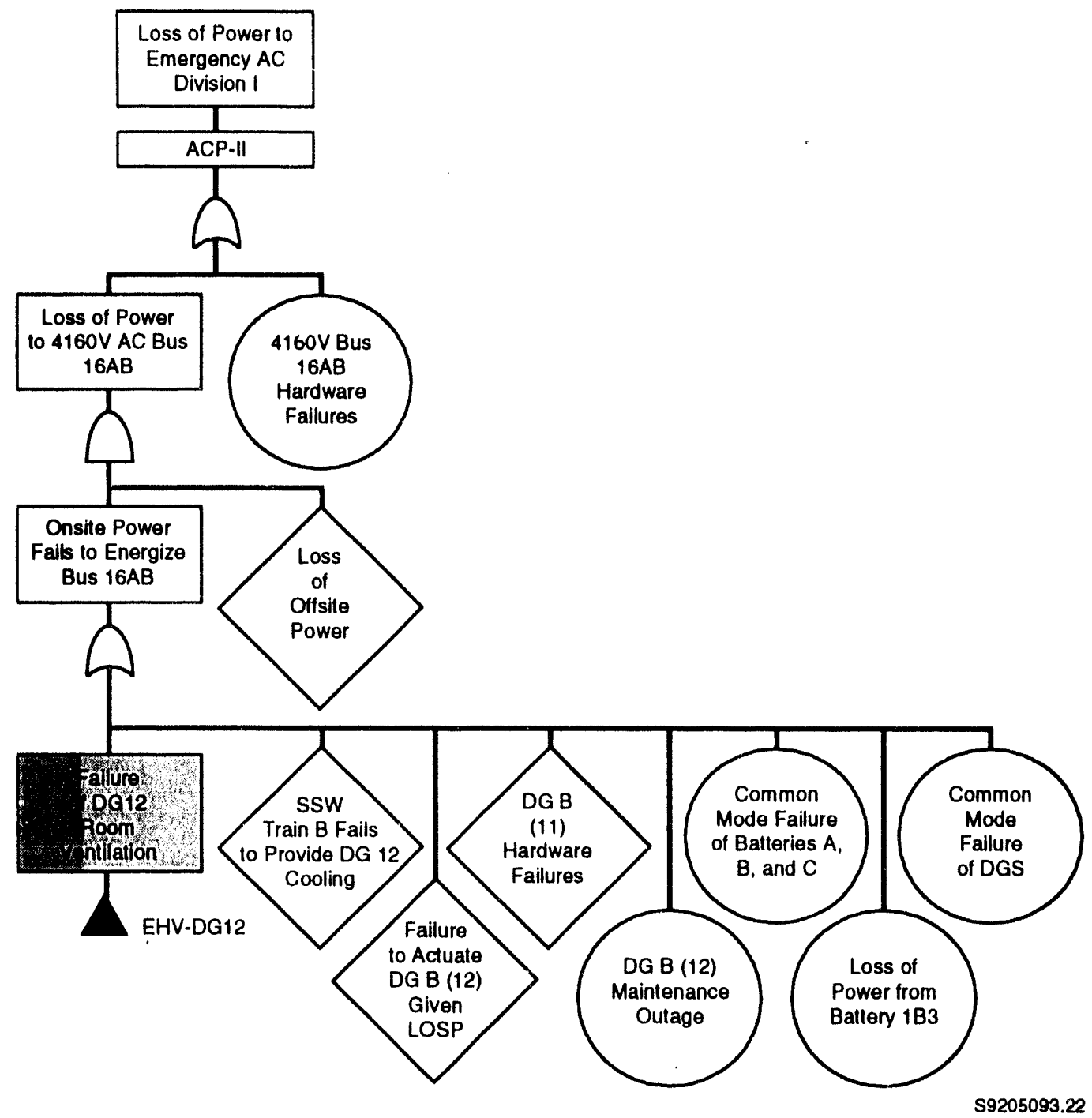

FIGURE C.25. Emergency AC Division 2 System Fault Tree

The SSW pumps are located in pump houses away from other buildings on the site, near the cooling tower. Room cooling is provided to the SSW pumps. However, loss of room cooling was assumed by Drouin et al. (1989) not to fail the pumps. Each pump house has normally open louvers on the walls, and air current from the cooling towers provides ample ventilation. Design calculations performed by the licensee confirmed that natural cooling was adequate to maintain the pump temperatures below the equipment qualification temperature for the pump, even under extreme outside temperature conditions.

The SSW system and EVS work jointly to provide room cooling for the diesel generators and safety-related pumps. The room cooling fault trees were simplified by "pruning" the branches that did not lead to room cooling 


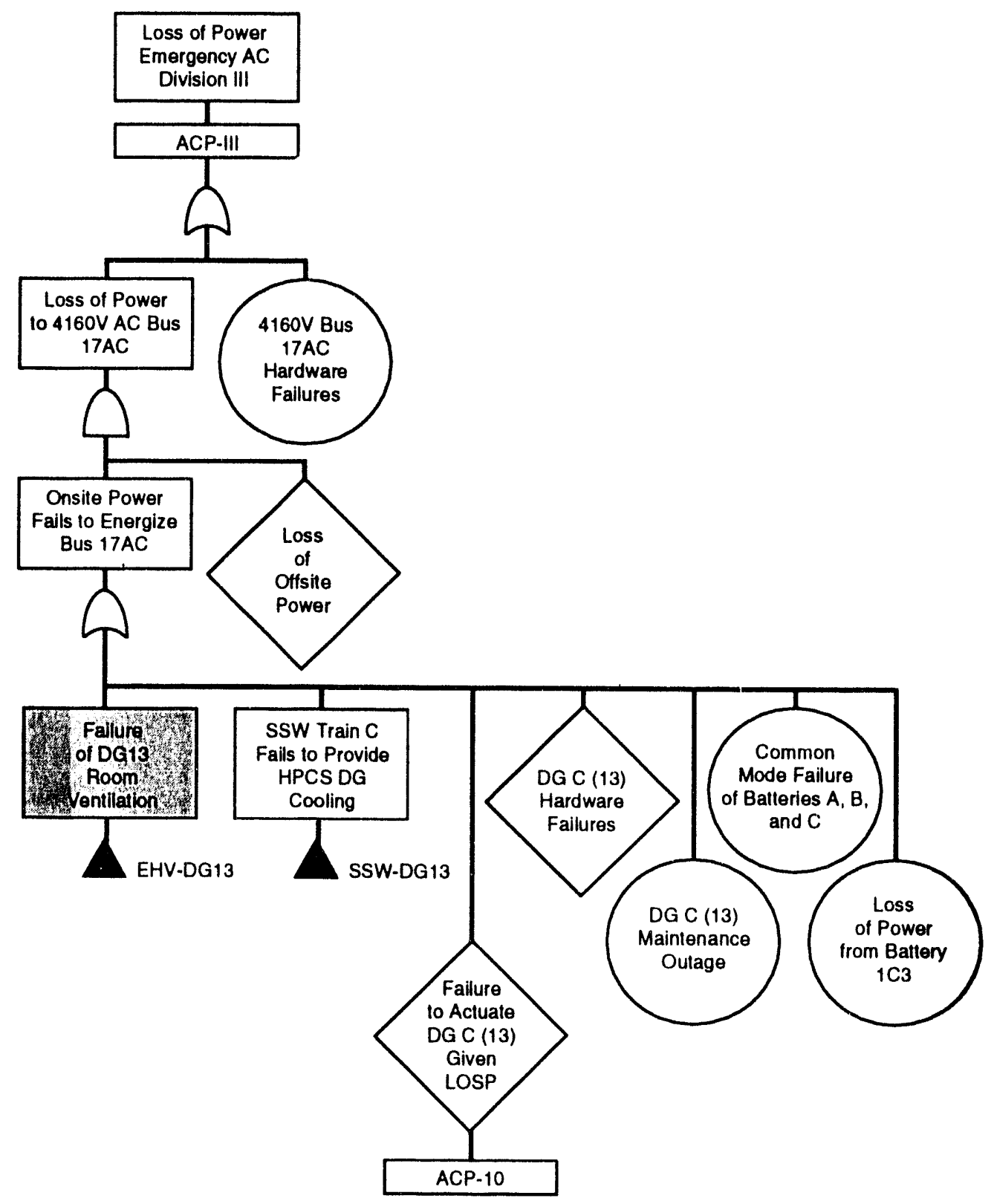

$\$ 9205093.23$

FIGURE C.26. Emergency AC Division 3 System Fault Tree

failure. The "pruned" branches were left as undeveloped events. The simplified room cooling failure fault trees for the RHR $A, B$, and $C$, and LPCS are shown in Figures $C .28$ through C.31. Refer to Section C.2.18 for room cooling failure fault trees in the diesel generator rooms, RCIC pump room, and HPCS pump room. 


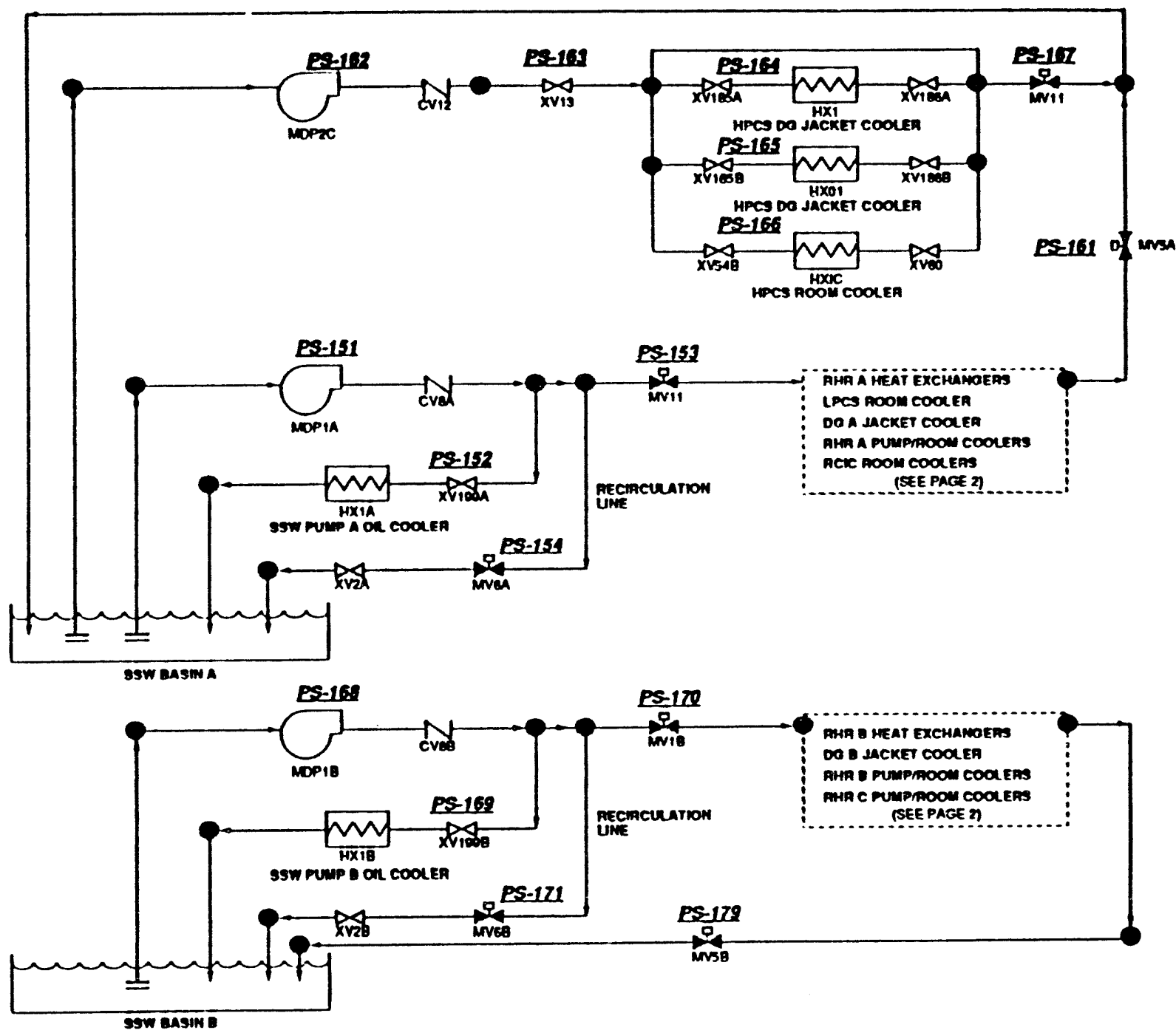

VALVE POSITIONS ARE SI TOWN W THEIR STANOBY MODE

FIGURE C.27. Standby Service Water System Schematic 


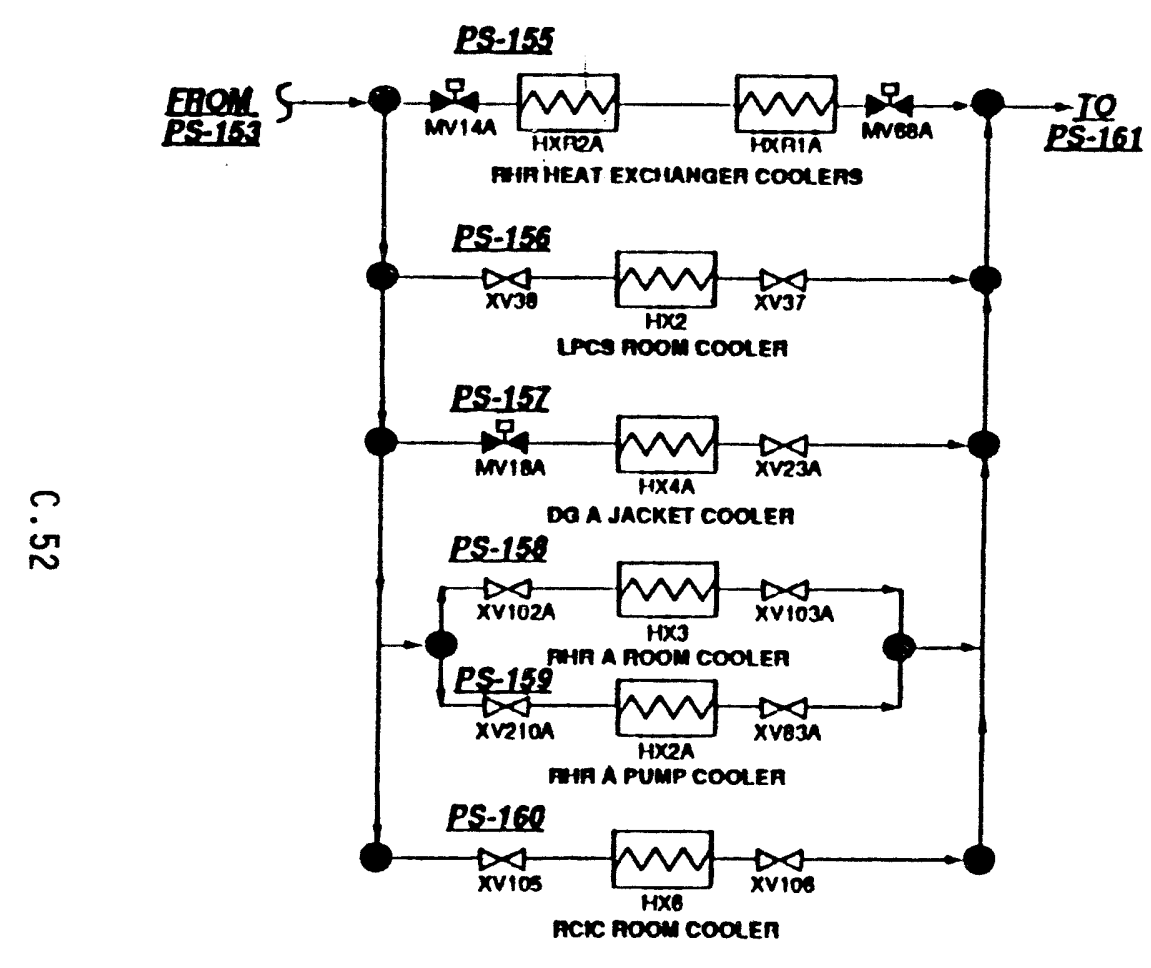

VALVE POSTTIONS ARE SHOWN IN THEIR STANDBY MODE

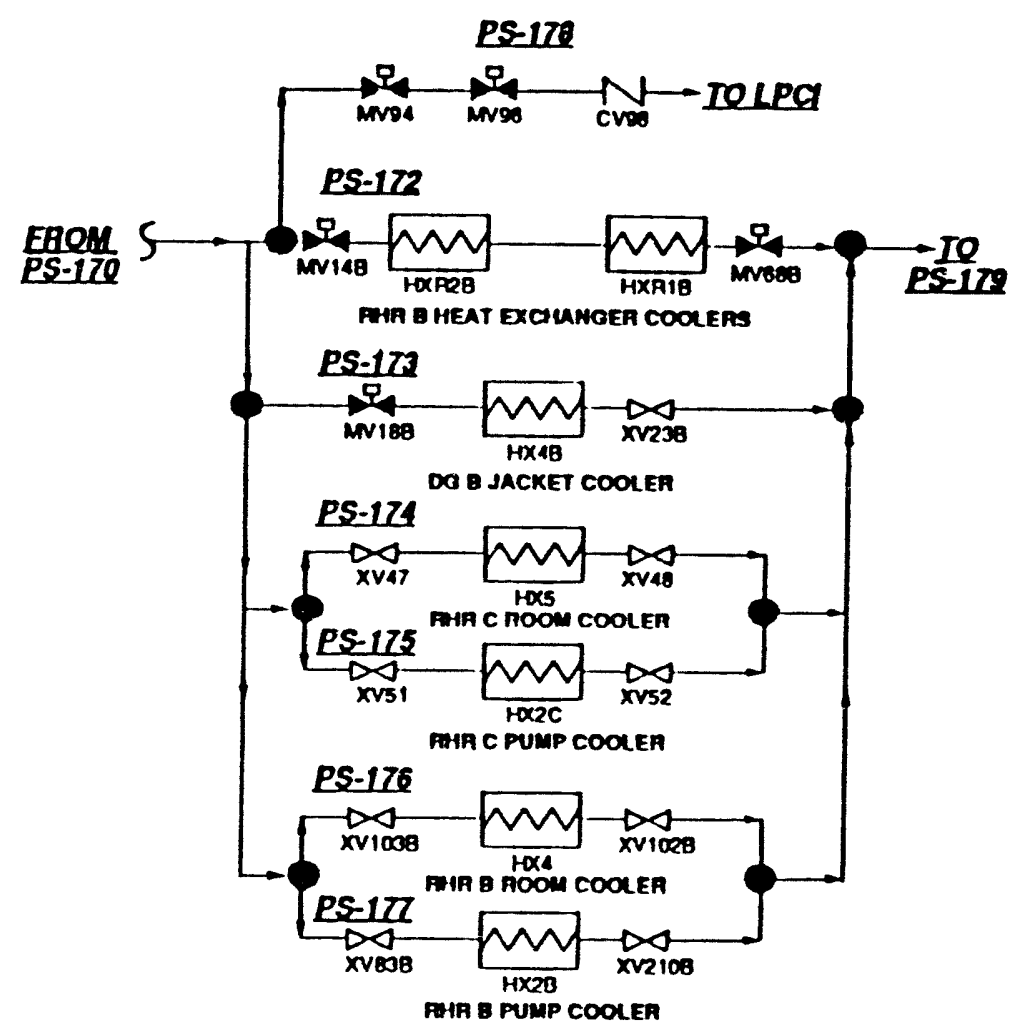

FIGURE C.27. (contd) 


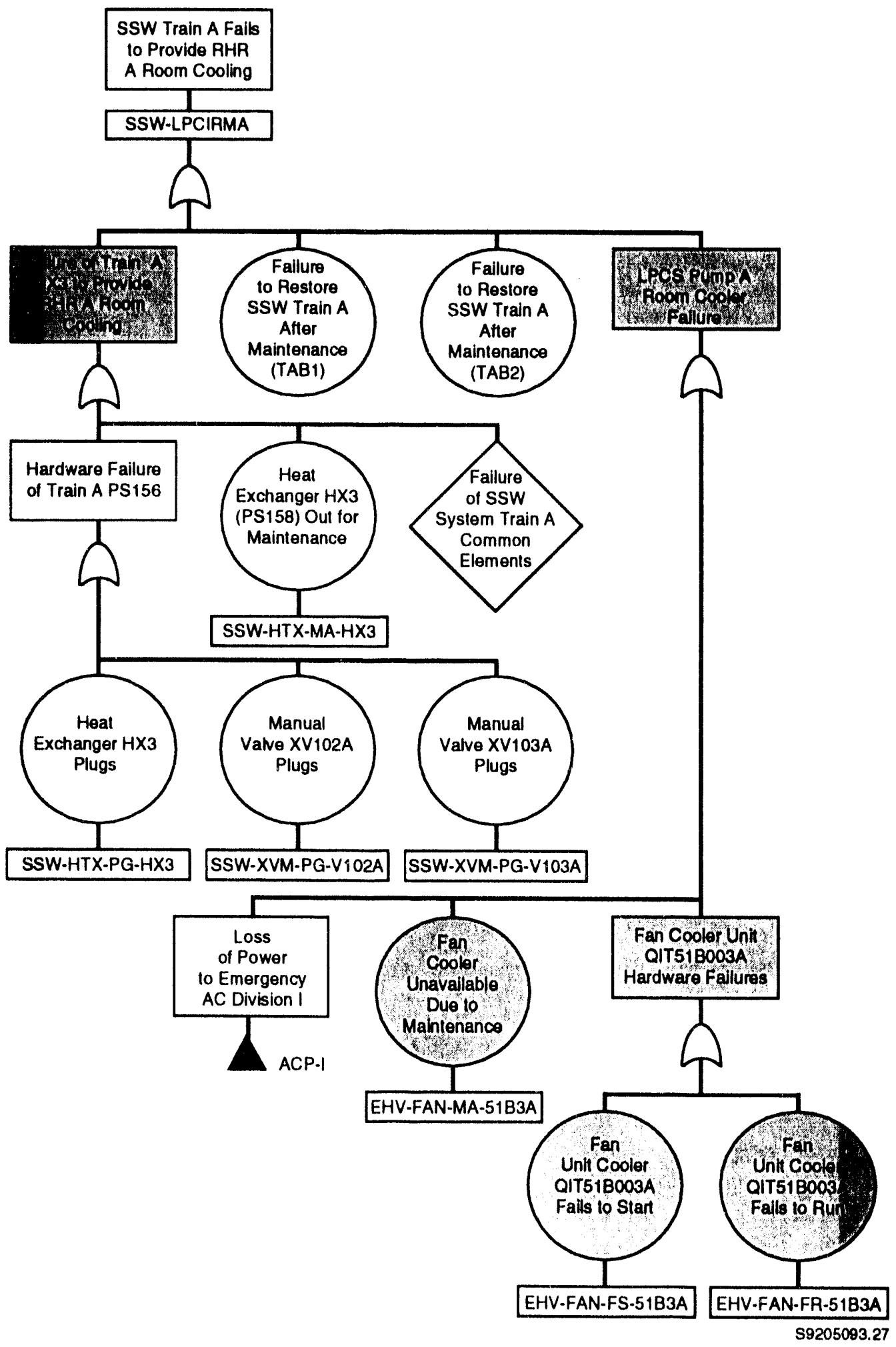

FIGURE C.28. RHR Pump A Room Cooling Fault Tree 


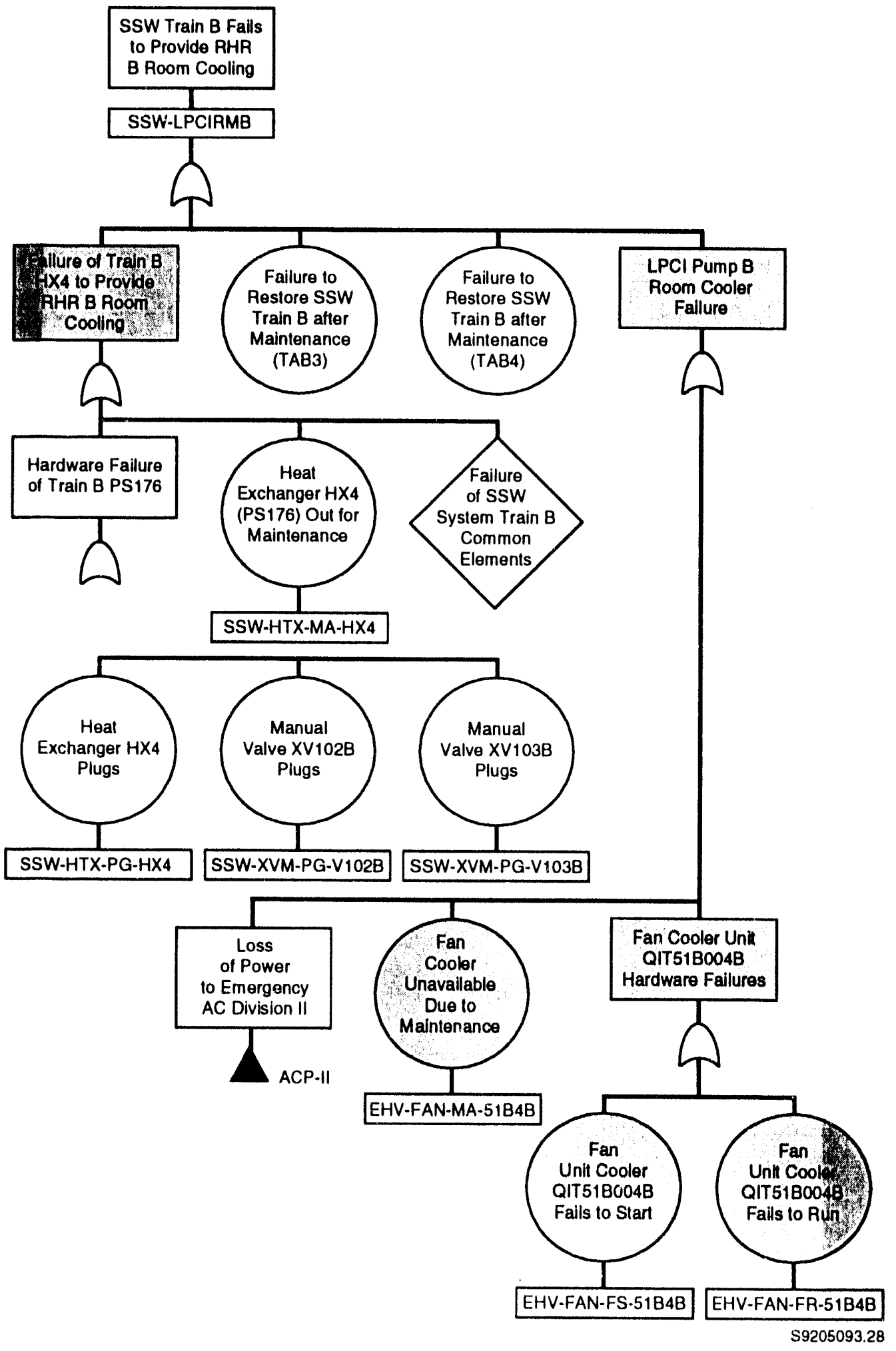

FIGURE C.29. RHR Pump B Room Cooling Fault Tree

C. 54 


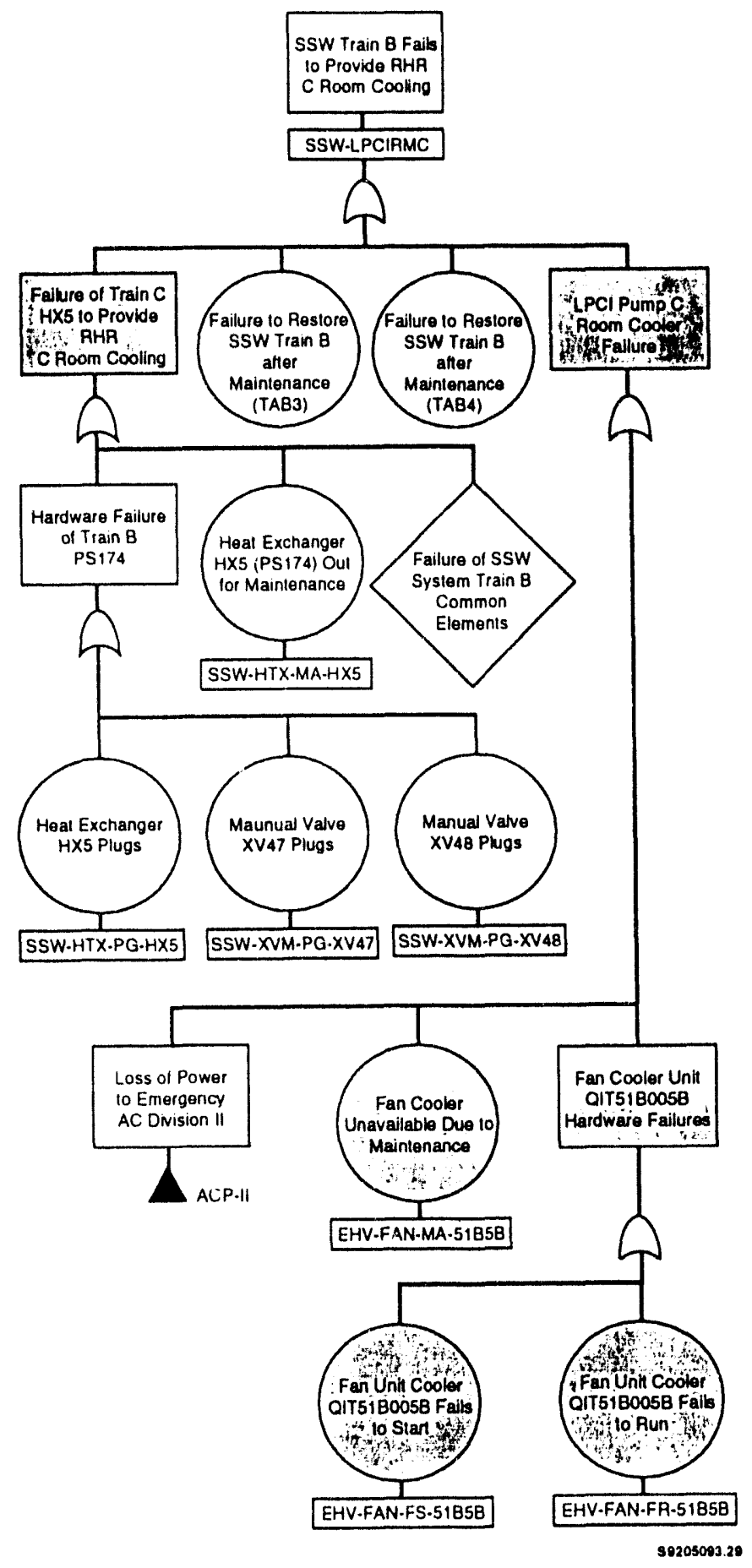

FIGURE C.30. RHR Pump C Room Cooling Fault Tree 


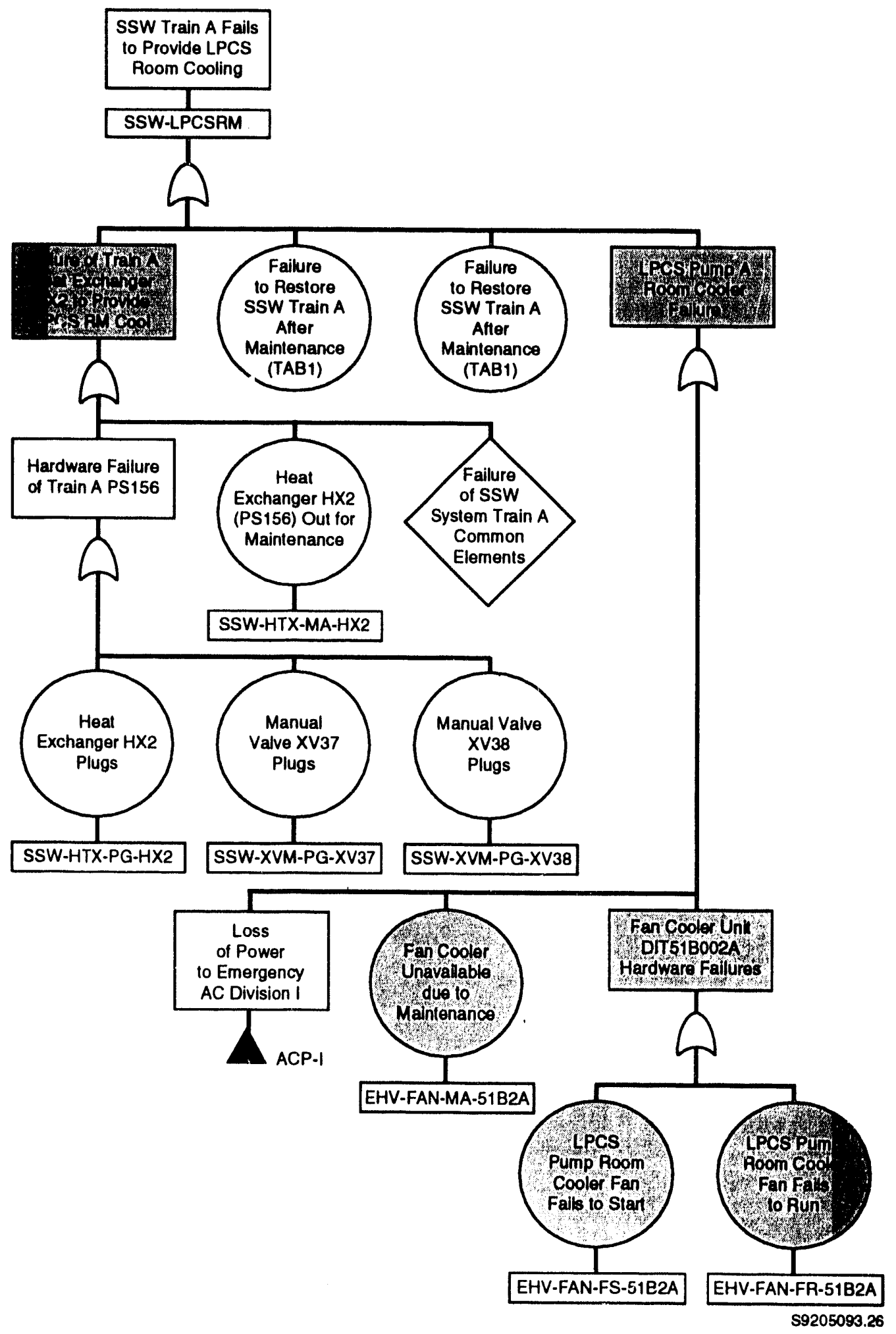

FIGURE C.31. Low-Pressure Core Spray Pump Room Cooling Fault Tree 


\section{C.2.18 Emergency Ventilating System.(EVS)}

The EVS maintains suitable temperatures in safety-related equipment rooms to prevent component failures. The EVS cools the following: 1) standby diesel generator rooms, 2) pump structure service water pump rooms, and 3) pump rooms for the ECCS, RCIC, HPCS, and LPCS systems. A schematic of the EVS is shown in Figure C.32.

Three independent subsystems, one per diesel generator room, each having $100 \%$ capacity, are provided for the emergency diesel generator rooms to maintain an indoor design temperature of $120^{\circ} \mathrm{F}$. Each diesel unit is provided with a fan damper system connected to the respective diesel engineered safety features bus. The fan is controlled to start on diesel generator startup and stop on diesel generator shutdown. The damper ofens on the same signals.

Each safety-related pump room is provided with one full-capacity fancoil unit to prevent the room temperature from exceeding $1500^{\circ} \mathrm{F}$ during pump operation. The SSW system provides cooling water for the fan-coil units. The units start automatically when the associated ECCS pump starts.

The ECCS pump room coolers are all cooled by the SSW system. The motive force for the fans for the RCIC, LPCS, and RHR-A pump room is provided by $A C$ Division 1. The fans for RHR-B and RHR-C pump rooms are powered by Division 2. The HPCS pump room fan is powered by HPCS dedicated AC Division 3.

Drouin et al. (1989) assumed that failure of the EVS would fail operating diesel generators in fifteen minutes. The low-pressure ECCS pumps were assumed to fail within four hours after loss of the associated room cooling. The HPCS and RCIC pumps were assumed to fail within 12 hours after loss of room cooling. Appendix $F$ describes calculated room heatup rates following loss of room cooling and subsequent failure rates at various temperatures for these components.

The EVS and SSW system work jointly to provide room cooling for the diesel generators and safety-related pumps. The simplified room cooling failure fault trees for the RHR A, B, and C, and LPCS pump rooms are developed under the SSW section. Room cooling failure fault trees in the diesel generator rooms, RCIC pump room, and HPCS pump room are shown in Figures C.33 through C.37.

\section{C.2.19 Instrument Äir System (IAS)}

The IAS provides a pneumatic supply to support operation of safetyrelated equipment. There are three units, each consisting of one fullcapacity, multistage, packed centrifugal compressor, complete with inlet filter, inlet air controller, and aftercooler. A schematic of the IAS is shown in Figure C.38. 


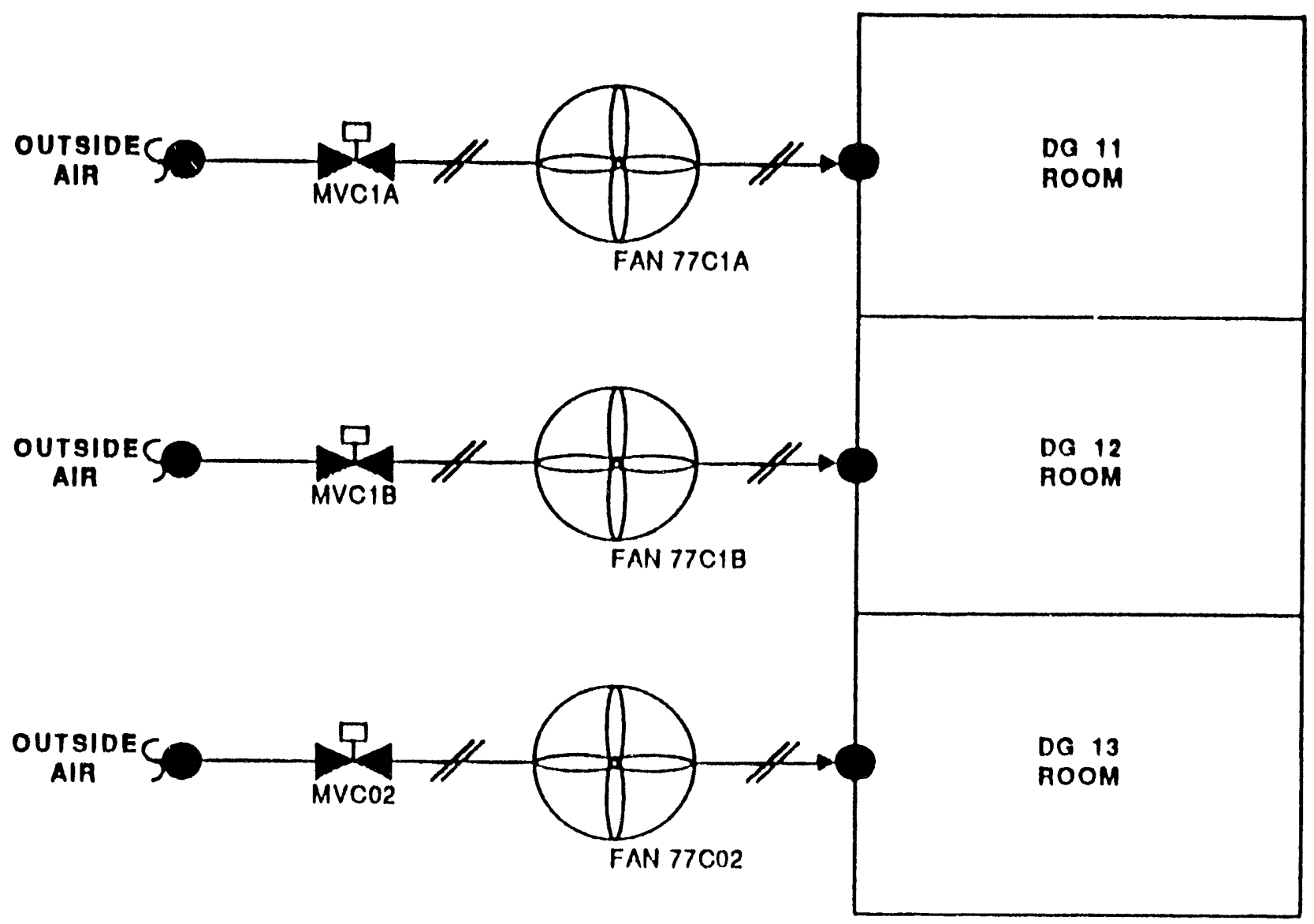

VALVE POSITIONS ARE SHOWN IN THEIR STANDBY MODE

FIGURE C.32. Emergency Ventilating System Schematic

The IASs of Units 1 and 2 can be connected by opening two AOVs from the control room. One instrument air compressor can supply all instrument air demands with the other compressor as a backup. The air-operated intertie valves fail open upon loss of air to their operators.

The service air system (SAS) is also arranged as an automatic backup supply to the IAS through a control valve that opens upon reduced line pressure in the IAS.

The Unit 1 IAS air compressor is powered from emergency AC Division 3. The Unit 2 IAS and the SAS air compressors are powered from nonsafety buses. Cooling requirements of the IAS and SAS air compressors and aftercooler are normally supplied by the nonsafety-related turbine building cooling water 


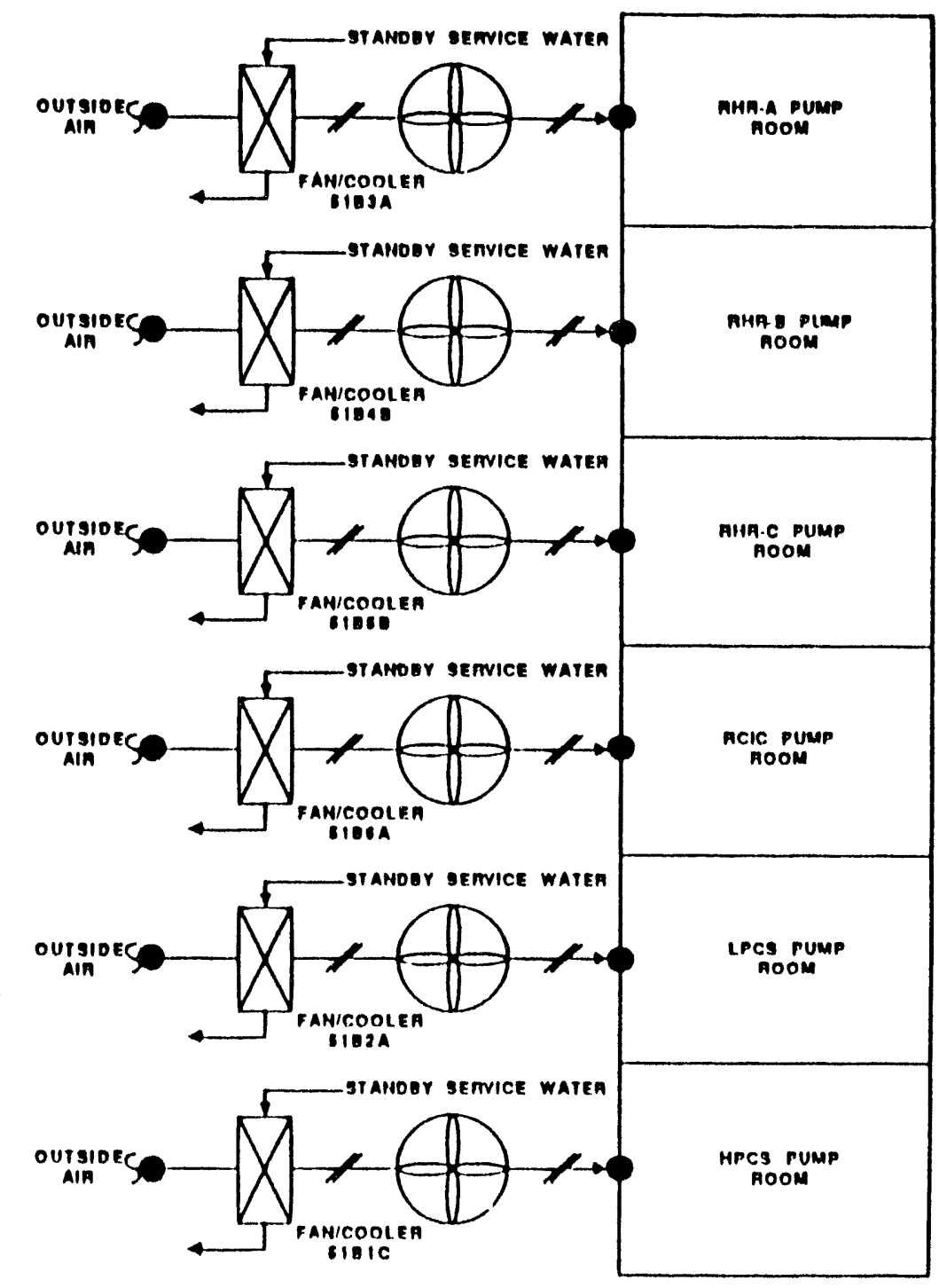

VALVE POSTIONS NAE SIIOWN W TIET STNIDBY MOOE

\section{FIGURE C.32. (contd)}

(TBCW) system. In the event of offsite power failure, the SSW system cools the air compressors and aftercoolers. No room cooling dependencies were identified.

\section{C.2.20 Reactor Protection System (RPS)}

The RPS provides protection against the onset and consequences of conditions that threaten the integrities of the fuel barrier and the nuclear system process barrier. 


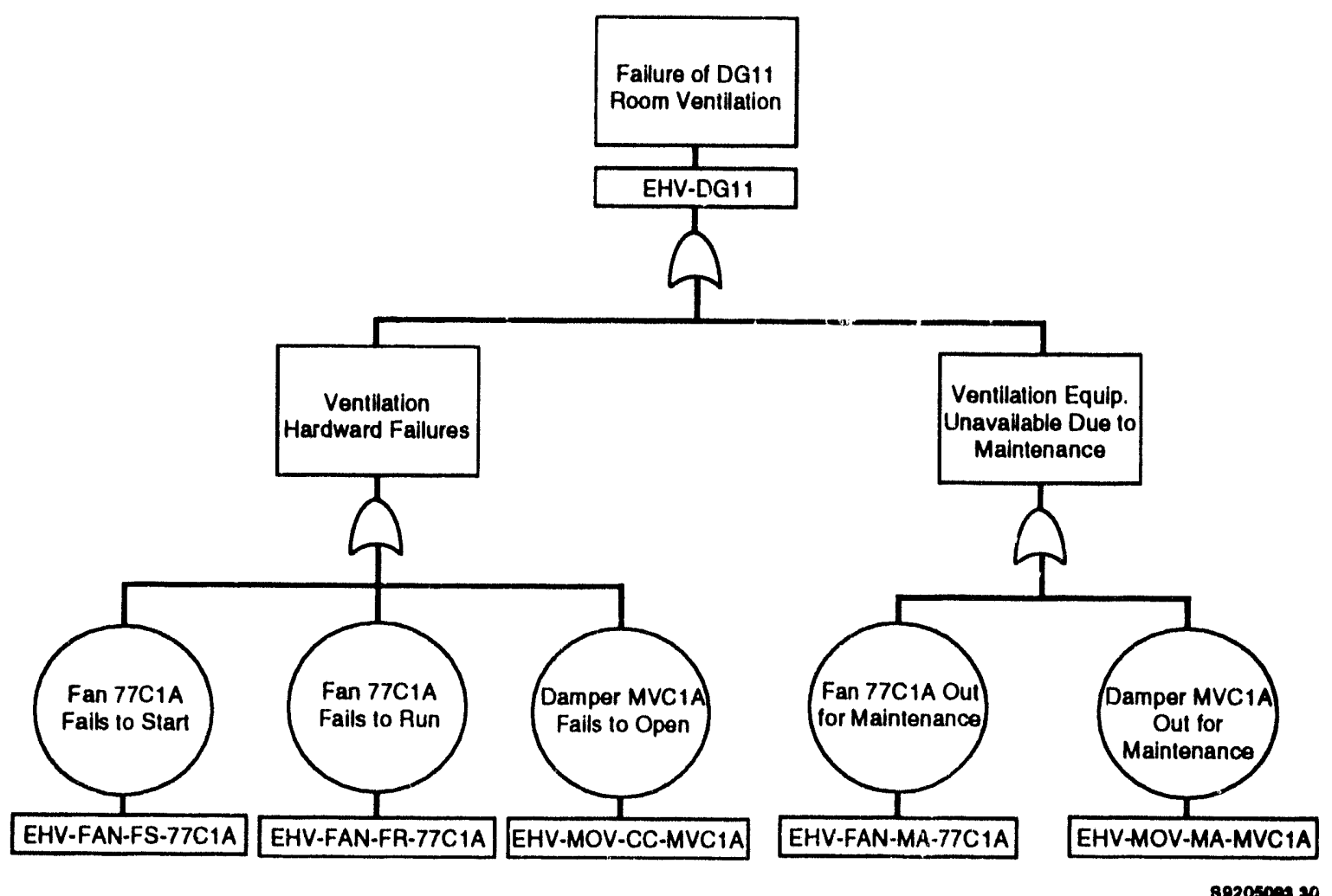

FIGURE C.33. Diesel Generator 1 Room Ventildtion Fault Tree

The RPS includes the motor-generated power supplies with associated control and indicating equipment, sensors, relays, bypass circuitry, and switches that cause rapid insertion of control rods (SCRAM) to shut down the reactor.

Power is supplied to each of the two reactor protection trip systems via a separate bus, by high-inertia, AC motor-generator sets. Alternate power is available to either RPS bus from nonessential instrument transformers. The alternate power switch prevents simultaneously feeding both buses from the same source. Power is not needed to SCRAM the reactor. There are no dependencies on any room cooling functions; therefore, fault trees were not developed for the RPS system.

\section{C.2.21 Standby Gas Treatment (SBGT) System}

The SBGT system limits the environmental release of radioisotopes, which can leak from either the containment or the fuel-handling area to the boundary area during accident conditions. This system does not provide an air-cooling function. 


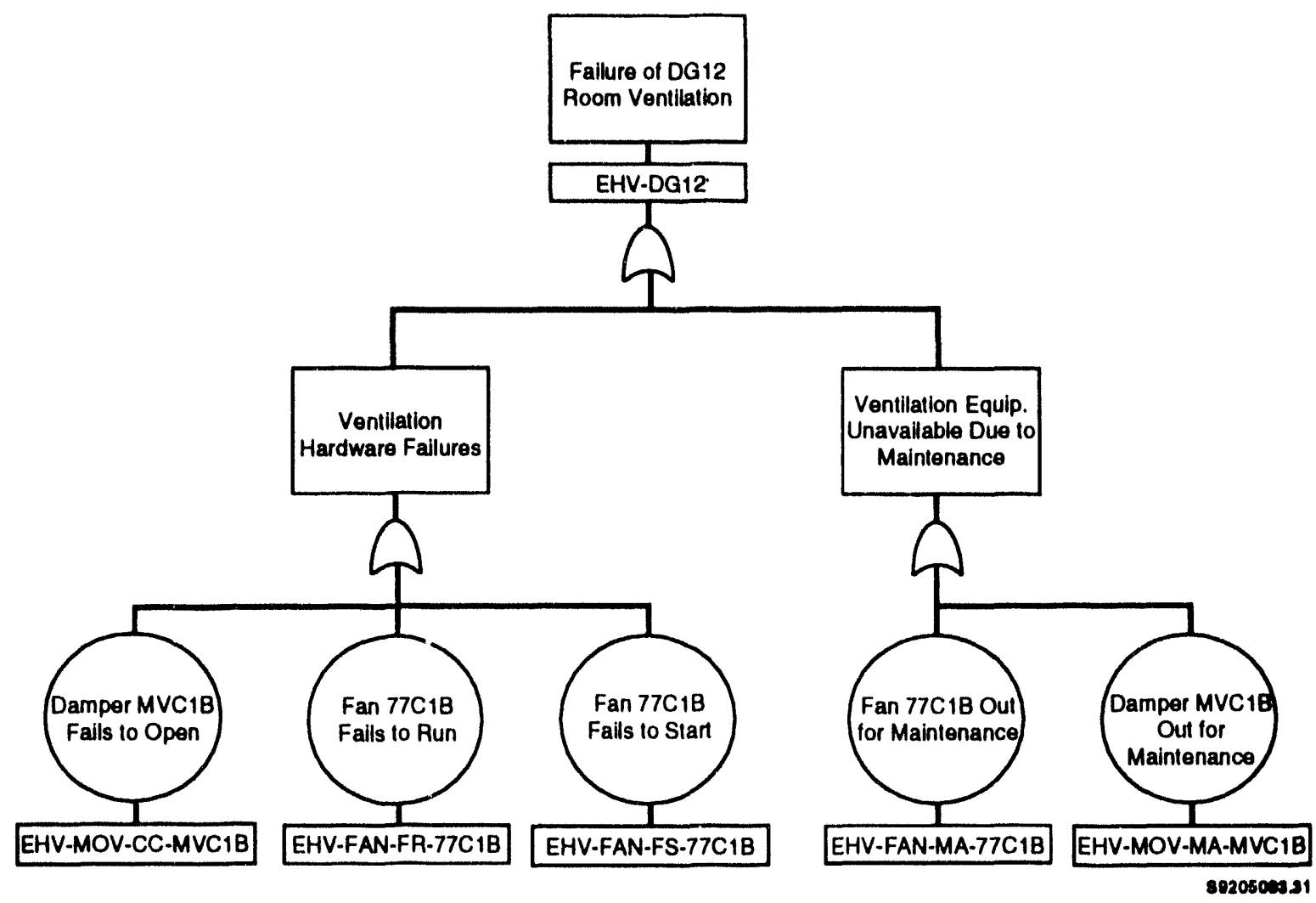

FIGURE C.34. Diesel Generator 2 Room Ventilation Fault Tree

The SBGT system draws air from within the Auxiliary Building, mixes this air with air from the enclosure building, and returns the mixed air to the upper enclosure building. A portion of this mixed air is then exhausted to the atmosphere through the exhaust filter trains to maintain the SBGT boundary at a negative pressure relative to the enclosure building.

The SBGT system includes two full-capacity enclosure building recirculation fans, two full-capacity exhaust fans, two full-capacity charcoal filter trains, and associated dampers, ducting, and controls. 


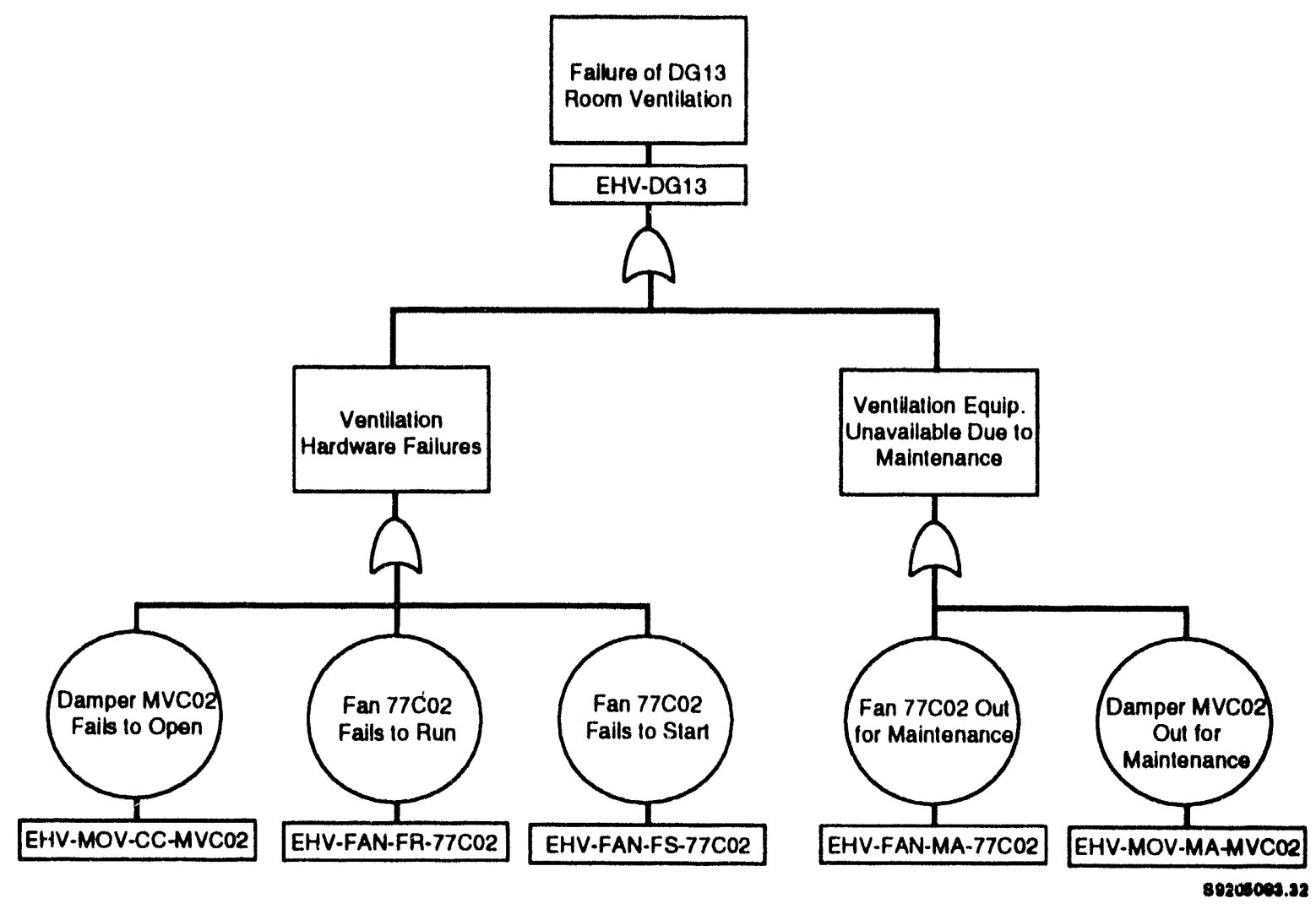

FIGURE C.35. Diesel Generator 3 Room Ventilation Fault Tree

The SBGT system fans require AC power to operate. One recirculation and exhaust fan is powered from Division 1 , and the other fans are powered from Division 3. The fans are loaded onto the emergency buses if offsite power is lost. There are no dependencies on any room cooling functions; therefore, fault trees were not developed for the SBGT system.

\section{C.2.22 Containment Isolation (CI) System}

The CI system provides the necessary isolation of the containment in the event of accidents or other conditions when the unfiltered release of containment contents cannot be permitted. This is accomplished by complete isolation of system lines penetrating the containment. Redundant valves are provided on all lines.

All values that are part of the $C I$ system depend on either $A C$ or $D C$ power to change positions; all air valves fail in the safe position on a loss of air. Electrical redundancy is provided in each isolation valve arrangement. This redundancy el iminates dependency on any one power source to attain isolation. There appear to be no dependencies on any room cooling functions, 


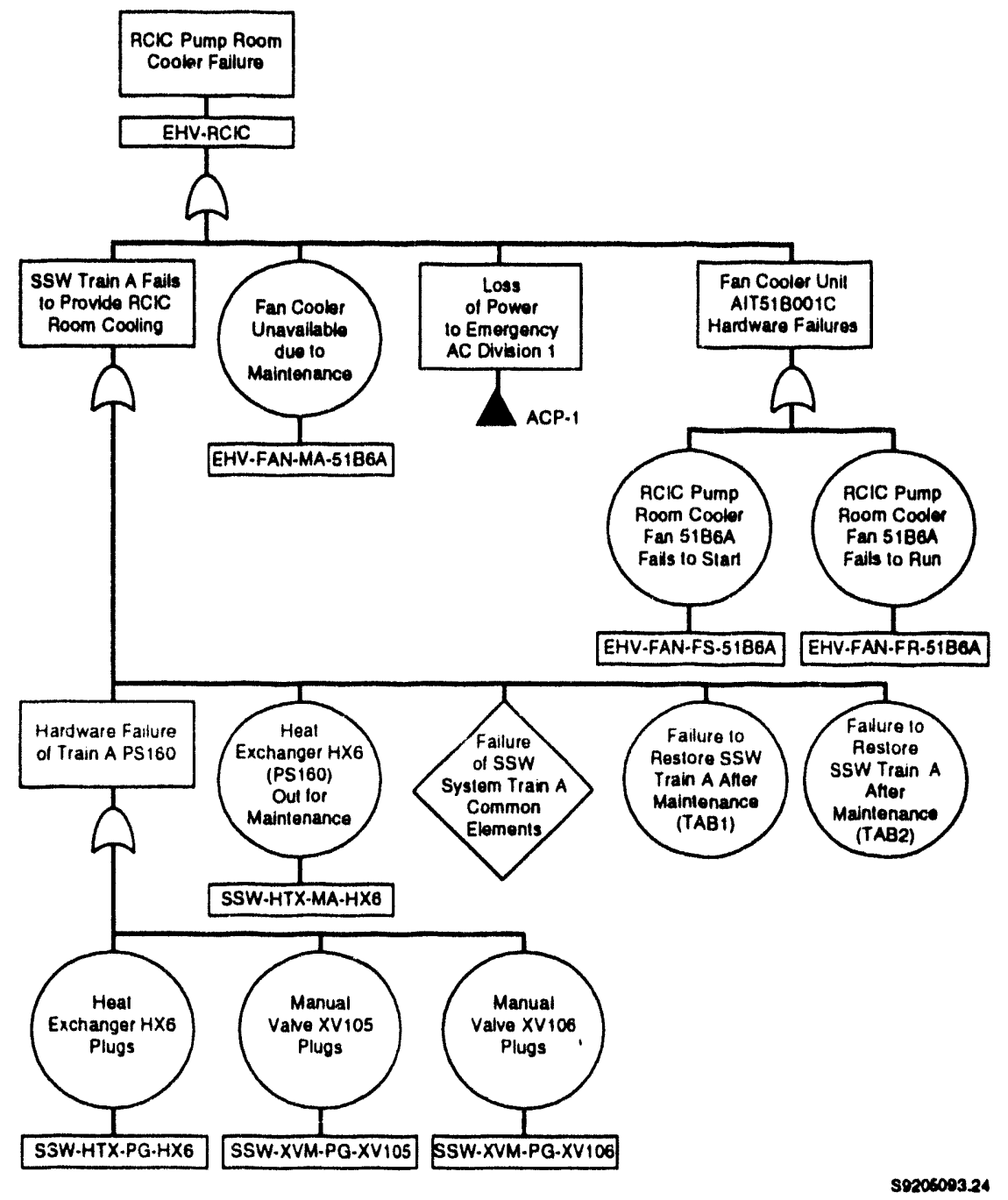

FIGURE C.36. RCIC Room Cooling Fault Tree

including containment HVAC systems. All valves are environmentally qualified to operate under severe containment temperature conditions, including conditions produced by LOCAs and main steam line breaks inside containment. Therefore, fault trees were not developed for the CI system.

\section{C.2.23 Hydrogen $\left(\mathrm{H}_{2}\right)$ Ignitor System}

The $\mathrm{H}_{2}$ ignitor system prevents the buildup of large quantities of hydrogen gas inside containment during accident conditions. This is accomplished by igniting, via a glow plug, small amounts of hydrogen before it has a chance to accumulate. 


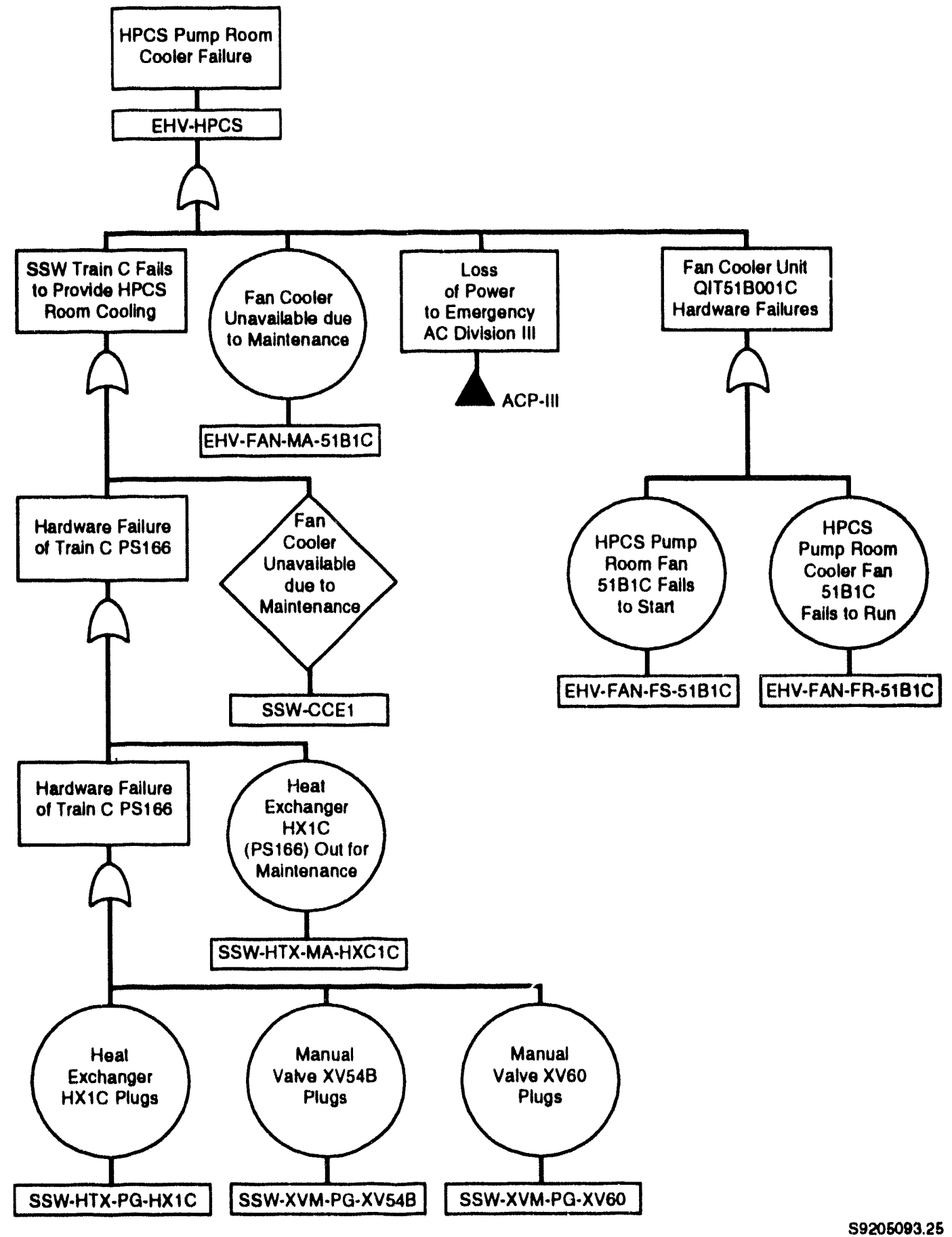

FIGURE C.37. HPCS Room-Cooling Fault Tree 
\&

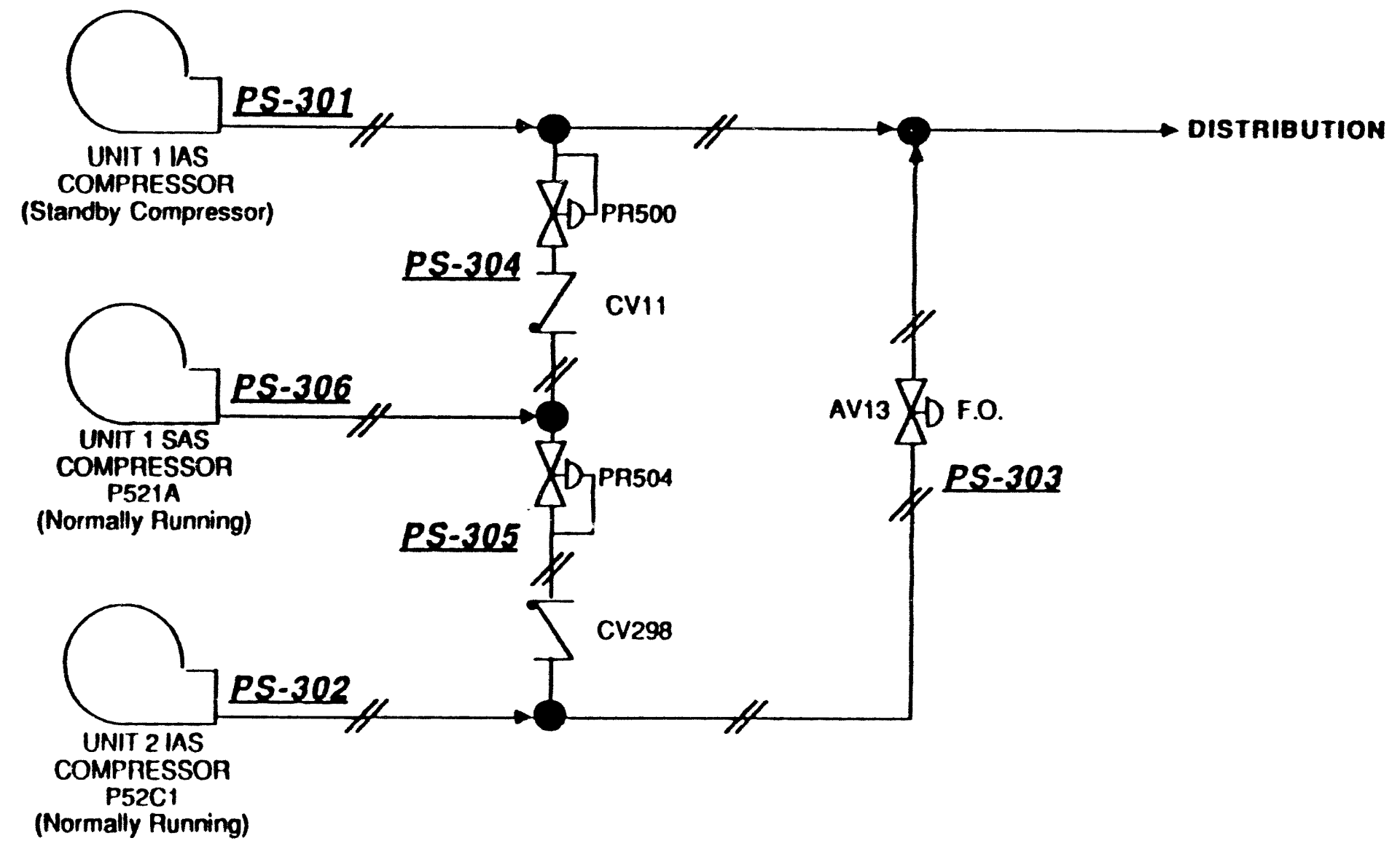

VALUE POSITIONS ARE SHOWN IN THEIR NORMALLY OPERATING MODE

FIGURE C.38. Instrument Air System Schematic 
The $\mathrm{H}_{2}$ ignitors have no major interfaces or dependencies except for $A C$ power. Redundancy in the system is provided so that fallure of any one division of $A C$ power will not fail the system. No dependencies on any room cooling functions were identified; therefore, fault trees ivere not developed for the $\mathrm{H}_{2}$ ignitor system.

\section{C.2.24 Heating, Ventilation, and Air Conditioning (HVAC) System}

The HVAC systems were not modeled as a contributor to the representative BWR core melt frequency. This was "... based on the degree of separation in the design of HVAC systems (at the representative BWR), the low heat loads in critical equipment areas such as the AC bus rooms, and the generally slow effects of loss of HVAC equipment which allow time for corrective action before a plant trip would occur (Drouin et al. 1989)." Although these observations are accurate, this study will evaluate the contributions of these systems to the overall CDF at the representative BWR, including the temperature rises in rooms following loss of HVAC, failure rates of components in the rooms when exposed to high temperatures, and the ability of plant operators to respond to loss of HVAC events.

\section{C.3 MINIMAL CUT SETS FOR THE REPRESENTATIVE BWR}

This section presents the dominant minimal cut sets containing HVAC and room cooling failures for the representative BWR. Table C.2 presents the accident sequences initiated by HVAC/room cooler failures, including failures of emergency switchgear room cooling, control room cooling, and DC equipment room cooling. Table C.3 provides the dominant cut sets that are initiated by failures other than HVAC/room cooling functions but which contain HVAC/room cooler failures as contributing events. This printout was created using the SARA computer code (Stewart et al. 1989). The cut sets are organized by accident sequence in the following order:

- Station Blackout (STABLA)

- Sequence 13

- Sequence 16

- Sequence 17

- Sequence 21

- Anticipated Transient Without SCRAM (ATWS)

In Table C.3, the basic events involving room cooler failures are identified in bold type.

\section{C.4 REFERENCES}

Drouin, M. T., et al. 1989. Analysis of Core Damage Erequency: Grand Gulf Unit l Internal Events. NUREG/CR-4550 Vol. 6, Rev. 1. Sandia National Laboratories, Albuquerque, New Mexico. 
Stewart, H. D., K. D. Russell, M. B. Sattison, W. W. Tullock, A. M. Espinosa, and M. A. Lenhart. 1989. Systems Analys is and Risk Assessment System (SARA) - Reference Manual, Version 4.0. NUREG/CR-5022 (EGG-2522), EG\&G Idaho Inc., Idaho Falls, Idaho. 
IABLE C.2. Minimal Cut Sets and Frequencies for Room Cooler Initiators

CONE DAMACE FREQUENCY CALCULATIOMS

No.

LSS OF BMERGENCY SWTTCHOENR ROOM COOUNO

TSW RSW ADS-XHE-ACT-MAN CRD-XHE-FO-MDPB ESF-CCF-MC-DPRES HCS-ICC-FT-MV12 TSW RSW ADS-XHE-ACT-MAN CRO-XHE-FO-MDPB ESF-CCF-MC-DPRES HCS-LOG-NO-HPCS

TSW RSW ADS-XHE-ACT-MAN CRD-XHE-FO-MDPB ESF-CCF-MC-DPRES HCS-MDP-FS-MDP1 TSW RSW ADS-XHE-ACT-MAN CRD-XHE-FO-MDPB ESF-CCF-MC-DPAES HCS-MDP-MA-MDP1 TSW RSW ADS-XHE-ACT-MAN CRO-XHE-FO-MDPB ESF-CCF-MC-DPRES HCS-MOV-CC-MV12 TSW RSW ADS-XHE-ACT-MAN CRD-XHE-FO-MOPB ESF-CCF-MC-DPRES HCS-MOV-CC-MVA TSW RSW AOS-XHE-ACT-MAN CRD-XHE-FO-MDPB ESF-CCF-MC-DPFES HCS-MOV-OO-MY1 TSW RSW ADS-XHE-ACT-MAN CRD-XHE-FO-MDPB ESF-CCF-MC-VSLVL HCS-ICC-FT-MV12 TSW RSW ADS-XHE-ACT-MAN CFO-XHE-FO-MDPB ESF-CCF-MC-VSLV HCS-CCC-TT-MV12 TSW RSW ADS-XHE-ACT-MAN CRD-XHE-FO-MDPB ESF-CCF-MC-VSLV HCS-LOG-NOHPCS TSW RSW ADS-XHE-ACT-MAN CRD-XHE-FO-MDPB ESF-CLF-MC-VSLM HCS-LOG-NO-HPCS TSW RSW ADS-XHE-ACT-MAN CRD-XHE-FOMDPB ESF-CCF-MC-VSLVL HCS-MDP-FR-MDPP TSW RSW ADS-XHE-ACT-MAN CRD-XHE-FO-MDPB ESF-CCFMC-VSLY HCS-MDP-FS-MDP1 TSW RSW ADS-XHE-ACT-MAN CRD-XHE-FO-MDPB ESF-CCF-MC-VSLV HCS-MDP-FS-MDP1 TSW RSW ADS-XHE-ACT-MAN CRD-XHE-FO-MDPB TSW RSW ADS-XHE-ACT-MAN CRD-XHE-FO-MDPB TSW RSW ADS-XHE-ACT-MAN CRD-XHE-FO-MDPB TSW RSW ADS-XHE-ACT-MAN CRD-XHE-FO-MDPB TSW RSW ADS-XHE-ACT-MAN CFD-XHE-FO-MDPB TSW REW ADS-XHE-ACT-MAN CRD-XHE-FO-MDPE TSW RSW ADE-XHE-ACTAMN CRD-XHEFO-MOPB TSW RSW ADS-XHE-ACT HEN CFE-XHE-FOMOPDE TSW REW ADS-XHE-ACT MAN CRD-XHE-FO-MDPB TSW RSW ADS-XHE-ACT-MAN CPD-XHE-FO-MDPB TSN RSW ADS-XHE-ACT-MAN CRD-XHE-FO-MDPE TSW RSW AOS-XHE-ACT-MAN CRD-XHE-FO-MDPB TSW RSW ADS-XHE-ACT-MAN CRO-XHE-FO-MDPE TSW RSW ADS-XHE-ACT-MAN CRD-XHE-FO-MDPB TSW RSW ADS-XHE-ACT-MAN ESF-CCF-MC-DPRES TSW RSW ADS-XHE-ACT-MAN ESF-CCF-MC-DPPES TSW RSW ADS-XHE-ACTMAN ESF-CCF-MC-DPRES HCS-MDPMA-MDP1 LOCA-SIGNAL TSW RSW ADS-XHE-ACT-MAN ESF-CCF-MC-DPRES HCS-MOV-CC-MV12 LOCA-SIGNAL TSW RSW ADS-XHE-ACT-MAN ESF-CCF-MC-DPRES HCS-MOV-CC-MV4 LOCA-SIGNAL

\section{RA-INJ-1HR}

RA-INJ-1HR

RA-INU-1HR

RA-INJ-1HR

RA-NNJ-1HR

RA-INJ-1HR

RA-INJ-1HR

RA-NNJ-1HR

RA-INJ-1HR

RA-INJ-1 HR

RA-INJ-1HR

RA-INU-PHR

RA-NU-1HR

RA-NNS-1HR

RA-INN-1HA

PAANN-1 HR

PATNJ-1HR

PA-NNJ-1HR

RA-INJ-1HR

RA-INU-1HR

RAENA-THR

RA-NU-1HR

RA-INJ-1HR

RA-INJ-1HR

PA-INJ-1HR

RA-PCS-1HR

RAPCS-1HR

RA-PCS-1HR

RA-INJ-1HR

PA-INJ-1HA

RA-INJ-1HR

RA-INJ-1HR

RA-INJ-1HR

RA-INJ-1HR
RA-PCS-1HA RA.PCS-1HA

RA-PCS-1HR RA-PCS-1HR PA.PCS-1HR RA-PCS-1HR RA.PCS-1HR PA-PCS-1HR RA-PCS-1HR RA-PCS-1HA AA-PCS-1HA PA-PCS-1HR RA-PCS-1HR PA-PCS-1HR RA-PCS-1HR RA-PCS-1HR RAPCS-1HR RA-PCS.1HA PA-PCS-1HR RA-PCS-IHA RAPCS-1HA PAPCS-1HR RAPCS-1HR AAPCSIHA RA-PCS-1HR RXINS-XHE-ADS RXINJ-XHE-ADS RXINU-XHE-AOS RA-PCS-1MR RA-PCS-1HR PA.PCS-1HR RA-PCS-1HR RA-PCS-1HR RA-PCS-1HA
ACI-TOP-FR-TDP1 RXINU-XHE-ADS ACI-TDPFATDP1 RXINJ-XHE-ADS RCL-TDP-FR-TOP1 RXINJ-XHE-ADS RCI-TDP-FR-TDP1 RXINU-XHE-ADS RCI-TDP-FR-TDPI RXINJ-XHE-ADS ACI-TDPFFTTDP1 RXINJ-XHE-ADS RCI-TDP-FR-TDP1 RXINJ-XHE-ADS BCI-TDP-FP-TDP1 RXINU-XHE-ADS RXINU-XHE-ADS RXINU-XHE-ACKC ACI-TDP-FFTDP1 RXINJ-XHE-ADS RXINJ-XHE-ADS RXINJ-XHE-ACIC RXINU-XHE-ADS RXINJ-XHE-ACIC ACL-TDP-FP-TDP1 RXINU-XHE-ADS RXINJ-XHE-AOS RXINU-XHE-PCIC ACL-TDPFARTDP1 PXXNU-XHE-ADS RXINU-XHE-ADS RXINJ-XHE-ACIC AC1-TDPFP-TDP1 PXINJ-XHE-ADS RXINU-XHE-ADS RXXNJ-XHE-ACKC ACL-TDP-FR-TDP1 RXINJ-XHE-ADS

RXINU-XHE-ADS RXINJ-XHE-ACIC PXNU-XHE-AOS RXONH-XHE-ACC RXINU-XHE-ADS PXXWU-XHEFACIC RCL-TDPFATDP1 RXINJ-XHE-ADS RXXINJ-XHE-ADS RXINH-XHE-PCIC RXINU-XHE-ADS RXINJ-XHE-FCIC RXINJ-XHE-ACIC SSW-HTX-PGHX RXINJ-XHE-ACIC SSW-MOP-FE-MOP RXNJ-XHE-ACIC SSW-MOV-MA-M ACI-TDP-FR-TDP1 RXINJ-XHE-ADS RCI-TDPFF-TDP1 RXINJ-XHE-ADS RCI-TDPFAR-TDP1 RXINJ-XHE-ADS ACL-TDP-FR-TDP1 RXINJ-XHE-ADS ACL-TDP-FR-TDP1 RXINJ-XHE-ADS ACL-TDP-FR-TDP1 RXINJ-XHE-ADS
Cur Set Frequeney

3.079E-10

3.D79E-10

3.079E-10

3.079E-10

3.078E-10

3.079E-10

3.079E-10

3.079E-10

$2.566 E-09$

3.079E-10

$2.666 E-\infty$

$2.568 E-0 \theta$

3.079E-10

2.666E-00

$3.079 E-10$

2.666E-00

$3.079 E-10$

2.666e-

3.079E-10

2.666E-00

$2.5065-00$

2.666E-0

3.079E-10

2.666E-OO

2.686E-C9

6.702E-O

2.668E-11

2.568E-11

3.079E-10

3.078E-10

3.079E-10

3.07eE-10

3. $079 \mathrm{E}-10$ 
RA-INJ-1HR RA-INJ-THR RA-INJ-1HF RA-INJ-1HR RA-INJ-1HR RA-INJ-1HR RA-INJ-1HR RA-INJ-1HR RA-INJ-1HR RA-INJ-1HR

AAINIIHA

RA-INS-1HF

RA-INJ-1KA

RA-INJ-1HF

RA-INJ-1HA

RA-INJ-THR

RA-INJ-1HA

RA-INJ-1HF

RA-INJ-1HR

RAPCS-1HR

IAS-XHEFOIAS

IAS-XHEFOIAS

AA-INJ-1 1 HA RA-INJ-1H

RA-INJ-1HRA RA-INJ-1HR

RA-NNJ-IHA RA-INJ-1HR

RA-INJ-1HR

RA-INU-1 HR

RA-INJ-1HR

RA-INU-THR

RA-INJ-THF

RA-INJ-1HR

RA-INJ-1 1 HP

RA-INJ-1 HA

RA-INJ-1HA

RA-INJ-1HA

RA-NNJ-1HR

RA-IN]-3HP

RA-INJ-1HR

RA-NJ-1HP
RA-PCS-1HR RA-PCS-1HR

RA.PCS-1HR RA-PCS-1HA RAPCS-1HR RA-PCS-1HRR RA-PCS-1HR RA-PCS-1HP RA-PCS-1HA RA-PCS-1HA RA-PCS-1HR MA-PCS-1HR RAPCS-1HR AA.PCS-1HR RA.PCS-1HR RA-PCS-1HR RA.PCS-1HP RA-PCS-1HR RXINJ-XHE-AOS PXINJ-XHE-ADS RA-INU-1HR RA-INS-1HP

AA-PCS-1HR RA.PCS-1HP

RA-PCS-1H

RA.PCS-1HR

RA.PCS-1HR PA-PCS-1HR

RA-PCS-1HR RA-PCS-1HRR RA-PCS-1HR PA-PCS-1HR RA.PCS-1HR RA-PCS-1HA RA-PCS-1H RA-PCS-1HR RA-PCS-1HP

RA-PCS-1HP RA-PCS-1HR RAPCS-1HF RA-PCS-1HR RA-PCS-1HA
RXINJ-XHE-ADS RXINH-XHE-RCIC RCI-TDP-FR-TDP1 RXINJ-XHE-ADS RXINJ-XHE-ADS RXINJ-XHE-PCIC RXINJ-XHE-ADS RXINJ-XHE-RCIC CI-TDP-FR-TDP1 RXIIJJ-XHE-ADS RXINS-XHE-ADS RXINS-XHE-PC RCI-TDP-FR-TDP1 RXINJ-XHE-ADS RXINJ-XHE-ADS RXINJ-XHE-ACIC RCI-TDP-FP-TDP1 RX'NJ-XHE-ADS RXINJ-XHE-ADS RXINU-XHE-ACIC RCI-TDP-FR-TDP1 RXINJ-XHE-ADS RXINJ-XHE-ADS RXINJ-XHE-RCIC RXINJ-XHE-ADS RXINJ-XHE-ACIC RXINJ-XHE-ADS RXINJ-XHE-ACIC RCI-TDP-FR-TDP1 RXINJ-XHE-ADS RXINJ-XHE-ADS RXINJ-XHE-RCIC RXINJ-XHE-ADS RXINJ-XHE-ACIC PXINJ-XHE-ACIC SSW-HTX-PG-HX RXINJ-XHE-ACIC SSW-MDP-FS-MDP RA-PCS-1HR RCI-TDP-FR-TOP RA-PCS-1HR RCI-TDP-FR-TDP TOTAL TSW

RCI-TDP-FA-TDPT RXINJ-XHE-ADS RCI-TDP-FR-TDP1 RXINJ-XHE-ADS ACI-TOP-FR-TDP1 RXINJ-XHE-ADS RCL-TDP-FR-TDPT RXINU-XHE-ADS RCI-TDP-FR-TDP1 RXINJ-XHE-ADS RCI-TDP-FR-TDPI PXINJ-XHE-ADS RCI-TDP-FR-TDP1 XINJ-XHE-ADS C1-TDP-FR-TDP1 RXINJ-XHE-ADS RXINJ-XHE-ADS RXINU-XYHE-ACIC RCL-TDP-FA-TDP1 PXINU-XHE-ADS XINU-XHE-ADS RXINJ-XHE-ACI RXINJ-XHE-ADS RXINJ-XHE-ACIC PCLTDP-FA-TDP1 RXINU-XHE-ADS RXINJ-XHE-ADS RXINU-XHE-ACIC ACL-TOP-FA-TOPT RXINU-XHE-ADS RXINJ-XHE-ADS RXINU-XHE-ACIC PCI-TDR-FR-TDP1 PXINU-XHE-ADS RXINJ-XHE-ADS RXINJ-XHE-RCK RCI-DDP-FA-TDP1 RXINU-XHE-ADS RXINJ-XHE-AOS PXXINJ-XHE-ACIC
3.079E-10 3.079E-10

2.666E-09

$3.079 E-10$

$2.686 E-09$

$2.688 E-00$

$3.079 E-10$

2.568E-DO

$3.078 \mathrm{E}-10$

2.686E- -9

$3.079 E-10$

2.600E-00

$3.079 E-10$

2.666E-09

$2.568 E-08$

$2.666 E-00$

$3.079 E-10$

2.686E- 09

$2.666 E-09$

$2.666 E-09$

2.568E-09

3.079E-10

$3.079 E-10$

$1.279 E-07$

7.090E-10

7.090E-10

7.080E-10

$7.080 \mathrm{E}-10$

7.000E-10

7.000E-10

7.000E-10

7.000E-10

6.008E-00

7.000E-10

$6.800 E-\infty 0$

6.800E- -0

7.000E-10

6.800E- $\infty$

7.000E-10

6.000E- -0

7.000E-10

6.908E- 00

7.000E-10

6.008E-00 
TABLE C.2. (contd)

Cut Ser Elements and Probabilities

Cut Set Frequency No.

TCR RCR ADS-XHE-ACT-MAN CRD-XHE-FO-MDPB ESF-CCF-MC-VSLVL HCS-MOV-MA-MV12 A-INJ-1HR TCR RCR ADS-XHE-ACT-MAN CRD-XHE-FO-MDPB ESF-CCF-MC-VSLVR HCS-MOV-MA-MV4 RA-INJ-1HR TCR ACR ADS-XHE-ACT-MAN CRD-XHE-FO-MDPB ESF-CCF-MC-VSLVL HCS-MOV-OO-MV1 TCR RCR ADS-XHE-ACT-MAN CRD-XHE-FO-MDPB ESF-CCF-MC-VSLVL HCS-MOV-OO-MV1 TCR RCR ADS-XHE-ACT-MAN CRD-XHE-FO-MDPB ESF-CCF-MC-VSLVL HCS-XHE-RE-HPCS TCR RCR ADS-XHE-ACT-MAN CRD-XHE-FO-MDPB ESF-CCF-MC-VSLVL RA-INJ-1HR TCR RCR ADS-XHE-ACT-MAN CRD-XHE-FO-MDPB ESF-CCF-MC-VSLVL RA-INJ-1HR TCR RCR ADS-XHE-ACT-MAN CRD-XHE-FO-MDPB ESF-CCF-MC-VSLVL RA-INJ-1HR TCR RCR ADS-XHE-ACT-MAN ESF-CCF-MC-DPRES HCS-ICC-FT-MV12 LOCA-SIGNAL TCR RCR ADS-XHE-ACT-MAN ESF-CCF-MC-DPRES HCS-LOG-NO-HPCS LOCA-SIGNAL TCR RCR ADS-XHE-ACT-MAN ESF-CCF-MC-DPRES HCS-MDP-FS-MDP1 LOCA-SIGNAL TCR RCR ADS-XHE-ACT-MAN ESF-CCF-MC-DPRES HCS-MDP-MA-MDP1 LOCA-SIGNAL TCR RCR ADS-XHE-ACT-MAN ESF-CCF-MC-DPRES HCS-MOV-CC-MV12 LOCA-SIGNAL TCR RCR ADS-XHE-ACT-MAN ESF-CCF-MC-DPRES HCS-MOV-CC-MV4 LOT.A-SIGNAL TCR RCR ADS-XHE-ACT-MAN ESF-CCF-MC-DPRES HCS-MOV-OO-MV1 LOCA-SIGNAL TCR RCR ADS-XHE-ACT-MAN ESF-CCF-MC-VSLVL HCS-ICC-FT-MV12 LOCA-SIGNAL TCR RCR ADS-XHE-ACT-MAN ESF-CCF-MC-VSLVL HCS-ICC-FT-MV12 LOCA-SIGNAL TCR RCR ADS-XHE-ACT-MAN ESF-CCF-MC-VSLVL HCS-LOG-NO-HPCS LOCA-SIGNAL TCR RCR ADS-XHE-ACT-MAN ESF-CCF-MC-VSLVL HCS-LOG-NO-HPCS LOCA-SIGNAL TCR RCR ADS-XHE-ACT-MAN ESF-CCF-MC-VSLVL HCS-MDP-FR-MDP1 LOCA-SIGNAL TCR RCR ADS-XHE-ACT-MAN ESF-CCF-MC-VSLVL HCS-MDP-FS-MDP1 LOCA-SIGNAL TCR RCR ADS-XHE-ACT-MAN ESF-CCF-MC-VSLVL HCS-MDP-FS-MDP1 LOCA-SIGNAL TCR RCR ADS-XHE-ACT-MAN ESF-CCF-MC-VSLVL HCS-MDP-MA-MDP1 LOCA-SIGNAL TCR RCR ADS-XHE-ACT-MAN ESF-CCF-MC-VSLVL HCS-MDP-MA-MDP1 LOCA-SIGNAL TCR RCR ADS-XHE-ACT-MAN ESF-CCF-MC-VSLV HCS-MOV-CC-MV12 LOCA-SIGNAL TCR RCR ADS-XHE-ACT-MAN ESF-CCF-MC-VSLVL HCS-MOV-CC-MV12 LOCA-SIGNAL TCR RCR ADS-XHE-ACT-MAN ESF-CCF-MC-VSLVL HCS-MOV-CC-MV4 LOCA-SIGNAL TCR RCR ADS-XHE-ACT-MAN ESF-CCF-MC-VSLVL HCS-MOV-CC-MY/4 LOCA-SIGNAL TCR RCR ADS-XHE-ACT-MAN ESF-CCF-MC-VSLVL HCS-MOV-MA-MV12 LOCA-SIGNAL TCR RCR ADS-XHE-ACT-MAN ESF-CCF-MC-VSLVL HCS-MOV-MA-MV4 LOCA-SIGNAL TCR RCR ADS-XHE-ACT-MAN ESF-CCF-MC-VSLVL HCS-MOV-OO-MV1 LOCA-SIGNAL TCR RCR ADS-XHE-ACT-MAN ESF-CCF-MC-VSLVL HCS-MOV-OO-MVI LOCA-SIGNAL TCR RCR ADS-XHE-ACT-MAN ESF-CCF-MC-VSLVL HCS-XHE-RE-HPCS LOCA-SIGNAL TCR RCR ADS-XHE-ACT-MAN ESF-CCF-MS-VSLVL LOCA-SIGNAL RA-INJ-1HR TCR RCR ADS-XHE-ACT-MAN ESF-CCF-MS-VSLVL LOCA-SIGNAL PA-INJ-1HR TCR RCR ADS-XHE-ACT-MAN CONT-ISO-SIGNAL ESF-CCF-MC-DPRES HCS-ICC-FT-MV12 TCR RCR ADS-XHE-ACT-HAN CONT-ISO-SIGNAL ESF-CCF-MC-DPRES HCS-LOG-NO-HPCS

A-INJ-1HR

RA-INJ-THR RA-INJ-1HR RA-PCS-1HR RA-PCS-1HR RA-PCS-1HR RA-INJ-1HR RA-INJ-1HR RA-INJ-1HR RA-INJ-1HR RA-INJ-1HR RA-INJ-1HR RA-INJ-1HR RA-INJ-1 HR RA-INJ-1HR RA-INJ-1 HR RA-INJ-1HR RA-INJ-1HR RA-INJ-1HR RA-INJ-1HR RA-INJ-1HR RA-INJ-1HR RA-INJ-1HR RA-INJ-1HR RA-INJ-1HR RA-INJ-1HR RA-INJ-1HR RA-INJ-1HR RA-INJ-1HR RA-INJ-1HR RA-INJ-1HR RA-PCS-1H RA-PCS-1HR

A-PCS-1HR RA-PCE-1HA RA.PCE-1HR RA.PCS-1HR RAPCS-1HR RXINJ-XHE-ADS RXINJ-XHE-ACIC SSW-HTX-FG-HX RXINJ-XHE-ADS RXINJ-XHE-ACIC SSW-MDP-FS-MDP RXINJ-XHE-ADS RXINJ-XHE-RCIC SSW-MOV-MA-MV RA-PCS-1HR ACI-TDP-FR-TDP1 RXINJ-XHE-ADS RA.PCS-1HR RCI-TOP-FR-TDP1 RXINJ-XHE-ADS RA-PCS-1HR RCI-TDP-FR-TDP1 RXINJ-XHE-ADS RA-PCS-THR RCI-TDP-FR-TDP1 RXINJ-XHE-ADS RA-PCS-1HR RCI-TDP-FR-TDP1 RXINJ-XHE-ADS RA-PCS-1HR ACI-TDP-FR-TDP1 RXINJ-XHE-ADS RA-PCS-1HR ACI-TDP-FR-TDPI RXINJ-XHE-ADS RA-PCS-1HR RCI-TDP-FR-TDP1 RXINJ-XHE-ADS RA-PCS-1HR RXINJ-XHE-ADS RXINJ-XHE-ACIC RA-PCS-1HR RCI-TDP-FR-TDP1 RXINJ-XHE-ADS RA-PCS-1HR RXINJ-XHE-ADS RXINJ-XHE-RCIC RA-PCS-1HR RXINJ-XHE-ADS RXINJ-XHE-ACIC RA-PCS-1HR RCI-TDP-FP-TDP1 RXINJ-XHE-ADS RA-PCS-1HR RXINJ-XHE-ADS RXINJ-XHE-RCIC RA-PCS-1HR RCI-TDP-FR-TDP1 RXINJ-XHE-ADS RA-PCS-1HR RXINJ-XHE-ADS RXINJ-XHE-RCIC RA-PCS-1HR RCI-TDP-FR-TDP1 RXINJ-XHE-ADS RA-PCS-1HR RXINJ-XHE-ADS RXINJ-XHE-RCIC RA-PCS-1HR ACI-TDP-FR-TDP1 RXINJ-XHE-ADS RA-PCS-1HR RXINJ-XHE-ADS RXINJ-XHE-RCIC RA-PCS-1HR RXINJ-XHE-ADS RXINJ-XHE-RCIC RA-PCS-1HR RXINJ-XHE-ADS RXINJ-XHE-RCIC RA-PCS-1HR RCI-TDP-FR-TDP1 RXINJ-XHE-ADS RA-PCS-1HR RXINJ-XHE-ADS RXINJ-XHE-ACIC RA-PCS-1HR RXINJ-XHE-ADS RXINJ-XHE-ACIC RXINJ-XHE-ADS RXINJ-XHE-ACIC SSW-HTX-PG-HX RXINJ-XHE-ADS RXINJ-XHE-ACIC SSW-MDP-FS-MDP IAS-XHEFOIAS RA-INJ-1HR RXINJ-XHE-ACIC SSW-MDP-FS-MDP
RA-PCS-1HR
RCI-TDP-FR-TDP RCL-TDP-FR-TDP

RCI-TDP-FR-TDP1 RXINJ-XHE-ADS RCI-TDP-FR-TDP1 RXINJ-XHE-ADS RCI-TDP-FR-TDP1 RXINJ-XHE-ADS RCI-TDP-FR-TDP1 RXINJ-XHE-ADS RCI-TDP-FR-TDP1 RXINJ-XHE-ADS RCI-TDP-FR-TDP1 RXINJ-XHE-ADS
$6.808 E-09$ 6.808E-09 7.090E-10

$6.908 E-09$

$6.908 E-09$

6.908E-09 6.808E-09 6.808E-09 7.090E-10 7.090E-10 7.090E-10 7.090E-10

7.090E-10 7.090E-10 7.090E-10 7.090E-10

. $908 E-09$ 7.090E-10 6.908E-09 6.908E-09

7.090E-10

6.808E-09

7.090E-10

6.908E-09

7.090E-10

6.908E-09

7.090E-10

$6.908 \mathrm{E}-09$

6.908E-09

6.808E-09

7.090E-10

6.800E-00

6.808E-08

$6.808 E-09$

6.908E-09

7.090E-10

7.090E-10

$1.808 E-07$

4.898E-10

4.896E-10

.896E-10

4.896E-10

4.896E-10

4.896E-10 
TABLE C.2. (contd) TDC RDC ADS-XHE-ACT-MAN CRD-XHE-FO-MDPB ESF-CCF-MC-VSLVL HCS-ICC-FT-MV12 TDC RDC ADS-XHE-ACT-MAN CRD-XHE-FO-MDPB ESF-CCF-MC-VSLVL HCS-ICC-FT-MV12 TDC RDC ADS-XHE-ACT-MAN CRD-XHE-FO-MDPB ESF-CCF-MC-VSLVL HCS-LOG-NO-HPCS TDC RDC ADS-XHE-ACT-MAN CRD-XHE-FO-MDPB ESF-CCF-MC-VSLVL HCS-LOG-NO-HPCS TDC RDC ADS-XHE-ACT-MAN CRD-XHE-FO-MDPB ESF-CCF-MC-VSLVL HCS-MDP-FP-MDP1 TDC RDC ADS-XHE-ACT-MAN CRD-XHE-FO-MDPB ESF-CCF-MC-VSLVL HCS-MDP-FS-MDPI TDC RDC ADS-XHE-ACT-MAN CRD-XHE-FO-MDPB ESF-CCF-MC-VSLVL HCS-MDP-FS-MDP1 TDC RDC ADS-XHE-ACT-MAN CRD-XHE-FO-MDPB TDC RDC ADS-XHE-ACT-MAN CAD-XHE-FO-MDPB TDC RDC ADS-XHE-ACT-MAN CRD-XHE-FO-MDPB TDC RDC ADS-XHE-ACT-MAN CRD-XHE-FO-MDPB TDC RDC ADS-XHE-ACT-MAN CRD-XHE-FO-MDPB TDC RDC ADS-XHE-ACT-MAN CRD-XHE-FO-MDPB TDC RDC ADS-XHE-ACT-MAN CRD-XHE-FO-MDPB TDC RDC ADS-XHE-ACT-MAN CRD-XHE-FO-MDPB TDC ROC ADS-XHE-ACT-MAN CRD-XHE-FO-MDPB TDE RDC ADS-XHE-ACT-MAN CRD-XHE-FO-MDPB TDC RDC ADS-XHE-ACT-MAN CRD-XHE-FO-MDPB TOC PDC ADS-XHE-ACT-MAN CRD-XHE-FO-MDPB TDC RDC ADS-XHE-ACT-MAN CRD-XHE-FO-MDPB TDC RDC ADS-XHE-ACT-MAN CRD-XHE-FO-MDPB TDC RDC ADS-XHE-ACT-MAN ESF-CCF-MC-DPRES TDC RDC ADS-XHE-ACT-MAN ESF-CCF-MC-DPRES TDC RDC ADS-XHE-ACT-MAN ESF-CCF-MC-DPRES TDC RDC ADS-XHE-ACT-MAN ESF-CCF-MC-DPRES TDC RDC ADS-XHE-ACT-MAN ESF-CCF-MC-DPRES TDC RDC ADS-XHE-ACTMAN TDC RDC ADS-XHE-ACT-MAN ESF-CCF-MC-VSLVL HCS-ICC-FT-MV12 LOCA-SIGNAL TDC RDC ADS-XHE-ACT-MAN ESF-CCF-MC-VSLVL HCS-ICC-FT-MVI2 LOCA-SIGNAL TDC RDC ADS-XHE-ACT-MAN ESF-CCF-MC-VSLVL HCS-LOG-NO-HPCS LOCA-SIGNAL TDC RDC ADS-XHE-ACT-MAN ESF-CCF-MC-VSLVL HCS-LOS-NO-HPCS LOCA-SIGNAL TDC RDC ADS-XHE-ACT-MAN ESF-CCF-MC-VSLVL HCS-MDP-FR-MDP1 LOCA-SIGNAL TDC RDC ADS-XHE-ACT-MAN ESF-CCF-MC-VSLVL HCS-MDP-FS-MDP1 LOCA-SIGNAL TDC RDC ADS-XHE-ACT-MAN ESF-CCF-MC-VSLVL HCS-MDP-FS-MDP1 LOCA-SIGNAL TDC RDC ADS-XHE-ACT-MAN ESF-CCF-MC-VSLVL HCS-MDP-MA-MDP1 LOCA-SIGNAL TDC RDC ADS-XHE-ACT-MAN ESF-CCF-MC-VSLVL HCS-MDP-MA-MDP1 LOCA-SIGNA TDC RDC ADS-XHE-ACT-MAN ESF-CCF-MC-VSLVL HCS-MOV-CC-MV12 LOCA-SIGNAL TDC RDC ADS-XHE-ACT-MAN ESF-CCF-MC.VSLVI HCS-MOV-CC-MV12 LOCA-SIGNAL TDC RDC ADS-XHE-ACT-MAN ESF-CCF-MC-VSLVL HCS-MOV-CC-MV4 LOCA-SIGNAL TDC RDC ADS-XHE-ACT-MAN ESF-CCF-MC-VSLVL HCS-MOV-CC-MV4 LOCA-SIGNAL TDC RDC ADS-XHE-ACT-MAN ESF-CCF-MC-VSLVL HCS-MOV-MA-MV12 LOCA-SIGNAL TDC RDC ADS-XHE-ACT-MAN ESF-CCF-MC-VSLVL HCS-MOV-MA-MV4 LOCA-SIGNAL TDC RDC ADS-XHE-ACT-MAN ESF-CCF-MC-VSLVL HCS-MOV-OO-MVI LOCA-SIGNAL
RA-INJ-1HR

RA-INJ-1HA

RA-INJ-1HA RA-INJ-1HA RA-INJ-1HR

RA-INJ-1HR

RA-INJ-IHR RA-INJ-1HR RA-INJ-1HR

RA-INJ-1HR RA-INJ-1HR RA-INJ-THR RA-INJ-1 HF

RA-INJ-1HR

RA-INJ-1HA RA-INJ-1HF RA-INJ-1 HR

RA-INJ-1HF RA-PCS-1H RAPCE-IH PA-PCE-1HR

RA-INJ-1HR RA-INJ-1 HR

RA-INJ-1HA RA-INJ-1HP RA-INJ-THR

PA-INJ-1HA

RA-INJ-1HR

RA-INJ-1 HR

PA-INJ-1HR

RA-INJ-1HR

RA-INJ-9HR

RA-INJ-1HR

PA-INJ-1HR

RA-INJ-1HR

RA-INJ-1HR

RA-INJ-1 TRR

RA-INJ-1HR

RA-INJ-1HR

RA-INJ-1HR

RA-INJ-1 HR

RA-INJ-1 HR

RA-NNJ-1 HR
RA-PCS-1HR AA-PCS-1HA

RA-PCS-1HA RA-PCS-1HA PA-PCS-1 HA RA-PCS-1HR

RA-PCS-1HR

PA.PCS-1HR

RA-PCS-1HA

RA.PCS-1HA

RA-PCS-1HR

RA-PCS-1HA

RA.PCE-1HR

RA-PCS-1HR

APCS-1HA

RA-PCS-1HR

RA.PCS-1HR

RA-PCS-1HR

AA-PCS-1H

RXINJ-XHE-ADS

RXINJ-XHE-ADS RXINJ-XHE-ADS

AAPC-1HA

RA.PCS-1HR

RA-PCS-1HR

BA-PCS-1HA

RA.PCS-1HR

RA-PCS-1HR

RA-PCS-1HR

RA.PCS-1HR

RA-PCS-1HR

RA-PCS-1HR

RA-PCS-1HA

RA-PCS-1HR

RA-PCS-1HR

RA.PCS-1HR

RA-PCS-1HR

RA-PCS-1HR

RA-PCS-1HR

AA-PCS-1HR

RA-PCS-1HR

A.PCS-1HR

RA-PCS-1HR

RA.PCS-1HR

RA-PCS-1HR Frequency 4.898E-10 4.896E-10

4.896E-10

$4.898 E-10$

$4.898 E-10$

$4.898 E-10$

4.896E-10

4.896E-10

$4.888 E-10$

4.886E-10

$4.828 E-10$

$4.898 E-10$

$4.886 E-10$

$4.896 E-10$

4.896E-10

4.898E-10

4.886E-10

4.896E-10

4.896E-10

4.896E-10

4.88BE-10

$4.896 E-10$

$4.896 E-10$

4.886E-10

4.896E-10

4.88BE-10

4.896E-10

4.896E-10

4.898E-10

4.898E-10

4.898E-10

4.896E-10

4.898E-10

4.896E-10

4.886E-10

4.896E-10

4.898E-10

4.896E-10

4.886E-10

4.896E-10

4.896E-10

4.896E-10

4.896E-10

4.896E-10

4.898E-10 


\section{TABLE C.2. (contd)}

TDC RDC ADS-XHE-ACT-MAN ESF-CCF-MC-VSLVL HCS-MOV-OO-MVI LOCA-SIGNAL

TDC RDC ADS-XHE-ACT-MAN ESF-CCF-MC-VSLVL HCS-XHE-RE-HPCS LOCA-SIGNAL

TDC RDC ADS-XHE-ACT-MAN ESF-CCF-MS-VSLVL LOCA-SIGNAL RA-INJ-1HR

\section{RA-INJ-1HR}

RA-INJ-1HA

RA-INJ-1HR

PA.PCS-1HR

$\operatorname{sxin}$

TOS, RDC ADS-XHE-ACT-MAN ESF-CCF-MS-VSLVL LOCA-SIGNAL RA-INJ-1HR

TDC RDC ADS-XHE-ACT-MAN CONT-ISO-SIGNAL ESF-CCF-MC-DPRES HCS-ICC-FT-MVI2

RA-PCS-1HR RXINJ-XHE-ADS RXINJ-XHE-ACIC

IAS-XHEFOIAS PA-INJ-1HR

TDC RDC ADS-XHE-ACT-MAN CONT-ISO-SIGNAL

IAS-XHEFOIAS RA-INJ-1HR

RA-PCS-1HR

RA-PCS-1HR

TOTAL

RXINJ-XHE-RCIC

RXINJ-XHE-RCIC

SSW-HTX-PG-HX

SSW-MDP-FS-MDP

PCI-TDP-FR-TDP

RCI-TDP-FR-TDP

Frequency

$4.896 E-10$

$4.896 E-10$

4.896E-10

4.898E-10

4.886E-10

4.898E-10

2.791E-08 
IABLE C.3. Dominant Cut Sets and Frequencies Containing HVAC/Room Coolers as Contributing Events

\begin{tabular}{|c|c|c|}
\hline $\begin{array}{l}\text { RISK CALCULATIONS } \\
\text { Accident Progression } \\
\text { Bin }\end{array}$ & $\begin{array}{l}\text { APB Conditional } \\
\text { Probability }\end{array}$ & APB Frequency \\
\hline $\begin{array}{l}1 \text { VB, early CF. } \\
\text { SPB, no CS }\end{array}$ & $1.880 E-01$ & $6.328 E-08$ \\
\hline $\begin{array}{l}2 \text { VB, earty CF, earty } \\
\text { SPB, CS }\end{array}$ & 3.100E-02 & $1.043 E-08$ \\
\hline $\begin{array}{l}3 \text { VB, earty CF, late } \\
\text { SPB }\end{array}$ & $6.000 E-03$ & $2.019 E-09$ \\
\hline $\begin{array}{l}4 \text { VB, early CF, no } \\
\text { SPB }\end{array}$ & $1.820 E-01$ & $6.126 E-08$ \\
\hline 5 VB, late CF & 3.080E-01 & $1.037 E-07$ \\
\hline 6 VB, venting & $3.200 E-02$ & $1.077 E-08$ \\
\hline 7 VB, no CF & $5.300 E-02$ & $1.784 \mathrm{E}-08$ \\
\hline 8 No VB & 2.010E-01 & $6.765 E-08$ \\
\hline \multicolumn{3}{|c|}{ AFFECTED CDF AND PUBLIC RISK SUMMARY } \\
\hline Accident Sequence & $\begin{array}{l}\text { CDF. } \\
\text { Per RY }\end{array}$ & $\begin{array}{l}\text { Public Risk, } \\
\text { Person-rem/RY }\end{array}$ \\
\hline TSW & $1.279 E-07$ & $6.162 E-02$ \\
\hline TCR & $1.808 E-07$ & 8.711E-02 \\
\hline TDC & $2.791 E-08$ & $1.345 \mathrm{E}-02$ \\
\hline TOTAL & 3.366E-07 & $1.622 \mathrm{E}-01$ \\
\hline
\end{tabular}

\begin{tabular}{ccccc}
$\begin{array}{c}\text { Source Term } \\
\text { Group }\end{array}$ & & $\begin{array}{c}\text { Conditional } \\
\text { Probability }\end{array}$ & & $\begin{array}{c}\text { Source Term } \\
\text { Group Frequency }\end{array}$ \\
\cline { 5 - 5 } GG-13-1 & & $6.350 E-01$ & & $4.018 E-08$ \\
GG-13-2 & & $3.650 E-01$ & & $2.310 E-08$ \\
GG-12-1 & & $3.870 E-01$ & & $4.038 E-09$ \\
GG-12-2 & & $6.130 E-01$ & & $6.396 E-09$ \\
GG-10-1 & & $8810 E-01$ & & $1.981 E-09$ \\
GG-10-2 & & $1.900 E-02$ & & $3.837 E-11$ \\
GG-10-1 & & $9.8: 0 E-01$ & & $6.009 E-08$ \\
GG-10-2 & & $1.900 E-02$ & & $1.16 E-09$ \\
GG-05-1 & & $5.930 E-01$ & & $6.147 E-08$ \\
GG-05-2 & & $4.070 E-01$ & & $4.219 E-08$ \\
GG-03-1 & & $6.730 E-01$ & & $7.248 E-09$ \\
GG-03-2 & & $3.270 E-01$ & & $3.522 E-09$ \\
GG-02-1 & & $4.990 E-01$ & & $8.901 E-09$ \\
GG-02-2 & & $5.010 E-01$ & & $8.937 E-09$ \\
GG-15-01 & $9.990 E-01$ & & $6.758 E-08$ \\
GG-15-02 & & $1.000 E-03$ & & $6.765 E-11$
\end{tabular}

\begin{tabular}{l}
$\begin{array}{c}\text { Consequences } \\
\text { Porson-rom/ovent }\end{array}$ \\
\hline $1.880 E+08$ \\
$2.010 E+06$ \\
$4.030 E+05$ \\
$4.180 E+05$ \\
$2.580 E+05$ \\
$2.300 E+06$ \\
$2.580 E+05$ \\
$2.300 E+05$ \\
$1.820 E+05$ \\
$1.810 E+05$ \\
$6.990 E+04$ \\
$8.000 E+04$ \\
$4.180 E+02$ \\
$4.180 E+02$ \\
$3.470 E+01$ \\
$1.170 E+02$
\end{tabular}

Public Risk

Porson-rom/RY

7.654E-02

4.642E-02

$1.627 \mathrm{E}-03$

2.674E-03

$5.111 E-04$

8.825E-06

1.550E-02

2.677E-04

1.119E-02

7.637E-03

$5.067 E-04$

2.818E-04

3.721E-06

3.736E-06

2.345E-06

$7.915 \mathrm{E}-\mathrm{O} 9$

1.622E-01 


\section{APPENDIX D}

SYSTEMS ANALYSIS AND MINIMAL CUT SETS

FOR THE REPRESENTATIVE COMBUSTION ENGINEERING

PRESSURIZED WATER REACTOR. 


\section{APPENDIX D \\ SYSTEMS ANALYSIS AND MINIMAL CUT SETS \\ FOR THE REPRESENTALIVE COMBUSTION ENGINEERING \\ PRESSURED WATER REACTOR}

This appendix presents the systems analysis and the affected minimal cut sets, values of each parameter in each cut set, and the cut set frequencies for the representative Combustion Engineering (CE) pressurized water reactor (PWR).

\section{D.1 PLANT DESCRIPTION}

The representative CE PWR contains three nuclear power plant units. The CE design consists of two independent primary coolant loops. Each unit, operating at full power, produces about $3817 \mathrm{MWt}$, for a nominal electric generating capacity of 1270 MWe. Unit 1 entered commercial operation in January 1986, Unit 2 in September 1986, and Unit 3 in January 1988. These plants are located in a hot, desert environment; thus they exhibit a relatively high reliance on HVAC and room cooler systems to maintain ambient temperatures that are conducive to equipment operability as well as to human occupational comfort.

\section{D.2 SAFETY SYSTEM DESCRIPTION AND SYSTEMS ANALYSIS}

This section presents summary-level descriptions and simplified schematic diagrams of the principal safety systems and presents the fault tree analyses on these systems. This information was used to identify the elements of the minimal cut sets in the existing plant Preliminary Risk Assessment (PRA) (Arizona Public Service Co. 1992) that involve failure to provide room cooling functions to safety systems. A secondary objective was to develop modifications to the systems analyses to model room cooler fallures in important systems that were not addressed in the existing PRA.

The following subsections describe the safety systems, including depen. dencies on other systems; present the fault trees for the systems that are dependent upon room cooling; and identify the cut set elements that represent failures of one or more trains of room cooling equipment. For completeness, all of the safety systems included in the existing PRA are reviewed; however, cut set data are presented for only the systems that are dependent upon room cooling.

The safety-related systems that are dependent upon HVAC/Cooling to support their operation are listed below: 
- High-pressure safety injection (HPSI pump room coolers)

- Low-pressure safety injection (LPSI pump room coolers)

- Containment spray (CS pump room coolers)

- Auxiliary feedwater (AFW pump room coolers)

- Essential cooling ivater (EW pump room coolers)

- $D C$ equipment room (essential HVAC)

- ESF switchgear room (essential HVAC).

- Control room (CR HVAC)

Descriptions and analyses of these and other safety-related systems are provided in this section. Dependencies on HVAC/room cooler systems are identified and described for each of the safety systems.

\section{D.2.1 High-Pressure Safety Injection}

The high-pressure safety injection (HPSI) system is a part of the safety injection (SI) system and functions to inject borated water into the reactor coolant system (RCS) following a small-break loss of coolant accident (LOCA) in which RCS pressure is expected to remain high (1255 psig) for a long period of time. HPSI is also capable of providing core heat removal for extended periods of time following a LOCA, and is used to inject borated water into the RCS to increase shutdown margin following a rapid cooldown of the primary system due to steam line rupture or a steam generator tube rupture (SGTR).

The HPSI system consists of two redundant, 100\%-capacity trains, each with one HPSI pump, one hot-leg injection line, and four branch headers. Each header discharges through a HPSI valve to a RCS cold leg. During the injection phase following a LOCA, the HPSI pumps take suction from the refueling water tank (RWT), which is also the initial suction source for the lowpressure safety injection (LPSI) and containment spray systems. The HPSI pumps are rated such that $75 \%$ of the flow of one of the pumps is sufficient to maintain adequate RCS inventory and boration for any of the three sequences listed above. Figure D.1 provides a schematic of the HPSI system.

The HPSI system also provides a long-term core cooling function referred to as high-pressure safety recirculation (HPSR). In this mode, the HPSI pumps recirculate primary coolant from the containment sump back to the RCS. This mode is automatically initiated by a recirculation actuation signal (RAS) when the RWT reaches a low level set-point of 7.4\%. At that time, the engineered safety features actuation system (ESFAS) opens containment sump valves and automatically aligns the HPSI and CS pump suction to the containment sump. 


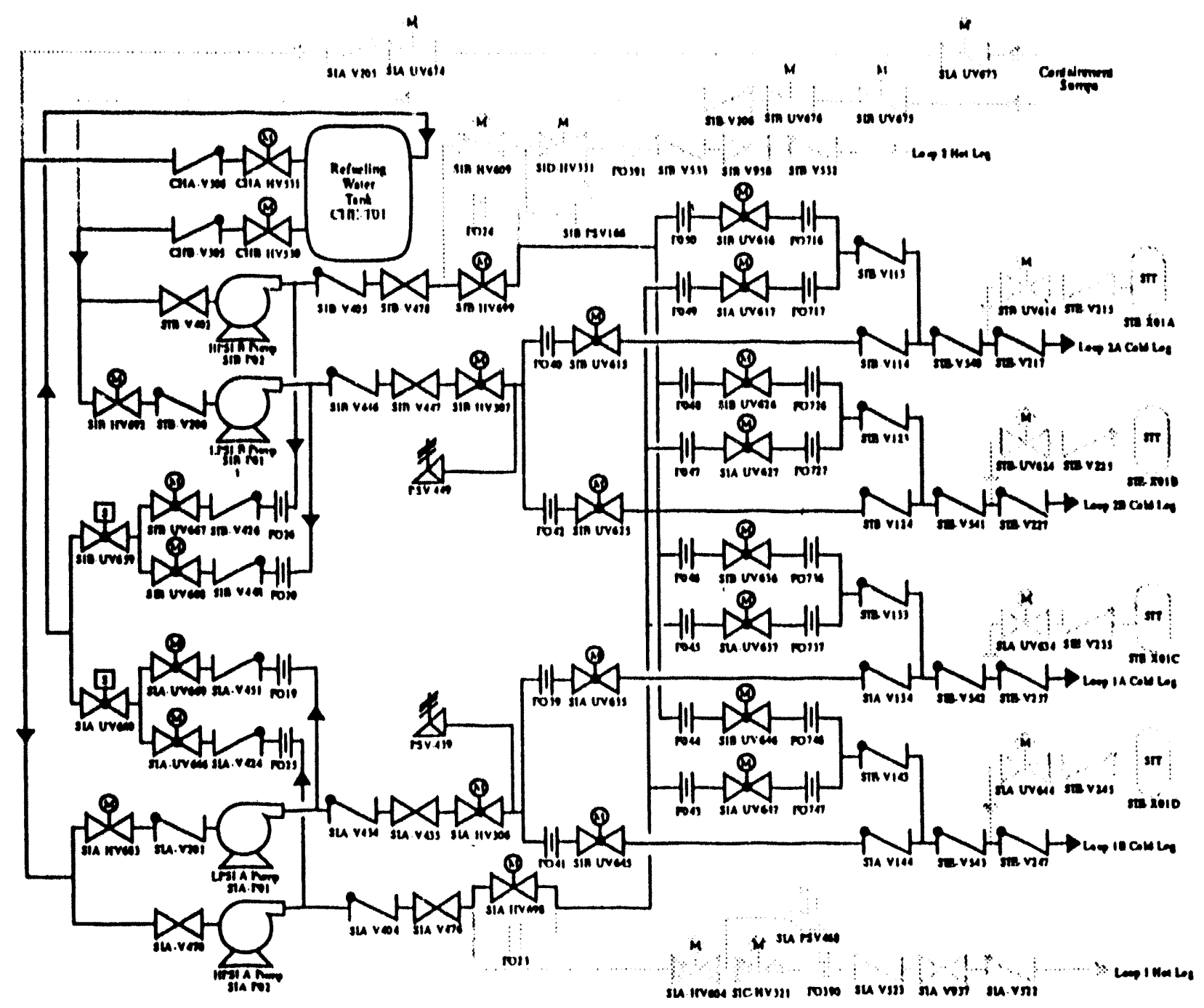

EIGURE D.1. Simplified Diagram of the HPSI and LPSI Systems

HPSI and HPSR system dependencies are discussed below:

- The safety injection actuation system (SIAS) signals the HPSI motoroperated valves (MOVs) to open.

- ESF emergency load sequencers, located in the control room, actuate the HPSI pumps. The load sequencers automatically load-shed the HPSI pump (and other safety-related equipment loads) from the associated emergency bus upon a loss of power (LOP) signal. After the diesel generator is up to speed and supplying power to the emergency bus, the HPSI pump is sequenced on if a SIAS or containment spray actuation signal (CSAS) is present. 
- The Class 1E 4.16-kV AC power system provides motive power to the HPSI pumps. Control power to the pump breaker is provided by the Class IE 125-V DC distribution boards.

- The Class IE 480-V AC motor control centers (MCCs) provide motive and control power to the HPSI MOVs.

- During normal operation, the Auxiliary Bullding HVAC system provides cooling to the HPSI pump cubicles. Following a SIAS signal, the normal room cooling system is tripped and dedicated emergency room coolers in each cubicle are started. Each room cooler consists of a fan and air cooling coils. The fan recirculates air inside the cubicle, passing the air over the cooling colls to transfer heat to chilled water from the essential chilled water (EC) system. The fan is powered from a Class $1 E$ 480-V AC MCC. High temperature alarms are provided that alarm in the control roam when ambient temperatures in the HPSI pump cubicles reach $105^{\circ} \mathrm{F}$.

- The RWT provides fluid inventory for the HPSI system. The containment sump provides fluid inventory during HPSR operation.

Failure of the HPSI pumps due to high room temperatures was included in the existing PRA. This HPSI failure mode could result from failure of the HPSI pump room coolers. Calculations indicated that the HPSI room could reach a maximum temperature of $1990 \mathrm{~F}$ within 24 hours following a loss of room cooling (see Appendix F). If the pump room door were to be opened at two hours after loss of the room cooler, the maximum temperature was calculated to be $165^{\circ} \mathrm{F}$. These temperatures were determined not to immediately result in HPSI pump fallure, although the reliability of the pumps is significantly degraded.

\section{D.2.2 Low-Pressure Safety Injection}

The low-pressure safety injection (LPSI) system is a part of the safety injection (SI) system and functions to inject borated water into the RCS following a large-break LOCA. LPSI is also used for small LOCAs and SGTR events when HPSI is failed. Control room operators must depressurize the RCS to below 140 psia to permit LPSI flow. The LPSI system also provides for low pressure safety recirculation (LPSR) in the event that both trains of HPSI are failed or if HPSI fails during the recirculation mode. The LPSI pumps are tripped upon receipt of a recirculation actuation signal (RAS) and must be restarted by control room operators to initiate LPSR. The LPSI pumps are also used for shutdown cooling in which RCS inventory is circulated through the shutdown cooling heat exchangers, LPSI pumps, and then returned to the reactor vessel.

The LPSI system consists of two redundant, 100\%-capacity trains. Each train has one LPSI pump and two branch headers. Each branch header discharges through its own injection MOV into a RCS cold leg. During the injection phase following a LOCA, the LPSI pumps take suction from the RWT, which is also the initial suction source for the HPSI and CS systems. A common RWT header is 
provided for the LPSI, HPSI, and CS pumps. For LPSR operation, the LPSI pumps take suction from the containment sump. The containment sump header is also a common header for the LPSI, HPSI, and CS pumps. See Figure D.l for a schematic of the LPSI system.

LPSI and LPSR system dependencies are discussed below:

- The SIAS signals the LPSI injection header MOVs to open.

- ESF emergency load sequencers actuate the LPSI pumps. The load sequencers automatically load-shed the LPSI pump (and other safetyrelated equipment loads) from the associated emergency bus upon a LOP signal. After the diesel generator is up to speed and supplying power to the emergency bus, the LPSI pump is sequenced on if a SIAS or CSAS signal is present.

- The Class IE 4.16-kV AC power system provides motive power to the LPSI pumps. Control power to the pump breaker is provided by the Class $1 E$ 125-V DC distribution boards.

- The Class IE 480-V AC MCCs provide motive and control power to the LPSI MOVs.

- Similar to the HPSI system, the Auxiliary Building HVAC system provides cooling to the LPSI pump cubicles during normal operation. If a SIAS signal occurs, the normal room cooling system is tripped and dedicated emergency room coolers in each cubicle are started. Each room cooler consists of a fan and air cooling coils. The fan recirculates air inside the cubicle, passing the air over the cooling coils tu transfer heat to chilled water from the EC system. The fan is powered from a Class 1E $480 \mathrm{~V}$ AC MCC. High temperature alarms arf provided which alarm in the control room when ambient temperatures in the LPSI pump cubicles reach $105^{\circ} \mathrm{F}$.

- The RWT provides fluid inventory for the LPSI system. The containment sump provides fluid inventory during LPSR operation.

Failure of the LPSI pumps due to high room temperatures was included in the existing PRA. This LPSI fallure mode could result from fallure of the LPSI pump room coolers. Calculations indicated that the LPSI room could reach a maximum temperature of $189^{\circ} \mathrm{F}$ within 24 hours following a loss of room cooling. If the pump room door were to be opened at two hours after loss of the room cooler, the maximum temperature was calculated to be $168^{\circ} \mathrm{F}$. If no backup cooling to the LPSI pump cubicle is established, the LPSI pumps fail within 24 hours. If the pump room door is opened within 2 hours after the loss of room cooling, the reliability of the pumps is significantly degraded, and the pump failure probability is increased above the probability used when room cooling is available. 


\section{D.2.3 Containment Spray System}

The primary function of the containment spray (CS) system is to provide a cool spray of water into the containment following a LOCA, steam line break, or feedwater line break. This water spray, delivered through containment spray header nozzles, maintains containment integrity by reducing containment pressure and temperature and limits the leakage of airborne radioactivity from the containment.

The CS system consists of two redundant and independent trains, with its own CS pump. Each CS train is normally aligned to pass flow though a shutdown cooling heat exchanger and a CS control MOV, and discharges borated water through a dual set of spray nozzle headers located in the upper part of the Containment Building. The CS system is automatically actuated by a containment spray actuation signal (CSAS), which occurs at high containment pressure. The pumps take suction from the RWT during the injection phase and from a common suction line with the HPSI and LPSI pumps from the containment sump during the recirculation phase. Pump suction is automatically transferred to the containment sump upon receipt of a RAS signal when low RWT inventory is reached. The shutdown cooling heat exchangers provide cooling to the CS injection water during both injection and recirculation phases. The heat exchangers are cooled by the essential cooling water (EW) system. A simplified diagram of the CS system is provided in Figure 0.2 .

CS system dependencies are discussed below:

- The CS pumps are automatically started on either a SIAS or CSAS signal. The CS injection valves open only upon receipt of a CSAS signal.

- ESF emergency load sequencers actuate the CS pumps.

- The Class IE 4.16-kV AC power system provides motive power to the CS pumps. Control power to the pump breaker is provided by the Class $1 E$ 125-V DC distribution boards.

- The Class 1E 480-V AC MCCs provide motive and control power to the LPSI MOVs.

- Similar to the HPSI and LPSI systems, the Auxiliary Building HVAC system provides cooling to the CS pump cubicles during normal operation. Should a SIAS signal occur, the normal room cooling system is tripped and dedicated emergency room coolers in each cubicle are started. Each room cooler consists of a fan and air cooling coils similar in design to the LPSI/HPSI pump room coolers. The fan is powered from a Class IE 480-V AC MCC. High temperature alarms are provided that alarm in the control room when ambient temperatures in the CS pump cubicles reach $105^{\circ} \mathrm{F}$.

- The RWT provides fluid inventory for the CS system. The containment sump provides fluid inventory during the recirculation phase. 


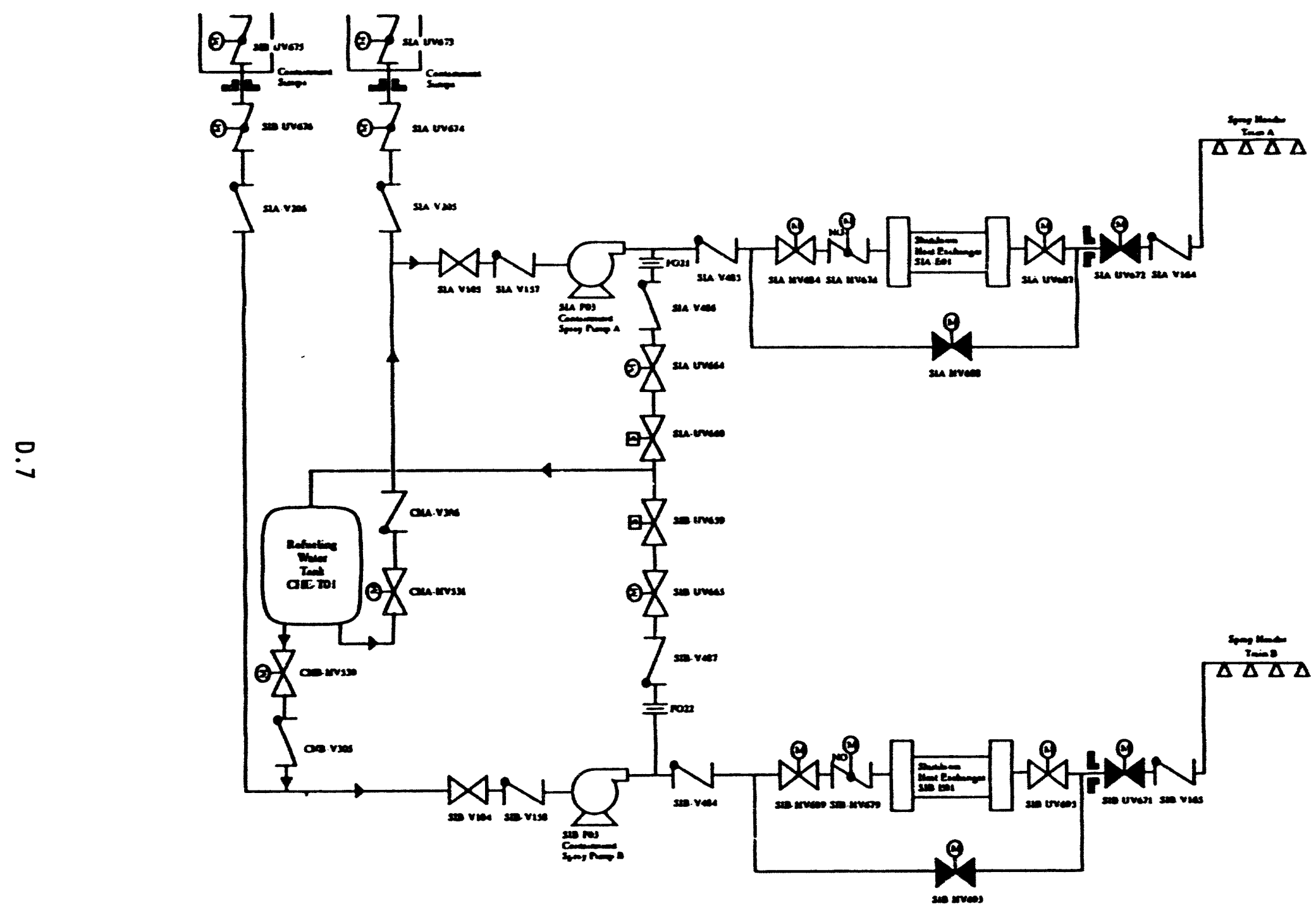

FIGURE D.2. Simplified Diagram of the Containment Spray System 
Failure of the CS pumps due to high room temperatures was included in the existing PRA. This failure mode could result from failure of the CS pump room coolers. Calculations indicated that the CS pump ronm could reach a maximum temperature of $189^{\circ} \mathrm{F}$ within 24 hours following a loss of room cooling. If the pump room door were to be opened at two hours following loss of the room cooler, the maximum temperature was calculated to be $168^{\circ} \mathrm{F}$. If no backup cooling to the CS pump cubicle is established, the CS pumps will fail within 24 hours. If the pump room door is opened within two hours following the loss of room cooling, the reliability of the pumps is significantly degraded and the pump failure probability is increased above the probability used when room cooling is available.

\section{D.2.4 Shutdown Cooling System}

The shutdown cooling system (SDC) is used to reduce the temperature of the RCS following reactor shutdown from approximately $350^{\circ} \mathrm{F}$ to the refueling temperature of $124^{\circ} \mathrm{F}$, and maintain heat removal for an extended period of time. The SDC system can also operate following an accident to remove heat through the SDC heat exchanger. The LPSI pumps are normally used during shutdown cooling. The SDC system is al so used during a SGTR event. During such an event, operators are required to reduce RCS pressure to minimize the RCS-to-secondary side leak. Operators would also cool down and depressurize the RCS to SDC entry conditions, establish SDC, and then cool the RCS to refueling temperature and pressure conditions.

The SDC system consists of two redundant, 100\%-capacity trains. The LPSI or CS pumps circulate RCS water from nozzles on each RCS hot leg, through an SDC heat exchanger, and back into the RCS through the four LPSI injection lines. CS pumps are used only when RCS temperatures are $200^{\circ} \mathrm{F}$. Three MOVS are provided to isolate the SDC system from the RCS hot leg. Each SDC loop is interlocked to remain closed until RCS pressure is below 410 psia. A simplified diagram of the SDC system is shown in Figure D.3.

The pumps and discharge valves used by SDC are the same as those described for LPSI (Section D.2.2) and CS (Section D.2.3) systems. The only major SDC components not covered previously are the SDC suction valves. One suction valve per train is a Class IE 125-V DC-powered MOV, and the other two per train are Class IE 480-V AC-powered MOVs.

SDC system dependencies are discussed below:

- The Class' IE 4.16-kV AC power system provides motive power to the CS and LPSI pumps. Control power to the pump breakers is provided by the Class IE $125-V$ DC distribution boards. The SDC suction MOVs are powered from the 480-V AC Class IE power system or through the Class IE 480-V inverter from Class $1 E$ 125-V DC power.

- Interlocks are provided from the RCS pressure transmitters which required $\mathrm{Class}$ IE $125-\mathrm{V}$ AC instrument power. 


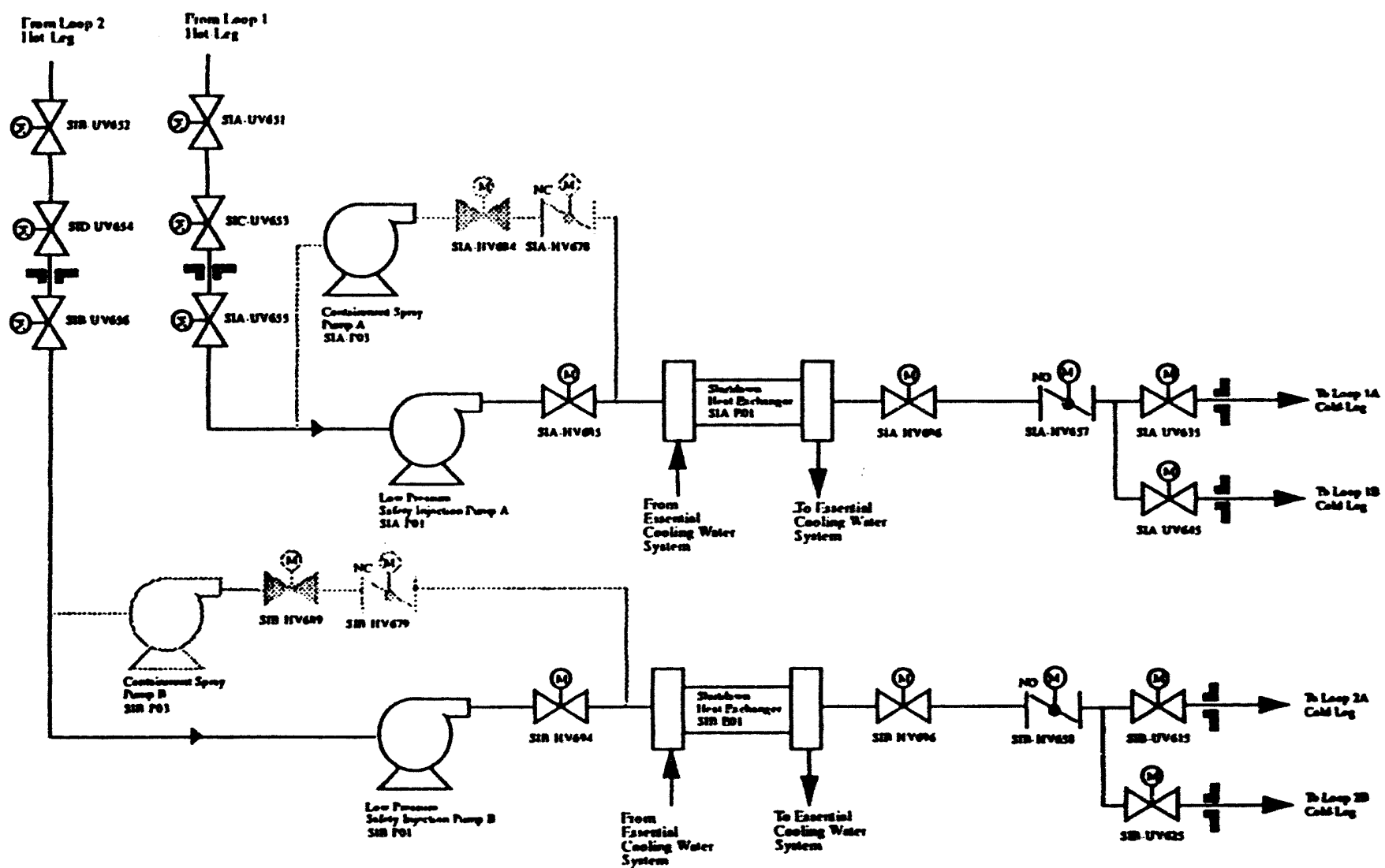

FIGURE D.3. Simplified Diagram of the Shutdown Cooling System 
- As discussed in Sections D.2.2 and D.2.3, dedicated emergency room coolers in each LPSI and CS pump room are started if a pump is in operation. Each room cooler consists of a fan and air cooling coils. The fan is powered from a Class $1 E$ 480-V AC MCC. High temperature alarms are provided that alarm in the control room when ambient temperatures in the LPSI and CS pump cubicles reach $105^{\circ} \mathrm{F}$.

\section{D.2.5 Safety Injection Tanks}

The safety injection tanks (SITs) flood and cool the reactor core with borated water following a large, medium, or small LOCA. Four SITs are provided, each connected to a RCS cold leg; they are normally isolated from the RCS cold legs by two isolation check valves. The SITs are normally pressurized to $610 \mathrm{psig}$ and do not operate during normal operations. If a transient occurs in which RCS pressure reduces to $610 \mathrm{psig}$, the check valves open to inject borated water into the core. Each SIT injection line also includes a normally open (key-locked) isolation MOV. Nitrogen is used to pressurize the SIT tanks; nitrogen is not required for operation of the SITs but may be needed if SIT tank pressure drops below $610 \mathrm{psig}$ due to a small leak or temperature changes. The SIT system is passive and is designed to function without requiring support systems, including HVAC and room cooling. No further examination of the SIT system is needed for this study.

\section{D.2.6 Auxiliary Feedwater System}

The auxiliary feedwater (AFW) system provides water to the steam generators (SGS) during normal, abnormal, and emergency conditions for removal of decay heat from the primary coolant system. The AFW system consists of three AFW pumps (two safety-related and one nonsafety), associated piping, valves, and instrumentation necessary to deliver water to the secondary sides of the SGs. One safety-related AFW pump is turbine-driven and the other is motor-driven. The nonsafety-related AFW pump is motor-driven. A simplified drawing of the AFW system is shown in Figure D.4.

The safety-related portion of the AFW system consists of two completely redundant trains. The turbine-driven pump (TDP) is provided with turbine steam supply lines from each SG. The motor-driven pump (MDP) is a Class $1 E$ pump powered from the Division 2 ESF switchgear. Each essential AFW pump takes independent suction from the condensate storage tank (CST) and discharges to one or both steam generators through the downcomer feedwater lines. A backup water source, requiring local manual operation, is available from the reactor makeup water tank (RMWT). The nonessential portion of the AFW system includes a class-powered, nonseismically qualified MDP. The nonessential pump takes suction from the CST; no connection to the RMWT is provided. The nonessential pump is used during plant startup as well as emergency conditions.

The AFW system is used for secondary-side heat removal. Under smallbreak LOCA conditions, AFW must be delivered to at least one SG from one of the three AFW pumps. For RCS depressurization (if HPSI has failed), AFW flow must be delivered to two SGs from one of three AFW pumps. Under feedwater and main steam line break conditions, AFW flow must be delivered from at least one 


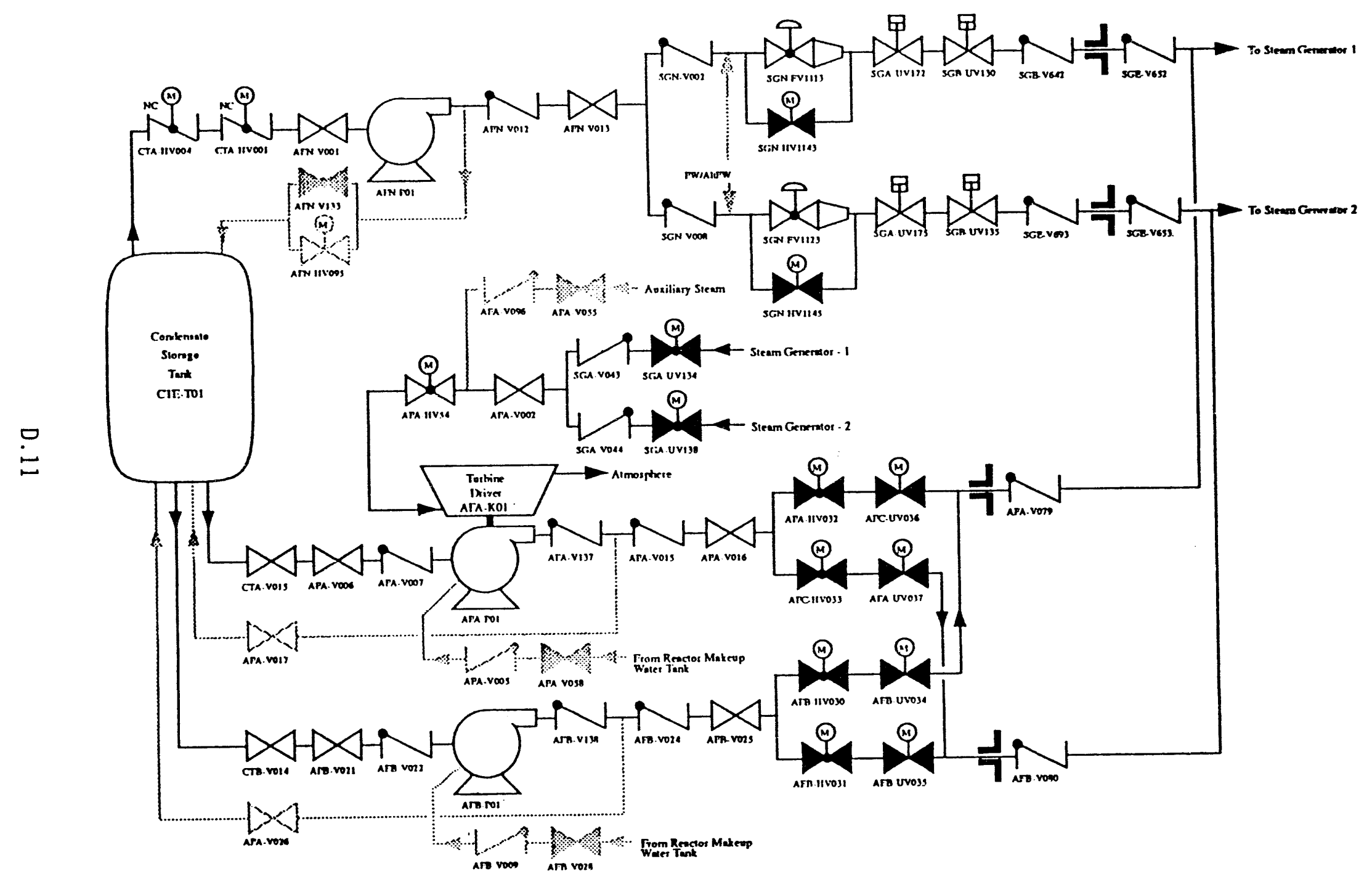

FIGURE D.4. Simplified Diagram of the Auxiliary Feedwater System 
AFW pump to the unaffected. Under loss of offsite power (LOOP), loss of main feedwater (MFW), and most other transient conditions, AFW flow must be delivered to at least one SG from one of the three AFW pumps. Under station blackout (SBO) conditions, the turbine-driven AFW pump must supply AFW to one SG for at least two hours. During later stages of an SBO event, AFW must be supplied from at least one AFW pump to one SG for at least 24 hours following recovery of offsite power.

Normally, the AFW pump discharge lines are isolated from the SGs by normally closed MOVs (one throttle and one isolation MOV in series). An AFW actuation signal (AFAS) signal (low water inventory in the SG) automatically starts and aligns the essential AFW pumps to the appropriate SG. The Train B motor-driven AFW pump receives a start signal on AFAS as well as following Train B LOP, SIAS, or CSAS signals. These signals are transmitted to the AFW pumps via the ESF load sequencer. The Train A TDP al so automatically starts on AFAS. The pump start signal also starts the respective essential room air conditioning unit. The nonessential pump has no automatic start signal and is automatically load-shed on SIAS or Train A LOP signals. Operator action is necessary to start and align the nonessential pump.

During normal power operations, the AFW system is in standby mode. Following a plant trip, an AFAS is generated in response to low level in either SG. The ESF load sequencers then automatically start both essential AFW pumps. The AFAS automatically aligns the AFW pumps to the appropriate SG and control SG level without operator intervention. However, operators are directed to override automatic control of the AFW pump discharge throttle values to more closely control SG levels. The nonessential (Train N) AFW pump is the preferred means of feeding the SGs following a normal reactor trip, followed in order of preference by the Train B MDP and then the Train A TDP. Operating procedures call for remote startup of the Train $N$ pump unless a main steam isolation signal (MSIS) is present, which results in closure of the downcomer feedwater isolation valves (FWIVs), which disables the Train N pump flowpath.

AFW system dependencies are the following:

- All three AFW pumps receive water through independent supply lines from the CST. A backup water supply from the RMWT is provided for the two essential AFW pumps.

- Normal cooling to the essential AFW pumps rooms, located in separate compartments in the main steam support structure (MSSS), is provided by the Auxiliary Building normal air handling units (AHUs). Upon receipt of a SIAS or CSAS, the normal cooling system is tripped and room cooling is provided by essential room coolers, consisting of a fan and air cooling coils. The EC system provides chilled water to the essential AFW pump room coolers.

- The Train A (turbine-driven) AFW pump room cooler is powered from Train A 480-V AC MCC. The Train B (essential motor-driven) AFW pump room cooler is powered from Train B 480-OV AC MCC. 
- The instrument air system (IAS) provides high-pressure nitrogen for operation of downcomer FWIVs, downcomer flow-control valves, and airoperated isolation dampers in the Auxiliary Building normal supply ducts. Therefore, failure of the IAS could result in failure of normal HVAC to the essential AFW pump rooms.

- Motive power for the turbine-driven AFW pump is provided by steam supply lines from each SG. Power to the turbine-driven AFW pump valves and instrumentation is provided by Class $1 \mathrm{E}$ power systems.

- Motive power for the essential motor-driven AFW pump is provided by Division 1 ESF switchgear. Control breaker power is provided by a $125-V$ DC distribution panel (Channel B). Failure of the DC equipment room HVAC is included as a contributor to failure to provide $125-V$ DC power.

- Division 2 ESF switchgear provides motive power to the nonessential AFW MDP. Breaker control power is provided by Channel A $125-V$ DC distribution panel. Failure of this panel may result from failure of the $D C$ equipment room HVAC system.

The existing PRA includes models of the normal and emergency HVAC systems for the essential AFW pump rooms. Calculations indicated that the essential MDP will survive for at least 12 hours with no HVAC and has a $50 \%$ chance of surviving for 24 hours without room heat removal. Similar calculations indicate a high probability that the turbine-driven AFW pump will survive for 24 hours without room cooling. In addition, both essential pumps are likely to survive at least 24 hours with only normal HVAC systems unavailable. However, normal HVAC is isolated through closure of isolation dampers by a SIAS resulting from LOCA, steam or feedwater line breaks, or SGTR events and will be unavailable under these conditions. A dominant event resulting in AFW system unavailability involves successful start of an essential AFW pump but failure to start the appropriate EC system chiller which serves the essential AFW pump room cooler. The essential AFW pump then fails due to extreme room temperature.

\section{D.2.7 Alternate Feedwater System}

The alternate feedwater (AltFW) system provides a means of restoring the feedwater levels in SGs in the event of simultaneous failure of main feedwater (MFW) and AFW systems. This function is accomplished through the use of one of three condensate (CD) pumps which deliver water to a depressurized steam generator via the downcomer feedwater lines. Successful operation of the AltFW system requires dump valves (ADVs) or the turbine bypass valves (TBVs). In most instances, successful operation of the AltFW system requires operation of one of three CD pumps, successful alignment of the system, and successful depressurization of the SG (i.e., either the ADV or TBV system must be available).

No dependencies on HVAC or room cooling systems were identified. Operation of the CD pumps does not require room cooling; therefore, no further examination of the AltFW system was performed for this study. 


\section{D.2.8 Chemical and Volume Control System}

functions:

The chemical and volume control system (CVCS) provides the following

- CVCS provides reactor coolant pump (RCP) seal injection and bleedoff control, and thus the CVCS is used to maintain RCS integrity by preventing RCP seal LOCAs. One charging pump is needed to maintain adequate seal cooling.

- CVCS provides borated water used to shut down the reactor following an anticipated transient without SCRAM (ATWS).

- CVCS provides water to the auxiliary pressurizer spray system (APSS) used to maintain operator control of RCS pressure when normal pressurizer sprays are unavailable.

The CVCS removes water from the RCS via the letdown line and passes the water through the regenerative heat exchanger, letdown heat exchanger, and purification ion exchanger, and then discharges the cooled and purified water into the volume control tank (VCT). The VCT water is then returned to the RCS using one or more charging pumps. The water returning to the RCS passes through the regenerative heat exchanger where it removes heat from the incoming letdown flow. Flow upstream of the heat exchanger is diverted to the RCP seal line. The seal injection water flows through a seal injection filter and heat exchanger prior to entering the RCP seals. Flow downstream of the regenerative heat exchanger supplies normal charging. A simplified drawing of the CVCS is provided in Figure D.5.

The CVCS includes three positive displacement charging pumps. The charging pumps normally take suction from the VCT, which accumulates letdown water from the RCS. Normal makeup for the VCT is provided by the RMWT and the RWT. If the VCT is unavailable, the charging pumps can take suction from the RWT.

CVCS system dependencies are discussed below:

- Two of the CVCS pumps are normally operating but are load shed on LOP to a Class 1E 4.16-kV AC bus. The previously running charging pumps are automatically restarted once power is restored or after the ESF load times out (about 40 seconds) if a SIAS signal is present with a LOP.

- The Class 1E 480-V AC power system provides motive power to the charging pumps. Control power to the pump breaker is provided by the Class IE 125-V DC distribution boards.

- Numerous valves require IA for operation, including charging valves which could fail closed on loss of IA, resulting in isolation of normal charging lines. 


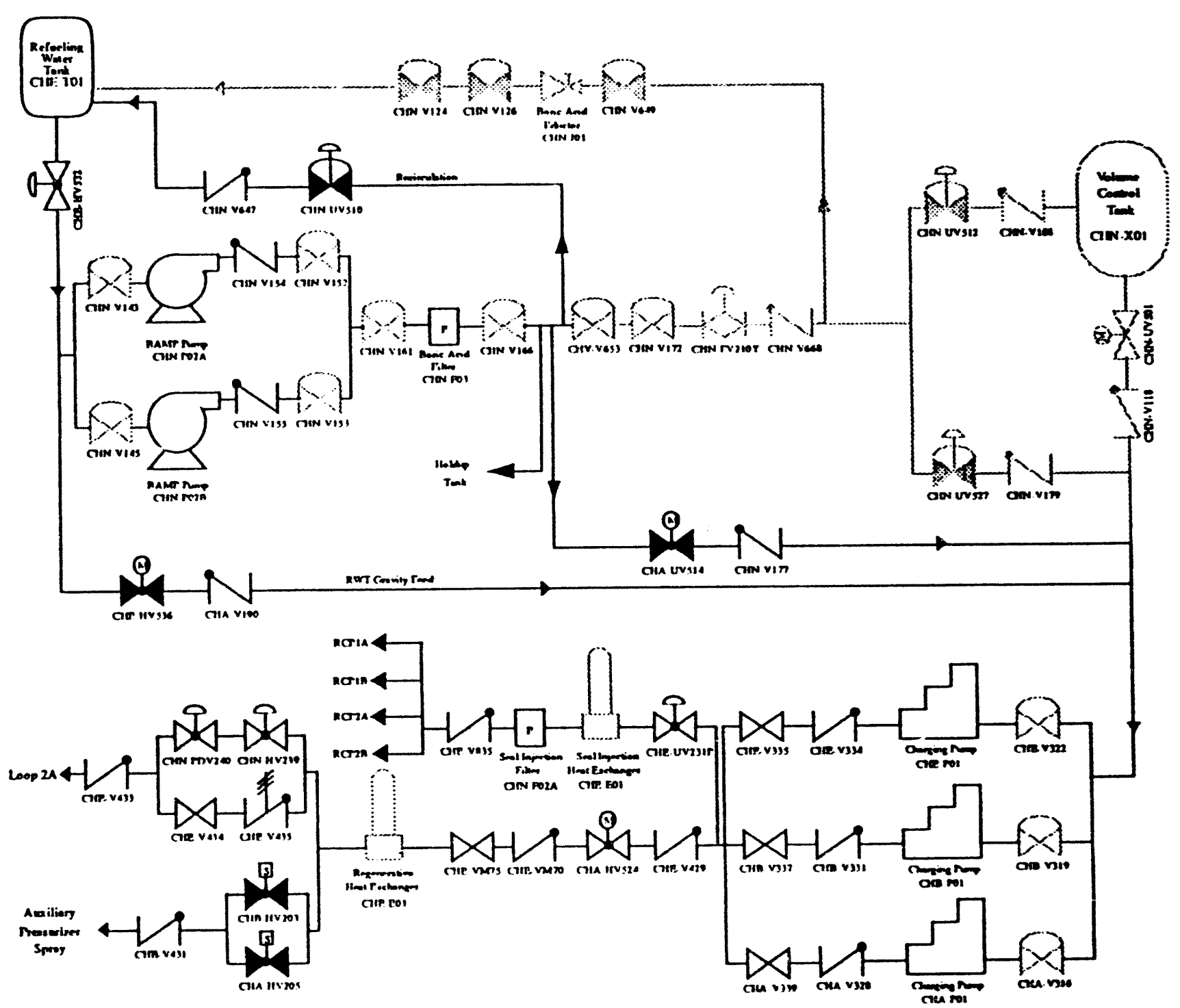

FIGURE D.5. Simplified Diagram of the Chemical and Volume Control System 
- The Auxiliary Bullding Normal HVAC system provides cooling to the CVCS pump cubicles during normal operation. Each pump also has its own dedicated room cooler, which is in operation when the assoctated pump is running. Each room cooler consists of a fan and air cooling colls simflar in design to the LPSI/HPSI pump room coolers. The fan is powered from a Class IE $480-V$ AC MCC.

Calculations indicated that the charging pumps are capable of withstanding a total loss of room cooling without threatening pump operability over its intended mission time. These calculations were reviewed and judged to be adequate to demonstrate a lack of dependence on room cooling to charging pump survivability under loss of room cooling conditions.

\section{D.2.9 Steam Generator Blowdown System}

The function of the steam generator blowdown (SGBD) system is to aid in the removal of contaminated secondary water in the event of a steam generator tube rupture (SGTR). The SGBD system receives flow from a ruptured SG as needed to prevent $S G$ overfill. Blowdown flow is normally taken from the hot leg of a ruptured SG and proceeds through flow control valves into the blowdown flash tank. Flow from the flash tank is routed through blowdown processing equipment, which includes a heat exchanger, filter, and demineralizer. The processed water is then returned to the main condenser for reuse. A level control valve on the flash tank outlet line regulates flow to the blowdown processing equipment. No dependencies on HVAC or room cooling were identified.

\section{D.2.10 Pressurizer Vent Valves}

The pressurizer vent valves provide a vent path from the top of the pressurizer to either the reactor drain tank or the containment atmosphere. The valves are used to remove steam from the pressurizer during accident conditions to allow operators to control RCS pressure. The pressurizer vent valves, consisting of five one-inch solenoid-operated valves, provide a means of depressurizing the RCS following a SGTR event. Operator action is necessary to open the pressurizer vent valves. No dependencies on HVAC or room cooling were identified.

\section{D.2.11 Iurbine Bypass Valves}

The turbine bypass valves (TBVs) function to reject steam from the main steam header to the main condenser and/or atmosphere. The TBV system allows operators to avoid unnecessary reactor trips and challenges to main steam safety valves (MSSVs) in the event of a turbine load-rejection event or turbine trip event.

The TBV system consists of eight air-operated, fail-closed, quickopening valves. The eight TBVs are grouped into five sequentially operated control banks. The first four banks discharge to the main condenser and the 
fifth discharges to the atmosphere. The bank that discharges to the atmosphere is the last to open and first to close to minimize loss of secondary coolant to the atmosphere.

In the event of a small LOCA, at least one of eight TBVs must open to vent secondary steam. If HPSI is unavallable and a rapid depressurization is necessary, at least two TBVs must open. In the event of a SGTR and most other transients, at least one of eight TBVs must open to relleve secondary steam pressure. In the event of a loss of MFW, at least one TBV must open in conjunction with proper AHFW operation. No dependencies on HVAC or room cooling systems were identified.

\section{D.2.12 Atmospheric Dump System}

The atmospheric dump valves (ADV's) provide a means of removing primary coolant system decay heat in the event that the turbine generator and main condenser are unavailable and in the event of a loss of AC power. The ADVs can be used to reduce secondary system pressure to entry conditions for AHFW in the event that AFW systems are unavailable. The ADVs can also be used in conjunction with HPSI following a small-break LOCA as a means of depressurizing the RCS to the point at which the LPSI pumps can provide RCS inventory control. At least one out of two ADVs must function in response to small LOCAs, SGTRs, steaml ine breaks, feedwater line breaks, transients, LOOP, loss of MFW, and SBO.

The AD system consists of four manually operated ADVs located in the MSSS. Each of the two SGs includes two redundant ADVs, one per main steam line. The ADVs are pneumatically operated and are provided with remote-manual control capability as well as local handwheels. There are no automatic initiating circuits provided. No dependencies on HVAC or room cooler systems associated with $A D$ valves or support equipment were identified.

\section{D.2.13 Essential Chilled Water System}

The essential chilled water (EC) system is a support system that provides chilled water to essential HVAC systems for the Control Building, Auxiliary Building, and MSSS. Essential HVAC and EC systems are safetyrelated systems that cool safety-related equipment rooms during emergencies.

The EC system is a normally standby system consisting of two $100 \%$ capacity, redundant, chilled water trains. Each train includes its own chiller, pump, expansion tank, chemical addition tank, control valves, piping, and instrumentation. Each train is a closed-loop system, and the trains are not cross-connected. Cooling water for the chiller condensers is provided by the essential cooling water (EW) system (see Section D.2.14). A simplified diagram of the EC system is provided in Figure D.6. 


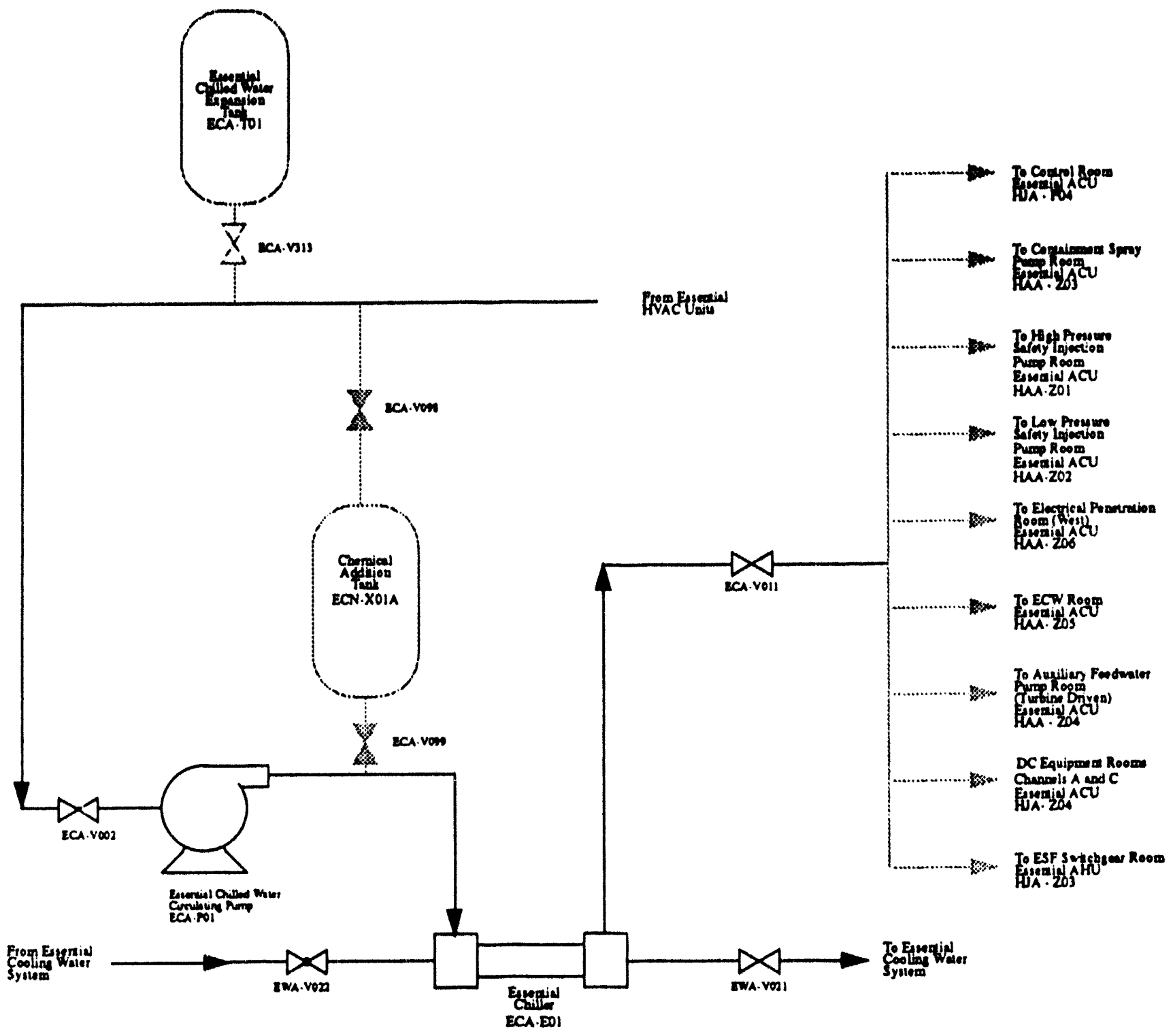

FIGURE D.6. Simplified Diagram of the Essential Chilled Water System Train A

The EC system provides chilled water to the following air conditioning units (ACUS) and air handling units (AHUS):

- Control room AHU

- HPSI pump rooms

- LPSI pump rooms

- ESF switchgear rooms (including battery rooms)

- $D C$ equipment rooms (includes inverters, battery chargers)

- Electrical penetration rooms 
- Auxiliary feedwater pump rooms

- Containment spray pump rooms

- Essential couling water pump rooms.

The EC system is actuated when the ESFAS starts the safety-related components in the rooms identified above. The EC system may also be started manually from the control room or locally from its switchgear.

The EC system is dependent upon the following for successful operation:

- ESF load sequencers send autostart signal on AFAS, SIAS, LOP, control room essential filtration actuation signal (CREFAS), and control room ventilation isolation actuation signal (CRVIAS). At the same time, the EW and spray pond systems are started automatically by the ESF load sequencer.

- The essential chillers receive motive power from separate Class 1E 4.16KV AC buses. The chilled water pumps receive power from separate Class IE 480-V AC MCCS. Control power is provided by separate Class IE DC panels.

- Each chiller requires essential cooling water for heat rejection.

Most of the relevant safety-related equipment room cooling information was presented in previous sections (e.g., HPSI pump room cooling, LPSI pump room cooling). It is important to note that failure of the EC system could lead to failure of the safety-related components in rooms cooled by room coolers that need the EC system to reject heat. In the existing PRA, it was assumed that the EC system must operate for 24 hours following an accident. This was stated to be conservative because even a few hours of EC operation is sufficient to prevent room temperatures from exceeding extreme environmental conditions. Calculations provided by the utility were reviewed, and this conclusion was judged to be adequately founded.

EC pump and chiller room cooling was not modeled in the existing PRA. The pumps and chillers are located in relatively large rooms compared with the much smaller HPSI, LPSI, and CS pump cubicles. Therefore, it would take much longer to heat the EC pump/chiller rooms to the point at which degradation would be expected. Based on the loss-of-HVAC analyses performed by the utility, it was concluded that the EC pump room temperature will not exceed equipment qualification temperatures within 24 hours, based on the available information. However, if the calculations in Section 4 of the main report indicates that failure of EC pumps is an important contributor to the core damage frequency, further analyses will be performed to determine actual heatup rates in these rooms.

The existing PRA determined that EC system failures were dominated by common cause failures of the chillers and EC pumps. Common cause failures of the EW and SP pumps were also found to affect the avallability of the EC system. In addition, it was found that scenarios in which one train of EC has already failed as a result of the initiating event or due to failures other 
than the EC system, the dominant fallures for the other EC train included autostart fallures due to load sequencer faults, maintenance unavallability, control circult faults, and chiller run fallures. The ESF load sequencers are located in an area adjacent to the control room cooled by the Control Room ACUs. Since the load sequencers are important to actuation of safety-related components, fallure of the ESF load sequencers due to fallure of control room cooling functions will be explicitly modeled in the study.

\section{D.2.14 Essential Cooling Water System}

The essential cooling water (EW) system removes heat from safety-related components at the plant, with the exception of the diesel generators. The safety-related EW system removes heat from the essential chillers and shutdown cooling heat exchangers, and rejects heat to the essential spray pond (SP) system. The EW system also serves as a backup for the nuclear cooling water system, which removes heat from the fuel pool cooling heat exchangers, reactor coolant pumps, control element drive mechanisms (CEDMs), and normal chillers.

The EW system consists of two redundant, closed-loop flow trains. One loop serves Train $A$ shutdown cooling heat exchanger and Train $A$ essential chiller, while the other EW loop serves Train B equipment. Each train includes a pump, heat exchanger, surge tank, piping, valves, controls, and instrumentation. Water is cooled by the EW heat exchanger, which rejects heat to the SP system, and is then pumped to the essential chiller and SDC heat exchanger before returning to the EW heat exchanger. Either EW loop is sufficient to allow safe plant shutdown. Figure 0.7 presents a simplified diagram of the EW system.

The EW system is normally standby and is actuated by ESF load sequencers on SIAS, AFAS, LOP, CSAS, CRVIAS, and CREFAS signals. As with the EC system, EW can also be manually started from the control room and locally started from its switchgear.

The EW system is dependent upon the following for successful operation:

- ESF load sequencers send autostart signal on AFAS, SIAS, LOP, CREFAS, and CRVIAS. In the presence of LOP signal, the ESF load sequencer first load sheds the EW pumps and then restarts them after the diesel generator starts and the $4.16-k V$ bus is repowered.

- The EW pumps receive power from separate Class 1E 4.16-kV AC buses. Control power is provided by separate Class IE $125-V$ DC panels.

- EW pump areas are cooled by an emergency ACU (see Section D.2.13).

- EW heat exchangers require the essential spray pond (SP) system for heat rejection. 


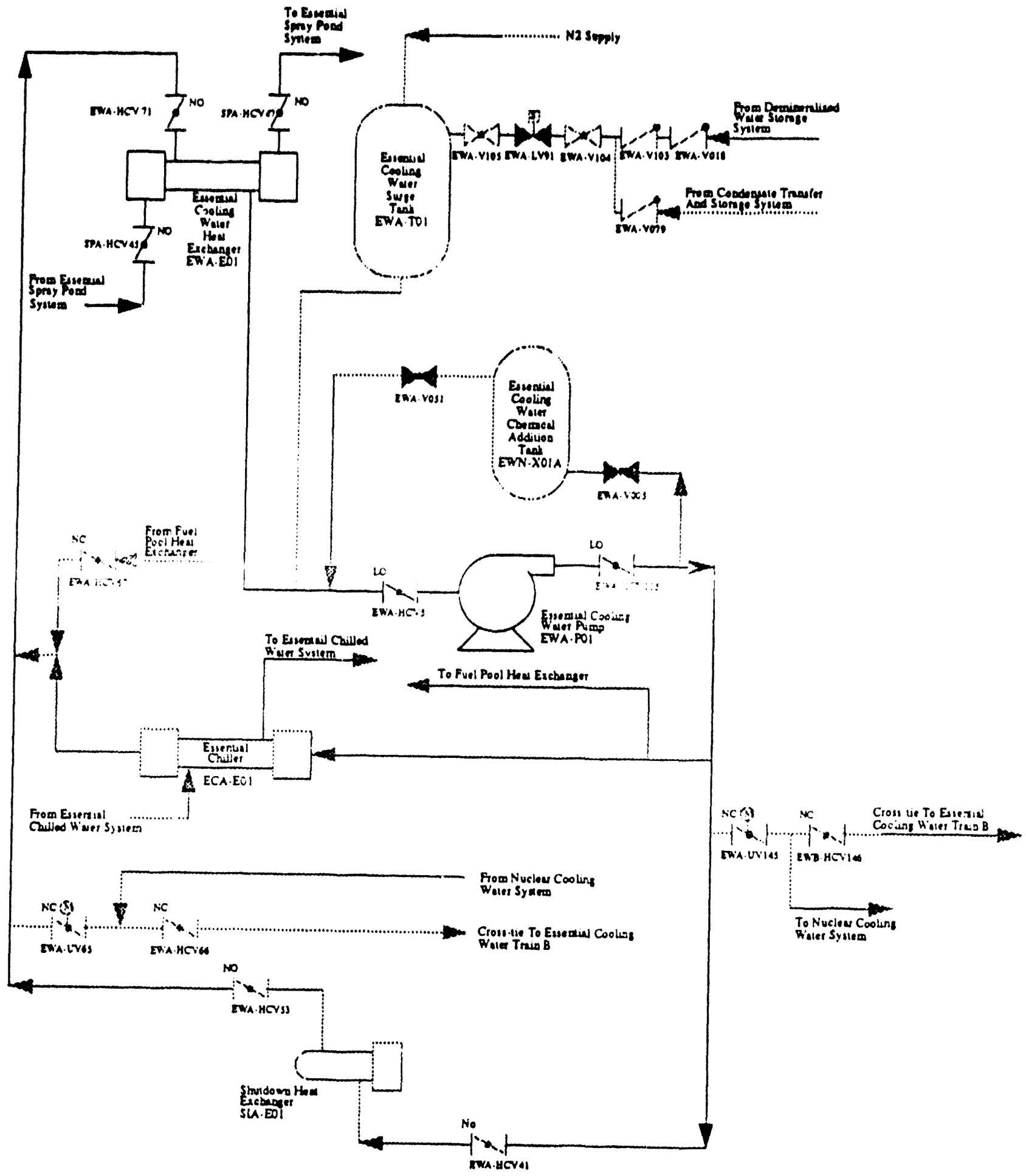

\section{EIGURE D.7. Simplified Diagram of the Essential Cooling Water System -
Train A}


As previously discussed, an emergency ACU is provided for the EW pump spaces. Cooling water for these spaces are provided by the EC system which is in turn cooled by the EW system. Therefore, fallure of the EC system could result in fallure of the EW pumps due to extreme temperatures. Calculations indicated that the EW pump room could reach a maximum temperature of $189 \circ \mathrm{F}$ within 24 hours following a loss of room cooling (see Appendix F). If the pump room door were to be opened two hours after loss of the room cooler, the maximum temperature was calculated to be $168^{\circ} \mathrm{F}$. If no backup cooling to the CS pump cubicle is established, the CS pumps will fail within 24 hours. It was determined that the reliability of the pumps is significantly degraded should room cooling fall. Therefore, the pump fallure probability is increased above the probability used when room cooling is available.

\section{D.2.15 Essential Spray Pond}

The essential spray pond (SP) system is the ultimate heat sink for the representative CE PWR. This system removes heat from the EW system and the diesel generator heat exchangers and dissipates the heat into the atmosphere.

The SP system is normally standby and is actuated by ESF load sequencers on SIAS, AFAS, LOP, CSAS, CRVIAS, and CREFAS signals. As with the EC and EW systems, SP can al so be manually started from the control room and locally started from its switchgear.

The SP system consists of two separate, 100\%-capacity, redundant flow trains. Each train includes its own spray pond, SP pump, piping, valves, controls, and instrumentation. Each flow train takes suction from its respective spray pond, pumps water to appropriate diesel generator and EW heat exchangers, and returns the water to the spray pond via the SP system cooling nozzles that spray into the spray pond. Figure 0.8 is a simplified drawing of the SP system.

The SP system is dependent upon the following for successful operation:

- ESF load sequencers send autostart signal on AFAS, SIAS, LOP, control room essential filtration actuation signal (CREFAS), and control room ventilation isolation actuation signal (CRVIAS). The SP system is also started automatically by a diesel generator start signal.

- The SP pumps receive power from separate Class IE 4.16-kV AC buses. Control power is provided by separate Class IE $125-V$ DC panels.

Although the SP system is important to successful operation of emergency ACUs in safety-related equipment rooms, no dependence on HVAC or room cooling to SP system components were identified. 


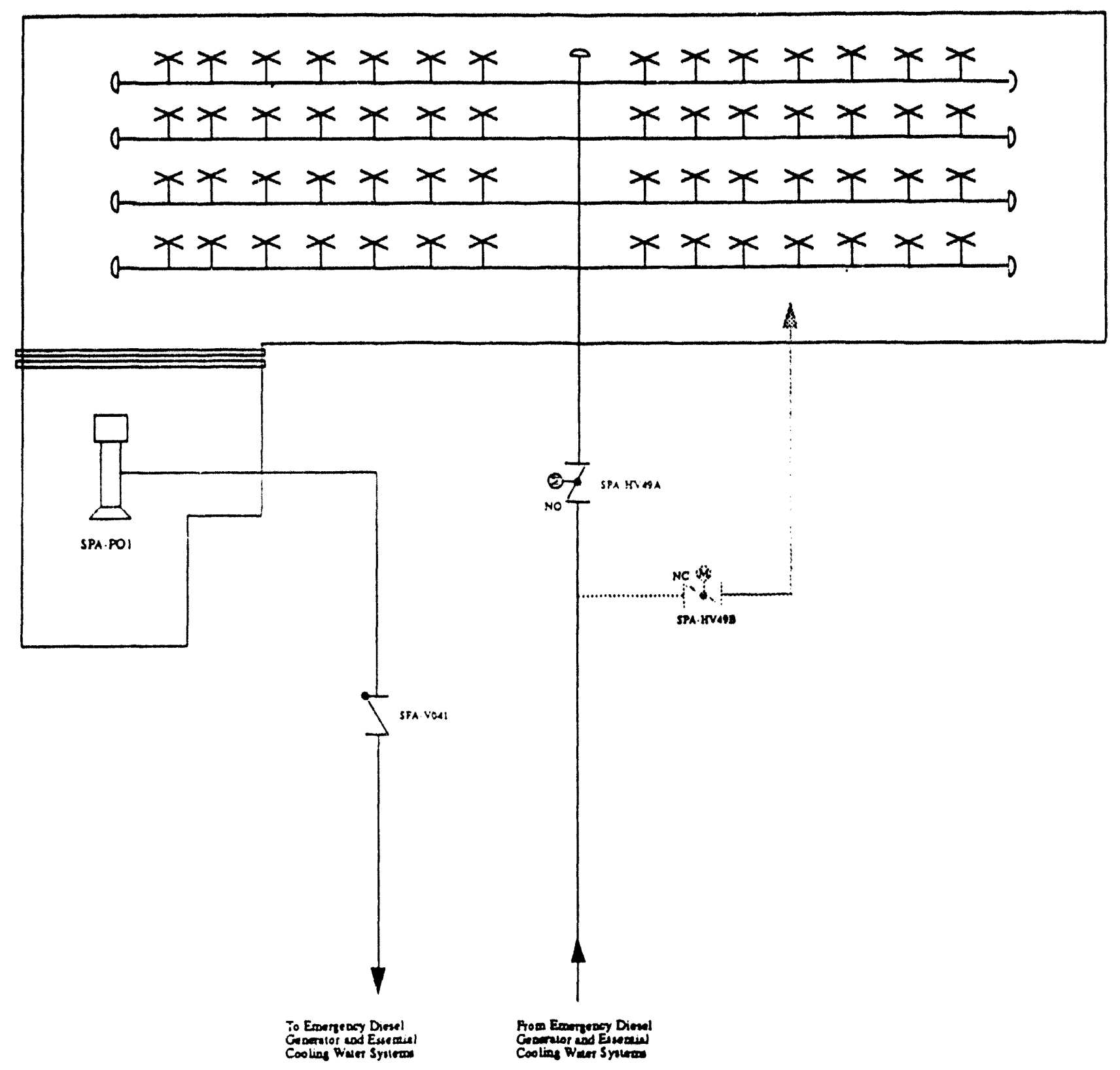

FIGURE 0.8. Simplified Diagram of the Essential Spray Pond System - Train A

\section{D.2.16 Instrument Air System}

The instrument air (IA) system provides a continuous supply of compressed air for operation of pneumatic instruments and control of pneumatic actuators. Three IA compressors in three identical, redundant trains are provided for this function. The IA system is required for plant startup and operation but is not required for safe plant shutdown. There are no dependencies on HVAC or room cooling systems. 


\section{D.2.17 ESF Switchgear "DC Equipment" Room HVAC}

The main function of the ESF switchgear room HVAC system is to provide room cooling to a specific elevation of the Control Building that houses the ESF switchgear, DC equipment, and battery rooms. These areas are provided with both normal and essential HVAC systems. During normal plant operations, these areas are serviced by two normally running AHUs. In the case of SIAS or LOOP signals, the switchgear areas will be isolated from the normal AHUs by closing air-operated HVAC dampers. The switchgear areas will then be served by the essential HVAC system. Separate trains of essential HVAC are provided for each division of switchgear. Each train of essential HVAC includes two essential ACUs, which are started automatically. One ACU in each train provides intake and exhaust area for the switchgear and battery rooms and draws return air from the $D C$ equipment room. The other $A C U$ supplies cooled air to only the DC equipment room. A simplified diagram of the ESF switchgear room cooling system is provided in Figure D.9.

The ESF switchgear room normal AHU consists of a cooling coil and fan. Chilled water is provided by the nonsafety-related normal chilled water (WC) system. The normal HVAC system is designed to maintain room temperatures between $60^{\circ} \mathrm{F}$ and $77 \circ \mathrm{F}$. The essential ACUs are similar in design but have smaller capacities than the normal AHUs. Each essential ACU is sized to remove the heat load of its associated rooms. Cooling water is provided by EC system. The essential ACUs are designed to maintain room temperatures between $40^{\circ} \mathrm{F}$ and $104^{\circ} \mathrm{F}$ to prevent equipment in the rooms from overheating and possibly failing.

The HVAC system is provided with fusible-link fire dampers that are dropped by either high room temperature or actuation of the fire protection system. Closure of a fire damper results in isolation of the respective room from outside air sources and all AHUs.

ESF switchgear room cooling dependencies include:

- Normal AHUs require non-class $480-V$ AC power to start and run. The essential ACUs require Class $1 E$ 480-V AC power to start and run.

Class IE 125-V DC power is required for the isolation dampers.

- The normal HVAC system AHUs require chilled water from the WC system. The essential ACUs require chilled water from the EC system.

- Instrument air is required for operation of the isolation dampers and to hold open the normal AHU chilled water inlet valves. Failure of IA results in failure of the normal HVAC system but not the essential ACUs.

The existing PRA stated that the most sensitive equipment in the DC equipment rooms was qualified to operate at ambient temperatures up to $104^{\circ} \mathrm{F}$. However, further investigations were performed and it was determined that the equipment can actually operate up to $122^{\circ} \mathrm{F}$. 


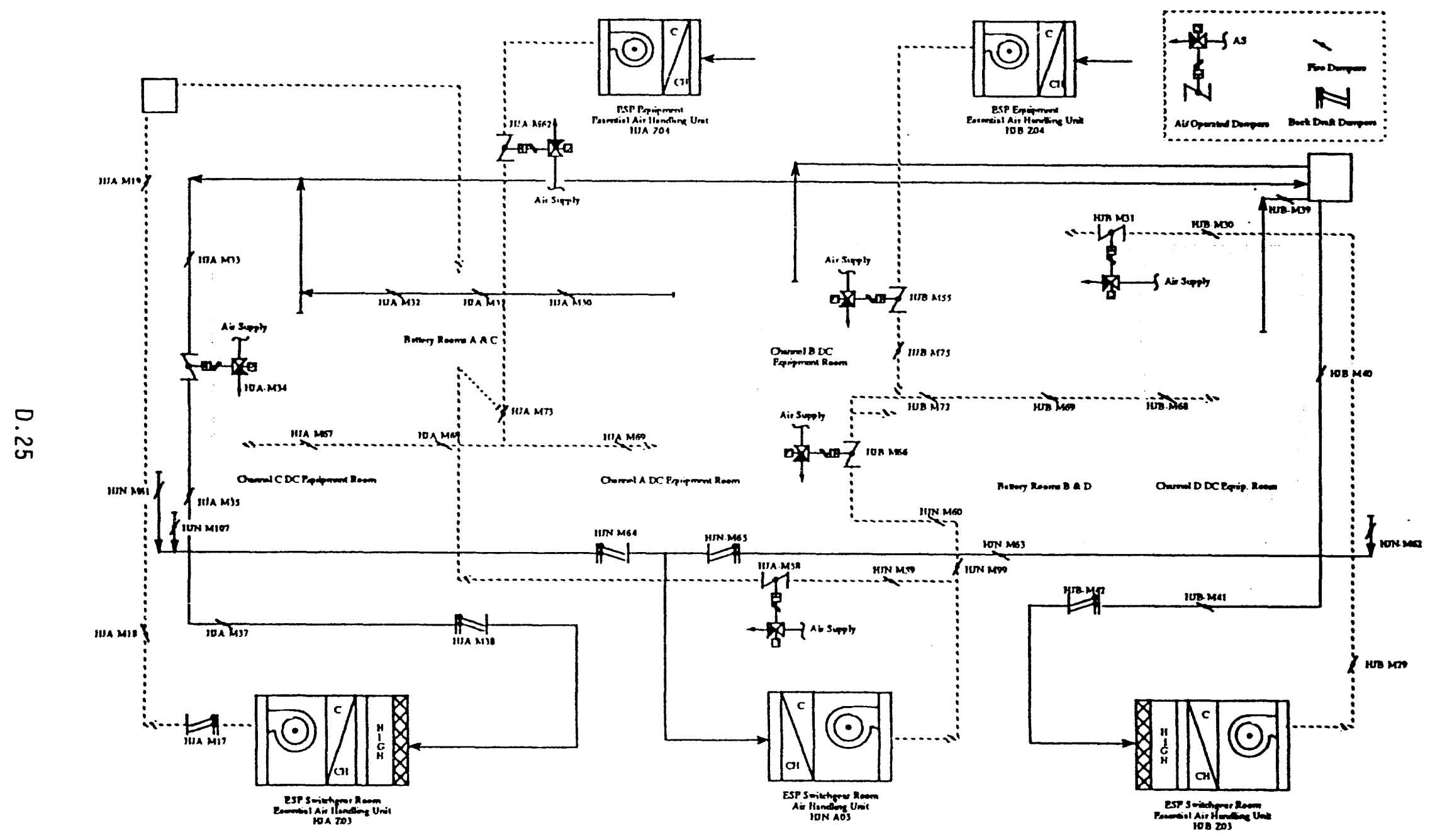

FIGURE D.9. ESF Switchgear Room HVAC System 
Failure of equipment in rooms is dependent upon the length of time that room cooling is unavailable and the condition of the plant at the time that room cooling is lost. It was stated in the representative CE plant's existing PRA that the time before equipment failure ranged from about 45 minutes

following a LOCA to as much as 12 hours following a LOOP. More time is available when the plant is in a normal operating condition. Failure times are also dependent on the type of failure that occurs. For example, closure of the HVAC dampers cuts off all airflow into the room. Temperature rise under these conditions will be much more rapid than the temperature rise experienced when cooling water is lost to an ACU but the fan continues to run. Calculations relative to the $D C$ equipment room indicate that it. would take up to 24 hours for temperatures to reach the $122^{\circ} \mathrm{F}$ solid-state equipment failure temperature if cooling water fails but the fans continue to run.

\section{D.2.18 Control Room HVAC}

The control room HVAC (CR HVAC) system provides cooling to the control room, control instrumentation cabinets, computer room, and various office spaces in the Control Building. The CR HVAC system includes a normally operating system and a two-train essential system. The normal HVAC system includes a normal AHU consisting of a cooling coil and fan. The cooling coil is provided with water from the nonessential WC system to cool the passing air flow. The essential CR HVAC system is provided with two redundant AHUs that are provided with chilled water from the safety-related EC system. Upon receipt of an SIAS, CRVIAS, CREFAS, or LOOP signal, the normal HVAC system is isolated by automatic closure of air-operated dampers and both essential AHUs are started. A simplified diagram of the CR HVAC system is shown in

Figure D.10.

System dependencies and interfaces include

- the ESFAS signals normal HVAC isolation dampers to close and starts the essential AHUS.

- Normal AHUs require non-class 480-V AC power to start and run. The essential AHUs require Class $1 E 480-V$ AC power to start and run. Class $1 E$ 125-V DC power is required to actuate the isolation damper solenoid values to open or close.

- The normal CR HVAC system AHUs require chilled water from the WC system. The essential AHUs require chilled water from the EC system.

- Instrument air is required for operation of the isolation dampers and to hold open the normal AHU chilled water inlet valves.

The ESF load sequencers were identified as the equipment of most concern relative to extreme temperatures cooled by the CR HVAC system. This equipment was qualified to operate at temperatures up to $120^{\circ} \mathrm{F}$. The load sequencer cabinets are provided with normally running fans that pull air from the control 


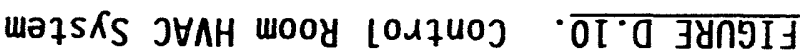

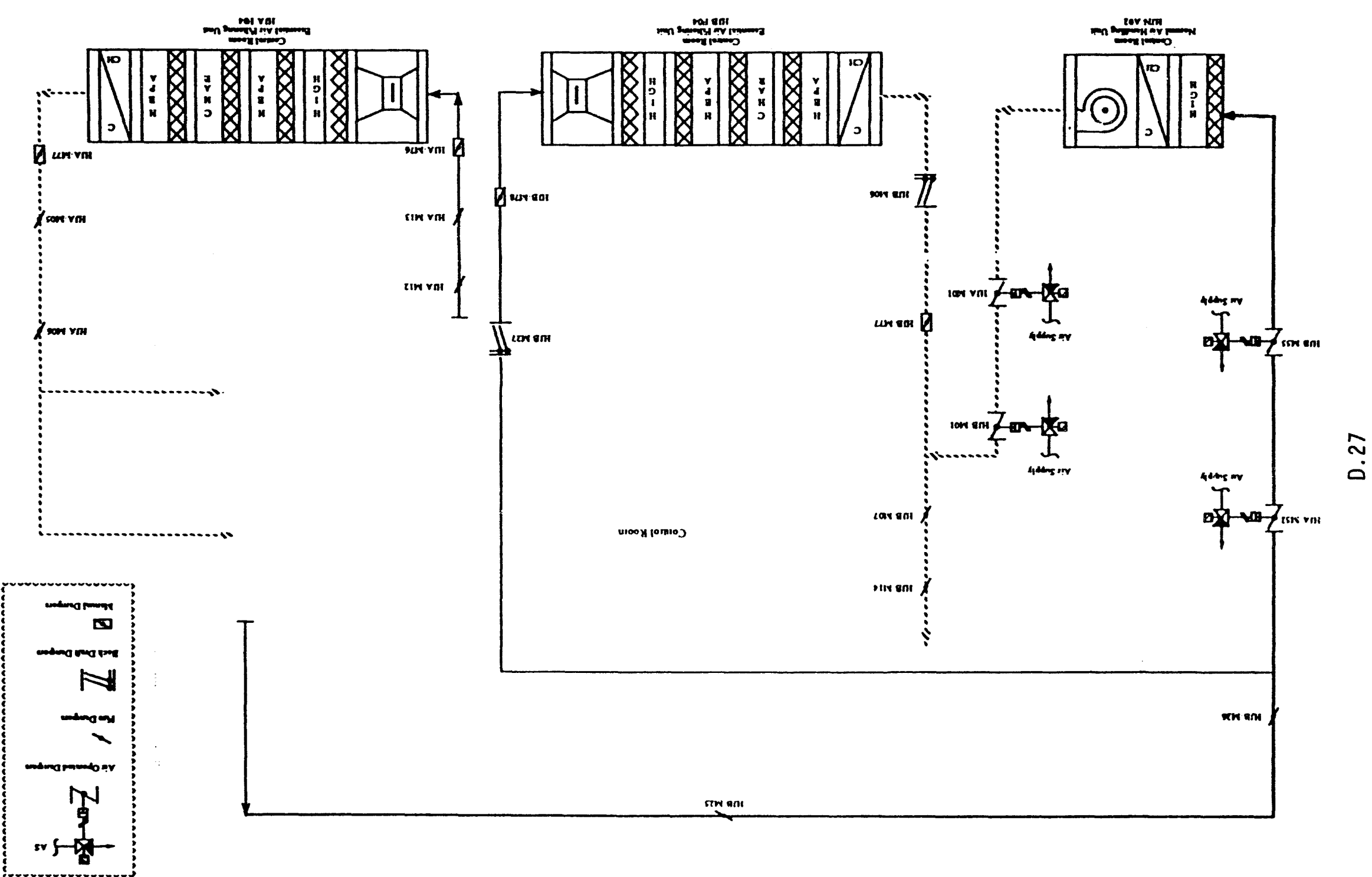


room into the cabinet to enhance cooling and exhaust air back to the CR atmosphere. Failure of the fans could result in heatup of the electronics and failure of the load sequencers.

Total failure of the CR HVAC system was stated in the existing PRA to result in ambient temperatures of about $120^{\circ} \mathrm{F}$ in 15 hours following loss of cooling. The calculations leading to this conclusion were reviewed in this study and judged to provide an adequate basis.

\section{D.2.19 Class 1E 4.16-kV AC Power System (PB)}

The Class IE 4.16-kV AC power system (PB) provides continuous AC power to two divisions of safety-related equipment loads. Power may be received from either the preferred offsite power source or from the emergency diesel generators. The PB system consists of two separate, redundant, $100 \%$-capacity Class $1 E$ 4.16-kv buses, which are powered from offsite sources through the non-Class IE power systems (13.8-kV and 4.16-kV systems) via the ESF service transformers. If offsite power is unavailable, each bus is also automatically supplied standby power from its respective diesel generator. A simplified schematic of the PB system is shown in Figure D.11.

Class $1 E$ loads supplied by the PB system include

- Motor-driven auxiliary feedwater pump (Train B)

- Essential spray pond pumps

- Containment spray pumps

- High-pressure safety injection pumps

- Low-pressure safety injection pumps

- Essential cooling water pumps

- Essential chiller

Each bus also provides power to three Class IE load centers per bus (six total) that step power down to $480-V$ AC for smaller loads. This system feeds $480-V$ AC power to the $480-V$ AC MCCs described below. Figure 0.11 lists the loads on both Class IE 4.16-kV buses.

The Class 1E 480-V AC MCCs are a separate system that distributes $480-V$ $A C$ power from the $480-V$ switchgear system to various valve motors, small fans, battery chargers, voltage regulators, and other small 480-V loads. The $480-V$ power MCC system consists of eight MCCs (four per load group) located in the electrical penetration rooms (6) and the Control Building ESF switchgear rooms (2). The MCCs are metal-enclosed cabinets cooled by air circulated through inlet louvers in the bottom of the cabinet and outlet louvers at or near the top. Fans are provided in some instances to enhance air circulation through the cabinets. The existing PRA stated that room cooling for these cabinets was not needed for the required 24-hour mission time. This assumption is examined further in this study.

The balance of plant (BOP) ESF actuation system (ESFAS) provides automatic sequencing of loads onto the PB buses. Upon loss or degradation of offsite power to either bus, the BOP ESFAS will trip normal and alternate 


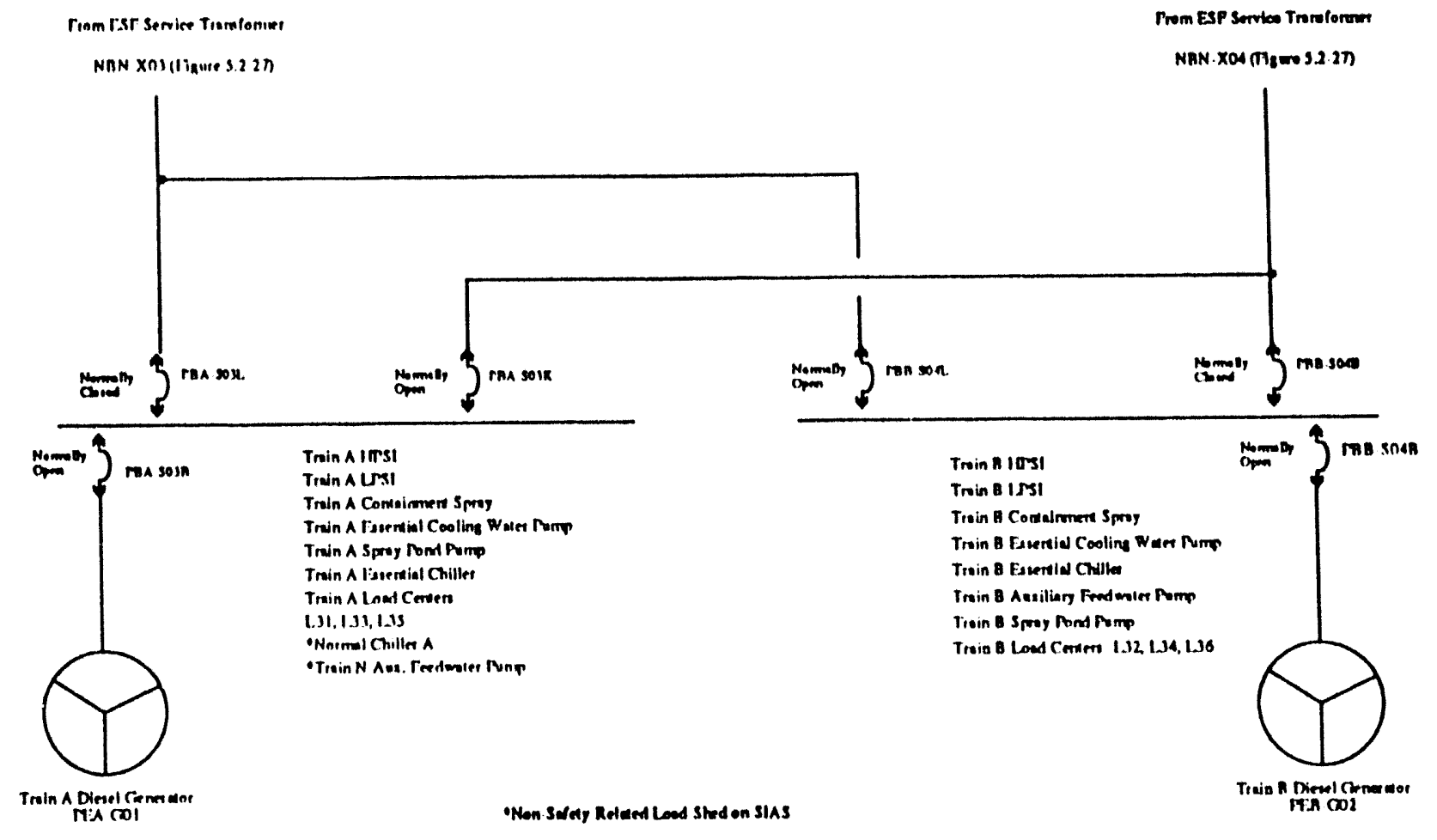

FIGURE D.11. Class 1E 4.16-kV AC Power System

offsite power supply breakers, start onsite diesel generators, load-shed the buses, close diesel generator output breakers, and sequence safety-related equipment loads back onto the buses.

The PB system is indirectly dependent upon control room HVAC. The BOP ESFAS cabinets are locatec adjacent to the CR. If CR HVAC is lost, the BOP ESFAS cabinets may overheat and generate spurious load-shed signals. Problems with the cabinet fans have been experienced in the past, resulting in elevated temperatures in the load sequencer cabinets, that resulted in a continuous load-shed signal being sent to the PB system buses. This effectively rendered inoperable one entire train of safety equipment, including HPSI, LPSI, CS, and AFW pumps, because of the inability to load the equipment onto the bus. Failure of load sequencers is explicitly modeled in the existing PRA as well as in this study.

The 4.16-kV buses were indicated, based on HVAC analyses, to not require room cooling to function properly over the 24-hour mission time required in the existing PRA.

\section{D.2.20 Standby Generating System}

The Class $1 E$ itandby generating system provides an independent source of onsite electric power for both trains of ESF equipment. This system consists 
of two diesel generators connected to the 4.16-kV buses described in Section D.2.19. The diesel generators are separate and independent from each other and are capable of providing all needed electrical power to ESF components for at least seven hours. The diesels are housed in separate rooms in a seismic category I structure that provides missile and fire protection between rooms to maintain physical separation. The standby generating system is shown in Figure D.11.

Each diesel generator room is provided with a once-through ventilation system that is automatically started when the diesel generators start. The ventilation system consists of intake and exhaust fans, ductwork, and dampers. The intake fan pulls outside air into the diesel generator room through a normally closed damper that must open to permit outside air into the room. The exhaust fans pull the air past the diesel generators and exhaust to the atmosphere to remove heat. The existing PRA assumes that the diesel generator building HVAC system is not needed to maintain operability over the required seven-hour mission time. However, loss of diesel generator HVAC will be considered as a contributor to failure of the onsite power system in this study due to the rapid heatup rates in these rooms given a loss of cooling. Perhaps as 1 ittle as 15 minutes following loss of HVAC may be needed to fail the solid state diesel generator control equipment housed in the room.

System dependencies and interfaces include the following:

- Class 1E 125-V DC power is needed for engine/generator control and for field flashing.

- The diesel generators supply 4.16-kV AC power to the ESF PB buses (see Section D.2.19).

- The diesel generators are started automatically by the BOP ESFAS on loss or degraded offsite power, AFAS, SIAS, or CAS signals. The diesel generators may also be started manually from the control room.

- The essential spray pond pump is required to provide cooling water to remove heat from the intake air, fuel oil, jacket water, and lube oil coolers.

As mentioned above, the existing PRA did not model the diesel generator room ventilation system. Failures of this system are considered in this study as potential contributors to failure of the diesels to run for the required seven-hour period following their actuation.

\section{D.2.21 Class 1E 125-V DC Power System}

The Class IE 125-V DC power system provides a source of continuous power for the four independent groups of Class $1 E$ DC loads and vital inverters. There are four channels of $125-V$ DC power, two associated with each load group, as shown in Figure D.12. Each channel consists of a battery, a DC control center, and dedicated battery charger. Each battery is located in a 
separate room, and each DC equipment control center, including the vital inverters and battery chargers, is located in a separate room.

System dependencies and interfaces include the following:

- Battery chargers receive power from the Class IE 480-V MCC system, each from a different MCC.

- The DC control centers provide control power to DC MOVs, an inverter for the 120-V vital AC power system, and a distribution panel. Channel $A$ al so provides power to the turbine-driven AFW pump speed governor. Channels $A$ and $B$ distribution panels al so provide power to $4.16-k V$ and $480-V$ switchgear breaker controls and diesel generator field flash and control power. Fallure of the DC systems would result in fallure of all these systems.

- The BOP ESFAS sheds and reloads the battery chargers.

- The DC equipment rooms are cooled under normal plant operating conditions by the Auxiliary Building normal HVAC system. Under accident conditions, the normal HVAC system is isolated, and the essential HVAC system is started (see Section D.2.17). The equipment most sensitive to high temperatures is the solid state components in battery chargers, vital $A C$ inverters, and backup voltage regulators. Failure temperatures for these components were estimated to be $122^{\circ} \mathrm{F}$ (see Appendix F).

\section{D.3 DOMINANT MINIMAL CUT SETS}

This section presents the dominant minimal cut sets for the CE PWR that were used as the basis for the CDF and public risk calculations in Section 4.3. These cut sets were taken from the existing PRA and used directly or modified as described in Section 4.3. Assumptions used in the quantification of affected parameters were presented in Section 4.3. Values for parameters not affected by this issue were taken from the existing PRA. The affected cut sets and their frequencies are presented in Table D.1. Because the cut sets were entered into a spreadsheet for calculation purposes, some "cells" contain values of 1.0 and are not associated with an event designation.

\section{D.4 REFERENCES}

Arizona Public Service Co. 1992. Palo Verde Nuclear Generating Station Individual Plant Examination. Prepared for the U.S. Nuclear Regulatory' Commission, Washington, D.C. 
TABLE D.1. Minimal Cut Sets Involving HVAC and Room Cooler Failures at the Representative CE PUR

\begin{tabular}{|c|c|c|c|c|c|c|c|c|}
\hline \multirow{2}{*}{$\frac{100}{1}$} & \multicolumn{7}{|c|}{ Cut Ser Eloments and Valives } & \multirow{2}{*}{ 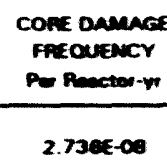 } \\
\hline & IEMISC & IALFW-GOMINS-HR & ISPUPAMFUTRAP-2OP & AFW-ABN-FAN & & & & \\
\hline 2 & IELOOP & LOOP.RECOVFO 2PW & & DGBFANFF24 & IPBASO3B-CXXFT & & & $2.711 E-\infty$ \\
\hline 3 & IELOOP & LOOP.RECOVRJ 2PW & & DGA-FAN-FR24 & IPBBSOAB-CXXFT & & & $2.711 E-\infty$ \\
\hline 4 & IELOOP & LOOP-RECOVFO-2PW & IPEBGO2-DG-2FA & DGA.FAN-FR24 & & & & $6.2776-\infty$ \\
\hline 6 & IEIOOP & LOOP.RECOVRB.2PW & IPEAGO1-DG - 2FR & DGB-FAN-FR24 & & & & $0.277 \in-\infty$ \\
\hline 6 & IELOOP & LOOP.RECOVR3 2PW & IPEAGOT-DG $\ldots F S$ & DGB-FAN-FR24 & & & & $2.264 E-\infty 8$ \\
\hline 7 & IFLOOP & LOOPRECOVR3 ZPW & IPEBGO2 DG 2FS & DGA-FAN-FRZZ4 & & & & $2.25 .4 E-\infty 8$ \\
\hline 8 & IELOOP & LOOP-RECOVR3.2PW & IPEAGOI DG CM & DGB-FAN-FR24 & & & & $1.712 E-\infty$ \\
\hline 9 & IELOOP & LOOP RECOVHJ 2PW & IPEBGOZ.DG CM & DGA-FAN-FR24 & & & & $1.712 E-\infty$ \\
\hline 10 & IEMISC & INANSO4B - CXXFT & & & AFW-ABN-FAN & & & $1.7335-08$ \\
\hline 11 & IEMISC & INANSOAB CBOFT & & & AFW-ABN-FAN & & & $1.200 E-08$ \\
\hline 12 & IECONDVAC & ISAOAFIOA HA & ISAOAFZOA HA & & IAFW-NOMFWMND HR & CRAC-FA-NAFEC & & $3.243 E-\infty 8$ \\
\hline 13 & IEPKBMMA2-HVAC & IAFAPOI TPAFS & & & IAFW-MFW -HA & & & $3.200<-\infty 0$ \\
\hline 14 & IEPKBMA2.HVAC & ISPURMAWTRAP-2OP & 1AFAPO1 TPAFS & & IAFW-NOMFW W.HA & & & $3.200 E-\infty 0$ \\
\hline 16 & IEFWP & ISAOAFIOA HR & ISAOAFZOA HR & & IAFW-NOMFWMND-HA & CRAC-FA NAEC & & $2.2506-00$ \\
\hline 16 & IETI & ISAOAF IOA W...HR & ISAOAF 2OA HA & & IAFW-MFW-MOINOHR & CRUC-FP.NAEC & & $2.2606-\infty 8$ \\
\hline 17 & IELOOP & LOOP-RECOVR7 2PW & IGANZBACKUP 2HR & DGB-FAN-FA24 & IAFAPO1-TPAFS & & & $9.204 E-\infty$ \\
\hline 18 & IELOOP & LOOP.RECOVPB 2PW & & DGA.FAN-FR24 & IAFBPOI MPAFA & & & $16000-\infty$ \\
\hline 19 & IET & ISAOAF IOA .....HR & ISAOAF ZOA WR HR & ISPURMFWTAAP ZOP & TAFW-NOMFWIND-HAR & CARC-FA-NAEC & & $1.02 E-\infty 8$ \\
\hline 20 & IELOOP & LOOP-RECOVRT-2PW & IGAN2BACKUP - 2HA & DGB-FAN-FR24 & IAFAFO1 ....TPAFF & & & $.3036-00$ \\
\hline 21 & IELOOP & LOOP RECOVR3 2PW & & DGA.FAN-FP24 & IAFBPO M MPQCM & & & $7.1336-\infty$ \\
\hline 22 & IELOOP & LOOP FECOVRI ZAW & IAFAPO1...TPAFS & DGI2-FAN-CC & & & & $1.3656-08$ \\
\hline 23 & IELOOP & LOOP.RECOVRI 2PW & IAFAPOI I...TPAFS & D.S12-DAMPER-CC & & & & 8. DTOE-10 \\
\hline 24 & IELOOP & IPKAMAI BAKUP.EE & LOOP-AECOVR1-2PN & DGB-FAN-FR24 & TPKAFI1-BX-PW & & & $0.6606-\infty$ \\
\hline 26 & IELOOP & 1AFBPOY-NOBACZOP & LOOP-RECOVR3-2PW & DGA.FAN-FR24 & IECBEO1-_-CXEFS & & & $6.130 x-\infty$ \\
\hline 26 & FELOOP & 1OOP-FECOVAT -2PW & 1PEBGO2.0G -2FA & nGA.FAN-FA24 & IAFAPO1-TPAFS & & & $6.062 E-\infty$ \\
\hline 27 & IELOOP & LOOP-RECOVRI 2PW & IPEAGO DG DFA & DGB-FAN-FR24 & IAFAPO1-TPAFS & & & $5.002 E-00$ \\
\hline 28 & IELOOP & LOOP-RECOVRT 2PW & 1PEBGO2-DG CM & DGA.FAN-FP24 & IAFAPO1_-TPAFS & & & $1.381 E-09$ \\
\hline 29 & IELOOP & LOOP RECOVRT 2PW & IPEAGOI DG CM & DGB-FAN-FA24 & IAFAPO 1-..TPAFS & & & $1381 E-\infty$ \\
\hline 30 & IELOOP & LOOP-RECOVRI ZPW & IPEBGO2-DG $2 \mathrm{FS}$ & DGA-FAN-FR24 & IAFAPO1 1...TPAFS & & & $1.0786-\infty$ \\
\hline 31 & IELOOP & LOOP-RECOVR! 2PW & IPEAGO1-DG W2FS & DGB-FAN-FF24 & IAFAPO1-TPAFS & & & 1.818E-00 \\
\hline 32 & ICRANC COOL12DHL & IEMOD & IHJAUVITA.7BCXXRO & ICR-ESSHVAC--2HR & & & & $1.806 \mathrm{E}-08$ \\
\hline 33 & ICRHVC-COOL12DHL & IEMOD & 1HJBUYBA-BBCXXRO & ICR-ESSHVAC-.2HR & & & & $1.006 \mathrm{E}-\infty$ \\
\hline 34 & ICRHVC COOL12DHL & IEMOD & IHJNHVAC CR -2OP & ICRESSHVAC-2HR & & & & $1761 \varepsilon-\infty$ \\
\hline 36 & IET & INANSOAB CXXFT & & & AFW-ABN-FAN & & & $3.6486-00$ \\
\hline 36 & IEMLOCA & ISAB-CSS FR & & & & CSSA-FAN-FA & & $1.0036-10$ \\
\hline 37 & HEMLOCA & ISIACSSS-FR & & & & CSSB-FAN-FA & & $10036-10$ \\
\hline 38 & IEMLOCA & & & & & CSSAB+AN-CC & & $1.6 \pi 5 E-\infty 8$ \\
\hline 39 & IEIAS & AE-1A-DGCOMP & ISGNXO2-ACUM-2OP & IGANZBACKUP - ZHR & 1AFBPOT-NOBACZOF & NAPOI-FANHFA24 & IECBEO1 CXBF & 6.6RAE-D \\
\hline 40 & IELOOP & LOOP-RECOVRT 2PW & IGANZBACKUP.-2HR & & AFAPOI-FAN-FR24 & IPBESOAB CXXFT & & 6. $187 E-\infty$ \\
\hline 41 & ETCW & PE-IA DGCOMP & ISGNX02-ACUM-2OP & IGANZZACKUP-.2HA & 1AFBPOI-МOBAC 2OP & AFAPOI FAN-FR24 & IECBEO & $6.0006-\infty$ \\
\hline 42 & IELOOP & IGANZBACKUP--2HR & 1 AFAPO1 $\ldots$ TPAFR & & & CRAC-FA.NPAC & & 5.8666 .00 \\
\hline
\end{tabular}


IABLE 0.1. (contd)

\begin{tabular}{|c|c|c|c|c|c|c|c|c|}
\hline \multirow{2}{*}{$\frac{\text { No. }}{43}$} & \multicolumn{7}{|c|}{ Cur Sin Elomentes and Velium } & \multirow{2}{*}{ 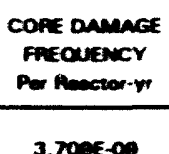 } \\
\hline & IELOOP & LOOPAECOVP3-2PW & DGBFANFA24 & 1SPAPS! Aapocm & & & & \\
\hline 4 & ELOOP & LOOPAECOVR3-2PW & DGAFANFR24 & 18pepo1_apeccu & & & & $3.2000--\infty 0$ \\
\hline 46 & ICAHVC-COOLI2OAL & IEMOD & INAUSO2E-CXEST & ICRESSHVAC-2HA & & & & $1.3476-\infty$ \\
\hline 46 & ELLOP & 1AFEPOI-NOBAC2OP & & & & Cractranac & 1EWEP01_ mpeccu & $2.3838-10$ \\
\hline 47 & NELOOP & 1AFEPO1-NOEACZOP & CRACFANAMC & 1SPAPO1 - MPPECM & & & & $2.3653 x-10$ \\
\hline 48 & EELOP & 1AFEPO1-NOBAC2OP & CRAC-FRARAC & 1EWEP01_- АPPCCM & & & & $2.3835-10$ \\
\hline 48 & NELOOP & IAFBPOI-NOBAC2OP & CrAC framaC & 1SPAPO1 - MPPOCM & & & & $2.393 E-1 C$ \\
\hline 60 & rens & RE-A-DGCOMP & $180 \mathrm{~N} \times 02-A C U M-20 P$ & 1GAN2BACKUP-2HA & 1AFBPO1 HOBAC2OP & AFAPO1 FAN-FE24 & 1Ecaeo1-Cxar & 5.cene- $-\infty$ \\
\hline 61 & ELOOP & LOOPAECOVR7-2PW & 1GAN2BACKUP-2HR & 1AFAPO1-TPAFS & DGBFANFR24 & & & $0.2006-00$ \\
\hline 62 & IELS & FE-AA-DGCOMP & ISGMXO2-ACUM-2OP & IGAN2BACKUR-2tR & 1AFEPO1-MOQAC2OP & NFAPOI IANFFR24 & 1ECEEO1 - ARTC & $4.1508-\infty$ \\
\hline 63 & Ielas & PE-LA-DGCOMAP & 18GNXX2-ACUMA-2OP & 1GAN2BACKUP-2HA & IAFEPOI MOBACZOP & AFAPO1-FANFA24 & IHEOHVACANW-20 & $4.168 E-00$ \\
\hline 64 & हाT & INANSOAB-CBOFT & & & APW-ABNFAN & & & $2.644 E-\infty 0$ \\
\hline 66 & ETCW & PEE-AA-DGCOMPP & 1SGNX02-ACUM-2OP & 1GAN28ACKUP-2HAR & 1 AFAPO1 HOBAC2OP & AFAPO1 + ANFFR24 & IECBEO1-CX8F & $6.0406-00$ \\
\hline 66 & GELOOP & 1 AFEPO1-NOEAC2OP & & DGAFANFR24 & & & 1ECBPO1 -Maff & $1.161 E-08$ \\
\hline 67 & ELOOP & 1AFEPO1 NOBAC2OP & & DGAFANFR24 & 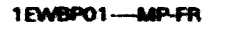 & & & $1.151 E-08$ \\
\hline 68 & IELOOP & 1APBPO1-MOBAC2OP & IECBEOI-ARYCM & 1SPAPO1-CXEFS & & & & $1.1686-07$ \\
\hline 69 & ELOOP & 1NFBPO1-MOBACZOP & IHAOHVACAFW-2OP & 1SPAPO1-CXEFS & & & & $1.160<-07$ \\
\hline 60 & IELOP & I AFEPO1 $\triangle \mathrm{NOBAC2OP}$ & CRAC-fRAREC & 1SPAPO1-CXEFS & & & & $2.016 e-10$ \\
\hline 61 & IELOOP & 1AFEPO1-NDEACZOP & & & & Crucfanduec & 1EWEPO1-CXEFS & $2.01 e x-10$ \\
\hline 62 & ETCW & PE-AA-DGCOMPP & $18 G N \times 02 . A C U M-20 P$ & 1GAN28ACKUR-2th & 1AFBPO1-NOQAC2OP & NFAPO1 FANAR24 & 1HWOHVACAFW-20 & $3.700 E-\infty$ \\
\hline 03 & IELOOP & 1АFBPO1-MOBAC2OP & DGAFANFFEA & & & & 1ECBEO1-CBFT & $1.0126-\infty$ \\
\hline 64 & IELOOP & IAFEPOI-NOEAC2OP & Crac-frantec & & & & 1ECAPO) - мересм & $1.8336-10$ \\
\hline 66 & IELOOP & 1GAN2BACKUP-2HR & 1AFEPOT-NOEAC2OP & CRAC-FrareC & & & 1ECBPO1-MPeCM & $1.8336-10$ \\
\hline 60 & IETCW & 1SGNX02-ACUM-2OP & IGAN2BACKUP-2HAP & 1AFEPO1 NOBAC2OP & 1AFAPO1-TPECM & CRAC-AndeC & & $1.833 E-10$ \\
\hline 67 & HETCW & 18GNX02-ACUM-2OP & IGAN2BACKUP-2BAP & 1 AFEPO1- $\mathrm{NOBAC2OP}$ & INFAPO1_TPECM & CRACFrafeC & & $1.8336-10$ \\
\hline 68 & EEMS & RE-AADSCOMP & 1SGNX02-ACUA-2OP & 1GANZBACKUP_2H & 1NFEPO1 ADQUC2OP & NFAPO1-FANFR241 & ECEEO1-APOC & $4.168 \varepsilon-\infty$ \\
\hline e日 & velas & PE-AADGCOMP & 1 SGNXX2-ACUM-2OP & 1 Gan28nCKUP-2tai & 1AFDPO1 AOEAC2OP & AFAPO1 FANFP24 & 1HUBHVACAFW-20 & $4.1586-\infty$ \\
\hline 70 & IELOOP & 1GAN28UCKUR-2HA & IAFEPO I - & CANCFAnéc & 1EWEFT162-ITFAO & & & $1.741 E-10$ \\
\hline 71 & ELOOP & 1AFEPO1- MOBAC2OP & & crac frnmEC & 1ECBRT634-ITANO & & & $1.741 E-10$ \\
\hline 72 & IELOOP & 1AFBPOI-NOBACZOP & & Cruc-FanfeC & 1EWERT162-TFNO & & & $1.741 E-10$ \\
\hline 73 & ELOOP & 1GAN28ACKUP-2HR & 1 AFBPO1 MOQAC2OP & CRUCFAREC & 1ECEFTE34-ITFNO & & & $1.741 E-10$ \\
\hline 74 & IEMO & 1CAHVC-COOL 12 2DHL & 1MANSO2-UV-28A & ICRESSHVAC-2HA & & & & $0.324 E-\infty$ \\
\hline 76 & UEPKBMMA2+HVAC & 1SA-MSES-2SA & IPBASO3L-CXXCC & & & & & $7.2806-10$ \\
\hline 76 & IELOOP & 1GANZEACKUR-2HR & 1 AFEPOI AOEAC2OP & AFAPO1 IANFFO24 & 1EWEFa162-MWFNO & & & $1.683 E-\infty 8$ \\
\hline 77 & IELOOP & 1GAN2BACKUR-2HA & 1 AFAPO1 MOEAC2OP & NFAPOI-FANFFO24 & 1ECarseb34-MFFNO & & & $1.603 E-08$ \\
\hline 78 & IELOOP & 1GANZZRCKUP-2HA & 1 AFBPO1 $\triangle$ МOBAC 2OP & IECBE01-CXEFs & $18 G A U$ VI 3AASVFO & & & 8.6enc- - \\
\hline 79 & IELOOP & 1 АFBPO1- ПОВАСС2ОР & DGAFANFR24 & IECBPOI MAPFS & & & & $0.614 E-\infty$ \\
\hline 80 & LELOOP & 1AFBPO1- ALEAC2OP & DGAFANFR24 & IECBEO1_ANAFS & & & & $8.614 E-\infty$ \\
\hline 81 & EELOP & 1AFBPO1-NOBACZOP & DGAFANFREA & 1EWepo1-Mefs & & & & $8.614 E-\infty 0$ \\
\hline 82 & IELOOP & 1 AFBPO1-NOBAC2OP & CRUCFAREFE & 1ECBPO1-CXefs & & & & $1.640 c-10$ \\
\hline 83 & LELOOP & IGANZBACKLUP-2HAR & 1AFBPO1 HOBAC2OP & CRAC-FAnAEC & 1ECBPO1-CXefs & & & $1.540 E-10$ \\
\hline 84 & HELOOP & 1AFBPO1 NOEAC2OP & DGAFANFR2A & 1ECAB-PO1-MPPCC & & & & $2.270 \varepsilon-\infty$ \\
\hline 86 & EELOP & 1 AFAPO1 NOAAC2OP & DGAFANFR2A & 1EWAB-PO1-AMPCC & & & & $2.278 E-\infty$ \\
\hline 86 & IELOOP & 1GAN2BACKUP-2HR & 1AFBPO1-NOBAC2OP & 1ECBEO1_CXBFS & IAFAHVOSG-LAVBCM & & & $8.284 E-\infty 8$ \\
\hline
\end{tabular}


IABLE D.1. (contd)

No.

Cut Sme Elemente and Venture

Cone Danace

Freovency

\section{IELOOP}

IEPKAMMA1 HVAC

1AFEPO1 NOBAC2OP 1ECBEO1-CXBFS

IAFNCPWR-ML HE-DEPEO-AFMNTT

1SPAHVOAOA-MVECM

INLFWEONANS-HAR

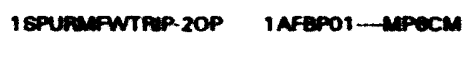

IECBE01-CXBFs

IPKAFI1-BX+W

TOTAL COF:

6.23en-0s

6.39ak-10

8.0006-00

$1.31 \times-\infty$ 
APPENDIX E

SYSTEMS ANALYSIS AND DOMINANT MINIMAL CUT SETS

FOR THE REPRESENTATIVE BABCOCK AND WILCOX

PRESSURIZED WATER REACTOR 


\section{APPENDIX E}

\section{SYSTEMS ANALYSIS AND DOMINANT MINIMAL CUT SETS FOR THE \\ REPRESENTATIVE BABCOCK AND WILCOX PRESSURIZED WATER REACTOR}

This appendix presents the detalled systems analysis, fault tree analysis, and dominant minimal cut sets for the representative Babcock and Wilcox pressured water reactor (B\&W PWR). This appendix supplements the information presented in Section 3.4. Included in this appendix are descriptions of each safety system at the representative B\&W PWR, highlighting the dependencies on HVAC and room cooling functions, as well as the fault tree analyses of the safety systems that are dependent upon successful HVAC/room cooling. In addition, this appendix presents the detalled minimal cut sets that include HVAC/room cooler failure events.

\section{E.1 PLANT AND SITE DESCRIPIION}

The representative B\&W PWR contains three nuclear power plant units. The nuclear steam supply system for each unit consists of two reactor-coolantsystem loops and two once-through steam generators (OTSGs). OTSGs are vertical straight-tube units that produce steam at constant pressure. In commercial operation since 1974, Unit 3, the representative B\&W PWR, produces 2568 MWt full power, generating about 860 MiWe.

\section{E.2 SAFETY SYSTEM DESCRIPTION AND SYSTEMS ANALYSIS}

This section contains a brief description and simplified schematic diagrams of the principal safety systems at the representative B\&W PWR. There are 17 safety systems included in the plant's existing PRA (Duke Power Co. 1990); however, only seven of these systems are affected by this issue.

The following subsections describe the representative plant's safety systems, including dependencies on other systems, and the fault trees for those systems that are related and dependent upon the cooling function.

The safety-related systems identified as having a dependency on HVAC/room cooler systems are listed below:

- Low-pressure injection/recirculation (LPI/R pump room coolers)

- Reactor Building spray system (RBSS pump room cooler)

- PC power system (Auxiliary Building HVAC)

- Standby shutdown facility (SSF HVAC system)

- Control room

An important system not listed above is the high-pressure injection (HPI) system. Operation of the HPI pumps is independent of HVAC systems because the pumps have been qualified to operate in much higher ambient temperatures than the HPI pumps at the other three representative plants. HPI 
pumps are located in a relatively large room connected to a larger common area outside the HPI pump room through open hatches at either end. Due to a large heat sink and the higher equipment qualification temperatures for the HPI pumps, room cooling is not needed for this safety system. In addition, AFW pumps (referred to as emergency feedwater or EFW pumps at the representative B\&W PWR) are located in large, open areas that will not rapidly heat up. Operation of the EFW pumps was judged to be independent of HVAC.

\section{E.2.1 Low-Pressure Injection/Recirculation System}

The low-pressure injection (LPI)/recirculation (LPR) system is designed to perform both normal and emergency functions in several modes of operation.

Under normal conditions, the most frequently used function is decay-heat removal (DHR) after a shutdown. In this mode of operation, the system removes fission-product decay heat during the later stages of cooldown, after the temperature and pressure of the reactor coolant system (RCS) have been reduced by heat removal via the steam generators. The system is also used to supply water for auxiliary spray to the pressurizer, maintain the proper reactor coolant temperatures for refueling, and provide a means for filling and draining the fuel transfer canal.

The emergency functions are LPI and LPR. In the LPI mode, the system provides two flow paths for injecting borated water from the borated-water storage tank (BWST) into the reactor vessel after a loss-of-coolant accident (LOCA). It is designed to cool the core after the core-flood tanks have exhausted their supply of cooling water after a LOCA. In the LPR mode, it also provides two flow paths for recirculating the reactor coolant spilled in a LOCA from the Reactor Building emergency sump back to the reactor vessel. The LPR mode can also be coupled with high-pressure pumps to provide highpressure recirculation capabilities.

Figure E.1 is a simplified diagram of the LPI system, which is a highcapacity, low-head system with appropriate separation and a sufficient number of components to provide two-train redundancy for the safeguards mode of operation. It includes three low-pressure centrifugal pumps, of which two, pumps $3 A$ and $3 B$, are normally available and aligned for LPI operation; pump $3 C$ is valved out and would be load-shed. For operation in the DHR mode, the system includes two decay-heat coolers.

The BWST provides suction for the LPI mode as well as borated water for filling the fuel transfer canal during refueling and for the engineered safeguards systems during emergency core cooling.

In conjunction with other engineered safeguards systems, LPI and LPR are designed to protect the core against overheating for the entire spectrum of RCS break sizes, up to and including a double-ended rupture of a 36-inch pipe. Each train of the LPI system is automatically actuated by a low RCS pressure of 500 psig or a high Reactor Building pressure of $4 \mathrm{psig}$. When the water in 


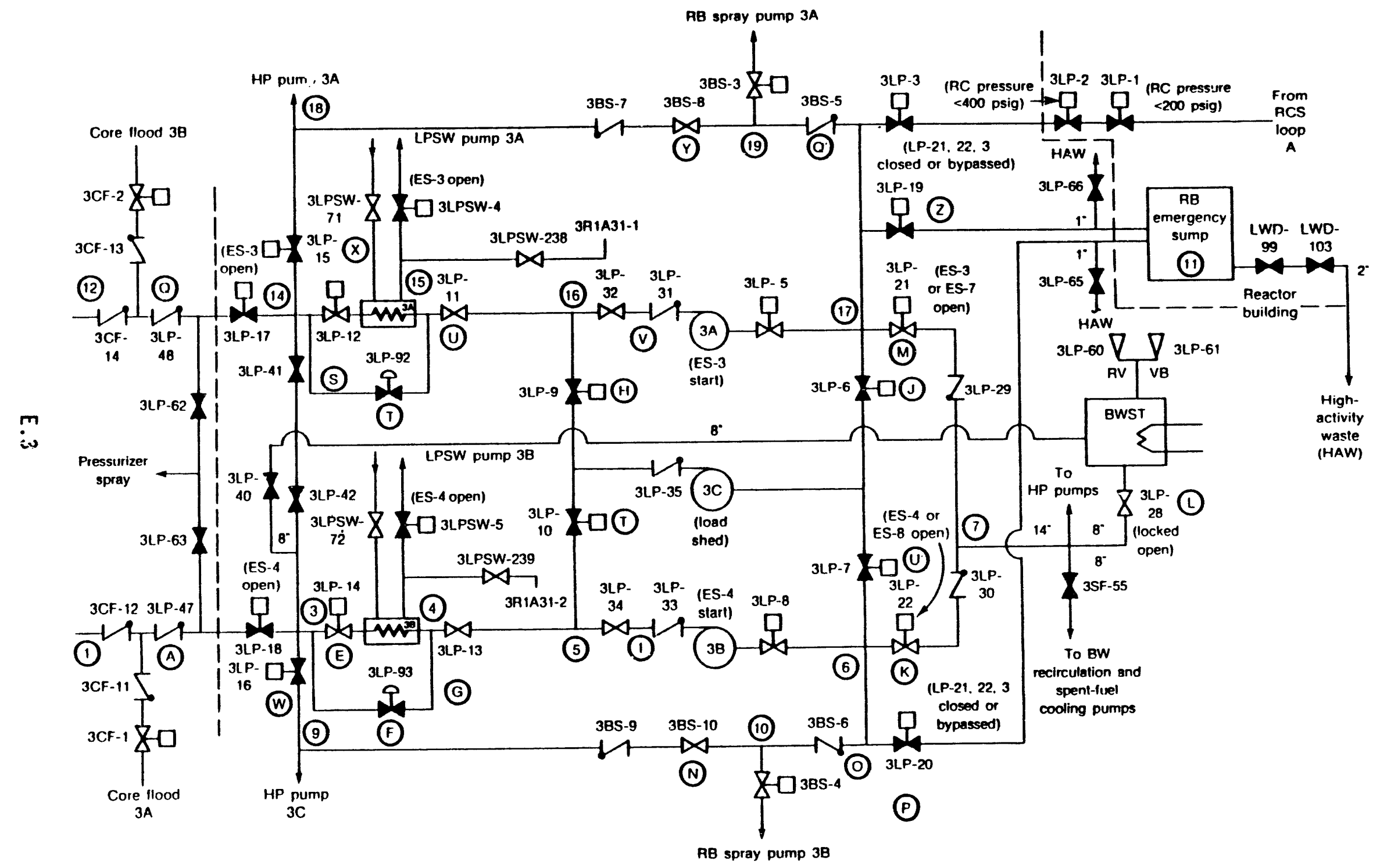

FIGURE E.1. Simplified Diagrams of LPI/LPR System 
the BWST reaches a low level during the LPI mode, a level alarm alerts the operator that the LPI pump suction must be switched from the BWST to the Reactor Building emergency sump.

Loss of HVAC will have an effect on the LPI/LPR systems. The LPI pumpmotor rooms are cooled by room coolers located in the pump rooms. Therefore, the LPI system will fail if HVAC fails.

Separate fault trees were developed for the LPI, LPR, and DHR modes. These fault trees are shown in Figures E.2, E.3, and E.4, respectively.

\section{Low-Pressure Injection}

LPI failure, top gate LP-1, represents failure to deliver flow to the core-flooding nozzles from one of two LPI trains. The fault trees for each train, top gates LP-3 and LP-4, are essentially identical. Top event LP-1 is an $O R$ gate and has two inputs:

- Failure to deliver flow from one of two LPI trains

- LPIS failure through human error.

The latter event is a basic event named $L P A B H$ and represents a human interaction whereby the operator inhibits the entire LPI system.

The failure of a single train will occur if the pump in that train fails to start or fails to continue running for the LPI mode, or if any valve in the flow path from the BWST to the reactor vessel fails to open, was left in the closed position after maintenance or testing, or was inadvertently closed and not reopened. In addition, if valves $3 L P-41,3 L P-42$, and $3 L P-40$ in Train $A$ were all left in the open position after testing or maintenance, the diversion of this flow from the main flow path back to the BWST was considered a failure of Train A. For Train B, failure would result from leaving valve 3 LP-40 in the open position. For certain types of failures, success for Train $A$ or Train B could be achieved by using one of the other LPI pumps and opening the necessary crossover valves, $3 L P-9$ and $3 L P-10$.

Suction flow for the HPI and Reactor Building spray pumps was modeled directly in the LPI and LPR models with the addition of logic for

- LP-15 and LP-16 for HPR

- BS-7, BS-8, BS-9, and BS-10 for the mode of the spray pumps requiring flow through the coolers.

For injection, the BWST suction source is the same for HPI and requires the BWST development, while the Reactor Building spray pumps may be able to draw suction from the discharge side of the LPI pumps. 


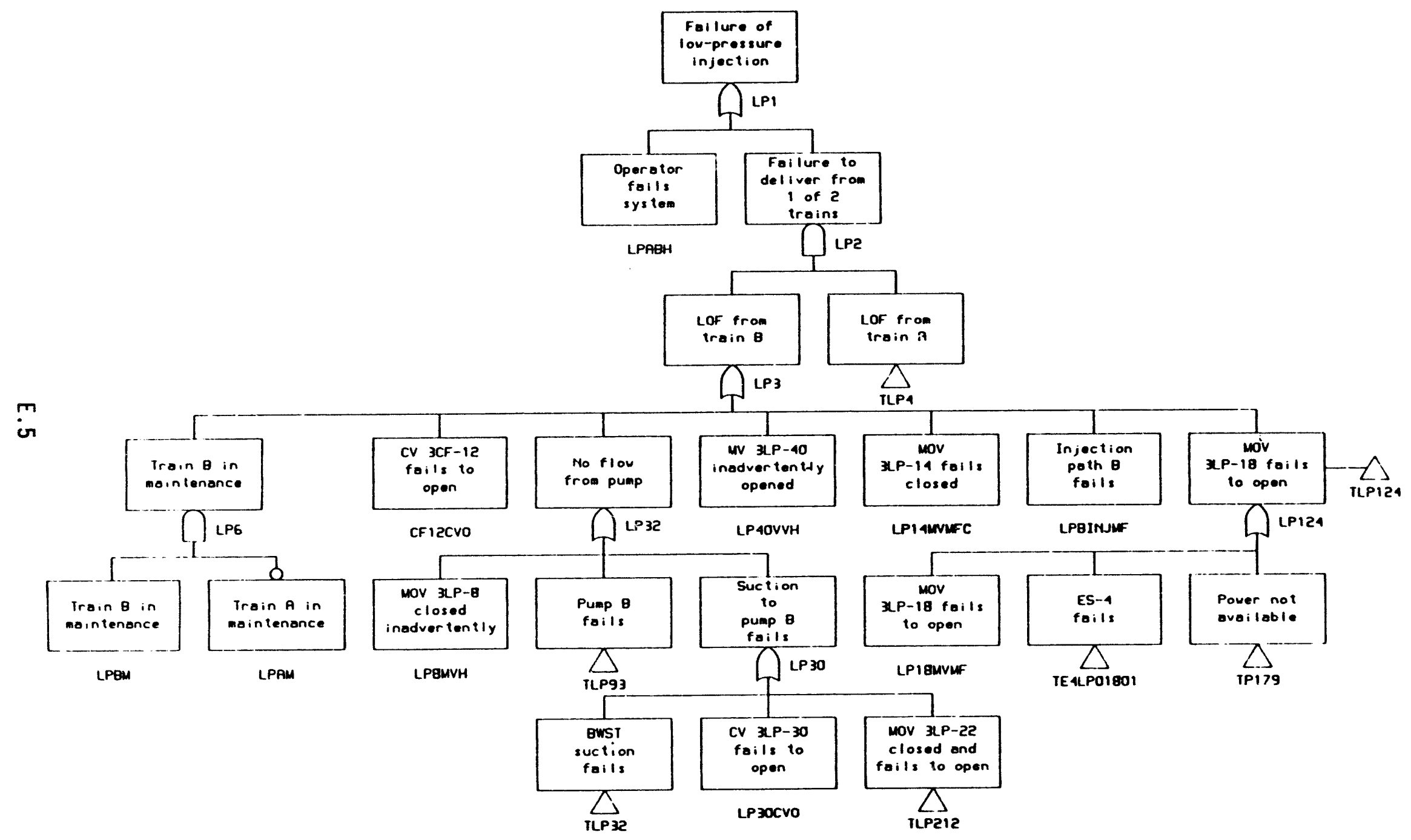

FIGURE E.2. LPI Fault Tree 


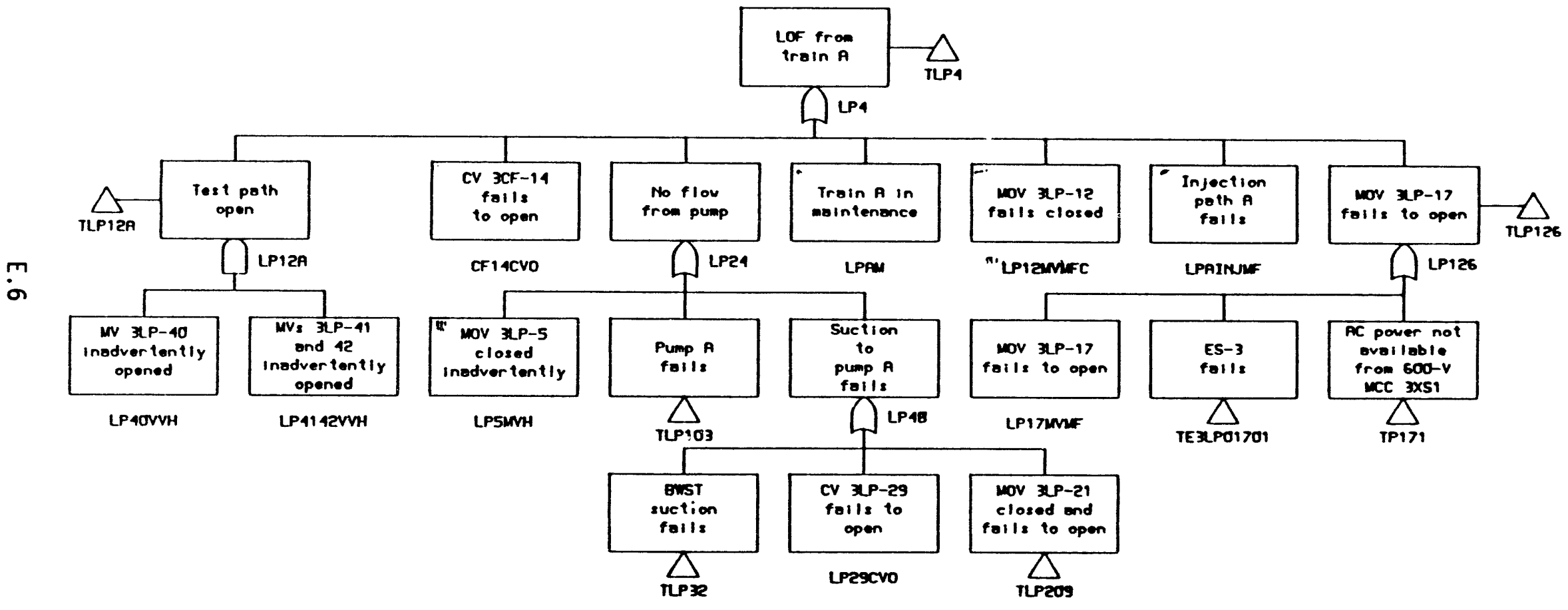

FIGURE E.2. (contd) 

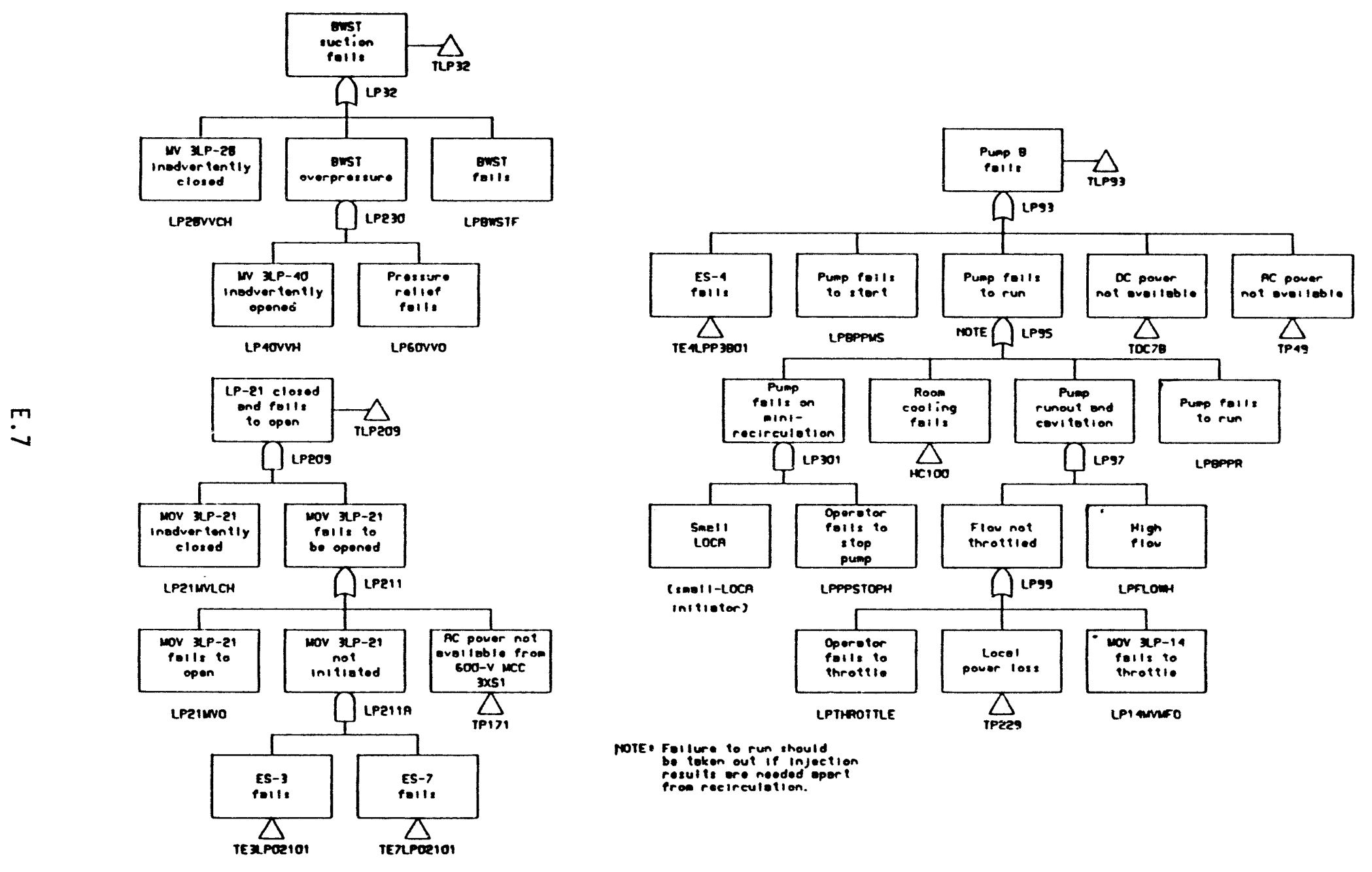

FIGURE E.2. (contd) 

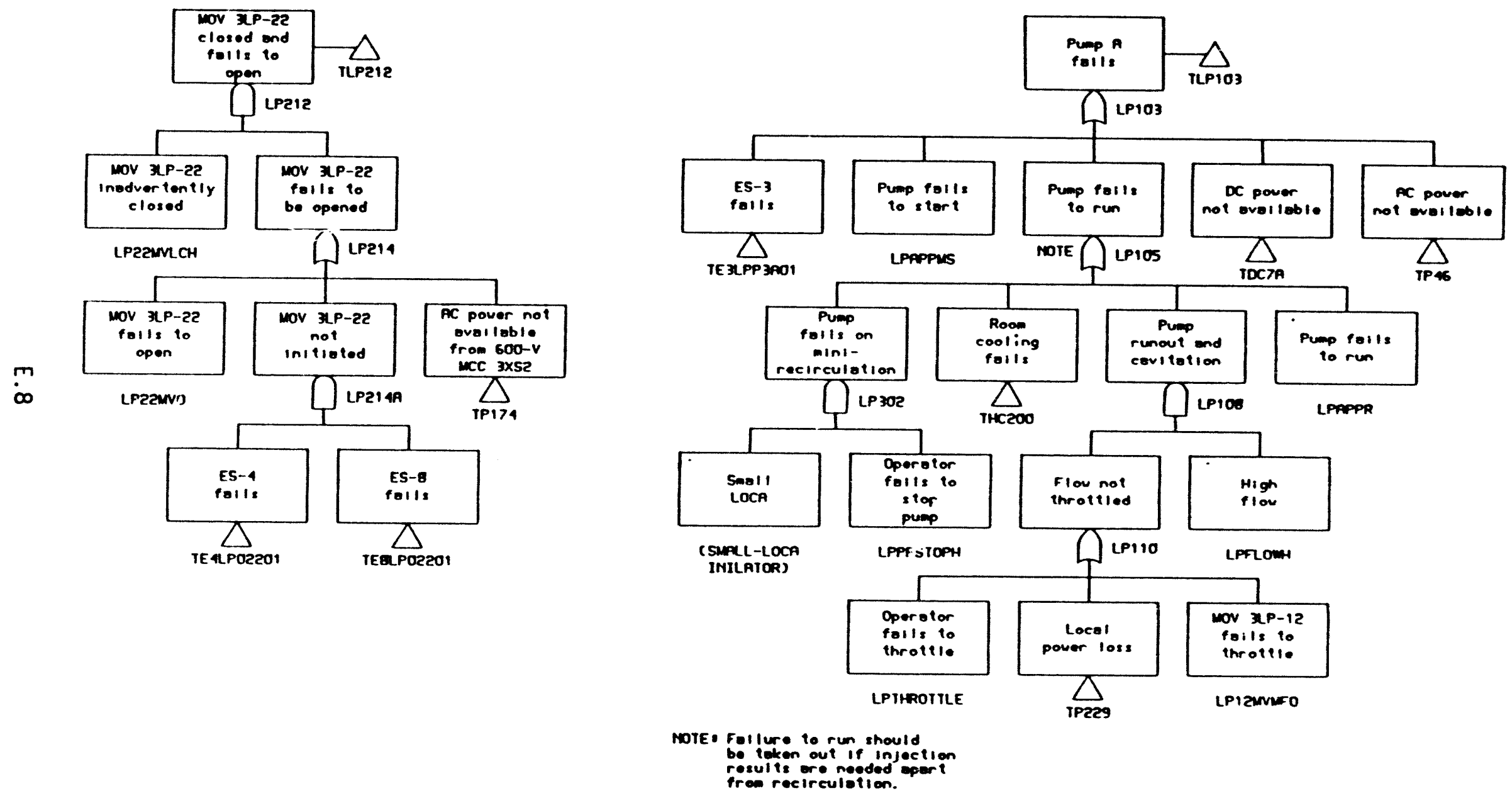

FIGURE E.2. (contd) 


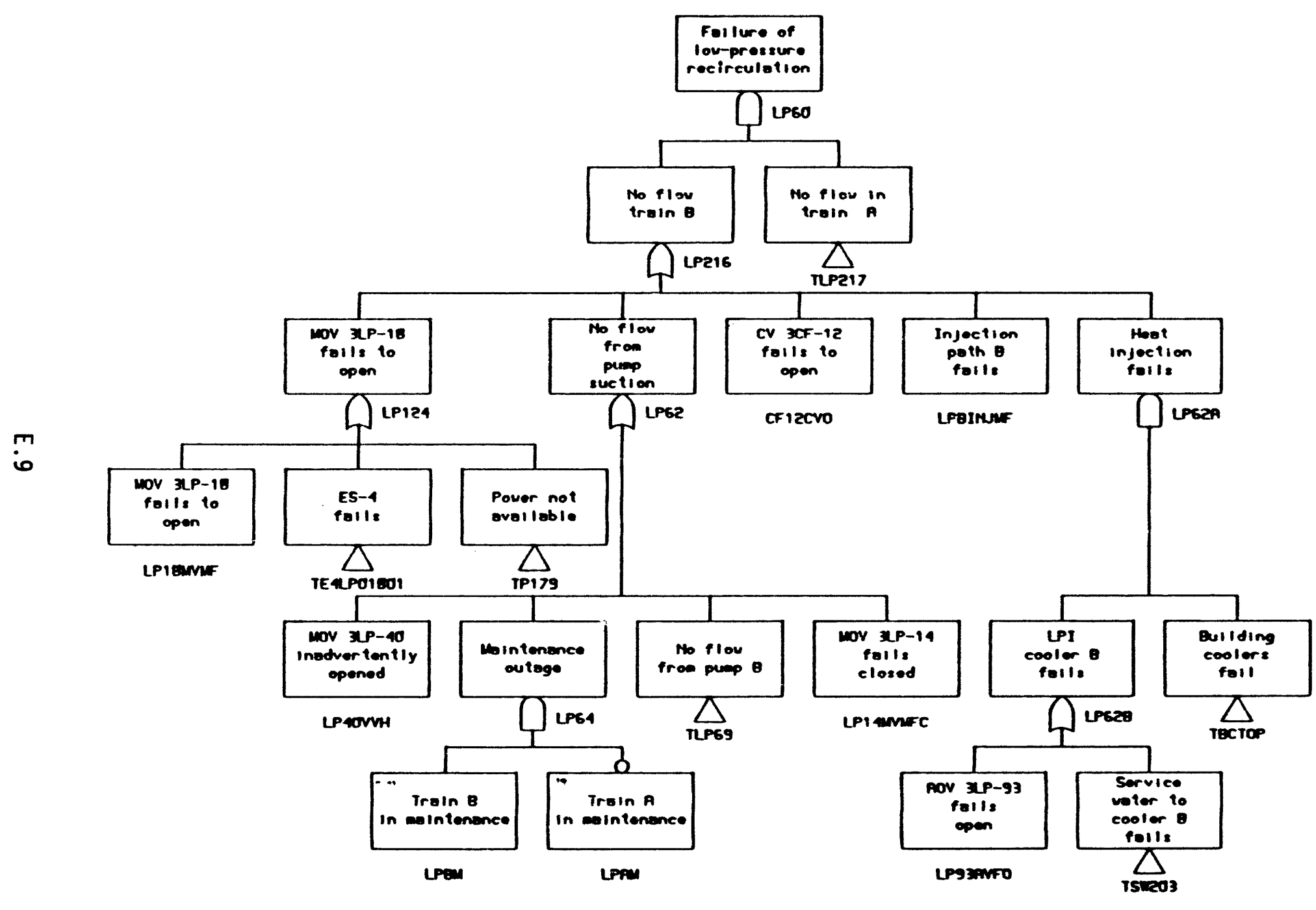

FIGURE E.3. LPR Fault Tree 


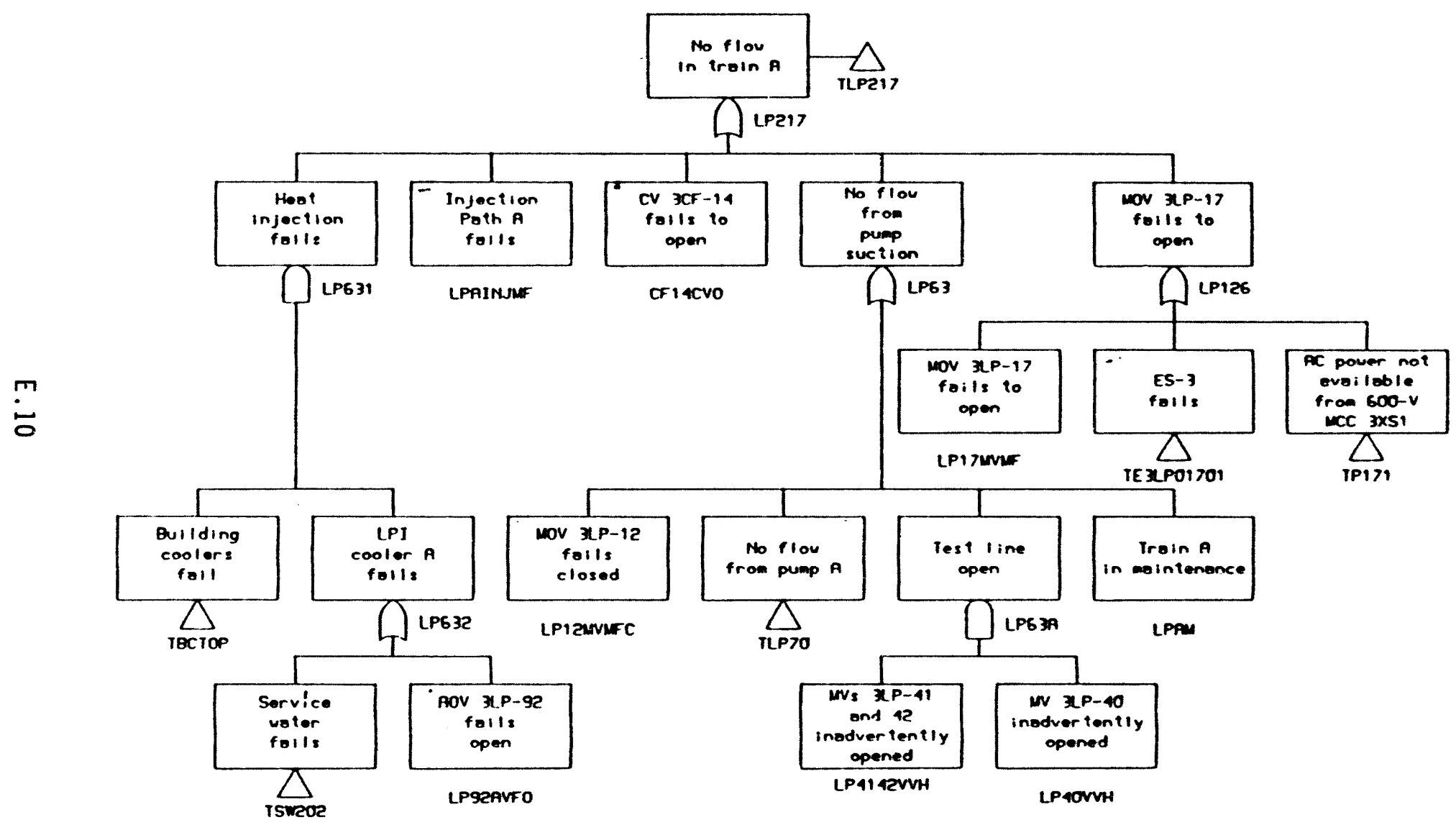

FIGURE E.3. (contd) 


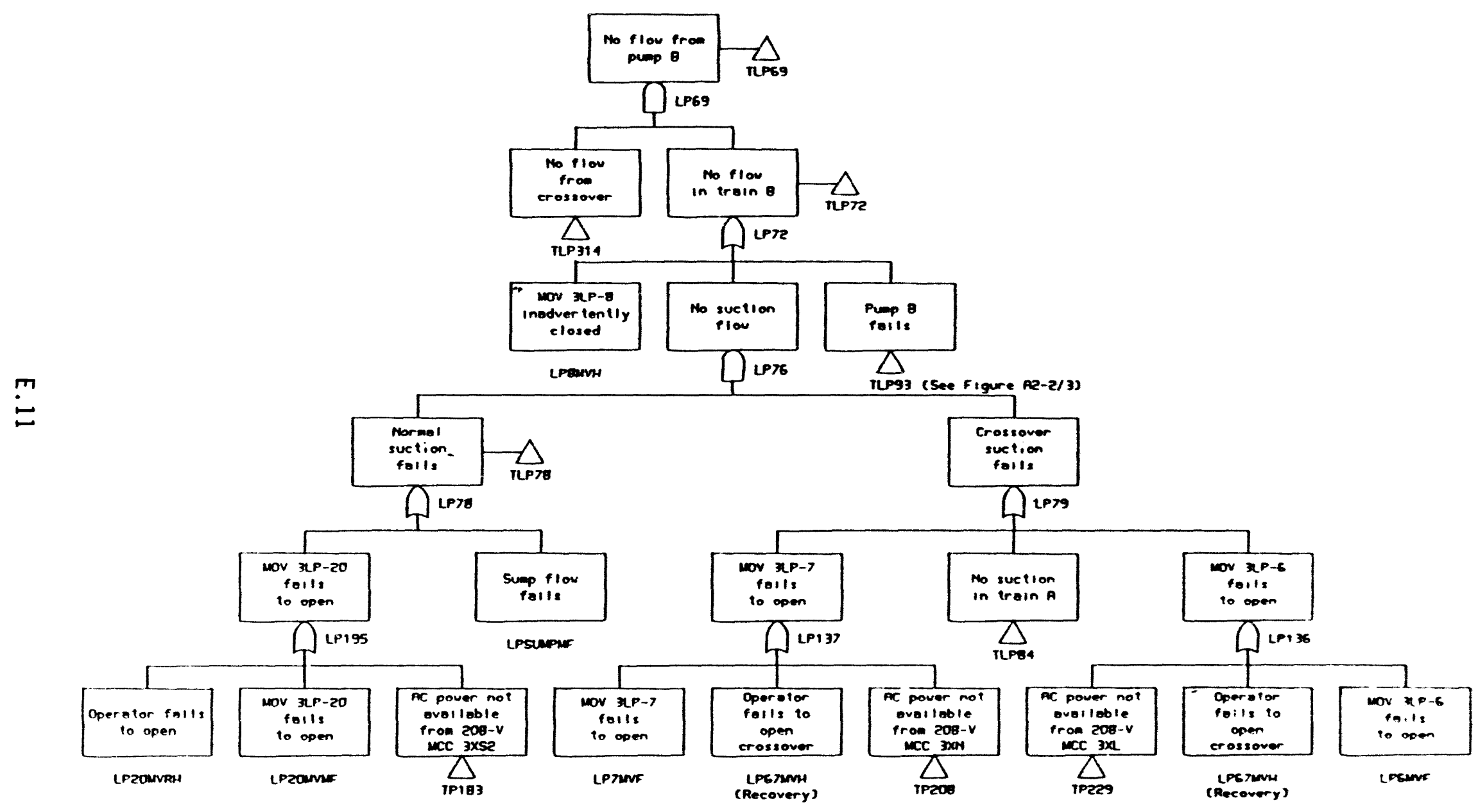

FIGURE E.3. (contd) 


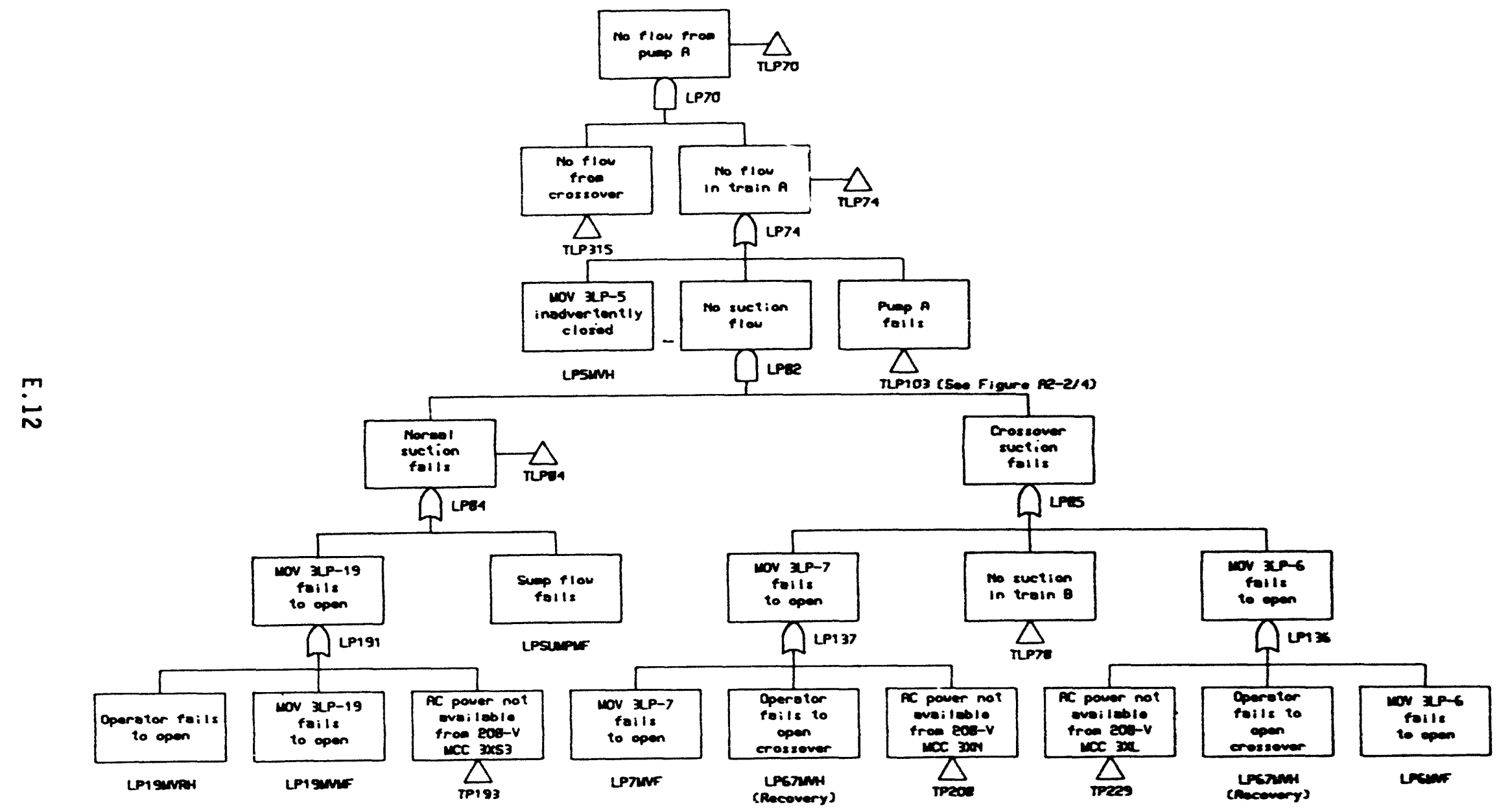

FIGURE E.4. Decay Heat Removal Fault Tree 


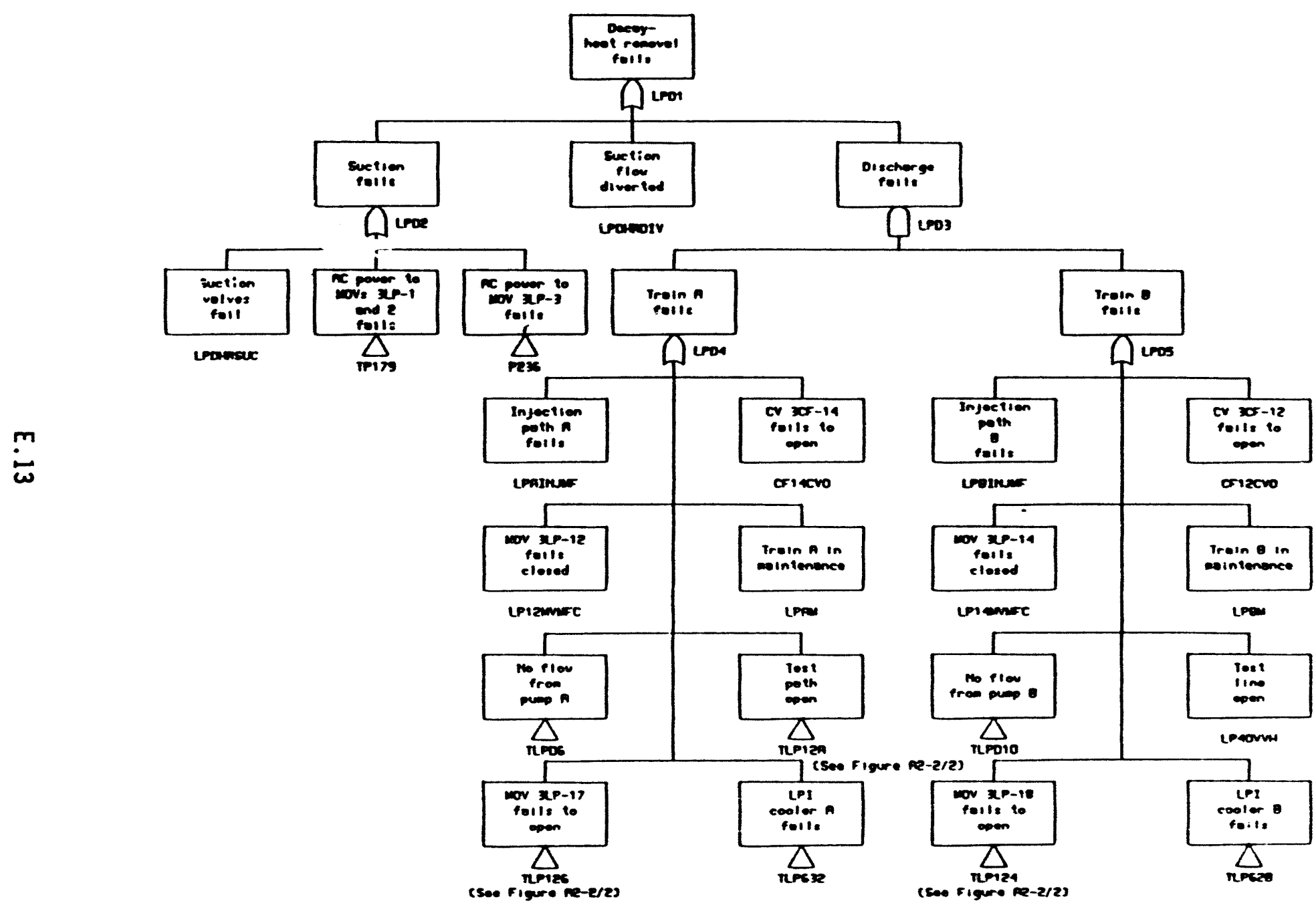

FIGURE E.4. (contd) 


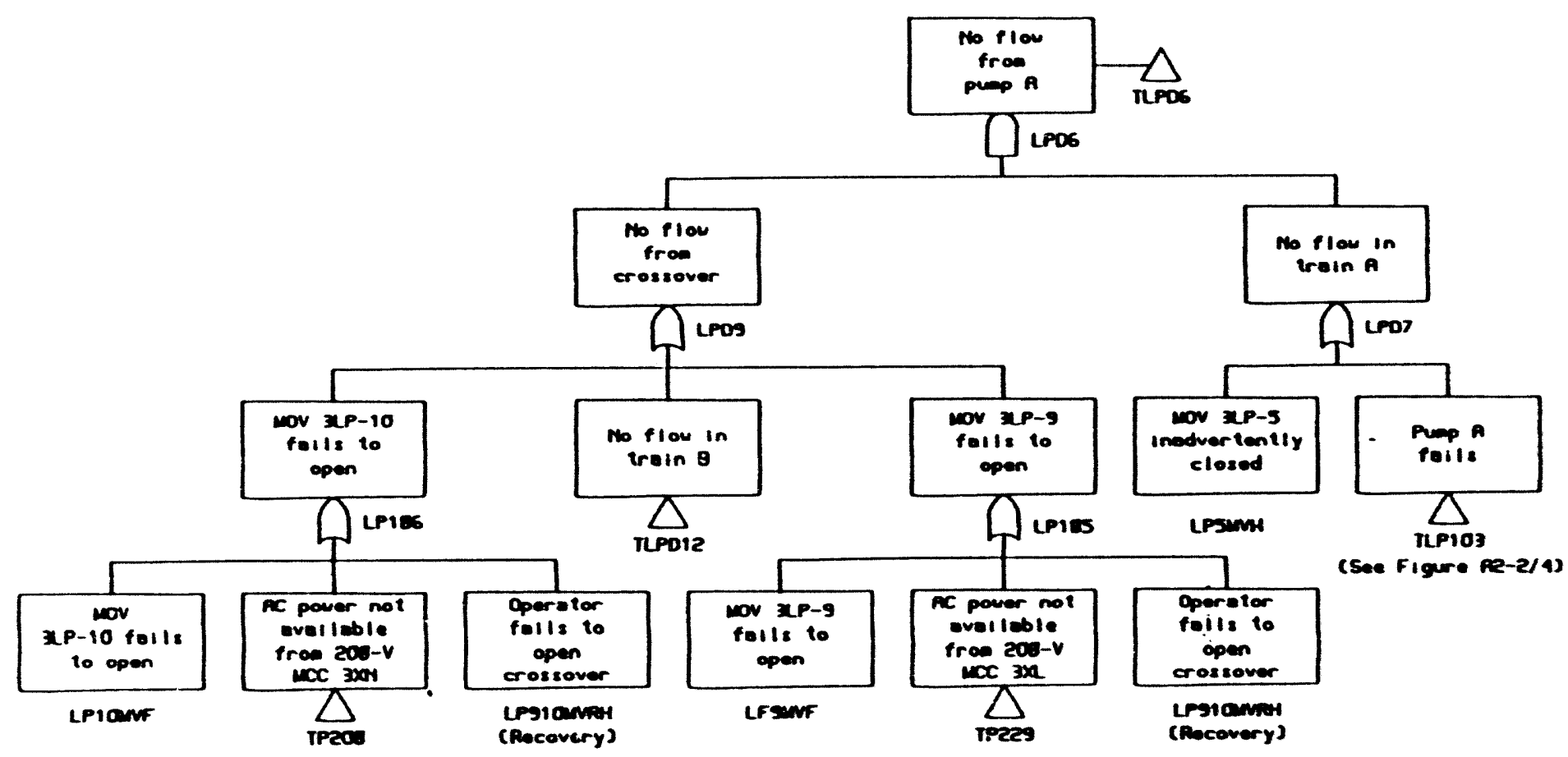

FIGURE E.4. (contd) 


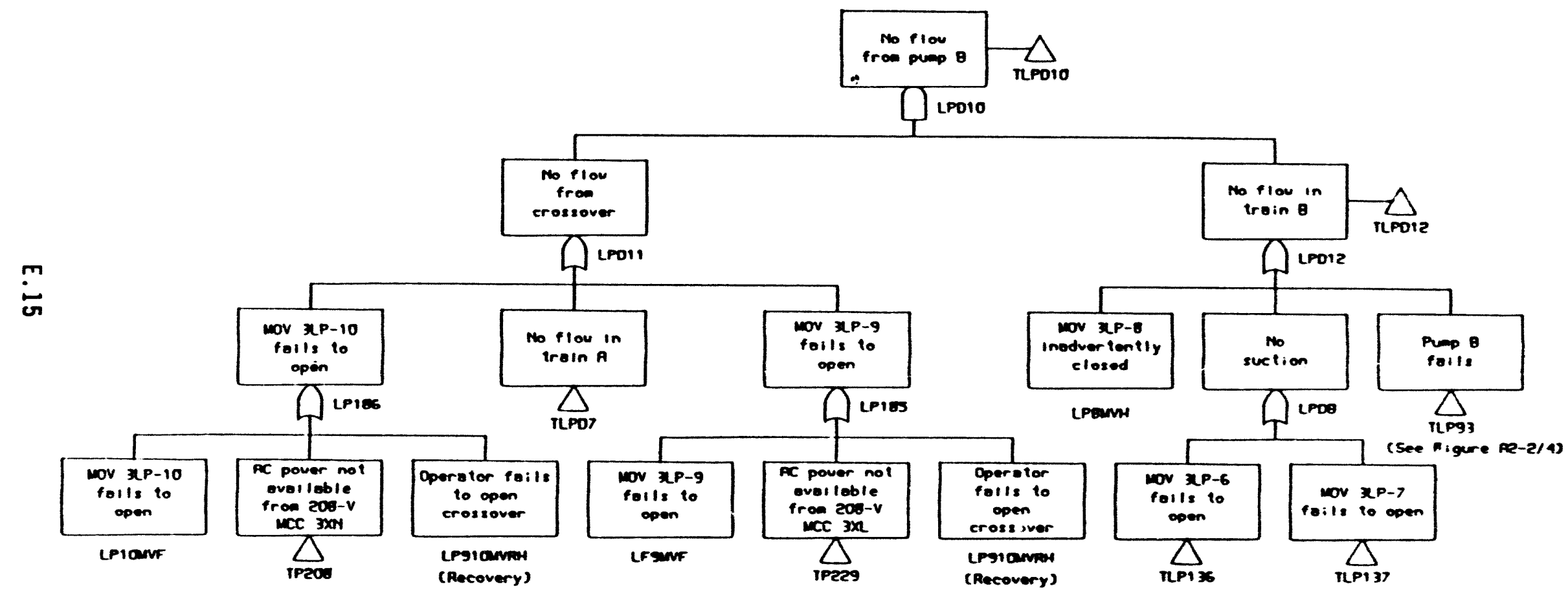

FIGURE E.4. (contd) 

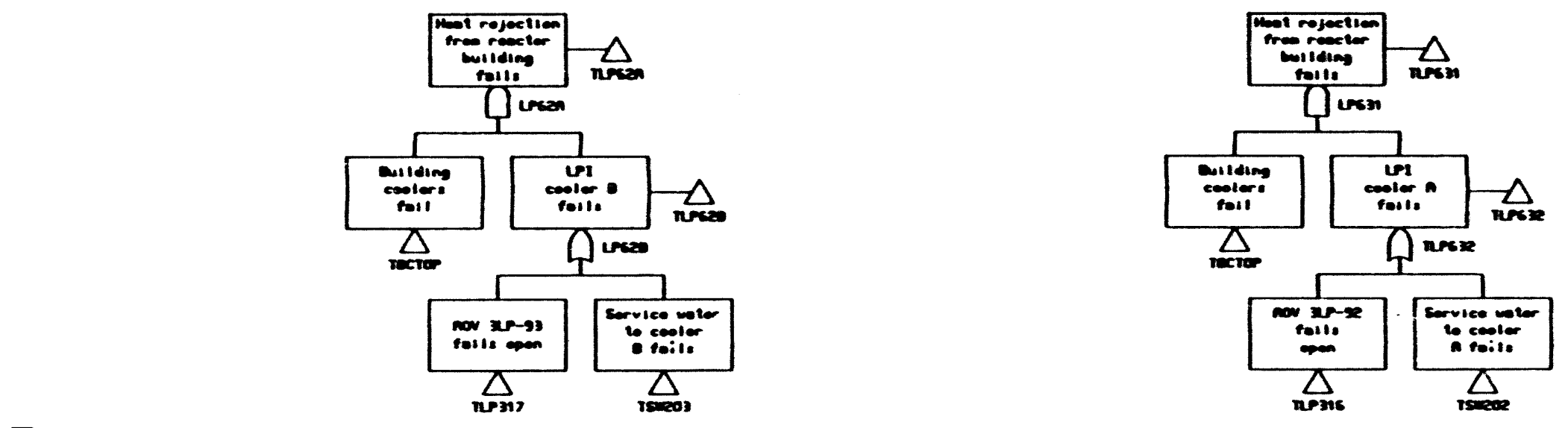

$\vdots$
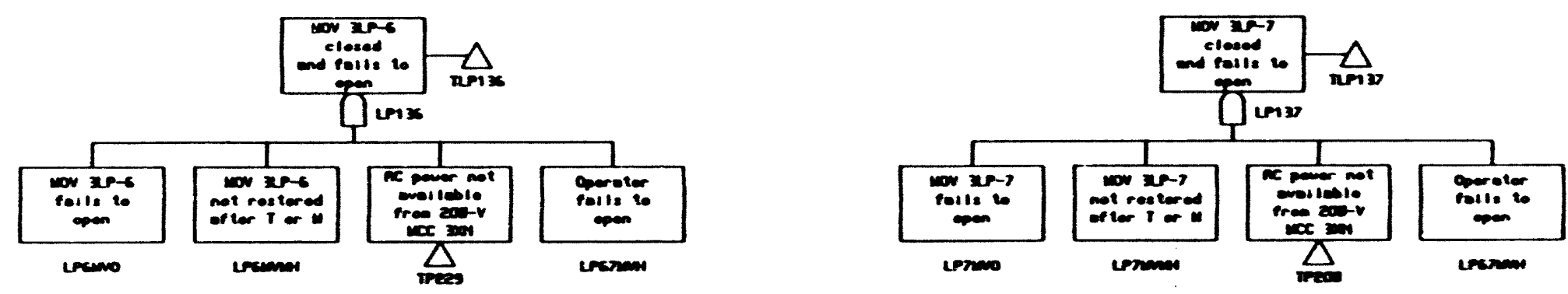

FIGURE E.4. (contd) 


\section{Low-Pressure Recirculation}

LPR failure, top gate LP-60 in Figure E.3, represents failure to deliver recirculated coolant to the core-flooding nozzles from one of two LPR trains. As in LPI, the fault trees for each train, gates LP-216 and LP-217, are essentially identical. Moreover, the fault tree for LPR is similar to that for LPI, but it includes the following additional failures:

- Failure to provide low-pressure service water to a DHR cooler was considered a failure of the corresponding LPR train when the cooling was included in the success requirements.

- A failure of the DHR-cooler bypass valve (LP-93, LP-92) in the open position was considered a failure of the corresponding LPR train when cooling of the recirculation water was required.

- Failure to manually realign suction from the BWST to the Reactor Building emergency sump was considered a failure of the train in which this failure occurred. Using Train $A$ as an example, failure to open $3 \mathrm{LP}-19$ would be a failure to realign Train A for recirculation. The decision to initiate recirculation is included in the top logic for the event trees.

- If the LPI pumps were intentionally stopped during the injection mode to prevent overheating, failure to manually restart these pumps in the recirculation mode would be a failure of the train in which this occurred.

\section{0ther LPI/LPR Model Developments}

The Reactor Building spray system interfaces with the LPI system. The fault tree developments needed to support the spray fault tree are illustrated in Figure E.4. Gate LP-50 and LP-51 support the spray-injection mode. Gates LP-88 and LP-91 are used when c00ling of the spray water in the decay-heat coolers is required. Finally, gates LP-901 and LP-902 describe system operation when direct cooling of the spray water is not required.

Decay-heat removal requires operator action to manually start the LPI pumps and open the appropriate valves to enter this mode of operation. Failure to open either valve $3 L P-1,3 L P-2$, or $3 L P-3$ in the reactor coolant outlet line would prevent entering the DHR mode. These failures, along with failure to provide coolant to the core-flooding nozzles as modeled in the LPR tree, were included in the DHR top event for steam generator tube rupture.

\section{E.2.2 High-pressure Injection/Recirculation Systems}

The high-pressure injection (HPI) system performs three functions that are important with respect to the event sequences of interest in evaluating the likelihood of core melt. The normal makeup/letdown system (MU/LDS), a portion of the HPI system, maintains the volume of the RCS within acceptable limits during most modes of plant operation. It also recirculates reactor 
coolant for purification, addition of chemicals for the control of RCS corrosion, and control of soluble boron concentration for long-term reactivity control. The MU/LDS function which is described here, and for which a faulttree model was constructed, is that of maintaining sufficient RCS volume for transient events. Reactor coolant pump seal cooling is provided by the sealinjection portion of the HPI system operating with the ccmponent cooling system (CCS). These seals serve to prevent the leakage of reactor coolant between the shaft and the housing of the RCPs. When the RCS is at a high temperature, the seals must be cooled to keep them from warping, to keep the seal faces from becoming cracked or eroded, and to prevent the 0 -rings from extruding. The interruption of cooling flow can result in seal damage, leading to increased RCS leakage and small-break LOCA conditions. The HPI system is designed to provide a high-pressure flow of water to maintain a adequate inventory in the RCS after small-break LOCAs and can be used to remove heat from the reactor core should the normal path of heat removal, through the steam generators, not be available.

The HPI system consists of three motor-driven, high-pressure centrifugal pumps, with two primary suction and discharge paths. The system configuration is shown in Figure E.5. The design features relevant to each of the system's three functions are described below in more detail.

\section{Makeup/Letdown System}

The makeup function is achieved primarily by a portion of the HPI system and the coolant storage and chemical addition systems. Makeup flow is supplied by either pump HP-P3A or HP-P3B and is controlled automatically to balance normal leakage. Letdown flow from the RCS accommodates small increases in RCS volume due to inleakage from the seals of the RCPs and variations in RCS temperature. Figure E.6 diagrams the letdown and suction supply portions of the MU/LDS.

\section{Cooling Systems for RCP Seals}

Seal-injection flow is provided by the HPI pump that is operating to supply normal RCS makeup. Figure E.7 is a simplified flow diagram of the seal injection and return portion of the HPI system. The injection flow is controlled by air-operated valve 3HP-31. It enters each RC pump at the face of the lower seal and divides such that some flow passes to the upper seal chamber while the remainder flows downward across a recirculation device and into the RCS. Approximately $40 \mathrm{gpm}$ is circulated through the lower seal chamber and an external heat exchanger, where heat is rejected to the CCS. This configuration is illustrated for a typical RCP in Figure E.7. The portion of the seal-injection flow that does not leak into the RCS is returned to the letdown storage tank (LDST) after being cooled by one of the two heat exchangers.

The configuration of the CCS is shown in Figure E.8. The CCS operates continuously to supply cooling flow to several components inside the Reactor Building in addition to the RCP seal heat exchangers. It is a closed-loop system with two electric pumps, one of which is normally operating. The pumps 


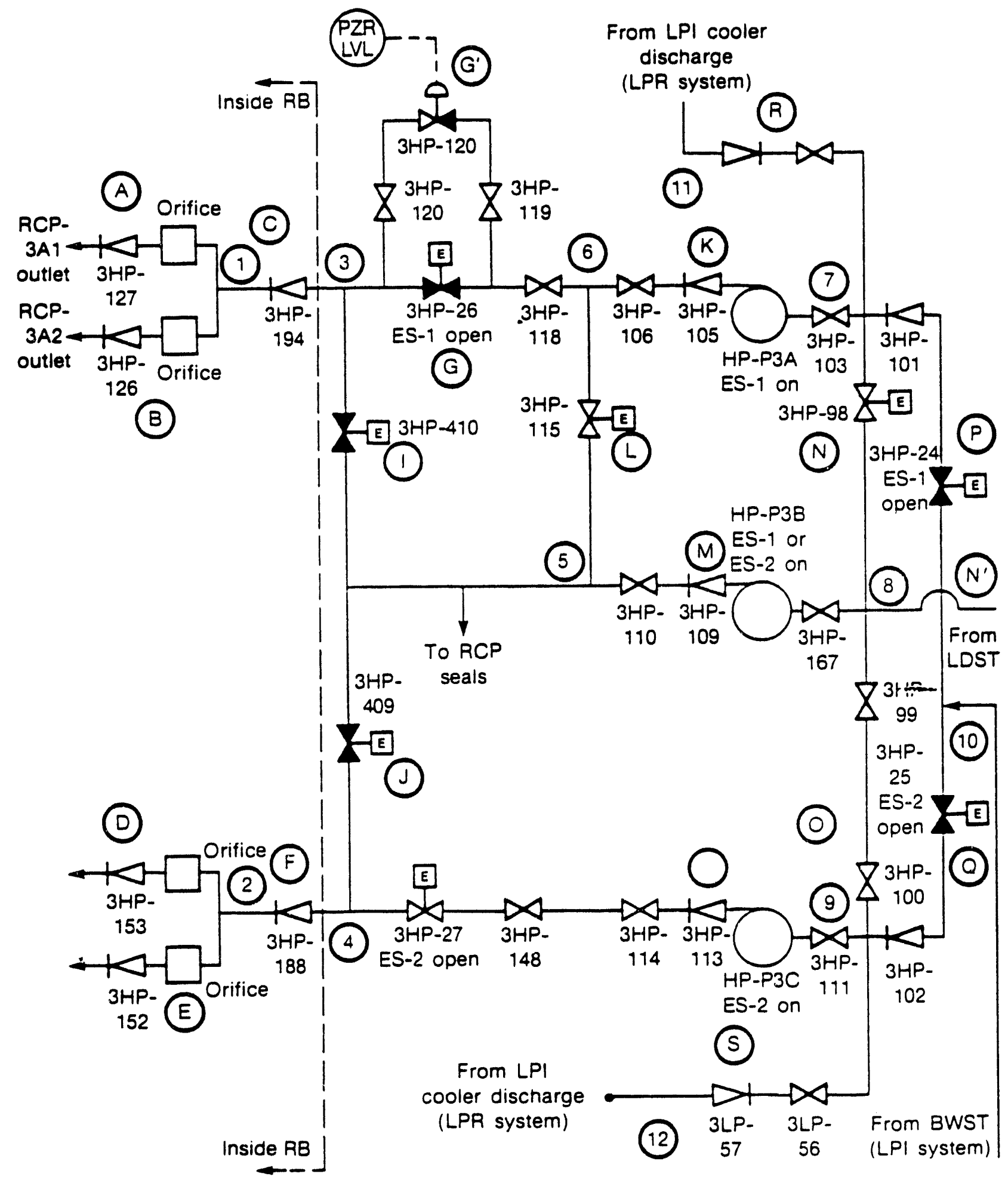

FIGURE E.5. Simplified Diagram of the HPI System 


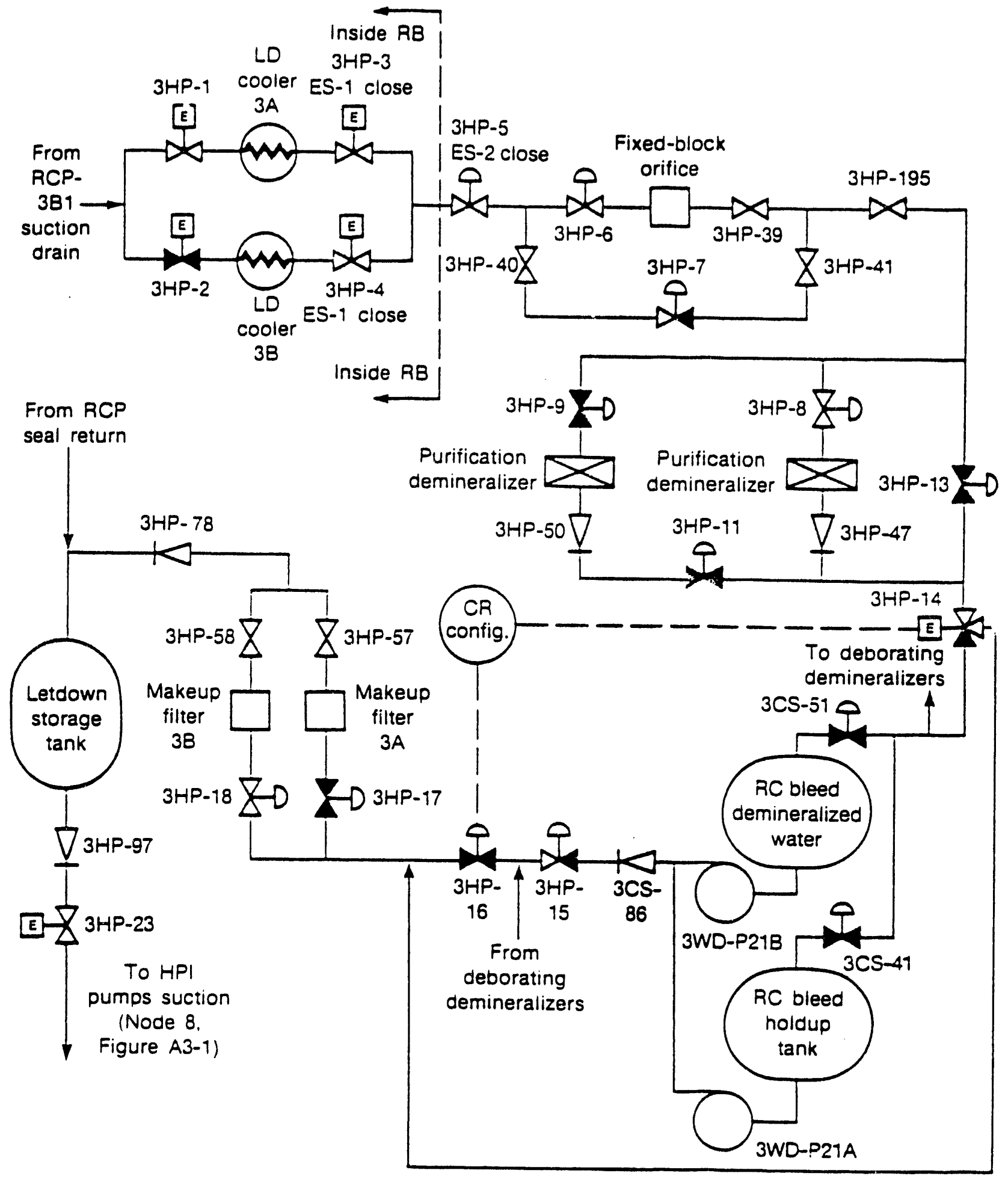

FIGURE E.6. Simplified Diagram of the RCS Makeup System 


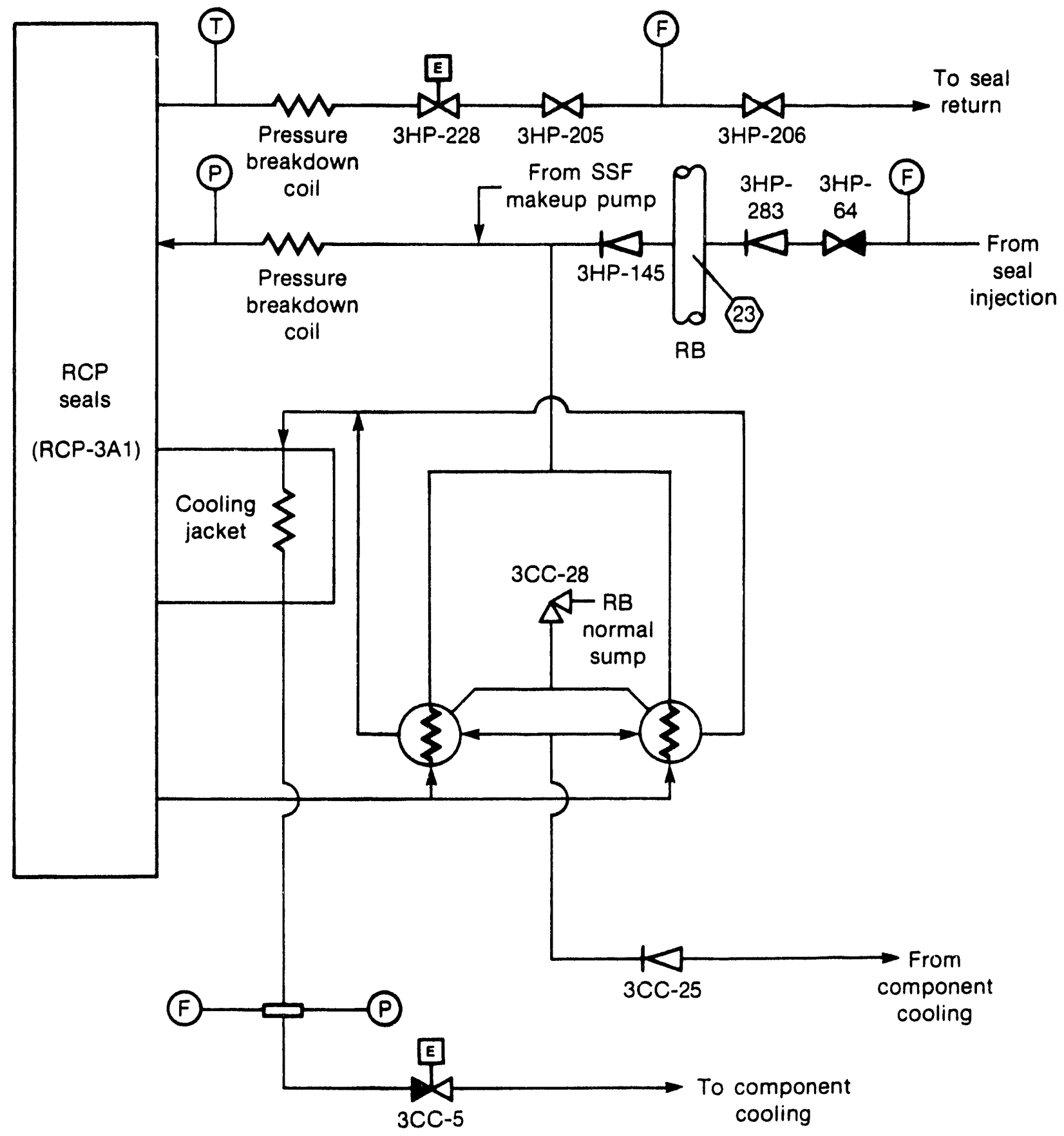

FIGURE E.7. Simplified Diagram of the RCP Seal Cooling System 


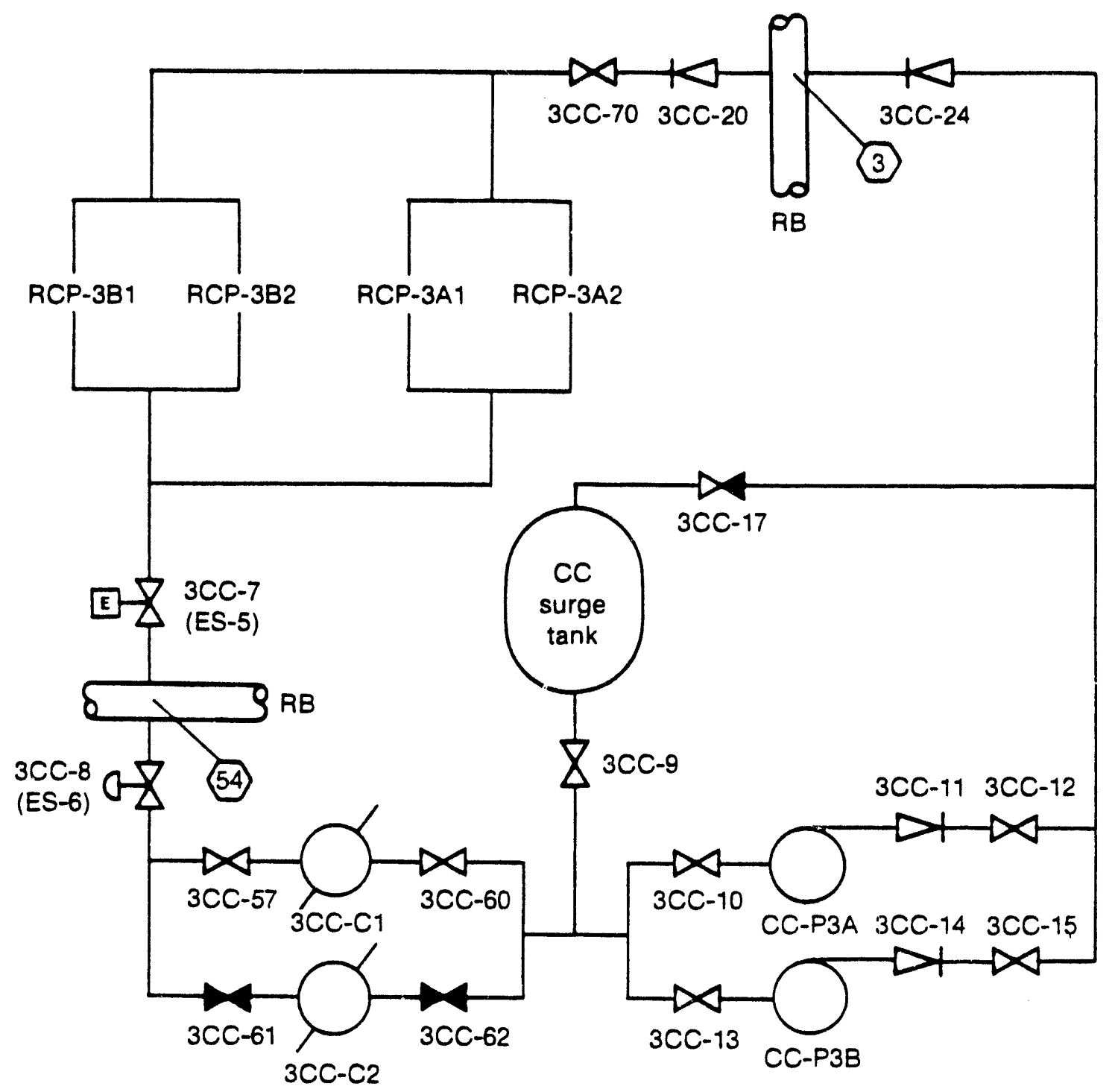

FIGURE E.8. Simplified Diagram of the Component Cooling System

are interlocked: one starts if the other trips. The two pumps are also interlocked with containment isolation valves $3 C C-7$ and $3 C C-8$ so that they trip if these valves are closed. The valves are closed upon actuation of engineered safeguards channels 5 and 6 , respectively, on high containment pressure. Cooling for the CCS flow is provided by the flow of low-pressure service water (LPSW) through one of two parallel heat exchangers.

\section{Emergency Injection Mode of the HPIS}

The HPIS provides emergency core cooling in the event of a small-break LOCA, and it also provides an alternative means of core heat removal if the ability to cool via the SGs is lost. The initiation of the HPI system requires the opening of at least one of the suction valves, $3 H P-24$ and $3 H P-25$, that isolate the HPI pumps from the emergency suction source, the BWST. A11 three pumps receive actuation signals on low RCS pressure and/or high Reactor 
Building pressure, although the signal is only confirmatory for the normally operating pump. Discharge valves $3 \mathrm{HP}-26$ and $3 \mathrm{HP}-27$ also receive signals to open, al though valve $3 \mathrm{HP}-27$ is normally left open. For most event sequences, flow from one pump is sufficient; for special cases, two pumps may be required to function. The HPIS is capable of supplying flow at a relatively high RCS pressure, with a shutoff head of $2900 \mathrm{psig.}$

The HPI and CC systems are designed to operate without support from any of the plant HVAC systems. The utility indicated that pump motor cooling was all that was required to ensure pump operability. The HPSI pumps are qualified to operate in much higher ambient temperature conditions $\left(212^{\circ} \mathrm{F}\right)$ than most other plants' engineered safety features (ESF) pumps (104 to $\left.120^{\circ} \mathrm{F}\right)$.

\section{Fault Tree Logic Models}

The existing PRA constructed and discussed a fault tree for each of the modes of operation of interest. The following fault trees are analyzed in the PRA:

- Makeup/letdown system fault tree

- Cooling systems for RCP seals fault tree

- High-pressure injection fault tree

- Success criterion of two of three pumps fault tree.

The fault trees listed above are not interfaced with HVAC systems; therefore, they are not addressed further in this report.

\section{High-Pressure Recirculation}

High-pressure recirculation (HPR) mode is designed to be initiated on depletion of the BWST supply if no other form of core-heat removal has been established. HPR is initiated by opening the two valves of Reactor Building emergency sump, valves $3 L P-19$ and $3 L P-20$, starting at least one LPI pump, closing valves $3 L P-21$ and $3 L P-22$ from the BWST, and opening valves $3 L P-15$ and $3 L P-16$ to the suction of the HPI pumps.

The recirculation mode is designed the same as the injection mode but instead of using the BWST as the suction source, it is provided by the LPI system. As discussed before, LPI room cooler failure will cause LPI system failures. Therefore, HPR will fail if LPI room cooling is unsuccessful.

The failure of HPR was modeled as shown in Figure E.9. The failure modes are nearly identical to those for HPI, except that suction flow to the HPI pumps must be provided from the LPI pumps through segment $R$ or $S$.

\section{E.2.3 Core-Flooding System}

The core-flooding system (CFS) is one segment of the representative plant's emergency core-cooling system. It is designed to reflood and cover the reactor core after a LOCA that begins with a large break. In such a LOCA, the RCS would be rapidly depressurized, and the reactor core could become 


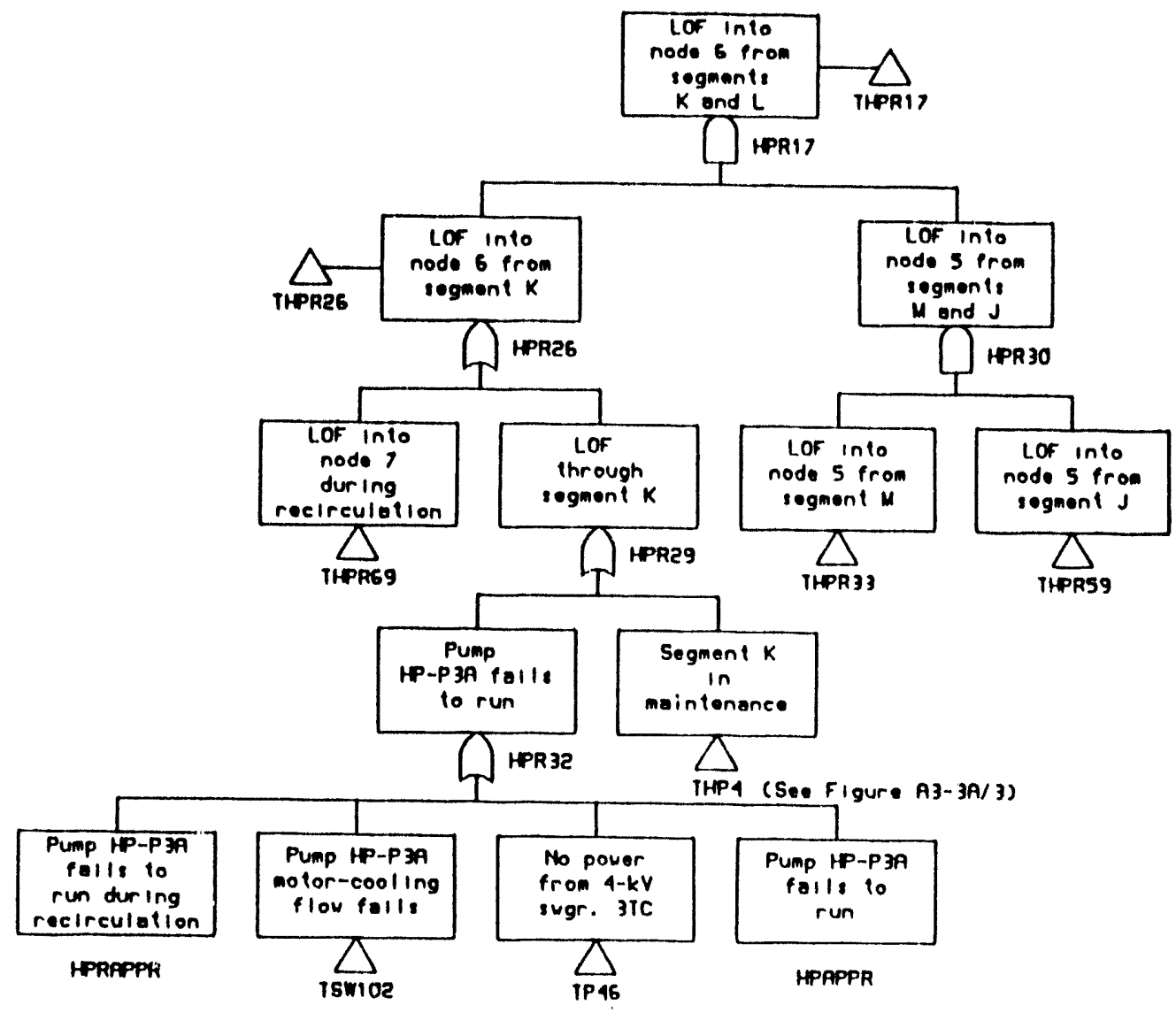

FIGURE E.9. Fault Tree for the HPR System

uncovered. The effectiveness of the HPI system would be limited, and the LPI system would require 15 seconds or longer to develop maximum flow and still longer to recover the core. The CFS reflooding provides cooling and reactivity control during the period between the loss of coolant and LPI cooling. The system serves no function during normal plant operation or for mitigating accidents not accompanied by rapid depressurization, including LOCAs induced by smaller breaks.

The CFS is a self-actuating system that injects borated water directly into the reactor vessel whenever RCS pressure drops below 600 psig as a result of a LOCA.

The system consists of two identical but independent trains, as shown in the system diagram (Figure E.10). Each train consists of a core-flooding tank, an isolation gate valve, two series check valves, instrumentation, and piping to the reactor vessel. In addition, there are provisions for pressure relief, pressurization, adding coolant, sampling inventory, and draining the system. The CFS is designed to operate without support from HVAC. 


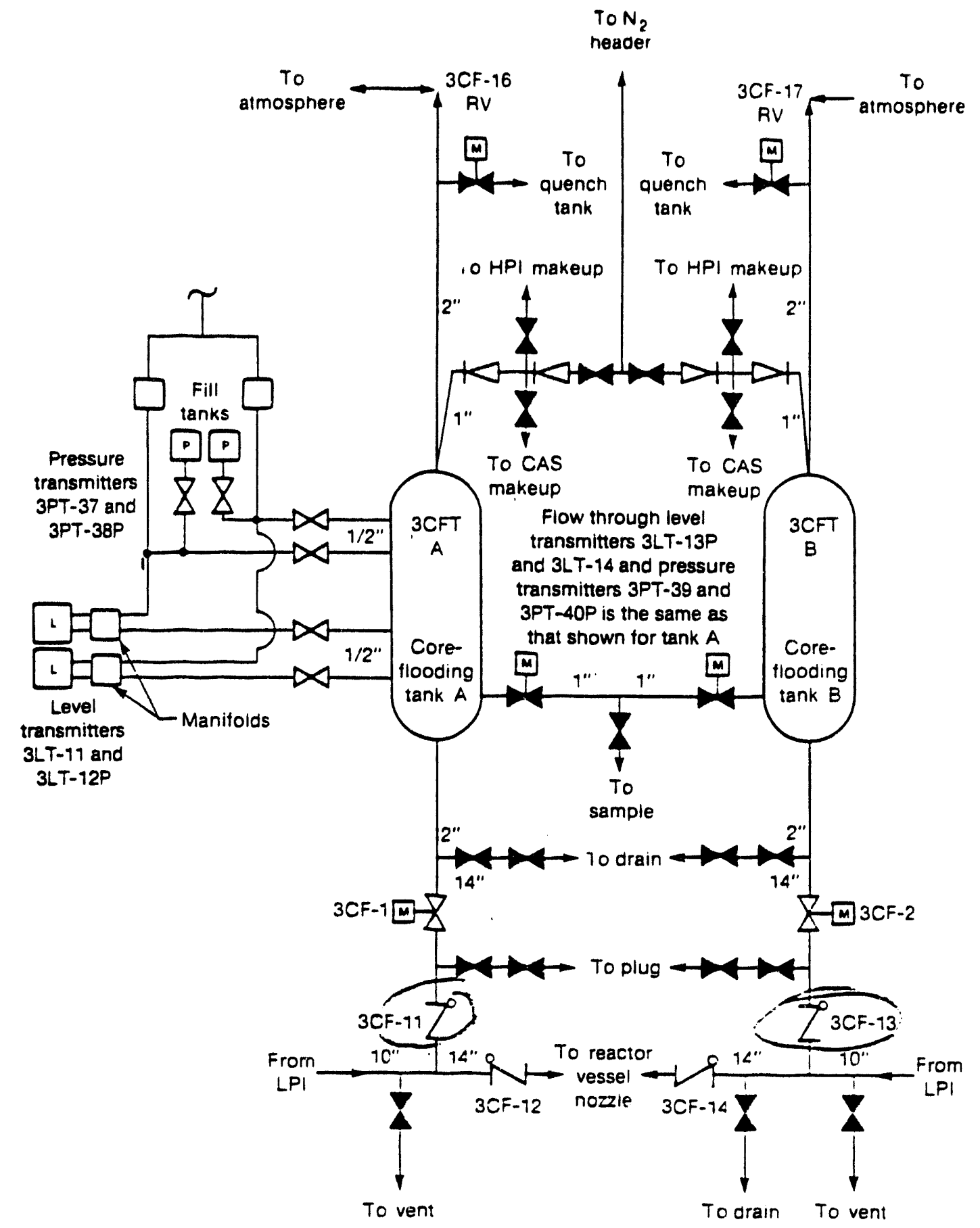

FIGURE E.10. Simplified Diagram of the Core Flooding System 


\section{Eault Tree Logic Model}

Because the CF system does not require support from HVAC system to operate, system fault trees are not addressed in this report.

\section{E.2.4 Reactor Building Spray System}

The Reactor Building spray system (RBSS) is designed to cool the atmosphere of the Reactor Building after an accident, thereby maintaining peak pressure below the Reactor Building design pressure and eventually reducing the pressure to nearly atmospheric. Together with the Reactor Building cooling system (RBCS), the sprays provide a redundant and diverse means of Reactor Building pressure reduction. The RBSS is an engineered safeguards system and performs no normal operating function.

The RBSS, shown in Figure E.11, is a once-through, two-train system taking suction from the LPI system suction header and discharging into the Reactor Building atmosphere. The RBSS operates during both the injection and the recirculation modes of LPI system operation. It sprays borated water into the Reactor Building atmosphere to remove post-accident energy from the atmosphere and transfer the energy through the decay-heat coolers to the LPSW system.

Each of the independent RBSS trains consists of a pump, a discharge header, spray headers, associated piping, valves, instrumentation, and controls. The spray pumps are single-stage, single-suction centrifugal pumps rated at a flow of $1500 \mathrm{gpm}$ against a head of 450 feet. The RBSS pumps take suction from the LPI system headers upstream of the LPI pumps: pump A from the header of LPI system Train A and pump B from the header of LPI system Train B. During the injection mode, the LPI suction headers are aligned to the borated-water storage tank (BWST); during the recirculation mode, they are aligned to the Reactor Building emergency sump. The RBSS pumps are capable of taking suction from either source without the LPI pumps running. From the LPI suction header, the borated water passes through a 10-inch RBSS suction header to the RBSS pump. Each RBSS suction line contains a check valve and a normally open motor-discharge header into the Reactor Building. The discharge header contains a check valve, a locked-open manual valve, and a normally closed motor-operated valve (MOV) that is automatically opened when the RBSS is initiated.

The RBSS pumps and MOVs require $A C$ power from the emergency electrical power supply system. The engineered safeguards (ES) activation system supplies signals to the pumps and the MOVs on the discharge headers. The pump motors are air-cooled and require AHUs located in the pump rooms for long-term operation. The RBSS requires the LPI suction headers as a water source. Therefore, failure of LPI will cause RBSS to fail to function because the LPI pumps require room cooling to operate successfully. Hence, the RBSS is dependent upon successful operation of the room cooler system. 


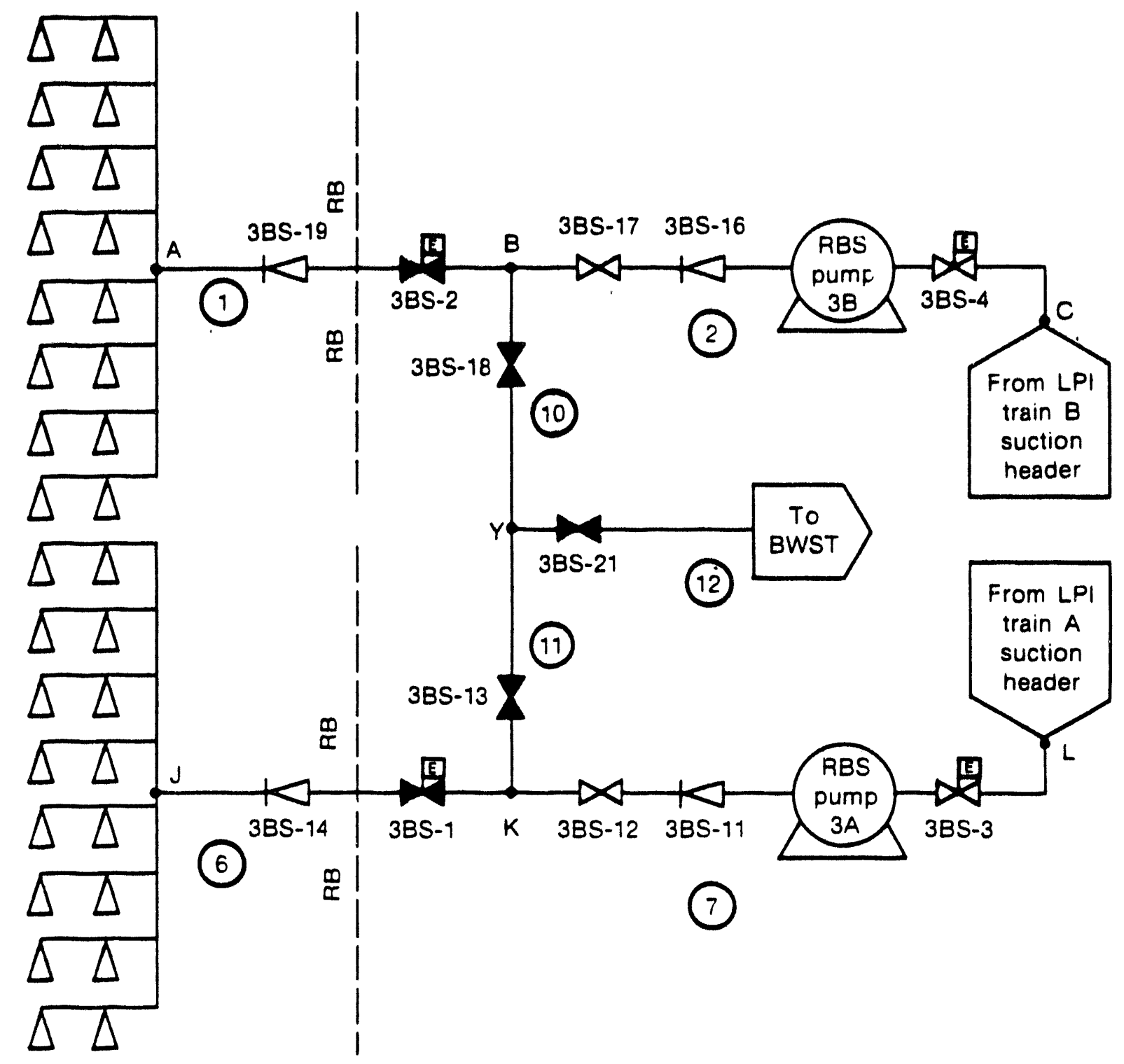

FIGURE E.11. Simplified Diagram of the Reactor Building Spray System

\section{Fault Tree Logic Model}

Three fault trees were developed for the RBSS, one for the injection mode and two for the recirculation mode. The detailed fault tree shown in Figure E.12 is the injection mode fault tree, and Figure E.13 is the recirculation mode tree.

The top event of the trees is the failure of one of the two RBSS trains to operate. This corresponds to a loss of flow through both the $A$ and $B$ train 


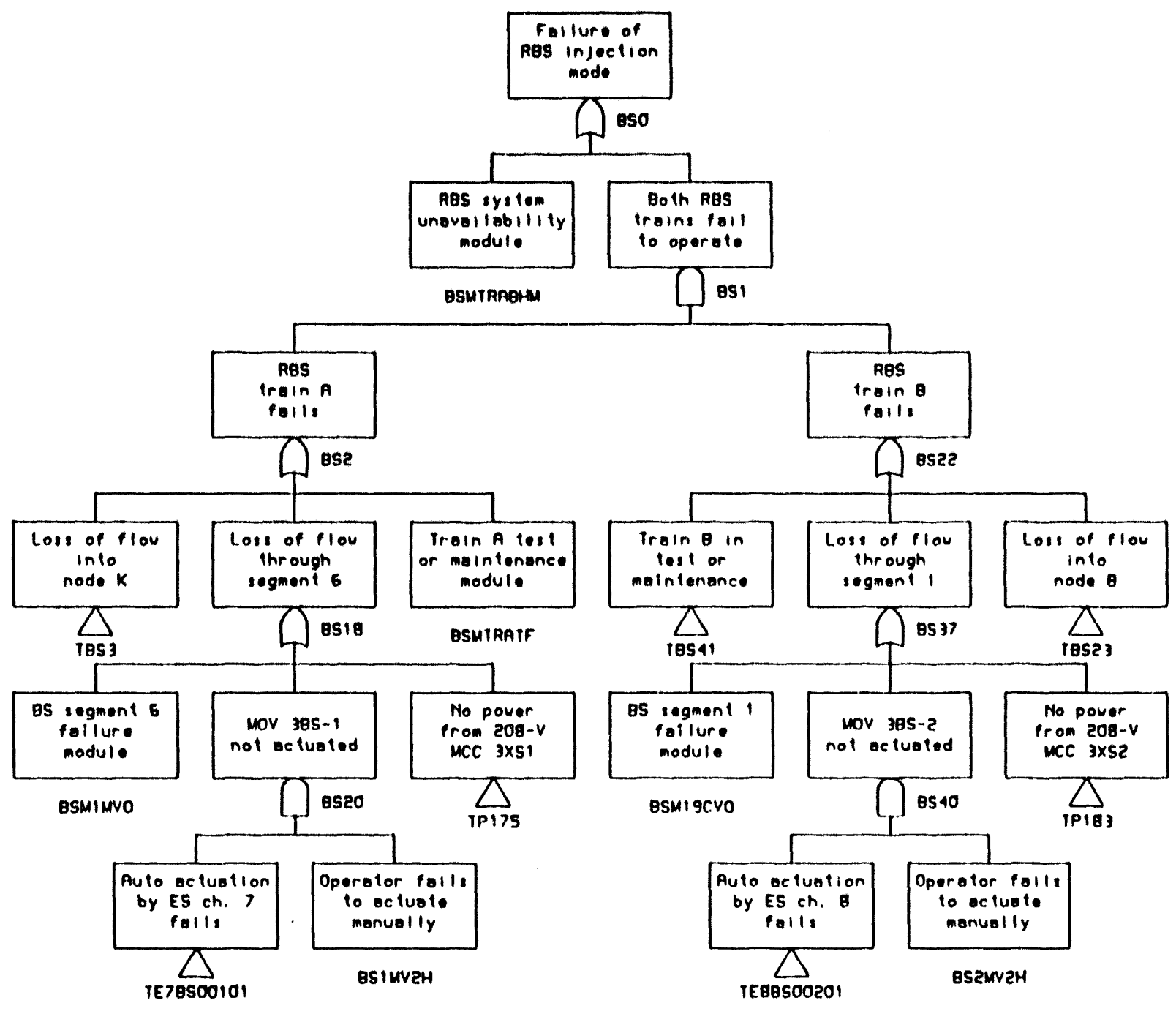

EIGURE F,12. Fault Tree for the RBSS - Injection Mode 


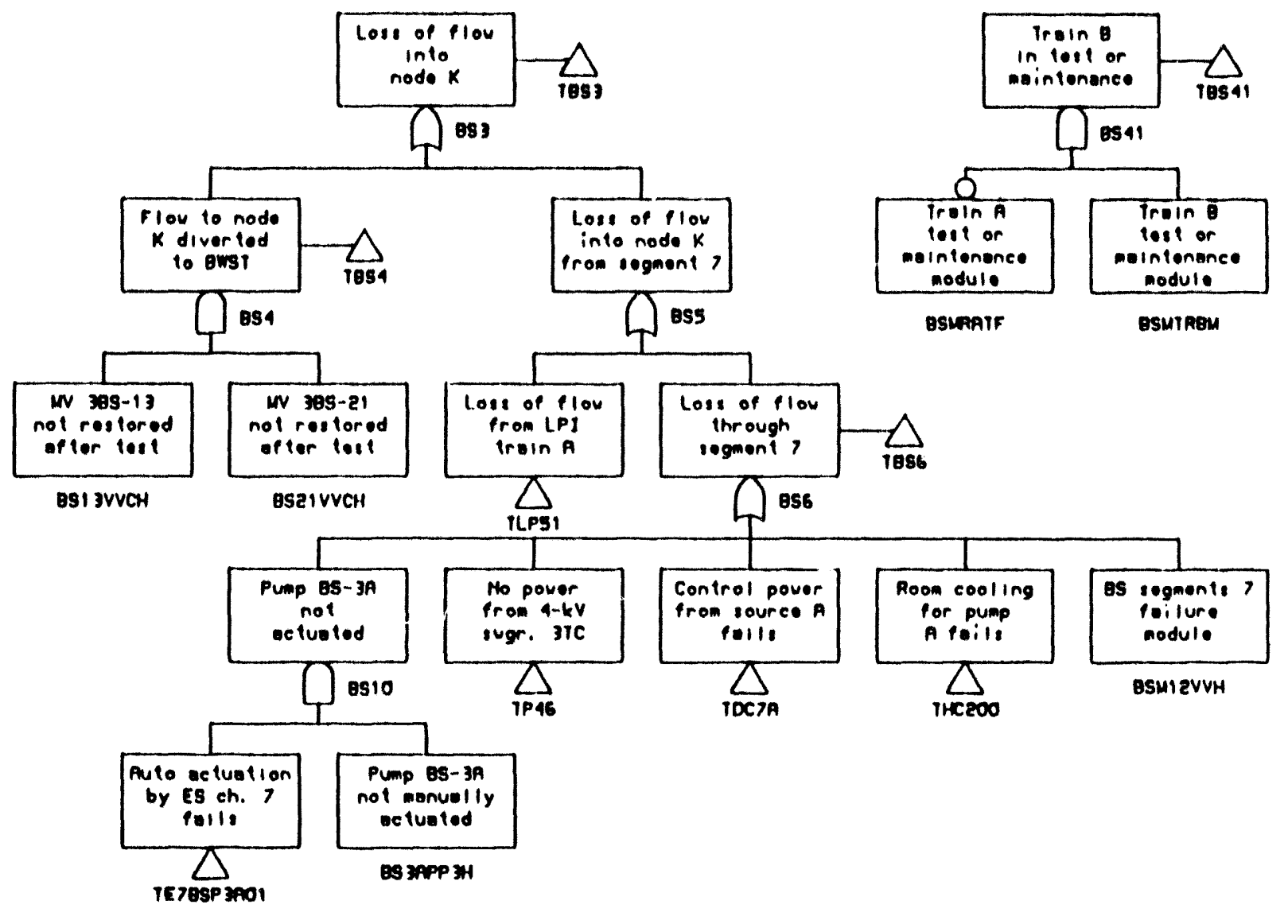

FIGURE E.12. (contd) 


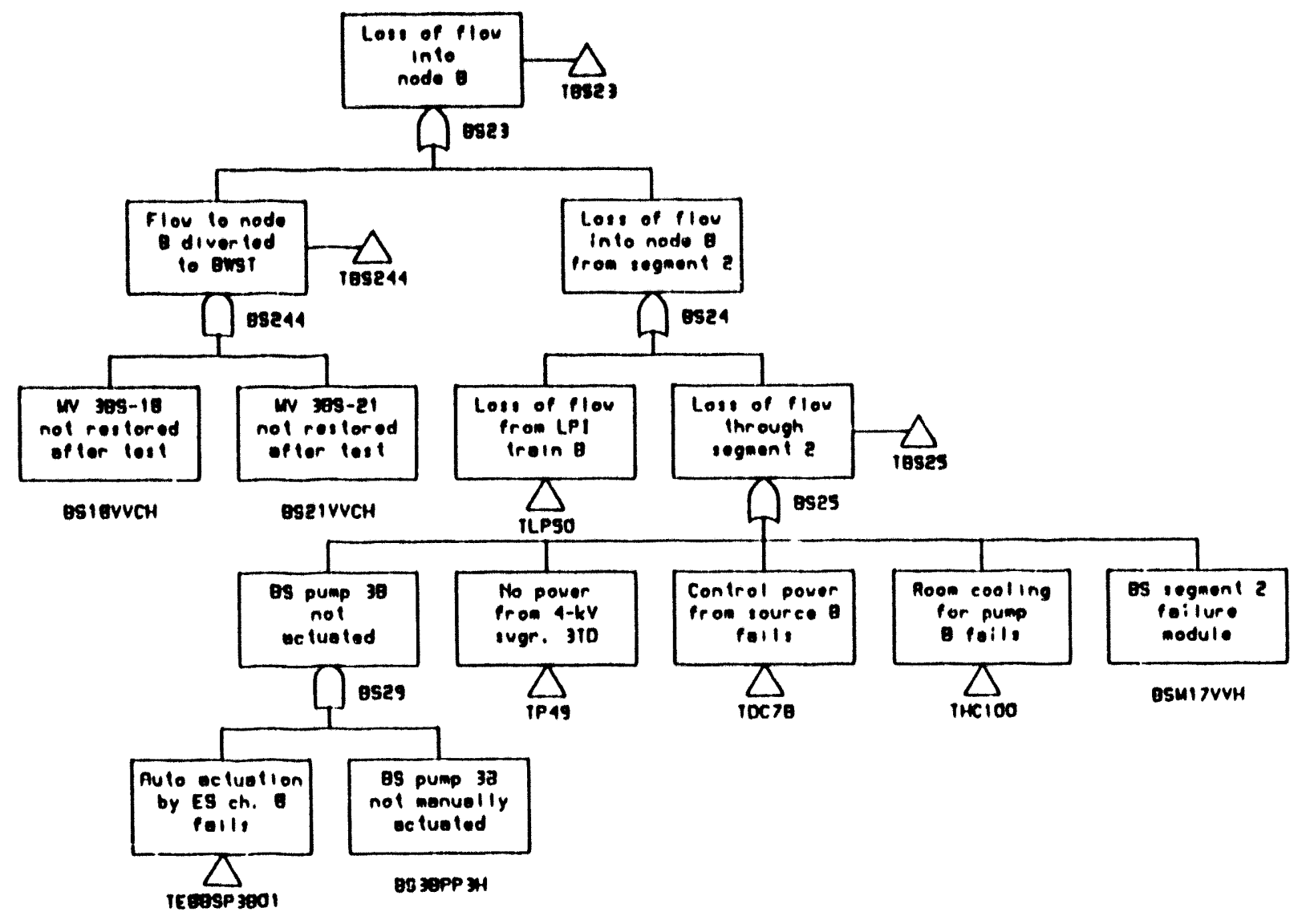

EIGURE E.12. (contd)

spray headers, nodes $J$ and $A$, respectively, in Figure E.12. Note that loss of flow into the pump-suction nodes, $C$ and $L$, is treated as a transfer to the LPI fault trees.

\section{E.2.5 Reactor Building Cooling System}

The Reactor Butlding cooling system (RBCS) is used to remove heat from the atmosphere of the Reactor Building. During normal operation, the RBCS serves as the principal means of controlling the temperature of the Reactor Building atmosphere. In an accident resulting in a fallure of the reactorcoolant-system pressure boundary, the RBCS provides protection for the integrity of the Reactor Butlding. It cools the post-accident Reactor Building atmosphere, condensing steam, and reduces an overpressurization challenge to the Reactor Butlding structure.

Post-accident Reactor Building integrity protection is also provided by the RBSS. Together the RBCS and the RBSS provide redundant and diverse means of post-accident Reactor Building pressure control. 


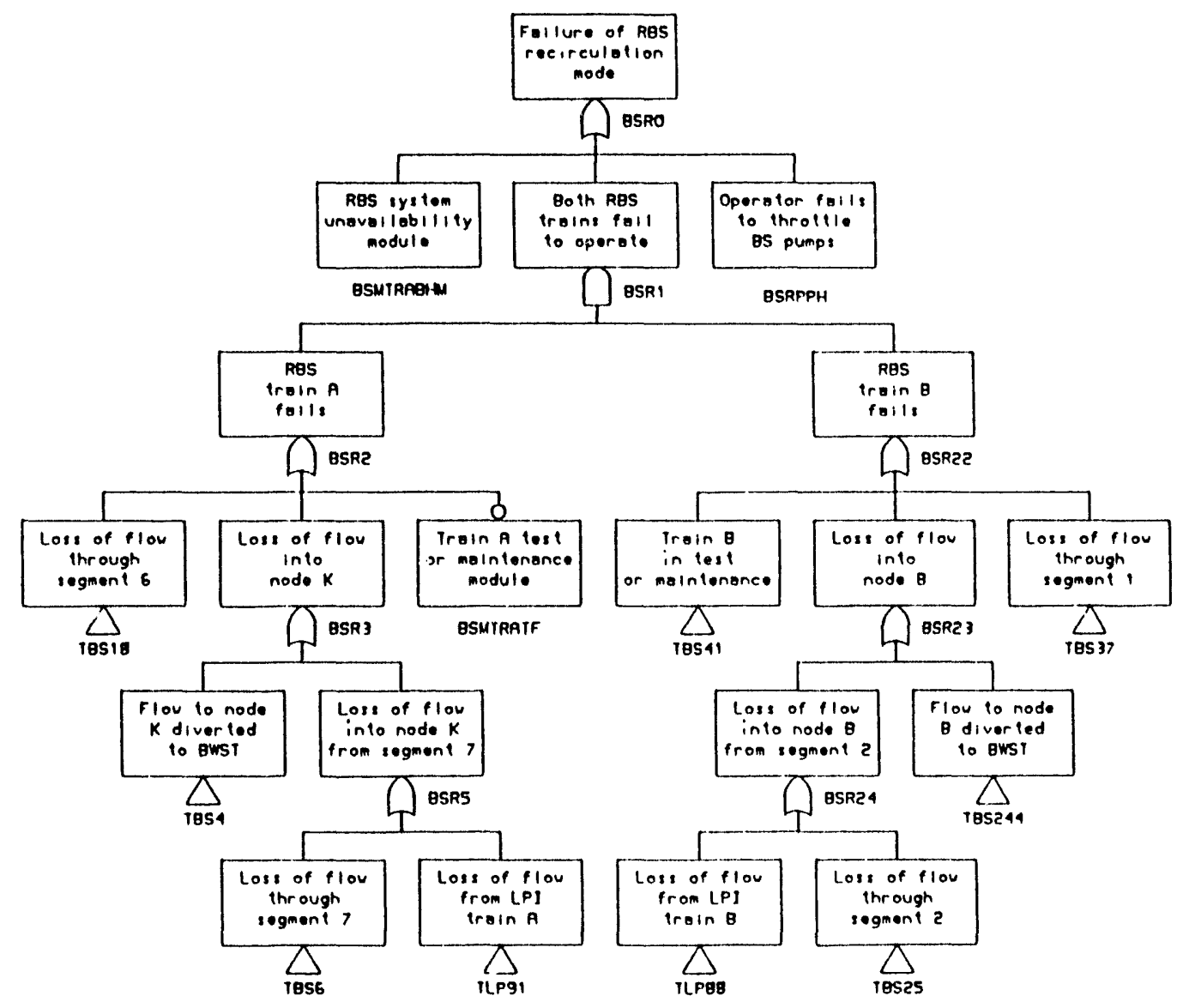

FIGURE E.13. Fault Tree for the RBSS - Recirculation Mode

The RBCS consists of three fan-and-cooler assemblies and the associated distribution-duct network. The RBCS fans are two-speed, air-cooled fans. Each draws air from the upper half of the Reactor Building atmosphere and pushes it through an air cooler. The RBCS coolers are air-to-water heat exchangers, with low-pressure service water serving as the tube-side coolant. The LPSW system piping associated with the RBCS is schematically diagrammed in Figure E.14. The remainder of the RBCS consists of a two-train, distributionduct network. The ducting directs the cooled-air flow from each fan-andcooler assembly through an electric-motor-operated flow damper into a common header, and then into each of the SG cavities of the containment and also into the reactor vessel cavity.

The RBCS fans, coolers, and LPSW valves are designed to operate in the post-accident containment atmosphere; they do not require HVAC. 


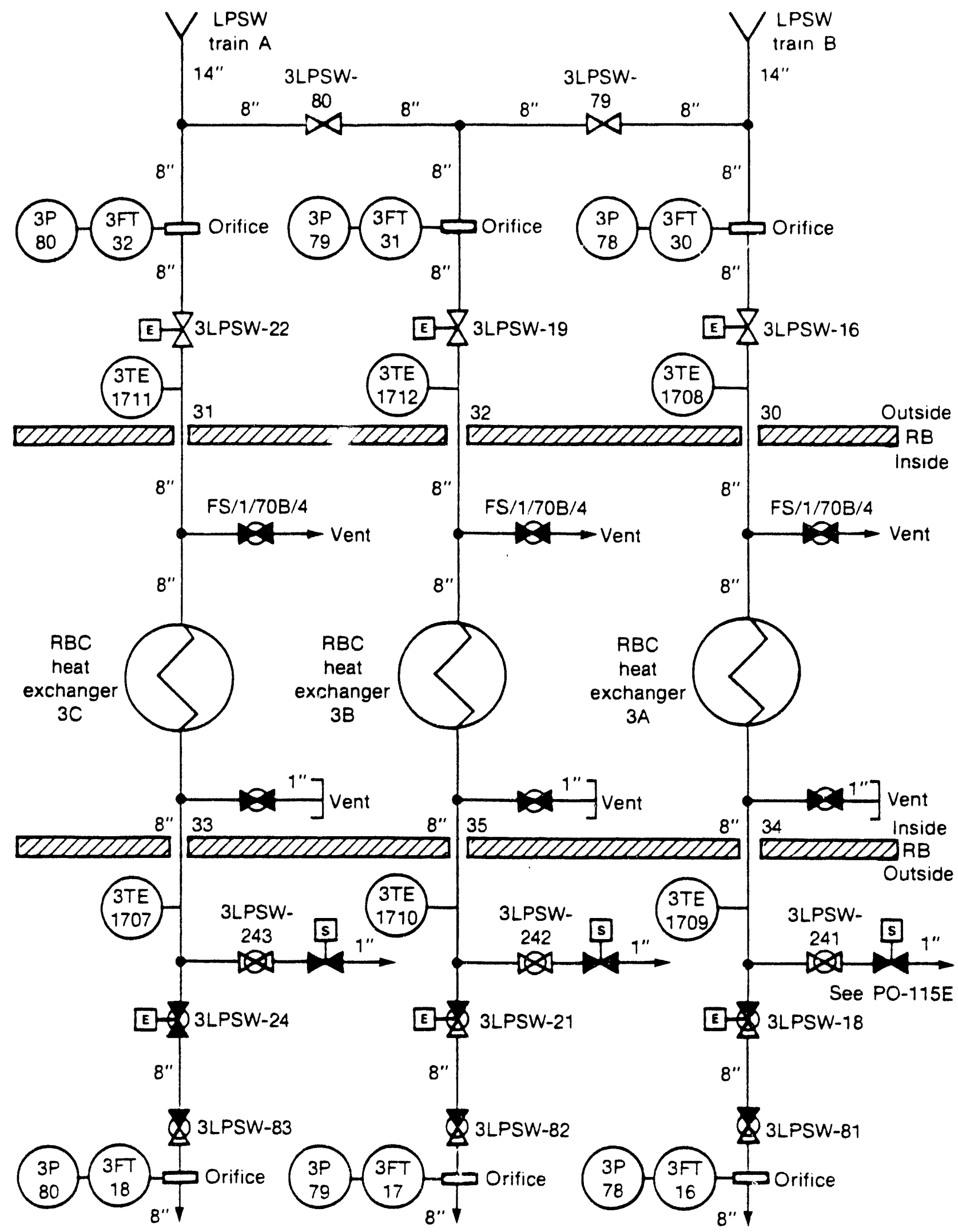

FIGURE E.14. Simplified Diagram of the Reactor Building Ccoling System 


\section{Fauit Tree Logic Model}

The existing PRA developed one fault tree for the RBCS with the top event "3 RBC units fail to provide Reactor Building cooling." Because the RBCS is not dependent upon HVAC systems, the RBCS fault tree is not addressed.

\section{E.2.6 Primary Pressure Control System}

The primary pressure control system (PPCS) is part of the reactor cooling system (RCS). During normal operation, the pressurizer establishes and maintains the RCS pressure within prescribed limits and provides a steam surge chamber and a water reserve to accommodate changes in the density of the reactor coolant. Level instrumentation on the pressurizer monitors RCS volume to determine makeup and letdown requirements.

Under abnormal conditions, the pressurizer performs two additional functions. The relief valves on the pressurizer are the only means of external pressure relief for the RCS. Also, the system can be employed with HPI to remove heat from the RCS when heat removal through the secondary system is not available.

The PPCS consists of the pressurizer equipped with pressure-relief valves, pressure-relief sprays, coolant heaters, and coolant level instrumentation. A detailed drawing of the pressurizer is shown in Figure E.15.

The primary pressure control system does not require support from any of the plant HVAC systems to operate.

\section{Fault Tree Logic Model}

Because HVAC systems are not needed for operation of the PPCS, no fault tree analysis is presented.

\section{E.2.7 Power Conversion System}

The power conversion system (PCS) removes heat from the RCS and converts the extracted heat into mechanical energy for subsequent corversion to electrical energy. It consists of the following systems:

- main feedwater system

- main steam system

- condensate system

- condenser circulating water system

- vacuum system. 


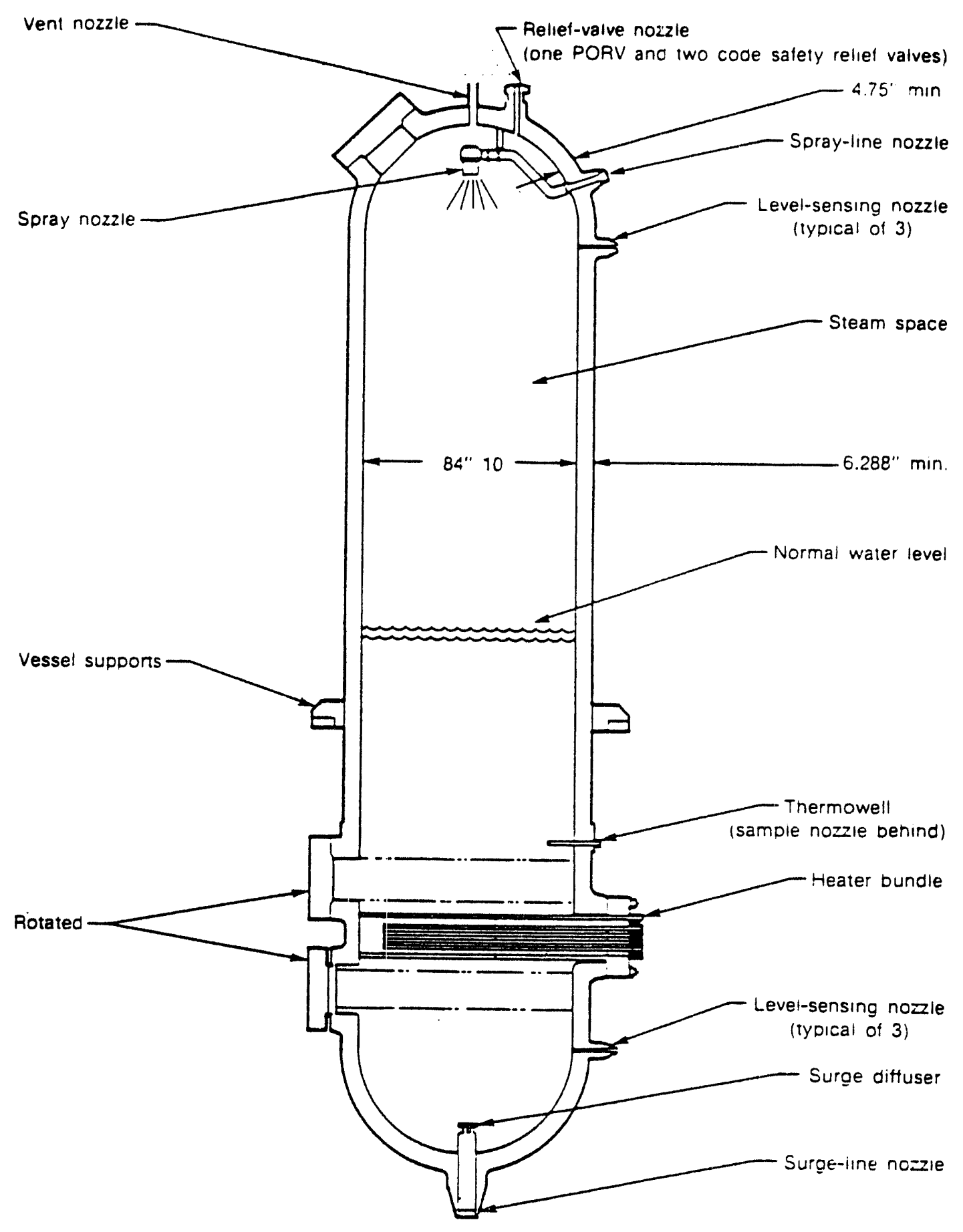

FIGURE E.15. Simplified Diagram of the Pressurizer 
Two other systems are provided, with the following functions:

- Auxiliary, or startup, steam system, which provides steam to equipment that must be operated when main steam is not available.

- Emergency feedwater system, which supplies the SGs in the event of a loss of MFW so that decay heat may be adequately removed.

Figure E.16 shows the MFW system in diagrammatic form. Main feedwater is normally supplied to each SG through the lower 14 -inch ring header. If all four reactor coolant pumps are tripped, feedwater is supplied through the upper header so that a higher level can be maintained in the SGs to promote natural circulation.

The control valves and their block valves are controlled by the integrated control system (ICS). Feedwater flows into the common header after leaving two high-pressure heater banks, $A$ and $B$. Each heater bank consists of two heaters, $A 1$ and $A 2$, and $B 1$ and $B 2$, respectively. Two trains of steamdriven feedwater pumps, $A$ and $B$, pump feedwater from the outlet of the lowpressure heaters to the inlet of the high-pressure heaters. At their suction, the feedwater pumps are cross-connected by a 24-inch header. Feedwater flows into the cross-connect header after passing through three banks of lowpressure heaters. Each bank consists of two heater trains that are crossconnected at both the inlet and the outlet. The flow of steam to the turbine is controlled by the governor system, which controls the position of seven low-pressure control valves and one high-pressure control valve. The eight control valves are designed to lift in a specific sequence. PCS components do not require HVAC to operate.

\section{Fault Tree Logic Model}

Several fault trees were developed in the existing PRA for the PCS; however, because the PCS is not dependent upon HVAC or room cooling systems, the fault trees are not addressed in this report.

\section{E.2.8 Emergency Feedwater System}

The emergency feedwater (EFW) system is used to supply feedwater to the SGs when the MFW system is not available. The function of the EFW system is to remove energy stored in the core and primary coolant. The EFW system provides a sufficient secondary-side SG heat sink for cooling down the RCS from a reactor trip at power operation to conditions at which the low-pressure decay-heat removal system may be used ( $350 \mathrm{psia}$ and $\left.250^{\circ} \mathrm{F}\right)$.

The EFW system is diagrammed in Figure E.17. It takes suction from either the upper surge tanks (USTs) or the condenser hotwell and delivers flow to both SGs through the EFW nozzles. The EFW system is equipped with three pumps: two MDPs powered by the emergency AC power system and one steam-driven pump supplied from both the main and auxiliary steam systems. The primary sources of water for the EFW system are the upper surge tanks (Figure E.18), two 36,000-gallon tanks valved together to make one 72,000-gallon tank. The 


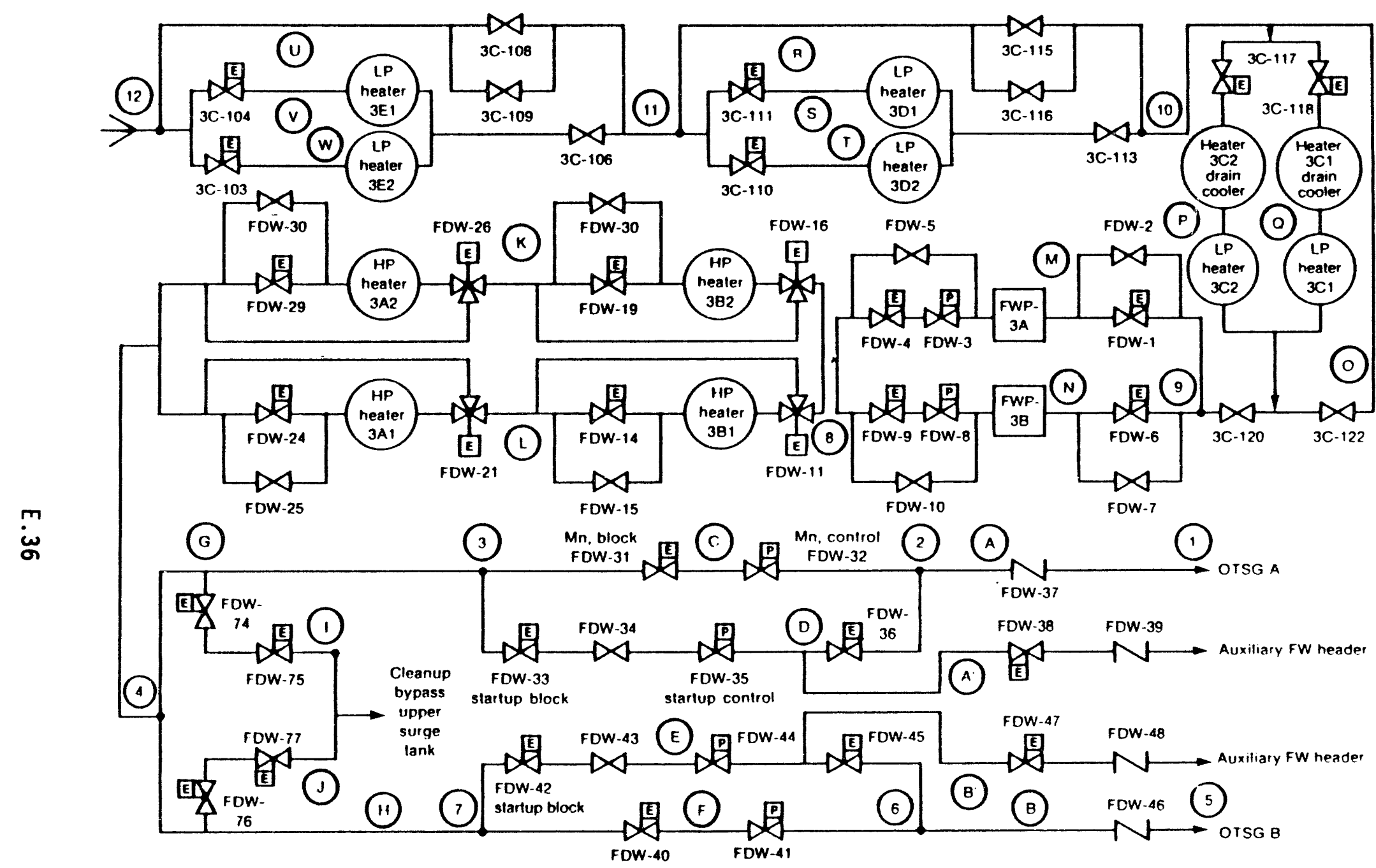

Note: Encircled letters Indicate flow segments and encircled numbers indicate nodes

FIGIIRE E.16. Simplified Diagram of the Main Feedwater System 


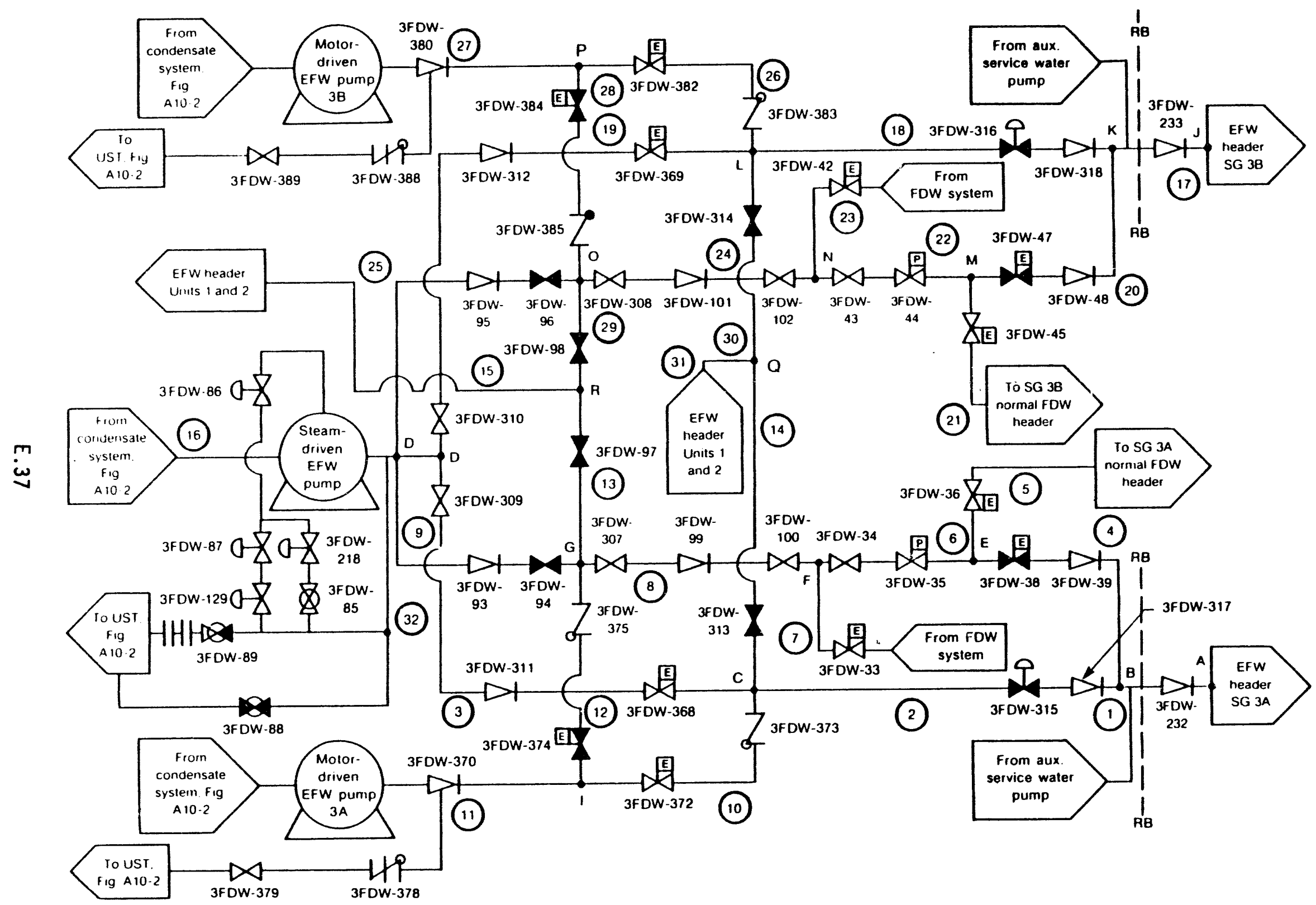

FIGURE E.17. Simplified Diagram of the Emergency Feedwater System 


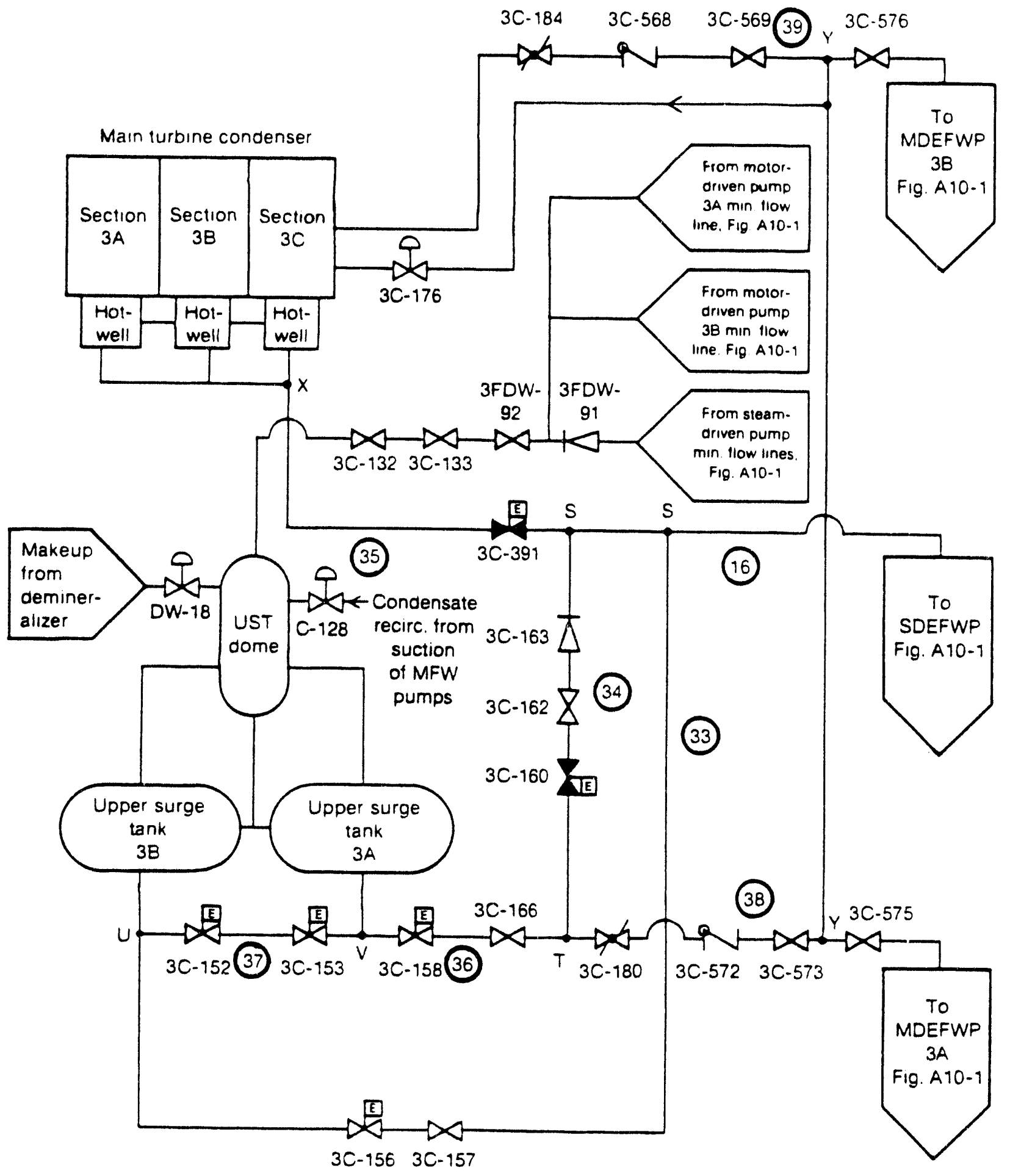

FIGURE E.18. Suction Sources and Valve Arrangements for the Emergency Feedwater System 
condenser hotwell can also serve as the source of suction to the EFW pumps and has a 142,000-gallon capacity. To take suction from the hotwell with the MDPs, the condenser vacuum must be broken, because a net positive suction head (NPSH) must be established.

The steam-driven pump takes suction from the bottom of the hotwell. Vacuum does not need to be broken to operate the steam-driven pump when aligned to the hotwell.

The EFW system mechanical components are designed to operate without support from the HVAC system. EFW pumps are located in open areas in the lower level of the Turbine Building. A large open area allows for effective dissipation of heat generated during pump operation.

\section{Fault Tree Logic Model}

The existing PRA developed a fault tree for the EFW system in which the top level of the fault tree is the failure of both EFW headers to deliver flow to the SGs. Because the EFW system is not dependent upon HVAC system for successful long-term operation, the fault tree is not addressed in this study.

\section{E.2.9 Engineered Safeguards System}

The engineered safeguards (ES) system is designed to detect failures in the integrity of the RCS and to provide digital trip signals that initiate automatic protective actions in the event of such failures.

The ES-actuated plant-protection systems provide the following function:

- Removal of decay heat from the core

- Protection of Reactor Building integrity

- Removal of radionuclides from the atmosphere of the Reactor Building and from any air leaking from the Reactor Building.

The first function is provided by the HPI and/or LPI systems; the second via Reactor Building isolation in conjunction with the RBCS or RBSS systems. The third ES-actuated function is provided by the Reactor Building penetration-room ventilation system.

A general schematic diagram of the ES system is provided in Figure E.19. As shown in the diagram, the ES system consists of two major subsystems, analog and digital.

The analog subsystem consists of three redundant channels designated $A$, $B$, and C. Each channel continuously monitors RCS and Reactor Building pressure. If either is observed to deviate from a preselected pressure setpoint, the channel that is associated with that setpoint is designed to trip. The trip signal from an analog channel is transmitted to the digital channel associated with the particular pressure parameter. In the digital channel, 


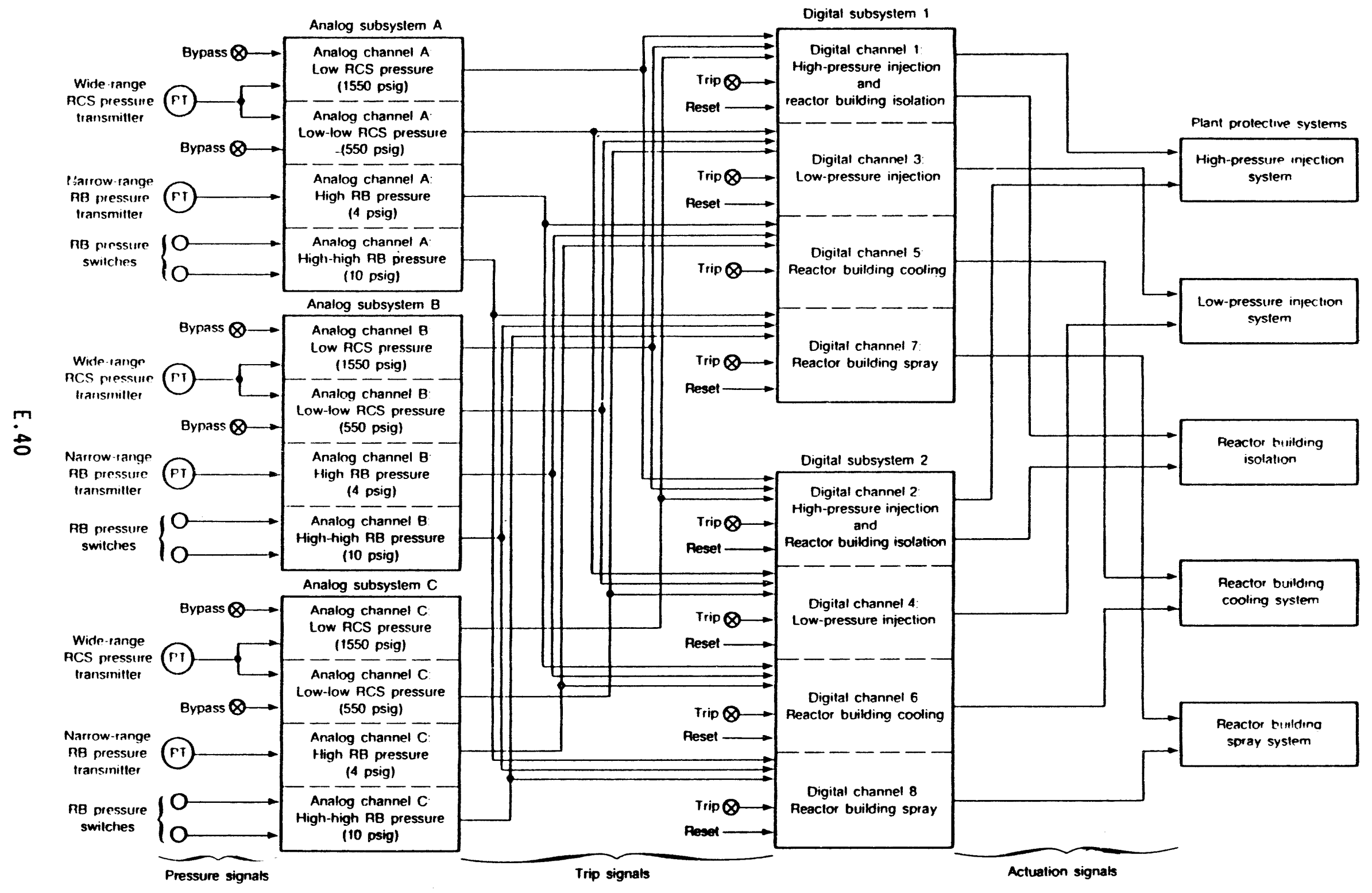

FIGURE E.19. Simplified Diagram of the Engineered Safeguards System 
the trip signals from the three analog channels are combined in a 2-of-3 logic configuration to trip that digital channel.

In all, there are eight digital channels, separated into odd and even groups. Each digital channel actuates a specific set of plant-protection equipment. The odd and even digital channels actuate redundant trains of protective equipment.

This system is located within the control room, and the control room cooling function is not discussed in the existing PRA. This dependency will be modeled in the core damage frequency (CDF) calculations (see Chapter 4).

\section{Fault Tree Logic Model}

The existing PRA developed several fault trees for the ES system. Each top gate represents a failure of ES to actuate a specific valve, pump, or other piece of plant safety equipment. Because the fault trees were modeled without HVAC failure, they are not shown here. However, as mentioned previously, the dependency of the ES system on control room cooling will be modeled in the CDF quantification process.

\section{E.2.10 The AC Power System}

The AC power system supplies electric power to the plant's external power grid during normal operation and to the unit auxiliaries under normal and accident conditions.

The representative $B \& W$ PWR's $A C$ power system is an interconnected set of several subsystems. In addition to the three 850 -MWe generators at the site, and the external power grid, it contains the following subsystems:

- The 230- and 525-kV switchyards.

- The auxiliary electric power systems, including the main transformer (T3), the auxiliary transformer (3T), the startup transformer (CT3), the emergency power underground transformer (CT4), and a 100-kV transformer (CT5).

- Emergency $A C$ power from a nearby hydropower station.

- Two combustion turbines at a nearby power station, the associated transmission line, and a 100-kV switchyard.

The layout of the $A C$ power system is shown in Figure E.20. A one-line diagram is presented in Figure E.21.

The external grid consists of 230-, 525-, and 100-kV transmission lines and their interconnections with the remainder of the utility's system or other interconnected systems. During normal operation, the units supply power to this external power grid. When the units are not operating, the external grid may supply power to the unit auxiliary electrical loads. 


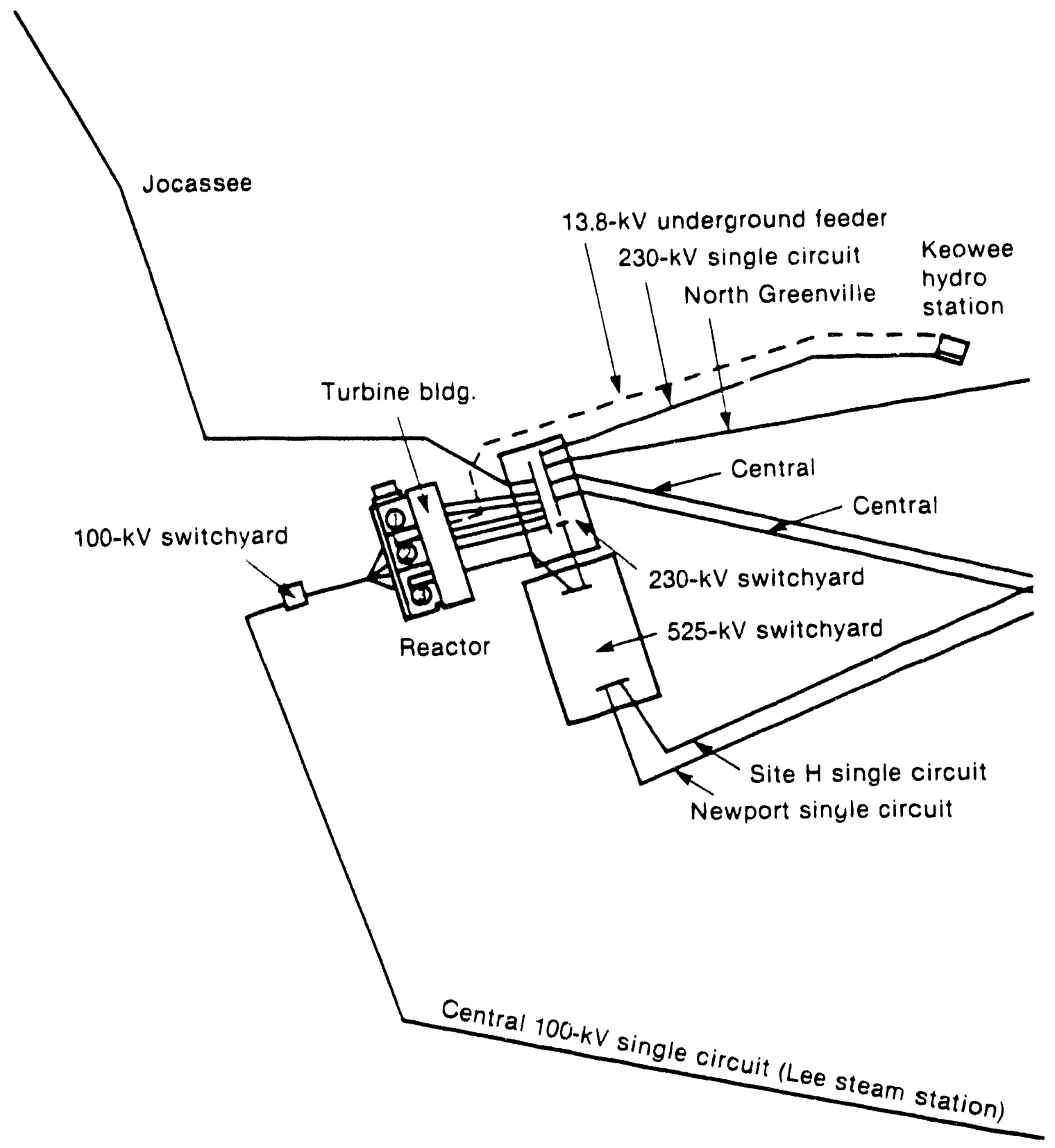

FIGURE E.20. Layout of the Representative Plant's AC Power System 


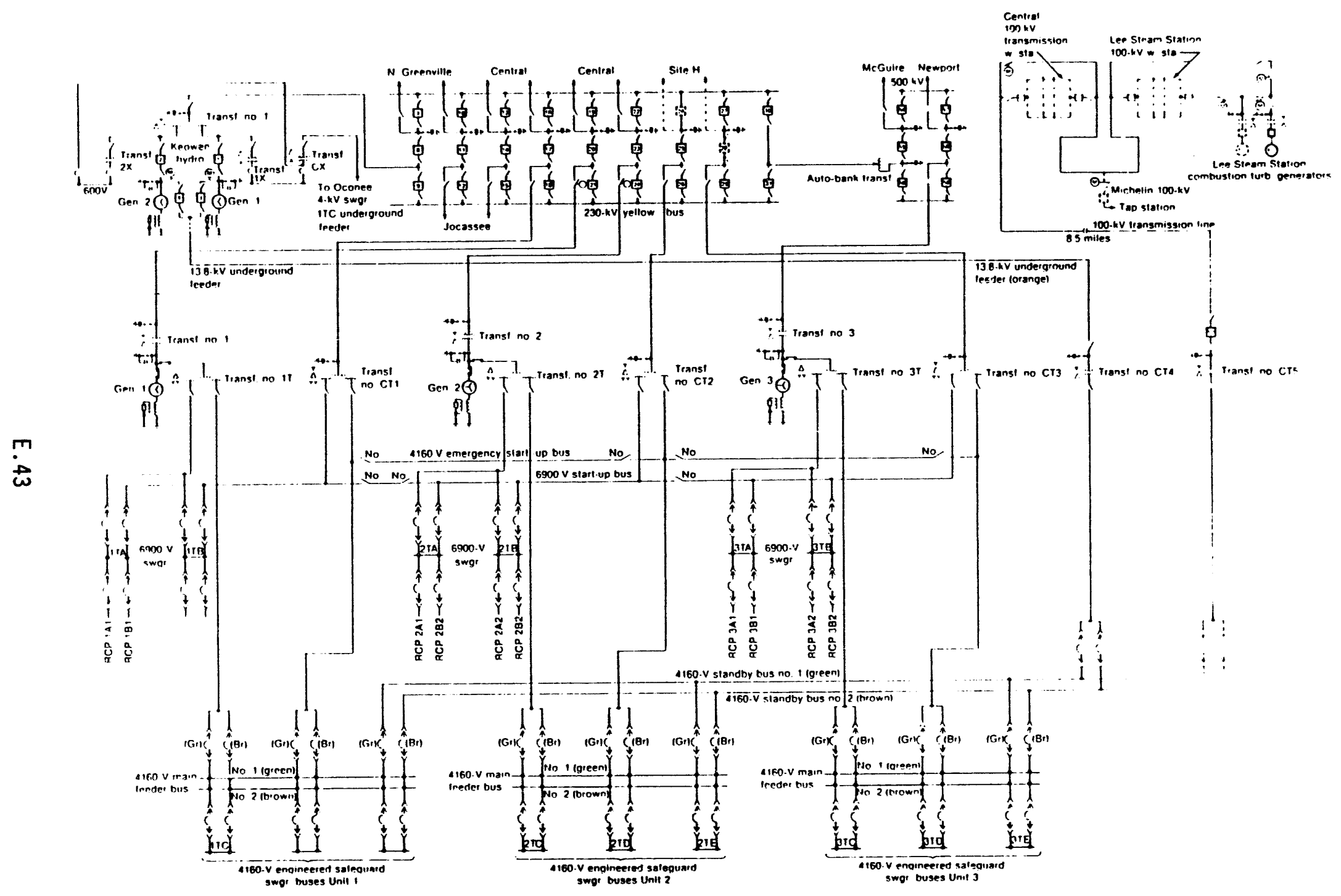

FIGURE E.21. Simplified Diagram of the AC Power System 
The unit generators are connected to the external power grid through their respective main step-up transformers, and the 230- and 525-kV switchyards at the site.

\section{AC Power System Supports HVAC}

The AC power system is the one used in normal operation. It supports other plant systems under both normal and accident conditions and is in turn supported by the DC power system and the ES system. One of the systems supported by AC power is the HVAC system.

HVAC fan motors require DC power to operate. Power for Train A fan motors is supplied by $208-V$ MCC $3 X L$ bus and power for Train B fan motors is supplied by 208-V MCC $3 X N$ bus. Loss of power from both of these buses will cause the HVAC system to fail.

\section{HVAC Supports AC Power}

The effect of HVAC failure on the operability of $A C$ power is not mentioned in the existing PRA. However, as discussed for the other representative plants, HVAC and room cooling systems are needed to support operation of MCCs that supply power to small fan motors and to the 4.16-kV AC power system that provides power to the ESF pump motors.

\section{Fault Tree Model}

The fault tree models for 208-V MCC 3XL and 208-V MCC 3XN bus failure are shown in Figure E.22. As shown, no dependencies on HVAC or room cooler systems are modeled in the fault tree. These dependencies will be included in the CDF calculations in Section 4 of the main report.

\section{E.2.11 DC Power System}

The representative B\&W PWR is provided with two separate DC power systems. One is the 125-V DC vital instrumentation and control (I\&C) power system; the other is a separate $125 / 250-V$ DC station power system that supplies large power loads. In addition to the $D C$ power systems associated with the site, there are the 125-V DC switching power system for the 230- and 525-kV switchyards and a 125-V DC station power system for each of the two emergency power units.

The 125-V DC vital I\&C power system, the 120-V vital AC I\&C power system, the 120-V AC integrated control system (ICS) power system, and the 240/120-V AC computer power system were examined in this study and are collectively called the $D C$ power system in the remainder of the discussion. The 120-V AC auxiliary power panelboard $(K X)$, which is not required to support any of the systems that were modeled, was excluded from this analys is. A portion of the 240/120-V AC regulated power system is also included in the analysis, because it provides an interface between the DC power system and the $600-V$ auxiliary power system. 

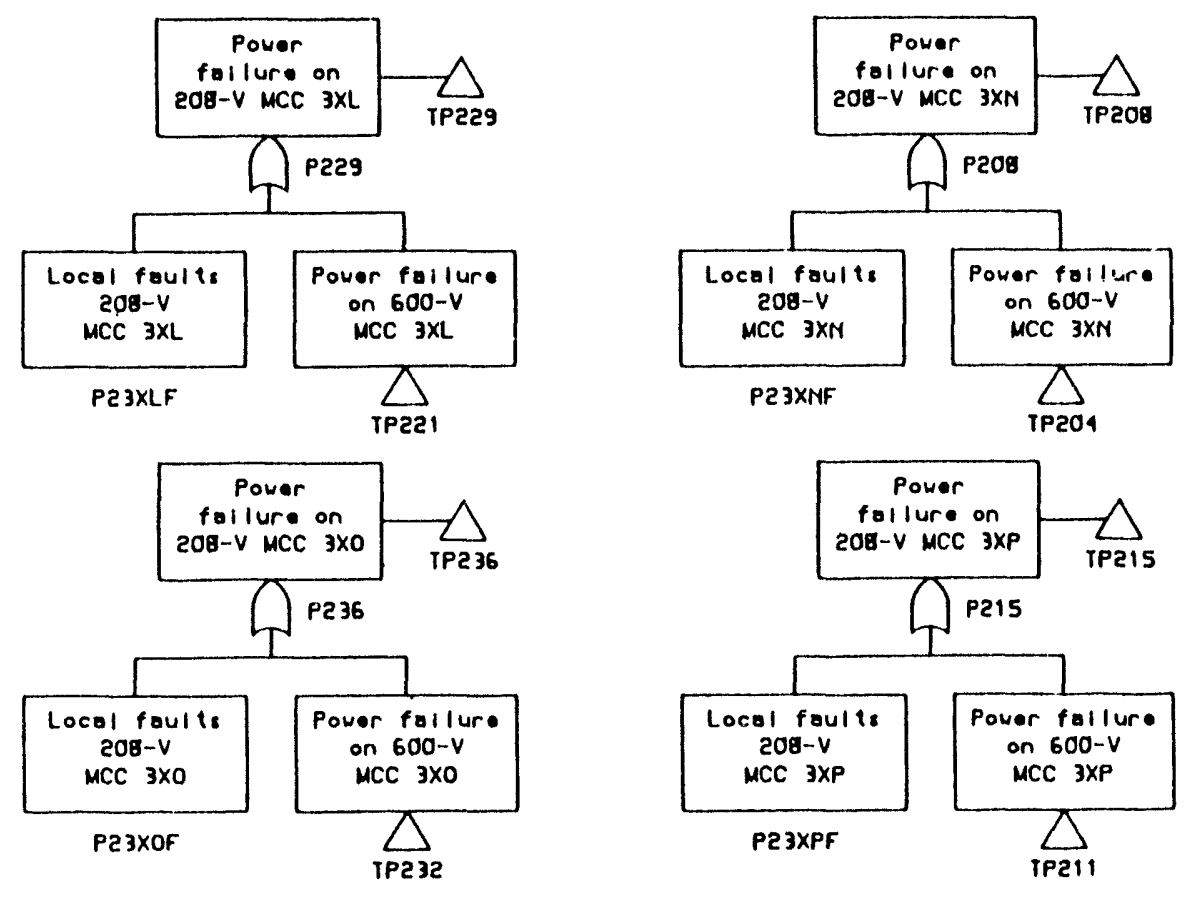

FIGURE E.22. Fault Tree for the AC Power System 


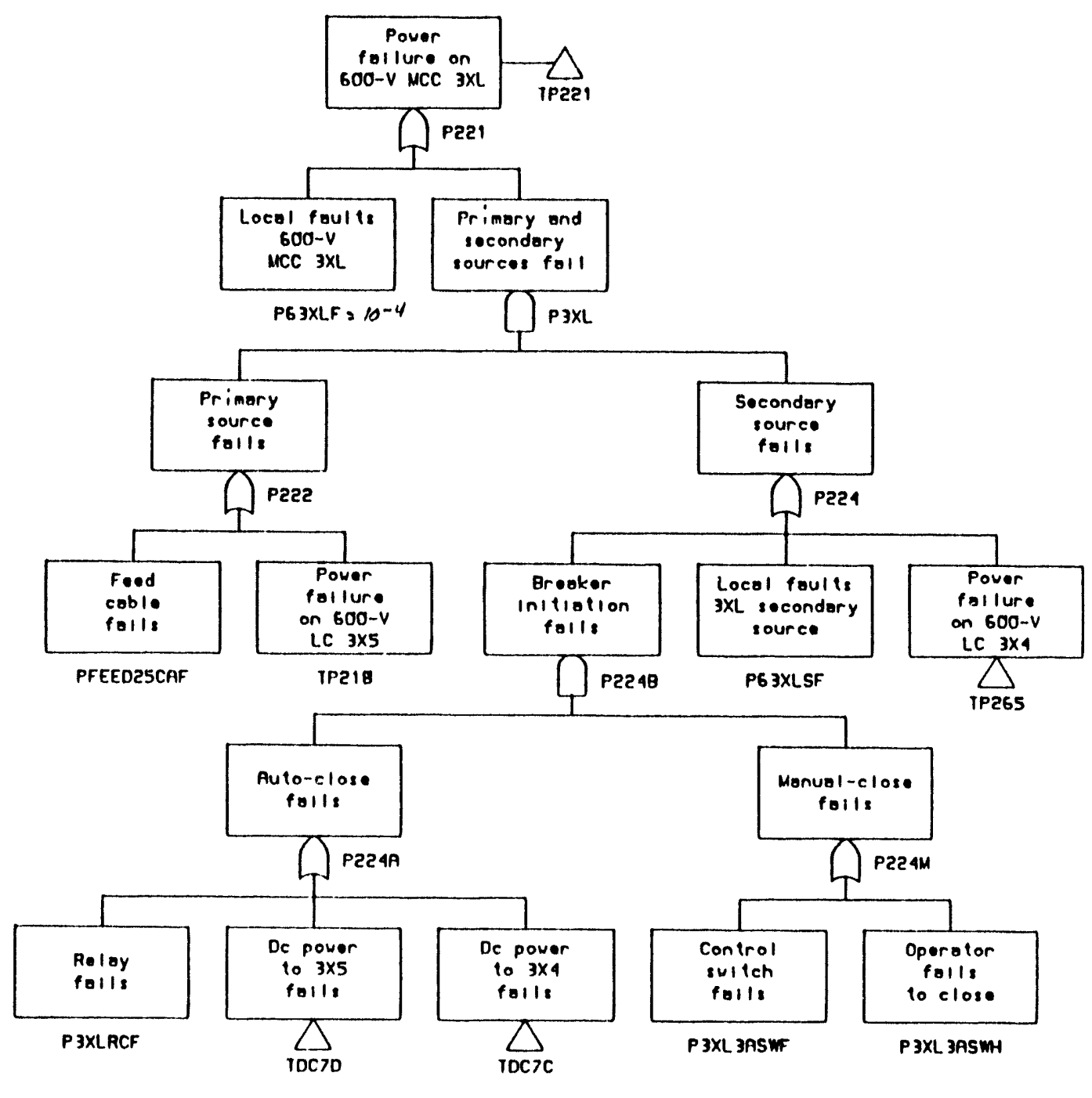

FIGURE E.22. (contd) 


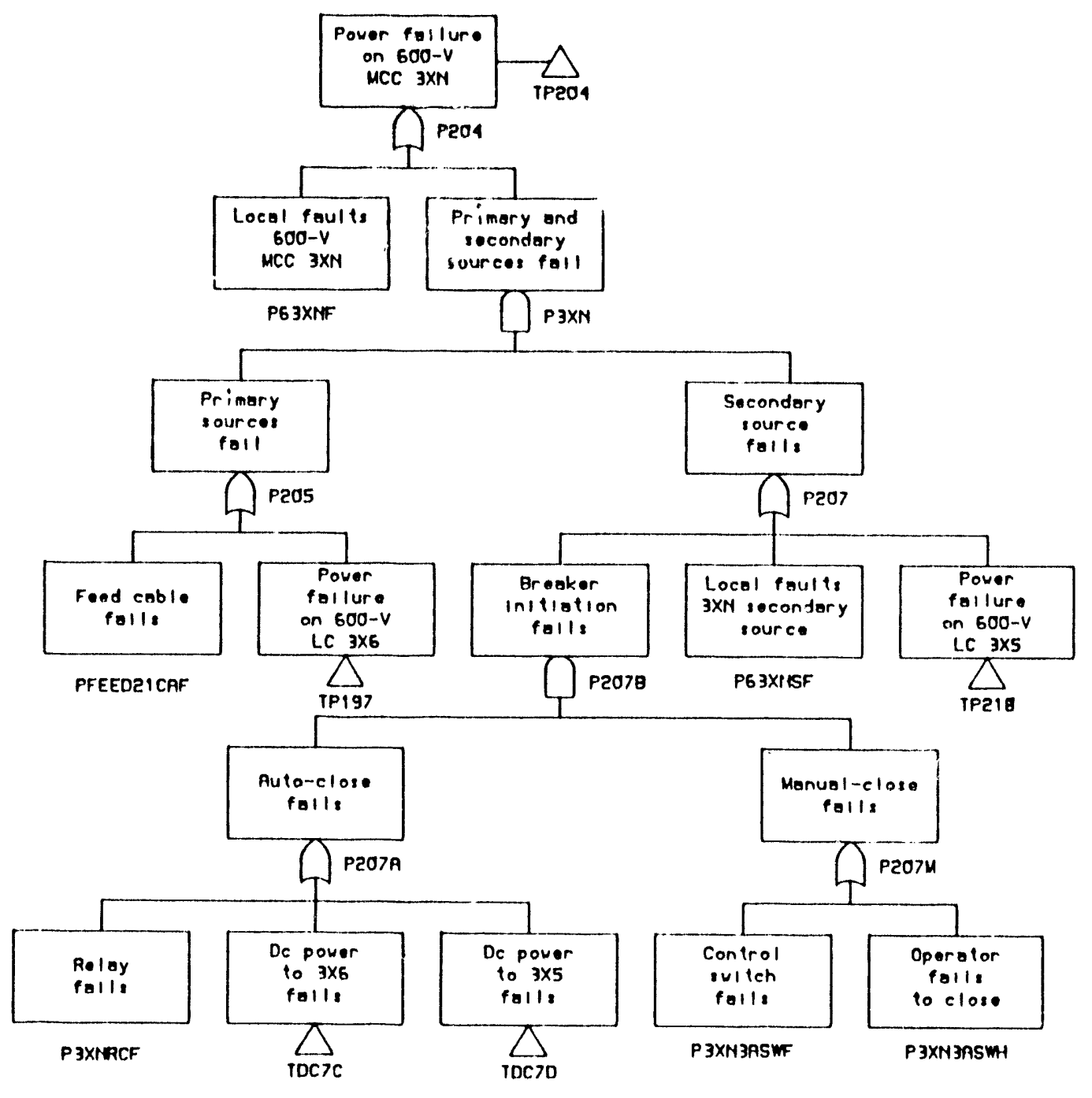

FIGURE E.22. (contd) 


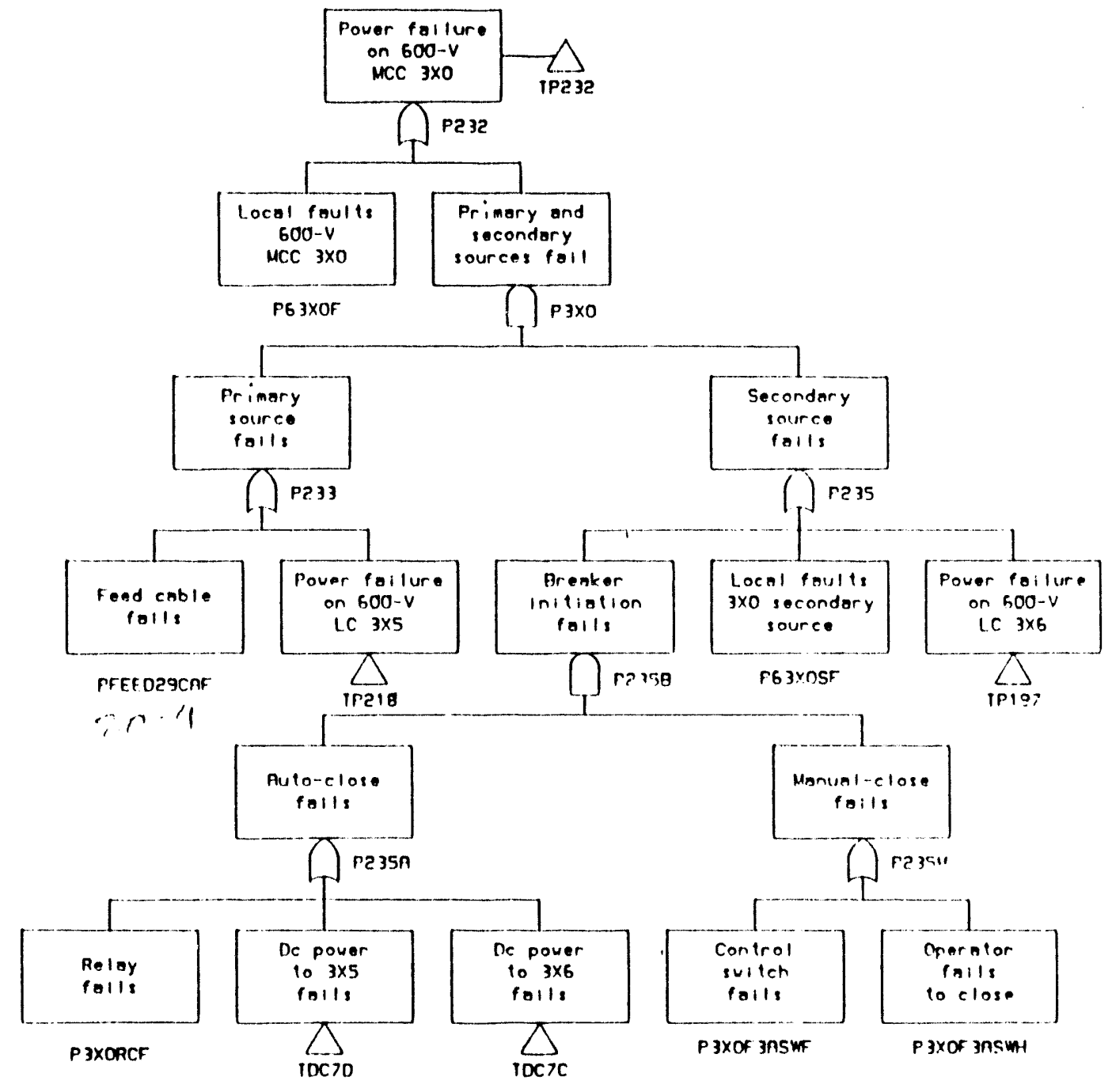

FIGURE E.22. (contd)

The $D C$ power system, shown in Figure E.23, consists of two distribution centers, two control-power batteries, three control-power battery chargers, four vital DC power panelboards, four vital AC power panelboards, an ICS power panelboard, and a computer-power panelboard. The typical schematic component chain is shown for channel $A$; channels $B, C$, and $D$ are identical. The vital power systems provide continuous power for safety-related control and instrumentation required for the startup, normal operation, and orderly shutdown of the plant.

Loss of HVAC will have an effect on the DC power system. High temperatures can be responsible for common-cause failures of inverters, chargers, and 


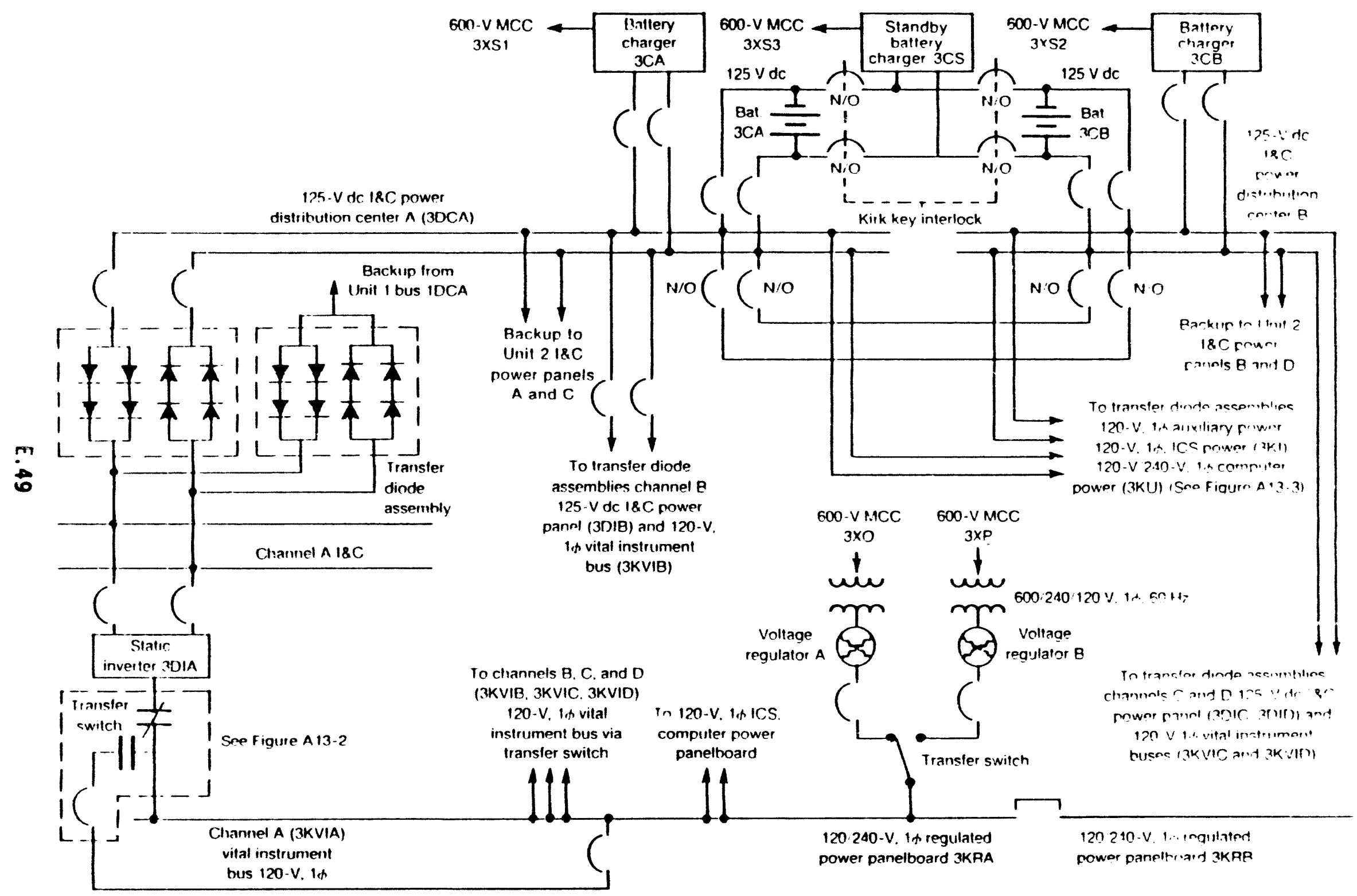

FIGURE E.23. Simplified Diagram 125-V DC Power System 
breakers in the cable rooms and equipment rooms. However, the existing PRA does not consider this effect and does not discuss HVAC failures in the DC power section. This dependency will be added to the DC power system models in this study.

\section{E.2.12 Service Water Systems}

Service water systems are used to remove waste heat generated in the plant. The specific needs for service water as a support system are identified at the component level in the fault trees of other systems.

Service water is supplied by four systems: 1) the low-pressure service water (LPSW) system; 2) the condenser circulating-water (CCW) system; 3) the high-pressure service-water (HPSW) system; and 4) the recirculating cooling water (RCW) system.

The LPSW supplies cooling for many emergency and nonemergency needs throughout the plant. The important functions of this system include

- cooling the motors of electric EFW pumps

- cooling the turbines and bearing 011 of the steam-driven EFW pumps

- cooling the motors of HPI pumps

- decay-heat removal through the heat exchangers of the LPI system

- supplying the ventilation cooling units of the Reactor Building

- cooling the motors of reactor coolant pumps

- supplying the ventilation units for the Auxiliary Building and LPI pump room.

The condenser circulating-water system supplies the large-volume cooling required by the main condensers for the normal operation of the turbine. Additional loads are also attached to the condenser circulating water, the most important being the oil cooler of the steam-driven EFW pump and the suction course for the LPSW and the HPSW system.

The HPSW supplies fire-protection systems throughout the plant. The system is also available as a backup source for LPSW if all LPSW pumping capability is lost.

The recirculating cooling-water system services the seal-return coolers of the reactor coolant pumps (RCPs) and the spent fuel cooling system.

Figure E.24 shows the relationships between the various service water systems. The LPSW was identified as being the most important with respect to safety and, in addition, LPSW is the only system related to the HVAC/room cooling system. Hence, only the LPSW system will be discussed in more detail. 


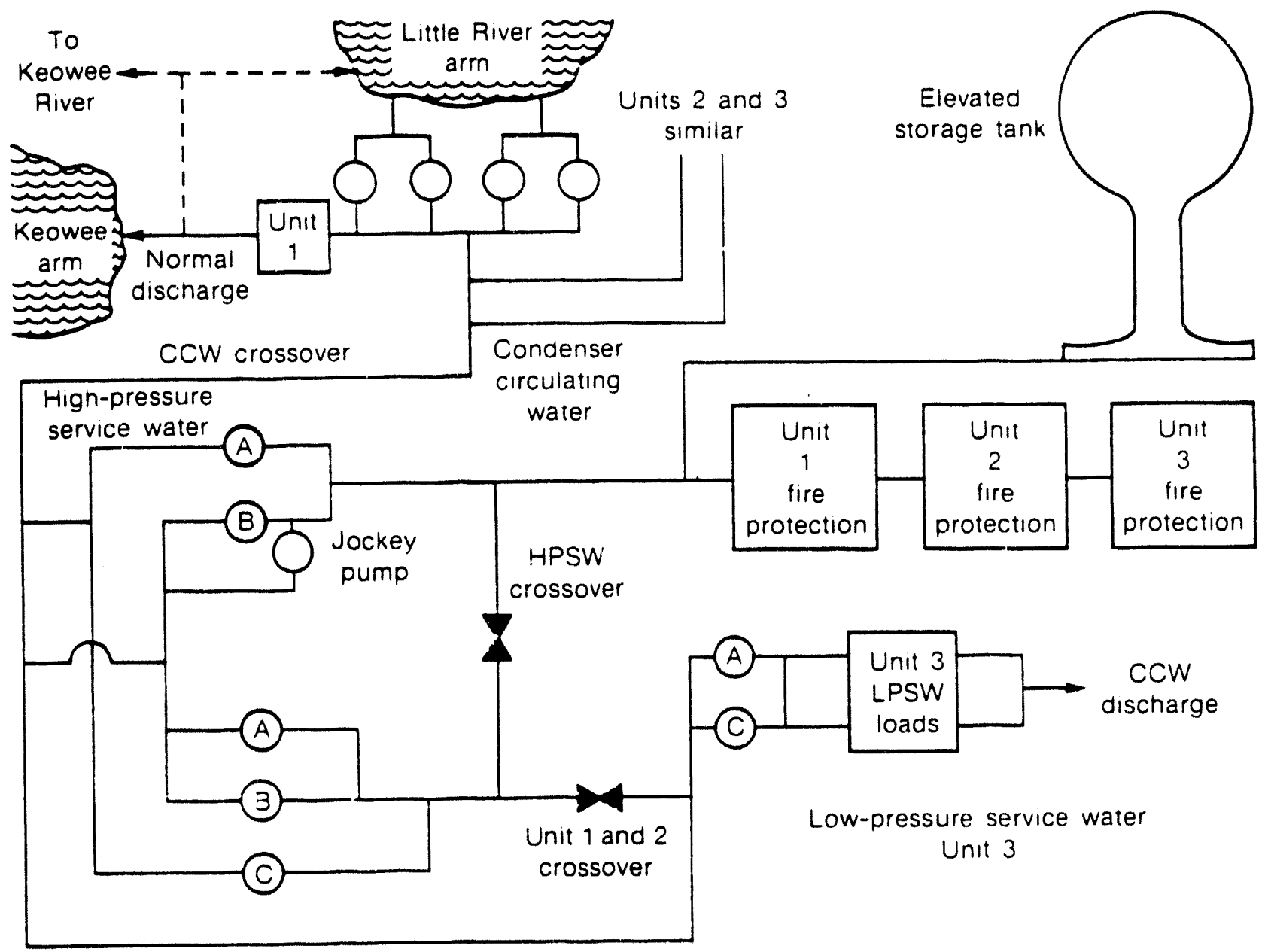

-ow-pressure service water

Units 1 and 2

\section{FIGURE E.24. Overview of Cooling Water Systems}

The LPSW system for Unit 3 is shown in Figures E.25 and E.26. Two 15,000-gpm pumps take suction from the CCW crossover. Because of the large volume of water available in the crossover lines, CCW flow is not required to maintain suction. The LPSW flow is delivered to the loads through two main headers, $A$, and $B$. The headers are normally cross-connected through normally open valve LPSW-132. Either pump is sufficient to supply lo ads during normal or emergency conditions. The pumps are fitted with suction strainers and a backwash header for cleaning the strainers.

The LPSW flow for AHUS 3-1 and 3-2 is obtained from header B as indicated in Figure E.27. These AHUs are required to provide cooling for the LPI pump room. 


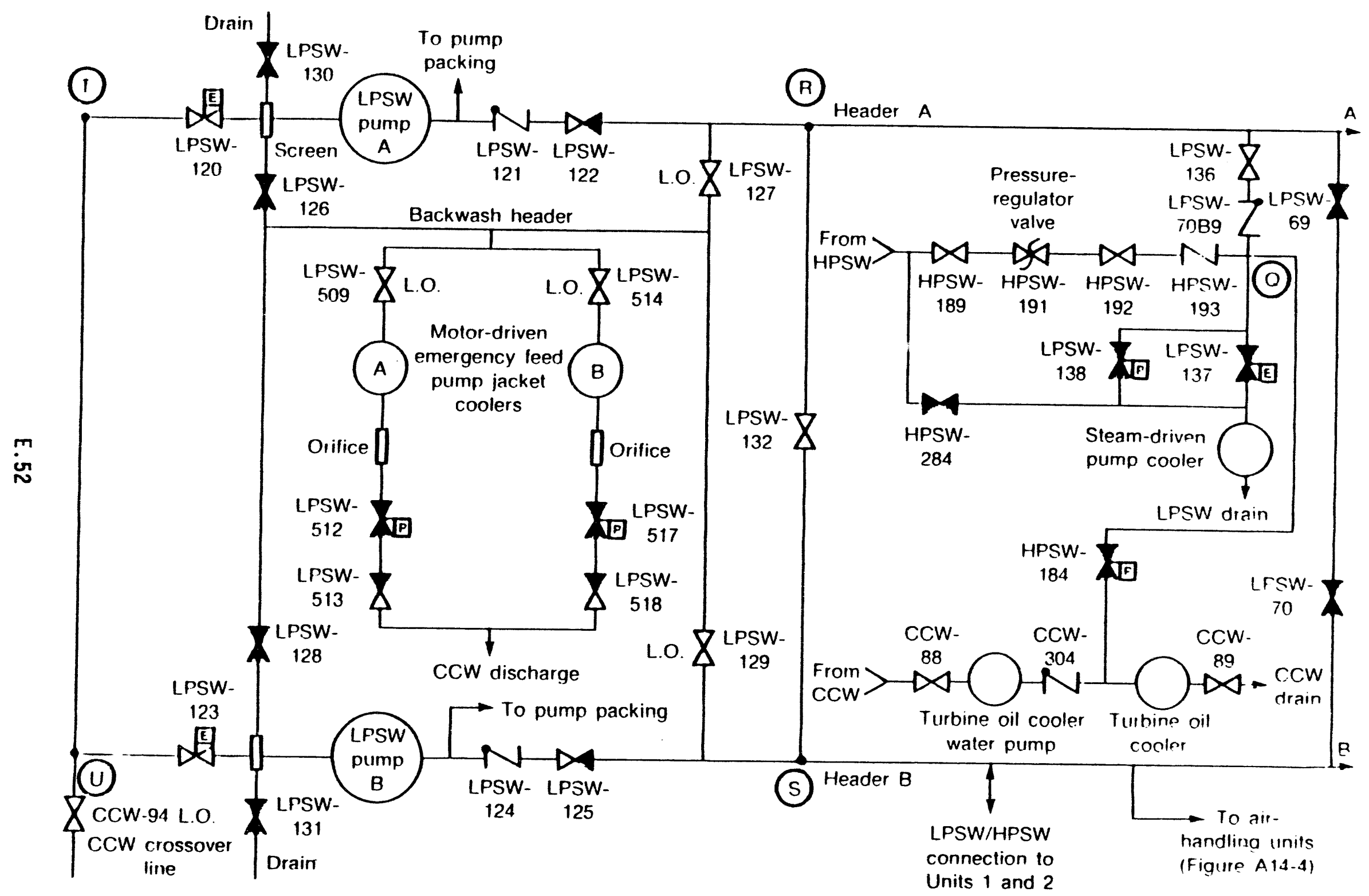

FIGURE E.25. Simplified Diagram of the Low-Pressure Service Water System 


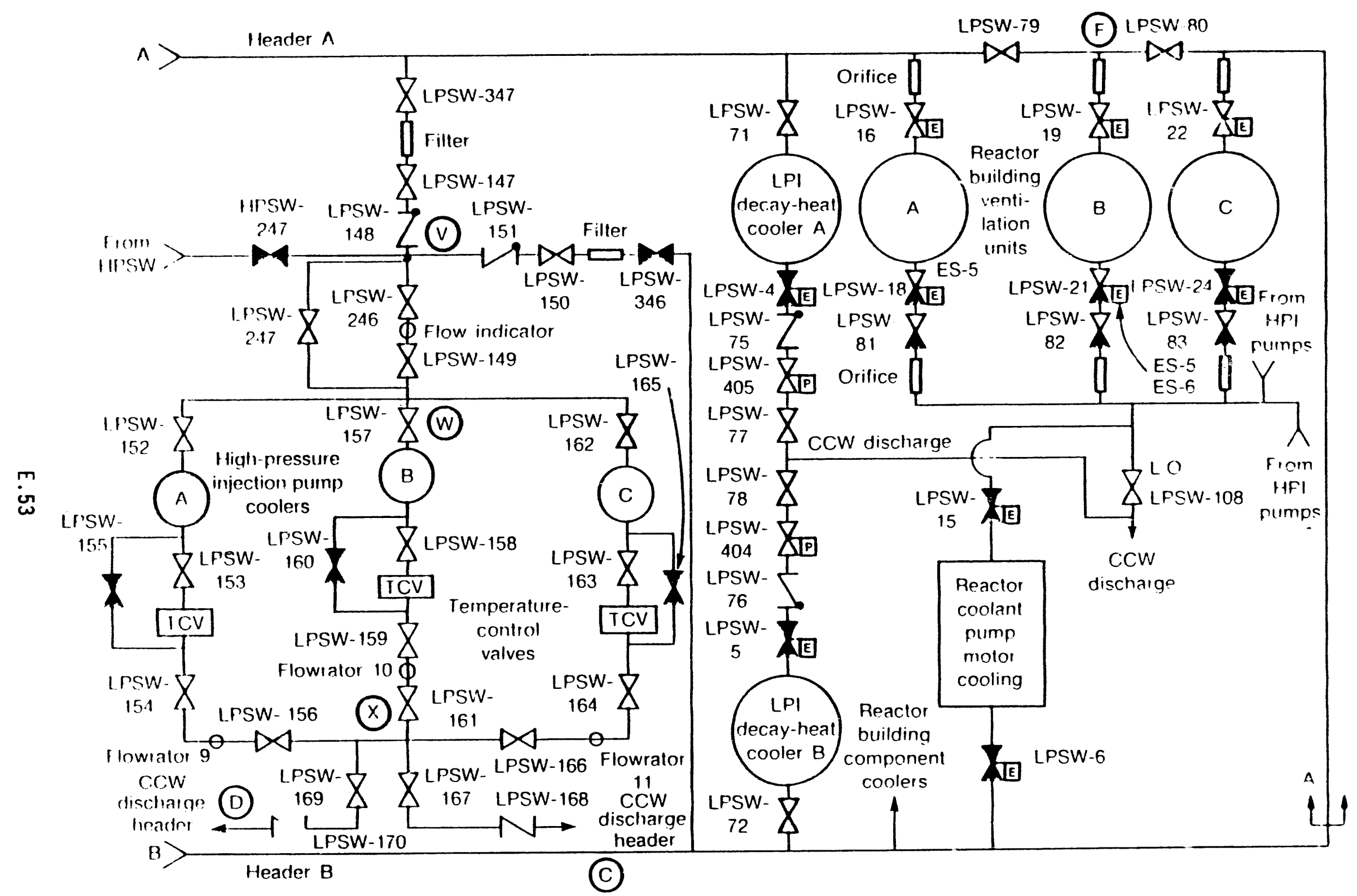

FIGURE E.26. Low-Pressure Service Water System Loads 


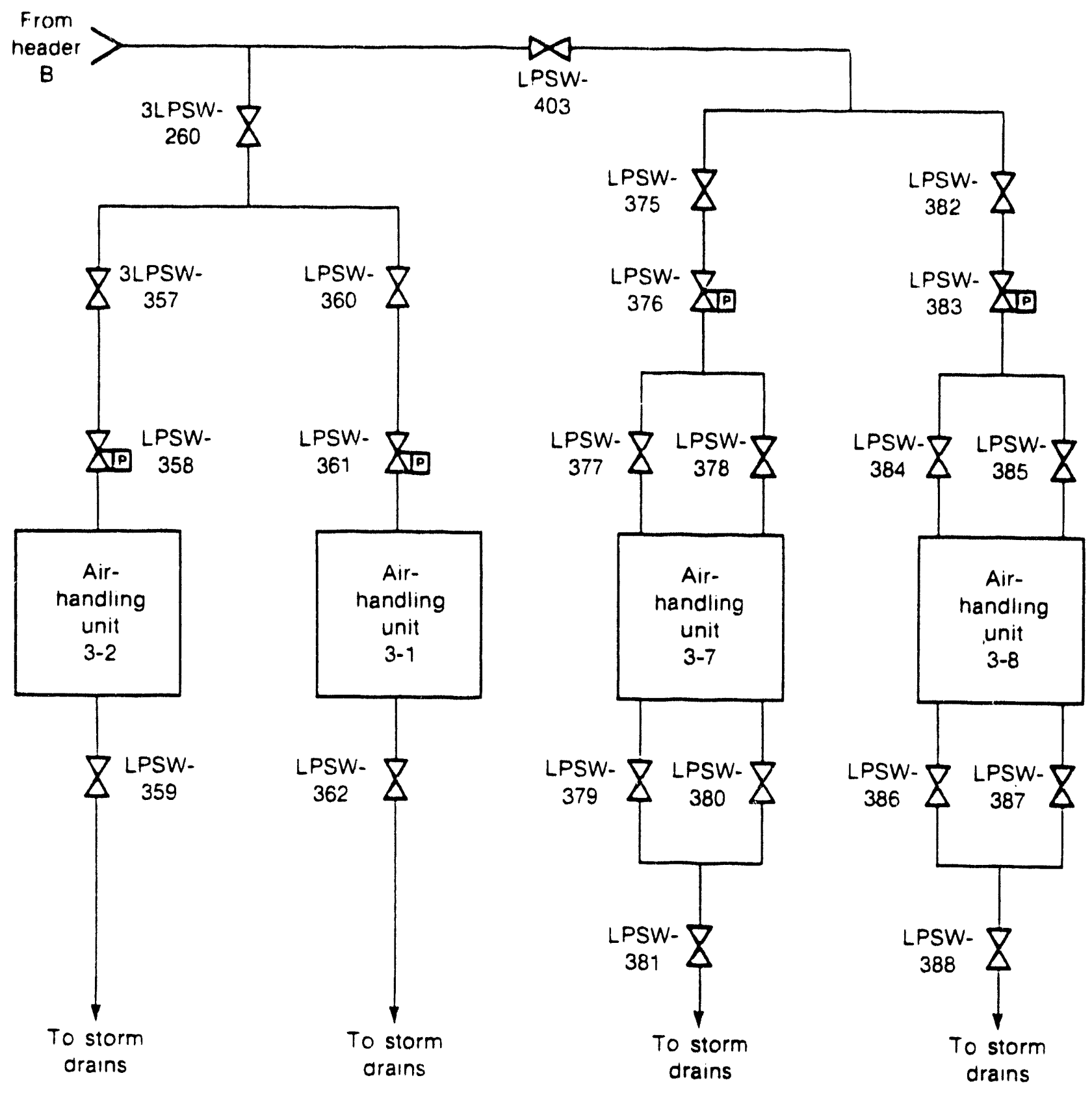

FIGURE E.27. Low-Pressure Service Water to Air-Handling Units

The LPSW system operates without support from HVAC, but cooling to AHUs 3-1 and 3-2 of the HVAC system is provided from header B of the LPSW system. Therefore, service water system failure has an effect on the room cooling to the LPI pump room cooling. 


\section{Eault Tree Model}

HVAC requires LPSW from header B. Therefore, Gate SW16 "No flow from LPSW header B," developed in the existing PRA, is included to provide more detail (see Figure E.28).

\section{E.2.13 Compressed Air System}

The compressed air system provides clean, dry, compressed air to various components throughout the Turbine and Auxiliary Buildings of all three units. The system operates at all times and controls numerous air-operated valves, instruments, switches, and positioners. On loss of air pressure, components are designed to fail to predetermined states and positions, and the operator

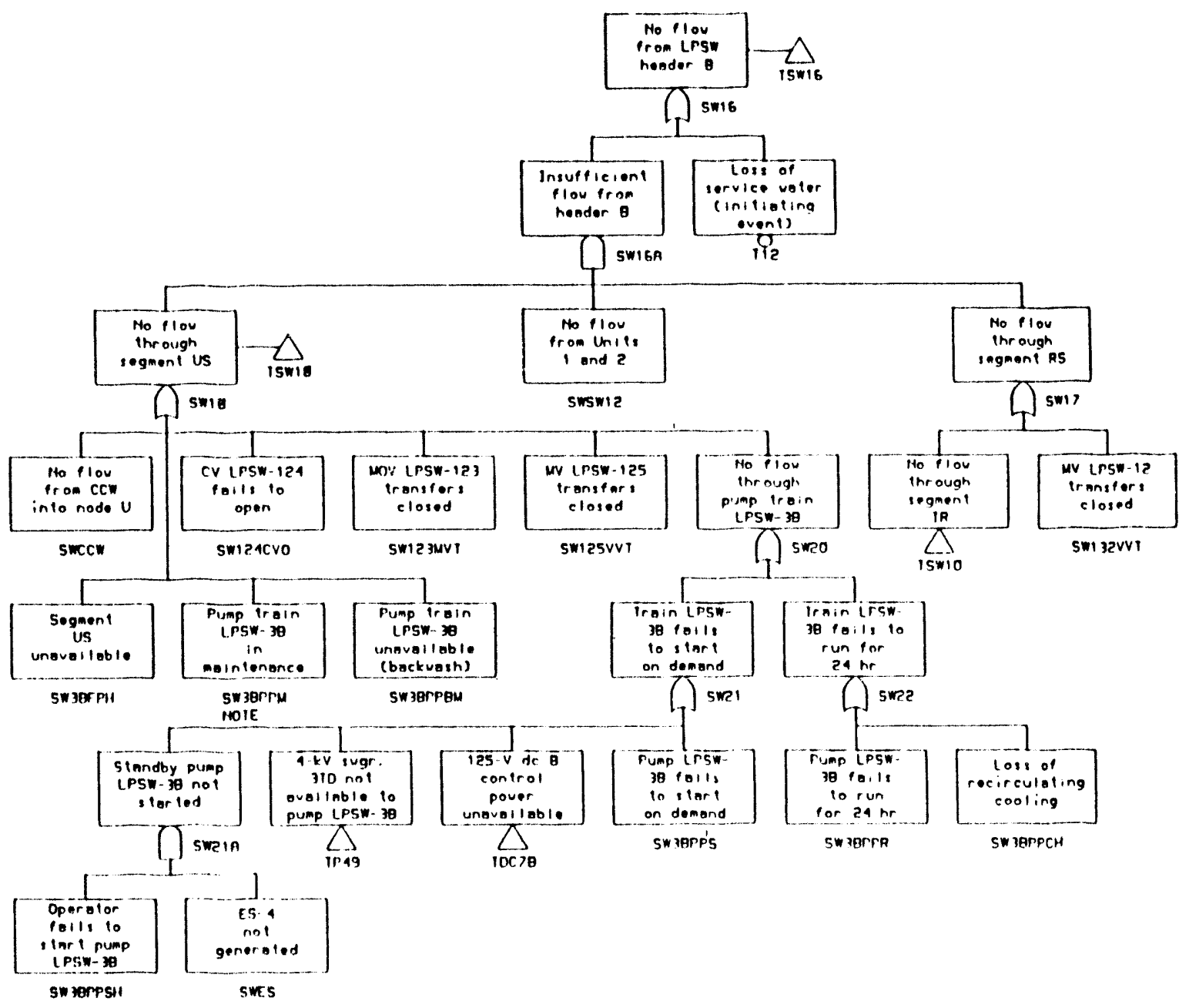

tole. Pump a uns olsumed lo be runningl mointenance for both

pumps $i t$ included in the development of pump $B$

FIGURE E.28. Fault Tree for the LPSW System 
initiates a reactor trip manually. With components in the failed state, emergency procedures prescribe the actions the operators must take to maintain stable reactor shutdown until air pressure is restored.

The compressed air system is diagrammed in Figure E.29. The system can be divided functionally into several segments: 1) the instrument air (IA) supply and conditioning train; 2) the backup service-air supply train; 3 ) the Turbine Building headers and component supplies; and 4) the Auxiliary Building headers and component supplies.

The compressed air system provides support for numerous systems in the plant. Some of the important interfaces that have been modeled in the existing PRA are those with HPI for RCP seal injection and makeup to the RCS, the MFW and EFW systems, LPSW, HVAC, and LPI.

Although the compressed air system provides support for HVAC, it does not require HVAC cooling to operate.

\section{Fault Tree Model}

The detailed fault tree for the loss of IA is shown in Figure E.30. As shown, there are no dependencies on HVAC or room cooling systems.

\section{E.2.14 Standby Shutdown Facility}

The standby shutdown facility (SSF) is a separate, bunkered installation that is constructed to provide a secure means for attaining and maintaining a hot shutdown condition in all three units. The SSF was designed principally to provide core cooling for incidents of industrial sabotage, fires, and flooding.

The SSF consists of two systems: the SSF auxiliary service water (ASW) system, which provides a backup supply of water to the steam generators; and the reactor coolant volume control system (RCVCS, also referred to as the reactor coolant makeup (RCM) system), which is designed to maintain sufficient inventory in the RCS to sustain natural circulation. All electrically operated equipment in the SSF can be powered from plant ES buses backed up by a diesel generator in the SSF.

The RCM system consists of three equipment trains, each housed within the Reactor Building of the unit being served, powered, and controlled through the SSF. Figure E.31 illustrates the major components of this system. The ASW system contains one pump that is capable of providing lake water to the SGs of any or all of the three units. The isolation and control valves are located within the units being served and are controlled and powered through the SSF. Figure E.32 illustrates the key components of this system.

The SSF electric power system is designed to provide motive and control power to all SSF equipment in the event that normal and emergency sources of plant power are lost. All MCCs and distribution panels included in the SSF EPS are located within the SSF building. Switching the bus loading and 


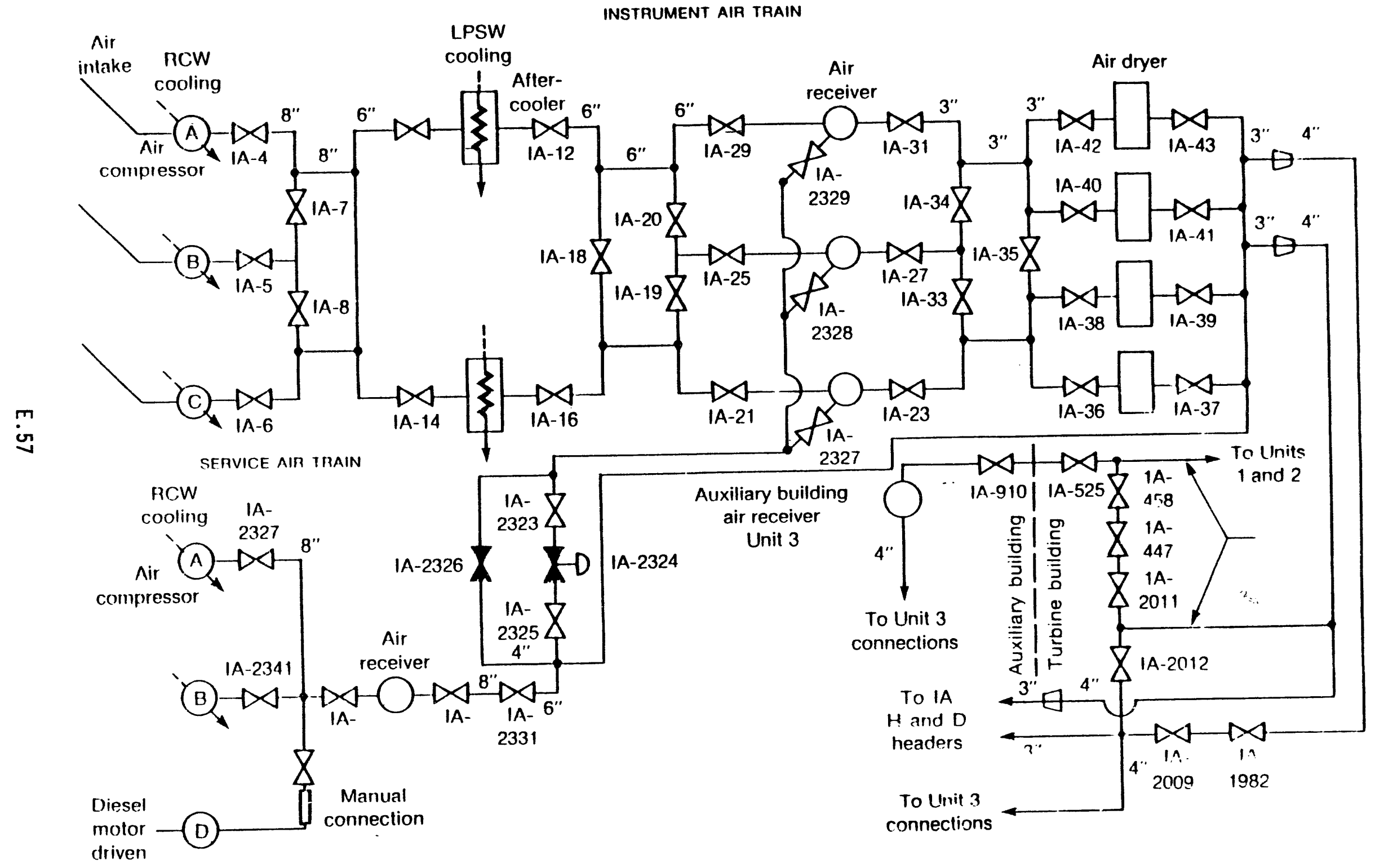

FIGURE E.29. Simplified Diagram of the Compressed Air System 


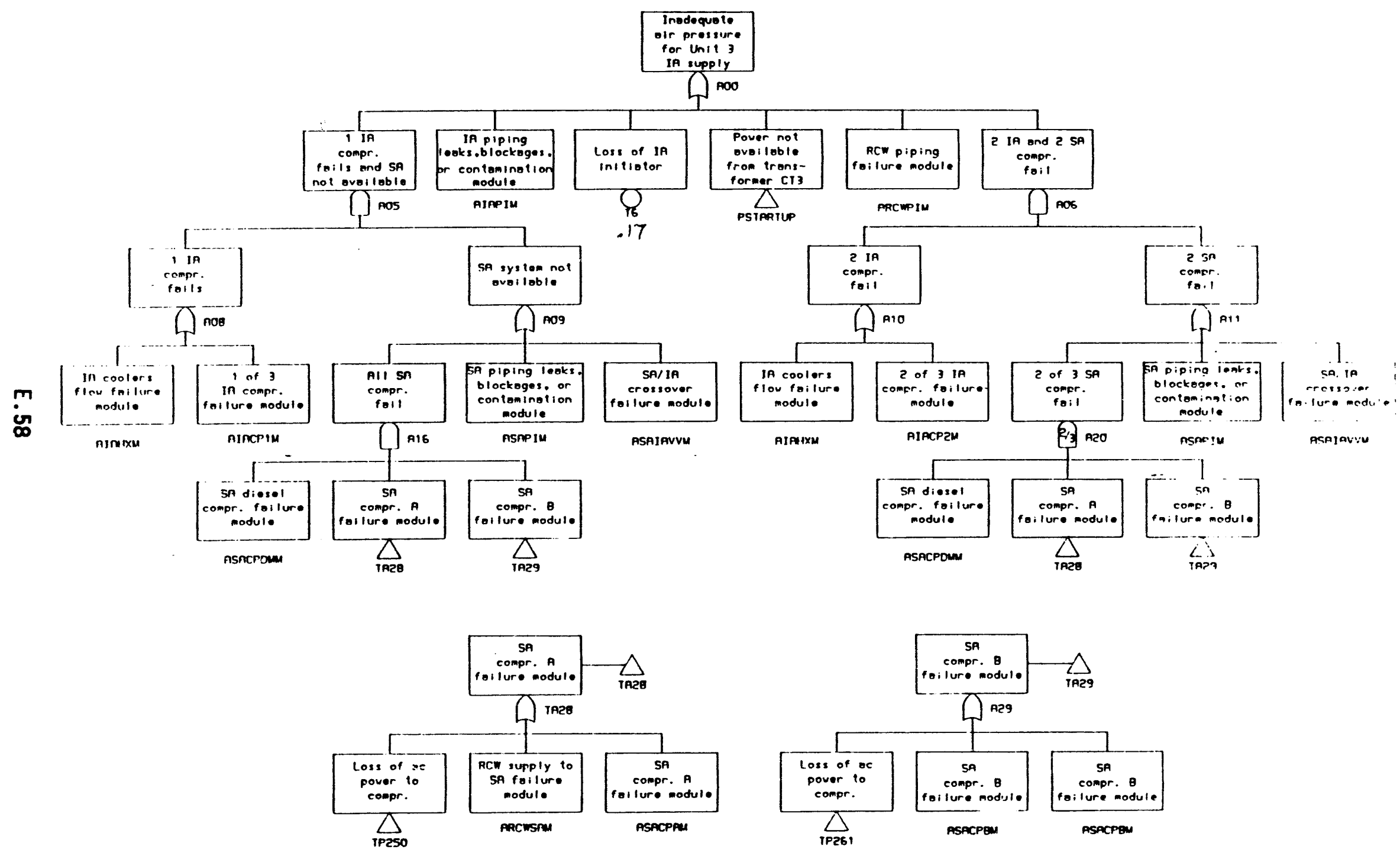

FIGURE E.30. Fault Tree for the Compressed Air System 


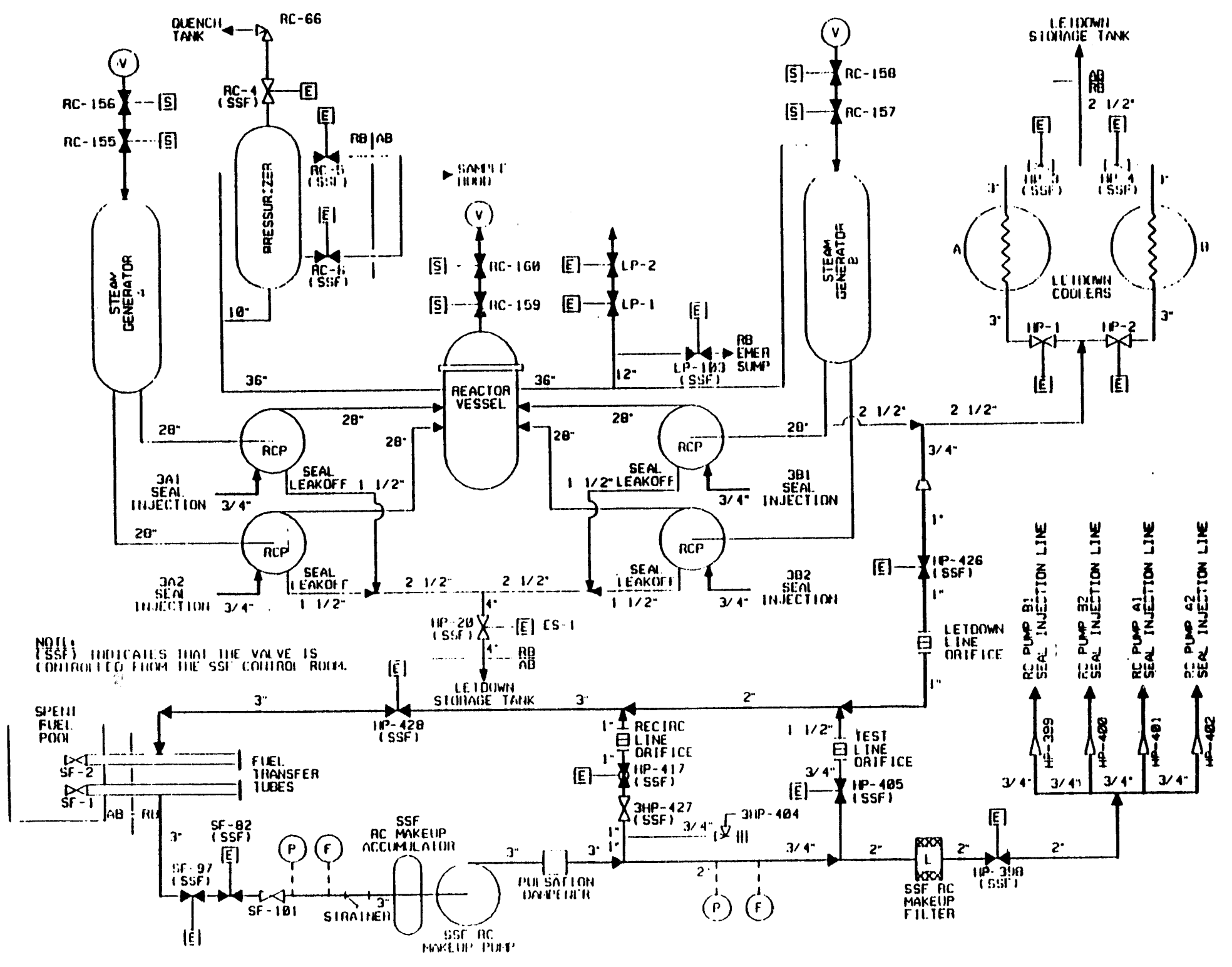

FIGURE E.31. Standby Shutdown Facility Reactor Coolant Makeup System

starting the diesel generator are manual actions performed in the SSF building. In the event that the 4.16-kV power supply from Unit 2 is lost, the SSF 4.16-kV is automatically separated from the feeder bus, and ine diesel generator must be started and connected manually. Other SSF EPS buses must be manually switched from normal power sources when those sources are lost. Figure E.33 is a block diagram of the electric power system, and Figure E.34 is a one-line schematic diagram. 


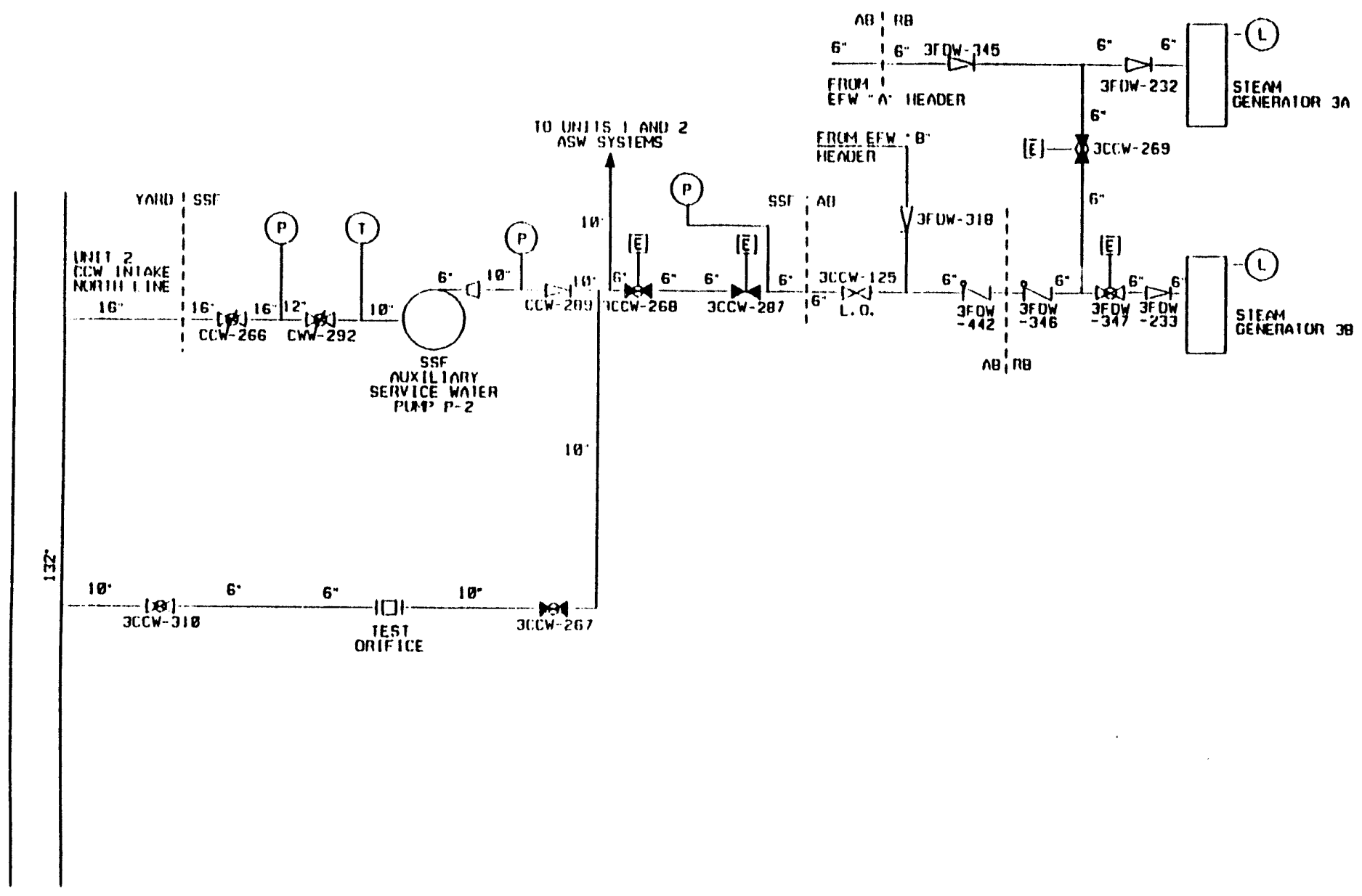

FIGURE E.32. Standby Shutdown Facility Auxiliary Service Water System

The SSF requires HVAC to operate; however, the SSF HVAC system is not analyzed or discussed in the existing PRA. This dependency will be added during the CDF quantification process.

SSF dependencies and interfaces include the following:

- Air systems. The SSF does not require any of the plant compressed air systems to operate. The diesel generator has its own starting air system.

- Cooling water systems. The SSF does not require any of the plant c001ing water systems to operate. The diesel has its own LPSW pump that provides a constant $500 \mathrm{gpm}$ of cooling water to the diesel engine jacket water heat exchangers. The pump is powered from the SSF electric power system. 


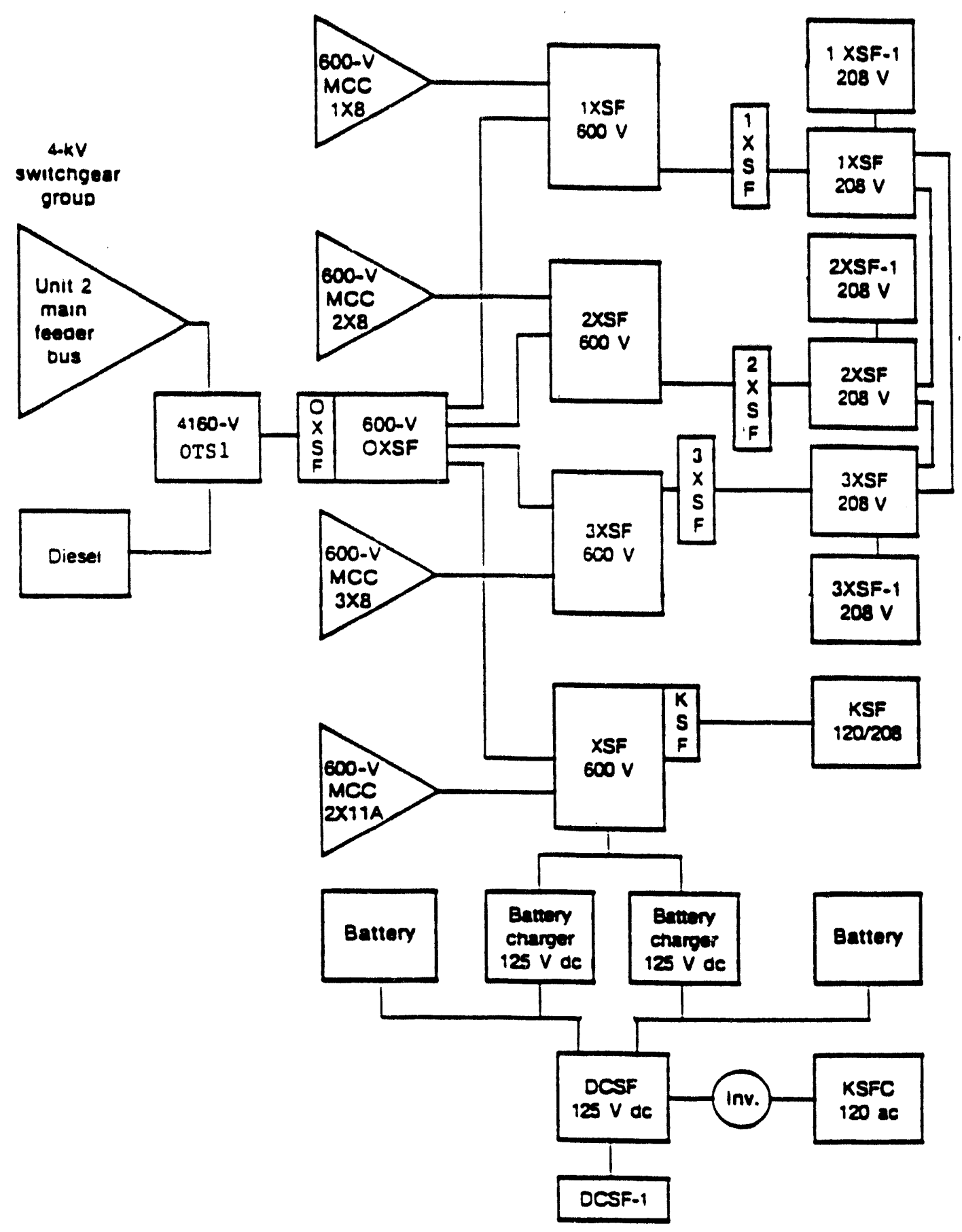

FIGURE E.33. Block Diagram of SSF Electric Power System 


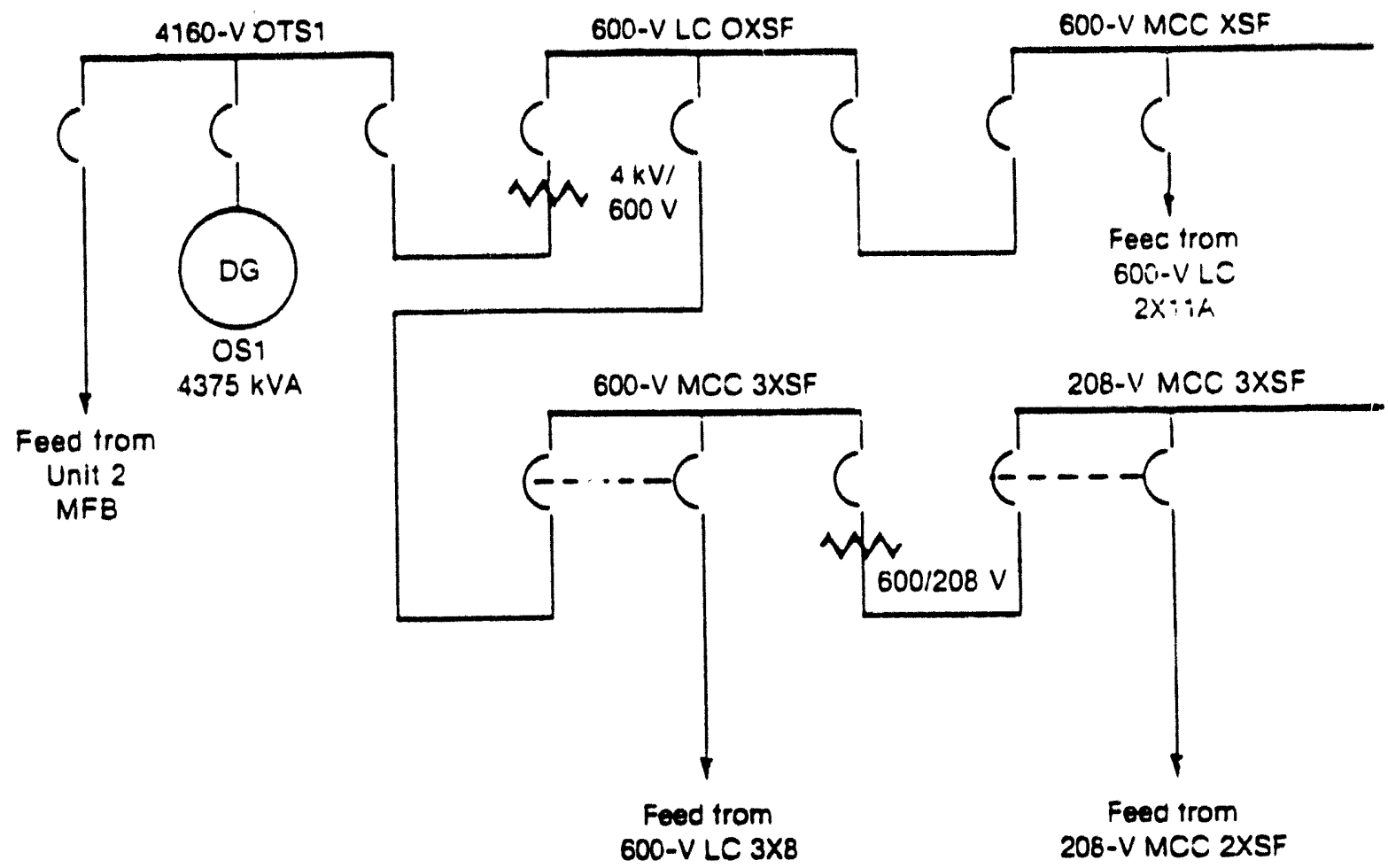

\section{FIGURE E.34. SSF Electric Power System Schematic}

- Electrical power systems. The SSF normally receives power from Unit 2 4160-V AC main feeder bus B2T compartment 4 . If this power is lost, the SSF $4160-V$ AC switchgear OTS1 is automatically isolated from B2T; the SSF diesel generator must be manually started and connected to OTS1.

- External control systems. The SSF is a self-contained facility; it is independent of all plant control systems.

- Heating, ventilation, and air conditioning (HVAC) systems. The SSF is an independent facility. It does not require support from the HVAC systems in the plant. The SSF has its own HVAC system, which is divided into these five subsystems:

1) SSF constant ventilation subsystem: The SSF constant ventilation subsystem is designed to supply outside air to and exhaust air from the switchgear room, pump room, HVAC room, and diesel generator room, as well as exhaust air from the battery room, the toilet, and the stairwell. The supply and exhaust fans and their controls are located in the HVAC room at elevation 817 . This subsystem provides continuous ventilation, which is using dampers and heaters to 
maintain the design temperature for those rooms that are serviced by the SSF constant ventilation subsystem, including maintaining these rooms above a minimum temperature of $60^{\circ} \mathrm{F}$.

2) SSF online ventilation subsystem: The SSF onl ine ventilation subsystem is designed to provide additional outside air to and exhaust air from the HVAC, switchgear, and pump rooms when the ASW pump is energized. The supply fan and the interlocked exhaust fans and their controls are located in the HVAC room. This subsystem is used to maintain those rooms below $104^{\circ} \mathrm{F}$.

3) SSF summer ventilation subsystem: The SSF summer ventilation subsystem is designed to provide additional outside air to and exhaust air from the switchgear room, pump room, HVAC room, and diesel generator room. When the outside air temperature rises above the designed set point, the supply and exhaust fans are energized to provide additional ventilation to these rooms. The supply and exhaust fans and their controls are located in the HVAC room. This subsystem is used to maintain these rooms below $104^{\circ} \mathrm{F}$.

4) SSE diesel generator engine ventilation subsystem: The EDG engine ventilation exhaust fan, in conjunction with its inlet and exhaust dampers and interlocks from the EDG start switch and fire protection system, provide intake and exhaust air flow for the EDG when it is running. The exhaust fan is controlled by a three-position switch and a purge pushbutton switch located on vendor control panel CP-1 in the HVAC room.

5) SSF air conditioning subsystem: The SSF air conditioning subsystem is designed to maintain the central alarm station, SSF control room, computer room, response room, and battery rooms with in their design temperature range. The $A C$, with its two compressors and fan with normal and standby motor and controls are located in the HVAC room with condenser water supplied from the HVAC service water subsystem. This subsystem is used to maintain the temperature between $60^{\circ} \mathrm{F}$ and $85^{\circ} \mathrm{F}$ during normal and accident conditions.

- SSF HVAC service water subsystem: The SSF HVAC Service Water Subsystem is designed to provide condenser water to the $A C$ unit. Two pumps, one in operation and one in standby, provide condenser water to the $A C$ via a common line. These pumps are alternated periodically to allow for balanced run time and maintenance. The two pumps are located in the pump room at elevation 745 with the controls in the HVAC room at elevation 817.

- Other system dependencies and interfaces: The SSF ASW pump takes its suction from the north leg of the Unit $2 \mathrm{CCW}$ intake. Upon a loss of power to the CCW pumps, the intake should be kept full by the CCW emergency siphon flow. If this siphon fails, the operators would have to deploy a portable pump in the intake canal. The portable pump would be powered from the SSF power system via cables kept stored in the SSF. 


\section{Eault Tree Model}

There are two top events in the SSF model: one is fallure of the SSF ASW system to provide secondary side heat removal, and the other is fallure of the SSF RCM system to provide RCP seal injection. For successful secondary side heat removal, the SSF ASW flow must reach either SG. However, SSF RCM flow must reach all four RCPs. Fallure of RCM flow to any one RCP, when needed, can lead to an RCP seal LOCA and is considered system failure. A simplified SSF fault tree is shown in Figure E.35.

Failure of the SSF ASW system to provide secondary side heat removal is modeled as an OR gate with inputs from 1) failure to provide sufficient flow, 2) three different human errors (i.e., Operators Fail to Deploy to the Standby Shutdown Facility in Time, SSF ASW System Left Unavailable After Test or Maintenance, and Operators Fail to Align the SSF ASW System for Operation), and 3) failure of SSF HVAC. Fallure to provide sufficient flow is modeled as an OR gate with inputs from 1) valve fallures, 2) SSF ASW pump failure, and 3) failure of the pump suction source. Fallure of the SSF ASW pump is modeled as an OR gate with inputs from 1) pump mechanical fallures, 2) loss of electrical power, and 3) fallure of the pump bearing cooling line.

Failure of the SSF RCM system to provide RCP seal injection is modeled as an OR gate with inputs from 1) failure to provide sufficient flow, 2) three different human errors (1.e., Operator Fall to Deploy to the Standby Shutdown Facility in Time, SSF RCM System Left Unavallable After Test or Maintenance, and Operators Fail to Align the SSF RCM System for Operation), and 3) failure of SSF HVAC. Failure to provide sufficient flow is modeled as three different OR gates: one represents fallure of pump discharge MOV HP-398, one represents failure of any RCP injection line check valve, and one represents failure of flow up to and through the RCM pump. Fallure of flow up to and through the RCM pump is modeled as an OR gate with inputs from 1) mechanical pump

failures, 2) failures of valves in the flow path, and 3) failure of electrical power to the pump motor.

Failure of the SSF electric power system is modeled as loss of power to the switchgear and MCCS supplying power to the pumps and valves within the SSF ASW and SSF RCM systems. Because the electric power system supports these front-line systems, it has no top event of its own. Loss of power to the required switchgear and MCCS is modeled as an OR gate with inputs from breaker and bus failures and from failure of the appropriate power source(s). Failure of power from the SSF diesel generator is modeled as an OR gate with inputs from loss of $D C$ control power, breaker failures, fallure of service water cooling to the diesel engine jacket, maintenance unavallability on the diesel, and failures of the diesel itself. Special events have been used to represent failure of normal plant power without transferring to the $A C$ power system fault tree. When plant power is available, the probabilities assigned to the special events represent independent hardware failures. When plant power is not available, the special events represent flags that are set to TRUE (probability of 1.0$)$. 
SSF - ASW Function

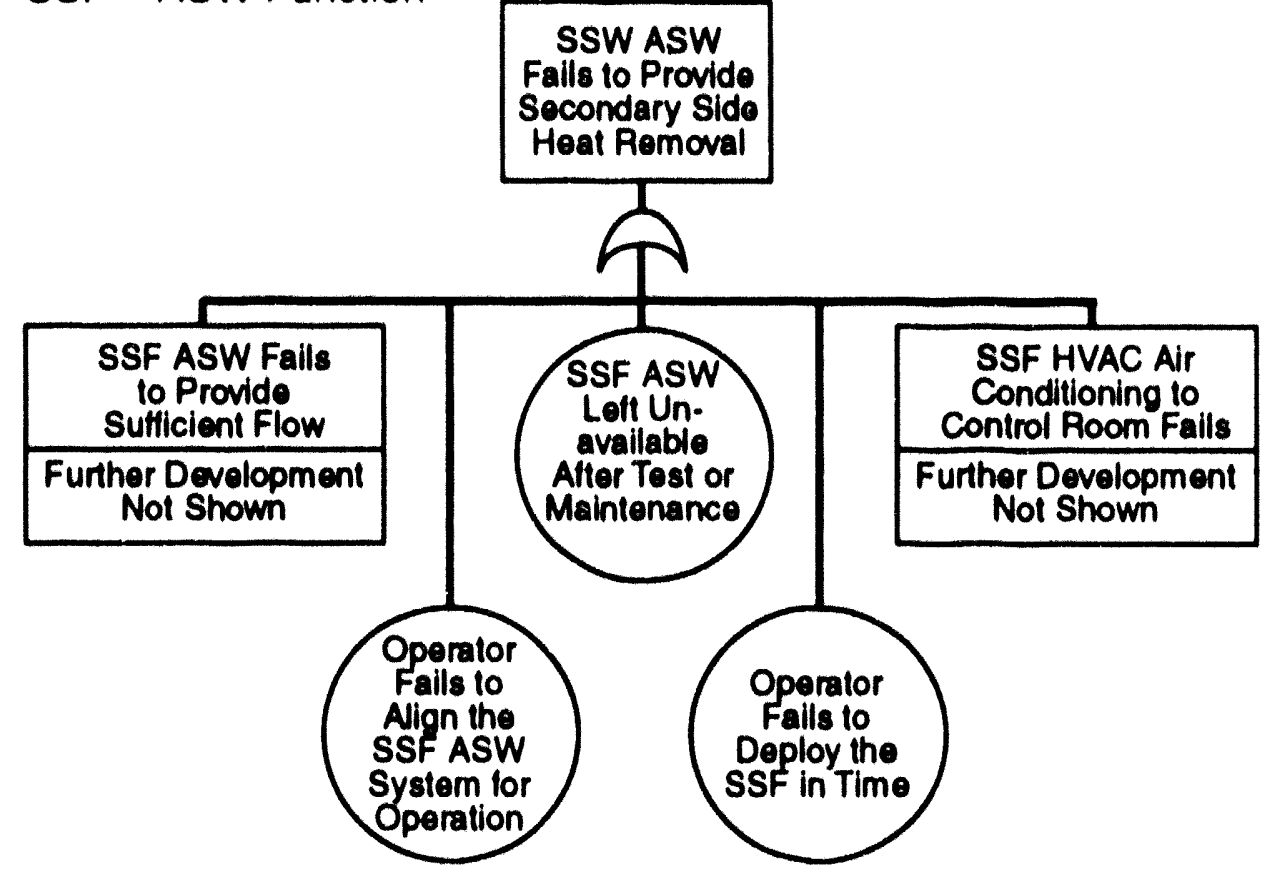

SSF - RCM Function (RCP Seal Cooling)

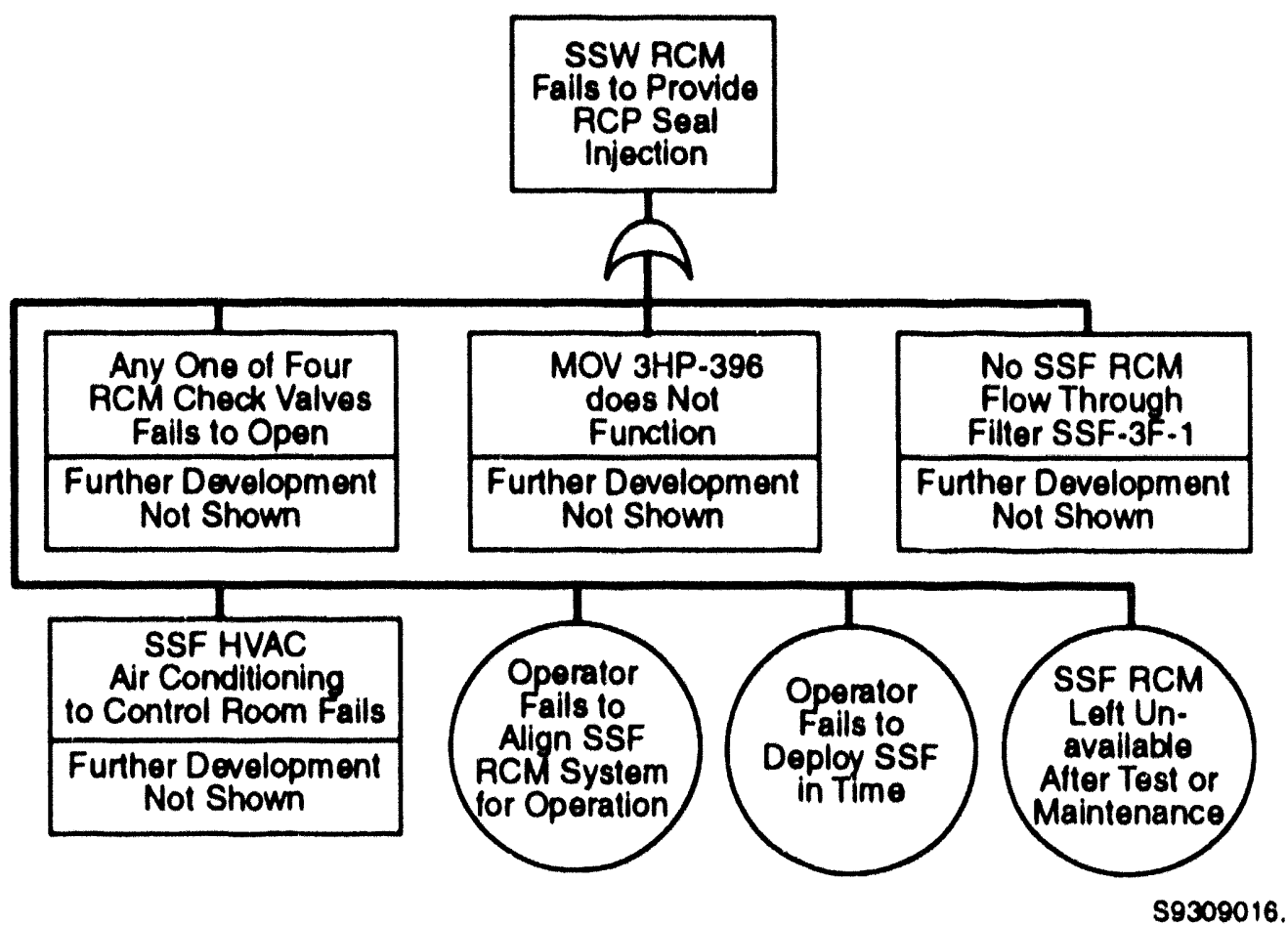

EIGURE E.35. Simplified Fault Tree Model for the SSF 
Fallure of the SSF HVAC air conditioning system is modeled as an OR gate with inputs from 1) fallure of the AHU, 2) failure of the refrigerant compressors and condensers, 3) fallure of HVAC service water to the condensers, and 4) failure of electrical power. Fallure of the refrigerant portion is modeled as an OR gate since both compressor/condenser pairs are needed. Failure of HVAC service water cooling is modeled as an AND gate since both pump trains must fail for the function to fall.

\section{E.2.15 Heating. Ventilating, and Air Conditioning System}

The heating, ventilating, and air conditioning (HVAC) functions at the representative B\&W PWR are performed by several independent systems, including

- The control-area ventilation system (CAVS)

- The Auxiliary Building ventilation system (ABVS)

- The spent fuel cooling system

- The Reactor Building purge

- The Administration Building ventilation system

- The AHUs that serve individual areas in the plant.

The IPE covers the systems that function as support systems in important accident sequences. These systems include the CAVS; the ABVS; and AHUS $3 A H U-1$ and $3 A H U-2$, which serve the LPR and RBSS pump rooms. Of these HVAC systems, only $3 A H U-1$ and $3 A H U-2$ appear explicitly in the accident sequences.

\section{Control-Area Ventilation System (CAVS)}

The CAVS heats, cools, and ventilates the control area as reyuired. The control area, which is located in the Auxiliary Bullding, consists of the control room, the cable room, and the electrical equipment room. Although most of the air is recirculated, some filtered outside air is provided to maintain a positive pressure for radioactivity control. The CAVS is a fulltime-running system. The IPE identified the CAVS as the most important HVAC system, and because it provides cooling to equipment such as inverters and battery chargers that are expected fail earlier than other equipment under high temperature conditions, it was the only HVAC system analyzed in the IPE. The other HVAC systems listed above are described for completeness but are not modeled.

The CAVS consists of three separate, nearly identical equipment trains for the control room, the electrical equipment room, and the cable room. They share redundant outside-air booster fans and trains of high-efficiency particulate air (HEPA) filters, which provide fresh air and positive pressure in the control area. They also share a common smoke-purge exhaust fan and a cooling water supply from the station's chilled water (WC) system.

The electrical equipment room and the control room are served by two $100 \%$ capacity AHUs. The AHUs are supplied with chilled water by the chilled water system. The chilled water system consists of two 100\%-capacity chillers arranged in parallel and two $100 \%$ capacity pumps also in parallel. A crossconnector is available so that either pump can be used with either chiller. 
Makeup water to the chilled water system is supplied from the plant drinking water (PDW) system. Simplified diagrams for the HVAC systems are shown in Figure E.36.

One AHU operates in each of the cable, equipment, and control rooms under normal conditions. The AHUs run continuously with chilled water flowing through the colls to control temperature. In the case of leakage, the chilled water system is replaced by the POW system, which delivers makeup water on a demand-only bases. If the operating AHU equipment falls, the standby AHU equipment can be manually started.

HVAC system dependencies and interfaces include the following:

- Instrument air (IA). One AHU per room requires IA for operation. Loss of IA pressure causes the WC minimum flow valve to open, starving the AHUs of their supply of chilled water.

- Low-pressure service water. LPSW is required by the chiller condensers.

- Electrical power supply. Power supplies are required by the following components: chilled water pumps, chiller compressor controls, AHUs, chillers, temperature controls, and chiller condenser pumps.

\section{Eault Tree Model}

The fault tree logic model describing failure of the CAVS to cool the electrical equipment room and the control room are developed and addressed in the IPE. There are two separate top events, one is the normal control room cooling fallure, and the other is Unit 3 electrical equipment room cooling failure. The modeling for these two rooms is very similar, with differing AHUs, dampers, and valves. One AHU for each room is assumed to be operating with the other in standby. Failure of normal control room cooling is modeled as an AND gate with inputs from 1) AHU 3-13 fails to provide control room cooling, 2) AHU 4-14 falls to provide control room cooling, and 3) operators fail to provide alternate means of room cooling. Fallure of Unit 3 electrical equipment room cooling is modeled as an AND gate with inputs from 1) Unit 3 equipment room cooling via AHU 3-15 fails, 2) AHU 3-16 fails to cool Unit 3 equipment room, and 3 ) operators fail to provide alternate means of room cooling.

\section{Auxiliary Building Ventilation System (ABVS)}

The ABVS heats, cools, and ventilates as required all areas of the Auxiliary Building that are not serviced by the CAVS. The ABVS is a oncethrough system with no recirculation. It is a full-time-running system.

The Auxiliary Building has no isolation between units, even though the ABVS for Unit 3 is separate from the ABVS for Units 1 and 2. Numerous single- 


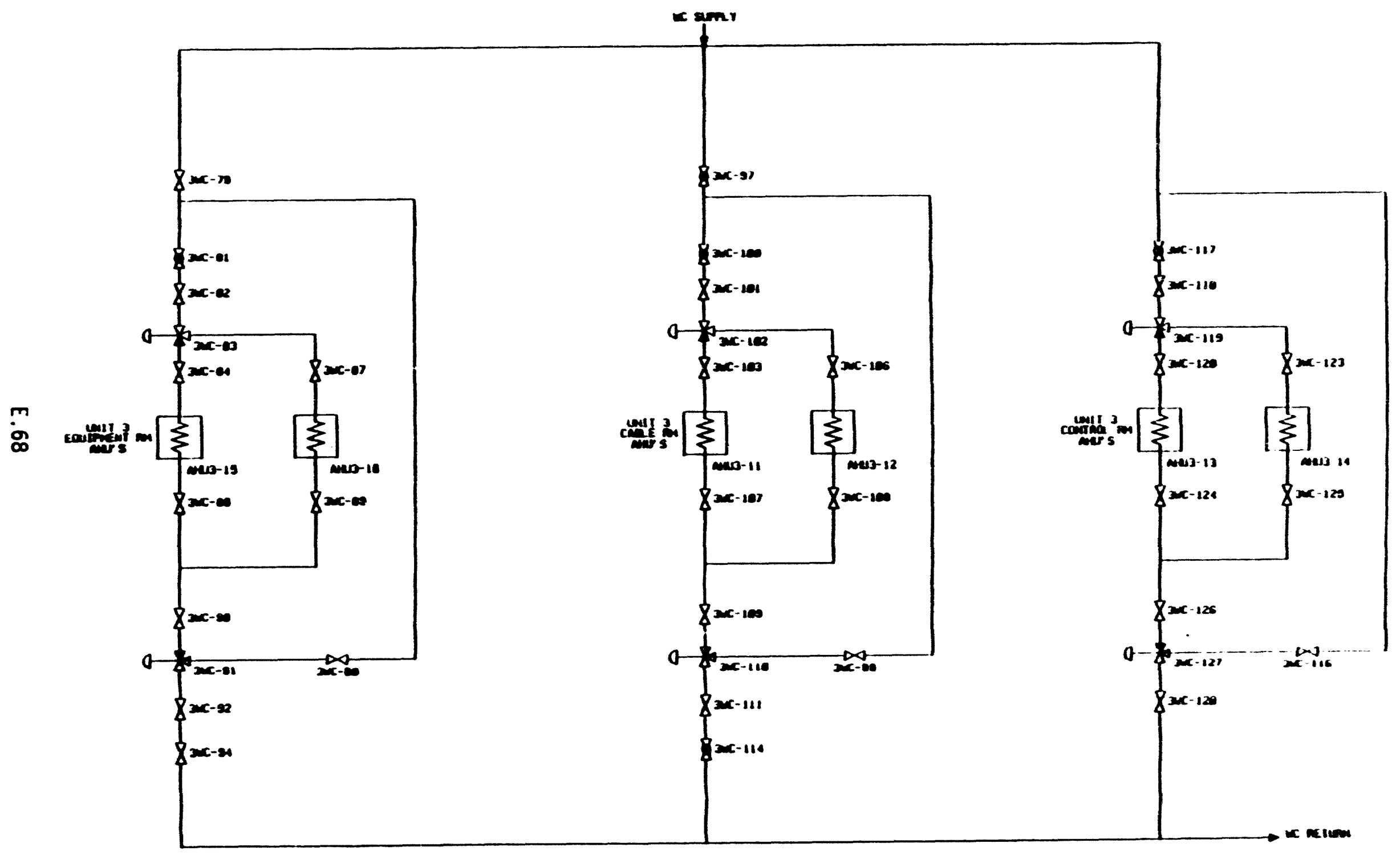

FIGURE E.36. Simplified Diagram of the Control Area Ventilation System 


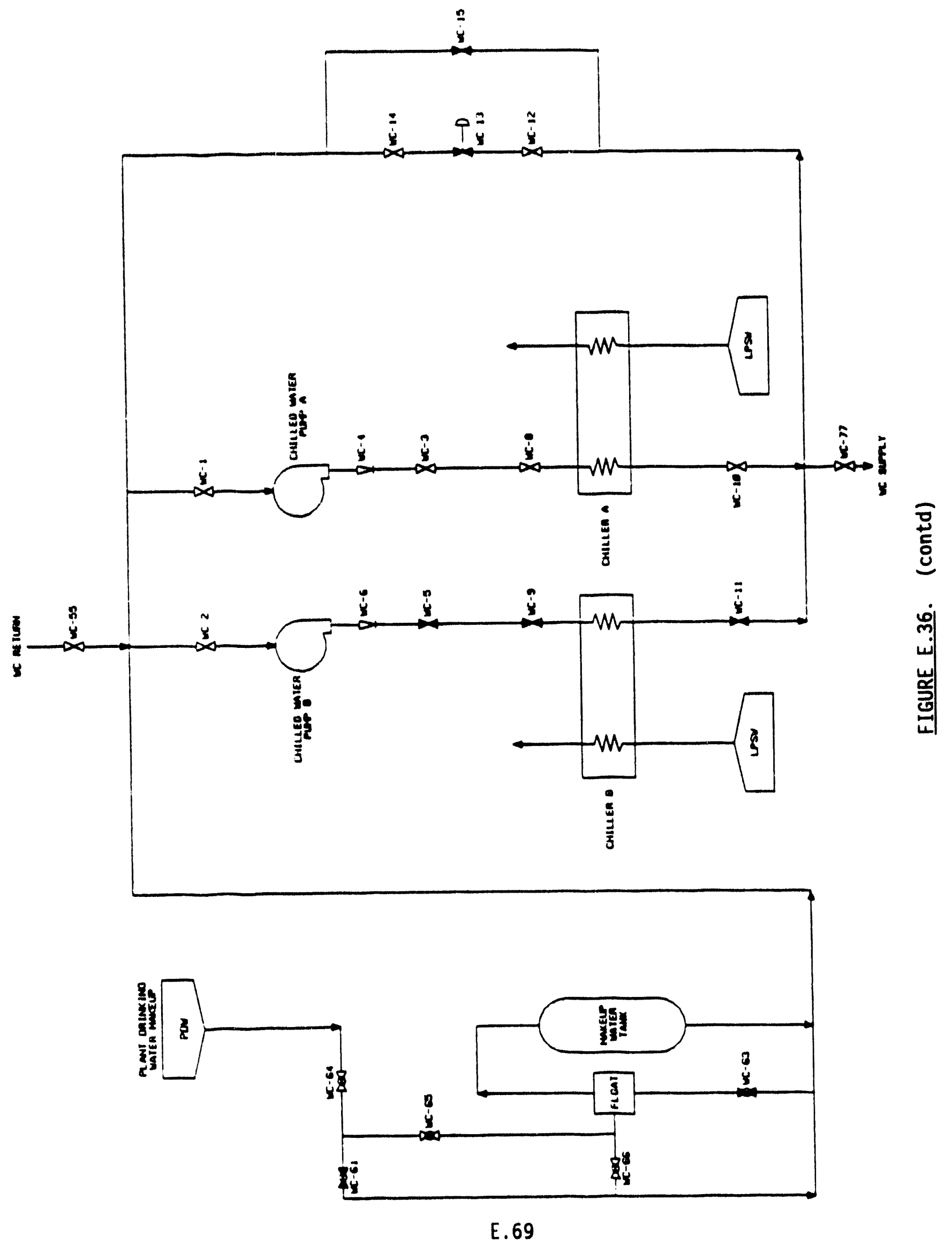




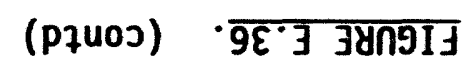

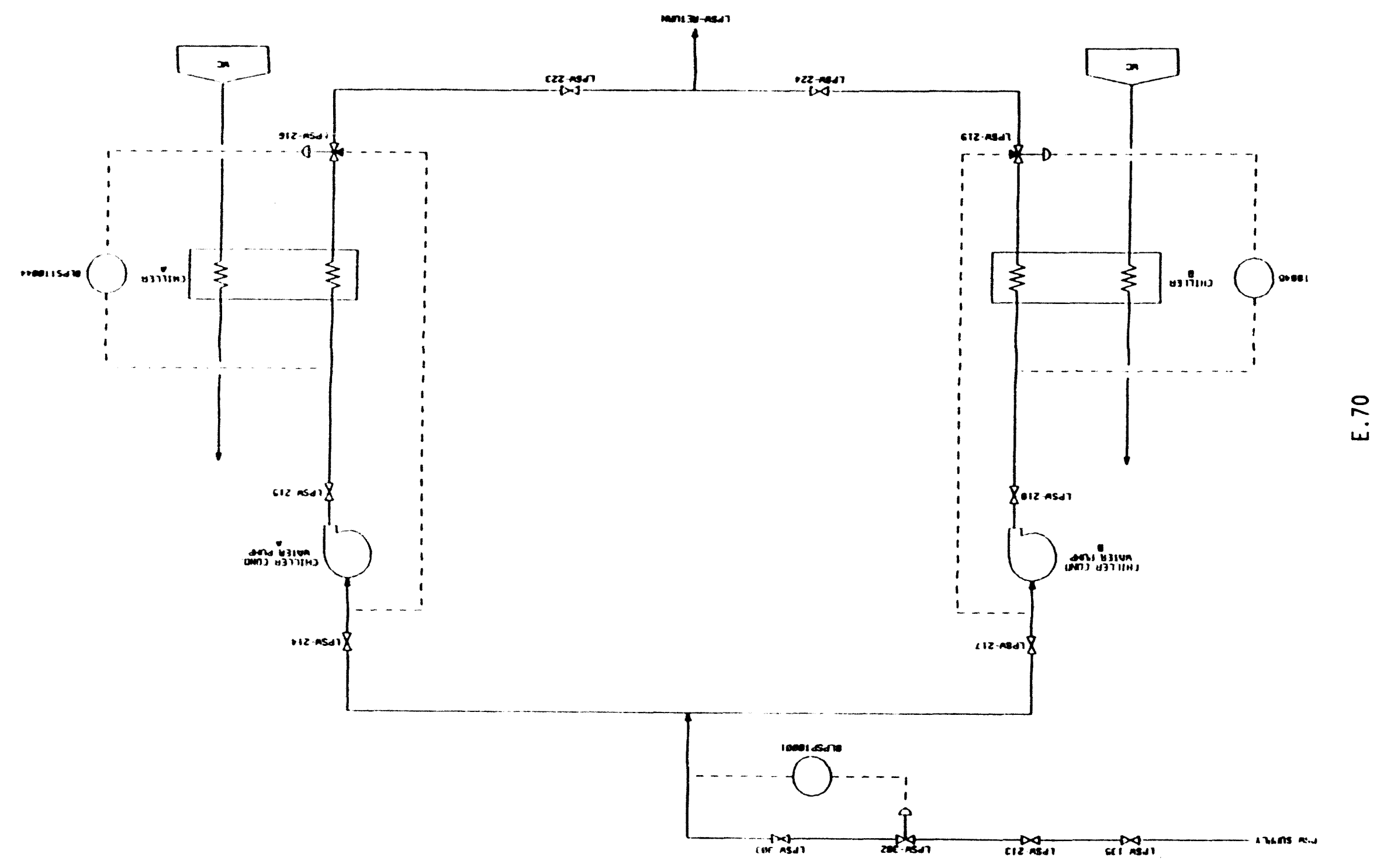


area recirculating AHUs serve portions of the Auxiliary Building, particularly where significant cooling capacity is required. These units are not considered part of the ABVS.

The unit 3 ABVS consists of two supply fan trains, ductwork to various areas and rooms in the Auxiliary Building, and two sets of exhaust fan trains. Each of the supply trains contains two fans, and each of the exhaust trains contains three fans. Each area of the Auxiliary Building is served by one of the supply trains and one of the exhaust trains. The system is balanced to maintain a negative pressure in the Auxiliary Building. The ABVS fans are not redundant and are all normally running.

Cooling water is supplied to each supply fan by the LPSW system. Heating is supplied to each supply fan by the auxiliary steam system. Instrument air is required for the control of heating and cooling as will as damper positioning.

\section{Air-Handling Units for LPI and RBS Pump Rooms}

The pump rooms in the Auxiliary Building are served not only by the ABVS but also by individual AHUs. These units cool the pump rooms, particularly during pump operation, and are necessary to prevent the pumps from overheating. Air-handling unit $3 A H U-1$ serves the room containing LPI pump 3B, LPI pump $3 C$, and RBS pump $3 B$; $3 A H U-2$ serves the room containing LPI pump $3 A$ and RBS pump $3 A$. For each AHU, ventilation is provided by fans and cooling is provided by LPSW. The LPSW cooling flow is controlled by air-operated valves.

The HVAC systems described here are all normally operating systems. Each of the CAVS subsystems in the control room, the cable room, and the equipment room has one of two redundant AHUs operating. These AHUs are not load-shed on loss of power from transformer CT3. On loss of instrument air, one of the two AHUs, 3AHU-13, will function with cooling provided.

The four supply fans and six exhaust fans of the ABVS are all normally operating. Power to these fans would be interrupted on loss of power from transformer CT3. It is essential that adequate exhaust fan capability be estored and maintained to keep a negative pressure in the Auxiliary Building for radioactivity control. Loss of instrument air would cause loss of LPSW cooling and ventilation.

The $3 A H U-1$ and $3 A H U-2$ room units operate automatically when the pumps are operating. On loss of instrument air, the valves fail open to permit LPSW cooling. On loss of normal power, the power for these units is not load-shed.

Malfunction of HVAC equipment in any system would not be alarmed or indicated in the control room. Equipment malfunction or personnel discomfort would be the first indication of system problems. In the Auxiliary Building, the loss of negative pressure would be alarmed, indicating a possible ABVS problem. 
HVAC system dependencies include

- Each of the HVAC systems described above requires $A C$ power for its operation.

- All AHUs, regardless of the system, also use instrument air for the control of dampers and cooling water as described above.

- The CAVS requires the chilled-water system for cooling water, while the ABVS and the room AHUs require LPSW for cooling.

Several components in the plant require. HVAC, particularly the cooling function, for proper operation. To prevent hydrogen buildup and rapid deterioration of batteries from high temperature, proper ABVS operation is required for the battery rooms. To prevent overheating and damage to LPI and RBS pumps during their operation, pump-room AHUs must operate. Electrical equipment, particularly in the control room, the cable room, and the equipment room, requires proper CAVS operation. These component and human interfaces were taken into account during the modeling of accident sequences and the evaluation of initiating events.

The HVAC 'system provides support for numerous plant systems. However, the important interfaces modeled in the IPE are

- Low-pressure injection

- Low-pressure recirculation

- High-pressure recirculation

- Reactor Building spray systems.

In all cases, the AHUs are required for pump room cooling to prevent pump failure.

\section{E.3 DOMINANT CUT SETS FOR THE REPRESENTATIVE B\&W PWR}

This section presents the dominant minimal cut sets for the representative B\&W PWR. The dominant minimal cut sets for loss of control room and loss of electrical equipment room cooling and their probabilities are also presented. Finally, the spreadsheet that was developed to facilitate calculation of the CDF associated with transient-initiated accident sequences is presented. The cut sets for room-cooler-initiated accident sequences were presented in Section 4.4 .1 of the main report.

Tables E.1 and E.2 provide a listing of the dominant cut sets for loss of control room cooling and loss of electrical equipment room cooling, respectively. The probabilities are also shown in the tables. The cut sets were derived from the CAVS fault tree presented in the IPE.

Tables E.3 and E.4 present the cut sets for the HVAC-initiated accident sequences. Table E.3 presents the cut sets and their frequencies as well as 
the total accident sequence frequency for loss of electrical equipment room HVAC initiators. Table E.4 presents the same data for loss of control room HVAC initiators.

Table E.5 presents the affected CDF and public risk calculations for room cooler contributors to transients and other accident sequences. The accident sequences listed in the table are described in Section 3.4 of the main report.

E.4 REFERENCES

Duke Power Company. 1990. Oconee Nuclear Station Unit 3 Probabilistic Risk Assessment, Vol. 1. Duke Power Company, Charlotte, North Carolina.

E.73 
TABLE E.1. HVAC System Dominant Minimal Cut Sets - Loss of Control Room Cooling

Probability

2. $96 \mathrm{E}-05$

1. $20 \mathrm{E}-06$

$5.02 \mathrm{E}-07$

2. $40 \mathrm{E}-07$

$1.80 \mathrm{E}-07$,

$1.44 \mathrm{E}-07$

$1.20 \mathrm{E}-07$

$1.20 \mathrm{E}-\mathrm{U} 7$

$1.00 \mathrm{E}-07$

$6.00 \mathrm{E}-08$

$6.00 \mathrm{E}-08$

$5.52 \mathrm{E}-08$

$5.48 \mathrm{E}-08$

$5.48 \mathrm{E}-08$

4. $86 \mathrm{E}-08$

4. $86 \mathrm{E}-08$

3. $60 \mathrm{E}-08$

3. $60 \mathrm{E}-08$

2. $64 \mathrm{E}-08$

2. $64 \mathrm{E}-08$

2. $40 \mathrm{E}-08$

1. $20 \mathrm{E}-08$

1. $20 \mathrm{E}-08$

1. $20 \mathrm{E}-08$

1. $10 \mathrm{E}-08$

3. $28 \mathrm{E}-05$
Cut Set Events

$\begin{array}{lcc}\text { VYCAHURCOM } & \text { VYCALTCREC } & \\ \text { VYCLMWLDEX } & \text { VYCFLOTLTF } & \text { VYCALTCREC } \\ \text { VYCCHLRCOM } & \text { VYCALTCREC } & \\ \text { VYCALTCREC } & \text { VYCTSTLTTF } & \\ \text { VYCCWPRCOM } & \text { VYCALTCREC } & \\ \text { VYCRLY3RYT } & \text { VYCALTCREC } & \\ \text { VACB3XTCLT } & \text { VYCALTCREC } & \\ \text { VAC3L11CLT } & \text { VYCALTCREC } & \\ \text { VYCLMWLDEX } & \text { VYCU1LSDEX } & \text { VYCALTCREC } \\ \text { VYCCHWTGPR } & \text { VYCBRECDHE } & \text { VYCALTCREC } \\ \text { VYCCONDGPR } & \text { VYCBRECDHE } & \text { VYCALTCREC } \\ \text { VYCSTATTWT } & \text { VYCALTCREC } & \\ \text { VYCCHWTGPR } & \text { VYCCWLBTRM } & \text { VYCALTCREC } \\ \text { VYCCONDGPR } & \text { VYCCWLBTRM } & \text { VYCALTCREC } \\ \text { VYCONDGPRR } & \text { VYCCHLBCRS } & \text { VYCALTCREC } \\ \text { VYCCHWTGPR } & \text { VYCCHLBCRS } & \text { VYCALTCREC } \\ \text { VLSO302AVT } & \text { VYCALTCREC } & \\ \text { VYCM127AVT } & \text { VYCALTCREC } & \\ \text { VYC3022PCF } & \text { VYCALTCREC } & \\ \text { VYC3021PCF } & \text { VYCALTCREC } & \\ \text { VYC13FRFNR } & \text { VYCALTCREC } & \text { VYCFTS6DHE } \\ \text { VYCCHWTGPR } & \text { VYCWCPBGPS } & \text { VYCALTCREC } \\ \text { VYCONDGPRR } & \text { VYCWCPBGPS } & \text { VYCALTCREC } \\ \text { VYCBRECDHE } & \text { VYCCHLACRR } & \text { VYCALTCREC } \\ \text { VYCCWLBTRM } & \text { VYCCHLACRR } & \text { VYCALTCREC } \\ \text { TotaI Fai1ure Probabi1 ity } & \end{array}$


IABLE E.2. HVAC System Dominant Minimal Cut Sets - Loss of Electrical Equipment Room Cooling

\begin{tabular}{l} 
Probability \\
\hline $2.96 E-05$ \\
$1.20 \mathrm{E}-06$ \\
$5.02 \mathrm{E}-07$ \\
$2.40 \mathrm{E}-07$ \\
$1.80 \mathrm{E}-07$ \\
$1.44 \mathrm{E}-07$ \\
$1.20 \mathrm{E}-07$ \\
$1.20 \mathrm{E}-07$ \\
$1.00 \mathrm{E}-07$ \\
$6.00 \mathrm{E}-08$ \\
$6.00 \mathrm{E}-08$ \\
$5.52 \mathrm{E}-08$ \\
$5.48 \mathrm{E}-08$ \\
$5.48 \mathrm{E}-08$ \\
$4.86 \mathrm{E}-08$ \\
$4.86 \mathrm{E}-08$ \\
$3.60 \mathrm{E}-08$ \\
$3.60 \mathrm{E}-08$ \\
$2.64 \mathrm{E}-08$ \\
$2.64 \mathrm{E}-08$ \\
$2.40 \mathrm{E}-08$ \\
$1.20 \mathrm{E}-08$ \\
$1.20 \mathrm{E}-08$ \\
$1.20 \mathrm{E}-08$ \\
$1.10 \mathrm{E}-08$ \\
$3.28 \mathrm{E}-05$ \\
\end{tabular}

Cut Set Events

$\begin{array}{lcc}\text { VYCAHURCOM } & \text { VYCALTCREC } & \\ \text { VYCLMWLDEX } & \text { VYCFLOTLTF } & \text { VYCALTCREC } \\ \text { VYCCHLRCOM } & \text { VYCALTCREC } & \\ \text { VYCALTCREC } & \text { VYCTSTLTTF } & \\ \text { VYCCWPRCOM } & \text { VYCALTCREC } & \\ \text { VYCRLY3RYT } & \text { VYCALTCREC } & \\ \text { VACB3XTCLT } & \text { VYCALTCREC } & \\ \text { VAC3L11CLT } & \text { VYCALTCREC } & \\ \text { VYCLMWLDEX } & \text { VYCUILSDEX } & \text { VYCALTCREC } \\ \text { VYCCHWTGPR } & \text { VYCBRECDHE } & \text { VYCALTCREC } \\ \text { VYCCONDGPR } & \text { VYCBRECDHE } & \text { VYCALTCREC } \\ \text { VYCSTATTWT } & \text { VYCALTCREC } & \\ \text { VYCCHWTGPR } & \text { VYCCWLBTRM } & \text { VYCALTCREC } \\ \text { VYCCONDGPR } & \text { VYCCWLBTRM } & \text { VYCALTCREC } \\ \text { VYCONDGPRR } & \text { VYCCHLBCRS } & \text { VYCALTCREC } \\ \text { VYCCHWTGPR } & \text { VYCCHLBCRS } & \text { VYCALTCREC } \\ \text { VLSO302AVT } & \text { VYCALTCREC } & \\ \text { VYCM127AVT } & \text { VYCALTCREC } & \\ \text { VYC3022PCF } & \text { VYCALTCREC } & \\ \text { VYC3021PCF } & \text { VYCALTCREC } & \\ \text { VYC13FRFNR } & \text { VYCALTCREC } & \text { VYCFTS6DHE } \\ \text { VYCCHWTGPR } & \text { VYCWCPBGPS } & \text { VYCALTCREC } \\ \text { VYCONDGPRR } & \text { VYCWCPBGPS } & \text { VYCALTCREC } \\ \text { VYCBRECDHE } & \text { VYCCHLACRR } & \text { VYCALTCREC } \\ \text { VYCCWLBTRM } & \text { VYCCHLACRR } & \text { VYCALTCREC } \\ \text { TotaI FaiTure Probability } & \end{array}$

VYCAHURCOM

VYCLMWLDEX

VYCCHLRCOM

VYCALTCREC

VYCCWPRCOM

VYCRLY3RYT

VAC3LIICLT

VYCLMWLDEX

VYCCHWTGPR

VYCCONDGPR

VYCSTATTWT

VYCCHWTGPR

VYCCONDGPR

VYCONDGPRR

VYCCHWTGPR

VLSO302AVT

VYCM127AVT

VYC3022PCF

VYC3021PCF

VYC13FRFNR

VYCCHWTGPR

VYCONDGPRR

VYCCWLBTRM

Total Failure Probability

\begin{abstract}
VYCALTCREC
VYCTSTLTTF

VYCALTCREC

VYCALTCREC

VYCUILSDEX

VYCBRECDHE

VYCALTCREC

VYCCWLBTRM

VYCCWLBTRM

VYCCHLBCRS

VYCCHLBCRS

VYCALTCREC

VYCALTCREC

VYCALTCREC

VYCALTCREC

VYCALTCREC

VYCWCPBGPS

VYCWCPBGPS

VYCCHLACRR

VYCCHLACRR
\end{abstract}

VYCALTCREC

VYCALTCREC 
TABLE E.3. Loss of Electrical Equipment Room Cooling Cut Sets

\begin{tabular}{|c|c|c|c|c|}
\hline $\begin{array}{l}\text { Seq. } \\
\text { Name }\end{array}$ & Event Name & Event Description & Probability & $\begin{array}{l}\text { Cut Set } \\
\text { Frequency }\end{array}$ \\
\hline TBX & $\begin{array}{l}\text { TEER } \\
\text { TRCSRVODEX } \\
\text { TLOMFATDEX } \\
\text { TTRHPRIDHE } \\
\text { FEFEFW2DHE } \\
\text { FEFEFW1REC } \\
\text { TMFFDW2REC }\end{array}$ & $\begin{array}{l}\text { Loss Of Electrical Equipment Room Cooling } \\
\text { RCS Safety Relief Valve Does Not Stick Open After Relieving } \\
\text { Loss Of MFW Following A Turbine Trip } \\
\text { Operators Fail To Initiate HPR } \\
\text { Operators Fail To Throttle EFW Pump Flow } \\
\text { Operators Fail To Align EFW From Another Unit } \\
\text { Operators Fail To Recover MFW Within } 45 \text { Minutes }\end{array}$ & $\begin{array}{l}1.10 \mathrm{E}-03 \\
9.00 \mathrm{E}-01 \\
6.00 \mathrm{E}-02 \\
5.00 \mathrm{E}-01 \\
5.00 \mathrm{E}-03 \\
5.00 \mathrm{E}-02 \\
9.00 \mathrm{E}-02\end{array}$ & $6.68 \mathrm{E}-10$ \\
\hline TQsU & $\begin{array}{l}\text { TEER } \\
\text { PACE1E2COM } \\
\text { PACE3E4REC } \\
\text { NSFORCMDHE }\end{array}$ & $\begin{array}{l}\text { Loss of Electrical Equipment Room Cooling } \\
\text { Common Cause Failure of Breakers E1 And E2 To Close } \\
\text { Operators Fail To Close Breakers E1 And E2 Within } 4 \text { Hours } \\
\text { Operators Fail To Align The SSF RCM System For Operation }\end{array}$ & $\begin{array}{l}1.10 \mathrm{E}-03 \\
1.00 \mathrm{E}+00 \\
1.00 \mathrm{E}-03 \\
1.00 \mathrm{E}-01\end{array}$ & $1.10 \mathrm{E}-07$ \\
\hline TBX & $\begin{array}{l}\text { TEER } \\
\text { AIAOLEKDEX } \\
\text { AIAOLEKDHE } \\
\text { FEFSWCHDHE } \\
\text { TTRHPRIDHE } \\
\text { NSFOASWDHE }\end{array}$ & $\begin{array}{l}\text { Loss of Electrical Equipment Room Cooling } \\
\text { Instrument Air System Major Leakage } \\
\text { Operators Fail To Find Instrument Air System Leak } \\
\text { Operators Fail To Switch TDEFW Pump Suction To Hotwell } \\
\text { Operators Fail To Initiate HPR } \\
\text { Operators Fail To Align The SSF ASW System For Operation }\end{array}$ & $\begin{array}{l}1.10 E-03 \\
1.20 E-03 \\
1.00 E-01 \\
5.00 E-02 \\
5.00 E-01 \\
1.00 E-01\end{array}$ & $3.30 E-10$ \\
\hline TQsU & $\begin{array}{l}\text { TEER } \\
\text { PACLINEDEX } \\
\text { PACKEO2HYM } \\
\text { PACXCT3THF } \\
\text { NSFORCMDHE }\end{array}$ & $\begin{array}{l}\text { Loss of Electrical Equipment Room Cooling } \\
100 \mathrm{kV} \text { AC Overhead Line to CT5 Fails } \\
\text { Both Emergency AC Units Are In Maintenance } \\
\text { Transformer CT3 Fails } \\
\text { Operators Fail To Align The SSF RCM System For Operation }\end{array}$ & $\begin{array}{l}1.10 \mathrm{E}-03 \\
7.80 \mathrm{E}-03 \\
1.93 \mathrm{E}-02 \\
3.62 \mathrm{E}-04 \\
1.00 \mathrm{E}-01\end{array}$ & Negligible \\
\hline TBU & $\begin{array}{l}\text { TEER } \\
\text { TRCSRVODEX } \\
\text { PACE1E2COM } \\
\text { PACE1E2REC } \\
\text { NSFOASWDHE } \\
\text { FEFTDFPTRM }\end{array}$ & $\begin{array}{l}\text { Loss of Electrical Equipment Room Cooling } \\
\text { RCS Safety Relief Valve Does Not Stick Open After Relieving } \\
\text { Common Cause Failure Of Breakers E1 And E2 To Close } \\
\text { Operators Fail To Close Breakers E1 And E2 Within } 40 \text { Min. } \\
\text { Operators Fail To Align The SSF ASW System For Operation } \\
\text { Turbine-Driven EFW Pump Is In Maintenance }\end{array}$ & $\begin{array}{l}1.10 \mathrm{E}-03 \\
9.00 \mathrm{E}-01 \\
1.00 \mathrm{E}+00 \\
5.00 \mathrm{E}-02 \\
1.00 \mathrm{E}-01 \\
9.40 \mathrm{E}-03\end{array}$ & \\
\hline
\end{tabular}


IABLE E.3. (contd)

\begin{tabular}{|c|c|c|c|c|}
\hline $\begin{array}{l}\text { Seq. } \\
\text { Name }\end{array}$ & Event Name & $\begin{array}{l}\text { Event Description } \\
\end{array}$ & Probability & $\begin{array}{l}\text { Cut Set } \\
\text { Frequency }\end{array}$ \\
\hline TQsU & $\begin{array}{l}\text { TEER } \\
\text { PACN1N2COM } \\
\text { PACN3N4REC } \\
\text { NSFORCMDHE }\end{array}$ & $\begin{array}{l}\text { Loss of Electrical Equipment Room Cooling } \\
\text { Common Cause Failure Of Breakers N1 And N2 To Open } \\
\text { Operators Fail To Open Breakers N1 And N2 Within } 4 \text { Hours } \\
\text { Operators Fail To Align The SSF RCM System For Operation }\end{array}$ & $\begin{array}{l}1.10 \mathrm{E}-03 \\
1.00 \mathrm{E}+00 \\
1.00 \mathrm{E}-03 \\
1.00 \mathrm{E}-01\end{array}$ & $1.1 \mathrm{E}-07$ \\
\hline TQsU & $\mid \begin{array}{l}\text { TEER } \\
\text { PACLINEDEX } \\
\text { PACKEOSHYM } \\
\text { PACXCT3THM } \\
\text { NSFORCMDHE }\end{array}$ & $\begin{array}{l}\text { Loss of Electrical Equipment Room Cooling } \\
100 \mathrm{kV} \text { AC Overhead Line To CT5 Fails } \\
\text { Both Emergency AC Units Are In Maintenance } \\
\text { Transformer CT3 Is In Maintenance } \\
\text { Operators Fail To Align The SSF RCCM System For Operation }\end{array}$ & $\begin{array}{l}1.10 \mathrm{E}-03 \\
7.80 \mathrm{E}-03 \\
1.93 \mathrm{E}-02 \\
1.74 \mathrm{E}-04 \\
1.00 \mathrm{E}-01\end{array}$ & Negligible \\
\hline TQSU & $\mid \begin{array}{l}\text { TEER } \\
\text { PACE1E2COM } \\
\text { PACE3E4REC } \\
\text { NSFORCMDHE } \\
\text { LPRO025LHE }\end{array}$ & $\begin{array}{l}\text { Loss of Electrical Equipment Room Cooling } \\
\text { Common Cause Failure Of Breakers E1 And E2 To Close } \\
\text { Operators Fail To Close Breakers E1 And E2 Within } 4 \text { Hours } \\
\text { Operators Fail To Align The SSF RCM System For Operation } \\
\text { Drain Valve 3PR-25 Is Left Open: Latent Human Error }\end{array}$ & $\begin{array}{l}1.10 E-03 \\
1.00 E+00 \\
1.00 E-03 \\
1.00 E-01 \\
3.00 E-03\end{array}$ & \\
\hline TQsU & $\begin{array}{l}\text { TEER } \\
\text { PACE1E2CON } \\
\text { PACE3H4REC } \\
\text { NSFORCMDHE } \\
\text { LPRPN6OLHE }\end{array}$ & $\begin{array}{l}\text { Loss of Electrical Equipment Room Cooling } \\
\text { Common Cause Failure Of Breakers E1 And E2 To Close } \\
\text { Operators Fail To Close Breakers El and E2 Within } 4 \text { Hours } \\
\text { Operatcrs Fail To Align The SSF RCM System For Operation } \\
\text { Drain Valve 3PR-23 Or 3PR-68 Left Open: Latent Human Error }\end{array}$ & $\begin{array}{l}1.10 E-03 \\
1.00 E+00 \\
1.00 E-03 \\
1.00 E-01 \\
3.00 E-03\end{array}$ & \\
\hline \multicolumn{5}{|c|}{ TOTAL } \\
\hline
\end{tabular}

Note: "Negligible" means less than 1E-10/RY. 
IABLE E.4. Loss of Control Room Cooling Cut Sets (Without Auxiliary Shutdown Panel).

\begin{tabular}{|c|c|c|c|c|}
\hline $\begin{array}{l}\text { Seq. } \\
\text { Name }\end{array}$ & Event Name & Event Description & Probability & $\begin{array}{l}\text { Cut Set } \\
\text { Frequency }\end{array}$ \\
\hline TBX & $\begin{array}{l}\text { TCR } \\
\text { RCR } \\
\text { TRCSRVODEX } \\
\text { TLOMFATDEX } \\
\text { TTRHPRIDHE } \\
\text { FEFEFW2DHE } \\
\text { FEFEFW1REC } \\
\text { TMFFDW2REC }\end{array}$ & $\begin{array}{l}\text { Loss of Control Room Cooling } \\
\text { Nonrecovery From Control Room Cool ing } \\
\text { RCS Safety Relief Valve Does Not St ick Open After Relieving } \\
\text { Loss Of Main Feedwater Foll lowing A Turbine Trip } \\
\text { Operators Fail To Initiate HPR } \\
\text { Operators Fail To Throttle EFW Pump Flow } \\
\text { Operators Fail To Align EFW From Another Unit } \\
\text { Operators Fail To Recover MFW Within } 45 \text { Minutes }\end{array}$ & $\begin{array}{l}4.49 E-02 \\
4.30 E-03 \\
9.00 E-01 \\
6.00 E-02 \\
5.00 E-01 \\
1.00 E+00 \\
1.00 E-01 \\
9.00 E-02\end{array}$ & $4.69 \mathrm{E}-08$ \\
\hline TQSU & $\begin{array}{l}\text { TCR } \\
\text { RCR } \\
\text { PACE1E2COM } \\
\text { PACE3E4REC } \\
\text { NSFORCMDHE }\end{array}$ & $\begin{array}{l}\text { Loss of Control Room Cooling } \\
\text { Nonrecovery From Control Room Cooling } \\
\text { Common Cause Failure Of Breakers E1 And E2 To Close } \\
\text { Operators Fail To Close Breakers E1 Ard E2 Within } 4 \text { Hours } \\
\text { Operators Fail To Align The SSF RCM System For Operation }\end{array}$ & $\begin{array}{l}4.49 E-02 \\
4.30 E-03 \\
8.90 E-05 \\
1.00 E-03 \\
1.00 E-01\end{array}$ & Neal iajble \\
\hline TBX & $\begin{array}{l}\text { TCR } \\
\text { RCR } \\
\text { AIAOLEKDEX } \\
\text { AIAOLEKDHE } \\
\text { FEFSWCHDHE } \\
\text { TTRHPRIDHE } \\
\text { NSF FASWDHE }\end{array}$ & $\begin{array}{l}\text { Loss of Control Room Cooling } \\
\text { Nonrecovery From Control Room Cool ing } \\
\text { Instrument Air System Major Leakage } \\
\text { Operators Fail To Find Instrument Air System Leak } \\
\text { Operators Fail To Switch TDEFW Pump Suction To Hotwell } \\
\text { Operators Fail To Initiate HPR } \\
\text { Operators Fail To Align The SSF ASW System For Operation }\end{array}$ & $\begin{array}{l}4.49 E-02 \\
4.30 E-03 \\
1.20 E-03 \\
1.00 E-01 \\
1.00 E-01 \\
5.00 E-01 \\
1.00 E-01\end{array}$ & Negligible \\
\hline TQSU & $\begin{array}{l}\text { TCR } \\
\text { RCR } \\
\text { PACLINEDEX } \\
\text { PACKEO2HYM } \\
\text { PACXCT3THF } \\
\text { NSFORCMDHE }\end{array}$ & $\begin{array}{l}\text { Loss of Control Room Cooling } \\
\text { Nonrecovery From Control Room Cooling } \\
100 \mathrm{kV} \text { AC Overhead Line To CT5 Fails } \\
\text { Both Emergency AC Units Are In Maintenance } \\
\text { Transformer CT3 Fails } \\
\text { Operators Fail To Align The SSF RCM System For Operation }\end{array}$ & $\begin{array}{l}4.49 \mathrm{E}-02 \\
4.30 \mathrm{E}-03 \\
7.80 \mathrm{E}-03 \\
1.93 \mathrm{E}-02 \\
3.62 \mathrm{E}-04 \\
1.00 \mathrm{E}-01\end{array}$ & \\
\hline
\end{tabular}


TABLE E.4. (contd)

\begin{tabular}{|c|c|c|c|c|}
\hline $\begin{array}{l}\text { Seq. } \\
\text { Name }\end{array}$ & Event Name & Event Description & Probability & $\begin{array}{l}\text { Cut Set } \\
\text { Frequency }\end{array}$ \\
\hline TBU & $\begin{array}{l}\text { TCR } \\
\text { RCR } \\
\text { TRCSRVODEX } \\
\text { PACE1E2COM } \\
\text { PACE1E2REC } \\
\text { NSFOASWDHE } \\
\text { FEFTDFPTRM }\end{array}$ & $\begin{array}{l}\text { Loss of Control Room Cooling } \\
\text { Nonrecovery From Control Room Cool ing } \\
\text { RCS Safety Relief Valve Does Not Stick Open After Relieving } \\
\text { Common Cause Failure of Breakers E1 And E2 To Close } \\
\text { Operators Fail To Close Breakers El And E2 Within } 40 \text { Min. } \\
\text { Operators Fail To Align The SSF ASW System For Operation } \\
\text { Turbine-Driven EFW Pump Is In Maintenance }\end{array}$ & $\begin{array}{l}4.49 E-02 \\
4.30 E-03 \\
9.00 E-01 \\
8.90 E-05 \\
5.00 E-02 \\
1.00 E-01 \\
9.40 E-03\end{array}$ & Negligible \\
\hline TQsU & $\begin{array}{l}\text { TCR } \\
\text { RCR } \\
\text { PACN1N2COM } \\
\text { PACN3N4REC } \\
\text { NSFORCMDHE }\end{array}$ & $\begin{array}{l}\text { Loss of Control Room Cooling } \\
\text { Nonrecovery From Control Room Cooling } \\
\text { Common Cause Failure of Breakers N1 And N2 To Open } \\
\text { Operators Fail To Open Breakers N1 And N2 Hithin } 4 \text { Hours } \\
\text { Operators Fail To Al ign The SSF RCM System For Operation }\end{array}$ & $\begin{array}{l}4.49 E-02 \\
4.30 E-03 \\
3.00 E-05 \\
1.00 E-03 \\
1.00 E-01\end{array}$ & Negligible \\
\hline TQsU & $\begin{array}{l}\text { TCR } \\
\text { RCR } \\
\text { PACLINEDEX } \\
\text { PACKEOSHYM } \\
\text { PACXCT3THF } \\
\text { NSFORCMDHE }\end{array}$ & $\begin{array}{l}\text { Loss of Control Room Cooling } \\
\text { Nonrecovery From Control Room Cooling } \\
100 \mathrm{kV} \text { AC Overhead Line To CTS Fails } \\
\text { Both Emergency AC Units Are In Maintenance } \\
\text { Transformer CT3 Is In Maintenance } \\
\text { Operators Fail To Al ign The SSF RCCm System For Operation }\end{array}$ & $\begin{array}{l}4.49 \mathrm{E}-02 \\
4.30 \mathrm{E}-03 \\
7.80 \mathrm{E}-03 \\
1.93 \mathrm{E}-02 \\
1.74 \mathrm{E}-04 \\
1.00 \mathrm{E}-01\end{array}$ & Negligible \\
\hline TQsU & $\begin{array}{l}\text { TCR } \\
\text { RCR } \\
\text { PACE1E2COM } \\
\text { PACE3E4REC } \\
\text { NSFORCMDHE } \\
\text { LPRO025LHE }\end{array}$ & $\begin{array}{l}\text { Loss of Control Room Cooling } \\
\text { Nonrecovery From Control Room Cooling } \\
\text { Common Cause Failure of Breakers E1 And E2 To Close } \\
\text { Operators Fail To Close Breakers E1 And E2 Within } 4 \text { Hours } \\
\text { Operators Fail To Align The SSF RCM System For Operation } \\
\text { Drain Valve 3PR-25 Is Left Open: Latent Human Error }\end{array}$ & $\begin{array}{l}4.49 \mathrm{E}-02 \\
4.30 \mathrm{E}-03 \\
8.90 \mathrm{E}-05 \\
1.00 \mathrm{E}-03 \\
1.00 \mathrm{E}-01 \\
3.00 \mathrm{E}-03\end{array}$ & \\
\hline
\end{tabular}


IABLE E.4. (contd)

\begin{tabular}{|l|l|l|c|c|}
\hline $\begin{array}{c}\text { Seq. } \\
\text { Name }\end{array}$ & Event Name & \multicolumn{1}{|c|}{ Event Description } & Probability & $\begin{array}{c}\text { Cut Set } \\
\text { Frequency }\end{array}$ \\
\hline TQSU & TCR & Loss Of Control Room Cooling & $4.49 E-02$ & Negligible \\
& RCR & Nonrecovery From Control Room Cooling & $4.30 E-03$ \\
& PACEIE2CON & Common Cause Failure Of Breakers E1 And E2 To Close & $8.90 E-05$ \\
& PACE3H4REC & Operators Fail To Close Breakers El and E2 Hithin 4 Hours & $1.00 E-03$ \\
& NSFORCMOHE & Operators Fail To Align The SSF RCM System For Operation & $1.00 E-01$ \\
& LPRPN60LHE & Drain Valve 3PR-23 Or 3PR-68 Left Open: Latent Human Error & $3.00 E-03$ & \\
\hline
\end{tabular}

Note: "Negligible" means less than lE-10/RY.

$\stackrel{m}{\infty}$ 
IABLE E.5. Affected CDF Calculations for the Representative B\&W PWR - Contributing Events

\section{AFFECTED CDF CALCULATIONS}

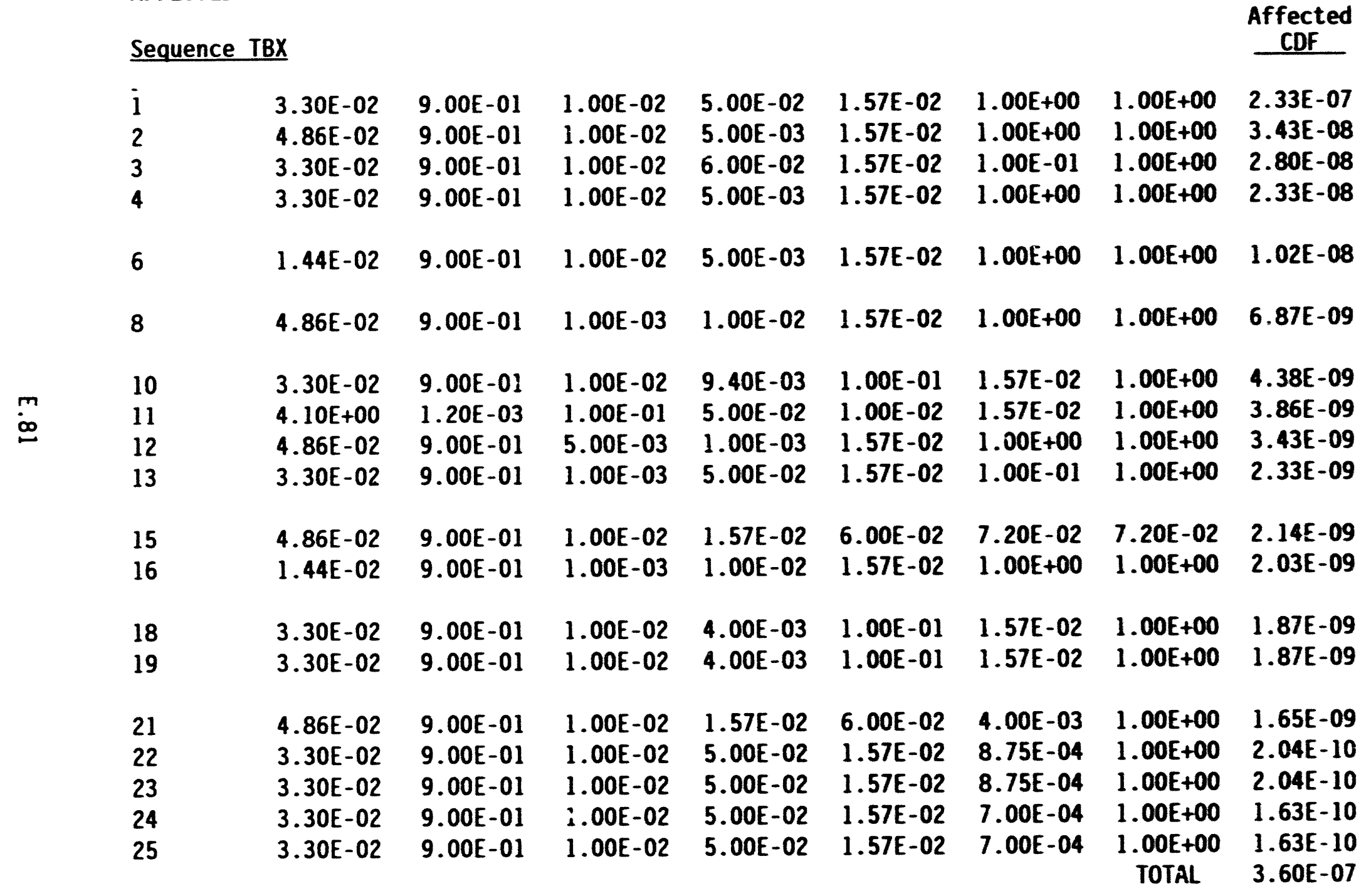


IABLE E.5. (contd)

Sequence TQsU

\begin{tabular}{|c|c|c|c|c|c|c|c|c|}
\hline 26 & $1.44 \mathrm{E}-02$ & $1.93 E-02$ & $1.57 \mathrm{E}-02$ & $1.00 \mathrm{E}-01$ & $2.20 \mathrm{E}-01$ & $1.00 E+00$ & $1.00 E+00$ & $9.60 E-08$ \\
\hline 27 & $1.44 \mathrm{E}-02$ & $3.36 E-03$ & $1.57 \mathrm{E}-02$ & $6.50 \mathrm{E}-02$ & $1.00 E+00$ & $1.00 E+00$ & $1.00 E+00$ & 4.94E-08 \\
\hline 29 & $1.44 E-02$ & $3.36 E-03$ & $1.57 \mathrm{E}-02$ & $5.10 \mathrm{E}-02$ & $1.00 E+00$ & $1.00 E+00$ & $1.00 E+00$ & $3.87 E-08$ \\
\hline 30 & $1.44 E-02$ & $1.93 \mathrm{E}-02$ & $1.00 \mathrm{E}-01$ & $1.57 \mathrm{E}-02$ & $6.50 \mathrm{E}-02$ & $1.00 E+00$ & $1.00 E+00$ & $2.84 E-08$ \\
\hline 31 & $1.44 \mathrm{E}-02$ & $3.36 E-03$ & $6.50 E-02$ & $1.57 E-02$ & $1.00 E+00$ & $1.00 E+00$ & $1.00 E+00$ & 4. $94 E-08$ \\
\hline 35 & $1.44 \mathrm{E}-02$ & $2.26 E-03$ & $7.20 \mathrm{E}-02$ & $1.57 E-02$ & $2.20 E-01$ & $1.00 E+00$ & $1.00 \mathrm{E}+00$ & 8.09E-09 \\
\hline 36 & $4.86 E-02$ & $7.80 E-03$ & $1.93 \mathrm{E}-02$ & $1.57 E-02$ & $6.50 \mathrm{E}-02$ & $1.00 E+00$ & $1.00 E+00$ & 7.47E-09 \\
\hline 38 & $4.10 E+00$ & $8.90 E-05$ & $1.00 E-03$ & $1.57 \mathrm{E}-02$ & $1.00 E+00$ & $1.00 \mathrm{E}+00$ & $1.00 E+00$ & $5.73 E-09$ \\
\hline 39 & $1.44 \mathrm{E}-02$ & $3.62 E-04$ & $1.57 \mathrm{E}-02$ & $6.50 \mathrm{E}-02$ & $1.00 \mathrm{E}+00$ & $1.00 E+00$ & $1.00 E+00$ & $5.32 E-09$ \\
\hline 40 & $1.44 \mathrm{E}-02$ & $1.00 E-04$ & $1.57 \mathrm{E}-02$ & $2.20 E-01$ & $1.00 E+00$ & $1.00 E+00$ & $1.00 E+00$ & 4.97E-09 \\
\hline 42 & $4.86 E-02$ & $7.80 \mathrm{E}-03$ & $1.93 \mathrm{E}-02$ & $1.57 \mathrm{E}-02$ & $5.10 E-02$ & $1.00 E+00$ & $1.00 E+00$ & $5.86 E-09$ \\
\hline 43 & $2.73 \mathrm{E}-02$ & $7.80 E-03$ & $1.93 \mathrm{E}-02$ & $1.57 E-02$ & $6.50 E-02$ & $1.00 E+00$ & $1.00 E+00$ & 4.19E-09 \\
\hline 44 & $1.44 \mathrm{E}-02$ & $3.36 E-03$ & $7.20 \mathrm{E}-02$ & $1.57 \mathrm{E}-02$ & $6.50 E-02$ & $1.00 E+00$ & $1.00 E+00$ & $3.56 E-09$ \\
\hline 45 & 4. $10 E+00$ & $7.80 E-03$ & $1.93 E-02$ & $3.62 E-04$ & $1.57 \mathrm{E}-02$ & $1.00 \mathrm{E}+00$ & $1.00 E+00$ & $3.51 E-09$ \\
\hline 46 & $1.44 \mathrm{E}-02$ & $3.62 E-04$ & $1.57 \mathrm{E}-02$ & $5.10 \mathrm{E}-02$ & $1.00 E+00$ & $1.00 E+00$ & $1.00 E+00$ & 4.17E-09 \\
\hline 49 & $2.73 E-02$ & $7.80 E-03$ & $1.93 \mathrm{E}-02$ & 1.57E-02 & $5.10 E-02$ & $1.00 E+00$ & $1.00 E+00$ & $3.29 E-09$ \\
\hline 50 & $1.44 E-02$ & $2.26 E-03$ & $2.00 \mathrm{E}-02$ & $1.57 \mathrm{E}-02$ & $2.20 \mathrm{E}-01$ & $1.00 E+00$ & $1.00 E+00$ & $2.25 E-09$ \\
\hline 51 & $4.86 E-02$ & $2.23 \mathrm{E}-03$ & $1.93 \mathrm{E}-02$ & $1.57 \mathrm{E}-02$ & $6.50 E-02$ & $1.00 E+00$ & $1.00 E+00$ & $2.13 E-09$ \\
\hline 53 & $4.10 E+00$ & $3.00 E-05$ & $1.00 E-03$ & $1.57 E-02$ & $1.00 E+00$ & $1.00 E+00$ & $1.00 E+00$ & $1.93 E-09$ \\
\hline 57 & 4. $10 E+00$ & $7.80 E-03$ & $1.93 \mathrm{E}-02$ & $1.74 E-04$ & 1.57E-02 & $1.00 E+00$ & $1.00 E+00$ & $1.69 \mathrm{E}-09$ \\
\hline 58 & $1.44 E-02$ & $1.93 \mathrm{E}-02$ & $1.57 \mathrm{E}-02$ & $1.00 \mathrm{E}-01$ & $2.20 \mathrm{E}-01$ & $3.00 E-03$ & $1.00 E+00$ & $2.88 E-10$ \\
\hline 59 & $1.44 \mathrm{E}-02$ & $3.36 E-03$ & $1.57 \mathrm{E}-02$ & $6.50 E-02$ & 3.00E-03 & $1.00 E+00$ & $1.00 E+00$ & $1.48 E-10$ \\
\hline
\end{tabular}


TABLE E.5. (contd)

$\begin{array}{ccccccccc}60 & 1.44 \mathrm{E}-02 & 3.36 \mathrm{E}-03 & 1.57 \mathrm{E}-02 & 6.50 \mathrm{E}-02 & 3.00 \mathrm{E}-03 & 1.00 \mathrm{E}+00 & 1.00 \mathrm{E}+00 & 1.48 \mathrm{E}-10 \\ 62 & 1.44 \mathrm{E}-02 & 1.93 \mathrm{E}-02 & 1.00 \mathrm{E}-01 & 2.20 \mathrm{E}-01 & 1.57 \mathrm{E}-02 & 3.00 \mathrm{E}-03 & \begin{array}{c}1.00 \mathrm{E}+00 \\ \text { T0TAL }\end{array} & \begin{array}{c}2.88 \mathrm{E}-10 \\ 3.27 \mathrm{E}-07\end{array}\end{array}$

Sequence TBU

\begin{tabular}{|c|c|c|c|c|c|c|c|c|}
\hline 63 & $1.44 E-02$ & $9.00 E-01$ & $1.93 \mathrm{E}-02$ & $1.00 \mathrm{E}-01$ & $1.57 \mathrm{E}-02$ & $6.00 \mathrm{E}-02$ & $6.67 E-01$ & $1.57 E-08$ \\
\hline 64 & $1.44 E-02$ & $9.00 E-01$ & $1.93 \mathrm{E}-02$ & $5.00 E-02$ & $1.00 E-01$ & $1.57 \mathrm{E}-02$ & $6.67 E-01$ & $1.31 E-08$ \\
\hline 65 & $2.73 E-02$ & $9.00 E-01$ & $3.36 \mathrm{E}-03$ & $1.57 E-02$ & $6.00 E-02$ & $1.40 \mathrm{E}-01$ & $1.00 E+00$ & $1.09 E-08$ \\
\hline 66 & $2.73 E-02$ & $9.00 \mathrm{E}-01$ & $5.00 E-02$ & $3.36 \mathrm{E}-03$ & $1.57 E-02$ & $1.40 E-01$ & $1.00 E+00$ & $9.07 E-09$ \\
\hline 67 & $1.44 \mathrm{E}-02$ & $9.00 E-01$ & $3.36 E-03$ & $1.57 E-02$ & $6.00 \mathrm{E}-02$ & $1.40 \mathrm{E}-01$ & $1.00 E+00$ & $5.74 E-09$ \\
\hline 68 & $1.44 \mathrm{E}-02$ & $9.00 \mathrm{E}-01$ & $5.00 E-02$ & $3.36 \mathrm{E}-03$ & $1.57 \mathrm{E}-02$ & $1.40 \mathrm{E}-01$ & $1.00 E+00$ & $4.79 E-09$ \\
\hline 69 & $1.44 \mathrm{E}-02$ & $9.00 E-01$ & $1.93 \mathrm{E}-02$ & $1.00 \mathrm{E}-01$ & $1.57 \mathrm{E}-02$ & $9.40 E-03$ & $6.67 E-01$ & $2.46 E-09$ \\
\hline 70 & $4.10 E+00$ & $9.00 \mathrm{E}-01$ & $8.90 E-05$ & $5.00 \mathrm{E}-02$ & $1.57 \mathrm{E}-02$ & $9.40 E-03$ & $1.00 E+00$ & $2.42 E-09$ \\
\hline 71 & $2.73 \mathrm{E}-02$ & $9.00 E-01$ & $3.36 E-03$ & $1.57 \mathrm{E}-02$ & $9.40 \mathrm{E}-03$ & $1.40 E-01$ & $\begin{array}{c}1.00 E+00 \\
\text { TOTAL }\end{array}$ & $\begin{array}{l}1.71 E-09 \\
6.59 E-08\end{array}$ \\
\hline & \multicolumn{8}{|c|}{ Sequence TBQrX } \\
\hline 72 & $3.30 \mathrm{E}-02$ & $1.00 \mathrm{E}-01$ & $1.00 \mathrm{E}-02$ & $5.00 \mathrm{E}-02$ & $1.57 \mathrm{E}-02$ & $1.00 E+00$ & $1.00 E+00$ & $2.59 E-08$ \\
\hline 73 & $4.86 E-02$ & $1.00 E-01$ & $1.00 \mathrm{E}-02$ & $5.00 E-03$ & $1.57 \mathrm{E}-02$ & $1.00 E+00$ & $1.00 E+00$ & $3.82 E-09$ \\
\hline 74 & $3.30 \mathrm{E}-02$ & $1.00 \mathrm{E}-01$ & $1.00 E-02$ & $1.00 \mathrm{E}-01$ & $1.57 \mathrm{E}-02$ & $6.00 E-02$ & $1.00 E+00$ & $3.11 E-09$ \\
\hline 75 & $3.30 E-02$ & $1.00 \mathrm{E}-01$ & $1.00 \mathrm{E}-02$ & $5.00 E-03$ & $1.57 \mathrm{E}-02$ & $1.00 E+00$ & $\begin{array}{c}1.00 E+00 \\
\text { TOTAL }\end{array}$ & $\begin{array}{l}2.59 E-09 \\
3.54 E-08\end{array}$ \\
\hline & \multicolumn{8}{|c|}{ Sequence TBQsU } \\
\hline 76 & $1.44 E-02$ & $9.00 E-01$ & $1.93 E-02$ & $1.00 \mathrm{E}-01$ & $1.57 \mathrm{E}-02$ & $6.00 E-02$ & $6.70 E-01$ & $1.58 E-08$ \\
\hline 77 & $1.44 \mathrm{E}-02$ & $9.00 \mathrm{E}-01$ & $1.93 E-02$ & $5.00 E-02$ & $1.00 E-01$ & $1.57 E-02$ & $6.70 E-01$ & $1.32 E-08$ \\
\hline 78 & $2.73 E-02$ & $9.00 \mathrm{E}-01$ & $3.36 \mathrm{E}-03$ & $1.57 E-02$ & $6.00 E-02$ & $7.30 \mathrm{E}-02$ & $1.00 E+00$ & $5.68 E-09$ \\
\hline 79 & $2.73 E-02$ & $9.00 E-01$ & $3.36 E-03$ & $1.57 \mathrm{E}-02$ & $6.00 E-02$ & $1.40 E-01$ & $1.00 E+00$ & $1.09 E-08$ \\
\hline 80 & $2.73 E-02$ & $9.00 \mathrm{E}-01$ & $5.00 E-02$ & $3.36 \mathrm{E}-03$ & $1.57 E-02$ & $7.30 E-02$ & $1.00 E+00$ & 4.73E-09 \\
\hline 81 & $2.73 E-02$ & $9.00 E-01$ & $5.00 \mathrm{E}-02$ & $3.36 E-03$ & $1.57 \mathrm{E}-02$ & $1.40 E-01$ & $1.00 E+00$ & $9.07 E-09$ \\
\hline
\end{tabular}


IABLE E.5. (contd)

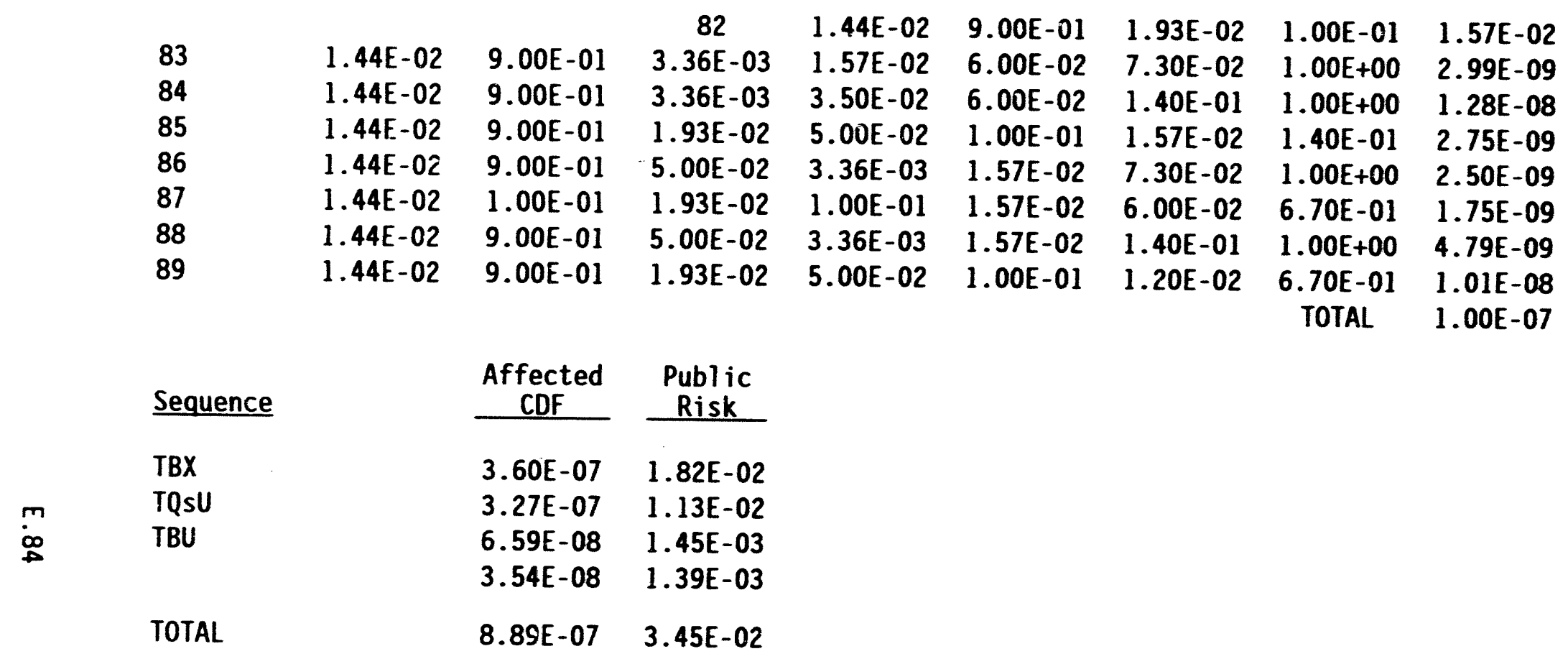


IABLE E.5. (contd)

RISK CALCULATIONS

\begin{tabular}{|c|c|c|c|c|c|c|c|}
\hline PDS & $\begin{array}{c}\text { Cut Set } \\
\text { Nos. }\end{array}$ & CDF & $\begin{array}{l}\text { Release } \\
\text { Category } \\
\end{array}$ & $\begin{array}{c}\mathrm{RC} \\
\text { Probability }\end{array}$ & $\begin{array}{c}\mathrm{RC} \\
\text { Consequences } \\
\end{array}$ & $\begin{array}{c}\text { Public Risk } \\
\text { Person-Rem } / Y_{r} \\
\end{array}$ & Totaì \\
\hline $13 B$ & 1 to 21 & $3.59 \mathrm{E}-07$ & $\begin{array}{ll}\mathrm{RC} & 9.01 \\
\mathrm{RC} & 9.02 \\
\mathrm{RC} & 9.04 \\
\mathrm{RC} & 8.01 \\
\mathrm{RC} & 5.01 \\
\mathrm{RC} & 5.02\end{array}$ & $\begin{array}{l}1.43 E-03 \\
1.41 E-01 \\
8.46 E-06 \\
8.56 E-01 \\
6.73 E-04 \\
5.51 E-04\end{array}$ & $\begin{array}{l}2.30 E+02 \\
4.90 E+03 \\
5.05 E+03 \\
3.40 E+04 \\
1.25 E+07 \\
1.26 E+07\end{array}$ & $\begin{array}{l}1.18 \mathrm{E}-07 \\
2.48 \mathrm{E}-04 \\
1.54 \mathrm{E}-08 \\
1.05 \mathrm{E}-02 \\
3.02 \mathrm{E}-03 \\
2.49 \mathrm{E}-03\end{array}$ & $1.62 \mathrm{E}-02$ \\
\hline $13 \mathrm{H}$ & 22 to 25 & $7.34 \mathrm{E}-10$ & $\begin{array}{ll}\mathrm{RC} & 5.01 \\
\mathrm{RC} & 5.02 \\
\mathrm{RC} & 4.05 \\
\mathrm{RC} & 4.06 \\
\mathrm{RC} & 4.07 \\
\mathrm{RC} & 4.08\end{array}$ & $\begin{array}{l}6.73 E-04 \\
5.51 E-04 \\
1.43 E-03 \\
1.41 E-01 \\
8.56 E-03 \\
8.47 E-01\end{array}$ & $\begin{array}{l}1.25 E+07 \\
1.26 E+07 \\
1.52 E+06 \\
1.52 E+06 \\
2.16 E+06 \\
2.80 E+06\end{array}$ & $\begin{array}{l}6.18 E-06 \\
5.10 E-06 \\
1.60 E-06 \\
1.57 E-04 \\
1.36 E-05 \\
1.74 E-03\end{array}$ & $1.93 E-03$ \\
\hline $7 F$ & 26 to 57 & $3.26 \mathrm{E}-07$ & $\begin{array}{ll}\mathrm{RC} & 9.04 \\
\mathrm{RC} & \mathbf{8 . 0 1} \\
\mathrm{RC} & 7.02 \\
\mathrm{RC} & 7.04 \\
\mathrm{RC} & 6.02 \\
\mathrm{RC} & 6.04 \\
\mathrm{RC} & 6.06 \\
\mathrm{RC} & 6.08\end{array}$ & $\begin{array}{l}7.29 \mathrm{E}-01 \\
2.47 \mathrm{E}-01 \\
4.41 \mathrm{E}-03 \\
1.67 \mathrm{E}-02 \\
2.47 \mathrm{E}-04 \\
2.42 \mathrm{E}-04 \\
9.38 \mathrm{E}-04 \\
9.17 \mathrm{E}-04\end{array}$ & $\begin{array}{l}5.05 E+03 \\
3.40 E+04 \\
4.27 E+05 \\
4.27 E+05 \\
1.40 E+06 \\
8.73 E+06 \\
1.42 E+06 \\
8.75 E+06\end{array}$ & $\begin{array}{l}1.20 \mathrm{E}-03 \\
2.74 \mathrm{E}-03 \\
6.14 \mathrm{E}-04 \\
2.32 \mathrm{E}-03 \\
1.13 \mathrm{E}-04 \\
6.89 \mathrm{E}-04 \\
4.34 \mathrm{E}-04 \\
2.62 \mathrm{E}-03\end{array}$ & $1.07 \mathrm{E}-02$ \\
\hline $7 \mathrm{~L}$ & 58 to 62 & $8.72 E-10$ & $\begin{array}{ll}\mathrm{RC} & 6.04 \\
\mathrm{RC} & 4.01 \\
\mathrm{RC} & 4.02 \\
\mathrm{RC} & 4.03 \\
\mathrm{RC} & 4.04\end{array}$ & $\begin{array}{l}1.13 E-03 \\
4.41 E-03 \\
4.90 E-04 \\
8.96 E-01 \\
9.95 E-02\end{array}$ & $\begin{array}{l}8.73 E+06 \\
3.54 E+05 \\
5.34 E+05 \\
5.34 E+05 \\
1.73 E+06\end{array}$ & $\begin{array}{l}8.60 E-06 \\
1.36 E-06 \\
2.28 E-07 \\
4.17 E-04 \\
1.50 E-04\end{array}$ & $5.78 \mathrm{E}-04$ \\
\hline
\end{tabular}


TABLE E.5. (contd)

\begin{tabular}{|c|c|c|c|c|c|c|c|}
\hline$\underline{\text { PDS }}$ & $\begin{array}{c}\text { Cut Set } \\
\text { Nos. }\end{array}$ & $\mathrm{CDF}$ & $\begin{array}{c}\text { Release } \\
\text { Category }\end{array}$ & $\begin{array}{c}\mathrm{RC} \\
\text { Probability } \\
\end{array}$ & $\begin{array}{c}\mathrm{RC} \\
\text { Consequences } \\
\end{array}$ & $\begin{array}{c}\text { Public Risk } \\
\text { Person-Rem/Yr }\end{array}$ & Total \\
\hline $12 \mathrm{~F}$ & 63 to 71 & $6.59 \mathrm{E}-08$ & $\begin{array}{ll}\mathrm{RC} & 9.04 \\
\mathrm{RC} & 8.01 \\
\mathrm{RC} & 7.02 \\
\mathrm{RC} & 7.04 \\
\mathrm{RC} & 6.02 \\
\mathrm{RC} & 6.04\end{array}$ & $\begin{array}{l}7.29 \mathrm{E}-01 \\
2.47 \mathrm{E}-01 \\
4.41 \mathrm{E}-03 \\
1.30 \mathrm{E}-02 \\
2.47 \mathrm{E}-04 \\
2.42 \mathrm{E}-04\end{array}$ & $\begin{array}{l}5.05 E+03 \\
3.40 E+04 \\
4.27 E+05 \\
4.27 E+05 \\
1.40 E+06 \\
8.73 E+06\end{array}$ & $\begin{array}{l}2.43 E-04 \\
5.53 E-04 \\
1.24 E-04 \\
3.66 E-04 \\
2.28 E-05 \\
1.39 E-04\end{array}$ & $1.45 E-03$ \\
\hline $5 B$ & 72 to 75 & $3.54 \mathrm{E}-08$ & 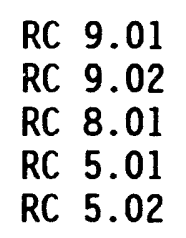 & $\begin{array}{l}1.01 E-03 \\
1.00 E-01 \\
8.98 E-01 \\
1.28 E-04 \\
5.28 E-04\end{array}$ & $\begin{array}{l}2.30 E+02 \\
4.90 E+03 \\
3.40 E+04 \\
1.25 E+07 \\
1.26 E+07\end{array}$ & $\begin{array}{l}8.23 E-09 \\
1.74 E-05 \\
1.08 E-03 \\
5.67 E-05 \\
2.36 E-04\end{array}$ & $1.39 E-03$ \\
\hline $9 \mathrm{~F}$ & 76 to 89 & $1.00 \mathrm{E}-07$ & 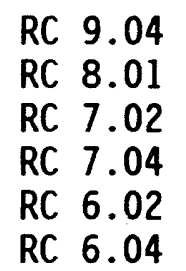 & $\begin{array}{l}7.29 \mathrm{E}-01 \\
2.47 \mathrm{E}-01 \\
4.41 \mathrm{E}-03 \\
1.30 \mathrm{E}-02 \\
2.47 \mathrm{E}-04 \\
2.42 \mathrm{E}-04\end{array}$ & $\begin{array}{l}5.05 E+03 \\
3.40 E+04 \\
4.27 E+05 \\
4.27 E+05 \\
1.40 E+06 \\
8.73 E+06\end{array}$ & $\begin{array}{l}3.69 \mathrm{E}-04 \\
8.42 \mathrm{E}-04 \\
1.89 \mathrm{E}-04 \\
5.56 \mathrm{E}-04 \\
3.47 \mathrm{E}-05 \\
2.12 \mathrm{E}-04\end{array}$ & $2.20 \mathrm{E}-03$ \\
\hline
\end{tabular}




\section{APPENDIX $F$}

THERMAL ANALYSIS AND TEMPERATURE SENSITIVITIES

IN ROOMS REOUIRING HVAC AND ROOM COOLERS 


\section{APPENDIX $F$ \\ IHERMAL ANALYSIS AND TEMPERATURE SENSITIVITIES}

IN ROOMS REQUIRING HVAC AND ROOM COOLERS

This appendix describes efforts to determine the temperature rise in rooms containing safety-related equipment and the sensitivities of safetyrelated equipment to increasing ambient temperatures. The data in this appendix were used in two ways. First, the room temperature heatup calculations were used to determine the amount of time available to restore cooling to prevent malfunctioning of safety-related components. This information was used to estimate human error probabilities for failure to restore room cooling. The second way in which these data were used was to estimate the probabilities of failure of safety-related equipment given a loss of room cooling. These probabilities were used in the probabilistic risk calculations presented in Chapter 4.0 of the main report.

This appendix contains two main subsections. Section F.l presents an assessment of room heatup calculations based on the heat generated by operating safety-related equipment and loss of room cooling. Section F.2 discusses and quantifies the failure rates for equipment subjected to high ambient temperature environments. The equipment subjected to higher-than-normal ambient temperatures is located in Control and/or Auxiliary Buildings at nuclear power plants and is not qualified to withstand the effects of "harsh" environments, as is expected for equipment located inside containment.

\section{F.1 ROOM HEATUP EVALUATION}

As part of the compliance effort to LER 88-017-00, owners of a Combustion Engineering PWR nuclear generating station supported thermal modeling efforts to study the room temperature heatup rates resulting from the loss of various HVAC equipment. Based on plant visits, these thermal calculations were judged to be applicable to most plant designs and HVAC/room cooler system configurations. Many important design parameters used in these calculations are approximately the same for most plants, including the following:

- Room sizes

- Most rooms are not normally open to adjacent rooms for air circulation.

- Materials of construction

- Pump room cooler designs were similar (e.g., belt-operated fan that blows air over chilled-or service water-cooled coils; air recirculated within pump room). 
- Control rooms, switchgear rooms, and DC equipment rooms were typically cooled by air circulated by large air-handling units (AHUs); air cooled by chiller that rejects heat to a circulating chilled water system.

This appendix describes the thermal modeling efforts and gives room heatup rates used elsewhere in this report.

Room heatup rates were studied for five key room designs containing safety-related equipment. These include the main control room, the switchgear room (including DC equipment room), the diesel generator control room, and the essential cooling water (ECW) pump room. Rooms for (ECW and other safetyrelated pumps, including high-pressure injection, low-pressure injection, and containment spray pumps, are similar). All analyses used similar so-called lumped parameter thermal modeling techniques; i.e., actual room geometries are not modeled spatially as in finite element methods. Thermal sources and masses are treated as discrete parameters. Several conservative assumptions were made in all four analyses, which will make the models tend to overpredict room temperature estimates. Thermal masses, for example, of many objects (primarily equipment and steel structures) were neglected. For a given heating rate, this will have the conservative effect of causing the temperatures of the remaining thermal masses to increase more rapidly. For all analyses described in this appendix, normal operating temperatures were used for initial conditions.

Transient thermal responses for the control room and switchgear room were determined in a detailed analysis involving failure of an ECW train. The ECW train involved ten rooms and nine ACUs. All ACU fans were assumed to function after flow in the ECW train ceased. Cooling effects of the thermal mass of the remaining ECW water was considered. For this reason, the transient responses of the ten rooms are coupled and must be solved simultaneously. Thermal transients calculated were for both loss of coolant accidents (LOCA) and non-LOCA conditions.

In these calculations, thermal masses consisted only of room air, water trapped in the chillers, and concrete forming the room walls, floor, and ceiling. Thermal masses of all equipment was neglected. The air mass in each room was assumed to be isothermal; i.e., thermal stratification effects were neglected. Heat-loading was essentially prescribed on the air mass and allowed to convect to the trapped chiller water and concrete mass.

The actual model for this coupled transient solution involved no fewer than 23 simultaneous equations and 23 unknowns. These equations resulted from energy balances of rooms and room components. Seven of the ten rooms have their own ACU connected directly to the ECW system. Three of the rooms (the $D C$ equipment room, the switchgear room, and the battery room) are simultaneously serviced (via air ducts) by two external ACUs, which will be designated $A C U A$ and $A C U B$. The 23 energy balance equations are 
- Ten equations representing energy balances of room air

- Ten equations representing energy balances of room concrete masses

- One equation representing energy balance of the stagnant water in the ECW loop

- Two equations representing energy balances of ACUA and ACUB.

The 23 unknowns are

- The ten room temperatures

- Ten temperatures representing concrete temperatures in the rooms

- The temperature in the stagnant water in the ECW line (assumed constant throughout the 100p)

- The return air temperatures in each of the air ducts from ACUA and ACUB.

Energy balance equations of room air take the form:

$$
M_{i} \frac{d T_{i}}{d t}=Q_{\text {sources }}+Q_{a i r}-Q_{\text {sink }}
$$

where:

$$
\begin{aligned}
& M_{i} \quad=\text { Thermal mass of the air in Room } i \\
& Q_{\text {sources }}=\text { Room heat generation rate } \\
& Q_{\text {air }}=\text { Heat addition or deletion (if any) due to HVAC air leaving } \\
& \text { or entering the room } \\
& Q_{\text {sink }}=\text { Heat transferred from the air to the concrete, heat leaving } \\
& \text { the room (if any) due to heat flow through open doors, and } \\
& \text { heat removed by AHUs. } \\
& Q_{\text {air }} \text { was calculated by using the equation: } \\
& Q_{\text {air }}=\dot{M}_{\text {in }} C T_{\text {in }}-\dot{M}_{\text {out }} C T_{\text {out }}
\end{aligned}
$$


where:

$$
\begin{aligned}
& \dot{M}_{\text {in }}=\text { Mass flow rate of incoming air } \\
& \dot{M}_{\text {out }}=\text { Mass flow rate of outgoing air } \\
& \mathrm{T}_{\text {in }}=\text { Temperature of incoming air } \\
& \mathrm{T}_{\text {out }}=\text { Temperature of outgoing air. }
\end{aligned}
$$

The contribution to $Q_{\text {sink }}$ caused by heat transferred from the air to the concrete was modeled as:

$$
Q=H\left(T_{A}-T_{C}\right)
$$

where:

$$
\begin{aligned}
& H=\text { Total convection coefficient } \\
& T_{A}=\text { Room air temperature } \\
& T_{C}=\text { Concrete surface temperature }
\end{aligned}
$$

Heat loss due to air flow through open doors between rooms was modeled by using a technique described in Nucler Management and Resources Council (NUMARK 1991). In this reference, air flow rates due to natural convection effects were studied to arrive at the following expression for heat loss through an open door.

$$
Q=.2 W H^{3 / 2} g^{1 / 2}\left[2\left(T_{A}-T_{0}\right) /\left(T_{0}+T_{A}\right)\right]^{2} \rho C_{p}\left(T_{A}-T_{0}\right)
$$

where:

$$
\begin{aligned}
& Q \quad=\text { Heat loss } \\
& W, H=\text { Door width and height } \\
& g \quad=\text { Acceleration of gravity } \\
& \rho, C_{P}=\text { Air density and specific heat } \\
& T_{A}, T_{0}=\text { Temperatures inside and outside of the room (absolute). }
\end{aligned}
$$


Heat loss to an AHU was modeled as:

$$
Q=H W\left(T_{A}-T_{W}\right)
$$

where:

$$
\begin{aligned}
& H W=\text { The transmissivity of the AHU } \\
& T_{W}=E C W \text { water temperature. }
\end{aligned}
$$

The type of model used for the concrete energy balance is described more fully in Goodman (1964). The form of the model used depended on the penetration depth of the heat in the concrete. A new temperature term $(Z)$ is defined as:

$$
Z=T_{c}-T_{c 1}
$$

where:

$$
\begin{aligned}
& T_{c}=\text { Current concrete room side skin temperature } \\
& T_{c i}=\text { Initial concrete temperature. }
\end{aligned}
$$

For $\frac{3 Z}{f}<L$ ( $f$ and $L$ defined later), the following differential equation for $Z$ was Used:

$$
\frac{d Z^{2}}{d t}=\frac{(h / k) Z^{2} \frac{d T A}{d t}+4 / 3 \alpha f^{3}}{f+Z(h / 2 K)}
$$

For $\frac{3 Z}{f} \geq L$, the differential equation used for $Z$ was:

$$
\frac{d z}{d t}=\frac{B A(B B+3) \frac{d T A}{d t}+\frac{12 \alpha}{L^{2}}(F L(B B+1)-B B \cdot Z)}{(12+5 B B)+(B B+3) B A}
$$


where:

$h$ - Heat transfer coeffictent between air and concrete

$K$ - Concrete wall thermal conductivity

$C=$ Concrete wall specific heat

$\rho=$ Concrete wall density

$\alpha=K / p C$

$f=h / K\left(\left(T_{A}-T_{c i}\right)-Z\right)$

$B A=$ Biot number $=h l$ of the hot side of the wall

$B B=$ Biot number of cold side of the wall

$=h_{1} L \frac{}{K}, h_{1}=$ heat transfer coefficient from cold side

$L=$ Wall thickness.

It is assumed that the stagnant water in the main ECW line exrhanges heat only with the ni.. ACU units; i.e., that it is perfectly insulated everywhere else. Additionally, it was assumed to be isothermal. An energy balance of this stagnant ECW water takes the form:

$$
\rho_{w} C_{w} V_{w} \frac{d T_{w}}{d t}=\sum_{i=1}^{g} H_{1}\left(T_{i}-T_{w}\right)
$$

where:

$P_{w}=$ Density of water

$C_{w}=$ Specific heat of water

$V_{w}=$ Volume or stagnant water

$T_{w}=$ Temperature of stagnant water

$H_{i}=$ Transmissivity of ACU $i$

$T_{i}=$ Temperature of water in room $i$. 
Two energy balance equations can be written to relate air inlet and outlet temperatures in ACUA and ACUB to instantaneous ECW temperature. These equations take the form:

$$
\dot{M} C\left(T_{\text {out }}-T_{1 n}\right)=H\left(T_{w}-T_{1 n}\right)
$$

where:

$$
\begin{aligned}
& \dot{M}=\text { Air flow rate of the ACU } \\
& C=\text { Specific heat of air } \\
& H=\text { Transmissivity of the ACU } \\
& T_{w}=\text { Temperature of stagnant ACU water } \\
& T_{\text {in }}=\text { Inlet air temperature } \\
& T_{\text {out }}=\text { Outlet air temperature. }
\end{aligned}
$$

The 23 unknown temperatures for this model were determined as a function of time by assuming initial temperatures and integrating numerically in time using the Euler method. Results for the control, switchgear, and DC equipment rooms for both LOCA and non-LOCA conditions are shown in Figures F.1 and F.2.

The diesel generator (DG) control room analys is simulated temperature rise following loss of the room AHU. Heat sources consisted mainly of lighting, solar heat, and heat generated by the DG control room equipment. Thermal mass of all electrical and mechanical equipment was neglected; only thermal mass of the room air and concrete walls was considered. The referenced calculation emphasized that even though the DG was assumed to be operat ing, no heat load was assumed for the DG neutral grounding transformer.

The DG control room was assumed to be thermally isolated from other rooms during the simulated transient condition. This greatly simplifies the detail required in the thermal model. The basic energy balance of the room takes the form: 


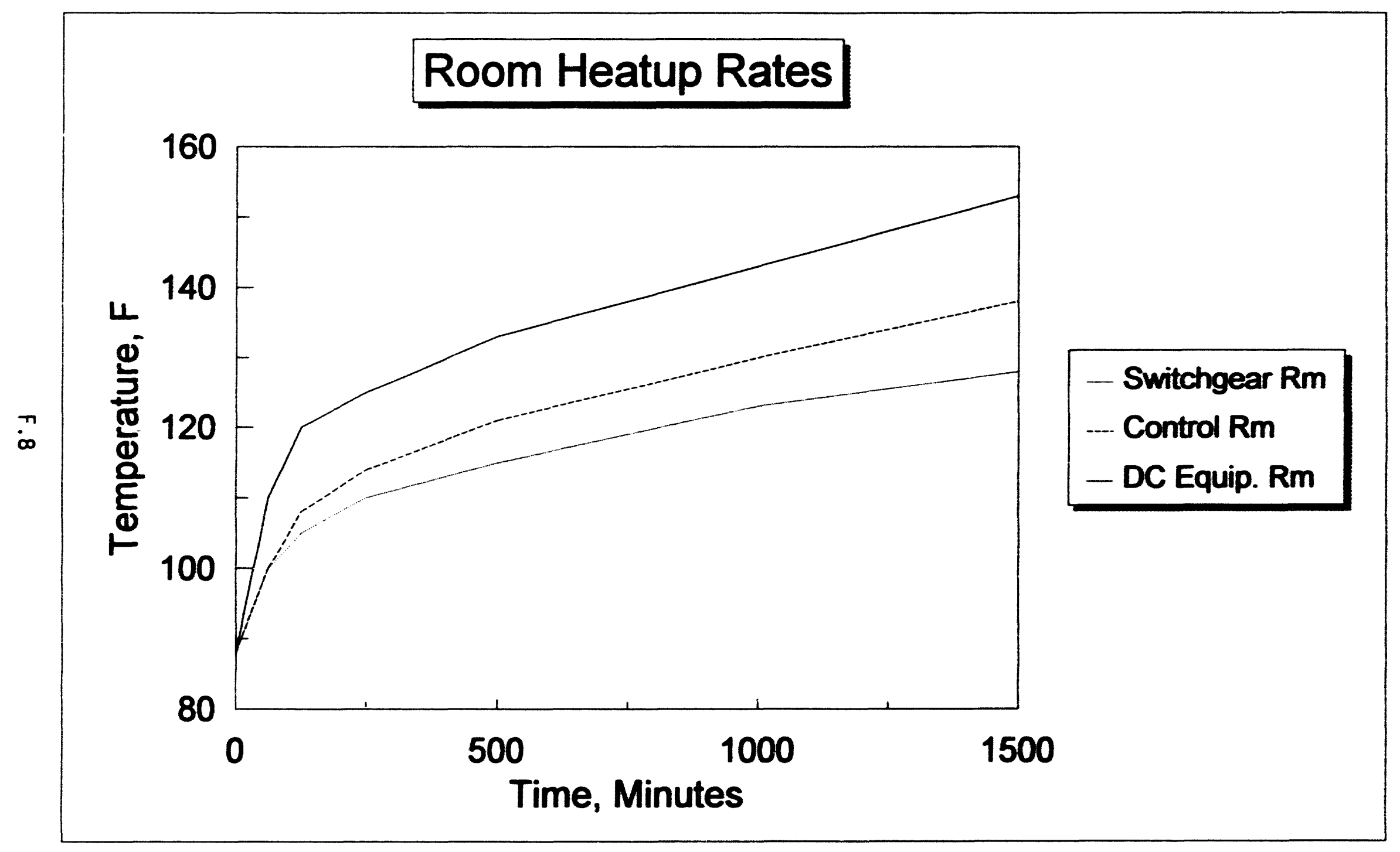

FIGURE F.1. Room Heatup Results for Control Room, DC Equipment Room, and Switchgear Room - LOCA conditions 


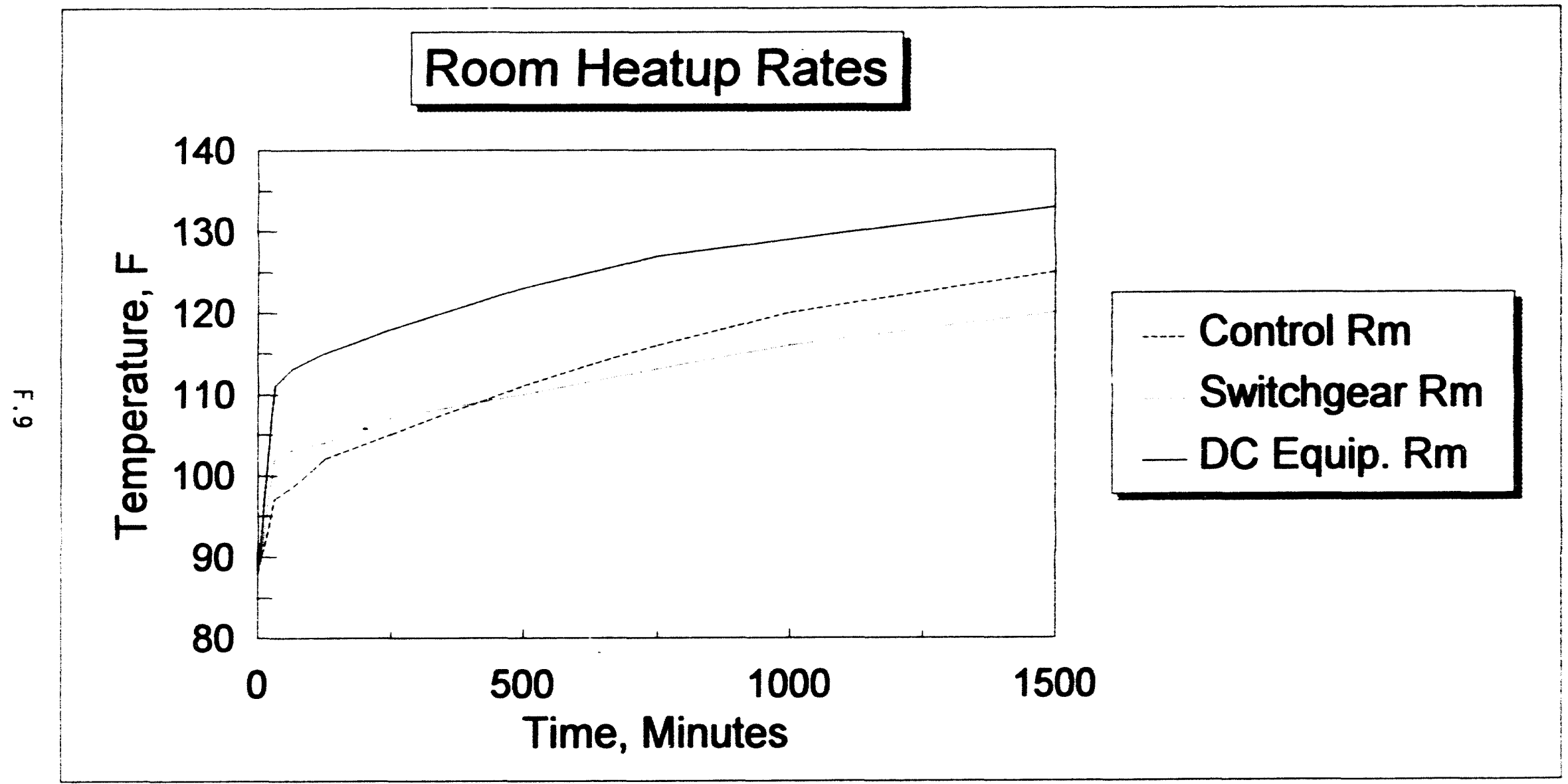

FIGURE F.2. Room Heatup Results for Control Room, DC Equipment Room, and Switchgear Room - Non-LOCA conditions 
Heat absorbed by the air = heat generated by sources - heat absorbed by the concrete:

$$
\text { Heat absorbed by the air }=\rho C V \frac{d T}{d t} \text {. }
$$

where:

$$
\begin{aligned}
& C=\text { Specific heat of air } \\
& p=\text { Density of air } \\
& V=\text { Volume of air. }
\end{aligned}
$$

$$
\text { Heat absorbed by the concrete }=h A\left(T-T_{c}\right)
$$

where:

$$
\begin{aligned}
& h \quad=\text { Convection coefficient between the concrete and air } \\
& A=\text { Surface area of concrete } \\
& T, T_{c}=\text { Air, concrete surface temperatures. }
\end{aligned}
$$

The concrete temperature through the wall thickness was obtained by using finite difference techniques to model one-dimensional heat transfer through the wall. The reported thermal transient prediction is shown in Figure F.3.

Thermal transients in safety-related pump rooms (including ECW, auxiliary feedwater (AFW), high-pressure safety injection (HPSI), and lowpressure safety injection (LPSI) pump rooms), were computed to simulate room heatup following a LOCA. The basic assumptions in this analysis were similar to those of the first three rooms studied. Heat load was almost totally due to pump mechanical losses. The heating effect of the large (20-in. diameter) piping was neglected. Early on in the transient, this piping would tend to heat the air, but later on, the room air exceeds the piping temperature (referenced as $125^{\circ} \mathrm{F}$ ) and the piping would in reality tend to be a heat sink. In the actual analysis performed, both the heat source and heat sink effects of the piping were neglected. The referenced calculation makes a very convincing argument supporting the conservatism of this assumption.

The overall energy balance for this model is

$$
Q_{\text {equip }}=Q_{\text {amb air }}+Q_{\text {wall }}+Q_{\text {outside air }}
$$




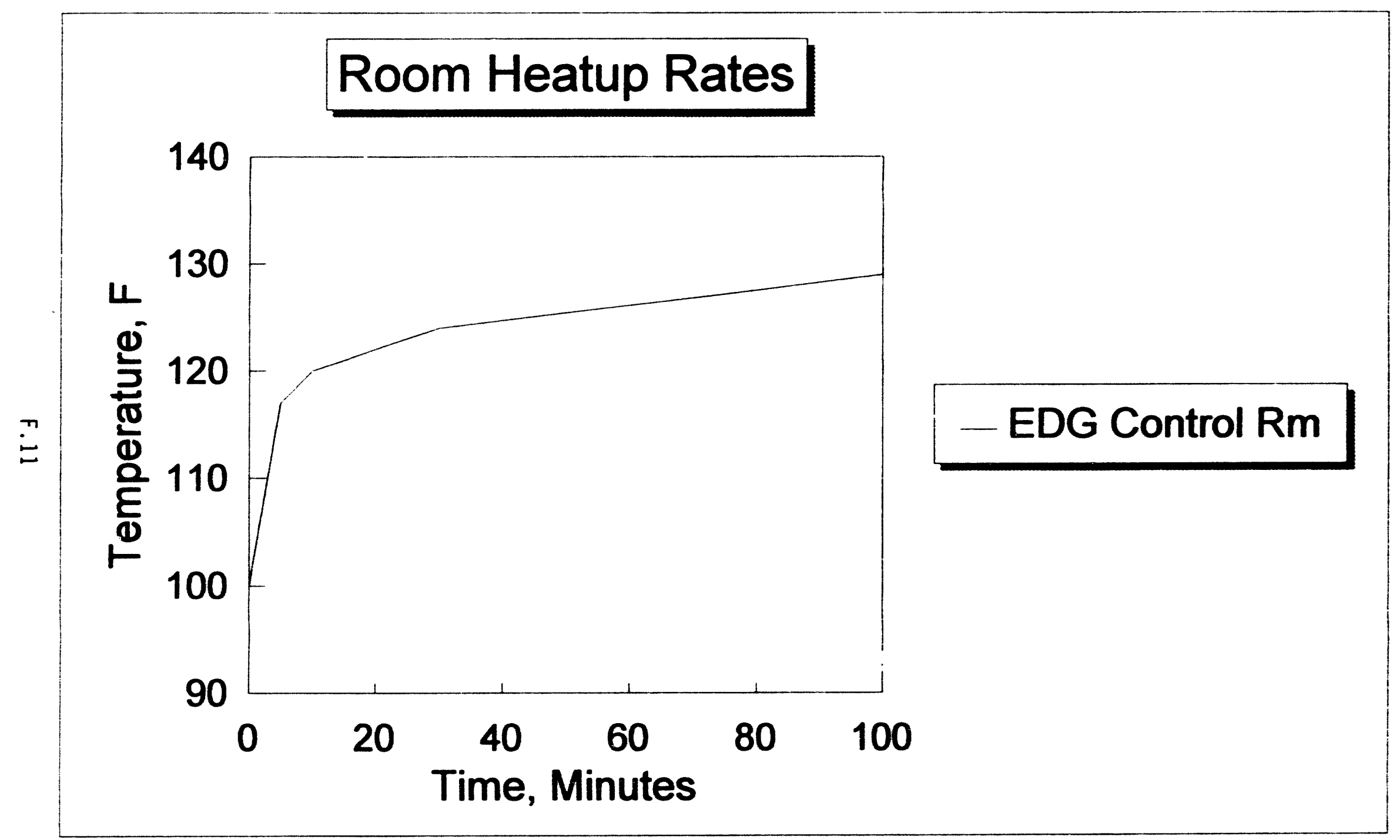

FIGURE F.3. Room Heatup Results for Diesel Generator Control Room 
where:

$$
\begin{array}{ll}
Q_{\text {equip }} & =\text { Heat generated from equipment or other source in the room } \\
Q_{\text {amb air }} & =\text { Heat transferred to the room air } \\
Q_{\text {wall }} & =\text { Heat stored in the room walls, ceiling, and floor } \\
Q_{\text {outside air }}=\text { Heat transferred to the outside air. }
\end{array}
$$

The actual thermal transient was simulated with a proprietary computer program and actual heat transfer equations were not provided. Modeling assumptions were provided, however. Heat-load items considered the ECW pump, the essential ACU fan, a radiation monitor, and room lighting. The only thermal masses consisted of the room air and the concrete of the walls, floor, and ceiling. Constant thickness $(2 \mathrm{ft})$ was assumed for these members. This essentially allowed a one-dimensional treatment of conduction through the concrete enclosure. The room air was treated as a lumped thermal mass based upon the room volume minus the equipment volume. The heat load was essentially placed on the air thermal mass and allowed to convect to the concrete, conduct through the concrete, and convect to an ambient temperature of $80^{\circ} \mathrm{F}$. The reported safety-related pump room temperature transients are shown in Figure F.4.

Additional room heatup calculations were performed to examine the effects of increasing air circulation into the pump rooms by opening doors. This allows some of the heat generated by operating pumps to be transferred to the air in adjacent rooms outside the pump rooms. The results of these calculations are presented in Figure F.5 for the HPSI pump room and Figure F.6 for the LPSI pump room. Figure F.7 presents the results of calculations on the AFW motor-driven pump room in which the essential HVAC system fails, but the normal HVAC system successfully functions to provide air circulation in the AFW pump room. The normal system provides only air circulation; no air cooling is provided. As shown in all three figures, the room temperature rises are substantially lower in the cases in which some air circulation is provided to the pump rooms. This will provide additional time for operators to restore essential cooling systems to the pump rooms to ensure continued, long-term operation of the pumps.

\section{F.2 TEMPERATURE SENSITIVITIES OF COMPONENTS}

This section examines the sensitivity of safety-related components in rooms cooled by HVAC and room cooler systems. The data in this section were used to establish temperature-dependent failure rates for sensitive equipment that were in turn provided to the probabilistic risk assessments (PRAs) and used in the assessment of affected core damage frequencies for the representative plants. 


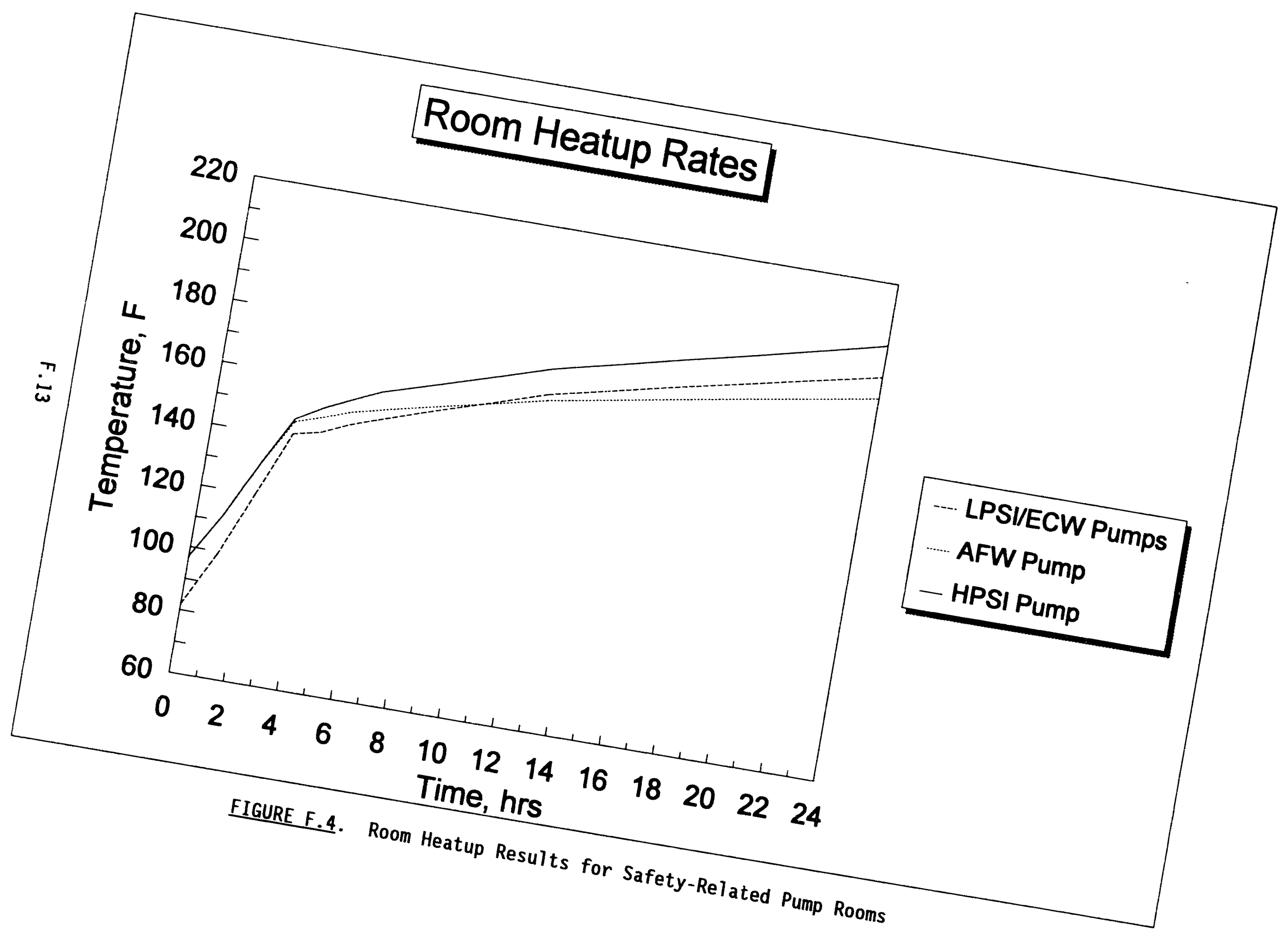




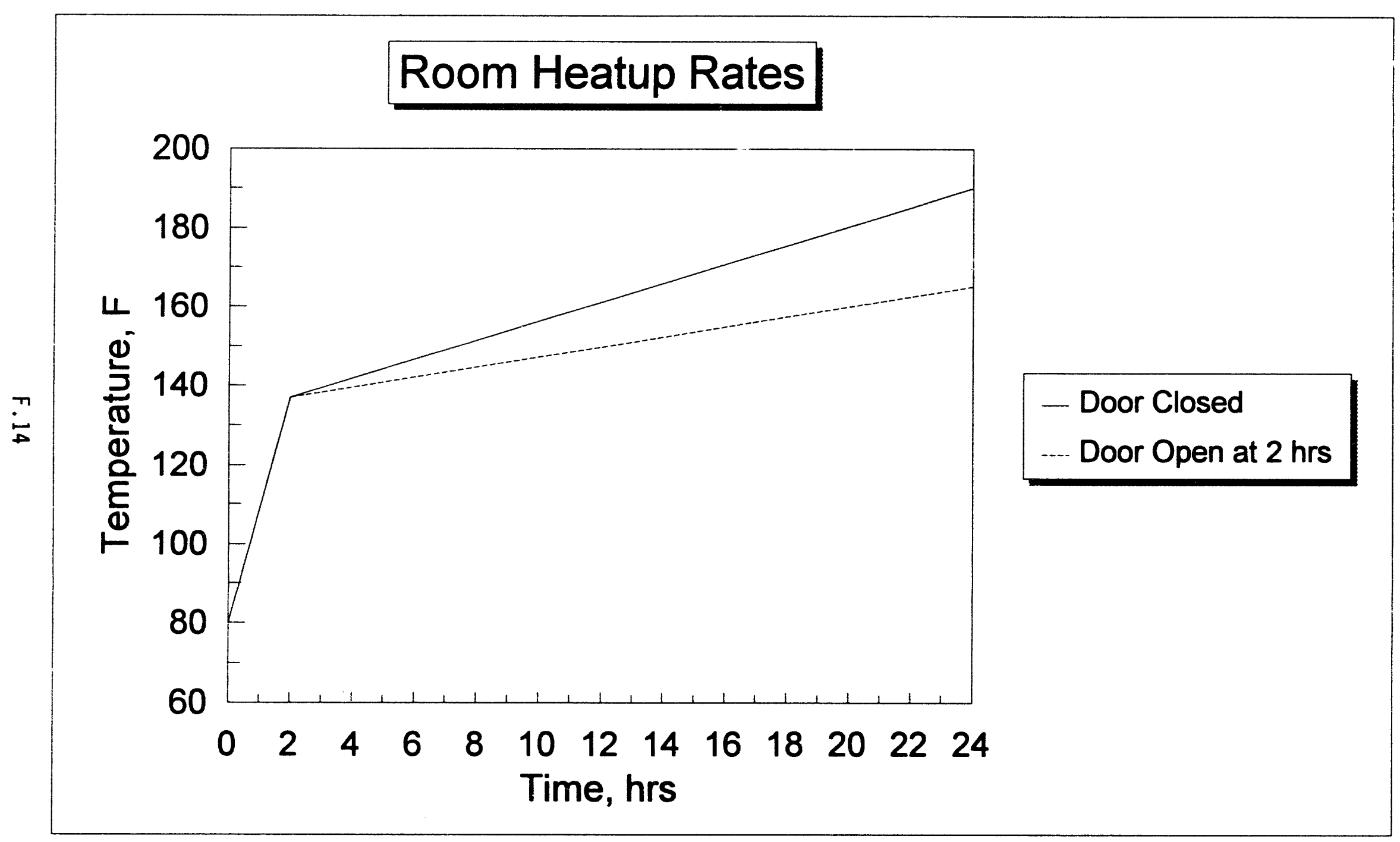

FIGURE F.5. Room Heatup Results for LPSI Pump Room - Door Opened at Two Hours 


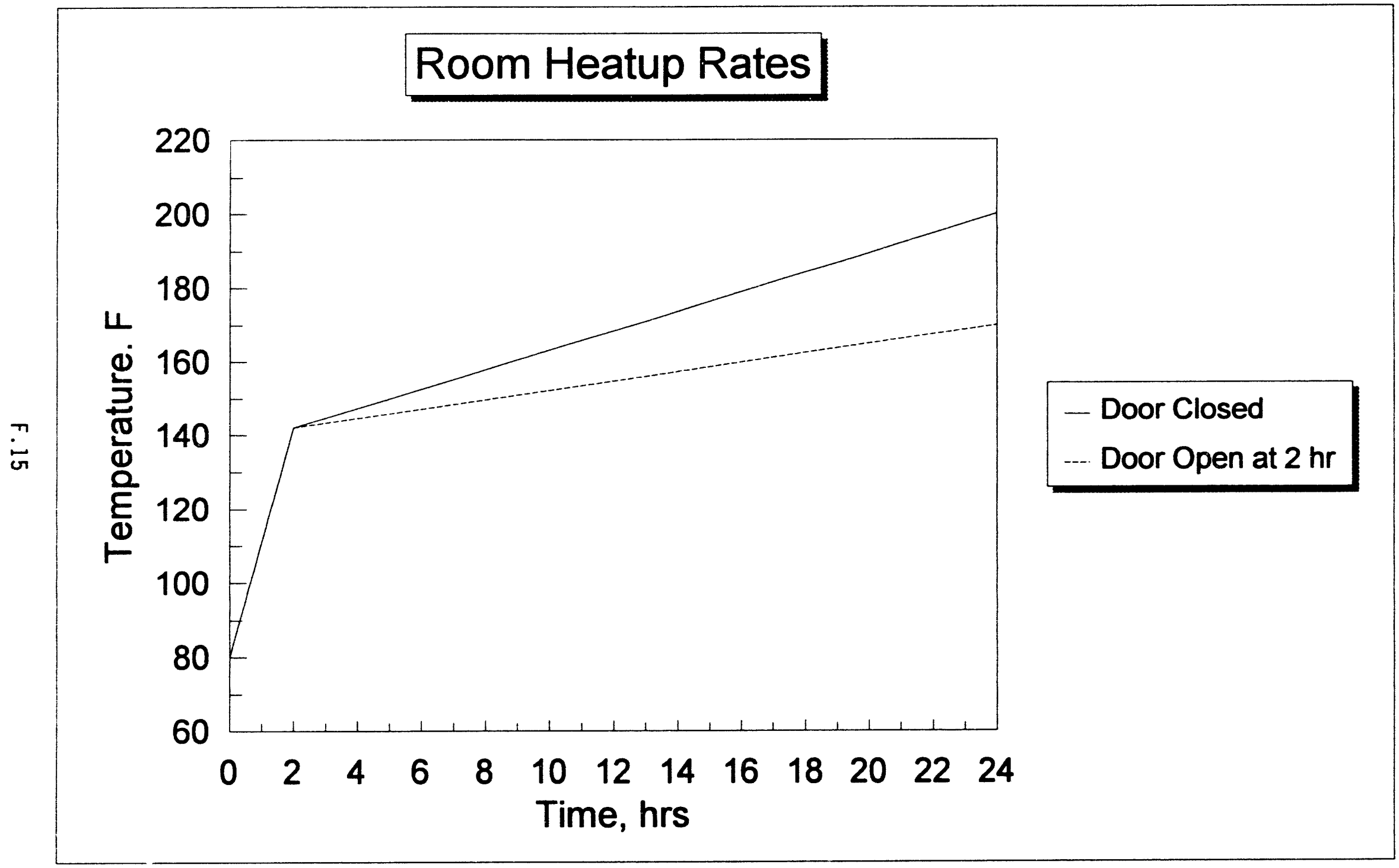

FIGURE F.6. Room Heatup Results for HPSI Pump Room - Door Opened at Two Hours 


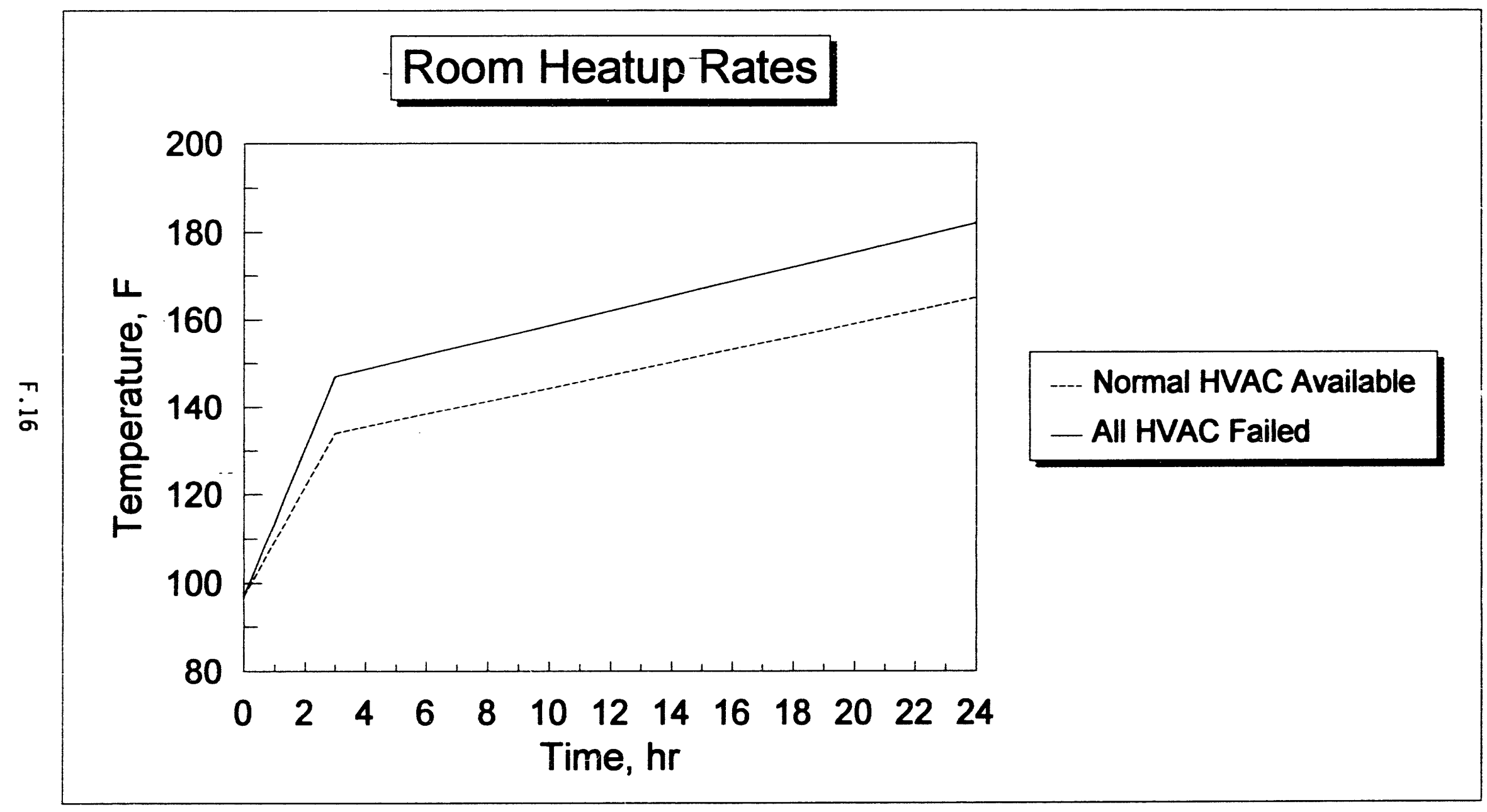

FIGURE F.7. -Room Heatup Results for AFW Motor-Driven Pump Room - Normal HVAC Continues Operating 
A review of temperature-dependent failure rate information in the open literature indicated that information in this area was lacking. Therefore, the major sources of information for this assessment were the utilities and equipment vendors. Information was obtained from utilities during plant visits. This included equipment qualification data in support of environmental qualification (EQ), station blackout, and fire protection analyses, test reports, and specific analyses that were performed in support of PRAs and other studies. Much of this information is unpublished; therefore no references are provided.

During early stages of this analysis, information collection activities focused on equipment qualification and testing data developed and maintained by utilities to ensure that the equipment installed in the plant is able to withstand the environmental conditions that may result from severe accidents. During the plant design and construction process, the utilities evaluate the effects of various design basis accidents and establish the design conditions in rooms and plant areas that could be affected. The environmental design parameters established for these rooms/areas include

- Room temperature (peak)

- Pressure (peak)

- Humidity (peak)

- Radiation dose (peak)

- Operating time (aging-related; sustained temperature, pressure, humidity, and radiation dose considered)

- Vibration.

As indicated above, the equipment must be demonstrated to be capable of operating in post-accident environments as well as in normal environments over the expected pllant life.

Each plant visited maintained voluminous equipment qualification records. Records are kept for valves, valve actuators, pumps, pump motors, attachment devices, heat exchangers, piping, batteries, battery chargers, inverters, sensing devices (pressure, temperature, etc.), and a wide variety of electrical equipment (relays, breakers, fuses, wiring). Test data that demonstrate component operability under the specified environmental conditions are included in the equipment qualification records. However, the test data are designed to demonstrate component operability, not to determine the actual failure thresholds of the component.

The data collected during these visits indicate that, in general, room cooling system design capacities are established using conservative methods. In addition, it appears that the EQ programs are structured with significant safety margins that result in components being capable of operating in more harsh environments than would be expected. under the specified EQ conditions. 
Much of the EQ information on specific components is obtained from vendor testing programs. Typically, a vendor may thermally qualify a component by placing it into an oven, increasing the oven temperature to some preestablished value and holding it there for a period of time, then testing the operability of the component. The goal is to demonstrate that the component will function following testing at the pre-established time-temperature conditions. Rarely, if ever, do the vendors test the components to actual failure. Consequently, the actual time-temperature conditions at failure are not known. However, because the components are demonstrated to be operable following the equipment qualification tests, it is evident that the actual failure temperatures are greater than the temperatures that they have been qualified to operate under. A list of safety-related components, their equipment qualification conditions, and actual test conditions is provided in Table F.1, which illustrates the margin designed into typical safety-related components. For most components, the margin is in the 20 to $30 \%$ range; however, the margin is greater than $50 \%$ in some cases (e.g., pump motors).

The impact on this study is as follows. The failure rate data being used in current PRAs is not dependent upon the ambient temperature in the rooms in which the components are located. The basic assumption is that under room temperature conditions following failure of HVAC systems and room coolers, the components in that room are assumed to fail unless room cooling can be restored before the room temperature reaches equipment qualification temperatures. This may result in conservative assumptions being used in PRAs; e.g., the assumption that a component fails at the instant that the ambient temperature reaches the design temperature. It is agreed that the component failure rates increase with increasing temperature. However, the failure rate does not go to 1.0 when the ambient temperature reaches the design temperature.

An investigation was conducted to develop time-temperature-dependent failure data for safety-related components. EQ data from several plants was collected. Some of the available EQ information was sufficient to plot curves of mean-time-to-fail versus ambient temperature. One such curve is provided in Figure F.8. As shown, the failure rate for pumps, motor-operated valves, and cables increases initially in a linear function with increasing temperature and then seems to reach a transition temperature at which a large increase in the failure rate occurs. The reader is cautioned that these data were taken from successful tests; i.e., the failure rate was calculated based on a successful test at the specified temperature. It is possible that the actual failure rates are lower than the calculated failure rates. Actual failure rates would be calculated only if they could have been based on tests that actually proceeded to component failures.

\section{F.2.1 ESF Pump Motors}

Data obtained from utilities and vendors were used to develop the following temperature-dependent failure rate estimates for engineered safety features (ESF) pump motors. One utility provided most of the data shown below. Information provided to the utility by pump vendors is summarized below: 
IABLE F.1. Comparison of Equipment Qualification Conditions and Actual Test Conditions for Typical Components

\begin{tabular}{|c|c|c|c|c|}
\hline & \multirow{2}{*}{$\begin{array}{c}\text { Equipment } \\
\text { Qualification } \\
\text { Temperature } \\
\text { of }\end{array}$} & \multicolumn{2}{|c|}{ Test Conditions } & \multirow[b]{2}{*}{$\underset{\%}{\text { Margin }}$} \\
\hline & & $\begin{array}{c}\text { Temperature } \\
{ }^{\circ} \mathrm{F}\end{array}$ & $\begin{array}{c}\text { Duration } \\
\mathrm{hr}\end{array}$ & \\
\hline Switchgear & 104 & 131 & 8 & 26 \\
\hline OC motorcontrol centers & 104 & 131 & 96 & 26 \\
\hline Load centers & 104 & 125.6 & Indefinite & 21 \\
\hline AC motorcontrol centers & 104 & 131 & 96 & 26 \\
\hline Voltage rejulator & 104 & 122 & NA & 17 \\
\hline Battery chargers & 104 & 122 & 8 & 17 \\
\hline Inverters & 104 & 131 & 24 & 26 \\
\hline Relays & 104 & 134.6 & 8 & 29 \\
\hline AFW pump motor & 104 & 143.6 & NA & 37 \\
\hline HPSI pump motor & 104 & 159.8 & NA & 54 \\
\hline LPSI pump motor & 104 & 135.8 & NA & 30 \\
\hline CSS pump motor & 104 & 135.8 & NA & 30 \\
\hline Chilled water pump motor & 104 & 164.3 & NA & 58 \\
\hline
\end{tabular}

- Motor-driven AFW pump motor: Assuming that this particular pump is operated in ambient $134.4^{\circ} \mathrm{F}\left(56.9^{\circ} \mathrm{C}\right)$ environment, the bearing temperature rise was estimated to be about $33^{\circ} \mathrm{C}$. The total bearing temperature is then $56.9+33=89.9^{\circ} \mathrm{C}$. The maximum allowable bearing temperature is $95^{\circ} \mathrm{C}$, which provides a $5^{\circ} \mathrm{C}$ temperature margin. The average insulation temperature was estimated to be $127.9^{\circ} \mathrm{C}$ and the qual ified maximum insulation temperature was given as $155^{\circ} \mathrm{C}$, using a $10^{\circ} \mathrm{C}$ hot-spot allowance. Therefore, the insulation temperature margin is about $27^{\circ} \mathrm{C}$, much greater than the bearing temperature margin. The vendor information concluded that this pump motor could operate continuously in a room temperature of $57^{\circ} \mathrm{C}\left(135^{\circ} \mathrm{F}\right)$ and for a short period of time (up to 16 hours) at a room temperature of $62^{\circ} \mathrm{C}\left(144^{\circ} \mathrm{F}\right)$. However, the qualified life of the pump motor would be reduced if operated at these room temperatures.

- ECW pump motor: Assuming that this pump is operated in ambient $131^{\circ} \mathrm{F}$ $\left(55^{\circ} \mathrm{C}\right.$ ) environment, the bearing temperature rise was estimated to be about $21.5^{\circ} \mathrm{C}$. The total bearing temperature is then $55+21.5=76.5^{\circ} \mathrm{C}$. The maximum allowable bearing temperature is $95^{\circ} \mathrm{C}$, which provides an $18.5^{\circ} \mathrm{C}$ temperature margin. The average insulation temperature was estimated to be $123^{\circ} \mathrm{C}$, and the qualified maximum insulation temperature was given as $155^{\circ} \mathrm{C}$, using a $10^{\circ} \mathrm{C}$ hot-spot allowance. Therefore, the insulation temperature margin is about $32^{\circ} \mathrm{C}$, much greater than the bearing temperature margin. The vendor information concluded that this pump motor could operate continuously in a room temperature of $68.5^{\circ} \mathrm{C}$ $\left(155^{\circ} \mathrm{F}\right)$ and for a short period of time (up to 16 hours) at a room 


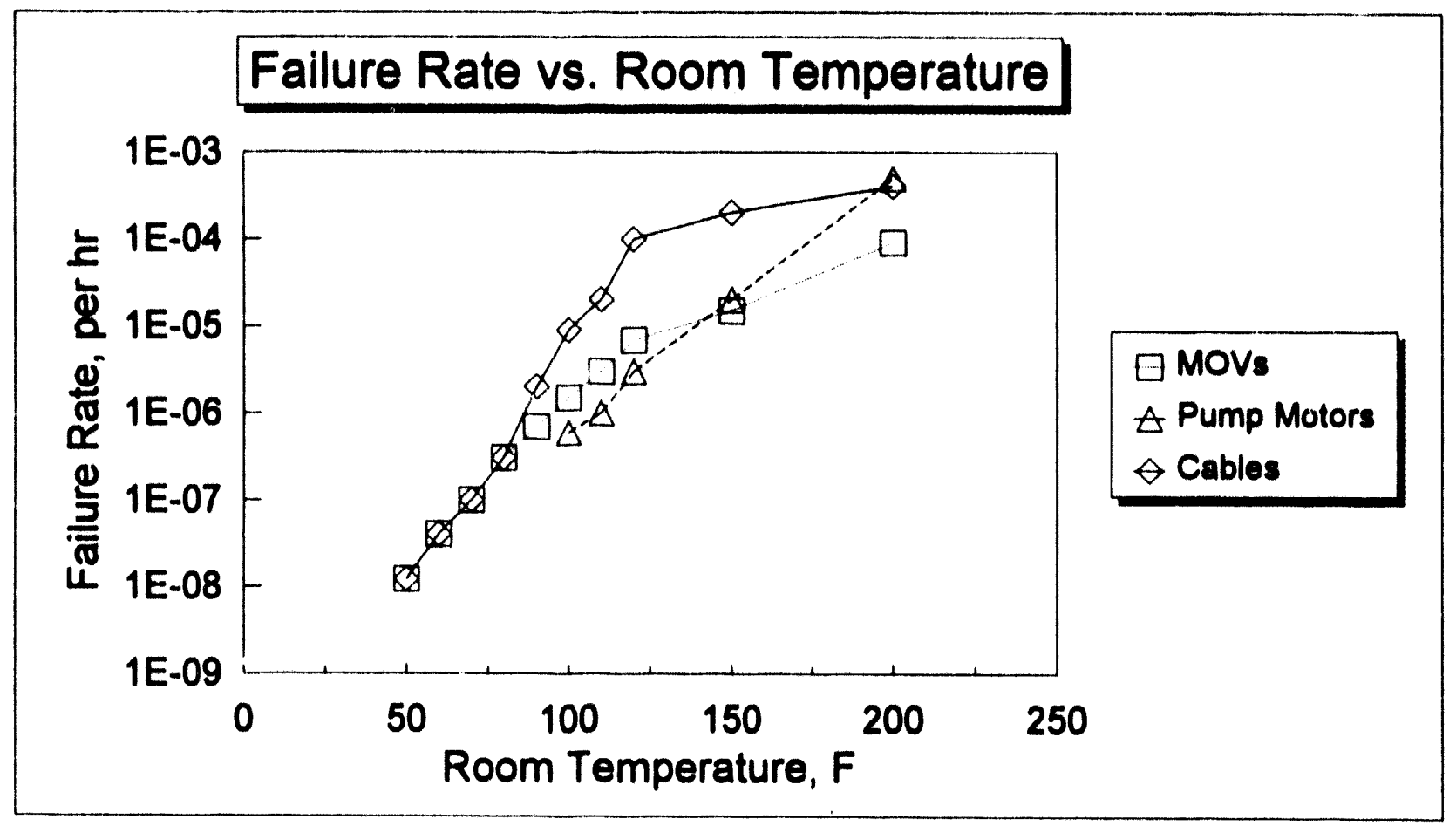

EIGURE F.8. Failure Rates as a Function of Temperature Based on EQ Data

temperature of $73.5^{\circ} \mathrm{C}\left(164^{\circ} \mathrm{F}\right)$. As with the AFW pump, the qualified life of the pump motor would be reduced if operated at these temperatures.

- HPSI pump motor: Similar calculations as those shown above were performed for the HPSI pump motor. Plant ambient temperature conditions were assumed to be $57.9^{\circ} \mathrm{C}$. The total bearing temperature was calculated to be $73.9^{\circ} \mathrm{C}$, resulting in a margin of $21.1^{\circ} \mathrm{C}\left(38^{\circ} \mathrm{F}\right)$. Total insulation temperature was calculated to be $141.9^{\circ} \mathrm{C}$ for a margin of $13.1^{\circ} \mathrm{C}$ $\left(23.6^{\circ} \mathrm{F}\right)$. Therefore, due to higher plant ambient temperatures, the HPSI pump motor insulation becomes the 1 imiting component. Based on the insulation temperature, the maximum room ambient temperature is $71^{\circ} \mathrm{C}$ $\left(159.8^{\circ} \mathrm{F}\right)$. Again, the qualified life of this pump motor is reduced if operated at this temperature.

- LPSI and containment spray pump motors: These pumps are essentially identical. Assuming these pumps are operated in ambient $135.8^{\circ} \mathrm{F}$ $\left(57.7^{\circ} \mathrm{C}\right.$ ) environment, the bearing temperature rise was estimated to be about $39^{\circ} \mathrm{C}$. The total bearing temperature is then $57.7+39=96.7^{\circ} \mathrm{C}$. The maximum allowable bearing temperature is $95^{\circ} \mathrm{C}$, which is $1.7^{\circ} \mathrm{C}$ less than the peak allowable bearing temperature. The insulation temperature was estimated to be $142.7^{\circ} \mathrm{C}$, and the qualified maximum insulation temperature was given as $155^{\circ} \mathrm{C}$. Therefore, the insulation temperature 
margin is about $12.3^{\circ} \mathrm{C}$. This margin is greater than the bearing temperature margin, so bearing temperature is ilimiting for these pump motors. Based on these data, the vendor information concluded that this pump motor could operate for a short period of time (up to six hours) at a room temperature of $57.7^{\circ} \mathrm{C}$. Operation beyond six hours at this temperature would greatly reduce bearing $11 \mathrm{fe}$ and the insulation system's qualified life.

Based on these data, the utility developed an equation to express the pump motor fallure rate as a function of temperature. The equation is based on the failure rate doubling for every $18^{\circ} \mathrm{F}$ increase in temperature above normal. This equation is

$$
F F(T)=F R_{T} * 2^{((T b-T) / 18)}
$$

where: $F R(T)$ = Failure rate as a function of ambient temperature (T)

$$
\begin{aligned}
& \mathrm{FR}_{\mathrm{T}} \text { = Fafliure rate at normal ambient temperatures } \\
& \text { Tb = Pump motor bearing temperature, }{ }^{\circ} \mathrm{F} \\
& \mathrm{T}=\text { Ambient temperature, }{ }^{\circ} \mathrm{F} \text {. }
\end{aligned}
$$

This equation was used to plot curves of failure rate as a function of temperature and failure rate for various pump motors, as shown in Figure F.9. These curves are essentially linear and represent the effects of ambient temperature conditions on the reliability of various safety-related pump motors. The curves show approximately an order of magnitude increase in pump motor failure rates for the first $50^{\circ} \mathrm{F}$ increase in room ambient temperature.

This equation and the room heatup data presented in Section F.1 were used to plot curves of failure rate as a function of time following loss of room cooling for the same motors. This plot is presented in Figure F.10. These curves were used to estimate the amount of time available to diagnose and restore room cooling failures before safety-related pumps are anticipated to malfunction due to high ambient temperatures. The curves also provide the failure rates for various pumps as a function of room cooler outage times. These data were used in the PRA to calculate pump unavailabilities for different loss of offsite power and station blackout transients that result in failure of pump room coolers.

\section{F.2.2 Emergency Diesel Generators}

To date, little information has been provided on the operability of on-site emergency power systems given loss of HVAC or room cooling. Based on discussions with utility personnel at several plants, diesel engines are not extremely sensitive to ambient temperatures. However, the diesel generator control systems are susceptible to failures at high ambient temperatures and will undoubtedly fail long before the diesel engine itself fails due to high 


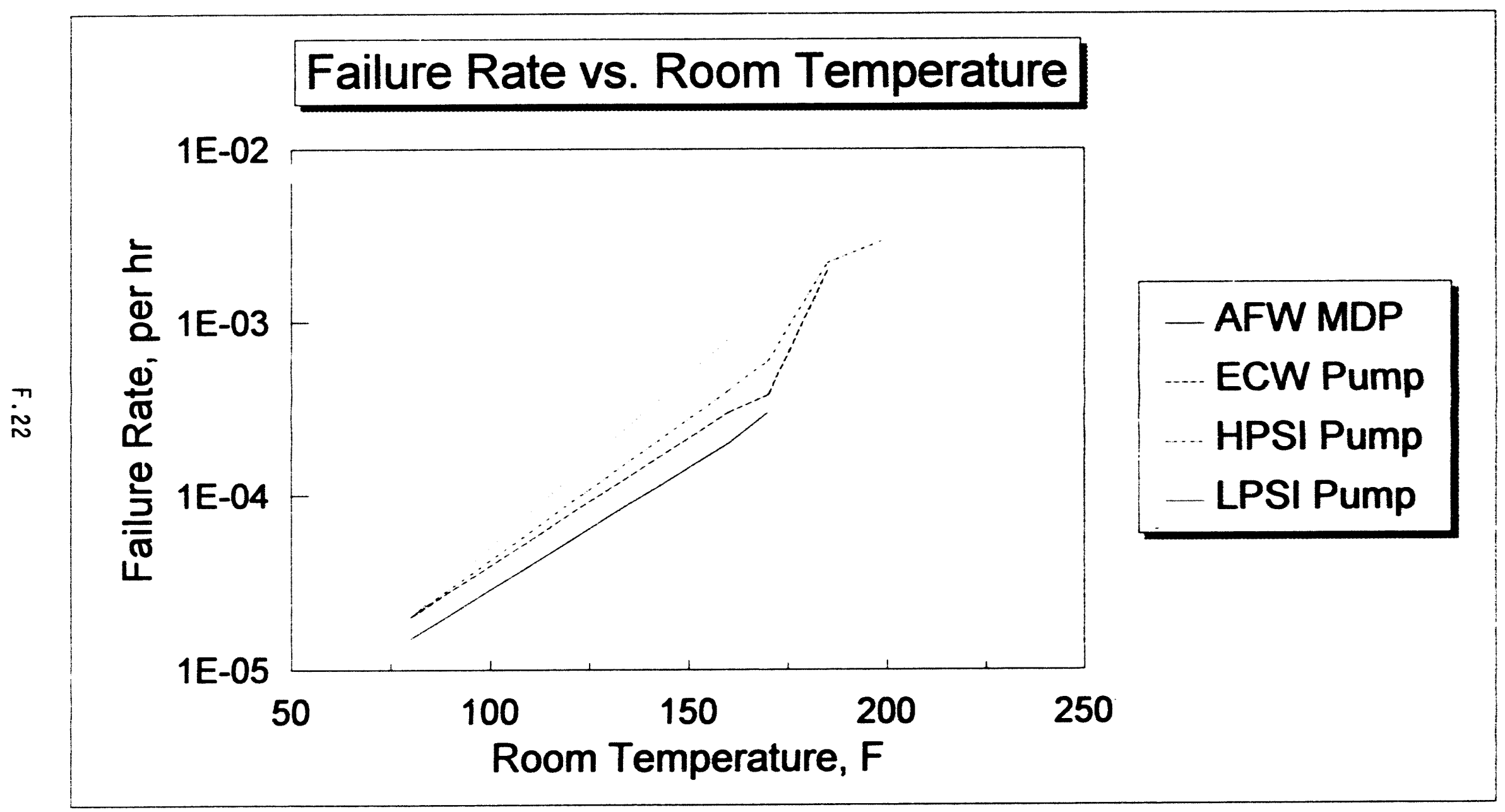

FIGURE F.9. Failure Rate as a Function of Room Temperature Based on Vendor Data 


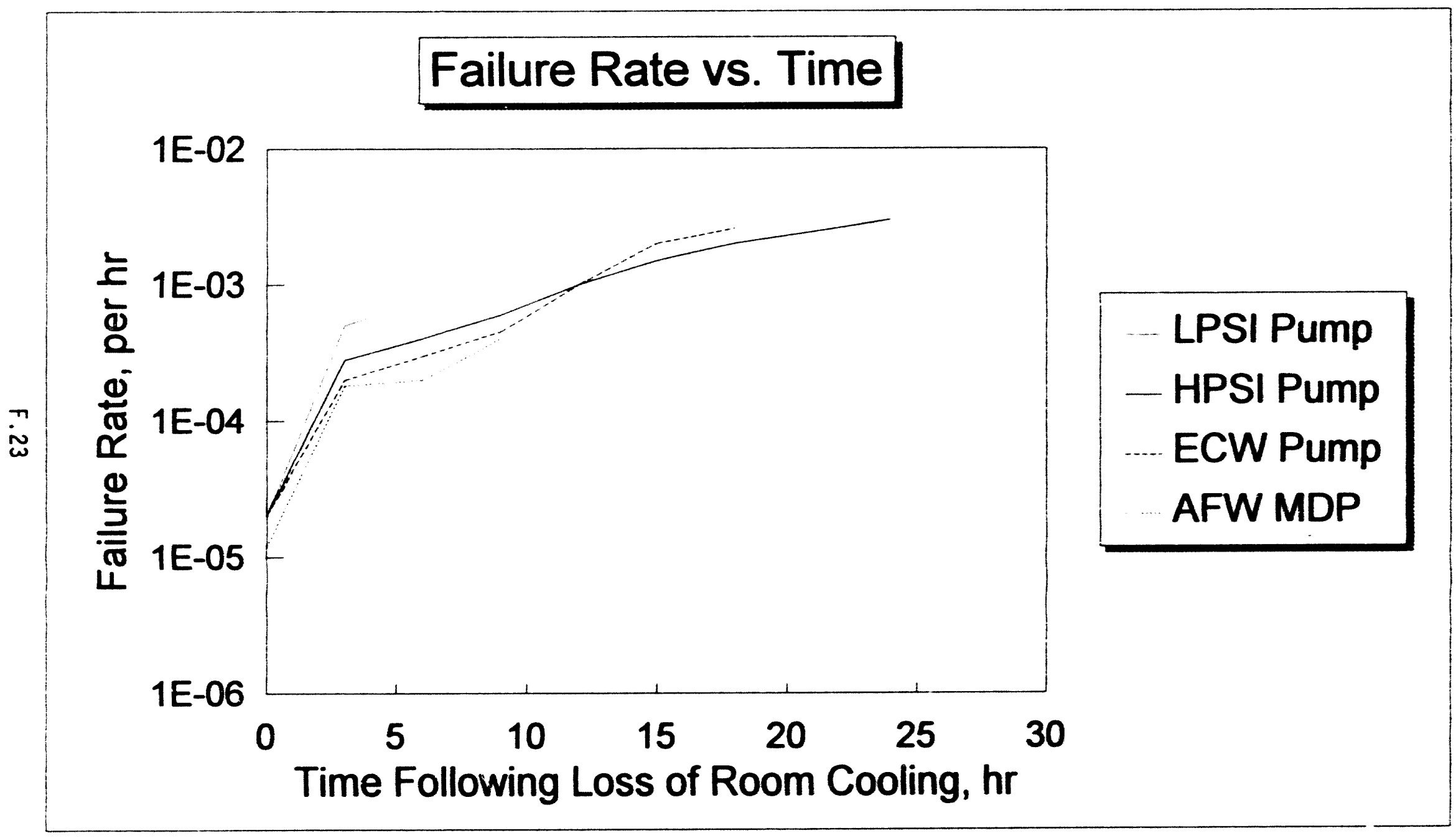

FIGURE F.10. Failure Rate as a Function of Time Following Loss of Room Cooling Based on Vendor Data 
ambient temperatures. Therefore, the safety-related ventilation systems in diesel generator rooms are much more important to the reliability of diesel generator control systems than to the engines.

Table F.l provides some actual fallure temperature information for sensitive components inside DG control cabinets. Examples include switchgear, load centers, and relays. The most temperature-sensitive electrical component appears to be load centers, which have been tested and perform adequately at ambient temperatures up to about $125^{\circ} \mathrm{F}$. Based on the DG control room temperature rise shown in Figure F.3, this temperature will be reached about 50 minutes following loss of ventilation with the diesel engines running. Other plants have smaller DG rooms than that analyzed in Section F.1. The plants with small rooms will have less than 50 minutes to implement recovery actions. In fact, Drouin et al. (1989) indicated that only 15 to 20 minutes were available following loss of their DG room ventilation system before failure is expected. This tends to support the assumption in the probabilistic risk calculations performed in this study that no credit was taken for recovery of falled DG ventilation systems.

\section{F.2.3 Electrical Equipment}

Electrical equipment reliability exhibits a strong temperaturedependence, particularly equipment referred to as "soft" (nonmetallic and organic) equipment. Electrical equipment, including instrumentation and control (I\&C) system components, is found in ESF pump rooms, switchgear rooms, $A C$ and $D C$ equipment rooms, diesel generator rooms, and the control room. High temperatures have been shown to cause electrical equipment failures as well as spurious actuations.

Utility data was reviewed that determined the most sensitive I\&C components in various rooms and compared the fallure temperatures with the ambient temperature in the specific rooms following a loss of HVAC. Vendor data on the limiting ambient temperatures for these components was collected and the most sensitive components in each room were determined. The data for the specific rooms is summarized in Table F.2. As shown, a significant margin exists for the ESF pump rooms, but there is no margin for the control room. Based on data in the table, failure of control room HVAC could lead to I\&C equipment failures or spurious actuations which could fail ESF equipment or produce erroneous signals, readings, and alarms. The evaluation included electrical switchgear rooms and it was concluded that there are no "soft" I\&C components in these rooms.

The control room is the location of many temperature-sensitive electrical components. Analyses of control room panels and cabinets were performed by one utility to determine the impacts of a loss of control room HVAC. As shown in Table F.2, a loss of the essential HVAC system results in an ambient temperature in the control room of $119 \circ \mathrm{F}$ after about seven hours. Test data for several safety-related panels and cabinets were obtained, as shown below: 
IABLEF.2. Comparison of Room Ambient Temperatures Following Loss of HVAC and Limiting Temperatures for I\&C Components

\begin{tabular}{|l|c|c|}
\hline ESF room & $\begin{array}{c}\text { Room Temperature } \\
7 \mathrm{hr} \text { after } \\
\text { loss of HVAC, of }\end{array}$ & $\begin{array}{c}\text { Limiting Ambient } \\
\text { Temperature for I\&C } \\
\text { Components, of }\end{array}$ \\
\hline AFW pump room & 134 & 140 \\
Containment spray pump room & 133 & 160 \\
Control room & 119 & 119 \\
Essential chilled water pump room & 131 & 200 \\
HPSI pump room & 136 & 160 \\
LPSI pump room & 136 & 160 \\
\hline
\end{tabular}

- Engineered safety features actuation system cabinet tested at $120^{\circ} \mathrm{F}$ for 160 hours. A similar cabinet was tested at $119^{\circ} \mathrm{F}$ for eight hours.

- Safety parameter display system cabinet tested at $137^{\circ} \mathrm{F}$ for eight hours.

- Main control boards tested at $122^{\circ} \mathrm{F}$ for 160 hours.

- Electronic isolation cabinet tested at $135^{\circ} \mathrm{F}$ for eight hours.

- Plant protection system cabinets tested at $119^{\circ} \mathrm{F}$ for eight hours.

Operability of the cabinet components was demonstrated following the thermal tests. As shown, the control room cabinets and panels should function satisfactorily following loss of control room HVAC. The ambient temperature should not reach component test temperatures for at least seven hours and then should ontinue to function properly for at least eight hours at that temperature. Therefore, it appears that as long as ambient temperatures in the control room do not exceed $119^{\circ} \mathrm{F}$, cabinets and panelboards should function properly. This does not account for loss of the cabinet-mounted fans that circulate air into and out of the cabinet to provide supplemental cooling to the cabinet internals.

Air temperatures inside cabinets are elevated with respect to ambient air temperatures outside the cabinet due to heat generated by internal components such as power supplies and circuit boards. Calculations obtained from a utility indicated that air temperatures inside a cabinet were estimated at $83^{\circ} \mathrm{F}$ when ambient temperature was $73^{\circ} \mathrm{F}$ and cabinet fans were running. This is about a $10 \circ \mathrm{F}$ temperature rise relative to ambient conditions. Therefore, using the control room heatup results in Table F.2, the temperatures of internal cabinet air may reach the limiting electrical equipment temperatures when the control room is at $109^{\circ} \mathrm{F}$. Using the control room heatup curve shown in Section F.1, control room temperatures may reach this level in about $250 \mathrm{~min}$ utes or approximately four hours following loss of HVAC. 
In a documented event at a nuclear power plant, all cooling to the control room was lost. After about 45 minutes in this condition, numerous alarms were received (e.g., high average temperature in reactor coolant loop C). The process control system cabinets began to heat up as a result of increased control room temperatures (up to about $90^{\circ} \mathrm{F}$ ) and spurious signals and alarms were received by control room operators. The documentation indicated that printed circuit boards should not be operated for extended periods outside a temperature range of $75+/-10^{\circ} \mathrm{F}$. The maximum temperature range was stated as 40 to $110 \circ \mathrm{F}$. Performance tests on the printed circuit boards had been performed at $140 \circ \mathrm{F}$ in 12 -hour cycles. It was stated that printed circuit boards should not be operated for extended periods of time at temperatures above $85^{\circ} \mathrm{F}$, with a maximum temperature of about $110^{\circ} \mathrm{F}$. It was al so stated that temperatures inside the cabinets are expected to be about $20 \circ \mathrm{F}$ higher than the ambient temperature. Therefore, for a maximum control room temperature of $72^{\circ} \mathrm{F}$, the maximum temperature inside the cabinet should be about $92^{\circ} \mathrm{F}$. Operators indicated that control room temperatures may have been as high as $90^{\circ} \mathrm{F}$, indicating internal cabinet temperatures should have reached about $110^{\circ} \mathrm{F}$, well below the failure temperature of $140^{\circ} \mathrm{F}$ indicated by performance tests.

The utility involved performed temperature measurements which indicated that, at $72 \circ \mathrm{F}$ room ambient temperature, the temperatures inside the cabinet were $73^{\circ} \mathrm{F}$ at the bottom and $109 \circ \mathrm{F}$ at top. Instrument racks inside cabinets were measured at $115^{\circ} \mathrm{F}$ at mid-level to $125^{\circ} \mathrm{F}$ at top rack (circuit boards are installed in racks). This indicates a maximum cabinet temperature rise of as much as $50^{\circ} \mathrm{F}$. Therefore, some high-heat-load cabinets may experience difficulties even under normal control room temperature conditions. These cabinets were not provided with cabinet fans, so all cooling is provided by natural convection. Louvered vents are installed at the top and bottom of the cabinets to facilitate airflow through the cabinets. For cabinets provided with fans, the operability of fans becomes even more important under conditions leading to a rise in control room temperatures.

\section{F.3 REFERENCES}

Drouin, M. T., et a1. 1989. Analys is of Core Damage Frequency: Grand Gulf Unit 1 Internal Events. NUREG/CR-4550 Vol. 6, Rev. 1. Sandia National Laboratories, Albuquerque, New Mexico.

Goodman, T. C. 1964. "Application of Integral Methods to Transient, NonLinear, Heat Transfers." Advances in Heat Transfer, Volume 1. Academic Press, New York.

Nuclear Management and Resources Council (NUMARC). 1991. "Analys is of Loss of Ventilation Under Station Blackout Conditions (Appendix H)." Guidelines and Technical Bases for NUMARC Initiatives Addressing Station Blackout at Light Water Reactors. NUMARC 87-100 Rev. 1. Washington, D.C. 


\begin{tabular}{|c|c|}
\hline $\begin{array}{l}\text { BIBLIOGRAPHIC DATA SHEET } \\
\text { (See instructions on the reverse) }\end{array}$ & 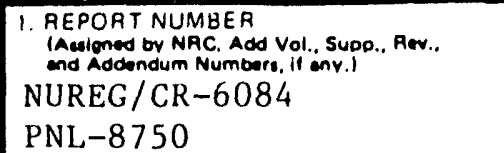 \\
\hline \multirow{3}{*}{$\begin{array}{l}\text { 2. TITLE ANO SUBTITLE } \\
\text { Value-Impact Analysis of Generic Issue 143, "Availability of } \\
\text { Heating, Ventilation, Air Conditioning (HVAC) and Chilled Water } \\
\text { Systems " }\end{array}$} & DATE REPORT PUBLISHED \\
\hline & \begin{tabular}{|c|c|} 
MONTH & YEAR \\
November & 1993
\end{tabular} \\
\hline & $\begin{array}{l}\text { 4. FIN OR GRANT NUMBER } \\
\text { L1915 }\end{array}$ \\
\hline \multirow[t]{2}{*}{$\begin{array}{l}\text { 5. AUTHOR(S) } \\
\text { P. M. Daling, J. E. Marler, T. V. Vo, H. Phan, J. R. Friley }\end{array}$} & $\begin{array}{l}\text { 6. TYPE OF REPOAT } \\
\text { Technical }\end{array}$ \\
\hline & $\begin{array}{l}\text { 7. PERIOD COVERED (InClusive Odes) } \\
1991-1993\end{array}$ \\
\hline \multicolumn{2}{|c|}{ 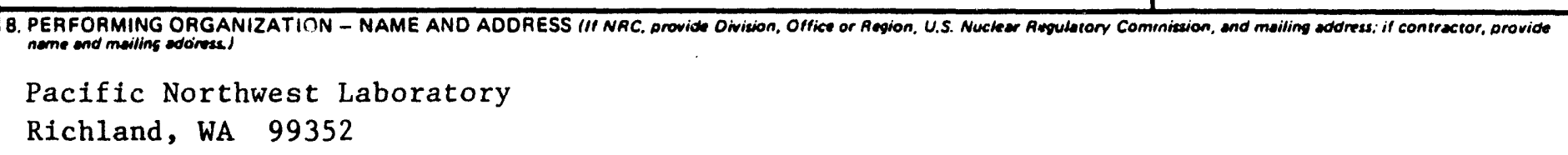 } \\
\hline \multicolumn{2}{|c|}{ 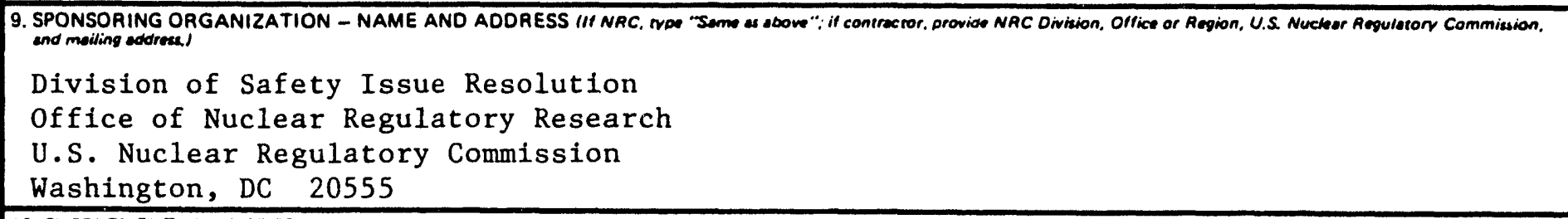 } \\
\hline \multicolumn{2}{|c|}{ 10. SUPPLEMENTARY NOTES } \\
\hline \multicolumn{2}{|c|}{ 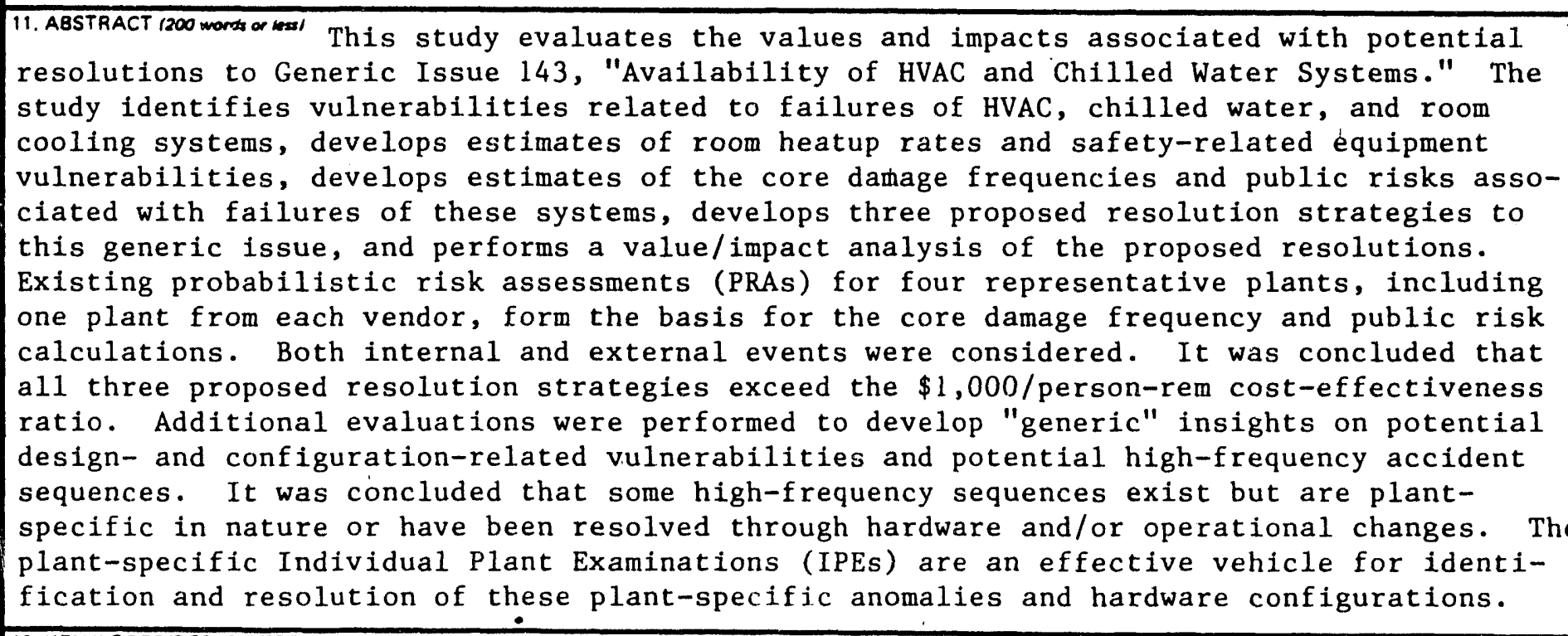 } \\
\hline \multirow{4}{*}{ 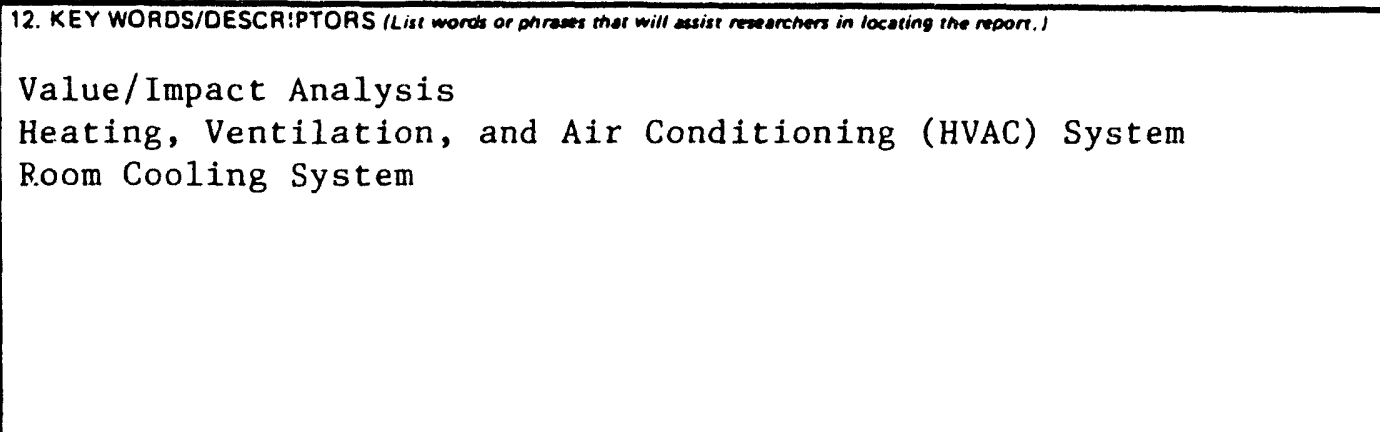 } & $\begin{array}{l}\text { 13. AVAILABILITY STATEMENT } \\
\text { Unlimited }\end{array}$ \\
\hline & $\begin{array}{l}\text { 14. SECUAITY CLASSIFICATION } \\
\text { TThis Pagel } \\
\text { Unclassified } \\
\text { This ReporI } \\
\text { Unclassified }\end{array}$ \\
\hline & 15. NIJMBEA OF PAGES \\
\hline & \\
\hline
\end{tabular}




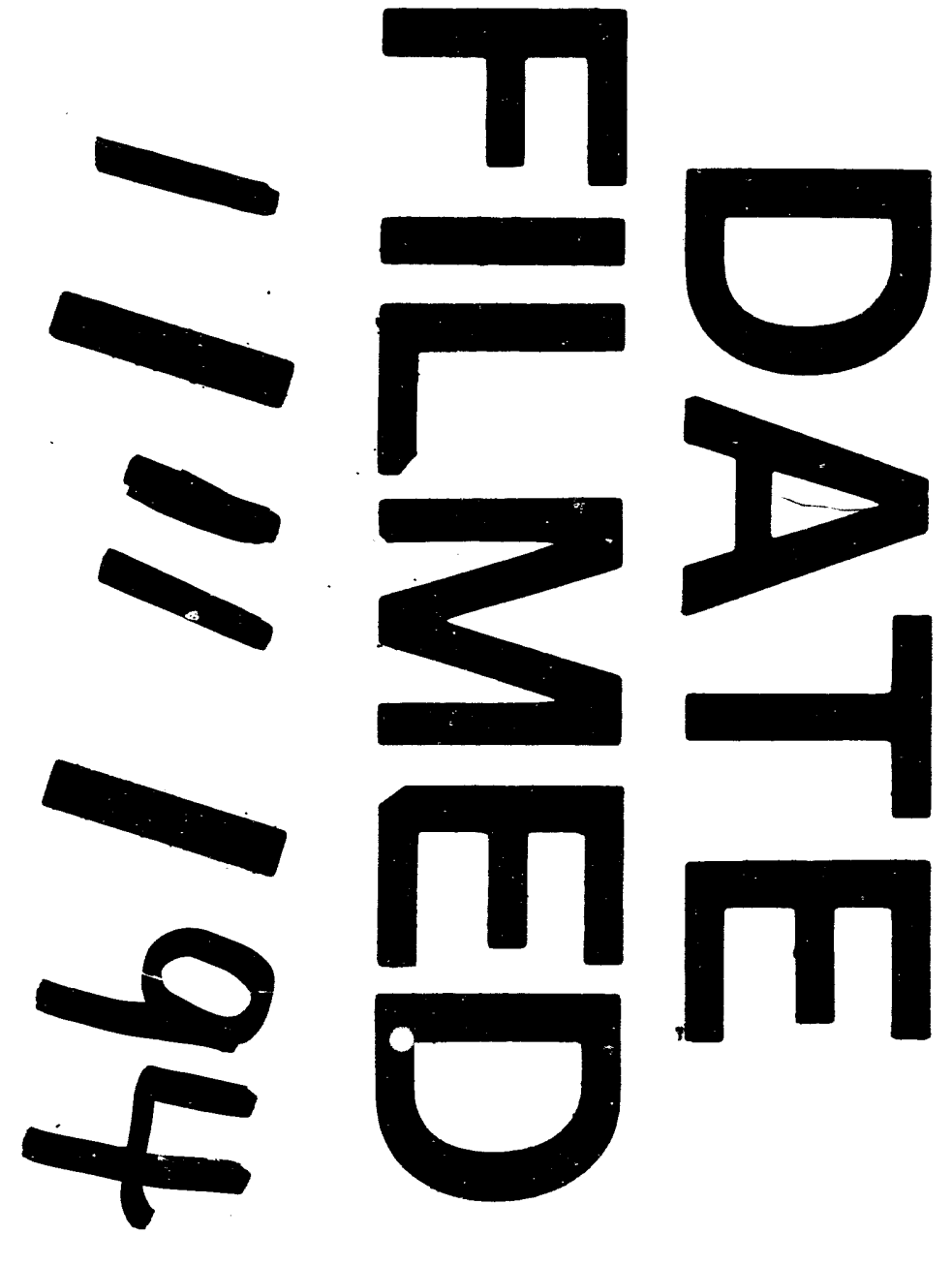


